
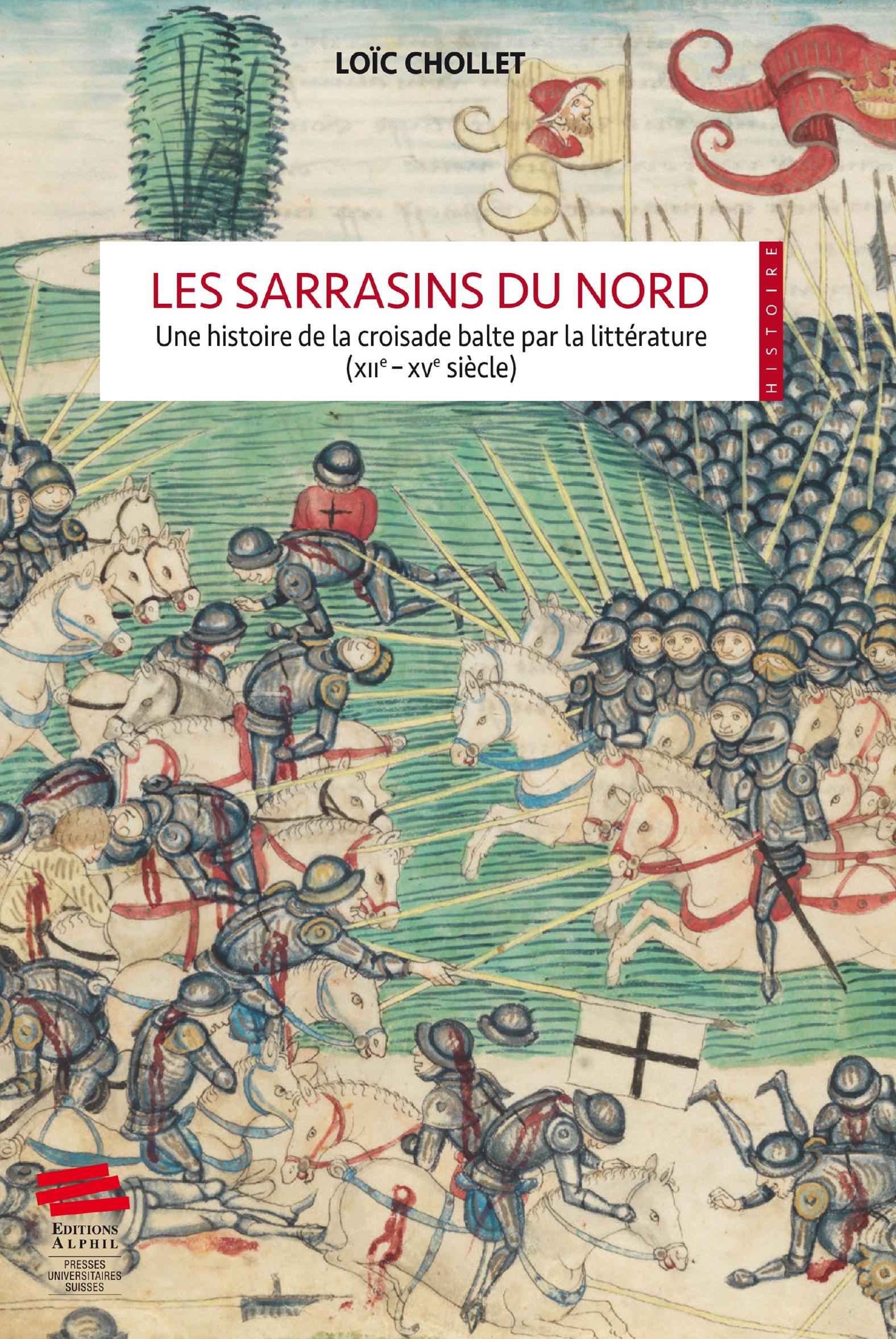



\section{Les Sarrasins du Nord}

UNE HISTOIRE DE LA CROISADE BALTE

PAR LA LITTÉRATURE $\left(\mathrm{XII}^{\mathrm{e}}-\mathrm{XV}^{\mathrm{e}}\right.$ SIÈCLES) 

LOÏC CHOLLET

\section{Les Sarrasins du Nord}

\section{UNE HISTOIRE DE LA CROISADE BALTE \\ PAR LA LITTÉRATURE $\left(\mathrm{XII}^{\mathrm{e}}-\mathrm{XV}^{\mathrm{e}}\right.$ SIÈCLES)}


(C) Éditions Alphil-Presses universitaires suisses, 2019

Case postale 5

2002 Neuchâtel 2

Suisse

www.alphil.ch

Alphil Diffusion

commande@alphil.ch

ISBN Papier : 978-2-88930-282-6

ISBN PDF : 978-2-88930-283-3

ISBN EPUB : 978-2-88930-284-0

DOI : 10.33055/ALPHIL.03134

Publié avec le soutien du Fonds national suisse de la recherche scientifique.

La publication de ce livre a été soutenue par la Commission des publications de la Faculté des lettres et sciences humaines de l'Université de Neuchâtel.

Les Éditions Alphil bénéficient d'un soutien structurel de l'Office fédéral de la culture pour les années 2016-2020.

Illustration de couverture: La bataille de Tannenberg, extrait de Diebold Schilling l'Ancien, Berner Chronik (1478-1483), Berne, Burgerbibliothek, Mss.h.h.I.1, fol. 304.

Ce livre est sous licence:

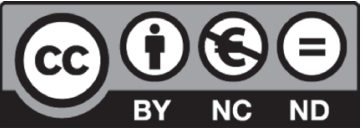

Ce texte est sous licence Creative Commons: elle vous oblige, si vous utilisez cet écrit, à en citer l'auteur, la source et l'éditeur original, sans modifications du texte ou de l'extrait et sans utilisation commerciale.

Responsable d'édition: Anne-Caroline Le Coultre 
À Sabina, Anaïs et Daphné 



\section{Préface}

$\mathrm{P}$

our qu'un ouvrage scientifique atteigne de l'importance, il faut qu'il soit aussi neuf que solide. Solide pour son érudition, neuf à cause de son regard. Un beau titre y ajoutera du lustre.

La thèse de Loïc Chollet a toutes ces qualités. Elle est très érudite, et ceci en plusieurs langues d'âges différents. Non seulement celle maternelle, mais aussi allemande, haute et basse, tchèque, polonaise et lituanienne, roumaine et russe (par l'entremise de personnes les sachant). Loïc Chollet est donc un Européen complet, roman, germanique et slavo-balte, ce qui est une qualité fort rare. Bien qu'il limite son observatoire au monde francophone y compris anglonormand, wallon, savoyard, il a tout lu, ou presque, a analysé ses textes avec circonspection, a réuni en sa personne le littéraire avec l'historien, ce qui est exceptionnel et ne réussit pas souvent.

Son titre rend évident le paradoxe du phénomène sur lequel il se penche: une croisade permanente pendant tout le XIV ${ }^{\mathrm{e}}$ siècle, organisée par l'Ordre teutonique contre des "Sarrasins", non pas en Terre sainte ou ailleurs au Proche-Orient, mais contre les Lituaniens au nord-est de l'Europe, païens donc "Sarrasins" eux aussi. Cette activité s'est finalement soldée par un échec, symbolisé par la bataille de Tannenberg en 1410, quand l'Ordre perd la suprématie régionale et doit renoncer à jamais à ses prétentions sur la Basse-Lituanie ou Samogitie. Elle a néanmoins attiré la participation de toute l'Europe chevaleresque dans ce "monde d'honneur et de glace». Elle était connue en détail, depuis une génération environ. On savait ce qu'était le "Voyage de Prusse».

Mais la perspective aristocratique, importée, étrangère au pays, n'était pas la seule possible. C'est en cela que l'ouvrage est neuf, donc important. Jusqu'ici, la recherche était centrée sur l'établissement des faits: qui, quand, chemins, finances, déroulement de la guerre en pays ennemi. Loïc Chollet présuppose toutes ces connaissances et choisit une autre approche, plus moderne, plus dangereuse aussi. Il veut savoir comment on parlait (de fait, écrivait) cette expérience, comment on apercevait gens et pays, comment on jugeait le phénomène. En bref: il donne une analyse du discours sur le "Voyage de Prusse». Dangereuse est cette approche quand elle se limite au phénomène 
secondaire sans s'occuper du primaire. Loïc Chollet ne tombe pas dans ce piège. Il maîtrise les deux niveaux et les met en relation.

Alors qu'est-ce qu'il voit? Il découvre une autre réalité qui ne concorde pas avec le contraste voulu et propagé par l'Ordre teutonique et la chevalerie occidentale: ici le noble cultivé qui importe sa manière de vivre en permanente représentation, là le païen féroce, plus animal qu'humain. La recherche récente, aussi bien lituanienne qu'allemande, avait déjà commencé cette révision, Loïc Chollet la poursuit et la perfectionne. Il attire l'attention sur le fait que dans les chroniques, on parle de rencontres paisibles, de pourparlers, de trêves conclues, de courtoisies accordées, de prisonniers échangés, de tolérance religieuse du côté des "infidèles", même de respect accordé aux lieux saints de côté et d'autre. Les nobles étrangers, et encore moins les frères Teutoniques, n'étaient pas incapables de voir et même d'exprimer ce qui de fait était. Mais plus loin, en France, en Angleterre, le simple contraste entre chrétien et païen subsistait, bien au-delà de la conversion du prince de Lituanie devenu roi de Pologne. Les deux visions coexistaient, celle réelle d'abord minoritaire, jusqu'à ce que la principauté soit regardée comme vraiment christianisée, désormais elle-même part de l'antemurale christianitatis contre les orthodoxes considérés comme schismatiques, les Mongols et les Turcs musulmans.

En même temps, cette thèse est une source concernant toute l'historiographie de l'Ordre teutonique et de tout texte apparenté. En sa grande richesse, elle permet de s'informer sur un grand nombre des acta et gesta de cette période peu connue par le lecteur occidental. Mais elle est beaucoup plus qu'une grande synthèse. Depuis un certain nombre d'années, l'historiographie sur l'Ordre teutonique s'est faite en bonne partie en langue française, voir les travaux de Sylvain Gouguenheim, Kristjan Toomaspoeg, Danielle Buschinger et Mathieu Olivier. Loïc Chollet, Suisse vivant à Neuchâtel près de la frontière linguistique, continue dignement cette lignée et traite ce qui s'est passé il y a plus de 600 ans dans cette région lointaine tant bouleversée depuis en sujet européen, ce qu'il a toujours été et ce qu'il continue d'être de nos jours.

Kronshagen, le 10 janvier 2019

Werner Paravicini 


\section{REMERCIEMENTS}

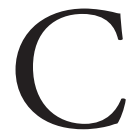

et ouvrage est l'adaptation d'une thèse de doctorat, soutenue en novembre 2017 à l'Université de Neuchâtel. Nombreuses sont les personnes sans qui cette belle aventure n'aurait pas été possible. Je tiens à exprimer toute ma gratitude à mon directeur, Jean-Daniel Morerod, pour sa confiance, son soutien et ses conseils avisés durant cette belle aventure; aux membres de mon jury de thèse, Olivier Marin, Jean-Claude Mühlethaler, Werner Paravicini et Mario Turchetti, dont les remarques ont hautement amélioré la qualité de ce travail; à Sylvain Gouguenheim, Sławomir Jóźwiak, Olivier Marin, Rasa Mažeika, Martin Nejedlý, Werner Paravicini et Sobiesław Szybkowski qui ont été mes guides sur les traces des chevaliers voyageant aux confins de la Chrétienté médiévale; à mes collègues et amis de l'Université de Neuchâtel, Nicolas Balzamo, Olivier Christin, Alain Corbellari, Fabrice Flückiger et Anton Serdeczny pour m'avoir fait profiter de leurs connaissances respectives et de leurs remarques pertinentes.

L'auteur de ces lignes a largement bénéficié de plusieurs séjours en Pologne, notamment à l'Université de Gdańsk, ce qui a été rendu possible par une bourse de recherche du Musée d'Histoire Polonaise (Muzeum Historii Polski), à Varsovie. J'en profite pour remercier Sławomir Jóźwiak, Tomasz Schramm, Sobiesław Szybkowski et Rafał Witkowski pour m'avoir accueilli avec courtoisie et m'avoir permis de me familiariser avec les immenses bibliographies polonaise et lituanienne.

À cet égard, je tiens à remercier mon épouse Sabina pour ses traductions à partir du tchèque et du roumain, ainsi que Rasa Mažeika et Rūta Valaitytė pour leurs traductions à partir du lituanien.

De grande utilité ont été les présentations orales que j'ai eu le plaisir de donner lors de plusieurs colloques, notamment Diversity of Crusading, organisé à Odense au printemps 2016 par la Society for the Study of the Crusades and the Latin East et Vom Frieden von Kalisch bis zum Frieden von Oliva, organisé à Varsovie par l'Institut Historique Allemand et les Archives Centrales des Actes Anciens, en mai 2013. Les conseils et les remarques dont j'ai pu alors bénéficier sont pour beaucoup dans l'orientation de mon travail. 
De même, toutes les personnes à qui je me suis permis de demander conseil et qui m'ont aimablement répondu, qui ont lu des chapitres de ce travail, ou m'ont aidé d'une manière ou d'une autre, méritent ma reconnaissance: Diane Antille, Renate Blumenfeld-Kosinski, Kristian Boulinguez, Tim Brennan, Tomas Čelkis, Barbara Diaz Kayel, François Fahrni, Simon Gabay, Donna Golaz, Elena Guillemard, Isabelle Guyot-Bachy, Catherine Herr-Laporte, Norman Housley, Stéphane Ischi, Zbigniew Kobyliński, Paweł Kras, Kristina Markman, Christine Morerod, Alan V. Murray, Krzysztof Ożóg, Aleksander Pluskowski, Valentin Portnykh, Guillaume Reich, Nathalie Romans, Claire-Marie Schertz-Lomenech, Ludwik Stomma, Jaroslav Svátek, Marek Tamm, Michał Targowski, William Urban, Rūta Valaityté, Ludovic Viallet, Jan Vojtíšek, René Wetzel, Stanisław Wielgus, Lysanne Wyser. Je remercie également Alain Cortat, Anne-Caroline Le Coultre, Agnès Renucci, Sylvie Vieillard, et toute l'équipe de la maison d'édition Alphil, à Neuchâtel, qui ont accepté de donner une seconde vie à mon texte en l'éditant sous forme de livre. La beauté du présent objet témoigne de la qualité de leur travail.

Enfin, et surtout, j'aimerais remercier ma famille pour son intérêt sans cesse renouvelé, sa compréhension et son soutien sans lequel rien n'aurait été possible: mon épouse Sabina (ma première lectrice), nos filles Anaïs et Daphné, mes parents Anne-Marie et Régis, ma sœur Delphine et son ami David. 


\section{Abréviations}

ACC Acta Concilii Constanciensis, éd. H. Finke, J. Hollnsteiner, H. Heimpel, 4 vol., Münster 1896-1928.

BP Bullarium Poloniae: litteras apostolicas aliaque monumenta Poloniae Vaticana continens, 7 vol., éd. I. Sułkowska-Kuraś, S. Kuraś, M. Kowalczyk, A. et H. Wajs, Rome-Lublin 1982-2006.

CDMP Codex diplomaticus maioris Poloniae $=$ Kodeks dyplomatyczny wielkopolski, 10 vol. éd. I. Zakrzewski, F. Piekosiński, J. Kraszewski, W. Lebinski, A. Gąsiorowski, R. Walczak, T. Jasinski, Poznań-Varsovie 1877-1990.

CDP Codex diplomaticus Prussicus. Urkunden-Sammlung zur älteren Geschichte Preussens aus dem Königl. Geheim-Archiv zu Königsberg nebst Regesten, 6 vol., éd. J. Voigt, Königsberg 1836 - 1861.

CES Codex epistolaris saeculi decimi quinti, 3 vol., éd. A. Sokolowski, S. Szujski, A. Lewicki, Cracovie 1876-1894.

CEV Codex Epistolaris Vitoldi, éd. A. Prochaska, Cracovie 1882.

CM Codex Mednicensis Seu Samogitae Diocensis, éd. P. Jatulis, Rome 1984.

DHLF Dictionnaire Historique de la Langue Française, 2 vol., dir. A. Rey, Paris 1992.

GL Gedimino Laiskai (Poslanija Gedimina), éd. V. Pašuto, I. Stal', Vilnius 1966. 
LUB Liv-Esth- und Kurländisches Urkundenbuch, 14 vol., éd. F. G. von Bunge, H. Hildebrand, Tallinn 1853-1914.

PUB Preussisches Urkundenbuch, vol. I, 1, éd. R. Philippi, Königsberg 1882.

PR Paravicini Werner, Die Preussenreisen des Europäischen Adels, 2 vol., Sigmaringen 1989-1995.

SRP Scriptores Rerum Prussicarum. Die Geschichtsquellen der preußischen der preußischen Vorzeit bis zum Untergang der Ordensherrschaft, 6 vol., éd. T. Hirsch, M. Töppen, E. Strehlke, W. Hubatsch, Leipzig $1861-1968$. 


\section{INTRODUCTION}

$\mathrm{E}$ n 1147, Bernard de Clairvaux parvient à convaincre le pape Eugène III d'accorder des indulgences à ceux qui iront combattre les païens vivant au bord de la mer Baltique. Sous le motif de la défense et de l'expansion de la Chrétienté, un vaste espace s'étendant du nord de l'actuelle Allemagne à la Finlande devient un objectif des guerriers de Dieu. Deux ordres militaires, purs produits de l'idéologie de croisade, sont le fer de lance de cette lutte: l'Ordre des Chevaliers du Christ, en Livonie, et l'Ordre des Chevaliers teutoniques, en Prusse ${ }^{1}$. Ce dernier s'impose comme le principal moteur de l'expansion du christianisme dans cette région. Alors que la noblesse appuie l'Ordre teutonique dans sa lutte contre les païens baltes, un débat s'engage parmi les clercs quant à la justification de cette entreprise. La question refait surface après l'évangélisation de la Lituanie (1387), dont les derniers habitants païens reçoivent le baptême en 1417, à la suite d'une décision du concile de Constance.

Durant tout le $\mathrm{XIV}^{\mathrm{e}}$ siècle, de nombreux chevaliers originaires du Saint Empire, mais aussi de France, d'Angleterre, d'Italie et d'ailleurs, prêtent main-forte à l'Ordre teutonique dans sa lutte contre les Lituaniens, les derniers païens d'Europe continentale 2 . Pour les nobles d'Europe de l'Ouest, la croisade balte représente une alternative à la reconquête de la Terre sainte, difficilement réalisable après la chute d'Acre (1291). La mode des "rèses " ${ }^{3}$, ou "voyages" en Prusse, comme on nomme les expéditions menées aux côtés des Chevaliers teutoniques, s'empare de l'aristocratie occidentale. Des princes aux aventuriers en passant par les poètes et les romanciers, nombreux sont ceux qui visitent les terres de l'Ordre, comme "hôtes" venant participer au combat contre les Lituaniens, ou comme ambassadeurs. Leurs expériences trouvent un écho

\footnotetext{
${ }^{1}$ La Livonie correspond à la moitié nord de l'actuelle Lettonie et au sud de l'Estonie; la Prusse au nord-est de la Pologne et à l'enclave russe de Kaliningrad. Voir les cartes p. 129-133.

${ }^{2}$ Comme le note D. Baronas, "Christians in Late Pagan, and Pagans in Early Christian Lithuania ", Lithuanian Historical Studies 19, 2004, p. 52, les Lituaniens ne sont pas tout à fait «les derniers païens d'Europe»; au nord de l'actuelle Finlande et de la Russie, des populations sami et finno-ougriennes ont gardé leur religion traditionnelle jusqu'à l'époque moderne.

${ }_{3}$ Pour une discussion de ce terme et de son étymologie, voir p. 147.
} 
dans les pays de langue anglaise et surtout française: des provinces encore mal connues au XIII ${ }^{\mathrm{e}}$ siècle comme la Prusse, la Livonie ou la Lituanie font leur apparition dans plusieurs romans, chroniques, poèmes; la croisade du Nord devient phénomène littéraire. L'on découvre alors un monde fait d'héroïsme et d'aventures, où émerge la figure du Lituanien, «Sarrasin» à convertir ou à combattre, qui intrigue plus qu'il ne dégoûte.

L'imaginaire de la croisade balte est donc au centre de cet ouvrage. L'on suivra plus particulièrement les traces de croisés originaires des royaumes rivaux de France et d'Angleterre et des territoires voisins, plus ou moins impliqués dans la guerre de Cent $\mathrm{Ans}^{4}$. Afin de cerner les raisons pour lesquelles la chevalerie occidentale s'engage dans cette lointaine région, il convient d'examiner le rôle joué par les instances pontificales aux $\mathrm{XII}^{\mathrm{e}}$ et XIII ${ }^{e}$ siècles dans la mise en place de la croisade nordique, et l'écho qu'une telle entreprise a rencontré chez les auteurs français ou anglais du temps. Mettre en perspective les témoignages laissés par ceux qui sont allés combattre sur le rivage balte à partir du XIV siècle et le savoir accumulé en Europe de l'Ouest durant les deux siècles précédents permet non seulement de cerner la place que le front balte jouait dans l'idéologie paneuropéenne de la croisade, mais aussi d'observer la naissance d'une représentation particulière de cette région dans les lettres occidentales. Refuge du rêve pour les chevaliers occupés à la guerre déchirant les royaumes de France et d'Angleterre, la Baltique se fige en une frontière mentale, un monde d'héroïsme situé aux marges de la Chrétienté latine.

\section{SOURCES ET MÉTHODOLOGIE}

Papes, princes, chevaliers laïcs, membres d'ordres militaires ou simples combattants, ecclésiastiques, missionnaires et légats, les acteurs de ce drame ont été nombreux. Les narrateurs aussi. Les récits les plus détaillés nous sont fournis par des chroniqueurs résidant à proximité de la Baltique, mais l'intérêt pour cette région existe ailleurs en Europe, notamment dans les pays de langue française et anglaise. Ainsi, la mort de deux pionniers de la mission auprès des païens baltes, Adalbert de Prague (m. 997) et Bruno de Querfurt (m. 1009), trouve un écho dans les chroniques contemporaines d'Adémar de Chabannes (1029) et de Raoul Glaber (1047). La Papauté romaine, puis avignonnaise, suit avec un soin certain le destin de ces provinces amenées à rejoindre son obédience, et les ordres religieux ne sont pas en reste. Des encyclopédistes comme Barthélemy l'Anglais ou

\footnotetext{
${ }^{4}$ Par convention, le terme "français» regroupe également les auteurs issus de régions qui ne faisaient pas parties du royaume de France, mais qui en étaient culturellement et linguistiquement proches (par exemple la Savoie ou les actuelles Suisse romande et Belgique wallonne). Le français étant utilisé en parallèle de l'anglais parmi la noblesse anglaise, plusieurs textes français produits en Angleterre apparaissent dans le corpus.
} 
Thomas de Cantimpré ont rendu compte de l'évangélisation de la Prusse et de la Livonie, tout en s'efforçant de donner un aperçu du mode de vie des natifs. Le savant Roger Bacon tire de ces récits des arguments nourrissant ses attaques contre la conversion par la violence.

C'est surtout à partir du XIV siècle que des auteurs français et anglais écrivent sur la lutte contre ces "Sarrasins du Nord», intégrant leurs propres expériences de croisade, ou celles d'informateurs, à leurs œuvres. Parmi eux, Guillaume de Machaut, Jean de Mandeville, Geoffrey Chaucer ou Philippe de Mézières, mais aussi des personnalités moins connues, comme le patricien messin Jacques d'Esch, les frères Hugues et Guillebert de Lannoy ou le héraut d'armes Gilles le Bouvier, qui ont parcouru la région en croisés et en diplomates juste après la christianisation de la Lituanie. Alors que la diplomatie européenne tente d'intégrer cette nouvelle venue à un vaste projet de croisade, contre les Turcs cette fois-ci, des écrivains comme Antoine de la Sale s'emparent à leur tour du potentiel héroïque de la croisade balte pour en rendre l'atmosphère dans un mélange de souvenirs épiques et de références à la géopolitique du temps (Jean de Saintré, v. 1456). Enfin, des échos des voyages en Prusse se retrouvent probablement dans le Mélusine de Jean d'Arras (1393) et sa version en vers par Coudrette (1401), dans le Myreur des Histors, la chronique romancée de Jean d'Outremeuse (v. 1400) ou dans les Cent Nouvelles Nouvelles (1464-1467).

Bien sûr, il serait impossible d'observer le phénomène du seul point de vue français ou anglais: un recours à d'autres ressources s'impose, notamment la correspondance pontificale et ecclésiastique ${ }^{5}$, mais aussi les sources narratives produites au sein de l'Ordre teutonique, en Europe du Nord-Est et plus largement dans l'Empire. Si l'on omet le récit du voyageur anglo-saxon Wulfstan (fin du IX ${ }^{e}$ siècle), les écrits concernant le pourtour de la mer Baltique sont assez tardifs; on commence à s'intéresser à la région une fois que celle-ci devient un objectif pour les missionnaires. C'est dans le cadre du grand mouvement d'évangélisation de l'Europe du Nord et de l'Est, autour de l'an mil, que la Baltique fait son apparition dans quelques textes. Dans un premier temps, ceux-ci sont essentiellement produits dans des régions géographiquement proches. Quelques chroniques composées en Allemagne du Nord, en Pologne ou au Danemark permettent de suivre les premiers pas de la Chrétienté balte, avant que Bernard de Clairvaux ne proclame la croisade dans la région: la Chronique de Thietmar de Mersebourg (1018), les Gesta Hammaburgensis ecclesiae pontificum d'Adam de Brême (v. 1075) ou les Gesta principum Polonorum du chroniqueur appelé "Gallus Anonymus» (v. 1115). Couvrant les premières décennies de la croisade balte, on citera la Chronica Slavorum de Helmold de Bosau (v. 1171) et de son continuateur Arnold de Lübeck

\footnotetext{
5 Sur ce point, voir I. Fonnesberg-Schmidt, The Popes and the Baltic Crusades, 1147-1254, Leiden \& Boston 2007, p. 65-75.
} 
(v. 1210), les Gesta Danorum de Saxo Grammaticus (entre 1186 et 1208) ou la Chronica Polonorum de Vincent Kadłubek (entre 1190 et 1208) ${ }^{6}$.

Deux sources narratives sont particulièrement mises à contribution par les historiens travaillant sur l'activité des ordres militaires, qui commence en Livonie au tout début du $\mathrm{XIII}^{\mathrm{e}}$ siècle. En premier lieu, la Chronicon Livoniae d'Henri de Livonie (v. 1227), un clerc écrivant pour le compte du troisième évêque de Livonie, Albert de Buxhövden, et qui a travaillé comme vicaire parmi les Lettes, dont il parlait la langue ${ }^{7}$. En second lieu, la Chronicon Terrae Prussiae du clerc membre de l'Ordre teutonique Pierre de Dusbourg (13261331), adaptée en moyen haut allemand par Nicolas de Jeroschin (Kronik von Pruzinlant, 1331-1335). À ces deux chroniques s'ajoute la Chronique rimée de Livonie (Livländische Reimchronik, 1290-1296), composée par un membre anonyme de l'Ordre teutonique ${ }^{8}$. La seconde moitié du XIV ${ }^{\mathrm{e}}$ siècle est racontée notamment par le chapelain du maitre de Livonie, Hermann de Wartberge (Chronicon Livoniae, 1378) ${ }^{9}$ et le héraut du grand-maître Conrad de Wallenrode, Wigand de Marbourg (Chronica nova Prutenica, 1394) ${ }^{10}$. Pour le début du $\mathrm{XV}^{\mathrm{e}}$ siècle, l'on peut se référer à d'autres textes écrits par des auteurs proches de l'Ordre teutonique, en particulier la Chronique attribuée à Jean de Posilge (mort en 1405, et continuée après sa mort), les Annales de Toruń (début du $\mathrm{xv}^{\mathrm{e}}$ siècle) ou la Chronique des Grands Maîtres (anonyme, 1431-1433) ${ }^{11}$. Du

\footnotetext{
${ }^{6}$ Voir notamment N. Blomkvist, Discovery of the Baltic: the Reception of a Catholic World-System in the European North (Ad 1075-1225), Leiden 2005, p. 513-515 passim.

7 Ibid., p. 179-180, 510-513; J. BRundage, "The Thirteenth-Century Livonian Crusade: Henricus de Lettis and the First Legatine Mission of Bishop William of Modena", Jahrbücher für Geschichte Osteuropas. Neue Folge 20/1, 1972, p. 5-6; C. Tyerman, «Henry of Livonia and the Ideology of Crusading", dans M. Tamm, L. Kaljundi, et C. S. Jensen (dirs.), Crusading and Chronicle Writing on the Medieval Baltic Frontier: A Companion to the Chronicle of Henry of Livonia, Farnham 2011, p. 23-24. Parmi les nombreux travaux portant sur Henri de Livonie, on citera les plus récents: R. Mažeika, L. Chollet, «Familiar Marvels? French and German Crusaders and Chroniclers Confront Baltic Pagan Religions", Francia. Forschungen zur westeuropäischen Geschichte, 43, 2016, p. 41-62; A. V. MurraY, "Henry of Livonia and the Wends of the Eastern Baltic», Studi Medievali, 54, 2013, p. 807-833; les articles rassemblés dans M. Tамм et al. (dirs.), Crusading and Chronicle Writing... Sur l'ensemble de la production historiographique au sein de l'Ordre teutonique, voir notamment les articles réunis dans J. Wenta, S. Hartmann (dirs.), Mittelalterliche Kultur und Literatur im Deutschordensstaat in Preussen: Leben und Nachleben, Torún 2008.

8 E. Christiansen, The Northern Crusades, Londres \& New York 1980, p. 90-91; K. Kưavinš̌, "The Ideology of Christianity and Pagan Practices among the Teutonic Knights», Journal of Baltic Studies, 37/3, 2006, p. 267-268.

9 R. Mažeika, L. Chollet, «Familiar Marvels?...», p. 52-62.

${ }^{10}$ La chronique de Wigand, qui se veut une continuation de la Kronike von Pruzinlant de Jeroschin, a été composée en moyen haut allemand. Le texte original est en grande partie perdu, mais il a survécu dans une traduction latine composée pour l'historien polonais Jan Długosz dans les années 1460: R. Mažeika, L. Chollet, «Familiar Marvels? ...»; E. Bojtár, Foreword to the Past: a cultural history of the Baltic people, Budapest \& New York 1999, p. 184.

${ }_{11}$ S. Gouguenheim, Les Chevaliers teutoniques, Paris 2007, p. 406-409.
} 
côté polonais, il importe de mentionner le célèbre historien Jan Długosz, qui a travaillé à ses Annales seu Cronicae incliti regni Poloniae depuis 1460 et environ jusqu'à sa mort $(1480)^{12}$. La première chronique lituanienne, dite de Bychow, date quant à elle du premier quart du $\mathrm{XVI}^{\mathrm{e}}$ siècle $^{13}$. Enfin, quelques épisodes de la lutte entre Lituaniens, Polonais et Chevaliers teutoniques apparaissent dans la production historique de l'ancienne Rus' kiévienne ${ }^{14}$, notamment dans la Chronique de Galicie-Volhynie (v. 1261) ou dans celles de Novgorod et de Pskov $\left(\mathrm{xv}^{\mathrm{e}} \text { siècle }\right)^{15}$.

Une première difficulté réside dans la diversité des textes que nous allons aborder, et que nous réunissons, par convention, sous le terme de "littéraire", par opposition aux documents diplomatiques ou comptables ${ }^{16}$. La plupart d'entre eux, qu'ils soient en prose ou en vers, n'appartiennent pas à un genre bien défini, mais relèvent à la fois du roman, du traité de morale, du récit historiographique, de la relation de voyage et de la description du monde. Face à un tel mélange des genres, il faut se garder d'imposer aux textes une classification trop stricte. Néanmoins, bien que les interférences registrales soient nombreuses d'un genre à l'autre, toutes nos sources narratives ne sauraient être lues sous le même angle: un chroniqueur tel qu'Enguerrand de Monstrelet ou le Religieux de Saint-Denis, qui relatent tous deux la célèbre bataille de Tannenberg (1410), écrivait certainement selon un agenda politique bien précis, et pouvait nourrir des objectifs de portée sociale (tels que moraliser la chevalerie ou illustrer sa grandeur); il n'en avait pas moins une prétention à la crédibilité qui n'était pas le fait d'un romancier, à l'image de Jean d'Arras. Le Liégeois Jean d'Outremeuse pose un problème différent: son Myreur des Histors (v. 1400) se présente comme une chronique universelle, mais inclut

\footnotetext{
12 S. Gouguenheim, Tannenberg 1410, Paris 2012, p. 42.

13 S. Ekdahl, Die Schlacht bei Tannenberg: Quellenkritische Untersuchungen, Berlin 1982, p. 344-353. La chronique de Bychow est éditée dans Khronika Bykhovtsa, éd. N.N. Ulaszczik, Moscou 1966.

${ }^{14}$ La Rus' kiévienne est le nom donné à l'État apparu au IX ${ }^{e}$ siècle et centré autour de Kiev, ce qui correspond dans les grandes lignes à la première Russie médiévale. "Ruthène» et "Ruthénie» définissent les habitants et les territoires de cette ancienne principauté, disparue au XIII ${ }^{\mathrm{e}}$ siècle: c'està-dire de grandes parties des actuelles Ukraine, Biélorussie et Russie occidentale. Dans le contexte de l'histoire lituanienne, "Ruthène» est utilisé pour parler des Slaves orientaux qui habitent dans le grand-duché; Z. KIaupa, The History of Lithuania, Vilnius 2005, p. 19. Par convention, nous utilisons le terme "russe» pour parler des habitants ou des territoires actuellement situés en Russie (Novgorod, Moscou, etc.) et «ruthène» pour ceux situés en Ukraine ou en Biélorussie. Pour plus de détails, voir D. BEAuvors, «Les controverses historiographiques autour de l'Ukraine-Ruthénie (France, Russie, Pologne) ", dans N. Aleksiun et al., Histoire de l'Europe du Centre-Est, Paris 2004, p. $643 \mathrm{sq}$.

15 S. Gouguenheim, Tannenberg..., p. 44. Pour une traduction anglaise de ces chroniques, voir The Galician-Volynian Chronicle, éd. G. A. Perfecky, Munich 1973; The Chronicle of Novgorod. 1016-1471, éd. R. Michel, N. Forbes, Londres 1914.

${ }^{16}$ Pour une histoire et une définition du concept de littérature, voir T. Todorov, «La notion de littérature", dans La notion de littérature et autres essais, Paris 1987, p. 9-26.
} 
de nombreux éléments relevant manifestement de la fiction, du roman de chevalerie ${ }^{17}$. À l'inverse, Philippe de Mézières utilise le style allégorique pour son Songe du vieil pelerin (1389), mais tient à y dépeindre le monde tel qu'il lui apparaît; son œuvre a donc, par moment, la prétention au réel d'une chronique ou d'un récit de voyage (l'auteur ayant d'ailleurs parcouru une bonne partie des pays qu'il décrit) ${ }^{18}$. À cette dernière catégorie appartient sans doute l'œuvre qui a rendu Guillebert de Lannoy célèbre: ses Voyages et ambassades, rassemblés par son chapelain après sa mort à partir des notes prises durant sa longue vie (1386-1462) ${ }^{19}$. Son contemporain Gilles le Bouvier, héraut d'armes de son état (on le connaît comme le "héraut Berry») a probablement, lui aussi, visité une bonne partie des régions qu'il décrit dans son Livre de la description des pays (v. 1451) ${ }^{20}$. En outre, des chroniques peuvent contenir des récits d'aventures nordiques auxquelles ont participé l'auteur ou son informateur: ainsi, le très probable auteur de la Chronique de Metz, Jacques d'Esch (13711455), figure-t-il parmi les croisés qui ont pris part à la campagne menée aux côtés des Chevaliers teutoniques en 1399-1400. De même, le chevalier Jean de Chastelmorand (m. 1429) a sans doute dicté ses souvenirs de Prusse au chroniqueur Jean Cabaret d'Orville pour sa Chronique du Bon duc Loys de Bourbon (1429) ${ }^{21}$.

Ces écrits ne sauraient être pris comme des sources d'information objectives sur la croisade de Prusse, les intentions des acteurs qui y ont pris part ou le mode de vie de leurs adversaires païens: ils nous renseignent toutefois sur les horizons d'attente des auteurs et de leur public, et permettent d'approcher la conception que se faisait un certain milieu (clérical ou aristocratique) du phénomène qui nous intéresse ${ }^{22}$. La littérature a sans doute joué un rôle dans l'élaboration

\footnotetext{
${ }^{17}$ P. PÉPORTÉ, Constructing the Middle Ages: historiography, collective memory and nationbuilding in Luxembourg, Leiden 2011, p. 171.

${ }^{18}$ Sur l'écriture de Philippe de Mézières, voir l'introduction de la récente édition du Songe du Viel Pelerin par J. Blanchard (Philippe de Mézières, Le Songe du vieil pelerin, éd. J. Blanchard, 2 vols, Genève 2015; ci-après: Blanchard); et les articles rassemblés dans R. Blumenfeld-Kosinski, K. Petrov (dirs.), Philippe de Mézières and his Age. Piety and Politics in the Fourteenth Century, Leiden \& Boston 2012, ainsi que dans J. Blanchard, R. Blumenfeld-Kosinski (dirs.), Philippe de Mézières et l'Europe, Genève 2017.

${ }_{19}$ Une mise au point tenant compte d'un dernier manuscrit récemment redécouvert (Bibliothèque royale à Bruxelles, Ms. II 6978) est faite par J. SvÁtek, Discours et récit de noble voyageur à la fin du Moyen Âge (Ogier d'Anglure, Nompar de Caumont, Guillebert de Lannoy, Bertrandon de la Broquière), Lille \& Prague 2012 (thèse de doctorat non publiée), p. 42-46, 62.

${ }^{20}$ Voir l'introduction de l'édition de Gilles le Bouvier dit Berry, Livre de la description des pays, éd. E.-T. Hamy, Paris 1908 (ci-après: Hamy), p. 1-28 (en particulier p. 8-9 en ce qui concerne l'Europe du Nord et de l'Est).

${ }^{21}$ O. Mattéoni, «Portrait du prince idéal et idéologie nobiliaire dans "La Chronique du bon duc Loys de Bourbon" " (1429)", Studi Francesi, 115, 1995, p. 4-9.

22 Voir notamment la présentation de la méthode appelée «sentient empathy» par J. RiLEY-SMith, "Some Modern Approaches to the History of the Crusades", dans T. Nielsen, I. FonnesbergSchmidt (dirs.), Crusading on the Edge. Ideas and Practice of Crusading in Iberia and the Baltic
} 
d'un imaginaire lié à la croisade balte, et fournissait un certain modèle social qui, à son tour, incitait les jeunes seigneurs à visiter eux-mêmes ce haut lieu de chevalerie qu'était devenue, pour les nobles de la fin du Moyen Âge, la Prusse teutonique ${ }^{23}$. L'on pense notamment aux poèmes didactiques, qui, dès le Confort d'ami de Guillaume de Machaut (1357), incitent les prétendants à la chevalerie à tester leur valeur en affrontant les «infidèles", "En ces voyages d'oultremer / Et de Pruce et de Barbarie»". À l'inverse, quelques moralistes, comme Philippe de Mézières ou John Gower, se montrent réservés à l'égard de ces expéditions, considérées comme des préoccupations de chevaliers mondains.

Les textes qui constituent la base de notre analyse relèvent, quelle que soit leur forme, du récit de voyage. Ce genre spécifique recouvre un double objectif: dans le prologue de son Livre de la description des pays, le héraut Berry dit écrire pour faire "vëoir le monde, et les diverses choses qui y sont» à ceux qui "veullent savoir sans y aller», et parler "des païs, des hommes, et des aultres choses estranges $»^{25}$. Autrement dit, il s'agit tout à la fois d'instruire et de divertir ${ }^{26}$. Le lecteur moderne ne doit donc pas être surpris de trouver dans ces textes, parmi des descriptions se voulant réalistes, des évocations de merveilles appartenant à une tradition ancienne. Un homme comme Guillebert de Lannoy, chevalier, militaire, poète et courtisan du duc de Bourgogne Philippe le Bon, peut évoquer le Prêtre Jean, les châteaux où se déroulèrent les aventures de Lancelot et d'Arthur, ou le "trau saint Patrice", supposée porte d'entrée vers le purgatoire, tout en consignant des notes très précises sur les fortifications mameloukes du

Region, 1100-1500, Turnhout 2016, p. 16-24. Par exemple, l'analyse de N. Blomkvist (Discovery..., p. 106-109) portant sur les chroniques écrites plus proches de la Baltique peut s'appliquer aux textes produits en France ou en Angleterre.

${ }^{23}$ W. Paravicini, "La Prusse et l'Europe occidentale», Cahiers de recherches médiévales et humanistes, 1 (1996), p. 176-191; S. VANDER Elst, "Chivalry, Crusade, and Romance on the Baltic Frontier ", Mediaeval Studies, 73, 2011, p. 287-328. Pour une réflexion plus générale sur la littérature de voyage et/ou de fiction comme incitation à la mobilité, voir F. Hartog, Le Miroir d'Hérodote, Paris 1980, p. 303; B. LÉVY, "Géographie et littérature. Une synthèse historique", Le Globe, 146, 2006, p. 25-52. Sur la notion d'imaginaire comme objet d'étude pour l'historien du Moyen Âge, J. Le Goff, L'Imaginaire médiéval. Essais, Paris 1985, p. I-VIII.

${ }^{24}$ Jean Petit, Les condicions qui sont requises à l'enfant d'un seigneur à estre droit gentilz, v. 2858-2859, dans Le Livre du champ d'or et autres poèmes inédits, éd. P. Le Verdier, Rouen 1895, p. 132. Le terme «infidèle(s)» est, par convention, utilisé dans le sens de non-chrétien, et regroupe les païens, chamanistes ou animistes comme les juifs et les musulmans; une nuance est apportée par C. Carpini, "The Conversion of a People: the Catholic Church in Lithuania between Crusade, Mission and Settlement", Studia Russica, 18, 2000, p. 36 et Idem, "La Crociata senza Terrasanta. Nota preliminare per una ricerca sulla Crociata nel Baltico", Res Balticae, 9, 2004, p. 179-193. Pour cet auteur, païens ou animistes ne sauraient être considérés comme des infidèles, tout en reconnaissant que du point de vue des médiévaux, tous les non-chrétiens sont rangés dans cette catégorie, qu'ils pratiquent une religion du Livre ou non.

${ }^{25}$ Hamy, p. 29.

${ }^{26}$ Sur ce double objectif du récit de voyage, voir P. Boucheron, "L'invitation au voyage», dans Héros et merveilles du Moyen Âge. Arthur, Renard, la licorne et les fées, Paris 2013, p. 78. 
Caire ou de Jérusalem et en rendant compte avec précision des distances entre deux lieux parcourus ${ }^{27}$. La mission que lui avait confiée le duc - espionner en vue d'une éventuelle croisade - ne l'a pas empêché de parsemer ses notes de quelques détails évoquant les merveilles que tous connaissaient. Ses lecteurs, stratèges mais aussi hommes de cour, pouvaient sans doute distinguer les informations utilitaires des plaisantes ${ }^{28}$.

Nées au cours du Moyen Âge ou puisant leurs racines dans la littérature antique, les merveilles les plus célèbres ont pour fonction de marquer les limites du monde; les Amazones ou les cynocéphales ne sauraient se trouver dans des pays connus. Le savoir livresque issu de l'Antiquité et du Haut Moyen Âge n'est pas directement remis en cause par l'exploration; par respect de la tradition, on s'efforce dans une certaine mesure de faire coïncider les données nouvelles avec les catégories héritées des Autorités, mais on n'hésite pas à reléguer les merveilles toujours plus loin, à mesure que la connaissance du monde progresse ${ }^{29}$. Ces êtres ne sont pas nécessairement

27 J. Svátek, Discours..., p. 305-306. Sur le «trou de saint Patrick»: W. Paravicini, «Fakten und Fiktionen: Das Fegefeuer des hl. Patrick und die europäische Ritterschaft im späten Mittelalter», dans E. Bremer et S. Röhl (dirs.), Jean de Mandeville in Europa. Neue Perspektiven in der Reiseliteraturforschung, Münich 2007, p. 111-163.

${ }^{28}$ P. Boucheron, «L'invitation...», p. 78-79, prend l'exemple d'un autre voyageur bourguignon envoyé comme espion en Orient par Philippe le Bon, Bertrandon de la Broquière, lequel fait exactement la même chose dans son Voyage d'Outremer (1457) - un récit qu'il publie, contrairement à Lannoy. Voir aussi M. Nejedlý, "Spisy středověkých cestovatelů jako podnět k "poutím mimo vyšlapané stezky" ", dans Guillebert de Lannoy, Cesty a poselstva, éd. et trad. J. Svátek, M. Nejedlý, O. Marin, P. Soukup, Prague 2009, p. 113-117. M. Holban, «Du caractère de l'ambassade de Guillebert de Lannoy dans le nord et le sud-est de l'Europe en 1421 ", Revue des études sud-est européennes: Civilisations - Mentalités, 5, 1967, p. 419-434, a établi deux phases d'écriture du récit de Lannoy: une première, sorte de canevas pour de possibles rapports écrits, qui rend compte de manière assez fidèle des lieux visités et des tâches accomplies en lien avec les fonctions officielles de l'auteur; puis une deuxième, datant sans doute des vieux jours de Lannoy, où celui-ci aurait dicté quelques souvenirs plus "épiques» à son chapelain, le goût du romanesque et de l'aventure l'emportant sur le souci d'authenticité. M. NejedLÝ, "Spisy...», p. 112, suppose que l'auteur entendait peut-être développer ses notes pour en faire un récit de voyage en bonne et due forme, mais n'en eut pas le temps; aussi, ses Voyages et ambassades seraient restés à l'état de brouillon. La description que Guillebert de Lannoy nous a laissée des principautés russes de Pskov et de Novgorod est en tout cas considérée comme fiable par les spécialistes, par exemple; S. Mund, "Guillebert de Lannoy, un observateur fiable de la réalité russe au début du XV siècle", dans C. Billen , J.-M. Duvosquel, A. Vanrie (dirs.), Hainaut et Tournaisis, Regards sur dix siècles d'histoire, Bruxelles 2000, p. 179-193; S. Mund, «Opisanie Novgoroda i Pskova v memuarakh Voyages et ambassades rytsarya Gil'bera de Lannoa (1413)", Drevniaia Rus': Voprosy medievistiki 1 (7), 2002, p. 47-50; A. V. Soloviev, «Le voyage de messire de Lannoy dans les pays russes», dans D. Gerhard (éd.), Orbis scriptus, Munich 1966, p. 791-796.

${ }^{29}$ C. Deluz, «Des Lointains merveilleux (d'après quelques textes géographiques et récits de voyage du Moyen Âge)", dans C. Deluz (dir.), De l'étranger à l'étrange ou la conjointure de la merveille, Aix-en-Provence 1988, p. 157-169 [en ligne]; N. Bouloux, «Les formes d'intégration des récits de voyage dans la géographie savante. Quelques remarques et un cas d'étude: Roger Bacon, lecteur de Guillaume de Rubrouck», dans H. Bresc, E. Tixier du Mesnil (dirs.), Géographes et voyageurs au Moyen Âge, Nanterre 2010, p. 119-146 [en ligne]. Pour une analyse du cas balte: M. TAMM, «A 
considérés comme réels par les auteurs médiévaux et leur public: marqueurs symboliques, ils répondent au goût des lecteurs pour le merveilleux, le fantastique ${ }^{30}$. Plus modestes, les merveilles naturelles ${ }^{31}$, tels qu'hivers particulièrement froids ou marais impénétrables, évoquent un monde héroïque, rendant possible l'émergence de souvenirs arthuriens; dans le cas qui nous occupe, le cadre de la croisade balte se confond volontiers avec celui des romans chevaleresques. Ce qui ne signifie pas que tout ce que l'on trouve dans nos sources littéraires ne soit qu'invention.

L'image des populations autochtones telle qu'elle apparaît dans les récits des chroniqueurs installés sur les rives de la Baltique est un bon point de départ. Les auteurs cherchant à donner une image complète de tous les protagonistes, on trouve dans leurs œuvres d'intéressantes descriptions "ethnographiques» des peuples baltes. Bien sûr, il importe de ne pas prendre ces témoignages à la lettre, étant donné le risque évident de biais induit par la différence religieuse. Ce dernier se manifeste de plusieurs manières: contrairement à une vision assez répandue faisant des païens l' «Autre» absolu, image inversée des bons chrétiens $^{32}$, Pierre de Dusbourg, un clerc membre de l'Ordre teutonique, entendait utiliser les païens comme modèles moraux, pour rappeler qu'à leur manière, ils étaient peut-être plus pieux que bien des chrétiens ${ }^{33}$. Une stratégie littéraire visant à édifier le lecteur, mais aussi à donner des adversaires dignes d'eux aux héros dont on raconte l'histoire. Ainsi, la très épique Chronique rimée de Livonie loue la bravoure des ennemis de la croix ${ }^{34}$, alors que les chroniqueurs du XIv siècle Hermann de Wartberge et Wigand de Marbourg dépeignent les guerriers lituaniens sous des traits chevaleresques ${ }^{35}$. Dès

New World into Old Words: The Eastern Baltic Region and the Cultural Geography of Medieval Europe", dans A. V. Murray (dir), The Clash of Cultures on the Baltic Frontier, Farnham 2009, p. 11-35.

30 P. Boucheron, «L'invitation... », p. 79; Idem, "La fausse lettre du Prêtre Jean », dans Héros et merveilles..., p. 80-81; C. Deluz, "Des Lointains merveilleux...»; J. Le Goff, «Le merveilleux dans l'Occident médiéval ", dans L'imaginaire médiéval..., p. 17-40. Sur le jeu littéraire autour de la frontière entre réel et imaginaire, voir notamment T. Todorov, Littérature et signification, Paris 1967, en particulier p. 91-118.

31 Sur les merveilles de la nature, C. DeLuz, «Des Lointains merveilleux...».

32 Par exemple, V. Matuzova, «Mental Frontiers: Prussians as Seen by Peter von Dusburg», dans A. V. Murray (dir.), Crusade and Conversion on the Baltic Frontier, 1150-1500, Aldershot 2001, p. 253-259.

33 S. C. Rowell, Lithuania Ascending: A Pagan Empire within East-Central Europe, 1295-1345, Cambridge 1994, p. 39. L' «autre» comme miroir de la société dont sont issus l'auteur et ses lecteurs semble être une constante dans la littérature occidentale, même s'il ne s'agit pas forcément de faire honte à ces derniers en leur montrant l'image de vertueux «barbares». F. Hartog, Le Miroir..., p. 52; T. Todorov, Nous et les Autres, Paris 1989, p. 297-303. Pour une comparaison avec le $\mathrm{XVII}^{\mathrm{e}}$ siècle, voir S. Requemora, «L'espace dans la littérature de voyage», Études littéraires, 34/1-2, 2002, p. 272.

${ }^{34}$ K. KL,avin̦š, "The Ideology... », p. 267.

${ }^{35}$ L'exemple le plus célèbre est celui du duc Kęstutis (m. 1382), censé prévenir le maréchal de l'Ordre avant d'attaquer la Prusse et faisant preuve de respect pour ceux de ses adversaires qu'il 
Henri de Livonie, les princes païens sont individualisés; certains aident les chrétiens, d'autres les combattent; on s'allie, on se trahit; on se méprise, on se respecte. Bien souvent, les pires injures ne sont pas réservées aux païens, mais aux apostats ${ }^{36}$.

Dans le cas de Pierre de Dusbourg, l'historienne canadienne Rasa Mažeika rappelle que sa Chronique visait, vraisemblablement, à donner des arguments au grand-maître Werner d'Orseln, dont la position face à la Papauté d'Avignon était rendue difficile. Afin de présenter la croisade menée par l'Ordre comme une guerre juste, Dusbourg ne dépeint donc les Prussiens ni comme des "nobles sauvages" ${ }^{37} \mathrm{ni}$ comme une "image inversée du christianisme»", mais comme des adversaires ambivalents, qui, par leur attitude, justifient l'action des Chevaliers teutoniques. Ainsi, on trouve, à côté de topoï aisément identifiables (l'adoration de la nature, la naïveté), quelques éléments qui donnent l'impression de détails plus réalistes, presque "ethnographiques ${ }^{39}$. Quant aux injures envers Dieu et à l'apostasie, qui reviennent souvent chez les Prussiens de Dusbourg, elles permettent de répondre à deux points de la doctrine médiévale de la guerre juste: se venger des insultes et ramener les apostats dans le troupeau de l'Église ${ }^{40}$.

Les auteurs écrivant en terres baltiques partagent une même culture chrétienne, latine, avec leurs pairs de France ou d'Angleterre: aux critères juridico-moraux devant justifier l'attitude de leurs patrons s'ajoute un fond culturel commun, profane comme religieux ${ }^{41}$. À titre d'exemple, un Rolandslied a été composé en l'honneur du duc de Saxe Henri le Lion, conquérant des Slaves de la Baltique (v. 1130-1195). Les mêmes topoï apparaissent dans des textes écrits en Prusse, en Allemagne du Nord ou à Paris : l'offrande et le bûcher lors des funérailles des païens, la forêt et les marais comme refuges de ceux-ci. Fait intéressant, une partie de ces traits sont confirmés par l'archéologie. Ainsi, la crémation et la pratique de l'offrande funéraire ont vraisemblablement existé dans certains contextes. Quant au caractère marécageux et sauvage de la forêt séparant la Prusse de la Lituanie, il est bien attestét ${ }^{42}$.

estime le plus: R. MAžEıKA, "An Amicable Enmity: some peculiarities in Teutonic-Balt relations», dans C. Ingrao, F. Szabo (dirs.), The Germans and the East, West Lafayette 2007, p. 49-58.

${ }^{36}$ R. Mažeika, "Pagans, Saints, and War Criminals: Direct Speech as a Sign of Liminal Interchanges in Latin Chronicles of the Baltic Crusades", Viator 45/2, 2014, p. 271-288.

37 S. C. Rowell, Lithuania Ascending..., p. 40.

38 V. Matuzova, «Mental Frontiers...», p. 253-259.

39 Ces détails avaient sans doute aussi pour but d'amuser les lecteurs. R. MAŽEIKA, «Violent Victims: Surprising Aspects of the Just War Theory in the Chronicle of Peter von Dusburg", dans A. V. Murray (dir.), The Clash of Cultures..., p. 125, parle d' "entertaining exotica».

${ }^{40}$ Ibid., p. 123-137.

41 Sur ce point, P. Borsa, C. Høgel, L. B. Mortensen, E. Tyler, «What is European Medieval Literature?», Interfaces 1, 2015, p. 7-24.

42 S. C. Rowell, Lithuania Ascending..., p. 128-130; voir notamment les études de M. Tамm, "Inventing Livonia: The Name and Fame of a New Christian Colony on the 
Aussi tend-on aujourd'hui à considérer une partie importante des détails racontés par ces chroniqueurs comme crédible. L'historien suédois Nils Blomkvist ${ }^{43}$ applique au cas balte les réflexions de Carlo Ginzburg à propos de l'ekphrasis dans les œuvres des historiens grecs ${ }^{44}$ : les chroniqueurs, en tant qu'historiens, mais aussi en tant que créateurs, en tant qu'écrivains, prétendaient convaincre leur public; celui qui cherche à convaincre ne dit pas forcément ce que lui-même pense être vrai, mais ce que son auditoire considère comme tel ${ }^{45}$. Le but d'une description insérée dans une ouvre littéraire est de créer un effet de réel. On peut donc postuler que pour que le mécanisme soit efficace, un chroniqueur doit rester vraisemblable: c'est ce qui fait la différence entre une fiction à caractère historique et l'œuvre d'un historiographe. Dans le cas des chroniques baltes, on remarque régulièrement une tendance à la rationalisation, une remise en cause des rumeurs. Si les chroniqueurs aiment raconter des histoires pour "faire vrai», ou plus simplement pour amuser leurs lecteurs, cela ne veut pas dire que tout ce qu'ils racontent est systématiquement faux ${ }^{46}$. Tout ne saurait donc être réduit à de simples clichés littéraires déconnectés d'une réalité devenue insaisissable.

Il convient encore de préciser le lien que peuvent avoir les textes produits sur le rivage balte avec ceux qui nous occupent principalement, à savoir les traités, les récits de voyages ou les romans de nos clercs et chevaliers français ou anglais. Les statuts de l'Ordre teutonique mentionnent que lecture doit être faite aux chevaliers pendant les repas, "afin que leur bouche ne reçoive pas seulement la nourriture, mais aussi que leurs oreilles soient affamées de la parole de Dieu ${ }^{47}$; on suppose que parmi les lectures de table, les œuvres historiques en langue vernaculaire figuraient en bonne place. Se basant sur une allusion de Pierre de Dusbourg, Rasa Mažeika juge probable que celui-ci ait espéré que sa chronique soit traduite et lue aux repas des membres de l'Ordre, ceci au

Medieval Baltic Frontier", Zeitschrift für Ostmitteleuropa-Forschung 60/2, 2011, p. 186-209; A. Pluskowski, The Archaeology of the Prussian Crusade: Holy War and Colonisation, Londres 2013; E. Bazaraité, T. Heitor, "Comparative Study of Christian and Pagan Burial Constructions", Mosklas - Lietuvos Ateitis/Science - Future of Lithuania 5/3, 2013, p. 317-318; H. Valk, "Christianisation in Estonia: A Process of Dual-Faith and Syncretism", dans M. Carver (dir.), The Cross goes North: Processes of Conversion in Northern Europe, AD 300-1300, Woodbridge 2003, p. 571-580.

43 N. Blomkvist, Discovery..., p. 106-109.

${ }^{44}$ C. Ginzburg, "Ekphrasis and Quotation», Tijdschrift Voor Filosofie, 50/1, 1988, p. 3-19. L'ekphrasis est, dans le contexte de la littérature antique, une description rendue en général dans un style soutenu.

45 N. Blomkvist, Discovery..., p. 109, n. 31.

46 Comme le note R. MAžEIKA, "The Grand Duchy rejoins Europe», Journal of Medieval History, 21, 1995, p. $290:$ : A topos can also be true».

47 "... ne sole eis fauces sumant cibum, sed et aures esuriant Dei verbum", Die Statuten des Deutschen Ordens nach den aeltesten Handschriften, éd. M. Perlbach, Halle 1890, p. 41. 
lieu des "faits des rois et des princes, et des vanités de ce monde» ${ }^{48}$ qui occupaient habituellement les chevaliers pendant leurs repas ${ }^{49}$.

Pour Mary Fischer, il ne fait pas de doute que la traduction de Dusbourg en allemand par Jeroschin ait fait partie des "textes de dévotion et d'inspiration" en langue vernaculaire que les dirigeants de l'Ordre mettaient à disposition des nombreux frères qui ne maîtrisaient pas le latin ${ }^{50}$. Par contre, il est envisageable que ce texte ait également été destiné à être lu en présence des hôtes venus combattre les païens aux côtés des Teutoniques, et plus encore à être diffusé au-delà de la Prusse ${ }^{51}$. Ainsi, le but premier des chroniques de Dusbourg et Jeroschin aurait été de justifier la croisade auprès de la Papauté et de populariser le combat de l'Ordre en terres d'Empire, d'où venaient les principaux soutiens au XIII et au début du XIV ${ }^{e}$ siècles ${ }^{52}$. Alan V. Murray fait la même constatation en ce qui concerne la Chronique rimée de Livonie, dont l'objectif aurait été à la fois de mettre à disposition des Teutoniques l'histoire de leur Ordre en Livonie et d'attirer de nouveaux croisés, sensibilisés aux aléas de la présence chrétienne en Europe du Nord-Est ${ }^{53}$. L'usage des chroniques de l'Ordre ne se limitait donc pas forcément au seul Tischlesung. Certes, la lecture d'œuvres pieuses aurait été

${ }^{48}$ Il s'agit d'une anecdote au sujet de l'apparition de la Vierge à un chevalier, à qui elle se plaint du choix des lectures faites aux repas des membres de l'Ordre: «ipse tristicie causam diligencius investigaret, ipsa respondit: hoc movet me ad turbacionem, quod dilecti filii mei, fratres tui, de domo Theutonica non referebant quondam in collacionibus suis, nisi de filio meo et me et de gestis sanctorum; modo non referunt, nisi de factis regum et principum et seculi vanitate, ita quod filius meus et ego et sanctorum vita rare vel nunquam recitatur", Pierre de Dusbourg, Chronicon Terre Prussie, éd. M. Töppen, Scriptores Rerum Prussicarum (ci-après: SRP), vol. 1, Leipzig 1861, p. 95. R. Mažeika («Violent Victims...», p. 125) suppose que cette remarque dévoile l’intention de Dusbourg de proposer un texte certes très héroïque, mais néanmoins assez moralisant pour être digne de remplacer les épopées dont raffolaient les chevaliers; un mélange des genres qui expliquerait que l'auteur ait placé plusieurs anecdotes amusantes dans son texte. L'édition de la chronique de Dusbourg par M. Töppen reste largement utilisée, mais il vaut la peine de noter qu'une nouvelle édition a vu le jour: Kronika ziemi pruskiej, éd. J. Wenta, S. Wyszomirski, Cracovie 2007. Des traductions existent notamment en allemand (Chronik des Preussenlandes, éd. et trad. K. Scholz, D. Wojtecki, Darmstadt 1984), en polonais (Kronika ziemi pruskiej, trad. S. Wyszomirski, J. Wenta, Toruń 2005) et en italien (Cronaca della terre di Prussia, éd. et trad. P. Bugiani, Spoleto 2012): R. Mažeika, "Violent Victims...", p. 123, n. 1; A. V. Murray, "Heathens, Devils and Saracens. Crusader Concepts of the Pagan Enemy during the Baltic Crusades (Twelfth to Fifteenth Centuries)", dans T. Nielsen, I. Fonnesberg-Schmidt (dirs), Crusading on the Edge..., p. 204.

${ }^{49}$ R. Mažeika, "Violent Victims...», p. 124-125. Voir aussi A. Mentzel-Reuters, Arma Spiritualia. Bibliotheken, Bücher und Bildung im Deutschen Orden, Wiesbaden 2003, p. 76-82.

${ }_{50}$ Nicolas de Jeroschin, The Chronicle of Prussia. A History of the Teutonic Knights in Prussia, 1190-1331, trad. et intro. M. Fischer, Aldershot 2011, p. 13-14; voir aussi le compte-rendu par S. Gouguenheim dans Francia-Recensio 2011/2 Mittelalter - Moyen Âge (500-1500) [en ligne].

51 R. G. PäsLER, Deutschsprachige Sachliteratur im Preussenland bis 1500. Intersuchungen zu ihrer Uberlieferung, Cologne etc. 2003, p. 283-284.

52 A. Kotov, "Novoe "pole boya" Tevtonskogo ordena», dans I. O. Dementiev (dir.), Studia Teutonica. Issledovaniya po istorii Nemetskogo Ordena, Kaliningrad 2012, p. 99.

53 A. V. Murray, "The structure, genre and intended audience of the Livonian Rhymed Chronicle», dans A. V. Murray (dir.), Crusade and Conversion..., p. 235-250. 
plus à même d'accompagner les repas des Teutoniques ${ }^{54}$, mais comme le montre la remarque de Dusbourg, ceux-ci préféraient se faire lire des épopées. À n’en pas douter, les chroniques racontant l'histoire de l'Ordre devaient aussi trouver un public dans les rangs des Chevaliers ${ }^{55}$.

Qu'elles aient été lues lors des repas des seuls Chevaliers teutoniques ou en présence des hôtes de marque, les chroniques composées par des membres de l'Ordre devaient être connues de leurs pairs ${ }^{56}$; il y a fort à parier que ceux-ci avaient en tête les événements décrits, auxquels certains d'entre eux avaient peut-être participé. Aussi étaient-ils en mesure de répondre aux questions des hôtes curieux, de leur conter quelques aventures et de leur dresser le portrait d'ennemis ou d'alliés - par exemple, des fameux Lituaniens, principaux adversaires à partir du XIV siècle. La transmission orale, attestée au moins dans le cas de Philippe de Mézières, expliquerait ainsi que quelques éléments se trouvent à la fois dans les chroniques de l'Ordre teutonique et dans des productions littéraires françaises ou anglaises ${ }^{57}$. Enfin, à côté des sources narratives, de rares images nous sont parvenues, et permettent d'appuyer quelques traits spécifiques de la perception de la croisade balte en Europe de l'Ouest; ces représentations visuelles, fresques, œuvres héraldiques ou illustrations de manuscrits, datent essentiellement des XIV et $\mathrm{XV}^{\mathrm{e}}$ siècles.

\section{ÉTAT DE LA QUESTION}

La confrontation entre l'Europe chrétienne et les derniers peuples païens du continent a fait couler beaucoup d'encre. Dès le Moyen Âge, chroniqueurs et historiens s'attachent à présenter une version des faits qui fasse jouer le beau rôle à leurs patrons, ou qui corresponde aux causes que l'on entend défendre ${ }^{58}$. C'est ainsi que la Prusse, la Pologne et la Lituanie médiévales font leur apparition dans le champ historique français lorsque Henri de Valois, élu roi de Pologne en 1573, commande plusieurs histoires de ce pays, adaptées d'une œuvre de l'ambassadeur polonais à Paris, Jan Herburt de Fulstin, qui a lui-même utilisé les travaux de Jan Długosz (m. 1480) et de Martin Cromer (m. 1589) ${ }^{59}$. Plus tard, l'auteur

\footnotetext{
54 A. Mentzel-Reuters, Arma Spiritualia..., p. 81; A. V. Murray, «The structure...", p. 242.

55 C'est l'avis de R. Mažeika et S. Gouguenheim, que je remercie. Voir aussi A. V. Murray, "The structure...», p. 250; K. KL̦Avinšs, «The Ideology...», p. 267-268.

${ }^{56}$ Sur la tradition interne à l'Ordre teutonique, voir J. WeNTA, "Od tradycji ustnej do tradycji pisanej na przykladzie Kroniki Piotra z Dusburga", Res Historica, 3, 1998, p. 73-85.

57 Il est peu probable que les auteurs français ou anglais aient lu les chroniques teutoniques, mais la question reste débattue parmi les historiens.

58 Pour un passage en revue de l'historiographie, D. Buschinger, M. Olivier, Les Chevaliers teutoniques, Paris 2007, p. 403-489; S. EKDaHL, "Crusades and Colonisation... ", p. 1-43.

59 Il s'agit notamment de l'Histoire des Roys et Princes de Pologne par François Bauduin (1573) et des Chroniques et Annales de Pologne (1573), ainsi que d'une Description du Royaume de Pologne et pays Adjacens (1573) par Blaise de Vigénère: J. KŁoczowski, M. Woznrweski, "Les premières histoires de la Pologne publiées en France, à l'occasion de l'élection d'Henri de Valois", dans
} 
protestant Jacques Lenfant insère quelques précisions sur la conversion de la Lituanie et de la Samogitie dans son Histoire du concile de Constance (1714), pour laquelle il se base également sur Długosz. Impopulaire pour les historiens polonais comme prussiens - ceux-ci écrivant après la guerre de Treize ans et la sécularisation de l'Ordre en Prusse -, la guerre menée par les Teutoniques représente, à l'époque des Lumières, l'apogée du fanatisme catholique médiéval ${ }^{60}$. À la fin du siècle, en 1784, paraît le premier volume de l'Histoire de l'Ordre teutonique par le baron von Wal, lui-même membre de l'Ordre, qui écrit en français et publie à Paris, dans le but, dit-il, de contrer "l'opiniâtreté avec laquelle [les historiens polonais] ont calomnié l'Ordre teutonique» "61. L'histoire de cet ordre militaire a par la suite été pris en otage par les nationalismes du XVIII ${ }^{\mathrm{e}}$ siècle finissant, et ceci jusqu'aux années 1950 au moins ${ }^{62}$.

Faire de l'Ordre teutonique un fer de lance de l'impérialisme allemand est l'une des principales préoccupations des historiens de la Prusse impériale, à partir d'Heinrich von Treitschke (m. 1896). Quant à eux, les patriotes polonais et lituaniens (aristocrates polonophiles et polonophones), tels que Theodor Narbutt (m. 1864) et Joachim Lelewel (m. 1861) s'attachent à faire revivre la mémoire de leurs ancêtres ${ }^{63}$. De vastes entreprises d'édition de sources viennent à l'aide des historiens du XIX ${ }^{\mathrm{e}}$ siècle, et leur utilité ne saurait être mise en doute à l'heure du numérique: entre autres, le Codex Diplomaticus Lithuaniae, édité par Edward Raczyński (1845), les Vetera monumenta Poloniae et Lithuaniae... par Augustin Theiner (1860-1864, quatre vols.) ou les Scriptores Rerum Prussicarum par Theodor Hirsch, Max Töppen et Ernst Strehlke (18611874, cinq vols.). Plus proche de nous, citons simplement la récente édition par Sławomir Jóźwiak, Adam Szweda et Sobiesław Szybkowski des documents de la mission du légat pontifical Antonio Zeno, chargé en 1422-1423 de trancher les différends entre l'Ordre teutonique et le royaume de Pologne ${ }^{64}$ ou celle, préparée par des chercheurs lituaniens et polonais, des documents de l'union de Horodło passée entre la Pologne et la Lituanie en $1413^{65}$.

R. SAuzet (dir.), Henri III et son temps: actes du colloque international du Centre de la Renaissance de Tours, octobre 1989, Paris 1992, p. 103-109; S. Gouguenheim, "Das Echo der Schlacht bei Grunwald im Frankreich des XV. und XVI. Jahrhunderts», dans K. OżóG, J. Trupinda (dirs.), Conflictus Magnus apud Grunwald 1410. Między Histori a Tradycją, Malbork 2013, p. 192-206;

D. Buschinger, M. Olivier, Les Chevaliers teutoniques..., p. 462-463.

${ }^{60}$ Ibid., p. 404-415; S. EKDAHL, "Crusades and Colonisation...", p. 12. Par convention, le terme «catholique» fait référence au christianisme romain, et «orthodoxe» au christianisme grec.

${ }^{61}$ W. E. J. von WaL, Histoire de l'Ordre teutonique par un chevalier de l'Ordre, Paris 1784, vol. 1, p. VI-V.

62 Sur la question, voir notamment S. EkDAHL, "Crusades and Colonisation...», p. 12-25.

63 D. Buschinger, M. Olivier, Les Chevaliers teutoniques..., p. 416-424.

${ }^{64}$ Lites ac res gestae inter Polonos Ordinemque Cruciferorum: akta postępowania przed Antonim z Mediolanu w latach 1422-1423, éd. S. Jóźwiak, A. Szweda, S. Szybkowski, Toruń 2015.

${ }^{65} 1413 \mathrm{~m}$. Horodles aktai: dokumentai ir tyrinejimai = Akty horodelskie z 1413 roku (dokumenty $i$ studia), éd. J. Kiaupienè, L. Korczak, P. Rabiej, E. Rimša, J. Wroniszewski, Vilnius \& Cracovie 2013. 
À partir des années 1950, les historiens polonais et lituaniens, certains en exil, ont participé à faire connaître le passé de leurs pays en Europe occidentale et en Amérique du Nord ${ }^{66}$. L'éclatement du bloc soviétique a vu un renouveau de l'étude du Moyen Âge balte, rendu possible par l'intérêt porté aux nouveaux États de Lituanie, Lettonie et Estonie, et la fin du carcan idéologique imposé aux intellectuels d'ex-URSS ${ }^{67}$. Les tensions politiques, exacerbées par les deux guerres mondiales, la récupération du mythe teutonique par l'Allemagne nazie ${ }^{68}$ puis le contexte de la Guerre froide, sont aujourd'hui apaisées, rendant possible une meilleure collaboration entre historiens allemands, baltes et polonais ${ }^{69}$. En guise d'exemple, le six centième anniversaire de la bataille de Tannenberg (1410), événement dont la mémoire avait longtemps cristallisé les rivalités nationales ${ }^{70}$, a permis la production de plusieurs études de qualité, réunissant des chercheurs d'horizons variés, issus d'Europe et d'ailleurs ${ }^{71}$.

L'histoire politique et religieuse particulière de cette région a attiré le regard d'historiens français ou anglo-saxons, qui se sont surtout intéressés à la conquête et à l'intégration des nouvelles provinces dans l'Europe chrétienne (Robert Bartlett ${ }^{72}$ ), à la destinée de l'Ordre teutonique (Sylvain Gouguenheim

${ }^{66}$ Outre l'emblématique médiéviste polonais Bronisław Geremek, citons, plus proches de nos domaines, Oskar Halecki, Henryk Paszkiewicz, Jerzy Wyrozumski, Alexander Gieysztor, Michał Giedroyć, Jerzy Kłoczowski, Petras Klimas, Joseph Koncius; voir les études réunies dans M. Zadencka, A. Plakans, A. Lawaty (dirs), East and Central European History Writing in Exile, Leiden 2015.

${ }^{67}$ R. Mažeika, "The Grand Duchy rejoins Europe...», p. 289-303. Citons notamment Edvardas Gudavičius, Alvydas Nikžentaitis, Alfredas Bumblauskas, Stephen C. Rowell, Rymvidas Petrauskas et Rasa Mažeika elle-même.

${ }_{68}$ Plusieurs spécialistes de l'Ordre teutonique ont collaboré, d'une manière ou d'une autre, à la propagande du régime hitlérien ou au pillage des archives en pays occupés : parmi eux, Erich Maschke, Erich Weise et Kurt Forstreuter. Voir M. Burleigh, Prussian Society and the German Order: An Aristocratic Corporation in Crisis c. 1410-1466, Cambridge \& New York 1984, p. 38; S. Ekdahl, "Crusades and Colonisation...", p. 14-15; B. SchneIder, Erich Maschke._Im Beziehungsgeflecht von Politik und Geschichtswissenschaft, Göttingen 2016; C. Hess, The Absent Jews. Kurt Forstreuter and the Historiography of Medieval Prussia, New York 2017. Sur le versant soviétique de la récupération historique, voir notamment S. EKDAHL, "Crusades and Colonisation...", p. 16-20.

69 S. Gouguenheim, Tannenberg..., p. 213; S. Ekdahl, "Crusades and Colonisation... ", p. 24. Une polémique a toutefois eu lieu en 2003, lorsque l'historien russe Yuri Klitsenko attaque les thèses de William Urban, jugées impérialistes; ibid., p. 28-29.

${ }^{70}$ A. Nikžentaitis, Ž. Mikailiené, «Lithuanian Žalgiris, Polish Grunwald: two National Topoï in the Context of Comparative Analysis", Zapisky Historyczne 75/2, 2010, p. 5-16; S. Gouguenheim, Tannenberg..., p. 209-213.

${ }^{71}$ Notamment les collaborations internationales réunies dans W. Paravicini, R. Petrauskas, G. Vercamer (dirs.), Tannenberg - Grunwald - Žalgiris 1410: Krieg und Frieden im späten Mittelalter, Wiesbaden 2012; K. OżóG, J. Trupinda (dirs.), Conflictus Magnus... À cet intérêt pour la bataille, on peut ajouter l'étude de S. Jóźwiak, K. Kwiatкowski, A. Szweda et S. SzYbKowski, Wojna Polski i Litwy z zakonem krzyżackim w latach 1409-1411, Malbork 2010.

72 R. Bartlett, The Making of Europe. Conquest, Colonization, and Cultural Change, 950-1350, Londres 1994; Idem, "The Conversion of a Pagan Society in the Middle Ages ", History, 70, 1985, p. 185-201. 
et Mathieu Olivier en France, William Urban aux États-Unis ${ }^{73}$ ) ou du grandduché de Lituanie, vaste pays multiculturel dirigé jusqu'en 1386 par une dynastie païenne (Stephen C. Rowell, Rasa Mažeika, Michał Giedroyćc ${ }^{74}$ ). À cet égard, la fusion de cultures et de traditions préchrétiennes, catholiques et orthodoxes dans le creuset que constituait la Lituanie médiévale a attiré le regard des historiens de l'art ${ }^{75}$ et des spécialistes de la mythologie comparée ou du folklore ${ }^{76}$. Enfin, le processus d'évangélisation et les débats juridiques l'accompagnant ont eu leurs historiens, surtout à partir des années $1960^{77}$; un nouveau regard est posé sur la question par des études plus récentes ${ }^{78}$.

73 Voir notamment S. Gouguenheim, Les Chevaliers teutoniques...; D. Buschinger, M. Olivier, Les Chevaliers teutoniques...; W. URBAn, The Teutonic Knights: a Military History, Londres 2003.

${ }^{74}$ S. C. Rowell, Lithuania Ascending...; R. MažEıkA, notamment les deux articles suivants: "When Crusader and pagan agree: conversion as a point of honour in the baptism of King Mindaugas of Lithuania (c. 1240-1263)", dans A. V. Murray (dir.), Crusade and Conversion..., p. 197-214, et "Bargaining for baptism: Lithuanian negotiations for conversion, 1250-1358", dans J. Muldoon (dir.), Varieties of Religious Conversion in the Middle Ages, Gainesville 1997, p. 131-145; M. GiedroyĆ, «The Arrival of Christianity in Lithuania: Baptism and Survival (13411387)", Oxford Slavonic Papers, 22, 1989, p. 34-57. Un survol de l'historiographie est proposé par R. MažEIKa, "The Grand Duchy rejoins Europe... », p. 289-303; A. Bumblauskas, "The Heritage of the Grand Duchy of Lithuania: perspectives of historical consciousness", dans G. PотAšEnko (dir.), The Peoples of the Grand Duchy of Lithuania, Vilnius 2002, p. 7-44. La Lituanie médiévale a aussi ses historiens dans d'autres pays d'Europe, par exemple avec l'Italien C. Carpini, Storia della Lituania. Identità europea e cristiana di un popolo, Rome 2007; "The Conversion of a People...", p. 35-38; «La Crociata senza Terrasanta...», p. 179-193 ; "Contra Gentem Potentem et Durissime Cervicis: l'immagine della Lituania e del suo popolo tra mito, propaganda e modelli culturali», Res Balticae, 8, 2002, p. 193-207.

75 G. Mickūnaitė, «Art historical research in Lithuania: making local global and the other way around", Acta historiae artium Balticae 1, 2005, p. 14-25; A. AleksandravičIūté, "Research into the Sacral Art of Lithuania: General Trends and Specific Aspects", Acta historiae artium Balticae 1, 2005, p. 26-38. Citons notamment le travail du célèbre historien de l'art J. BaLtrusaitis, Lithuanian Folk Art, Munich 1948.

${ }^{76}$ Dans leurs œuvres, G. Dumézil (par ex. Le Problème des Centaures. Études de mythologie comparée indo-européenne, Paris 1929) ou C. Ginzburg (Le Sabbat des sorcières, Paris 1992) prennent volontiers appui sur des données issues de la culture lituanienne. Les travaux les plus connus portant exclusivement sur la mythologie balte sont ceux de M. Gimbutas, The Balts, Londres 1963, et d'A. Greimas, Des Dieux et des hommes: études de mythologie lituanienne, Paris 1985.

${ }_{77}$ Notamment S. F. Belch, Paulus Vladimiri and his doctrine concerning international law and politics, 2 vol., Londres \& La Haye 1965; H. Boockmann, Johannes Falkenberg, der Deutsche Orden und die polnische Politik. Untersuchungen zur politischen Theorie des späteren Mittelalters. Mit einem Anhang: Die Satira des Johannes Falkenberg, Göttingen 1975.

${ }^{78}$ Voir notamment les articles réunis dans W. Sieradzan (dir.), Arguments and Counter-Arguments. The Political Thought of the 14th-and 15th Centuries during the Polish-Teutonic Order Trials and Disputes, Torun 2012; T. M. Brennan, Just war, sovereignty, and canon law. Legal arguments over the Lithuanian Crusade and the rights of unbelievers at the Council of Constance (1414-1418), thèse de doctorat non-publiée, Lawrence, Kansas 2006; D. Baronas, S. C. Rowell, The Conversion of Lithuania: from Pagan Barbarians to Late Medieval Christians, Vilnius 2015; P. KRAs, "The Conversion of Pagans and Concept of Ius Gentium in the Writings of Cracow Professors in the First Half of the Fifteenth Century: An Overview», Bažnyčios Istorijos Studijos - Studies in Church 
Si les récits de bataille ont, dès l'origine, enflammé les imaginaires, les relations entre Chevaliers teutoniques et païens de la région balte n'étaient pas que violentes. L'importance de la coopération et du respect mutuel, voire de l'amitié, entre les adversaires a récemment été mise en avant par Rasa Mažeika, Werner Paravicini, Rymvidas Petrauskas ou Stephen C. Rowell ${ }^{79}$. Des études portant sur les chroniques écrites dans le milieu des missionnaires et des ordres militaires (Henri de Livonie et Pierre de Dusbourg surtout) ont permis de remettre en question l'opposition radicale entre chrétiens et païens, longtemps considérée comme allant de $\operatorname{soi}^{80}$. Ce changement de paradigme a été rendu possible par un vaste mouvement de relecture des sources, élargi par Marek Tamm aux encyclopédies composées en Europe occidentale: repérant les topoï littéraires ou les arguments à visée juridique (liés notamment à la théorie de la guerre juste), plusieurs études ont mis à nu le mécanisme d'écriture de ces textes clefs pour l'histoire balte médiévale ${ }^{81}$. Cette région est de plus en plus analysée par des historiens de l'Europe médiévale au sens large, et fournit un terrain propice à l'exploration de réflexions théoriques sur les concepts d'altérité, de cohabitation religieuse ou de confrontation interculturelle ${ }^{82}$. En témoigne la série d'études éditées par Alan V. Murray, qui réunit les travaux de chercheurs anglo-saxons, allemands, scandinaves, baltes, russes et polonais, sur ces thématiques variées ${ }^{83}$.

History, 6, 2013, p. 23-53; W. ŚwIEBODA, Innowiercy w opiniach prawnych uczonych polskich w XV wieku, Cracovie 2013 (résumé en anglais); K. OżóG, Uczeni w Monarchii Jadwigi Andegawenskiej $i$ Wladyslawa Jagielly (1384-1434), Cracovie 2004; V. AlıšAuskas (dir.) Dzieje Chrześcijaństwa na Litwie, Varsovie 2014 (notamment les deux premiers chapitres, p. 21-119).

${ }^{79}$ R. MažEIKA, «An Amicable Enmity...», p. 49-58; W. PARAvicini, "Litauer: vom heidnischen Gegner zum adligen Standesgenossen", dans W. Paravicini, R. Petrauskas, G. Vercamer (dir.), Tannenberg - Grunwald - Žalgiris..., p. 253-282; R. PetrausKas, «Litauen und der Deutsche Orden: Vom Feind zum Verbündeten", dans W. Paravicini, R. Petrauskas, G. Vercamer (dir.), Tannenberg - Grunwald-Žalgiris..., p. 237-251; S. C. Rowell, «Unexpected Contacts: Lithuanians at Western Courts, c. 1316-1400", The English Historical Review, 111/442, 1996, p. 557-577.

${ }^{80}$ Notamment R. Mažeika, "Violent Victims...», p. 123-140; R. Mažeika, L. Chollet, "Familiar Marvels?...", p. 52-62.

${ }^{81}$ M. TAмM, "A New World...», p. 11-35; Idem, «Inventing Livonia...», p. 187-209; Idem, «How to justify a crusade? The conquest of Livonia and new crusade rhetoric in the early thirteenth century", Journal of Medieval History, 39/4, 2013, p. 431-455; R. MAžEIKA, "Pagans, Saints and War Criminals...", p. 271-288; Eadem, "Violent Victims...", p. 123-137; Eadem, "Granting Power to Enemy Gods in the Chronicles of the Baltic Crusades», dans D. Abulafia, N. Berend (dirs.), Medieval Frontiers: Concepts and Practices, Aldershot 2002, p. 153-171; K. KL,Aviňš, «The Ideology....», p. 260-276.

${ }^{82}$ Notamment N. Blomkvist, Discovery...; E. Feistner, «Vom Kampf gegen das "Andere": Pruzzen, Litauer und Mongolen in lateinischen und deutschen Texten des Mittelalters", Zeitschrift für deutsches Altertum, 132, 2003, p. 281-294; V. Scior, Das Eigene und das Fremde, Berlin 2002. À noter également, sur la même thématique, A. GuÉNOLÉ, Les peuples païens et l'expansion des États chrétiens au nord-est de l'Europe: discours et politique (fin $X^{e}$ - début XIV siècle) (thèse de doctorat non-publiée), Poitiers, 2011.

83 A. V. Murray (dir.), Crusade and Conversion...; Idem (dir.), The Clash of Cultures...; Idem (dir.), The North-Eastern frontiers of medieval Europe: the expansion of Latin Christendom in the Baltic Lands, Farnham 2014. 
Le concept de "croisade», utilisé pour définir les campagnes d'évangélisation et de conquête lancées dans la Baltique, et idéologiquement soutenues par la Papauté, mérite qu'on s'y arrête. C'est avec William Urban (1975) qu'apparaît la notion de "croisade balte»; le sujet traité est ce que l'auteur définit comme " $a$ part of one crusade that occurred in the distant past in a remote part of Europe» ${ }^{84}$, à savoir la conquête de la Livonie au XIII ${ }^{\mathrm{e}}$ siècle. Le médiéviste américain, aux ambitions de vulgarisateur ${ }^{85}$, a popularisé la thématique avec ses ouvrages The Livonian Crusade (1980), The Prussian Crusade (1982) et The Samogitian Crusade (1989). Les bornes géographiques et chronologiques du phénomène sont posées dans un autre livre à grand succès, celui d'Eric Christiansen, The Northern Crusades (1980), qui traite du combat contre les Slaves de la Baltique à la suite de l'appel de Bernard de Clairvaux, jusqu'à la guerre entre la Pologne, la Lituanie et l'Ordre teutonique au Xv $\mathrm{V}^{\mathrm{e}}$ siècle, en passant par la conquête de la Livonie et les campagnes suédoises en Finlande et en Russie ${ }^{86}$. Les termes de "croisade balte» ou de "croisade nordique» tendent, dans l'historiographie, à se confondre, même si le terrain privilégié reste la conquête des actuels pays baltes. Le paradigme s'est rapidement imposé dans l'historiographie anglosaxonne: Jonathan Riley-Smith inclut la Baltique dans What were the Crusades? (1977) et Crusades: a Short History (1987), alors que Norman Housley consacre plusieurs chapitres à la croisade en Europe du Nord-Est dans son grand livre sur les croisades tardives (The Later Crusades, 1992) ${ }^{87}$.

Il va de soi que le concept de croisade balte ne peut fonctionner que selon

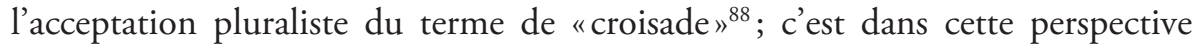

\footnotetext{
${ }^{84}$ W. Urban, The Baltic Crusade, DeKalb 1975, p. XI.

${ }^{85}$ Comme il l'exprime par exemple dans la préface de Tannenberg and After, Chicago 2002,
} p. IX-X. À noter que les livres de W. Urban comprennent quelques erreurs factuelles (toponymes, localisations, etc.), mais ont le mérite de proposer une réflexion assez originale quant aux motivations des acteurs historiques; on lira avec profit ses articles, volontiers polémiques, par exemple: «Roger Bacon and the Teutonic Knights", Journal of Baltic Studies, 19/4, 1988, p. 363-370.

${ }^{86}$ Sur le rôle d'Eric Christiansen et William Urban dans la popularisation du concept de croisade balte, voir K. Toomaspoeg, "La guerre baltique au regard des sociétés de l'Europe méditerranéenne à la fin du Moyen Âge», dans D. Baloup, P. Josserand (dirs.), Regards croisés sur la guerre sainte. Guerre, religion et idéologie dans l'espace méditerranéen latin (XI'-XIII siècle). Actes du Colloque international tenu à la Casa de Velázquez (Madrid) du 11 au 13 avril 2005, Toulouse 2006, p. 400, n. 4.

${ }^{87}$ R. MAŽEIKA, «The Grand Duchy rejoins Europe...", p. 289.

${ }^{88}$ Le terme de croisade n'apparaît qu'au cours du xiII ${ }^{\mathrm{e}}$ siècle dans le contexte de la Reconquista, et reste longtemps peu usité. Les médiévaux parlent plus volontiers de peregrinatio, expeditio en latin, voyage ou passage en français - bien que ces mots ne se limitent guère à la guerre sainte. Plusieurs écoles s'opposent quant à l'utilisation du terme de croisade: selon l'acceptation dite traditionnaliste, il s'agirait uniquement d'une guerre visant la libération de la Terre sainte ou la défense des chrétiens orientaux, entreprise dans une optique de rédemption et avec l'accord de la Papauté. À l'inverse, selon le point de vue dit pluraliste, toute expédition soutenue par la Papauté et visant à combattre de supposés ennemis de la Chrétienté, y compris des hérétiques, est considérée comme une croisade. Mentionnons enfin l'approche dite populariste, selon laquelle ce qui importe pour une croisade est 
qu'il est utilisé dans la plupart des productions actuelles, notamment celles des historiens finlandais et scandinaves ${ }^{89}$, mais également en France $^{90}$ ou en Pologne ${ }^{91}$. Par "croisade balte», ou "croisade nordique», on entend donc les campagnes lancées dans la foulée de la proclamation de la deuxième croisade par Bernard de Clairvaux (1147), c'est-à-dire des guerres menées contre les païens d'Europe du Nord et entreprises avec la même idéologie, le même état d'esprit que les croisades en Terre sainte ou en Espagne ${ }^{92}$. S'il ne s'agit pas de récupérer le tombeau du Christ et les lieux de la Passion, le motif d'expansion et de défense de la foi trouve grâce aux yeux des acteurs et des penseurs du temps ${ }^{93}$. Formellement, seules les premières de ces campagnes bénéficient du soutien actif de la Papauté (en 1147, Eugène III donne aux hommes partis soumettre les païens les mêmes privilèges qu’à ceux qui vont libérer Jérusalem): à la suite d'Alexandre IV (m. 1261), qui donne aux Chevaliers teutoniques le privilège de distribuer eux-mêmes des indulgences et d'organiser le prêche de la croisade, les papes successifs tolèrent le phénomène mais n'essayent plus de le contrôler. Jusqu'à l'interdiction de la guerre contre la Lituanie (1395/1403), les campagnes contre les païens étaient donc menées avec l'accord tacite de la Papauté ${ }^{94}$. Plus que d'une vaste opération menée depuis Rome, la croisade balte relève d'un jeu de va-et-vient entre le centre (Rome ou Paris), diffuseur de concepts idéologiques, et leurs adaptations par des potentats régionaux, dirigeants des ordres militaires y compris ${ }^{95}$.

la manière dont les contemporains décrivaient ce combat, plutôt que des critères formels définis après coup. Les approches pluralistes ou popularistes ont actuellement la préférence de la majorité des spécialistes. Pour plus de détails, V. PORTNYKH, «La croisade anti-russe a-t-elle jamais existé au treizième siècle? Réflexions sur le livre récent d'Anti Selart ", Revue d'histoire ecclésiastique 113/3-4, 2018, p. 885-888; J. Riley-Smith, «Some Modern Approaches...», p. 9-27; J. Paviot, Les ducs de Bourgogne, la croisade et l'Orient (fin XIV-XVe siècle), Paris 2003, p. 12-13; voir aussi la préface du même ouvrage par J. RichaRD, p. 9-10.

${ }^{89}$ Entre autres, T. Lehtonen, K. V. Jensen (dirs.), Medieval History Writing and Crusading Ideology, Helsinki 2005; I. Fonnesberg-Schmidt, The Popes... et les récentes études réunies dans T. K. Nielsen et I. Fonnesberg-Schmidt (dirs.), Crusading on the Edge....

90 S. Gouguenheim, Les Chevaliers teutoniques...; D. Buschinger, M. Olivier, Les Chevaliers teutoniques....

${ }^{91}$ M. Gtadysz, The Forgotten Crusaders. Poland and the Crusader Movement in the Twelfth and Thirteenth Centuries, Leiden \& Boston 2012.

92 K. Toomaspoeg, «La guerre baltique...», p. 400 sq.

${ }^{93}$ K. Guth, «Pomeranian Missionary Journeys of Otto I of Bamberg», dans M. Grevers (dir.), The Second Crusade and the Cistercians, New York 1992, p. 14; T. TANase, "L'Universalisme romain à travers les registres de lettres de la Papauté avignonnaise", Mélanges de l'École française de Rome-Moyen Âge, 123-2, 2011, p. 587.

94 I. Fonnesberg-Schmidt, The Popes..., p. 240-242; A. Ehlers, «The crusade against Lithuania reconsidered", dans A. V. Murray, Crusade and Conversion..., p. 21-44; Idem, Die Ablasspraxis des Deutschen Ordens im Mittelalter, Marbourg 2007, p. 50-59; C. T. MaIER, Preaching the Crusades: mendicant friars and the cross in the thirteenth century, Cambridge 1994, p. 92-93.

${ }^{5}$ B. BombI, "Innocent III and the praedictio to the Heathens in Livonia (1198-1204)», dans T. Lehtonen, K. V. Jensen (dirs.), Medieval History Writing..., p. 232-238; 
En ce qui concerne la participation de Français ou d'Anglais aux combats contre les païens baltes, elle a été mise en avant par des travaux allemands ${ }^{96}$ et polonais ${ }^{97}$ ainsi que par quelques études portant chacune sur un cas précis ${ }^{98}$, la période la plus traitée étant le $\mathrm{XIV}^{\mathrm{e}}$ siècle, époque où de nombreux chevaliers et écuyers de toute l'Europe mettent leurs épées au service des Teutoniques. La présence de nobles laïcs aux côtés des moines soldats "spécialisés» dans la croisade balte est traditionnellement présentée comme un symptôme de l'«automne» tardo-médiéval, selon le point de vue cher à Johan Huizinga"

I. Fonnesberg-Schmidt, "Pope Alexander III (1159-1181) and the Baltic Crusades», dans T. Lehtonen, K. V. Jensen (dirs.), Medieval History Writing..., p. 251.

${ }_{96}$ E. Maschke, «Burgund und der preußische Ordensstaat. Ein Beitrag zur Einheit der ritterlichen Kultur Europas im Spätmittelalter», publication originale dans Syntagma Friburgense. Historische Studien Hermann Aubin dargebracht zum 70. Geburtstag am 23. 12. 1955, Lindau \& Konstanz 1955. Réimprimé dans E. Maschke (dir.), Domus Hospitalis Theutonicorum. Europäische Verbindungslinien der Deutschordensgeschichte. Gesammelte Aufsätze aus den Jahren 1931-1963, Bonn \& Bad Godesberg 1970, p. 15-34.

${ }_{77}$ A. F. Grabski, Polska w Opiniach Europy Zachodniej, XIV-XV w., Varsovie 1968.

${ }_{98}$ Par exemple, O. Halecki, "Gilbert de Lannoy and his Discovery of East Central Europe", Bulletin of the Polish Institute of Arts and Sciences in America, 2, 1944, p. 314-331; V. KiparsKY, "Philippe de Mézières sur les rives de la Baltique», Neuphilologische Mitteilungen, 41/3-4, 1940, p. 61-67; J. JaKštas, Das Baltikum in der Kreuzzugsbewegung des 14. Jhs. Die Nachrichten Philipps de Mézières über die baltischen Gebiete, Bonn 1959; A. Prioult, "Un poète voyageur: Guillaume de Machaut et la "Reise" de Jean l'Aveugle, roi de Bohême en 1328-1329", Les Lettres Romanes, 4/1, 1950, p. 3-29; T. De Puymaigre, "Une campagne de Jean de Luxembourg, roi de Bohême», Revue des questions historiques, 42, 1887, p. 168-180; L. Devillers, "Sur les expéditions des comtes de Hainaut et de Hollande en Prusse», Compte rendu des séances de la Commission royale d'histoire, 5/4, 1878, p. 127-144; F. R. H. Du BoulaY, "Henry of Derby's crusade in Prussia", dans F. R. H. Du Boulay, C. Barron (dirs.), The Reign of Richard II: Essays in Honour of May McKisack, Londres 1971, p. 153-172; P. Dobrowolski, "Miles christianus" czy turysta? Uwagi o wyprawie Henryka Hragiego Derby do Prus w r. 1390-1391", Poznańskie Towarzystwo Przyjaciót Nauk. Sprawozdania, 100, 1984, p. 36-46; W. Urban, "When was Chaucer's Knight in "Ruce"?», The Chaucer Review, 18/4, 1984, p. 347-353; M. KeEN, "Chaucer's Knight, the English Aristocracy and the Crusade", dans V. J. Scattergood, J. W. Sherborne (dirs.), English Court Culture in the Later Middle Ages, Londres 1983, p. 45-61; P. Dемвоwsкi, «Reflets chevaleresques du Nord-Est dans l'œuvre de Jean Froissart", Roczniki Humanistyczne, 34/2, 1986, p. 137-143; C. Higounet, «De La Rochelle à Toruń: aventure de barons en Prusse et relations commerciales", dans C. Higounet, Paysages et villages neufs du Moyen Âge: recueil d'articles, Bordeaux 1975, p. 443-447; F. Pasquier, Gaston Phoebus en Prusse (1357-1358), Foix 1893; A. S. Cook, "Beginning the Board in Prussia", Journal of English and German Philology, 14, 1915, p. 375-388. La participation des chevaliers français et anglais à la croisade balte est également mentionnée par J. KlaczKo, "Une Annexion d'autrefois. - Le royaume de Jagello et son dernier historien. Première partie», La Revue des Deux Mondes 82, 1869, p. 5-38 et "Une Annexion d'autrefois. II. - L'Ordre teutonique et le royaume de Jagello. Dernière partie ", La Revue des Deux Mondes 82, 1869, p. 652-681, qui est l'un des premiers historiens à utiliser l'expression «Sarrasins du Nord". 99 J. Huizinga, L'Automne du Moyen Âge, Paris 1975, p. 115. Pour Huizinga, la fin du Moyen Âge correspond à une période où le formalisme de cour et l'immitation de modèles chevaleresques datant des $\mathrm{XII}^{\mathrm{e}}$-XIII ${ }^{\mathrm{e}}$ siècles cacheraient une forme de nostalgie et de pessimisme de la part d'une noblesse inquiète face à l'évolution sociale en marche. Par exemple, W. Urban résume de manière 
Il faut attendre l'immense travail de Werner Paravicini pour que l'on prenne conscience de l'ampleur et de la complexité du phénomène. Le premier article du médiéviste allemand consacré au sujet ${ }^{100}$ et les deux volumes des Die Preussenreisen des europäischen Adels qui ont suivi ont jeté un coup de projecteur sur l'importance de la croisade balte dans la vie des nobles de toute l'Europe, ce dont a rapidement tenu compte l'historiographie anglo-saxonne et francophone $\mathrm{e}^{101}$. Étant donné cette nouvelle prise de conscience du caractère plus largement européen de la croisade balte, les sources narratives produites en Occident, déjà mises en avant par Andrzej Grabski ${ }^{102}$, reçoivent peu à peu l'attention qui leur est due ${ }^{103}$. Toutefois, une étude portant spécifiquement sur la perception et l'imaginaire de la croisade balte dans la production littéraire d'Europe occidentale, y compris à une époque antérieure aux premières «rèses» internationales, restait à écrire. C'est dans ce vide historiographique que s'inscrit le présent ouvrage.

\section{Questions DE RECHERCHE ET PLAN DE L'OUVRAGE}

Comme évoqué, la recherche se focalise sur la manière dont les lettrés de France et d'Angleterre ont suivi la conquête et l'évangélisation de la Baltique et comment ils ont découvert et assimilé les connaissances sur cette ultime région païenne d'Europe. Les nobles français et anglais partageaient une même culture, et dans une moindre mesure, une même langue; lorsque le voyage de Prusse battait son plein, ils s'affrontaient dans la guerre de Cent Ans ${ }^{104}$. Pour les

significative ce qu'est, pour lui, la croisade de Prusse au XIv ${ }^{e}$ siècle dans son premier ouvrage: "Prussia served more as a showplace for the bored chivalry of Europe than a theater for real crusading" (The Baltic Crusade..., p. 267). Sur les idées de Huizinga, voir notamment M. VAlE, War and Chivalry: Warfare and Aristocratic Culture in England, France and Burgundy at the End of the Middle Ages, Londres 1981, p. 1-12.

100 W. Paravicini, «Die Preußenreisen des europäischen Adels», Historische Zeitschrift 232, 1981, p. 25-38.

${ }_{101}$ N. Housley, The Later Crusades, 1274-1580: from Lyon to Alcazar, Oxford 1992; M. Keen, Chivalry, New Haven 1984 (rééd. 2005).

102 A. F. Grabski, Polska w Opiniach Obcych, X-XIII w., Varsovie 1964; Idem, Polska w Opiniach Europy... ; voir aussi Idem, "La Pologne et les Polonais vus par les étrangers du $\mathrm{x}^{\mathrm{e}}$ au XIII ${ }^{\mathrm{e}}$ siècle», Acta Poloniae historica 13, 1965, p. 22-43.

${ }^{103}$ Les sources francophones sur la croisade balte ont été exploitées à l'occasion de quelques articles, notamment: S. Gouguenheim, "Das Echo...», p. 193-206; A. V. Murray, "Saracens of the Baltic: Pagan and Christian Lithuanians in the Perception of English and French Crusaders to Late Medieval Prussia", Journal of Baltic Studies, 41/4, 2010, p. 413-429; L. Chollet, "Les "Voyages en Prusse" vus de France: la perception de la croisade contre la Lituanie dans quelques sources francophones (1384-1414)", Studia z Dziejów Średniowiecza, 19, 2015, p. 51-80. Sur le caractère européen de la noblesse et le rôle que le voyage y joue, W. Paravicini, "Gab es eine einheitliche Adelskultur Europas im späten Mittelalter?», dans J. Hirschbiegel, W Paravicini (dirs.), Edelleute und Kaufleute im Norden Europas, Ostfildern 2007, p. 273-302.

104 Sur ce point, A. V. Murray, «Saracens... », p. 413-429; A. CRÉPIN, "Quand les Anglais parlaient français", Comptes rendus des séances de l'Académie des Inscriptions et Belles-Lettres, 148/4, 2004, 
chevaliers de France et d'Angleterre, aller combattre l'infidèle dans le lointain Nord-Est permettait de vivre l'idéal chevaleresque et de faire exister l'ambition d'une Chrétienté réunie dans la lutte contre les ennemis de la foi. Bien que cet ouvrage reste centré sur les productions littéraires des deux royaumes rivaux et des régions francophones relevant de l'Empire (Wallonie, Savoie, Neuchâtel), une ouverture sera faite sur d'autres parties de l'Europe occidentale (Saint Empire, Italie ${ }^{105}$, péninsule Ibérique), sans pour autant aboutir à un traitement exhaustif de la question. Les textes produits dans la région balte seront utilisés comme points de comparaison et pour éclairer les différents contextes auxquels se réferrent nos auteurs. Pour saisir comment s'est forgée une certaine perception $\mathrm{du}$ monde balte dans les lettres occidentales, une chronologie longue est nécessaire. Observer ce que l'on savait de cette lointaine terre de mission et de croisade avant que les premiers Français et Anglais ne s'y rendent permet de mettre en avant la continuation, mais aussi l'évolution, d'un certain nombre de parti-pris et de stéréotypes. En ce qui concerne le cadre géographique, nous nous intéresserons essentiellement aux provinces du sud-est de la Baltique, à savoir la Poméranie, la Prusse, la Lituanie, la Livonie et l'Estonie, ce qui correspond approximativement au nord de l'actuelle Pologne jusqu'à l'Estonie, en passant par l'enclave russe de Kaliningrad, la Lituanie et la Lettonie. L'évangélisation de la Scandinavie, de la Finlande et du Nord de l'actuelle Russie, en revanche, sort de notre champ d'étude ${ }^{106}$.

Nos questions de recherche se posent dans les termes suivants:

Que savaient les lettrés d'Europe occidentale du monde balte et du conflit religieux qui s'y déroulait?

Comment ont-ils réagi aux campagnes de conquête et d'évangélisation lancées dans cette lointaine région?

Selon quelles modalités l'accumulation de témoignages directs ou indirects a-t-elle permis l'émergence d'un imaginaire du monde balte dans les lettres occidentales?

Et dans quelle mesure cet imaginaire balte a-t-il influencé la représentation ultérieure de la frontière est-européenne?

p. 1569-1588. À la suite de la conquête normande en Angleterre, le français (ou plus précisément la variété linguistique dite anglo-normand) s'impose parmi la noblesse, avant de décliner au cours du $\mathrm{xIV}^{\mathrm{e}}$ siècle. À noter toutefois que plusieurs auteurs, notamment Geoffrey Chaucer et John Gower, utilisent encore le français en parallèle de l'anglais.

105 Par convention, les termes "Italie», "Suisse», "Allemagne», etc. sont utilisés dans un sens géographique, en référence aux nombreuses entités politiques amenées à former les futurs États connus sous ces noms.

106 Voir notamment M. Carver (dir.), The Cross goes North...; R. Fletcher, The Conversion of Europe: from paganism to Christianity, 371-1386 AD, Londres 1988. 
Soulignons en premier lieu que l'essentiel de nos témoins appartiennent, par leurs parcours de vie ou le milieu dans lequel ils évoluent, à deux catégories sociales: les clercs et les aristocrates ${ }^{107}$. Les premiers forment la quasi-exclusivité des auteurs qui ont écrit sur la Baltique avant le milieu du XIV siècle, période d'émergence du voyage de Prusse dans la vie de la noblesse occidentale. Jusqu'à la perte d'Acre (1291), chevaliers et écuyers de France, d'Angleterre et d'ailleurs dirigeaient essentiellement leurs pas vers la Terre sainte. Les affaires baltes leur étaient étrangères; ainsi, les seuls Occidentaux à nous avoir laissé des traces des événements survenus en Europe du Nord-Est étaient les savants, chroniqueurs, et autres encyclopédistes, intéressés par les progrès de la Chrétienté dans ces contrées éloignées.

La situation évolue au milieu du XIV siècle. À la suite de Jean de Mandeville et de Guillaume de Machaut, le voyage de Prusse fait son apparition dans de nombreux poèmes didactiques, récits de voyages ou descriptions du monde prisés par le public aristocratique. Le monde balte (Prusse et Livonie teutoniques, Lituanie païenne puis chrétienne) devient familier aux membres de la noblesse et aux auteurs qui écrivent pour eux. La préoccupation est alors, pour l'essentiel, militaire, chevaleresque: ce n'est pas l'évangélisation de la Lituanie que notent les chroniqueurs, mais la défaite des Chevaliers teutoniques et de leurs hôtes à la bataille de Tannenberg. Si la Papauté d'Avignon et du temps du Schisme (13781417) continue de suivre l'évolution de la cause chrétienne dans la région balte et donne tout son appui au baptême de la Lituanie, les ecclésiastiques francophones du XIV ${ }^{\mathrm{e}}$ siècle semblent ne s'en être que peu préoccupés ${ }^{108}$. Une situation qui s'explique sans doute par le caractère de plus en plus temporel, «mondain» de la culture écrite; plus que d'un éventuel désintérêt des ecclésiastiques français pour les affaires baltes, ce changement relève plutôt de l'engouement de l'aristocratie pour l'écrit en vernaculaire à la fin du Moyen Âge ${ }^{109}$. Un changement qui se lit au sens premier du terme, par la langue de nos sources: alors que les premières sont quasiment toutes en latin (langue de l'Église par excellence), le français est par la suite privilégié dans le cas des productions émanant de la noblesse, au côté de l'anglais dans le royaume insulaire. Cela n'empêche pas qu'une partie importante de notre corpus, notamment plusieurs chroniques, soit toujours écrite en latin.

\footnotetext{
107 Fait remarquable, très peu de marchands nous ont laissé des témoignages sur les affaires baltes; les seuls documents dont nous avons eu connaissance sont les lettres de récriminations et les documents juridiques liés aux querelles opposant les marchands anglais et bourguignons à leurs concurrents de la Hanse. Ces documents ne concernant pas la situation religieuse (au sens de large) de la région, il n'en sera pas tenu compte.

108 Pierre d'Ailly et Guillaume Fillastre parlent toutefois des affaires baltes dans le cadre de leur participation au concile de Constance; voir chap. V.

109 Sur ce point, voir B. Guenée, Histoire et culture historique dans l'Occident médiéval, Paris 1980, p. 315-323.
} 
Utiliser des sources composées dans des milieux plus ou moins proches des participants à la croisade balte rend possible une comparaison révélant comment les enjeux étaient perçus par les différents témoins: d'une part ceux qui, à l'exemple des savants et des chroniqueurs du XIII ${ }^{\mathrm{e}}$ siècle, s'intéressent aux affaires de la Chrétienté universelle, mais qui n'ont pas eu l'occasion de se rendre eux-mêmes dans ces nouvelles terres de l'Église, et d'autre part les nobles qui visitent le front balte pour livrer bataille aux païens. Certes, on ne devrait pas envisager de séparation trop nette entre ces catégories; l'une des premières œuvres narrant les aventures chevaleresques des croisés de la Baltique est ainsi écrite par un clerc, Guillaume de Machaut, tandis que le récit de la bataille de Tannenberg est raconté par Michel Pintoin, autrement dit le Religieux de Saint-Denis. De plus, la pratique de parrainer un enfant lituanien lors de son baptême, et parfois de l'emmener en Occident, montre que les croisés de Prusse avaient le souci de voir la foi chrétienne s'implanter dans le pays où ils allaient se battre. La prouesse chevaleresque se confond, pour eux, avec le service rendu à Dieu; si peu d'entre eux évoquent explicitement des motifs spirituels, ou la rédemption, il n'y a pas lieu de croire que l'unique motivation des seigneurs engagés dans la croisade balte ait été la recherche d'honneur mondain ${ }^{110}$. Une chose est sûre: à quelques exceptions près, ces nobles français, anglais, ou savoyards ne pouvaient espérer un gain matériel immédiat en se rendant en Prusse $^{111}$. Les moins fortunés d'entre eux pouvaient se faire rembourser leurs dépenses par un prince soucieux de chevalerie, mais beaucoup voyageaient à leurs propres frais.

Pour ce point comme pour d'autres, l'étude des documents comptables et diplomatiques menée notamment par Werner Paravicini dans ses Preussenreisen se montre d'une aide inestimable. Confronter les sources comptables, épistolaires et narratives permet de mieux saisir les attentes d'une partie de nos témoins, mais aussi de reconstituer certains événements dont nous parlent les chroniques. Pour reprendre l'exemple des enfants lituaniens baptisés et emmenés en Occident, plusieurs livres de comptes confirment l'existence de cette pratique, que les chroniqueurs mentionnent (et illustrent) avec fierté. Aussi, notre travail sur les matériaux littéraires ou iconographiques n'est-il possible que grâce au dépouillement attentif des documents d'archives effectué par d'autres chercheurs.

Cet ouvrage s'articule autour de quatre parties. La première s'intéresse à la croisade balte "vue de loin", autrement dit, à l'attitude des Occidentaux face à l'évangélisation de la région balte avant que le voyage de Prusse ne devienne

\footnotetext{
110 C. Tyerman, England and the Crusades, Chicago \& Londres 1988, p. 274-276; J. Paviot, "Noblesse et croisade à la fin du Moyen Âge», Cahiers de recherches médiévales et humanistiques, 13, 2006, p. 84; N. Housley, Later Crusades..., p. 401; W. Paravicini, «Fahrende Ritter: Literarisches Bild und gelebte Wirklichkeit im Spätmittelalter », M. Neumeyer (dir.), Mittelalterliche Menschenbilder, Ratisbonne 2000, p. 233-237.

111 M. Keen, "Chaucer's Knight...», p. 58-59.
} 
populaire. L'intérêt des chroniqueurs et des savants français et anglais pour cette lointaine région commence avec le profond changement survenu autour de l'an mil, quand la Pologne et les pays scandinaves adoptent le christianisme et la royauté; dans la foulée du baptême de la Pologne (966) et de la création du Saint Empire Romain Germanique (963), des campagnes d'évangélisation sont lancées pour convertir les habitants païens du littoral balte. Le binôme entre mission et lutte contre les païens de la Baltique est systématisé à la suite de l'appel de Bernard de Clairvaux, et s'intègre à l'idéologie paneuropéenne de croisade. Dans un premier temps, il s'agira de faire connaissance avec ceux qui vont occuper une place centrale dans ces pages, à savoir les Baltes et leurs voisins directs, mais aussi de présenter les bases idéologiques de la croisade du Nord, et comment celle-ci s'insère dans la conception des relations entre chrétiens et infidèles. D'Eugène III à Jean XXII, la politique pontificale a façonné l'attitude des Occidentaux envers les païens de la Baltique, jetant les bases d'une posture que l'on retrouve, en partie, chez les croisés des siècles suivants. La défense et l'expansion de la Chrétienté servaient de moteur à l'entreprise, mais la possibilité de traiter avec un prince païen désireux de recevoir le baptême n'était jamais négligée. Après avoir présenté les considérations stratégiques et juridiques des papes successifs et de leurs légats, nous verrons quelles étaient les positions des savants et des chroniqueurs de France et d'Angleterre face aux aléas de la christianisation de ces lointains pays, ainsi que la manière dont la diffusion de l'idéologie de croisade et son adaptation au contexte balte ont participé à forger une certaine perception de la lutte contre les "Sarrasins du Nord", avant même que la noblesse occidentale ne commence à y participer activement.

La deuxième partie est consacrée aux hommes qui se sont déplacés depuis la France, l'Angleterre ou la Savoie pour rejoindre les Chevaliers teutoniques dans leur combat. Les chroniques et les récits de voyages, mais aussi les poèmes didactiques florissants à la fin du Moyen Âge, permettent de comprendre les raisons qui ont poussé ces chevaliers et écuyers à traverser une grande partie de l'Europe pour passer quelques mois auprès des Teutoniques avant de regagner leur foyer ou de poursuivre leur périple, jusqu'en Terre sainte par exemple. Les textes écrits par des participants aux rèses, ou par des auteurs ayant pu bénéficier de témoignages de première, voire de seconde main, nous renseignent sur la manière dont ces expéditions étaient vécues par les nobles qui s'y trouvaient engagés: aux objectifs affichés par la hiérarchie ecclésiastique s'ajoutent les considérations quant à l'honneur et aux idéaux chevaleresques propres à la noblesse combattante.

Le basculement causé par la conversion de la Lituanie au tournant du $\mathrm{XV}^{\mathrm{e}}$ siècle est au cœur de la troisième partie. L'époque s'étendant de la proclamation du baptême à Vilnius en 1387 jusqu'à la conversion des derniers païens baltes (1417) marque un tournant dans l'histoire européenne. En ce qui concerne notre sujet, l'Ordre teutonique trouve de moins en moins d'hôtes intéressés par le combat contre des gens que l'on sait désormais chrétiens. La 
Lituanie ne disparait toutefois pas du champ de la croisade; ses dirigeants successifs prennent soin d'intégrer leur propre politique d'expansion au schéma défendu par Rome. Comme en écho au changement géopolitique, plusieurs textes écrits en France font du grand-duc de Lituanie un héros de la guerre contre les infidèles. Les voyages en Prusse restent un souvenir hérö̈que jusqu'au milieu du Xv $v^{e}$ siècle, avant de se voir tourner en ridicule dans les Cent Nouvelles Nouvelles; déjà critiquée par quelques moralistes qui y voyaient un plaisir mondain, la croisade balte tombe en désuétude.

Enfin, la quatrième et dernière partie de ce travail est dédiée à la construction d'un imaginaire "balte» dans les lettres occidentales. Depuis le XIII ${ }^{e}$ siècle au moins, les terres du Sud-Est de la Baltique sont perçues comme une vaste zone frontière où le christianisme s'oppose au paganisme. La production littéraire contemporaine à la croisade balte permet de suivre l'élaboration d'une représentation relativement figée de la nature de ces pays, mais laisse entrevoir un changement de perspective en ce qui concerne leurs habitants. Une comparaison entre les chroniqueurs qui nous ont donné les premières descriptions des Prussiens en France autour de l'an mil et les traités savants du XIII ${ }^{\mathrm{e}}$ siècle met ce glissement en évidence: de persécuteurs cruels, les païens baltes deviennent de naïfs idolâtres, dont on pense avoir aisément compris le système de croyance. Les textes produits dans le milieu de l'aristocratie occidentale offrent une image quelque peu différente: les Lituaniens - derniers païens baltes - sont des guerriers, dont la religion se réduit en bonne partie à la crémation, réservée aux plus nobles d'entre eux. Pairs autant qu'ennemis, ils remplissent leurs quotas d'exotica. Alors que les roys lituaniens deviennent des adversaires romanesques, la forêt enneigée et les marais glacés font office de Brocéliande hivernale. Le monde bien réel du voyage de Prusse prend des teintes arthuriennes, avant de se confondre avec le cadre d'une lutte épique et fictive entre chrétiens et infidèles.

Ainsi, si le voyage de Prusse était peut-être, à l'origine, une «croisade de substitution" pour beaucoup de chevaliers occidentaux, il n'en devient pas moins un phénomène très prisé parmi une bonne partie de la noblesse, un modèle d'aventure lointaine, effectuée au service de la foi et dans un esprit éminemment chevaleresque. Qu'elle soit peinte dans un roman ou dans une chronique, la croisade balte participe d'une plus large invitation au voyage. De même, bon nombre de ses adeptes avaient cheminé dans l'Europe chrétienne et étaient allés affronter le "mécréant"sur d'autres fronts de la Chrétienté, en Espagne ou en Orient. Gadifer de la Salle, ancien croisé de Prusse, s'est même engagé dans une entreprise qui, à plus d'un titre, préfigure les expéditions lancées par les puissances maritimes d'Europe au $\mathrm{Xv}^{\mathrm{e}}$ siècle: la conquête des îles Canaries $^{112}$.

112 A. Sadourny, «Les expéditions de Jean de Béthencourt aux Canaries: une préfiguration des expéditions du début des temps modernes?», dans M. Arnoux, A.-M. Flambard Héricher (dirs.), La Normandie dans l'économie européenne (XII'-XVII siècle), Caen 2010, p. 201-208; M. KeEN, 
La région balte, encore très mal connue au $\mathrm{XII}^{\mathrm{e}}$ siècle, est apparue dans les textes des clercs occidentaux comme un terrain de mission, puis de croisade. C'est précisément ce statut qui incitait les chevaliers d'Europe occidentale à s'y rendre. La Baltique faisait certes moins rêver que l'Orient, et présentait bien moins de merveilles que le lointain Nord ou l'Asie des Tatars et des Indiens ${ }^{113}$. Néanmoins, c'était la frontière du monde chrétien qu'il était le plus facile de rejoindre. La croisade balte a-t-elle servi de marchepied dans la formation d'une culture propre aux explorateurs occidentaux, héritiers d'une chevalerie rêvant d'honneur et d'aventure autant que de servir Dieu? Et en quoi la croisade lancée contre les derniers païens d'Europe a-t-elle influencé notre manière de voir l'autre, et - question intrinsèquement liée à la première - de nous définir nous-même en donnant une frontière à l'Europe, "notre» monde? Telles sont les ouvertures possibles à cette vaste aventure.

"Gadifer de la Salle: A Late Medieval Knight Errant», dans C. Harper-Bill, R. Harvey (dirs.), The Ideals and Practice of Medieval Knighthood. Papers from the First and Second Strawberry Hill Conferences, Woodbridge 1986, p. 74-85.

${ }_{113}$ M. Rodinson, La fascination de l'islam suivi de Le seigneur bourguignon et l'esclave sarrasin, Paris 1989, p. 191; S. Mund, "Guillebert de Lannoy...», p. 185, remarque toutefois que l'un de nos principaux témoins, Guillebert de Lannoy, consacre bien moins de pages au royaume maure de Grenade, sans doute relativement connu des Français du Xv siècle, qu'aux pays d'Europe du Nord-Est. 



\section{Première partie Aux Marges de la Chrétienté}





\section{INTRODUCTION DE LA PREMIÈre PARTIE}

orsqu'en mars 1147, Bernard de Clairvaux parcourt l'Empire pour recruter des participants à la croisade en Terre sainte, il est pris à partie par une assemblée de grands seigneurs allemands à Francfort, qui se proposent d'aller combattre les païens vivant sur les côtes de la mer Baltique plutôt que de s'embarquer pour le lointain Orient ${ }^{1}$. Bernard se laisse convaincre et le pape Eugène III approuve la mesure. Il publie le 11 avril 1147 la bulle Divini dispensione, qui apporte son soutien au combat contre les païens d'Europe du Nord-Est. Les indulgences sont les mêmes que celles données aux croisés du Proche-Orient et de la péninsule Ibérique ${ }^{2}$; ceux qui avaient auparavant juré de libérer le tombeau du Christ reçoivent la permission de marcher contre les Slaves et les Baltes. Un troisième front s'ouvre dans la guerre que mène la Chrétienté contre les infidèles ${ }^{3}$.

Avec la démarche de l'abbé de Clairvaux et le soutien d'Eugène III, la Papauté et les personnalités les plus marquantes de l'Église tournent leurs yeux vers cette vaste zone frontière où des chrétiens côtoyaient encore des "infidèles" polythéistes, les affrontant souvent en luttes militaires de dimension locale. Dans un premier temps, la croisade balte est essentiellement une affaire allemande et centre-européenne; occupés par la plus fameuse croisade en Terre sainte, les chevaliers français et anglais ne s'intéressent guère au front nordique de la Chrétienté. La région fait cependant son apparition dans les lettres occidentales: jusqu'à la première moitié du XIV siècle, ce sont des hommes d'Église, des savants, encyclopédistes et chroniqueurs concernés par l'expansion de la foi, qui écrivent au sujet de la Baltique. S'y ajoute l'entourage des papes, qui correspondent avec certains princes baltes et s'efforcent de les attirer dans

\footnotetext{
${ }^{1}$ Sur ce qui suit, I. Fonnesberg-Schmidt, The Popes..., p. 29-37; M. GŁadysz, The Forgotten Crusaders..., p. 69-70.

${ }^{2}$ Les privilèges temporels, notamment juridiques, sont toutefois moindres pour les croisés de la Baltique que pour leurs pairs de Terre sainte: I. Fonnesberg-Schmidt, The Popes..., p. 33-34.

${ }^{3}$ Sur la politique des papes par rapport à la croisade balte, I. Fonnesberg-Schmidt, The Popes...; E. Pitz, Papstreskript und Kaiserreskript im Mittelalter, Niemeyer, Tübingen 1971; M. GŁadysz, The Forgotten Crusaders..., p. 72 sq.
} 
les rets de l'Église. Les connaissances sur la lointaine région balte, diffusées par les réseaux monastiques, viennent nourrir les réflexions des clercs quant au bien-fondé de l'usage de la force dans l'activité missionnaire, et s'ajoutent à l'idée contrastée que l'on se fait des ordres militaires. Avant de prendre la route avec les chevaliers de France ou d'Angleterre, observons ce que leurs compatriotes disaient de la situation balte jusqu'à la première moitié du XIV siècle.

Après une présentation des populations baltes et des connaissances dont les savants de l'Europe latine disposaient à leur sujet, le premier chapitre présente la manière dont l'Église catholique appréhendait la mission auprès des païens de la Baltique, de l'époque des premiers missionnaires martyrisés autour de l'an mil jusqu'aux négociations ouvertes sous le pontificat de Jean XXII avec le grand-duc Gediminas de Lituanie (1322-1324). Entre ces deux bornes chronologiques a été mise en place la croisade balte, d'abord soutenue par la Papauté puis tolérée tacitement. La tension entre croisade et mission se cristallise lors de l'implantation de l'Ordre teutonique sur le rivage balte, à partir du XIII ${ }^{\mathrm{e}}$ siècle.

Le chapitre suivant est dédié à la réaction des clercs d'Europe occidentale face à la progression du christianisme en Europe du Nord-Est. À partir des $\mathrm{XII}^{\mathrm{e}}$-XIII ${ }^{\mathrm{e}}$ siècles, des provinces longtemps méconnues comme la Prusse ou la Livonie font leur apparition dans les écrits occidentaux: encyclopédistes, cosmographes, savants et auteurs de récits de voyage transmettent des informations alors inédites sur ces nouvelles terres chrétiennes, mais aussi sur les pays où le paganisme domine encore, Lituanie et Samogitie. Le discours contrasté de ces auteurs au sujet des peuples baltes, néophytes ou païens, est mis en regard avec leurs critiques parfois radicales des croisés qui entendent faire progresser le christianisme par l'épée. Toutefois, l'Ordre teutonique consolide progressivement sa place dans la politique balte. Justifiées par la résistance des Lituaniens, ses activités militaires ont la faveur des chevaliers européens privés de croisade suite à la perte de Saint-Jean-d'Acre (1291). 


\section{Chapitre I Sous L'cEIL DE ROME}

\section{LES DERNIERS PAÏENS D'EUROPE}

Avec l'affirmation des royaumes chrétiens de Pologne, de Hongrie et de Bohême aux $\mathrm{IX}^{\mathrm{e}}-\mathrm{x}^{\mathrm{e}}$ siècles, une ligne de démarcation s'est formée en Europe du Nord-Est entre la Chrétienté latine et un monde «infidèle» ou «schismatique» ${ }^{1}$. L'un de ces nouveaux pays en particulier jouera le rôle de "passeur» culturel entre la Lituanie païenne et l'Occident chrétien: c'est le royaume des Polanes, une population slave, qui a donné son nom à la Pologne ${ }^{2}$. Formée en tant que communauté étatique sous l'impulsion d'une dynastie que les historiens du XviI siècle nommeront Piast ${ }^{3}$, la Polonia se voit imposer le catholicisme par le prince Mieszko en 966. Un choix peut-être autant guidé par le pragmatisme politique que par une réelle ouverture au christianisme et à la culture latine: pour Mieszko, comme pour les princes scandinaves, tchèques, moraves ou hongrois qui choisissent le christianisme latin pour les pays dont ils tiennent les rênes, le baptême représente une clef pour être accepté comme un dirigeant légitime par les puissances chrétiennes, et notamment

\footnotetext{
${ }^{1}$ Sur l'émergence des royaumes chrétiens de Pologne, Hongrie et Bohême, voir en particulier G. Bührer-Thierry, Aux Marges du monde germanique: l'évêque, le prince, les païens (VIII ${ }^{-}$XI siècles), Turnhout 2014; J. KŁoczowski, La Pologne dans l'Église Médiévale, Aldershot 1993; J. KŁoczowski (dir.), Histoire religieuse de la Pologne, Paris 1987; P. Knoll, The Rise of of Polish Monarchy: Piast Poland in East Central Europe, 1320-1370, Chicago 1972; N. Berend, P. Urbańczyk, P. Wiszewski, (dirs.), Central Europe in the High Middle Ages. Bohemia, Hungary and Poland, c. 900-c. 1300, Cambridge 2013; N. BERENd (dir.), Christianization and the Rise of Christian Monarchy, Cambridge 2007 ; P. URBAŃCZyK (dir.), Europe around the Year 1000, Varsovie 2001. Les dirigeants de Pologne sont appelés «dux», "princeps» ou "rex» dans les documents latins. En fait, certains princes à la tête de la Pologne ont été couronnés rois, mais jusqu’à la réunification sous Ladislas Le Bref, ce n'est pas automatique. Par convention, nous utiliserons le mot « royaume» pour parler de l'État polonais.

2 B. GuenéE, L'Occident aux XIV et XVe siècles. Les États, Paris 1971, p. 114-115.

${ }^{3}$ Le nom Piast vient d'un ancêtre légendaire éponyme. T. Dunin-Wasowicz, «Autour du baptême de Mieszko I ${ }^{\text {er }}$ de Pologne", dans M. Rouche (dir.), Clovis. Histoire et Mémoire, Paris 1997, vol. 2, p. 370-371.
} 
par l'Empereur ${ }^{4}$. C'est, en même temps, une impulsion donnée à l'intégration de leurs pays dans l'ensemble culturel et politique élaboré en Europe occidentale durant le Haut Moyen Âge ${ }^{5}$. Les ordres monastiques, d'abord les Cisterciens, puis les Dominicains et les Franciscains, s'implantent progressivement dans ces nouveaux royaumes chrétiens ${ }^{6}$. Comme ailleurs en Europe, on commence à rédiger les premières histoires "nationales»; en ce qui concerne la Pologne, cette tâche est assumée par celui que l'historiographie a désigné sous le nom de Gallus Anonymus (mort au début du XII ${ }^{e}$ siècle) et par Vincent Kadłubek (mort en 1223), dont le style et le profil témoignent d'une proximité certaine avec les modèles intellectuels occidentaux ${ }^{7}$. Tout en gardant ses spécificités, la classe des milites s'identifie peu à peu aux pratiques de la chevalerie occidentale, par ses valeurs esthétiques et culturelles ${ }^{8}$.

Tous les peuples d'Europe du Nord-Est ne suivent pas le même processus. Les populations slaves, baltes et fenniques vivant près de la mer Baltique étaient restées autonomes par rapport au jeune royaume de Pologne9, et seront

\footnotetext{
${ }^{4}$ Sur le baptême de la Pologne par Mieszko, voir notamment Ibid., p. 369-385; R. Michalowski, "La christianisation de la Pologne aux x ${ }^{\mathrm{e}}$-XII ${ }^{\mathrm{e}}$ siècles", dans M. Rouche (dir.), Clovis..., p. 419-434; Z. Sulowski, "Le baptême de la Pologne", dans Millénaire du catholicisme en Pologne, Lublin, 1969, p. 33-85; P. UrbańczyK, S. Rosik, "The Kingdom of Poland with an Appendix on Polabia and Pomerania between paganism and Christianity", dans N. Berend (dir.), Christianization..., p. 263-300; N. Berend et al. (dirs.), Central Europe..., p. 118-124; E. Weibel, Mille ans d'Allemagne: histoire et géopolitique du monde germanique, Paris 2004, p. 88-91; F. Conte, Les Slaves, Paris 1986, p. 77-79; A. Besançon, "Les baptêmes de l'Europe de l'Est", dans M. Long, F. Monnier (dir.), La France, l'Église. Quinze siècles déjà, Genève 1997, p. 16.

5 A. VAuCHEZ, «Lachristianisation commeélément d'intégration», dansJ. KŁOCzowski, H. ŁaszKIEwICZ (dirs.), East-Central Europe in European history, Lublin 2009, p. 99-100; A. PleszCZYNSKI, «Poland as an ally of the Holy Roman Empire», dans P. UrbańczyK (dir.), Europe..., p. 409-425; L. KöRnTGen, "The Emperor and his Friends: the Ottonian realm in the year 1000 », dans P. UrbaŃCZYK (dir.), Europe..., p. 465-488; A. GIEYSZToR, «Sylvestre II et les Églises de Pologne et Hongrie», dans Gerberto. Scienza, storia e mito. Atti del Gerberti Symposium (Bobbio 25-27 Iuglio 1983), Bobbio 1985, p. 733-746. Sur les liens entre Pologne et Europe occidentale (France et surtout Lotharingie) jusqu'à l'époque de la première croisade, M. GŁadysz, The Forgotten Crusaders..., p. 19-21.
}

${ }^{6}$ J. KŁoczowsкi (dir.), Histoire religieuse..., p. 72; P. Knoll, The Rise..., p. 15; N. Blomkvist, Discovery..., p. 91; M. Derwich, «Les deux fondations de l'abbaye de Lubin dans le cadre de l'implantation du monachisme bénédictin en Pologne (moitié du XI ${ }^{e}$-fin du XII ${ }^{e}$ siècle) ", Le Moyen Âge, 2002/1, p. 22-24.

B. Guenée, L'Occident..., p. 123. Le premier est vraisemblablement d'origine française, allemande ou italienne, alors que le second semble avoir étudié à Paris et à Bologne; P. KNoll, "Wenta, Jarosław, Kronika tzw. Galla Anonima: Historyczne (monastyczne i genealogiczne) oraz geograficzne konteksty powstania", Speculum 88/1, 2013, p. 357-358.

${ }^{8}$ Dès le xiII ${ }^{\mathrm{e}}$ siècle, la noblesse d'Europe du Centre-Est se distinge par l'organisation de tournois et le port des armoiries. S. KuczyŃski, «Les hérauts d'armes dans la Pologne médiévale», dans B. Schnerb (dir.), Le héraut, figure européenne (XIV'-XVI siècle), Villeneuve d'Ascq 2006, p. 651-653; R. Petrauskas, «Knighthood in the Grand Duchy of Lithuania from the Late Fourteenth to the Early Sixteenth Centuries", Lithuanian Historical Studies 11, 2006, p. 44-45.

9 Sur ces populations, parfois aussi appelées «Polabes»: C. LÜвкE, «The Polabian Alternative: Paganism between Christian Kingdoms", dans P. UrbańczyK (éd.), Europe..., p. 379-389; P. UrbańczyK, S. Rosik, "The Kingdom of Poland (Appendix)", dans N. Berend (éd.), Christianization..., p. 300-318; F. Lотter, «The Crusading Idea and the Conquest of the Region East of the Elbe», dans 
amenées à être converties relativement rapidement. C'est plus au nord et à l'est que se trouvent les hommes qui vont nous occuper dans les pages à venir. De l'embouchure de la Vistule, soit près de Gdańsk, jusqu'à l'actuelle région de Klaipèda en Lituanie, englobant à l'intérieur des terres le nord-est de l'actuelle Pologne et toute l'enclave russe de Kaliningrad, vivaient les Prussiens, connus dès le $\mathrm{Ix}^{\mathrm{e}}$ siècle par cet ethnonyme (Pruze ou Pruzzi en allemand, Prutheni en latin, aussi appelés Vieux-Prussiens, Borusses ou Pruthènes en français $)^{10}$. Il s'agit d'une population balte, divisée en tribus, dont les principales sont les Galindiens, les Sambiens, les Nadringiens, les Jatvingiens, également appelés Sudoviens ${ }^{11}$. Autour de l'actuelle Vilnius et jusqu'à la côte (région de Palanga) se trouvent les Lituaniens, qui se divisent en deux groupes, nommés en fonction de la région qu'ils occupent: Aukštaitija («Hautes terres»), ou "Lituanie propre» ${ }^{12}$ pour la région de Vilnius et de Trakai, et Žemaitija ("Basses terres»), appelée Samogitie en français, pour celle qui s'étend de l'actuelle Kaunas jusqu'à la côte ${ }^{13}$. Gardons cette division en tête, puisqu'elle aura une importance capitale au moment de la christianisation des derniers païens de la région: alors que les Lituaniens des Hautes terres seront baptisés avec leur grand-duc en 1387, les Samogitiens resteront païens jusqu'en 1417. La première attestation du terme de Lituanie date de 1009, quand "Lituae» est mentionnée dans les Annales de Quedlimbourg, qui retracent le martyre de Bruno de Querfurt, tombé sous les coups des païens "aux confins de la Russie et de la Lituanie»" ${ }^{14}$.

R. Bartlett, A. MacKay (dirs.), Medieval Frontier Societies, Oxford 1989, p. 265-306. La participation de certains de ces peuples aux guerres menées par Charlemagne est notamment racontée par Eginhard, Vie de Charlemagne, éd. et trad. M. Sot et al., Paris 2014, chap. 12, p. 26-29. Pour les Slaves de la Baltique à l'époque païenne et le récit de leur conversion au christianisme, les sources principales sont: Helmold de Bosau (Chronica Slavorum, éd. G. Pertz, Hanovre 1866), Thietmar de Mersebourg (Chronicon, éd. R. Holtzmann, W. Trillmich, Darmstadt 1974), Saxo Grammaticus (Gesta Danorum, éd. K. Friis-Jensen, trad. P. Fischer, Oxford 2005), et les trois vies d'Othon de Bamberg (Monumenta Poloniae Historica, nova series 7/2, éd. J. Wikarjak, K. Liman, Varsovie 1969). On y ajoute le témoignage du voyageur espagnol Ibrahim Ibn Yaqub (D. Mishin, "Ibrahim Ibn-Ya'qub At-Turtuhi's Account of the Slavs from the Middle of the Tenth Century", Annual of medieval studies at CEU 1994-1995, p. 184-199; Regesten zur Geschichte der Slaven an Elbe und Oder (vom Jahr 900 an), éd. C. Lübke, vol. 2, doc. 139, p. 190-191). Pour les sources archéologiques, J. Herrmann, «Les Slaves du Nord», dans D. WILsOn (dir.), Les mondes nordiques. Histoire et héritage de l'Europe barbare, V’-XIf s, Paris 1980, p. 193-206; W. Filipowiak, M. Konopka, «The identity of a town: Wolin, Town-State $-9^{\text {th }}-12^{\text {th }}$ Centuries", dans Quaestiones Medii Aevi Novae, vol. 13, 2008, p. 243-288.

${ }_{10}$ M. Gimbutas, The Balts..., p. 24.

11 W. Mannhardt, Letto-Preussische Götterlehre, Riga 1936, p. 1-7. Les Jatvingiens, appelés aussi Sudoviens (notamment dans les sources allemandes, Sudauer) sont considérés par l'auteur comme parlant une langue balte à part (Ibid., p. 6-7). Pour la question de l'appartenance linguistique de ce peuple qui occupait le sud-est de l'ensemble balte, A. Pluskowski, The Archaeology..., p. 46; E. Bojtár, Foreword..., p. 158.

12 «Lithuania proper» (ang.), S. C. RowelL, Lithuania Ascending..., p. XIII.

13 L. Teiberis, La Lituanie, Paris 1995, p. 18-19.

${ }^{14}$ Voir la copie datée de 1550 par P. Albinus (von Weiss) et G. Fabricius (Goldschmidt), Mscr. Dresd.Q.133, Nr. 4 (Dresde, Sächsische Landesbibliothek - Staats - und Universitätsbibliothek, 
Au nord des Lituaniens et des Samogitiens vivent les différents peuples qui formeront l'actuelle Lettonie: Sémigalliens, Coures, Séloniens, Lettes et Lives. Si les quatre premiers parlent, comme les Lituaniens, les Samogitiens et l'ensemble des tribus prussiennes, des langues baltes, les derniers sont de langue fennique, tout comme les Estes ou Estoniens ${ }^{15}$, qui habitent le nord de l'actuelle Estonie. Linguistiquement et culturellement proches de ces derniers, on peut encore mentionner les Finnois, qui seront évangélisés au cours des $\mathrm{XII}^{\mathrm{e}}$ et $\mathrm{XIII}^{\mathrm{e}}$ siècles par les Suédois ${ }^{16}$. À l'époque qui nous intéresse, d'autres peuples fenniques (Caréliens, Izhoriens et Vodes) vivent dans l'actuelle Russie et pratiquent encore leur religion traditionnelle, avant d'être progressivement évangélisés depuis Novgorod jusqu'au début du Xv' siècle $^{17}$.

Les spécialistes considèrent que les peuples baltes et fenniques étaient appelés Aesti dans l'Antiquité et au Haut Moyen Âge ${ }^{18}$. Par la suite, cette dénomination générique s'est resserrée jusqu'à ne désigner que les seuls Estoniens ${ }^{19}$. À partir du Moyen Âge central et jusqu'au XIX ${ }^{\mathrm{e}}$ siècle, les peuples baltes ou fenniques de la région sont simplement appelés "Lives", "Samogitiens", "Lituaniens», "Prussiens», "Sémigalliens», etc. Le terme collectif "balte» était utilisé pour parler de la Mare balticum, et non des peuples autochtones; la première occurrence sûre date d'Adam de Brême (vers 1075) ${ }^{20}$. Désignation géographique à l'origine, balte s'est appliqué dans un deuxième temps aux

consultable en ligne: http://digital.slub-dresden.de/werkansicht/dlf/2891/1/cache.off ) : "Sanctus Bruno... XI. conversionis suae anno in confino Rusciae et Lituae a paganis capite plexus cum suis XVIII, VII Id. Martii petiit coelos»; pour une édition récente, Annales Quedlinburgenses, éd. M. Giese, MGH SRG 72, 2004, p. 527. Pour des attestations du terme "Lituae» en rapport avec le même épisode par d'autres chroniques (Chronique de Magdebourg, Annalista Saxo et Marianus Scotus), voir Skarbiec diplomatów papiezkich, cesarskich, krolewskich, ksiązęcych..., éd. I. Daniłowicz, Vilnius 1860, vol. 1, p. 36. Le nom de la Lituanie (auj. Lietuva) dérive probablement d'un hydronyme: T. Baranauskas, "On the Origin of the Name of Lithuania", Lituanus 55/3, 2009, p. 28-36.

${ }_{15}$ Pour éviter la confusion avec les Aesti de Tacite et des auteurs du Haut Moyen Âge, nous utiliserons leur ethnonyme actuel pour désigner les habitants fenniques de l'Estonie.

${ }^{16}$ E. Christiansen, The Northern Crusades..., p. 113-122.

${ }^{17}$ Ibid., p. 116; E. Nazarova, "The Crusades against Votians and Izhorians in the Thirteenth Century", dans A. V. Murray (dir.), Crusade and Conversion..., p. 177-180; J. H. Lind, "Consequences of the Baltic crusades in Target Areas: The Case of Karelia», dans A. V. MurraY (dir.), Crusade and Conversion..., p. 133-150.

18 W. K. Matthews, «Baltic Origins», Revue des études slaves 24/1, 1948, p. 50.

19 J. Bately, "Wulfstan's Voyage and his description of Estland: the text and the language of the text", dans A. Englert, A. Trakadas (dirs.), Wulfstan's Voyage, Roskilde 2009, p. 15-17; P. URBAŃCZYK, "On the reliability of Wulfstan's report", dans Ibid., p. 44; S. LebeCQ, Hommes, mers et terres du nord au début du Moyen Âge, vol. 1, Villeneuve d'Ascq 2011, p. 229; T. Baranauskas, "Saxo Grammaticus on the Balts", dans T. Nyberg (dir.), Saxo Grammaticus and the Baltic Region, 2004, p. 67; J.-P. Minaudier, Histoire de l'Estonie et de la nation estonienne, Paris 2007, p. 31-32; A. Pluskowski, The Archaeology..., p. 44.

${ }^{20}$ Il est possible que la forme Balcia que Pline utilise pour désigner une île de l'Europe du Nord soit identifiable à notre "balte», ce qui en ferait la première occurrence. W. K. MATTHEws, «Baltic Origins", Revue des études slaves 24/1, 1948, p. 48-50. 
populations d'origine allemande installée dans ces régions après la conquête de l'époque médiévale, et par extension à l'espace géographique correspondant à l'ancienne Livonie ${ }^{21}$. Puis vint le moment où les études linguistiques déterminèrent l'appartenance du lituanien, du letton et de l'ancien prussien (disparu autour du $\mathrm{XvI}^{\mathrm{e}}$ siècle) à un groupe linguistique commun: l'on utilisa dès 1845 le terme «balte" pour nommer ce nouvel ensemble ${ }^{22}$. Le terme s'étant répandu en français pour parler non seulement de la mer Baltique, mais aussi des langues baltes et par conséquent des pays baltes, nous l'utiliserons - suivant en cela l'usage de l'historiographie francophone - pour parler des peuples habitant les régions correspondant à l'ancienne Prusse, à la Lituanie et à la Samogitie, ainsi qu'au territoire que l'on appellera la Livonie (c'est-à-dire les actuelles Lettonie et Estonie), à l'exclusion des Slaves habitant la côte, des Finnois vivant en Finlande, et des différents peuples fenniques païens de Russie. Pour notre enquête, "balte» regroupera donc ce qui se réfère aux coutumes des peuples autochtones ${ }^{23}$ de la région, qu'ils parlent une langue fennique ou proprement «balte» ${ }^{24}$.

Les Baltes sont connus depuis l'Antiquité. On attribue, sans consensus toutefois, leur première mention à Hérodote ${ }^{25}$. La rivière Vistula apparaît

${ }^{21}$ On parle encore de "germano-baltes» pour désigner les minorités allemandes qui habitaient ces régions jusqu'au début du $\mathrm{xx}^{\mathrm{e}}$ siècle, et de "barons baltes" pour designer les junkers, aristocrates d'extraction allemande; J.-P. Minaudier, Histoire de l'Estonie..., p. 9, n. 1.

${ }_{22}$ M. Gimbutas, The Balts..., p. 21; le terme «balte» est utilisé pour la première fois dans ce sens par le linguiste G. Neselman, The Origin of Prussian Language, 1845 (A. Kuncevičius, dans Z. Kiaupa, J. Kiaupiené, A. Kuncevičıus, The History of Lithuania before 1795, Vilnius 2000, p. 24).

${ }^{23}$ La question de l'autochtonie pose un nouveau problème; les peuples locuteurs des langues "baltes» dites indo-européennes sont établis dans la région avant le premier millénaire de notre ère (A. Kuncevičius, dans Z. Kiaupa, J. Kiaupiené, A. Kuncevičius, The History of Lithuania before 1795..., p. 24-27; J.-P. Minaudier, Histoire de l'Estonie..., p. 35). Les peuples parlant des langues dites "fenniques", qui appartiennent au groupe linguistique ougro-finnois, semblent être parmi les premières populations implantées dans la région; leur installation à l'Est de la mer Baltique devance celle de leurs voisins de plusieurs millénaires (Ibid., p. 33-34). Par «indigène» ou "autochtone", nous entendrons les populations issues de ces deux groupes qui vivaient depuis plusieurs siècles au moins sur le territoire de la mer Baltique, par opposition aux colons majoritairement germanophones originaires de l'Empire, qui peuplent les villes de la région après la conquête du XIII ${ }^{\mathrm{e}}$ siècle.

24 J.-P. Minaudier, Histoire de l'Estonie..., p. 9, n. 1.

${ }^{25}$ Hérodote, Enquêtes, IV, 17, dans Euvres complètes d'Hérodote et Thucydide, éd. et trad. A. Braguet, D. Roussel, Paris 1964, p. 294. M. Gimbutas, The Balts..., p. 101 ; Z. Kiaupa, The History of Lithuania..., p. 17. C'est l'hypothèse que suit, avec réserve, C. Ginzburg, Le Sabbat..., p. 154-155; l'archéologue tchèque Z. Vana les identifie plutôt aux proto-slaves (Le Monde slave ancien, Paris 1983, p. 10-11), tout en soulignant qu' 'il s'agit d'une hypothèse que rien n'a permis, à ce jour, d'infirmer ou de confirmer» (p. 11). L'identification des Neures avec les Baltes est discutée par E. Bojtár, Foreword..., p. 102-104; W. Matthews, «Baltic Origins... », p. 51-55; B. Lévy, "Les racines culturelles de l'exotisme géographique, du Moyen Âge à la Renaissance européenne", Le Globe, 148, 2008, p. 35. 
sur une carte préparée pour Auguste ${ }^{26}$, et est mentionnée par Pline l'Ancien (m. 79), dans le livre IV de son Histoire naturelle ${ }^{27}$, qui relate au moins trois expéditions ayant atteint l'Océan nordique, c'est-à-dire la Baltique ${ }^{28}$. Dans sa Germania, Tacite présente de manière relativement détaillée les Aesti vivant aux confins de la Germanie, et que les spécialistes identifient comme des Baltes ${ }^{29}$. $\mathrm{Au}$ deuxième siècle de notre ère, le géographe Ptolémée cite deux tribus distinctes dans la région de la Baltique, les Galindai et les Soudinoi, qui sont vraisemblablement les ancêtres des habitants des provinces de Galindia et Sudua, mentionnés dans les sources teutoniques du XIII ${ }^{\mathrm{e}}$ siècle $^{30}$. Dans l'Antiquité, la région balte est essentiellement identifiée au commerce de l'ambre; c'est encore le cas au vi ${ }^{\mathrm{e}}$ siècle, époque où le roi Théodoric le Grand (m. 526) aurait fait écrire par son secrétaire Cassiodore une lettre aux Haesti pour les remercier de lui avoir fait parvenir des cadeaux faits de cette matière ${ }^{31}$.

De producteurs d'ambre, les Baltes deviennent, dans les sources, un simple peuple pris dans les bouleversements politiques du Haut Moyen Âge, avant de susciter un certain intérêt en raison de leur paganisme. Pour Jordanès, qui abrège vers 551 une Histoire des Goths de Cassiodore aujourd'hui perdue, les Aesti forment un peuple pacifique qui vit à l'est de la Vistule ${ }^{32}$ et a été conquis par le roi ostrogoth Hermanaric ${ }^{33}$. Quelques siècles plus tard, Eginhard, dans sa Vie de Charlemagne (v. 817-827), les situe à peu près au même endroit, et

${ }^{26}$ P. Urbańczyк, "On the reliability...», p. 44; M. Gimbutas, The Balts..., p. 21-22; A. Kuncevičius, «Les Origines», dans Y. Plasseraud (dir.), Histoire de la Lituanie. Un Millénaire, Crozon 2009, p. 33-34; Idem, dans Z. Kiaupa, J. Kiaupiené, A. Kuncevičius, The History of Lithuania before $1795 \ldots$.. p. 29-31; E. Bazaraité, T. Heitor, «Comparative study...», p. 316.

${ }^{27}$ Pline L'Ancien, Histoire naturelle: Livre IV, éd. et trad. H. Zehnacker et A. Silberman, Paris 2005 , p. 72.

${ }_{28}$ Ibid., p. 71; Pline L'Ancien, Livre XXXVII, 11, The Natural History of Pliny, trad. J. Bostock, vol. 6, Londres 1857, p. 402. A. Buiujiene, Northern gold: amber in Lithuania (c. 100 to c. 1200), Leiden 2011, p. 40-50; P. UrbańCZYK, "On the reliability...", p. 43-44.

29 Tacite, La Germanie, 45, éd. et trad. J. Perret, Paris 1949, p. 98-99. L'indentification des Aesti avec les tribus baltes de Prusse et de Courlande fait consensus: A. Kuncevičıus, "Les Origines...», p. 33-34; M. Gimbutas, The Balts..., p. 21-22; Z. Kiaupa, The History of Lithuania..., p. 15-18; K. InNo, "Aestii, the Estonians, and the Origin of Eesti", Ural-Altaische Jahrbücher, 54, 1982, p. 57-85; W. NowaKowsкi, "Baltes et proto-Slaves dans l'Antiquité. Textes et archéologie», Dialogues d'histoire ancienne 16/1, 1990, p. 382 ; J.-P. Minaudier, Histoire de l'Estonie..., p. 31.

30 W. Nowakowski, «Baltes...", p. 388-389. Pour une adaptation du texte en latin du XVI siècle, voir Baltu Religijos ir Mitologijos Šaltiniai, éd. N. Vèlius, Vilnius 1996, p. 150 ; M. Grmbutas, The Balts..., p. 22; Z. KIAUpa, The History of Lithuania..., p. 18.

31 M. Gimbutas, The Balts..., p. 144-145, qui cite T. Hodgins (éd.), The Letters of Cassiodorus, Londres 1886, p. 265-266. Il est difficile de savoir si cette lettre a réellement été envoyée, ou s'il s'agissait simplement d'un exercice exécuté par Cassiodore sans lien avec une quelconque ambassade; A. Bliujiene, Northern Gold..., p. 24, 210-212.

32 Jordanès, Getica, V, 36, éd. T. Mommsen, Munich 1882, p. 63; Jordanès, Histoire des Goths, trad. O. Devillers, Paris 2004, p. 15.

33 Jordanès, Getica..., XXIII, 120, p. 89; Jordanès, Histoire des Goths..., p. 48. 
indique qu'ils sont voisins des Slaves ${ }^{34}$. C'est aussi ce que dit le voyageur anglosaxon Wulfstan, dont les souvenirs ont été intégrés à l'adaptation vernaculaire de l'Histoire contre les païens d'Orose, commandée par le roi Alfred le Grand (m. 899) $)^{35}$.

Les Prussiens, situés plus au sud, ont été les premiers à entrer en contact avec le monde romain, puis chrétien. Ils sont décrits par Adam de Brême comme accueillants et honnêtes, une exception louable parmi des païens généralement féroces, au nord desquels le chroniqueur situe un univers de froid, de glace et de ténèbres, peuplé d'Amazones ou de cynocéphales ${ }^{36}$; depuis l'Antiquité, ces créatures marquent symboliquement les limites du monde connu ${ }^{37}$. Comme l'a bien montré David Fraesdorff, l'imaginaire du Nord comme bastion du paganisme permet de réactiver de très anciens topö̈, qui font appel à tout un savoir hérité des descriptions par les auteurs gréco-romains de la Scythie, pays barbare situé aux confins nordiques de l'Europe et de l'Asie ${ }^{38}$. À la suite du chanoine de Brême, ces référentiels se font plus discrets, mais les chroniqueurs d'Europe du Nord-Est continuent de caractériser les Baltes comme

${ }_{34}$ Eginhard, Vie de Charlemagne..., chap. 12, p. 26-27; M. Gimbutas, The Balts..., p. 22.

35 J. Bately, «Wulfstan's Voyage...», p. 20-21. Sur le témoignage de Wulfstan, voir les études rassemblées dans A. Englert, A. Trakadas (dirs.), Wulfstan's Voyage..., et S. LebecQ, "Ohthere et Wulfstan: deux marchands-navigateurs dans le Nord-Est européen à la fin du IX siècle», dans H. Dubois, J.-C. Hocquet, A. Vauchez (dirs.), Horizons marins, itinéraires spirituels, Paris 1987, p. 167-169; S. Rossignol, «Early Towns and Regional Identities on the Eastern Coast of the Baltic Sea and in the Land of the Rus' as Perceived in Western and Central European Sources (9th-Early 12th Centuries)", dans J. Nómm (dir.), Ethnic Images and Stereotypes - Where Is the Border-line? (Russian-Baltic Cross-cultural Relations), Narva 2007, p. 241-252.

36 Adam de Brême, Gesta Hammaburgensis ecclesie pontificum, éd. B. Schmeidler, Hanovre 1917, IV, 15-19, p. 243-248; Adam de Brême, Histoire des archevêques de Hambourg, trad. J.-B. BrunetJailly, Paris 1989, p. 205-207.

37 Une littérature importante existe sur les « races monstrueuses». En lien avec l'Europe du Nord-Est, voir notamment D. Fraesdorff, Der barbarische Norden: Vorstellungen und Fremdheitskategorien bei Rimbert, Thietmar von Merseburg, Adam von Bremen und Helmold von Bosau, Munich 2005, p. 302-303; E. Matthews SAnford, «Ubi lassus deficit orbis», Philological Quarterly 13/4, 1934, p. 357-369; J. Friedman, Monstrous Races in Medieval Art and Thought, Cambridge, Mass. 1981, p. 84-85; D. White, Myths of the Dog-Man, Chicago 1991, p. 60-63; M. Sosnowski, «Prussians as Bees, Prussians as Dogs: Metaphors and the Depiction of Pagan Society in the Early Hagiography of St. Adalbert of Prague», Reading Medieval Studies, 39, 2013, p. 25-48; J.-C. DucÈne, "L'île des Amazones dans la mer Baltique», Rocznik Orientalistyczny, 54, 2002, p. 171-182; C. Lecouteux, «Les cynocéphales. Étude d'une tradition tératologique de l'Antiquité au XII ${ }^{\mathrm{e}}$ s.», Cabiers de civilisation médiévale, 24/94, 1981 p. 117-128; G. BüHrer-Thierry, Aux Marges..., p. 217-222; I. Wood, "Categorising the cynocephali», dans R. Corradini, M. Gillis, R. McKitterick, I. van Renswoude (dirs.), Ego Trouble: authors and their identities in the Early Middle Ages, Vienne 2010, p. 125-36; T. BARNwell, Missionaries and Changing Views of the Other from the Ninth to the Eleventh Centuries, Leeds 2011 (thèse de doctorat non publiée), p. 224-228.

${ }_{38}$ D. Fraesdorff, Der barbarische Norden..., p. 290-308; voir aussi Idem, "The Power of Imagination: The Christianitas and the Pagan North during Conversion to Christianity (800-1200)», Medieval History Journal, 5/2, 2002, p. 309-332. 
d'irréductibles païens, avec qui les relations sont en général conflictuelles ${ }^{39}$. À titre d'exemple, le chroniqueur d'origine ouest-européenne Gallus Anonymus décrit les voisins de la Pologne, son pays d'adoption, comme suit: "Sur la mer $d u$ Nord [i. e. Baltique] [...], elle a comme voisins trois nations de barbares païens des plus sauvages, la Selencia ${ }^{40}$, la Poméranie et la Prusse, contre lesquelles le duc de Pologne combat sans arrêt pour les convertir à la foi»" ${ }^{41}$. Sans grand résultat, puisque, nous dit le chroniqueur, les chefs païens défaits ne cessent d'apostasier après avoir "cherché le refuge dans le baptême»" ${ }^{42}$. Au-delà de ces païens et autres apostats, "il y a d'autres peuples païens barbares et des îles inhabitées, où il y a de la neige et de la glace à perpétuité» ${ }^{43}$.

Cette impression semble partagée jusqu'à la cour des Hauteville de Sicile, où le géographe arabe Muhammad Al-Idrīisi dirige l'exécution d'une mappemonde et en écrit le commentaire (après 1154) ${ }^{44}$. Dans la section consacrée à l'Europe du Nord, on trouve une description du "pays des Madjous», c'est-à-dire des idolâtres ${ }^{45}$ : "la majeure partie de ces contrées est déserte et inhabitée, bien qu'on $y$ trouve quelques villages peuplés. Les neiges $y$ sont éternelles ${ }^{46}$. Le terme de "Madjous» est utilisé dans les textes arabes pour parler des païens, censément adorateurs du feu: appliqué d'abord aux Perses, il devient caractéristique de l'Europe du $\mathrm{Nord}^{47}$. Pour Al-Idrīsī, l'Estlanda est donc explicitement terre de

39 Par exemple, Helmold de Bosau, Chronica Slavorum..., I.1, p. 5-6. T. BaranausKas, "Saxo Grammaticus...", p. 63-79; M. Gimbutas, The Balts..., p. 153-154; D. Fraesdorff, Der barbarische Norden..., p. 220 passim.

${ }^{40}$ Il s'agit d'un pays slave non identifié, peut-être celui des Lutices (Wilzes); Gallus Anonymus, Gesta Principum Polonorum: The Deeds of the Princes of the Poles, éd. et trad. P. W. Knoll, F. Schaer, Budapest 2003, p. 12, n. 6.

${ }^{41}$ Ibid., p. 12.

${ }^{42}$ Id.

43 Ibid., p. 12-13. Sur Gallus et les Prussiens, J. Lelewel, Géographie du Moyen Âge, vol. 3, Bruxelles, 1852 p. 157-158.

44 P. Gautier Dalché, "Géographie arabe et Géographie latine", Medieval Encounters, 19/4, 2013, p. 424; J.-C. DucÈne, "L’Europe dans la cartographie arabe médiévale», Belgeo, 3-4, 2008, p. 251-268 [en ligne]; A. NeF, "Al-Idrīsī, un complément d'enquête biographique», dans H. Bresc, E. Tixier du Mesnil (dir.), Géographes et voyageurs au Moyen Âge, p. 63-64. Sur les sources d'Al-Idrīisi, J.-C. DucÈne, "L'Europe...»; P. Gautier Dalché, "Géographie...", p. 424-425; T. LeWICKI, "La voie Kiev-Vladimir (Wodzimiercz Wolynski) d'après le géographe arabe du XII ${ }^{\mathrm{e}}$ siècle», Rocznik Orientalistyczny 13, 1937, p. 92, 104; J. LeLEwel, Géographie..., vol. 3, p. 92, 175. Pour la région qui nous intéresse, on peut penser, entre autres, à l'ambassade hongroise qui a été reçue à Palerme aux environs de 1150 ou aux récits de quelques navigateurs scandinaves.

${ }^{45}$ Muhammad Al-Idrīsī, Livre de la récréation de l'homme désireux de connaître les pays, $4^{\mathrm{e}}$ section, $7^{\mathrm{e}}$ climat, trad. P. A. Jaubert, Paris 1840, vol. 2, p. 431.

46 Id.

47 B. Lewis, Comment l'Islam a découvert l'Europe, Paris 1992, p. 137; A. Melvinger, Les premières incursions vikings dans les sources arabes, Uppsala 1995, p. 70-85. Le lien entre le feu et la religion des païens d'Europe du Nord peut avoir été renforcé par les pratiques comme la crémation des morts, ou l'usage d'un foyer sacré parmi les Baltes et les Slaves païens (ibid., p. 81-82). Pourtant 
paganisme, en contraste des autres provinces d'Europe déjà chrétiennes. Plus au nord, c'est l'océan Ténébreux, quantité d'îles désertes, et enfin, celles des Amazones ${ }^{48}$; comme chez ses pairs chrétiens, l'imaginaire issu de l'Antiquité est convoqué pour illustrer le monde lointain et encore méconnu au-delà de la Baltique ${ }^{49}$. Cet extrait prouve que par le truchement de voyageurs arabes ou chrétiens, marchands ou diplomates, une certaine connaissance de la région balte et de ses habitants était à la disposition d'un auteur écrivant au milieu du XII ${ }^{\mathrm{e}}$ siècle à la cour des rois normands de Sicile ${ }^{50}$. Jusqu'au Moyen Âge central, les Baltes ne font donc en aucun cas figure d'inconnus, mais les connaissances sur ces populations restent assez limitées: pour les contemporains de l'évangélisation de la Baltique, les habitants de la région sont, au fond, des peuples nouveaux, qui restent à découvrir ${ }^{51}$.

Les études spécialisées, notamment archéologiques, bien relayées par une littérature assez récente, permettent de se faire une certaine idée du mode de vie des Baltes avant l'arrivée du christianisme ${ }^{52}$. Pour l'essentiel, ces différents peuples vivaient d'agriculture, d'élevage, de chasse, de pêche, mais aussi de commerce, notamment d'ambre ${ }^{53}$. Dès le Haut Moyen Âge, ils échangent avec les Scandinaves, les Russes et les Byzantins ${ }^{54}$. Des relations indirectes ont dû exister à une époque antérieure, puisque les sources archéologiques attestent que des

assez prolixe quant à l'organisation politique et militaire des peuples d'Europe centrale et orientale dont il parle, Ibrahim Ibn Yaqub, l'autre auteur arabophone à nous renseigner sur la région, ne dit rien de la religion des Bruzi (Prusiens païens), mais il s'étend sur la conversion au christianisme des Bulgares. Voir D. Mishin, "Ibrahim Ibn-Ya'qub...», p. 189; D. WalczaK, K. Vandenborre, «Entretien avec Jean-Charles Ducène», Slavica bruxellensia 7, 2011, p. 5.

${ }^{48}$ Muhammad Al-Idrīsī, Livre de la récréation..., p. 433. Il s'agit de deux îles, l'une étant habitée par des femmes, l'autre par des hommes.

${ }^{49}$ H. Norris, Islam in the Baltic: Europe's Early Muslim Community, Londres \& New York 2009, p. 8-9; sur cette question, J.-C. DucÈne, "L'île des Amazones...», p. 171-182.

50 W. Mannhardt, Letto-Preussische Götterlehre..., p. 12-13; préface de l'édition de P. A. Jaubert, Muhammad Al-Idrīīi, Livre de la récréation..., p. XX-XXII.

${ }^{51}$ M. Tамм, «A New World...», p. 13; N. Blomkvist, Discovery..., p. 44. Sur le sens du terme de "découverte» (à comprendre du point de vue ouest-européen), ibid., surtout p. 15-21.

52 Les travaux de Marija Gimbutas restent essentiels pour une première approche de la culture, de la religion et de l'histoire des Baltes avant la conquête du XIII ie siècle. Voir notamment M. Gimbutas, The Balts... Une autre bonne synthèse en langue anglaise est la première partie (par A. Kuncevičius) de Z. Kiaupa, J. Kiaupienè, A. Kuncevičius, The History of Lithuania before $1795 \ldots$... ; voir aussi N. Blomkvist, Discovery...; A. Bliujiene, Northern Gold... Plus spécialisé et essentiellement orienté vers la culture religieuse, E. Bojtár, Foreword.... À l'exception de A. Greimas, Des dieux et des hommes..., qui porte plus sur la mythologie que sur l'histoire, les travaux fouillés en langue française sur l'époque préchrétienne balte font défaut; on se référera aux synthèses récentes d'A. Kuncevičıus, «Les Origines...» et J.-P. Minaudier, Histoire de l'Estonie...

${ }_{53}$ M. Gimbutas, The Balts..., p. 113-123; A. Kuncevičıus, «Les Origines...», p. 32. voir aussi A. Bliujiene, Northern Gold...

54 A. Kuncevičius, «Les Origines...», p. 39-40; N. Blomkvist, Discovery..., p. 35-36; H. Steuer, "Principles of trade and exchange: trade good and merchants», dans A. Englert, A. Trakadas (dirs.), Wulfstan's Voyage..., p. 302. 
éléments d'origine romaine ont pénétré leur culture matérielle 55 . La présence de l'ambre sur les côtes baltes attire des marchands, qui développent quelques centres d'échanges dans la région ${ }^{56}$. Les Baltes sont confrontés aux Vikings ${ }^{57}$, et certains d'entre eux vont piller les côtes de la Scandinavie aux $\mathrm{x}^{\mathrm{e}}$ et $\mathrm{XI}^{\mathrm{e}}$ siècles $^{58}$. Enfin, un art spécifique se développe parmi les différentes populations baltes durant le Haut Moyen Âge et les premiers siècles du deuxième millénaire ${ }^{59}$.

En comparant les sources textuelles de l'époque de la conquête, les textes de lois qui ont été rédigés pour les peuples autochtones au $\mathrm{XVI}^{\mathrm{e}}$ siècle, et les matériaux archéologiques disponibles, Nils Blomkvist parvient à dégager une vue d'ensemble de la manière dont les sociétés de la région balte pouvaient fonctionner à l'époque qui nous intéresse ${ }^{60}$. Le constat qui s'impose est celui d'une grande diversité. Les peuples du nord et de l'est des actuels pays baltes, notamment les Lettes, mais aussi une partie des peuples fenniques de l'actuelle Estonie, vivaient pour l'essentiel des produits de la forêt, de chasse et d'agriculture ${ }^{61}$. Les témoignages des époques médiévale et moderne font état de la place exceptionnelle dont jouissaient les femmes dans ces sociétés, vraisemblablement matrilinéaires; la Chronique rimée de Livonie nous dit notamment que certaines d'entre elles montent à cheval «à la manière de leurs pères ${ }^{62}$. Ces indications pourraient n'être qu'une forme d' «altérisation» par inversion des catégories de genre, mais elles se révèlent en bonne partie confirmées par l'archéologie et l'étude des codes de lois tardifs ${ }^{63}$.

55 J.-P. Minaudier, Histoire de l'Estonie..., p. 37-38. La présence de coutumes ou de mythes similaires dans le monde balte et dans l'espace méditerranéen ou occidental n'est pas sans soulever quelques problèmes. Si l'influence de topoï littéraires sur les descriptions de la religiosité balte ne peut être exclue, il ne s'agit pas toujours de simples reprises de thèmes plus anciens que les auteurs occidentaux plaqueraient sur les peuples «étrangers» d'Europe du Nord, et qui seraient déconnectés de toute réalité. Toutefois, il n'entre pas dans notre propos de trancher entre une hypothèse diffusionniste ou celle postulant une évolution parallèle, à partir d'un fond commun. Pour une mise au point se référant à d'autres objets, mais qui garde toute sa validité pour ce qui nous occupe, voir C. LÉvi-STrauss, "Le dédoublement de la représentation dans les arts de l'Asie et de l'Amérique», dans Anthropologie structurale, Paris 1958, p. 269-294, surtout p. 272-273, 284; C. GinzBurg, Le Sabbat..., p. 206-212.

56 A. Bliujiene, Northern Gold..., p. 313-324.

57 A. Kuncevičius, «Les Origines... », p. 37-38.

${ }^{58}$ Le poète Snorre Sturlesson raconte notamment que l'on récitait au milieu du XI ${ }^{e}$ siècle des prières dans les églises de Norvège - alors chrétienne - pour se protéger des pirates coures; M. Gimbutas, The Balts..., p. 155-158; T. BaranausKas, "Saxo Grammaticus...», p. 77-79.

59 Voir par exemple le catalogue de l'exposition Art of Balts. The Guide of Exhibition, Vilnius Academy of Arts Press, 2009, et la synthèse de M. Gimbutas, The Balts....

${ }^{60}$ Sur ce qui suit, N. Blomkvist, Discovery..., p. 169-198.

${ }^{61}$ Ibid., p. 181.

${ }^{62}$ "Ir wib sint wunderlich gestalt. / Und haben selzene cleit; / Sie riten als ir vater reit.", Livländische Reimchronik v. 346-348, éd. L. Meyer, Padeborn 1876, p. 9; N. Bцомкvist, Discovery..., p. 180. Pour une traduction en anglais, The Livonian Rhymed Chronicle, trad. W. Urban, J. Smith, Chicago 2001, p. 5.

${ }^{63}$ Ibid., p. 182-194; sur les sources archéologiques, notamment pour l'Estonie; Ibid., p. 196-198; R. MAŽEIKA, " "Nowhere was the Fragility of their Sex Apparent": Women Warriors in the Baltic 
Les sources narratives ou diplomatiques rapportent, chez les peuples vivant plus au sud (Courlande ${ }^{64}$, Lituanie, Prusse), des rapports de genre eux aussi très différents de la norme chrétienne. Cette fois-ci, ils sont drastiquement inversés par rapport à ce que l'on dit des Lettes; pour Pierre de Dusbourg, par exemple, les Prussiens tiendraient leurs femmes dans un état nettement inférieur, les obligeant à laver les pieds de leurs hôtes ${ }^{65}$. Quel que soit la crédibilité que l'on puisse accorder à ce genre de descriptions, le supposé caractère "masculin" des sociétés baltes du sud est à mettre en lien avec la propension à la violence que leur attribuent les auteurs chrétiens de l'époque de la conquête ${ }^{66}$. À cet égard, il semble que les structures sociales de ces populations aient été, à l'époque médiévale, relativement bellicistes - peut-être en réaction aux pressions politiques, militaires et culturelles exercées par les royaumes chrétiens voisins ${ }^{67}$. De fait, Coures, Prussiens et surtout Lituaniens sont ceux qui donneront le plus de fil à retordre aux croisés.

En étudiant la mythologie lituanienne, Algirdas Greimas a cru observer une certaine militarisation de la société datant des premiers siècles du deuxième millénaire. Une religion plus structurée, centrée autour d'un dieu guerrier, solaire et masculin (Perkunas), aurait accompagné l'émergence d'un pouvoir fort, issu des clans de guerriers qui se sont vraisemblablement imposés dans les premiers siècles de l'an mil. Pour le grand sémiologue, cette structure sociale aurait permis la naissance du pouvoir dynastique que l'on retrouvera sous le nom de grand-ducal ${ }^{68}$. De leur côté, les sources archéologiques indiquent qu'une organisation sociale de plus en plus hiérarchisée se met en place chez les Coures, Lituaniens et Prussiens ${ }^{69}$. Les clans familiaux et tribaux s'unifient pour former

Crusade Chronicles", dans A. V. Murray (dir.), From Clermont to Jerusalem: The Crusades and Crusader Societies, 1095-1400, Turnhout 1998, p. 241.

${ }^{64} \mathrm{La}$ Courlande, qui correspond approximativement au sud-ouest de l'actuelle Lettonie, est habitée par les Coures, une population de langue balte.

${ }_{65}$ Pierre de Dusbourg, Chronicon..., SRP 1, p. 54. Voir aussi le traité dit de Christbourg, passé entre les Prussiens et l'Ordre teutonique: Preussisches Urkundenbuch, vol. I, 1, éd. R. Philippi, Königsberg 1882 (ci-après PUB), doc. 218, p. 161.

${ }^{66}$ Attention à ne pas perdre de vue les biais inhérents aux sources chrétiennes, qui tendent à renforcer la mise à distance des sociétés "étrangères" en décrivant des rapports de genre soit trop favorables aux femmes (comme dans le cas des Lettes), soit trop défavorables (dans le cas des Prussiens). Faire des adversaires païens des guerriers frustes et très éloignés des normes courtoises et chrétiennes permet aussi de mettre en avant leur altérité; voir notamment R. MAžEIKA, «Nowhere...", p. 229-248; N. Blomkvist, Discovery..., p. 182.

${ }^{67}$ Ibid., p. 172-177; sur le cas des Slaves païens de la Baltique, G. Bührer-Thierry, Aux Marges..., p. 243-245, 249 .

68 A. Greimas, Des dieux et des hommes..., p. 197-205; Idem, «Les voix du mythe en Lituanie. Entretien avec Algirdas Julien Greimas", Lalies 10, 1992, p. 9-39. Voir aussi G. Beresnevicius, "Religious Reforms of the Balts», dans J. Trinkunas (éd.), Of Gods and Holidays, Vilnius 1999, p. 56-61.

${ }^{69}$ Z. SAWICKI et al., "Survival at the Frontier of Holy War», European Journal of Archeology 18/2, 2015, p. 282-311. 
de plus grandes communautés, construisant notamment des forteresses de bois protégées par des palissades ${ }^{70}$. Les sources appellent parfois rex les principaux chefs baltes, ce qui semble attester que leur pouvoir dépassait celui d'un simple chef clanique ${ }^{71}$. Dès le XII ${ }^{e}$ siècle, ceux-ci sont capables de tenir tête aux princes de Kiev et de Novgorod $^{72}$.

Malgré la diversité qui prévalait parmi les différents peuples du sud-est de la Baltique, les textes produits dans l'Europe chrétienne, et même au-delà, leur attribuent un dénominateur commun: le paganisme. Adam de Brême pose les traits essentiels que l'on retrouvera par la suite: les Coures disposent, dit-il, d'un clergé puissant et respecté, alors que les Prussiens, en général bienveillants envers les étrangers, exigent d'eux le respect des bois sacrés ${ }^{73}$. Au moment où le chanoine rédige ces descriptions, ces peuples sont alors loin d'être soumis aux puissances chrétiennes. C'est à peine si quelques missionnaires ont tenté d'y apporter la Parole divine, sans succès ${ }^{74}$. Dans l'Histoire des Archevêques de Hambourg, les Prussiens, les Coures, les Estoniens et les Slaves encore païens font figure de peuples lointains qui restent à convertir et justifient ainsi la mission de l'archevêque de Hambourg-Brême, lequel disputait aux rois chrétiens scandinaves l'hégémonie sur ces futures terres de mission ${ }^{75}$.

Des informations plus précises, et que l'on peut considérer comme relativement fiables, parviennent aux auteurs chrétiens dès les lendemains de la conquête de la Prusse et de la Livonie; après l'implantation des ordres militaires au cours du $\mathrm{XIII}^{\mathrm{e}}$ siècle, des chroniqueurs au service des Chevaliers teutoniques mettent en récit la conquête, où les ennemis de l'Ordre tiennent un rôle essentiel. Henri de Livonie

\footnotetext{
70 N. Blomkvist, Discovery..., p. 168-172; G. Iwanowska, «Excavations at the Jegliniec hillfort - recent developments in Balt archaeology", Antiquity 65/248, 1991, p. 684-695.

71 D. Buschinger, M. Olivier, Les Chevaliers teutoniques..., p. 97; Z. Kiaupa, The History of Lithuania..., p. 22.

72 A. Selart, Livonia, Rus' and the Baltic Crusades in the Thirteenth Century, Leiden 2014, p. 62-64; V. Portnykh, "La croisade anti-russe... », p. 885-894; H. Paszkiewicz, The Origin of Russia, Londres 1954, p. 190-192.

73 Adam de Brême, Gesta..., IV, 16-18, p. 244-246. Un clergé païen semble avoir existé chez les Slaves de la Baltique, peut-être sous influence des sociétés chrétiennes voisines; Saxo Grammaticus, Gesta..., 14, 39.7, vol. 2, p. 1278-1281 ; Helmold de Bosau, Chronica Slavorum..., I.6, p. 23-24. Pour une discussion des preuves archéologiques, J. Herrmann, "Les Slaves du Nord...», p. 199-200; A. Tummuscheit, "Pre-Christian Cult at Arkona. A short summary of the archeological evidence», dans A. Andren, K. Jennbert, C. Raudvere (dirs.), Old Norse Religion in long-term perspectives. Origins, Changes and Interactions, Lund 2006, p. 234-237.

${ }^{74}$ Adam de Brême, Gesta..., IV, 16, p. 244 ; Rimbert, Vita Anskarii auctore Rimberto, éd. G. Waitz, Hanovre 1884, chap. 30, trad. C. RoBinson, Ansgar: The Apostle of the North, Londres 1921, p. 96-100; M. Gimbutas, The Balts..., p. 152-154; N. Blomkvist, Discovery..., p. 206-210.

75 I. Garipzanov, "Christianity and Paganism in Adam of Bremen's narrative", dans Idem (dir.), Historical Narratives and Christian Identity, Turnhout 2011, p. 13-29; H.-W. Goetz, "Constructing the Past. Religious Dimensions and Historical Consciousness in Adam of Bremen's Gesta Hammaburgensis ecclesiae Ponificum", dans L. B. Mortensen (éd.), The Making of Christian Myths in the Periphery of Latin Christendom, Copenhague 2006, p. 46-47.
} 
(Chronique de Livonie, 1225-1229), l'anonyme Chronique rimée de Livonie (12901296) et surtout la Chronique de la terre de Prusse de Pierre de Dusbourg (13261331) nous ont laissé des peintures vivantes et colorées des mœurs des païens baltes. Une autre source contemporaine est le Descriptiones terrarum anonyme (autour de 1255), probablement une description des pays avoisinant l'Empire mongol. On trouve également des mentions de la religion des Baltes dans l'encyclopédie de Barthélemy l'Anglais, De proprietatibus rerum (v. 1245) et dans l'Opus maius de Roger Bacon (1268), sans doute composées à partir d'informations obtenues par le truchement des réseaux monastiques auxquels appartenaient ces deux auteurs $^{76}$, ainsi que dans les récits des voyageurs occidentaux des $\mathrm{XIV}-\mathrm{XV}^{\mathrm{e}}$ siècles, qui ont rapporté quelques anecdotes concernant les pratiques culturelles dont ils avaient eu vent lors de leurs pérégrinations dans les terres de l'Ordre teutonique. À cela, ajoutons les chroniques russes, comme la Chronique des temps passés (dite Chronique de Nestor), composée à Kiev au début du XII ${ }^{\mathrm{e}}$ siècle, la Chronique de Volhynie-Galicie, datée du XIII ${ }^{\mathrm{e}}$ siècle, ainsi qu'un passage d'une adaptation vernaculaire de la chronique byzantine de Jean Malalas ${ }^{77}$. Voilà pour les sources contemporaines; il nous reste encore les récits de chroniqueurs écrivant après la disparition "officielle» des pratiques païennes baltes, notamment le Polonais Jan Długosz ( $\mathrm{xv}^{\mathrm{e}}$ siècle), qui pour sa description des coutumes des Prussiens reprend en partie la chronique de Dusbourg, mais y ajoute une digression quant à l'origine antique de ce peuple ${ }^{78}$.

L'ensemble de ces textes permet d'observer l'évolution ou la permanence d'un certain nombre de points de vue extérieurs au sujet de la religiosité balte; cette thématique, développée à partir des auteurs originaires d'Occident (France, Angleterre, Italie) nous occupera dans le chapitre VIII de cette enquête. Pour les spécialistes cherchant à reconstituer la religion préchrétienne des Baltes, ces sources littéraires sont complétées par le folklore, plutôt bien conservé à travers les chants, les contes, les locutions proverbiales et les poèmes épiques ${ }^{79}$,

\footnotetext{
${ }^{76}$ M. TAMm, "Communicating Crusade. Livonian mission and the Cistercian network in the thirteenth century», Ajalooline Ajakiri 3/4 (129/130), 2009, p. 357-359; W. Urban, "Roger Bacon...», p. 195-212.

77 Il s'agit d'un récit inclus dans une version datée de 1262 de la traduction du Chronographe de Jean Malalas, concernant un personnage appelé Sovius, qui a longtemps été considéré comme une figure mythologique balte. La recherche plus récente tend à nuancer le caractère exclusivement balte de ce mythe; R. Valaityte, "The Myth of Sovijus and its Relation to Lithuanian Cultural Memory», Tarpdalykiniai kulTüros Tyrimai, 1/1, 2013, p. 14-30; I. Lemeshkin, "Baltijskaja "basnja" v sostave khronografa 1261 goda. Folklornyj narrativ o Sovii ", Tautosakos darbai (Folklore Studies), 30, 2005, p. 140-165. Sur les autres chroniques russes, A. Greimas, Des dieux et des hommes..., p. 131; N. Blomkvist, Discovery..., p. 6-7.

${ }^{78}$ Jan Długosz, Annales seu cronicae incliti Regni Poloniae = Historiae Polonicae, II, dans Opera Omnia, éd. Ż. Pauli, A. Przezdziecki, vol. 10, Cracovie 1873, p. 151-154; Jan Długosz, Annals, trad. et abr. M. Michael, Chichester 1997, p. 8-11.

79 A. Greimas, Des dieux et des hommes..., utilise notamment ce genre de sources, les traitant avec l'approche propre à la sémiotique.
} 
les données de l'archéologie et de la mythologie comparée ${ }^{80}$. Il n'entre pas dans notre propos de tenter ici une présentation, aussi succincte soit-elle, de la complexe mythologie balte. Contentons-nous pour le moment de dire que les Baltes - ici, à comprendre comme les peuples parlant une langue balte ${ }^{81}-$ peuvent être considérés comme des polythéistes, au sens que plusieurs dieux et êtres surnaturels figuraient dans leur panthéon. Parmi ceux-ci, on trouve des figures dont les noms varient selon les textes, les régions et les époques, et qui correspondent, pour certains d'entre eux au moins, à la triade dite indo-européenne identifiée par Georges Dumézil ${ }^{82}$. D’autres personnages étaient plus étroitement en rapport avec le monde paysan; enfin, un certain nombre de fêtes rythmaient la vie, le tout constituant un ensemble cohérent de pratiques et de mythes qui forment cette religion que nous appelons "païenne» ${ }^{83}$. Gardons encore à l'esprit que celle-ci ne saurait être considérée comme un bloc monolithique; les phénomènes religieux étant étroitement liés aux structures sociales, ils se transforment sous l'impulsion des bouleversements politiques et sociaux $^{84}$, ce qui peut expliquer que la religion des Aesti de Tacite differe assez radicalement de celle que les chroniqueurs médiévaux prêtent aux Prussiens ou aux Lituaniens. Ainsi furent élaborés au fil des siècles et sous diverses influences une religiosité, un panthéon et des mythes complexes, dont les significations et les évolutions dans le temps sont toujours discutées par les spécialistes ${ }^{85}$.

\section{UNE CROISADE DANS LE NORD: PROPAGATIO ET DEFENSIO FIDEI}

Les premières tentatives de conversion visent les Prussiens dès la constitution du royaume chrétien de Pologne. Le fils de Mieszko I ${ }^{\text {er }}$, Boleslas I ${ }^{\text {er }}$, couronné en 1025, soutient la mission d'un évêque tchèque, Vojtěch (connu sous son nom chrétien comme Adalbert ${ }^{86}$ ), lequel est tué par les Prussiens en $997^{87}$. Boleslas

\footnotetext{
${ }^{80}$ Par exemple, N. VĖLıUs, «Marija Gimbutas: The Investigator of Baltic Mythology», dans K. Jones-Bley, M. E. Huld (éds.), The Indo-Europeanization of Northern Europe, Washington CD 1996, p. 181-190.

${ }^{81}$ Pour une rapide présentation de la religion des Estoniens et des autres peuples fenniques de Livonie avant la christianisation, voir J.-P. Minaudier, Histoire de l'Estonie..., p. 47-49.

82 A. Greimas, Des dieux et des hommes..., p. 129-135.

${ }^{83}$ Ibid., passim. Voir aussi l'introduction de N. Vèlius, Baltu Religijos..., p. 67-71.

${ }^{84}$ T. Jonuks, "Archeology of religion: possibilities and prospects", Journal of Estonian Archelogy, 9/1, 2005, p. 49. La remarque a été dite dans le contexte fennique, mais elle reste bien sûr valide en contexte balte. Voir aussi G. Beresnevicius, «Religious Reforms...», p. 56. Pour A. Greimas, Des dieux et des hommes..., p. 17-19, les changements socio-politiques ont une influence sur la religiosité lituanienne, mais en dépit des nombreuses variantes produites au fil du temps, les structures profondes de celle-ci restent dans l'ensemble les mêmes.

85 R. Valaityte, "The Myth of Sovijus...", p. 22-24.

${ }^{86}$ G. BüHrer-Thierry, Aux Marges..., p. 274.

${ }^{87}$ I. Wood, Missionary Life, New York 2001, p. 211, 215-220; H. Henrix, «Adalbert von Prag (um 956-23. April 997) - ein europäischer Heiliger", dans H. Henrix (dir.), Adalbert von Prag. Brückenbauer zwischen dem Osten und Westen Europas, Baden-Baden, Nomos, 1997, p. 12. Sa mort
} 
fait amener son corps à Gniezno, qui est érigé en archevêché en $999^{88}$. En 1009, un second missionnaire, Bruno de Querfurt, marche sur les traces d'Adalbert et subit, lui aussi, le martyre ${ }^{89}$. La mort des deux hommes, rapidement canonisés, connaît un certain retentissement en Europe; des Vies de saint Adalbert et de saint Bruno sont composées dans l'Empire, mais aussi en Italie, et leur destinée est mentionnée dans au moins deux chroniques françaises ${ }^{90}$. L'événement marque aussi le début d'un intérêt polonais pour la mission auprès des infidèles vivant près de la Baltique, mais les efforts seront plutôt dirigés vers les Slaves de Poméranie: «laissons les Prussiens avec les bêtes sauvages», disait le chroniqueur Gallus Anonymus ${ }^{91}$.

Les Slaves de la région balte sont soumis à une plus forte pression de la part des puissances chrétiennes. À en croire Adam de Brême, la rapacité des Saxons chargés de leur évangélisation serait la cause des révoltes qui secouent ces terres de mission entre 983 et $1066^{92}$. La violence supposée des Slaves sert

est racontée dans plusieurs récits hagiographiques (Vita Adalberti Prior, éd. J. Karwasinska, Varsovie 1962) et mentionnée dans les chroniques d'Adam de Brême (Gesta..., IV, 18, p. 246) ou de Gallus Anonymus, Gesta..., 1, 6, p. 3-35. En ce qui concerne les Vies d'Adalbert, J. KarwasinsKa, Les trois rédactions de "Vita I" de Saint Adalbert, Rome 1958; C. Gaspar, "The Life of Saint Adalbert, bishop and martyr", dans Saints of the Christianisation of Central Europe (Tenth-Eleventh Centuries), éd. G. Klaniczay, Budapest 2012, p. 79-94.

${ }^{88}$ R. Michalowsкi, The Gniezno Summit. The Religious Premises of the Founding of the Archbishopric of Gniezno, Leiden 2016; Idem, "La christianisation de la Pologne... », p. 429; L. KöRnTgen, "The Emperor and his friends...», p. 472-474; J. KŁoczowski (dir.), Histoire religieuse..., p. 36-37; A. Buko, «Between Wolin and Truso: the Southern part of the Baltic Rim at the time of Rise of the Polish State (an archaeological perspective)", dans The Image of the Baltic. A Festschrift for Nils Blomkvist, Visby 2012, p. 53-70; Z. SAWICKI et al., «Survival...», p. 285-286.

${ }^{89}$ D. Baronas, "The year 1009: St Bruno of Querfurt between Poland and Rus'», Journal of Medieval History 34, 2008, p. 1-22; M. Sosnowski, «Prussians... », p. 25-48; I. Wood, Missionary Life..., p. 215-220; R. MAŽEIKA, «Probleme der ersten urkundlichen Erwähnung Litauens und der Interpretation der biographischen Quellen des heiligen Bruno", dans V. Dolinskas (dir.), Lietuvos krikšcionejimasVidurio Europas kontekst, Vilnius 2005, p. 86-108; R. Wenskus, Studien zur Historisch-Politischen Gedankenwelt Bruns von Querfurt, Münster-Cologne 1956.

${ }^{90}$ Le martyre de Bruno est notamment rapporté par Die Annales Quedlinburgenses...., p. 527; Thietmar de Mersebourg, Chronicon..., VI, 95, p. 388 et Helmold de Bosau, Chronica Slavorum..., I.1, p. 30-31. Une Vie d'Adalbert a été composée en Italie: Vita Adalberti..., et une digression portant sur Bruno de Querfurt a été inséré par Pierre Damien dans sa Vie de saint Romuald (Petri Damian vita beati Romualdi, éd. G. Tabacco, Rome 1957, p. 56-61); C. Phipps, Saint Peter Damian's Vita Beati Romualdi, Londres 1988 (thèse de doctorat non publiée), p. 215-230. La mort d'Adalbert et de Bruno est également mentionnée par Adémar de Chabannes, Chronicon, III, 31, éd. J. Chavanon, Paris 1897, p. 152-153, Chronique, trad. Y. Chauvin, G. Pon, Turnhout 2003, p. 238-241, et Raoul Glaber (Histoires, Livre I, 10, éd. et trad. M. Arnoux, Turnhout 1999, p. 60; trad. ibid., p. 61).

91 "Pruzos cum brutis animalibus relinquamus», Gallus Anonymus, Gesta..., p. 196;

E. Christiansen, The Northern Crusades..., p. 47.

92 Notamment Adam de Brême, Gesta..., III, 23, p. 166. Voir aussi G. BüHrer-Thierry, Aux Marges..., p. 239-242; F. Dvornik, Les Slaves: histoire et civilisation de l'Antiquité aux débuts de l'époque contemporaine, Paris 1970, p. 264-265. 
de prétexte à l'appel dit de Magdebourg, soit une lettre écrite au début du $\mathrm{XII}^{\mathrm{e}}$ siècle au nom des ducs de Saxe, et adressée à plusieurs prélats et princes de France, d'Allemagne et de Lotharingie, notamment au champion de la première croisade Robert de Flandre ${ }^{93}$. Les destinataires sont appelés à prêter main forte à une vaste offensive contre les infidèles vivant près des côtes baltes, visant notamment à reconquérir "notre Jérusalem, libre à l'origine, et rendue esclave par la cruauté des païens $»^{94}$. La référence à la Ville sainte, prise en 1099, vise certainement à assimiler la guerre dans la Baltique à celle que mènent les croisés au Proche-Orient ${ }^{95}$. La tonalité de l'appel s'inscrit donc à la fois dans la tradition impériale de la lutte contre les infidèles et dans la foulée de la proclamation de la première croisade à Clermont par Urbain II (1095), telle que rapportée par Robert le Moine ${ }^{96}$. On précise encore que grâce à la participation à cette guerre, "vous pourrez sauver vos âmes, et si cela se peut, acquérir la meilleure terre dans laquelle on puisse vivre»" ${ }^{97}$. Dans une entreprise où la conquête militaire et l'expansion de la foi se révèlent étroitement liées, les récompenses temporelles et spirituelles ne sont pas incompatibles ${ }^{98}$. À la même époque, le duc de Pologne Boleslas III Bouche-Torse charge l'évêque Othon de Bamberg de la mission auprès des Poméraniens, non sans avoir dans un premier temps soumis et incorporé ces derniers à son royaume. Le chroniqueur contemporain Gallus Anonymus décrit l'entreprise comme une guerre sainte ${ }^{99}$.

${ }^{33}$ Le document est édité dans "Aus Handschriften", éd. W. Wattenbach, Neues Archiv der Gesellschaft für ältere deutsche Geschichtskunde 7, 1882, p. 624-626. Pour une traduction en anglais, L. et J. Riley-Smith, The Crusades. Idea and Reality, Londres 1981, p. 75-77. Traditionnellement, on date la lettre de 1107-1108; une fourchette entre 1120-1125 a été proposée par R. FLETCHER, The Conversion of Europe..., p. 486-487. L'auteur peut être un clerc d'origine flamande employé au service de l'archevêque de Magdebourg. La question de savoir si ce document a été envoyé, ou s'il s'agissait d'un brouillon, n'est toujours pas tranchée: G. Constable, «The Place of the Magdebourg Charter of 1107/1108 in the History of Eastern Germany and of the Crusades", dans F. Felten, N. Jaspert (dirs.), Vita Religiosa. Festschrift für Kaspar Elm zum 70. Geburtstag, Berlin 1999, p. 283-299; K. Jensen, «Crusading at the End of the World. The Spread of the Idea of Jerusalem after 1099 to the Baltic Sea Area and to the Iberian Peninsula», dans T. Nielsen, I. Fonnesberg-Schmidt (dirs.), Crusading on the Edge..., p. 168-170.

${ }^{4}$ "Hierusalem nostra ab initio libera, gentilium crudelitate facta est ancilla", "Aus Handschriften... ", p. 626.

95 R. Fletcher, The Conversion of Europe..., p. 486.

${ }^{96}$ K. Jensen, "Crusading at the End...", p. 169; G. Constable, "The Place...", p. 290, qui fait référence à l'article de P. KNOCH, "Kreuzzug und Siedlung", Jahrbuch für die Geschichte Mittelund Ostdeutschlands, 23, 1974. L'influence française est notamment marquée dans la phrase de conclusion: "Qui Gallos ab extremo occidente progressos in brachio virtutis sue contra inimicos suos in remotissimo triumphavit oriente, ipse tribuat vobis voluntatem et potentiam hos affines et inhumanissimos gentiles subjugare et in omnibus bene prosperari", "Aus Handschriften", p. 626.

${ }_{97} \mathrm{Id}$.

${ }^{98}$ N. Bцомкvist, Discovery..., p. 19.

${ }^{99}$ Gallus Anonymus, Cronica, 3, epilogus 1, cité par R. Bartlett, "The Conversion...", p. 19. Nous reprenons ici l'idée de guerre sainte telle que définit par J. Flori, La Guerre sainte. La 
Dans la foulée de l'appel à la croisade du pape Eugène III et de Bernard de Clairvaux, lesquels ont au printemps 1147 promis indulgences et privilèges à ceux qui marcheraient contre les infidèles de l'Est européen, des forces allemandes, danoises et polonaises marchent contre les derniers païens slaves, à l'est de l'Elbe et sur le rivage de la Baltique, sans résultat immédiat ${ }^{100}$. Il faut l'alliance du duc de Saxe Henri le Lion et du roi de Danemark Valdemar Ir pour que le dernier prince païen de la région, Niklot, soit écrasé ${ }^{101}$. Même s'il est difficile d'affirmer que l'épisode ait été directement provoqué par l'appel de saint Bernard ${ }^{102}$, l'idée d'une croisade nordique fait peu à peu son chemin dans les esprits. Les expéditions orientales ont relativement peu de succès auprès des chrétiens nordiques ${ }^{103}$, mais plusieurs raids sont lancés par des princes polonais contre les Prussiens dans la seconde moitié $\mathrm{du} \mathrm{XII}^{\mathrm{e}}$ siècle. Ces expéditions, qui peuvent avoir été inspirées par les bulles papales ou plus largement par l'enthousiasme général en faveur des croisades, sont racontées comme des guerres saintes par Vincent Kadłubek ${ }^{104}$. D’autres chroniqueurs présentent les expéditions baltes comme faisant partie d'une même grande entreprise menée sur plusieurs fronts contre tous les "ennemis de la Chrétienté»" ${ }^{105}$. Pour le Danois Saxo Grammaticus, qui écrit vers 1200, "le pape a réalisé que l'inondation du paganisme risquait de noyer l'Église, alors il écrivit à toute l'Europe pour appeler les fidèles à combattre contre tous les ennemis de la foi. Chaque province de l'Église reçut l'ordre de combattre les barbares les plus proches» ${ }^{106}$. Si ce ne fut pas forcément

formation de l'idée de croisade dans l'Occident, Paris 2001, p. 271-272. Voir aussi C. Erdmann, The Origin of the Idea of Crusade, Princeton 1977.

100 M. GŁadysz, The Forgotten Crusaders..., p. 69 sq; I. Fonnesberg-Schmidt, The Popes..., p. 35-36; J. Brundage, The Crusades. A documentary survey, Milwaukee 1962, p. 104-105.

${ }^{101}$ Helmold de Bosau, Chronica Slavorum..., I, 108; Saxo Grammaticus, Gesta..., 14.39, cités par F. LotTer, «The Crusading Idea... », p. 299-300.

${ }^{102}$ De fait, jusqu'à la fin du XII ${ }^{\mathrm{e}}$ siècle, l'évangélisation des païens est largement une entreprise locale, menée par les princes et les structures ecclésiastiques de la région, qui en réferent rarement à la Papauté; I. Fonnesberg-Schmidt, The Popes..., p. 34-35, 43-48.

${ }^{103}$ Il semble que les Européens du Nord-Est avaient relativement peu d'eux d'intérêt pour le Proche-Orient, situé très loin de chez eux; J. OssowsKa, «Polish Contribution to the expeditions to the Holy Land", Folia Orientalia 26, 1989, p. 177-178. Un prince appelé «roi des Polonais» est toutefois mentionné dans la chronique grecque de Kinnamos: D. von GüTtner-SporzYnski, "Constructing Memory: holy war in the Chronicle of the Poles by Bishop Vincentius of Cracow", Journal of Medieval History 40/3, 2014, p. 13. Sur la réponse polonaise à la croisade de Terre sainte, Idem, Poland, Holy War, and the Piast Monarchy, Turnhout 2014.

${ }_{104}$ M. Geadysz, The Forgotten Crusaders..., p. 92-95, 128 sq; S. Gouguenheim, Les Chevaliers teutoniques, p. 151; D. von GütTner-Sporzynski, "Constructing Memory...», p. 276-291 [numération de l'auteur: p. 1-16]; Idem, «Holy War and Proto-Crusading. Twelfth-Century Justifications for the Campaigns against the Pomeranians and Prussians", dans T. Nielsen, I. Fonnesberg-Schmidt (dirs.), Crusading on the Edge..., p. 225-244.

105 J. Riley-Smith, Les Croisades..., p. 117; N. Blomkvist, Discovery..., p. 214-217.

106 Saxo Grammaticus, Gesta..., 14, 3.5, vol. 2, p. 1000-1001. Une impression similaire se dégage de la Chronica Slavorum d'Helmold de Bosau (m. v. 1177): J. Riley-Smith, Les Croisades..., p. 117; I. Fonnesberg-Schmidt, The Popes..., p. 46-47. 
le cas des princes contemporains, leurs successeurs - et les chroniqueurs qui écrivaient pour eux - ont su faire leur le programme de Bernard et d'Eugène III, et considéraient la guerre contre leurs voisins païens comme une forme de guerre sainte comparable à ce qui se déroulait alors au Levant ${ }^{107}$.

La progression de l'idée de croisade en Europe du Nord-Est se reflète également par la manière de désigner les adversaires. Ceux-ci sont, jusqu'au milieu du XII ${ }^{e}$ siècle au moins, appelés par leurs ethnonymes, ou qualifiés de pagani $^{108}$, gentile $^{109}$, barbari ${ }^{110}$. Par la suite, le chroniqueur Vincent de Prague (m. 1170) note que le duc polonais Ladislas le Banni s'est allié avec des Ruthènes orthodoxes et des "Sarrasins " ${ }^{111}$; tout porte à croire qu'il s'agit dans ce cas des Prussiens ${ }^{112}$, ce qui serait une première attestation de l'emploi du terme "Sarrasins» pour désigner des païens baltes. Lorsqu'il relate les expéditions de Casimir le Juste contre les Jatvingiens baltes en 1192, Vincent Kadłubek appelle les ennemis du duc "Saladinistes» et "idolâtres»" ${ }^{113}$; une référence à Saladin (Șalāḥ ad-Dīn), le chef des Musulmans qui donnait tant de fil à retordre aux croisés en Orient ${ }^{114}$. Les païens baltes se trouvent, sur le plan du vocabulaire, assimilés aux musulmans levantins, ce qui deviendra au XIV ${ }^{\mathrm{e}}$ siècle une sorte de paradigme, permettant à de nombreux auteurs français et anglais d'appeler «Sarrasins» les Lituaniens. Nous y reviendrons.

Les contacts épistolaires et les relations personnelles entre les cours princières d'Europe du Nord-Est et d'Occident ont joué un rôle dans ce processus. Une lettre de l'abbé de Cluny, Pierre le Vénérable, au roi Sigurd de Norvège (m. 1130) le félicite de ses efforts "pour repousser les ennemis de la croix du Christ des pays chrétiens, non seulement aux limites de vos terres, mais aussi dans

107 C. Tyerman, "Henry of Livonia...", p. 43; M. Starnawska, "Military Orders and the Beginning of Crusades in Prussia", North-Eastern Frontiers, p. 125; J. Ashcroft, "Konrad's Rolandlied, Henry the Lion, and the Northern Crusade», Forum for Modern Language Studies 22, 1986 ", p. 184-208.

${ }^{108}$ Par exemple, la lettre du pape Alexandre III aux princes de Scandinavie: «et aliorum paganorum...", Liv-Esth-und Kurländisches Urkundenbuch, éd. F. G. von Bunge, H. Hildebrand, Tallinn 1853 (ci-après LUB), 1-1, doc. 5, col. 5.

109 Appel de Magdebourg: «Gentiles isti pessimi sunt» («Aus Handschriften... », p. 626) ; F. LotTer, "The Crusading Idea...", p. 277, n. 30.

110 Saxo Grammaticus, Gesta..., 14, 3.5, vol. 2, p. 1000: «barbarice tempestatis procella rem diuinam pene obrutam euersamque [...]. Singule autem catholicorum prouincie confinem sibi barbariem incessere iubebantur»; Gallus Anonymus, Gesta..., livre 1, p. 12: «barbarorum gentilium ferocissimas naciones».

111 Vincent de Prague, Annales, éd. W. Wattenbach, MGH SS 17, Hanovre 1861, p. 664.

${ }^{112}$ L'historiographie polonaise considère ces «Sarrasins» comme étant des Prussiens, mais qu'il a aussi pu s'agir de Coumans (Polotsves), un peuple turcophone païen d'Europe orientale; M. GŁadysz, The Forgotten Crusaders..., p. 95, n. 119.

113 Vincent Kadłubek, livre IV, chap. 19, p. 166: «contra Saldanistas, contra sacre professionis hostes, contra spuricissimos idolatras pugnatoros", cité par M. GŁADYsz, The Forgotten Crusaders..., p. 130.

${ }_{114}$ D. von Güttner-Sporzynski, "Constructing Memory...», p. 14; Idem, "Holy War...», p. $243-244$. 
l'Orient et le sud lointain ${ }^{115}$; l'allusion porte autant sur les guerres menées par le roi contre les Slaves de la Baltique que sur ses combats en Méditerranée ${ }^{116}$. Cet extrait montre qu'un clerc du XII ${ }^{e}$ siècle, fer de lance du mouvement de croisade, pouvait assimiler un simple raid mené contre des païens du Nord aux prouesses d'un croisé ${ }^{117}$. L'exemple polonais permet de suivre des échanges non seulement épistolaires, mais aussi personnels entre les deux régions d'Europe qui nous occupent. Déjà à l'époque de Boleslas Bouche-Torse, soit avant la proclamation de saint Bernard, la cour polonaise entretenait des contacts relativement soutenus avec la Curie, qui envoya au moins trois légats en Pologne entre 1102 et $1147^{118}$. Parmi ceux-ci, un certain Galon, évêque de Paris, originaire de Lorraine, est nommé pour faire appliquer la réforme grégorienne en Pologne, et installe un autre Lorrain, Baudouin, sur le siège épiscopal de Cracovie. Dariusz von Güttner-Sporzynski note que la présence de ces deux hommes aux côté du duc Boleslas n'est sans doute pas étrangère à la pénétration des idées de croisade en Pologne; tous deux avaient en effet été des disciples d'Yves de Chartres, qui a joué un rôle dans l'émergence progressive de ce mouvement ${ }^{119}$. Une fois la Poméranie envahie, Boleslas se tourne vers Rome pour légitimer l'incorporation de ce territoire au royaume polonais; c'est un clunisien, Gilon de Tusculum, légat pontifical en 1123-1125, qui donne son aval à l'organisation de la nouvelle province ecclésiastique ${ }^{120}$.

Mais plus que l'allée et venue de quelques légats, c'est l'immigration lotharingienne parmi la noblesse et le clergé qui a pu accélérer la diffusion de l'idéal de croisade. L'étude de Mikółaj Gładysz permet de suivre plusieurs destins individuels, qui illustrent assez bien le processus d'européanisation de l'Europe cher à Robert Bartlett ${ }^{121}$. La figure de l'évêque de Płock, Alexandre de Malonne (m. 1156), semble caractéristique de ce phénomène: né dans le diocèse de Liège, promut au siège de Płock en Mazovie, il est décrit par Vincent Kadłubek comme un fervent défenseur de sa province face aux Prussiens, "un évêque et un chevalier, autant prompt aux armes que pieux» ${ }^{122}$.

115 Regesta Norvegica, éd. E. Gunnes, Oslo 1989, vol. 1, doc. 65, p. 44; Pierre le Vénérable, Letters of Peter the Venerable, éd. G. Constable, Cambridge, Mass. 1967, vol. 1, doc. 44, p. 140.

${ }_{116}$ Pierre le Vénérable, Letters..., vol. 2, p. 128.

117 N. Blomkvist, Discovery..., p. 310-312,

118 D. von Güttner-Sporzynski, "Poland and the Papacy before the second crusade», dans M. Balard (dir.), La Papauté et les croisades / The Papacy and the Crusades, Farnham 2011, p. 257. 119 Ibid., p. 257-259; P. David, "Un disciple d'Yves de Chartres en Pologne - Galon de Paris et le droit canonique", dans La Pologne au VII congrès des sciences historiques, vol. 1, Varsovie 1933, p. 99-113. Pour J. Flori, Yves de Chartres "n'est pas un partisan de la croisade» (La Guerre sainte..., p. 157) mais n'en légitime pas moins l'usage de la force dans une guerre contre des ennemis de Dieu, notamment contre les Sarrasins (Ibid., p. 186-187).

120 D. von Güttner-Sporzynski, «Poland and the Papacy... », p. 262-263.

121 M. GŁadysz, The Forgotten Crusaders...; R. BartLETt, The Making of Europe...

${ }_{122}$ Mistrza Wincentego zwanego Kadtubkiem kronika poslka, éd. M. Plezia, Cracovie 1994, p. 93, cité par M. GŁadysz, The Forgotten Crusaders... , p. 20-21. 
Le chroniqueur Gallus Anonymus, vraisemblablement originaire d'Europe occidentale et que l'on pense lié au monastère de Saint-Gilles en Provence, haut lieu de diffusion de l'esprit de croisade, constitue lui-même un excellent représentant de cette immigration, emmenant dans ses bagages des idées neuves en Pologne quant à la lutte contre les infidèles, musulmans ou païens ${ }^{123}$. Il n'est donc guère étonnant que son récit de la campagne de Bouche-Torse contre les Poméraniens soit truffé de références implicites à une guerre sainte et approuvée par Dieu, car livrée, fait-il dire au duc, pour «écraser l'idolâtrie des Poméraniens et leur orgueil martial» ${ }^{124}$. Autre exemple, le chevalier Hugues Butyr, originaire des Pays-Bas, et peut-être le fils d'un participant à la première croisade ${ }^{125}$ : émigré en Pologne avant 1146, il participe à la défense du pays contre les Prussiens, puis mène les armées du duc Boleslas le Frisé contre ceux-ci ${ }^{126}$. S'il s'agit bien d'un rejeton d'une maison impliquée dans la croisade levantine, rien n'empêche de suivre Mikółaj Gładysz, pour qui «l'on peut se demander si les activités d'Hugues en Pologne au service de Boleslas le Frisé n'étaient pas pour lui une opportunité de prendre part aux activités de croisade par lui-même, en combattant les "Sarrasins du Nord" ${ }_{1}{ }^{127}$.

Il y aurait donc eu, déjà au $\mathrm{XII}^{\mathrm{e}}$ siècle, une participation occidentale aux croisades d'Europe nordique. Certes, les "croisés" comme le chevalier Hugues Butyr ou l'évêque Alexandre de Malonne étaient relativement peu nombreux, et s'étant installés pour longtemps en Pologne, ils étaient devenus des acteurs permanents de la vie politique, militaire et religieuse locale. Plus que des combattants zélés attirés par la promesse d'une guerre contre des païens, ils ont été des passeurs, partis vivre en Europe du Nord-Est pour diverses raisons et apportant dans leur nouveau pays l'idéologie de croisade ${ }^{128}$. Néanmoins, un lien se noue peu à peu entre Baltique et croisade, pour la

\footnotetext{
${ }^{123}$ Ibid., p. 23-24. L'origine de Gallus Anonymus fait encore l'objet de discussions dans l'historiographie: P. Knoll, "Wenta, Jarosław, Kronika tzw. Galla Anonima», p. 357-358. Sur les liens du monastère de Saint-Gilles avec la Pologne, P. DAvid, «La Pologne et les pays slaves dans l'Obituaire de Saint-Gilles au XII siècle", Comptes rendus des séances de l'Académie des Inscriptions et Belles-Lettres 83/6, 1939, p. 614-616.

124 Gallus Anonymus, Gesta III, 1, p. 224; D. von Güttner-Sporzynski, «Poland and the Papacy... », p. 260-261 ; M. Gładysz, The Forgotten Crusaders... , p. 25-26.

125 Sur ce personnage, Ibid., p. 23.

${ }^{126}$ La participation d'Hugues Butyr dans la guerre contre les Prussiens est mentionnée par Pierre de Dusbourg, Chronicon..., SRP 1, p. 39.

127 M. GŁadysz, The Forgotten Crusaders..., p. 23.

${ }^{128} \mathrm{Ibid}$., p. 38; les régions francophones de Lotharingie entretenaient des liens commerciaux et culturels spécifiques avec le nord de l'Empire, ce qui explique que l'on trouve plusieurs de leurs ressortissants en Pologne: L. GÉnicot, "Wallons en Pologne au moyen âge», Annales de la Société archéologique de Namur, 64, 1985/86, p. 9-16; J. HockaY, "Alexandre et Gauthier. Deux Malonnois en Pologne au XII ${ }^{\mathrm{e}}$ siècle», Le Guetteur Wallon, 1978, № 2, p. 41-61; № 3, p. 81-95; F. Rousseau, «L'Expansion wallonne et lorraine vers l'Est, aux XI ${ }^{\mathrm{e}}$ et XII ${ }^{\mathrm{e}}$ siècles», Les dialectes belgoromans 1, 1937, p. 171-198; sur le rôle de la noblesse francophone dans la diffusion du modèle sociétal né en Europe occidentale, R. BARTLETt, The Making of Europe...
} 
noblesse chevaleresque internationale comme pour l'Église. La Terre sainte et Jérusalem restent privilégiées, mais cette lointaine région d'Europe apparaît comme une alternative pour ceux qui désirent prendre les armes contre les "ennemis de la foi»" 129 .

Au-delà de la défense de la Chrétienté, la mission mobilise l'attention de quelques personnalités ecclésiastiques. Parmi elles, le fondateur des Prémontrés, Norbert de Xanten (m. 1134), prêcheur itinérant en France et en Flandre avant de devenir archevêque de Magdebourg, où il se consacre activement à la prédication auprès des païens slaves ${ }^{130}$. Dans la deuxième moitié du XII ${ }^{\mathrm{e}}$ siècle, les activités missionnaires s'étendent aux extrêmes limites du pourtour balte. Le pivot de cette nouvelle entreprise est Eskil, l'archevêque de Lund ${ }^{131}$. Exilé en France, celui-ci entend mettre sur pieds une mission auprès des païens de l'actuelle Estonie. Très proche des Cisterciens, il travaille pourtant à la mission estonienne avec un bénédictin, Pierre de Celle, abbé de Moutierla-Celle ${ }^{132}$. Autour de 1167, un certain Fulco, moine de la même abbaye, peut-être d'origine danoise ${ }^{133}$, est consacré «évêque des Estoniens" à Sens ${ }^{134}$. En 1171-1172, le pape Alexandre III demande qu'un moine d'origine estonienne accompagne l'évêque, sans doute pour servir de traducteur, et écrit aux princes de Danemark, Suède et Norvège pour leur assurer que des indulgences seraient attribuées à ceux qui, en cas de besoin, iraient combattre les Estoniens ${ }^{135}$. Les privilèges spirituels conférés sont généreux, à peine moins que ceux qui portent sur Jérusalem ${ }^{136}$. Le souverain pontife semble avoir tardé à afficher son soutien à l'entreprise, ce que l'historienne danoise Iben Fonnesberg-Schmidt attribue à l'attitude traditionnellement prudente de la Papauté en ce qui concerne la mission auprès des infidèles ${ }^{137}$. À moins que l'influence de l'abbé de Celle n'ait suffi à fléchir le pontife ${ }^{138}$, le revirement de celui-ci peut être attribué à

\footnotetext{
${ }^{129}$ M. G£adysz, The Forgotten Crusaders..., p. 132.

130 I. Fonnesberg-Schmidt, The Popes..., p. 48-49.

131 Sur ce qui suit, Ibid., p. 52-56; N. Bourgeors, "Les Cisterciens et la croisade de Livonie», Revue Historique 307/3, 2005, p. 526-538.

132 A. Bysted, J. C. Jensen, K. V. Jensen, J. H. Lind, Jerusalem in the North: Denmark and the Baltic Crusades, 1100-1522, Turnhout 2012, p. 139-140.

133 À la suite de P. Johansen, Nordische Mission: Revals Gründung und die Schwedensiedlung in Estland, Stockholm 1951, p. 90, on considère Fulco comme un Français; P. Rebane, «From Fulco to Theodoric: The Changing Face of the Livonian Mission», dans A.V. Muray (dir.), The NorthEastern Frontiers..., p. 90, n. 12, y voit un Danois.

134 Diplomatarium Danicum, vol. 1/3, éd. C. A. Christiansen et al., Copenhague 1977, n. 81, 88; LUB, 1-1, doc. 2-3-4, col. 2-5.

135 LUB, 1, doc. 5, col. 5-6; Diplomatarium Danicum..., vol. 1/3, doc. 27, cité par I. FonnesbergSchmidt, The Popes..., p. 55.

${ }^{136}$ L'indulgence accordée à ceux qui partent en armes contre les Estoniens est égale à celle que reçoivent les pèlerins de Jérusalem, mais les croisés qui s'engagent pour défendre la ville sainte ont droit à une indulgence plénière; I. Fonnesberg-SChmidt, The Popes..., p. 60-65.

137 Ibid., p. 56.

138 P. Rebane, «From Fulco...» p. 91-92.
} 
l'archevêque Henri de Reims, qui n'était autre que le frère du roi de France Louis VII, et un proche de Bernard de Clairvaux comme de Pierre de Celle ${ }^{139}$.

Une "connexion française» aurait donc servi d'appui au premier projet missionnaire balte: Eskil était un ami des Cisterciens et un admirateur de saint Bernard, qu'il rencontre dans les années 1150 lors d'une visite à Clairvaux ${ }^{140}$. Il est séduisant de penser que le prélat danois a agi sous l'influence de Bernard ${ }^{141}$, mais rien ne permet de l'affirmer: Nicolas Bourgeois a bien montré que le projet mis sur pied par l'archevêque Eskil était une affaire essentiellement danoise, et que les amis français du prélat scandinave y ont joué un rôle de relais, non de moteur $^{142}$. La suite de l'aventure est mal connue; on ne sait même pas si Fulco s'est réellement rendu en Estonie ${ }^{143}$. Quant à l'archevêque Eskil, il s'est retiré des affaires en 1177, pour terminer sa vie... à Clairvaux ${ }^{144}$. Son successeur, Absalon, ne s'intéresse pas à la mission d'Estonie; à part quelques raids menés par des princes séculiers, la Baltique orientale sort de la sphère d'influence danoise, mais pour quelques décennies seulement ${ }^{145}$.

La première colonie chrétienne de la Baltique orientale prend pied autour de la Daugava (Dvina), le fleuve qui traverse l'actuelle Lettonie. Cette région est appelée par les marchands allemands Livonie, du nom des Lives, le peuple fennique qui y vivait ${ }^{146}$. Le début de la mission catholique y est étroitement lié à la personnalité d'un certain Meinhard, un moine du monastère augustin de Segeberg, dans le Holstein ${ }^{147}$. En 1186, il est consacré évêque d’Üxküll

139 I. Fonnesberg-Schmidt, The Popes..., p. 58-59.

140 N. Blomkvist, Discovery..., p. 411-412. N. Bourgeois ( LLes Cisterciens...», p. 530-531) rappelle toutefois que les liens entre Eskil et les Cisterciens étaient loin d'être exceptionnels, au regard des habitudes des princes et prélats de l'époque.

141 I. Fonnesberg-Schmidt, The Popes..., p. 53; A. Bysted, J. C. Jensen, K. V. Jensen, J. H. Lind, Jerusalem in the North..., p. 139.

142 N. Bourgeois, "Les Cisterciens...", p. 532-538.

143 P. Rebane, «From Fulco...» p. 93-94; N. Bourgeois, «Les Cisterciens...», p. 534.

144 P. Rebane, «From Fulco...», p. 95.

145 A. Bysted, J. C. Jensen, K. V. Jensen, J. H. Lind, Jerusalem in the North..., p. 142-143.

${ }^{146}$ Cette étymologie est proposée pour la première fois par Balthasar Russow, dans sa Chronique de Livonie (1584); elle fait aujourd'hui consensus. Sur ce sujet, voir M. TАмм, «Inventing Livonia... », p. 190-192; R. Siminski, "Ex Livonia ultima regione Europae. L'image de la Livonie dans la Littérature de l'Europe occidentale du Ix ${ }^{\mathrm{e}}$ au début du Xvi siècle", dans A. Gautier, S. Rossignol (dirs.), De la Mer du Nord à la mer Baltique, Lille 2012, p. 192; T. KALA, "The Incorporation of the Northern Baltic Lands", dans A. V. Murray (dir.), Crusade and Conversion..., p. 7. Jusqu'au Moyen Âge central, l'ambre, et peut-être plus encore les fourrures, le miel et la cire, sont des produits très demandés en Europe occidentale, et au-delà des terres peuplées par les païens, se trouve Novgorod, le grand centre de commerce de la partie nord de la Rus' kiévienne. Sur l'influence (discutée) des marchands au début de la mission et de la croisade en Livonie, M. MüNZINGER, «The Profit of the Cross", dans A. V. Murray (dir.), North-Eastern Frontiers..., p. 330.

147 Sur ce qui suit, C. S. Jensen, "The Early Stage of Christianisation in Livonia", dans T. Lehtonen et K. V. Jensen (dirs.), Medieval History Writing, p. 207-215; I. FonnesbergSchmidt, The Popes..., p. 65-75; N. Blomkvist, Discovery..., p. 505-563; P. Rebane, «From Fulco...", p. 96 sq.; A. Selart, Livonia..., p. 71-80. 
par l'archevêque de Hambourg-Brême, Hartwig, qui obtient le soutien de Rome pour la campagne d'évangélisation des Lives ${ }^{148}$. Meinhard, qui disposait vraisemblablement d'une escorte d'hommes d'armes, fait construire des forteresses pour lui et les Lives qui accepteraient de se convertir ${ }^{149}$. Quand ceux-ci prennent les armes pour résister, un compagnon de Meinhard, Théodoric, se rend à Rome pour obtenir la permission de prêcher une croisade en Europe $\mathrm{du} \mathrm{Nord}^{150}$. La force est également utilisée par son successeur malheureux, Berthold, qui meurt en affrontant ses ouailles révoltées à l'été $1198^{151}$. Les mésaventures des premiers évêques de Livonie servent à renforcer l'idée que l'épée est nécessaire pour permettre au christianisme de s'implanter parmi les Baltes ${ }^{152}$.

Une mise au point est ici nécessaire. En dépit du vocabulaire de guerre sainte employé par maints chroniqueurs et apologistes, la conversion forcée est restée, durant tout le Moyen Âge, formellement interdite ${ }^{153}$. Pourtant, dans une lettre adressée aux barons allemands au printemps 1147 , peu après qu'il ait cédé à leurs demandes, Bernard de Clairvaux leur demande de mener la guerre contre les païens "jusqu'à ce que, avec l'aide du Seigneur, leur religion ou leur nation soit détruite»" ${ }^{154}$. Les historiens se sont interrogés sur le sens de cette formule; le chantre de la deuxième croisade prônait-il la conversion sous la contrainte ${ }^{155}$ ? Il semblerait plutôt que Bernard ait voulu inciter les croisés à combattre les païens jusqu'à ce que ceux-ci soient convertis ou totalement soumis, au lieu de trouver

\footnotetext{
148 B. BомвI, «Innocent III...», p. 232.

149 N. Bourgeors, «Les Cisterciens...", p. 540-543.

${ }^{150}$ Henri de Livonie, Heinrichs Livländische Chronik (Heinrici Chronicon Livoniae), I, 12, éd. L. Arbusow, A. Bauer, Hanovre 1955, p. 6-7; pour une traduction en anglais, Henri de Livonie, Chronicle, trad. J. Brundage, New York 2004, p. 29-30. Voir aussi I. Fonnesberg-Schmidt, The Popes..., p. 68; M. Tамм, «How to justify... », p. 440; P. Rebane, «From Fulco», p. 99-101.

${ }_{151}$ Henri de Livonie, Heinrichs Livländische Chronik..., II, 1-10, p. 8-11.

152 P. Rebane, "From Fulco...", p. 101-102. Pour un survol historiographique, N. Bourgeors, "Les Cisterciens...», p. 538-540.

153 J. Muldoon, Popes, Lawyers and Infideles, The Church and the Non-Christian World, 1250-1550, Philadelphie 1979, p. 11 ; J. Brundage, Medieval Canon Law, Londres - New York 1995, p. 19-21. 154 "... donec auxiliante Domino aut ritus ipse aut natio deleatur», lettre 457 de Bernard de Clairvaux (S. Bernardi Opera, vol. 8, n. 457) cité par F. Dvornik, Les Slaves..., p. 267.

155 E. Johnson, dans K. Setton (éd.), A History of the Crusade, vol. 3, Madison 1975, p. 553, en fait même le slogan du «mouvement». Pour J. Riley-Smith (Les Croisades..., p. 116), l'argument aurait été utilisé par Bernard pour résoudre le dilemme de la conversion des infidèles dans un sens susceptible de plaire aux barons saxons: "Un des problèmes auxquels on se trouve confronté avec la propagande en faveur des croisades [...] réside dans la contradiction entre le désir de conversion - ou peut-être la conviction que leur succès créerait des conditions politiques favorables au prosélytisme - et la tradition chrétienne bien établie de ne pas obliger les infidèles d'abjurer leurs erreurs, mais de les en convaincre. Devant la nécessité d'émouvoir une audience qui n'appréciait pas la subtilité et comprenait à peine les nuances théologiques, Bernard et Eugène III ne furent pas les seuls propagandistes des croisades germaniques conduits à effectuer des déclarations d'une douteuse orthodoxie».
} 
un arrangement après une courte période de combats ${ }^{156}$. La lettre indique aussi que, tenaillés par le diable, les païens ne cessent de harceler les chrétiens, risquant de provoquer le découragement et l'apostasie des néophytes; les princes doivent donc débarrasser la région de ce péril en se montrant implacables ${ }^{157}$. Plus qu'une simple guerre défensive, ce que Bernard prône, c'est la liquidation totale du paganisme; l'idée sous-jacente est qu'une fois les païens soumis à un pouvoir chrétien fort, et peut-être plus encore, une fois leurs structures sociales et politiques traditionnelles démantelées, ils cesseront de représenter une menace pour leurs voisins chrétiens, et pourront à leur tour être évangélisés ${ }^{158}$.

À partir de Bernard de Clairvaux, la défense (defensio) et l'expansion (dilatatio, propagatio) de la Chrétienté marchent main dans la main ${ }^{159}$. La lettre adressée par Alexandre III en 1171-1172 aux princes scandinaves reflète une idée similaire; on commence par décrire la menace que les Estoniens font peser sur "les fidèles de Dieu et ceux qui travaillent pour la foi chrétienne» ${ }^{160}$. Les destinataires de la lettre sont incités à prendre les armes pour voler au secours des missionnaires persécutés, "pour défendre bravement la foi chrétienne et étendre le nom chrétien avec force " ${ }^{161}$. Le fait que des chrétiens seraient menacés en Estonie aussi tôt, alors que la mission ne fait, au mieux, que commencer, est considéré comme relevant de la «fiction légale» par Marek Tamm; il s'agit d'un argument qui puise ses forces dans la théorie de la guerre juste et dans la prétention au pouvoir universel de l'Église de la réforme grégorienne ${ }^{162}$. Le vocabulaire utilisé par Innocent III dans une bulle au roi de Danemark, quelques décennies plus tard, reste dans la même veine. Il s'agit "d'étendre les frontières de la Chrétienté» et de protéger les missionnaires que "ceux qui adhèrent aux cultes des idoles [...] persécutent méchamment» ${ }^{163}$. Ce qui n'empêche pas le pape de rappeler que,

\footnotetext{
156 F. Lotter, "The Crusading Idea...», p. 288-292; I. Fonnesberg-Schmidt, The Popes..., p. 53, qui cite le De consideratione, III :1, PL, vol. 182, cols 757-60 de Bernard.

157 D. von Güttner-Sporzynski, «Constructing Memory... », p. 8-9.

158 F. Lotter, «The Crusading Idea... », p. 290-292. D’après R. Bartlett, «The Conversion...», p. 197-198, c'est déjà cette idée qui soutenait les mesures radicales prises par Othon de Bamberg et Boleslas Bouche-Torse dans l'évangélisation de la Poméranie.

159 M. ТАмм, «How to justify...», p. 441-442. N. Blomkvist, Discovery..., p. 214-221, note qu'en proclamant la croisade balte, saint Bernard a contribué à intégrer la tradition locale de la guerre contre les païens, à l'idée plus neuve, paneuropéenne, de croisade.

${ }_{160}$ LUB 1-1, doc. 5, col. 5; Diplomatarium Danicum..., vol. 1/3, doc. 27, cité par I. FonnesbergSchmidt, The Popes..., p. 59-60.

161 Id.

162 M. ТАмм, «How to justify...», p. 437-440.

163 Bullarium Danicum Pavelige Aktstykker vedrørende Danmark 1198 - 1316, éd. A. Krarup, Copenhague 1932, doc. 73, p. 72. Cette bulle concerne une expédition en Prusse; une autre bulle, adressée au même roi, mais concernant une opération dans la Baltique orientale, donne comme but "ad extirpandum paganitatis errorem et terminos Christiane fidei dilatandos" (Diplomatarium Danicum..., vol. 1/4, n ${ }^{\circ} 162$; trad. L. et J. Riley-Smith, The Crusades..., p. 77-78), sans jamais mentionner la protection des chrétiens. Voir R. MAžEIKA, "Granting... », p. 154, n. 4; M. TAMM, "How to justify... », p. 443. Sur la politique balte de Valdemar II, S. M. SzAchersKa, «Valdemar II’s
} 
conformément au droit canon, les Prussiens ne sauraient être convertis contre leur gré et qu'une fois baptisés, ils doivent jouir de leurs droits ${ }^{164}$.

En théorie, la conversion par la menace reste donc interdite. Pourtant, en justifiant la présence d'hommes armés censés défendre les missionnaires et briser la résistance des païens, les papes tendent à légitimer l'utilisation de la force pour amener ceux-ci au baptême ${ }^{165}$. La conversion forcée, qui s'est dans les faits pratiquée au moins depuis Charlemagne, gagne une certaine reconnaissance en 1147 avec l'appel de saint Bernard, puis devient systématique dans la Baltique orientale $^{166}$. En outre, si le droit canon interdit la coercition, il laisse, à partir d'Innocent III, la porte ouverte à l'utilisation de la violence en distinguant la contrainte absolue de la contrainte conditionnelle, qui requiert le consentement de l'individu que l'on baptise; en clair, si l'on place un infidèle devant le choix entre la conversion ou la mort et qu'il choisit d'accepter le baptême, celui-ci est considéré comme valide ${ }^{167}$.

Un autre argument est fréquemment avancé pour justifier l'utilisation de la force: à plusieurs reprises, les chroniqueurs racontent que telle ou telle tribu aurait accepté le christianisme à la suite d'une défaite militaire, ou en échange d'avantages quelconques, avant de revenir à ses anciens dieux, "comme des chiens retournant à leur vomi» ${ }^{168}$. Cette référence biblique (Prov. 26:11) n'est pas sans conséquence, puisque le droit canon autorise l'usage de la violence pour forcer les apostats à l'obéissance; la coercition se trouve ainsi justifiée face à des Baltes dépeints en rebelles, et non plus en simples païens ${ }^{169}$. L'idée du christianisme progressant à la pointe de l'épée s'exprime ouvertement cent ans plus tard, chez les acteurs de la croisade balte, ce qui semble indiquer qu'elle a été intériorisée ${ }^{170}$. Dans le prologue de sa chronique, Pierre de Dusbourg constate avec satisfaction qu'au moment où il écrit, "tous les gens de la terre

expedition to Pruthenia and the mission of Bishop Christian", Mediaeval Scandinavia 12, 1988, p. 44-75; A. Bysted, J. C. Jensen, K. V. Jensen, J. H. Lind, Jerusalem in the North ..., p. 232-239.

164 M. ТАмм, «How to justify...», p. 442-443; B. ВомвI, «Innocent III...», p. 232-238.

165 I. Fonnesberg-Schmidt, The Popes..., p. 61.

${ }^{166}$ M. Tамm, "How to justify...", p. 441-444. Du reste, une même justification de la force pour convertir existait dans le contexte de la croisade méditerranéenne: B. Kedar, Crusade and Mission: European approaches toward the Muslims, Princeton 1984, p. 159 sq. Sur Charlemagne, L. G. Duggan, "For Force Is Not of God"? Compulsion and Conversion from Yahweh to Charlemagne», dans J. Muldoon (dir.), Varieties of Religious Conversions..., p. 49-52.

167 I. Poutrin, «La conversion des musulmans de Valence (1521-1525) et la doctrine de l'Église sur les baptêmes forcés", Revue historique 648/4, 2008, p. 837-838; 852 ; F. H. RussEL, "Augustine: Conversion by the Book», dans J. Muldoon (dir.), Varieties of Religious Conversions..., p. 26.

168 C'est, par exemple, la métaphore qu'Henri de Livonie met dans la bouche de l'évêque Berthold, successeur de Meinhard: Henri de Livonie, Heinrichs Livländische Chronik..., II, 5, p. 9.

169 C. S. Jensen, «Early Stage...», p. 211; M. TАмм, «How to justify...», p. 440-441; P. Buc, Guerre sainte, martyre et terreur, Paris 2017, p. 274.

170 R. MAŽEIKA, «Granting...», p. 154-156. 
de Prusse sont [...] exterminés par les frères [teutoniques] ${ }^{171}$; le pays est donc débarrassé du paganisme et gagné à la foi catholique. Le propos est bien sûr exagéré, mais l'essentiel est dans l'intentionnalité de l'auteur: faire disparaître les païens revient à "dilater les limites de la Chrétienté»; une interprétation radicale du programme mis en place par Bernard de Clairvaux, même si, comme le note Iben Fonnesberg-Schmidt, la politique pontificale était bien plus réactive que proactive ${ }^{172}$.

\section{Les ordres militaires en Prusse et en Livonie}

La première moitié du XIII ${ }^{\mathrm{e}}$ siècle voit une tentative de prise en main de la croisade balte par la Papauté, avec pour corollaire un nouvel écho de l'aventure parmi les auteurs - d'abord ecclésiastiques - d'Europe occidentale. Cette européanisation progressive du phénomène passe notamment par la création d'ordres militaires spécialement affectés à la lutte contre les païens, mais aussi par l'envoi de légats, par la participation croissante des Cisterciens puis des Mendiants à la prédication dans les nouvelles plantations chrétiennes, et par de retentissants procès portant sur des disputes territoriales et opposant prélats, ordres militaires et puissances séculières.

Un premier ordre religieux-militaire organisé sur le modèle des Templiers est fondé au début du siècle, sous l'épiscopat du troisième évêque de Livonie, Albert de Buxhövden ${ }^{173}$. Il s'agit de l'Ordre des Chevaliers du Christ de Livonie (Fratres Militiae Christi), surnommés "Chevaliers PorteGlaives» en raison de leurs manteaux frappés d'une croix et d'une épée ${ }^{174}$. L'installation d'ordres religieux-militaires dans la Baltique et la péninsule Ibérique est rendue possible par l'exemple de la Terre sainte. L'idéologie de ces formations nouvelles se reflète notamment dans le De Laude novae militiae (v. 1136) de Bernard de Clairvaux, sorte de manifeste en faveur des Templiers, qui d'après lui représentent l'alliance parfaite entre les qualités des chevaliers et celles des moines ${ }^{175}$. Ils peuvent donc mener une

\footnotetext{
171 SRP 1, p. 23.

172 I. Fonnesberg-Schmidt, The Popes..., p. 21; C. T. Maier, Preaching the Crusades..., p. 44-45.

${ }_{173}$ Albert de Buxhövden a déplacé le siège de son évêché à Riga, ville nouvellement fondée avec l'aide de marchands.

${ }^{174}$ Le cistercien Théodoric, collaborateur de Meinhard et de ses successeurs, est vraisemblablement à l'origine de la fondation de cet ordre; il semble qu'il en ait pris l'initiative pendant qu'Albert était absent, et il n'est pas exclu qu'il ait reçu pour ce faire le soutien du pape Innocent III: E. Mugurevics, "The Military Activity of the Order of the Sword Brethen (1202-1236)", dans A. V. Murray (dir.), North Eastern Frontiers..., p. 117; F. Benninghoven, Der Orden der Schwertbrüder: Fratres milicie Christi de Livonia, Cologne 1965, p. 44-53; I. FonnesberGSchmidt, The Popes..., p. 91.

${ }^{175}$ Y. Katzir, "The Second Crusade and the Redefinition of Ecclesia, Christianitas and Papal Coercive Power", dans M. Grevers (éd.), The Second Crusade and the Cistercians...,
} 
vie pieuse dans leurs couvents tout en faisant trembler les ennemis du christianisme sur le champ de bataille; tuer l'un de ces derniers leur est, nous dit le saint homme, non seulement permis, mais même méritoire ${ }^{176}$. Pour Jacques de Vitry, fameux prédicateur et évêque de Saint-Jean-d'Acre (m. 1240), les ordres militaires participent d'une même mission de défense de la Chrétienté, qu'ils soient implantés en Terre sainte, en péninsule Ibérique ou sur la Baltique orientale: "Tous [...] s'investissent dans la défense conjointe de l'Église contre les infidèles" ${ }^{177}$. Un point de vue partagé par Rome, qui depuis un demi-siècle justifie l'expansion militaire dans la région balte par la défense de la Chrétienté. En 1204, Innocent III, qui suivait de près le progrès de l'évangélisation en Livonie, approuve le fait que l'évêque Albert ait à ses côtés, outre les Cisterciens et d'autres moines, "des fidèles laïcs qui, sous la règle des Templiers, protègent avec force et courage la nouvelle plantation de la foi chrétienne des barbares qui la harcèlent»" ${ }^{178}$.

Le précédent de la Livonie annonce l'aventure des Chevaliers teutoniques en Prusse. Là aussi, un évêque missionnaire ouvre la voie: Christian, un cistercien, est consacré évêque des Prussiens lors du concile de Latran, où il se rend avec des autochtones convertis $(1215)^{179}$. Soucieux de protéger la mission, il n'hésite pas à demander l'aide du bras séculier ${ }^{180}$. Le pape

p. 3-11;; A. Graboïs, "Militia and Malitia: the Bernardine Vision of Chivalry", dans M. Grevers (éd.), The Second Crusade and the Cistercians..., p. 49-56; ; J. Fleckenstein, "Die Rechtfertigung der geistlichen Ritterorden nach der Schrift "De laude novae militiae" Bernhards von Clairvaux", dans J. Fleckenstein, M. Hellmann (dir.), Die geistlichen Ritterorden Europas, Sigmaringen 1980, p. 9-22; A. Vauchez, "La notion de Miles Christi dans la spiritualité occidentale aux XII ${ }^{\mathrm{e}}$ et $\mathrm{XIII}^{\mathrm{e}}$ siècles", dans M. Aurell, C. Girbea (dirs.), Christianisme et chevalerie, Rennes 2011, p. 67-76; A. Demurger, Chevaliers du Christ, Paris 2002; J. Flori, Croisade et Chevalerie XI'-XII siècles, Paris \& Bruxelles 1998, p. 29, cite les critiques d'Isaac de l'Étoile, Sermo 48, P. L., t. 194, col. 533.

176 J. Flori, Croisade..., p. 28-29; B. Kienzle, J. Walton, «Bernard of Clairvaux (1090-1153)...» dans A. V. Murray (dir.), The Crusades: an Encyclopedia, vol. 1, p. 162-163.

177 J.-B. Pitra, Analecta novissima spicilegii Solesmensis, t. II, Frascati 1888, p. 405, trad. par P.-V. Claverie, Honorius III et l'Orient: étude et publication de sources indites des archives vaticanes (ASV), Leiden 2013, p. 236.

${ }_{178}$ LUB, 1-1, doc. 14, p. 19; B. BомBI, «Innocent III... », p. 236.

179 Dès les années 1200, des missionnaires avaient obtenu quelques conversions parmi les autochtones. La venue en Prusse d'un certain Godefroy, prédécesseur de Christian, est mentionnée par Albéric de Trois-Fontaines, Chronica Albrici monachi Trium Fontium, a monacho Novi Monasterii Hoiensis interpolata, éd. P. Scheffer-Boichorst, MGH Scriptores 23, Hanovre 1874, p. 887. M.-L. Favreau-Lilie, «Mission to the Heathen in Prussia and Livonia: The Attitudes of the Religious Military Orders Toward Christianization", dans G. Armstrong, I. Wood (dirs.), Christianizing People and Converting Individuals, Turnhout 2000, p. 147; B. Kedar, Crusade and Mission..., p. 141.

${ }^{180}$ L'origine de la rivalité entre Polonais et Prussiens est difficile à saisir; pour D. Buschinger, M. Olivier, Les Chevaliers teutoniques..., p. 99, l'enjeu était le contrôle du commerce maritime, ce qui ne vaut cependant que pour les régions côtières. De même, on rappelle l'émergence d'une société hiérarchisée parmi les Prussiens, où le pouvoir a été confisqué par des chefs organisant des 
Honorius III accepte d'"absoudre du vou concernant le voyage à Jérusalem au moins les deux duchés de Pologne qui sont le plus proche des païens, à condition qu'ils combattent contre ces païens» ${ }^{181}$. Mais l'aide apportée par des croisés laïcs ne suffit pas. Les ordres du Temple, de l'Hôpital et de Calatrava sont pressentis pour protéger la mission prussienne ${ }^{182}$, avant que le duc Conrad de Mazovie ne songe à fonder un ordre religieux-militaire "ad exemplar militie Christi de Livonia»" ${ }^{183}$. Autour de 1225, le même Conrad de Mazovie suit le conseil du duc de Silésie Henri le Barbu, qui avait ses entrées auprès des princes d'Empire, et commence des pourparlers avec une milice fondée quelques décennies auparavant: l'Ordre des Chevaliers teutoniques ${ }^{184}$.

L'apparition de l'Ordre de l'Hôpital de Sainte-Marie des Teutoniques a sans doute joué un rôle dans l'européanisation de la croisade balte ${ }^{185}$. Cet Ordre hospitalier de Terre sainte, fondé aux environs de 1190 par des pèlerins allemands, ne tarde pas à se militariser ${ }^{186}$. Entre 1211 et 1225 , les Teutoniques ont été installés en Hongrie pour défendre le royaume contre les Coumans, un peuple païen d'origine turque installé dans la région de l'actuelle

expéditions de pillage dans les terres voisines. C'est un phénomène analogue à ce qui est généralement accepté pour expliquer l'émergence de l'État lituanien à la même époque: M. GŁadysz, The Forgotten Crusaders... , p. 176-177; R. BARTLETT, The Making of Europe..., p. 303-306.

181 Codex Diplomaticus Prussicus (ci-après: CDP), 1, doc. 1, p. 2; M. GŁadysz, The Forgotten Crusaders..., p. 159-160, 180-186; E. Pitz, Papstreskript..., p. 85-97; I. Fonnesberg-Schmidt, The Popes..., p. 177-180.

182 R. Bartlett, The Making of Europe... p. 267; M. Geadysz, The Forgotten Crusaders..., p. 180-181, 209-211. Fondé en 1158, l'ordre religieux-militaire de Calatrava était proche des rois de Castille et actif sur le front ibérique de la croisade, aux côtés d'autres ordres religieuxmilitaires. L'éventuelle influence des événements en péninsule Ibérique, où les princes territoriaux utilisaient les ordres militaires comme appuis pour combattre les musulmans, n'est pas impossible (notamment via le réseau cistercien et la personnalité d'un homme comme le duc Henri de Silésie), mais reste difficile à prouver.

${ }^{183}$ D'après la confirmation des statuts de l'Ordre par Grégoire IX, en 1228 (PUB 1-1, doc. 69, p. 51). Plusieurs hypothèses concernant la date de fondation et la personne du fondateur de cet éphémère ordre religieux-militaire, connu sous le nom d' "Ordre de Dobrzyń", sont discutées par M. Gładysz, The Forgotten Crusaders... , p. 178-180; M. Starnawska, «Military... », p. 126-128; L. Pósán, "Prussian mission and the invitation of the Teutonic Order into Kulmerland", dans A. V. Murray (dir.), North-Eastern Frontiers..., p. 141-142.

${ }^{184}$ M. GŁadysz, The Forgotten Crusaders... , p. 209-210; L. Pósán, «Prussian mission... », p. 143, discute la possibilité de l'influence de l'évêque Christian dans l'appel aux Teutoniques.

${ }^{185}$ Il existe une importante littérature consacrée à l'Ordre teutonique. Parmi les ouvrages de référence, H. Boockmann, Der Deutsche Orden, Munich 1982; K. Militzer, Von Akkon zur Marienburg, Marbourg 1999; M. Tumler, Der Deutsche Orden, Vienne 1955, et en français S. Gouguenheim, Les Chevaliers teutoniques...; D. Buschinger, M. Olivier, Les Chevaliers teutoniques...; H. Bogdan, Les Chevaliers teutoniques, Paris 1995; K. Toomaspoeg, Histoire des Chevaliers teutoniques, Paris 2001.

186 S. Gouguenheim, Les Chevaliers teutoniques..., p. 23-24; A. Demurger, Les Hospitaliers, Paris 2013, p. 75-78. 
Transylvanie ${ }^{187}$. Bien que liés essentiellement à l'Empire ${ }^{188}$, les Teutoniques ne sont pas des inconnus en France et en Angleterre; ils semblent notamment avoir été appréciés du roi Louis IX, qui collaborait volontiers avec les ordres militaires lors de son expédition en Terre sainte dans les années $1250^{189}$; c'est par la sympathie dont faisait preuve le saint roi envers l'Ordre que l'on a expliqué, au $\mathrm{XVI}^{\mathrm{e}}$ siècle, la présence de quatre fleurs de lys sur les armes du grand-maître ${ }^{190}$. Quoi qu'il en soit, la participation commune aux aventures proche-orientales semble avoir créé des liens entre l'Ordre et quelques seigneurs français; d'après Henri d'Arbois de Jubainville, les donations à l'Ordre teutonique en France proviennent, en grande partie, de participants à la cinquième croisade ${ }^{191}$. Le nombre de possessions françaises de l'Ordre n'est certes pas très important ${ }^{192}$, mais celles-ci permettent aux Teutoniques de s'implanter dans le royaume, où plusieurs commanderies apparaissent au siècle suivant ${ }^{193}$. La présence de l'Ordre est plus significative dans les régions francophones de Lotharingie, notamment à Liège, ce qui peut s'expliquer par la proximité des terres germanophones, où il est solidement implanté ${ }^{194}$. À noter que les statuts de l'Ordre ont été traduits

187 Quellen zur Geschichte des Deutschen Ordens, éd. W. Hubatsch, Göttingen 1954, doc. 3, p. 36-39. Sur l'expérience hongroise de l'Ordre teutonique, H. Zimmermann, Der deutsche Orden in Siebenbürgen. Eine diplomatische Untersuchung, Cologne 2001; Idem., "Der Deutsche Ritterorden in Siebenbürgen ", dans J. Fleckenstein, M. Hellmann, Die geistlichen Ritterorden..., p. 267-298; S. Gouguenheim, Les Chevaliers teutoniques, p. 43-53; R. Hautala, "The Teutonic Knights' Military Confrontation with the Cumans during Their Stay in Transylvania (12111225)", Golden Horde Civilisation 8, 2015, p. 80-89.

${ }^{188}$ K. Militzer, "The Teutonic Knights between Emperors and Popes", dans J. Sarnowsky, Mendicants, Military Orders, and Regionalism, Aldershot 1999, p. 72.

189 S. Lotan, "The Battle of La Forbie (1244) and its Aftermath - Re-eximination of the Military Order's Involvement in the Latin Kingdom of Jerusalem in the mid-Thirteenth Century", Ordines Militares. Yearbook for the Study of the Military Orders 17, 2012, p. 53-67.

${ }^{190}$ L'anecdote selon laquelle Louis IX aurait autorisé le grand-maitre à faire figurer les fleurs de lys sur sa bannière apparaît en premier dans la Jüng Hochmeister Chronik et dans la Waiblinger Chronik, avant d'être reprise entre autres par le baron von Wal, Histoire de l'Ordre teutonique..., vol. 1, p. 466-468, puis T. De Puymaigre, "Une campagne...", p. 169. L'origine de ce meuble héraldique sur la bannière du grand maître reste inconnue: M. Tumler, Der Deutsche Orden..., p. $418-419$, n. 25.

${ }^{191}$ H. D'Arbois de Jubainville, «L'Ordre teutonique en France», Bibliothèque de l'École des Chartes 32, 1871, p. 63-83. L'étude est effectuée à partir du dépouillement des chartes de la commanderie de Beauvoir (fonds de Clairvaux, archives de l'Aube). Voir aussi K. Militzer, Von Akkon..., p. 36; S. Lotan, "The Teutonic Knights and their Attitude about Muslims", dans C. Hess, J. Adams (dirs.), Fear and Loathing in the North, Berlin 2015, p. 317; K. Toomaspoeg, Histoire des Chevaliers teutoniques..., p. 136-137; K. Polejowski, "Les comtes de Brienne et l'Ordre teutonique (XIII ${ }^{\mathrm{e}}$-XIV ${ }^{\mathrm{e}}$ siècle)", La Vie en Champagne 32, 2002, p. 4-8.

192 Comme le fait remarquer W. Paravicini, "La Prusse...», p. 178; S. Gouguenheim, Les Chevaliers teutoniques..., p. 84; M. Tumler, Der Deutsche Orden..., p. 178-180.

193 H. D’Arbois de Jubainville, «L'Ordre teutonique..., p. 63-67.

194 W. Paravicini, «La Prusse ... », p. 178; D. Heckmann, «L'Ordre teutonique à Metz et à Liège au Moyen Âge», dans J. Sarnowsky, Mendicants, Military Orders, and Regionalism, Aldershot 1999, p. 59-68. 
en français, vers le milieu du $\mathrm{XIV}^{\mathrm{e}}$ siècle ${ }^{195}$ : il nous reste au moins un manuscrit dans cette langue, contre 4 en latin, 4 en néerlandais et plus d'une vingtaine dans différents dialectes allemands ${ }^{196}$. Les Chevaliers teutoniques ne possèdent pas de terres en Angleterre, mais à partir d'Henri III, les rois s'engagent à leur payer une rente ${ }^{197}$.

À l'instar des autres ordres religieux-militaires médiévaux, l'Ordre teutonique possède une organisation relativement complexe, dans laquelle les chevaliers proprement dits ne représentent qu'une minorité. Les ecclésiastiques, évêques, prieurs ou simples prêtres jouent un rôle important dans l'exécution des tâches administratives. Ce sont eux qui entretiennent la mémoire de l'Ordre et qui se chargent de l'essentiel des affaires spirituelles ${ }^{198}$. Originaires pour l'essentiel de la petite noblesse allemande, les chevaliers doivent quant à eux surtout savoir se battre et être de bons administrateurs ${ }^{199}$. Les prescriptions les plus rigoureuses de l'Ordre sont rapidement assouplies, pour permettre aux combattants de remplir leur devoir militaire ${ }^{200}$. Les combattants non-nobles, les auxiliaires autochtones et les mercenaires forment le gros de la troupe et des garnisons. À la tête de l'Ordre se trouve un grandmaître, élu à vie et dont le siège est à Acre, jusqu'à la prise de la ville par les Mamelouks en $1291^{201}$. Il est assisté d'un chapitre général et des principaux officiers, parmi lesquels on peut citer le maréchal ${ }^{202}$.

Les milices nouvellement installées sur le territoire balte sont d'une efficacité redoutable, mais des plaintes émanant des évêques de Prusse et de Livonie ne tardent pas à parvenir jusqu'à Rome; ni les Porte-Glaives, ni les Chevaliers teutoniques ne semblent être des partenaires faciles ${ }^{203}$. Qui plus est, les Danois

\footnotetext{
195 H. Suchier, dans Die Statuten des Deutschen Ordens..., p. LIX.

196 Quellen..., p. 33. Des extraits des statuts sont publiés dans Ibid., doc. 2, p. 33-35. Les statuts sont publiés en version latine, française, allemande, bas-allemande et hollandaise dans Die Statuten des Deutschen Ordens....

197 W. Paravicini, Die Preussenreisen des Europäischen Adels, Sigmaringen 1989 (ci-après: PR), vol. 1, p. 115-117.

198 S. Gouguenheim, Les Chevaliers teutoniques..., p. 414.

199 K. Militzer, Von Akkon..., p. 424-441.

200 Ibid., p. 70-77, 87-88. L'exigence en matière religieuse demandée aux membres combattants est diversement appréciée selon les auteurs; pour rester dans le domaine francophone, K. GóRSKI, "L'Ordre teutonique. Un nouveau point de vue», Revue Historique 230/2, 1963, ", p. 292 ou H. Samsonowicz, "L'ordre des Chevaliers teutoniques", dans N. Aleksiun et al., Histoire de l'Europe du Centre-Est..., p. 672, rappellent que les novices avaient entre six mois et une année pour apprendre le Pater et le Credo, ce qui signifierait qu'ils ne le savaient pas forcément avant d'entrer dans l'ordre; à l'inverse, H. Bogdan avance que "les frères de l'Ordre teutonique n'ont jamais cessé d'être des religieux» (Les Chevaliers teutoniques..., p. 138).

201 À la suite de quoi le siège de l'Ordre sera déplacé à Venise, puis à Marienbourg (Malbork) en 1309.

${ }^{202}$ H. Samsonowicz, "L'ordre des Chevaliers teutoniques... », p. 681.

${ }^{203}$ J. Brundage, "The Thirteenth-Century...», p. 4-5; I. Fonnesberg-Schmidt, The Popes..., p. $170-176$.
} 
ne tardent pas à s'emparer du nord de l'Estonie, et les ducs polonais disputent âprement à l'Ordre teutonique le contrôle de la Prusse ${ }^{204}$. Malgré les moyens limités à sa disposition ${ }^{205}$, Innocent III tente d'imposer la paix entre les différentes factions et de sauvegarder la liberté des convertis, quitte à ne pas exiger d'eux le respect de toutes les prescriptions du christianisme ${ }^{206}$. D'après Henri de Livonie, Césaire de Heisterbach et l'auteur de la Chronique rimée de Livonie, il aurait reçu avec grand intérêt le chef live converti Caupo, qui a accompagné le cistercien Théodoric dans l'un de ses voyages à Rome, en $1203^{207}$. Ce personnage aurait pu jouer le rôle du prince autochtone accédant à la royauté en baptisant son peuple, mais il meurt dans une bataille contre les Estoniens en $1217^{208}$. Il faudra attendre l'émergence du grand-duché de Lituanie pour rencontrer à nouveau des princes assez forts pour travailler avec la Papauté à la christianisation de leur pays.

En attendant, le Saint-Siège dépêche plusieurs légats, parmi lesquels Guillaume, évêque de Modène, nommé en Livonie et Estonie (1225-1226, 1229-1230), en Prusse (1228-1230) et dans l'ensemble de la Baltique (1234$1242)^{209}$. D'après Iben Fonnesberg-Schmidt, l'homme montrait un vif intérêt pour la mission auprès des païens baltes, intérêt qu'il paraît avoir partagé avec des personnages aussi importants que le pape Honorius III lui-même, mais encore François d'Assise et Dominique de Guzman ${ }^{210}$. Proche de ce dernier, Guillaume entendait orienter la mission balte vers la prédication et la

\footnotetext{
204 Sur ce qui suit, I. Fonnesberg-Schmidt, The Popes..., p. 80-81; E. Christiansen, The Northern Crusades..., p. 97; N. Blomkvist, Discovery..., p. 538-539; P. Rebane, «From Fulco...» p. 108-113.

${ }^{205}$ E. Johnson, dans History of the Crusade..., vol. 3, p. 565, rappelle qu'Innocent et ses successeurs ne pouvaient s'aliéner les princes ou les ordres militaires en prenant des mesures trop draconiennes, quand bien même leurs méthodes leur déplaisaient; de plus, la croisade ayant déjà été mise en place et légitimée, il était difficile de revenir en arrière.

206 N. Blomkvist, Discovery..., p. 537-538.

207 Henri de Livonie, Heinrichs Livländische Chronik..., VII, 3, p. 20-21; Livländische Reimchronik, éd. F. Pfeiffer, Stuttgart 1844, v. 304-436, p. 8-11; Skarbiec..., I, p. 41; Caesarii Heisterbacensi Liber VIII miraculorum I, 31, cité par M. TAMM, "Les miracles en Livonie et en Estonie à l'époque de la christianisation (fin XII ${ }^{\mathrm{e}}$-début XiII ${ }^{\mathrm{e}}$ siècles)", dans J. Kivimäe, J. Kreem (dirs.), Quotidianum Estonicum, Krems 1996, p. 38. Le cistercien de Cologne Césaire de Heisterbach a sans doute entendu l'histoire de Caupo par Bernard de Lippe, évêque cistercien de Sémigallie (Ibid., p. 71; Idem, "Communicating Crusade...", p. 357-359.

208 Sur Caupo, N. Blomkvist, Discovery..., p. 551-558; T. K. Nielsen, «Mission and Submission: Societal Change in the Baltic in the Thirteenth Century", dans T. Lehtonen et K. V. Jensen (dirs.), Medieval History Writing..., p. 216-231.

${ }^{209}$ Voir notamment Henri de Livonie, Heinrichs Livländische Chronik..., XXIX, 2-3, , p. 208-211; et les instructions de Grégoire IX à Guillaume de Modène (8 et 9 mars 1238), LUB 1-1, doc. 157-158, col. 202-204; I. Fonnesberg-Schmidt, The Popes..., p. 178-179; B. Kedar, Crusade..., p. 148-149; P.-V. Claverie, Honorius III et l'Orient..., p. 253-254.

${ }^{210}$ Ibid., p. 153-162; 173. Sur la mission balte de Guillaume de Modène: E. Pitz, Papstreskript..., p. 120-145; G. A. Donner, Kardinal Wilhelm von Sabina, Helsingfors 1929.
} 
communication avec les néophytes, notamment en développant l'apprentissage des langues autochtones ${ }^{211}$.

Ce légat est peut-être, si l'on en croit Sylvain Gouguenheim, à l'origine d'un document qui nous renseigne sur les fondements idéologiques de la mission des Chevaliers teutoniques, dont il semble avoir été proche ${ }^{212}$. Il s'agit du traité de Kruschwitz, passé entre Conrad de Mazovie et les représentants de l'Ordre en juin $1230^{213}$. Le texte fait dire au duc Conrad que «ces dits frères ont de bonne foi promis, [...] d'affronter à nos côtés, en tout temps, sans ruse ni feinte, les Prussiens et les autres Sarrasins à nous avoisinants qui attaquent notre terre, aussi longtemps que ceux-ci sont ennemis de la foi et du culte $d u$ Christ $\rangle^{214}$. Les Prussiens sont présentés comme des agresseurs, qu'il faudra détruire par la force si l'on ne peut en venir à bout autrement ${ }^{215}$. Quand ils seront vaincus, leurs biens et leurs personnes pourront être soumis à l'Ordre ${ }^{216}$. Le terme «Sarrasin» utilisé ici à trois reprises pour désigner les Prussiens permet de saisir un aspect de l'européanisation progressive de la croisade balte ${ }^{217}$. Au moment de s'établir en Prusse, l'Ordre teutonique reste concerné par les affaires de Terre sainte, où ont servi plusieurs frères qui rejoignent ensuite la Baltique ${ }^{218}$. Pourtant, dans les chroniques de l'Ordre (Chronique rimée de Livonie, chroniques de Dusbourg et de Jeroschin), «Sarrazînen» et «Sarraceni» désignent uniquement les musulmans de Terre sainte ou d'Espagne ${ }^{219}$. Du côté

${ }^{211}$ S. Gouguenherm, "Un Italien dans la Baltique. Guillaume de Modène en Norvège et en Suède", dans T. M. S. Lehtonen et E. Mornet (éds.), Les élites nordiques et l'Europe occidentale (XII $-X V^{*}$ siècle), Paris 2007, p. 142.

212 Ibid., p. 141-144; D. Buschinger, M. Olivier, Les Chevaliers teutoniques..., p. 105; G.-A. Donner, Wilhelm von Sabina..., p. 264-265 passim.

${ }^{213}$ Un débat a opposé les historiens pour savoir si ce traité a bien été signé entre Conrad de Mazovie et les représentants de l'Ordre teutonique, ou s'il s'agit d'un faux, forgé par l'Ordre quelques années plus tard pour légitimer a posteriori sa position en Prusse: D. SiкоRsкi, Przywilej Kruszwicki: studium z wczesnych dziejów zakonu niemieckiego w Prusach, Varsovie 2001, p. 11-40; S. Gouguenheim, Les Chevaliers teutoniques..., p. 168-173. La question est actuellement tranchée dans le sens de l'authenticité du traité: voir T. JAsINSKI, "Uwagi a autentycznosci Przywileju Kruszwickiego z Czerwca 1230 R.», Personae Colligationes Facta, Toruń, 1991, p. 226-239; S. Gouguenheim, "L'Ordre teutonique en Prusse», dans L'expansion occidentale (XI'-XV siècles), Paris 2003, p. 103. Dès le XIV ${ }^{e}$ siècle, la donation de la Prusse aux Chevaliers teutoniques a opposé les historiens et les juristes polonais et allemands, qui y voyaient le point de départ des querelles opposant l'Ordre au Royaume durant le XIV et le $\mathrm{XV}^{e}$ siècle. Il reste quelques zones d'ombres en ce qui concerne l'auteur du traité. Si S. Gouguenheim y voit la main de Guillaume de Modène, qui était un ami de l'Ordre (Les Chevaliers teutoniques..., p. 169), pour H. Boockmann (Der Deutsche Orden..., p. 89), il pourrait s'agir d'un clerc membre de l'Ordre teutonique rompu au droit romain.

${ }_{214}$ PUB 1-1, doc. 78, p. 60.

215 Ibid., p. 58.

216 Ibid., p. 59.

217 H. Boockmann, Der Deutsche Orden..., p. 89; S. Gouguenheim, Les Chevaliers teutoniques..., p. 169.

218 A. V. Murray, «Saracens...», p. 415.

219 Ibid., p. 415. S. Lotan, "The Teutonic Knights... », p. 323-324, mentionne un membre de l'Ordre teutonique surnommé "Sarracenus" par Dusbourg, et suggère que ce surnom 
polonais, ce vocable n'est que rarement utilisé dans le contexte balte ${ }^{220}$. Il faudra attendre l'arrivée des croisés venus d'Europe occidentale au XIV siècle pour que l'usage d'appeler les païens baltes (en l'occurrence, les Lituaniens) «Sarrasins» se généralise ${ }^{221}$.

Dariusz Sikorski montre que le programme ébauché dans le traité rappelle l'idéologie développée par Bernard de Clairvaux, dont on reconnaît l'essentiel des idées ${ }^{222}$. Mais l'historien polonais remarque aussi que le contenu du texte ressemble aux thèses de Thomas d'Aquin sur la guerre juste, au détail près que l'usage de la force pour convertir les païens était interdit par le docteur angélique ${ }^{223}$. Ce point expliquerait donc l'utilisation du terme "Sarrasin ", lequel pourrait viser à assimiler les Prussiens aux hérétiques ou aux schismatiques, dont la conversion forcée était autorisée ${ }^{224}$. Or, rien n'indique que la conversion des païens, même par la force, ait été le but des Teutoniques; on parle en effet "de ces dits infidèles, dont on espère la conversion à l'avenir, la grâce de Dieu aidant ${ }^{225}$. Leur conversion reste bien dans l'horizon d'attente, mais personne ne semble imaginer qu'elle ait lieu dans un avenir proche ou qu'elle soit le fait desdits Chevaliers. De plus, l'influence probable de Bernard de Clairvaux suffit à expliquer l'usage du terme "Sarrasin", que nous avons déjà rencontré dans le contexte balte sous la plume de quelques chroniqueurs du XII ${ }^{e}$ siècle; au début du siècle suivant, l'empereur Othon de Brunswick fait également référence aux païens de Livonie en les appelant "Sarrasins»" ${ }^{226}$. L'auteur du traité de Kruschwitz, qu'il s'agisse effectivement de Guillaume de Modène ou non, étant très vraisemblablement un proche de la Curie, il n'est guère étonnant qu'il ait recours à ce genre de terminologie pour désigner les ennemis de la Chrétienté. Quoi qu'il en soit, l'utilisation de ce terme rapproche le document de l'atmosphère des croisades d'Orient, et situe ainsi l'action de l'Ordre dans un contexte bien plus large que la géopolitique régionale du nord de la Pologne ${ }^{227}$.

D'autres documents viennent renforcer la position de l'Ordre teutonique. Proche de l'Empereur comme du Pape, le grand-maître Hermann de Salza obtient de précieux privilèges des deux souverains symboliques de la Chrétienté.

peut lui avoir été attribué du fait qu'il a peut-être combattu en Orient avant de poursuivre sa carrière en Prusse.

${ }^{220}$ M. Starnawska, «Military...», p. 128; L. Pósán, «Prussian mission...», p. 147. Par exemple, le privilège accordé en mars 1237 par le duc de Mazovie à l'Ordre de Dobrzyń ( PUB 1-1, doc. 126, p. 95-96) parle de "hereticis et Pruthenis seu cuius(!) libet christiane fidei inimicis» (p. 95).

${ }^{221}$ Sur cette question, voir l'article d'A. V. Murray, "Saracens...", qui ne mentionne pas le texte du privilège de Kruschwitz.

222 D. SiкоRski, Przywilej..., p. 56-57.

223 Ibid., p. 57.

${ }^{224}$ Id. Sur l'idéologie de la guerre juste et l'installation des Chevaliers teutoniques en Prusse, voir notamment R. MAŽEIKA, "Violent Victims... », p. 123-140.

225 PUB 1-1, doc. 78, p. 60.

${ }^{226}$ LUB 1-1, doc. 25, col. 33; S. Lotan, "The Teutonic Knights...», p. 322.

227 D. Sikorski, Przywilej..., p. 58. 
En $1235^{228}$, l'empereur Frédéric II, par la bulle dite de Rimini, octroie aux Teutoniques la souveraineté et les privilèges impériaux sur les territoires qu'ils pourront conquérir ${ }^{229}$, non sans avoir accordé sa protection aux convertis de Prusse, de Livonie et d'Estonie $(1224,1228,1232)^{230}$. L'initiative vient vraisemblablement de Guillaume de Modène, qui était à ce moment en contact avec l'Empereur ${ }^{231}$. La Papauté n'est pas en reste, puisqu'en 1225, Honorius III prend lui aussi les Prussiens convertis sous sa protection et promet qu'ils garderont leur liberté232. Pour James Brundage, il y a tout lieu de penser que ce sont les rapports du même Guillaume de Modène qui ont aiguisé l'intérêt de Rome pour la Baltique, à un moment où les papes essayent de mieux contrôler les territoires conquis par les croisés ${ }^{233}$. Le petit groupe rassemblé autour d'Honorius III, de Dominique de Guzman et du futur Grégoire IX faisant preuve d'un intérêt particulier pour la mission auprès des non-chrétiens, Honorius et ses successeurs sont plutôt disposés à soutenir l'Ordre teutonique, que l'on voit comme un défenseur efficace des missionnaires ${ }^{234}$. Un peu plus tard, en 1234, Grégoire IX place la Prusse sous la protection de saint Pierre et délègue son administration aux Teutoniques ${ }^{235}$. L'évêque Christian, Conrad de Mazovie et les autres ordres militaires auxquels on avait, dans un premier temps, fait appel, sont mis sur la touche ${ }^{236}$.

Débarrassé de ses rivaux, l'Ordre peut se lancer dans la conquête de la Prusse $^{237}$. Des colons, venus essentiellement d'Allemagne et de Pologne, sont

${ }^{228}$ La bulle d'or de Rimini est datée de 1226 (ainsi H. Boockmann, Der Deutsche Orden..., p. 80-87), mais plusieurs historiens ont supposé qu'elle remonterait en réalité à 1235 et aurait été antidatée: T. JAsinski, "The Golden Bull Allegedly Issued in 1226 by Friedrich II for the Teutonic Order ", Quaestionnes Medii Aevi Novae 3, 1998, p. 221-244, suivi par S. Gouguenheim, "L'Ordre teutonique en Prusse...», p. 101-102. Pour D. Buschinger, M. Olivier, Les Chevaliers teutoniques..., p. 104, ce document daterait bien de 1226, mais aurait été «discrètement retouché après 1231-1232 pour tenir compte de l'évolution de la situation sur le terrain".

${ }^{229}$ Quellen..., doc. 5, p. 46-54; PUB 1-1, doc. 56, p. 41-43; S. Gouguenherm, Les Chevaliers teutoniques..., p. 179-183.

${ }^{230}$ PUB 1-1, doc. 52, p. 38-39; T. Manteuffel, "La mission balte de l'ordre de Cîteaux", dans La Pologne au Xe Congrès international des sciences historiques à Rome, Varsovie, 1953, p. 111-112.

231 E. Pitz, Papstreskript..., p. 133-134; I. Fonnesberg-Schmidt, The Popes..., p. 204-203.

232 PUB 1-1, doc. 54, trad. S. Gouguenheim, Les Chevaliers teutoniques..., p. 157; I. FonnesbergSchmidt, The Popes..., p. 177-179.

${ }^{233}$ J. Brundage, "The Thirteenth-Century...», p. 7-8.

${ }^{234}$ C. T. Maier, Preaching..., p. 51 ; R. Spence, «Pope Gregory IX and the Crusade in the Baltic», The Catholic Historical Review 69/1, 1983, p. 18-19. Il semble notamment que le futur saint Dominique ait envisagé de participer lui-même à une croisade missionnaire en Estonie: M. TAMM, "When Did the Dominicans Arrive in Tallinn?», Past: Ajalookultuuri ajakiri, Special issue on the history of Estonia, 2009, p. 35-36.

${ }^{235}$ Quellen..., doc. 8, p. 72-75; PUB 1-1, doc. 108, p. 83-84; S. Gouguenheim, Les Chevaliers teutoniques..., p. 173-178, 157-159.

${ }^{236}$ L'Ordre de Dobrzyń est définitivement absorbé par l'Ordre teutonique en 1235; M. StaRnawsKa, «Military...», p. 129-130.

237 Sur Christian de Prusse, D. Buschinger, M. Olivier, Les Chevaliers teutoniques..., p. 99-103. 
appelés pour peupler les terres prises et développer les villes nouvellement fondées, comme Toruń et Chełmno autour de 1230, Elbląg en 1234 ${ }^{238}$. L'Ordre se montre assez généreux pour que son appel à la colonisation reste attractif, mais il se réserve un contrôle étendu sur la population ${ }^{239}$. On évite notamment qu'une aristocratie foncière trop puissante ne se développe ${ }^{240}$. En 1237, les Chevaliers Porte-Glaives, affaiblis par une lourde défaite contre les Sémigalliens et les Lituaniens (bataille de Saule, 1236), sont incorporés à l'Ordre teutonique, qui obtient la gestion de leurs possessions livoniennes ${ }^{241}$. Afin d'apaiser les relations entre l'Ordre et les Prussiens, un traité est passé sous la houlette du légat Jacques Pantaléon de Troyes, le futur Urbain IV; on prévoit notamment d'accorder des droits égaux à ceux qui se convertiraient (traité de Christbourg, $1249)^{242}$. La tentative est cependant ruinée par de nouveaux troubles, et pour mater les rebelles ou conquérir d'autres territoires, les Teutoniques font appel, entre autres, au puissant roi de Bohême Ottokar ${ }^{243}$. Fidèle à la politique imprimée par Honorius III, la Papauté continue durant tout le XIII ${ }^{\mathrm{e}}$ siècle à soutenir la croisade balte ${ }^{244}$, qui garde alors une importance quasiment égale à celle de Terre sainte ${ }^{245}$.

${ }^{238}$ Sur la fondation de Toruń: Pierre de Dusbourg, Chronicon..., SRP 1, p. 49-50; Chełmno: ibid., p. 56; Elbląg: ibid., p. 60; sur la conquête de la Prusse par l'Ordre teutonique, notamment S. Gouguenheim, Les Chevaliers teutoniques..., 189-211.

239 W. Paravicini, "L'Ordre teutonique et les courants migratoires en Europe centrale $\mathrm{XIII}^{\mathrm{e}}$ XIV ${ }^{e}$ siècles", dans S. Cavaciocchi (éd.), Le Migrazioni in Europa Secc. XIII-XVIII, Florence 1994, p. 312-313.

${ }_{240}$ Ibid., p. 315; S. Gouguenheim, Les Chevaliers teutoniques, p. 378-382.

241 Quellen..., doc. 9, p. 76-79; F. Benninghoven, Der Orden der Schwertbrüder..., p. 353; S. Gouguenheim, Les Chevaliers teutoniques, p. 255-257.

242 PUB 1-1, doc. 218, p. 158-165; R. Wenskus, «Über die Bedeutung des Christburger Vertrages für die Rechts- und Verfassungsgeschichte des Preußenlandes», dans E. BAHR (dir.), Studien zur Geschichte des Preußenlandes. Festschrift Erich Keyser, Marbourg 1963, p. 97-118; H. Patze, «Der Frieden von Christburg vom Jahre 1249", Jahrbuch für die Geschichte Mittel- und Ostdeutschlands 7, 1958, p. 39-91; S. Gouguenheim, Les Chevaliers teutoniques..., p. 505-506; C. T. Maier, Preaching..., p. 91 ; J. Powierski, «Die Stellung der pommerellischen Herzöge zur Preussen-Frage im 13. Jahrhundert", dans U. ARnold, M. Biskup (dir.), Der Deutschenordensstaat, Marbourg 1982, p. 120.

243 Pierre de Dusbourg, Chronicon..., SRP 1, p. 92; P. HLavÁčeK, "A Reflection on the Political and Religious Role of Bohemia ", dans J. KŁoczowski, H. Łaszkiewicz (dirs.), East Central Europe in European history, p. 133-134.

${ }^{244}$ Il semble que Clément IV (m. 1268) ait été le dernier pape à avoir directement soutenu la croisade menée par l'Ordre teutonique; après les révoltes des années 1260, la Papauté laisse les membres de l'Ordre s'occuper eux-même de la prédication et de la distribution d'indulgence aux croisés venus leur prêter main-forte: C. T. MaIER, Preaching..., p. 92-93.

${ }^{245}$ En 1245, Innocent IV rappelle que la croisade de Terre sainte ne doit pas se faire au détriment de celle de la Baltique (PUB 1-1, doc. 169, p. 125); C. T. Maier, Preaching..., p. 78; A. Ehlers, Die Ablasspraxis..., p. 38; Idem, "The Use of Indulgences by the Teutonic Order in the Middle Ages", dans V. Mallia-Milanes (éd.), The Military Orders. History and Heritage, vol. 3, Aldershot 2008, p. 141-142. 


\section{LE GRAND-DUCHÉ DE LITUANIE, UN PARTENAIRE PAÏEN}

Le grand-duché de Lituanie apparaît dans l'histoire européenne sous le pontificat d'Innocent IV (m. 1254), qui est aussi l'un des principaux théoriciens des relations entre pouvoirs chrétiens et infidèles. L'arrivée des Mongols aux portes de l'Occident catholique, dans les années 1240, incite Rome à réfléchir à la manière de traiter avec une puissance non-chrétienne ${ }^{246}$. Lors de leur expansion vers l'Ouest, les Mongols, que l'on appelle aussi Tatars, ont dévasté la Hongrie et mis à mal la Pologne ${ }^{247}$. La Chrétienté peut, à raison, se sentir menacée; mais on s'aperçoit rapidement qu'une fois leurs conquêtes accomplies avec une extrême brutalité, les khans laissent un territoire relativement pacifié, octroyant une large autonomie religieuse et culturelle à ceux qui se sont soumis ${ }^{248}$. On découvre alors un monde nouveau, qui laisse présager de grandes opportunités commerciales et politiques. Innocent IV, qui espère convertir les Mongols pacifiquement, doit traiter avec eux sur un pied d'égalité. Commentant la décrétale d'Innocent III Quod super his, qui concerne la commutation des voux de croisade, le pape élabore une théorie considérant que les infidèles doivent bénéficier de droits politiques et personnels ${ }^{249}$. L'argument clef est le droit naturel: en tant que créatures rationnelles, les infidèles comme les chrétiens peuvent régner ou posséder des biens, et c'est un crime de les en empêcher. Ce n'est que s'ils venaient à manquer de respect à la loi naturelle, par exemple en adorant une idole, que le pape pourrait déclarer leur gouvernement illégitime ${ }^{250}$.

Une ligne plus dure est tracée par un autre commentateur de Quod super his, Henri de Suse, dit Hostiensis (m. 1271) ${ }^{251}$. Bien qu'il rejoigne Innocent IV sur plusieurs points essentiels, il s'en distingue en considérant que le pouvoir a été retiré aux infidèles dès l'arrivée du Christ sur Terre ${ }^{252}$ : l'Église peut tolérer leurs États, mais un prince chrétien est autorisé à déclarer la guerre contre ceux-ci. C'est, au fond, un retour à la position carolingienne puis ottonienne. Pourtant, l'approche d'Innocent IV l'emporte parmi les juristes, même si les deux courants de pensée restent vivants jusqu'à la fin du Moyen Âge ${ }^{253}$. En ce qui concerne la coercition, les deux penseurs sont formels: la conversion forcée est

\footnotetext{
246 Sur les contacts avec les Mongols et la réflexion sur les fondements de la tolérance, voir C. Nederman, "Toleration in Medieval Europe: Theoretical Principles and Historical Lessons", dans J. Muldoon (dir.), Bridging the Medieval-Modern Divide, Farnham 2013, p. 50 ; J. Muldoon, Popes, Lawyers..., p. 36 sq.

${ }^{247}$ K. Setton et al., A History of the Crusades..., vol. 2, p. 717.

${ }^{248}$ F. Conte, Les Slaves..., p. 452.

${ }^{249}$ Le texte est édité dans Die Staatsschriften des Deutschen Ordens, éd. E. Weise, Göttingen 1970, vol. 1, , p. 48-62.

250 B. Kedar, Crusade..., p. 159-169; C. Reid, «Paulus Vladimiri, the Tractatus, Opinio Hostiensis, and the Rights of Infidels", dans P. Krafl (dir.), Sacri Canones Servandi Sunt, Prague 2008, p. 418-419; J. Muldoon, Popes, Lawyers..., p. 6-15.

251 Ibid., p. 15-18; Die Staatsschriften..., p. 49 sq.

252 Die Staatsschriften..., p. 63-64.

${ }^{253}$ C. Reid, «Paulus Vladimiri...», p. 419-420; T. Brennan, Just War..., p. 19-22
} 
interdite, mais le Pape peut utiliser la force pour obliger les infidèles à accepter des prêcheurs parmi eux ${ }^{254}$. Il ne s'agit donc pas de condamner l'utilisation de la violence comme appui à la mission; pour Iben Fonnesberg-Schmidt, le juriste de formation qu'est Innocent IV, autant intéressé que ses prédécesseurs Honorius III et Grégoire IX aux affaires missionnaires, aurait essayé de donner un cadre légal à un phénomène qui existait depuis longtemps dans les zones où des seigneurs chrétiens combattaient et soumettaient des infidèles ${ }^{255}$. L'idée était de brider l'usage de la violence, et surtout, de permettre qu'il soit supervisé par le Pape, puisque c'est à lui de déterminer si l'on peut ou non recourir à la force ${ }^{256}$.

En 1245, Innocent IV envoie une ambassade à la découverte de l'Asie, afin d'établir des relations diplomatiques avec le nouveau chef suprême mongol; trois ans plus tard, le roi de France Louis IX lui emboîte le pas ${ }^{257}$. Plusieurs explorateurs, ambassadeurs puis marchands, parcourront la route qui mène à la Chine et à la vaste Tartarie. Des contacts diplomatiques, commerciaux et même religieux avec les souverains de ce nouvel empire sont donc possibles ${ }^{258}$, mais Innocent IV préfere assurer la sécurité de la Chrétienté de plusieurs manières. Le saint père propose aux princes russes de Souzdal et de Galicie de collaborer avec l'Ordre teutonique afin de se protéger des attaques mongoles, et soutient les efforts des souverains d'Europe orientale désirant rejoindre le monde catholique. L'idée est de constituer un "cordon sanitaire" protégeant la Chrétienté latine, et correspond à la tradition pontificale, qui favorise volontiers les princes païens ou orthodoxes souhaitant se rapprocher de Rome ${ }^{259}$.

${ }^{254}$ Die Staatsschriften..., p. 58. L'approche d'Innocent ne signifie pas qu'il ait été moins favorable à la croisade balte que ses prédécesseurs; au contraire, I. Fonnesberg-Schmidt rappelle qu'il considérait même celle-ci comme aussi importante que les opérations en Terre sainte, ce qui pourrait s'expliquer par son intérêt pour la mission (The Popes..., p. 240). Mission et croisade continuent donc de fonctionner de concert.

255 Id. B. KedAR (Crusade..., p. 202) a cette belle formule: «the Innocentian conception of crusade paving the way for mission".

256 I. Fonnesberg-Schmidt, The Popes..., p. 239-240.

257 J. Muldoon, Popes, Lawyers..., p. 42-45. L'ambassade mongole auprès de Louis IX est notamment décrite dans Les Grandes chroniques de France, vol. 7, éd. J. Viard, Paris 1932, p. 121-124, 128-132. Sur les rapports entre Innocent IV, Louis IX de France et les Mongols, A. Ruotsala, "The Crusaders and the Mongols», dans T. Lehtonen et K. V. Jensen (dirs.), Medieval History Writing..., p. 302-309.

${ }^{258}$ Bénéficiant de la tolérance dont font preuve les souverains mongols, l'Église met en place une mission pour l'extrême Orient: C. CahEn, "The Mongols and the Near East", dans K. Setton et al., A History of the Crusades, vol. 2, p. 722-723; A. Ruostala, Europeans and Mongols in the Middle of the Thirteenth Century: Encountering the Other, Helsinki 2001, p. 38-39.

${ }^{259}$ H. Samsonowicz, "Chapitre premier - Histoire de l'Europe du Centre/Est des origines au débuts du Xive siècle», dans N. Aleksiun et al., Histoire de l'Europe du Centre-Est..., p. 78-80; I. Fonnesberg-Schmidt, The Popes..., p. 232; J. Lind, «Mobilisation of the European Periphery against the Mongols", dans J. Staecker (éd.), The Reception of Medieval Europe in the Baltic Sea Region, Papers of the XIIth Visby Symposium held at Gotland University, Visby 2009, p. 75-90. 
C'est au-delà des Prussiens, des Coures et des Jatvingiens, que les Teutoniques entameront des négociations avec un homme qui entend justement jouer ce rôle, souverain d'un peuple resté relativement en retrait pendant la conquête de la Prusse et de la Livonie. Vivant à l'intérieur des terres, dans une région séparée des pays côtiers par une épaisse forêt parsemée de zones marécageuses, les habitants de ces régions n'étaient pas en première ligne lors des événements $\mathrm{du}$ début du siècle ${ }^{260}$. Les chroniques latines ou allemandes les appellent "Letouwen», "Lethwini» ou "Letthones» ${ }^{261}$. Dans les bulles papales, leur pays est nommé "Lectovia»" ${ }^{262}$ "Luthowia» ${ }^{263}$ : ce sont les Lituaniens. Dès le milieu du $\mathrm{XI}^{\mathrm{e}}$ siècle, ils affrontent les princes de la Rus' kiévienne ${ }^{264}$. La Geste du Prince Igor, épopée du XII ${ }^{\mathrm{e}}$ siècle, mentionne le prince russe Iziaslav de Polotsk (m. v. 1185), tombé en les affrontant ${ }^{265}$. Pour Henri de Livonie, ils sont "les seigneurs de tous les peuples, autant chrétiens que païens, qui habitent dans ces pays" ${ }^{266}$. Se basant sur la narration du chroniqueur, Kristina Markman parle même d'un "état prédateur» lituanien ${ }^{267}$. Un point de vue qui semble correspondre à une certaine réalité, même si, cette auteure le reconnaît elle-même dans sa thèse ${ }^{268}$, les chroniqueurs proches des ordres militaires avaient tendance à exagérer la puissance de l'ennemi. C'est en tout cas parmi eux que s'organise au début du $\mathrm{XIII}^{\mathrm{e}}$ siècle la seule forme étatique balte viable sur une longue durée, ce qui paraît avoir considérablement renforcé leur capacité de résistance à la christianisation et aux invasions pendant plus de 150 ans.

L'historiographie explique l'émergence d'un État lituanien par plusieurs facteurs: aux considérations anciennes sur la défense face aux menaces d'invasion venues de l'Ouest s'ajoute l'attention portée plus récemment à l'émergence d'un pouvoir guerrier, résultant de l'importance prise par les raids en terres ruthènes et de la nécessité de les coordonner plus efficacement ${ }^{269}$. Quoi qu'il en soit, des traités passés entre des princes

\footnotetext{
260 S. C. Rowell, Lithuania Ascending..., p. 289-290.

${ }^{261}$ Skarbiec..., I, p. 36.

262 Id.

263 Vetera monumenta Poloniae et Lithuaniae ..., éd. A. Theiner, vol. 1, Rome 1860, doc. 105, p. 50, cité par M. Hellmann, «Die Päpste und Litauen», dans La Cristianizzazione della Lituania. Atti del Colloquio internazionale di storia ecclesiastica in occasione del 6 centenario della Lituania cristiana (1387-1987). Roma, 24-26 giugno 1987, Vatican 1989, p. 40.

264 Skarbiec..., I, p. 37-38.

${ }^{265}$ La Geste du Prince Igor, trad. C. Pighetti, Paris 2005, p. 55.

266 Henri de Livonie, Heinrichs Livländische Chronik..., XIII, 4, p. 69. D'autres mentions des Lituaniens ("Litwini») dans les sources sont recensées par I. Danilowicz, Skarbiec..., I, p. 47 passim. ${ }^{267}$ K. Markman, «Tactics of Manipulation: A Revisionist Study of Gediminas and the Threat of Teutonic Invasion, 1315-1342», Comitatus 42, 2011, p. 120.

${ }^{268}$ K. Markman, Between Two Worlds: A Comparative Study of the Representations of Pagan Lithuania in the Chronicles of the Teutonic Order and Rus', Los Angeles 2015 (thèse de doctorat non publiée), p. 80-92.

269 S. C. Rowell, Lithuania Ascending..., p. 289-292. M. GŁadysz, The Forgotten Crusaders..., p. 176-177 note qu'un processus similaire est accepté dans le cas de la Prusse par l'historiographie
} 
russes et lituaniens dans la seconde décennie du XIII ${ }^{\mathrm{e}}$ siècle indiquent que ces derniers avaient déjà atteint une certaine importance sur la scène politique régionale ${ }^{270}$. La Lituanie est sérieusement confrontée à l'expansion des ordres militaires lors de l'expédition lancée de Livonie en 1236, qui se termine par l'anéantissement des Porte-Glaives à la bataille de Saule. La pression militaire, politique et sociale exercée par les arrivants catholiques sur les populations baltes voisines des Lituaniens pousse un certain nombre de Prussiens, de Coures et de Sémigalliens à fuir vers la Lituanie, linguistiquement, géographiquement et culturellement voisine, qui les assimile rapidement ${ }^{271}$. Relativement isolé, le pays n'est pas directement menacé par les hordes mongoles. Emmené par une élite de guerriers parmi lesquels émergent quelques dirigeants à la poigne de fer, le jeune État lituanien peut se développer sans trop d'encombres.

Parmi les princes les plus ambitieux se trouve un certain Mindaugas, qui, recourant autant à la force qu'à la conciliation, entreprend de regrouper les divers clans autour d'un pouvoir central ${ }^{272}$. La Lituanie a désormais à sa tête un dirigeant unique, appelé en français moderne grand-duc (Kunigaiksttis ou didysis Kunigaikstis, parfois "grand-prince»). Mindaugas intègre les territoires orthodoxes déjà ciblés par les raids de ses prédécesseurs à l'ensemble politique qu'il est en train de constituer ${ }^{273}$. Souhaitant confirmer son autorité par un titre royal, il traite avec l'Ordre teutonique, qui accepte de négocier une couronne pour lui en échange de son baptême $(1251)^{274}$. Deux ans plus tard, l'évêque de Chełmno couronne Mindaugas roi de Lituanie, avec la bénédiction d'Innocent IV. Celui-ci a été informé des intentions du prince par un ambassadeur lituanien, qui a probablement voyagé jusqu'en Italie accompagné de membres de l'Ordre teutonique ${ }^{275}$. Le pape s'empresse alors d'écrire aux évêques des provinces baltes pour leur enjoindre de soutenir Mindaugas dans

polonaise récente; sur le rôle des pillages en Russie dans l'émergence du pouvoir lituanien, H. Paszkiewicz, The Origin..., p. 192; il met toutefois en garde contre une interprétation trop littérale des sources latines et russes, fortement biaisées (p. 186-187). Sur le caractère «impérial» de la Lituanie médiévale, Z. Norkus, "Grand Duchy of Lithuania: A Comparative Historical Sociology Retrospective", World Political Science Review, 3/4, 2007, p. 1-41; A. NikžEnTaitis, "The "Imperial" Diplomacy of Lithuania ", Lithuanian Foreign Policy Review, 2004, n" 1-2 (13-14), p. 41-47.

270 Z. Kiaupa, The History of Lithuania..., p. 28; H. Paszkiewicz, The Origin..., p. 196.

${ }^{271}$ N. Blomkvist, Discovery..., p. 171 ; G. Ротаšenko, Multinational Lithuania. History of Ethnic Minorities, Vilnius 2008, p. 21-22; Z. KIAUPA, The History of Lithuania..., p. 42.

272 H. Paszkiewicz, The Origin..., p. 199; M. Hellmann, «Die Päpste und Litauen... », p. 36-46. 273 J. KŁoczowski (dir.), Histoire religieuse..., p. 108; H. Paszkiewicz, The Origin..., p. 192 sq.

${ }^{274}$ En s'adressant à l'Ordre teutonique pour obtenir une couronne, Mindaugas entendait doubler un prince rival qui avait eu la même idée, mais s'était tourné vers l'archevêque de Riga: R. MAŽEIKA, "Bargaining... », p. 131-132; Z. Kiaupa, The History of Lithuania..., p. 28-38.

275 Vetera monumenta..., vol. 1, doc. 102, p. 49. 
son entreprise, et rappelle que ses droits et son pouvoir doivent être respectés ${ }^{276}$. Au principal intéressé, il écrit pour le féliciter et lui faire part de sa protection ${ }^{277}$.

Une cathédrale est fondée sur le site de l'actuelle Vilnius ${ }^{278}$, et un membre livonien de l'Ordre teutonique est désigné pour occuper le siège épiscopal créé pour le jeune diocèse de Lituanie ${ }^{279}$. Toutefois, même si les lettres pontificales mentionnent le baptême d' "une nombreuse multitude de pä̈ens» ${ }^{280}$, la christianisation semble, dans les faits, n'avoir concerné que la personne du roi et quelques-uns de ses partisans. De plus, Rome est loin de la Baltique, et les querelles de pouvoir reprennent vite le dessus ${ }^{281}$. En 1261, Mindaugas prend les armes contre l'Ordre teutonique et s'allie aux Prussiens révoltés, avant d'être assassiné deux ans plus $\operatorname{tard}^{282}$. C'en est fini, pour le moment, de la christianisation de la Lituanie: la cathédrale bâtie par le malheureux roi est détruite ${ }^{283}$. Avec la soumission de la Prusse à l'Ordre en 1283, quand le chef jatvingien Skomantas accepte le baptême en échange d'une importante donation $^{284}$, le dernier adversaire païen des croisés baltes est désormais le grandduché de Lituanie, où une nouvelle dynastie ne tarde pas à émerger ${ }^{285}$.

Dans les premières décennies du $\mathrm{XIV}^{\mathrm{e}}$ siècle, le grand-duc Vytenis ${ }^{286}$, et surtout son frère Gediminas, profitent de la situation difficile de l'Ordre

276 Ibid., doc. 101, p. 49. Les autres lettres d'Innocent IV concernant le baptême de Mindaugas sont publiées dans ibid., doc. 102-106. p. 49-51. Voir aussi J. Muldoon, Popes, Lawyers..., p. 32-33; R. Mažeıra, «When Crusader... », p. 200 ; M. Hellmann, «Die Päpste und Litauen... », p. 39.

277 Vetera monumenta..., vol. 1, doc. 102, p. 49.

278 A. KajaCKas, "Archeological Investigations of Vilnius Cathedral», dans La Cristianizzazione della Lituania..., p. 270-272. L'importance de l'actuelle Vilnius dans la religiosité lituanienne date probablement d'avant l'époque de Mindaugas: S. C. Rowell, Lithuania Ascending..., p. 132 sq.

279 R. MAžEıKA, "When Crusader...", p. 206-7.

280 "cum numerosa multitudine paganorum", Vetera monumenta..., vol. 1, doc. 102, p. 49.

R. MažEıKa considère cette formule comme "an expression of pious desire» ("When Crusader...", p. 206).

281 Ibid., p. 206-209; J. Muldoon, Popes, Lawyers..., p. 33.

${ }^{282}$ Mindaugas est très certainement tombé sous les coups de rivaux lituaniens, qui s'appuyaient sur le parti païen de la noblesse; sur les événements des années 1250-1260, Z. Kiaupa, J. KiaupienĖ, A. Kuncevičrus, The History of Lithuania before 1795..., p. 62-66; R. MažEIKA, "Bargaining... », p. 132.

${ }^{283}$ R. MAŽEIKA, «When Crusader...", p. 213.

${ }^{284}$ H. Samsonowicz, "L'ordre des Chevaliers teutoniques...», p. 679-680; S. Gouguenheim, Les Chevaliers teutoniques..., p. 413.

285 Sur ces événements, S. C. Rowell, Lithuania Ascending..., p. 51-52; Z. Kiaupa, J. Kiaupienė, A. Kuncevičius, The History of Lithuania before 1795..., p. 64-71, 111-112; H. Paszkiewicz, The Origin..., p. 199-203.

${ }^{286}$ Jusqu'au règne éphémère de Mindaugas II (juillet-novembre 1918), plus aucun dirigeant de la Lituanie ne sera couronné roi selon les normes de l'Europe catholique. Gediminas comme ses successeurs portent donc le titre de kunigaikstis, le plus souvent traduit par "grand-duc" ou "grandprince», et leur État est appelé dans l'historiographie "Grand-Duché de Lituanie», même si le titre «Rex» est fréquemment utilisé dans la correspondance diplomatique et les sources narratives avant le $\mathrm{Xv}^{\mathrm{e}}$ siècle. Voir H. Paszkiewicz, The Origin..., p. 218, n. 5. 
teutonique pour se constituer un réseau d'alliances, et s'insèrent ainsi dans la politique internationale européenne. Au tournant du $\mathrm{XIV}^{\mathrm{e}}$ siècle, la situation des ordres religieux-militaires est rendue précaire par l'affermissement des États d'Europe et par la chute de Saint-Jean-d'Acre, qui sonne la fin des principautés latines du Levant $(1291)^{287}$ : on connaît le sort fait aux Templiers par le roi de France Philippe le Bel. Les Teutoniques établissent pour un temps leur capitale à Venise, ce qui laisse entendre que la défense de la Terre sainte n'est pas abandonnée. Mais dans les faits, la Baltique est bien leur préoccupation principale $^{288}$. En septembre 1309, le grand-maître Siegfried de Feuchtwangen déplace le siège de l'Ordre à Marienbourg (actuellement Malbork en Pologne), une puissante forteresse construite en Prusse à la fin du XIII ${ }^{\mathrm{e}}$ siècle $^{289}$.

La position de l'Ordre teutonique est contestée par l'archevêque de Riga, Frédéric de Pernstein, et le duc de Coujavie, Ladislas le Bref, maître d'une Pologne réunifiée ${ }^{290}$. Plusieurs procès, intentés par Riga (1310-1312) et la Pologne (1320-1321, puis 1339) viennent mettre à mal la position internationale des Chevaliers ${ }^{291}$. Des légats sont dépêchés sur place, des tribunaux convoqués, mais les sentences en demi-teinte ne permettent pas de trouver de solutions viables aux conflits, qui resteront encore latents au moins jusqu'à la paix de Kalisz, entre l'Ordre et la Pologne (1343) ${ }^{292}$. Alors que l'archevêque, réfugié à Avignon, tente de défendre ses droit face aux Teutoniques, le duc puis roi de Pologne Ladislas et son fils Casimir cherchent à arrêter l'expansion de l'Ordre en Poméranie orientale ${ }^{293}$. La lutte pour le contrôle du territoire se double d'une

287 Sur ce qui suit, E. Christiansen, The Northern Crusades..., p. 146-151; N. Housley, The Later Crusades..., p. 325-326; Idem, The Avignon papacy and the Crusades, Oxford 1986, p. 266-280; M. Aurell, Des chrétiens contre les croisades, Paris 2013, p. 338-344.

${ }^{288}$ La faction «balte» s'était opposée à ceux qui, parmi les Teutoniques, préféraient essayer de reprendre la Terre sainte; profitant des événements politiques et bénéficiant de l'appui du grandmaître Siegfried de Feuchtwangen, les premiers l'ont emporté: K. Militzer, "The Teutonic Knights...", p. 78-81; S. Lotan, "The Teutonic Knights...», p. 321.

289 PR 1, p. 24; R. Wenskus, «Das Ordensland Preußen als Territorialstaat des 14. Jahrhundert», dans H. Patze (dir.), Der deutsche Territorialstaat im 14. Jahrhundert, Sigmaringen 1970, vol. 1, p. 347-382.

290 P. Knoll, The Rise..., p. 14-41 ; N. Housley, The Avignon papacy..., p. 279-280.

291 S. Gouguenheim, «Le procès pontifical de 1339 contre l'Ordre teutonique», Revue historique 647/3, 2008, p. 567-603; K. Górski, A. Toмczak, Polska-Francja: dziesiec wieków zwiazków politycznych, kulturalnych i gospodarczych, Varsovie 1983, p. 21-22. Pour les documents du procès d'Inowrocław (1320-1321), voir Lites ac res gestae inter Polonos ordinemque Cruciferorum, éd. H. Chłopocka, Varsovie 1970; pour celui de Varsovie (1339), Lites ac res gestae inter Polonos Ordinemque Cruciferorum, éd. I. Zakrzewski, J. Karwasinska, Poznań 1890, vol. 1.

${ }^{292}$ Le 18 juillet 1312, le légat François de Moliano excommunie les membres de l'Ordre en Prusse et en Livonie; l'excommunication est toutefois levée en mai de l'année suivante. Les procès de 1321 et 1339 furent gagnés par la Pologne, mais les Teutoniques refusèrent de reconnaître la sentence (prononcée par des juges favorables à la cause polonaise), et le pape se garda de la confirmer: S. Gouguenheim, Les Chevaliers teutoniques..., p. 514-520.

${ }^{293}$ L'Ordre teutonique achète au margrave Valdemar de Brandebourg ses droits sur la région (Pommersches Urkundenbuch, éd. G. Winter, Szczecin 1903, vol. 4/2, doc. 2550, p. 380), achat 
stratégie visant à contester aux Teutoniques le rôle symbolique de bouclier contre les infidèles en Europe du Nord-Est. La confrontation avec les Mongols a fait apparaître la Pologne comme l'un des principaux «avant-postes» de la Chrétienté latine, ce qui est parfois interprété dans l'historiographie polonaise comme ayant donné au pays une fonction de «rempart de l'Occident» devant protéger la Chrétienté et répandre la foi du Christ auprès des infidèles ${ }^{294}$. Un point de vue qui semble avoir été utilisé par les maîtres du pays dès l'époque médiévale; la dévastation de la Pologne et de la Hongrie par les Mongols en 1241 étant relatée par Vincent de Beauvais et Matthieu Paris, on sait qu'un écho de ces événements était parvenu en France et en Angleterre, notamment par voie épistolaire ${ }^{295}$.

Lorsque les nobles et les prélats réunis en mars 1318 à Sulejów décident d'exhorter Jean XXII à restaurer la royauté polonaise et à en donner la couronne à Ladislas, ils ne manquent pas de rappeler le rôle de la Pologne dans la défense et la propagation de la foi ${ }^{296}$. Comme l'indique l'historien Henryk Samsonowicz, "[Ladislas] le Bref n'était alors en guerre ni contre la Lituanie pä̈enne ni contre la "Rus" orthodoxe; la justification de la pétition n'était ainsi qu'un procédé diplomatique, mais elle indiquait l'orientation des élites dirigeantes dans la politique

confirmé par l'empereur Henri VII dans une lettre du 12 juillet 1311 (Quellen..., doc. 18, p. 132-135). Un épisode célèbre de cette lutte est la capture de Gdańsk par les Teutoniques, en novembre 1308. Le pape Clément V dit, dans une lettre à l'archevêque de Brême, avoir entendu que l'Ordre y aurait tué 10000 personnes (Vetera monumenta..., vol. 1, doc. 204, p. 121); un chiffre exagéré selon S. Gouguenheim, Les Chevaliers teutoniques..., p. 516; P. Knoll, The Rise..., p. 28-31.

${ }^{294}$ J. Tazbir, "The Bullwark Myth», Acta Poloniae Historica 91, 2005, p. 73-97; P. Knoll, "Poland as "Antemurale Christianitatis" in the Late Middle Ages", The Catholic Historical Review 60/3, 1974, p. 381-401. Citons deux exemples dans l'historiographie francophone: T. WYrWA, La pensée politique polonaise à l'époque de l'humanisme et de la Renaissance: un apport à la connaissance de l'Europe moderne, Paris-Londres 1978, p. 40-41: "Désormais, la Pologne, après sa première bataille livrée contre les hordes orientales en 1241, considéra que sa mission était de défendre l'Europe chrétienne contre le danger de l'Est. [...] Ce rôle de défendre la Chrétienté laissa une empreinte souvent décisive sur la pensée politique polonaise, et ce au cours de tous les siècles de son existence». Autre exemple, l'historien Valérien Meysztowicz a intitulé un chapitre de son livre La Pologne dans la Chrétienté, 966-1966, Paris 1966, "La défense de l'Occident (1241-1683)", faisant correspondre la bataille de Legnica à l'épisode où Vienne est délivrée des Turcs par une coalition placée sous les ordres du roi de Pologne Jean III Sobieski.

${ }^{295}$ G. G. Guzman (cf. p. 98 note 24), "The encyclopedist Vincent de Beauvais and his Mongol extracts", Speculum 49, 1974, p. 287-307; Matthieu Paris, Grande chronique, trad. A. HuillardBréholles, Paris 1840, vol. 5, p. 143-161; le chroniqueur anglais fait référence aux lettres parvenues d'Europe centrale, notamment à celles de Frédéric II Hohenstauffen. A. GrabsKI, «La Pologne ... », p. 41-42; Idem, Polska w opiniach Obcych..., p. 309-314; P. HlavaceK, "A Reflection... », p. 133; N. Berend et al., Central Europe..., p. 443-448.

296 Ibid., p. 37-38; A. Grabski, «La Pologne ...», p. 41. La lettre de Jean XXII qui répond aux nobles et prélats polonais concernant le couronnement de Ladislas Le Bref est éditée dans Codex diplomaticus maioris Poloniae, vol. 2, éd. J. Kraszewski, W. Lebinski, Poznań 1878 (ci-après: CDMP), doc. 1013, p. 350-351. 
européenne» ${ }^{297}$. La double fonction alors revendiquée par la Pologne n'est probablement pas sans rapport avec le conflit contre l'Ordre teutonique, que l'on sait fermement ancré dans ce rôle ${ }^{298}$; la stratégie aurait visé à faire entendre au pape que le royaume restauré devait être amené à remplacer la vieille corporation de moines-soldats comme bastion du catholicisme ${ }^{299}$. Peut-être moins convaincu par cet argument que par le poids des alliances politiques, Jean XXII accorde son soutien à Ladislas, qui est couronné roi de Pologne en $1320^{300}$. La position difficile de l'Ordre teutonique incite le grand-duc Vytenis (m. env. 1316) à se rapprocher de Riga en fournissant une garnison lituanienne à la ville ${ }^{301}$. Son frère et successeur Gediminas continue de collaborer avec les hommes de l'archevêque, tout en se rapprochant de la Pologne. En dépit de sa posture de champion du christianisme en Europe orientale, Ladislas n'hésite pas à marier son fils et héritier Casimir à la fille de Gediminas, baptisée sous le nom d'Anne ${ }^{302}$.

C'est dans ce contexte que le grand-duc Gediminas écrit à Jean XXII, aux villes marchandes d'Allemagne du Nord et aux Franciscains et Dominicains de Saxe, entre 1322 et $1324^{303}$. Une lettre a même été préparée pour être copiée et envoyée "aux villes aussi loin que Rome», mais elle semble avoir été détruite peu après avoir atteint Riga ${ }^{304}$. Ces missives sont signées «Gedeminne

${ }^{297}$ H. Samsonowicz, «Histoire de l'Europe...", p. 104-105.

298 A. Grabski, "La Pologne ... », p. 42; N. Housley, The Avignon papacy..., p. 280. L'argument faisant de l'Ordre teutonique un bouclier de l'Église et de la foi est notamment utilisé par ses défenseurs lors des procès intentés par l'archevêque de Riga dans les années 1310; Das Zeugenverhör des Franciscus de Moliano (1312), éd. A. Seraphim, Königsberg 1912, p. 175-178.

299 J. KŁoczowski, "Les pays d'Europe du Centre-Est du XIV au Xvir e siècle», dans N. Aleksiun et al., Histoire de l'Europe du Centre-Est..., p. 171. Sur l'utilisation du concept d' "antemurale Christianitatis» dans le discours royal, N. Berend, "Défense de la Chrétienté et naissance d'une identité. Hongrie, Pologne et péninsule Ibérique au Moyen Âge ", Annales. Histoire, Sciences Sociales 58/5, 2003, p. 1009-1027.

300 W. Авraнam, "Staniwisko Kurii papiejskiej wobec koronacji Lokietka», Ksiega pamiatkowa wydana przez Uniwersytet lwowski ku wzczeniu 500-letniego jubileuszu Uniwersytetu krakowskiego, Lwow 1900, p. 1-34 cité par P. Knoll, The Rise..., p. 38-39.

301 S. C. Rowell, Lithuania Ascending..., p. 57-58; R. Petrauskas, «La formation du Grand Duché aux XIII ${ }^{e}$ et XIV ${ }^{e}$ siècles", dans Y. Plasseraud (dir.), Histoire de la Lituanie..., p. 60-61.

${ }^{302}$ P. Knoll, The Rise..., p. 47. Sur la politique matrimoniale de Gediminas, S. C. Rowell, "Pious Princesses or the Daughters of Belial: Pagan Lithuanian Dynastic Diplomacy, 1279-1423", Medieval Prosopography 15/1, 1994, p. 3-79.

303 Sur l'épisode dit des lettres de Gediminas, voir notamment R. MAŽEıKA, "Bargaining...", p. 131-145; K. Markman, "Tactics...", p. 115-133; Chartularium Lithuaniae res gestas magni duci Gedeminne illustrans, éd. S. C. Rowell, Vilnius, 2003, p. 365-401; S. C. RowelL, «The Letters of Gediminas: "Gemachte Lüge"? Notes on a Controversy ", Jahrbücher für Geschichte Osteuropas. Neue Folge 41/3, 1993,", p. 321-360; Id., Lithuania Ascending..., p. 189-228; R. MAžEIKA, S. C. Rowell, "Zelatores Maximi: Pope John XXII, Archbishop Frederick of Riga and the Baltic Mission 1305-1340», Archivum Historiae Pontificiae 31, 1993, p. 33-68; M. Hellmann, "Die Päpste und Litauen...", p. 46-51.

304 S. C. Rowell, "The Letters...", p. 326-328. Pour une discussion de la chronologie habituellement admise (1322-1324), Ibid., p. 352-353; Chartularium..., p. 370-375. Les lettres 
Dei gratia Letwinorum et multorum Ruthenorum rex» ${ }^{305}$, une formule faisant sans doute référence à l'expansion lituanienne sur les terres de la Rus' kiévienne (Kiev est prise en 1321), qui a fait passer sous la domination des grands-ducs une population orthodoxe numériquement et culturellement très importante ${ }^{306}$. L'intitulé "Dei gratia", quant à lui, indique la volonté de ce prince non baptisé d'être reconnu comme souverain en Lituanie ${ }^{307}$, alors que le terme "roi" était fréquent dans la correspondance diplomatique lituanienne avant que le titre de "Magnus Dux» ne remplace celui de "Rex» $\mathrm{au} \mathrm{XV}^{\mathrm{e}}$ siècle $^{308}$. Le but premier de ces lettres est d'inviter les Occidentaux à venir découvrir la capitale du grand-duché, Vilnius, où les chrétiens de confession catholique comme orthodoxe sont les bienvenus, et parfois chargés de missions importantes à la cour; des franciscains sont notamment employés comme scribes par le grand-duc ${ }^{309}$. L'autre objectif visé par l'envoi des lettres est de se mettre à l'abri des raids teutoniques en négociant directement avec le pape pour une éventuelle conversion.

Dans sa première lettre (1322), le grand-duc accuse notamment les Teutoniques de retarder le baptême de son peuple par toutes sortes de machinations, y compris en s'en prenant à l'archevêque Frédéric de Riga et à ses

sont éditées dans Ibid., et Gedimino Laiskai, éd. V. Pašuto, I. Stal', Vilnius 1966 (ci-après: GL). La phrase "usque Romam» rappelle une formule utilisée dans les textes russes de la même époque, qui signifiait "jusqu'aux confins de la Chrétienté»; c'est sans doute dans ce sens qu'il faut la comprendre dans cette lettre du grand-duc (Chartularium..., p. 372).

305 Par exemple, GL, p. 23, 29, 37, cité par S. C. Rowell, "The Letters...», p. 343.

${ }^{306}$ Lors de l'expansion lituanienne sur les principautés de l'ancienne Rus', les Lituaniens ne bouleversent pas les traditions politiques, religieuses et sociales ruthènes et ne demandent qu'une participation militaire aux entreprises dirigées par le grand-duc. Une bonne partie de l'historiographie souligne ainsi que les Lituaniens étaient préférés aux Tatars, plus durs et sans cesse divisés entre plusieurs factions rivales (ce qui impliquait une certaine insécurité); ainsi, M. Heller, Histoire de la Russie et de son empire, Paris 1997, p. 118, Z. Kiaupa, The History of Lithuania..., p. 43-47, H. Paszkiewicz, The Origin..., 221; A. Bohdanowicz, "La Horde d'Or, la Pologne et la Lituanie (1242-1430)", Revue Internationale d'Histoire Politique et Constitutionnelle, Nouvelle Série 19-20, 1955, p. 192; F. Dvornik, Les Slaves..., p. 545-547 et N. Riasanovsky, Histoire de la Russie, Paris 1994, p. 149-150. À ce sujet, W. Urban, Tannenberg..., p. 10, avance que les ducs lituaniens partageaient l'essentiel des valeurs des nobles et bourgeois ruthènes. D. Beauvois («Les controverses...», p. 648-649) mentionne toutefois qu'une partie de l'historiographie russe - courants «slavophile» puis « eurasiste» - voit l'influence mongole comme positive, et au contraire se montre hostile à l'Occident, représenté notamment par la Pologne et la Lituanie.

307 K. Markman, «Tactics...», p. 115; S. C. Rowell, «The Letters... », p. 344.

308 Ibid., p. 343-345; H. Paszkiewicz, Origin, p. 218, n. 5. L'usage du titre de «rex» et de la formule "Dei gratia" par un souverain païen qui n'a pas été couronné selon les normes catholiques peut aussi, propose S. C. Rowell, trahir une imitation par le scribe du style diplomatique occidental, notamment des formules utilisées dans la correspondance de Mindaugas et dans les bulles papales (Chartularium..., p. 396-397).

309 R. Petrauskas, «La formation du Grand Duché...», p. 65; S. C. Rowell, "The Letters...», p. 339-341. 
hommes ${ }^{310}$. La similitude entre ces accusations et celles que l'on rencontre dans d'autres rapports visant les activités des ordres militaires baltes, notamment dans le cadre des procès intentés par le même archevêque, pourrait laisser penser qu'il y a eu connivence entre Gediminas et Frédéric ${ }^{311}$. Les Chevaliers teutoniques eux-mêmes ont accusé l'archevêque d'avoir forgé ces lettres pour leur nuire ${ }^{312}$; une interprétation encore défendue en 1955 par l'historien allemand Kurt Forstreuter ${ }^{313}$. Or, pour le meilleur spécialiste actuel du grand-duc, Stephen C. Rowell, le Lituanien devait bien être à l'origine de l'entreprise. Le rôle joué par Riga n'aurait été que celui de messager, puisque la ville a accepté de transmettre les missives de son allié à leurs destinataires ${ }^{314}$.

La campagne du grand-duc s'inscrit de fait dans un conflit beaucoup plus large, opposant le pape Jean XXII à l'empereur Louis de Bavière ${ }^{315}$. En 1317, le grand-duc avait reçu une lettre du pape, qui enjoignait aux princes de Lituanie et de Ruthénie d'accepter le christianisme romain ${ }^{316}$. Cinq ans plus tard, Gediminas donne une réponse favorable; l'idée semble lui être finalement venue de se rapprocher des partisans du pape que sont la Pologne et Riga ${ }^{317}$. En 1323, une paix est signée et entre temps, le Lituanien écrit une deuxième fois au pape, qui en informe le roi de France Charles IV ${ }^{318}$. En juin 1324, Jean XXII répond à Gediminas et lui annonce que des légats seront bientôt dépêchés ${ }^{319}$. Agacé par le soutien des Teutoniques à Louis de Bavière, le pape leur interdit toute action pouvant faire échouer le baptême ${ }^{320}$. En septembre 1324, les bénédictins français Barthélemy, évêque d'Alet et Bernard, abbé de Saint-Chaffré du

310 GL, p. 23. Pour une traduction en anglais de la lettre envoyée à Jean XXII, voir W. URBAn, The Samogitian Crusade, Chicago 1989 p. 70-71.

311 Par exemple, le témoignage du dominicain de Riga Nicolas Berca, interrogé lors de la légation de Francis de Moliano en 1311-1312: Das Zeugenverhör..., p. 100.

312 L'accusation est mentionnée dans une lettre adressée par Riga à Lübeck; GL, doc. 15, p. 147;

S. C. Rowell, "The Letters...", p. 332-334.

${ }^{313}$ K. Forstreuter, «Die Bekehrung des Litauerkönigs Gedimin», Jahrbuch der AlbertusUniversität, 6 (1955), p. 142-158; pour un survol historiographique de la question, S. C. RowelL, "The Letters...", p. 345-351.

314 Ibid., p. 340.

315 K. Markman, "Tactics...», p. 121-122.

316 S. C. Rowell, "The Letters...", p. 334-335. S. C. Rowell remarque que certaines lettres sont composées selon le modèle de celles envoyées aux princes orthodoxes (Chartularium..., p. 386). Les missives adressées au pape ont sans doute été écrites par des franciscains qui travaillaient comme secrétaires à la cour du grand-duc, mais en suivant les instructions de ce dernier, à l'aide d'un interprète (S. C. RowelL, «The Letters... », p. 339-341).

317 K. Markman, «Tactics... », p. 122; S. Gouguenheim, «Le Procès...», p. 570.

318 GL, doc. 10, p. 84-85; Chartularium..., doc. 28, p. 92-93.

319 Vetera monumenta..., vol. 1, doc. 293-295. p. 193-195; Ibid., doc. 290, p. 190-192.

320 Vetera monumenta..., vol. 1, doc. 296, p. 196. Voir aussi J. Muldoon, Popes, Lawyers..., p. 88; J. Richard, «Les Papes d'Avignon et l'évangélisation du monde non-latin à la veille du grand schisme", dans Genèse et début du grand schisme d'Occident, Paris 1980, p. 305-315. T. TANASE, "L'Universalisme romain...", p. 590, note que Gediminas s'est surtout adressé à Jean XXII comme à un «arbitre des souverains chrétiens». 
Puy, arrivent à Riga. Ils dépêchent des envoyés à Vilnius, qui rencontrent le grand-duc au cours du mois de novembre ${ }^{321}$. Coup de théâtre: Gediminas, qui confirme le reste du contenu de ses lettres, met en scène son refus du baptême en évoquant le comportement des Chrétiens ${ }^{322}$ - de ses ennemis teutoniques du moins: "où trouve-t-on plus d'injustice, d'iniquité, de violence, de malhonnêteté et d'avidité que chez les chrétiens, et surtout chez ceux qui paraissent pieux, comme par exemple chez les croisés [cruciferi, c'est-à-dire les Chevaliers teutoniques] „323.

Les auteurs du rapport racontent s'être livrés, en marge des rencontres officielles, à une véritable enquête. Il en ressort que les Teutoniques auraient incité des nobles de Samogitie, province stratégique mais relativement indépendante par rapport à Vilnius, à menacer le grand-duc de rébellion si celui-ci devait accepter le baptême; qui plus est, les Ruthènes orthodoxes auraient joint leurs menaces à celles des Samogitiens. Le rapport se clôt par un témoignage racontant que le grand-duc pleura pendant la nuit après son entretien avec les délégués, ce qui indiquerait qu'au fond de lui-même, il désirait le baptême mais ne pouvait l'accepter à cause des menaces qui pesaient sur son pays $^{324}$. L'image, toute littéraire qu'elle puisse être, ne pouvait qu'éveiller un peu de sympathie chez le lecteur.

Rien n'empêche de penser que le grand-duc ait, dans un premier temps, envisagé de recevoir le baptême et de faire de la Lituanie un royaume chrétien, et que s'étant rendu compte qu'une conversion mettrait son pouvoir en danger sans lui apporter la paix avec les Teutoniques, il se soit rétracté; mais une autre explication est proposée par Stephen C. Rowell ${ }^{325}$. D'après l'historien anglais, Gediminas aurait volontairement demandé à son scribe d'utiliser un ton ambigu pour capter l'attention de ses lecteurs tout en évitant de trop s'engager dans la voie d'une éventuelle conversion ${ }^{326}$. En feignant d'être sur le point de se convertir puis en se rétractant à la dernière minute, le souverain lituanien avait un atout dans les relations diplomatiques: mettre la conversion de tout un peuple dans la balance permettait d'entamer des négociations au moment

321 Ce qui suit est reporté par le rapport des délégués papaux sur l'entrevue de Vilnius, inclus dans GL, p. 116-145. Voir aussi R. MAŽEIKA, «Bargaining...», p. 133-134; S. C. Rowell, Lithuania Ascending..., p. 222-3.

322 S. C. Rowell, "The Letters...», p. 337. Les envoyés précisent bien que le roi donna une audience devant une vingtaine de ses conseillers, "quod nobis multum displicuit, quia sperauimus ipsum solum invenire» (GL, p. 123).

323 Ibid., p. 129.

324 GL, p. 145.

325 S. C. Rowell, Lithuania Ascending..., p. 195 sq.

326 Ibid., p. 196-197. L'explication de S. C. Rowell repose notamment sur l'interprétation ambiguë de la phrase "fidem catholicam recipere» (GL, p. 27), qui aurait pu être compris comme "tolérer» autant que comme "recevoir" la foi catholique. Après que le grand-duc ait assuré aux envoyés des légats qu'il n'a jamais voulu que le souhait de son baptême figure dans la lettre, ceux-ci ont interrogé le scribe et le traducteur, qui ont tous deux soutenus que c'est bien ce qu'avait demandé le grand-duc (Ibid., p. 139 sq.). 
opportun, quitte à les abandonner par la suite ${ }^{327}$. Il était donc peu tentant de sacrifier cet immense avantage en devenant définitivement chrétien ${ }^{328}$, d'autant que le grand-duc devait être conscient qu'adopter une politique de christianisation n'allait pas sans danger ${ }^{329}$. Toutefois, les envois répétés au pape montrent que cette démarche était constante et parfaitement assumée ${ }^{330}$; pour Stephen C. Rowell, les lettres de Gediminas sont à considérer comme le chef d'œuvre d'un diplomate extrêmement doué, qui a su "manipuler la diplomatie chrétienne pour défendre un royaume multiconfessionnel, pluriethnique, de l'attention de ses voisins et persuader les chrétiens catholiques et orthodoxes qu'il était sûr de vivre et de prospérer dans le grand-duché païen de Lituanie»"331. Une politique de "quasi-conversion" qui deviendra presque une constante dans l'histoire lituanienne, jusqu'à la date de $1387^{332}$. En outre, utiliser le vocabulaire de la conversion n'était pas une exclusivité lituanienne; la lettre «mongole» reçue par Louis IX de France en 1248 pouvait laisser entendre que l'immense empire était sur le point de se convertir, alors qu'elle n'émanait que d'un général proposant une alliance momentanée contre les puissances musulmanes ${ }^{333}$.

Si l'on peut suivre l'avis de Stephen C. Rowell, doit-on en déduire que les auteurs du rapport ont été bernés par le rusé souverain? Ou peut-on imaginer que ces émissaires, vraisemblablement Rigiens et donc hostiles aux Teutoniques, auraient intentionnellement biaisé leurs notes? Il semble que ceux-ci aient essayé de sauver ce qui pouvait l'être de la réputation du grand-duc, en ne le dépeignant pas en manipulateur, mais en prince bien disposé quoique malchanceux. En ce qui concerne la manière dont l'Ordre teutonique est décrit dans le rapport, il y a tout lieu de croire que les auteurs devaient être au courant des sentiments du pape vis-à-vis de celui-ci; du reste, rien n'interdit de penser que les manigances qu'on lui prête ont bien eu lieu. Si Gediminas

\footnotetext{
327 Voir notamment R. MAŽEIKA, «Bargaining... », p. 131-145.

328 S. C. Rowell, "The Letters...", p. 338-339.

329 R. MAŽEIKA, «Bargaining....", p. 134.

330 S. C. Rowell compte trois lettres envoyée par Gediminas à Jean XXII, dont deux nous sont parvenues; le rapport des légats mentionne une première tentative d'envoi, avortée par le fait que les Teutoniques se seraient saisis des messagers, ce qui explique que l'on a dû faire appel à Riga pour transmettre les lettres (GL, p. 133-135).

331 S. C. Rowell, "The Letters...», p. 354; le fait de considérer Gediminas comme un habile manipulateur, qui a utilisé la possibilité de se convertir pour renforcer son État alors relativement tolérant "n'a pas été [...] du goût des chercheurs nationalistes" (Ibid., p. 354), qui préféraient voir le Lituanien comme «stupid or a noble savage» (p. 352). L'approche de S. C. Rowell est suivie par K. Markman ("Tactics...», passim).

332 S. C. Rowell, "The Letters...», p. 339; R. Petrauskas, «La formation du Grand Duché... », p. 62.

333 A. Ruotsala, "The Crusader and the Mongols...», p. 303-304; les doutes soulevés par la lettre étaient assez similaires aux accusations portées par les Teutoniques : était-ce bien là la volonté du khan, ou une manipulation de son entourage nestorien? Et pouvait-on se fier à des païens comme les Mongols? Voir Les Grandes Chroniques..., vol. 7, p. 121-124; Matthieu Paris, Grande Chronique..., vol. 6, , p. 499-501.
} 
était un politicien doué, les Teutoniques n'étaient pas en reste. En présentant le souverain lituanien de manière plutôt positive, les envoyés peuvent certes avoir cherché à «sauver la face» tout en faisant porter la responsabilité de l'échec de la conversion à l'Ordre rival, mais cet exemple indique aussi que les organes de la Papauté savaient se montrer bienveillants avec les princes païens même si ceux-ci n'étaient pas fermes dans leurs intentions ${ }^{334}$; peut-être espérait-on qu'une autre occasion puisse aboutir, et que la Lituanie deviendrait enfin chrétienne - et donc constituer un allié solide dans la lutte contre l'Empereur ${ }^{335}$.

Par la suite, la position du partenaire des Lituaniens, l'archevêque Frédéric de Riga, décline progressivement; l'«alliance balte» perd de son importance dans la politique pontificale. Jean XXII se détourne alors d'un potentiel allié qui n'avait pas rempli ses promesses, et dont il n'a plus besoin ${ }^{336}$. Gediminas meurt entre 1341 et $1342^{337}$. Après quelques troubles, deux de ses fils s'imposent et gouvernent en proches collaborateurs: Algirdas hérite du titre de grand-duc et Kęstutis de celui de duc de Trakai. Au-delà de ses implications politiques particulières, l'histoire des lettres de Gediminas illustre à merveille l'attitude de la Papauté face à l'évangélisation dans la région balte. Depuis l'époque de Bernard de Clairvaux, les pontifes ont légitimé, encouragé et cherché à encadrer les croisades menées contre les païens. Celles-ci étaient pensées comme un renfort à la mission, assurant la protection des prêtres et des néophytes, et brisant la résistance des autochtones qui refuseraient que l'on prêche sur leurs terres; pourtant, la Papauté s'est efforcée de sauvegarder les droits de ceux qui viendraient à se convertir. Quand c'est possible, on préfère traiter directement avec un prince qui dispose d'un pouvoir assez solide parmi les siens, comme Caupo en Livonie, ou Mindaugas et Gediminas en Lituanie. Rome entend se porter garante du fait que le prince converti ne perde rien dans l'entreprise: tout est mis en ouvre pour que l'indépendance de son pays soit renforcée après le baptême ${ }^{338}$. D'une certaine manière, l'Ordre teutonique peut être vu comme un bras armé de l'Église, qui laisserait aux dirigeants païens le choix entre l'affrontement militaire ou la conversion pacifique. Lorsque cette dernière option l'emporte, la Papauté se tourne systématiquement vers le candidat au baptême afin de lui offrir les meilleures garanties possibles, quitte à mettre l'Ordre sur la touche ${ }^{339}$.

\footnotetext{
334 R. MAŽEIKA, «Bargaining... », p. 134, note bien que ni le pape, ni les légats n'ont rejeté la trêve conclue en 1323.

335 S. C. Rowell, Lithuania Ascending..., p. 228.

336 R. MažeiKa, S. C. Rowell, «Zelatores..."», p. 63.

337 S. C. Rowell, Lithuania Ascending..., p. 270-271.

338 J. Jakstas, Das Baltikum..., p. 156-157.

339 Ibid., p. 156-159: c'est dans cette optique qu'ont eu lieu les négociations avec Gediminas et ses fils; on peut ajouter celles avec Mindaugas, dans les années 1250.
} 


\section{Chapitre II \\ Croisade et mission vues D'OCCident}

\section{DE NOUVELLES TERRES CHRÉTIENNES}

Dans une bulle de 1204 envoyée à l'archevêque de Hambourg-Brême, Innocent III parle de la région balte comme de "la limite de la Terre» ${ }^{1}$; une formulation qui semble cristalliser l'idée d'une contrée du bout du monde, quasiment inconnue des Européens occidentaux ${ }^{2}$. Puis, les croisades régulières ayant permis l'établissement de centres de pouvoir catholiques en Prusse et en Livonie, ces deux ensembles politiques intègrent la Chrétienté. Danois, Rigiens, Porte-Glaives ou Chevaliers teutoniques y développent des villes, construisent des châteaux et accueillent des Mendiants dans leurs possessions; forts de l'appui du légat Guillaume de Modène, les Dominicains s'installent en Estonie, en Livonie et en Prusse, où ils collaborent - bon gré mal gré - avec l'Ordre teutonique ${ }^{3}$. Les Franciscains, quant à eux, sont appelés dans les années 1260 pour appuyer la prédication de la croisade ${ }^{4}$ avant que le Saint-Siège n'autorise les Teutoniques à s'en charger eux-mêmes, y compris en distribuant des indulgences ${ }^{5}$.

L'historiographie a longtemps présenté l'action des Chevaliers teutoniques comme une entreprise de conversion forcée, ou à l'inverse, comme une conquête

\footnotetext{
${ }^{1}$ LUB 1-1, doc. 14, col. 18; M. TAмм, «A New World...», p. 28.

2 Sur les documents concernant la Baltique orientale avant les dernières décennies du XII siècle, L. Arbusow, "Die mittelalteriche Schriftüberlieferung als Quelle für die Frühgeschichte der ostbaltischen Völker», Baltische Lande 1, 1939, p. 167-203; pour M. Tamm, les textes de cette époque restent très vagues ("Inventing Livonia... », p. 196).

3 M. ТАмм, "When Did the Dominicans...", p. 35-45. Sur les relations entre Dominicains et Teutoniques, S. Gouguenheim, Les Chevaliers teutoniques..., p. 516; J. KŁoczowski, La Pologne..., XIII, p. 509-511.

${ }^{4}$ Ibid., p. 51-52, 87-93; I. Fonnesberg-Schmidt, The Popes..., p. 241 ; M.-L. Favreau-Lilie, "Mission...", p. 153-154. Pour T. Manteuffel ("La mission balte...", p. 123), le remplacement progressif des Cisterciens par les mendiants en Prusse et en Livonie est symptomatique de la politique papale, qui au milieu du XIII ${ }^{\mathrm{e}}$ siècle préfere s'appuyer sur les nouveaux ordres mendiants, au détriment des ordres monastiques plus anciens.

${ }^{5}$ C. T. MaIer, Preaching..., p. 92-93.
} 
purement territoriale, dénuée de toute considération évangélisatrice ${ }^{6}$. Il convient de rappeler que leur rôle assigné par le Saint-Siège était celui de protecteurs armés de la mission, non de prédicateurs; une fois les païens soumis, les Mendiants sont chargés de leur apporter le baptême ${ }^{7}$. Une tâche difficile, étant donné le problème posé par la maîtrise des langues, mais qui n'a pas été aussi vaine que ce que l'historiographie a longtemps affirmé ${ }^{8}$. Dans les possessions de l'Ordre, une cohabitation entre les immigrés, originaires essentiellement de l'Empire, et les natifs plus ou moins christianisés semble avoir été la règle; le christianisme dominait dans les villes et les châteaux, alors qu'un syncrétisme entre ancienne et nouvelle foi se développait à la campagne9. Baltes et Allemands se côtoyaient, notamment dans le cadre militaire, puisque de nombreux guerriers autochtones étaient recrutés comme auxiliaires dans les armées chrétiennes ${ }^{10}$. À cet égard, une étude de l'historien letton Kaspars Klaviņš a pu montrer que les pratiques traditionnelles de certains mercenaires baltes étaient respectées par leurs alliés teutoniques ${ }^{11}$. Les codes de loi rédigés au $\mathrm{XVI}^{\mathrm{e}}$ siècle, mais

\footnotetext{
${ }^{6}$ Pour une mise au point, S. Gouguenheim, Les Chevaliers teutoniques..., p. 216-217; J. SARnowsky, "Preussen und Rhodos als multiethnische Gesellschaften des 15. Jahrhunderts", Beiträge zur Geschichte Westpreussens 20/21, 2006/2008, p. 175-181 ; R. Wenskus, "The Teutonic Order and the Non-German Population of Prussia", dans A. V. Murray (dir.), The North-Eastern Frontiers..., p. 308-309; C. Higounet, Les Allemands en Europe centrale et orientale, Paris 1989, p. $250-251$.

7 M.-L. Favreau-Lilie, «Mission...», p. 148-149; S. Gouguenheim, Les Chevaliers teutoniques..., p. 53; E. Christiansen, The Northern Crusades..., p. 147-148. Pour W. Urban, "The Teutonic Order and the Christianization of Lithuania", dans La Cristianizzazione della Lituania..., p. 105-106, les Teutoniques basent leur politique sur la parabole du banquet (Luc, 14:15-24), où le Christ demandait que l'on force les indécis à rejoindre son Église, même contre leur gré: "compellere intrare». C'est aussi l'avis de S. Wielgus, que je remercie (correspondance personnelle, lettre du 4 février 2011).

${ }^{8}$ M. TAMm, "Culture ecclésiastique et culture folklorique dans la Livonie médiévale. Échos des "exempla" dans les contes populaires estoniens", Études finno-ougriennes 28, 1996, p. 53-54; T. KALA, "The Incorporation...", p. 15-19; Eadem, "Rural society and religious innovation: Acceptance and Rejection of Catholicism among the Native Inhabitants of Medieval Livonia ", dans A. V. Murray (dir.), The Clash of Cultures..., p. 184-189. Rappelons que les traces de «survivances païennes" apparaissant dans les documents normatifs étaient censées démontrer l'incapacité du clergé local à maintenir leurs ouailles dans le respect de la foi, et ne peuvent donc pas être prises à la lettre; Ibid., p. 189. Pour le cas de la Lituanie, S. C. Rowell, "Customs, rites and power in mediaeval and early modern Lithuanian society", dans D. Kaukenas, Kulturu Sankirtos, Vilnius 2000, p. 55-62; A. Greimas, «Les voix du mythe...», p. 13.

9 E. Christiansen, The Northern Crusades..., p. 200-206, 218; R. Bartlett, The Making of Europe..., p. 300-301; S. Gouguenheim, Les Chevaliers teutoniques..., p. 370-373; E. Weibel, Mille ans d'Allemagne..., p. 231-232; W. Urban, "Victims of the Baltic Crusades", Journal of Baltic Studies, 29/3, 1998, p. 204-205. Pour le cas de la Livonie, K. KụAvin̦šs, "The Ideology... », p. 260-276.

${ }_{10}$ Idem, "The Significance of the Local Baltic Peoples in the Defence of Livonia (Late ThirteenthSixteenth Centuries)", dans A. V. Murray (dir.), The Clash of Cultures..., p. 321-340; les Chevaliers teutoniques avaient l'habitude d'employer les Turcopoles, des soldats turcs chrétiens, comme auxiliaires en Terre sainte: S. Lotan, "The Teutonic Knights...», p. 319.

${ }^{11}$ K. Kựavin̦š, «The Ideology... », p. 260-276.
} 
qui reflètent des dispositions prises au cours de la conquête, montrent que les peuples baltes et fenniques ont pu garder certains de leurs usages, notamment en ce qui concerne le domaine matrimonial ${ }^{12}$. Bien que les coutumes religieuses et sociales des Baltes persistent jusqu' au $\mathrm{XVI}^{\mathrm{e}}$ siècle, et même au-delà, le processus d'évangélisation et d' "européanisation" transforme, peu à peu, la société de ces nouvelles terres chrétiennes ${ }^{13}$.

En parallèle à la christianisation de la Prusse, de la Livonie et de l'Estonie, toute la région est progressivement intégrée au savoir "géographique» de la Chrétienté ${ }^{14}$. Dans un premier temps, plusieurs descriptions de ces nouvelles terres de mission visent à s'approprier symboliquement l'espace. À ce genre de textes appartiennent les premières chroniques "locales", comme la Chronique rimée de Livonie et celles d'Henri de Livonie ou d'Arnold de Lübeck ${ }^{15}$. Plus intéressant pour notre problématique, le livre XV du De proprietatibus rerum du franciscain Barthélemy l'Anglais a été le principal vecteur de la diffusion des connaissances sur la région balte en Europe occidentale ${ }^{16}$. Cette encyclopédie composée autour de 1245 a connu un grand succès, et a été traduite en plusieurs langues vernaculaires à partir du XIV siècle $^{17}$. Son auteur, qui a enseigné à Paris puis à Magdebourg, possédait visiblement une plutôt bonne connaissance des provinces baltes, notamment de la Livonie. Il est possible que Barthélemy ait été nommé légat par Alexandre IV en Europe centrale pour prêcher la croisade et défendre les droits des néophytes, mais cette hypothétique immersion dans les affaires baltes aurait eu lieu après la rédaction de son encyclopédie, qu'il n'a pas modifiée ${ }^{18}$. Quoiqu'il en soit, il a pu puiser auprès de collègues

\footnotetext{
12 N. Blomkvist, Discovery..., p. 191-195.

13 Voir notamment R. Bartlett, The Making of Europe...; N. Blomkvist, Discovery..., p. 198-20. Dans le cas de la Lituanie, baptisée plus tardivement, le processus d'européanisation est passé par l'influence ruthène, slave et orthodoxe, prépondérante entre le milieu du XIII ${ }^{e}$ et la fin du XIV siècle, avant d'être remplacée par l'influence culturelle polonaise, prisée de la noblesse dès le $\mathrm{XV}^{e}$ siècle; E. Gudavičius, «Lithuania’s Road... », p. 15-27; A. Bumblauskas, "The Heritage of the Grand Duchy...", p. 23-25.

${ }^{14}$ Sur le processus d'intégration de nouvelles connaissances à une image du monde héritée de l'Antiquité, N. Bouloux, "Les formes d'intégration...», p. 119-146; P. Gautier Dalché, "Remarques...", p. 43-56.

15 À ce sujet, M. Tamm, "A New World...»; Idem, «Inventing Livonia...»; R. Siminski, «Ex Livonia...».

${ }^{16}$ M. TAмm, "A New World...», p. 17; Idem, «Inventing Livonia...», p. 208; A. V. Murray, "Heathens...», p. 202.

${ }_{17}$ M. TAмM, «Signes d'altérité. La représentation de la Baltique orientale dans le De proprietatibus rerum de Barthélemy l'Anglais (vers 1245)", dans Frontiers in the Middle Ages..., p. 153-154. Sur la datation, M. C. Seymour et al, Bartholomaeus Anglicus and his Encyclopedia, Aldershot 1992, p. 29-35, qui suppose que l'auteur aurait tenu compte des informations transmises par Jean de Plan Carpin, un missionnaire franciscain revenu d'une mission auprès des khans mongols en 1247. ${ }_{18}$ M. Seymour et al, Bartholomaeus..., p. 7-8; J. Lidaka, "Bartholomaeus» dans J. Friedman, K. Figg (dir.), Trade, Travel, Exploration in the Middle Ages: an Encyclopedia, New York 2000, p. 48-49.
} 
franciscains un certain nombre d'informations sur la région balte, alors en train d'être découverte par les conquérants allemands et les missionnaires qui les accompagnaient ${ }^{19}$. Bien que se basant, comme il était habituel, sur les autorités établies (notamment Isidore, Pline et Orose), Barthélemy intègre plusieurs données nouvelles dans le traité de géographie que forme le livre XV de son encyclopédie ${ }^{20}$. Ces informations, attribuées à un ou des contemporain(s) qu'il nomme sans doute de manière imagée "Erodatus» (Hérodote), recouvrent de nombreuses régions d'Europe, parmi lesquelles six provinces baltes: la Lituanie, la Livonie, la Revalie (région de Tallinn), la Sambie, la Sémigallie et la Vironie (nord-est de l'Estonie) ${ }^{21}$.

Notre encyclopédiste n'est pas le seul en Europe occidentale à mentionner ces contrées. L'arrivée des Mongols aux portes de l'Europe et le départ de missions franciscaines pour l'Orient créent une demande d'information; les récits des voyageurs sont très populaires ${ }^{22}$. La région balte est mentionnée par l'émissaire italien d'Innocent IV, Jean de Plan Carpin (1245-1247), qui raconte que le nouveau khan en personne entend envoyer une armée en Prusse et en Livonie, dans le dessein de conquérir l'Europe ${ }^{23}$. La même impression émerge de la chronique du Wallon Albéric de Trois-Fontaines (1241) ${ }^{24}$, qui raconte

${ }^{19}$ L'Ordre Mineur disposait notamment d'un couvent à Riga. Ibid., p. 48; Barthélemy l'Anglais, Le Livre des propriétés des choses: une encyclopédie au XIV siècle, trad. J. Corbechon, éd. B. Ribémont, Paris 1999, p. 32; S. C. Rowell, "Of Men and Monsters: Sources for the History of Lithuania in the Time of Gediminas", Journal of Baltic Studies 24, 1993, p. 91; M. TAмm, "Signes...", p. 153-156; R. Siminski, «Ex Livonia... », p. 202.

${ }^{20}$ M. Seymour et al., Bartholomaeus..., p. 158-159; M. ТАмм, «Signes...», p. 155-156.

${ }^{21}$ Ibid., p. 156-157; P. Gautier Dalché, «Représentations géographiques de l'Europe - septentrionale, centrale et orientale - au Moyen Âge», dans I. Baumgärtner, H. Kugler (éds.), Europa im Weltbild des Mittelalters, Berlin 2008, p. 63-79.

${ }_{22}$ G. G. Guzman, «European clerical envoys to the Mongols: Reports of Western merchants in Eastern Europe and Central Asia, 1231-1255", Journal of Medieval History 22/1, 1996, p. 53-67; M. Tamm, "A New World...", p. 34-35; A. Kehnel, "Le sacrifice du cheval. Une brève histoire de sa découverte d'Hérodote à Dumézil», dans B. Andenmatten, A. Paravicini Bagliani et E. Pibiri (dirs.), Le cheval dans la culture médiévale, Florence 2015, p. 29.

${ }^{23}$ Jean de Plan Carpin, Storia dei Mongoli, éd. et trad. E. Menestò, M. C. Lungarotti et al., Spoleto 1989, p. 295-296; Idem, Dans l'Empire mongol, trad. T. Tanase, Toulouse 2014, p. 124. En se rendant en Orient, Jean de Plan Carpin et ses compagnons ont notamment résidé chez le duc Conrad de Mazovie, qui a «invité»l'Ordre teutonique en Prusse; A. Selart, Livonia..., p. 212.

${ }^{24}$ Albéric (Aubri) de Trois-Fontaines a longtemps été considéré comme un Champenois, mais M. Schmidt-Chazan ("Aubri de Trois-Fontaines, un historien entre la France et l'Empire», Annales de l'Est 36/3, 1984, p. 189-191) a proposé une hypothèse différente: il serait originaire du sud de la principauté de Liège, et aurait composé sa chronique universelle pour des moines champenois intéressés à l'histoire «internationale» de leur ordre. Albéric a pu s'informer des affaires baltes lors d'enquêtes menées dans la région de Liège, où Théodoric, le missionnaire cistercien devenu évêque d'Estonie, a trouvé refuge entre 1213 et 1218, et d'où était originaire Baudoin d'Aulne, le légat malheureux de Grégoire IX avec qui notre chroniqueur a pu s'entretenir à plusieurs reprises, ce qui explique qu'il soit relativement bien informé sur les événements de la Baltique': ibid, p. 177-178; M. ТАмм, "Communicating Crusade...», p. 359-360. 
l'arrivée des Mongols en Europe orientale et, relayant des rumeurs parvenues jusqu'en France, leur prête la destruction de "païens Prussiens sans nombre»" ${ }^{25}$. À l'inverse, Guillaume de Rubrouck, l'envoyé de Louis IX (1253-1255), fait de la Prusse une citadelle fermement tenue par les Chevaliers teutoniques, qui pourrait même servir de base à une croisade contre les Tatars ${ }^{26}$.

C'est sans doute à la préoccupation mongole que devait répondre un document anonyme appelé Descriptiones terrarum, dont un unique manuscrit a été retrouvé en 1979 à Dublin ${ }^{27}$. Il s'agit vraisemblablement d'une introduction à un travail de plus grande ampleur sur l'histoire et les mœurs des Mongols: l'extrait qu'il nous reste offre une description plutôt détaillée de l'Europe du Nord et de l'Est; le pourtour balte est en particulier bien représenté. L'auteur se présente comme un ancien missionnaire actif dans la région ${ }^{28}$. Il peut s'agir d'un moine irlandais engagé par l'archevêque de Riga Albert Suerbeer, légat d'Innocent IV pour les affaires baltes, ou d'un prélat originaire d'Europe centrale $^{29}$. Pour Stephen C. Rowell, il y a lieu de penser qu'il était franciscain ${ }^{30}$. Étant donné que les événements racontés avec le plus d'emphase datent de 1255, l'éditeur du texte, Marvin Colker, situe la rédaction du Descriptiones peu après cette année ${ }^{31}$.

Dans le savoir géographique du XIII ${ }^{\mathrm{e}}$ siècle, les provinces baltes sont traitées comme des pays d'Europe du Nord, placés à la limite orientale de la Chrétienté. Barthélemy l'Anglais affirme que la Livonie est séparée de l'Allemagne par la mer, alors que la Vironie est située loin à l'est du Danemark; la Révalie, autrement dit la région de Tallinn, confine à la Scythie, alors que Lituanie,

\footnotetext{
${ }_{25}$ Albéric de Trois-Fontaines, Chronica..., p. 911; K. Brewer, Prester John: the Legend and its Sources, Ashgate 2015, p. 148. Albéric suit la tradition née à la suite d'un document des années 1220, la Relatio de Davide, qui fait de Gengis Khan un roi chrétien nommé David, descendant du Prêtre Jean: Ibid., p. 107; J. Richard, «L'Extrême orient légendaire au Moyen Âge: Roi David et Prêtre Jean ", Annales d'Ethiopie 2/1, 1957, p. 233-235. Toutefois, à la fin du même paragraphe, le chroniqueur met en doute le caractère chrétien de l'énigmatique conquérant: "dicunt enim quidam, quod neque christiani sunt neque Sarraceni», Albéric de Trois-Fontaines, Chronica..., p. 911; K. Brewer, Prester John..., p. 146.

${ }^{26}$ Guillaume de Rubrouck, dans Guillaume de Rubrouck, Jean de Plan Carpin, The Texts and Versions of John de Plano Carpini and William de Rubruquis, éd. C. Raymond Beazley, Londres 1903, p. 161 ; trad. dans Guillaume de Rubrouck, Marco Polo, Deux voyageurs en Asie au XIIt siècle: Guillaume de Rubruquis et Marco Polo, éd. E. Muller, P. Bergeron, Paris 1888, p. 49.

${ }_{27}$ M. Colker, "America Rediscovered in the Thirteenth Century?», Speculum 54/4, 1979, p. 712-726; M. ТАмм, «A New World...», p. 16-17; Idem, "Inventing Livonia... », p. 202-203;

P. Gautier Dalché, «Représentations...», p. 75.

${ }^{28}$ M. Colker, "America..." p. p21-722.

29 W. Urban, «Roger Bacon...», p. 365-366; J. Wenta, "Zu Gog und Magog. Einige Bemerkungen über die Verfasserschaft der "Descriptiones Terrarum" ", Etudes médiévales 7, 2006, p. 331-339; K. Górski, "The Author of the Descriptiones Terrarum: A New Source for the History of Eastern Europe», The Slavonic and East European Review 61/2, 1983, p. 254-258.

30 S. C. Rowell, "Of Men...", p. 92.

${ }^{31}$ M. Colker, «America...»p. 715.
} 
Sambie et Sémigallie y appartiennent ${ }^{32}$. La Scythie fait ici référence à l'Asie $\mathrm{du}$ Nord d'après la tradition classique, mais utiliser ce terme chargé d'une forte connotation «barbare» est aussi un moyen de souligner l'altérité de ces régions - en l'occurrence, le paganisme réel ou supposé des habitants ${ }^{33}$. Un autre célèbre franciscain, Roger Bacon, décrit rapidement les provinces baltes dans son Opus maius (1268) et leur consacre quelques pages concernant le déroulement de la mission ${ }^{34}$. Pour Bacon, la Lituanie est un pays aussi grand que l'Allemagne, à l'Ouest de la Russie; tout comme l'Estonie, la Livonie, la Courlande, la Sémigallie et la Prusse, elle est baignée par la "mer de l'Est», autrement dit, la Baltique. Les peuples de tous ces pays sont païens ${ }^{35}$. D'autres auteurs mentionnent les régions baltes sans donner de détails, mais tous en font des provinces nordiques: dans le chapitre De Europa a parte Septentrionis de ses Otia imperialia (v. 1211-1216), Gervais de Tilbury situe la Jatvingie et la Livonie païennes au nord, au-delà de la Pologne $e^{36}$; pour Albert le Grand, la Prusse et la Livonie forment la limite de l'Europe, juste avant la "Gothie» (Suède) et la "Dacie» (Danemark) ${ }^{37}$. Albéric de Trois-Fontaines place la Livonie "entre la Suède, la Prusse et la Pologne»" ${ }^{38}$. Le traité anonyme Descriptio Europae Orientalis (v. 1311), qui par son but - promouvoir une campagne contre les chrétiens orthodoxes des Balkans - s'intéresse surtout à l'Europe du Sud-Est ${ }^{39}$, se contente de nommer les Pruzeni parmi les peuples de langue slave, sans donner d'indications quant à leur situation géographique ${ }^{40}$. À partir

32 Barthélemy l'Anglais, De proprietatibus rerum, Liber 15, BNF lat. 16098, cité par M. TAмm, «Signes...", p. 168-170.

33 Notamment D. Fraesdorff, Der barbarische Norden..., p. 290 sq.

34 Roger Bacon, Opus Maius, éd. J. H. Bridges, 3 vol., Oxford 1897-1900, rééd. Frankfurt am Main 1964, vol. 1, p. 358-360; ibid., vol. 2, p. 366-377; ibid. vol. 3, p. 120-122; N. Bouloux, «Les formes d'intégration...», p. 130; R. Siminski, «Ex Livonia...», p. 197-198. Pour une traduction, voir Roger Bacon, Opus Maius, trad. R. B. Burke, Philadelphie \& Londres 1928.

35 Roger Bacon, Opus Maius..., éd. J. H. Bridges, vol. 1, p. 358-360; P. Gautier-Dalché, «Représentations», p. 74.

${ }^{36}$ Gervais de Tilbury, Otia imperialia: recreation for an emperor, 2, 7, éd. et trad. S. E. Banks, J. W. Binns, Oxford 2002, p. 246; trad. Ibid. p. 247; R. Siminski, "Ex Livonia... », p. 196.

${ }^{37}$ Albert le Grand, De natura locorum, trad. dans J. P. Tilman, Geographical Works of Albertus Magnus, Univ. of Michigan 1971, p. 138; la Livonie est située dans le "quartier nord» du monde habitable, avec la Dacia, Gothia, et les pays slaves (ibid, p. 127); R. Siminski, "Ex Livonia...", p. 197.

38 Albéric de Trois-Fontaines, Chronica..., p. 872.

${ }^{39}$ L'attribution du Descriptio Europae Orientalis à un dominicain français au service de l'empereur de Constantinople Charles de Valois (Anonymi Descriptio Europae Orientalis, éd. O. Górka, Cracovie 1916, p. III-XVI) est mise en doute par les auteurs d'une récente édition; Anonymi Descriptio Europae orientalis, éd. et trad. T. Živković, V. Petrović, A. Uzelac, D. Kunčer, Belgrade 2013, p. 185-188; quant à la date, O. Górka proposait 1308, alors que T. Živković et al., p. 187, préferent peu après 1311 .

${ }_{40}$ Ibid., p. 131. Le fait que les Prussiens parlent une langue non-slave, car différente du tchèque maternel du missionnaire Adalbert de Prague, a été noté par Bruno de Querfurt dans sa Vie de saint Adalbert; M. Sosnowski, «Prussians as Bees...», p. 28. 
de la fin du XIII ${ }^{e}$ siècle, les principales provinces baltes apparaissent sur des cartes, notamment la célèbre mappemonde d'Ebstorf, que l'on a longtemps attribuée à Gervais de Tilbury, et qui reprend en bonne partie les commentaires d'Adam de Brême pour l'Europe nordique ${ }^{41}$. Riga y figure en bonne place, apparaissant même comme la cité la plus importante d'Europe du Nord-Est ${ }^{42}$.

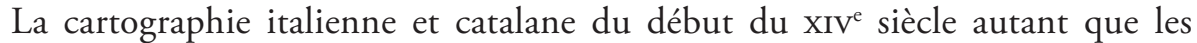
portulans ${ }^{43}$ attestent que les principales villes de la côte balte étaient connues à Venise, à Gênes ou à Majorque ${ }^{44}$. La Lituanie vole la vedette à la Prusse et à la Livonie, déjà intégrées à la Chrétienté; Marino Sanudo, géographe et voyageur vénitien, qui devait relativement bien connaître la région puisqu'il dit s'être rendu jusqu'en Poméranie pour sensibiliser les princes à son projet de croisade, note ainsi dans son Secreta fidelium crucis (v. 1321) que les Lituaniens confinent à l'archevêché de Riga et aux Chevaliers teutoniques ${ }^{45}$. Le grand-duché païen fait figure d'ultime bastion du paganisme.

Les provinces baltes faisant, dans la conception géographique médiévale, partie de l'Europe, elles se voient attribuer des caractéristiques positives semblables aux autres pays du continent, comme la vigueur des habitants ${ }^{46}$. Ces derniers ont droit à une certaine attention de la part de nos auteurs: ceux qui, par leur fonction, ont pu obtenir des informations de première main, distinguent notamment les peuples récemment évangélisés de ceux qui ne le sont pas encore. L'auteur du Descriptiones terrarum ne s'étend pas sur l'Estonie et la Livonie, au sujet desquelles il rapporte simplement l'anecdote, répandue dans la région, du château érigé par les premiers chrétiens et que les

\footnotetext{
${ }^{41}$ W. IWANCZAK, "La Mer Baltique dans la cartographie médiévale» dans A. Gautier, S. Rossignol (dirs.), De la Mer du Nord à la Baltique..., p. 31 ; P. Gautier-Dalché, "À propos de la mappemonde d'Ebstorf", Médiévales 55, 2008 [en ligne]; L. S. Chekin, Northern Eurasia in Medieval Cartography, Turnhout 2006, p. 146-151.

42 Ibid., p. 148.

${ }^{43}$ Les portulans sont des cartes maritimes utilisées à partir de la fin du XIII ${ }^{\mathrm{e}}$ siècle, notamment pour indiquer les ports et informer les navigateurs de la configuration des côtes.

${ }_{44}$ Par exemple, les cartes attribuées à Pietro Vesconte et qui accompagnaient le Secretum fidelium crucis de Marino Sanudo (v. 1321-1337), ainsi que la carte de Giovanni da Carignano (v. 13106-1314), celle de Dalorto (1325) et celle de Dulcert (1339): W. IwanczaK, "La Mer Baltique...", p. 34-38; A. E. Nordenskiöld, Facsimile-Atlas to the early history of cartography, New York 1973, p. 52-55; A.-D. von DEN BRINCKen, "Die kartographische Darstellung Nordeuropas durch italienische und Mallorquinische Portolanzeichner im 14. und in der ersten Hälfte des 15. Jahrunderts ", Hansiche Geschichtsblätter 92, 1974 , p. 45-58; E. Moritz, Die Entwickelung des Kartenbildes der Nord-und Ostseeländer bis auf Mercator, Amsterdam 1967, p. 47-55.

${ }_{45}$ Marino Sanudo, Secretum Fidelium Crucis, Lib. 1, part. V, chap. 1, éd. J. Bongars, Gesta Dei per Francos, vol. 2, Hanovre 1611, p. 32; voir S. C. Rowell, "Of Men...", p. 93; W. Iwanczak, «La Mer Baltique...», p. 36-37; sur le projet de Sanudo, C. Tyerman, «Marino Sanudo Torsello and the Lost Crusade: Lobbying in the Fourteenth Century", Transactions of the Royal Historical Society, 32, 1982, p. 57-73.

46 P. Gautier-Dalché, «Représentations...», p. 75.
} 
autochtones auraient essayé de jeter à bas, sans succès ${ }^{47}$. Par contre, notre ancien missionnaire est à même de dresser un état des lieux de la situation religieuse des provinces où il a travaillé: si la Prusse proprement dite a reçu la foi de l'évêque Christian, il a fallu l'intervention du roi de Bohême Ottokar Přemysl pour amener le prince des Sambiens aux fonts baptismaux ${ }^{48}$. Toujours d'après cet auteur, l'évangélisation de la Lituanie et de la Jatvingie semble s'opérer de manière plus pacifique ${ }^{49}$, et seuls les Samogitiens donnent du fil à retordre aux missionnaires ${ }^{50}$. Barthélemy l'Anglais note, de son côté, que les habitants de Livonie ont été "forcés de passer du service des démons à la foi et au culte du Dieu unique par les Allemands" ${ }^{51}$, tout comme ceux de Révalie, qui "était une province barbare, très éloignée du Danemark, mais qui obéit maintenant à la foi de Dieu et est soumise au roi du Danemark»"25. Quant aux Vironiens, ils "étaient barbares, rustres, sauvages et cruels " ${ }^{53}$, avant que leur pays ne soit occupé par les Allemands et les Danois, qui par leur présence y font progresser la foi catholique. Notre encyclopédiste ne se prive pas de souligner le caractère brutal des natifs, ce qui peut se lire comme une justification de la conquête et de la colonisation ${ }^{54}$.

Toutefois, force est de constater que les habitants des trois régions «scythes», restées païennes en leur temps ${ }^{55}$, ne sont pas dépeints sous un jour uniquement négatif. Ainsi, alors que les Sémigalliens sont "barbares et incultes, rustres et cruels" ${ }^{56}$, les Lituaniens sont "des hommes robustes et forts, belliqueux et féroces ${ }^{57}$, dont les raids en territoires russes sont mentionnés par le voyageur Jean de Plan Carpin ${ }^{58}$. Quant aux Sambiens, déjà loués par Adam de Brême ${ }^{59}$, Barthélemy leur prête, "au milieu des autres barbares, un corps superbe, un esprit hardi, et [ils] ressortent parmi les autres nations de la région par leur talent, leurs capacités artistiques et leur savoir-faire" ${ }^{60}$. Ce peuple n'ayant pas encore été évangélisé, son caractère positif ne saurait être attribué aux seules vertus

\footnotetext{
${ }^{47}$ C'est un motif courant, présent aussi dans les contes populaires, et qui apparaît à plusieurs occasions chez les chroniqueurs de la Baltique médiévale: M. TAмM, "Inventing Livonia...», p. 203-205.

48 M. Colker, «America... », p. 721-722; trad. Ibid., p. 715-716.

49 Ibid., p. 723.

50 Ibid., p. 722.

51 Barthélemy l'Anglais, cité par M. TAмm, «Signes... », p. 169; trad. ibid, p. 165.

52 Ibid., p. 169.

53 Ibid., p. 170.

${ }_{54}$ M. TAMM, «Signes...», p. 147-170.

55 Il s'agit de la Sémigallie, la Sambie et la Lituanie; Ibid., p. 168-170.

56 Ibid., p. 170.

${ }^{57}$ Ibid., p. 168.

58 Jean de Plan Carpin, Storia dei Mongoli..., p. 304; voir aussi ibid., p. 308.

59 Adam de Brême, Gesta..., IV, 18, p. 245-246; T. BARnwell, «Fragmented identities: otherness and authority in Adam of Bremen's History of the Archbishops of Bremen", dans C. Gantner, R. McKitterick, S. Meeder (dir.), The Ressources of the Past in Early Medieval Europe, Cambridge 2015, p. 206-224 (en particulier, p. 217-218).

${ }^{60}$ M. ТАмм, «Signes...», p. 164.
} 
du christianisme ${ }^{61}$. De même, Gervais de Tilbury nous dit que la Livonie est habitée par un "peuple très vertueux de païens" ", alors qu'il ne donne aucune précision sur les Jatvingiens, mis à part leur identité religieuse ${ }^{63}$. Quoi qu'il en soit, ceux-ci ne sont pas caractérisés par la férocité, comme peuvent l'être ceux que Gervais nomme Coralli (peut-être les Coumans), qui vivent entre la Russie et la Grèce: "une tribu très féroce de païens qui vit de chair crue pour nourriture" ${ }^{64}$. La connaissance des régions baltes progresse donc au même rythme que la foi chrétienne; chroniqueurs, encyclopédistes et géographes peuvent s'en réjouir. À partir des années 1220, c'est du succès des Chevaliers teutoniques que dépend le salut de ces habitants "des limites de la Terre»" ${ }^{65}$. Voyons comment ceux qui ont à charge de briser les forces des païens tout en protégeant les chrétiens sont considérés par leurs contemporains du XIII ${ }^{\mathrm{e}}$ siècle.

\section{POUR LA FOI OU POUR LE POUVOIR?}

Les témoignages sur les activités de l'Ordre teutonique parvenus en Europe occidentale proviennent essentiellement, au XIII ${ }^{\mathrm{e}}$ siècle, de deux milieux: les ordres religieux actifs sur le terrain, Cisterciens et surtout Franciscains, et la chancellerie pontificale ${ }^{66}$. Bien qu'installés sur le rivage balte avec l'approbation du Saint-Siège, les ordres monastiques n'étaient pas exempts de toute critique. Le légat wallon Baudoin d'Aulne, qui succède à Guillaume de Modène avant de s'immiscer dans le jeu politique balte pour devenir évêque de Sémigallie, lance de graves accusations contre les Porte-Glaives. Celles-ci sont parvenues aux oreilles du pape Grégoire IX, qui les résume dans une lettre en 1234: les membres de la milice feraient non seulement preuve d'une violence extrême envers les représentants de l'Église, mais encore, ils opprimeraient les néophytes et empêcheraient les autochtones de recevoir le baptême ${ }^{67}$. Des accusations relativement fréquentes, même en contexte méditerranéen ${ }^{68}$, mais qui sont

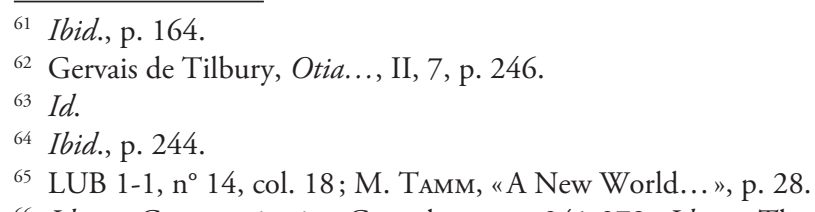

${ }^{66}$ Idem, "Communicating Crusade...", p. 341-372; Idem, "The Livonian Crusade in Cistercian Stories of the Early Thirteenth Century", dans T. Nielsen, I. Fonnesberg-Schmidt (dirs), Crusading on the Edge, p. 365-398.

${ }^{67}$ Fontes Historiae Latviae Medii Aevi, éd. A. Švābe, vol. 2/1, Riga 1937, doc. 204, p. 175-181. Sur le contexte, A. Selart, Livonia..., p. 132-133; G. A. Donner, Wilhelm von Sabina..., p. 167-168.

${ }^{68}$ Voir notamment la lettre de Grégoire IX, qui en 1237 accuse les princes séculiers et les ordres militaires de Terre sainte d'empêcher les esclaves de recevoir le baptême; S. Gouguenheim, Les Chevaliers teutoniques... p. 508; B. Kedar, Crusade..., p. 148-147; la lettre est éditée dans Ibid., p. 212, doc. 2. Voir aussi les anecdotes racontées par Guillaume de Tyr et Gautier Map selon lesquelles les Templiers empêcheraient volontairement le baptême des musulmans pour garder leur raison d'être; M. Aurell, Des chrétiens...p. 107-108. Comme le rappelle M. Aurell (Des chrétiens..., p. 111-112), les critiques contre les ordres militaires rappellent les accusations d'orgueil 
pour beaucoup dans la mauvaise réputation des Porte-Glaives: même les Teutoniques semblent avoir eu des réticences à l'idée de les soutenir ${ }^{69}$. Pourtant, ceux-ci n'étaient pas toujours en odeur de sainteté, comme en témoigne Boniface, ancien évêque de Lausanne, en 1239: "les frères de l'Ordre allemand ne sont pas en grâce auprès du seigneur pape, car ils l'ont offensé, ainsi que je l'ai entendu dire à la Curie, du seigneur pape lui-même» ${ }^{70}$. Grégoire IX, en plein conflit avec l'empereur Frédéric II, n’apprécie sans doute pas la proximité des Teutoniques avec ce dernier. Son successeur, Innocent IV, reste plutôt favorable à l'Ordre, mais ne transige d'aucune manière sur les droits des convertis que son légat Jacques Pantaléon, l'artisan du traité de Christbourg, s'efforce de faire respecter $^{71}$. Porte-Glaives puis Teutoniques trouvent leur légitimité comme bras armés de la mission, mais le Saint-Siège n’entend pas leur donner une licence totale. Une image ambiguë résulte de la tension entre le devoir des ordres militaires et leur comportement sur le terrain, tel que rapporté par les plaintes parvenues jusqu'à Rome.

Une certaine ambivalence prévaut également dans les descriptions que l'on trouve dans les textes narratifs issus d'Europe occidentale, du moins jusqu'au milieu du $\mathrm{XIV}^{\mathrm{e}}$ siècle, avant que la chevalerie française et anglaise ne s'implique massivement dans la croisade. Stephen C. Rowell a remarqué que les Franciscains ont été plus soucieux que leurs collègues dominicains de consigner par écrit leurs observations sur les affaires baltes, ce qui permet de se faire une idée d'un réseau d'information qui couvrait toute la Chrétienté ${ }^{72}$, mais aussi d'observer quel regard certains frères mineurs originaires d'Angleterre ou de France portaient sur les activités des ordres militaires chargés de défendre et d'étendre le christianisme dans la Baltique.

Comme en ce qui concerne le portrait des natifs baltes, la diversité des points de vue est la règle. Le franciscain d'origine anglaise Barthélemy notait dans son De proprietatibus rerum qu'au moins trois provinces baltes, la Livonie, la Révalie et la Vironie étaient gagnées au christianisme par la conquête danoise et allemande. Arrêtons-nous sur le destin des habitants de Livonie: "[leurs] coutumes religieuses étaient étonnantes avant qu'ils ne soient forcés de passer du service des démons à la foi et au culte du Dieu unique par les Allemands» ${ }^{73}$.

\footnotetext{
lancées fréquemment contre la noblesse; elles forment donc, dans une certaine mesure, un topos utilisé pour des raisons politiques et moralisatrices.

${ }^{69}$ E. Christiansen, The Northern Crusades..., p. 98. L'auteur cite un rapport dressé par Hartman von Heldrungen, un officier et futur grand-maitre de l'Ordre teutonique qui a visité les Porte-Glaives entre 1235 et 1238: Fontes Historiae..., vol. 2/1, doc. 212, p. 189-192.

${ }^{70}$ Die Berichte der Generalprokuratoren des Deutschen Ordens an der Kurie, éd. K. Forstreuter, H. Koeppen, vol. 1, doc. 6, Göttingen 1961, p. 174; S. Gouguenheim, Les Chevaliers teutoniques..., p. 507.

71 I. Fonnesberg-Schmidt, The Popes..., p. 233-235; S. Gouguenheim, Les Chevaliers teutoniques..., p. 508-513.

${ }^{72}$ Chartularium..., p. 399.

${ }^{73}$ M. ТАмм, «Signes...», p. 169.
} 
Barthélemy ne mentionne directement ni les Porte-Glaives ni les Chevaliers teutoniques, mais le terme «cogerentur» laisse présager que c'est par la force que les Lives ont été convertis ${ }^{74}$. Le rôle positif attribué, sans doute, aux moines soldats, est confirmé par la dernière phrase du paragraphe consacré à la Livonie, qui clôt la description des rituels païens: "On croit que cette province, ensorcelée par l'erreur des démons depuis un temps ancien, est, avec beaucoup d'autres régions assujetties et annexées, en grande partie libérée de ces erreurs par la grâce et avec l'aide de la puissance des Allemands" ${ }^{75}$. Guillaume de Rubrouck, l'envoyé de Louis IX auprès des Mongols, va plus loin lorsqu'il fait de la Prusse, «que depuis peu les Chevaliers teutoniques ont subjuguée entièrement», une citadelle chrétienne pouvant servir de base à une croisade de grande ampleur contre les Tatars: «ils pourraient en faire autant et bien aisément de toute la Russie, s'ils voulaient s'y employer. Car si les Tartares savaient que notre grand pontife, le pape, fit croiser les peuples contre eux, ils s'enfuiraient tous bien vite et s'iraient cacher dans leurs déserts ${ }^{76}$. Le propos est exagéré, car la principauté russe de Novgorod imposa ses limites à l'expansion catholique ${ }^{77}$, mais la rodomontade du voyageur flamand est révélatrice de la haute estime dans laquelle les chevaliers à la croix noire étaient tenus. Pour ces auteurs, ceux-ci se chargent fidèlement et efficacement de la tâche que leur avait confiée l'Église lors de leur établissement en Prusse, et leurs armes sont un appui important à la cause chrétienne ${ }^{78}$.

Néanmoins, tous ne sont pas nécessairement favorables aux ordres militaires. Commençons par l'auteur du Descriptiones terrarum. Nous avons vu qu'il distingue les provinces où l'évangélisation peut se dérouler de manière pacifique de celles où le glaive y est nécessaire: tel est cas de la Samogitie, où "personne n'y a jamais prêché sans l'épée ${ }^{79}$. À l'inverse, les Lituaniens, les Jatvingiens et d'autres habitants des régions baltes reçoivent aisément le baptême, du fait qu'ils sont élevés par des nourrices chrétiennes $^{80}$. L'acculturation en douceur est donc considérée comme un moyen possible de conversion. Il souligne que la Prusse, "avec l'aide de Dieu, a obtenu le commencement de sa conversion de Christian, un cistercien, et le premier évêque de cette région, par la grâce du baptême et non par l'épée»" ${ }^{81}$. Christian lui-même a pourtant appelé à l'aide des croisés, avant d'être supplanté par les Teutoniques. Il est frappant que l'auteur gomme ici le rôle de ces derniers; face aux moines soldats lourdement

\footnotetext{
74 A. Grabski, Polska w opiniach obcych..., p. 278.

75 M. Tамм, «Signes...», p. 169.

${ }^{76}$ Guillaume de Rubrouck, dans Guillaume de Rubrouck, Jean de Plan Carpin, The Texts and Versions..., p. 161 ; trad. dans Guillaume de Rubrouck, Marco Polo, Deux voyageurs..., p. 49.

77 E. Nazarova, «The Crusades...», p. 177-195.

${ }^{78}$ Notons qu'un auteur comme Olivier de Paderborn, qui mentionne rapidement la conversion des Baltes, ne l'attribue pas explicitement aux Teutoniques: Olivier de Paderborn, Die schriften des Kölner domscholasters, späteren bischofs von Paderborn und Kardinal-Bischofs von S. Sabina Oliverus, éd. H. Hoogeweg, Tübingen 1894, p. 157.

79 M. Colker, «America... », p. 722.

${ }^{80}$ Ibid., p. 723.

${ }^{81}$ Ibid., p. 721.
} 
armés, un simple évêque missionnaire semble avoir sa préférence. L'auteur, qui dit avoir pris part aux campagnes d'évangélisation auprès des Jatvingiens, a lui-même participé à deux cérémonies princières: le couronnement de Mindaugas, "premier roi baptisé» ${ }^{82}$ de Lituanie, et le baptême du prince des Sambiens, administré sous la houlette du roi de Bohême ${ }^{83}$.

Ce dernier événement peut être considéré comme l'un des antécédents importants des croisades nobiliaires paneuropéennes dans la région balte. En 1254-1255, Ottokar Přemysl II, le puissant roi de Bohême, mène avec le margrave de Brandebourg, le duc d'Autriche et d'autres seigneurs d'Europe centrale, une croisade en Sambie, que les Chevaliers teutoniques n'avaient pas encore réussi à mater ${ }^{84}$. C'est en son honneur que fut nommée la ville de Königsberg, fondée sur une citadelle prise aux Prussiens (actuellement Kaliningrad, en Russie) ${ }^{85}$. Les chroniqueurs, y compris Pierre de Dusbourg, insistent sur la présence de nombreux princes aux côtés du roi de Bohême; ce groupe de grands seigneurs vole quelque peu la vedette aux Chevaliers teutoniques, qui restent toutefois mentionnés comme recevant la protection des néophytes et la gestion de la terre prise aux païens par les Annales d'Ottokar ${ }^{86}$. Si cette dernière chronique, de même que le Descriptiones terrarum, raconte non sans fierté le baptême du prince sambien par le monarque tchèque, les Annales de Prague donnent un aperçu bien plus cru de ce à quoi a pu ressembler l'expédition: "le prince de Bohême et le margrave de Brandebourg entrant en Prusse, la dévastèrent par le vol, l'incendie et la rapine, et ils tuèrent de plusieurs façons un très grand nombre de personnes, n'épargnant ni le sexe, ni l'âge" ${ }^{87}$. Pour l'auteur du Descriptiones terrarum, la violence peut donc avoir une certaine légitimité dans la conversion des infidèles, lorsque les méthodes pacifiques ne font pas l'affaire. Plus qu'une critique de leur supposée brutalité, l'absence de mention des Chevaliers teutoniques peut indiquer une certaine défiance de l'auteur envers cette corporation de moines soldats. Ce qui s'expliquerait assez facilement si celui-ci pouvait, selon l'hypothèse avancée par William Urban, être un proche de l'archevêque de Riga et adversaire de l'Ordre Albert Suerbeer ${ }^{88}$.

De fait, une rivalité politique est souvent sous-jacente aux positions défavorables à l'Ordre teutonique. Christian de Prusse lui-même, l'un des

\footnotetext{
82 Ibid., p. 722.

83 Ibid., p. 721-722.

${ }^{84}$ Annales Otakariani, éd. R. Koepke, MGH SS 9, Hanovre 1851, p. 181-182; Pierre de Dusbourg, Chronicon..., SRP 1, p. 90-92; M. Colker, "America...», p. 722, n. 18. Un certain Barthélemy, Franciscain, a été chargé par le pape Alexandre IV de prêcher la croisade en Europe centrale (Annales Otakariani..., p. 181, n. 79).

85 Pierre de Dusbourg, Chronicon..., SRP 1, p. 92; Annales Otakariani..., p. 182; P. HLAváČEK, "A Reflection...", p. 133 sq.

${ }^{86}$ Annales Otakariani..., p. 182.

${ }^{87}$ Annales Pragensis éd. R. Koepke, MGH SS 9, Hanovre 1851, p. 175.

88 W. Urban, «Roger Bacon...", p. 365-366.
} 
premiers rivaux des Chevaliers, rapporte que ceux-ci préféraient les baptêmes en masse, parfois forcés, et négligeaient de prendre en considération si un individu faisait part de l'intention de se convertir ${ }^{89}$. De telles accusations ne manquent pas de rappeler celles lancées contre les Porte-Glaives par le légat Baudoin d'Aulne, devenu évêque de Sémigallie. Ce personnage est sans aucun doute à l'origine du portrait très sombre de cet ordre militaire que l'on lit sous la plume d'un chroniqueur francophone, Albéric de Trois-Fontaines ${ }^{90}$. La dernière rencontre entre ces hommes, tous deux cisterciens liés au diocèse de Liège, date de 1232, soit à l'époque où les Porte-Glaives n'étaient pas encore incorporés à l'Ordre teutonique ${ }^{91}$. L'image qu'Albéric donne des membres de la milice armée n'est pas sans rappeler les mots de certains historiens modernes ${ }^{92}$ : "alors qu'ils se disent tenir de l'Ordre du Temple, ils ne sont nullement soumis aux Templiers; mais comme ce sont des marchands, des gens fortunés et tous ceux qui ont été bannis de Saxe pour des crimes, ils se sont à présent tant accrus qu'ils croyaient pouvoir vivre sans loi ni roi» ${ }^{93}$. Plusieurs chroniqueurs d'Europe occidentale rapportent que des individus chargés de crimes prennent la croix pour aller en Terre sainte, afin d'échapper à la justice; l'accusation d'Albéric n'est donc pas isolée dans un $\mathrm{XIII}^{\mathrm{e}}$ siècle où se fait de plus en plus sentir une défiance relative envers la croisade ${ }^{94}$. A l'inverse, Albéric présente la deuxième mission de Guillaume de Modène en Prusse (1228) en des termes qui trahissent ses préférences quant à une approche pacifique de l'évangélisation: «envoyé par le pape comme légat, il attira de nombreux païens à la foi, par sa sagesse et son talent, et non par la force; et il a appris leur langue en grande partie»" ${ }^{95}$; s'en suit une note sur la traduction d'un "art grammatical», ce qui fait sans doute écho au programme d'apprentissage des langues baltes cher au légat italien ${ }^{96}$.

\footnotetext{
${ }^{89}$ M.-L. Favreau-Lilie, «Mission...», p. 151-152.

${ }^{90}$ M. Tамм, "Communicating Crusade...", p. 366, 368-370, qui rappelle qu'en parlant des affaires baltes, Albéric entendait avant tout illustrer l'importance des Cisterciens pour la cause de la mission.

${ }^{91}$ M. Tамм, "Communicating Crusade...», p. 369; Idem, "The Livonian Crusade...», p. 373-376. Albéric, qui connaissait bien le milieu liégeois, a pu être en contact avec d'autres personnages qui disposaient d'informations sur la situation balte, puisque Liège a notamment abrité Théodoric, le compagnon cistercien de Meinhard, lors d'un exil loin de son siège estonien. En outre, le successeur désigné de Baudoin d'Aulne sur le siège épiscopal de Sémigallie semble avoir été lui aussi Liégeois.

92 Par exemple T. Manteuffel, "La mission balte...», p. 110: «les chevaliers [Porte-Glaives] - moines qui se recrutaient dans une grande mesure d'entre les aventuriers et les individus brouillés avec la loi...".

${ }^{93}$ Albéric de Trois-Fontaines, Chronica..., p. 930.

94 M. Aurell, Des chrétiens..., p. 136-137; les critiques visent surtout les impôts servant à financer les expéditions, et le manque de moralité des croisés.

${ }^{9}$ Albéric de Trois-Fontaines, Chronica..., p. 921.

${ }^{96}$ Idem; M. ТАмм, "Communicating Crusade...", p. 367-368. Le commentaire du chroniqueur cistercien est d'autant plus remarquable que le légat italien était plus favorable aux Dominicains
} 
Le célèbre savant et théologien franciscain Roger Bacon n'aurait sans doute pas manqué d'approuver lui aussi ce genre de méthode ${ }^{97}$. L'Opus maius (1268), dédié au pape Clément IV, contient un programme dédié à l'œuvre d'évangélisation, que l'auteur souhaite voir menée par la parole et le raisonnement intellectuel. Partant de l'idée que «la connaissance des langues est nécessaire aux Latins pour la conversion des infidèles", il se montre très critique de la manière dont les ordres militaires mènent la mission «outre-mer, en Prusse et dans les terres voisines de l'Allemagne», où "ils perturbent la conversion des infidèles à cause des guerres qu'ils mènent sans cesse, et parce qu'ils veulent les dominer entièrement ${ }^{98}$. Afin de plaider pour une conversion par la parole et basée sur le raisonnement intellectuel, Bacon s'empare du cas balte, qui lui paraît le plus à même d'illustrer les conséquences fâcheuses de la politique de conversion armée ${ }^{99}$ :

"Il n'y a pas de doute que toutes les nations infidèles au-delà de l'Allemagne auraient été converties depuis longtemps, s'il n'était la violence des frères de l'Ordre teutonique, parce que le peuple des païens était souvent prêt à recevoir la foi en paix, après la prédication. Mais ceux de l'Ordre teutonique ne veulent pas se retenir, parce qu'ils veulent les subjuguer et les plonger dans la servitude, et par des ruses très subtiles, ils trompent depuis de longues années l'Église catholique. ${ }^{100}$

La Papauté a en effet largement légitimé l'action de l'Ordre teutonique, pensé comme le protecteur armé de la mission plus que comme le conquérant que dénonce Bacon, mais il reste difficile de dire que les chevaliers à la croix noire ont leurré l'Église. Cette dernière remarque devait sans doute permettre à l'auteur de se mettre à l'abri, en laissant entendre que Rome n'y est pour rien dans l'installation de l'Ordre sur les rivages baltes ${ }^{101}$.

Cette opinion rappelle celles des chroniqueurs des $\mathrm{XI}^{\mathrm{e}}$ et $\mathrm{XII}^{\mathrm{e}}$ siècles Adam de Brême et Helmold de Bosau, pour qui la rapacité des ducs saxons empêchait d'évangéliser les Slaves ${ }^{102}$ et, pour une époque plus proche de celle de Bacon, le portrait déjà évoqué des Porte-Glaives par Albéric de Trois-Fontaines.

qu'aux Moines Blancs dans le contexte de la mission balte: S. Gouguenherm, «Un Italien dans la Baltique...", p. 141-144; G.-A. Donner, Wilhelm von Sabina..., p. 264-265 passim.

${ }^{97}$ Sur ce qui suit, S. C. Rowell, "Of Men...», p. 91-92; W. Urban, "Roger Bacon...», p. 363-370; J. Tolan, Les Sarrasins: l'islam dans l'imagination européenne au Moyen Âge, Paris 2003, p. 301-306; B. Kedar, Crusade..., p. 177-180; A. Power, Bacon and the defense of Christendom, Cambridge 2013, p. 238; M. Aurell, Des chrétiens..., p. 318-322. Sur la vie et l'oeuvre de Roger Bacon, J. HACKeTt, «Roger Bacon: his life, career and works», dans J. НACкETT (dir.), Roger Bacon and the sciences. Commemorative essays, Leiden 1997, p. 9-23.

${ }_{98}$ Roger Bacon, Opus Maius..., éd. J. H. Bridges, vol. 3, p. 121.

99 A. Grabski, Polska w opiniach obcych..., p. 279.

${ }^{100}$ Roger Bacon, Opus Maius..., éd. J. H. Bridges, vol. 3, p. 122.

101 A. Power, Bacon..., p. 239.

102 Id.; W. URBAN, «Roger Bacon... », passim. 
Au-delà des stéréotypes sur les «mauvais» évangélisateurs, la situation balte est donc loin d'être inconnue des commentateurs d'Europe occidentale au $\mathrm{XIII}^{\mathrm{e}}$ siècle. Enseignant à l'Université de Paris, Bacon a pu avoir vent des plaintes lancées contre l'Ordre teutonique par Albert Suerbeer, archevêque de Riga et d'Armagh en Irlande, qui a passé un certain temps en Angleterre et en France, dans l'entourage d'Innocent IV en exil à Lyon ${ }^{103}$. De même, il est possible que la nouvelle de la conversion de Mindaugas soit parvenue aux oreilles de notre théologien ${ }^{104}$. Même si, comme le remarque William Urban, c'est pour illustrer ses théories sur la mission et non pour défendre leur cause que Bacon s'intéresse aux païens de la Baltique ${ }^{105}$, il n'en reste pas moins que le savant anglais était relativement bien informé à leur sujet.

Les païens baltes réapparaissent dans la partie de l'Opus maius consacrée à la philosophie morale, qui permet d'en savoir plus sur la manière dont l'auteur pensait les gagner au christianisme. Partant de la tradition franciscaine, qui entend prêcher par la parole et la raison, Roger établit plusieurs types de «religions, qui sont par le monde» ${ }^{106}$. Celles-ci, nous dit-il, ne sont pas irrémédiablement mauvaises, mais attestent de l'ignorance des peuples non-chrétiens; néanmoins, tous cherchent à connaître Dieu, du fait même de leur pratique religieuse, qui bien qu'erronée, indique une certaine soif de connaissance. Dans cette vision, si ces gens venaient à rencontrer des missionnaires assez habiles pour leur démontrer la vérité du christianisme, ils seraient sans aucun doute aisément convertis ${ }^{107}$.

Les «Prussiens et les nations voisines» sont choisis comme exemple des païens qui forment la première religion, celle dont les sectateurs «ont le moins de connaissance de Dieu; ils n'ont pas de sacerdoce, mais chacun façonne un dieu selon sa propre volonté, et adore ce qu'il veut, et sacrifie ce qu'il lui plait» ${ }^{108}$. Leur religion est plus simple que celle des idolâtres (autrement dit les bouddhistes), qui adorent plusieurs dieux, mais ont néanmoins des prêtres et des temples, et celle des Tatars, qui vénèrent un dieu unique ${ }^{109}$. Bacon utilise ici les informations rapportées d'Orient par les explorateurs franciscains, Guillaume de Rubrouck et Jean de Plan Carpin,

${ }^{103}$ Ibid., p. 365. Albert Suerbeer a participé au concile de Lyon en 1245: A. Selart, Livonia..., p. 212-213. Sur la dispute entre l'archevêque Albert et les Teutoniques, Ibid., p. 197-198; P. Milliman, The Slippery Memory of Men. The Place of Pomerania in the Medieval Kingdom of Poland, Leiden 2013, p. 55-61.

104 W. Urban, «Roger Bacon... », p. 367.

105 Ibid., p. 363-370.

106 Roger Bacon, Opus Maius..., éd. J. H. Bridges, vol. 2, p. 367. Roger Bacon utilise le terme "secta» dans le sens de "religion», sans connotation péjorative: Z. KALUZA, «L'œuvre théologique de Richard Brinkley, O.F.M.", Archive d'histoire doctrinale et littéraire du Moyen Âge, 64, 1989, p. 194 , n. 60 .

107 J. Tolan, Les Sarrasins..., p. 302-303; B. Kedar, Crusade..., p. 177-178.

${ }_{108}$ Roger Bacon, Opus Maius..., éd. J. H. Bridges, vol. 2, p. 370.

109 Ibid., p. 370. 
qu'il cite explicitement lorsqu'il parle des Tatars ${ }^{110}$. Notre savant a eu l'occasion de rencontrer personnellement Rubrouck à Paris, et a pu s'entretenir avec lui sur la géographie de l'Asie et le mode de vie de ses habitants ${ }^{111}$; il y a lieu de penser que ses informations concernant les Baltes lui sont parvenues d'une manière similaire, vraisemblablement par d'autres franciscains. William Urban imagine qu'il a pu entendre les récits des missionnaires à l'origine du Descriptiones terrarum ${ }^{112}$. Si ceux-ci ont, comme le suppose l'historien américain, voyagé dans le sillage de l'archevêque Albert Suerbeer, notre savant aurait pu les rencontrer et apprendre certains faits de la vie religieuse des Baltes à leur contact ${ }^{113}$. Nous aurons l'occasion d'y revenir dans le chapitre VIII.

Si Roger Bacon n'est pas le premier à essayer de comprendre la religion des Baltes ${ }^{114}$, la nouveauté chez lui consiste à mettre ces connaissances au service d'une théorie sur la mission. Ainsi, la spiritualité simple des Baltes les rendrait faciles à convertir, car ceux qui pratiquent une religion peu élaborée accepteraient plus volontiers les arguments capables de leur démontrer la supériorité du christianisme ${ }^{115}$. En particulier, la croyance des Baltes en un au-delà laisse espérer qu'ils seraient aisément convaincus par des missionnaires leur présentant la doctrine du salut ${ }^{116}$. Ce qui force à penser que c'est bien la violence à laquelle ils sont confrontés qui empêche les Baltes d'être convertis:

"Quand les chrétiens parlent avec des païens comme les Prussiens ou d'autres nations voisines, ceux-ci sont facilement convaincus, et se rendent compte qu'ils sont dans l'erreur. La preuve en est qu'ils deviendraient très volontiers chrétiens, si l'Église leur permettait de garder leur liberté et de profiter de leurs possessions en paix. Mais les princes chrétiens qui travaillent à leur conversion, et spécialement les frères de l'Ordre teutonique, désirent les réduire en esclavage, comme en sont conscients les Dominicains et les Franciscains, ainsi que les autres hommes bons à travers l'Allemagne et la Pologne. Et pour cette raison ils contre-attaquent; c'est contre la violence qu'ils résistent, pas contre la raison d'une religion meilleure. ${ }^{117}$

\footnotetext{
110 Ibid., p. 368-369; F. SCHMIEDER, «Tartarus valde sapiens et eruditus in philosophia. La langue des missionnaires en Asie», dans L'étranger au Moyen Âge. Actes des congrès de la Société des historiens médiévistes de l'enseignement supérieur public, 30 congrès, Göttingen 1999, p. 278, n. 21 ; N. Bouloux, "Les formes d'intégration...", p. 125 sq; D. Woodward et H. Howe, "Roger Bacon on geography and cartography", dans J. Hacketт (dir.), Roger Bacon and the sciences, p. 201-202; M. Guéret -LAFerté, «Le voyageur et le géographe: l'insertion de la relation de voyage de Guillaume de Rubrouck dans l'Opus majus de Roger Bacon", dans La Géographie au Moyen Âge. Espaces pensés, espaces vécus, espaces rêvés, 1998, p. 81-96.

111 N. Bouloux, «Les formes d'intégration...», p. 125-126.

112 W. Urban, «Roger Bacon...», p. 365-366.

${ }_{113}$ Ibid., p. 365-366.

114 Voir chap. VIII.

115 Roger Bacon, Opus Maius..., éd. J. H. Bridges, vol. 2, p. 376.

116 C'est du moins la lecture qu'en fait W. UrBan, «Roger Bacon...», p. 366.

117 Roger Bacon, Opus Maius..., éd. J. H. Bridges, vol. 2, p. 376-377; E. Christiansen, The Northern Crusades..., p. 145-146.
} 
Le dernier argument se rapproche d'une mention que l'on trouve dans la lettre du grand-duc lituanien Gediminas à Jean XXII datée de 1322: "Nous n'attaquons pas les chrétiens pour détruire la foi catholique, mais pour résister aux injustices qui nous sont faites» ${ }^{118}$. Même si rien ne permet d'affirmer que le scribe franciscain du grand-duc ait eu l'œuvre de Bacon en tête, la similitude de l'argumentation est frappante. Sans faire du théologien anglais un inspirateur de Gediminas, on peut supposer qu'un certain point de vue, hostile à la force dans la mission et peut-être surtout à l'Ordre teutonique en tant que rival, avait cours parmi une partie des frères mineurs. Pourtant, les courtes notices de Rubrouck et de Barthélemy l'Anglais relatives à la christianisation de la Prusse et de la Livonie par les Teutoniques indiquent que tous les frères mineurs étaient loin de partager les réticences d'un Bacon quant aux méthodes des moines guerriers.

Même si la peinture du cas balte par l'auteur de l'Opus maius est moins subtile que ce que l'on trouve dans le Descriptiones terrarum, qui précise que l'épée peut être nécessaire pour seconder les missionnaires auprès de certains peuples, une même ligne de pensée émane des deux documents. Cette idée que la douceur devrait être le premier outil employé dans l'œuvre de conversion s'exprime par un exposé théologique pacifique pour Bacon, et par une acculturation par des nourrices pour l'auteur du Descriptiones. Si ce dernier montre un point de vue ambivalent quant à la coercition, le premier condamne radicalement ce style missionnaire, au moins dans le contexte balte ${ }^{119}$, et dresse les Chevaliers teutoniques en contre-modèles. Une position qui s'appuie sur une longue tradition de critique envers l'usage de la force dans la mission, et qui n'est pas sans écho dans l'historiographie ${ }^{120}$.

$\mathrm{Du}$ reste, les critiques contre les actions des Teutoniques ne sont pas isolées dans l'Europe du XIII siècle: ainsi, un clerc de Passau mentionne vers 1260 que les hérétiques vaudois, qui sont d'une manière générale opposés à la croisade, "condamnent ceux qui prêchent la croix, [disant] que les Prussiens et les païens ne deuraient pas être forcés à la foi par le glaive, mais attirés par la prédication» ${ }^{121}$. En 1272, le dominicain français Humbert de Romans, qui entend favoriser la croisade «missionnaire» en Terre sainte, écrit dans son Opusculum tripartitum adressé au pape Grégoire X que les Prussiens sont en passe d'être convertis et pacifiés ${ }^{122}$. À la

\footnotetext{
118 GL, p. 27.

119 Roger Bacon n'est pas un pacifiste absolu: reconnaissant qu'un certain nombre d'infidèles ne pourraient pas être convertis, même par des missionnaires appliquant ses méthodes, il recommande d'utiliser des techniques scientifiques pour les vaincre. Celles-ci, par exemple les miroirs censés terroriser les défenseurs et ainsi permettre de prendre Jérusalem sans effusion de sang, relèvent presque de la guerre psychologique: B. Kedar, Crusade..., p. 178-180.

${ }^{120}$ S. Gouguenheim, Les Chevaliers teutoniques..., p. 412-413; par exemple, E. Lavisse, Études sur l'histoire de la Prusse, Paris 1879, p. 116-117.

121 A. Patschovsky, K.-V. Selge (éd.), Quellen zur Geschichte der Waldenser, Gütersloh 1973, cité et traduit par B. Kedar, Crusade..., p. 174.

${ }^{122}$ Humbert de Romans, Opusculum Tripartitum, dans Fasciculum Rerum Expentendarum et Fugiendarum (Appendix), éd. E. Brown, Londres 1690, p. 195. Sur l'auteur, voir
} 
fin du siècle, le poète allemand anonyme surnommé «le Chancelier» qualifie les croisades de Prusse de "Pillage et incendies sur le chemin de Dieu» ${ }^{123}$. Toutefois, ces critiques restent relativement marginales, et relèvent plus de réflexions individuelles, ou de tendances minoritaires internes aux ordres religieux; dans l'ensemble, l'Église maintient un soutien mesuré mais constant à l'Ordre teutonique.

Dans la première moitié du XIv ${ }^{\mathrm{e}}$ siècle, les déboires des Chevaliers n'ont pas été sans retentissement en Europe de l'Ouest, même au-delà de l'administration pontificale. Il nous reste au moins un document composé dans la région du lac de Constance qui rend compte des procès intentés par l'archevêché de Riga (1310-1312) puis par le royaume de Pologne (1320-1321, 1339), ainsi que de l'affaire des lettres de Gediminas. Le chroniqueur franciscain Jean de Winterthour (m. v. 1348) montrait un vif intérêt pour les affaires de son ordre en Europe centrale et plus largement, pour le conflit entre le Pape et l'Empereur. Partisan de ce dernier, il commente la position de l'Ordre teutonique dans les années 1340, et revient sur la proposition de baptême adressée par Gediminas quelque temps auparavant ${ }^{124}$ :

"En ces temps-là, comme j'en ai été informé par une relation digne de foi, les porte-croix [cruciferi - autrement dit, les Chevaliers teutoniques] qui possédaient déjà une longue et large province en Prusse, réduirent sous leur domination une grande partie du royaume du roi de Lituanie, à qui ils firent la guerre avec puissance. Dans le but de la récupérer, celui-ci promit fermement de recevoir la foi catholique. Mais quand [les Teutoniques] refusèrent de faire ce qui devait être fait, le roi de Lituanie dit: "En cela, je comprends clairement qu'ils ne veulent pas ma foi, comme ils le simulent, mais mon argent: ainsi, je reste dans le paganisme". Au sujet de ces croisés on rapporte la parole lamentable, et si cela est vrai, hostile à la vraie foi - qu'il n'en soit rien! - qu'ils préferent laisser tous les païens dont ils ont fait leurs tributaires par la guerre dans le paganisme et sous leur tribut, plutôt que les exempter de taxes et de les laisser devenir des pratiquants de la foi catholique, comme ils le réclamaient pieusement et le réclament encore de nos jours. ${ }^{125}$

Humbert de Romans, De Predicatione Crucis, éd. V. Portnykh, Turnhout 2018; E. Christiansen, The Northern Crusades..., p. 152.

${ }^{123}$ Deutsche Liederdichter des 13. Jahrhunderts, éd. C. von Kraus, Tübingen 1952 (réimpr. 1978), p. 209; trad. D. Buschinger, M. Olivier, Les Chevaliers teutoniques..., p. 121.

124 S. C. Rowell, "Of Men...», p. 92-93; S. C. Rowell, "Lithuania and the West», Journal of Baltic Studies 20/4, 1989, p. 307-308. Jean de Winterthour ne respectant pas une chronologie stricte dans sa chronique, rien n'indique que l'acompte de la conversion avortée d'un "rex Litaonie» insérée entre des événements datés de 1343 doive être rapporté à la même année. On peut donc suivre S. C. Rowell, id., qui suppose que Jean de Winterthour a inséré l'affaire des «lettres de Gediminas", relative à une époque antérieure, pour introduire le contentieux entre la Pologne, Riga et l'Ordre teutonique, lequel aboutit à la paix de Kalisz en 1343.

${ }^{125}$ Jean de Winterthour, Die Chronik Johanns von Winterthur, éd. F. Baethgen, Berlin 1924, p. 202; Idem, Die Chronik Johann's von Winterthur, trad. B. Kreuler, Winterthour 1866, p. 257. 
Même si Jean de Winterthour est plutôt hostile à Jean XXII ${ }^{126}$, force est de constater que les méfaits qu'il attribue (non sans une certaine hésitation) à l'Ordre sont dans la droite ligne des accusations portées par les partisans du camp pontifical. Comme le rappelle Rasa Mažeika, la formulation «recipere fidem katholicam» est précisément celle employée dans les lettres que Gediminas a envoyées au pape, aux ordres mendiants et aux villes d'Europe du Nord entre 1322 et $1324^{127}$; de même, la manière dont le «roi» de Lituanie refuse le baptême rappelle l'explication que donnent les envoyés des légats de Jean XXII qui ont eu l'occasion de s'entretenir avec le grand-duc. Il y a donc lieu d'identifier le «rex Litaonie» avec Gediminas ${ }^{128}$. Le chroniqueur suisse a sans doute été, comme Bacon avant lui, informé des affaires baltes par des collègues franciscains, à moins qu'il ne doive ses informations au seul «chevalier du roi de Cracovie" qu'il cite comme informateur ${ }^{129}$. Jean de Winterthour continue en effet en rapportant que:

"L'archevêque de Riga, de l'ordre des frères mineurs, a levé ces accusations contre eux devant le pape il y a plusieurs années, alors qu'il menait un procès contre eux pour l'une de ses terres. On raconte aussi qu'ils n'envahissent pas uniquement les terres des princes infidèles, mais aussi des fidèles, comme le roi de Cracovie, à qui, dit-on, ils ont violemment pris deux terres. Jusqu'à aujourd'hui, celui-ci, bien qu'il soit un roi fort et puissant, ne peut se défendre contre eux, ni reprendre les terres usurpées de leurs mains, tout comme c'est le cas du roi païen de Lituanie, qui a neuffils, comme l'a dit un chevalier du roi de Cracovie.» ${ }^{130}$

Ce dernier est sans doute Casimir le Grand, le fils de Ladislas le Bref, qui a conclu la paix de Kalisz avec les Chevaliers teutoniques en 1343, c'est-à-dire à la période où l'on peut situer les événements racontés dans la chronique avant et après cet épisode ${ }^{131}$. Le fait que Casimir ait eu les mêmes démêlés que son père avec l'Ordre (on lui doit notamment un procès en 1339) permet au chroniqueur de revenir sur les querelles des deux décennies passées ${ }^{132}$. En liant explicitement les propos du «roi de Lituanie» déçu par l'attitude des Teutoniques aux accusations de l'archevêque de Riga, puis aux dommages faits à la Pologne tels que rapportés par un chevalier de ce pays, le texte fait apparaître toute la trame

126 I. Heullant-Donat, «En amont de l'observance», dans F. Meyer, L. Viallet (dirs.), Identités franciscaines à l'âge des réformes, Clermont-Ferrand 2005, p. 87.

127 GL, doc. 2, p. 27 ; doc. 3, p. 29; S. C. RowelL, "Of Men...», p. 92-93; Idem, "Lithuania and the West...", p. 308.

${ }^{128}$ Ibid., p. 308.

129 Ibid., p. 316.

${ }^{130}$ Jean de Winterthour, Die Chronik..., éd. F. Baethgen, p. 202-203.

131 S. Gouguenheim, Les Chevaliers teutoniques..., p. 478-479; le texte du traité est édité et traduit par W. Hubatsch dans Quellen..., doc. 20, p. 140-145.

132 S. C. Rowell, "Lithuania and the West...", p. 307-308. 
des alliances du début du XIv ${ }^{e}$ siècle ${ }^{133}$. Un franciscain suisse, intéressé par le conflit entre Jean XXII et Louis de Bavière, a donc un avis relativement bien informé sur les affaires baltes. Ses sources polonaises et peut-être franciscaines sont certes biaisées, mais le fait qu'il prenne quelque distance avec les propos de ses informateurs indique qu'il était conscient de rapporter le point de vue des adversaires des Teutoniques. Néanmoins, les charges concernant le manque de zèle à convertir les païens et l'oppression politique qu'on leur imposerait n'étaient visiblement pas rares dans l'Europe du XIv siècle. Les critiques que l'on a pu lire sous la plume de Roger Bacon et d'auteurs moins célèbres au siècle précédent paraissent avoir été réanimées par les procès internationaux et par les démarches du grand-duc de Lituanie Gediminas.

\section{L'ALTERNATIVE LITUANIENNE}

Mis en difficulté par les procès retentissants engagés par Riga et la Pologne, les Chevaliers teutoniques entendent défendre leur réputation et s'intégrer davantage dans les réseaux des puissances européennes ${ }^{134}$. C'est à cette tâche que se consacre le grand-maître Charles de Trèves, élu en $1311^{135}$. Ayant rempli différentes charges en France et en Lorraine ${ }^{136}$, l'homme est un familier du monde francophone. D'après le chroniqueur Pierre de Dusbourg, «il connaissait le français comme sa propre langue et il parlait au pape et aux cardinaux sans interprètes. Il était si aimable et éloquent que même ses ennemis se plaisaient à l'écouter» ${ }^{137}$. Charles de Trèves parvient à maintenir de relativement bons contacts avec Rome, ce qui évite une marginalisation dangereuse ${ }^{138}$. Sous

\footnotetext{
${ }^{133}$ Ibid., p. 308, considère que les deux terres prises au roi de Pologne sont sans doute la Poméranie et la Terre de Dobrzyń, que Ladislas le Bref essayait de récupérer par le procès de 1321. Son fils Casimir le Grand fera une nouvelle tentative en 1339, avant de signer une paix avec l'Ordre en 1343, date à laquelle cet épisode se rapporte dans la chronique.

${ }_{134}$ W. Paravicini, «La Prusse...», p. 178, montre que l'Ordre était très présent dans les principautés de l'actuelle Belgique et des Pays-Bas, un peu moins en Italie et en Espagne, et de manière encore plus rare en France, où H. d'Arbois de Jubainville ("L'Ordre teutonique... », p. 167 sq.) n'identifie que quatre commanderies au début du XIV siècle. Voir aussi K. Polejowski, "Les comtes de Brienne...", p. 4-8. Notons que les commanderies teutoniques en France ne servant pas de relais pour l'appel à la croisade, elles ne jouaient pas de rôle important dans le mouvement de la croisade balte: PR 1, p. 91; K. Polejowski, "The Teutonic Order's Propaganda in France during the Wars against Poland and Lithuania (Fifteenth Century)", dans K. Borchardt, L. Jan (dirs.), Die geistlichen Ritterorden in Mitteleuropa. Mittelalter, Brno 2011, p. 235. Sur le contexte, notamment PR 1, p. 23-24.

135 N. Housley, The Avignon papacy..., p. 271. Voir notamment U. Niess, Hochmeister Karl von Trier (1311-1324). Stationen einer Karriere im Deutschen Orden, Marburg 1992.

${ }^{136}$ Il a notamment été commandeur de Beauvoir pendant dix ans, de 1301 à 1311;

S. Gouguenheim, Les Chevaliers teutoniques..., p. 327-328.

137 Pierre de Dusbourg, Chronicon..., III, 314, SRP 1, p. 178; S. Gouguenheim, Les Chevaliers teutoniques..., p. 327.

${ }^{138}$ Ibid., p. 328.
} 
son successeur, Werner d'Orseln (1324-1330), le temps de la contre-attaque est venu: accusés par leurs voisins de faillir à leur mission, les hommes de Marienbourg entendent montrer que leur rôle reste celui qui leur a été assigné au début de l'aventure prussienne.

L'échec de la tentative de conversion de Gediminas est une aubaine pour l'Ordre, qui peut affermir ses positions tout en discréditant ses adversaires ${ }^{139}$. Un événement survenu quelques années plus tard vient renforcer sa cause ${ }^{140}$ : en février 1326, le roi de Pologne Ladislas le Bref fait appel aux services d'un prince lituanien, David de Grodno, qui mène une armée contre le margrave de Brandebourg, fils de l'empereur Louis IV et allié des Chevaliers teutoniques ${ }^{141}$. Si l'on croit ce que rapportent certains chroniqueurs d'Europe centrale et occidentale ${ }^{142}$, l'emploi de mercenaires lituaniens par le roi de Pologne aurait été sanctionné par le pape, qui n'hésitait pas à faire appel à des souverains infidèles mais favorables aux chrétiens pour atteindre ses buts ${ }^{143}$. Jean XXII, qui avait appelé les princes à se soulever contre l'empereur, n'a probablement pas hésité à soutenir une alliance polono-lituanienne contre son rival, d'autant plus que l'on espérait toujours - au moins formellement - la conversion de Gediminas $^{144}$. Rappelons encore qu'il était conforme au droit canon d'utiliser des infidèles dans une guerre considérée comme juste; de son point de vue, Jean XXII ne fautait donc pas ${ }^{145}$. Pourtant, les dévastations que les Lituaniens font subir à une terre d'Empire n'ont pas manqué de choquer certains chroniqueurs. Jean de Winterthour, qui compte au rang des adversaires du pape français, raconte les atrocités et les blasphèmes qui accompagnent la progression des «païens» au Brandebourg, dans un style qui n'est pas sans rappeler les descriptions des exactions païennes des premiers siècles de la conquête des pays baltes $^{146}$. Ajoutons que pour lui, ce ne sont pas les Lituaniens qui sont tenus pour responsables de ce "fait exécrable», mais bien le pape en personne ${ }^{147}$.

Le récit du chroniqueur suisse sur l'attaque du Brandebourg, tout stéréotypé qu'il soit ${ }^{148}$, n'en reflète pas moins l'indignation qui s'est propagée en Europe, au moins parmi les partisans de l'empereur. Alors que de nombreuses voix s'élèvent dès le XIII ${ }^{\mathrm{e}}$ siècle pour rappeler les droits des convertis et prôner une

\footnotetext{
139 W. Urban, The Samogitian Crusade..., p. 74.

140 Ibid., p. 77-78; S. C. Rowell, Lithuania Ascending..., p. 234-237.

${ }^{141}$ Conformément à la paix signée en 1324, ceux-ci ont laissé passer les troupes lituaniennes: Ibid., p. 235.

${ }^{142}$ L'attaque menée par les Lituaniens contre le Brandebourg est mentionnée par les chroniqueurs Jean de Winterthour, Henri de Selbach (dit «le sourd») et Guillaume d'Egmond; Ibid, p. 235-236.

${ }_{143}$ Ibid., p. 236.

144 Ibid., p. 236, n. 38.

145 Ibid., p. 236-237.

146 Jean de Winterthour, Die Chronik..., éd. F. Baethgen, p. 101-103.

147 Ibid, p. 101.

${ }^{148}$ La désacralisation d'hosties en particulier est un topos attaché aux prétendues atrocités des infidèles; D. Baronas, "Christians in Late Pagan... », p. 63.
} 
mission pacifique, ce tristement célèbre épisode tombe à pic pour rappeler que les Lituaniens sont loin d'être inoffensifs: ainsi, les grands-ducs auraient beau jeu d'ouvrir leur pays aux missionnaires quand eux-mêmes refusent la conversion au dernier moment et continuent de malmener leurs voisins chrétiens ${ }^{149}$. Pour les défenseurs des Chevaliers teutoniques, la conclusion est sans appel: la conversion pacifique étant inefficace et inutile, seule la force permet de triompher de ces irréductibles païens. En somme, s'ils veulent réussir la mission qui leur a été confiée, les Chevaliers sont obligés de se montrer implacables ${ }^{150}$. Leur argumentation est à rapprocher de l'avis du canoniste Hostiensis (mort en 1271), pour qui les païens ont perdu tous leurs droits depuis l'arrivée du Christ sur la terre, et peuvent donc être spoliés ou tués sans que cela ne constitue une faute morale ${ }^{151}$.

C'est dans ce contexte que Pierre de Dusbourg, un prêtre de l'Ordre teutonique, compose sa Chronicon Terrae Prussiae (1326 - continué jusque vers $1330^{152}$ ) sur la commande du grand-maitre Werner d'Orseln, qui avait semblet-il besoin d'arguments légaux pouvant être envoyés aux défenseurs à la Curie; la chronique est donc avant tout une justification de l'existence prussienne de l'Ordre ${ }^{153}$. Concrètement, il s'agit d'expliciter sa mission: «Explicit bellum Prussie. Incipit bellum Lethowinorum» "154. Autrement dit, après avoir conquis et pacifié la Prusse, les Teutoniques se dressent contre les Lituaniens. Commence alors une nouvelle étape de la guerre contre les ennemis de la foi, à laquelle ont déjà pris part, du temps où le chroniqueur écrit, de nombreux princes et chevaliers venus de toute la Chrétienté ${ }^{155}$. Le système d'autoreprésentation proposé par Dusbourg repose sur une interprétation guerrière des Écritures, illustrée par les héros belliqueux de l'Ancien Testament, en premier lieu les Macchabées ${ }^{156}$. Radicalisant le propos, un plaidoyer théologique écrit autour de 1335 par un clerc membre de l'Ordre teutonique affirme que celui-ci est une institution d'origine divine, équivalent à la Jérusalem céleste, et que ses

\footnotetext{
149 N. Housley, The Avignon Papacy..., p. 273-274.

150 Ibid., p. 271-272. E. Christiansen, The Northern Crusades..., p. 152-154, fait référence à un rapport envoyé quelque temps plus tôt (1273) au pape Grégoire X par l'évêque Bruno d'Olomouc, partisan du roi de Bohême Ottokar Přemysl, l'hôte de l'Ordre teutonique en 1255: Bruno d'Olomouc, Relationes Episcopi Olomucensis Pontifici Porrectae, éd. J. Schwalm, MGH Const. 3, Hanovre 1906, doc. 620, p. 589-594.

151 S. C. Rowell, "Custom...», p. 47.

152 PR 1, p. 21, n. 4.

153 S. Gouguenheim, Les Chevaliers teutoniques..., p. 406-407; R. MažEıKA, «Violent victims... », p. 123-137.

154 SRP 1, p. 146.

155 PR 1, p. 22-24.

156 S. Gouguenheim, «Les guerres des ordres militaires furent-elles des guerres chevaleresques? L'exemple de la conquête de la Prusse par l'Ordre teutonique (1230-1283)", dans M. Aurell et C. Girbea (dirs.), Chevalerie et christianisme..., p. 307-313.
} 
adversaires - en l'occurrence, l'archevêque de Riga! - ne sauraient être que des suppôts de Satan ${ }^{157}$.

Le but visé par ce nouveau "profilage» idéologique est bien sûr de rappeler le rôle de l'Ordre teutonique comme défenseur de la Chrétienté; en somme, affirmer qu'il ne s'est pas installé en Prusse en usurpateur mais en protecteur des chrétiens, et qu'il s'est entièrement dédié à la tâche de défendre ceux-ci contre les agressions des païens. Les religieux chargés de prêcher la croisade - souvent des dominicains ou des membres de l'Ordre teutonique - utilisent les arguments qui ont servi au XIII ${ }^{\mathrm{e}}$ siècle contre les Prussiens, à savoir la tâche de combattre les ennemis de la croix et de protéger les fidèles ${ }^{158}$. Les Chevaliers s'appuient sur les documents et les privilèges qui leur ont été conférés par la Papauté au siècle précédent, notamment les lettres d'Alexandre IV, qui les autorisent à prêcher la croisade et leur permettent de donner des indulgences à ceux qui se joignent à leur combat ${ }^{159}$. L'habitude ayant été prise, l'Ordre peut continuer cette pratique tout au long du XIV ${ }^{\mathrm{e}}$ siècle, sans que la Papauté n'y trouve à redire ${ }^{160}$.

Les expéditions prussiennes procurent ainsi à la noblesse européenne une alternative au voyage en Palestine, rendu de plus en plus difficile depuis la chute des États latins ${ }^{161}$. Que la guerre en Lituanie puisse être considérée comme une croisade au sens "canonique» du terme ou non ${ }^{162}$, tout porte à croire qu'elle fut regardée comme telle par les contemporains, qui se souviennent du rôle joué depuis quelque temps par l'Ordre comme champion de la Chrétienté en Europe du Nord-Est ${ }^{163}$. Le point de vue des dirigeants occidentaux peut être résumé dans une lettre envoyée en 1366 par Urbain V à l'empereur Charles IV, et qui qualifie l'Ordre de «mur très sûr de la Chrétienté, glorieux propagateur de la foi chrétienne et assaillant magnifique des infidèles ${ }^{164}$. Le rôle des Teutoniques est pensé comme celui d'un bras armé, qui, sous le contrôle de Rome, doit protéger

\footnotetext{
157 S. Gouguenheim, Les Chevaliers teutoniques..., p. 413-414.

158 W. Urban, The Samogitian Crusade..., p. 20-21. Il ne nous reste que peu d'information en ce qui concerne la prédication de la croisade contre la Lituanie au cours du XIV ${ }^{e}$ siècle; il semble néanmoins que des campagnes de recrutement aient eu lieu et que celles-ci étaient organisées par l'Ordre, au bénéfice de privilèges reçus au XIII ${ }^{\mathrm{e}}$ siècle: A. EHLERs, "The crusade against Lithuania...", p. 41.

159 A. Ehlers, "The use of Indulgences...», p. 142; Idem, Die Ablasspraxis..., p. 38-50.

160 Occasionnellement, le pape accorde directement une indulgence à un grand seigneur et à sa troupe, comme à Thomas Beauchamp et à Henri de Lancastre. A. Ehlers, "The crusade against Lithuania...", p. 21-44.

${ }^{161}$ La notion de croisade balte comme «alternative» est notamment utilisée par A. Ehlers en ce qui concerne la commutation des vœux (même s'il n'est pas nécessaire de se vouer pour participer à une expédition en Prusse) : Ibid., p. 35 ; aussi PR 1, p. 24 . Sur l'attitude générale de la Papauté vis-à-vis de la croisade menée par l'Ordre au xive siècle, N. Housley, The Avignon Papacy..., p. 292.

162 Sur ce point, ibid., p. 101, 272; A. Ehlers, "The Crusade against Lithuania... », p. 23-24.

${ }^{163}$ Ibid., p. 42-44.

${ }_{164}$ Raynaldus, XVI, a. 1366, p. 463, cité dans J. Jakstas, Das Baltikum..., p. 156.
} 
les terres chrétiennes limitrophes des attaques des païens et soumettre ceux-ci avant de les évangéliser ${ }^{165}$.

Ce qui ne semble constituer, au fond, qu'un retour au "bon vieux temps" de la conquête de la Prusse se double en réalité d'une transformation plus profonde, qui induira un rapprochement du monde balte et de l'Europe occidentale, au travers non plus de rares missionnaires et émissaires pontificaux, mais de nombreux chevaliers amenés à faire le déplacement pour combattre aux côtés des Teutoniques. Malgré quelques tentatives visant à garantir un certain niveau moral parmi ses troupes, le visage de l'Ordre se fait plus chevaleresque et mondain, moins "monastique»; pour Karol Górski, "le règne de Winrich von Kniprode (1351-1382) apporta le triomphe de l'esprit laïque parmi les chevaliers» ${ }^{166}$. Le jugement de l'historien polonais, qui fait référence à la période faste des croisades contre la Lituanie, est bien sûr péremptoire, mais il exprime un phénomène sur lequel on doit s'arrêter.

Il demeure difficile de séparer l'histoire de l'Ordre teutonique et de la croisade balte en deux phases distinctes - l'une "spirituelle» et monastique contre les Prussiens au XIII ${ }^{e}$ siècle, l'autre "temporelle» et chevaleresque au siècle suivant contre les Lituaniens - ou de prétendre que les membres de l'Ordre cachaient, plus ou moins bien selon les époques, leurs ambitions territoriales sous un vernis religieux. En effet, si les aspects spirituels et temporels étaient bel et bien présents côte à côte dans l'autoreprésentation de l'Ordre, ils n'étaient pas nécessairement antagonistes. Il serait anachronique de concevoir le christianisme médiéval, du moins dans sa version aristocratique et chevaleresque, comme détourné du monde; non seulement la violence, surtout tournée vers des "ennemis de la foi», était acceptable pour l'essentiel des chevaliers, mais encore l'honneur pouvait se confondre avec une prouesse militaire exécutée au service de Dieu ${ }^{167}$. De la même manière, depuis la première croisade au moins, il était communément admis que participer à une "guerre sainte» contre les ennemis de l'Église pouvait trouver une récompense légitime dans l'accroissement de la richesse ou du pouvoir ${ }^{168}$. La culture des guerriers médiévaux ne souffrait pas de contradiction entre soif d'avantages matériels, souci de sa propre renommée, et désir sincère de servir Dieu ${ }^{169}$ : l'Ordre teutonique ne faisait aucunement

\footnotetext{
165 Ibid., p. 156-159.

166 K. GóRsKI, «L'Ordre teutonique...», p. 293. Sur la culture de cour dans l'État de l'Ordre teutonique, W. Paravicini, «Von der ritterlichen zur höfischen Kultur: Der Deutsche Orden in Preußen", dans J. Wenta et al. (dirs.), Mittelalterliche Kultur und Literatur im Deutschordensstaat in Preussen: Leben und Nachleben, Torun 2008, p. 15-54.

${ }^{167}$ N. Housley, "One man and his wars: the depiction of warfare by Marshal Boucicaut's biographer", Journal of Medieval History 29/1, 2003, p. 31-32; J. РАVIOT, "Boucicaut et la croisade", dans M. Nejedlý, J. Svátex (dirs), La noblesse et la croisade à la fin du Moyen Âge (France, Bourgogne, Bohême), Toulouse 2009, p. 82-83

168 J. FloRI, La Guerre sainte..., p. 320-323.

169 S. Vander Elst, "Chivalry...», p. 290.
} 
exception, pas plus que les laïcs qui venaient lui prêter main forte ${ }^{170}$. Le roi Ottokar de Bohême, qui a aidé à la conquête de la Sambie en 1255 et dont les successeurs resteront traditionnellement liés à l'Ordre, entendait sans doute tirer de son exploit une gloire utile: en 1273, l'un de ses partisans, l'évêque Bruno d'Olomouc, écrit au pape Grégoire X pour souligner qu'Ottokar, défenseur des marges orientales de la Chrétienté, mériterait le titre impérial, et qu'il était plus urgent de se protéger contre les Lituaniens, les Ruthènes et les Coumans que d'essayer de récupérer Jérusalem ${ }^{171}$.

En outre, une certaine inclinaison «chevaleresque» se fait sentir dans plusieurs productions littéraires de l'Ordre teutonique, à commencer par l'adaptation vernaculaire de l'œuvre de Dusbourg; Stefan Vander Elst a remarqué que la Krônike von Prûzinlant de Nicolas de Jeroschin (v. 1331-1341) utilise un style (versifié), une structure et une langue adaptée au milieu aristocratique des terres germanophones de l'Empire. En y ajoutant plusieurs anecdotes rappelant les romans courtois plutôt que la chronique au ton très religieux de Dusbourg, l'auteur cherchait sans doute à plaire à un public noble ${ }^{172}$. Pour reprendre Sylvain Gouguenheim, cette chronique aux couleurs de poème épique "arrive à point nommé pour galvaniser ceux qui viennent combattre en Lituanie» ${ }^{173}$. Le nombre de manuscrits retrouvés et leur dispersion géographique indiquent que la Krônike von Prûzinlant a été diffusée bien au-delà de la Prusse; elle a eu en tout cas plus de succès que la version latine originale ${ }^{174}$. Dans la même optique, la Chronicon Livoniae d'Hermann de Wartberge (v. 1378), chapelain du maître de Livonie, justifie la raison d'être de l'Ordre par la seule bravoure de ses membres ${ }^{175}$. L'on y parle surtout hauts faits et batailles, tout comme dans la chronique rimée que compose vers 1394 Wigand de Marbourg, le héraut du grand-maître Conrad de Wallenrode, à une date où la Lituanie était déjà chrétienne. Ces textes, destinés à un public de nobles intéressés avant tout par la chose militaire, avaient pour but de fixer l'image chevaleresque des Teutoniques, aussi peut-on postuler qu'ils étaient lus lors des repas réunissant les membres de l'Ordre et leurs hôtes ${ }^{176}$.

Paradoxalement, la chute d'Acre, qui avait entraîné une certaine exaspération envers les ordres militaires, participe à redorer le blason de l'Ordre teutonique. Au début du XIV ${ }^{e}$ siècle, la Méditerranée orientale garde un fort attrait pour de nombreux chevaliers en quête de gloire et de profits, mais aucune entreprise

\footnotetext{
170 M. GŁadysz, The Forgotten Crusaders..., p. 333-345.

171 Bruno d'Olomouc, Relationes... p. 589-594. PR 1, p. 34. K. GóRsKI, "The Author... », p. 257, remarque toutefois que l'évêque Bruno ne mentionne pas le rôle des Teutoniques dans les exploits de son patron.

172 S. VANder Elst, "Chivalry...", p. 287-328.

173 S. Gouguenheim, Les Chevaliers teutoniques..., p. 407.

174 Id.; R. G. PÄSLER, Deutschsprachige Sachliteratur..., p. 279-281.

175 R. Mažeika, L. Chollet, «Familiar Marvels? ... », p. 53-54.

176 S. Gouguenheim, Les Chevaliers teutoniques..., p. 408, 414-415.
} 
ne parvient à capitaliser sur cet élan pour relancer une offensive majeure ${ }^{177}$. La perte du dernier bastion latin interdisant de facto toute nouvelle expédition en Palestine, la Prusse apparaît pour ceux qui avaient fait le vœu de se rendre en Terre sainte comme un nouveau terrain de croisade possible ${ }^{178}$. La lutte contre les païens baltes change alors de visage: jusque là, les appuis venaient surtout de Scandinavie, des régions septentrionales de l'Empire et d'Europe centrale $^{179}$, l'engagement d'Occidentaux restant rare au XIII ${ }^{\mathrm{e}}$ siècle. Certes, un procès d'armoirie engagé devant la cour du roi d'Angleterre Richard II révèle qu'un certain Robert Morley serait mort aux côtés des Teutoniques autour de 1288; des témoins étaient capables d'affirmer que son corps reposait en Prusse, alors que son cœur avait été ramené en Angleterre ${ }^{180}$. De même, Jean Cabaret d'Orville raconte dans sa Chronique de Savoie (v. 1416) qu'un certain Humbert, fils du comte Thomas I ${ }^{\text {er }}$ de Savoie, serait tombé en combattant le "roy de Leyto" au côté du "Grant Maistre de Prusse», en 1235 déjà ${ }^{181}$. Ces deux personnages seraient-ils des pionniers du "voyage en Prusse», ou indiqueraient-ils que des seigneurs d'Europe occidentale participaient à la guerre balte bien avant le XIv ${ }^{\mathrm{e}}$ siècle? Pour le cas de Robert Morley, il s'agit sans doute d'une erreur induite par la popularité des rèses à la fin du XIV ${ }^{e}$ siècle, époque où le document a été produit ${ }^{182}$. Le deuxième exemple est plus difficile à réfuter, car une tradition historiographique indépendante de Cabaret d'Orville relate également la mort d'Humbert de Savoie face aux Prussiens, en citant le nom de Conrad de Mazovie; pour Werner Paravicini, ce personnage a donc effectivement pu se rendre en Prusse, peut-être même avant l'arrivée des Chevaliers teutoniques ${ }^{183}$. Si l'on se souvient du Flamand Hugues Butyr et du Wallon Alexandre de Malonne, engagés dès le XII ${ }^{\mathrm{e}}$ siècle dans la lutte contre les Prussiens, on doit en déduire que quelques individus pouvaient être amenés à accomplir leurs destins de guerriers de Dieu en Europe du Nord-Est ${ }^{184}$. De tels cas étaient néanmoins exceptionnels, et c'est un mouvement de bien plus grande ampleur qui s'empare de la noblesse occidentale dans la seconde moitié du XIv ${ }^{\mathrm{e}}$ siècle.

\footnotetext{
177 N. Iorga, Philippe de Mézières (1327-1405) et la croisade au XIV siècle, Paris 1896, p. 31-44.

178 E. Christiansen, The Northern Crusades..., p. 154-155.

179 PR 1, p. 21-23. À titre d'exemple, le dernier noble laïc connu à avoir participé à la conquête de la Prusse est un Saxon, Thierry, margrave de Misnie, en hiver 1272-1273: Pierre de Dusbourg, Chronicon..., III, 133, SRP 1, p. 116.

${ }^{180}$ PR 1, p. 121; T. Guard, Chivalry, Kingship and Crusade. The English Experience in the Fourteenth Century, Woodbridge 2013, p. 84.

181 Jean Cabaret d'Orville, Chronique de Savoye, éd. D. Chaubet, Chambéry 2006, p. 97-98.

${ }_{182}$ PR 1, p. 121, n. 518a.

183 Il s'agit de Samuel Guichenon, Histoire généalogique de la royale maison de Savoie, vol. 1, Lyon 1660, p. 255; PR 3/1, Abschnitt 2 a (12) (à paraître).

184 C. Tyerman, England..., p. 267, mentionne également le cas d'un certain évêque Thomas, un Anglais qui aurait essayé de convertir la Finlande en 1230, mais le considère comme exceptionnel.
} 
Relativement méconnue des auteurs du Haut Moyen Âge, cette nouvelle terre de mission et de croisade qu'est la Baltique attire les regards de l'élite intellectuelle européenne. Pendant longtemps, l'intérêt est essentiellement lié à la progression de la foi dans ces contrées. Si quelques poètes d'expression allemande mentionnent les croisades contre les Slaves et les Baltes, leurs pairs francophones semblent négliger le combat mené dans le Nord ${ }^{185}$. La Pologne, le grand royaume chrétien confinant à la Baltique, attire bien quelques ecclésiastiques et chevaliers lotharingiens, mais pas assez pour que des liens durables s'établissent entre noblesses polonaise et française ${ }^{186}$. Les choses changent au cours du XIV e siècle, lorsque la participation aux croisades baltes de nombreux Français et Anglais met l'aristocratie en contact direct avec cette périphérie du monde chrétien ${ }^{187}$.

\footnotetext{
185 Plusieurs chercheurs ont tenté de reconnaître des ethnonymes baltes dans la Chanson de Roland. Pour K. Kựavin̦š, «Le tracé de l'identité européenne de l'Espagne aux Pays Baltes», dans F. Sabaté (éd.), Identities on the Move..., p. 98, les "Leus» (v. 3258) seraient les Lives. Quant aux «Pinceneis» (v. 3241), leur ethnonyme rappelle les «Pincenati», qui pour Adémar de Chabannes sont les Prussiens, mais dont le nom peut aussi désigner les Petchénègues, un peuple turcophone d'Europe orientale. L'auteur d'une édition récente du texte, Cesare Segre, préfere y voir ces derniers ( $L a$ Chanson de Roland, éd. C. Segre, M. Tyssens, B. Guidot, vol. 1, Genève 2003, p. 309); sans doute est-ce aussi le cas des «Pincenars» (v. 1289) de la Chanson des Saxons de Jean Bodel (éd. F. Menzel, E. Stengel, vol. 1, Marbourg 1906, p. 77). Les «Esclavoz» (v. 3225) sont mentionnés dans la Chanson de Roland parmi les peuples alliés de Marsile; s'il peut s'agir des païens slaves de la Baltique, on peut aussi y voir, d'une manière plus générale, les Slaves récemment christianisés de l'Europe centrale.

186 N. Berend et al., Central Europe..., p. 263; A. Grabski, «La Pologne ... », p. 23-25.

${ }^{187}$ L'importance des croisades de Terre sainte, mais aussi de celles d'Espagne et d'Albi, a sans doute également joué un rôle dans le désintérêt de la noblesse française pour les affaires baltes: M. Tамм, "Communicating Crusade... », p. 369; S. Gouguenheim, «Das Echo... », p. 193-194; E. Maschke, "Der Ordensstaat Preußen in seinen deutschen und europäischen Beziehungen", dans E. Maschke (dir.), Domus Hospitalis Theutonicorum. Europäische Verbindungslinien der Deutschordensgeschichte, Bonn-Bad Godesberg 1970, p. 11.
} 



\section{Deuxième Partie Le Temps des CROISÉS}





\section{INTRODUCTION DE LA DEUXIÈME PARTIE}

ux prémices du xIv ${ }^{\mathrm{e}}$ siècle, en 1304, des chevaliers originaires $A$ d'Argovie et des pays rhénans sont mentionnés par le chroniqueur 1 Pierre de Dusbourg parmi les hôtes de l'Ordre teutonique ${ }^{1}$ : il s'agit des premiers nobles étrangers à venir croiser le fer avec les Lituaniens, derniers païens autonomes de la région balte depuis la soumission de la Prusse (v. 1283) ${ }^{2}$. Parmi eux se trouve Werner, comte de Homberg (Hohenberg) en Argovie, un jeune minnesänger qui se souviendra peut-être de cet épisode lorsque dans l'un de ses poèmes il mentionnera son départ "zuo den heiden" ${ }^{3}$. Ces visiteurs venus de loin sont les premiers d'une longue série: alors que des princes polonais, saxons, tchèques ou danois avaient participé à la conquête de la Prusse et de la Livonie, de nombreux seigneurs de toute l'Europe, grands princes ou petits nobles, seront amenés à rejoindre les Chevaliers teutoniques, le temps d'une saison, pour marcher contre le "royaume» de Lettow, Layco ou l'Estoe, comme on nomme le grand-duché de Lituanie.

Pendant les premières décennies du siècle, ce sont des seigneurs d'Allemagne et de Bohême, ainsi qu'un duc de Silésie ${ }^{4}$; en 1325, et ceci malgré la paix signée à Vilnius l'année précédente, un chevalier quitte Utrecht pour aller combattre les Lituaniens 5 . De la région rhénane et des environs, l'attrait pour la croisade nordique se répand parmi les chevaliers anglais et français, aux côtés desquels de nombreux seigneurs néerlandais ou allemands combattaient lors des premières phases de la guerre de Cent Ans $^{6}$. Lorsqu'en 1329, Jean, comte de Luxembourg et roi de Bohême,

\footnotetext{
${ }^{1}$ Pierre de Dusbourg, Chronicon..., SRP 1, p. 170.

2 Du moins, depuis le margrave de Misnie en hiver 1272-1273, aucun visiteur n’est mentionné par Dusbourg, dont la chronique couvre la période; SRP vol. 1, p. 170, n. 2; PR 1, p. 21 ; A. EhLers, Die Ablasspraxis..., p. 50-52.

${ }_{3}$ PR 1, p. 21, n. 1, qui cite K. BarTsch (éd.), Die schweizerischen Minnesänger, Frauenfeld 1917, p. 279 , doc. 3 , v. 6 .

${ }^{4}$ Sur ce qui suit, PR 1, p. 25.

5 S. C. Rowell, Lithuania Ascending..., p. 231, n. 6.

${ }^{6}$ T. Guard, Chivalry..., p. 73.
} 
participe à sa première expédition en Prusse, il est accompagné de "multi nobiles regni Alemannie et Anglie» ${ }^{7}$ - parmi lesquels le célèbre poète Guillaume de Machaut, son secrétaire ${ }^{8}$. En 1335, des Français anonymes sont mentionnés en Prusse ${ }^{9}$; l'année d'après, ce sont des Flamands de langue française, des Bretons, des Normands, des Bourguignons ${ }^{10}$. À partir de 1340, la "rèse» ou le "voyage de Prusse», comme on nomme cette pratique, devient "une véritable institution en France et en Angleterre" Toute l'Europe est concernée par le phénomène: dans la seconde moitié du siècle, des chevaliers viennent d'Italie, d'Écosse, du sud de la France, de la péninsule Ibérique et de Pologne ${ }^{12}$. Les nobles français, traditionnellement très impliqués dans le mouvement de croisade $^{13}$, figurent parmi les plus assidus ${ }^{14}$. La plupart d'entre eux viennent de la moitié nord du royaume, du Bourbonnais et du Poitou jusqu'en Flandre, de la Bretagne et la Normandie à la Champagne et à la Bourgogne ducale ${ }^{15}$. La comté de Bourgogne, tout comme la Savoie, la Lorraine, le Hainaut et les autres régions relevant de l'Empire, mais linguistiquement, culturellement et politiquement proches de la France sont bien représentés ${ }^{16}$. En ce qui concerne l'Angleterre, les régions d'Est-Anglie, Lincolnshire et Yorkshire ont fourni l'essentiel des croisés insulaires ${ }^{17}$.

\footnotetext{
7 Pierre de Dusbourg, Chronicon..., SRP 1, p. 215.

${ }^{8}$ C'est ainsi que le désigne la critique; pour une discussion quant à ses fonctions, V. ČErnÝ, "Guillaume de Machaut au service du roi de Bohême", dans Guillaume de Machaut, poète et compositeur. Colloque-Table Ronde organisé par l'Université de Reims, Reims, 19-22 avril 1978, Paris 1982, p. 67-68.

9 Wigand de Marbourg, Chronica Nova Prutenica, éd. T. Hirsch, SRP 2, p. 488; PR 1, p. 25.

${ }^{10}$ PR 1, p. 25.

11 W. Paravicini, «La Prusse...», p. 179.

12 Ibid., p. 178; PR 1, p. 88-142. Des hôtes polonais de l'Ordre apparaissent, de façon épisodique, même après la christianisation de la Lituanie, alors que le royaume polonais a joué un rôle important dans le processus; Ibid., p. 141-142.

${ }^{13}$ X. HÉLAVY, "Le "dégoût" de la noblesse française à l'égard de la croisade à la fin du XIII e siècle», dans M. Nejedlý, J. Svátex (dirs.), La noblesse et la croisade..., p. 17.

${ }^{14}$ A. V. Murray, «Saracens...», p. 418. W. Paravicini, PR 1, p. 122 relativise en rappelant que la France comptait plus de nobles que l'Angleterre, et que par conséquent, plus de documents ont été trouvés.

${ }^{15}$ Sur la provenance des croisés de Prusse, PR 1, p. 103-104, et tab. 8, p. 103. Les provinces du sud du royaume sont un peu moins représentées, mais ont fourni plusieurs croisés, à commencer par le célèbre vicomte de Foix et Béarn, Gaston Fébus, en 1357-1358. Pour une liste des hôtes français de l'Ordre teutonique, Ibid., tab. 7, p. 94-101.

${ }^{16}$ Ibid., p. 72-87.

${ }_{17}$ T. Guard, Chivalry..., p. 93, qui remarque que les aristocrates de l'est de l'Angleterre étaient traditionnellement plus impliqués dans le mouvement de croisade, et que des contacts commerciaux existaient entre les villes portuaires et la Prusse teutonique depuis le XIII ${ }^{\mathrm{e}}$ siècle, ce qui explique que le monde balte n'était pas étranger aux chevaliers originaires de ces provinces. Voir la liste des croisés anglais dans Ibid., p. 217-240; PR 1, tab. 9, p. 123-127.
} 
Pour ces guerriers, qui, outre la langue française, partagent une même culture aristocratique $^{18}$, la croisade balte fait en quelque sorte figure d'échappatoire au conflit opposant la France à l'Angleterre. Mettre son épée au service de Dieu en combattant les «Sarrasins » de Lituanie permet de purifier son âme - ce sur quoi les textes ne s'attardent guère - mais aussi d'acquérir une gloire mondaine et de faire vivre l'idéal d'une chevalerie unie, au-delà des antagonismes nationaux ou de partis, dans la lutte contre l'infidèle. Héritière de la fameuse croisade d'Orient, l'entreprise des voyages en Prusse s'impose dans la littérature comme dans la vie des nobles.

Après avoir étudié le profil des croisés de la Baltique, le chapitre III répond à la question de savoir pourquoi les chevaliers et les écuyers de toute l'Europe se rendent en Prusse: à partir de textes littéraires composés en France et en Angleterre, il s'agit de cerner la charge d'héroïsme inhérant à l'activité chevaleresque par excellence qu'est devenue la croisade balte, mais aussi de mettre en avant un processus littéraire d'incitation au départ. De nombreux textes destinés à l'éducation de jeunes nobles incitent ces derniers à se mettre en route pour aller affronter les "Sarrasins" - et ceux de la Baltique font très bien l'affaire. Qui plus est, des auteurs français et dans une moindre mesure anglais n'hésitent pas à donner une touche courtoise à leurs récits de la croisade balte: le combat contre les Lituaniens devient alors une prouesse d'amour, inséparable du service rendu à la dame.

Le chapitre IV, quant à lui, porte sur les objectifs que les croisés de Prusse prétendaient remplir en marchant les armes à la main contre les païens. Convertir ces derniers afin de faire progresser la foi chrétienne est au coeur de la justification théologique de la croisade balte, et le baptême des Lituaniens est mis en avant dans plusieurs textes occidentaux. Néanmoins, ce qui ressort le plus de nos témoignages, ce sont les activités guerrières. La lutte contre les Lituaniens est décrite comme dure et cruelle, mais pas nécessairement pire que celles qui dévastaient l'Europe occidentale à la même époque. Enfin, les contacts entre chrétiens et païens n'étaient pas, loin s'en faut, que belliqueux: les négociations de paix, les baptêmes individuels de quelques seigneurs lituaniens, les alliances et les contacts entretenus lors des activités militaires ont permis un certain rapprochement entre les chevaliers occidentaux et les guerriers de la Baltique.

\footnotetext{
${ }^{18}$ Sur l'usage de la langue française en Angleterre, A. CRÉPIN, «Quand les Anglais parlaient français...", p. 1569-1588.
} 



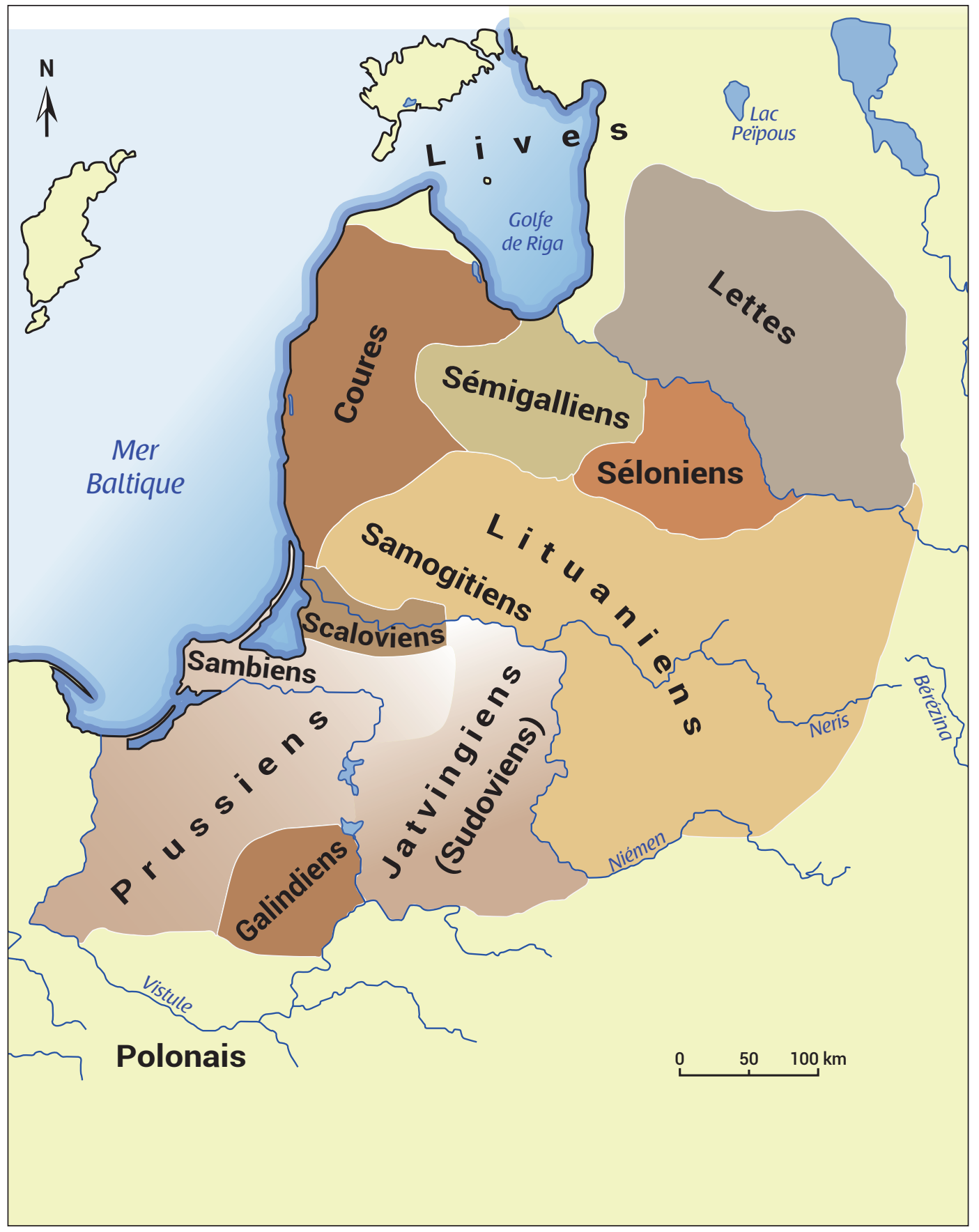

Carte 1. Les populations baltes vers 1200

Réalisation: S. Vieillard 


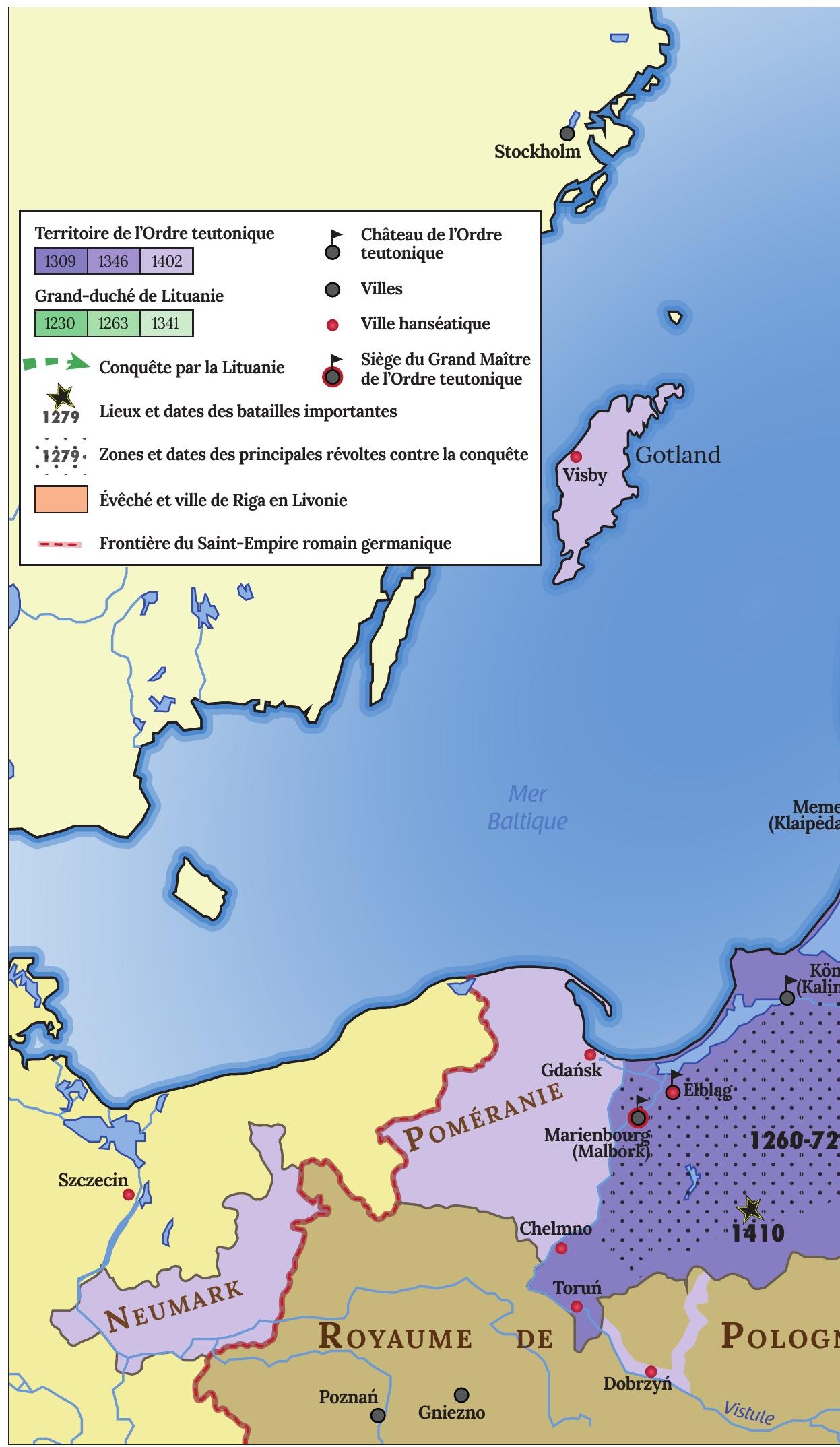

Carte 2. L'État de l'Ordre teutonique entre 1260 et 1410

Réalisation: S. Vieillard 


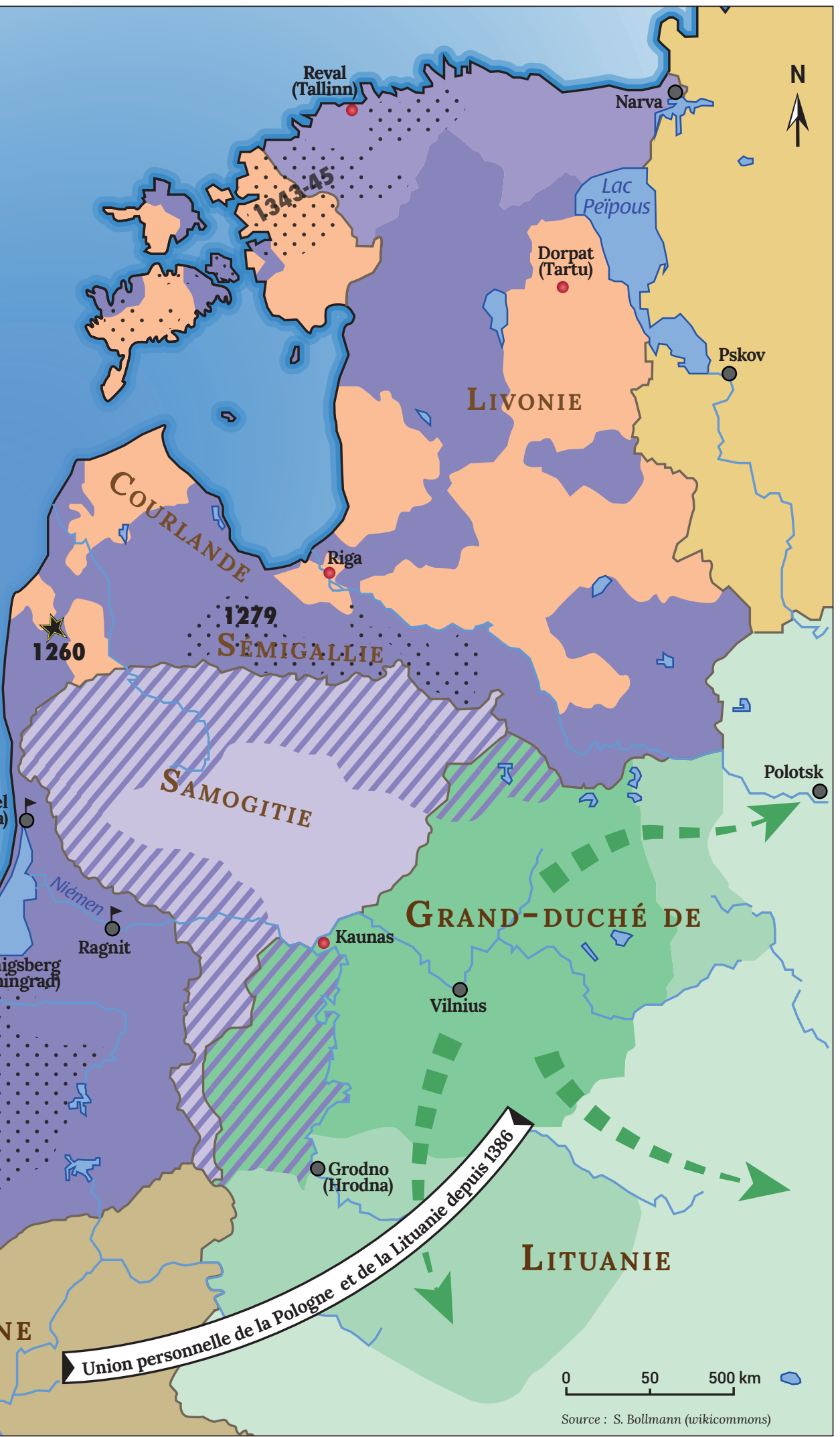




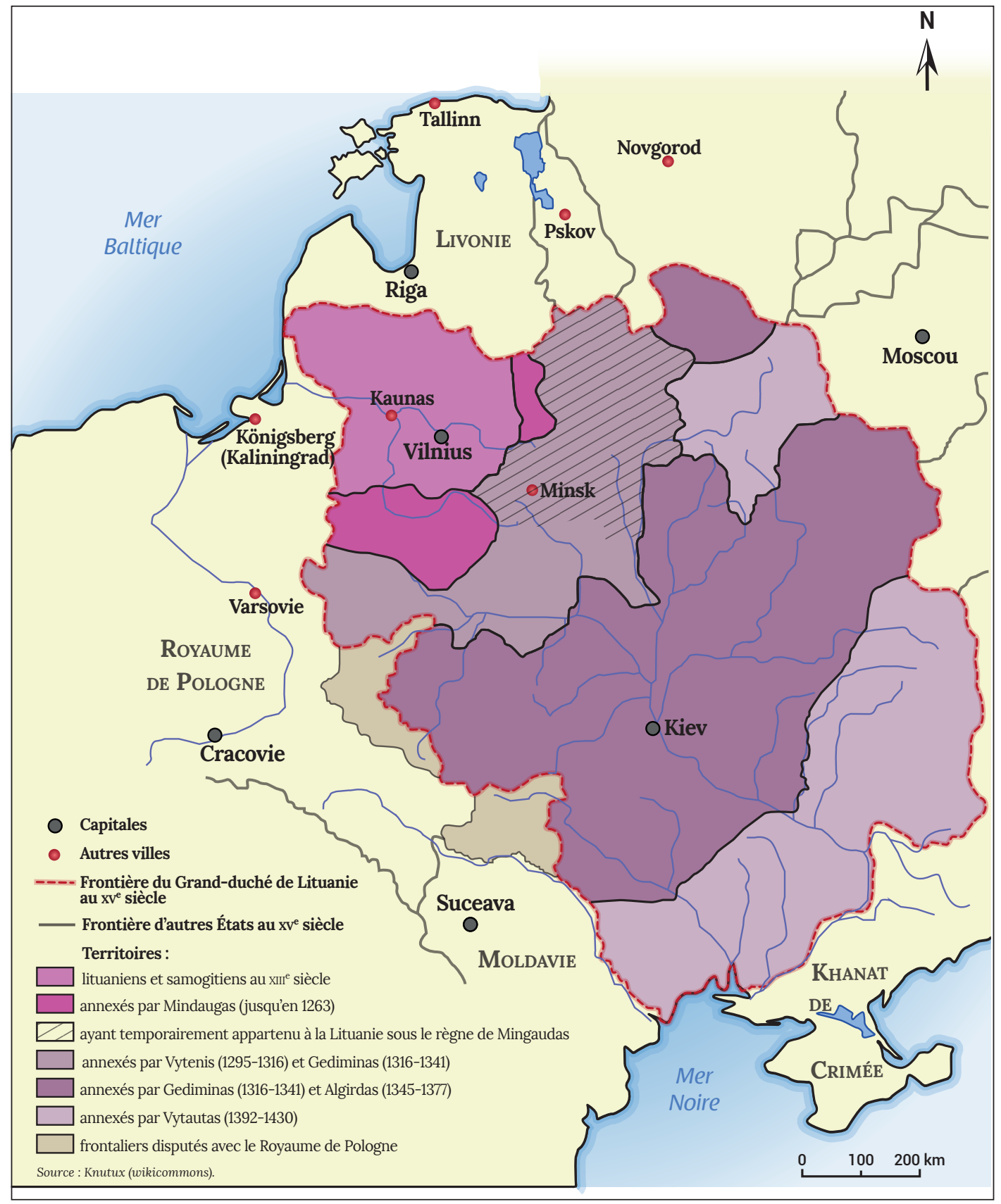

Carte 3. L'expansion territoriale du Grand-duché de Lituanie du XIII ${ }^{\mathrm{e}}$ au $\mathrm{Xv}^{\mathrm{e}}$ siècle Réalisation: S. Vieillard 


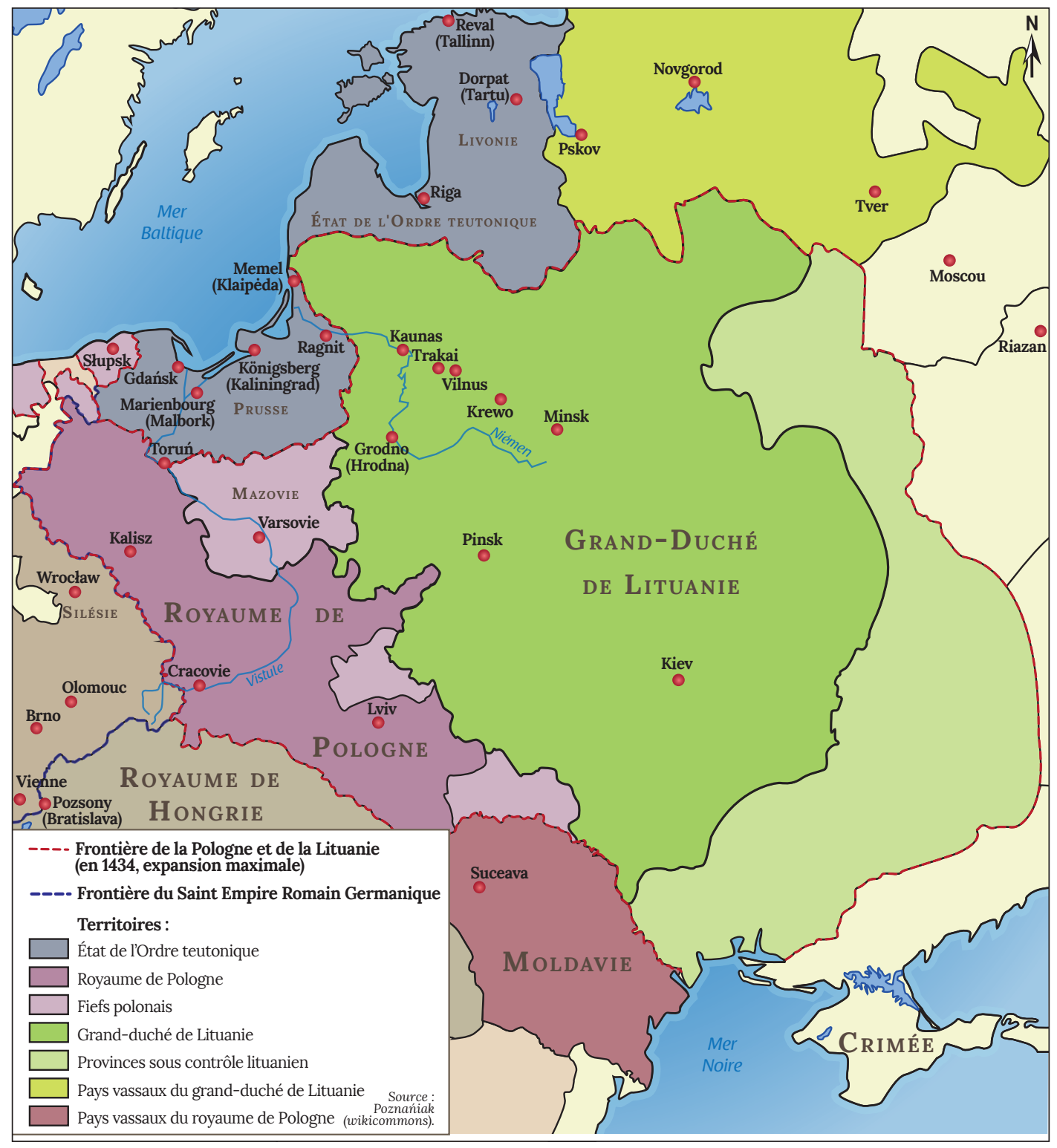

Carte 4. La Pologne, la Lituanie et l'État de l'Ordre teutonique sous le règne de Ladislas Jagellon et Vytautas (v. 1386-1434)

Réalisation: S. Vieillard 


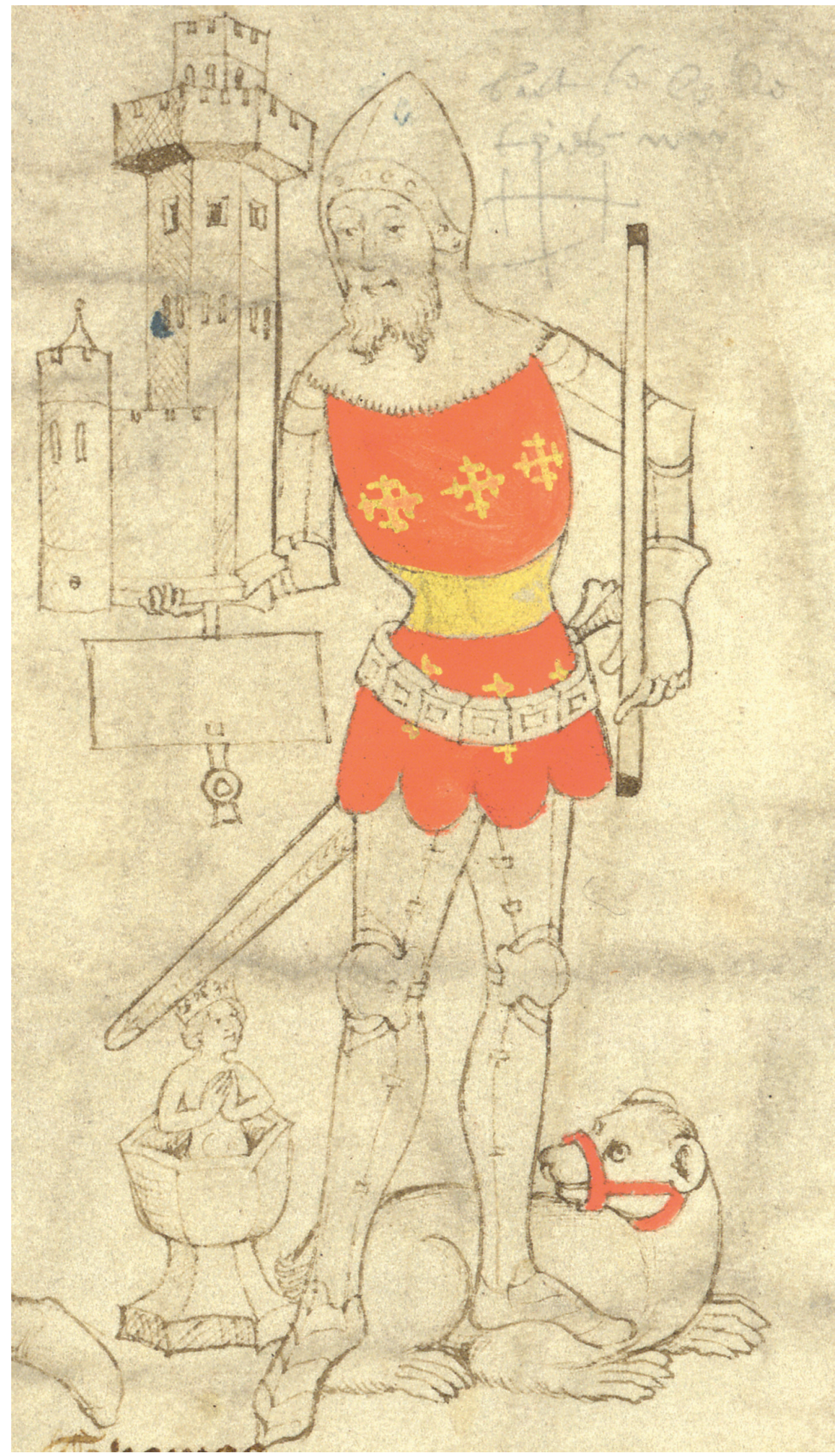

Figure 1. Thomas Beauchamp, comte de Warwick, et un fils du roi de Lituanie. The Rous Roll (1483-1484) (C) The British Library Board, Add Ms 48976. 

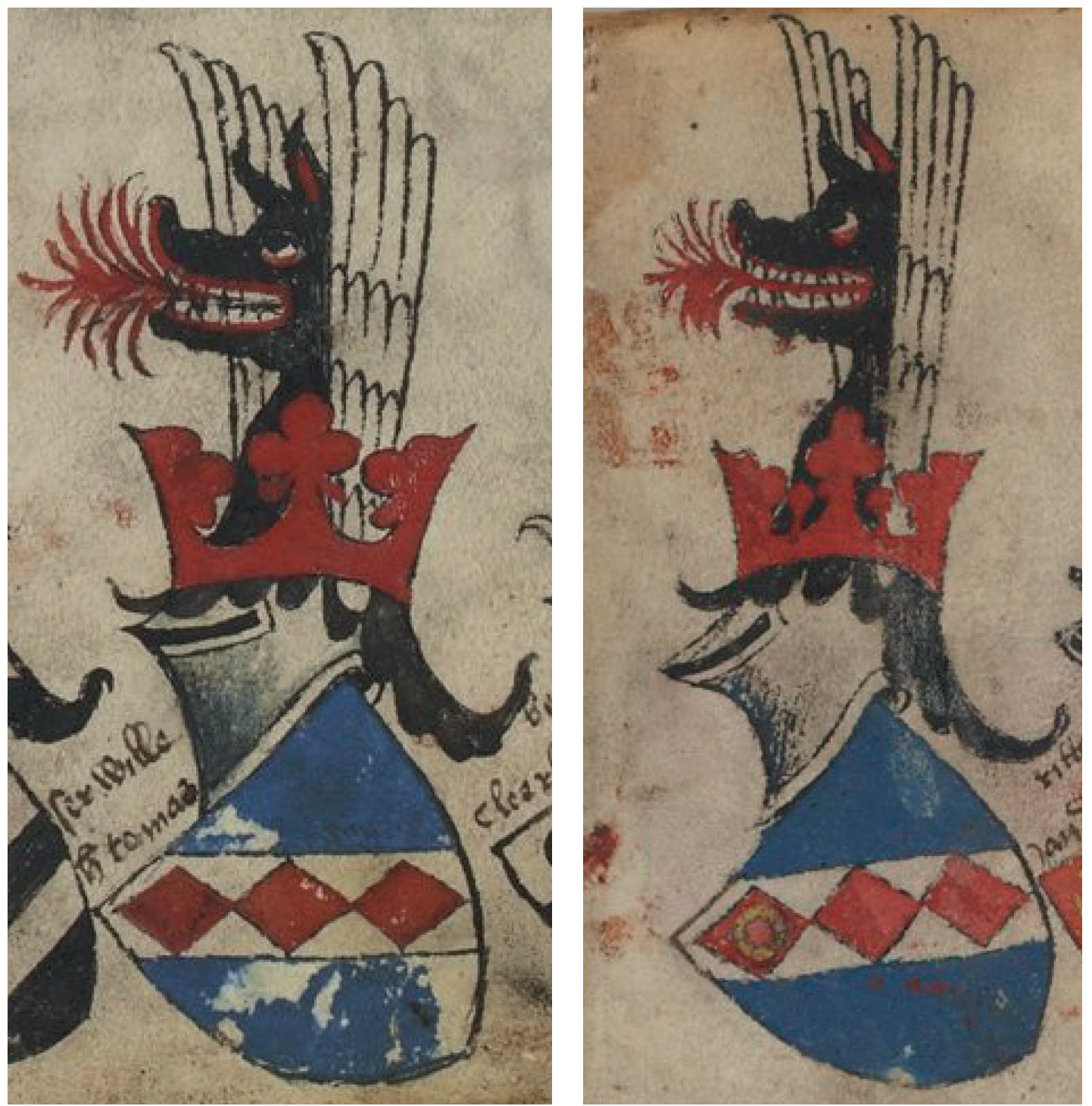

Figure 2a et 2b. Armoiries de Thomas Surville et de son frère Jean (avec brisure). Armorial Bellenville, copie du Xv ${ }^{\mathrm{e}}$ siècle, Paris, BNF, Ms. Français 5230, folio 62v et 63r. 


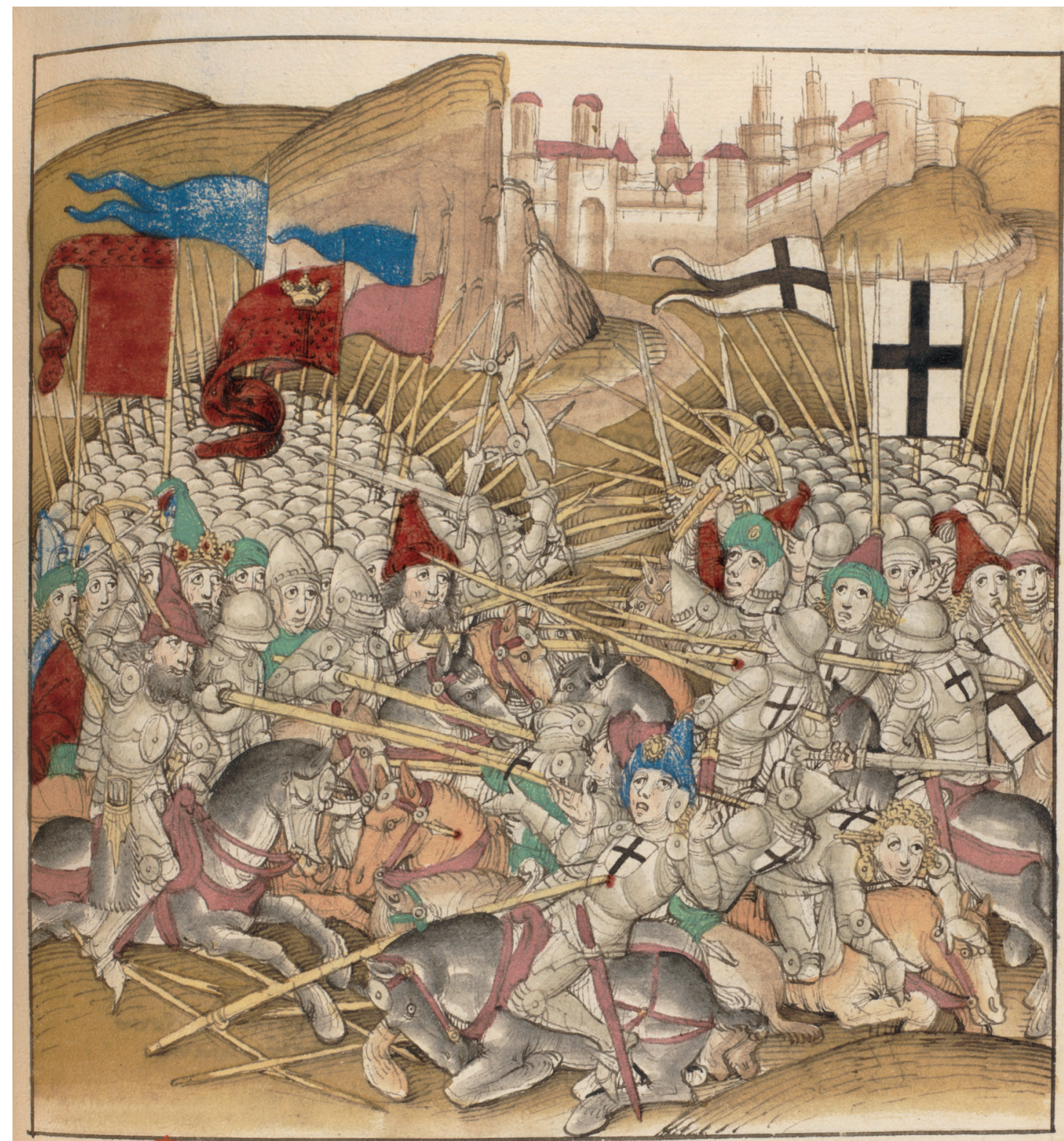

的 


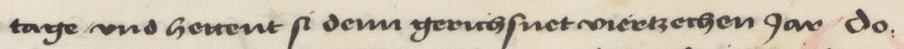

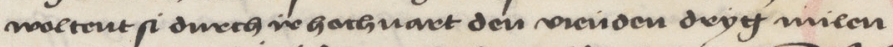

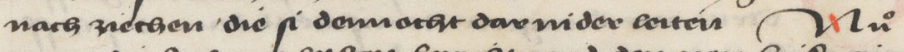

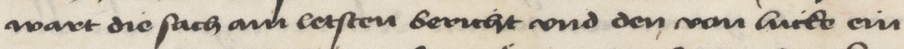

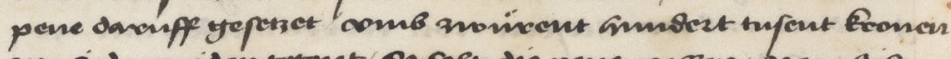

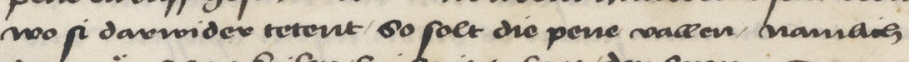

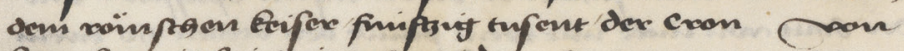

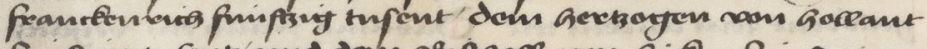

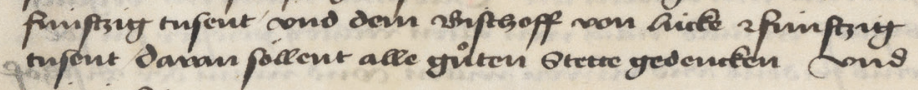
moiking pin

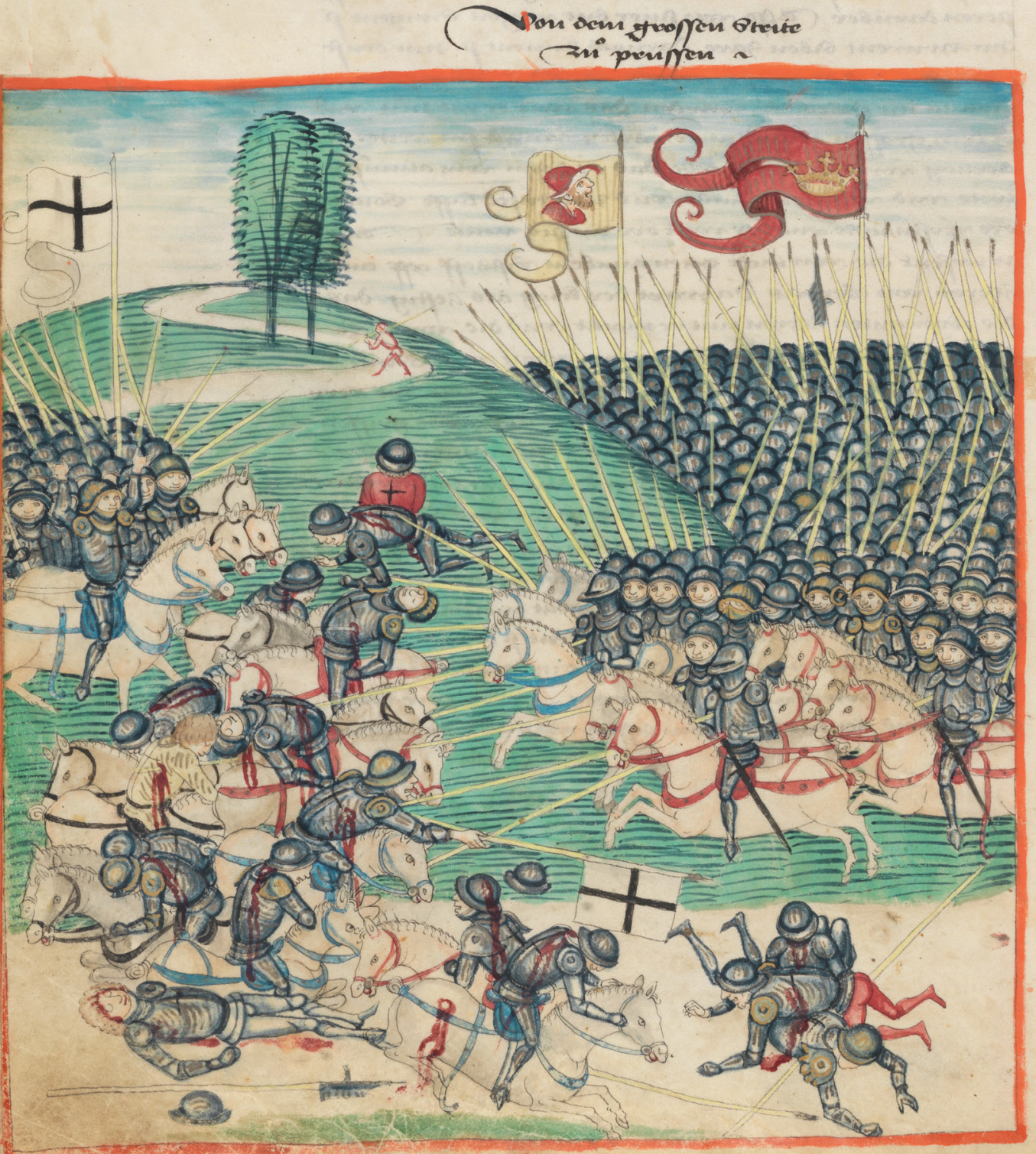

Figure 4. Diebold Schilling l'Ancien, La bataille de Tannenberg, extrait de la Berner Chronik (1478-1483), Berne, Burgerbibliothek, Mss.h.h.I.1, fol. 304 (www.e-codices.ch). 


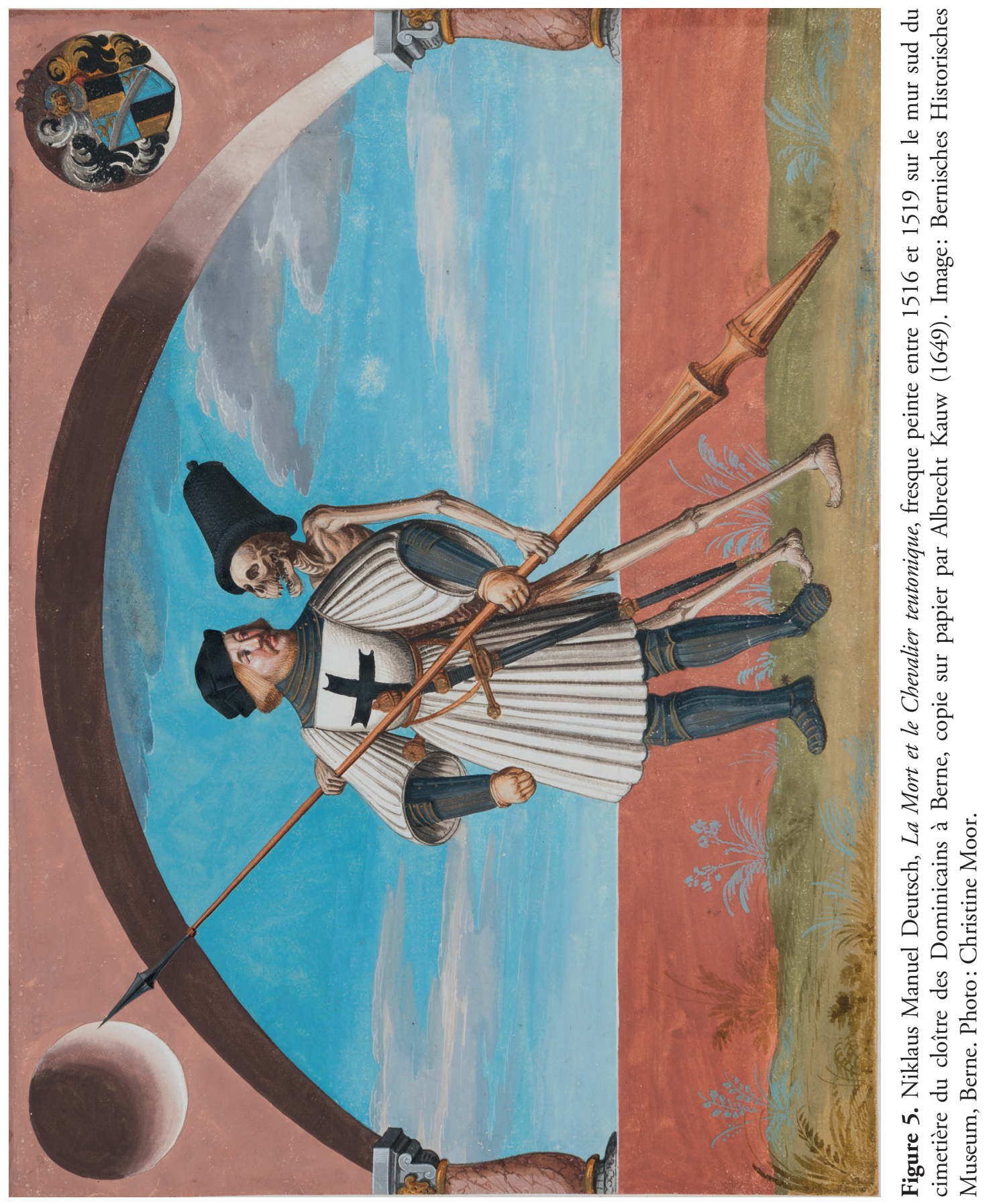




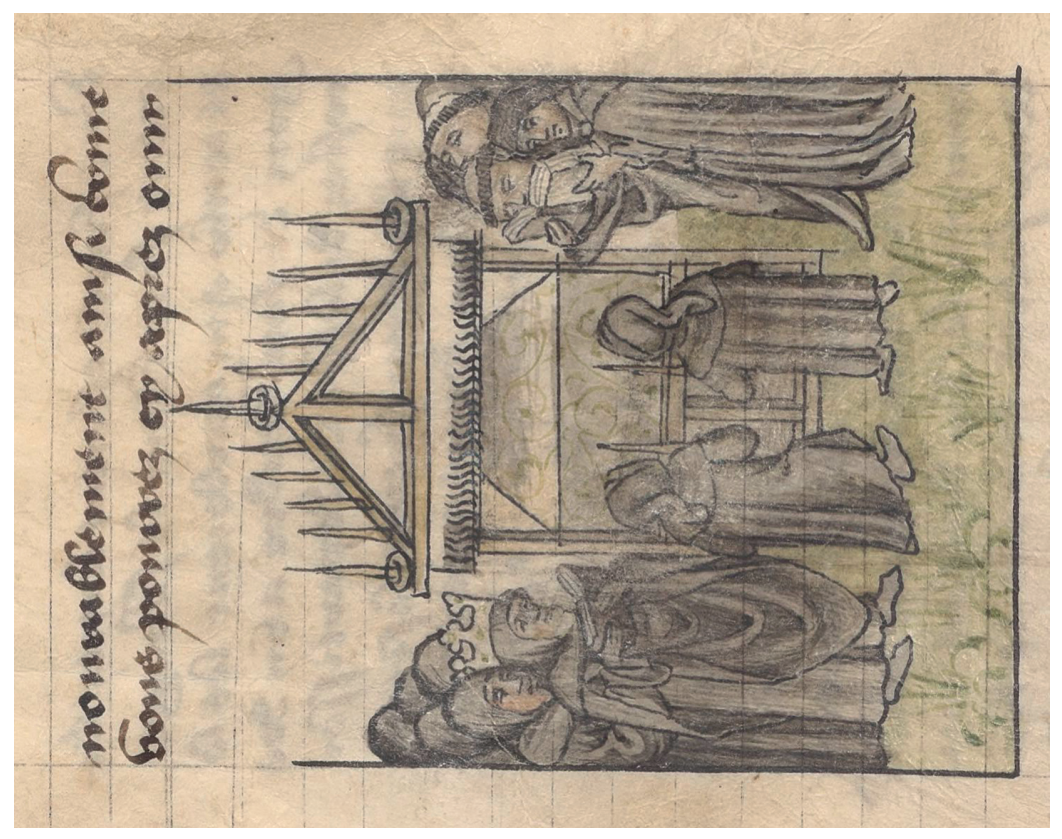

$\frac{\pi}{2}$

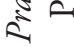

ชั ปูป

- $\frac{\pi}{2}$

这

$\approx$ ₹

$\checkmark$ के

\&

离芯

है

ป ฐี บ

ல்

次

然

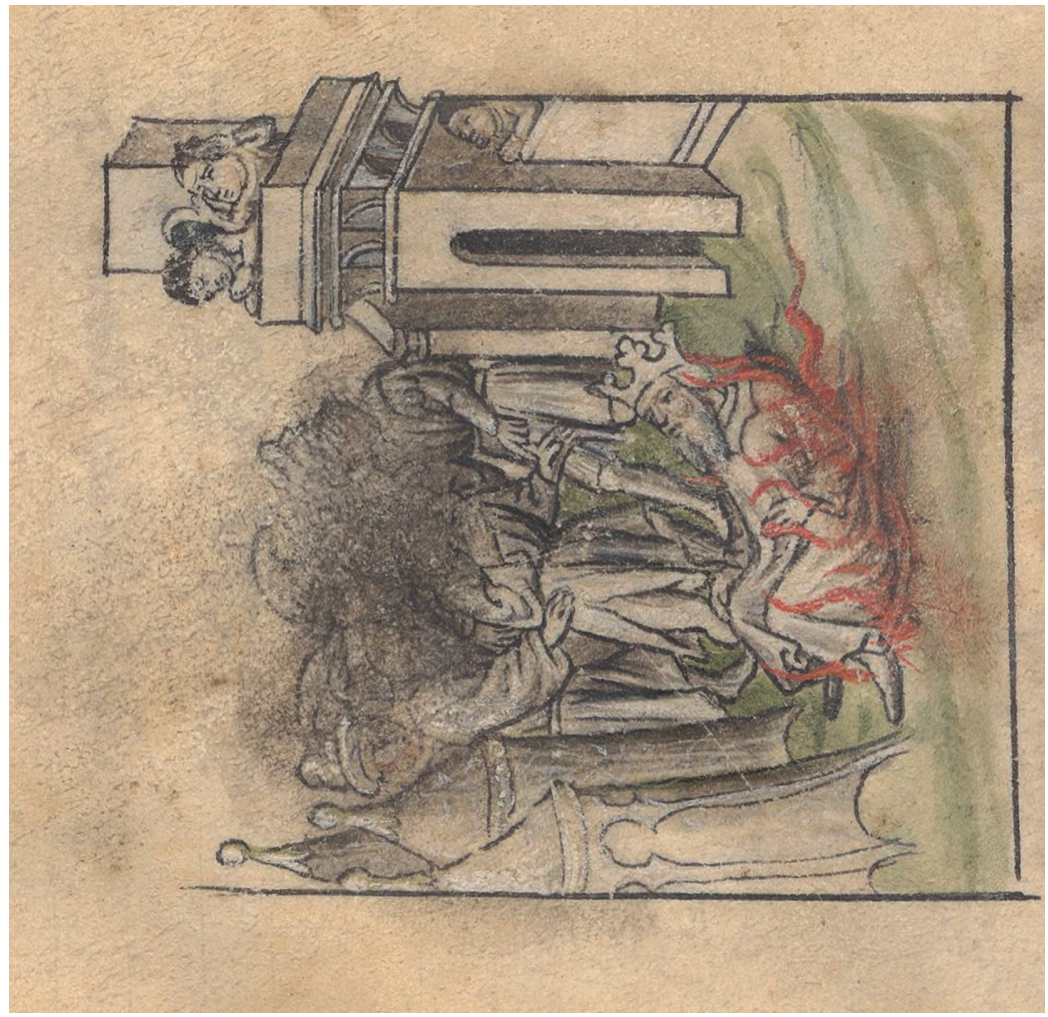

ชี

: 롱

这吉

흥

₹

노ำ

o

ปู \&

8

एँ

डे \&

造 ह

เ ฐิ

ปै

ชั运

용

क $\cong$

$\approx \frac{0}{2} \tilde{n}$

ปे

\& $\Sigma$

ई त्ञี

药

社至 



\section{Chapitre III À LA RECHERCHE DE L'HONNEUR}

\section{Les rèses de Prusse et les Sarrasins de Lituanie}

Lorsqu'il relate la bataille de Crécy, qui oppose Français et Anglais en août 1346, le moine cistercien qui rédige la Chronique de l'abbaye poméranienne d'Oliwa (v. 1348-1351), sujet de l'Ordre teutonique, souligne l'effroi que lui cause l'idée de ce massacre, alors que tant de chevaliers auraient pu, au lieu de s'entretuer, sacrifier leurs vies pour protéger la Chrétienté des infidèles ${ }^{1}$. Ce genre de propos se situe dans la droite ligne de l'idéologie de croisade forgée au moins à partir de Bernard de Clairvaux, mais il rencontre également une figure qui nous sera désormais familière: celle du chevalier voyageur ${ }^{2}$. À partir de la fin du XIII ${ }^{\mathrm{e}}$ siècle, ménestrels et chroniqueurs se font fort d'inciter ceux qui aspirent à la chevalerie à chercher l'honneur lors des tournois ou des batailles. ${ }^{3}$. Une parfaite illustration de ce modèle se trouve dans le prologue des Chroniques de Jean Froissart, chantre par excellence de la chevalerie des derniers siècles du Moyen Âge:

"Ossi en armes aviennent tant de grans merveilles et de belles aventures, que [...] vous verés et trouverés en ce livre se vous le lisiés comment pluiseur chevalier

\footnotetext{
1 SRP 5, p. 618; E. Christiansen, The Northern Crusades..., p. 176.

2 Sur ce qui suit, W. Paravicini, "Fahrende Ritter...", p. 204-254; Idem, Die ritterlich-höfische Kultur des Mittelalters, Munich 2011, p. 17-18; Idem, "Von der Heidenfahrt zur Kavalierstour. Über Motive und Formen adeligen Reisens im späten Mittelalter ", dans H. Brunner, N. R. Wolf, (éds.), Wissensliteratur im Mittelalter und in der Frühen Neuzeit, Wiesbaden 1993, p. 97-98; W. van Anrooij, "Heralds, knights and travelling», E. Kooper (dir.), Medieval Dutch Literature in its European Context, Cambridge 1994, p. 46-61.

${ }^{3}$ Pour la seconde moitié du XIII ${ }^{e}$ siècle, voir notamment Baudouin de Condé, Li contes dou baceler, dans Dits et contes de Baudouin de Condé et de son fils Jean, éd. A. Scheler, Bruxelles 1866, vol. 1, p. 45-62; pour le début du XIv siècle, un bel exemple est l'éloge funèbre de Gauthier de Châtillon, connétable de France, par le ménestrel hennuyer Watriquet de Couvin (1329): "Et en la presse des chevaus, / Comme Tristans ou Perchevaus, / I faisoit sa force cognoistre, / Lui douter et son pris acroistre", Li dis du connestable de France, v. 95-99, dans Watriquet de Couvin, Dits, éd. A. Scheler, Bruxelles 1868, p. 46. Le même auteur incite, déjà dans le premier tiers du XIve siècle, les chevaliers à voyager pour parfaire leur renommée ( $L i$ di du preux chevalier, Ibid., p. 77-97) et à guerroyer contre les infidèles (Li dis des Mahommés, Ibid., p. 77-82).
} 
et escuier se sont fait et avanciet plus par leur proèce que par leur linage. Li noms de preu est si haus et si nobles et la vertu si clère et si belle que elle resplendist en ces sales et en ces places où il a assamblée et fuison de grans signeurs et se remonstre dessus tous les autres, et l'ensegn-on au doit et dist-on: "Velà cesti qui mist ceste cevaucie ou ceste armée sus [...] ou qui se combati si vassaument ou qui entreprist ceste besongne si hardiement". " ${ }^{4}$

Pour les membres de la noblesse qui se plaisent à suivre un mode de vie inspiré des romans courtois, l'interminable lutte entre la France et l'Angleterre, et les multiples troubles qui y sont plus ou moins liés offrent bien des occasions d'aventures honorifiques, avec leurs batailles rangées, leurs sièges et leurs tournois mettant aux prises les tenants des divers partis. Toutefois, l'aventure magnifiée dans les romans de chevalerie se trouve également ailleurs. Geoffroi de Charny (m. 1356), auteur d'un célèbre Livre de Chevalerie et dont la biographie relève à bien des égards d'un modèle du genre, regardait la participation aux tournois ou aux guerres "nationales" comme fort louable, mais considérait que «doit l'en bien prisier et honorer telz gens qui ainsi mettent leurs corps en peril et travail pour les estranges choses veoir et lointains voiages faire. Et de ce faire leur soufist pour les grans choses estranges qu'ilz y ont veues et encores ont volenté de veoir». Même si les chevaliers qui voyagent ont moins d'occasion de se battre que leurs pairs restés au pays, la chose reste pour lui tout à fait honorable: "qui plus fait, miex vault" ${ }^{5}$. Presque un siècle plus tard, on trouve un conseil similaire dans le poème didactique Enseignement de la vraie noblesse, attribué à Hugues de Lannoy ${ }^{6}$, seigneur de Sente en pays wallon et vassal du duc de Bourgogne:

"Il est bien seant en temps de paix que jones gentilz hommes voisent serquier les estranges contrees et facent voyages, comme de Jherusalem, Sainte Katherine, Rome, Saint Jacques et les royaulmes chrestiens. Et qui plus est, qu'ilz s'employent en guerre contre les Sarrazins et meschans, car jone homme ne peut nulle part

\footnotetext{
${ }^{4}$ Jean Froissart, Chroniques, dans Euvres complètes, éd. J. Kervyn de Lettenhove, vol. 2, Bruxelles 1867, p. 8-9; voir aussi W. Paravicini, "Von der Heidenfahrt... ", p. 113.

${ }^{5}$ Geoffroi de Charny, The Book of Chivalry, éd. et trad. R. W. Kaeuper, E. Kennedy, Philadelphia 1996, p. 90-93 (ici, p. 92); W. Paravicini, "Von der Heidenfahrt...», p. 97-98; M. Margue, "Jean l'Aveugle, prince idéal et chevalier parfait: images et réalité», Hémecht. Zeitschrift für Luxemburger Geschichte, 48, 1996, », p. 374-375.

${ }^{6}$ La paternité du texte a longtemps été attribuée à Guillebert de Lannoy, grand voyageur et auteur d'un récit de voyage qui nous sera très utile dans les chapitres suivants; mais des recherches récentes proposent de voir Hugues de Lannoy, frère aîné de Guillebert, comme l'auteur de l'Instruction d'un jeune prince et d'autres manuels didactiques: Enseignement de la vraie noblesse et Enseignements paternels; voir B. STERCHI, "Hugues de Lannoy, auteur de l'Enseignement de vraie noblesse, de l'Instruction d'un jeune prince et des Enseignements paternels", Le Moyen Âge 110/1, 2004, p. 79-117. Comme le remarque M. NejEdlÝ, «Spisy...», p. 110, les deux frères appartenaient au même milieu sociologique et se soutenaient mutuellement.
} 
mieulx apprendre les affaires du monde que par voyagier et hanter le fait des armes en estranges contrees et pays. ${ }^{7}$

Qu'elles aient agi sur les comportements ou qu'elles se contentent de les refléter, ces injonctions ont dû correspondre à une certaine réalitée. L'auteur de l'Enseignement de la vraie noblesse a lui-même combattu en Prusse et en Lituanie lors du retour d'un périple qui le mena jusqu'à Jérusalem, alors que son jeune frère, Guillebert, a accompli l'habituelle rèse en Prusse, mais aussi visité le Danemark, la Livonie, Novgorod, Pskov, la Lituanie, la Pologne et la Bohême après avoir parcouru la Terre sainte, la Méditerranée orientale et la péninsule Ibérique comme croisé et pèlerin pendant ses jeunes années.

Bien plus que le pèlerinage, le voyage contre l'infidèle représente une activité typiquement aristocratique: quoi de plus honorable que de partir au loin pour mettre son épée au service de la lutte contre les ennemis de la foi ${ }^{9}$ ? Même si la chute d'Acre rend la croisade palestinienne difficilement envisageable - quoique celle-ci reste dans tous les esprits - plusieurs théâtres offrent la possibilité d'un tel engagement. Celui qui veut accroître sa renommée peut continuer la lutte en Méditerranée, en prêtant main-forte aux Chevaliers de Saint Jean, établis à Rhodes, ou en participant aux quelques expéditions princières menées occasionnellement contre les Turcs, les Maures et les Mamelouks. À cela s'ajoute la longue Reconquista ibérique, qui débouche au début du Xv siècle sur l'implantation portugaise à Ceuta, en Afrique du Nord. Néanmoins, tous ces champs de bataille, pour glorieux qu'ils puissent être, sont dépassés par le voyage en Prusse ${ }^{10}$. D'après Werner Paravicini, il serait difficile de trouver une famille noble d'Europe du Nord-Ouest qui, dans la seconde moitié du XIv ${ }^{e}$ siècle, n'aurait pas envoyé au moins un rejeton sur le chemin de Prusse ${ }^{11}$. Souvent, ceux-ci ont déjà participé à d'autres voyages, guerriers ou non, en pays lointain.

Expédition nobiliaire par excellence, le voyage en Prusse peut s'intégrer à un plus long périple, qui passe en général par Venise et Jérusalem ${ }^{12}$. On voyage parfois seul, mais souvent en groupe d'une dizaine de familiers réunis autour d'un chef ${ }^{13}$. Les périodes de paix entre France et Angleterre permettent d'entreprendre plus facilement ce genre de voyage; quand on n'a pas besoin

\footnotetext{
7 Bruxelles, K. B. R. ms. 11 047, f84 vº., cité par B. STerchi, «Hugues de Lannoy...», p. 113; M. NeJEdLÝ, «Spisy...», p. 110.

8 Ibid., p. 109. Sur la mode des poèmes didactiques visant à entretenir l'idéal chevaleresque, particulièrement florissante à la cour de Bourgogne et d'Angleterre, M. VALE, War and Chivalry..., p. 14-32.

9 W. Paravicini, «Von der Heidenfahrt...», p. 98 ; pour le cas des chevaliers anglais, T. Guard, Chivalry...; C. Tyerman, England....

${ }^{10}$ W. Paravicini, «Von der Heidenfahrt...., p. 97.

11 Ibid., p. 116.

12 Ibid., p. 96-97.

13 O. Mattéoni, Servir le Prince: les officiers des ducs de Bourbon à la fin du Moyen Âge (13561523), Paris 1998, p. 443.
} 
de leurs services au pays, les guerriers sont libres d'aller chercher l'aventure ailleurs. De fait, les rèses les plus courues ont eu lieu après la paix de Brétigny (1360) et dans les années 1390, quand Richard II et Charles VI menaient une politique de rapprochement entre leurs royaumes ${ }^{14}$. Plusieurs grands noms de la noblesse européenne ont fait le déplacement: Jean de Luxembourg, roi de Bohême, en hiver 1328-1329, 1337 et 1344-1345, mais aussi le duc Pierre de Bourbon, qui l'accompagne en 1344-1345, le duc Henri de Lancastre en 1351-1352, Gaston Fébus, comte de Foix et de Béarn, en 1357-1358, le duc Léopold III d'Autriche en 1371-1372 ou Henri «Bolingbroke», comte de Derby, duc de Lancastre et futur Henri IV d'Angleterre, en 1390-1391 puis une fois encore en $1392^{15}$. En ce qui concerne l'âge et le rang social, le profil des "hôtes» de Prusse est assez varié16 : aux grands princes se joignent des comtes, des barons, des seigneurs de la moyenne noblesse déjà établis, mais aussi des écuyers et de jeunes chevaliers, des patriciens. Parfois, ce sont des nobles ruinés ou bannis, des aventuriers et des mercenaires, venus chercher l'honneur et, à partir $\mathrm{du} \mathrm{Xv}^{\mathrm{e}}$ siècle, la solde, en servant quelque temps l'Ordre teutonique ${ }^{17}$. Certains croisés ont rempli des missions diplomatiques au moins officieuses, comme le Bourguignon Guillebert de Lannoy en 1413-1414, mais la plupart des voyageurs ne se souciaient vraisemblablement pas de ce genre d'activités ${ }^{18}$.

Malgré la diversité apparente des profils, la plupart des voyageurs de Prusse français ou anglais se ressemblent: à l'exception de Guillaume de Machaut, probablement d'origine roturière mais introduit auprès des plus hauts princes de

\footnotetext{
${ }_{14}$ PR 1, p. 122; S. H. Rigby, "The Knight», dans A. Minnis, S. H. Rigby (dirs.), Historians on Chaucer. The "General Prologue" to the Canterbury Tales, Oxford 2014, p. 58-59.

${ }_{15}$ Voir le tableau dressé par W. Paravicini, PR 1, p. 147-150, tab. 12; sur la participation de Pierre Ir de Bourbon et les liens entre les ducs de Bourbon, les Luxembourg et l'Empire, J.-L. FraY, «Le mécénat artistique des ducs de Bourbon ( $\mathrm{XV}^{\mathrm{e}}$ et début $\mathrm{XVI}^{\mathrm{e}}$ siècles): entre culture du Nord, Italie et France centrale", dans A. Bárány, I. Orosz, K. Papp, B. Vinkler (dirs.), Learning, Intellect and Social Roles: Aristocrats in Hungary and Europe, Debrecen 2014, p. 21-24. Henri de Derby est retourné en Prusse en 1392, avant de se rendre en Terre sainte.

16 Sur ce qui suit, PR 1, p. 143-161.

${ }_{17} \mathrm{~W}$. Paravicini remarque que des mercenaires payés par l'Ordre n'apparaissent qu'à partir de 1409 dans les documents comptables; PR 1, p. 35. Au XIV siècle, des aventuriers pouvaient néanmoins se rendre en Prusse, souvent payés par plus riches qu'eux. On retrouve notamment les armoiries du célèbre John Hawkwood, alias Giovanni Acuto, dans l'armorial Bellenville parmi une liste de participants à un voyage en Prusse. Il n'est pas donc pas impossible que ce futur condottiere italien soit lui aussi passé par la Prusse; W. Paravicini, «Mercenaires au Voyage de Prusse», dans G. Pépin, F. Lainé, F. Boutoulle, Routiers et mercenaires pendant la guerre de Cent Ans, Bordeaux 2016, p. 277-301.

${ }^{18}$ Autre exemple, le duc de Gloucester était chargé par son neveu le roi Richard II de négocier certaines affaires avec les représentants de l'Ordre, mais son périple a été annulé à la suite d'une tempête ayant dispersé sa flotte dans la mer du Nord. T. Guard, Chivalry..., p. 91-92; F. R. H. Du Boulay, "Henry of Derby's crusade... », p. 167-168, qui note qu'au moins dans le cas des Anglais "the professional work of negotiation was done by English clerks and merchants from London and York, not by war-lords whose talents lay elsewhere» (p. 168).
} 
la Chrétienté ${ }^{19}$, il s'agit d'hommes de noblesse plus ou moins ancienne, qui se sont battus sur plusieurs fronts de croisade, fréquentent les cercles aristocratiques les plus prestigieux de leurs temps, se piquent de poésie, et souvent se connaissent mutuellement ${ }^{20}$. Tels sont les croisés que nous retrouverons au fil de notre histoire. D'autres voyageurs ont parcouru la région non pour combattre les infidèles mais pour accomplir des missions diplomatiques, comme ce fut certainement le cas de l'écrivain Philippe de Mézières en 1364 et du héraut de Charles VII Gilles le Bouvier, dit Berry, au milieu du Xve siècle.

En se déplaçant jusqu'aux confins nordiques de la Chrétienté, les croisés de Prusse venaient chercher, au moins pour une bonne part, la renommée. Celle-ci est portée par le bouche-à-oreille, comme nous le dit Froissart dans l'extrait précédemment cité. Il existe toutefois un corps de métier qui s'en est fait une spécialité, plus encore que les chroniqueurs ou les ménestrels: ce sont les hérauts d'armes, dont la principale fonction est d'attribuer l'honneur aux chevaliers qui le méritent, et de propager la bonne renommée de ces derniers ${ }^{21}$. Ces professionnels de la réputation chevaleresque jouent un rôle particulier dans le cas qui nous intéresse, qu'ils soient employés par le grand-maître de l'Ordre teutonique ou par les hôtes de celui-ci. Tout comme les chevaliers dont ils louent les mérites, les hérauts d'armes sont de grands voyageurs: souvent, ils accompagnent leurs seigneurs jusqu'en Prusse, pénètrent parfois en Lituanie, et choisissent ceux qui sont dignes de siéger à la fameuse Table d'Honneur... ou qui, au contraire, ne sauraient s'y asseoir ${ }^{22}$. La composante «héraldique»

${ }^{19}$ L. Earp, Guillaume de Machaut. A Guide to Research, New York-Londres 1995, p. 3-5.

${ }^{20}$ Jean de Chastelmorand, Boucicaut et Guillebert de Lannoy étaient membres de la Cour amoureuse, Chastelmorand appartenant également à l'Ordre de l'Écu vert, fondé par Boucicaut. Tout comme ses deux frères Hugues et Baudoin, Guillebert de Lannoy est l'un des premiers membres de l'Ordre de la Toison d'Or, fondé en 1430 par le duc Philippe le Bon. En outre, Guillebert de Lannoy et Boucicaut ont composé quelques poèmes, en imitant dans le cas du premier le style du célèbre poète savoyard - et lui-même voyageur de Prusse en 1392 - Othon de Grandson; A. Piaget, «Ballades de Guillebert de Lannoy et de Jean de Werchin », Romania 39/154-155, 1910, p. 324-368; D. Lalande, Jean II le Meingre, dit Boucicaut (1366-1421): étude d'une biographie hérö̈que, Genève 1988., p. 28-29; W. Paravicini, «Nobles Hennuyers sur les chemins du monde: Jean de Werchin et ses amis autour de 1400 ", dans U. C. Ewert et al. (éds.), Noblesse: Studien zum adeligen Leben im spätmittelalterlichen Europa, Ostfildern 2012, p. 292. Voir aussi les notices de Hugues, Guillebert et Baudoin de Lannoy dans R. DE Smedt (dir.), Les Chevaliers d'Ordre de la Toison d'or au XV' siècle, Francfort 2000, p. 14-17, 26-29, 44-45.

${ }^{21}$ W. Paravicini, "Le héraut d'armes: ce que nous savons et ce que nous ne savons pas», dans B. Schnerb (dir.), Le héraut, figure européenne..., p. 465-490; G. Melville, «Pourquoi des hérauts d'armes? Les raisons d'une institution", dans Ibid., p. 491-502; W. van Anroolj, "Heralds...", p. 50-56; C. Boudreau, «Messagers, rapporteurs, juges et "voir-disant". Les hérauts d'armes vus par eux-mêmes et par d'autres dans les sources didactiques (XIV'-XVI e siècles)", dans C. BoudreAU K. Fianu, C. Gauvard et M. Hébert (dirs.), Information et société à la fin du Moyen Âge. Actes du colloque international tenu à l'Université du Québec à Montréal et à l'Université d'Ottawa (9-11 mai 2002), Paris 2004, p. 233-245.

${ }^{22}$ W. Paravicini, "Heraldische Quellen zur Geschichte der Preußenreisen im 14. Jahrhundert», Ordines Militares 4, 1987, p. 111; PR 1, p. 329-332. 
du voyage de Prusse est notamment illustrée par deux célèbres armoriaux de la fin du XIV ${ }^{e}$ siècle, dits de Gelre et Bellenville, où figurent des listes d'armoiries appartenant très vraisemblablement à de croisés de Prusse ${ }^{23}$. Sous la forme d'Ehrenreden, l'armorial de Gelre (dernier quart du XIve siècle) dresse les louanges de douze chevaliers réputés pour leur valeur et leur courtoisie ${ }^{24}$. Parmi eux, plusieurs sont dits avoir participé aux expéditions de Prusse, comme Rodolphe IV de Nidau, comte titulaire de Neuchâtel (m. 1375): "il a passé la mer et voyagé en Grèce, en Prusse et en Espagne»" 25 . La guerre contre les infidèles assure donc une renommée certaine à ce seigneur de haute lignée, dont le père côtoyait le roi Édouard d'Angleterre et avait été honoré par une rose d'or du pape Jean XXII ${ }^{26}$. Tout comme les chroniqueurs, les ménestrels et les poètes de cour, les hérauts d'armes participent de plein pied à l'élaboration du voyage contre l'infidèle en étape obligatoire pour celui qui aspire à l'honneur. Ainsi, le héraut autrichien Pierre Suchenwirt rédige un poème à la gloire du duc Albert III de Habsbourg, qu'il a accompagné en rèse en $1377^{27}$. Tandis que le rôle des hérauts comme propagateurs de l'idéal du chevalier voyageur est attesté pour l'Angleterre par des poèmes de John Gower (m. 1408) ${ }^{28}$, il faut attendre Gilles le Bouvier pour qu'un héraut d'armes français ne nous laisse une description du monde balte - et nous sommes alors au milieu du Xve siècle, soit plusieurs décennies après les derniers voyages de Prusse.

Le chevalier dont les expéditions lointaines sont racontées par ces professionnels de la renommée est donc assuré de tenir son rang et de jouir de la considération de ses pairs - et parfois de son suzerain, dont le propre

\footnotetext{
${ }^{23}$ L'armorial Bellenville comporte plus d'une dizaine de rôles occasionnels où figurent les armoiries de participants au voyage de Prusse; quant à l'armorial de Gerle, on y trouve un ensemble d'armoiries brabançonnes vraisemblablement liées à une expédition du même genre: W. Paravicini, "Heraldische Quellen...", p. 111-134; Idem, "Bellenville". Wappenbücher, Herolde und Preußenfahrten in europäischer Forschung", Francia, 32/1, 2005, p. 185-190.

${ }^{24}$ B.R. Ms. 15652-56, fol. 9v ${ }^{\circ}-21$, reprod. J. van Helmont, Gelre, B.R. Ms. 15652-56, Louvain 1992, p. 47-70; M. KeEN, "Chaucer's Knight...», p. 60-61.

25 "Over meer heeft he ghevaren / In Griecken, in Prusen inde in Spangen", B.R. Ms. 15652-56, fol. 15v' reprod. J. van Helmont, Gelre..., p. 59; transcription dans P. Aeschbacher, Die Grafen von Nidau und ihre Erben, Bienne 1924, p. 237.

${ }_{26}$ PR 1, p. 49. Sur l'honneur réservé à Rodolphe IV après sa mort, P. Aeschbacher, Die Grafen von Nidau..., p. 236-241; sur la rose d'or de Rodolphe III de Nidau, A. Paravicini Bagliani, «Autour de la Rose d'or du "comte de Neuchâtel" au Musée de Paris", dans P. Henry, M. De Tribolet (dir.), In Dubiis Libertas, Hauterive 1999, p. 59-65.

${ }_{27}$ Pierre Suchenwirt, Von Herzog Albrechts Ritterschaft, SRP 2, p. 161-169; voir la traduction de W. Urban, «Peter von Suchenwirt», Lituanus 31/2, 1985, p. 5-26.

28 John Gower, Le Mirour de l'Omme, v. 23896-23937, dans Complete Works, éd. G. C. Macaulay, vol. 1, Oxford 1899, p. 264; Idem, Confessio Amantis, 4, v. 1620-33, dans Ibid., vol. 2, p. 345; S. Vander Elst, "Chivalry...», p. 289-290. W. van Anrooij, "Heralds...», p. 53-54, note que Geoffrey Chaucer devait certainement connaître le genre des Ehrenreden, plutôt familier aux hérauts d'armes du Saint Empire qu'aux poètes anglais ou français, et en aurait utilisé le canevas pour son portrait du chevalier dans le prologue des Contes de Canterbury.
} 
honneur est augmenté par les prouesses d'un chevalier de sa cour. Dans ce cas, accomplir un voyage lointain peut se traduire par un avancement, surtout dans les royaumes de France et d'Angleterre ${ }^{29}$. De même, il n'est pas rare que les participants au voyage de Prusse, tout comme ceux qui visitent les hauts lieux de pèlerinages aristocratiques que sont devenus à la fin du Moyen Âge le Saint Sépulcre ou Sainte-Catherine du Sinaï, fassent peindre ou graver leurs armes pour qu'elles restent bien en vue des futurs visiteurs ${ }^{30}$. Emblématiques sont à cet égard les blasons peints ou fixés sur les murs de la cathédrale de Königsberg, lieu de départ des expéditions contre les Lituaniens, avec casques et cimiers, et parfois la figuration des chevaliers armés de pied en cap ${ }^{31}$. Faire figurer ses armes sur les lieux de passage est particulièrement prisé parmi la noblesse des pays germaniques $^{32}$, mais les procès d'armoiries qui nous sont restés pour la cour de Richard II montrent qu'en Angleterre également on pouvait se référer à un blason représenté quelque part en Prusse, notamment à Königsberg, même de longues années après que celui-ci ait été peint ${ }^{33}$.

Avec la participation fréquente des nobles de France et d'Angleterre à la croisade balte, la Prusse et la Lituanie apparaissent dans les chroniques, les poèmes et les romans composés en Europe de l'Ouest, notamment en langue française. Ces campagnes sont souvent qualifiées de "voyage», ce qui ne saurait nous surprendre puisque ce terme s'utilisait pour évoquer autant un pèlerinage qu'une expédition en armes ${ }^{34}$. Souvent cependant, on préfere parler de "rese», "reze» ou "reise», en français comme en anglais; au $\mathrm{XIV}^{\mathrm{e}}$ siècle, le latin intègre, au côté de "expeditio", le terme "reysa»" Ce mot a été emprunté, peut-être directement en Prusse, à l'allemand militaire "Reise», qui désignait une expédition menée contre les territoires ennemis dans le but d'affaiblir les capacités économiques et la volonté de résistance des

\footnotetext{
${ }^{29}$ Ibid., p. 47, 52-53.

${ }^{30}$ W. Paravicini, "Von der Heidenfahrt...», p. 115-116; J.-D. Morerod, «La Force du vœu. Le pèlerinage à Jérusalem de Guillaume de Chalon et ses témoins (1453-1454)", dans A. Paravicini Bagliani et al. (dirs.), L'itinérance des seigneurs (XIV'-XVI siècles), Lausanne 2003, p. 89-102. Au sujet des armoiries, noms ou devises que les voyageurs nobles font figurer aux étapes et aux destinations de leurs parcours, voir l'étude de D. KraAcK, Monumentale Zeugnisse des spätmittelelalterlichen Adelsreise, Göttingen 1997.

${ }^{31}$ Id., tab. 2, p. 322-327, 391-399; W. ParavicinI, "Verlorene Denkmäler europäischer Ritterschaft: Die heraldischen Malereien des 14. Jahrhunderts im Dom zu Königsberg», dans E. BöCKLER (dir.), Kunst und Geschichte im Ostseeraum, Kiel 1990, p. 67-168. La cathédrale est aujourd'hui détruite, mais des représentations des blasons, cimiers et figures qui y étaient peints ont été réalisées au début du $\mathrm{xx}^{\mathrm{e}}$ siècle; Ibid., p. 125-168.

32 Idem, "Von der Heidenfahrt...", p. 95. Toutefois, les seigneurs Guillaume de Chalon et Jean de Valangin firent déposer leurs bannières dans l'église du Saint Sépulcre: J.-D. Morerod, «La Force du vœu... ", p. 98-99.

33 PR 1, p. 119-121; M. KeEn, "Chaucer's Knight...", p. 53-55.

34 E. Gaucher, "Deux regards sur une défaite: Nicopolis", Cahiers de recherches médiévales 1, 1996, p. 97.

${ }^{35}$ A. V. Murray, «Saracens...», p. 414; PR 2, p. 13.
} 
populations civiles ${ }^{36}$. L'article du Dictionnaire de l'ancienne langue française de Frédéric Godefroy rend reise par "expédition militaire, incursion sur une terre ennemie", en donnant plusieurs exemples qui ont à voir avec la Lituanie, mais pas uniquement ${ }^{37}$. En parlant des préparatifs d'une expédition contre le port tunisien de Mahdia, le biographe de Boucicaut parle d' «aler faire une rese sur les ennemis de la foy " ${ }^{38}$. Néanmoins, on ne parlait pas de "rèse" qu'en cas d'attaque contre des non-chrétiens; plusieurs utilisations de ce terme s'inscrivent dans le cadre des guerres de Liège ou Metz, c'est-à-dire des régions dont sont issus de nombreux chevaliers ayant participé aux guerres de Prusse ${ }^{39}$. Cet emploi est daté de la fin du XIv siècle, soit à une époque où le terme avait eu le temps de passer dans le vocabulaire pour désigner une campagne militaire contre les Lituaniens. Dans ces territoires proches des terres de langue allemande, ce vocable avait sans doute gardé ou retrouvé son sens originel d'expédition militaire, sans forcément sous-entendre que l'adversaire soit spécifiquement païen. Le parallèle avec le terme voyage, utilisé fréquemment comme équivalent de «rèse» en français, est patent.

Les rèses, comme nous appellerons désormais ces expéditions, ont généralement lieu deux fois l'an, à l'occasion des fêtes mariales: celle d'été débute à l'Assomption ou à la Nativité de la Vierge, et celle d'hiver à la Chandeleur ${ }^{40}$. Christopher Tyerman remarque qu'au XIII ${ }^{\mathrm{e}}$ siècle, Henri de Livonie mentionne à plusieurs reprises des campagnes lancées contre les païens à l'occasion d'une fête dédiée à la Vierge ${ }^{41}$. Celle-ci jouit en effet d'un statut particulier dans le système d'autoreprésentation de l'Ordre de la Maison de Sainte-Marie des Teutoniques: une tradition régionale née au XIII ${ }^{\mathrm{e}}$ siècle en fait la patronne de la Livonie, et les noms des principaux châteaux de l'Ordre (Marienbourg, Marienwerder) témoignent de l'importance qu'on lui donne au siècle suivant ${ }^{42}$. L'habitude

\footnotetext{
36 Ibid. 2, p. 13; F. Benninghoven, «Zur Technik spätmittelalterlicher Feldzüge im Ostbaltikum » Zeitschrift für Ostforschung 19, 1970, p. 631-633. On retrouve également ce thème dans le contexte des guerres hussites, lesquelles sont nommées « rayse» par Leonard Heff, le traducteur de la Chronica summorum pontificum et imperatorum Romanorum d'André de Ratisbonne (1471): P. SoukuP, "Religion and violence in the hussite wars", dans W. Palaver, H. Rudolph, D. Regensburger (dirs.), The European Wars of Religion, Farnham 2016, p. 25. Ce terme pourrait être une réminiscence des croisades baltes.

${ }^{37}$ F. Goderroy, Dictionnaire de l'ancienne langue française, VI, Paris 1889, p. 755

${ }^{38}$ Le Livre des Fais du bon messire Jehan le Meingre dit Boucicquaut, mareschal de France et gouverneur de Jennes, éd. D. Lalande, Genève 1985, p. 221 ; N. Housley, "One man and his wars...", p. 31. ${ }^{39}$ La Guerre de Metz en 1324, str. 153f, éd. E. de Bouteiller, Paris 1875; Jean de Stavelot, Chronique, éd. A. Borgnet, Bruxelles 1861 p. 196, cités par F. Godefroy, Dict. de l'ancienne langue française, $\mathrm{p} 755$.

${ }^{40}$ D. Buschinger, M. Olivier, Les Chevaliers teutoniques..., p. 164-165; S. C. Rowell, Lithuania Ascending..., p. 245, qui remarque que les dates des rèses varient, sans doute pour des raisons pratiques. Voir la liste des rèses de 1305 à 1409 établie par W. Paravicini, PR 2, tab. 49, p. $20-45$.

${ }^{41}$ C. Tyerman, «Henry of Livonia... », p. 32.

${ }^{42}$ Ibid., p. 31-33.
} 
d'engager des raids de grande ampleur en l'honneur de la Vierge n'est donc pas une innovation du XIV siècle, pas plus que celle de combattre aux côtés de croisés laïcs. En ce qui concerne les dates des rèses, il convient de remarquer que les jours mariaux choisis correspondent à des périodes particulièrement favorables à l'entreprise, puisque les marécages bordant la Lituanie interdisent à une grande armée d'y pénétrer à n'importe quel moment de l'année ${ }^{43}$. Seuls une fin d'été très sèche ou un hiver très froid permettent de traverser la Wildnis, cette grande étendue de forêts et de marécages qui sépare la Prusse des terres habitées de Lituanie et de Samogitie. En effet, comme le disait déjà Barthélemy l'Anglais au XIII ${ }^{e}$ siècle, le meilleur moyen d'envahir la Lituanie est d'attendre que les marais et les rivières soient gelées, ce qui explique que la rèse d'hiver ait été privilégiée ${ }^{44}$. Le fait de mener campagne en hiver étant, dans l'Europe médiévale, relativement rare, cette pratique exceptionnelle est plus souvent mentionnée dans les textes que la rèse d'été, pourtant volontiers fréquentée par les hôtes des Teutoniques ${ }^{45}$.

L'afflux massifs de croisés venus d'Europe occidentale implique encore un changement dans la manière de dénommer l'ennemi lituanien. Alors que Pierre de Dusbourg et les autres chroniqueurs proches de l'Ordre teutonique traitaient leurs adversaires baltes de "païens", "démons", «incroyants" ou «fils de Bélial» quand ils ne les appelaient pas tout simplement par leurs ethnonymes ${ }^{46}$, les sources narratives occidentales qualifient fréquemment les Lituaniens de "Sarrasins». Comment ce terme, utilisé à l'origine pour désigner les Bédouins arabes, puis, à partir de la première croisade, tous les musulmans du Proche-Orient ${ }^{47}$, a-t-il fait son apparition dans le contexte balte? Nous avons vu que le document signé entre l'Ordre teutonique et le duc de Mazovie en 1230 appelait déjà les Prussiens Sarraceni ${ }^{48}$, usage qui avait fait une timide apparition chez quelques chroniqueurs d'Europe centrale au XII ${ }^{e}$ siècle. Alan V. Murray a montré que c'est au cours du XIv ${ }^{e}$ siècle que cette habitude se généralise dans la sphère culturelle francophone et en Angleterre ${ }^{49}$. Dans ce contexte, la première occurrence provient vraisemblablement d'une continuation française du Memoriale historiarum de Jean de Saint-Victor, qui se termine en 1330 et raconte l'expédition du roi Jean de Bohême contre des «Sarazins» qui ne peuvent être que nos Lituaniens ${ }^{50}$. Puis, en 1349, le même terme est utilisé par

\footnotetext{
43 S. C. Rowell, Lithuania Ascending..., p. 245.

44 Voir chap. VII.

45 PR 2, p. 54-55.

46 A. V. Murray, «Saracens...», p. 415; S. C. Rowell, «Unexpected...», 1996, p. 561, n. 2.

47 Sur l'origine et les premières occurrences du terme, J. Tolan, Les Sarrasins....

48 «... contra Prutenos et alios Sarracenos nobis conterminos», Traité de Kruschwitz, PUB 1-1, doc. 78 , p. 60 .

49 PUB 4, p. 416-17; A. V. MurraY, «Saracens...», p. 416.

${ }^{50}$ Les Grandes chroniques..., vol. 9, p. 334-335. Sur ce texte, I. Guyot-Bachy, J.-M. Moeglin, "Comment ont été continuées les Grandes Chroniques de France dans la première moitié du XIV siècle", Bibliothèque de l'école des chartes, 163/2, 2005, p. 385-433.
} 
des croisés anglais dans une supplique pour obtenir une indulgence plenière les récompensant d'avoir financé l'érection et la garnison d'un château "in confinibus Sprucie in terra Sarracenorum videlicet regis de Letto " ${ }^{51}$.

En 1356 parait une œuvre qui a pu également influencer la manière dont les Lituaniens étaient désignés dans le milieu nobiliaire de cette période ${ }^{52}$. Il s'agit du Livre des merveilles du monde de Jean de Mandeville, auteur énigmatique que la critique récente considère, sans pouvoir l'affirmer, comme un chevalier anglais ayant vécu à Liège ${ }^{53}$. Cette description du monde rédigée par un personnage prétendant avoir lui-même beaucoup voyagé est pour grande partie une compilation de récits antérieurs, agrémentée de légendes connues de l'Antiquité et du Moyen Âge. Son caractère encyclopédique et son immense popularité lui ont valu de faire référence dans le milieu littéraire parisien ${ }^{54}$. En énumérant les différents chemins par lesquels on peut se rendre en Terre sainte, Mandeville mentionne la voie qui part de la Prusse et traverse un pays de «Sarazins», dont il ne donne pas l'identité:

"Qar homme ne poet faire ceo chemin bonement, sy noun par temps d'yvern, pur les chaitives eawes et pur les marois qe sont en celles parties, qe homme ne poet passer s'il ne giele durement, et s'il n'ad durement neigee par dessure. Qar si la noif n'estoit, homme ne porroit passer la glace, ne homme ne chival. Il y ad bien III jornees de tiel chemin a passer par Prusse jusques a la terre de Sarazins habitable. Et convient qe les christiens qe y vont touz les aunz pur combattre a eux portent toutes les vitailles ovesqez eux, qar la ne troeveront ils nuls biens. Et font charoier lour vitaille par dessure la glace as charioz sans roes q'ils appellent soleies. Et tant come lour vitaille dure ils poent la demorer, et nient plus, qar la ne troveroient ils qe lour vende rien. " 55

Mandeveille s'est sans doute inspiré de Guillaume de Rubrouck et de Marco Polo, auprès de qui il puise plusieurs détails de sa description de

\footnotetext{
51 PUB 4, p. 416-17; A. V. Murray, «Saracens...», p. 416.

52 Ibid., p. 416-418.

53 Ibid., p. 416. Sur les différentes hypothèses, C. Deluz, Le livre de Jehan de Mandeville: une "géographie" au XIV siècle, , Louvain-la-Neuve 1988, p. 6-24; Jean de Mandeville, Voyage autour de la Terre, éd. et trad. C. Deluz, Paris 1993, p. XII-XIV. Mandeville pourrait être un chevalier anglais de la région de Saint-Alban ayant dû, pour une raison ou une autre, quitter l'Angleterre avant de s'installer à Liège. Si la plupart de ses descriptions de l'Asie relèvent d'une compilation de sources écrites au XIII ${ }^{\mathrm{e}}$ siècle, rien n'interdit de penser que ce fils de la noblesse ait accompli un pèlerinage à Jérusalem ou à Sainte-Catherine. Il est en tout cas relativement éduqué: il connaît Isidore de Séville, Oderic de Pordenone, La Fleur des histoires du prince arménien Héthoum, les encyclopédies de Brunet Latin et de Vincent de Beauvais, tout comme le Roman d'Alexandre et le corpus connu, comme la Lettre du Prêtre Jean.

${ }^{54}$ Un auteur comme Philippe de Mézières a notamment pu y piocher; S. RöHL, «Le Livre de Mandeville à Paris", dans G. Croennen, P. Ainsworth (éds.), Patrons, Authors and Workshops, Louvain etc. 2006, p. 293-294.

55 Jean de Mandeville, Le livre des merveilles du monde, éd. C. Deluz, Paris 2000, p. 267-268.
} 
l'Asie, pour décrire ce chemin, comme nous aurons l'occasion de le voir au chapitre VII ${ }^{56}$. Toutefois, Alan V. Murray a remarqué que les trois jours nécessaires pour rejoindre la "terre de Sarazins habitable», les moyens logistiques mis en œuvre, ainsi que le paysage fait de marais gelés, rappellent tout simplement les rèses contre les Lituaniens - ce que confirme l'allusion aux "christiens qe y vont touz les aunz pur combattre a eux»" ${ }^{57}$. En outre, Mandeville avoue ne pas connaître la route menant jusqu'à Jérusalem, mais dit avoir parcouru plusieurs pays d'Europe du Nord-Est, ce qui pourrait laisser entendre qu'il a lui-même participé à une rèse, ce qui n'aurait rien d'étonnant pour un aristocrate en exil:

"Jeo n'ay point esté par cest chemin et si ay esté as autres terres marchisantz a cest, come en la terre de Russie, et en la terre de Niflan, et el roialme de Crake et de Leto, et en roialme d'Arasten ${ }^{58}$, et en plusours autres lieux en celle marche, mes jeo n'alay unques par cest chemin a Jerusalem pur quoy jeo ne le porroy bien deviser. " ${ }^{59}$

L'auteure de l'édition la plus récente du Livre de Mandeville, Christiane Deluz, remarque que celui-ci fait très rarement usage de la première personne dans son œuvre, ce qui tend à donner à ses descriptions un caractère «scientifique» propre aux encyclopédies ${ }^{60}$. Or, le court passage consacré à la Prusse commence justement par une mention de sa propre expérience, exprimée à la première personne, ce qui tranche avec le reste du récit. Immédiatement après, Mandeville dit que "si cest matiere plest a ascun vaillant homme qe ad esté par ce chemin, il le poet ycy adjouster si ly plest, a la fin qe cils qe vouroient faire ceo viage par ceo cousté y puissent savoir quel chemin il y ad» ${ }^{61}$. Que ceux qui s'y connaissent ajoutent leurs commentaires; autrement dit, sa description du chemin qui part de Prusse pour Jérusalem est un mélange de souvenirs de rèses (directs ou indirects ${ }^{62}$ ) et de divers récits de voyages, notamment ceux de Marco Polo et de Guillaume de Rubrouck relatifs à l'Orient tatar. Dans

\footnotetext{
56 X. Walter, Avant les grandes découvertes: une image de la terre au XIV siècle, "Le voyage de Mandeville”, Roissy 1997, p. 334; C. Deluz, «Partir, c'est mourir un peu. Voyages et déracinement dans la société médiévale", dans Voyages et voyageurs au Moyen Âge - Actes des congrès de la Société des historiens médiévistes de l'enseignement supérieur public, 26 congrès (Limoges-Aubazine, mai 1995), Paris 1996, p. 298. Voir chapitres VI et VII.

57 Jean de Mandeville, Le livre des merveilles..., p. 271, n. 34; A. V. Murray, "Saracens...", p. 417-418.

58 Pour C. Deluz («Partir, c'est mourir un peu...», p. 271, n. 33), «Arasten» serait un terme désignant «les terres orientales lointaines» dans les chansons de geste.

59 Ibid., p. 266-267.

${ }^{60}$ C. Deluz, Le livre..., p. 34-35.

${ }^{61}$ Jean de Mandeville, Le livre des merveilles..., p. 267.

${ }^{62}$ Il reste bien sûr la possibilité que l'auteur se soit renseigné oralement auprès de chevaliers revenus d'une rèse, qui commençaient à devenir populaires à l'époque où il écrivait.
} 
ce contexte, les "Sarrasins» dont parle Mandeville peuvent autant être les Lituaniens que les Tatars, établis en Russie et convertis à l'islam au XIV ${ }^{\mathrm{e}}$ siècle $^{63}$.

Quel que soit le rôle joué par le «best-seller" de Mandeville, la seconde moitié du XIV siècle voit s'imposer l'usage de définir les infidèles de la Baltique comme des Sarrasins. Les Lituaniens, avec leurs princes et leur noblesse, rappelaient-ils les Turcs et les Arabes du Moyen Orient aux hôtes occidentaux de l'Ordre teutonique ${ }^{64}$ ? D’une manière générale, comme le note John Tolan "pour de nombreux Européens de l'Ouest, et ce tout au long du Moyen Âge, les Sarrasins étaient des pä̈ens, et les païens des Sarrasins; les deux mots deviennent interchangeable» ${ }^{65}$. Toutefois, nos auteurs paraissent avoir été conscients des nuances ethniques qui différenciaient les Lituaniens des Turcs, Tatars ou Persans; tous sont qualifiés de "Sarrasins", par exemple dans le Livre des fais du maréchal Boucicaut (terminé en 1409), mais sans que ce terme n'assimile forcément les Baltes aux musulmans méditerranéens ${ }^{66}$. Ainsi, "Sarrasins» devrait se comprendre comme un simple qualificatif regroupant tous les infidèles, les "ennemis de la Chrétienté " ${ }^{67}$ - et occasionnellement comme une insulte, attestée en France dans le cadre de la guerre civile des Armagnacs et des Bourguignons ${ }^{68}$.

Du reste, le rapprochement des païens baltes avec les occupants de la Terre sainte n'était en rien étranger à l'idée d'un unique et gigantesque combat mené sur plusieurs fronts contre les ennemis de la croix; c'est sans doute ce qui animait déjà, aux siècles précédents, le rédacteur du traité de Kruschwitz, identifié comme un clerc proche de la Curie, et les chroniqueurs tchèques ou polonais qualifiant les Prussiens de "Sarrasins» ou de "Saladinistes». L'utilisation de ce terme pour qualifier les païens baltes dans le milieu aristocratique d'Europe occidentale ne fait que renforcer l'identification de la croisade balte avec celles d'Espagne et d'Orient, et permet de capter une partie du capital symbolique attaché aux anciennes expéditions de Terre sainte ${ }^{69}$. Il existe toutefois quelques exceptions; ainsi, pour le poète Guillaume de Machaut, qui écrivait au même moment que Jean de Mandeville, les païens baltes sont simplement des

\footnotetext{
${ }^{63}$ Comme le note A. V. Murray, «Saracens... », p. 418, Mandeville ne distingue pas ses «Sarazins» d'Europe orientale de ceux du Proche-Orient, qu'il décrit de manière plus détaillée dans une autre partie de son récit.

${ }^{64}$ A. V. Murray, «Heathens...», p. 222.

${ }^{65}$ J. Tolan, Sarrasins..., p. 186.

${ }^{66}$ Sur ce point, M. SzKILnIK, Jean de Saintré. Une carrière chevaleresque au XV siècle, Genève 2003, p. 114 .

${ }^{67}$ C'est ainsi que le comprend, entre autres, A. LeguAI, «Bourbonnais et Auvergnats à la croisade de Prusse", Études Bourbonnaises 1991, p. 97, n. 6.

68 W. PARAVICINI, «Litauer... », p. 254 ; C. TAYLOR, Chivalry and the Ideals of Knighthood in France during the Hundred Years, Cambridge 2013, p. 221-223. Notons aussi le surnom attribué par ses ennemis à Charles le Téméraire, "Turc d'Occident".

69 J. Tolan, Les Sarrasins..., p. 161; 184-187; A. V. Murray, «Heathens... », p. 217-223.
} 
"mescreans $»^{70}$, alors que pour Philippe de Mézières, les Lituaniens du Songe du vieil pelerin sont "ydolatres», "sans lettre et sans clergie»" ${ }^{71}$, mais nulle part ils ne se voient qualifiés de Sarrasins.

\section{UN IDÉAL ARISTOCRATIQUE}

Confrontées aux documents comptables et à d'autres pièces d'archives, les sources narratives permettent de reconstituer ce à quoi pouvait ressembler une rèse, telle que la vivaient les chevaliers qui vont nous occuper dans les pages à venir ${ }^{72}$. Une fois arrivés en Prusse, notamment via Toruń, ou débarqués dans les ports de la côte (Gdańsk par exemple), les "hôtes" sont conduits à Königsberg, la forteresse de Sambie qui sert de point de départ aux rèses ${ }^{73}$. Les chevaliers occidentaux vivent quelque temps aux côtés des membres de l'Ordre dans un cadre raffiné, où on leur propose tournois et banquets ${ }^{74}$. Les privilégiés invités à faire halte à Marienbourg peuvent admirer en sus la richesse des quartiers du grand-maître ${ }^{75}$. Quand les conditions météorologiques le permettent, on pénètre alors en territoire ennemi; la cible principale est, à partir des années 1330, la Samogitie, très stratégique province côtière qui sépare la Prusse de la Livonie ${ }^{76}$. Le but était d'affaiblir les défenses du grand-duché, pour permettre dans un second temps de pénétrer jusqu'en son cœur ${ }^{77}$. Toutefois, il n'est pas rare que la rèse soit annulée, et que les hôtes rentrent sans avoir pu combattre. Prendre part à une véritable bataille est de ce fait quasiment exceptionnel, mais sans doute plus prestigieux encore ${ }^{78}$ : Werner Paravicini cite l'exemple de l'Ordre du Tiercelet, un ordre de chevalerie fondé par des nobles du Poitou et de la Saintonge, qui indique dans ses statuts que celui des membres ayant participé à un voyage en Prusse pourra l'indiquer sur son enseigne; une distinction est faite entre "celi qui fera ladicte reize et sera en bataille» et celui qui y participera, mais sans s'être battu ${ }^{79}$.

\footnotetext{
${ }^{70}$ Guillaume de Machaut, «Le Confort d'ami», v. 3034, dans Euvres, éd. E. Hoepffner, Paris 1908, vol. 3, p. 107.

${ }^{71}$ Blanchard, vol. 1, p. 207.

${ }^{72}$ Pour ce qui suit, les travaux de W. Paravicini, à commencer par les Preussenreisen des Europäischen Adels (PR), vol. 1, 1989, vol. 2, 1995, vols. 3-5 à paraître, sont irremplaçables.

73 PR 1, p. 192-201, 265-272.

74 W. Paravicini, «La Prusse...", p. 180.

${ }^{75}$ Id.; W. Urban, The Samogitian Crusade..., p. 104, 108, rappelle que pour ces hôtes d'appartenance nobiliaire, l'abondance de biens n'est pas contradictoire avec la vocation religieuse de l'Ordre teutonique.

76 S. C. Rowell, Lithuania Ascending..., p. 254; R. Wenskus, «The Teutonic Order... », p. 326.

77 W. Urban, The Samogitian Crusade..., p. 11, 54.

78 PR 2, p. 13-19.

79 PR 1, p. 104, qui cite M. VALE, "A Fourteenth-Century Order of Chivalry: the "Tiercelet" ", English Historical Review 82, 1967, p. 332-341.
} 
Bien que le combat au côté des Teutoniques soit, du moins à l'origine, récompensé par des indulgences, relativement peu de chevaliers semblent avoir pris la croix avant de se rendre en Prusse $^{80}$. Cette pratique reste plutôt l'apanage des grands seigneurs, et encore disparaît-elle progressivement à partir des années $1360^{81}$. Parmi les princes, certains font dire des messes en leur honneur, ce qui peut refléter un souci tout aussi spirituel que mondain ${ }^{82}$. Si la plupart des textes restent muets sur les motivations religieuses de ces "croisés", il paraît probable qu'une partie d'entre eux au moins aient vu dans le fait de combattre des infidèles une forme de pèlerinage, devant leur permettre d'expier leurs péchés et d'obtenir une rétribution spirituelle ${ }^{83}$. Du reste, le conformisme, voire une certaine pression sociale, peut expliquer le succès rapide et croissant du voyage de Prusse dans la seconde moitié du XIv ${ }^{e}$ siècle; un chevalier digne de ce nom doit partir au loin et se battre pour la croix. Aussi n'y a-t-il pas de contradiction à voir la recherche de reconnaissance et d'honneur se confondre avec la piété pour une partie non négligeable des hôtes de l'Ordre teutonique: se couvrir de gloire au service de la foi faisait partie intégrante de la dévotion des nobles du Moyen Âge ${ }^{84}$.

$\mathrm{Si}$, sauf exception, les rèses n'offrent aucune possibilité de s'enrichir, ni par le pillage ni par le salaire ${ }^{85}$, elles représentent donc l'occasion d'accomplir des exploits au service de Dieu, ce que les biographes de nos croisés n’hésitent pas à embellir quelque peu. Ainsi, la dernière expédition de Jean le Meingre, plus connu sous le sobriquet de Boucicaut, se transforme-t-elle dans Le livre des fais en une campagne hérö̈que, tout à la gloire du futur maréchal (1391):

"Et en celle besongne, pour ce que messire Bouciquaut vit que la chose estoit grande et moult honorable et belle, et qu'il y avoit grant compaignie de chevaliers et d'escuyers et de gentilz hommes, tant du royaume de France comme d'ailleurs, leva premierement baniere et fist en celle besongne tant d'armes que tous l'en louerent. $»^{86}$

La Prusse apparaît ici comme un théâtre possible d'héroïsme, au moins sur le mode imaginaire. Car le récit de hauts faits des voyageurs de Prusse ne doit pas toujours être pris au pied de la lettre; ainsi lorsque l'auteur anonyme de la Chronique des Quatre Premiers Valois (fin du XIV siècle) relate l'exploit accompli

${ }^{80}$ C. Tyerman, England..., p. 275.

81 T. Guard, Chivalry..., p. 96-97.

82 Ibid., p. 94.

${ }^{83}$ On peut penser notamment au premier duc de Lancastre, Henri de Grosmont, qui dans son Livre de Seyntz Medicines, dit regretter avoir fait couler le sang et chercher la gloire durant sa jeunesse; M. Keen, "Chaucer's Knight...", p. 58.

${ }^{84}$ W. Paravicini, «Fahrende Ritter...», p. 233-237; J. Paviot, «Boucicaut et la croisade...», p. $82-83$.

${ }^{85}$ M. Keen, "Chaucer's Knight... », p. 58-59.

${ }^{86}$ Le Livre des Fais..., p. 77. 
par l'Anglais Henri de Grosmont, premier duc de Lancastre en 1351-1352 et chevalier célèbre en son temps ${ }^{87}$ :

"En ce temps estoit le bon duc Henry de Lencastre en Prusse. Et comme il fut à Estonevergne [Königsberg ${ }^{88}$ ], les crestiens en firent leur chief. Et là estoient moult de grans seigneurs et barons d'Alemaigne. Les crestiens firent leur reze sur le roy de l'Estone [Lituanie ${ }^{89}$ ] et le roi de Graco [Cracovie ${ }^{90}$ ], lesquelz s'estoient aliés à grant nombre de mescreans pour desconfire les crestiens. Les crestiens assemblerent aux mescreans qui estoient infini nombre et avoient grant chevalerie. Les Alemans se commencerent si à desconfire que l'estandart des crestiens chey à terre. Et quant ce vit le bon duc Henry de Lencastre, il point celle part et o sa force et chevalerie redrecha la baniere des crestiens. Dont par ce fait s'esvertuerent tant les crestiens que par la voulenté nostre Seigneur Jhesu Crist les mescreans furent tous desconfis et les crestiens ourent victoire. ${ }^{91}$

L'histoire serait belle, si le duc Henri n'avait pas en réalité été retardé par des incidents survenus sur le chemin, où des nobles allemands ont rançonné tout son équipage ${ }^{92}$. De ce fait, le duc est arrivé après le départ de la rèse à la fin du mois de janvier ${ }^{93}$, et si l'on croit le chroniqueur anglais Thomas Gray, "il manqua de combattre avec les infidèles. Henri alla alors à Cracovie, où les Tatars firent une incursion, et repartit peu après son arrivée» ${ }^{94}$; ce qui illustre le fait que la Pologne pouvait être une destination de croisade occasionnelle, et que combattre les Tatars qui la menaçaient valait bien une rèse de Prusse ${ }^{95}$. L'exploit du duc de Lancastre contre les Lituaniens serait donc imaginaire ${ }^{96}$; à moins que l'auteur de la Chronique des Valois, qui écrivait en 1393, ait mélangé les exploits du premier duc de Lancastre avec ceux de son petit-fils homonyme, racontés par plusieurs chroniques anglaises.

\footnotetext{
${ }^{87}$ P. Dobrowolski, «Miles...», p. 37.

${ }_{88}^{8}$ PR 1, p. 132, n. 561.

${ }^{89}$ Id. Et non "Estonie», comme le proposent K. Fowler, The King's Lieutenant, Londres 1969,

p. 106 ou T. Guard, Chivalry..., p. 75.

${ }^{90}$ PR 1, p. 132, n. 561.

${ }_{91}$ Chronique des Quatre Premiers Valois, éd. S. Luce, Paris 1862, p. 13-14.

${ }_{92}$ Henri de Herford, Liber de rebus memorabilioribus sive Chronicon, éd. A. Potthast, Göttingen 1859, p. 286; Henri Knighton, Knighton's Chronicle, éd. et trad. G. H. Martin, Oxford 1995, p. 110-113; PR 1, p. 129-134; W. PARAvicini, «Fürstliche Ritterschaft: Otto von BraunschweigGrubenhagen», dans Edelleute und Kaufleute..., p. 87-126; K. Fowler, King's Lieutenant..., p. 103-110.

${ }_{93}$ Henri Knighton, Knighton's Chronicle..., p. 112.

94 Thomas Gray, Scalacronica (John Leland's Abstract), éd. A. King, Woodbridge 2005, p. 139; PR 1, p. 133, n. 562.

${ }^{55}$ Le chroniqueur Geoffrey Le Baker note ainsi: «domino duce Lancastrie Spruciam profecto et deinde apud regem Crakkowye et Polonie contra Turcos demorante", Chronicon Galfridi le Baker de Swynebroke (1303-1356), éd. E. M. Thompson, Oxford 1889, p. 119, cité par PR 1 p. 133, n. 562. ${ }_{96}$ PR 1, p. 132.
} 
Henri Bolingbroke, comte de Derby puis duc de Lancastre, et futur roi Henri IV d'Angleterre, effectue sa première expédition en Prusse à l'été 1390. Ses aventures sont connues des Anglais par la Chronique de Westminster (1394), la continuation de la Chronique d'Henri Knighton (1396), l'Historia Anglicana ou Chronica Maiora de Thomas Walsingham (1422) et le Liber de illustribus Henricis de John Capgrave (v. 1446), qui sont pour l'essentiel confirmés par les chroniques de l'Ordre teutonique ${ }^{97}$. En voici une synthèse: le comte débarque en août dans la région de Gdańsk et se rend à Königsberg avant de rejoindre les forces du maréchal de Prusse. Celui-ci, accompagné $\mathrm{du}$ duc lituanien Vytautas, l'accueille "avec un sourire de plaisir et toutes les marques de la courtoisie ${ }^{98}$; les chrétiens passent le Niémen et gagnent une première bataille contre les forces du "roi de Lituanie, nommé Skirgalle»" autrement dit le prince Skirgaila, frère du roi de Pologne Ladislas Jagellon et lieutenant de celui-ci. Là où Wigand de Marbourg ne fait que mentionner la présence du duc de Lancastre ${ }^{100}$, la Chronique de Westminster fait des Anglais les principaux artisans de la victoire: "le comte [= Bolingbroke] mérita de nombreux remerciements en conséquence de l'aide apportée par les siens, en particulier par ses archers ${ }^{101}$. Skirgaila, dit-on, fuit et se réfugie à Vilnius, aussitôt attaqué par les croisés: ceux-ci parviennent à prendre le bourg, mais échouent à faire tomber la citadelle. Qu'à cela ne tienne, l'aventure est tout à l'honneur du prince anglais, et servira à valoriser sa réputation auprès de ses compatriotes ${ }^{102}$. On raconte même que "l'auteur de la capture de la ville est ledit comte, qui avec les siens se distingua dans l'assaut, et planta le premier sa bannière sur les murs de la ville» ${ }^{103}$. D'après Thomas Walsingham, Vilnius tombe "grâce au grand courage du comte et des siens"; "certains, qui étaient de sa maison, grimpèrent les premiers sur les murs (que les autres fussent ignorants ou pleins de torpeurs), et déposèrent sa bannière sur

\footnotetext{
${ }_{97}$ The Westminster Chronicle, éd. et trad. L. C. Hector, B. F. Harvey, Oxford 1982 (ci-après: Westminster), p. 445-449; Thomas Walsingham, The Chronica Maiora, éd. et trad. J. Taylor, W. R. Childs et L. Watkiss, Oxford 2003-2011, vol. 1, p. 902-903 (ci-après: Walsingham); Idem, The Chronica Maiora, trad. D. Preest, J. C. Clark, Woodbridge 2005, p. 278-279; Henri Knighton, Knighton's Chronicle..., p. 536-537; John Capgrave, Liber de illustribus Henricis, dans SRP 2, p. 794-795. Pour les sources prussiennes: Wigand de Marbourg, Chronica..., SRP 2, p. 642-644; Jean de Posilge, Chronique, SRP 3, p. 166-168; Annales de Toruń, ibid., p. 168. Sur l'expédition d'Henry de Derby en Prusse, voir PR 1, p. 134-135; P. Dobrowolski, "Miles...», p. 36-46; F. R. H. Du Boulay, «Henry of Derby...», p. 153-172.

${ }_{98}$ Westminster, p. 446; Walsingham, vol. 1, p. 902; la rencontre entre Bolingbroke et Vytautas est également mentionnée par John Capgrave, Chronicle of England, éd. F. C. Hingeston, Londres 1858, p. 254.

99 Westminster, p. 446; Walsingham, vol. 1, p. 902.

100 Wigand de Marbourg, Chronica..., SRP 2, p. 642-643.

101 Westminster, p. 446.

102 S. Rigby, "The Knight...», p. 59. Par exemple, John Capgrave, Liber de illustribus Henricis...

(v. 1446), SRP 2, p. 794-795; Henri Knighton, Knighton's Chronicle..., p. 536.

103 Westminster, p. 448.
} 
la muraille» ${ }^{104}$. Un cadeau offert par Henri à l'un de ses hommes, que l'on dit avoir été le premier sur la muraille, figure en effet dans son livre de comptes ${ }^{105}$.

Si les chroniqueurs proches de l'Ordre teutonique mentionnent la présence d'Henri de Lancaster, ils ne relatent pas l'épisode de la bannière ${ }^{106}$. Néanmoins, la chronique de Jean de Posilge (1405), précise que le prince anglais «avait avec lui beaucoup de bons archers, qui firent de bien bonnes choses» ${ }^{107}$; d'un point de vue strictement militaire, les nobles croisés occidentaux sont en effet bien plus utiles lorsqu'ils emmènent avec eux des soldats spécialisés ${ }^{108}$. Si les chevaliers lourdement armés, montés sur des destriers caparaçonnés, ne sont pas d'une aide irremplaçable dans la Wildnis ou lors des sièges ${ }^{109}$, leur présence est essentielle à l'Ordre pour des raisons avant tout diplomatiques. Entretenir des contacts réguliers avec les maisons les plus importantes de la Chrétienté présentait de solides avantages, y compris sur le plan militaire: ainsi en est-il de la compagnie d'arbalétriers génois envoyés par le duc de Bourgogne Philippe le Hardi ${ }^{110}$.

Car les plus grand princes ne se déplacent pas forcément eux-mêmes; un Henri de Derby, qui après y avoir passé une saison en 1390-1391, retourne en Prusse à l'été $1392^{111}$, fait presque figure d'exception. À l'inverse, aller se battre aux confins de la Chrétienté peut être une forme de bannissement, ce qu'illustre l'exemple du duc de Norfolk, Thomas de Mowbray, chassé du royaume d'Angleterre sur l'ordre de Richard II en $1398^{112}$. Voilà la teneur du décret le concernant tel que rapporté par la Chronicque de la traïson et de la mort de Richart deux roy Dengleterre:

"Oez le jugement du Roy et du conseil. Il est ainsi que Thomas Mowbray duc de Noruolt sera banny du royaume a tousioursmays. Et commanda le Roy que Thomas de Mowbray deuisast ou il vouldroit demourer ou en Pruce ou en Bahaigne ou en Hongrye, ou quil alast droicte voye oultre mer en la terre des Sarrazins mescreans, et quil ne retournast jamaiz et sans mettre le pie sur la terre Crestiens. ${ }^{113}$

\footnotetext{
${ }^{104}$ Walsingham, vol. 1, p. 902.

105 Expeditions to Prussia and the Holy Land made by Henry, earl of Derby, éd. L. Toulmin Smith, Londres 1894; PR 2, p. 153-154.

106 Wigand de Marbourg, Chronica..., SRP 2, p. 642-643; Annales de Toruń, SRP 3, p. 164; Jean de Posilge, Chronique..., SRP 3, p. 167.

107 Id.

108 PR 2, p. 153-155.

109 Ibid., p. 155.

110 Ibid., p. 154; W. Paravicini, «La Prusse...», p. 184.

111 PR 1, p. 134.

112 Sur cette affaire, PR 1, p. 128; T. Guard, Chivalry..., p. 85. Aller exercer sa force contre les "Sarrasins" lorsque l'on est chassé de son pays n'est, du reste, pas propre aux croisés de Prusse; en 1404, le grand seigneur français Charles de Savoisy, en disgrâce momentanée, s'embarque à Marseille pour aller faire la course aux navires musulmans, d'où il ramena sans doute un certain nombre de prisonniers; voir M. Rodinson, La fascination..., p. 172-173.

${ }^{113}$ Chronicque de la traïson et de la mort de Richart deux roy Dengleterre, éd. B. Williams, Londres 1846 , p. 22 (graphie et ponctuation simplifiées). W. Paravicini précise que les archives du
} 
Être envoyé sur les marges de la Chrétienté, sans doute pour y combattre, était certes une punition honorable, mais en aucun cas à prendre à la légère. C'est que le voyage n'est pas sans risque, comme a pu le constater un autre puissant, Thomas de Woodstock, duc de Gloucester: malgré un départ en grande pompe en été 1391, il n'atteindra jamais la Prusse, car son navire ne put franchir la mer du Nord. Débarquant finalement sur les côtes écossaises, il sera de retour en Angleterre avant Noël ${ }^{114}$. Aussi les grands préfèrent-ils donner congé à leurs proches qui en demandent l'autorisation, et ne rechignent pas à supporter leurs dépenses; la présence de ses familiers sur divers fronts de croisade assure un prestige certain au prince, sans mettre sa personne en danger ${ }^{115}$.

Le voyage en Prusse est donc surtout l'affaire de courtisans, sur lesquels s'étendent moins les chroniques, mais qui nous ont parfois laissé de précieux témoignages. Un système de crédit, avec des ramifications allant des villes de Flandre jusqu'à la Prusse, se met en place dès la moitié du XIv ${ }^{\mathrm{e}}$ siècle pour permettre aux chevaliers de se déplacer sans trop d'argent sur eux ${ }^{116}$. Ceux-ci doivent payer tous les frais lors de leur séjour, et nombreux sont ceux qui s'endettent pendant les périodes d'attente ${ }^{117}$. Il nous reste ainsi une note témoignant d'une dette contractée à Elbląg par les frères Jean et Geoffroy le Meingre, dits Boucicaut, et Jean de Sempy, qui promettent de la rembourser après leur retour auprès d'un banquier de Bruxelles ${ }^{118}$. Les princes volent parfois à l'aide de leurs favoris, comme c'est le cas du

Parlement notent «en Almayne, Beme \& Hungry»; la chronique est sans doute plus précise en comptant la Prusse parmi ces marches de la Chrétienté (Rolls of Parliament, III 383, éd. Th. Rymer, Foedera, conventiones..., La Haye 1739-1745, III 4, p. 147-149, cité par PR 1, p. 128, n. 531). Mowbray, qui est mort l'année suivante à Venise après avoir effectué un pèlerinage à Jérusalem, ne s'est probablement pas rendu sur le rivage balte.

${ }_{114}$ PR 1, p. 134-135; Westminster, p. 478-485.

115 W. Paravicini, "La Prusse...", p. 184-188. Parmi les chevaliers soldés, Gadifer de la Salle, futur conquérant des Canaries; sur l'intérêt des princes à financer le voyage en Prusse, il peut être intéressant de se référer à la politique du prince Philippe le Hardi, duc de Bourgogne à partir de 1363: B. Schnerb, Jean sans Peur: le prince meurtrier, Paris 2005, p. 72-75; J. Magee, «Le temps de la croisade bourguignonne: l'expédition de Nicopolis", dans J. Paviot, M. Chauney-Bouillot (dirs.), Nicopolis 1396-1996. Actes du colloque international, Dijon 1996 (Annales de Bourgogne 68), Dijon 1997 p. 50-51 ; J. Рaviot, Les Ducs de Bourgogne..., p. 56.

116 W. Paravicini, «La Prusse... », p. 181-183; Idem, «Nobles artésiens et marchands lubecquois: une opération de change en 1349», dans J. Hirschbiegel, A. Ranft, J. Wettlaufer (dirs.), Edelleute und Kaufleute..., p. 329-335; PR 2, p. 163-308.

117 Par exemple, les chevaliers de France occidentale présentés par C. Higounet, «De La Rochelle à Toruń...», p. 443-447; W. PAravicinı, "Prasmingas švaistymas: žygiai ị Prūsiją ir Lietuvą Pierre'o Bourdieu kapitalų teorijos požūiriu ", Lietuvos istorijos studijos 26, 2010, p. 9-21 (résumé en anglais) propose de lier les dépenses des croisés de Prusse comme moyen d'acquérir de l'honneur à la théorie du capital économique et symbolique de Pierre Bourdieu.

118 "Campagne de Boucicault en Prusse", Bibliothèque de l'École des chartes, 38, 1877, p. 491-492; PR 2, p. 301-302. 
duc de Bourgogne Philippe le Hardi, qui à partir des années 1370 finance volontiers les chevaliers désireux de se rendre en Prusse, ou couvre leurs frais à leur retour ${ }^{119}$. Son proche collaborateur Pierre de la Trémoille, mais aussi le maréchal Boucicaut ${ }^{120}$, bénéficient de ses largesses, tout comme le sire de Sempy, "pour l'aider à supporter les grands frais et missions qu'il a soutenus au voyage de Prusse, où il fut l'année passée [1392], dont il est encore endetté»" ${ }^{121}$. Si l'apport financier n'est pas sa priorité, l'Ordre teutonique s'enrichit néanmoins aux dépens des chevaliers désœuvrés qui attendent le départ de l'expédition ${ }^{122}$, Bénéficiant de la conjoncture économique généralement favorable aux pays d'Europe centrale, les Teutoniques sont à la tête d'une immense fortune ${ }^{123}$, une assurance financière qui leur permet d'entretenir leurs hôtes dans un cadre somptueux, ce qui est pour beaucoup dans le succès des voyages en Prusse.

Alors que leurs familiers vont croiser le fer avec les païens, les princes d'Europe reçoivent fréquemment des cadeaux de la part du grand-maittre et de ses ambassadeurs, lesquels s'efforcent d'attirer toujours plus d' "hôtes" ${ }^{124}$. Afin de récompenser ces derniers, pour qui la guerre en Europe du Nord peut paraitre plus rude et moins profitable que des campagnes menées en terrain familier ${ }^{125}$, les Teutoniques ont soin de mettre en scène un cérémonial imprégné d'une symbolique chevaleresque, qui fait notamment référence à la célèbre Table Ronde du roi Arthur ${ }^{126}$. Les hôtes qui, d'après les hérauts d'armes, méritent le plus d'être honorés, sont invités à s'asseoir à la table d'honneur (Ehrentisch) que l'on dresse avant ou après l'expédition, événement que les hérauts, les poètes et les chroniqueurs se chargeront d'immortaliser. C'est dans le même souci de

\footnotetext{
119 B. Schnerb, L'État bourguignon 1363-1477, Paris 1999, p. 116-117; W. Paravicini, «La Prusse... ", p. 185-186. Par exemple, le duc Louis II de Bourbon aide son familier Guichard Daupin à s'aquitter des frais de son voyage de Prusse: O. Mattéoni, Servir le Prince..., p. 381, n. 71.

${ }^{120}$ Itinéraires de Philippe le Hardi et de Jean sans Peur, ducs de Bourgogne (1363-1419), d'après les comptes de leur hôtel, éd. E. Petit, Paris 1888, p. 543: "Le duc fit don à messire Boucicaut le jeune, chevalier, chambellan du roy et $d u d u c$, de la somme de 500 livres pour les frais qu'il fit au voyage de Prusse où il a demeuré longuement. [...] le duc fit don à Pierre de la Trimouille, escuyer, son chambellan, de 300 livres pour les frais de son voyage de Prusse»; le même document mentionne un don fait à l'un des participants à l'expédition du duc Louis de Bourbon contre Mahdia (1390). Voir O. HaLeCKI, "Gilbert de Lannoy...", p. 317.

121 Arc. Dép. Côte-d'Or, B 11 932, cité et adapté par B. Schnerb, L'État bourguignon..., p. 116.

122 T. Guard, Chivalry..., p. 93.

${ }^{123}$ K. GórsKI, «The Teutonic Order in Prussia», dans A. V. Murray (dir.), The North-Eastern Frontiers..., p. 240-241; les Teutoniques ont imposé un quasi-monopole sur la vente de céréales, ce qui assure leur fortune.

${ }^{124}$ Le grand-maitre offre volontiers des faucons à ses partenaires politiques; W. PARAVICINI, «Tiere aus Norden", dans J. Hirschbiegel, A. Ranft, J. Wettlaufer (dirs.), Edelleute und Kaufleute, p. 249-272.

${ }^{125}$ M. Keen, Chivalry..., p. 172.

126 PR 1, p. 324, note néanmoins que la table d'honneur des Teutoniques n'était pas ronde; voir aussi A. S. Соoк, «Beginning the Board...», p. 375-388.
} 
rendre publique leur renommée que les participants à la rèse font figurer leurs blasons sur les murs de la cathédrale Sainte-Marie de Königsberg ${ }^{127}$.

L'impression que le décorum et l'atmosphère entretenus par l'Ordre teutonique produisaient sur l'imagination des visiteurs, et de ceux qui entendaient leur prêter la plume, se reflète dans la Chronique du bon duc Loys de Bourbon (1429), de Jean Cabaret d'Orville ${ }^{128}$. Quatre pages de l'édition d'A. M. Chazaud sont consacrées aux aventures prussiennes d'un groupe de chevaliers de l'entourage du duc de Bourbon, emmenés par celui qui a dicté ses souvenirs au chroniqueur, Jean de Chastelmorand. L'homme était célèbre en son temps: chambellan du duc de Bourbon et de Louis d'Orléans, membre de plusieurs ordres chevaleresques, il participe, entre autres, à la libération des prisonniers capturés à Nicopolis (1397) et aux expéditions méditerranéennes du maréchal Boucicaut ${ }^{129}$. Ce fin connaisseur des affaires orientales, diplomate, guerrier et courtisan doté de "réelles qualités intellectuelles»" est un témoin de choix, mais il accuse déjà un âge avancé lorsqu'il assiste Cabaret d'Orville dans la rédaction de la chronique. Pour Olivier Mattéoni, celui qui dicte ses souvenirs au chroniqueur à une époque où les croisades baltes sont terminées est un vieil homme nostalgique du temps de sa jeunesse et farouche défenseur de sa classe sociale ${ }^{131}$. Sa description de l'expédition prussienne peut donc être vue comme une illustration des valeurs d'une chevalerie à la fois idéalisée et révolue.

$\mathrm{Du}$ reste, la rèse se révèle difficile à situer dans le temps, étant donné le manque de rigueur du texte quant aux dates ${ }^{132}$. Si l'on suit l'ordre chronologique, il s'agirait de l'hiver 1374-1375, ce qui correspond aux documents diplomatiques et aux récits des chroniqueurs prussiens ${ }^{133}$. Pourtant, on nous dit que les Bourbonnais ont rencontré à Marienbourg le maréchal

\footnotetext{
${ }^{127}$ Voir également p. 147, 337. PR 1, p. 316-344; W. PARAVicinı, "Verlorene Denkmäler...»", p. 67-168.

128 Jean Cabaret d'Orville, Chronique du bon duc Loys de Bourbon, éd. A.M. Chazaud, Paris 1876 (ci-après: Chazaud), p. 62-66.

129 Sur Jean de Chastelmorand, O. MatTÉONI, «Portrait... », p. 4-9.

${ }^{130}$ Ibid., p. 5.

131 Ibid., p. 22-23.

132 Ibid., p. 4; A. V. Murray, «Saracens», p. 419.

133 Des arguments convaincants sont proposés par O. Troubat, La Guerre de Cent Ans et le Prince Chevalier, Montluçon 2001, vol. 1, p. 571-585, qui note entre autres la présence en Prusse de Hutin de Vermeilles, chambellan du roi Charles V, mentionnée par Cabaret d'Orville et rapportée par Wigand de Marbourg en février 1375 (Chronica..., SRP 2, p. 574-575). Une lettre de Winrich de Kniprode datée de 1375 mentionne une rèse d'hiver lors de laquelle le château de Drakin (Trakai) est capturé, et où l'armée teutonique était accompagnée de «magnatibus baronibus nobilibus militibus et militaribus de Francia et Alemania", dans Lucas David, Preussische Chronik, éd. Ernst Hennig, vol. 7, Königsberg 1815, p. 129; Ibid., 128-130; CDP 3, p. XIX. Voir aussi PR 1, p. 97.
} 
Boucicaut ${ }^{134}$, lequel était en Prusse en $1384-1385^{135}$ et $1390-1391^{136}$ - années lors desquelles, selon les sources prussiennes, les hivers ont été doux, et il n’y eut donc pas de rèse ${ }^{137}$. La contradiction est évidente. Il faut donc supposer que Cabaret d'Orville, ou Chastelmorand, a amalgamé deux expéditions distinctes en une seule: la rèse de 1374-1375, à laquelle Chastelmorand a certainement participé et pour laquelle il rapporte des éléments vérifiables par ailleurs, et les souvenirs de chevaliers ayant rencontré Boucicaut lors d'une expédition ultérieure ${ }^{138}$. Même si la question de la date précise reste ouverte, l'extrait "prussien" de la Chronique du bon duc Loys de Bourbon présente l'intérêt exceptionnel de nous fournir de nombreux détails sur l'une des grandes rèses internationales du dernier quart $\mathrm{du} \mathrm{XIV}^{\mathrm{e}}$ siècle, restitué vraisemblablement d'après les souvenirs, lointains il est vrai, d'un participant.

Voyons donc comment est raconté le retour des croisés en Prusse, à l'issue d'une rèse pleine de succès. Les visiteurs sont invités à Marienbourg, où ils ont l'occasion d'assister au cérémonial de la table d'honneur:

"Pour l'honneur du jour, le service divin accompli, en son chastel de Mariembourg [le grand-maitre] fit couvrir la table d'honneur, et voult que à celle table fussent assis douze chevaliers de plusieurs royaumes; et du royaume de France y seirrent ou hault dois messire Hutin de Vermeilles, et messire Tristan de Magneliers, que toutes gens clamoient le bon chevalier, et des autres païs deux jusques à XII, par l'ordonnance du maistre, qui furent servis, pour la haultesse du jour, ainsi qu'il leur appartenoit. Et grâces dictes à Dieu, à iceulx douze devisa l'en l'ordre de la table, et comme elle fut establie. Et puis, ung des chevaliers frères de la religion à ung chascun bailla ung mot par escript en lettres d'or sur leurs espaules "Honneur vain tout!" Et l'en demain les chevaliers prindrent congie du hault maistre de Prusse, et s'en retourna ung chascun en sa contrée. "139

Pour l'auteur de la chronique, la table d'honneur dressée dans la plus grande forteresse de l'Ordre teutonique fait figure de clou du spectacle. Un point de vue partagé par un certain nombre de contemporains, puisqu'à plusieurs occasions, le grand-maître prend la peine d'écrire à ses destinataires que les participants à

${ }_{134}$ Chazaud, p. 64. Les rèses de Boucicaut datent de l'été 1384, hiver 1384-1385, hiver-été 1390-1391.

135 Le Livre des Fais..., p. 42, n. 2; D. LaLAnde, Jean II le Meingre..., p. 18.

136 S. Gouguenheim, Les Chevaliers teutoniques..., p. 585-586.

137 Voir les extraits des Annales de Toruń et de la Chronique de Posilge, PR 2, p. 16-17.

138 À cet égard, Cabaret d'Orville rapporte que la guerre était menée contre un «roi de Norgalles», ce qui peut être une référence au prince lituanien Korybutas, prince de Novhorod-Siverskyi (act. Ukraine), contre qui l'Ordre teutonique guerroyait dans les années 1390. Voir notamment Wigand de Marbourg, Chronica..., SRP 2, p. 641 passim; Annales de Toruń et Jean de Posilge, Chronique..., SRP 3, p. 172-176; Codex Diplomaticus Lithuaniae, éd. E. Raczyński, Wrocław 1845, p. 76-78.

139 Chazaud, p. 65-6. 
la prochaine rèse se verront honorés par la fameuse table, sans doute pour attirer plus de volontaires ${ }^{140}$.

D'autres cérémonies chevaleresques avaient lieu en plein territoire ennemi, comme ce banquet de septembre 1377 célébré en Samogitie, dont fait mention le poète autrichien Pierre Suchenwirt, qui raconte la rèse du jeune duc Albert de Habsbourg ${ }^{141}$. De même, certains chevaliers, comme Boucicaut, trouvent dans les combats contre les Lituaniens l'occasion de lever pour la première fois bannière, autrement dit d'acquérir le titre de banneret ${ }^{142}$. D'autres se voient confier le privilège de porter des bannières bien spécifiques, celles de Saint Georges et de la Vierge Marie, coutume répandue sur d'autres fronts de croisade $^{143}$. À en croire les chroniqueurs, ce devait être un honneur recherché, puisque même un prince comme Henri de Derby, duc de Lancastre, "avait un grand intérêt pour la bannière de Saint Georges; mais il ne l'obtint pas»" ${ }^{144}$. Dans le roman d'Antoine de la Sale, Jean de Saintré (v. 1456-1460), la bannière de NotreDame est tenue lors d'une grande rèse prussienne par un personnage qui porte le nom d'un voyageur de Prusse ayant réellement existé, Gadifer de la Salle, "quy une aultre foiz l'avoit portee ${ }^{145}$. Porter bannière en Prusse peut aussi s'accomplir sous le patronage d'un autre ordre de chevalerie; ainsi, les statuts de l'Ordre de la Nef, fondé en 1381 par le roi de Naples Charles d'Anjou-Durazzo précise que «se aucuns des compaignons estoient en Prusse, et sur ce eussent especial licence du prince, il pourront lever et porter baniere ou penon de l'ordre" ${ }^{146}$.

Sans doute plus facile à satisfaire est l'adoubement en territoire ennemi, pratiqué depuis le tout début du XIv ${ }^{\mathrm{e}}$ siècle. En hiver 1305, Werner de Homberg, le chevalier argovien déjà mentionné au début de ce chapitre, reçoit l'ordre de chevalerie devant un château ennemi nommé Jedemine, avec d'autres nobles ${ }^{147}$. Philippe Contamine a remarqué qu'à la fin du Moyen Âge, l'adoubement correspond moins à un rite de passage pour un jeune noble atteignant l'âge adulte qu'à un événement venant récompenser une carrière d'homme d'armes déjà relativement avancée; de ce fait, les nombreux écuyers que l'on trouve en Prusse pouvaient déjà avoir une longue expérience militaire derrière eux. À

\footnotetext{
140 A. S. Cook, «Beginning the Board...», p. 375-388.

141 PR 2, p. 127-129; Pierre Suchenwirt, Von Herzog..., v. 401-410, SRP 2, p. 166-167.

${ }^{142}$ En 1391 «[Boucicaut] leva premierement baniere»; Le Livre des Fais..., p. 77. Pour d'autres exemples, PR 2, p. 129-130.

${ }_{143}$ PR 2, p. 139-152; on ne sait pas précisément comment le chevalier ou l'écuyer honoré était choisi; peut-être était-ce par les hérauts d'armes, comme pour ceux qui siégeaient à la table d'honneur (ibid., p. 150).

144 Annales de Toruń, SRP 3, p. 168.

${ }_{145}$ Antoine de la Sale, Jehan de Saintré, éd. J. Blanchard, trad. M. Quereuil, Paris 1995 (ci-après: Blanchard, Quereuil), p. 376. On ne sait toutefois pas si le Gadifer de la Salle "historique» a vraiment porté la bannière.

146 "The middle french Statutes of the monarchical order of the Ship", éd. A. Boulton, Medieval Studies 47, 1985, p. 264, cité par PR 1, p. 108, n. 452.

147 Pierre de Dusbourg, Chronicon..., SRP 1, p. 170-171; PR 2, p. 130-132.
} 
cette époque où la plupart des adoubements ont lieu à l'occasion de batailles rangées ${ }^{148}$, les auteurs de récits didactiques notent qu'être fait chevalier lors d'une bataille contre des infidèles est tout à fait louable ${ }^{149}$. Ainsi, Hugues de Lannoy, proche des ducs de Bourgogne et lui-même croisé de Prusse, énumère dans l'Instruction d'un jeune prince, un autre traité didactique, les occasions de recevoir la chevalerie:

«La première, quant empereurs et roys tenoient solempnelles festes, [...]

La seconde, que pluseurs aultres, [...] sont alés en la sainte terre aourer le saint sépulcre, et illec, par grant dévotion, ont prins ordre de chevalerie.

Et la tierce, que es guerres sur Sarrasins mescréans nostre foy ou es apparans périlz de bataille mortelles ou cruelz assaulx de villes, chasteaulx ou citez, confiant en la grâce de Dieu et en la diligence de leurs corps, en espérance ad ce jour d'acquérir honneur et bonne renommée, ont a telz grands besoings et périlz requis ordre de chevalerie, espérans que par icelle leur force et vertu en croistroit. $»^{150}$

Fait caractéristique, la croisade balte apparait directement dans le prologue du poème, qui met en scène un chevalier picard rentrant par la mer de Prusse et de Livonie, où il est allé "acquérir honneur et bonne renommée»" ${ }^{151}$. Chassé par une tempête sur les côtes de Norvège, il visite une église du pays, où son clerc découvre le manuscrit contenant lesdites instructions ${ }^{152}$. Rien d'étonnant à ce discours lorsque l'on sait que le frère de l'auteur, Guillebert, a été adoubé en Prusse après avoir participé à un raid contre les ennemis polonais des Teutoniques ${ }^{153}$. Dans les faits, une telle pratique semble avoir été relativement rare, ce qui devait la rendre encore plus prestigieuse ${ }^{154}$. Jean Froissart raconte que Raoul, fils du comte de Gruyère, avait plusieurs fois refusé d'être adoubé lors de batailles livrées dans le cadre de la guerre de Cent Ans. En 1380, lorsque le comte de Buckingham, sous les ordres de qui il servait, lui propose de le faire chevalier non loin de Troyes, l'écuyer refuse en ces termes:

"Li escuiers s'escusa enssi que escusé s'estoit autrefois [devant Arde et devant Saint Omer], et dist: "Monsigneur, Dieux vous puist rendre et merir le bien et honneur que vous me vollés, mès je ne serai ja chevaliers, se mes naturés

${ }_{148}$ P. Contamine, «Points de vue sur la chevalerie en France à la fin du Moyen Âge», Francia 4, 1976, p. 281.

149 N. Housley, The Later Crusades, p. 394.

150 Guillebert de Lannoy, Euvres de Ghillebert de Lannoy, voyageur, diplomate et moraliste, éd.

C. Potvin, Louvain 1878 (ci-après: Potvin), p. 413; P. Contamine, «Points de vue... », p. 272.

151 Potvin, p. 337.

152 Ibid., p. 337-347; G. Doutrepont, La littérature Française à la cour des ducs de Bourgogne, Paris 1909, p. 314-315.

153 Guillebert de Lannoy, Voyages et ambassades, dans Potvin, p. 27; d'après son épitaphe, l'auteur lui-même aurait "receut l'ordre de chevalerie au très saint lieu de Jhérusalem": B. DE LANNoy, Hugues de Lannoy, le bon seigneur de Santes, Bruxelles 1957, p. 167; PR 1, p. 32.

154 P. Contamine, «Points de vue...", p. 273. 
sires li contes de Savoie ne le me fait où bataille de crestiiens operé ne soit l'un contre l'autre". On ne l'examina plus avant: e $[\mathrm{n}]$ ssi fu il deportés à estre adonc chevaliers. Et depuis, l'année apriès, le fu il en Prusse; et eurent adonc li crestiien rèse. ${ }^{155}$

Le choix de refuser l'accolade à l'occasion d'une bataille livrée contre d'autres chrétiens semble tout à fait honorable au chroniqueur, qui définit Raoul comme "uns mout gentils escuiers de la conté de Savoie»" la valeur exemplaire de ce cas pour illustrer l'attrait des croisades menées contre les infidèles des marges de la Chrétienté sur les nobles de la fin du Moyen Âge, la Prusse étant l'une des destinations favorites ${ }^{157}$. Àtel point qu'elle figure en bonne place sur l'épitaphe des chevaliers bourguignons Hugues de Lannoy et Jean V de Roubaix, tous deux membres de l'Ordre de la Toison d'Or. Le premier mit ses conseils en pratique puisqu'il alla en Terre sainte, où il fut fait chevalier, puis au retour il combattit en Prusse aux côtés du "maistre de Liflant»" et du duc converti Vytautas ${ }^{158}$. Quant au second, il est célébré pour avoir participé à plusieurs expéditions dans les Balkans, la Méditerranée, en Espagne: "Et passa les périls mortels de plusieurs batailles contre les infidèles, c'est asçavoir... en Prusse, contre les Rétaux [sans doute faut-il lire «Létaux», autrement dit les Lituaniens], etc. ${ }^{159}$

Ce qui attirait les nobles européens en Prusse était sans doute, selon la belle formule de Werner Paravicini, "l'idéal réalisé»" ${ }^{160}$ si à la fin du Moyen Âge, les idéaux de la noblesse sont, sur le champ de bataille, de moins en moins appliqués, aller combattre l'infidèle aux marges de la Chrétienté devient l'apanage des aristocrates ${ }^{161}$. En analysant le groupe familial d'un voyageur de Prusse poitevin déjà mentionné, Gadifer de la Salle (m. 1422/3), le grand

\footnotetext{
155 Jean Froissart, Chroniques, éd. G. Raynaud, vol. 9, Paris 1894, p. 264; PR 2, p. 134.

156 Jean Froissart, Chroniques..., éd. G. Raynaud, vol. 9, p. 263.

157 P. Dembowski, «Reflets chevaleresques...», p. 139-140; voir aussi PR 1, p. 86; P. Contamine, "Points de vue...», p. 273, n. 76; J. Jakstas, Das Baltikum..., p. 146; W. Paravicini, "Von der Heidenfahrt...», p. 97.

158 Épitaphe d'Hugues de Lannoy, citée par B. De Lannoy, Hugues de Lannoy..., p. 167; PR 1, p. 32. Voir ci-dessous, p. 312.

159 Épitaphe de Jean de Roubaix, cité dans T. Leuridan, Histoire des seigneurs et de la seigneurie de Roubaix, vol. 2, Roubaix 1862, p. 92. Jean V, seigneur de Roubaix, s'est rendu à deux reprises en Prusse avant 1408: PR 1, p. 101; sur les expéditions auquel a participé le personnage, N. HousLEY, The Later Crusades..., p. 396.

160 W. Paravicini, «La Prusse...», p. 188; P. Dobrowolski, «Miles...», p. 40.

161 T. Guard, Chivalry..., p. 210-211. Sur l'opposition entre code chevaleresque et pratique militaire à la fin du Moyen Âge, T. Lassabatère, "Théorie et éthique de la guerre chez Eustache Deschamps», dans P. Contamine, O. Guyotjeannin (dirs.), La guerre, la violence et les gens au Moyen Âge, vol. 1, Paris 1996, p. 44-45; C. GAIER, "La cavalerie lourde en Europe occidentale du XII ${ }^{\mathrm{e}}$ au XVI ${ }^{\mathrm{e}}$ siècle: un problème de mentalité", dans Idem (dir.), Armes et combats dans l'univers médiéval, Bruxelles 1995, p. 299-310. Un point déjà soulevé par J. Huizinga, L'Automne du Moyen Âge..., p. 113-129.
} 
spécialiste des Preussenreisen a constaté que ces soldats de métier, issus de la petite noblesse, semblent hantés par la littérature courtoise, la matière de Rome ou de Bretagne: la plupart d'entre eux portent des noms inspirés de romans (Gadifer, Gui d'Amours, Brandelis, Perceval), l'un a même écrit un Mélusine, et lorsqu'en 1402 Gadifer s'embarque dans le projet de conquête des îles Canaries, il emporte "des livres de romans»" ${ }^{162}$. Ce chevalier poète, membre de la Cour amoureuse de Charles VI, n'en est pas moins un redoutable traîne-sabre, chef de routiers qui a servi les Anglais avant de tenir le parti du duc d'Orléans, tout en étant mêlé à plusieurs affaires troubles ${ }^{163}$.

On peut raisonnablement penser que ce genre de personnage, mû par un goût littéraire qui reflète sans doute la hauteur de ses aspirations, ne dédaignait aucune occasion de croiser le fer avec les «ennemis de la foi». Qu'on en juge: outre deux voyages en Prusse ${ }^{164}$, Gadifer est allé prêter main forte aux Hospitaliers de Rhodes et a participé à l'expédition de 1390 contre Mahdia en Tunisie, avant d'entreprendre la conquête des îles Canaries au côté de Jean de Béthencourt ${ }^{165}$ ! Ce personnage, inspiré et nourri par la littérature courtoise, deviendra lui-même une figure littéraire, puisqu'en plein $\mathrm{Xv}^{\mathrm{e}}$ siècle, il apparaît dans Le Jouvencel de Jean de Bueil et que, nous l'avons vu, un héros de Prusse du Petit Jean de Saintré d'Antoine de la Sale porte son nom ${ }^{166}$. La recherche d'honneur "mondain", le souci de la renommée, et l'aspiration à atteindre aux modèles littéraires du chevalier idéal rejoignent donc l'idéologie mise en place par l'Église à partir du milieu du XII ${ }^{e}$ siècle. La défense de la Chrétienté, qui justifiait les guerres menées contre les voisins non-chrétiens des royaumes de toute l'Europe, est devenue une cause qui attire au XIV siècle les chevaliers privés de la très honorable croisade en Terre sainte.

Parmi d'autres destinations possibles, l'État de l'Ordre représente ainsi « le lieu de rassemblement privilégié des chevaliers occidentaux pour combattre les païens» ${ }^{167}$;

\footnotetext{
162 W. Paravicini, «La Prusse... », p. 187.

163 W. Paravicini, "Fahrende Ritter...", p. 237-240; M. Keen, "Gadifer de la Salle...", p. 74-85.

164 À l'hiver 1378-1379 et 1390-1391: PR 1, p. 97-99, p. 176. Ce personnage étant probablement né vers 1350 (Ibid., p. 75), le Gadifer de la Salle repéré par W. Paravicini en Prusse en 1358 (PR 1, p. 96) doit être un homonyme.

165 W. Paravicini, «La Prusse...», p. 187. Sur l'identification des chevaliers aux modèles littéraires, M. Pastoureau, "Jouer au roi Arthur: anthroponymie littéraire et idéologie chevaleresque", dans Une histoire symbolique du Moyen Âge occidental, Paris 2004, p. 293-305. Dans l'extrait de la Chronique du bon duc Loys de Bourbon cité plus haut, on trouve un "messire Tristan de Magneliers" (Chazaud, p. 65) qui est choisi pour siéger à la table d'honneur; le fait qu'un voyageur de Prusse porte un nom «littéraire» très répandu semble emblématique du phénomène; d'autant plus que pour M. Pastoureau (Ibid.), à la fin Moyen Âge, les noms arthuriens sont particulièrement répandus dans la petite noblesse et la haute bourgeoisie.

166 W. Paravicini, «La Prusse... », p. 186; C. A. Knudson, «Saintré’s Prussian Expedition», dans Études de langue et de littérature du Moyen Âge, Paris 1973 p. 275.

167 J. Jakstas, Das Baltikum..., p. 148.
} 
Jonathan Riley-Smith fait même des croisades de Prusse des "paquets-cadeaux destinés à la noblesse européenne ${ }^{168}$. Il est vrai que celles-ci étaient rendues relativement aisées par les structures - notamment financières - mises en place par l'Ordre teutonique. Pour Werner Paravicini, «l'entreprise exerçait une réelle fascination et était auréolée d'un prestige tout particulier» ${ }^{169}$ : au décorum mis en scène par les maîtres de la Prusse s'ajoute la traversée de la Wildnis, qui a pu être vue par ceux qui y pénétraient pour la première fois comme une matérialisation de la «forêt aventureuse" des romans ${ }^{170}$. Le jeune noble qui participe à une rèse se trouve dans un petit monde idéalisé, avec ses seuls pairs, entourés de hérauts d'armes qui ne manqueront pas de magnifier les exploits accomplis: «ici, le gentilhomme pouvait enfin être ce qu'il voulait et devait être» ${ }^{171}$.

La question se pose de savoir comment, au sein de l'Ordre teutonique, on a eu l'idée de mettre en scène le voyage de Prusse pour qu'il corresponde si bien au goût des nobles européens. Pour William Urban, le grand-maitre Luther de Braunschweig (m. 1335), lui-même descendant du premier croisé d'importance à s'être rendu en Prusse au XIII ${ }^{\mathrm{e}}$ siècle, serait le véritable promoteur de l'institution des rèses: au cours des années 1320, il aurait eu l'idée d'instaurer la Table d'honneur ainsi que la coutume d'adouber les jeunes nobles après leur participation au combat contre les Lituaniens ${ }^{172}$. Werner Paravicini ${ }^{173}$ préfere une chronologie plus tardive: le rituel de la Table d'honneur serait apparu à l'époque du grand-maitre Winrich de Kniprode (1352-1382), et puiserait son inspiration dans les coutumes des ordres de chevalerie d'Europe occidentale, qui, à l'instar de l'Ordre de l'Étoile du roi de France Jean le Bon, choisissent les membres les plus méritants pour les installer à "une table appellée la table d'onneur» aux jours de fête ${ }^{174}$. À cet égard, il n'est pas douteux que les rèses très ritualisées proposées par l'Ordre teutonique appartiennent au même mouvement que les ordres de chevalerie séculiers, qui fleurissent dans les États princiers d'Europe à la suite de la création de l'Ordre de la Bande, fondé par Alphonse XI de Castille autour de 1330, et du célèbre Ordre de la Jarretière d'Édouard III d'Angleterre (1348), qui a servi de modèle à beaucoup d'autres. Ces ordres de chevalerie, essentiellement honorifiques, n'avaient que peu de rapports avec les ordres

\footnotetext{
168 J. Riley-Smith, Les Croisades..., p. 242.

169 W. Paravicini, «La Prusse... », p. 188.

${ }^{170} \mathrm{Id}$; ; voir chap. VII.

171 Id.

172 W. Unban, "The Teutonic Knights and Baltic Chivalry", The Historian, 56/3, 1994, p. 519-530; nous savons pourtant que Werner de Homberg a été adoubé lors d'une rèse contre les Lituaniens déjà en 1305 (voir p. 162). Sur les connexions familiales entre les grands-maîtres et les princes d'Empire qui ont participé aux rèses, PR 1, p. 145-146. Sur Luther de Braunschweig et les liens de sa famille avec l'Ordre teutonique, W. Paravicini, "Fürstliche Ritterschaft...", p. 91-92.

173 PR 1, p. 327-328.

${ }^{174}$ L. Pannier, La noble maison de Saint-Ouen, la villa Clipiacum et l'Ordre de l'Etoile, Paris 1878, p. 90, cité dans PR 1, p. 328, n. 506a.
} 
religieux-militaires issus des croisades, tel que l'Ordre teutonique, mais par leur utilisation massive des références au monde de la littérature courtoise, ils participent à l'exaltation des valeurs chevaleresques que l'on met en scène à Marienbourg ou à Königsberg ${ }^{175}$. Que l'Ordre teutonique ait, comme le suggère Maurice Keen ${ }^{176}$, intentionnellement profité du phénomène de renouveau chevaleresque de la fin du Moyen Âge en encourageant la pratique des voyages en Prusse ou non, la croisade de Lituanie tombait à point nommé pour assouvir la soif d'aventure qui saisissait alors une grande partie de la noblesse.

\section{Guillaume de Machaut et Jean l’Aveugle : un Croisé modèle}

Parmi les premiers hôtes de l'Ordre teutonique, le plus prestigieux est sans doute le roi de Bohême Jean de Luxembourg, dit l'Aveugle, fils de l'empereur Henri VII. Ses exploits nous ont été racontés par son secrétaire, Guillaume de Machaut, avant de servir d'inspiration à d'autres auteurs de la fin du Moyen Âge, tels que Jean d'Outremeuse, Jean d'Arras, Coudrette et Antoine de la Sale. Il convient donc de s'arrêter quelques instants sur ses expériences. Par ses origines familiales, mais plus encore par son éducation et ses relations, Jean de Luxembourg est très lié à la cour de France, notamment aux rois Charles IV et Philippe de Valois ${ }^{177}$. Surtout, Jean se rêvait en chevalier idéal - ou du moins est-ce de cette manière que les lettrés qui lui étaient acquis le présentaient ${ }^{178}$.

Parmi toutes ses expéditions, la croisade de Jean de Luxembourg en Lituanie est restée célèbre; encore fallait-il qu'elle soit racontée. Ce sera notamment le fait des poètes et chroniqueurs francophones $\mathrm{du} \mathrm{XIV}^{\mathrm{e}}$ siècle, qui ont en grande partie créé la réputation chevaleresque du roi de Bohême ${ }^{179}$. Un premier témoignage

\footnotetext{
175 M. Keen, Chivalry..., p. 179-182.

176 Ibid., p. 174.

177 Jean devient roi de Bohême en 1310, après avoir épousé en premières noces Elisabeth, l'héritière de la dynastie des Přemyslides: M. Margue, «Jean l'Aveugle... », p. 367-378; V. ŽŮreK, «Sur les traces des grands croisés. Le goût pour la croisade de Jean et Charles de Luxembourg et l'inspiration française", dans M. Nejedlý, J. Svátex (dirs.), Histoires et mémoires des croisades à la fin du Moyen Âge, p. 274.

${ }_{178}$ Jean Froissart, qui relate sa mort héroïque à Crécy, et surtout Guillaume de Machaut ont fait de Jean de Luxembourg l'exemple d'un roi chevaleresque héroïque et généreux envers ses amis; à l'inverse, le chroniqueur Pierre de Zittau exprime les critiques provenant de Bohême, pour qui Jean négligeait son royaume et se contentait de le piller pour entretenir ses troupes de chevaliers et financier ses expéditions belliqueuses - nous y reviendrons. À ce sujet, voir notamment P. PÉPORTÉ, "When "Jan Lucembursky" meets "Jean l'Aveugle": a comparison of King John of Bohemia's representation in the Czech Lands and Luxembourg", Husitsky Tabor, 17, 2012, p. 31-34.

179 V. Ž ŮReK, «Sur les traces...», p. 282. M. Margue, "Jean l'Aveugle...», p. 375-378, note que des portraits laudatifs de Jean de Luxembourg apparaissent de son vivant ou juste après sa mort, notamment chez le héraut d'armes Jean de Biteri et dans une lettre du pape Clément VI au fils de Jean, le futur empereur Charles IV; Jean Froissart et Guillaume de Machaut ne sont donc pas ses premiers thuriféraires.
} 
figure dans la continuation de Jean de Saint-Victor, terminée en 1330 et intégrée au cycle des Grandes chroniques de France ${ }^{180}$. En relatant les troubles survenus en Flandre suite au couronnement de Philippe VI, le chroniqueur anonyme introduit une digression par laquelle il raconte les exploits du roi de Bohême, allié au roi de France dans sa lutte contre les Flamands:

"Entour yver passé devant, estoit passez en terre de Sarazins, et prist grant païs et regions suz eus; et en vindrent à foi de crestienté par lui pluseur, car il estoit et fu trouvés en ces fais preuz, vigreuz, hardis et entreprenans, loyaus et larges et très bons paieres, charitables et preudons, vers Dieu en bonne conscience; et pour ce li asist en tous ses fais. ${ }^{181}$

Jean de Bohême est, dès cette époque, présenté comme un prince chevaleresque et un croisé accompli dans la chronistique française; or, son plus grand laudateur n'est autre que le poète et musicien Guillaume de Machaut, que le monarque s'est attaché autour de 1323. Né aux environs de 1300 en Champagne, Guillaume de Machaut est un clerc, peut-être d'origine roturière ${ }^{182}$. Après avoir fréquenté l'Université, il entre au service de Jean de Luxembourg comme secrétaire et aumônier. Impressionné, nous dit Théodore de Puymaigre, "par son esprit, par ses goûts aventureux, par [sa] galanterie chevaleresque»" ${ }^{183}$, Jean en fait son familier, et l'emmène avec lui dans ses nombreuses expéditions ${ }^{184}$. Après lui avoir donné le rôle de juge d'un débat amoureux dans son poème Le Jugement du Roy de Behaingne (écrit autour de 1340) ${ }^{185}$, Guillaume fait du roi Jean un modèle de chevalerie dans les ouvres qu'il continue d'écrire pour d'autres princes ${ }^{186}$.

C'est dans Le Confort d'ami, écrit entre 1356 et 1357 pour le roi de Navarre Charles le Mauvais, alors emprisonné par le roi de France Jean le Bon, que Machaut fixe le portrait de Jean de Luxembourg ${ }^{187}$. Le poème, destiné à consoler son destinataire, est surtout l'occasion de conseiller le lecteur et

${ }^{180}$ Il s'agit du Ms. BNF Fr. 10132, fol. 41r-v, éd. par J. Viard dans Les Grandes chroniques..., vol. 9, p. 334-335.

181 Ibid., p. 334.

182 Sur la vie de Guillaume de Machaut, L. Earp, Guillaume de Machaut.., 1995, p. 3-5;

Guillaume de Machaut, Poèsies lyriques, éd. V. Chichmaref, Genève 1973, vol. 1, p. XI.

183 T. De Puymaigre, «Une campagne...», p. 173.

${ }^{184}$ Il semble que Guillaume ait quitté le service de Jean avant la mort de ce dernier lors de la bataille de Crécy (1346); Euvres..., vol. 1, p. XXV.

185 Ibid., vol. 1, p. LIX.

186 Ibid., vol. 1, p. XXVII-XXVIII.

${ }^{187}$ Ibid., vol. 3, p. XI-XII. On peut trouver une allusion aux campagnes du roi de Bohême contre la Lituanie dans Le Dit dou Lyon, composé en 1342 (v. 1444-1455, dans Euvres..., vol. 2, p. 209-210); ibid, vol. 2, p. LXI; A. Prioult, "Un poète voyageur...", p. 18. Dans La Fontaine amoureuse (v. 1360-1361), le poète dit avoir suivi le roi de Bohême dans des pays étrangers, mais sans préciser qu'il s'agisse de la Prusse ou de la Lituanie (v. 139-155, dans Euvres..., vol. 3, p. 148). 
de donner "un véritable traité des devoirs des rois et de la noblesse» ${ }^{188}$, soutenu par de nombreux exemples tirés de la Bible ou de la littérature, mais aussi de l'expérience personnelle de l'auteur. Apparaissant dans la dernière partie du poème, Jean de Bohême est présenté comme un modèle auquel devraient se conformer les princes, et en premier lieu, Charles de Navarre lui-même ${ }^{189}$. Largement diffusé et recopié jusqu'au $\mathrm{xv}^{\mathrm{e}}$ siècle, Le Confort d'Ami est l'une des œuvres les plus influentes de Machaut; les conseils politiques qu'il y distille autant que le portrait du roi Jean l'Aveugle ont marqué plusieurs auteurs écrivant à sa suite, notamment Eustache Deschamps et Jean Froissart ${ }^{190}$. Pour ce dernier, qui s'essaye à la poésie dans sa Prison amoureuse (v. 1371-1373), il est difficile de trouver plus généreux et noble que Jean de Luxembourg:

"[Le roi Jean] tant fu larges et courtois

Que de Prusse jusqu'en Artois,

Non, jusqu'en Constantinoble

Ne eut plus larges ni plus noble. ${ }^{191}$

La Prusse n'a peut-être pas ici comme seule fonction de marquer les limites de l'Europe; pour Froissart, qui écrit à l'époque où les expéditions baltes sont très à la mode parmi la noblesse, la mention de l'État de l'Ordre teutonique doit évoquer tout un univers chevaleresque à ses lecteurs. Dans la présentation de Jean de Luxembourg en roi chevalier idéal, l'expédition lituanienne revêt donc une place non négligeable. Qui plus est, c'est à cette occasion qu'apparaissent les premiers témoignages français sur les croisades baltes ${ }^{192}$.

La participation de Jean de Luxembourg, et par conséquent celle de Guillaume de Machaut, à la croisade contre la Lituanie intervient dans le cadre de la reprise des hostilités à la fin de la trêve négociée en 1324 par les légats du pape entre l'Ordre teutonique et la Lituanie ${ }^{193}$. Tentant de briser l'alliance entre Riga et le grand-duc Gediminas, le grand-maître Werner d'Orseln appelle en 1328 Jean de Luxembourg pour lui proposer de lutter contre les Lituaniens ${ }^{194}$. Sans doute la tradition unissant les rois de Bohême à l'Ordre teutonique a-t-elle valu au roi Jean de renouer avec les exploits de Přemysl Ottokar, en l'honneur de qui Königsberg a été fondée ${ }^{195}$. Selon Théodore de Puymaigre, Jean, toujours à la recherche d'aventures, "s'empressa de saisir une nouvelle occasion

\footnotetext{
188 Ibid, vol. 3, p. II.

189 W. Vorsé, "Guillaume de Machaut w Polsce i o Polsce», Muzyka 10/3, 1965 p. 53.

190 Ibid., vol. 3, p. XVIII.

191 Poésies de Froissart, éd. Scheller, t. 1, p. 213, cité par T. DE Puymaigre, "Jean l’Aveugle et la France", Revue des questions historiques, 52, 1892, p. 411.

192 A. Prioult, «Un poète voyageur....", p. 11.

193 S. C. Rowell, Lithuania Ascending..., p. 239.

194 S. C. Rowell, "Lithuania and the West...», p. 314.

195 P. KNOLL, The Rise..., p. 51.
} 
de tirer l'épée et accueillit joyeusement les ouvertures de Werner d'Orseln "196; peut-être la mort de Charles IV de France, avec qui il prévoyait d'organiser une croisade au Proche Orient, l'a-t-elle décidé à déplacer le but du voyage qu'il s'était engagé à faire en prenant la croix ${ }^{197}$. Le caractère du roi et son ambition chevaleresque ne doivent toutefois pas faire oublier qu'un motif plus politique a pu inciter l'impétueux monarque à tourner son regard vers le nord. Le roi Jean de Bohême, en tant qu'héritier des Přemyslides dont un représentant avait été couronné roi de Pologne, revendiquait le trône de ce pays depuis 1319, et ce malgré les prétentions de Ladislas le Bref, qui s'emparera de la couronne une année plus $\operatorname{tard}^{198}$. De fait, Jean de Luxembourg n'espérait pas posséder l'ensemble du royaume, ce qui, au vu de la position de force que son rival y occupait, n'aurait pas été réaliste: c'était plutôt la riche Silésie, partagée en de nombreux petits duchés et très autonome par rapport à Cracovie, qui excitait son ambition. Aussi en 1327 Jean a-t-il attaqué les princes de cette région pour ensuite marcher sur Cracovie ${ }^{199}$.

Participer à une rèse en Lituanie lui permet donc de se rapprocher des Teutoniques, adversaires du roi Ladislas ${ }^{200}$. En mars 1329, au retour de Lituanie, Jean tourne ses armes contre les Polonais, qui avaient profité d'attaquer l'Ordre, puis marche sur la Poméranie, Dobrzyń et la Cujavie, et, au nom du droit qu'il prétendait détenir sur la couronne polonaise, vend certains de ces territoires à l'Ordre, avant de rentrer en Silésie où il pousse encore quelques ducs à reconnaître son pouvoir ${ }^{201}$. Les intentions du roi de Bohême sont sans doute moins sublimes que ne le laissent entendre Machaut et ses autres thuriféraires, même si le fait de mêler la politique à la croisade

\footnotetext{
196 T. De Puymaigre, "Une campagne... », p. 171. Le caractère aventureux et fantasque du roi de Bohême est relativisé par M. MARGUE, "Jean l'Aveugle... ", p. 368-372, qui rappelle que ses actions politiques obéissaient toutes à un même but: obtenir la couronne impériale.

197 V. ŽŮReK, "Sur les traces...», p. 274-275. La prise de croix de Jean de Luxembourg nous est connue par la réponse de Jean XXII, éditée dans Monumenta Vaticana res gestas Bohemicas illustrantia, tomus prodroms, Acta Clementis V., Johannis XXII. et Benedecti XII, 1305-1342, éd. Z. Hledikova, Prague, 2003, p. 268, n. 395-6, cité par V. ŽŮ̊neK, loc. cit., n. 3. S. C. RowelL, Lithuania Ascending..., p. 239, remarque que Jean de Luxembourg avait prévu d'aller combattre les Maures à Grenade cette année-là, mais qu'il préféra finalement aller en Prusse. N. Housley (The Avignon Papacy..., p. 67, n. 110) note qu'aucune bulle de croisade relative à l'expédition de Jean de Bohême en Lituanie n'a été découverte.

198 S. C. Rowell, Lithuania Ascending..., p. 240. Václav II de Bohême, de la dynastie des Přemyslides, a régné en Pologne de 1300 à 1305; son fils, Václav III, revendiquait le trône polonais, mais a été assassiné en 1306. Jean de Luxembourg, leur héritier en Bohême, abandonna ses revendications sur la Pologne en 1335.

199 Ibid., p. 59-61. Pour une discussion sur la chronologie des événements, A. Prioult, «Un poète voyageur...", p. 22-23; Guillaume de Machaut, Poèsies..., p. XIX-XXI.

${ }^{200}$ PR 1, p. 80.

${ }^{201}$ P. KnOlL, The Rise..., p. 51-54. Il est par ailleurs fait mention de l'expédition prussienne du roi de Bohême dans le préambule de l'une de ses chartes: E. Christiansen, The Northern Crusades..., p. 156.
} 
contre les Lituaniens n'est bien sûr pas l'apanage du seul Luxembourg: le roi de Hongrie Louis d'Anjou, qui disputait aux fils de Gediminas les terres de l'ancienne principauté russe de Galicie, effectue lui aussi plusieurs croisades contre ses adversaires païens ${ }^{202}$, et participe en 1344-1345 à une rèse depuis la Prusse aux côtés de notre Jean de Luxembourg et du beau-frère de celui-ci, le duc Pierre de Bourbon ${ }^{203}$.

Signe de l'intérêt du roi de Bohême pour cette région, il participe encore à deux rèses, en hiver 1337 et 1344-1345 $5^{204}$. Dans le premier cas encore, un projet de croisade visant à libérer la Terre sainte venait d'échouer ${ }^{205}$ : Jean a sans doute préféré substituer à cette très ambitieuse entreprise une nouvelle expédition lituanienne, qui lui aurait permis d'accomplir son vœu - dont nous n'avons toutefois pas traces dans les sources - tout en marquant sa présence militaire face à son rival polonais ${ }^{206}$. Ces campagnes, entreprises avec son fils Charles, le futur empereur et roi de Bohême ${ }^{207}$, n'ont pas bénéficié de la plume d'un Machaut pour en immortaliser le souvenir; celui-ci se contente de les mentionner dans le Confort d'ami ${ }^{208}$. Il faut dire que notre poète aurait eu du mal à y trouver beaucoup de hauts faits à relater; retenus en Prusse par le mauvais temps, les croisés devront rentrer sans affronter les païens ${ }^{209}$. Â vrai dire, ces campagnes n'apportent rien de bon au roi chevalier. En 1337, il contracte une grave infection à l'œil droit, qui s'aggrave et lui fait perdre la vue; le roi de Bohême n'y gagne que son surnom de "Jean l'Aveugle", qui n'est pas étranger à la réputation de parfait chevalier que lui vaudra sa mort héroïque à la bataille de Crécy ${ }^{210}$. Mais les chroniqueurs tchèques relatent que l'on considéra, en Bohême du moins, cette maladie comme une punition pour la vente des ornements du tombeau de Saint Wenceslas, à Prague, que le roi organisa pour financer son expédition ${ }^{211}$. La participation aux rèses contre la Lituanie n'était donc pas toujours vue comme un acte de piété louable, ou du moins, pas à n'importe quel prix.

\footnotetext{
202 G. Kristo, P. Engel, A. Kubinyi, Histoire de la Hongrie médiévale, vol. 2, Rennes 2008, p. 69-70.

${ }^{203}$ En secondes noces, Jean de Luxembourg a épousé Bonne, la sœur du duc Pierre I ${ }^{\text {er }}$ de Bourbon: PR 1, p. 26-27; 147.

${ }^{204}$ Ibid., p. 79.

${ }^{205}$ V. ŽŮrReK, «Sur les traces...», p. 276-281. Il s'agit d'une croisade organisée par Philippe de Valois et Pierre Thomas, l'archevêque de Rouen (futur Clément VI).

206 Ibid., p. 282.

${ }^{207}$ Id.; PR 1, p. 79-80.

208 "Puis fut il par deus fois en Prusse / A moult grant honneur, et en Russe», v. 3051-3052, dans Euvres..., vol. 3, p. 108.

209 Chronicon Aulae Regiae, dans Fontes Rerum Bohemicarum, éd. J. Emler, Prague 1874, vol. 4, p. 334; Chronicon Francisci Pragensis, ibid., p. 425.

${ }^{210}$ P. PÉ́torté, «When "Jan Lucembursky”... », p. 33-34.

211 T. De Puymaigre, "Jean l'Aveugle et la France...», p. 439; sur le pillage du tombeau de saint Wenceslas, Chronicon Francisci Pragensis, dans Fontes Rerum..., p. 425.
} 
En effet, le caractère de Jean de Bohême n'est pas vu uniquement de manière positive par ses contemporains. Parcourant l'Europe pour participer à de nombreux tournois et opérations militaires, Jean de Luxembourg était souvent loin de son royaume. Les nobles tchèques, nous dit le chroniqueur Pierre de Zittau, lui reprochaient d'être trop occupé à parfaire sa réputation pour s'occuper de ses sujets autrement qu'en les taxant ${ }^{212}$. Le même auteur se fend d'une narration quelque peu ambiguë de la rèse à laquelle a participé le roi :

"Cette année au jour de saint Urbain, Jean, roi de Bohême et de Pologne, rentré heureux des régions de Prusse et de Lituanie, est reçu dans la ville de Prague. Lors des guerres, il avait accompli de grandes et magnifiques oeuvres contre les Lituaniens et les païens, comme le rapporte la renommée du commun des hommes. En effet, d'après ce que l'on dit, il pénétra jusqu'aux dernières limites du territoire des païens, là où avant ce prince, personne ne fut dont on garderait la mémoire parmi les modernes. ${ }^{213}$

La formule "d'après ce que l'on dit» juste avant la mention du fait que le roi Jean alla plus loin que tous ses prédécesseurs peut faire ressortir une pointe de moquerie, suggérant que les exploits du roi pourraient avoir été grossis à son retour à Prague; en partisan de l'aristocratie de Bohême, le chroniqueur raille volontiers les aspirations chevaleresques du protagoniste ${ }^{214}$. Autre critique, le bénédictin néerlandais Guillaume d'Egmond attribue à l'attitude jusqu'au-boutiste du roi de Bohême la mort de nombreux frères de l'Ordre teutoniques ${ }^{215}$. La supposée déroute de l'armée croisée permet à ce partisan de Louis de Bavière de flétrir son rival en donnant une image d'un Jean de Bohême radicalement différente de celle qui s'imposera en France ${ }^{216}$. Le roi chevalier avait donc ses détracteurs, que les aventures baltes laissent de marbre. Àl'inverse, lisons le portrait qu'en donne Guillaume de Machaut dans son Confort d'Ami:

\section{"Pren garde au bon roy de Behaingne}

Qui en France et en Alemaingne,

En Savoie et en Lombardie,

En Dannemarche et en Hongrie,

${ }^{212}$ M. Margue, "Jean l'Aveugle...», p. 370; P. Péporté, "When "Jan Lucembursky"...», p. 33-34.

213 Chronicon Aulae Regiae, dans Fontes Rerum..., p. 293.

${ }^{214}$ P. PÉPorté, Constructing the Middle Ages..., 178-182.

215 Guillaume d'Egmond, Willelmi Capellani in Brederode postea Monachi et Procuratoris Egmondensis Chronicon, éd. C. Pijnacker Hordikj, Amsterdam 1904, p. 264. La datation de la chronique n'étant pas claire, il est difficile de savoir si cet extrait fait référence à la rèse célébrée par Machaut ou à l'une des expéditions ultérieures.

216 S. C. Rowell, Lithuania Ascending..., p. 248; sur l'orientation «bavaroise» de Guillaume d'Egmond, ibid., p. 236. 


\section{En Pouleinne, en Russe, en Cracoe,}

\section{En Masouve, en Prusse, en Letoe,}

Ala pris et honneur conquerre. $»^{217}$

Avant de prendre la route avec notre poète et son héros, arrêtons-nous sur une question de toponymie. "Masouve» désigne la Mazovie (région de Varsovie), qui était un duché plus ou moins indépendant jusqu'au début du XvI ${ }^{\mathrm{e}}$ siècle ${ }^{218}$; c'est en Mazovie, dont les ducs étaient alliés à l'Ordre teutonique, que se déroulaient les combats entre celui-ci et le maitre de la Pologne, Ladislas le Bref ${ }^{19}$. On peut par contre être surpris par le dédoublement des allusions à la Pologne, appelée dans ce vers "Pouleinne» et "Cracoe», qui ne s'explique pas seulement par la licence poétique et l'exigence de la rime. Ces formules ressemblent beaucoup à la titulature de Jean de Luxembourg, qui s'intitulait "Rex Bohemie et Polonie», et se référait à son rival comme un simple "rex Cracovie»" 220 . Dans le poème de Machaut, "Pouleinne» peut donc renvoyer au titre que revendiquait son patron à l'époque où la rèse de 1329 a lieu, alors que selon les partisans du roi de Bohême du moins, Ladislas ne portait que le titre de "roi de Cracovie", en référence à la capitale du royaume; c'est aussi ce titre que le chroniqueur Jean de Winterthour donne au souverain polonais ${ }^{221}$. Nous rencontrerons encore à plusieurs reprises, chez d'autres auteurs, le personnage du "roi de Cracovie", que l'on peut raisonnablement identifier comme un «roi de Pologne», réel ou imaginaire.

La présence d'une région appelée "Russe» n'est pas non plus sans poser de problème: répété lorsque Guillaume évoque plus en détail les rèses nord-européennes de son patron ${ }^{222}$, ce terme peut être une allusion à la Russie, dont Gediminas et ses successeurs revendiquaient la possession dans leurs lettres. Toutefois, William Urban a montré que le vocable «Rusye», ou "Ruezzen», utilisé notamment dans des lettres de donation de l'empereur Louis IV de Bavière en $1337^{223}$, ne signifiait vraisemblablement pas l'ancienne Rus' kievienne, ni les principautés qui s'en sont détachées, mais bien plus probablement la région de Rossenia, en Samogitie (aujourd'hui Raseiniai) ${ }^{224}$. En suivant le raisonnement de l'historien américain au sujet

\footnotetext{
217 Guillaume de Machaut, «Le Confort d'ami...», v. 2923-2929, p. 103.

218 W. Vorsé, «Guillaume de Machaut w Polsce...», p. 61.

219 P. KNOLL, The Rise..., p. 50-54.

220 R. Grodecki, Kongres Krakowski w roku 1364, Cracovie 1939, cité par W. VoIsÉ, "Guillaume de Machaut w Polsce...», p. 61; Idem, «Guillaume de Machaut en Pologne», dans Guillaume de Machaut..., p. 51-52.

${ }^{221}$ Voir ci-dessus, chap. II.

222 "Puis fut il par deus fois en Prusse / A moult grant honneur, et en Russe», "Le Confort d'ami...", v. 3051-3052, p. 108.

${ }_{223}$ Tabulae Ordinis Theutonici, éd. E. Strehlke, Berlin 1869, doc. 210, p. 202; doc. 211, p. 203.

224 W. Urban, "The Correct Translation of "Ruce" ", Journal of Baltic Studies 13/1, 1982, p. 12-14.
} 
de Geoffrey Chaucer, qui une génération après Machaut décrit un chevalier ayant mené rèses en "Lettow" et en "Ruce», on peut imaginer que notre poète a confondu ce toponyme avec la Russie proprement dite, qui, par l'intermédiaire des vassaux orthodoxes du grand-duc, fournissait des soldats aux contingents lituaniens ${ }^{225}$. Rien n'interdit toutefois de penser que Machaut, et Chaucer après lui, n'aient pas voulu se priver du plaisir d'exagérer peut-être sciemment les exploits de leurs héros, capables de combattre non seulement en Lituanie, mais aussi dans ce lointain et encore plus mystérieux pays schismatique ${ }^{226}$.

Revenons au poème. Parcourant la Pologne, mais aussi la Prusse, la Lituanie, et d'autres pays, Jean de Luxembourg est un voyageur, qui parcourt l'Europe pour chercher "prix et honneur»; ses campagnes militaires sont donc présentées sous un jour positif. Machaut conseille même à Charles de Navarre de l'imiter, en partant se battre à l'étranger lorsque la situation le permet:

«Et si tu n'as de guerre point,

Tu pues mettre dou tien a point,

Bien acquis, et non autrement,

Pour servir bien richement

Tes bons amis, s'ils ont a faire;

Ou se hors dou païs vues traire

Et aler en estrange terre

Honneur et vasselage aquerre,

Soit en Castelle ou en Grenade,

Qui est une voie moult sade,

En Alemaingne, en Rommenie,

Ou en Prusse ou en Lombardie. "227

Quand la paix règne, le prince a le choix entre s'occuper de son domaine et des siens, ou partir au loin pour une expédition en terres étrangères, pourquoi pas aux confins de la Chrétienté, là où l'on affronte l'infidèle, en Castille, dans les possessions latines de "Rommenie» (Grèce) ou en Prusse. Avant de se rendre en Lituanie, Jean de Luxembourg était en négociation avec le roi d'Aragon pour aller lui prêter main forte contre les Maures, mais ce projet échoua; son fils, le

\footnotetext{
225 W. Urban, «When was Chaucer's Knight...», p. 347-353.

226 Sur la perception de la Russie dans l'Occident médiéval, S. Mund, "Constitution et diffusion d'un savoir occidental sur le monde "russe" au Moyen Âge (fin $\mathrm{x}^{\mathrm{e}}$-milieu Xv $\mathrm{x}^{\mathrm{e}}$ siècle) ( $1^{\text {re }}$ partie) ", Le Moyen Âge, 110/2, 2004, p. 275-314; Idem, "Constitution et diffusion d'un savoir occidental sur le monde "russe» au Moyen Âge (fin $\mathrm{x}^{\mathrm{e}}$-milieu Xv siècle) (2 ${ }^{\mathrm{e}}$ partie) », Le Moyen Âge, 110/3, 2004, p. 539-593.

${ }^{227}$ Guillaume de Machaut, «Le Confort d'ami...», v. 3273-3284, p. 116.
} 
futur empereur Charles IV, avait lui aussi voulu s'y rendre dans sa jeunesse, avant que son père ne le rappelle à ses côtés ${ }^{228}$. Le voyage d'Espagne est mis en parallèle avec la croisade de Prusse, comme un événement auquel il est convenable pour un prince de participer, si la guerre ne gronde pas à ses portes. Guillaume recommande encore de faire ces expéditions avec «la milleur chevalerie», et non celle "qu'on porra pour or trouver" ${ }^{230}$. L'emploi de mercenaires dans ces guerres lointaines n'est pas indiqué; ces expéditions semblent réservées à des chevaliers motivés par le souci de leur honneur, pas par le pillage ou le salaire. Voici, nous dit le poète et courtisan Guillaume de Machaut, pourquoi et dans quel état d'esprit il est recommandé de se rendre en Prusse pour y combattre les païens. Avant de suivre son héros en Lituanie, observons ce que d'autres auteurs en disent.

\section{L'AMOUR ET LE RENOM : LES POÈTES ET LA CROISADE BALTE}

Les poèmes de Guillaume de Machaut peuvent, dans une certaine mesure, refléter la manière dont les nobles évoluant dans la haute société laïque de la fin du Moyen Âge aimaient voir leur propre milieu. Dans le cas qui nous intéresse, le Confort d'ami a pu influencer une certaine représentation que l'on se faisait de la croisade contre les Lituaniens. L'œuvre du Champenois a eu un succès certain, et même au-delà de la sphère culturelle française; en 1449 encore, l'Espagnol Inigo Lopez Mendoza, marquis de Santillane, le cite parmi les meilleurs poètes français dans une lettre "au Condestable de Portugal» ${ }^{231}$. Non seulement des grands noms de la poésie française tels que Jean Froissart ou Othon de Grandson, qui était en Prusse en 1392, ont fait des emprunts à ses poèmes ${ }^{232}$, mais il est maintenant admis que le célèbre poète anglais Geoffrey Chaucer (m. 1400) a puisé une partie de son inspiration chez Guillaume de Machaut ${ }^{233}$.

L'aventure balte de Jean l'Aveugle n'est certes pas le sujet le plus prisé des disciples de Machaut, mais il semble possible que sa manière de décrire les rèses comme des expéditions héroïques et violentes, menées autant pour la foi que pour l'honneur guerrier, ne soit pas restée sans influence. On peut notamment rapprocher du portrait du prince voyageur dans le Confort d'ami une pièce bien

\footnotetext{
228 V. ŽŮrek, «Sur les traces...», p. 276; 284; T. De Puymaigre, "Jean l'Aveugle et la France...», p. 439.

229 Guillaume de Machaut, «Le Confort d'ami...», v. 3288, p. 116.

${ }^{230}$ Guillaume de Machaut, "Le Confort d'ami...», v. 3290, p. 116.

${ }^{231}$ Euvres..., vol. 1, p. VIII. Othon de Grandson, qui a participé à une rèse en 1392 aux côtés d'Henri Bolingbroke, est également cité par le marquis de Santillane parmi les plus grands poètes français.

${ }^{232}$ Euvres..., vol 1, p. VII.

${ }^{233}$ W. CALIN, "Machaut's Legacy: the Chaucerian Inheritance Reconsidered», Studies in the Literary Imagination, 20/1, 1987, p. 9-22; Th. P. CAMPBELL, "Machaut and Chaucer: "Ars Nova" and the Art of Narrative", The Chaucer Rewiew, 24/4, 1990, p. 275-289.
} 
connue des historiens de la croisade balte: la présentation du chevalier dans le prologue des Contes de Canterbury, commencé par Chaucer en $1384^{234}$. Ce personnage, comme le roi de Bohême qui sert de modèle au prince idéal de Machaut, a voyagé aux quatre coins du monde, "as wel in cristendom as in hethenesse» ${ }^{235}$, pour acquérir «sovereyn prys»"

"Maintes fois il fut le premier à la table d'honneur

En tête de toutes les nations en Prusse.

En Lituanie il combattit, et en Ruce ${ }^{237}$,

Plus souvent qu'aucun chrétien de son rang. ${ }^{238}$

Parmi les destinations faisant références à des hauts faits connus des hommes du XIV siècle $^{239}$, la Prusse figure en bonne place et la mention de la table d'honneur indique que le cérémonial était bien connu des compatriotes de Chaucer au moment où il rédigeait son prologue. Contrairement à ce que suggère Terry Jones dans son célèbre livre, le chevalier des Contes de Canterbury n'était vraisemblablement pas pensé comme une figure négative; au contraire, Chaucer paraît l'avoir choisi pour représenter un personnage bien vu de ses contemporain $s^{240}$. La critique a cherché à voir qui a pu servir d'inspiration au poète, sans trouver de candidat idéal, aussi préfere-t-on y voir un idéal-type plutôt qu'un individu réel ${ }^{241}$. Étant donné l'emphase mise sur ce thème, la figure du chevalier voyageur parcourant les fronts de croisade forme presque un topos de la littérature du Moyen Âge tardif ${ }^{42}$.

L'archétype d'une vie chevaleresque telle que mise en scène par les poètes de cour est représenté par Le livre des fais du bon messire Jehan le Maingre, dit Bouciquaut $(1409)^{243}$. D'après ce texte, le jeune Boucicaut, né autour de 1364 ,

${ }^{234}$ Geoffrey Chaucer, Les Contes de Canterbury et autres auvres, éd. et trad. A. Crépin et al., Paris 2010 , p. 43 , n. 2.

${ }^{235}$ Ibid., v. 49, p. 42.

236 Ibid., v. 67, p. 42.

237 Voir plus haut, p. 173.

${ }^{238}$ Geoffrey Chaucer, Les Contes de Canterbury..., v. 52-55, p. 42.

${ }^{239}$ Ibid., v. 51-66, p. 42. Le poète mentionne notamment Alexandrie, dont la capture par Pierre de Lusignan en 1365 a été célébrée par Guillaume de Machaut; PR 1, p. 119.

${ }^{240}$ T. Jones, Chaucer's Knight..., Londres 1980 ; prenant le parti de démontrer le caractère négatif du chevalier, T. Jones dresse un sombre portrait des rèses, empruntant aux critiques médiévaux tels que John Gower ou Paul Vladimiri: ibid., p. 49-59. Pour un point de vue plus nuancé, M. Keen, "Chaucer's Knight...», p. 47; S. Rigby, "The Knight...», p. 42-62; W. Paravicini, «Mercenaires...», p. 277-301.

${ }^{241}$ Pour un survol de l'historiographie, PR 1, p. 119; W. Urban, «When was Chaucer's Knight... », p. 347-349.

${ }_{242}$ M. Nejedlý, «Spisy...», p. 108-111; P. Dobrowolski, «Miles...», p. 39, qui remarque que la tradition d'énumérer les pays lointains où s'est distingué le héros apparaît déjà dans la chanson de Roland (Ibid., p. 39, n. 13).

${ }^{243}$ H. Millet, "Qui a écrit Le livre des faits du bon messire Jehan Le Maingre dit Bouciquaut?", dans M. Ornato, N. Pons (dirs.), Pratiques de la culture écrite en France au XV' siècle, Turnhout 
se rend une première fois en Prusse en été 1384. Quelques mois plus tard, il y retourne pour la rèse de l'hiver 1384-1385. Sa troisième participation à une campagne contre les Lituaniens est liée à une autre grande expédition, celle lancée par le duc Louis II de Bourbon en juillet 1390 contre Mahdia, important port d'Afrique du Nord et repaire de corsaires. Ce "voyage de Barbarie», censé rapprocher Anglais et Français en réunissant des chevaliers des deux royaumes, soulève une vague d'enthousiasme pour la croisade, ce qui explique peut-être l'afflux d'hôtes occidentaux en Prusse dans les années 1390-1395244. D'après son biographe, Boucicaut aurait voulu prendre part à cette expédition, mais le roi le lui aurait interdit; déçu, notre chevalier se rend en Prusse pour participer à la rèse d'hiver, qui n'a pas lieu. Comme pour Jean de Luxembourg, la Prusse est une alternative à un "voyage» auquel on doit renoncer, prévu contre des «Sarrasins» méditerranéens que valent bien les Lituaniens. Alors qu'il patiente auprès des Chevaliers teutoniques ${ }^{245}$, Boucicaut rencontre son frère Geoffroy, rentré du "voyage de Barbarie» dont il a été privé. En été 1391, il peut enfin combattre ${ }^{246}$.

La raison invoquée pour partir en Prusse ne peut que rappeler les conseils donnés par Machaut dans le Confort d'ami: d'après son biographe, Boucicaut effectua sa première rèse en 1384 "comme communement font les bons qui voyager desirent pour accroistre leur pris» ${ }^{247}$. C'est également ce que dit la Chronique $d u$ duc de Bourbon, qui raconte le départ des courtisans du duc en Prusse, au moment où celui-ci prend congé de son beau-frère de Savoie:

"aucuns de ses gentilhommes lui requirent qu'il lui pleust leur donner licence de aller dehors pour cellui hiver, c'est assavoir en Prusse, ou, pour celle reise accomplir et suivir, alloient maints chevaliers de plusieurs pays. Et fut le duc de Bourbon moult lie de la bonne voulenté qu'ils avoient, et leur demanda en riant: "Avez-vous argent?" - "oui", dirent-ils, "assez, car nous avons bien faites nos besongnes ès voyages dont vous venez, et monseigneur le duc d'Anjou nous a donné de son or et de la vaisselle." Ces paroles escoutées le conte Vert [Amédée VI de Savoie] dit au duc de Bourbon: "Beau frere, vous avez bonnes gens, car ils ne celent point les biens qu'ils ont, mais les veulent employer honnorablement". "248

S’en suit une énumération des chevaliers qui se rendent en Prusse, parmi lesquels on trouve Jean de Chastelmorand, qui a dicté ce passage au chroniqueur. Puis, le duc de Bourbon leur recommande d'être de retour

1995, p. 135-149 propose d'identifier l'auteur avec le chanoine Nicolas de Gonesse, confesseur de Boucicaut.

${ }^{244}$ N. Housley, The Later Crusades..., p. 355.

245 Boucicaut a dû attendre en Prusse de janvier 1390 à août 1391; PR 1, p. 270.

246 Sur la participation de Boucicaut aux croisades en Prusse, PR 1, p. 216; D. Lalande, Jean II le Meingre..., p. 17-18, 36-38.

${ }^{247}$ Le Livre des Fais..., p. 40.

${ }^{248}$ Chazaud, p. 62-63. 
peu après Pâques. Les louanges du comte vert, lui-même héros d'une croisade méditerranéenne en 1366, montrent que Machaut n’est pas le seul à considérer que combattre l'infidèle ne devrait pas être motivé par l'attrait du salaire, et ceci même si le prince payerait volontiers les frais du voyage $^{249}$. Ainsi, les documents comptables nous apprennent que Boucicaut a bénéficié des largesses du duc de Bourgogne Philippe le Hardi, qui couvre les frais de son dernier voyage en Prusse ${ }^{250}$ - don sur lequel son biographe ne s'étend pas.

Dans un cas au moins, l'importance de l'autonomie financière des hôtes de l'Ordre teutonique est explicitée. D'après la Chronique de Metz (v. 1434-1438), sans doute rédigée par Jacques d'Esch, chevalier appartenant au patriciat messin et lui-même participant à une rèse ${ }^{251}$, seuls ceux qui voyagent à leurs propres frais ont le droit de s'asseoir à la table d'honneur. Le "voyage» contre les Lituaniens n'est pas à la portée de tous, et pouvoir l'accomplir à ses frais est une marque d'honorabilité252. En novembre 1399, l'auteur supposé de la chronique et quelques compagnons "s'en allont a Nancey pour aller en la compaignie de Charle duc de Loheraine en Prusse. Et y allont a leur proppre frais et despens" ${ }^{253}$. Décision qui n'est pas sans faire sourciller le duc de Lorraine, et exciter la jalousie de ses chevaliers:

"Item quant on volt alleir en la reise, le duc fist querrir que ciaulx de Metz volcissent traire desoubz son panon en la dite reise et il leur paieroit vollantier leur despens allans et venant et sejournant. Lesquels de Metz s'acusont qu'ilz ne le pouroient ne non seroient faire, pour tant qu'ilz en seroient blasmez de leur amis. Et pour tant le dit duc leur en monstrait ung pou les greignes; car se ciaulx de Metz heussent prins leur despens dudit duc, ilz n'eussent mis sceus a la tauble d'onnour, car il ne n'y siet nulz for que ciaulx que sont a leur despens. Et pourtant que lesdits de Metz estoient a leur despens, seurent ilz a la dite tauble d'onnour auvec le dit duc et autrez qui y estoient a leur despens; car on tient ciaulx que sont a leur despens a plux grant honnour, que ciaulx que sont aus despens d'autruis.

Et ne seurent mie a la tauble d'onnour sgr. Herman de Biche, sgr. Olris de Blaumon, ne piece des dis Lorrains, pour tant qu'ilz estient aus frais dudit duc.

${ }^{249}$ O. Mattéoni (Servir le Prince..., p. 381, n. 71) remarque que la proposition de Louis II de Bourbon (la question "avez-vous argent?» peut se comprendre comme telle) est confirmée par au moins deux documents d'archives, qui font état des dons octroyés par le duc à deux de ses familiers pour leur permettre d'aller en Prusse ou en Hongrie.

${ }^{250}$ Itinéraires de Philippe le Hardi et de Jean sans Peur, éd. E. Petit, p. 543: "Le duc fit don à messire Boucicaut le jeune, chevalier, chambellan du roy et du duc, de la somme de 500 livres pour les frais qu'il fit au voyage de Prusse où il a demeuré longuement."; W. PARAvicini, "La Prusse... », p. 185-186.

251 Jacques d'Esch, Die Metzer Chronik des Jaique Dex über die Kaiser und Könige aus dem Luxemburger Hause, éd. G. Wolfram, Metz 1906 (ci-après: Wolfram), p. LXXIII.

252 PR 1, p. 157.

253 Wolfram, p. 336-337. 
Lesqueilx avoient aucune foix belcopt d'envie sus ciauls de Metz secreitement, conbien c'on leur faisoit adez bonne chiere. ${ }^{254}$

Privés de table d'honneur, les Lorrains font savoir qu'ils sont prêts à s'engager pour un nouveau raid avant de rentrer. Soucieux de relever le défi, Jacques d'Esch fait entendre que lui et ses Messins voulaient "alleir en Ynflandre [Livonie] veoir une reise» ${ }^{255}$. Le duc de Lorraine intervient, l'affaire s'arrange et tout le monde rentre en compagnie du prince ${ }^{256}$. Derrière la rivalité entre le patriciat messin et les courtisans du duc se dessine l'idée que seule une rèse couronnée par la table d'honneur est vraiment méritoire. Mais aussi celle, non moins révélatrice, qu'une expédition en Livonie, dans un territoire encore plus lointain, peut être mise en concurrence avec la "classique» rèse de Prusse.

La rivalité entre les nobles, qui emmènent leurs antagonismes voire leurs haines héréditaires avec eux, peut s'exprimer à l'occasion de manière bien plus violente ${ }^{257}$. Réunissant des chevaliers venus de toute l'Europe contre l'infidèle, la croisade de Prusse rappelle les grandes expéditions censées sceller la paix entre factions rivales ${ }^{258}$; pourtant, l'une des grandes rèses des années $1390 \mathrm{a}$ été le théâtre d'un affrontement mortel entre Anglais, Écossais et Français. Cette anecdote survenue en été 1391 est connue du biographe de Boucicaut, l'un des protagonistes, et de chroniqueurs prussiens, anglais et écossais ${ }^{259}$. D'après Walter Bower, l'auteur de la Scotichronicon (v. 1447), un certain noble écossais, William Douglas, s'était vu honoré par le grand-maître, qui l'aurait choisi pour siéger à la table d'honneur. Cependant, un chevalier anglais jaloux, Thomas Clifford, provoque une querelle lors de laquelle cet implacable ennemi de sa nation est tuééc0.

On ne sera pas surpris d'apprendre que les chroniques anglaises donnent une version passablement différente de l'incident: d'après la Chronique de Westminster, William Douglas aurait été chassé d'une église où un prêtre s'apprêtait à célébrer la messe, sous prétexte que l'on ne saurait y tolérer la présence de schismatiques. Furieux, Douglas se retire en faisant porter la faute à Clifford et aux Anglais, partisans du pape de Rome: "une fois la messe terminée, le dit William Douglas, avec l'aide des siens, mena un assaut furieux contre les Anglais, dans les rues, et mutila un certain écuyer, qui, blessé, se lança contre lui avec son épée nue et lui porta un coup mortel, qui l'étendit sans vie par terre»" ${ }^{261}$.

\footnotetext{
${ }^{254}$ Ibid., p. 338.

255 Ibid., p. 339.

256 Ibid., p. 339-340.

257 PR 1, p. 130-136; T. GUARD, Chivalry..., p. 90-91.

258 Par exemple, la croisade de Mahdia (1390) ou celle de Nicopolis (1396).

259 PR 1, p. 126.

${ }^{260}$ Joannis de Fordun Scotichronicon cum supplementis ac continuatione Walteri Boweri Insulae s. Columbae abbatis, éd. Walter Goodall, Edimbourg 1759, dans SRP 2, p. 797.

${ }^{261}$ Westminster, p. 474.
} 
Le chroniqueur nous dit encore que les Anglais furent rejoints dans la bagarre par des hommes d'Allemagne, de Bohême et de Gueldre, alors que seuls les Français - dont Boucicaut - prirent le parti des Écossais; «sous la persuasion d'un homme important du pays»" ${ }^{262}$ on cessa les hostilités, "bien que dans leurs cours ils restassent implacablement opposés» ${ }^{263}$. Les hôtes originaires de divers pays et affiliés à des partis rivaux, qui sont autant de soldats sourcilleux quant à leur honneur, ne cohabitent pas en Prusse sans heurt. Quelques décennies plus tôt, les disputes qui éclatent lors de la campagne de 1344 entre Charles de Moravie et Casimir de Pologne, respectivement fils de Jean de Luxembourg et de Ladislas le Bref, servent de prétexte à une courte guerre des Tchèques contre la Pologne en $1345^{264}$.

Dans la plupart de nos textes, l'ambiance est toutefois plus à la courtoisie qu'à la mâle rivalité entre professionnels de la guerre. Tel est le cas dans le récit d'une autre grande campagne internationale par Jean de Chastelmorand. Bien qu'ils voyagent à leurs propres frais, lui et ses compagnons ne dédaignent pas les dons que leur octroient la comtesse de Savoie et la reine de Bohême, qu'ils rencontrent lors de leur étape à Prague, où ils croisent la route de chevaliers français allant eux aussi en Prusse:

"Et à leur partir, la contesse de Savoie, seur au duc de Bourbon, donna à chascun des compaignons allant en Prusse, ung dyamant dont ils furent moult joyeulx du don des dames, et de Savoie se partirent les compaignons, passèrent par Lorraine et Allemaigne, et tirèrent en Boesme à Prague, ou ils trouvèrent la roine tante au duc de Bourbon ${ }^{265}$, qui les vit voulentiers et de bon cueur en leur donnant de ses dons. ${ }^{266}$

Le fait que des dames de la haute noblesse cautionnent, par leurs dons, ce départ en croisade permet d'en dire un peu plus sur l'imaginaire du voyage en Prusse tel qu'il se reflète dans les sources narratives. Geoffroi de Charny notait déjà, au milieu du XIV ${ }^{\mathrm{e}}$ siècle, que certains "gens d'armes» sont incités par leurs dames à "travailler et acquerir les biens et grans honnours la ou les bons

\footnotetext{
${ }^{262}$ Sans-doute le maréchal de l'Ordre: PR 1, p. 135.

263 Westminster, p. 476. Le meurtre du chevalier écosssais est également raconté par Le Livre des Fais..., p. 76-77, qui met Boucicaut en scène comme défenseur de l'Écossais «occis en trahison de certains Anglais» (p. 76); Wigand de Marbourg, Chronica..., SRP 2, p. 644. PR 1, p. 315, considère la version de la Chronique de Westminster comme plus crédible.

${ }^{264}$ G. Kristo et al., Histoire de la Hongrie médiévale..., vol. 2, p. 69-71.

265 Il s'agit sans doute d'une allusion à Béatrix de Bohême, seconde épouse de Jean de Luxembourg. Étant donné qu'elle est morte en 1383, la mention de son nom pourrait mettre un terminus ad quem à la rèse, mais la chronique nous dit que les chevaliers la rencontrèrent à Prague; or, la reine Béatrix ne résida que peu dans son royaume, et après la mort de Jean de Luxembourg, en 1346, elle se retira en France, où elle garda toutefois le titre de reine de Bohême. La datation reste donc assez floue: A. LeguaI, «Bourbonnais et Auvergnats...", p. 93.

${ }^{266}$ Chazaud, p. 63.
} 
quierent $»^{267}$. Dans le domaine littéraire, il n'est pas rare que d'aucuns marchent contre les Lituaniens par amour. Ainsi, Pierre Suchenwirt postule que dans la suite d'Albert d'Autriche, "beaucoup des fiers héros / qui étaient au service de l'amour / portés par leur ardeur et leur joie, / portaient des guirlandes et des couronnes de plumes d'autruches» ${ }^{268}$. Des poètes anglais de la seconde moitié du $\mathrm{XIV}^{\mathrm{e}}$ siècle remarquent, non sans réserve, que l'une des raisons pour prendre la croix peut être de servir sa dame ${ }^{269}$; ainsi John Gower, dans le livre 4 de sa Confessio amantis, ou Geoffrey Chaucer, qui rend grâce à l'héroïne du Livre de la Duchesse de ne pas envoyer ses favoris "into Walakye, / To Prusye, and into Tartarye, / To Alysaundre, ne into Turkye» ${ }^{270}$.

Pour Stefan Vander Elst, cette assimilation de la croisade balte au service à la dame, typique de l'amour courtois, serait en partie dû aux efforts de l'Ordre teutonique, qui avait réussi à entourer ces expéditions bisannuelles d'une aura tout arthurienne. En particulier, la Krônike von Prûzinland de Nicolas de Jeroschin regorge d'histoires de nobles dames sauvées des païens, ce qui pourrait avoir participé à l'héroïsation progressive du voyage en Prusse ${ }^{271}$. Les membres de l'Ordre teutonique devaient connaître une bonne partie des anecdotes racontées dans cette œuvre, et pouvaient en communiquer la substance à leurs hôtes $^{272}$. Si l'on considère que ceux-ci partageaient leurs expériences une fois rentrés au pays, cette interprétation ne manque pas d'intérêt. Toutefois, on sait que le service aux dames, qu'il soit lié explicitement à la Prusse ou non, fait pleinement partie de la culture aristocratique de la fin du Moyen Âge. Boucicaut, chevalier «exemplaire» et plusieurs fois voyageur de Prusse, n'a-t-il pas fondé l'Ordre de l'Écu Vert à la Dame Blanche pour servir les veuves et les orphelines $^{273}$ ? D'après son biographe, l'amour incite les jeunes nobles à chercher l'aventure pour gagner la renommée ${ }^{274}$ :

"Amours oste paour et donne hardement, fait oublier toute peine et prendre en gré tout le traveil que on porte pour la chose amee. Et qu'il soit vray, qui veult lire les histories des vaillans trespassez, assez trouvera de ce preuve, si comme on lit de Lancelot, de Tristan et de plusieurs autres que Amours fist bons et

\footnotetext{
${ }^{267}$ Geoffroi de Charny, The Book of Chivalry..., p. 94.

268 Pierre Suchenwirt, Von Herzog..., v. 246-249, SRP 2, p. 165; S. VANder Elst, "Chivalry...», p. 322. Les guirlandes et autres couronnes de plumes sont probablement des éléments du cimier que les chevaliers portaient sur leur casque: PR 2, p. 122-123.

269 S. VANDER ElST, "Chivalry...", p. 287-291.

${ }^{270}$ John Gower, Confessio... 4, v. 1620-1633, dans Complete Works..., vol. 2, cité par S. Vander Elst, "Chivalry...», p. 290; Geoffrey Chaucer, The Book of the Duchess, 342, v. 1024-26, cité ibid., p. 291, n. 11 ; T. Guard, Chivalry..., p. 164.

271 S. VANDER Elst, "Chivalry...", passim.

${ }^{272}$ Sur la fonction de la chronique de Jeroschin et la discussion quant à sa mise à disposition auprès des hôtes ainsi que de la noblesse allemande, Nicolas de Jeroschin, The Chronicle of Prussia..., p. 13-14; R. G. PASLer, Deutschsprachige Sachliteratur..., p. 283-284.

${ }^{273}$ D. Lalande, Jean II le Meingre..., p. 94.

274 S. VAnder Elst, "Chivalry...», p. 300-301.
} 
a renommee attaindre; et mesmement en noz vivans assez de nobles hommes en France et d'autre part en veons et avons veu, si comme on dit de messire Othe de Gransson, du bon connestable de Sensarre et d'autres assez, qui lonc seroient a dire, lesquieulx le service d'Amours ot fait devenir vaillants et bien moriginez. ${ }^{275}$

L'exemple d'Othon de Grandson, seigneur savoyard et poète célèbre en son temps (qui, fait intéressant, ne se met jamais en scène comme chevalier), illustre le type de personnage auquel Boucicaut se rattache; lui-même participa à une rèse au côté d'Henri de Derby, en $1392^{276}$. Certes, la Prusse teutonique est essentiellement représentée comme un monde d'hommes, dont les seigneurs sont supposés vivre en célibataires, et les comptes ne permettent pas d'observer une quelconque présence féminine auprès des hôtes ${ }^{277}$. Pourtant, le fond imaginaire qui tend à faire de ce genre d'expédition un acte d'amour - la littérature courtoise liant volontiers amor et arma - se manifeste également en ce qui concerne le voyage de Prusse ${ }^{278}$. De ce fait, la mention du "don des dames» au départ des courtisans du duc de Bourbon peut se rattacher à une certaine tradition courtoise. Dans sa Chronique de Metz, Jacques d'Esch raconte que la compagnie du duc de Lorraine assure aux croisés rentrant de Prusse d'être accueillis avec tous les honneurs partout où ils passent:

"Et fuit une belle honnour que ciaulx de Metz y virent en allant et revenant et sejourant auvec le dit duc. Car per toutes lez bonnez villez ou ilz passoient, lez sgrs. princez et autrez leur venoient en l'encontre et lez reconduisoient si nettement comme ilz povoient; et faisoient dancier les dammez et leur monstroient leur artillerie et la faisoit li boin veioir lez estas et lez honnours dez seigneurs et bonnez villez. "279

Les danses que l'on partage avec les dames de la noblesse semblent n'être, ici, qu'un élément de l'accueil princier, habituel lorsqu'un important visiteur était de passage dans une ville. Sans doute la présence du duc est-elle pour partie dans le traitement auxquels les croisés ont droit, mais on remarque que, comme dans la Chronique du bon duc de Bourbon, ceux-ci bénéficient de la caution des plus hauts princes et de leurs dames. La participation de ces dernières, toute ritualisée qu'elle puisse être, donne une touche romanesque à l'aventure racontée par nos chroniqueurs. Pierre Suchenwirt fait même du voyage vers la Prusse

\footnotetext{
275 Le Livre des Fais..., p. 27-28.

${ }^{276}$ M. Nejedlú, «Spisy...», p. 105-107, identifie les poèmes d'Othon de Grandson comme une source d'inspiration importante pour les poèmes de jeunesse d'un autre croisé de Prusse, Guillebert de Lannoy.

277 W. Paravicini, "Von der ritterlichen....", p. 36-37.

278 S. VANder Elst, "Chivalry...», p. 322-325.

${ }^{279}$ Wolfram, p. 340.
} 
une traversée d'un "monde de femmes ${ }^{280}$, en montrant ses héros accueillis uniquement par des dames à Wrocław et à Toruń281.

Si Guillaume de Machaut, pas plus qu'Esch ou Chastelmorand, ne lie explicitement le combat contre les Lituaniens au service d'une dame, le moraliste Jean Petit n'hésite pas à faire du voyage lointain, apprentissage obligé pour les fils de la noblesse, une épreuve galante. Ainsi, dans son poème didactique Le Livre du champ d'or, fait-il peindre par dame Gentillesse le portrait du jeune noble idéal:

"Ainsi la belle servira

Et, en la servent s'en yra,

Si tost com se pourra armer,

En ces voyages d'oultremer

Et de Pruce et de Barbarie.

Et pour Dieu ne s'espairgne mie,

Mais a la mort nostre Seigneur

Vengier mette peine greingneur

Qu'il pourra, selon sa puissance. "282

Assimilé au devoir de vengeance contre les ennemis du Christ, la croisade contre de lointains infidèles permet d'apprendre à mener la guerre et à évoluer en société, mais doit surtout transformer le jeune noble en un chevalier prisé - ce qui, dit explicitement l'auteur, ne peut que faciliter sa vie amoureuse:

"Lors se verra bon chevalier,

Et se fera partout prisier,

En son pais retournera,

Et ses parens visitera;

Et les dames et damoiselles

De son pais et les pucelles

Diront: c'est monsieur cellui,

N'est nul qui se compare a lui

En bonté, n'en sens, n'en vaillance

En tout le royaulme de France.

La dame est de bonne heure nee

Qui pourra de lui estre amee. ${ }^{283}$

\footnotetext{
280 S. VANder Elst, "Chivalry... ", p. 324.

${ }^{281}$ Ibid., p. 322-324.

${ }^{282}$ Jean Petit, Les condicions...v. 2855-2863, p. 132. Sur ce poème didactique, Ibid., p. 11-13;

W. Paravicini, «Von der Heidenfahrt...», p. 113-114.

283 Jean Petit, Les condicions..., v. 2881-2892, p. 133.
} 
L'amour comme moteur de la croisade de Prusse est mis en scène dans un roman du milieu du $\mathrm{xv}^{\mathrm{e}}$ siècle, Le Petit Jean de Saintré d'Antoine de la Sale (v. 1456-1460). Cette œuvre de fiction, composé sur le modèle de la biographie chevaleresque, se veut un "monument à la gloire d'une chevalerie [...] qui joue largement au chevalier» ${ }^{284}$ : comme l'a bien montré Michelle Szkilnik, le roman reprend les codes courtois et arthuriens mais les détourne pour en faire une sorte de parodie du genre ${ }^{285}$. Le personnage principal, qui porte le nom de deux chevaliers s'étant réellement rendu en Prusse (autour de 1350 et 1392) ${ }^{286}$, est un jeune niais, "éduqué" par une noble dame, que l'auteur prétend n'appeler que Madame des Belles Cousines eut égard à sa réputation. En imposant à son protégé toutes sortes d'exploits prisées des chevaliers de son temps (tournois, emprises, pas d'armes), elle parvient à en faire l'un des nobles les plus en vue du royaume de France. Alors qu'une croisade se prépare en Prusse, Saintré se voit obligé d'y participer par les injonctions de sa dame, qui lui conseille de profiter de l'occasion pour recevoir les éperons:

"Vous, par armes que ayez faittes, a la requeste de monseigneur le roy ne aultres ne avez voullu estre chevalier, vous excusant que jamaiz ne le seriez, se n'estoit contre les Sarrasins, ou soubz la baniere de mondit seigneur; [...] pour ce, me suis appenssee que vraiement il vous fault estre comme voz predecesseurs ont esté, et pour ce faire me semble que plus sainttement et honnorablement ne le porriez estre que ad ce tressaint voyaige de Prusse, a celle tressainte battaille qui doit estre a l'encontre des Sarrasins. ${ }^{287}$

La croisade, prisée si ce n'est vécue au $\mathrm{XV}^{\mathrm{e}}$ siècle, est un motif incontournable dans les romans et les biographies chevaleresques de la fin du Moyen Âge ${ }^{288}$; si l'Orient, sans doute plus prestigieux, est souvent privilégié, La Sale décide de faire se dérouler cet épisode en Prusse, au départ de Toruńn ${ }^{289}$, c'est-à-dire là où la plupart des chevaliers ayant pu servir de modèle à son héros se sont

\footnotetext{
${ }^{284}$ Pour reprendre l'expression de B. Ribémont, dans sa recension de "M. Szkilnik, Jean de Saintré. Une carrière chevaleresque au XV siècle", Cahiers de recherches médiévales et humanistes [En ligne], 2003, mis en ligne le 15 juillet 2008, consulté le 17 août 2014. URL: http://crm.revues.org/255, p. 3.

${ }^{285}$ M. Szkilnik, Jean de Saintré..., passim; J.-C. Mühlethaler, «D’Énée à Jehan de Saintré: l'idéal littéraire à l'épreuve de la cour", dans L. Harf-Lancner et al. (éds.), Conter de Troie et d'Alexandre, Paris 2006, p. 115-133.

286 PR 1, p. 44, 95, 100; pour C. KNUdson, «Saintré...», p. 272, un certain Jean de Saintré est attesté dans les années 1340 et 1350; Antoine de la Sale, qui cite son épitaphe (imaginaire?), le fait mourir en 1368.

${ }^{287}$ Blanchard, Quereuil, p. 332.

${ }^{288}$ M. Szkilnik, Jean de Saintré..., p. 102; J. TaYlor, "La fonction de la croisade dans Jehan de Saintré", Cahiers de recherches médiévales et humanistes, 1, 1996, p. 194-195; M.-T. DE Medeiros, «L'idée de croisade dans la Mélusine de Jean d'Arras», Cahiers de recherches médiévales et humanistes, 1, 1996, p. 153-154.

289 "Torrin», Blanchard, Quereuil, p. 360, 362.
} 
rendus ${ }^{290}$. Il serait même tentant de dire que le noble effectuant son voyage en Prusse représente l'archétype dont le romancier se moque. La croisade de Prusse, unique occasion où Saintré se bat pour une cause ${ }^{291}$, représente l'ultime aventure que doit effectuer un jeune noble; c'est, en tout cas, la dernière que Belle Cousine demande au héros d'accomplir ${ }^{292}$. Lorsque celui-ci, après son retour de Prusse, s'engage dans une nouvelle "emprinse» sans demander l'avis de sa dame et de son roi, ses ennuis commencent ${ }^{293}$. Au courroux de ce dernier s'ajoute le mépris de la première, qui n'hésite pas à tromper le malheureux jeune homme avec un abbé de son voisinage!

Nous reviendrons sur la couleur grivoise qui entoure le voyage de Prusse, aventure chevaleresque par excellence, dans quelques ouvres $\mathrm{du} \mathrm{Xv}^{\mathrm{e}}$ siècle. Contentons-nous pour le moment de mentionner le fait que Jean de Saintré est parti en Prusse sur la demande de sa dame, et qu'il y a été adoubé avant une gigantesque bataille, de la main d'un roi de Bohême que l'on peut sans trop de risque identifier comme Jean de Luxembourg ${ }^{294}$. Le roman, qui reprend et grossit les ficelles des biographies chevaleresques du siècle précédent (Boucicaut et Gadifer de la Salle apparaissent comme compagnons de Saintré295), fait sien le nec plus ultra que représente l'adoubement lors de l'affrontement contre l'infidèle ${ }^{296}$. Jean de Saintré, qui, tout comme Raoul de Gruyère, refusait de recevoir l'ordre de chevalerie si ce n'est sous la bannière du roi de France ou «contre les Sarrasins» ${ }^{297}$, est dignement adoubé lors du voyage de Prusse. À cet égard, il est notable que l'événement soit lié au personnage du roi de Bohême, mis en scène dans le célèbre poème de Machaut ${ }^{298}$.

${ }^{290}$ C. Knudson, «Saintré...», p. 271-277.

${ }^{291}$ M. Szkilnik, Jean de Saintré..., p. 141. Pour J. Taylor, "La fonction de la croisade...", p. 193-204, la croisade de Prusse, plongée dans le monde «viril» du compagnonnage chevaleresque, fait du protagoniste un chevalier à part entière, capable d'écarter sa dame et de vivre sans elle; c'est un détournement du modèle traditionnel de l'amour courtois, où l'amour de la dame représente l'ultime désir du chevalier.

${ }^{292}$ M. Szilnik, Jean de Saintré..., p. 99-100.

293 Blanchard, Quereuil, p. 396 sq.

${ }^{294}$ Ibid., p. 214. À cet égard, C. KNUdson, « Saintré... », p. 274, remarque que La Sale ne mentionne pas que le roi de Bohême soit aveugle, ce qui le conduit à penser qu'il ne s'agit peut-être pas de Jean, mais de son fils Charles; or, celui-ci n'étant pas resté dans les mémoires comme un héros de Prusse, il y a lieu de penser que le roi en question soit bien Jean de Luxembourg. Même si l'argument «chronologique» n'est pas forcément convainquant lorsqu'il s'agit d'une œuvre littéraire, on peut rappeler que Jean n'était pas encore aveugle lors de sa première expédition prussienne, celle dont Machaut nous a laissé un souvenir. À ce sujet, M. Szkilnik, "Jean de Saintré ou le rêve d'une internationale chevaleresque", dans R. Bellveser (dir.), La Novel-la de Joanot Martorell i l'Europa del segle $X V$, Valence, 2011, p. 380-381.

295 J. TAYLOR, «La fonction de la croisade...», p. 200-202.

296 Dans son poème didactique La Salade, Antoine de la Sale recommande que l'écuyer soit adoubé sur le champ de bataille; ibid., p. 196-197.

297 Blanchard, Quereuil, p. 330; M. SzKilnik, Jean de Saintré..., p. 100.

298 J. TAYLOR, «La fonction de la croisade... », p. 194. 
Il faut dire que ce héros "lituanien", bien connu des Français pour sa mort héroïque à Crécy, est devenu à lui seul un thème littéraire: on le retrouve explicitement dans le Myreur des Histors de Jean d'Outremeuse, et il est difficile de ne pas y voir au moins une allusion dans le personnage de Renaud de Lusignan, qui dans le Mélusine de Jean d'Arras (1393) vole au secours d'une Bohême assiégée par les "Sarrasins» du roi Selodus de Craco (Cracovie). L'œuvre était commandée par le duc Jean de Berry, sa sœur Marie de Bar et leur cousin Josse de Moravie, tout trois liés à la maison de Luxembourg. La légende de Mélusine permet d'appuyer les revendications politiques des commanditaires; en particulier, Jean de Berry lorgnait sur la puissante forteresse de Lusignan, héritage d'une famille que l'on considérait comme liée aux Luxembourg 299 . L'idée était de faire du célèbre roi de Bohême le pivot permettant de rattacher le duc de Berry, son petit-fils, aux Lusignan/Luxembourg ${ }^{300}$. Par ailleurs, l'histoire de Renaud de Lusignan pouvait servir les ambitions de Josse de Luxembourg, cousin et rival du roi Wenceslas de Bohême ${ }^{301}$. Bien que l'on doive se garder de vouloir à tout prix identifier les figures littéraires du Mélusine de Jean d'Arras à des personnages historiques ${ }^{302}$, il est sans doute permis de voir un souvenir des aventures lituaniennes de Jean l'Aveugle dans l'histoire du Lusignan/ Luxembourg Renaud, devenu roi de Bohême après avoir défait des "Sarrasins» menés par un roi de Cracovie ${ }^{303}$. Fait remarquable, Coudrette, qui a utilisé le roman de Jean d'Arras comme modèle pour son Mélusine en prose, a gardé l'épisode pragois des aventures des fils de la fée, alors que son ouvre était dédiée aux Parthenay, une famille qui pouvait se revendiquer des Lusignan mais n'avait aucun rapport avec la Bohême ${ }^{304}$.

Si l'on peut se permettre de voir une inspiration "lituanienne» à cet épisode, on notera avec intérêt qu'en détruisant les païens, Renaud, son frère Antoine et leur cousin le roi d'Alsace volent au secours de la fille du précédent roi de Bohême, tué par le païen Selodus. Une fois Prague libérée et la situation

\footnotetext{
299 Jean d'Arras, Mélusine ou la noble histoire de Lusignan, éd. et trad. J.-J. Vincensini, Paris 2003, p. 22-23; L. Harf-Lancner, "Le roman vrai de Mélusine», dans Héros et merveilles du Moyen Age..., p. 40-43; notice de J.-C. Mühlethaler, «Lusignan», sur le site du projet Regeneration, dirigé par D. WallaCe (2010) : http://www.english.upenn.edu/ dwallace/europe/nodes/lusignan. html. Voir aussi l'étude de M. Nejedlý, Stredověký mýtus o Meluzinè a rodová pověst Lucemburkư, Prague 2014. L'identification des Lusignans, famille noble de l'ouest de la France possessionnée en Orient (Arménie, Chypre) avec les Luxembourg repose notamment sur le fait que les deux familles possèdent des armoiries semblables.

300 M.-T. De Medeiros, «L’idée de croisade... », p. 149.

${ }^{301}$ M. Nejedlý, Středověký mýtus..., passim.

302 Idem, "Comment le roy Selodus fist ardoir le corps du roy Fedric de Bahaigne devan la porte de Prange". Les Tchèques et la croisade contre les Sarrasins dans Mélusine de Jean d'Arras (vers 1393)», dans Histoires et mémoires, p. 266.

303 M.-T. De Medeiros, «L'idée de croisade...», p. 149.

${ }^{304}$ Coudrette, Mélusine (Roman de Parthenay ou Roman de Lusignan), éd. et trad. M. W. Morris, J.-J. Vincensini, Lewiston 2009, p. 1-30; M. Nejedlý, Středověký mýtus..., p. 247.
} 
rétablie, Renaud épouse l'héritière et monte sur le trône de Bohême. La défense des chrétiens menacés, chère au discours ecclésiastique sur la croisade, peut tout à fait se coupler à une trame amoureuse et à une politique matrimoniale ambitieuse. L'amour, ou du moins le mariage, est directement lié à l'aventure prussienne de Jean de Luxembourg dans le Myreur des Histors, du liégeois Jean des Preis, dit d'Outremeuse (m. v. 1400). Le schéma n'est toutefois pas le même que dans Jean de Saintré ou Mélusine; l'œuvre, qui a forme de chronique universelle mais peut se lire comme une fiction romanesque aux influences arthuriennes $^{305}$, présente Jean de Luxembourg en un croisé de Prusse qui a cœur de gagner le "roy" lituanien au christianisme. Devenu ami de celui-ci, le roi Jean "se volt aviseir que amour de femme faisoit toute faire", et lui dépêche donc "la plus belle pucelle»" ${ }^{306}$ de sa compagnie, qui essaye, en vain, de le séduire pour l'inciter à recevoir le baptême ${ }^{307}$.

L'amour terrestre, mis ici au service d'une tentative de conversion d'un souverain païen, a donc sa place dans un voyage de Prusse tel que raconté par un chroniqueur wallon épris de romanesque. Ces quelques œuvres marquent une certaine distance par rapport à l'action balte; on n'y trouve pas la prétention au témoignage direct d'un Machaut, qui dit ne raconter que ce qu'il a vu "des yeus de [sa] teste» ${ }^{308}$. Dans le Confort d'ami, le poète citait la rèse de Jean l'Aveugle pour donner à ses lecteurs l'exemple d'une action digne d'être entreprise par un grand seigneur. On y va pour l'honneur, nous dit Machaut; Boucicaut semble marcher sur les traces du glorieux roi de Bohême, puisqu'il y va pour accroître son prix; les hommes du duc de Bourbon, qui vont là où "alloient maints chevaliers de plusieurs pays» ${ }^{309}$, ne disent pas explicitement qu'ils cherchent la renommée, mais le fait que les princes assistant à leur départ les encouragent prouve que l'on est dans la même ligne. Le voyage de Prusse effectué par les familiers du prince attire un peu de gloire sur sa maison, et mérite donc d'être raconté $^{310}$. Le don reçu par la comtesse de Savoie contribue sans doute à fortifier leur détermination, tout comme l'amour, nous dit le biographe de Boucicaut, pousse le chevalier à accomplir de grandes choses... parmi lesquelles, rapporte Antoine de la Sale, le voyage de Prusse. Rien d'étonnant donc à ce que le petit monde des Lituaniens et des Teutoniques inspire une scène courtoise à un Jean d'Outremeuse ou, c'est une hypothèse, à Jean d'Arras. À la suite de

\footnotetext{
305 P. PÉPorté, Constructing the Middle Ages..., p. 171.

306 Jean d'Outremeuse, Ly Myreur des Histors. Chronique et geste de Jean des Preis dit d'Outremeuse, éd. S. Bormans, Bruxelles 1880, vol. 6 (ci-après: Bormans), p. 415.

307 Ibid., p. 415-416. Nous aurons l'occasion de revenir sur cet épisode, où les couleurs courtoises traduisent une impression d'intercompréhension entre Lituaniens et croisés occidentaux, au chapitre VIII.

308 "Car presens fui a ceste feste, / Je le vi des yeus de ma teste», "Le Confort d'ami... », v. 3049-3050,

p. 108; W. VoIsÉ, "Guillaume de Machaut en Pologne... », p. 52.

${ }^{309}$ Chazaud, p. 63.

310 O. Troubat, La Guerre de Cent ans..., p. 571.
} 
Guillaume de Machaut, le roi de Bohême fait figure de croisé balte modèle, presque de «saint patron» de la Prusse.

La recherche de l'honneur, motivé ou non par l'amour d'une dame, la volonté d'imiter les pairs les plus prestigieux et de se plonger dans un cadre se rapprochant le plus possible des romans chevaleresques, expliquent le succès du voyage de Prusse; la défense des chrétiens opprimés, honorable en soi, donne un but tout à fait acceptable à l'entreprise. Du reste, le caractère mondain de ces motifs n'est pas incompatible avec un réel sentiment de dévotion, motivé peut-être en partie par les indulgences que distribue l'Ordre teutonique. Car les rèses sont certes des opérations militaires, capables de rapporter gloire et honneur, mais elles n'en visent pas moins la conversion des infidèles. Reprenons la route avec Guillaume de Machaut et son héros, Jean de Luxembourg. On sait pourquoi on va en Prusse; observons maintenant ce que l'on pense y faire. 


\section{Chapitre IV \\ ENTRE LE VERBE ET L'ÉPÉE}

\section{CONVERTIR OU CONQUÉRIR?}

Jean de Luxembourg est donc un prince combattant, qui savait porter le fer aux quatre coins du continent. Pour illustrer les activités de son héros, le poète mentionne avec plus de détails quelques combats en Allemagne ou en Bohême, puis passe à une description de l'expédition de 1328-1329 en Silésie, en Pologne et en Lituanie. C'est l'occasion pour notre poète de revenir sur le voyage qui l'a mené en Lituanie. Curieusement, les Chevaliers teutoniques ne sont pas mentionnés dans ce passage d'une quarantaine de vers. Contrairement aux poètes et chroniqueurs ultérieurs, Machaut semble ignorer l'existence de l'Ordre: le lecteur peu familiarisé avec le monde balte pourrait imaginer que Jean de Luxembourg a organisé de son propre chef la campagne, sans aucune intervention du grand-maitre Werner d'Orseln et de ses hommes. Ce qui n'est pas sans rappeler la rapide mention de la conquête de la Sambie dans le document Descriptiones terrarum, qui n'en attribue la réussite qu'au seul roi Ottokar de Bohême. À l'inverse, la Chronicon Aulae Regiae du moine lusacien Pierre de Zittau fait état de l'appui logistique et des conseils fournis par les Teutoniques, sans qui les exploits du roi Jean n'auraient pas été possibles ${ }^{1}$.

Achevé presque trente ans après l'événement, le poème de Machaut ne peut garantir que les souvenirs de l'auteur soient de première fraîcheur ${ }^{2}$; celui-ci se contente de relater, d'un ton épique, les exploits guerriers de Jean de Luxembourg, sans décrire ses adversaires autrement qu'en les qualifiant de "mescreant». Les Lituaniens ne jouent qu'un rôle passif dans cette affaire ${ }^{3}$; le seul personnage à agir est Jean, et dans une certaine mesure, Guillaume, qui à deux reprises rappelle avoir été directement témoin des événements: "Je le vi, pour ce le tesmong / Car partout

\footnotetext{
${ }^{1}$ Chronicon Aulae Regiae, dans Fontes Rerum... p. 293-294.

2 A. Prioult, «Un poète voyageur...", p. 28-29.

3 Ibid., p. 29.
} 
en seray tesmong» ${ }^{4}$ nous prévient-il au moment d'aborder la première campagne de 1327 en Silésie, qui dans son texte précède directement l'expédition de Lituanie ${ }^{5}$ :

"Et puis il s'en alla de la

Droit en royaume de Cracoe [Cracovie]

Et par les glaces en Letoe [Lituanie].

Crestienner fit en une ville,

Des mescreans plus de sis mille.

Li lieus avoit nom Medouagle. " ${ }^{6}$

Le philologue Vladimir Chichmaref identifie cette ville avec une place forte appelée Medewagen par les chroniqueurs allemands, et qui peut correspondre à l'actuel site de Medvegalis, situé au centre-ouest de la Samogitie ${ }^{7}$. En suivant l'identification des autres localités mentionnées plus loin par le poète, il apparaît que l'action se déroule dans cette région, principale cible des rèses: "Gegusë» semble correspondre à Geguzkalnis, située près de Medvegalis, "Aukahan" serait Aukaimas, un sanctuaire païen sur la rivière Dubysa. Quant à "Xedeyctain», il s'agirait d'une petite localité près de Medininkai (actuellement Varniai, au centre de la Samogitie), tandis que "Gedemine» serait une place forte indéterminée, toujours en Samogitie ${ }^{8}$. Remarquons que Machaut, comme la majorité des auteurs francophones, ne distingue pas cette province du reste de la Lituanie?

L'épisode de la prise de Medvegalis est relaté par plusieurs sources narratives proches des Chevaliers teutoniques, où ces derniers jouent cette fois un rôle important dans le récit. Pierre de Dusbourg raconte qu'en 1329, Jean de Luxembourg arriva en Prusse "avec des nobles de son royaume", d'autres princes "et avec beaucoup de nobles du royaume d'Allemagne et d'Angleterre» ${ }^{10}$.

\footnotetext{
${ }^{4}$ Guillaume de Machaut, "Le Confort d'ami...», v. 3027-3028, p. 107; et un peu plus loin: "Car presens fui a ceste feste, / Je le vi des yeus de ma teste», v. 3049-3050, Ibid., p. 108. L'éditeur E. Hoepffner précise que Machaut avait pour habitude de se mettre en scène dans ses œuvres, même si le sujet ne le concernait pas directement; le fait de souligner à deux reprises qu'il a été témoin des actions de Jean de Bohême en Lituanie se rattache à cette stratégie (Ibid., vol. 1, p. II). 5 V. 3021-3025, p. 107. Pour P. Knoll, The Rise..., p. 51, Jean de Luxembourg transite par Wrocław, où il passe Noël 1328 avant de se rendre en Prusse; de nombreux princes silésiens rejoignent son ost.

${ }^{6}$ Guillaume de Machaut, «Le Confort d'ami...», v. 3030-3035, p. 107.

7 Guillaume de Machaut, Poèsies..., vol. 1, p. XXIV; S. C. Rowell, Lithuania Ascending..., p. 240. La colline de Medvegalis se trouve au centre de l'actuelle région de Samogitie, à 180 km environ de Kaunas. ${ }^{8}$ La meilleure identification est résumée par ibid., p. 240, n. 53, qui cite A. Vaiciulaitis, «Viduriniu amziu poetas Machaut Lietuvoje», Lietuviu Kataliku Mosklo Akademijos Leidinys, 3, 1939 (Rome 1972), p. 318. On remarque la ressemblance phonétique entre le "Gedemine» de Machaut, le "Jedemine» de Dusbourg, où Werner de Homberg aurait été adoubé, et le nom du grand-duc Gediminas.

9 S. Zajączkowski, «Wilhelm de Machaut i jego wiadomosci do dziejéw Polski i Litwy w XIV w.», Kwartalnik Historyczny 43/1-2, 1929, p. 222.

${ }_{10}$ Pierre de Dusbourg, Chronicon..., suppl., SRP 1, p. 215. S. C. Rowell, Lithuania Ascending..., p. 239, mentionne que des chevaliers sont venus non seulement d'Allemagne et d'Angleterre, mais
} 
Nous avons vraisemblablement affaire à l'une des premières grandes rèses d'envergure internationale. Le chroniqueur de l'Ordre continue ainsi :

"Avec eux tous le frère Werner [d'Orseln] avec deux cents frères, et 18 milliers de combattants, outre les fantassins, marcha contre la Lituanie, et la veille de la Purification de sainte Marie il assiégea le château de Medewagen, et après beaucoup d'assauts, ils [les Lituaniens] se soumirent à la foi chrétienne et 6000 hommes dudit château furent baptisés au nom du Seigneur, mais peu après ils apostasièrent. ." ${ }^{11}$.

Même si, à la fin du Moyen Âge, les chroniqueurs cherchaient plutôt la précision des chiffres que leur charge symbolique pour signifier qu'un grand nombre de personnes étaient en jeu, il convient de rester méfiant avec les nombres de 18000 et de $6000^{12}$; on remarque toutefois que le nombre de 6000 correspond également à ce qu'avance Machaut (la Chronicon Aulae Regiae en rapporte $3000^{13}$ ). Bien que la continuation de Jean de Saint-Victor soit beaucoup plus modeste en ne mentionnant que "pluseur» Sarrasins qui "vindrent a foi de crestienté»" ${ }^{14}$, le nombre de païens à recevoir le baptême a dû être assez important pour que l'anecdote soit mentionnée dans plusieurs textes, dont la chronique du moine bénédictin néerlandais Guillaume d'Egmond ${ }^{15}$.. Pour le chroniqueur de l'Ordre teutonique, rien n'indique que le roi de Bohême y ait contribué, même s'il est facile de remarquer que la scène diffère des combats habituellement menés en Samogitie, qui se soldent plus souvent par un massacre que par un baptême collectif, fût-il passager.

Le chroniqueur et héraut d'armes teutonique Wigand de Marbourg, écrivant plusieurs décennies après les faits, nous fournit plus de renseignements sur l'épisode du baptême de Medvegalis ${ }^{16}$. Il raconte que "le roi de Bohême proposa d'entrer en terre de Prusse; ainsi, le duc [comte] de Luxembourg vint avec 300 hommes d'armes et d'autres fidèles du Christ en protection de la foi etc., voulant entrer en Lituanie» ${ }^{17}$. Le temps de conclure une trêve avec la Pologne, et la rèse peut débuter. Le siège est mis devant Medvegalis:

"Une fois celui-ci pris, ils trouvèrent une grande foule que le [grand] maître voulait totalement anéantir, mais par ses prières, le roi Jean leur sauva la vie, et

aussi des Pays-Bas et de France - sans doute une allusion à la présence de Guillaume de Machaut, puisque W. Paravicini repère les premiers hôtes venus directement de France seulement en 1335-1336 (PR 1, p. 95).

${ }_{11}$ Pierre de Dusbourg, Chronicon..., suppl., SRP 1, p. 215.

12 S. C. Rowell, Lithuania Ascending..., p. 246.

${ }_{13}$ Chronicon Aulae Regiae, dans Fontes Rerum..., p. 293. Le texte de l'Epitome Gestorum Prussie dit simplement "transiens fines Litwanorum quatuor castra cremavit et quintum expugnavit, donec se traderent gracie sue, et baptismum receperunt», SRP vol. 1, p. 287.

${ }_{14}$ Les Grandes chroniques..., vol. 9, p. 334.

15 Guillaume d'Egmond, Willelmi capellani..., p. 236.

16 S. C. Rowell, Lithuania Ascending..., p. 239-241.

17 Wigand de Marbourg, Chronica..., SRP 2, p. 462-463. 
par le baptême ils furent incorporés à la foi catholique au jour de la Purification de la Vierge; et ils donnèrent des garanties au maître en ce qui concerne la solidité de leur foi, ce qui plut beaucoup au roi. Mais une fois l'hiver terminé, ils commencèrent à avoir la nausée du baptême et à soupirer après le paganisme. Ainsi, le maître pensait-il que les chances étaient modestes de pouvoir s'attendre à une paix ferme. Or, avec le roi Jean, il a fait l'expérience que la paix serait violée par les païens. ${ }^{18}$

Ainsi, le grand-maitre Werner d'Orseln aurait été prêt à massacrer la population du fort, mais son royal hôte aurait intercédé pour que l'on fasse grâce aux Lituaniens et qu'on les baptise. Si l'on compare avec un autre passage de Dusbourg où il est question de la prise d'un fort lituanien, on en déduit que la mise à mort des assiégés était bien le programme habituel des Teutoniques, à quelques nuances près ${ }^{19}$. L'action se situe plutôt lors d'un conflit de frontières «normal» que pendant une rèse, puisqu'une ruse de guerre est employée, et que la présence de nobles venus d'ailleurs n'est pas mentionnée:

"En ces temps [1328], 60 frères et une troupe d'hommes de Prusse partirent contre le château de Gartha et comme ils comprirent que ceux-ci étaient prévenus, ils envoyèrent 400 hommes, qui entrèrent sur le territoire dudit château, et le ravagèrent, puis retournèrent à l'armée des frères. Un autre jour, pendant que les Lituaniens, qui croyaient les frères rentrés sur leur terre, étaient allés à leurs champs, les frères avec toute leur armée entrèrent avec puissance sur ladite terre; et jusqu'à six lieues, ils la dépeuplèrent par l'incendie et la rapine. Mais encore, beaucoup de nobles dudit châtean avec toute leur maisonnée et leur famille, jusqu'à 94 âmes, se sont adjoints aux frères, et venant en Prusse, reçurent la grâce du baptême. ${ }^{20}$

Les terres des Lituaniens sont brûlées et pillées, mais une partie importante des nobles sont emmenés en Prusse et baptisés; une pratique attestée dans plusieurs autres chroniques. Si la guerre que mène l'Ordre est violente, les plus importants des Lituaniens bénéficient d'une échappatoire en acceptant, bon gré mal gré, la conversion. Il y a toutefois une différence avec l'histoire de Medvegalis: à Gartha, seuls les nobles sont sauvés et convertis; le nombre de 94 personnes, comparé aux 6000 convertis qu'avancent Machaut et Dusbourg, montre une différence non négligeable dans le nombre de Lituaniens que l'on baptise. Néanmoins, rien ne permet d'affirmer que le massacre des païens ait été pratiqué partout: l'extrait cité ne dit rien de la mise à mort de la population de Gartha. Même si bien sûr, les termes "depopulati sunt incendio et rapina» ne laisse rien imaginer de bon pour le commun des habitants, il serait exagéré d'imaginer que tous ces derniers aient été mis à mort systématiquement.

\footnotetext{
${ }_{18}$ Ibid., p. 463.

19 S. C. Rowell, Lithuania Ascending..., p. 240.

${ }^{20}$ Pierre de Dusbourg, Chronicon..., SRP 1, p. 214.
} 
D'autant que lorsque c'est le cas, les chroniqueurs proches de l'Ordre ne se gênent pas de le mentionner.

Une autre différence est que si les habitants de Medvegalis semblent avoir été laissés sur place, dans le cas de Gartha, l'on prend soin de déporter les nobles convertis en Prusse, pour éviter que ceux-ci soient tentés de revenir au paganisme - ou plus prosaïquement, de reprendre les armes contre les Teutoniques. La stratégie de l'Ordre semble avoir été, pour les 200 ans de combats contre les païens baltes, proche de ce que l'on voit ici raconté pour la prise de Gartha: une dévastation des campagnes (l'usage guerrier habituel dans l'Europe médiévale ${ }^{21}$ ), puis la conversion des potentats locaux que l'on intègre à la noblesse chrétienne - ce qui peut expliquer que la déportation ait été pratiquée. En Lituanie, comme dans leurs possessions prussiennes et livoniennes, les Teutoniques utilisent fréquemment la noblesse autochtone, convertie et ralliée, comme un soutien, alors que la majorité des habitants sont laissés, pour l'essentiel, au paganisme ${ }^{22}$. On peut alors penser qu'en menant ses opérations militaires en Samogitie et ailleurs en Lituanie, l'Ordre cherchait surtout à briser la résistance des Baltes, et si possible à se rallier la noblesse; il ne s'agissait sûrement pas de convertir toute la population, même par la menace.

La demande de Jean de Luxembourg avait donc de quoi laisser perplexe le grand-maître, peu enclin à ce genre de marchandage, ce qui explique que selon Wigand, il ne donnait pas lourd de la paix ainsi obtenue. Il n'est en effet pas surprenant que les habitants de Medvegalis, soumis à ce qui ressemble fort à une conversion forcée (il est peu probable que les croisés leur eussent laissé la vie sauve s'ils avaient décliné l'offre du roi), aient apostasié peu de temps après le départ des troupes chrétiennes. Quoi qu’il en soit, Machaut souligne ce baptême avec fierté; pour lui, qui ne pouvait pas connaître la suite des événements, c'est un fait glorieux, propre à magnifier la mémoire de Jean l'Aveugle ${ }^{23}$, qui rejoint ainsi son prédécesseur Ottokar Přemysl, crédité par les chroniqueurs de son temps du baptême de la Sambie en 1255 .

La conversion des Lituaniens n'est peut-être pas la préoccupation principale des princes d'Europe centrale, mais elle peut s'inscrire occasionnellement à leur agenda politique. Ainsi, en 1349, le roi Casimir le Grand de Pologne propose le baptême et une couronne au duc Kęstutis, fils de Gediminas; deux ans plus tard, Louis d'Anjou, roi de Hongrie, lui fait la même offre, mais le Lituanien décline une nouvelle fois ${ }^{24}$. En 1358, c'est au tour du fils de Jean de Luxembourg, Charles, empereur et roi de Bohême, d'entamer des démarches visant à attirer

\footnotetext{
${ }_{21}$ P. Contamine, La guerre au Moyen Âge, Paris 1980, p. 365.

22 S. Gouguenheim, Les Chevaliers teutoniques..., p. 370-373; R. Wenskus, "The Teutonic Order...", p. 207-238.

23 W. Vorsé, "Guillaume de Machaut en Pologne... », p. 52-53.

${ }^{24}$ S. C. Rowell, «Unexpected...», p. 559-560.
} 
Kęstutis et son frère Algirdas aux fonts baptismaux ${ }^{25}$. Fidèles à la tradition établie par leur père, les Lituaniens entrent en négociation pour maintenir un calme relatif à leur frontière occidentale, avant de provoquer l'échec de la démarche. À lire ce que rapporte le chroniqueur Hermann de Wartberge, les compensations exigées par les deux frères étaient tout simplement irréalistes ${ }^{26}$. Plus intéressant, "ils demandèrent que l'Ordre soit localisé vers les déserts entre les Tatars et les Ruthènes, pour qu'ils les défendent des assauts des Tatars ${ }^{27}$; l'idée étant que si les Lituaniens reçoivent le baptême, leurs anciens adversaires n'auraient plus lieu de tenir la Prusse, et devraient se rendre utiles ailleurs ${ }^{28}$.

En montrant son intérêt pour les affaires baltes et la conversion des derniers païens de la région, le roi de Bohême entend marquer son hégémonie dans les affaires religieuses d'Europe centrale et orientale. En outre, s'attaquer à la tâche impériale par excellence qu'est la conversion des infidèles lui permet de faire de son royaume héréditaire le cœur politique et religieux de l'Empire ${ }^{29}$. À cet égard, son règne marque la fin de la participation des sujets de la couronne de Bohême aux voyages de Prusse; Charles lui-même s'y est rendu avec son père Jean, en 1344-1345, sans grande conviction ${ }^{30}$. C'est le moins que l'on puisse dire, puisque d'après son autobiographie, "beaucoup de grands hommes, frustrés de leurs voeux, gaspillèrent des efforts et des dépenses»" ${ }^{31}$. Quelle différence d'appréciation par rapport au portrait élogieux qu'un Guillaume de Machaut donne des actions de son père!

L'approche plutôt pacifique de l'empereur Luxembourg lui vaut tout de même les louanges du poète champenois, qui n'a pas maintenu avec lui les liens l'unissant jadis à son père, mais semble avoir néanmoins été tenu au courant des grandes lignes de sa politique ${ }^{32}$. Charles de Bohême fait son apparition dans La Prise d'Alexandrie, un panégyrique à la gloire du roi de Chypre Pierre de

\footnotetext{
${ }^{25}$ D'après Ibid., p. 572, il s'agissait de reconnaître aux fils de Gediminas leur statut de princes, mais non de leur donner une couronne, ce qui marque une différence par rapport à l'approche du Saint-Siège. Voir aussi R. MažEIKA, "Bargaining...", p. 137-140; D. Baronas, S. C. Rowell, The Conversion..., p. 141-143.

${ }^{26}$ Hermann de Wartberge, Chronicon Livoniae, SRP 2, p. 79-80, note que les émissaires lituaniens demandaient non seulement la Mazovie, mais encore les pays riverains du Danube!

${ }^{27}$ Hermann de Wartberge, Chronicon Livoniae..., SRP 2, p. 80.

${ }^{28}$ J. Sarnowsky, "The Teutonic Order Confronts Mongols and Turks», dans M. Barber (dir.), The Military Orders 1. Fighting for the Faith and Caring for Sick, Aldershot 1994, p. 259.

29 S. C. Rowell, "Unexpected...», p. 571-574. Une lettre du pape Clément VI, datée du 9 mai 1346, mentionne une demande de Charles d'installer en Bohême des bénédictins croates célébrant la liturgie en slavon, dans un but missionnaire. Toutefois, rien ne permet d'affirmer que le grandduché de Lituanie ait été en particulier ciblé. Voir Monumenta vaticana res gestas Bohemicas illustrantia, éd. L. Klicman, vol. 1, Prague 1903, doc. 653, p. 389-390.

30 V. ŽŮreK, "Sur les traces...», p. 282; S. C. Rowell, «Unexpected...», p. 573.

${ }^{31}$ Charles IV de Luxembourg, Vita Karoli, IV, ch. 16, éd. et trad. P. Monnet, J.-C. Schmitt, Paris 2010, p. 128-129.

32 Guillaume de Machaut, Euvres..., vol. 1, p. 29-30.
} 
Lusignan, composé peu après 1369. Au début du poème, Machaut présente le voyage effectué par son héros à travers la Chrétienté dans le but de rallier les têtes couronnées à son projet de croisade. En 1364, à Prague puis à Cracovie, il rencontre l'empereur, "fils dou bon roy de Behaigne», qui a notamment à son crédit de faire régner la paix sur une grande partie de l'Europe:

"Pais a mis par toute Alemaingne,

En Osteriche et en Behaingne,

En Misce, en Baiviere, en Hongrie,

Jusques es marches de Russie,

En Morave, en Prusce, en Cracoe,

Voire, par Dieu, jusque en l'Estoe,

Au meins jusques en Ranguenite,

Qui n'est mie chose petite. ${ }^{33}$

Par Ranguenite, on reconnaît Ragnit, le nom d'une importante forteresse teutonique, étape de nombreuses rèses; sans doute que Machaut avait en tête quelques souvenirs de jeunesse, et se rappela d'un toponyme entendu lorsqu'il accompagna le père de l'empereur dans son expédition contre les Lituaniens ${ }^{34}$. Dans ce cas, "l'Estoe» est sans doute une variante graphique du "Letoe» du Confort d'ami; l'un des manuscrits a "l'Etoe»" ${ }^{35}$, ce qui nous amène au nom couramment attibué à la Lituanie dans les sources francophones du XIV ${ }^{\mathrm{e}}$ siècle. La pacification de l'Ordre teutonique et de la Lituanie pourrait ainsi se lire comme une allusion à la politique «lituanienne» de l'empereur. Machaut ne mentionne pas explicitement la tentative d'évangélisation (qui avait par ailleurs échoué), mais il peut avoir été marqué par la "propagande»" ${ }^{36} \mathrm{du}$ roi de Bohême, qui dans sa volonté d'instaurer une monarchia mundi se pensait en protecteur de la Lituanie. À cet égard, lorsque vers 1367-1368 le prince Butautas vient à Prague lui demander asile, l'empereur prend grand soin à le faire baptiser et à s'en faire un familier portant le titre de "dux Lituanorum» ${ }^{37}$. On peut supposer que ces éléments n'ont pas échappé à Guillaume de Machaut, qui n'insiste peut-être pas sur l'étendue du pouvoir pacificateur de l'empereur par seul effet de style.

Si cette hypothèse est correcte, son informateur était peut-être un chevalier poitevin du nom de Perceval de Coulonge, compagnon du roi de Chypre, qui

\footnotetext{
33 Guillaume de Machaut, La Prise d'Alexandre, v. 1033-1040, éd. S. Hardy, Orléans 2011 (thèse de doctorat non publiée), p. 31.

34 S. ZającZKowSKI, "Whilhelm de Machaut...", p. 222.

35 Il s'agit du ms. BNF 22546; Guillaume de Machaut, La Prise d'Alexandrie, éd. M.-L. de Mas Latrie, Genève 1877, p. 32, n. C.

36 Sur l'application du concept de propagande à l'époque médiévale, S. Menache, The Vox Dei, New York-Oxford 1990, p. 175-176.

37 S. C. Rowell, «Unexpected...», p. 574.
} 
a participé à une rèse en Prusse en hiver 1368-1369, soit peu après l'arrivée de Butautas dans l'entourage du roi de Bohême, et juste avant que Machaut n'écrive sa Prise d'Alexandrie $e^{38}$. Que ce soit par ce personnage ou par d'autres croisés de retour d'une rèse, la nouvelle du rapprochement entre la Lituanie et l'Empire a pu parvenir à notre poète, qui dans le Confort d'ami saluait déjà la conversion des «mescreans» par le père de l'empereur. Ces quelques épisodes, visiblement connus d'au moins quelques poètes d'Europe occidentale ${ }^{39}$, montrent qu'il y avait parmi les puissances d'Europe du Centre-Est une volonté d'évangéliser "pacifiquement" la Lituanie, quitte à aller contre l'Ordre teutonique, lequel considérait ces tentatives comme un empiètement sur sa mission ${ }^{40}$. Une telle approche sera à l'origine de la conversion effective du grand-duché, lorsqu'en 1385, princes polonais et lituaniens entameront des négociations devant mener au baptême du fils d'Algirdas et petit-fils de Gediminas, Jogaila, en échange de la main de la reine de Pologne, Hedwige.

Les démarches hongroise, tchèque et polonaise n'empêchent pas ces pays d'avoir à plusieurs reprises croisé le fer avec les Lituaniens; toutefois, l'intérêt des puissances d'Europe centrale à l'évangélisation du grand-duché marque une certaine différence d'approche par rapport à l'Ordre teutonique. D'après Rimvydas Petrauskas, celui-ci, depuis le début du siècle au moins, ne songeait plus sérieusement à convertir les Lituaniens par une manœuvre diplomatique. Côtoyant de près Gediminas puis ses fils, les responsables de l'Ordre connaissaient bien les ruses de leurs adversaires, et considéraient que seule la soumission du pays - ou au moins de la Samogitie - pourrait permettre au christianisme de s'y implanter. Du reste, aucun des deux adversaires n'avait intérêt à mettre fin aux raids et contre-raids quasiment annuels, qui constituaient une importante source de richesse de part et d'autre ${ }^{41}$.

Même si la plupart de nos auteurs français ou anglais décrivent les rèses dans un registre essentiellement militaire, Guillaume de Machaut n'est pas le seul à évoquer la conversion dans le cadre de ce genre de croisade. Nous avons déjà fait la connaissance de Gadifer de la Salle, chevalier baroudeur qui s'est rendu à plusieurs reprises en Prusse avant de s'embarquer avec un Normand du nom de

\footnotetext{
${ }^{38}$ Perceval de Coulonge faisait partie de l'entourage de Jean de Blois, grand seigneur possessionné en Hainaut et Hollande, qui s'est vraisemblablement porté garant de l'emprunt contracté par Coulonge en Prusse, et a essayé en vain de récupérer son argent: W. Paravicini, "La Prusse...», p. 182-183; PR 1, p. 96-97; P. Contamine, «De Chypre à la Prusse et à la Flandre. Les aventures d'un chevalier poitevin: Perceval de Couloigne, seigneur de Pugny, du Breuil-Bernard et de Pierrefite (133.-141.)", dans D. Coulon et al (dirs.), Chemins d'Outre-Mer, vol. 1, Paris 2004, p. 149-157. En ce qui concerne La Prise d'Alexandrie, Perceval de Coulonge est considéré comme un informateur potentiel de Machaut (certes moins important que Jean de Reins) par S. Hardy, p. cxx, n. 149.

39 Pétrarque fait référence aux négociations entre Kęstutis et Louis de Hongrie en 1351 (voir chap. VIII).

${ }^{40}$ H. Paszkiewicz, The Origin..., p. 242-243; J. Jakstas, Das Baltikum..., p. 157-159.

${ }^{41}$ R. Petrauskas, "Litauen...», p. 240 passim.
} 
Jean de Béthencourt pour entreprendre la conquête des îles Canaries. L'aventure, pour laquelle le pape d'Avignon Benoît XIII a accordé des indulgences, a été racontée dans la chronique Le Canarien (1402), due aux chapelains des deux chefs $^{42}$. Le prologue de l'œuvre indique que les rédacteurs se placent dans une tradition bien précise:

"Pour ce qu'il est vray que mains chevaliers en oyant retraire les grans aventures, les vaillances et les beaux fais de ceulx qui ou temps passé ont entreprins de faire les voyages et les conquestes sur mescreans en esperance de les tourner et convertir à la foy crestienne, ont pris cuer, hardement et voulenté de les ressembler en leurs biensfais, et à fin de eviter tous vices et estre vertueux et que à la fin de leurs jours puissent acquerir vie permanable, Gadifer de la Sale et Jehan de Bethencourt, chevalliers nez du royaume de France, ont entrepris ce voyage à l'honour de Dieu, et au soustenement et acroissement de nostre sainte creance. ${ }^{43}$

Il n'est pas fait explicitement référence à la Baltique, mais le parcours des personnages dont il est question, en particulier de Gadifer de la Salle, laisse penser que les voyages en Prusse font partie des expéditions ayant servi de modèles à la conquête des Canaries ${ }^{44}$; en tout cas, la méthode de conversion est celle qui était habituellement utilisée en Europe du Nord-Est ${ }^{45}$. Les "voyages et les conquestes" aux marges de la Chrétienté auraient donc comme but ultime l'évangélisation des "mescreans». Le ton du prologue, qui mentionne explicitement la recherche de rétribution spirituelle, laisse entendre que les préoccupations des conquérants sont loin d'être uniquement mondaines. Nous sommes ici dans un registre sensiblement différent de la plupart des récits français qui concernent directement les croisades baltes.

L'évangélisation de la Lituanie résultant des actions de l'Ordre teutonique - et non explicitement des seules rèses menées en compagnie des "hôtes» - est mentionnée par Guillebert de Lannoy, qui s'est rendu auprès de l'Ordre comme croisé en 1413, soit après la conversion du pays. Après avoir été adoubé, il quitte la Prusse pour la Livonie, Novgorod, Pskov et enfin la Lituanie, avant de rentrer au printemps 1414 par la Prusse, la Pologne et la Bohême. Lorsqu'il parcourt la Lituanie, il remarque que «sont les gens dudit royaume cristiens nez nouvellement par la constrainte des seigneurs de l'ordre de Prusse et de Livland» ${ }^{46}$. Or, le

\footnotetext{
${ }^{42}$ Il s'agit de Pierre Boutier et de Jean le Verrier. Une seconde version de la chronique a été composée par un proche de Jean de Béthencourt, qui gomme le rôle joué par Gadifer : voir les deux versions comparées dans Le Canarien - Crónicas francesas de la conquista de Canarias, éd. E. Serra et A. Cioranescu., 3 vols., La Laguna de Tenerife 1959-1964.

43 Ibid., vol. 3, p. 15.

44 W. Paravicini, «La Prusse...., p. 187.

${ }^{45}$ D'après Le Canarien..., on a d'abord converti le «roi» des Guanches de Lanzarote, puis son peuple l'a suivi; M. Keen, "Gadifer de la Salle...», p. 81; A. Sadourny, "Les expéditions...», p. 205-206.

46 Potvin, p. 39-40.
} 
baptême des Lituaniens étant une décision politique, prise par le prince Jogaila (futur Ladislas Jagellon), Marienbourg n'y a pas joué un rôle déterminant, si ce n'est peut-être celui d'incitateur, une réalité qui n'empêche pas Guillebert d'attribuer aux Teutoniques le succès de la conversion des «Sarrasins» que l'on allait combattre en Prusse pendant des générations. Le terme de "constrainte» fait comprendre que dans l'esprit du voyageur bourguignon, la manière forte a été utilisée, ce qui rejoindrait le récit de l'épisode de Medvegalis par Machaut, et plus encore par les chroniques teutoniques; la force était donc implicitement reconnue comme un moyen pouvant amener à la christianisation des «mécréants» baltes. Néanmoins, l'efficacité de la conversion forcée semble être considérée comme douteuse par certains de nos auteurs français.

Plus tôt pendant son voyage entre la Prusse et la Livonie, Guillebert de Lannoy a laissé une description des rites funéraires des Coures, qu'il dit être «cristiens natifz par force» ${ }^{47}$. L'évangélisation de cette population balte, soumise au XIII siècle, n'est pas explicitement liée à l'action des Teutoniques, mais Guillebert, qui note avec soin les langues que parlent les peuples dont il traverse le territoire, devait être au courant du fait que les Coures étaient sujets de l'Ordre. Or, leur christianisme apparait comme bien superficiel, puisque "ont lesdis Corres, jasoit ce qu'ilz soient cristiens natifz par force une secte que après leur mort ilz se font ardoir en lieu de sépulture, vestus et aournez chascun de leurs meilleurs aournemens en ung leur plus prochain bois ou forest qu'ilz ont, en feu fait de purain bois de quesne»" ${ }^{48}$. On reconnait la description "habituelle» du bûcher funéraire, ce qui laisse entendre que le chevalier bourguignon attribuait à ces habitants de la Livonie teutonique des mours au caractère explicitement païen ${ }^{49}$. Le poète Philippe de Mézières, qui a visité la Prusse comme ambassadeur du roi de Chypre en 1364, notait pour sa part que les autochtones de ce pays, "nouvellement venus a la foy", n'avaient pas intégré correctement la religion chrétienne. Une description détaillée de la Prusse apparaît dans le premier livre de son roman Le Songe du vieil pelerin, qui met en scène un groupe de figures allégoriques parcourant le monde pour dresser un état de la manière dont la religion catholique se porte. Selon le procédé du rêve allégorique, l'auteur se présente voyageant à côté de la Reine Vérité et de ses suivantes qui, dans chaque pays où elles s'arrêtent, dressent une forge pour examiner la valeur du "besant" local, ceci afin de voir si le signe de Tau y est bien figuré; autrement dit, si le Christ est convenablement honoré dans le pays ${ }^{50}$. Le résultat est excellent en ce qui concerne les membres de l'Ordre teutonique, le clergé et les bourgeois de Prusse, mais les autochtones ont droit à une appréciation différente:

"Et fu trouvé que le signe de Thau y estoit figuré en apparence et non pas en existence, car il sont nouvellement venus a la foy. Et ne pevent pas bien ou veulent

\footnotetext{
${ }^{47}$ Cette phrase est absente du manuscrit de la famille de Lannoy (Xvi ${ }^{\mathrm{e}}$ siècle); Potvin, p. 30, n. 4.

48 Ibid., p. 30.

49 N. Blomkvist, Discovery..., p. 175. Voir chap. VIII.

${ }^{50}$ Blanchard, vol. 1, p. LXXVII-LXXX.
} 
laissier en leurs cuers l'ydolatrie et la loy de leurs vieulz anchissours [ancêtres]. Toutefois par l'alkemie soubtille de la saincte religion petit a petit leur besant amendera. $»^{51}$

Autrement dit, les Prussiens ne peuvent être convertis en un jour; Mézières semble être conscient de la lenteur avec laquelle la religion chrétienne s'impose parmi les natifs, dont il note que la place est tout en bas de la hiérarchie sociale ${ }^{52}$. Pour l'auteur, pourtant sensible aux questions religieuses, la conversion des infidèles ne semble pas faire partie des tâches de l'Ordre teutonique, qu'il décrit comme une sorte de modèle pour la chevalerie chrétienne. La consigne que leur donne la Reine Vérité suffit à clarifier quelle est leur mission: «la guerre contre les anemis de la foy vaillaument poursivés" "53. Pour Mézières, comme pour la plupart des francophones écrivant sur la croisade balte, l'Ordre teutonique est essentiellement une corporation guerrière, et son combat contre les Lituaniens est louable en tant que tel. Néanmoins, la christianisation des "mécréants» appartient à l'horizon d'attente des auteurs, et la violence semble être un moyen comme un autre pour y parvenir. En tout cas, elle n'est pas explicitement condamnée par Guillebert de Lannoy, qui dit que les Coures et les Lituaniens ont été convertis par la force et la contrainte. Une conversion qui est perçue par Philippe de Mézières comme toute superficielle; mais, dans d'autres cas, elle vaut la peine d'être mentionnée comme un beau geste. C'est l'option choisie par Guillaume de Machaut, qui loue Jean de Luxembourg et son fils, l'empereur Charles, pour avoir converti les Lituaniens lors de la rèse du premier, et étendu la paix (chrétienne?) à tout le pays dans le cas du second. Le poète champenois reste notre guide principal dans les étapes qu'il nous reste à franchir pour comprendre comment le voyage en Prusse pouvait être perçu par les chevaliers occidentaux de la fin du Moyen Âge.

\section{«GRANT DESTRUCCION DE SARRASINS» : LA GUERRE EN PAYS BALTE}

Mettre son épée au service de la foi faisait du voyage en Prusse une entreprise toute chevaleresque, honorable et méritoire. Conformément à l'idéologie de la croisade balte, les païens devaient non seulement être combattus (defensio fidei), mais aussi convertis (propagatio fidei). Nos sources montrent qu'une partie au moins de ceux qui allaient chercher l'honneur en affrontant les Lituaniens pouvaient espérer qu'à l'issue des combats, ceux-ci recevraient le baptême. Pourtant, en dépit des tentatives de conversion plus ou moins pacifique,

\footnotetext{
${ }^{51}$ Ibid., p. 215.

52 "mais en la nef de l'Église estoit tout le peuple du pays naturel qui s'appellent les Prusses; et estoient sans nombre que plus n'en pooit en la nef de l'Église» (Blanchard, vol 1, p. 212); «la monnoie de metal, ce sont les harelars, estoient appropriés au commun du pays, assés nouvelement conquesté a la foy, c'est aus Prussenaires" (ibid., p. 213).

53 Ibid., vol. 1, p. 225.
} 
la guerre reste la réalité de la région durant presque tout le $\mathrm{xIV}^{\mathrm{e}}$ siècle. S’il est difficile d'affirmer que les Teutoniques n'ont jamais cherché à convertir personne, il semble bien que l'on n'ait pas eu les moyens de poursuivre un effort missionnaire efficace, quelle qu'ait pu être la volonté des grands-maîtres successifs $^{54}$. De ce fait, la campagne contre la Lituanie se transforme en une longue guerre, qui bien que chargée d'une forte connotation religieuse, s'éloigne peu à peu d'une perspective évangélisatrice ${ }^{55}$.

D’après l'historien lituanien Juozas Jakštas, l'épisode de Medvegalis donne à la rèse du roi de Bohême une touche plus spirituelle, qui la rapproche de l'idée profonde de croisade - au sens où l'action porte également sur la conversion ${ }^{56}$. Pourtant, si on lit la suite du Confort d'ami, on s'aperçoit vite que le roi chevalier proposé comme modèle par Guillaume de Machaut n'a pas toujours été aussi magnanime:

"Et ne tien pas que ce soit fable,

Qu'encor prist il quatre fortresses

Qui dou pais furent maistresses:

Xedeyctain et Gedemine,

Gegusë, Aukahan; et si ne

Demoura la homme ne fame

Qui ne perdist le corps et l'ame,

Ne riens qui demourast en vie,

Maugré le khan de Tartarie

De qui Litau est tributaire

Et encor leur fist tel contraire

Qu'il leur gasta plus de païs

Qu'il n'a de Burges a Paris;

Car presens fui a ceste feste,

Je le vi des yeus de ma teste. ${ }^{57}$

La conversion des défenseurs de Medvegalis ressort parmi cette énumération de villes détruites comme une notable exception; en dépit du khan tatar, que

\footnotetext{
54 S. Gouguenheim, Les Chevaliers teutoniques..., p. 438-439.

55 R. Petrauskas, «Litauen...», p. 243; P. Rabikauskas, "Les Jagellons», dans M. Rouche (dir.), Clovis. Histoire et Mémoire. Actes du Colloque International d'Histoire de Reims, du 19 au 25 septembre 1996, vol. 2, p. 391.

${ }^{56}$ J. Jakstas, Das Baltikum..., p. 149.

${ }^{57}$ Guillaume de Machaut, «Le Confort d'Ami... », v. 3036-3050, p. 107-108.
} 
Machaut considère comme le souverain des Lituaniens ${ }^{58}$, le pays est mis à feu et à sang sur le passage du roi de Bohême. Cela ressemble assez à la manière dont on mène la guerre sur la frontière balte ${ }^{59}$ : Pierre de Dusbourg mentionne non sans détails le sort qui est fait à la citadelle d'Aukaimas, que l'on peut sans trop de risque identifier comme le "Aukahan" dont parle notre poète français ${ }^{60}$. L'action est censée s'être déroulé en 1328, soit peu avant la rèse racontée par Machaut:

"Peu de temps après cela, les frères de Ragnit avec leurs hommes attaquèrent les faubourgs ${ }^{61}$ du château d'Aukaim, pendant que les habitants du château dormaient, et brûlèrent tout; à l'exception de quatre hommes, qui étaient dans le château et des quelques-uns qui s'échappèrent, tous, avec les femmes, les enfants, le bétail et les troupeaux, furent tués par le feu ou par le glaive. " ${ }^{62}$

La scène est violente, mais elle aurait tout aussi bien pu se dérouler dans un château assiégé par les païens. À partir du milieu du XIV ${ }^{\mathrm{e}}$ siècle, Lituanie et Ordre teutonique lancent l'un contre l'autre des raids dévastateurs, les fameuses Reisen, équivalent des rèses de nos auteurs français. Entre 1362 et 1382, plus d'une cinquantaine de ces expéditions ont été menées depuis la Prusse, et 22 depuis la Livonie $^{63}$. Les ripostes lituaniennes sont un peu moins fréquentes - on en compte une quarantaine entre 1345 et $1382^{64}$-, mais non moins violentes. De part et d'autre, on vise à faire tomber une forteresse de l'adversaire ou à ravager ses terres, détruire ses récoltes, capturer du bétail ou prendre des prisonniers, hommes, femmes et enfants, lesquels peuvent occasionnellement être massacrés, mais sont la plupart du temps gardés comme esclaves ${ }^{65}$. En

\footnotetext{
58 Guillaume de Machaut, Poèsies..., p. XXVI: «Si Gédimine se donnait officiellement le titre de prince de Russie, rien d'étonnant à ce que Machaut et ses contemporains l'aient tenu pour un vassal du Khan: à cette époque-là, les princes [russes] étaient réellement tributaires de la Horde d'Or».

59 PR 2, p. 56-59; S. C. Rowell, Lithuania Ascending..., p. 244.

${ }^{60}$ Ibid., p. 240, n. 53.

${ }^{61}$ Dusbourg utilise le terme de "preurbium" pour parler des habitations entourant les forteresses construites par les Baltes comme par les Polonais ou les Teutoniques; A. Pluskowski, The Archaeology..., p. 97-98.

${ }^{62}$ Pierre de Dusbourg, Chronicon..., SRP 1, p. 215. Pour un autre exemple: Wigand de Marbourg, Chronica..., SRP 2, p. 572; E. Christiansen, The Northern Crusades..., p. 167. La cruauté des Teutoniques et de leurs hôtes constitue un thème prisé du chroniqueur polonais Jan Długosz (m. 1480), qui écrivait à une époque de vives tensions entre son pays et l'Ordre teutonique; par exemple, Annales IX, dans Opera Omnia..., vol. 12, p. 236.

${ }_{63}$ S. Gouguenheim, Les Chevaliers teutoniques..., p. 440-441. Pour une liste des rèses entre 1305 et 1409 , PR 2, tab. 49 , p. 20-45.

${ }^{64}$ I. Lalkoù, Aperçu de l'histoire politique du Grand-Duché de Lithuanie, Paris 2000, p. 24.

${ }^{65}$ S. Ekdahl, "Treatment of Prisoners of War", dans M. Barber (dir.), The Military Orders $1 \ldots$, p. 263-269, suppose que l'Ordre teutonique utilisait les captifs lituaniens pour servir de main-d'œuvre, en remplacement des colons qui ont cessé de venir en Prusse à partir du milieu du XIv ${ }^{e}$ siècle. Cette pratique semble avoir également existé du côté lituanien; A. NikžEntaitis, "Prisoners of War in Lithuania and the Teutonic Order State (1283-1409)», Der Deutsche Orden
} 
dehors des grands raids, relativement faciles à prévoir pour la population, les deux camps emploient volontiers des soldats irréguliers, très proches des routiers occidentaux $^{66}$. Les Baltes qui acceptent de servir l'Ordre teutonique se voient offrir des fiefs en Prusse ou d'importantes terres en Lituanie une fois le pays conquis ${ }^{67}$, mais sont également motivés par le code d'honneur traditionnel, qui glorifie le devoir de vengeance - les raids menés par les hommes du grand-duc sur les terres de leurs ancêtres ne devaient pas rester impunis ${ }^{68}$.

Naturellement, les œuvres littéraires françaises ou anglaises ne font référence qu'aux rèses où les hôtes s'illustrent. Une atmosphère de violence se dégage alors de bien des textes; l'apogée du genre est sans doute due au héraut d'armes du duc Albert III d'Autriche, Pierre Suchenwirt, qui prit part à la rèse de son patron en 1377. La critique a remarqué le ton très violent de son poème Von Herzog Albrechts Ritterschaft, dans lequel les Lituaniens sont assimilés à des renards et des lapins que l'on chasse, ou à des bêtes sauvages qui attaquent hommes et chevaux avant de se réfugier dans des marais. Le massacre, la capture et l'humiliation de ceux-ci, femmes et enfants compris, sont décrits d'un ton épique et avec un cruel souci du détail ${ }^{69}$. Nos auteurs français et anglais se complaisent moins volontiers dans le morbide, mais le ton général de leurs œuvres laisse entendre à quoi avaient droit les païens qui croisaient la route de l'armée chrétienne. Ainsi, la biographie de Boucicaut, relatant la rèse de l'été 1391: "ilz estoient bien.CC.M. chevaulx qui tous passerent ou royaume de Lectho, où ilz firent grant destruccion de Sarrasins, et y pristrent par force et de bel assault plusieurs fors chastiaulx» ${ }^{70}$. L'histoire des princes de Deols, seigneurs de ChasteauRaoulx de Jean de la Gogue (v. 1422) fait allusion à une expédition menée en hiver 1377-1378 par Guy II de Chauvigny, qui bataillait en Italie «et puis bien peu après il entendist dire, qu'aulcuns seigneurs de chrestienté faisoient assemblée pour aller sur les Sarrazins», sans doute en Prusse ${ }^{71}$. Ayant reçu la bénédiction de son parent, le pape Grégoire XI, et rassemblé "une moult belle compaignie

in der Zeit der Kalmarer Union, 1397-1521 (Ordines militares. Colloquia Torunensia Historica X), éd. Z. H. Nowak, R. Czaja, Toruń, 1999, p. 193-208.

66 S. C. Rowell, Lithuania Ascending..., p. 245-246.

${ }^{67}$ Ibid., p. 201-202. Par exemple, Quellen..., doc. 17, p. 130-131.

${ }_{68}$ W. Urban, The Samogitian Crusade..., p. 56, 66-67.

${ }^{69}$ Pierre Suchenwirt, Von Herzog..., en particulier les v. 256-262, 308-312, 363-367, SRP 2, p. 165-166. Pour un commentaire, W. Paravicini, "Litauer...», p. 254; S. VAnder Elst, "Chivalry...», p. 320-327; H. Birkhan, «Les croisades contre les païens de Lituanie et de Prusse: idéologie et réalité", dans D. Buschinger (dir.), La Croisade: réalités et fictions, Göppingen 1989, p. 40.

${ }^{70}$ Le Livre des Fais..., p. 77.

${ }^{71}$ L'éditeur de la chronique, A. Grillon des Chapelles, n'est pas parvenu à identifier la destination de Guy de Chauvigny et de ses gens; PR 1, p. 97, 108, considère qu'il s'agit d'une rèse contre les Lituaniens. Les Annales de Toruń mentionnent en 1378 un "filius fratris domini pape Gregorii XI» (SRP 3, p. 107), que W. Paravicini identifie comme Guy de Chauvigny, gendre de l'un des frères du dernier pape français (PR 1, p. 172). 
de noblesse et de gent de traict», le seigneur de Chauvigny et ses compagnons partirent de Naples pour l'Europe du Nord: «se firent compaignons d'armes et s'en allèrent sur le pas de [Prusse] où ils restèrent huit jours et destruisirent bien deux mille de celle gent ${ }^{72}$. Quant aux croisés qui accompagnent Henri de Derby en été 1390, la Chronique de Westminster nous dit qu'ils attaquèrent Vilnius "avec la volonté de la détruire de manière virile, par le fer et le feu»"

En règle générale, les rèses se résument à de brutales parties de dévastation, où l'on cherche à briser le moral de l'adversaire, à détruire son économie et à prendre des prisonniers ${ }^{74}$. Toutefois, si l'occasion le permet, on en profite pour édifier un fort en territoire ennemi ${ }^{75}$; c'est ce à quoi a assisté Boucicaut en 1391, événement également célébré dans les Annales de Toruñ ${ }^{76}$. Si l'on en croit l'auteur du Livre des fais du maréchal Boucicaut, le Français est à créditer au même titre que le grand-maître pour l'érection de ce château:

"par l'entremise de lui avec le hault maistre de Prusse, fu fondé et fait en cellui pays de Sarrasins, ou royaume de Lectho [Lituanie], malgré leurs ennemis et a force, un fort et bel chastel en une isle, et nommerent le dit chastel en françois "le Chastel des chevaliers", et demourerent sur le lieu le dit hault maistre et Boucicaut accompaignez de belle compaignie de gens d'armes, pour garder la place tant que il fust achevé. " 77

De même, l'aide apportée par l'informateur de Cabaret d'Orville, Jean de Chastelmorand, et ses compagnons, permet non pas de construire, mais de conquérir un château, que l'on peut éventuellement identifier avec la forteresse de Trakai en Lituanie ${ }^{78}$ : «le hault maistre de Prusse, par le secours des chevaliers et autres nobles hommes de plusieurs nations qu'il avoit en sa compaignie, se porta si vaillamment qu'il conquist le chastel d'Endrach sur eulx [les Lituaniens], et les chassièrent es grans fourets de Prusse» ${ }^{79}$.

Une autre méthode utilisée pour marquer l'emprise de l'Ordre sur le territoire et tenir en respect les païens est d'exiger d'eux serments et otages, en

\footnotetext{
72 Jean de la Gogue, Histoire des princes de Deols, seigneurs de Chasteau-Raoulx, éd. A. Grillon des Chapelles, dans Esquisses biographiques du département de l'Indre, Paris, éd. B. Duprat, 2éd., 1865, vol. 3, p. 405.

73 Westminster, p. 446.

74 PR 2, p. 56-59; F. Benninghoven, «Zur Technik...», p. 631-651.

75 PR 2, p. 59-64.

${ }^{76}$ SRP, 3, p. 172. Il s'agit du château appelé Ritterswerder, près de Kaunas: S. Gouguenheim, Les Chevaliers teutoniques..., p. 584.

77 Le Livre des Fais..., p. 77; PR 2, p. 64; S. Gouguenheim, Les Chevaliers teutoniques..., p. 584.

${ }^{78}$ Ibid., p. 585, remarque que les Annales de Toruń signalent la prise de Trakai en août 1391

(SRP 3, p. 172), soit l'année où il situe la rèse à laquelle Jean de Chastelmorand et ses compagnons ont pris part. Nous avons vu que d'autres éléments parlent pour la rèse d'hiver 1375, notamment la prise d'un "castrum principale Drakin Kinstuti principis Litwanorum fratris regis» mentionnée dans une lettre de Winrich de Kniprode (Lucas David, Preussische Chronik..., vol. 7, p. 129).

${ }^{79}$ Chazaud, p. 64.
} 
général choisis parmi la famille des nobles. Ainsi, la Chronique de Metz raconte comment se clôt la rèse de l'hiver 1400, lancée contre les Samogitiens, habitants récalcitrants de la dernière province païenne de Lituanie laissée par traité à $l^{\prime} O r d r e$ teutonique ${ }^{80}$ : «Et quant ilz [les Samogitiens] se sentont ainsi promonez, ilz vinxent a obeysance permey ce qu'ilz debvoient avoir leur femez et enffens qui estoient prins et donnont seuretei d'estre en obeyxance " ${ }^{81}$. La pratique est évoquée dans certains traités passés entre l'Ordre teutonique et les princes lituaniens ${ }^{82}$, mais aussi par le chroniqueur prussien Jean de Posilge, notamment à la fin de la rèse dont il est question dans la Chronique de Metz ${ }^{83}$. Le motif est avant tout politique, mais il peut déboucher sur un début d'évangélisation. Posilge raconte ainsi que l'an suivant, en 1401, les "meilleurs boyards de la terre de Samogitie» ont reçu le baptême avec leur famille à Marienbourg et que leurs enfants ont été gardés comme otages ${ }^{84}$. L'auteur de la Chronique de Metz précise pour sa part qu'à la fin de l'expédition, les vaincus acceptent de livrer leurs femmes et leurs enfants, mais le thème de la déportation apparaît également lorsqu'il résume le déroulement de la rèse: "Et en celle rotte estoit le dit duc de Lorraine qui fuit fait chevalier et ciaulx de Metz, et disoit on qu'ilz avoient bien destruictz LX luez de payx de longe et XL de lairge et y ot IIIm et Vc villez arses et destruitez et d'omes et de femes et d'enffans prins sens nombre; car lesdis Salmaite volxent combatre les Crestiens» ${ }^{85}$. Rien ne permet de dire que ces "ommes, femes et enffans" soient uniquement les otages dont il est fait mention juste après, et rien ne dit qu'ils ont été pris dans le but d'être baptisés; quand bien même Jacques d'Esch l'eût su, il n'a pas daigné le noter.

À l'inverse, la dernière phrase permet d'en savoir plus sur la manière dont les expéditions contre les Lituaniens étaient perçues. La capture des prisonniers, peut-être destinés à travailler pour le compte de l'Ordre ${ }^{86}$, est présentée par l'auteur messin comme un acte de répression, justifié du fait que les Samogitiens envisageaient de combattre les chrétiens. La seule intention supposément

\footnotetext{
${ }^{80}$ Le grand-duc Vytautas et le roi de Pologne Jagellon, cousin et suzerain de celui-ci, acceptent de laisser la Samogitie à l'Ordre teutonique par le traité de Salynas/Sallinwerder, en 1398: Die Staatsverträge des Deutschen Ordens in Preußen im 15. Jahrhundert, éd. E. Weise, vol. 1, Königsberg 1939, doc. 1-3, p. 7-13.

${ }^{81}$ Wolfram, p. 337.

82 Par exemple, le traité de Racianz (1404) : Die Staatsverträge..., vol. 1, doc. 23, p. 32.

${ }^{83}$ Jean de Posilge, Chronique..., SRP 3, p. 236. Sur la prise d'otage pour valider les serments passés entre l'Ordre teutonique et les représentants des Samogitiens, R. Petrauskas, "Litauen...», p. 245; L. Chollet, «Vom Friedenverträgen bis zum Konzil von Konstanz: Schemaiten und die Rechtliche Stellung von Heidnischen Völkern », dans A. Bues et al. (dir.), Od traktatu kaliskiego do pokoju oliwskiego/ Vom Frieden von Kalisch bis zum Frieden von Oliva, Varsovie 2014, p. 227-240.

${ }^{84}$ Jean de Posilge, Chronique..., SRP 3, p. 240.

85 Wolfram, p. 337. La même rèse est relatée dans les Annales de Toruń (SRP 3, p. 235-236) et par Jean de Posilge (ibid.).

${ }^{86}$ R. Petrauskas, "Litauen...», p. 243; PR 2, p. 99-105; S. Ekdahl, "Treatment...», p. 263-269.
} 
belliqueuse de ceux-ci suffit comme casus belli; dans le même ordre d'idée, la Chronique du bon duc Loys de Bourbon nous apprend que Jean de Chastelmorand et ses compagnons «estoient venus si bien à point que merveilles. Car le roi de Letho, sarrasin, avoit fort emprins de grever et conquester l'ordre de Prusse» ${ }^{87}$. La rèse serait donc, dans ces deux cas, une vengeance, ou une contre-attaque visant à briser l'élan guerrier des païens. La limite entre offensive et légitime défense est floue ${ }^{88}$.

Nous savons que la protection des chrétiens était l'une des grandes causes justifiant la croisade balte au moins depuis Bernard de Clairvaux ${ }^{89}$. De ce fait, souligner que les héros dont on loue les mérites participaient à protéger ou à venger des chrétiens supposément menacés renforce la gloire qu'ils étaient allés chercher en Prusse. Du reste, la volonté de légitimation ne s'arrête pas aux seules actions intentées contre des non-chrétiens, puisque le biographe de Boucicaut, «fidèle» de la croisade balte, note que celui-ci ne prend part qu'à des guerres justes; or on sait que l'homme n'a pas hésité à affronter de nombreux chrétiens, ne fussent-ils que les ennemis du roi de France ${ }^{90}$.

Ainsi, les rèses ont souvent été décrites comme des sortes de jeux où les croisés "chassent» le païen sans prendre trop de risques ${ }^{91}$. À cet égard, l'extrait d'un "guide de Lituanie» destiné aux armées de croisés montre que l'Ordre planifiait avec sérieux les expéditions auxquels se joignaient les hôtes ${ }^{92}$, mais ne laisse aucun doute quant à leur but: «le pays, bien peuplé, est propre à être dévasté " ${ }^{93}$. Cette impression est toutefois à nuancer, car c'est bien d'une guerre qu'il s'agissait, et plusieurs chevaliers occidentaux ne sont pas revenus de Prusse, que ce soit à cause des attaques lituaniennes ou des dangers qu'impliquent le terrain et les conditions climatiques rigoureuses ${ }^{94}$. La mention par Froissart de deux Hennuyers morts lors de la rèse où Raoul de Gruyère fut adoubé est là pour nous rappeler que l'aventure était loin d'être dénuée de péril ${ }^{95}$.

\footnotetext{
87 Chazaud, p. 64.

${ }^{88}$ Sur ce point, R. MažEIKa, "Violent Victims...", p. 123-137.

${ }^{89}$ M. ТАмM, «How to justify...», p. 437-440.

90 J. РАViot, "Boucicaut et la croisade...", p. 77, 81.

${ }^{91}$ Par exemple: "[participer aux rèses] permettait de "se maintenir en forme" dans "une espèce de chasse à l'homme"”, M. Rodinson, La fascination..., p. 172, qui cite D. Cantimori et E. Sestan, "Teutonico (ordine) ", Enciclopedia Italiana, t. 33, 1937, p. 749 et Eidem, «Prussia», Enciclopedia Italiana ..., t. 28,1935 . L'idée de la rèse comme chasse se retrouve notamment dans le poème de Pierre Suchenwirt; H. BirKHAN, «Les croisades contre les païens...», p. 40.

92 S. C. Rowell, Lithuania Ascending..., p. 245.

93 SRP 2, p. 679, cité par S. Gouguenheim, Les Chevaliers teutoniques..., p. 579.

94 W. Paravicini, "La Prusse...", p. 180-181; PR 2, p. 110-116; sur les chevaliers morts en Prusse, Ibid., p. 116-122.

95 "Et depuis, l'année apriès [1381], le fu il en Prusse; et eurent adonc li crestiien rèse: che fu adonc quant li sires de Mastaing et Jehans d'Obies et li aultre de Hainnau i demorèrent ", Jean Froissart, Chroniques..., éd. G. Raynaud, vol. 9, p. 264; l'édition de Kervyn propose la variante: «et maint autre noble homme de Haynaut y furent occis", Jean Froissart, Chroniques..., éd. J. Kervyn de Lettenhove, vol. 9, p. 267, n. 14-15; PR 1, p. 86, n. 335. Sur Mastaing et Jean d'Obies, PR 1, p. 78.
} 
Des Anglais sont également tombés lors de ces expéditions, comme le dénommé John Loudham, compagnon de Bolingbroke tué pendant la bataille que livrent les croisés contre le prince lituanien Skirgaila sur les bords du Niémen, en été $1390^{96}$. En outre, quelques procès concernant le port d'armoiries engagés devant la Cour de Chevalerie du roi d'Angleterre Richard II font état de chevaliers morts en Prusse. Prenons le cas qui oppose la famille Scrope à celle des Grosvernors en 1386: l'un des arguments est fourni par l'histoire de Geoffrey Scrope de Masham, dont plusieurs témoins disent avoir vu la tombe dans la cathédrale de Königsberg, et sont à même de raconter sa fin, en avril 1363 lors de la prise de Veliuona, une forteresse située sur le Niémen"7. Ainsi, l'écuyer John de Rither: "mons. Geffray Lescrop alast en la compaignie dez chivalers en Pruce \& la a une reise a la saute de Wellon en Leitowe estoit mort en cez armez ${ }^{98}$. D'après Maurice Keen, la mort de ces hommes tombés contre les ennemis de la foi aurait été entourée d'un respect particulier ${ }^{99}$; moins grave bien sûr, mais tout de même digne d'être noté, Guillebert de Lannoy dit avoir été blessé par un carreau d'arbalète lors de l'assaut sur la ville de Polleur ${ }^{100}$, où il fut adoubé par un membre de l'Ordre teutonique ${ }^{101}$.

Du reste, la guerre contre les Lituaniens n'est pas le propre des Teutoniques et de leurs hôtes. Au milieu du XIv ${ }^{e}$ siècle, les principautés ruthènes de Galicie et de Volhynie excitent l'appétit des voisins polonais, hongrois et lituaniens ${ }^{102}$. En 1349, le roi Casimir III de Pologne conquiert la première, alors que la seconde passe sous la suzeraineté lituanienne, ce qui sera une véritable pomme de discorde jusqu'au rapprochement entre les deux pays en $1387^{103}$. Casimir lance alors plusieurs campagnes soutenues par des bulles de croisade contre les

\footnotetext{
96 Westminster, p. 446; la mort d'un certain « miles Johannes de Lutam» est également mentionnée par Wigand de Marbourg (Chronica..., SRP 2, p. 643), mais située lors de l'assaut contre Vilnius qui a suivi cette première bataille; PR 1, p. 125; pour quelques autres cas, Ibid., 2, p. 117-118. ${ }_{97}$ Voir Hermann de Wartberge, Chronicon Livoniae..., SRP 2, p. 84; Wigand de Marbourg, Chronica..., SRP 2, p. 539, 545-547; PR 1, p. 120, n. 511.

98 Témoignage non daté, dans N. H. Nicolas (éd.), The controversy between Sir Richard Scrope and Sir Robert Grosvenor, Londres 1832, p. 146, cité par PR 1, p. 120.

${ }_{99}$ M. Keen, Chivalry..., 1985, p. 195.

100 Potvin, p. 26: d'après J. Svátek, Discours..., p. 212, il pourrait s'agir soit de Płoty (Plathe en allemand), près de Maszewo, en Poméranie, soit de Pułtusk, en Mazovie.

101 "Auquel assault me fut donné l'ordre de chevallerie par la main d'un noble chevallier nommé le Ruffe de Palleu, et eus illecq le bras perchié d'un vireton très durement», Potvin, p. 27. Le personnage nommé Ruffe ou Russe (variante dans le ms. de Lannoy) de Palleu peut être identifié avec un membre de la famille Reuss de Plauen, dont plusieurs représentants étaient membres de l'Ordre teutonique et actifs en Prusse: J. Svátek, Discours, p. 212.

$102 \mathrm{~J}$. Wyrozumski, "The East and the West in the Politics of Casimir the Great", dans J. Kıoczowski, H. Łaszkiewicz (dirs.), East-Central Europe, p. 193-203; D. Beauvois, "Les controverses...", p. 650-651.

${ }^{103}$ F. Dvornik, Les Slaves..., p. 544.
} 
Lituaniens, ce qui renforce l'identification de son royaume à un "antemurale Christianitatis», barrage contre les païens et autres schismatiques ${ }^{104}$.

Même s'ils peuvent être des alliés occasionnels contre l'Ordre teutonique ${ }^{105}$, voire des partenaires, comme les négociations visant le baptême le prouvent, les païens lituaniens restent dépeints comme des guerriers implacables par les chroniqueurs polonais ${ }^{106}$. Et dans ce «jeu à trois» ${ }^{107}$, la Pologne n'a pas que ses voisins infidèles à craindre. En 1331, le roi Ladislas le Bref défait les Teutoniques à la bataille de Płowce; parmi les hôtes de ceux-ci se trouvait "Thomas d'Ufford, un comte d'Angleterre, qui peu de temps auparavant, était venu avec cent lances aider l'Ordre contre les mécréants" ${ }^{108}$. Le chroniqueur semble presque oublier que si le roi polonais était à cette époque un allié des Lituaniens, son pays était tout de même chrétien depuis trois siècles et demi ${ }^{109}$.

Même après la conversion de la Lituanie au catholicisme en 1386, certains croisés occidentaux se trouvent mêlés à la rivalité polono-teutonique. C'est le cas de Guillebert de Lannoy, qui dans ses Voyages et ambassades, affirme être parti en mars 1413 "pour aller en Prusse contre les mescréans en une armée que faisoient les seigneurs de Prusse ${ }^{110}$. Après avoir patienté un certain temps, "pour ce que la rese de Prusse n'estoit point preste» ${ }^{111}$, il apprend que "que les seigneurs de Prusse feroient rèse, sur l'esté, sur le roy de Poulane et sur le duc de Pomère qui favorisoient les Sarrasins " ${ }^{12}$. Autrement dit, il s'agit d'attaquer le roi Ladislas Jagellon de Pologne et l'un de ses alliés, ici vraisemblablement Bogusław VIII de Słupsk, duc de Poméranie ${ }^{113}$. Guillebert poursuit son récit:

"Et m'en alay avecq eulz en armes parmy les forestz de Prusse, l'espace de huit jours, costiant les frontières de Poulane, entrèrent à puissance en la duché de Pomère où ils furent quatre jours et quatre nuitz, ardirent bien cincquante villes à clocquiers et prindrent proye de bestial grant nombre. " ${ }^{114}$

\footnotetext{
${ }^{104}$ P. Knoll, The Rise..., p. 174-177; N. Housley, The Avignon Papacy..., p. 66-70.

105 Ibid., p. 277-278.

106 Jan Długosz, Annales IX, dans Opera Omnia..., vol. 12, p. 246.

107 N. Housley, The Avignon Papacy..., p. 278.

108 Wigand de Marbourg, Chronica..., SRP 2, p. 483.

109 PR 1, p. 27, 178.

110 Potvin, p. 20. Guillebert lui-même situe son départ au printemps 1412, ce qui placerait sa première aventure balte en 1412-1413; or, celle-ci doit avoir eu lieu en 1413-1414: E. GACHET, Examen critique des Voyages et ambassades de Ghillebert de Lannoy, Bruxelles 1843, p. 14-15;

M. Holban, «Du caractère...», p. 420.

${ }_{111}$ Potvin, p. 23.

112 Ibid., p. 26. Pour l'historien lituanien P. Klimas (Ghillebert de Lannoy in medieval Lithuania, New York 1945, p. 52), la décision d'attaquer les vassaux et alliés du roi de Pologne indiqueraient que les Teutoniques n'osaient pas s'en prendre directement à Vytautas, trop puissant.

113 J. Zdrenka, Polityka Zagraniczna Ksiazzat Szczecińskich w Latach 1295-1411, Słupsk 1985,

p. 264; G. Bєaszczyк, Dzieje Stosunków Polskich-Litewskich. Tom II, Od Krewa do Lublina, Poznań 2007, p. 479.

114 Potvin, p. 26.
} 
Le nombre de villages brûlés est certes exagéré115, mais l'opération est menée comme s'il s'était agi de païens, dans le même style que celles auxquels Jacques d'Esch ou Boucicaut ont pris part. Comme le montre bien Jaroslav Svátek, l'utilisation de verbes conjugués à la première puis soudain à la troisième personne du pluriel peut indiquer que Guillebert prend une certaine distance avec le comportement des troupes teutoniques ${ }^{116}$; ce qui pourrait rejoindre l'avis de l'historien polonais Oskar Halecki, pour qui le Bourguignon regrette d'avoir dû se battre contre des chrétiens ${ }^{117}$. Le style dépouillé et le ton neutre du texte interdisent d'en dire plus, mais la précision que l'on attaque des princes chrétiens "qui favorisoient les Sarrasins" ne manque pas d'intérêt. Cette remarque, que l'on imagine entendue de la bouche des Teutoniques et rapportée de mémoire, peut être rapprochée d'autres textes produits dans des contextes proches du voyage en Prusse.

En rentrant de l'expédition menée en 1390 contre Mahdia, le duc Louis de Bourbon cherchait à compenser le relatif insuccès de l'opération; son biographe, Jean Cabaret d'Orville, nous apprend que le capitaine génois lui suggéra que "le chastel de Caillé [Cagliari?]", en Sardaigne, ferait une proie honnête, car ses habitants commercent avec les Tunisiens ${ }^{118}$. Norman Housley rapproche les arguments des Chevaliers teutoniques rapportés par Lannoy de ceux que les Génois auraient soufflés au duc de Bourbon ${ }^{119}$. Ce qui fait dire à l'historien britannique que "ceux qui se sont engagés dans une croisade par impulsion chevaleresque n'avaient que peu de compréhension ou d'intérêt pour les régions dans lesquelles ils se battent» ${ }^{120}$. Une impression qui semble en tout cas valable dans le cas de Philippe d'Artois, comte d'Eu, qui est, comme une bonne partie des participants à l'expédition de Mahdia, un ancien croisé de Prusse, où il s'est rendu lors de l'hiver 1387-1388 121 . En 1393, ce prince de sang répond à une invitation du roi de Hongrie Sigismond de Luxembourg, qui essayait d'organiser une croisade pour défendre son pays contre les Turcs Ottomans. Voici comment Michel Pintoin, l'auteur de la Chronique du Religieux de Saint-Denis, présente l'affaire:

"Pendant que la trêve conclue entre la France et l'Angleterre durait encore, monseigneur Philippe d'Artois, comte d'Eu, cousin du roi de France et connétable du royaume, ne voulant pas que l'éclat de sa valeur s'éclipsât au sein du repos,

\footnotetext{
115 Ibid., p. 26, n. 7, qui cite Guillebert de Lannoy, Guillebert de Lannoy et ses voyages en 1413, 1414 et 1421, éd. J. Lelewel, Poznań-Bruxelles 1844.

116 J. Svátek, Discours..., p. 232-233.

117 O. Halecki, "Gilbert de Lannoy...", p. 318.

118 Chazaud, p. 251-252; N. HousLey, The Later Crusades..., p. 401-402.

119 Id.

${ }^{120}$ Ibid, p. 402.

${ }^{121}$ PR 1, p. 98.
} 
avait résolu d'aller porter secours au roi de Hongrie, qui était vivement pressé par les Turcs et leur chef Lamorat. ${ }^{122}$

Philippe d'Artois parvient à convaincre le roi Charles VI, qui était d'abord réticent à le laisser quitter le royaume; enfin, il part pour la Hongrie à la tête d'une troupe de chevaliers, d'arbalétriers et de fantassins. Une fois arrivés, les Français "n'eurent aucune occasion de signaler leur valeur, ainsi qu'ils l'avaient longtemps désiré» ${ }^{123}$. La raison avancée par le chroniqueur fait honneur à la réputation des armes françaises, mais semble avoir plongé le roi Sigismond dans un certain désarroi :

"Le roi des Turcs avait été, dit-on, instruit de l'approche des Français, et comme il croyait que le roi de France commandait en personne l'expédition, il s'était retiré après avoir vaincu les Hongrois, et était allé lever de nouvelles forces pour résister à l'ennemi.

Le roi de Hongrie vit avec peine la retraite des barbares. Après avoir fait le plus brillant accueil aux Français et aux auxiliaires des autres pays, et les avoir comblés de présents, il songea à leur fournir l'occasion de combattre, et leur conseilla de tourner leurs forces contre le royaume de Bohême [lat: in regnum Boecie] qui confinait au sien. Voici le motif qui le poussait à entreprendre cette guerre. Le roi de Bohême [sic] et ses sujets, qui étaient chrétiens, mais qu'on appelait Patarins, parce qu'ils ne pratiquaient pas toutes les observances de la religion chrétienne, refusaient de reconnaître sa souveraineté. Voulant donc les soumettre par la force des armes, le roi de Hongrie fit partir en avant le connétable avec ses Français, et ne tarda pas à le suivre lui-même avec le reste de ses troupes. ${ }^{124}$

S'en suit une dévastation du pays et la soumission du roi "patarin", c'està-dire hérétique. Contrairement à ce que laisse penser la traduction française reprise par l'éditeur de la chronique, Michel Pintoin ne se référait probablement pas à la Bohême (Boemia en latin); en 1393, le royaume tchèque n'avait rien d'hérétique. Jan Vojtíšek a identifié le Boecia du texte latin comme étant la Bosnie, ce qui, en tenant compte du contexte historique, fait bien plus de sens ${ }^{125}$. Le roi qualifié d'hérétique serait alors Stjepan Dabiša, roi de Bosnie à partir de 1391 et grand rival politique de la Hongrie pour le contrôle des Balkans occidentaux. La Bosnie abritant une importante population bogomile

122 Chronique du religieux de Saint-Denis, vol. 2, éd. et trad. L. Bellaguet, Paris 1840 (ci-après: Bellaguet), p. 123.

${ }_{123}$ Id.

124 Ibid., p. 123-125.

125 Déjà au $\mathrm{Xv}^{\mathrm{e}}$ siècle, les traductions françaises de la chronique rendaient «Bohême» pour Boecia, sans doute sous l'influence de la crise hussite, mouvement hérétique s'étant imposé en Bohême dans les années 1420. Je remercie J. Vojtíšek d'avoir bien voulu partager les premiers résultats de sa recherche avec moi et M. Nejedlý d'avoir attiré mon attention sur ce point. 
qualifiée d'hérétique par l'Église catholique ${ }^{126}$, Sigismond a utilisé ce prétexte pour attaquer victorieusement ce pays au début de l'année 1394. Il y a fort à parier que les Français mentionnés par Pintoin comme partant en croisade à la fin l'année précédente ont effectivement participé à ce raid.

Deux éléments ressortent de cet extrait: d'une part que, les Turcs s'étant retirés, le roi de Hongrie devait donner à ses hôtes l'occasion de s'illustrer ailleurs, et d'autre part, que les sujets du roi de Bosnie qualifiés de rebelles et d'hérétiques devenaient des cibles légitimes, tout comme les Sardes dans la Chronique du bon duc Loys de Bourbon et les Polonais de Guillebert de Lannoy. Peut-on en déduire qu'il suffisait au promoteur d'une croisade d'accuser n'importe quel rival chrétien de sentir l'hérésie ou d'être trop proche des "Sarrasins" pour autoriser les armées chrétiennes à ravager ses terres à bon droit?

Une comparaison avec les descriptions d'assauts menés dans d'autres contextes, au cœur de l'Europe occidentale, nous invite à la prudence ${ }^{127}$. Certes, une solidarité entre anciens croisés est attestée par quelques sources narratives. Ainsi en est-il de cet épisode de la guerre de succession de Bretagne raconté par Froissart. En été 1341, le comte de Montfort met le siège devant une citadelle près de Landerneau:

"Chils qui chastelains en estoit, veoit que li contes avoit grant host et que tous li pays se rendoit à lui, siques par l'enhort et le conseil monsigneur Hervi de Lyon, avoech qui il avoit estet grans compains en Grenate et en Prusse et en aultres estragnes contrées, il s'acorda au dit conte et li fist féaulté, et demora gardyens del dit chastiel de par le conte. ${ }^{128}$

Froissart suit ici le chroniqueur liégeois Jean le Bel, qui rapporte un autre cas où le connétable de France Raoul de Brienne et le seigneur Jean de Tancarville, perchés sur les murailles de Caen, reconnaissent parmi les assiégeants anglais un ancien compagnon de Prusse:

"Ainsy qu'ilz regardoient en grand paour ces gens tuer, ilz perchurent ung gentil chevalier qui n'avoit que ung oeul, qu'on appelloit messire Thomas de Holande, et V ou VI bons baceliers avecques luy qui avoient aultres foys compaignié et veu l'ung l'aultre en pluseurs chevauchiers en Prusse, en

${ }^{126}$ Les «hérétiques» de Bosnie était souvent appelés patarins, un terme qui s'appliquait à tous les supposés hérétiques dualistes: F. Conte, Les Slaves..., p. 593-594; P.-L. Thomas, «L'Église médiévale de Bosnie était-elle dualiste?», Slavica occitania 16, 2003, p. 113-131.

127 Rappelons que des accords pouvaient être conclus entre chrétiens et «infidèles», comme celui que mentionne Jean Cabaret d'Orville (Chazaud, p. 65). Voir T. Lassabatère, "Théorie et éthique...", p. 39.

${ }_{128}$ Jean Froissart, Chroniques..., éd. J. Kervyn de Lettenhove, vol. 3, p. 369 ; ce passage est repris de Jean le Bel, Chronique, éd. J. Viard, E. Déprez, Paris 1904, vol. 1, p. 258, qui ne mentionne toutefois que la "Guernade», et non la Prusse. PR 1, p. 311. Pour d'autres exemples, ibid., p. 310-313. 
Grenade et en aultre part. Si les appellerent et leur dirent en priant: "Ha! pour Dieu, seigneurs chevaliers, venez à mont, et nous deffendez des gens sans pitié qui nous tueront s'ilz nous tiennent ainsy que les aultres". Quant les entendi messire Thomas et il les recongnut, il en fut moult joyeux; aussy furent les aultres compaignons et monterent en la porte jusques à eulx, et ledit connestable et le chambellan qui là estoient retrais se rendirent prisonniers, et ledit messire Thomas et ses compaignons les recheurent voulentiers et se penerent de les garder, et puis mirent bonnes gardes entour eulx affin que on ne leur fist mal. $»^{129}$

Peut-être faut-il lier à ces épisodes la fraternité d'armes conclue lors de la rèse de l'hiver 1377-1378 entre Guy II de Chauvigny, seigneur de Châteauroux, et le duc Jean ${ }^{\text {er }}$ de Lorraine ${ }^{130}$. La participation commune aux expéditions contre l'infidèle favorise le respect et l'amitié entre seigneurs chrétiens, ce qui peut avoir une implication dans la manière de mener la guerre au pays. Néanmoins, nous avons aussi vu qu'en Prusse, les relations entre croisés issus de partis opposés peuvent être entachées de violence. Et la guerre en Occident n'est pas moins rude, au point que la bonne fortune des seigneurs ayant été reconnus par leurs adversaires ressort comme une notable exception dans un univers généralement caractérisé par une extrême brutalité.

À en croire les témoignages, la campagne menée en 1324 par Jean de Luxembourg et ses alliés contre la ville de Metz ne devait pas être bien différente de la rèse lituanienne que raconte Guillaume de Machaut. Le poème anonyme La Guerre de Metz relate que les armées des princes ligués contre la ville pillent l'abbaye de Sainte-Croix, et manquent de peu de la brûler; une chance que n'ont pas les bourgs et manoirs environnants ${ }^{131}$. Incendier les villages, détruire les récoltes et prendre les chevaux ou le bétail faisait partie des activités habituelles des guerriers du Moyen Âge ${ }^{132}$. Guillebert de Lannoy note que lors de la campagne menée par Guillaume de Bavière contre Liège, où il fit ses premières armes, "y eut, de ceste armée de six à sept cens villaiges brulez oudit païs de Liège» ${ }^{133}$.

Dans leur effort de moraliser la chevalerie, les écrivains proches du trône de France se montrent très critiques envers ces exactions; celles-ci seraient, dit-on, le fait de "guerres mortelles», par opposition aux «bonnes guerres»,

\footnotetext{
129 Jean le Bel, Chronique... vol. 2, p. 58. Voir aussi Jean Froissart, Chroniques..., éd. J. Kervyn de Lettenhove, vol. 4, p. 406-407; PR 1, p. 311.

${ }_{130}$ PR 1, p. 310 ; PR 4, doc. 29 (à paraître).

131 La Guerre de Metz..., p. 172-173; T. De Puymaigre, «Jean l'Aveugle et la France...», p. 416.

132 C. TaYlor, Chivalry..., p. 207-212. La capture des chevaux est mentionnée par Guillebert de Lannoy, Potvin, p. 19. Pour d'autres cas, G. Guerrie Dall'oro, «Les mercenaires dans les campagnes napolitaines de Louis le Grand, roi de Hongrie, 1347-1350", dans J. FranCE (éd.), Mercenaries and Paid Men. The Mercenary Identity in the Middle Ages, Leiden, 2008, p. 61-88. 133 Potvin, p. 13.
} 
aux "guerres loyales»" ${ }^{134}$. Michel Pintoin, l'auteur de la Chronique du religieux de Saint-Denis, semble même considérer que la destruction des terres ennemies ne ferait pas partie des mours françaises; ainsi, lorsqu'il dit qu'en 1392, "le vaillant comte de Saint-Pol était entré en Allemagne à la tête d'un corps nombreux de Français, et il courait le pays à la manière des Allemands, mettant tout à feu et à sang sur son passage, et commettant les plus grands dégâts sur les terres de Wencleslas, roi de Bohême» ${ }^{135}$; plus loin, le même chroniqueur raconte qu'en 1407, le duc de Lorraine se porta au secours de la ville de Metz, attaquée par des chevaliers allemands: "Le duc rassembla une troupe nombreuse et mit à feu et à sang les terres de l'ennemi; car c'est ainsi qu'on fait la guerre en ce pays»" ${ }^{136}$. Si les institutions étatiques françaises parviennent à limiter, dans une certaine mesure, les ravages causés à l'intérieur du royaume par les guerres privées ${ }^{137}$, les troubles de la guerre de Cent Ans et surtout de la longue querelle des Armagnacs et des Bourguignons laissent le champ libre aux aventuriers de toute sorte ${ }^{138}$. Ceux qui, à l'image des routiers désœuvrés, pillent et désobéissent à leur roi, sont perçus de manière particulièrement négative, car leurs faits d'armes ne visent pas la protection du royaume mais l'enrichissement personnel ${ }^{139}$. Exemple parmi d'autres, Jean Cabaret d'Orville nous raconte que Jean de Chastemorand, notre croisé de Prusse, a dû mettre fin aux exactions exercés par un écuyer savoyard du nom d'Amédée de Viry sur les terres du duc de Bourbon ${ }^{140}$. Michel Pintoin, qui relate les mêmes événements ${ }^{141}$, nous dit que Viry «courut le pays librement, ravageant tout sur son passage, comme un torrent impétueux, massacrant sans pitié tous les habitants, laboureurs ou autres, qu'il rencontrait, et n'épargnant ni l'âge, ni le sexe, ni le rang. En un mot, il mit tout à feu et à sang»" ${ }^{142}$. Contrairement aux rèses de Lituanie, ces faits sont présentés comme étant l'exception et non la règle en France; il ne s'agirait pas du comportement de chevaliers dignes de ce

\footnotetext{
${ }^{134}$ C. Taylor, Chivalry..., p. 212-227; P. Contamine, «L'idée de guerre à la fin du Moyen Âge; aspects juridiques et éthiques", Comptes rendus des séances de l'Académie des Inscriptions et BellesLettres, 123/1, 1979, p. 70-86.

135 Bellaguet, vol. 2, p. 40-41; Valéran de Luxembourg, comte de Saint Pol, était apparenté au roi Wenceslas de Bohême, avec qui il avait des différends en raison d'une dette impayée, nous dit Pintoin (ibid., p. 41); B. Schnerb, L'État bourguignon..., p. 91. Le même comte de Saint-Pol mena un raid sur l'île de Wight en 1403, où ses hommes "alèrent fuster aucuns meschans village du pays et bouter les feux en aucuns lieux» (Enguerrand de Monstrelet, Chronique: en deux livres, avec pièces justificatives: 1400-1444, éd. L. Douët d'Arcq, Paris 1857, vol. 1, p. 92; ci-après: Douët d'Arcq). 136 Bellaguet, vol. 3, p. 369. La pratique d'incendier les villages en Souabe et en Wurtemberg est mentionnée par P. Contamine, Azincourt, Paris 1964, p. 14.

${ }_{137}$ Par exemple, des tribunaux avaient été fondés pour régler les différends entre chevaliers; ibid., p. 103-132.

138 Bellaguet, vol. 4, p. 451-455; ibid., p. 513.

139 T. Lassabatère, "Théorie et éthique... ", p. 40-41.

140 Chazaud, p. 294-302.

${ }_{141}$ Bellaguet, vol. 4, p. 241-249.

${ }_{142}$ Ibid., vol. 4, p. 243.
} 
nom, mais de mercenaires et de soudards, dont la cruauté soulève le cœur d'un Michel Pintoin ${ }^{143}$.

À en croire nos chroniqueurs, les Anglais avaient bien moins de scrupules. À maints égards, les raids menés en France ressemblent beaucoup aux rèses; c'est la même méthode et le même objectif: "de grandes chevauchées dévastatrices qui ont pour but de ruiner économiquement l'adversaire et de le décourager moralement» ${ }^{144}$. Du moins, à lire Jean Juvénal des Ursins, autre chroniqueur français du règne de Charles VI, vers 1380, les Anglais, cherchant la "destruction totale» ${ }^{145}$ du royaume de France, n'agissent pas de manière bien différente des croisés de Prusse:

"Souuent venoient en armes d'Angleterre en France, \& aucunesfois descendoient en Guyenne, autresfois en Bretaigne, Normandie, Picadrie \& specialement vers les riuaiges de la mer, boutoient feu és maisons du plat pays, comme és grains, \& par tout où ils pounoient, prenoient prisonniers, \& les menoient en Angleterre, \& piteusement les traictoirent. ${ }^{146}$

La France serait ainsi une autre Lituanie, traitée par les Anglais de la même façon que celle-ci l'est par les Teutoniques et leurs hôtes occidentaux. Pourrait-on dire alors, avec Alan V. Murray, que la surreprésentation de Français parmi ces derniers s'explique par l'envie d'une noblesse en butte à la poussée anglaise de compenser son échec, ou de se rassurer, en allant combattre un ennemi moins "coriace» sous d'autres cieux ${ }^{147}$ ? L'hypothèse est séduisante ${ }^{148}$, mais l'on doit constater qu'un nombre important d'Anglais se rendaient également en Prusse en même temps que leurs pairs d'Outre-Manche ${ }^{149}$. William Urban va plus loin, en supposant que les habitudes de la soldatesque employée en France ont contribué à durcir la guerre en Lituanie ${ }^{150}$ : pourtant, à lire les témoignages de Machaut, de Dusbourg et de Wigand pour la première grande rèse internationale de 1329, les Teutoniques n’ont pas appris le massacre généralisé au seul contact de leurs hôtes anglais et français ${ }^{151}$ !

\footnotetext{
${ }^{143}$ Néanmoins, et malgré les nombreux plaidoyers visant à moraliser la chevalerie française et à discipliner les armées, il semble que les gens d'armes au service du roi de France ne se soient pas comportés de manière bien différente de leurs ennemis anglais, ou des troupes de l'Ordre teutonique en Lituanie; C. TAYLOR, Chivarly..., p. 208-213.

144 P. Contamine, Azincourt..., p. 49.

145 Jean Juvénal des Ursins, Histoire de Charles VI, éd. A. Pacard, Paris 1614, p. 2.

146 Id.

147 A. V. Murray, «Saracens...», p. 418. Voir PR 1, tableau 5, p. 94-101.

148 P. Contamine, Azincourt.., p. 49, constate que "pendant une génération, jusqu'en 1380, la caste militaire [française] n'ose plus heurter de front, en une bataille rangée, les quelques milliers de cavaliers exaltés et intrépides qui peuvent ainsi, tout à leur aise, traverser le royaume de part en part».

${ }_{149}$ PR 1, p. 123-17.

150 W. Urban, The Samogitian Crusade..., p. 122.

${ }^{151} \mathrm{Du}$ reste, la guerre menée au XIII ${ }^{\mathrm{e}}$ siècle contre les Prussiens n'était pas moins cruelle que celle menée en Lituanie au XIV ${ }^{e}$ siècle; S. Gouguenheim, "Les guerres des ordres militaires...", p. 292-297.
} 
Dans l'ensemble, on a l'impression que la guerre que l'on menait au cœur de l'Occident médiéval devait ressembler à celle qui faisait rage en Lituanie; lors de raids destructeurs, le respect du code d'honneur chevaleresque garantissait tout au plus un certain ménagement des combattants nobles ${ }^{152}$. Encore que ce ne fût pas toujours le cas, comme l'a appris à ses dépens Guillebert de Lannoy, capturé lors de la bataille d'Azincourt ${ }^{153}$. Le jeune chevalier, qui était rentré de son premier voyage balte l'année précédente, fait partie de ceux que le roi d'Angleterre, croyant à une réplique française, avait ordonné de mettre à $\operatorname{mort}^{154}$ :

"L'an mille quatre cens et quinse, fus en la bataille de Rousseauville [Azincourt] navré au genoul et en la teste et couchié avecq les mors, mais à les despoullier, je fus prins prisonnier et gardé par une espace et mené en une maison près de là avecq dix ou douse autres prisonniers, tous impotens. Et lors, à une rencharge que fist monseigneur le duc de Brabant, on crya que chascun tuast ses prisonniers, dont, pour avoir plus tost fait, on bouta le feu en la maison, où entre nous impotens estièmes. Mais, par la grâce de Dieu, je me trainay hors du feu à quatre piez, où je fus tant que les Anglés, noz ennemis, revindrent, où derechief fus prins et vendu à monseigneur de Cornuaille, cuidant que je fusse ung grant maistre, pour ce que, la Dieu mercy, j'estoye assez honnestement en point, quant je fus pris la première fois, selon le temps de lors. ${ }^{155}$

Ce récit illustre crûment le danger inhérent à la vie de guerrier, danger que Guillebert a connu à plusieurs reprises, notamment lors de ses voyages en Prusse et en Espagne ${ }^{156}$; il montre également que la mise à mort de prisonniers n'était pas réservée aux "mécréants ${ }^{157}$. Du reste, le code de l'honneur exigeant le respect de l'adversaire noble ne tarde pas à s'appliquer en Lituanie, où officiers teutoniques et ducs païens partagent plus en commun que ne peuvent le laisser penser les brèves descriptions de pillages que nous avons lues jusqu'ici.

\footnotetext{
152 PR 2, p. 56-59; P. Contamine, La Guerre au Moyen Âge..., p. 460-461.

153 Guillebert de Lannoy figure parmi les prisonniers selon Jean le Fèvre, seigneur de Saint-Remy (Chronique, éd. F. Morand, vol. 1, Paris 1876, p. 269); celui-ci, qui a vécu la bataille du côté anglais, dit s'appuyer sur les témoignages de Guillebert et de son frère Hugues pour établir la liste des tués et des prisonniers côtés français (Ibid., p. 268). Jean de Wavrin, Anchiennes cronicques d'Engleterre, éd. E. Dupont, vol. 1, Paris 1858, p. 200-201, se réfere également aux témoignages des frères de Lannoy de Lannoy, mais compte Hugues et non Guillebert parmi les prisonniers. Peut-être a-t-il simplement confondu les deux frères.

154 J. Favier, La Guerre de Cent Ans, Paris 1980, p. 442; D. Paladilhe, La bataille d'Azincourt, 1415, Paris 2002, p. 120-122; le massacre est raconté dans Jean le Fèvre, Chronique..., vol. 1, p. 258.

155 Potvin, p. 49-50.

156 J. Svátek, Discours..., p. 233-234; M. NejedlÝ, «Spisy...», p. 111.

157 Lorsque les circonstances l'exigeaient, les Teutoniques n'hésitaient pas à passer leurs prisonniers au fil de l'épée (S. EKDahl, "Treatment...», p. 265-266); un cas de figure dont se rapprocherait alors la décision d'Henri $\mathrm{V}$.
} 


\section{LES LITUANIENS ET LA CHEVALERIE OCCIDENTALE}

La guerre, aussi cruelle qu'elle puisse paraître dans nos sources narratives, n'était pas vue comme une fatalité inéluctable. C'est ce que remarque Jacques d'Esch, lui-même ancien croisé de Prusse et probable auteur de la Chronique de Metz, dans ce commentaire relatif aux trois princes les plus sages du monde:

"Coment le hault maistre de Prusse, que pour le temp estoit, et le roy Sidregal roy de Laitue en Sarasinem, lequel roy s'appelloit le boin roy Sidrega, et le dit empereur Charle avoient la renommee d'estre les III plus saiges princez du monde. Et nom obstant qu'ilz se faisoient ades guerre l'un l'autre, le dit roy de Laitue et le dit halt maistre, s'estoient il bien souvent [accordes] ensemble par esxurement et s'alloient veoir l'un l'autre en leur payx et se faisoient tres bonne chiere l'un l'autre tant comme ilz estoient en sorsceance. " 158

Cette image est passée dans la tradition historiographique messine, sans doute par l'intermédiaire de Jacques d'Esch, qui a pu apprendre en Prusse quels rapports le grand-maître de l'Ordre entretenait avec certains de ses adversaires ${ }^{159}$. Il nous est resté de nombreux traités passés entre l'Ordre teutonique et la Lituanie, surtout pour les dernières décennies du $\mathrm{XIV}^{\mathrm{e}}$ siècle; comme l'avait bien compris le chroniqueur messin, on pouvait établir des relations diplomatiques, même à l'époque où Vilnius était gouverné par des princes ouvertement païens ${ }^{160}$. Pour les membres de l'Ordre, les adversaires n'étaient pas que des infidèles amenés à être massacrés ou convertis; ils étaient aussi des pairs, avec qui l'on partageait un certain style de vie, une certaine façon de combattre ${ }^{161}$. L'historien lituanien Rymvidas Petrauskas remarque avec justesse que les récits des rèses tendent à occulter l'importance des relations personnelles entre nobles lituaniens et officiers teutoniques, qui comme partout ailleurs dans l'Europe médiévale, jouaient un rôle crucial en politique ${ }^{162}$, et dans le cas qui nous intéressent, permettent notamment de conclure des trêves ou des alliances occasionnelles ${ }^{163}$.

\footnotetext{
158 Wolfram, p. 315.

159 PR 2, p. 136. Le «boin roy Sidrega» porte le nom du prince Švitrigaila (m. 1452), qui dans les années 1390 disputait le trône grand-ducal à son cousin Vytautas avant de lui succéder en 1431, soit peu avant la date de composition de la Chronique de Metz (1434-1438): Wolfram, p. 315, n. 2; Z. Kiaupa, J. KiaupienĖ, A. Kuncevičius, The History of Lithuania Before 1795..., p. 205-211. Bien que Švitrigaila ait coopéré occasionnellement avec l'Ordre teutonique, comme la plupart des princes lituaniens, le profil du «roy de Laitue» dont parle la Chronique de Metz rappelle plus Kęstutis (m. 1382), le contemporain de l'empereur Charles IV de Bohême, dont il est question dans cet extrait. Le «hault maistre de Prusse» serait alors Winrich de Kniprode, mort en 1382 (Wolfram, p. 136, n. 1).

160 R. Petrauskas, «Litauen... », p. 241 sq.; W. Paravicini, «Litauer... », p. 267.

161 Ibid., p. 254.

162 R. Petrauskas, «Litauen...», p. 245-246.

163 Ibid., p. 241-242. Les alliances lituano-teutoniques sont souvent dirigées contre un rival lituanien ou les principautés russes de Novgorod et de Pskov. Des alliances similaires entre princes
} 
Les parties de chasse commune sont souvent l'occasion de rencontres; à cet égard, les documents diplomatiques nous indiquent qu'un prince lituanien avait le droit de chasser sur les terres de l'Ordre et vice-versa ${ }^{164}$. Surtout à partir de la fin du XIV siècle, on s'échange de nombreux cadeaux, parmi lesquels des faucons et même des aurochs; ces animaux, offerts par les ducs lituaniens, sont parfois renvoyés depuis Marienbourg à des cours d'Europe ${ }^{165}$. L'un des objectifs de cette diplomatie est de limiter les risques inhérents aux raids lancés, quasiment chaque année, sur les terres de l'adversaire: en dépit du discours généralement très violent qui entoure les récits de rèse, on savait parfaitement où s'arrêter ${ }^{166}$. $\mathrm{Si}$, dans le souci d'une évangélisation efficace, les papes traitent volontiers avec les chefs païens qui envoient des signaux favorables, les Teutoniques n'hésitent pas à négocier avec les ducs lituaniens, même sans qu'il soit question pour ces derniers de se convertir.

Cette intercompréhension mutuelle s'explique en partie par le fait que les guerriers lituaniens ressemblaient passablement à leurs adversaires teutoniques, et partageaient avec ceux-ci un même code de l'honneur. Rasa Mažeika a pu montrer que la manière dont la Chronique rimée de Livonie présente l' «apostasie» du roi Mindaugas (m. v. 1263) révèle qu'un certain respect pour les Lituaniens prévalait au moins depuis la fin du XIII ${ }^{\mathrm{e}}$ siècle $^{167}$. Mindaugas ayant, d'après les Teutoniques, fait de grandes donations à l'Ordre, on essayait de le présenter sous un jour favorable, surtout auprès de Rome, car les actes juridiques d'un apostat n'auraient pas eu de valeur ${ }^{168}$. Cela explique qu'en 1268 encore, soit cinq ans après sa mort, Mindaugas était présenté par le pape Clément IV comme un homme d' «illustre mémoire» - c'est-à-dire un chrétien ${ }^{169}$. De manière similaire, la Chronique rimée, écrite une trentaine d'année après la mort du roi, essaye de présenter les actions de celui-ci de manière acceptable pour les Chevaliers ${ }^{170}$.

chrétiens et musulmans n'étaient pas rares à l'époque des royaumes latins d'Orient; voir notamment A. Maalouf, Les croisades vues par les Arabes, Paris 1983.

164 R. Petrauskas, «Litauen...", p. 242; W. Paravicini, «Litauer...», p. 268.

${ }^{165}$ Id. Sur l'échange d'animaux comme cadeaux diplomatiques, Idem, "Tiere aus Norden...", p. 249-272; Idem, "Des animaux pour un roi mourant: Louis XI et les Hanséates de 1479 à 1483 », dans Edelleute und Kaufleute, p. 450-471. La pratique, entre seigneurs de différentes religions, est attestée dans le monde méditerranéen: S. Kinoshita, "Noi siamo mercatanti Cipriani”: How to Do Things in the Medieval Mediterranean", dans R. Blumenfeld-Kosinski, K. Petkov (dirs.), Philippe de Mézières and his Age..., p. 47.

166 R. Petrauskas, «Litauen...», p. 250-251.

167 R. MAŽEIKA, «When Crusader...», p. 197-214.

168 Ibid., p. 203. Les donations de 1260 à l'Ordre sont éditées dans Quellen..., doc. 14, p. 114-117; plusieurs lettres attestent que Mindaugas a cédé certains territoires à l'Ordre, notamment dans la région côtière de Samogitie; le Lituanien a vraisemblablement donné des territoires qu'il ne contrôlait pas. Notons que l'authenticité de certains dons est discutée.

169 R. MažEika, «When Crusader...», p. 203-205; Z. Kiaupa, The History of Lithuania..., p. 36.

170 Ceci alors que la Chronique de Galicie, composée en 1261 dans la Rus' orthodoxe, prétend que le prince lituanien jouait un double jeu (The Galician-Volynian Chronicle..., p. 63, cité par E. Christiansen, The Northern Crusades..., p. 137). La version de la Chronique de Galicie 
La narration attribue le retournement du roi au discours d'un prince païen de Samogitie, Treniota, qui joue essentiellement sur la notion d'honneur ${ }^{171}$; l'anecdote peut avoir été inventée pour dramatiser l'événement, mais elle signifie aussi que renoncer au christianisme pour respecter son honneur était compréhensible, et d'une certaine manière admissible, pour les membres de l'Ordre teutonique ${ }^{172}$. Ce n'est qu'après la conversion définitive de la Lituanie au christianisme que la figure de Mindaugas prend une teinte plus sombre dans les chroniques de l'Ordre, qui en font un hypocrite rusé, prédécesseur supposé de Ladislas Jagellon et de ses pairs ${ }^{173}$.

Le partage de valeurs communes par les sociétés guerrières aux prises dans la région balte explique qu'à l'instar de Jacques d'Esch, plusieurs auteurs d'Europe occidentale aient pu remarquer qu'un respect, voire une amitié, était possible entre individus chrétiens et païens. Sans doute l'assimilation - au moins sur le plan du vocabulaire - des Lituaniens aux "Sarrasins» du ProcheOrient rendait-elle une telle attitude imaginable, puisque depuis le XIII ${ }^{\mathrm{e}}$ siècle au moins, nombre de romans ou de chroniques dépeignent les adversaires musulmans des croisés de Terre sainte en personnages chevaleresques, partageant un même souci de l'honneur que leurs pairs chrétiens ${ }^{174}$. Du reste, de tels épisodes apparaissent déjà lors de la conquête de la Prusse racontée par Pierre de Dusbourg ${ }^{175}$, puis deviennent relativement fréquents dans les chroniques prussiennes ou livoniennes de la seconde moitié du XIV ${ }^{\mathrm{e}}$ siècle $^{176}$. Wigand de Marbourg, notamment, met en scène plusieurs échanges bravaches entre le prince Kęstutis, fils de Gediminas, et les officiers teutoniques ${ }^{177}$. Le même chroniqueur note qu'en 1377 , quand l'armée des croisés passe près de Trakai pour attaquer Vilnius, Kęstutis invite le maréchal à des pourparlers et

est considérée comme plus réaliste par J. Lind, "Mobilisation...», p. 81; du reste, les deux interprétations ne sont pas forcément incompatibles.

${ }^{171}$ Livländische Reimchronik..., v. 6357-6426, p. 146-147; trad. dans E. Christiansen, The Northern Crusades..., p. 137.

172 R. MaŽEIKA, "When Crusader...", p. 214.

173 R. Petrauskas, «Litauen...», p. 238; M. Olivier, «La figure du roi... », p. 234-248.

174 A. V. Murray, "Heathens...», p. 221-222; S. Kinoshita, "Noi siamo..."”, p. 45.

175 Notamment Pierre de Dusbourg, Chronicon..., SRP 1, p. 101, 142; S. Gouguenheim, «Les guerres...", p. 295.

176 A. NikžEntaitis, «Die litauische Gesellschaft der vorchristlichen Zeit (13.-14. Jahrhundert) zwischen Rom und Byzanz", dans M. Müller-Wille (dir.), Rom und Byzanz im Norden, Stuttgart, 1997, vol. 2, p. 115-130; R. Mažeika, "An Amicable Enmity...", p. 49-58; W. Paravicini, «Litauer...», p. 253-282; R. Petrauskas, «Litauen...», p. 237-251; S. C. Rowell, "Unexpected...", p. 557-577.

177 Notamment l'échange entre le grand-maître Winrich de Kniprode et le prince Kęstutis lors du siège de Kaunas, en 1362: Wigand de Marbourg, Chronica..., SRP 2, p. 534-536. Pour K. Kwiatkowski («Prolog und Epilog temporis sanctis. Die Belagerung Kauens 1362 in der Beschreibung Wigands von Marbourg», Zeitschrift für Ostmitteleuropa-Forschung 57/2, 2008, p. 250-251), Wigand, qui aurait composé sa chronique sur le modèle du drame liturgique, aurait voulu rappeler le dialogue du Christ et de Ponce Pilate. 
offre à dîner à un membre de l'Ordre teutonique, Günther de Hohenstein, qui est parrain de sa fille Danuta, baptisée et mariée au duc Janusz de Mazovie ${ }^{178}$. Le fils de Kęstutis, Vytautas (devenu grand-duc en 1392/1401) entretenait de bons rapports avec plusieurs Chevaliers, qui faisaient office de personnes de contacts. De ce fait, les membres de l'Ordre teutonique capables de s'immerger dans la société lituanienne et d'en parler la langue étaient très appréciés, de part et d'autre ${ }^{179}$.

De leur côté, les princes lituaniens parlaient couramment l'allemand comme le ruthène, langue de leurs sujets orthodoxes ${ }^{180}$. Habitués qu'ils étaient à jouer une politique religieuse pour le moins ouverte, plusieurs parmi eux portaient trois noms, l'un lituanien, le deuxième orthodoxe, le troisième latin ${ }^{181}$. Comme à l'époque de Gediminas, les chrétiens orthodoxes et catholiques étaient les bienvenus à Vilnius tant qu'ils ne créaient pas de troubles. Dès le milieu du $\mathrm{XIV}^{\mathrm{e}}$ siècle, certains Chevaliers teutoniques capturés sont emmenés à la cour des grands-ducs, où ils servent de conseillers et enseignent les coutumes occidentales aux jeunes princes ${ }^{182}$ : l'historien lituanien Alvydas Nikžentaitis explique ainsi l'éducation et les mœurs "chevaleresques" d'un Kęstutis ${ }^{183}$. De tels cas ont dû parvenir aux oreilles de Philippe de Mézières lors de son passage en Prusse en automne 1364, lorsqu'il relate dans Le Songe du vieil pelerin l'histoire d'un Teutonique fait prisonnier lors d'un accrochage contre les Lituaniens et devenu l'ami et le conseiller du grand-duc ${ }^{184}$.

Si Mézières lui-même ne s'est sans doute pas rendu en Lituanie, il a pu entendre l'anecdote à la cour du grand-maitre, à Marienbourg ${ }^{185}$. Rares parmi les "hôtes" de l'Ordre étaient en effet ceux qui avaient l'occasion de visiter la principauté païenne par eux-mêmes, en dehors des rèses où ils étaient encadrés par les Teutoniques. Il existe toutefois des exceptions: on sait, par un document comptable du Hainaut, qu'un certain Jacques, bâtard de Briffoeil, rentre en 1387 après avoir été retenu prisonnier par les Lituaniens ${ }^{186}$. Cet épisode a eu lieu juste avant que le pays ne passe au christianisme latin. Wigand de Marbourg nous raconte également que quelques années plus tôt, en 1382, un noble rhénan de la famille des Isenburg a décidé de se rendre à Vilnius depuis la Livonie, pour rencontrer le «roi de Lituanie», auprès de qui il reçoit les honneurs et demeure

\footnotetext{
178 Wigand de Marbourg, Chronica..., SRP 2, p. 589.

179 R. Petrauskas, «Litauen... », p. 248-249.

180 W. Paravicini, «Litauer...", p. 255.

181 Ibid., p. 260.

182 S. C. Rowell, «Unexpected...», p. 563; A. NikžEnTAitis, «Die litauische Gesellschaft...», p. 126-127.

183 Ibid., p. 127.

184 S. C. Rowell, Lithuania Ascending..., p. 130-132; W. Paravicini, «Litauer...», p. 259. Voir chap. VIII.

185 Ibid., p. 258.

186 Ibid., p. 259; Idem, "Nobles Hennuyers... », p. 270.
} 
huit jours, avant de rentrer en Prusse ${ }^{187}$. En présentant cette aventure audacieuse à son public, Wigand révèle qu'un tel voyage, organisé par l'intermédiaire de messagers et où l'accord du «roi» lituanien est demandé, était considéré comme possible ${ }^{188}$.

En sens inverse, plusieurs princes lituaniens ont eu l'occasion de visiter l'État de l'Ordre teutonique, et bien au-delà. La plupart ont connu la Prusse en tant que prisonniers, dont les plus célèbres sont sans doute Kęstutis et son fils Vytautas. L'évasion du premier, survenue en 1361, est parvenue jusqu'à un chroniqueur anglais, qui lie cet épisode romanesque à la prise de Kaunas survenue l'an d'après. Écrite en anglo-normand par un chevalier originaire du nord de l'Angleterre, la Scalacronica de Thomas Gray d'Hetton illustre le retentissement qu'ont pu avoir ces événements dans une région éloignée d'Europe, mais qui fournissait de nombreux «hôtes" aux contingents des croisés de Prusse:

"En meisme lan susdit, fust le Roy de Lettow pris, par lez seignours de Spruz qe par enbussement ly suppristerent, al issu qe lost dez Cristiens isserent sa terre apres la Pasche, com testousement il lour poursuy. ${ }^{189}$

L'épisode est relaté par Wigand de Marbourg, selon qui c'est bien à la fin d'une rèse que le duc de Trakai est capturé, alors que les Lituaniens harcelaient l'armée chrétienne sur le chemin du retour ${ }^{190}$. Le prisonnier est emmené à Marienbourg, où il n'est gardé que de jour, ce qui lui permet de penser à son évasion ${ }^{191}$. Ayant remarqué un trou dans le mur de la chambre où il est gardé, il s'efforce, avec la complicité d'un serviteur d'origine lituanienne, de l'agrandir, jusqu'au jour où il peut s'enfuir ${ }^{192}$. Une fois hors de sa cellule, il revêt le manteau blanc à croix noire de l'un des frères, puis quitte le château sur le propre cheval du commandeur ${ }^{193}$ ! Avec moins de détails, le récit de la Scalacronica donne tout de même l'essentiel, y compris sur le rôle joué par un

\footnotetext{
187 Wigand de Marbourg, Chronica..., SRP 2, p. 620; W. PARAvicini, «Litauer...", p. 260 ; PR 2, p. 136-137; R. Petrauskas, «Litauen...», p. 241.

188 PR 2, p. 136; R. Petrauskas, "Litauen...", p. 241, n. 21. Se rendre auprès d'un prince infidèle et même le servir comme mercenaire était également possible en contexte musulman. Ainsi, Boucicaut et le comte d'Eu, Philippe d'Artois, servirent un certain temps le sultan Murad, à condition de ne pas devoir se battre contre d'autres chrétiens: N. Housley, "One man and his wars...", p. 33.

189 Thomas Gray, Scalacronica..., p. 196.

${ }_{190}$ Wigand de Marbourg, Chronica..., SRP 2, p. 527-528.

191 Ibid, p. 528.

192 Novembre 1361; SRP 2, p. 528, n. 554.

193 Selon le récit de Wigand de Marbourg, Chronica..., SRP 2, p. 528; voir aussi S. C. Rowell, "Unexpected...», p. 560; D. Baronas, "Kestucio pabegimas is Marienburgo», Lietuvos istorijos studijos 11, 2003, p. 23-33 (résumé en anglais), suppose que Kęstutis était plus utile à l'Ordre libre qu'en prison: tant que la Lituanie avait à sa tête ce païen conservateur, qui avait refusé les projets d'évangélisation pacifique, la raison d'être de l'Ordre teutonique n'était pas remise en cause.
} 
serviteur lituanien de l'Ordre: "Le auaunt dit Roy de Lettow eschapa meisme la sesoun de prisoun par myne, et par couyn dun renegat Lettow, qe norriz estoit od lez ditz seignours de Spruce» ${ }^{194}$. Le chevalier Thomas Gray était donc au courant du rôle joué par un "renegat Lettow", autrement dit le "serviteur, dit Alpf, qui bien qu'étant chrétien, était à l'origine un païen ${ }^{195}$. Ce personnage illustre l'habitude des Teutoniques d'employer des serviteurs d'origine lituanienne, parfois des prisonniers de guerre ${ }^{196}$, qui - dans ce cas au moins - gardaient une certaine solidarité avec leurs compatriotes récemment capturés. Si le chroniqueur anglais semble accuser le complice du prince de trahison, ou au moins d'ingratitude puisqu'il avait été nourri par les Teutoniques, Wigand s'abstient de condamner explicitement ce personnage, sur lequel il ne s'attarde pas. Il continue plutôt son récit en disant qu'en sortant de Marienbourg, un chevalier teutonique croise Kęstutis et le salue sans le reconnaitre, ce qui semble indiquer que le prince lituanien devait être familiarisé avec les usages de ses ennemis pour arriver à passer ainsi inaperçu ${ }^{197}$.

Toujours selon Wigand de Marbourg, Kęstutis se réfugie momentanément chez son gendre, Janusz de Mazovie, puis retourne en Lituanie, d'où il repart en guerre contre l'Ordre. C'est alors que les Teutoniques entreprennent d'attaquer Kaunas, importante place forte située au confluent du Niémen et de la Neris, en mars 1362. La Scalacronica présente cet assaut comme une suite logique de l'escapade du prince lituanien: "par enchesoun de quel eschap, la sesoun procheigne, lez ditez seignours firent vn graunt arme par nefe en Lettow assistrent le chastel de Coun sure le Memil [Memel, c'est-àdire le Niémen], le pristrent de assaute par beaux fetz darmis» ${ }^{198}$. La mention du transport fluvial ("par nefe»), que l'on retrouve chez Wigand, suggère que Thomas Gray était bien renseigné; de fait, le chroniqueur teutonique mentionne que des "hospites de Anglia, Ytalia, Almania" participèrent à l'aventure ${ }^{199}$. Même si le chevalier chroniqueur lui-même n'a pas été de la partie, il en a sans doute entendu parler par des participants rentrés en Angleterre.

Les princes lituaniens sont ainsi connus de quelques chroniqueurs occidentaux, sans doute par le truchement des chevaliers partis se battre en Prusse. Ceux-ci ont l'occasion de rencontrer non seulement les membres de l'Ordre teutonique, mais aussi quelques nobles lituaniens qui participent aux banquets organisés à Marienbourg ${ }^{200}$ ou accompagnent les croisés lors des rèses.

\footnotetext{
194 Thomas Gray, Scalacronica..., p. 198.

195 Wigand de Marbourg, Chronica..., SRP 2, p. 528.

196 S. C. Rowell, «Unexpected...», p. 562.

197 Ibid., p. 560.

198 Thomas Gray, Scalacronica..., p. 198.

199 Wigand de Marbourg, Chronica..., SRP 2, p. 531.

${ }^{200}$ R. Mažeika, «An Amicable Enmity...», p. 53-54; W. Paravicini, «La Prusse...», p. 180; PR 2, p. 127-128.
} 
Parmi eux, le fils de Kęstutis, Vytautas ${ }^{201}$, sera amené à jouer un rôle considérable dans la transformation de la Lituanie en principauté chrétienne. Pendant sa jeunesse, Vytautas est un habitué des séjours auprès des Teutoniques, que ce soit en tant que prisonnier ou en tant qu'allié. Occasionnellement, la Prusse lui sert même de refuge lors des disputes qui l'opposent à son cousin Jagellon au début des années $1380^{202}$. En 1384, il se fait baptiser une première fois et reçoit le nom de Wigand, d'après son parrain Wigand de Baldersheim, commandeur de Ragnit $^{203}$. Il semble que cet ambitieux prince se soit fait à nouveau baptiser en compagnie de son cousin, avec qui il était momentanément réconcilié, deux ans plus tard; il reçut à cette occasion le nom de baptême Alexandre, qu'il utilisera désormais dans les documents diplomatiques ${ }^{204}$.

En 1390, Vytautas participe à l'attaque menée contre Vilnius, alors tenu par Skirgaila pour le compte de Jagellon. La Chronica Maiora de Thomas Walsingham et la Chronique de Westminster rapportent que le duc Henri de Lancastre, comte de Derby et futur roi Henri IV, participe à l'expédition aux côtés du maréchal de l'Ordre et "d'un certain roi appelé "Wytot" "205. Dix ans plus tard, Jacques d'Esch dit combattre au côté du "duc Withate de Laitue Saraisin, aidant des Prusois» ${ }^{206}$. Bien qu'il ait reçu le baptême depuis au moins quatorze ans, Vytautas est toujours qualifié de "Sarrasin», autrement dit de païen; ce qui n'empêche pas le chroniqueur d'admettre que le prince lituanien collabore avec les Chevaliers teutoniques, pour défaire les "Salmaite» (Samogitiens), qui "volxent combatre les Crestiens" ${ }^{207}$. À en croire l'auteur de la Chronique de Metz, des soldats d'origine et de religion très diverses participent à la campagne, puisque Vytautas «avoit bien que de son payx de Laitue que de Poulaine, que dez Russe, que des Tertez IIII ${ }^{X X}$ millez chevalx» ${ }^{208}$; souverain

\footnotetext{
${ }^{201}$ Witold en polonais. Considéré de nos jours comme l'un des héros nationaux lituaniens, il est connu sous le nom de Vytautas le Grand. Nous donnerons donc la forme lituanienne de son nom, comme pour Gediminas (Giedymin), Algirdas (Olgierd), Kęstutis (Kiejstut) et Mindaugas (Mendog ou Mindowe). Parmi les souverains lituaniens, nous n'adaptons que le seul nom de Jogaila, qui est connu en français comme Jagellon (Jagiełło en polonais). La dynastie qu'il a fondé porte ce nom jusqu'au XvI ${ }^{\mathrm{e}}$ siècle.

202 R. Petrauskas, «Litauen...», p. 240.

203 W. Paravicini, «Litauer...», p. 261.

${ }^{204}$ Les circonstances de ce nouveau baptême sont relativement mystérieuse; Vytautas avait-il auparavant été baptisé orthodoxe (F. Dvornik, Les Slaves..., p. 555-556) ? La cérémonie de 1386 n'était-elle qu'une confirmation de son premier baptême (J. Koncius, Vytautas the Great. Great Duke of Lithuania, Miami 1964, p. 33)? Voir G. Mickūnaité, Making a Great Ruler: Grand Duke Vytautas of Lithuania, Budapest 2006, p. 5-6; S. C. RoweLL, "Unexpected... », p. 567.

205 Walsingham, vol. 1, p. 902. D'après la Chronique de Westminster, Henri rencontre Vytautas peu après son arrivée en Prusse et une courte halte à Königsberg, le temps d'y organiser son armée: Westminster, p. 446.

206 Wolfram, p. 337.

${ }^{207}$ Id. Nous sommes après le traité de Salynas/Sallinwerder (1398), par lequel la Samogitie, non baptisée, est cédée à l'Ordre teutonique.
}

${ }_{208} \mathrm{Id}$. 
d'un immense pays où cohabitaient, à cette époque, lituaniens fraîchement baptisés, Ruthènes orthodoxes et Tatars musulmans, le grand-duc de Lituanie mène fréquemment des contingents de soldats issus de ces différents peuples sur le champ de bataille.

Rien ne permet d'affirmer que Jacques d'Esch ait fait la différence entre les obédiences religieuses des hommes de Vytautas, mais ce qui est sûr, c'est que celui-ci était considéré comme un allié des croisés, et que le chroniqueur messin ne semble nullement perturbé par l'idée d'avoir pris part à un combat mené aux côtés d'autant de "Sarrasins» et de schismatiques. Pas plus que l'auteur de la Chronique de Saint Thiébaut de Metz (1445), qui relate l'expédition à laquelle participa Jacques d'Esch et ses compagnons. Tout comme ce dernier, le chroniqueur anonyme note que "le duc de Witaire, ung duc Sarazin de Lytowe, que servoit les Prussiens pour celle reze, avoit $L X X X^{M}$ chevaulx pour sa routte»" ${ }^{209}$, avant de préciser que "avoit le dit duc de Witaire en sa compaignie tres grand foisons de gens dou pays de Tartarie» ${ }^{210}$. Les chroniqueurs d'Europe occidentale pouvaient donc identifier quelques figures parmi les princes lituaniens, savaient que ceux-ci collaboraient occasionnellement avec les croisés de Prusse, et leur différence religieuse réelle ou supposée ne les rendait pas nécessairement infréquentables.

$\mathrm{Si}$ Vytautas jouait sa carrière en Lituanie, où il réussit à définitivement s'emparer du pouvoir en 1392, plusieurs de ses compatriotes restèrent sous les bannières teutoniques ou gagnèrent l'Europe occidentale. Nous avons déjà évoqué le destin de son frère Butautas, qui a rejoint la cour de l'empereur Charles IV à Prague autour de 1368. Trois ans plus tôt, en été 1365, ce prince avait reçu le baptême à Königsberg sous le nom d'Henri, vraisemblablement d'après son parrain, le commandeur de Ragnit Henri de Schöningen ${ }^{211}$. Deux nobles anglais assistèrent à l'événement: Thomas Beauchamp, comte de Warwick, et Thomas d'Ufford ${ }^{212}$. Il est probable que l'un des suivants de Butautas, un dénommé Survila (peut-être est-il son frère ${ }^{213}$ ) ait eu comme parrain le comte de Warwick ${ }^{214}$; on le retrouve, lui ou son fils, sous le nom de Thomas Surville parmi les nobles fidèles à l'Ordre teutonique ${ }^{215}$. Le baptême d'un Lituanien nommé Thomas a également été immortalisé dans deux pièces tardives à la gloire de la famille Beauchamp. Il s'agit du manuscrit illustré du

\footnotetext{
${ }^{209}$ Chronique ou Annales du Doyen de S. Thiébaut de Metz, cité dans SRP 3, p. 454.

${ }^{10}$ Ibid., p. 455.

211 W. Paravicini, «Litauer...», p. 261.

212 Wigand de Marbourg, Chronica..., SRP 2, p. 551; PR 2, p. 108.

213 I. BARANAUSKIENĖ, "Survila ir Survilaičiai - dar kartą apie nepripažintus Kęstučio palikuonis », Istorija, 99/3, 2015, p. 18-33 (résumé en anglais). Le texte de Wigand a: «rey Butaw dictus, ... cum bayoribus suis et aliis et fratre suo Surwillo" (Chronica..., SRP 2, p. 550); pour l'acceptation de "frater" au sens de compagnon, S. C. Rowell, "Unexpected...", p. 568.

${ }^{214}$ Wigand de Marbourg, Chronica..., SRP 2, p. 550-552.

215 S. C. Rowell, «Unexpected...» p. 569; W. Paravicini, «Litauer...», p. 263.
} 
prêtre John Rous, composé vers 1483, et The Beauchamp Pageant, qui raconte les exploits du petit fils de Thomas, Richard (v. 1485/1490) ${ }^{216}$. Le Rous Roll présente une illustration de Thomas Beauchamp l'aîné portant le bâton de maréchal d'Angleterre, un château et une charte, avec à ses pieds un ours muselé, emblème de la famille. À son côté, on voit un enfant, ou un petit personnage, couronné dans un font baptismal (fig. 1); le texte qui accompagne l'image nous dit que parmi de nombreux hauts faits, Thomas "a combattu trois ans [trois fois ${ }^{217}$ c chez les païens, et qu'il a ramené avec lui le fils du roi de Lituanie et l'a baptisé à Londres, et l'a appelé Thomas d'après lui-même»" ${ }^{218}$. Le second texte, composé dans les mêmes années, raconte que Richard Beauchamp, dernier croisé anglais dont nous connaissons le nom (il était en Prusse en été $1409^{219}$ ), a voyagé "en Russie, en Lituanie, en Pologne et en Prusse», tout comme ses aînés, "spécialement le comte Thomas son grand-père, qui a pris en guerre le fils du roi de Lituanie et l'a emmené en Angleterre et l'a baptisé à Londres, en l'appelant Thomas d'après lui-même»" 220 .

L'épisode du baptême à Londres repose, d'après Stephen C. Rowell, sur une interprétation erronée de la chronique de Jean de Reading, moine de Westminster mort en 1369, qui mentionne effectivement le baptême d'«un certain fils du roi de Lituanie», nommé Thomas en l'honneur du comte, mais ne précise pas qu'il fut emmené en Angleterre et encore moins baptisé à Londres ${ }^{221}$. Autre source de confusion possible, la chronique Eulogium Historiarum, de quelques années antérieure (1366) raconte que le roi de Chypre, Pierre de Lusignan, a visité Londres en novembre 1363, avec, dans sa suite, "un roi païen de Lituanie», prisonnier, et un converti libre, nommé «seigneur de Jérusalem» ${ }^{222}$. Werner Paravicini remarque qu'il ne peut pas s'agir de Butautas, qui n'a reçu le baptême que deux ans plus tard, mais peut-être de son frère Waydot, dont les

\footnotetext{
${ }^{216}$ Ibid., p. 261. L'événement est également célébré dans le poème allemand «Le Lituanien", de Schondoch (SRP 6, 1968, p. 50-60); Ibid, p. 261-262.

${ }_{217}$ PR 1, p. 170, n. 140a.

${ }^{218}$ John Rous, The Rous Roll. With an historical introduction, éd. C. Ross, Gloucester 1980, doc. 47, avec les explications sur l'iconographie; trad. W. PARAVICINI, PR 1, p. 170 ; le manuscrist BL Add. MS 48976 est mis en ligne sur le site de la British Library, Digitised manuscripts: http:// www.bl.uk/manuscripts/FullDisplay.aspx?ref=Add_MS_48976 (consulté le 9 mars 2016). L'ours, muselé ou non, apparaît également aux pieds d'autres membres de la famille (John Rous, The Rous Roll..., doc. 48 et 50) et est représenté sur les tombeaux de plusieurs comtes de Warwick: M. Hicks, Warwick the Kingmaker, Oxford 1998, p. 61. Un ours a également été sculpté sur la tombe du duc Jean de Berry, ce que M. Pastoureau (L'Ours: histoire d'un roi déchu, Paris 2007, p. 266-268) considère comme exceptionnel.

219 PR 1, p. 34-35.

${ }^{220}$ Pageant of the birth, life and death of Richard Beauchamp, Earl of Warwick, K.G., 1389-1439, éd. J. Hope, H. Dillon, Londres 1914, tab. XXII, trad. PR 1, p. 34. L'image montre une scène de tournoi, à priori sans rapport avec la Lituanie.

221 S. C. Rowell, «Unexpected... », p. 568, n. 2. Par contre, pour I. Baranauskienè («Survila... », p. 18-33), le fils de Survila aurait bien accompagné le comte Thomas de Warwick en Angleterre.

${ }^{222}$ Eulogium historiarum sive temporis..., éd. F. S. Haydon, Londres 1863, vol. 3, p. 233.
} 
sources teutoniques disent qu'il a été capturé lors de la prise de Kaunas en 1362, événement auquel assistèrent des croisés anglais ${ }^{223}$.

Une légende, au moins interne à la famille des comtes de Warwick, se forme toutefois autour d'un prince lituanien baptisé en Angleterre ${ }^{224}$. Cette extrapolation, que Stephen C. Rowell pointe comme symptomatique de la mode qu'il appelle "Baltic "pagan chic" " et de la confusion entre les différents "Sarrasins» que l'on peut rencontrer aux marges de la Chrétienté225, atteste d'une habitude née avec les rèses internationales: celle de parrainer un converti et éventuellement de le ramener en Europe occidentale, peut-être comme preuve vivante du périple accompli parmi ces lointains infidèles ${ }^{226}$. Déjà en 1347, le chroniqueur Jean de Winterthour raconte que le margrave Louis de Brandebourg, fils aîné de l'empereur Louis de Bavière, rentra de Prusse "apportant avec lui un roi des païens captif, ou trois, avec plusieurs de ses satrapes, qu'il a, d'après ce que l'on le rapporte, distribués à divers princes catholiques, comme ses propriétés. Ceux-ci sont le témoignage évident de son magnifique triomphe» ${ }^{227}$. On sait qu'il était d'usage de s'offrir des prisonniers maures en Espagne, autre zone frontière où les nobles accouraient pour combattre l'infidèle; de rares sources narratives et quelques documents comptables attestent qu'une telle pratique avait également lieu en Prusse ${ }^{228}$. Les Lituaniens dont il s'agit sont soit capturés lors de la rèse, soit achetés à des chrétiens de Prusse, voire à d'autres ressortissants du grand-duché ${ }^{229}$. À lire la chronique d'Hermann de Wartberge, qui dit que lors d'une rèse en 1375 on déporta 715 Lituaniens, "à l'exception des prisonniers que les hôtes prirent» ${ }^{230}$, on peut imaginer qu'une partie des jeunes nobles emmenés en Prusse pour y être baptisés étaient distribués ou vendus aux hôtes de passage ${ }^{231}$. En 1377-1378, Guy II de Chauvigny rentra de ce qui semble être la Prusse, "en ameina un enfant, lequel il fist baptiser» ${ }^{232}$.

Henri de Derby n'est pas en reste; alors que la Chronique de Westminster raconte qu'en se retirant de Vilnius, "le maréchal de Prusse prit avec lui huit mille prisonniers de Lituanie pour qu'ils soient faits chrétiens, et que le maître de Livonie en prit 3500» ${ }^{233}$, il semble que quelques-uns d'entre eux aient, bon gré mal gré, rejoint le futur monarque. En effet, ce dernier acheta plusieurs Lituaniens,

\footnotetext{
${ }^{223}$ Wigand de Marbourg, Chronica..., SRP 2, p. 537; Hermann de Wartberge, Chronicon Livoniae..., SRP 2, p. 81 sq.; PR 2, p. 109.

224 S. C. Rowell, «Unexpected...», p. 569.

225 Id.

226 Ibid., p. 571; PR 2, p. 108.

227 Jean de Winterthour, Die Chronik..., éd. F. Baethgen, p. 270.

${ }_{228}$ PR 2, p. 109-110.

229 Ibid., p. 107.

${ }^{230}$ Hermann de Wartberge, Chronicon Livoniae..., SRP 2, p. 107.

231 PR 2, p. 105.

232 Jean de la Gogue, Histoire des princes de Deols..., p. 405.

233 Westminster, p. 448; sur la source nommée "le rouleau du maréchal», PR 2, p. 104-105;

Walsingham, vol. 1, p. 902, mentionne également ces baptêmes de masse.
} 
vraisemblablement deux femmes et des enfants, lors de son premier voyage en Prusse $^{234}$. Ses comptes de voyage mentionnent un Lituanien baptisé, nommé Henri (sans doute en référence à son parrain, qui ne serait autre que le Lancastre lui-même ${ }^{235}$ ), qui l'accompagne lors de sa seconde rèse en 1392, puis en Terre sainte ${ }^{236}$. À Rhodes, le comte acquiert un jeune Turc, converti et également baptisé $\mathrm{Henri}^{237}$. La pratique ne concernait pas que les seuls Lituaniens, comme l'illustre le cas de Charles de Savoisy, grand seigneur proche du roi Charles VI et ancien croisé de Prusse, qui, selon la Chronique du règne de Charles VII du héraut Berry, aurait capturé des «Sarrasins» lors d'une expédition maritime en Méditerranée, puis les aurait mis à contribution pour construire son château dans l'Auxerrois ${ }^{238}$.

Ceux qui faisaient l'acquisition de ces jeunes convertis semblent s'être souciés de leur entretien: les comptes mentionnent plusieurs pièces d'habillages, lits, manteaux ou chaussures que l'on achète pour eux ${ }^{239}$. On investit aussi dans leur éducation, comme le sénéchal de Hainaut, Jean de Werchin, qui semble avoir fait inscrire un certain "Wallerant de Letto" comme élève du "Grand Maistre d'Escolle de Tournay", le fait vêtir et lui paye des professeurs de musique et de chant. Ce personnage est sans doute un Lituanien ramené d'un voyage entrepris peu avant septembre 1407 (date à laquelle il apparaît dans les comptes), et baptisé d'un prénom en vogue dans la puissante famille des Luxembourg, à laquelle Werchin est lié par son épouse ${ }^{240}$. Toujours en Hainaut, les documents comptables font apparaître une "Magritte le Sarazine» mariée à Jean de Namur, peut-être un bâtard du comte du même nom, qu'un certain "Tieris de Mairs ramena de Prusse» à la fin du XIv siècle ${ }^{241}$. Depuis 1393, c'est tout un

\footnotetext{
${ }^{234}$ Voir les comptes de ses voyages, Expeditions..., p. 52, 67, 68, passim.

235 PR 2, p. 108.

${ }^{236}$ Expeditions..., p. 90, 91 passim.

237 Id., p. 230 ; sur ces personnages, PR 2, p. 107-108.
}

${ }^{238}$ C'est le sujet d'une belle étude de M. Rodinson, «Le seigneur bourguignon et l'esclave sarrasin », dans La fascination..., p. 141-197, qui cite Gilles le Bouvier dit le Héraut Berry, Les Chroniques du roi Charles VII, éd. H. Courteault et al., Paris 1979, p. 14. Charles de Savoisy était en Prusse en hiver 1392-1393, puis y retourne peut-être en 1397-1398, assurément en hiver 1398-1399 (M. Rodinson, La fascination..., p. 171-172; PR 1, p. 100-101.). En difficulté à la cour, il part en mer en 1404 et d'après le héraut Berry, c'est à cette occasion qu'il capture deux navires musulmans avec leurs équipages.

239 PR 2, p. 105-110.

240 Ibid., p. 106. J. Bataille, Cysoing, les seigneurs, l'abbaye, la ville, la paroisse, Lille, 1934, p. 302-305, a retrouvé dans les comptes de la baronie de Cysoing plusieurs entrées, à partir de septembre 1407, concernant Wallerant, éduqué à l'école de Tournai aux frais de Jean de Werchin et de ses proches. Celui-ci s'est sans doute rendu en Prusse peu avant 1407, d'où il a pu ramener ce jeune Lituanien. Ainsi, "Wallerant de Letto" n'est sans doute pas le fils «du premier mariage de Marguerite de Luxembourg avec le comte de Liche» comme le suppose J. Bataille (Cysoing..., p. 302). W. Paravicini, «Hennuyers...», p. 301.

241 Ibid., p. 301, n. 159, qui cite les comptes du domaine du Quesnoy, année 1402 (Lille, ADN, B 9062); W. Paravicini, "Das Haus Namur im Ostseeraum», dans J. Hirschbiegel, A. Ranft, J. Wettlaufer (dirs.), Edelleute und Kaufleute..., p. 49-86. 
groupe de Lituaniens qui sont entretenus par le duc Guillaume de Gueldre et de Juliers $^{242}$; parmi eux, la mère d'un certain Guillaume, sans doute le bâtard du duc, que les documents appellent "Willemken der heyde» ou "van Lyctouwen " ${ }^{243}$. La plupart de ces émigrés involontaires devaient être baptisés, sauf dans les cas exceptionnels, comme ce jeune Lituanien amené en Frise, et qui, refusant de devenir chrétien, aurait été éliminé ${ }^{244}$. Même si un certain respect pouvait exister, en Prusse comme en Lituanie, entre chrétiens et païens, la conversion au christianisme latin représente la clef essentielle pour qu'un Balte soit définitivement intégré au monde de l'aristocratie occidentale. Du reste, le fait de voir plusieurs croisés figurer comme parrains lors de baptêmes en Prusse ${ }^{245}$ ou ramener des Lituaniens dans leurs patries d'origine pour les y faire baptiser illustre l'importance que l'on donnait au caractère missionnaire des rèses, dont le but avoué n'était pas uniquement de faire "grant destruccion de Sarrasins", mais bien de promouvoir le christianisme en offrant le baptême aux habitants du pays $^{246}$.

Si l'on peut se référer aux cas suffisamment documentés, la plupart des Lituaniens baptisés sont parfaitement intégrés à leur nouvelle société, au moins les plus nobles d'entre $e^{247}$. Butautas/Henri, à qui Charles IV a donné le titre de duc de Lituanie, reste un proche de l'empereur, l'accompagne en Italie et figure comme témoin dans plusieurs chartes impériales ${ }^{248}$. Son fils Vaidutis, qui semble avoir grandi en Lituanie avant de fuir à son tour en Bohême, où il est baptisé en 1381, paraît avoir suivi des études de théologie à l'Université de Prague et être devenu recteur de l'Université de Cracovie juste avant sa mort, en $1402^{249}$. Thomas Surville quant à lui réalise une belle carrière au service de l'Ordre et intègre le milieu de la chevalerie chrétienne. Sa renommée devait être relativement importante, puisque quand il tombe avec son frère Jean devant les Tatars à la bataille de la Vorskla (1399), leurs noms sont les seuls retenus par le chroniqueur

\footnotetext{
${ }^{242}$ En 1403, après la mort du duc, ils reçoivent une somme d'argent qui leur permet de rentrer en Lituanie; PR 2, p. 106-107; E. Schubert, «L'étranger et les expériences de l'étranger dans l'Allemagne médiévale et moderne", dans L'Étranger au Moyen Âge..., p. 210-211.

243 PR 2, p. 107.

${ }^{244}$ Ibid., p. 105-106. Il s'agit de l'un des deux jeunes garçons emmenés par un noble du nom de Rienck Bockema, qui a accompagné le duc de Gueldre et Juliers à sa rèse de 1393; l'histoire de la mort du jeune garçon qui se moquait des sacrements est racontée par le prieur de Thabor, Worp Tyaerda (m. 1538), qui dit encore que le compagnon de ce malheureux est devenu moine (trad. PR 2, loc. cit). PR 2, p. 107, suppose que la mère du bâtard Guillaume «der heyde» était peut-être restée païenne.

245 Ibid., p. 108.

246 P. Dobrowolski, «Miles... », p. 41; A. Nikžentaitis, «Prisoners of war... », p. 195, remarque toutefois qu'un tel traitement était exceptionnel.

247 W. Paravicini, «Litauer...», p. 262.

${ }^{248}$ Id.; S. C. Rowell, "Unexpected...", p. 570-571.

${ }^{249}$ Ibid., p. 575; K. OżóG, Uczeni..., p. 39.
} 
prussien Jean de Posilge ${ }^{250}$. Les armes de Thomas Surville figurent dans l'armorial Bellenville, composé dans la seconde moitié du XIV siècle par un héraut anonyme ayant vraisemblablement voyagé dans toute l'Europe ${ }^{251}$. À peine plus loin dans l'armorial, les mêmes armes sont répétées mais avec une brisure (fig. 2); bien que ce dernier blason soit anonyme, il y a lieu de suivre Werner Paravicini, qui l'attribue à Jean Surville, le frère cadet de Thomas. Il est alors remarquable que l'on ait usé de la pratique de la brisure, inconnue en Prusse ou en Pologne, pour distinguer les armes des deux frères lituaniens ${ }^{252}$. Le fait que celles-ci figurent dans un rôle d'armes, expression parfaite, s'il en est, de l'idéologie chevaleresque, indique que Thomas et Jean Surville ont été pleinement admis dans le monde de la noblesse européenne.

En parallèle à l'intégration progressive de quelques individus nobles dans l'aristocratie catholique, une noblesse héréditaire s'impose au cours du XIV $^{\mathrm{e}}$ siècle en Lituanie, et fait siennes les habitudes occidentales, y compris le port d'armoiries ${ }^{253}$. L'influence est réciproque, au moins en ce qui concerne l'armement, puisque les Teutoniques n'hésitent pas à utiliser des armes de facture lituanienne, lesquelles sont parfois achetées par des hôtes venus d'Occident ${ }^{254}$. Progressivement, les normes de la guerre chevaleresque pénètrent sur le champ de bataille. Une certaine confiance mutuelle, ou du moins une intercompréhension, rend possibles des pratiques courantes dans l'Occident chrétien: ainsi, certains textes font écho de duels opposant un guerrier païen et un chrétien, parfois un hôte venu de bien loin ${ }^{255}$. Plusieurs chroniqueurs d'Europe centrale racontent ainsi que Jean de Luxembourg aurait terrassé un Lituanien gigantesque; c'est

\footnotetext{
250 Jean de Posilge, Chronique..., SRP 3, S. 230; W. PAravicini, «Litauer...», p. 263-264.

251 Pour L. Jéquier, L'Armorial Bellenville. Cahiers d'Héraldique V, Paris 1993, p. 31-32, l'auteur était probablement un poursuivant puis héraut d'armes des comtes de Hainaut et de Hollande, qui a consigné de nombreuses armoiries à l'occasion de plusieurs voyages à travers l'Europe. Sur l'intérêt de cet armorial quant à l'étude du voyage de Prusse, W. Paravicini, "Bellenville"...", p. $185-190$

252 Ibid., p. 188; PR 1, p. 287 ; S. C. RoweLl, «Unexpected...», p. 559, voit une tête de chien sur le cimier de Thomas Surville, ce qui, d'après lui, ne serait peut-être pas un hasard pour un converti (le chien étant fréquemment lié au paganisme sur le plan symbolique). Toutefois, W. Paravicini («Litauer...», p. 264, n. 65) remarque que l'animal est désigné comme une panthère dans l'édition récente Armorial Bellenville, éd. M. Pastoureau, M. Popoff, Lathuile 2004, doc. 1532, 1534, p. 285-286.

${ }^{253}$ R. Petrauskas, «Knighthood...», p. 40-41; W. Paravicini, «Litauer...», p. 265, note que la noblesse lituanienne utilisait probablement l'héraldique avant le pacte d'Horodło (1413), qui fixe le rapprochement des noblesses lituanienne et polonaise.

${ }^{254}$ Ibid., p. 255. Lors de son troisième voyage en Prusse (1344-1345), le comte Guillaume II de Hainaut acheta deux "targes de Prusse» à Königsberg. L'un de ces boucliers, typiques de la région balte, figure dans un inventaire de la salle d'arme des comtes de Hainaut daté de 1358: C. GaIER, "Achats d'armes et expéditions militaires en Prusse et autres lieux du comte Guillaume II de Hainaut (1336-1344)", dans Idem (dir.), Armes et combats..., p. 229-242.

255 Ibid., p. 256.
} 
même l'unique détail que donne le Carinthien Jean de Victring (m. v. 1347) lorsqu'il mentionne la rèse à laquelle prit part le roi de Bohême en $1329^{256}$. Pierre de Zittau, pourtant critique à l'égard du monarque, rapporte également l'événement ${ }^{257}$. Il ne s'agit pas encore à proprement parler d'un duel entre chevaliers, exécuté selon les normes courtoises; c'est pourtant sous cet angle que le chroniqueur Jean d'Outremeuse évoque l'épisode dans son Myreur des Histors (v. 1400) ${ }^{258}$. Nous y reviendrons dans le dernier chapitre.

Pour Werner Paravicini, le respect dû aux adversaires païens nobles est avant tout le propre des membres de l'Ordre teutonique: vivant sur une longue période dans la région balte, leur attitude était sans doute plus nuancée que celle de la plupart des hôtes de passage ${ }^{259}$. Pourtant, certains parmi ces derniers devaient également être au courant des contacts existant entre les adversaires. Le court extrait de Jacques d'Esch sur l'amitié entre le "roy de Laitue» et le grand-maître, comme la scène du duel entre Jean de Bohême et son adversaire lituanien chez Jean d'Outremeuse, et celle du prisonnier teutonique chez Philippe de Mézières, sont là pour en témoigner ${ }^{260}$. De même, le fait que l'on traite avec les "Sarrasins" n'avait rien de secret pour les hôtes étrangers, comme l'attestent les souvenirs de Jean de Chastelmorand, courtisan du duc de Bourbon et informateur du chroniqueur Cabaret d'Orville :

"Et tant firent chrestiens que les sarrasins furent tous lies d'eulx en realler en leur pays, parmi l'ordonnance faite que, de certain temps, les Sarrasins de Letho ne de Norgalles ne pilleroient nulles esglises des chrestiens ne les brusleroient, ne aussi les chrétiens, chevaliers de la religion, tant de Prusse, comme de Niffelant [Livonie], en leur pays de Letho ou es marches, n'arderoient les saints bois (que ainsi ils appellent) des pins, ou ils consumoient les corps de leurs morts par feu, et en faisoient sacrifice. ${ }^{261}$

Il nous reste des documents attestant que des trêves étaient possibles entre l'Ordre teutonique et ses ennemis, y compris lituaniens ${ }^{262}$, mais aucun accord concernant le respect des bois sacrés et des églises n'est mentionné. On sait toutefois que les Teutoniques savaient faire preuve d'une certaine tolérance, toute pragmatique, envers les pratiques païnnes de leurs sujets baltes; l'épisode

\footnotetext{
256 Jean de Victring, Iohannis abbatis Victoriensis liber certarum historiarum, éd. F. Schneider, vol. 2, MGH SS 36, Hanovre 1910, vol. 2, p. 135; W. PARAvicini, «Litauer...», p. 256.

257 Chronicon Aulae Regiae, dans Fontes Rerum..., p. 294; T. De Puymaigre, «Jean de Luxembourg et la France...", p. 423.

258 PR 2, p. 256; S. C. Rowell, Lithuania Ascending..., p. 240.

259 W. Paravicini, «Litauer... », p. 254-255.

260 Voir ci-dessous, chap. VIII.

${ }^{261}$ Chazaud, p. 65.

${ }^{262}$ Par exemple, la trêve entre l'Ordre teutonique, le roi de Pologne, "Lithwanos et Ruthenos», le 8 avril 1391: Codex Diplomaticus Lithuaniae..., p. 77; CDP 4, p. 126-128.
} 
raconté par Chastelmorand paraît donc crédible ${ }^{263}$. Il nous renseigne également sur la perception des rèses dans la conscience de la chevalerie occidentale. L'auteur de la chronique ne voit aucun déshonneur au fait que la campagne se termine par une trêve rendant la cohabitation religieuse possible. Bien au contraire, puisqu'il enchaîne directement sur l'évocation de la fameuse table d'honneur:

"Si fut octroyé d'une part et d'autre, et par ainsi fut la paix criée par les provinces; et le hault maistre de Prusse qui vit que celle reise s'estoit si bien portée à l'honneur de soi [...] festoya la chevalerie qui o lui estoit moult haultement, et pour l'honneur du jour, le service divin accompli, en son chastel de Mariembourg fit couvrir la table d'honneur. "264

Si l'on s'en tient à cet extrait, les rèses ressemblent à des épisodes de guerre médiévale typique, des raids menés sur les terres de l'adversaire, qui se terminent par la conclusion d'une paix provisoire en attendant la prochaine occasion d'en découdre $^{265}$. L'idéologie des croisades baltes telles que mises en place sous la houlette de la Papauté s'est peu à peu adaptée aux exigences du terrain; les païens sont régulièrement attaqués pour défendre la Chrétienté et étendre ses frontières, mais les combattants savent qu'il est possible de trouver un modus vivendi avec eux. Aussi, la clause du traité concernant le respect des églises peut se lire comme un moyen de défendre le christianisme: les Lituaniens, brisés par les faits d'armes des croisés, jurent de ne pas brûler les églises voisines à condition que les Teutoniques fassent de même. Une paix religieuse qu'imposeraient les circonstances, en quelque sorte. Même si la conversion des "Sarrasins» de Lituanie reste envisagée comme un but dans certains textes, ceux qui relatent le voyage en Prusse savent que l'art de la guerre exige certains compromis; aussi, l'on ne s'offusque pas de constater que les Lituaniens ne sont pas systématiquement évangélisés, ni même qu'on garantisse leur liberté religieuse à l'occasion d'un traité. A titre de comparaison, dans le Mélusine de Jean d'Arras, les croisés emmenés par les fils de la fée, Urien, Guyon et Geoffroy, acceptent de conclure une paix avec les "Sarrasins" de Damas, sans exiger la conversion: dans le contexte oriental aussi, une paix religieuse imposée par réalisme politique et intérêts communs était considérée comme louable ${ }^{266}$.

Jusqu'à la conversion de la Lituanie, la plupart des hôtes occidentaux avaient peu de contacts avec les Baltes, qu'ils ne rencontraient qu'en tant que domestiques ou soldats auxiliaires, éventuellement comme ennemis lors d'un accrochage en campagne ou comme prisonniers ${ }^{267}$. De fait, Werner Paravicini

\footnotetext{
S. C. Rowell, Lithuania Ascending..., p. 121.

${ }^{4}$ Chazaud, p. 65.

265 P. Contamine, La Guerre au Moyen Âge..., p. 365.

266 Jean d'Arras, Mélusine..., p. 648-650; M.-T. De Medeiros, «L’idée de croisade... », p. 150-151.

${ }^{267}$ PR 1, p. 287 sq; 2, p. 84 sq.
} 
postule que les aristocrates de passage étaient trop centrés sur eux-mêmes pour vraiment $s^{\prime}$ intéresser aux autochtones baltes ${ }^{268}$. Une impression similaire ressort du poème de Guillaume de Machaut, où les Lituaniens ne jouent qu'un rôle passif: être baptisés ou mis à mort ${ }^{269}$. De même, la biographie de Boucicaut ne parle des «Sarrasins» que pour dire que beaucoup d'entre eux ont été détruits; s'il est impossible de savoir ce que le maréchal en pensait, son biographe nous dépeint les Lituaniens comme des infidèles tout ce qu'il y a de plus atones, qui ne jouent d'autre rôle que celui de se faire massacrer. Bien que l'usage du terme "Sarrasin» puisse le suggérer, les païens baltes n'étaient pas nécessairement confondus avec les musulmans de Turquie ou d'Afrique du Nord, mais ils leur étaient implicitement assimilés; ce sont des infidèles qui, en tant que tels, représentent une menace pour la Chrétienté, et qu'il est donc glorieux de combattre. Même si dans les faits, la guerre qu'on leur mène n'est pas forcément plus violente ni plus cruelle que celle qui ravage la France à la même époque.

Une certaine coexistence entre adversaires, rendue possible par le partage de valeurs communes, est soulignée par certains voyageurs, dont Jacques d'Esch, Jean de Chastelmorand et Philippe de Mézières, qui remarquent que les rapports entre les Teutoniques et leurs ennemis allaient bien au-delà du simple affrontement guerrier. Lorsqu'il est possible de procéder à un baptême, celui d'un prince ou d'un groupe entier de la population, le fait est rapporté avec fierté270: le Lituanien concerné devient, à certaines occasions, un faire-valoir du héros dont on raconte la rèse, comme dans le cas de Survila, baptisé en présence de Thomas Beauchamp. De ces figures émerge une certaine individualité, notamment celle du grand-duc Vytautas, prince lituanien converti et, dans sa jeunesse, allié des Teutoniques. La situation ambiguë des guerres baltes est amenée à changer par le baptême proclamé en 1387, et qui se conclura bien plus tard par la conversion de la Samogitie, officiellement reconnue en 1417 par le concile de Constance.

\footnotetext{
${ }^{268}$ W. Paravicini, «Litauer...", p. 260.

269 A. Prioult, «Un poète voyageur...", p. 29.

${ }^{270}$ Le baptême des ennemis infidèles à la fin du combat est un classique de la littérature chevaleresque, à commencer par la Chanson de Roland (v. 3975-3991), éd. et trad. P. Jonin, Paris 1979, p. 378. W. Besnardeau, Représentation littéraires de l'étranger au XII siècle. Des chansons de geste aux premières mises en roman, Paris 2007, p. 138, remarque toutefois qu'à partir du XII ${ }^{\mathrm{e}}$ siècle, les «Sarrasins» des chansons de geste ne sont plus systématiquement convertis ou tués.
} 


\section{Troisième partie \\ LE GRAND TOURNANT}





\title{
INTRODUCTION DE LA TROISIÈME PARTIE
}

\begin{abstract}
u début de l'année 1387, le prince lituanien Jogaila proclame la foi $A$ chrétienne à Vilnius. Lui-même baptisé l'année précédente, l'homme est 1 devenu roi de Pologne par mariage: Ladislas II Jagellon, comme on le nomme en français, est à la tête d'un immense ensemble territorial recouvrant le royaume de Pologne et le grand-duché de Lituanie, désormais chrétien. C'est un véritable basculement géopolitique, qui signifie à terme la fin de la croisade balte.
\end{abstract}

Paradoxalement, celle-ci connait ses plus grandes heures aux lendemains du baptême de Vilnius. L'évangélisation de la Lituanie est encadrée et reconnue par Rome, mais la province de Samogitie échappe à ce processus. Théoriquement, il reste donc des païens à combattre sur les rives de la Baltique. Les tensions sont vives entre le nouveau bloc polono-lituanien et l'Ordre teutonique, qui se trouve soudain dans une situation délicate. Dans un premier temps, toutefois, de nombreux croisés accourent d'Europe occidentale, incités par l'exemple de la croisade de Mahdia (1390) et laissés libres de partir, du fait de la période de détente entre la France et l'Angleterre. Profitant d'une querelle entre Jagellon et son cousin Vytautas, les Chevaliers teutoniques et leurs hôtes lancent des rèses dévastatrices contre la Lituanie, manquant de prendre Vilnius. En 1392, néanmoins, les deux cousins se rapprochent et forment une alliance qui s'avérera solide. Commencent alors deux décennies très indécises, faites alternativement de guerres et de paix, jusqu'à la bataille de Tannenberg, qui voit l'effondrement de la puissance teutonique (1410). Le nouveau grand-maitre réclame de l'aide, mais bien peu lui répondent. Entre temps, les chevaliers français et anglais se sont progressivement désintéressés de la croisade balte.

La reprise des hostilités en France et le traumatisme consécutif à la défaite de Nicopolis face aux Turcs (1396) expliquent partiellement la baisse de popularité de la croisade balte auprès de la noblesse occidentale. Mais l'élément le plus important est sans doute l'évangélisation de la Lituanie: à mesure que la nouvelle concernant le baptême de 1387 se diffuse en Europe, de moins en moins de chevaliers se mettent en peine de faire le chemin jusqu'en Prusse. Lorsque la Samogitie reçoit le baptême, en 1417 , la croise balte est déjà presque terminée. Dans le domaine 
littéraire, par contre, le voyage en Prusse reste une thématique prisée, même si des changements notables apparaissent: dans les œuvres $\mathrm{du} \mathrm{Xv}^{\mathrm{e}}$ siècle, le cadre reste celui qui était familier aux contemporains des rèses, mais les acteurs évoluent. Ce ne sont plus contre les Baltes que vont se battre les croisés de Prusse, mais contre les Tatars ou les Turcs; les Lituaniens, quant à eux, font office de héros de la croisade dans certains textes français du milieu du $\mathrm{Xv}^{\mathrm{e}}$ siècle.

Le chapitre $\mathrm{V}$ couvre la période allant de la proclamation du christianisme à Vilnius en 1387 au baptême de la Samogitie en 1417, et s'intéressera notamment à la correspondance épistolaire, essentielle pour saisir comment la conversion de la Lituanie a été perçue en Europe occidentale, auprès des princes et de la hiérarchie ecclésiastique, mais aussi des écrivains. Le fait que la foi progresse soudainement parmi les «Sarrasins» de la Baltique sans que l'Ordre teutonique n'y joue le rôle principal met ce dernier dans une position relativement ambiguë, bien qu'il reste considéré avec respect par une partie importante de l'aristocratie occidentale. Lorsque la nouvelle de la défaite infligée aux Teutoniques à Tannenberg retentit en Europe de l'Ouest, les chroniqueurs français qui en rendent compte adoptent un point de vue clairement favorable à l'Ordre, ce qui est moins évident en Angleterre et ailleurs en Europe. Enfin, les discussions au concile de Constance autour du contentieux entre Cracovie, Vilnius et Marienbourg provoquent un certain fléchissement dans le soutien occidental envers l'Ordre teutonique. S'emparant du cas samogitien, Jagellon et Vytautas se présentent comme des défenseurs et des propagateurs zélés du christianisme auprès des derniers infidèles de la Baltique. Après avoir vaincu l'Ordre sur le champ de bataille, ils parviennent à lui faire concurrence sur le terrain politique.

La fin réelle du voyage en Prusse et sa survivance dans la littérature est au cœur du chapitre VI. Il importe bien sûr de comprendre pourquoi les chevaliers occidentaux ont cessé de se rendre auprès des Teutoniques dès la fin des années 1390, alors qu'ils étaient auparavant nombreux à prendre part aux rèses contre la Lituanie de Jagellon. Une certaine hésitation quant au bien-fondé de nouvelles croisades se dégage des sources, alors que la connaissance du changement survenu en 1387 pénètre peu à peu les esprits. Et le fait que l'Ordre teutonique reste célébré comme une institution chevaleresque honorable ne change rien à l'évolution qui se met en place: sur le terrain, mais aussi dans le domaine des lettres, les Teutoniques doivent composer avec leurs rivaux lituaniens et polonais, qui entendent bien se présenter en fer de lance de la croisade. Au milieu du $\mathrm{Xv}^{\mathrm{e}}$ siècle, des écrivains comme Antoine de la Sale ou le héraut d'armes Berry donnent les Tatars comme adversaires aux croisés de Prusse, puis le souvenir de cette croisade nordique s'estompe. Avant de terminer cette troisième partie, nous découvrirons quelques textes critiques envers l'institution des rèses de Prusse: même lorsque celle-ci battait son plein, il se trouvait des auteurs pour s'en moquer ou pour la qualifier de perte de temps et de vanité. 


\section{Chapitre V \\ LA LITUANIE CHRÉTIENNE}

\section{Un roi lituanien pour la Pologne}

Alors que dans le dernier quart du XIv ${ }^{e}$ siècle le voyage en Prusse bat son plein, plusieurs changements surviennent dans la vie politique et religieuse de la Lituanie, qui à terme signifieront la fin de la croisade balte et un tournant dans la manière dont les lettrés occidentaux perçoivent le grand-duché. Dans une étude récente, Darius Baronas explique ce basculement par une évolution des partis à l'intérieur de la noblesse lituanienne ${ }^{1}$. Bien que le pouvoir ait été tenu, depuis la mort de Mindaugas, par une dynastie païenne, les chrétiens catholiques et orthodoxes n'étaient pas absents de la vie politique et sociale du grand-duché. Tout en s'efforçant de maintenir la cohésion sans rien imposer à personne ${ }^{2}$, Gediminas et ses fils s'appuyaient sur les tenants de la religion traditionnelle - et leur politique rencontrait une adhésion certaine tant que le succès militaire était au rendez-vous. La particularité religieuse lituanienne permettait de faciliter les négociations internationales en faisant miroiter la conversion, mais elle servait aussi de prétexte à la continuation des raids incessants contre le grand-duché3. Selon cette interprétation, la prise retentissante de Kaunas en 1362, racontée par la Scalacronica, aurait sonné l'heure des "partis chrétiens", menés par les jeunes fils d'Algirdas et de Kęstutis.

Plusieurs raisons peuvent avoir poussé la jeune génération de princes lituaniens à envisager sérieusement la conversion ${ }^{4}$. A l'époque où le pouvoir des grandsducs s'affirme en Lituanie comme à l'international, le pays manque de structures

${ }^{1}$ D. Baronas, "Christians in Late Pagan...", notamment p. 61-65.

2 À cet égard, S. C. Rowell a pu parler de "Pax Lithuanica» (Lithuania Ascending..., p. 294).

3 W. Urban, The Samogitian Crusade..., p. 140-142.

${ }^{4}$ Sur cette période, D. Baronas, "Christians in Late Pagan...", p. 51-81; D. Baronas, S. C. Rowell, The Conversion..., p. 221-260; M. Giedroyć , "The Arrival of Christianity...», p. 34-57. Sur la fille de Vytautas régente de Moscou et veuve du grand-prince, I. LaLKoù, Aperçu..., p. 28 ; sur la suzeraineté lituanienne dans l'actuelle Roumanie, N. Riasanovsky, Histoire..., p. 150; sur le soutien de l'Église russe à Moscou, M. Heller, Histoire..., p. 119-120. 
éducatives, gérées dans les pays voisins par l'Église 5 . À cela s'ajoute l'obligation de trouver un allié stable. Les projets d'Algirdas, qui se rêvait en héritier de la Rus' kiévienne, sont contrecarrés par l'Église orthodoxe, plutôt favorable au grand-prince de Moscou, alors en pleine ascension. La Moldavie, la Valachie et la Bessarabie passent sous contrôle lituanien à la fin du XIv siècle et Algirdas entreprend d'écrire au patriarche de Constantinople pour présenter la Lituanie comme un rempart de l'Église orthodoxe contre l'Ouest latin, mais sans résultat: la balance penche en faveur des princes moscovites. À la mort d'Algirdas (1377), le grand-maitre Winrich de Kniprode entreprend de faire tomber la diarchie en soutenant le fils du défunt, Jogaila, contre le vieux Kęstutis. Jogaila prend Vilnius avec l'aide des Teutoniques et force son rival à se rendre; celui-ci, emprisonné, meurt dans des circonstances peu claires à l'été $1382^{6}$. Jogaila peut s'emparer du pouvoir, que lui dispute pendant une dizaine d'années son cousin Vytautas, à son tour allié occasionnel de l'Ordre. Ainsi commence le règne de celui que l'on retrouvera en français sous le nom de Jagellon, fondateur de la dynastie qui porte son nom et qui a régné en Pologne et en Lituanie jusqu'en $1572^{7}$.

En Pologne, l'époque est également marquée par de grands changements. Le roi Casimir le Grand, sans héritier direct, choisit son neveu Louis d'Anjou, roi de Hongrie, pour lui succéder (novembre 1370). Profitant de la rare présence du monarque, la haute noblesse s'arroge une part importante du pouvoir ${ }^{8}$. À la mort de Louis d'Anjou (10 septembre 1382), le trône de Pologne échoit à sa jeune fille Hedwige, couronnée "rex» en 1384 et fiancée à Guillaume d'Autriche, un prince de la maison de Habsbourg'. Le pouvoir effectif reste cependant détenu par l'oligarchie cracovienne, composée de membres de la haute noblesse et de prélats, qui ne veulent pas du Habsbourg comme roi. C'est à ce moment-là que des émissaires lituaniens, notamment Skirgaila, un frère de Jagellon, proposent un marché aux magnats polonais ${ }^{10}$ : le grand-duc serait prêt à recevoir le baptême pour épouser Hedwige et devenir ainsi roi de Pologne et en échange, il s'engage à convertir la Lituanie ${ }^{11}$. La proposition est tentante; d'une part, la conversion du dernier bastion européen du paganisme amènerait une gloire certaine à

\footnotetext{
${ }^{5}$ Z. KIaUpa, The History of Lithuania..., p. 43; Z. Sulowski, «Le baptême... », p. 53, remarque que c'est l'une des raisons qui a rendu le christianisme attractif aux royaumes de l'Europe centrale et septentrionale aux $\mathrm{X}-\mathrm{XI}^{\mathrm{e}}$ siècles.

${ }^{6}$ L'historiographie tend à considérer que Kęstutis, son épouse et ses proches, ontété exécutés, probablement sur l'ordre de Jagellon. Lors du concile de Constance, les délégations polonaises et lituaniennes uniront leurs voix pour nier cette accusation: S. C. RoweLL, «Pious Princesses...», p. 25, n. 44.

7 H. Paszkiewicz, The Origin..., p. 233-235.

${ }^{8}$ B. GUEnÉE, Histoire et culture historique..., p. 154-155; S. GaWLAS, «Polen - eine Ständegesellschaft an der Peripherie des lateinischen Europa», dans R. C. Schwinges, C. Hesse, P. Moraw (dirs.), Europa im späten Mittelalter. Politik - Gesellschaft - Kultur, Munich 2006, p. 237-261.

9 Sur Hedwige d'Anjou, O. HaLeCKI, Jadwiga of Anjou and the rise of East Central Europe, Boulder etc. 1991.

${ }^{10}$ Dans la Pologne et la Hongrie médiévale, un magnat est un membre de la haute noblesse.

11 D. Baronas, S. C. Rowell, The Conversion..., p. 242-243.
} 
l'Église polonaise, alors que le rapprochement entre les deux pays permettrait de mettre un terme aux raids lituaniens et de gagner un appui solide contre l'Ordre teutonique, dont la mainmise sur les régions septentrionales du royaume inquiète la noblesse ${ }^{12}$. Face aux Tatars et à Moscou, les deux pays ont également un intérêt géopolitique commun ${ }^{13}$. Comme au temps de Ladislas le Bref, le grand empire païen est un parti intéressant, nettement plus que l'Autriche.

Du côté lituanien, Jagellon semble avoir préféré la conversion de son pays à une éternelle résistance armée contre les Teutoniques. Dans un premier temps, c'est le monde orthodoxe qui est en vue, lorsqu'en 1384, le grand-prince Dimitri de Moscou propose à Jagellon d'épouser sa fille et de convertir toute la Lituanie à la foi orthodoxe. Ce projet ne se concrétisant pas ${ }^{14}$, l'option catholique s'impose ${ }^{15}$. Le 14 août 1385, un accord est conclu à Krewo entre Jagellon et les délégués polonais, qui lui promettent la main d'Hedwige et l'accession au trône de Pologne en échange de sa conversion et de celle de son pays. Les deux États devant être réunis sous la couronne du roi de Pologne, il s'agit plus d'une union personnelle que de la fusion entre la Pologne et la Lituanie $^{16}$.

Le 15 février 1386, à Cracovie, le grand-duc de Lituanie est baptisé par l'archevêque de Gniezno, Bodzanta de Kosowice, et reçoit le prénom chrétien de Ladislas (ou Władysław, en polonais); il sera désormais connu comme Ladislas Jagellon. Le 18 février 1386, il épouse Hedwige et est couronné roi de Pologne le 4 mars par l'archevêque de Raguse Maffiolo Lampugnano, le légat du pape romain Urbain $\mathrm{VI}^{17}$. Contraints ou non, les princes lituaniens et ruthènes témoignent rapidement de leur fidélité à Jagellon, mais aussi à Hedwige et dans certains cas, à la couronne polonaise ${ }^{18}$. Au début de l'année suivant son couronnement, Jagellon proclame la foi catholique à Vilnius et y fait édifier une cathédrale sur les ruines du temple païen ${ }^{19}$. L'année d'après,

\footnotetext{
12 H. Paskiewicz, The Origin..., p. 239-241.

13 Ibid., p. 245-6.

14 Ibid., p. 236-237; P. RabikausKas, "Les Jagellons... », p. 393-394.

${ }^{15}$ Le point de vue traditionnel de l'historiographie est illustré, en langue française, par F. Dvornik, Les Slaves..., p. 553-555, n. 8: "Seule l'acceptation du christianisme latin pouvait mettre un terme à l'activité "missionnaire" de l'Ordre». Pour une approche récente, insistant plus sur les décisions du "parti» catholique lituanien, D. BAronas, "Christians in late pagan...", p. 51-81; H. PAszKiewicz, The Origin..., p. 246-247, notait déjà que les influents marchands allemands de Vilnius, lassés par les incursions de l'Ordre teutonique, peuvent avoir joué un rôle dans les démarches de Jagellon.

${ }^{16}$ Le traité est édité dans Akta unji Polski z Litwa 1385 - 1791, éd. St. Kutrzeba, Wł. Semkowicz, Cracovie 1932, doc. 1, p. 1-3. Pour une étude récente, R. Frost, The Oxford History of PolandLithuania: Volume I: The Making of the Polish-Lithuanian Union 1385-1569, Oxford 2015.

${ }_{17}$ J. Koncius, Vytautas..., p. 33.

${ }_{18}$ Par exemple, Codex Epistolaris Vitoldi, éd. A. Procharska, Cracovie 1882 (ci-après: CEV), doc. 29 et 30, p. 10; sur le contexte: D. Baronas, S. C. Rowell, The Conversion..., p. 261-326.

19 A. KaJaCKas, «Archeological Investigations...», p. 273-276.
} 
un évêché est créé, avec le Polonais Andrzej Jastrzębiec comme premier titulaire, et d'autres églises sont bâties ailleurs en Lituanie ${ }^{20}$. La nouvelle province ecclésiastique est rattachée au diocèse de Gniezno, des missionnaires dominicains, franciscains et augustins sont établis dans le pays et des églises paroissiales voient le jour ${ }^{21}$. Lorsque Jagellon et Hedwige entreprennent de restaurer l'Université de Cracovie tombée en désuétude après sa fondation par Casimir le Grand en 1364, ils justifient la création d'une faculté de théologie par le besoin de former des prêtres pour l'évangélisation de la Lituanie ${ }^{22}$. Quelques années avant sa mort (survenue le 17 juillet 1399), la reine avait également financé la création d'un collège lituanien à l'Université de Prague, qui devait accueillir les étudiants en théologie amenés à travailler à la mission dans le grand-duchéén.

La cour et l'Église de Pologne ont certes participé à la propagation du christianisme auprès des Lituaniens - et la reine Hedwige semble avoir eu à cœur d'apporter sa pierre à l'édifice ${ }^{24}-$, mais c'est avant tout le choix du prince et de ses proches qui a défini l'orientation religieuse et géopolitique du grandduché $^{25}$. À cet égard, Jagellon semble avoir pris soin de présenter le passage à la nouvelle religion comme une initiative venant de lui-même, et non de

20 Sur la christianisation de la Lituanie, D. Baronas, S. C. Rowell, The Conversion..., p. 261-326; D. Baronas, "Christians in Late pagan... », p. 65-68; J. KŁoczowski, «La Pologne et la christianisation de la Lituanie", dans La Cristianizzazione della Lituania..., p. 148-151; M. ZAHAJKIEWICZ, "Théorie et pratique de l'évangélisation dans le processus de christianisation de la Lituanie", dans La Cristianizzazione della Lituania..., p. 205-218; S. ZajĄCZKowsKI, "The Christianisation of Lithuania by Poland", dans J. Braun (dir.), Poland in Christian Civilisation, Londres 1985, p. 189-193.

${ }^{21}$ D. Baronas, S. C. Rowell, The Conversion..., p. 459-517.

22 P. Knoll, "A Pearl of Powerful Learning": The University of Cracow in the Fifteenth Century, Leiden 2016, p. 34 passim.

${ }^{23}$ Ibid., p. 29-30; O. MARIn, L'archevêque, le maître et le dévot. Genèses du mouvement réformateur pragois. Années 1360-1419, Paris 2005, p. 116; K. OżóG, Uczeni..., p. 35.

${ }^{24}$ Le rôle d'Hedwige est souvent mis en avant dans l'historiographie polonaise: cette femme populaire, cultivée et dévouée peut certes être vue comme un jouet entre les mains de l'oligarchie de Cracovie, mais semble avoir joué un certain rôle en secondant son mari dans les efforts d'évangélisation menés en Lituanie, et en maintenant des relations cordiales avec l'Ordre teutonique. Participant à la rénovation de l'Université de Cracovie, elle meurt en 1399, une année avant d'en voir le fruit. La mémoire nationale polonaise l'a rapidement considérée comme une sainte, et Jean-Paul II l'a officiellement canonisée en 1997. Voir T. SiLnicki, "Queen Jadwiga (1374-1399)", dans J. Braun (dir.), Poland..., p. 211-244 et O. Halecki, Jadwiga.... Contrairement à ce qu'affirme le chroniqueur Jan Długosz, la reine ne s'est toutefois pas rendue elle-même en Lituanie pour participer à l'évangélisation; P. RabiKauskas, "Les Jagellons... », p. 395. Sur Hedwige d'Anjou comme passeuse de culture entre l'Occident et la Pologne, M. Bogucka, "The court of Anne Jagiellon. Its Size, Structure and Functions", dans U. BorkowsKa, M. Hörsch (dirs.), The Culture of the Jagellonian and related Courts, Ostfildern 2010, p. 99; K. OżóG, «University masters at the royal court of Hedwige of Anjou and Wladyslaw Jagiello», dans P. Gorecki et al. (éd.), Central and Eastern Europe in the Middle Ages: a cultural history, Tauris 2009, p. 147-160.

25 S. Gouguenheim, Les Chevaliers teutoniques..., p. 441. 
l'étranger ${ }^{26}$. La religion jouant, dans l'ancienne Lituanie, le rôle de tissu social, il était somme toute naturel de suivre le prince au moment où celui-ci décide de recevoir le baptême ${ }^{27}$. De plus, la noblesse autochtone était déjà largement familiarisée avec le mode de vie occidental, et n'avait ainsi que peu de réticence à embrasser la foi catholique ${ }^{28}$. Enfin, une communauté chrétienne relativement importante existait dans les principaux centres urbains de Lituanie, ce qui fait que la nouvelle foi n'était pas inconnue des habitants ${ }^{29}$.

En 1392, Jagellon laisse les rênes du grand-duché à son cousin Vytautas, avec qui il s'est définitivement réconcilié la même année, lors du traité d'Astrava; en mars 1401, Vytautas obtient le titre de grand-duc à la suite de l'Union de Vilnius et Radom ${ }^{30}$. Bien que Jagellon reste officiellement supremus dux Lithuania, son cousin gouverne le pays de manière autonome ${ }^{31}$. Prince énergique, Vytautas aurait été à la fin de sa vie - en 1430 - prêt à se faire couronner roi, avec l'appui de Jagellon et Sigismond de Luxembourg, roi de Hongrie et roi des Romains, mais la légende veut que les nobles polonais aient intercepté la couronne envoyée par le pape $^{32}$. La Lituanie reste donc formellement attachée à la Pologne par l'union dynastique, mais maintient une certaine autonomie.

Le baptême du souverain lituanien est connu très tôt au-delà des frontières. Les premiers concernés sont sans doute les Habsbourg, dont l'un des représentants, Guillaume, a été éconduit pour que sa fiancée Hedwige puisse épouser Jagellon ${ }^{33}$. Un dédommagement financier est versé au père du malchanceux, le duc Léopold. S'estimant floué, celui-ci essaye de protester mais ne rencontre pas de soutien en dehors des Chevaliers teutoniques, et lorsqu'après la mort d'Hedwige, en juillet 1399, Guillaume d'Autriche essayera

\footnotetext{
26 P. Rabikauskas, «Les Jagellons... », p. 395 ; J. KŁoczowski, « La Pologne et la christianisation... », p. 147.

27 A. Besançon, «Les baptêmes...", p. 18. Rappelons que la religion traditionnelle des Lituaniens était loin d'être aussi «militante» et exclusive que les sources teutoniques ne le laissent entendre; il n'y avait pas de religion païenne unifiée, mais plusieurs pratiques et coutumes propres aux artisans, aux soldats, etc. Aussi le christianisme n'était-il pas confronté à un front "anti-chrétien " uni: D. Baronas, S. C. Rowell, The Conversion..., p. 277, 333-335 (sur le cas spécifique de la Samogitie); S. C. Rowell, Lithuania Ascending..., p. 118 sq.

${ }_{28}$ S. C. Rowell, «Unexpected...", p. 557.

${ }^{29}$ D. Baronas, S. C. Rowell, The Conversion..., p. 221-226; les enquêtes archéologiques ont notamment révélé la présence de croix dans le cimetière de la ville de Kernavé, ce qui indique que les communautés chrétiennes (orthodoxes ou catholiques) n'étaient pas cantonnées dans la capitale. ${ }^{30}$ Le texte de l'Union de Vilnius et Radom est édité dans Codex Diplomaticus Poloniae quo continentur Privilegia, éd. L. Rzyszczewski et al., Varsovie 1847, vol. 1, doc. 151, p. 271-274. R. Frost, The Oxford History..., vol. 1, p. 86, remarque que le titre porté par Vytautas (dux, magnus $d u x$, supremus $d u x$ ) change selon les circonstances et les sources. G. Mickūnaité, Making..., p. 6, rappelle que Vytautas dirigeait de manière effective le pays depuis son deuxième retournement.

31 R. Frost, The Oxford History..., p. 92-93.

${ }^{32}$ L. TeIBeris, La Lituanie..., p. 47.

33 Sur ce qui suit, voir notamment O. Halecki, Jadwiga..., p. 113-172; S. Gouguenheim, Tannenberg..., p. 25-26.
} 
de faire valoir sa prétention au trône polonais, même le grand-maître de l'Ordre Conrad de Jungingen prendra ses distances ${ }^{34}$. Tout porte à croire que pour les dirigeants de l'Europe chrétienne, le baptême de Jagellon et la conversion de la Lituanie étaient plus importants que le respect des droits du prince autrichien ${ }^{35}$.

Les lettres diplomatiques qui nous sont restées attestent que l'Église de Rome suivait avec soin le processus. Le 24 juillet 1386, autrement dit déjà avant le baptême officiel de la Lituanie, Maffiolo Lampugnano, le légat «romain " qui a présidé au couronnement de Jagellon, peut annoncer à l'archevêque de Cologne cette bonne nouvelle:

"Avec un très grand bonheur, nous avons découvert de manière évidente que l'illustre prince Ladislas, roi de Pologne, venant alors des ténèbres des erreurs à la lumière de la vérité, et ayant reçu avec la dévotion de l'humilité le sacrement du baptême, en compagnie de certains ducs ses frères et d'une grande multitude de son peuple de Lituanie, est célébré par tous comme révérant Dieu et la religion chrétienne de manière authentique et reconnue. ${ }^{36}$

La conversion personnelle de Jagellon s'est donc accompagnée de celle de plusieurs de ses «frères" et d'une partie non négligeable de courtisans $s^{37}$. La suite de la lettre informe le puissant archevêque, membre du collège des électeurs impériaux, que le mariage entre Hedwige et Jagellon «existe d'une façon qui plait au seigneur et a été consommé de manière lonable ${ }^{38}$, ce qui écarte les revendications des Habsbourg et de leurs alliés. Jagellon est, en outre, engagé du côté romain ${ }^{39}$, ce qui, dans le contexte du Schisme, a son importance. Malgré les quelques tentatives engagées par Clément VII d'Avignon pour faire imposer «son" candidat à la succession de Louis d'Anjou ${ }^{40}$, la Pologne - et avec elle la Lituanie en voie de conversion - reste attachée à Rome, tout comme l'Ordre teutonique ${ }^{41}$.

Dans une bulle du 30 décembre 1387, le pape de Rome, Urbain VI, fait part de sa joie aux ducs de Mazovie et à d'autres princes polonais à

\footnotetext{
${ }^{34}$ G. B£AszczyK, Dzieje..., p. 101; 104.

35 T. Silnicki, "Queen Jadwiga...", p. 121-123; A. Grabski, Polska w Opiniach Europy..., p. 195-201; O. Halecki, Jadwiga..., p. 167 sq.

${ }^{36}$ Codex epistolaris saeculi decimi quinti, éd. A. Lewicki, vol. 2, Cracovie 1891 (ci-après: CES), doc. 8, p. 10.

37 R. Frost, The Oxford History..., p. 76.

${ }^{38}$ CES 2, doc. 8, p. 10.

39 Ibid.

${ }^{40}$ Ladislas le Blanc (mort en 1388) était un prince de la maison des Piast, qui avait pris part en 1366 à une croisade en Lituanie aux côtés des Chevaliers teutoniques. Il est ensuite devenu bénédictin à Dijon, pour être relevé de ses vœux et envoyé en Pologne par Clément VII afin d'en revendiquer le trône; K. Górski, A. Tomczak, Polska-Francja..., p. 23-24; N. Valois, La France et le grand schisme d'Occident, Paris 1896, vol. 2, p. 310-311.

${ }^{41}$ Sur cette lettre et la mission du légat Lampugnano en Pologne, O. Halecki, Jadwiga..., p. $158-159$.
} 
la nouvelle de la conversion du grand-duc de Lituanie ${ }^{42}$. En dépit du rapport de l'archevêque de Raguse, il faut attendre presque deux ans pour que le pontife ne gratifie Jagellon d'une lettre de congratulation. Pour Norman Housley, un tel retard est imputable à l'obstruction faite par les Teutoniques et à la moindre efficacité des canaux de communication polonais ${ }^{43}$. On peut aussi penser que le pape a simplement attendu que l'affaire opposant les Habsbourg à Jagellon soit réglée avant de normaliser ses relations avec ce dernier. En effet, Urbain explique, dans cette même lettre aux princes polonais, qu'étant donné la plainte autrichienne au sujet du mariage d'Hedwige, il ne peut pas qualifier Jagellon, "très cher et aimé fils en Dieu», de roi, mais seulement de duc ${ }^{44}$. Celui-ci est pourtant nommé aux côtés d'Hedwige et appelé "roi de Pologne" dans les bulles suivantes, ce qui paraît attester que la validité du mariage ainsi que le titre royal de Jagellon ont enfin été reconnus ${ }^{45}$.

Moins de trois mois plus tard, le 12 mars 1388, Urbain VI écrit à l'évêque de Poznań, Dobrogost, au sujet d'une église fondée à Vilnius, au lieu même où, avant le baptême du roi, "les Lituaniens et les autres infidèles adoraient superstitieusement, en ce sanctuaire, les vaines puissances des dieux et des idoles» ${ }^{46}$. L'église, dédiée à la Trinité et à Saint Stanislas, reçoit le statut de cathédrale, et un évêque est nommé pour occuper le siège épiscopal ${ }^{47}$. Le cardinal italien Bonaventura, envoyé avant 1388 par le pape pour établir un rapport dans l'affaire opposant Jagellon aux Habsbourg, peut constater alors l'existence de l'évêché de Vilnius ${ }^{48}$. La Papauté se tient informée par ses légats, qui, comme aux siècles passés, sont dépêchés pour se renseigner et épauler les efforts de conversions, et par les missives des prélats polonais - en premier lieu, celles de l'énergique évêque Dobrogost de Poznań, à qui Grzegorz Błaszczyk attribue le succès de la campagne d'information au sujet du baptême de la Lituanie $^{49}$. À titre d'exemple, le 17 avril 1388, Urbain VI écrit à Jagellon pour lui faire part des bonnes impressions de l'évêque, qui l'a informé de la progression de la

\footnotetext{
${ }^{42}$ La bulle est éditée dans Lucas David, Preussische Chronik..., vol. 7, p. 201-203; CEV, doc. 36, p. 14.

43 N. Housley, The Later Crusades..., p. 354-355.

${ }_{44}$ Lucas David, Preussische Chronik..., vol. 7, p. 201-203.

${ }^{45}$ Voir notamment Bullarium Poloniae: litteras apostolicas aliaque monumenta Poloniae Vaticana continens, éd. I. Sułkowska-Kuraś, S. Kuraś, M. Kowalczyk, A. et H. Wajs, Rome-Lublin 1982-2006 (ci-après BP), volume 3, doc. 51, p. 11; doc. 52, p. 11; O. НALECKI, Jadwiga..., p. 169-171

${ }_{46}$ BP 3, doc. 51, p. 11; doc. 52, p. 11; la bulle est éditée au complet dans Codex diplomaticus ecclesiae cathedralis necnon Dioeceseos Vilnensis, éd. J. Fijalek, W. Semkowicz, Cracovie 1932, vol. 1, doc. 10, p. 20-22.

47 BP 3, doc. 51, p. 11 ; doc. 52, p. 11.

${ }^{48}$ La mission du cardinal Bonaventura est racontée par le chroniqueur padouan Andrea Gatari;

A. Grabski, "Jadwiga-Wilhelm-Jagiello w opiniach europejskich», Nasza Przesztość, vol. 23, Cracovie 1966, p. 117-166; O. Halecki, Jadwiga..., p. 167-170.

${ }^{49}$ G. B£aszczyK, Dzieje..., p. 444-5.
} 
foi en Lituanie ${ }^{50}$. L'année précédente, une ambassade polonaise s'était rendue auprès du pontife à Lucques ${ }^{51}$.

La Lituanie est donc, aux yeux de Rome, en bonne voie d'évangélisation. Mieux encore, son prince peut devenir, de païen qu'il était, un champion du Christ. Le premier avril 1388, le pape écrit directement à «l'illustre roi de Pologne Ladislas, très cher fils en Dieu» pour lui octroyer des indulgences afin de combattre "en faveur de la foi contre les Turcs, les Tatars, et les autres nations barbares ennemies du nom chrétien $"^{52}$. Dans une seconde lettre du 17 avril, le souverain pontife demande à Jagellon de conclure la paix avec l'Ordre teutonique ${ }^{53}$. Ces bulles attestent d'efforts importants pour intégrer le roi converti à la politique européenne: en incitant Jagellon à se croiser contre les musulmans et à régler pacifiquement ses relations avec l'Ordre, Urbain VI entendait le traiter comme un souverain chrétien légitime, lui demandant d'appliquer le programme habituel taillé sur mesure pour un prince idéal: en paix avec ses voisins chrétiens, en croisade contre les infidèles. Tout semble indiquer qu'à Rome, on a rapidement intégré le fait qu'une fois le souverain de la Lituanie converti, son peuple ne représente plus de menace. Les rèses effectuées depuis un bon demi-siècle avec l'accord plus ou moins tacite de la Papauté doivent à présent être remplacées par des expéditions contre d'autres infidèles, ayant cette fois-ci le statut officiel d'une croisade, avec indulgences données aux combattants sur la permission explicite du Saint-Siège. En 1395, le roi des Romains, Wenceslas de Luxembourg, interdit les croisades contre le grand-duché, ce qui, malgré les protestations des Chevaliers teutoniques, est confirmé en 1403 par le pape de Rome Boniface IX ${ }^{54}$.

À partir du printemps 1388 en tout cas, l'isolement diplomatique de la Lituanie est brisés5. Un document que l'on peut dater d'entre 1386 et $1388^{56}$, trouvé et édité par l'historien français Noël Valois, atteste que la cour française a été tenue au courant de la conversion du souverain lituanien relativement rapidement. Il s'agit d'une lettre envoyée par la chancellerie de Charles VI à Ladislas Jagellon, où l'on apprend que c'est par l'intermédiaire d'un membre de l'Ordre teutonique que le roi français a appris l'événement: "de la relation de notre cher Jean de Strate, chevalier de l'éminent ordre des seigneurs chevaliers

\footnotetext{
50 BP 3, doc. 53, p. 11.

${ }^{5}$ O. Halecki, Jadwiga ..., p. 170.

52 CES 2, doc. 13, p. 17; BP 3, doc. 52, p. 11.

53 BP 3, doc. 54, p. 12; CES 2, doc. 14, p. 18-19.

${ }^{54}$ L'interdiction par Wenceslas de Luxembourg est mentionnée par Jean de Posilge, Chronique..., SRP 3, p. 196-197. Une protestation du grand-maitre Conrad de Jungingen est éditée dans CDP 5, doc. 137, p. 186-192. G. BŁaszczyк, Dzieje..., p. 445; S. Gouguenheim, Les Chevaliers teutoniques..., p. 441-442; G. MicKūNaItĖ, Making..., p. 37.

55 Ibid., p. 36-38.

56 Pour la datation, A. Grabski, Polska w Opiniach Europy..., p. 209; J. Jakstas, Das Baltikum..., p. 172.
} 
de Prusse, nous avons appris que votre personne, avec quatre autres de vos frères, est digne d'être visitée pieusement et sainement, avec bonté et dignité» ${ }^{57}$. Jean de Strate, que Charles VI recommande à son destinataire, est décrit comme un sujet français membre de l'Ordre teutonique, "une personne assidue à la défense de la vraie foi, par de nombreuses auvres de chevalerie " ${ }^{58}$. Les données recueillies par Werner Paravicini confirment cet impressionnant palmarès: chevalier flamand, Jean de Strate (Jan van der Straten) s'est vraisemblablement rendu quatre fois en Prusse comme hôte, entre 1363 et 1377, avant de devenir membre de l'Ordre teutonique ${ }^{59}$. Un parcours exceptionnel pour un sujet du roi de France.

Un ajout en marge d'un des manuscrits du Songe du vieil pelerin indique que son auteur, Philippe de Mézières, a également été tenu au courant de la christianisation de la Lituanie après avoir terminé la rédaction de son œuvre, en 1389. D’après les recherches menées par Joël Blanchard, l'écrivain aurait fait rédiger par un scribe professionnel ce "manuscrit "matrice" " ${ }^{60}$ autour de $1390^{61}$, avant de le modifier par des ajouts, dont quelques-uns de sa propre main $^{62}$. C'est le cas de deux passages qui font figurer la Lituanie parmi les pays chrétiens $^{63}$, ce qui signifie que Mézières a eu connaissance de la conversion du pays - ou a décidé que cette nouvelle donne devait être prise en compte - après avoir terminé la rédaction de l'ouvrage confié au scribe, soit après 1390. À noter que les deux phrases qui nous intéressent sont intégrées dans le corps du texte d'un manuscrit du Songe rédigé quelques années plus tard, vraisemblablement pour le connétable de France, Arthur de Richemont. Cela peut indiquer que le caractère chrétien de la Lituanie était considéré comme acquis au début du $\mathrm{XV}^{\mathrm{e}}$ siècle, date de composition de ce deuxième manuscrit ${ }^{64}$.

L'extrait en question se trouve au livre III du Songe, qui regroupe les conseils que l'auteur donne au roi Charles VI, destinataire de l'œuvre. Il y est notamment question des ambassadeurs que la cour de France devrait envoyer aux têtes couronnées de par le monde. L'un d'entre eux devrait se rendre en Norvège, Suède et Danemark, puis en Prusse, "au grant maistre de l'amirable et saincte religion" ${ }^{65}$. Le même ambassadeur "porra aler aussi ou royaume de Polane,

\footnotetext{
57 Bibl. Cambrai, Ms. 940, n 100, fol. 43v.; N. Valors, La France et le grand schisme..., vol. 2, p. 311-312, n. 3 .

58 Ibid., p. 311; K. Polejowski, "The Teutonic Order's Propaganda... », p. 237.

59 PR 1, p. 71.

${ }^{60}$ Blanchard, p. XXIII.

${ }^{61}$ En se basant sur une analogie entre l'âge du roi et le nombre de cors du cerf-volant figurant sur une miniature du manuscrit Arsenal mss. 2682-2683, J. Blanchard (Ibid., p. XV, n. 4), pense pouvoir situer l'exécution de ce manuscrit dans l'année des 21 ans de Charles VI, soit entre fin 1389 et le 2 décembre 1390.

62 Ibid., p. XII-XXIII.

${ }^{63}$ Arsenal ms. 2683, fol. 190v et fol. 193v.

${ }^{64}$ Le manuscrit de Richemont n'a pas été identifié avec certitude; il a toutefois servi de modèle au manuscrit de la BNF (ms. fr. 22542). Sur sa datation, Blanchard, p. XXXV-XXXVI.

${ }^{65}$ Blanchard, vol. 2, p. 1262.
} 
qui joint a Prusse, et es seignouries d'entour, partout faisant son office» ${ }^{66}$. La note marginale, vraisemblablement de la main de Mézières lui-même, ajoute:

"duquel roiame de Polane le roy de Laito [Lituanie], a cause de sa feme, roine de Polaine, fille du vaillant roy de Honguerie, est devenu rois et bon Crestien, aveuc. iiii. de ses freres et son peuple de Laito, par la bonté de mon Pere, a grant honnour de la foy crestienne. " ${ }^{67}$

Le lecteur aura reconnu Jagellon et son épouse Hedwige d'Anjou. La mention du baptême des quatre frères de Jagellon rappelle le message envoyé par Charles VI au roi néophyte, ce qui attesterait une source commune: en l'occurrence Jean de Strate, le chevalier teutonique flamand mentionné dans la lettre du roi de France ${ }^{68}$. Philippe de Mézières, bien que retiré au couvent des Célestins de Paris à partir de 1380, était resté proche de la cour, et continuait d'écrire pour promouvoir la libération de la Terre sainte. L'ancien chancelier de Chypre, qui se maintenait au courant des affaires religieuses et politiques d'Europe, a sans doute entendu parler de la conversion du nouveau roi de Pologne $^{69}$. Qui plus est, les informations dont il disposait sont plus fournies que celles données par la chancellerie royale dans la lettre adressée à Jagellon. Mézières a-t-il eu vent de ces détails par d'autres canaux, ou Jean de Strate était-il le seul informateur?

La missive envoyée par Charles VI au roi de Pologne est plus laconique que l'ajout marginal que l'on trouve dans le manuscrit du Songe. Ni le rôle joué par Hedwige, ni la conversion du peuple lituanien n'y trouvent mention. D'après Juozas Jakštas, qui estime que la lettre date d'après 1388, cela indiquerait que la cour française a été informée du baptême du seul prince, et non de celui de son peuple. Curieusement, l'historien lituanien en attribue la faute à la personne même du messager ${ }^{70}$. Celui-ci, en tant que membre de l'Ordre teutonique, aurait cherché à protéger les intérêts de sa corporation, laquelle aurait voulu empêcher que la christianisation de la Lituanie ne soit connue en Europe occidentale afin de ne pas remettre en cause sa raison d'être. Jean de Strate aurait pris soin de laisser dans l'ombre l'évangélisation du peuple lituanien, pour ne pas répandre

${ }^{66} \mathrm{Id}$.

${ }^{67}$ Ibid., p. 1263.

${ }^{68}$ J. Jakštas, Das Baltikum..., p. 172; A. Grabski, Polska w Opiniach Europy..., p. 210.

${ }^{69}$ Le mariage de la reine Hedwige d'Anjou et du grand-duc de Lituanie est également mentionné par Antoine de la Sale, qui consacre un court extrait de La Salade (v. 1442-1444) à Louis d'Anjou et à ses filles: "La II ${ }^{\text {e }}$ de ses deux filles fust Madame Avigan [Hedwige], qui fust mariee au filz du roy de Lecthoen, sarrasin et hors de nostre foy. Ceste dame succeda après son pere, le roy de Honguerie, es royaumes de Poullaine et de Craco. Lesquelx royaumes ledit roy avoit eu par succession maternelle. Lequel roy Loj̈s trespassa en l'an de Nostre Seigneur mil IIIC IIIIXX et deux" (Antoine de la Sale, Euvres complètes, vol. 1, éd. F. Desonay, Paris-Liège 1935, p. 181). On remarque que si les informations concernant les Anjou sont correctes, l'auteur ne mentionne pas que le "roy de Lecthoen" (c'est-à-dire Jagellon) a reçu le baptême; A. Grabski, Polska w Opiniach Europy..., p. 211.

70 Sur ce qui suit, J. JakšTas, Das Baltikum..., p. 172-173. 
en France - grande pourvoyeuse d' "hôtes", on le sait - une nouvelle gênante... L'hypothèse est osée, d'autant plus que rien ne permet d'affirmer que la lettre date d'après le baptême proclamé à Vilnius au début de 1387 . Une année s'étant écoulée entre le baptême personnel de Jagellon et le moment où il proclame le christianisme dans le grand-duché, il est fort possible que Jean de Strate soit parti de Prusse sans avoir eu connaissance des événements survenus à Vilnius.

Mais comment expliquer alors que Mézières ait, lui, eu connaissance du baptême des Lituaniens? Avait-t-il accès à d'autres réseaux d'information, qui lui auraient permis de compléter ses connaissances de la situation lituanienne? $\mathrm{Ou}$ plus probablement, le vieux poète, sensible aux affaires religieuses européennes, aurait pris la peine de noter la conversion du peuple lituanien en même temps que le rôle d'Hedwige, alors que pour les diplomates de la cour royale, mentionner la conversion personnelle de Jagellon et de ses frères aurait suffi dans une missive adressée de roi à roi. Dans ce cas, le message complet délivré par Jean de Strate aurait été que Jagellon, ses quatre frères, et son peuple de Lituanie ont reçu le baptême à l'occasion du mariage du prince à la reine de Pologne. Ce qui se rapprocherait des informations connues des réseaux pontificaux, telles que l'atteste la lettre du légat Maffiolo Lampugnano à l'archevêque de Cologne ${ }^{71}$.

Le dossier des relations diplomatiques entre la France et la Pologne de Ladislas Jagellon est compliqué par une note des Voyages et ambassades de Guillebert de Lannoy, qui a parcouru la Livonie, la Russie, la Lituanie et la Pologne après avoir effectué une rèse aux côtés des Teutoniques à l'automne 1413. Arrivé au printemps suivant dans le royaume, il rencontre Jagellon à Kalisz, qui le reçoit avec les honneurs, et passe les fêtes de Pâques avec lui. Le jeune chevalier, à qui le grand-maître Henri de Plauen avait déjà confié une lettre appelant la noblesse bourguignonne à l'aide ${ }^{72}$, se voit demandé de remplir une autre mission diplomatique, quelque peu antagoniste:

"Me fist ledit roy [...] sëoir à sa table, puis au partir me donna une couppe dorée, armoyée de ses armes, et escripvy par moy lettres de créance au roy de France laquelle créance estoit qu'il se complaignoit de luy, qui estoit principal de tous les roys cristiens, pour ce que tous les rois cristiens l'avoient visité par leurs ambaxades depuis sa nouvelle créacion d'avoir esté fait roy cristien, et ledit roy de France non. ${ }^{73}$

Les lettres que mentionne Lannoy n'ont pas été conservées ${ }^{74}$; toutefois, rien ne permet de mettre en doute leur authenticité, puisque comme l'indique la chronique de Długosz, Jagellon se trouvait effectivement à Kalisz à Pâques 1414,

\footnotetext{
CES 2, doc. 8, p. 10.

2 PR 1, p. 40.

73 Potvin, p. 47.

74 J. Svátek, Discours..., p. 264.
} 
ce qui correspond aux indications fournies par le voyageur français ${ }^{75}$. En outre, la présence de plusieurs hôtes français à la cour polonaise est attestée pour les années 1412-141576. Le peu de détails fournis par les documents comptables ne permet pas d'identifier notre Bourguignon, mais il apparaît que sa rencontre avec le roi n'a rien d'impossible.

D'après l'éditeur polonais des Voyages et ambassades, Joachim Lelewel, ce commentaire attesterait le manque de suivi diplomatique entre la France et la Pologne, expliqué par la folie de Charles VI et la guerre civile entre Armagnacs et Bourguignons: les affaires de Pologne auraient tout simplement été oubliées ${ }^{77}$. Pourtant, nous savons que le roi de France avait recommandé l'un de ses sujets à son homologue polonais peu après le baptême de ce dernier, même si la plainte rapportée par Lannoy paraît indiquer que le message n'est pas arrivé à destination. Si l'on suit Juozas Jakštas, pour qui le messager Jean de Strate aurait joué un double jeu, on peut penser que celui-ci aurait tout simplement négligé de remplir sa mission. Cette hypothèse, toutefois, ne tient pas compte du caractère «international» des liens qui unissaient les nobles de la fin du Moyen Âge; nous savons qu'avant comme après la conversion de la Lituanie, officiers teutoniques et nobles lituaniens ou polonais pouvaient entretenir des relations courtoises, voire ponctuellement s'entraider. De plus, un messager ayant donné sa foi ne trahirait sûrement pas intentionnellement sa mission, même pour défendre les intérêts du groupe auquel il appartient. Il n'en reste pas moins qu'apparemment, le message et le messager ne sont pas parvenus auprès de Jagellon, qui en 1414 encore, se plaignait de n'avoir reçu la visite d'aucun ambassadeur français. En l'absence de sources, nous sommes réduits à des conjectures ${ }^{78}$.

Une autre hypothèse est avancée par Karol Górski, qui fait porter la responsabilité de l'échec des relations diplomatiques entre Charles VI et

\footnotetext{
75 Jan Długosz, Lib. XI cité dans l'édition de J. Lelewel, Guillebert de Lannoy, Guillebert de Lannoy et ses voyages..., p. $52, \mathrm{n} \cdot 50$.

76 O. Halecki, "Gilbert de Lannoy...", p. 322; Rationes Curiae Vladislai Iagellonis et Hedvigis Regum Poloniae (1388-1420) = Rachunki Dworu Króla Wladyslawa Jagielly, éd. F. Piekosinski, Cracovie 1896, p. 405-462 passim, mentionnent plusieurs «hospites de Francie» de passage à la cour.

77 Guillebert de Lannoy, Guillebert de Lannoy et ses voyages..., p. 53, n. 51.

${ }^{78}$ La visite de Jean de Strate n'est pas mentionnée dans les recueils de documents diplomatiques polonais édités. Il serait difficile de déduire de ce silence que Jean de Strate n'a pas atteint la cour polonaise: en effet, la première visite de Guillebert de Lannoy n'est pas mentionnée explicitement, pourtant son témoignage porte à croire qu'il a bien rencontré Jagellon. Par contre, sa deuxième visite en 1421, comme ambassadeur officiel cette fois-ci, est mentionnée dans Liber cancellariae Stanislae Ciotek: ein Formelbuch der polnischen Königskanzlei aus der Zeit der Husitischen Bewegung, vol. 1-2, éd. J. Caro, Vienne 1871, doc. 46-47, p. 85-86, et une lettre de Jagellon à Charles VI dans Ibid., doc. 54, p. 94-96; Index actorum saeculi decimi quinti $X V$ ad res publicas Poloniae spectantiumin “Codice epistolari saeculi XV", éd. I. Lewicki, Cracovie 1888, doc. 1116, p. 131 et doc. 1185 p. 138, ainsi que par Jan Długosz, Annales XI, dans Opera Omnia..., vol. 13, p. 273-274. Voir Guillebert de Lannoy, Guillebert de Lannoy et ses voyages..., p. 64, n. 62.
} 
Jagellon au duc de Bourgogne Philippe le Hardi, qu'il estime être un allié de l'Ordre teutonique ${ }^{79}$. Une lettre datée de la fin de l'année 1389 par laquelle le grand-maître remercie le duc de Bourgogne d'avoir rendu possible l'amitié entre le roi de France et l'Ordre peut aller dans ce sens ${ }^{80}$. Le prince, alors homme fort du royaume, collaborait avec Marienbourg, notamment en faisant venir des navires de Prusse pour garnir sa flotte basée en Flandre ${ }^{81}$. On sait par ailleurs que Philippe le Hardi soutenait volontiers ses familiers désireux de se croiser en Prusse; des sympathies qui ne sont peut-être pas gratuites de la part du puissant duc de Bourgogne, également maître de la Flandre. Des lettres du $1^{\text {er }}$ mai 1389 attestent que le grand-maître lui promet de l'aide dans des démêlés avec les marchands hanséatiques, et enjoint à ceux-ci de trouver une issue amicale avec le Bourguignon ${ }^{82}$. Plus tôt, des relations commerciales avaient été établies entre Marienbourg et la cour de France: en 1383, Charles VI octroyait la liberté d'entrer et de commercer sur les territoires français aux marchands prussiens $s^{83}$ et avisait le grand-maître Conrad Zöllner de Rothenstein qu'il avait ordonné de ne plus molester les marchands hanséatiques ${ }^{84}$.

La Prusse joue donc un rôle dans la politique du duc de Bourgogne: avant d'entreprendre l'expédition censée venir appuyer le roi Sigismond de Hongrie contre les Turcs et qui s'est terminée par le désastre de Nicopolis (1396), Le Hardi entendait organiser une croisade internationale aux côtés de l'Ordre teutonique. L'idée était de réunir en une grande aventure contre l'infidèle les ducs de Lancastre et d'Orléans aux troupes de son propre fils Jean, comte de Nevers, pour concrétiser le rapprochement franco-anglais des années $1390^{85}$. Alors que des négociations étaient entamées avec le grand-maitre Conrad de Jungingen, celui-ci fait savoir en octobre 1394 que pour des raisons d'ordre climatique l'expédition ne peut être garantie ${ }^{86}$. L'idée d'une grande rèse

\footnotetext{
${ }^{79}$ K. Górski, Polska-Francja..., p. 25.

${ }^{80}$ Index actorum..., doc. 119, p. 15; CDP 4, doc. 61, p. 82-83.

81 J. Раviot, La Politique navale des ducs de Bourgogne, Lille 1995, p. 50-51. Des vaisseaux de Prusse étaient prévus pour l'invasion de l'Angleterre, en 1386; P. Contamine, Azincourt..., p. 70. Jean Cabaret d'Orville fait dire au duc de Bourgogne, dans son discours au conseil du roi: "monseigneur [le roi Charles VI] il faut que vous mandez au hault Maistre de Prusse, qui bien est vostre allié, qu'il vous envoie ce nombre qu'il pourra de vaisseaulx» (Chazaud, p. 182).

${ }^{82}$ CDP 5, doc. 37 et 38, p. 46-48.

${ }_{83}$ CDP 4, doc. 17, p. 18.

${ }^{84}$ Ibid., doc. 16, p. 18.

85 Voir notamment O. Catellieri, Geschichte der Herzöge von Burgund 1363-1477, vol. 1: Philipp der Kühne, Leipzig 1910, doc. X, p. 145-146: "pour accomplir le voiage, que nous avons emprins de faire au plaisir de Dieu à la nouvelle saison prochain venant avecques noz tres chiers neveu et frere les ducs d'Orleans et de Lancastre devers les parties de Honguerie ou de Prusse». Voir aussi J. Magee, "Le temps de la croisade bourguignonne...", p. 54; A. Grabski, Polska w Opiniach Europy..., p. 192.

${ }^{86}$ CDP 5, doc. 57, p. 70; J. Рaviot, Les Ducs de Bourgogne..., p. 25.
} 
en Prusse est abandonnée, et c'est la Hongrie qui est choisie... avec les résultats que l'on sait ${ }^{87}$.

La France, et surtout les régions aux mains du duc de Bourgogne, avait besoin de l'Ordre teutonique, mais cela ne signifie pas que l'on négligeait d'entretenir des relations diplomatiques avec la Pologne. En effet, en avril 1400, lorsque Charles VI envoie une ambassade composée d'universitaires et de conseillers, parmi lesquels Simon de Cramaud, Jean Courtecuisse et le chambellan du roi Guillaume de Tignonville, auprès des princes du Saint Empire pour tenter de les rallier à la cause du pape d'Avignon, il lui octroie des lettres de créance pour se rendre auprès de Jagellon, appelé "serenissimo principi regi Polonie et Sarakonie»" On ne sait pas si cette ambassade a rejoint la Pologne ${ }^{89}$; il n'est possible de la suivre par la Flandre et Liège que jusqu'à Francfort, où elle assiste à la diète impériale. En dépêchant ses ambassadeurs, le but premier du conseil royal était de régler les problèmes du schisme, tout en s'immisçant dans la politique intérieure de l'Empire. Si une visite diplomatique à la cour polonaise faisait apparemment partie de son programme, cela n'était pas l'unique tâche de l'ambassade ${ }^{90}$.

En dépit de la plainte de Ladislas Jagellon transmise par l'intermédiaire de Guillebert de Lannoy, il paraît donc clair que des tentatives avaient été faites à Paris pour établir des relations diplomatiques avec le roi de Pologne, dont on savait qu'il a reçu le baptême avec certains de ses "frères". Comme le prouve la note laissée vraisemblablement par Philippe de Mézières en marge d'un manuscrit du Songe du vieil pelerin, la conversion du peuple de Lituanie était connue des élites du royaume de France: a-t-on besoin d'imaginer des manœuvres des Chevaliers teutoniques ou de leur allié bourguignon pour expliquer que les ambassades françaises n'aient pas atteint la Pologne? La question reste ouverte. L'hypothèse de Juozas Jakštas a cela d'intéressant qu'elle prend en compte les graves tensions qui existaient entre Marienbourg, Cracovie et Vilnius après la conversion du grand-duché et de ses dirigeants.

\footnotetext{
${ }^{87}$ En septembre 1396, une armée franco-hongroise emmenée par Jean de Bourgogne est anéantie par les troupes du sultan Bajazet ${ }^{\mathrm{Ir}}$, devant les murs de Nicopolis (act. Bulgarie).

${ }^{88}$ H. Moranvilué, «Relations de Charles VI avec l'Allemagne en 1400 », Bibliothèque de l'Ecole des Chartes, 47, 1886, pièce justificative $\mathrm{n}^{\circ}$ IV, p. 501. Le terme "Sarakonie» peut être une déformation du titre "rex Cracovie», fréquemment attribué aux monarques polonais, mais rappelle aussi une contamination de Saraceni, ce qui renverrait à la manière de qualifier les païens baltes à l'époque où les rèses battaient leur plein. Si l'on retient cette interprétation, on ne peut que constater la difficulté de perdre les vieilles habitudes linguistiques au sujet des Lituaniens, même dans un domaine aussi formel que la diplomatie.

89 Ibid., p. 491; O. Halecki, "Gilbert de Lannoy... », p. 321.

${ }^{90}$ H. Moranvillé, «Relations...», p. 491-493.
} 


\section{L'ORDRE TEUTONIQUE FACE À LA NOUVELLE DONNE}

L'acte de 1387 promu par Jagellon marque la fin de l'exception lituanienne sur le plan religieux. Théoriquement, la mission de l'Ordre teutonique touche à sa fin $^{91}$. Pourtant, le grand-maitre Conrad Zöllner est loin d'être satisfait ${ }^{92}$. Une partie de l'historiographie considère que les Teutoniques refusaient de reconnaitre la christianisation de la Lituanie pour ne pas voir leur raison d'être s'évanouir et pour ne pas perdre leurs fiefs de Prusse et de Livonie. Les chevaliers à la croix noire auraient alors tout mis en œuvre pour faire échouer les plans d'évangélisations préparés à Cracovie et à Vilnius ${ }^{93}$. Cela expliquerait le soutien apporté à Guillaume d'Autriche par le grand-maître, car si l'on parvenait à établir qu'Hedwige était déjà mariée avec le prince autrichien, cela signifierait que son union avec Jagellon serait illégitime, et que celui-ci n'aurait donc aucun droit à la couronne polonaise ${ }^{94}$. Plus grave, Marienbourg accuse Jagellon et Vytautas de n'avoir accepté le baptême que pour la forme, sous-entendant que l'évangélisation de la Lituanie serait un leurre ${ }^{95}$. À cet égard, les officiers de l'Ordre teutonique, qui avaient en mémoire les quasiconversions coutumières des grands-ducs lituaniens, ont pu sincèrement douter que les cousins se montreraient plus fermes dans leurs démarches que ne le furent leurs prédécesseurs ${ }^{96}$.

Plusieurs lettres attestent que les deux parties cherchaient à orienter la politique pontificale dans un sens qui leur serait favorable ${ }^{97}$. Dès 1386, Jagellon

${ }_{91}$ S. Gouguenheim, Les Chevaliers teutoniques..., p. 446.
${ }_{92}$ W. Urban, "The Teutonic Order and the Christianisation of Lithuania... », p. 130-131.
${ }_{93}$ C'est la version retenue majoritairement par l'historiographie polonaise; pour un exemple récent, G. BŁaszczyк, Dzieje..., p. 444. Voir aussi S. Ekdahl, "Christianisierung - SiedlungLitauerreise. Die Christianisierung Litauens als Dilemma des Deutschen Ordens", dans V. Dolinskas (dir.), Lietuvos krikščionejjimas Vidurio Europas kontekste $=$ die Christianisierung Litauens im mitteleuropäischen, Vilnius 2005, p. 189-205.

${ }^{4}$ Hedwige avait été formellement mariée à Guillaume à l'âge de cinq ans; la question était de savoir si ce mariage avait été consommé ou non: G. BŁAszczyK, Dzieje..., p. 444-445; R. Frost, The Oxford History..., p. 34

${ }^{95} \mathrm{Id}$.

${ }^{96}$ Cette question est très débattue; W. Urban (The Samogitian Crusade..., 180 passim) rappelle que les Chevaliers n'étaient pas les hypocrites ou les "fanatiques» dépeints par une partie de l'historiographie ou de la littérature, mais des moines-guerriers dévoués à leur cause et qui se méfiaient des promesses lituaniennes, trop souvent trahies. Plus nuancé, R. Petrauskas, «Litauen...», p. 243-244, rappelle que les officiers de l'Ordre teutonique n'avaient pas de relations sociales en Prusse et en Livonie, et qu'ils appartenaient, en bonne partie, à la génération qui avait longtemps combattu les Lituaniens païens; en conséquence, il leur était difficile d'abandonner leur schéma mental belliciste pour faire place à la coopération. S. Gouguenheim (Les Chevaliers teutoniques..., p. 446) résume en disant: "En guerre depuis un siècle, les Teutoniques étaient en quelque sorte prisonniers de la longue durée et se refusaient à croire qu'un seul événement ponctuel puisse tout changer".

${ }^{97}$ Sur ce qui suit, S. Gouguenherm, Tannenberg..., p. 27-28; S. C. Rowell, «The Grand Duchy of Lithuania and the Beginning of the Union with Poland: the Background to Grunwald», dans 
explique au pape que le grand-maître fait tout pour l'empêcher de recevoir le baptême ${ }^{98}$, alors qu'en mai 1388, ce dernier fait part au Saint-Siège de ses inquiétudes quant à une apostasie des "Lituaniens et des Ruthènes»99. Dans les années qui suivent, les Teutoniques, par le biais des lettres et des ambassadeurs qu'ils envoient aux cours d'Europe, affirment que le baptême de Jagellon et de Vytautas est tout sauf solide ${ }^{100}$, alors que leur procureur à la Curie s'efforce d'émettre des doutes sur l'efficacité de la campagne d'évangélisation ${ }^{101}$. En 1403, des lettres en allemand et en latin sont expédiées au roi de France et à d'autres princes pour se plaindre du prétendu double jeu du roi de Pologne et de son cousin Vytautas, comparant les néophytes lituaniens à des chiens retournés à leur vomi, selon la métaphore biblique utilisée pour qualifier les apostats et les relaps (Prov. 26: 11) ${ }^{102}$.

L'idée était-elle, en s'adressant à un milieu aristocratique, de faire jouer les relations patiemment construites au fil des ans par l'entremise des rèses, pour convaincre les princes européens que l'ennemi si héroïquement combattu pendant de longues décennies ne pouvait être soudain devenu un partenaire chrétien respectable? À cet égard, la terminologie employée dans les documents de l'Ordre se fait plus dure à l'égard des Lituaniens après le baptême de ceux-ci. Nous avons vu que les chroniqueurs de l'Ordre désignaient les païens baltes par leurs ethnonymes, quitte à leur attribuer quelques épithètes tels que "incroyants» ou "fils de Bélial», et qu'ils réservaient en règle générale l'usage du terme «Sarrasins» aux musulmans du Proche-Orient. Malgré l'assimilation des païens baltes à ces derniers par les hôtes occidentaux, il semble qu'à l'époque où la Lituanie était païenne, cette habitude n'eut pas prise sur les clercs de l'Ordre teutonique. Pourtant, dès la fin des années 1380, l'Ordre se met à taxer ses adversaires baltes de "Sarrasins» ${ }^{103}$. Comme le souligne Eric Christiansen ${ }^{104}$,

W. Paravicini, R. Petrauskas, G. Vercamer (dir.), Tannenberg - Grunwald - Žalgiris 1410: Krieg und Frieden im späten Mittelalter, Wiesbaden 2012, p. 43-51.

98 Skarbiec..., I, doc. 524, p. 261. En automne 1385, le prince lituanien André avait donné sa principauté de Polostk à l'Ordre teutonique pour le reprendre en fief de celui-ci, ce qui indique qu'une coalition contre Jagellon était vraisemblablement envisagée; CDP 4, doc. 33, p. 39. En juillet de la même année, l'Ordre passe une alliance avec les ducs de Szczecin: ibid., doc. 38, p. 45. Voir S. Gouguenheim, Tannenberg..., p. 25.

$99 \mathrm{CEV}$, doc. 41, p. 15; CDP 4, doc. 52, p. 68-69.

${ }^{100}$ Hochmeister Chronik, SS III, 610, cité par H. Gersdorf, Der Deutsche Orden im Zeitalter der polnisch-litauischen Union, Marbourg 1957, p. 253, n. 19.

101 W. Urban, "The Diplomacy of Teutonic Knights at the Curia», Journal of Baltic Studies 9/2, 1978, p. 116-128; H. Gersdorf, Der Deutsche Orden..., p. 102.

102 CDP 5, doc. 135, p. 181-186; «ad solitum prodicionis vomitum redeundo» (ibid., p. 184). La même expression était déjà utilisée en 1396, dans un document où Vytautas jure de rester fidèle au christianisme ( CDP 5, doc. 40, p. 114). G. MickŪnaité, Making..., p. 40-41.

${ }^{103}$ Le ton semble s'être encore durci après la défaite de Tannenberg (1410). À titre de comparaison, le terme «barbari» n'est appliqué aux Lituaniens qu'après leur conversion de 1387, et dans un sens rétrospectif: A. V. MurraY, «Saracens...», p. 415.

104 E. Christiansen, The Northern Crusades..., p. 176. 
l'utilisation de ce terme dans le vocabulaire des Chevaliers teutoniques après la christianisation de la Lituanie n'est pas innocente. Tout se passe comme si l'on s'était efforcé de maintenir un climat de croisade, en assimilant les adversaires néophytes aux Ottomans qui menaçaient l'Europe balkanique, et surtout en escamotant le fait qu'après 1387, les Lituaniens étaient officiellement chrétiens. Pour que cette politique qualifiée d' «illusionniste» ${ }^{105}$ fonctionne, il importait donc de se réapproprier le vocabulaire des croisés venus de France ou d'Angleterre.

Plusieurs sources paraissent attester que ces derniers n'avaient pas saisi tout de suite le changement qui avait eu lieu dans le grand-duché. La dernière rèse à laquelle participe le maréchal Boucicaut date de 1391, soit quatre ans après l'introduction du christianisme à Vilnius, mais tous les Lituaniens semblent être considérés comme des "Sarrasins", sans que distinction ne soit faite entre néophytes et païens. Plus explicitement, la Chronique de Westminster, qui raconte la rèse de l'été 1390 à laquelle a participé Henri de Derby, fait du «roi» Skirgaila (autrement dit le frère de Jagellon, régent de Lituanie) le chef des "païens", quand bien même celui-ci a été baptisé orthodoxe ${ }^{106}$. Le caractère païen des Lituaniens n'est mentionné que discrètement, comme quelque chose de connu; tout porte à croire que les lecteurs de la Chronique savaient contre qui était allé se battre le comte de Derby, et que le caractère néophyte d'une partie au moins des Lituaniens n'était pas pris en compte ${ }^{107}$. Il peut être utile de rappeler ici que l'auteur mentionne à plusieurs reprises un certain «rouleau du maréchal», ce qui trahit l'utilisation d'une source écrite, sans doute également utilisée quelques décennies plus tard par Thomas Walsingham. Il s'agit probablement d'une note confectionnée en Prusse par l'un des participants à la rèse, qui l'aurait ramenée en Angleterre ${ }^{108}$. Quoi qu'il en soit, force est de constater que l'informateur de nos chroniqueurs suit la ligne des Chevaliers teutoniques, ce qui ne saurait nous étonner étant donné que ceux-ci avaient tout loisir de présenter leur point de vue à leurs hôtes.

Peu après l'accession de Jagellon au trône polonais, une rivalité militaire, diplomatique et idéologique oppose l'Ordre teutonique non seulement à la Lituanie, mais aussi à la Pologne $e^{109}$. La noblesse polonaise, qui garde une certaine prépondérance dans le gouvernement, voyait d'un mauvais œeil la

\footnotetext{
105 Le terme a été introduit par E. Maschke, «Burgund...».

106 R. Frost, The Oxford history..., p. 30.

107 Notamment lors de la bataille au bord du Niémen: Westminster, p. 446; Walsingham, vol. 1, p. 902. Aucune distinction entre Samogitiens et néophytes originaires de Lituanie proprement dite n'est faite.

${ }^{108}$ PR 2, p. 104-105; Westminster, p. 444-445, n. 1; F. R. H. Du Boulay, «Henry of Derby's crusade...», p. 156 sq. La chronique de Thomas Walsingham présente les mêmes événements, mais donne certains détails supplémentaires, ce qui indique que l'auteur n’a pas uniquement résumé les faits présentés par la Chronique de Westminster.

109 S. Gouguenheim, Les Chevaliers teutoniques..., p. 446-447.
} 
puissance teutonique s'étendre en Europe du Nord. L'expansion territoriale de l'Ordre avait en effet atteint son maximum à la fin du siècle, avec l'acquisition de l'île de Gotland en mai $1399^{110}$ et de la Nouvelle Marche (Neumark) en septembre $1402^{111}$. En outre, l'Ordre parvient à faire déposer l'archevêque de Riga, réfractaire à sa politique, et installe à sa place Jean de Wallenrode, neveu du grand-maittre Conrad de Wallenrode $(1393)^{112}$.

La rivalité polono-teutonique se reflète dans les chroniques proches de l'Ordre. Jean de Posilge, par exemple, raconte que les Polonais tombés aux mains des Teutoniques n'étaient pas mieux traités que leurs compagnons russes ou lituaniens ${ }^{113}$. Certaines sources narratives produites en Europe occidentale confirment cette animosité. On apprend ainsi dans la Chronique de Westminster qu'au retour de la rèse en Lituanie, le maréchal de l'Ordre teutonique a eu vent d'une tentative d'invasion polonaise: «le huitième jour après le retour du maréchal et du comte [de Derby] à Königsberg, la nouvelle parvint que le roi de Pologne et de Cracovie préparait l'invasion de la patrie prussienne avec une immense armée»" ${ }^{114}$. Henri se voit demander de l'aide, et accepte d'affronter le roi de Pologne. Les chroniqueurs proches de l'Ordre ne mentionnent pas de guerre contre la Pologne dans la première moitié de l'année $1391^{115}$, mais cette indication dénote clairement un biais hostile envers Jagellon. Il n'est ainsi pas étonnant qu'un frère de celui-ci soit compté parmi les morts à la fin de l'assaut contre Vilnius ${ }^{116}$. De la même manière, la Chronique des Quatre Premiers Valois situe un "roi de Graco" comme allié du "roy de l'Estone», adversaire des chrétiens lors d'une rèse qui voit la participation d'un duc de Lancastre pouvant avoir emprunté des traits autant au grand-père qu'au petit-fils ${ }^{117}$. Pour

\footnotetext{
${ }_{110}$ Quellen..., doc. 27, p. 162-167.

111 Ibid., doc. 28, p. 168-171.

${ }_{112}$ Peu satisfait de son rôle d'archevêque de Riga, Jean de Wallenrode (v. 1370-1419) se rapproche du roi de Hongrie, Sigismond de Luxembourg, dont il devient un conseiller, et joue un rôle important au concile de Constance; puis, définitivement brouillé avec l'Ordre, il finit sa vie comme prince-évêque de Liège: B. JÄHNIG, Johann von Wallenrode O.T. : Erzbischof von Riga, Königlicher Rat, Deutschordensdiplomat und Bischof von Lüttich im Zeitalter des Schismas und des Konstanzer Konzils (um 1370-1419), Bonn-Godesberg 1970; D. Buschinger, M. Olivier, Les Chevaliers teutoniques..., p. 296-297; W. Urban, "The Teutonic Knights at the Council of Constance», dans M. Pelaez (éd.), Estudios de Historia de la Iglesia, Barcelone 1990, p. 4050-4051.

113 Jean de Posilge, Chronique..., SRP 3, p. 176; S. F. Belch, Paulus Vladimir..., vol. 1, p. 123.

114 Westminster, p. 448.

115 Toutefois, les Annales de Toruń et la Chronique de Posilge mentionnent qu'en 1390, le roi de Pologne avait interdit de traverser son royaume pour se rendre en Prusse; SRP 3, p. 168.

116 Walsingham, vol. 1, p. 902. Wigand de Marbourg mentionne la mort d'un «quidam rex nomine Karigal» (Chronica..., SRP 2, p. 643), qui était l'un des frères de Jagellon (ibid., n. 1888).

117 "Les crestiens firent leur reze sur le roy de l'Estone et le roi de Graco, lesquelz s'estoient aliés à grant nombre de mescreans pour desconfire les crestiens", Chroniques des Quatre Premiers Valois, p. 14. Le "roy de Craco" apparait à plusieurs reprises dans la chronique: par exemple, il figure parmi les alliés du roi d'Angleterre Édouard I ${ }^{\text {er }}$, qui est dit attaquer la Flandre en 1329 (p. 4); bien qu'adversaire de la France, ce personnage figure donc parmi les princes chrétiens. Si chronologiquement, le «duc
} 
Andrzej Grabski, le chroniqueur a sans doute entendu cet avis de la bouche de croisés récemment rentrés de rèses, qui eux-mêmes n’auraient fait que répéter les propos des membres de l'Ordre teutonique ${ }^{118}$.

Fait intéressant, la chronique se termine en 1393, qui est aussi la date de rédaction du Mélusine de Jean d'Arras. Ce célèbre roman met en scène un groupe de chevaliers menés par l'un des fils de la fée pour porter secours au roi de Bohême, dont la capitale est assiégée par un certain "Selodus, roy de Craco", lequel, à la tête d'une armée de "payens» et de "Sarrasins", fait trembler jusqu'au duc de Bavière ${ }^{119}$. Alors que l'épisode peut être une allusion à la rèse de Jean de Luxembourg, roi de Bohême et grand-père maternel du duc Jean de Berry, l'un des commanditaires de l'œuvre, la figure de l'ennemi semble surgir plus directement des années 1390. Martin Nejedlý a sans aucun doute raison de mettre en doute l'idée selon laquelle le Selodus de Jean d'Arras devrait nécessairement correspondre à une figure historique ${ }^{120}$. Toutefois, il est frappant de voir apparaître un "roy de Craco» comme chef de "Sarrasins» en Europe centre-orientale, et ceci précisément à l'époque où les rèses contre l'axe polonolituanien battaient leur plein ${ }^{121}$.

Au début des années 1390, plusieurs auteurs anglais et français considéraient donc toujours les Lituaniens comme des païens, et n'hésitaient pas à faire de leurs alliés polonais des ennemis de la cause chrétienne. Ce point de vue peut refléter celui d'une partie au moins des hôtes de l'Ordre teutonique. Ainsi, Jan Długosz raconte qu'en 1390, des chevaliers polonais et français voulaient se battre en duel à Prague, devant le roi Wenceslas, avant que celui-ci ne les réconcilie. L'affaire remontait à une querelle survenue lors du siège de Vilnius, en 1390: "les Polonais étant accusés par les Français d'apporter leur aide aux barbares contre les fidèles, [ils] réfutèrent en disant agir pieusement et de manière sainte, car ils défendaient, en faveur de la foi, des néophytes contre des religieux

de Lencastre» pourrait être Henri de Grosmont, lequel se rendit en 1351-1352 auprès de l'Ordre teutonique, le contexte tendu entre l'Ordre et la Pologne rappelle plutôt les années 1390, lors desquelles son petit-fils, Henri de Derby, a fait sa fameuse rèse. A. Grabski, Polska w Opiniach Europy..., p. 68-69.

${ }^{118}$ Ibid., p. 69.

119 Dans l'édition de J.-J. Vincensini, Jean d'Arras, Mélusine..., p. 496-546; voir aussi la version en vers de Coudrette, Mélusine...

${ }^{120}$ M. Nejedlý, "CComment le roy Selodus..."”, p. 266; voir aussi M.-T. de Medeiros, "L'idée de croisade... ", p. 149. Gardons-nous de voir derrière cette figure de fiction uniquement "le» Jagellon historique - Jean d'Arras a pu entendre parler d'un certain roi de Cracovie dans un contexte défavorable, et garder ce titre pour en faire un adversaire de ses héros. Du reste, l'avancée ottomane dans les Balkans et les appels à l'aide du roi Sigismond de Hongrie (appartenant justement à la maison de Luxembourg) ont pu donner une source d'inspiration supplémentaire à l'auteur.

${ }^{121}$ La Pologne est directement mise en cause dans le revirement de Vytautas, qui en 1392 s'allie à Jagellon et tourne ses armes contre les Teutoniques; par exemple, Wigand de Marbourg, Chronica..., SRP 2, p. 648. 
pervers ${ }^{122}$. Wigand de Marbourg, qui relate une scène similaire située en 1394, raconte que le maréchal de l'Ordre Werner Tetinger tenta de refroidir le zèle de ses hôtes en leur disant qu' «il n'obtient aucun honneur, celui qui leur livre un duel [aux chevaliers polonais], car ce sont des ennemis de la foi ${ }^{123}$. Andrzej Grabski remarque que si les chevaliers français accusaient leurs pairs polonais de soutenir les "barbares" lituaniens, ils ne les traitaient pas moins comme leurs égaux, autrement dit, comme d'autres chevaliers chrétiens; les visiteurs venus d'Occident ne partageaient pas forcément l'intransigeance des officiers teutoniques ${ }^{124}$.

Les tensions entre le camp polono-lituanien et leurs adversaires se cristallisent autour de la très stratégique Samogitie, cible principale des rèses depuis le début du XIV siècle. Cette province côtière n’a pas été concernée par la campagne d'évangélisation lancée par Jagellon et Vytautas en 1387. D'après Grzegorz Błaszczyk, la Samogitie aurait été formellement évangélisée en même temps que le reste du grand-duché1 ${ }^{125}$, sans que Vilnius n'ait eu la possibilité d'y imposer le christianisme, faute de coopération des boyards locaux ${ }^{126}$. À l'inverse, Darius Baronas et Stephen C. Rowell postulent que suite à une manœuvre de l'Ordre teutonique, la province n'a pas été incluse dans le diocèse de Vilnius. Les Chevaliers teutoniques ayant brandi les prétendues donations de Mindaugas, par lesquelles le roi converti du XIII ${ }^{\mathrm{e}}$ siècle est censé avoir cédé la Samogitie à l'Ordre, la Papauté n'aurait pas pu disposer de ce territoire au statut juridique contesté ${ }^{127}$. Quoiqu'il en soit, le pouvoir des grands-ducs n'y est pas très solide à la fin du XIV ${ }^{\mathrm{e}}$ siècle $^{128}$; les chefs de clans qui tiennent le pays se placent alternativement sous l'obédience lituanienne puis teutonique, ceci afin de se garantir un maximum d'autonomie ${ }^{129}$. Au tournant du $\mathrm{Xv}^{\mathrm{e}}$ siècle, Vytautas cède à deux reprises la province à l'Ordre (traité de Salinwerder, 1398; traité de Racianz, 1404130). L'homme fort de Vilnius était alors préoccupé par ses

\footnotetext{
122 Jan Długosz, Annales X, dans Opera Omnia..., vol. 12, p. 491-492. La même anecdote est racontée par Jean de Posilge, Chronique..., SRP 3, p. 201, et Wigand de Marbourg, Chronica..., SRP 2, p. 660, qui la situent en 1394; A. Grabski, Polska w Opiniach Europy..., p. 69-70, 193-194; G. MickūNaItĖ, Making..., p. 36.

123 Chronica..., SRP 2, p. 660. Wigand ne précisant pas le motif du défi et situant la scène quatre ans après Długosz, il n'est pas impossible qu'il s'agisse d'un autre duel.

124 A. Grabski, Polska w Opiniach Europy..., p. 69-70.

${ }^{125}$ G. BŁaszczyк, Dzieje..., p. 216.

126 Ibid., p. 193.

127 Sur les donations de Mindaugas et leur importance dans la politique de l'Ordre teutonique, R. MAŽEIKA, "When Crusader...», p. 203. D. Baronas et S. C. Rowell (The Conversion..., p. 336-337) remarquent que l'Ordre teutonique a fait exécuter des copies de ces documents, et les a utilisées dans des négociations avec la Pologne en 1389 (H. Boockmann, Johannes Falkenberg..., p. 57).

128 D. Baronas, S. C. Rowell, The Conversion..., p. 336.

129 G. B£aszczyK, Dzieje..., p. 216.

130 Die Staatsverträge..., vol. 1, doc. 1-3, p. 7-13 (traité de Sallinwerder/Salynas); Ibid., doc. 22-31, p. 31-40 (traité de Racianz); S. Kubon, «Der Friede von Racianz/Raciazek», Ordines Militares 18, 2013, p. 39-53.
} 
campagnes contre les Tatars, et devait faire une concession à Marienbourg, qui renforce ainsi la légitimité de ses actions en territoire balte, puisqu'en cherchant à s'imposer en Samogitie, les Teutoniques peuvent affronter des ennemis restés effectivement païens - et non des néophytes protégés par le pape ${ }^{131}$.

C'est sans doute dans cette région que l'on doit situer une partie au moins des aventures baltes de nos croisés français et anglais ${ }^{132}$. Du moins, l'auteur de la Chronique de Metz note explicitement que la rèse à laquelle lui-même et ses compagnons ont participé, et qui était menée de concert avec Vytautas, était dirigée contre les "Salmaite», c'est-à-dire les Samogitiens ${ }^{133}$. La rèse, selon le chroniqueur messin, avait pour but de briser la force des païens, qui «volxent combatre les Crestiens» ${ }^{134}$; un but défensif donc, qui laisse dans l'ombre la mission évangélisatrice. Il semble en effet que lorsque l'Ordre possédait le pays, l'on se soit contenté de briser la résistance politique des païens, et d'essayer de se créer des appuis parmi la noblesse, que ce soit par la force ou la séduction: comme noté dans la Chronique de Metz, les nobles samogitiens qui acceptaient de prêter serment devaient fournir des otages ${ }^{135}$, mais ils recevaient aussi des privilèges confirmant leur statut ${ }^{136}$. A quelques occasions, le baptême des nobles ralliés à l'Ordre est noté137, mais dans l'ensemble, les Teutoniques préféraient ne pas troubler la situation religieuse de leurs sujets, auprès de qui ils se savaient très peu en faveur. Même si la présence de Vytautas a permis à quelques occasions de brûler les bois sacrés ${ }^{138}$, on évitait d'allumer le brasier de la révolte en convertissant le pays par la force, ce qui par ailleurs aurait été interdit par le droit canon ${ }^{139}$.

131 G. Mickūnaité, Making..., p. 6-7.

${ }^{132}$ La bataille des bords du Niémen racontée par les chroniques anglaises de Westminster et de Thomas Walsingham s'est vraisemblablement déroulée au moins à proximité de la province païenne; on sait par d'autres sources qu'elle mettait aux prises des soldats samogitiens, fidèles à Vytautas, contre les Lituaniens de Skirgaila (Jean de Posilge, Chronique..., SRP 3, p. 164; Annales de Toruń, Ibid., p. 165). À l'inverse, la Chronique de Metz note qu'une dizaine d'année plus tard, les croisés se sont battus contre les Samogitiens, cette fois-ci dans le camp adverse de Vytautas, de nouveau allié à l'Ordre.

133 Wolfram, p. 337.

134 Ibid., p. 337.

135 Ibid., p. 337.

136 R. Petrauskas, «Litauen...», p. 245.

137 Notamment Jean de Posilge, Chronique..., SRP 3, p. 240 ; D. Baronas, S. C. Rowell, The Conversion..., p. 340 .

${ }^{138}$ G. Mickūnaité, Making..., p. 7. La prise d'un bois sacré est mentionnée par la Chronique de Metz (p. 337), mais comme un fait militaire permettant la soumission des Samogitiens, non leur conversion.

139 D. Baronas, S. C. Rowell, The Conversion..., p. 337-341; R. Wenskus, «The Teutonic Order...", p. 326. L'historiographie nationaliste lituanienne explique le conservatisme religieux des Samogitiens par la brutalité des guerres menées par l'Ordre; par exemple, J. Koncius, Vytautas..., p. 129-130. À l'inverse, D. Baronas et S. C. Rowell (The Conversion..., p. 337-341) postulent que l'extrême attachement des Samogitiens au paganisme est en grande partie une invention des chroniqueurs teutoniques, puis polonais. 
La collaboration n'était toutefois pas amenée à durer; lorsque la Samogitie se soulève en 1401, Vytautas et le grand-maître écrivent aux princes de la Chrétienté pour s'accuser mutuellement d'avoir manqué à la justice, et de cacher leurs sombres desseins sous des dehors chrétiens ${ }^{140}$. Utilisant le même medium que ses adversaires, le souverain de Lituanie avait fait sienne la pratique, répandue en Europe occidentale, d'envoyer des lettres justificatives aux voisins $s^{141}$. L'Ordre teutonique n'arrive pas à créer une grande dynamique anti-lituanienne; quelques chevaliers occidentaux s'engagent bien à son côté, mais ils sont bien moins nombreux que dix ans auparavant ${ }^{142}$. Le temps des grandes rèses internationales semble passé.

\section{LA BATAILlE DE TANNENBERG}

Malgré les troubles secouant la Lituanie, une "paix armée»" ${ }^{143}$ précaire a prévalu entre l'Ordre et la Pologne durant les deux décennies suivant l'accession au trône de Jagellon. Les choses changent lorsqu'une nouvelle révolte secoue la Samogitie en mai 1409. Si l'on suit le récit de Jan Długosz, toute la région été touchée par la famine; les Polonais ayant entrepris d'envoyer du grain en Lituanie, par voie fluviale, les Teutoniques auraient intercepté les navires en y découvrant, selon leurs dires, des armes, logiquement destinées aux rebelles Samogitiens. Véridique ou non, le prétexte d'une invasion de la Pologne était trouvé ${ }^{144}$.

Traditionnellement, l'historiographie impute la responsabilité des événements au grand-maitre Ulrich de Jungingen, réputé belliqueux ${ }^{145}$. Un point de vue plus nuancé devrait toutefois être adopté. En effet, une partie des nobles polonais pouvaient percevoir la mainmise croissante de l'Ordre sur le nord du royaume comme une provocation ${ }^{146}$, mais beaucoup d'entre ceux

${ }_{140} \mathrm{CEV}$, doc. 238, p. 75-76; Ibid., doc. 241, p. 77-78; CDP 6, doc. 109, p. 111-112. Le grand-maitre a notamment envoyé des plaintes contre Vytautas au duc de Bourgogne ( CDP 6, doc. 116, p. 155-156) ainsi qu'au roi de France, au pape et au collège des cardinaux (Ibid., doc. 122, p. 163-165). Sur le contexte, G. Mickūnaité, Making..., p. 40-42; H. Boockmann, Johannes Falkenberg..., p. 72-82; K. Polejowski, "The Teutonic Order's Propaganda...", p. 237-238.

${ }^{141}$ Par exemple, Bellaguet, vol. 4, p. 419-435; V. NovÁK, «La source du savoir. Publication officielle et communication informelle à Paris au début du $\mathrm{xv}^{\mathrm{e}}$ siècle», dans C. Boudreau et al. (dirs.), Information et société..., p. 162-163.

${ }_{142}$ PR 1, p. 30-34 (tab. 3); W. Paravicini, "Vom Kreuzzug zum Soldzug: Die Schlacht bei Tannenberg und das Ende der Preussenfahrten des europäischen Adels», dans K. OżóG, J. Trupinda (dirs.), Conflictus Magnus apud Grunwald 1410, Malbork 2013, p. 119-120.

${ }_{143}$ S. Gouguenheim, Les Chevaliers teutoniques..., p. 447.

${ }_{144}$ Jan Długosz, Annales X, dans Opera Omnia...vol. 12, p. 572-574.

145 Pour un résumé de la question, S. Gouguenheim, Tannenberg..., p. 28-30. Une synthèse en langue polonaise et une discussion des problèmes historiographiques sont proposées par G. BŁaszczyк, Dzieje..., p. 297-317.

146 W. Unban, Tannenberg..., p. 105, 126, n. 83: la mort d'Hedwige en 1399 aurait poussé Jagellon à se rapprocher du camp des "patriotes" polonais, bien plus vindicatifs que la reine, qui 
qui étaient possessionnés près de la zone frontalière avaient aussi l'habitude de cohabiter avec ce puissant voisin ${ }^{147}$. Une étude récente menée par un collectif d'historiens polonais a montré que la partie la plus intéressée à la guerre était sans doute Jagellon et Vytautas: la révolte samogitienne, effectivement soutenue par le grand-duc, faisait peut-être partie d'un plan visant à pousser Jungingen à la guerre. Du reste, celui-ci s'est vu ouvertement provoqué par l'archevêque de Gniezno, qui lui a fait savoir qu'une attaque contre la Lituanie, représailles obligées, ne resterait pas impunie. Acculé, le grand-maitre aurait alors décidé de lancer ses troupes contre la Pologne ${ }^{148}$. En manœuvrant pour forcer leur adversaire à commencer la guerre, les dirigeants de Pologne et de Lituanie s'assuraient non seulement la sympathie des nobles des régions frontalières, dont les possessions seraient tout à coup dévastées par les troupes de l'Ordre, mais aussi des princes occidentaux et de l'Église ${ }^{149}$.

L'invasion du nord de la Pologne marque le début d'une campagne diplomatique de grande ampleur ${ }^{150}$. Alors que l'Ordre se contente d'accuser la Lituanie et la Pologne d'aider les rebelles, ses adversaires préparent des arguments bien plus efficaces sur le plan idéologique ${ }^{151}$. À l'Université de Cracovie, les théologiens réfléchissent au concept de guerre juste, en se penchant notamment sur les droits des infidèles à jouir d'une certaine liberté, ce qui priverait les rèses d'une partie de leur légitimité152. Le 9 septembre 1409, le chevalier polonais Jarosław d'Iwno, porte-bannière de Poznań, reçoit une lettre de créance pour qu'il puisse se rendre auprès du roi de France Charles VI ${ }^{153}$. Deux lettres,

tenait à maintenir la paix avec l'Ordre. Sur l'expansion de l'Ordre dans les régions polonaises (Terre de Dobrzyń) ou proches de la Pologne (Nowa Marchia / Neumark), voir D. Buschinger, M. Olivier, Les Chevaliers teutoniques..., p. 259-262.

147 S. Gouguenheim, Tannenberg..., p. 25; S. Jóźwiak et al., Wojna..., p. 749.

148 Ibid., p. 55, 748.

149 S. JóźWiak et al., Wojna..., p. 748-750. Quant à la raison de l'attitude de Jagellon et de Vytautas, il semble probable que ce soit ce dernier qui ait poussé son cousin à la guerre, par ambition de récupérer la Samogitie.

150 Sur ce sujet, A. SzWEDA, «Polish and Teutonic diplomatic activity in Europe during the conflict of 1409-1411», History.pth.net.pl 1 (2011).

151 Sur la "propagande" polonaise et teutonique lors de la guerre de 1409-1411, S. Gouguenheim, Tannenberg..., p. 41-47; S. JóźwiaK et al., Wojna..., p. 187-189; P. Knoll, "A Pearl of Powerful Learning”..., p. 227-233; S. Ekdahl, Die Schlacht bei Tannenberg..., p. 320-344; G. B£aszczyк, Dzieje..., p. 445-448; L. Chollet, «Ecrire l'histoire de la conquête: l'utilisation de l'histoire dans la polémique contre l'Ordre teutonique au sujet des droits des infidèles (1386-1418)", Hereditas Monasteriorum 4, 2014, p. 26-29.

152 S. Gouguenheim, Les Chevaliers teutoniques..., p. 488. D. Buschinger, M. Olivier, Les Chevaliers teutoniques..., p. 258, rappellent que l'Ordre a essayé de fonder une université à Chełmno en 1386, sans succès, puis envoyait de "jeunes Prussiens prometteurs» étudier à l'étranger "pour en faire par la suite les avocats de sa cause». L'Université de Cracovie a été fondée en 1364, puis restaurée par Ladislas Jagellon (1400), qui y fit établir une faculté de théologie: P. KNoLL, « $A$ Pearl of Powerful Learning»...; J. Wyrozumski (dir.), L'Université et la ville au Moyen Âge et autres questions du passé universitaire, Cracovie 1993.

153 CDMP 7, doc. 647, p. 434-5. 
datées du même jour, l'accompagnent ${ }^{154}$ : l'une est signée au nom du roi de Pologne, l'autre du grand-duc de Lituanie ${ }^{155}$. À côté des plaintes portant sur les conflits territoriaux, le pouvoir polonais et lituanien accuse l'Ordre d'utiliser la conversion des infidèles comme prétexte pour usurper les terres des Samogitiens, tout en refusant de reconnaitre les efforts faits en Lituanie pour y implanter le christianisme ${ }^{156}$. L'efficacité de l'évangélisation des Baltes, qui a servi d'argument à la mise en place des croisades en Europe nordique, est directement questionnée; la politique teutonique ne serait que pillage et oppression, illégitime et inefficace du point de vue missionnaire. Précédé par le héraut d'armes Pollalant ${ }^{157}$, le chevalier Jarosław semble avoir accompli sa mission auprès des cours européennes, et pas uniquement en France. Par le truchement d'une lettre d'un envoyé du grand-maître en Angleterre, Dietrich de Logendorf, on sait que les Polonais se sont présentés devant Henri IV en automne 1409, après avoir rencontré le roi de France et le duc de Bourgogne. L'ancien croisé de Prusse devenu roi annonça à l'émissaire prussien qu'il avait ostensiblement décliné la demande d'aide polonaise - sans toutefois s'engager du côté de l'Ordre autrement que par de belles paroles ${ }^{158}$.

À la suite de cette première crise, Wenceslas de Bohême, le roi des Romains alors en difficulté, tente d'imposer une trêve, à la condition que les Polonais cessent de soutenir les Samogitiens ${ }^{159}$. Les dirigeants teutoniques auraient vraisemblablement préféré une solution diplomatique au conflit, mais Cracovie n'entendait pas en rester là. Tout en faisant échouer les arbitrages proposés par Wenceslas, puis par son frère Sigismond de Luxembourg, Jagellon et Vytautas préparent minutieusement l'invasion de la Prusse ${ }^{160}$. En juin 1410, les forces

\footnotetext{
${ }^{154}$ A. SZWEDA, «Polish and Teutonic diplomatic activity...». Sur cet épisode, voir aussi S. JóźwIAK et al., Wojna..., p. 187-201.

155 CEV, doc. 426, p. 194-199; Ibid., doc. 427, p. 199-201.

156 L'accusation la plus détaillée se trouve dans la lettre écrite au nom de Vytautas; Ibid., doc. 427, p. 201. La lettre signée de Jagellon mentionne également le problème de la Samogitie; Ibid., $\mathrm{n}^{\circ}$ 426, p. 197. Voir aussi une lettre de Jagellon datée du 10 septembre, dans Jan Długosz, Annales X, dans Opera Omnia..., vol. 12, p. 584-588.

157 S. KuCZYŃski, "Les hérauts d'armes...", p. 654-656: à partir de 1403, on trouve mention d'un "heraldus regis Laurentius", qui porte le nom officiel de Pollalant, par analogie avec les hérauts Gelre, Preussenland, Ungarland, etc.

158 Hanserecesse 1/5, éd. K. Koppmann, Leipzig 1880, doc. 639-640, p. 492-495; J. H. WyLie, History of England under Henry the Fourth, Londres 1898, vol. 4, p. 14-15.

159 S. Gouguenheim, Tannenberg..., p. 35-36. Le biographe de Paul Vladimiri, S. F. Belch, Paulus Vladimiri..., p. 124-125, cite le manuscrit d'une première version d'un discours prononcé à Constance par le juriste cracovien, où ce dernier explique que lors de la révolte de 1409, les chefs samogitiens ont envoyé des lettres justifiant leur cause aux princes d'Europe, ainsi qu'une ambassade au roi de Pologne, et qu'ils menaçaient de se soumettre aux Tatars si celui-ci refusait de les soutenir.

160 S. Jóźwiak et al., Wojna..., p. 211-231; S. Ekdahl, « Politics, Diplomacy and the Recruitment of the Mercenaries before the Battle of Tannenberg-Grunwald-Žalgiris in 1410 ", dans P. W. EdburY (dir.), The Military Orders, vol. 5, p. 329-336.
} 
des deux pays sont rassemblées, et le $1^{\text {er }}$ juillet, l'armée polono-lituanienne passe la Vistule. Outre les troupes polonaises et lituaniennes, la coalition regroupe des contingents russes et tatars, alliés et vassaux, de même que des mercenaires moldaves et tchèques, qui sont commandés par un futur chef de guerre hussite, Jan Žižka z Trocnova. De leur côté, les Teutoniques se sont employés à engager une immense armée de mercenaires, et à faire venir les habituels "hôtes» d'Europe occidentale ${ }^{161}$. Ces derniers ne sont guère nombreux ${ }^{162}$, mais les documents d'archives autant que les sources narratives laissent voir que quelques chevaliers étaient venus de France ou d'Allemagne occidentale pour soutenir l'Ordre ${ }^{163}$. D'après les Annales de la Province et du Comté du Hainaut, de rédaction tardive (v. 1648), le puissant cardinal français Pierre d'Ailly aurait apporté son soutien aux Teutoniques en fournissant des indulgences à ceux qui iraient leur prêter main forte ${ }^{164}$ :

"Furent publiées indulgences au pays de Haynaut par Pierre d'Ailly, évesque de Cambray, pour ceux qui iroient à l'assistance des chevaliers de l'Ordre teutonique en Prusse, qui avoient guerre puissante contre les Polonois, Lithuaniens, Tartares et autres nations ennemies de l'Empire. Sur ce quelque nombre de chevaliers et gentilhommes dudit pays de Haynaut s'armèrent et se transportèrent en Prusse. Les principaux chevaliers furent: messires Huge de Lalaing et Guillaume de Pottes. ${ }^{165}$

L'affrontement, l'un des plus grands de l'Europe médiévale par les forces en présence, a lieu le 15 juillet 1410, entre les villages de Tannenberg et de Grunwald $^{166}$. La victoire appartient au camp polono-lituanien: le grand-maitre est tué avec les principaux dignitaires, et les troupes de l'Ordre qui ne sont pas décimées fuient ou préferent se rendre. Si l'on peut croire le chroniqueur Enguerrand de Monstrelet, plusieurs Français sont tombés au combat: «Entre

\footnotetext{
${ }_{161}$ PR 1, p. 34-39; S. Gouguenheim, Tannenberg..., p. 33-40.

162 Ibid., p. 34, rappelle que ni la France, ni l'Angleterre (alors en pleine guerre) n'étaient en mesure d'envoyer beaucoup d'hôtes aux Teutoniques.

163 W. Paravicini (PR 1, p. 39) estime à 100 ou 200 hôtes volontaires, soit plus que lors des premières années du $\mathrm{Xv}^{\mathrm{e}}$ siècle, mais pas assez pour jouer un rôle militaire significatif.

164 PR 1, p. 38 ; S. Wielgus, The Medieval Polish Doctrine of the Law of Nations: Ius Gentium, Lublin 1998, p. 58.

${ }_{165}$ François Vinchant, Annales de la Province et Comté du Hainaut, vol. 4, Mons 1860, p. 40-41. Le personnage nommé Hugues de Lalaing peut être plutôt Simon de Lalaing, dont la présence à Tannenberg est signalée par Monstrelet; PR 1, p. 38.

166 Cette bataille est connue dans l'historiographie francophone sous le nom de "Tannenberg", selon l'usage allemand. On l'appelle "Grunwald» en Pologne, "Žalgiris» en Lituanie. S. Gouguenheim, Tannenberg...; le travail collectif de S. Jóźwiak et al., Wojna...; les recueils d'articles de W. Paravicini et al., Tannenberg - Grunwald-Žalgiris...; K. OżóG, J. Trupinda (dirs.), Conflictus Magnus... ainsi que le commentaire de K. OżóG, dans l'ouvrage commémoratif d'A. Bujak, K. Ożóg, L. Sosnowski, The Glory of Grunwald, Cracovie 2010. Pour une recension des discussions récentes, K KwiatKowski, "New Research into the Battle of Grunwald/Tannenberg/ Žalgiris. Attempt at an Overview», Historical Annals 79, 2013, p. 1-31.
} 
lesquelz furent mors le grant maistre de Pruce et ung gentil chevalier de Normandie, nommé sire Jean de Ferrières, filz au seigneur de Vieuville. Et de Picardie, y mourut le filz du seigneur du Bois d'Annequin " ${ }^{167}$. La machine de guerre teutonique, qui tenait en respect les royaumes séculiers d'Europe du Nord, est mise à mal. Quelques jours après la bataille, Jagellon met le siège devant le château de Marienbourg. De nombreux chevaliers, bourgeois et évêques font allégeance à la Pologne, quitte à expulser de leurs villes les châtelains fidèles à l'Ordre. Jagellon fait enterrer le corps de Jungingen à Marienbourg alors que sa chancellerie prépare les documents confirmant la situation légale de ses nouveaux vassaux ${ }^{168}$. C'est grâce à l'énergie d'un simple chevalier teutonique, Henri de Plauen, que l'Ordre évite le pire. Il faut dire que Jagellon est abandonné par Vytautas, dont les troupes souffrent de dysenterie; l'armée polonaise ne peut pas à elle seule tenir le siège face aux forces teutoniques qui se regroupent depuis la Livonie et la Neumark ${ }^{169}$. De plus, le roi Sigismond de Hongrie, allié des Teutoniques, menace le sud de la Pologne; Jagellon doit se retirer et les négociations peuvent s'ouvrir. L'Ordre, affaibli mais pas à terre, accepte les conditions polonaises: concessions territoriales (notamment la Samogitie, qui retourne à Jagellon et à Vytautas jusqu'à leur mort ${ }^{170}$ ) et payement d'une indemnité de guerre. On désigne aussi le pape comme arbitre suprême pour les conflits suivants. En février 1411, la paix de Toruń est signée ${ }^{171}$.

Les vainqueurs profitent de leur avantage pour resserrer les liens entre leurs pays. Signé le 2 octobre 1413, l'union de Horodło consacre l'alliance de plusieurs familles nobles polonaises et lituaniennes, et voit certaines structures politiques polonaises être appliquées à la Lituanie ${ }^{172}$. Tout comme le traité de Toruń, celui de Horodło contient une injonction à propager la foi chrétienne ${ }^{173}$. D'après Jan Długosz, une fois la cérémonie terminée, Jagellon et Vytautas se rendent en Samogitie, où le roi entreprend de prêcher à la population, fait construire des églises et désacraliser les idoles et les autels païens ${ }^{174}$. Même si le récit de Długosz n'est jamais à prendre à la lettre, de nombreux historiens considèrent qu'il reflète bien les actions de Jagellon en automne 1413, et attribuent cet embryon de conversion au désir de celui-ci de battre en brèche les accusations des Teutoniques, qui n'auraient pas manqué de fuser si rien n'avait été fait pour

\footnotetext{
167 Douët d'Arcq, vol. 2, p. 76; PR 1, p. 101; S. Gouguenheim, Tannenberg..., p. 52.

168 Ibid., 159-160.

169 K. Ożóg, dans A. Buјak, K. Ożóg, L. Sosnowski, The Glory of Grunwald..., p. 73, explique que les Teutoniques ont stocké assez de nourriture pour soutenir un long siège.

${ }_{170}$ Cette clause est mentionnée dans le traité de paix de Toruń (1 ${ }^{\text {er }}$ février 1411); Die Staatsverträge..., doc. 83 , p. 86 .

${ }^{171}$ Ibid., doc. 82-85, p. 82-90.

172 Codex Diplomaticus Poloniae..., vol. 1, doc. 162, p. 286-289; 1413 m. Horodles aktai...; pour une synthèse des discussions historiographiques, G. BŁAszczyк, Dzieje..., p. 369.

${ }_{173}$ Die Staatsverträge..., doc. 83, p. 88; 1413 m. Horodlés aktai..., p. 38-39, cité par D. Baronas, S. C. Rowell, The Conversion..., p. 342.

174 Jan Długosz, Annales XI, dans Opera Omnia..., vol. 13, p. 159-163.
} 
évangéliser les Samogitiens ${ }^{175}$. Or, Darius Baronas et Stephen C. Rowell ont récemment montré que les souverains de Pologne et de Lituanie ne se sont probablement pas rendus personnellement au cœur de la province, et que si un certain nombre de nobles samogitiens ont été baptisés après la paix de Toruń, rien n'indique qu'ils l'aient été précisément à l'automne 1413. La raison est sans doute que l'Église n'avait pas donné l'autorisation explicite d'organiser une structure ecclésiastique pour cette province au statut contesté ${ }^{176}$.

De leurs côtés, les Chevaliers teutoniques entendent tourner la défaite à leur avantage, en la présentant comme la débâcle du christianisme devant une coalition d'hérétiques, de païens et d'infidèles ${ }^{177}$. Alors qu'il était encore assiégé dans Marienbourg, Plauen écrit dès juillet 1410 cet appel à l'aide:

"À tous les princes, barons, chevaliers et hommes en armes et tous les autres Chrétiens loyaux que ces lettres atteignent. Nous, frère Henri de Plauen, castellan de Swetz, agissant en place du grand-maître des Chevaliers teutoniques de Prusse, vous notifions que le Roi de Pologne et le Duc Vytautas, avec une grande force et des Sarrasins infidèles ont assiégé le château de Marienbourg. Dans ce siège, vraiment toute la faculté et toute la puissance de l'Ordre sont engagés. Ainsi, nous vous demandons, pour autant que vous le puissiez, illustres et nobles seigneurs, de permettre à vos sujets qui désirent nous assister et nous défendre par amour du Christ et de toute la Chrétienté, ou, en un mot, pour une bonne indemnité et un salaire, de venir à notre aide aussi tôt que possible pour qu'avec votre assistance nous puissions leur résister et les chasser. "178

Plusieurs aspects de ce message méritent notre attention. D'une part, le recours aux mercenaires est directement évoqué: il est admis que le voyage de Prusse pourrait être un simple moyen de gagner de l'argent, tout en combattant pour une noble cause ${ }^{179}$. D'autre part, nous retrouvons le terme sarrasin, auparavant inusité dans la production littéraire et épistolaire de l'Ordre. D'après William Urban, il ne ferait pas que souligner la présence dans les troupes polono-lituaniennes de Tatars musulmans, mais aurait pour but d'exaspérer le «sentiment anti-polonais» qui pouvait exister alors ${ }^{180}$. On peut toutefois supposer

175 Z. Kiaupa, The History of Lithuania..., p. 71-72; O. Halecki, «Problems of the New Monarchy: Jagello and Vitold» dans W. F. RedDaway et al. (éd.), The Cambridge History of Poland, p. 217-218; P. Rabikauskas, "La Cristianizzazione della Samogizia», dans La Cristianizzazione della Lituania..., p. 227-229.

176 D. Baronas, S. C. Rowell, The Conversion..., p. 342-347. Voir ci-dessus, p. 254.

177 S. Gouguenheim, Les Chevaliers teutoniques..., p. 490-493; S. Ekdahl, Die Schlacht bei Tannenberg..., p. 180-192.

${ }_{178}$ M. Biskup, "Das Echo der Tannenbergschlacht und der Belagerung Marienburgs im deutschen Zweig des Deutschen Ordens im Sommer 1410 ", dans U. ARnold (dir.), Beiträge zu der Geschichte des Deutschen Ordens, vol. 2, Marbourg 1993, p. 120.

179 S. Ekdahl, Die Schlacht bei Tannenberg..., p. 10-12.

180 W. URBan, Tannenberg..., p. 163. 
que l'auteur de la lettre cherchait autant à stigmatiser l'adversaire qu'à évoquer directement chez ses lecteurs le décor exotique d'une croisade conventionnelle, renouant avec les «beaux jours» des années 1390 .

Henri de Plauen, élu grand-maitre à la fin de l'année 1410, est le dernier dirigeant de l'Ordre qui recourra de manière répétée à l'appel à l'aide auprès de la noblesse occidentale ${ }^{181}$. Jusqu'à sa chute en octobre 1413 , ses lettres, relayées par les commanderies d'Allemagne ou par divers messagers, continuent d'arriver aux cours européennes ${ }^{182}$. L'exemple cité ici donne le ton général de ces appels: le roi de Pologne a trahi la Chrétienté en s'alliant avec des infidèles pour faire couler le sang chrétien. L'une des thématiques utilisées consiste à insister sur la cruauté des Tatars, qui représentaient de fait la majorité des soldats «infidèles» enrôlés dans la coalition polono-lituanienne ${ }^{183}$. Les instructions préparées par Plauen pour le voyage du commandeur de Toruń, Georg Eglinger, auprès des "princes et seigneurs d'Allemagne etc." sont claires: il doit raconter à ses nobles auditeurs que peu avant la bataille de Tannenberg, les Tatars se sont livré à des actes tels que viols, infanticides, anthropophagie et profanation d'hosties lors de la prise de Gilgenbourg (actuellement Dąbrowno, en Pologne) ${ }^{184}$.

Pour expliquer la défaite de l'Ordre à Tannenberg, le nouveau grand-maitre fait appel à ce que nous appellerions aujourd'hui une "théorie du complot» - manière commode de sauver l'honneur tout en laissant espérer des chances de vengeances ${ }^{185}$. Le bouc émissaire est la Ligue du Lézard, une organisation de nobles séculiers de la région de Chełmno fondée en 1397, qui s'opposaient au pouvoir autoritaire de l'Ordre et semblent avoir souhaité l'incorporation de leur terre à la Pologne ${ }^{186}$. On accuse ces chevaliers, qui en tant que vassaux de l'Ordre ont participé à la bataille de Tannenberg, d'avoir baissé leur bannière prématurément, ce qui aurait causé la panique dans les rangs et provoqué la défaite: leur chef, Nicolas de Renys, est décapité sans procès en $1411^{187}$. Le seul fait probant était que les chevaliers de la bannière de Chełmno se sont effectivement rendus pendant la bataille - comme beaucoup d'autres combattants ${ }^{188}$.

De son côté, la Pologne maintient la ligne idéologique forgée en 1409: le royaume est dans son bon droit, les «infidèles» ayant servi lors de la bataille ne sont que des sujets qui exécutaient leur devoir, et l'Ordre teutonique, entaché du péché d'orgueil, a été justement puni. De telles idées sont autant destinées à soutenir la

\footnotetext{
181 PR 1, p. 39.

182 Ibid., p. 39-41; H. Boockmann, Johannes Falkenberg..., p. 90-96.

183 S. EKDAHL, Die Schlacht bei Tannenberg..., p. 219-221.

${ }^{84}$ CEV, p. 233-247.

185 W. Urban, Tannenberg..., p. 168.

186 S. Gouguenheim, Les Chevaliers teutoniques..., p. 548.

${ }^{187}$ H. Kruse, W. Paravicini et A. Ranft (dirs.), Ritterorden und Adelsgesellschaften im spätmittelalterlichen Deutschland, Francfort 1991, notice 40, p. 183-188.

188 A. Bujak, K. Ożóg, L. Sosnowski, The Glory of Grunwald..., p. 259.
} 
cause polonaise à l'étranger qu'à conforter les troupes, comme c'est le cas du sermon délivré peu avant la bataille par l'évêque de Płock Jacob Kurdwanowski ${ }^{189}$ ou du discours intitulé De bellis iustis, vraisemblablement écrit et publié entre 1410 et 1414 par le chapelain de la reine ${ }^{190}$ et conseiller royal Stanislas de Skarbimierz ${ }^{191}$. Au lendemain de la bataille, Jagellon écrit à sa seconde épouse, la reine Anne, et aux prélats Nicolas Kurowski, archevêque de Gniezno et Albert Jastrzębiec, évêque de Poznań, pour leur faire part de la victoire ${ }^{192}$. Ce dernier envoie une lettre aux Polonais en place à la Curie, pour les informer de ce qui s'est passé à Tannenberg et leur fournir des arguments à même de répondre aux accusations de l'Ordre ${ }^{193}$. C'est la première fois que la place des infidèles et des «schismatiques» dans la guerre polono-teutonique est justifiée ${ }^{194}$. À l'automne 1411, le futur évêque de Poznań André Laskary (Andrzej Łaskarz) se rend auprès du pape "pisan» Jean XXIII ${ }^{195}$ pour plaider la cause polonaise, et expliquer qu'en luttant contre l'Ordre, Jagellon n'aurait fait que mener une guerre juste ${ }^{196}$.

\section{L'ÉCHO de LA déFAITE EN Europe OCCIDENTALE}

Quel a été l'impact de ces démarches diplomatiques auprès des cours occidentales? La bataille, qui a mis aux prises un nombre impressionnant de soldats, a été notée par des chroniqueurs de toute l'Europe ${ }^{197}$. Certains, comme l'auteur de la Chronique de Lübeck, dite de Rufus (v. 1430) ${ }^{198}$, ou l'Anglais

189 P. Knoll, «A Pearl of Powerful Learning»..., p. 231.

${ }^{190}$ Il s'agit d'Anne de Cilley, seconde épouse de Ladislas Jagellon. Hedwige d'Anjou est morte en 1399.

${ }^{191}$ Ou De bello justo, comme l'écrit G. BŁaszczyк, Dzieje..., p. 446; le traité est édité par L. Ehrlich, Polski wyktad prawa wojny xv wieku: kazanie Stanistawa ze Skarbimierza De bellis iustis, éd. L. Ehrlich, Varsovie 1955, p. 90-145; voir H. Boockmann, Johannes Falkenberg..., p. 171-175; B. Chmielowska, «Stanislas de Skarbimierz, le premier recteur de l'Université de Cracovie", Mediaevalia Philosophica Polonorum 24, 1979, p. 73-112.

${ }^{192}$ La lettre à la reine Anne est éditée dans SRP 3, p. 425-426; celle à l'archevêque de Gniezno par E. Schnippel, "Vom Streitplatz zum Tannenberge», Prussia 31, 1935, p. 65-67; celle à l'évêque de Poznań par SRP 3, p. 426-427.

193 SRP 3, p. 427-429.

194 S. Gouguenheim, Tannenberg..., p. 185-186.

195 Avant la conclusion du concile de Constance, trois papes revendiquaient le pouvoir sur l'Église: celui de Rome, celui d'Avignon, et celui que s'est choisi le concile de Pise, Alexandre V, puis Jean XXIII. La Pologne, tout comme l'Ordre teutonique, reconnaissait la légitimité de ce dernier. ${ }^{196}$ Le discours de Laskary ne nous est connu que par une copie partielle envoyée par le procureur de l'Ordre, Pierre Wormditt, au grand-maitre; Die Berichte..., vol. 2, doc. 75, p. 158-159. Le texte est édité par S. EKDahl, Die Schlacht bei Tannenberg..., p. 297-307.

${ }^{197}$ Sur l'écho de la bataille de Tannenberg dans les chroniques d'Europe occidentale, voir S. Gouguenheim, Tannenberg..., p. 40-47; E. Christiansen, The Northern Crusades..., p. 221 ; G. Mickūnaité, Making..., p. 42; et la liste exhaustive contenue dans S. Ekdahl, Die Schlacht bei Tannenberg....

${ }^{198}$ Die sogenannte Rufuschronik, dans Die Chroniken der Niedersächsischen Städte: Lübeck, éd. C. Hegel, K. Koppman, vol. 3, Leipzig 1902, p. 52. 
Thomas Walsingham (m. 1422) se montrent favorables au roi de Pologne et condamnent l'Ordre pour son orgueil et sa rapacité199. Pour Walsingham, "l'ennemi du genre humain" a semé le scandale entre chrétiens; le "roi de Cracovie», ayant reçu le baptême, s'est tourné vers les maîtres de la Prusse, qu'il pensait à même de le défendre contre ses anciens alliés restés païens, qui menacent de le tuer. Mais les Teutoniques, "qui, avant que le roi ne devienne chrétien, avaient pour habitude d'envahir ses terres et d'en tirer du butin par le droit de la guerre», préférèrent attaquer celui-ci, pour le mettre en difficulté et éviter ainsi de devoir renoncer à leurs rentables opérations. Mal leur en prit: non seulement le roi converti les écrasa, mais il conquit encore leurs terres, tout en se montrant magnanime envers ses nouveaux sujets et en respectant leurs privilèges ${ }^{200}$.

Pour d'autres chroniqueurs, la bataille est une tragédie ayant mis aux prises deux armées chrétiennes. Jean Brandon, chroniqueur de l'abbaye des Dunes à Bruges (m. 1428), écrit que "beaucoup sont venus d'Allemagne, de France, d'Angleterre, de Brabant, de Flandre, et d'autres régions occidentales auprès du grand-maître, croyant, comme on le rapporte, combattre contre des infidèles et des ennemis de la foi chrétienne; mais, malheureusement, chacune des deux armées était chrétienne» ${ }^{201}$; la victoire est polonaise, "après un échange réciproque de coups et une grande effusion de sang chrétien ${ }^{202}$. S'ensuit la dévastation des terres de Prusse et de Livonie, puis l'élection d'un nouveau grand-maitre et la signature de la paix de Toruń, au sujet de laquelle le chroniqueur flamand semble plutôt bien informé. Se référant sans doute à l'un des articles du traité, il rapporte que l'on s'est mutuellement promis de convertir les infidèles à la foi, ou de les expulser ${ }^{203}$.

Un ton moins passionné est adopté par l'humaniste italien Énée Sylvio Piccolomini, qui aborde l'histoire balte dans plusieurs ouvrages. Le futur pape Pie II montre un certain intérêt pour la région, lui qui avant son élection au trône de Saint Pierre (19 août 1458) était pressenti pour occuper le siège épiscopal de Warmie, en Prusse, et fréquentait la cours du grand-maitre comme celle du roi de Pologne ${ }^{204}$. Pour Sylvain Gouguenheim, Piccolomini a

199 E. Christiansen, The Northern Crusades..., p. 221 ; T. Guard, Chivalry..., p. 88.

${ }^{200}$ Walsingham, vol. 2, p. 594-596; trad. dans Idem, The Chronica Maiora..., trad. D. Preest, J. C. Clark, p. 380. Le texte de Walsingham est repris, avec la date rectifiée, par le chroniqueur anglais John Capgrave (m. 1464) : John Capgrave, The Chronicle..., p. 298; SRP 2, p. 795.

${ }^{201}$ Jean Brandon, Chronodromon, éd. J. Kervyn de Lettenhove, Chroniques relatives à l'histoire de Belgique sous la domination des ducs de Bourgogne, vol. 1, Bruxelles 1870, p. 145.

${ }^{202}$ Id.

203 Ibid., p. 145-146; le chroniqueur liste une partie des personnalités ayant apposé leur sceau au traité de Toruń (1411), qui au final contient effectivement une clause visant à promouvoir la foi chrétienne sur les terres des deux adversaires; voir Die Staatsverträge..., vol. 1, doc. 83, p. 88-89; D. Baronas, S. C. Rowell, The Conversion..., p. 342; PR 1, p. 37.

204 S. Ekdahl, Die Schlacht bei Tannenberg..., p. 244-259; S. Gouguenheim, Tannenberg..., p. 45-46; Énée Sylvio Piccolomini, Europe (c. 1400-1458), trad. R. Brown, N. Bisaha, Washington 2013, p. 150 , n. 338. 
eu le mérite d'emprunter aux pamphlets des deux adversaires, ce qui confère une certaine impartialité à ses récits ${ }^{205}$. La bataille de Tannenberg est évoquée plusieurs fois, et présentée comme résultant d'une lutte politique entre le roi de Pologne et l'Ordre teutonique plus que comme un acte de guerre contre des mécréants ${ }^{206}$. Si l'origine du roi polonais est mentionnée, elle ressort plus comme une anecdote - dont le futur pontife est friand - que comme un élément à charge allant dans le sens des Teutoniques ${ }^{207}$.

De même, la relation insérée par Conrad Justinger dans sa Chronique de Berne (v. 1430) raconte l'événement d'un ton très neutre; la participation d'infidèles ou l'origine du roi de Pologne ne sont pas mentionnés, la bataille semblant n'avoir mis aux prises que les Polonais et les Chevaliers teutoniques ${ }^{208}$. Les illustrations de Diebold Schilling l'Ancien, à la fin du siècle, ne permettent pas non plus d'identifier les adversaires des Teutoniques comme infidèles (figs. 3 et 4$)^{209}$. Du reste, la tradition historiographique bernoise considère que les Chevaliers ont été perdus par leur rapacité, car les deux parties ayant fait appel à des mercenaires, "une grande chevalerie vint auprès de l'Ordre teutonique, qui voulait épargner son argent, et a laissé les chevaliers et les écuyers lui tourner le dos; ceux-ci allèrent auprès du roi de Pologne, qui les accueillit volontiers ${ }^{210}$. Le recrutement tardif des mercenaires de l'Ordre s'explique probablement plus par les manœuvres diplomatiques de leurs adversaires que par la négligence ${ }^{211}$, mais qu'à cela ne tienne, Justinger affirme "que Dieu a puni l'Ordre pour son arrogance ${ }^{212}$. Bien qu'Henri de Plauen ait tout mis en ouvre pour diffuser sa vision des faits, les chroniqueurs des pays occidentaux sont loin d'avoir retenu une explication unilatérale de l'événement.

En France pourtant, les documents du $\mathrm{Xv}^{\mathrm{e}}$ siècle font ressortir une opinion plutôt favorable à Marienbourg. Commençons par les deux chroniqueurs qui

\footnotetext{
${ }^{205}$ C'est le cas pour le plus détaillé, Historia de Europa, SRP 4, p. 233.

206 Libro de viris aetate sua claris (1444-1450), SRP 4, p. 239-240; De situ et origine Pruthenorum (1454), SRP 4, p. 219; De dictis et factis Alfonsis (1456), cité par S. EKDahl, Die Schlacht bei Tannenberg..., p. 247, n. 16; Historia de Europa (1458), SRP 4, p. 233 (trad. par R. Brown, Énée Sylvio Piccolomini, Europe..., p. 151-153); S. Ekdahl, Die Schlacht bei Tannenberg..., p. 249, n. 25. Pour le Xvi siècle, François de Belleforest, La Cosmographie Universelle de tout le Monde, Paris 1575, col. 1608 - lequel reprend en bonne partie Piccolomini.

207 Ainsi dans Libro de viris aetate sua claris, SRP 4, p. 239-240.

208 Conrad Justinger, Berner Chronik, éd. E. Stierlin, J. R. Wyss, Berne 1819, p. 268.

${ }^{209}$ La bataille est racontée et illustrée dans la Berner Chronik (Berner Burgerbibliothek, Mss.h.h.I.1, fol. 304, env. 1485) et la Spiezer Chronik (Berner Burgerbibliothek, Mss.h.h.I.16, fol. 567, env. 1483) de Diebold Schilling l'Ancien, qui reprend le texte de Justinger.

${ }^{210}$ Conrad Justinger, Berner Chronik..., p. 268.

211 S. Ekdahl, «Politics, Diplomacy...», p. 329-336.

${ }^{212}$ Conrad Justinger, Berner Chronik..., p. 268. Contrairement à ce que peut laisser croire Długosz, il est peu probable qu'un contingent suisse ait participé à la bataille de Tannenberg: G. MarchaL, "Schweizerfahne und Schweizer in der Schlacht bei Tannenberg 1410?: zum schweizergeschichtlichen Ertrag einer Faksimileedition der "Banderia Prutenorum»", Revue d'Histoire Suisse 28/1, 1978, p. 66-72; PR 1, p. 85, n. 322.
} 
nous ont laissé des relations relativement détaillées de l'événement, et qui nous renseignent sur la manière dont la nouvelle a été transmise ${ }^{213}$. Michel Pintoin, l'auteur de la Chronique du Religieux de Saint-Denis, annonce dès le début de sa narration que c'est un messager de l'Ordre teutonique qui a directement informé la cour de France. L'historien suédois Sven Ekdahl a montré qu'il s'agit vraisemblablement du chevalier Wenceslas de Miska, envoyé dès août 1410 auprès des princes d'Europe par Sigismond de Hongrie, pour porter une lettre appelant à la défense de l'Ordre ${ }^{214}$ :

"Le mois suivant, un envoyé des religieux de l'Ordre teutonique vint annoncer au roi le triste et déplorable échec que les chrétiens avaient essuyé en Prusse, en combattant contre les Turcs. Je m'informai avec intérêt auprès de cet envoyé des circonstances de cette bataille; je retracerai ici sommairement le récit qu'il m'en fit. ${ }^{215}$

Le terme "Turcs» est à rapprocher de "Sarrasins», ce qui renvoie à la présence de non-chrétiens dans l'armée polono-lituanienne, et en dit long sur le partipris de l'auteur, ou plutôt de son informateur. Tout comme Michel Pintoin, le chroniqueur d'obédience bourguignonne Enguerrand de Monstrelet dit tenir ses informations directement de Prusse: "tout ce fut rapporté par héraulx, et aussi par le bastard d'Escoce, qui se appelloit conte de Hembe» ${ }^{216}$, ce qui atteste du rôle des hérauts d'armes comme messagers de l'Ordre auprès de la cour française ${ }^{217}$. Directement après, on apprend que "Si y estoient aussi le seigneur de Quievrain et Jehan de Gros, hennuiers" ${ }^{218}$, que l'annaliste du XVII ${ }^{\mathrm{e}}$ siècle François Vinchant compte parmi les fuyards ${ }^{219}$; ont-ils eu aussi rapporté quelque information à

${ }^{213}$ Bellaguet, vol. 4, p. 335-337; Douët d'Arcq, vol. 2, p. 61-63, 75-77. Voir aussi la version, légèrement différente, proposée dans Enguerrand de Monstrelet, Chroniques, vol. 2, éd. J. A. Buchon, Paris 1826, p. 123-125, 138-140.

${ }^{214}$ S. EKDAHL, Die Schlacht bei Tannenberg..., p. 183-184, qui précise qu'après la mort de son rival Ruprecht de Palatinat (18 mai 1410), Sigismond entendait se faire élire roi des Romains; aussi, il avait intérêt à se présenter en protecteur zélé de l'Ordre. La lettre de Sigismond transmise par Wenceslas de Miska est éditée dans SRP 3, p. 403-404.

215 Bellaguet, vol. 4, p. 335.

216 Douët d'Arcq, vol. 2, p. 76.

${ }^{217}$ PR 1, p. 37; S. Gouguenheim, «Das Echo... », p. 196, considère que la chronique du Religieux de Saint-Denis représente d'une certaine manière l'opinion de la cour et de l'élite parisienne. Quant à lui, Monstrelet dit travailler à partir des témoignages de "plusieurs hommes nobles et autres notables personnes", "roys d'armes, heraulx et poursuyvans dignes de foy et de credence qui ont esté presens au besongnes»; H. Moranvillé note que si cette indication apparaît au prologue du Livre II, le chroniqueur ne spécifie pas ses sources pour le Livre I, où se trouve la description de la bataille de Tannenberg. H. Moranvillé, "Note sur l'origine de quelques passages de Monstrelet», Bibliothèque de l'École des chartes, 62, 1901, p. 56.

${ }^{218}$ Douët d'Arcq, vol. 2, p. 76.

219 "et d'autant que les Hongrois s'enfuirent aussi, lesdits seigneurs messires Simon de Lalaing, seigneur de Kiervaing, et Jean de Grez, chevaliers hennuyers, avec eux bien vingt-quatre hommes du pays de Haynaut eurent moyen de se sauver et retourner sains et saufs en leurdit pays", François Vinchant, 
notre chroniqueur? Du fait de leurs sources, les chroniqueurs français font donc tous deux ressortir le point de vue cher aux Chevaliers teutoniques. S'il est difficile de savoir la date précise à laquelle ces textes ont été composés, ils reflètent les premiers arguments forgés par la chancellerie teutonique, avant que la polémique ne se complexifie lors du concile de Constance ${ }^{220}$.

Michel Pintoin, qui relate directement le récit que lui fit l'envoyé de l'Ordre, rend compte de l'affaire des armes supposément fournies aux rebelles de Samogitie:

"Le roi chrétien de Cracovie, cédant aux instantes prières d'un roi sarrasin son frère, lui avait expédié par la Prusse une provision de blé, et y avait fait cacher des cuirasses en quantité suffisante pour équiper trois cents hommes. Les chevaliers de Prusse, ayant été informés de cet envoi, s'en saisirent en vertu du droit commun, attendu qu'il n'était pas permis à des chrétiens de fournir des armes aux infidèles et en disposèrent à leur gré. Cette circonstance alluma une guerre acharnée entre les deux nations. Le roi de Cracovie et son frère, après avoir vainement demandé par messages et par lettres la restitution des armes saisies, se liguèrent, malgré la diversité de leurs croyances, pour tirer vengeance de l'outrage qui leur était fait. ${ }^{221}$

Le chroniqueur distingue clairement le roi de Cracovie, chrétien, de son frère sarrasin, "roi» de Lituanie; même plus de vingt ans après son baptême, le grand-duché semble être considéré comme païen dans son entier. Il est vrai que la situation de la Samogitie, dont la rébellion a servi de casus belli, et la présence de Tatars musulmans dans les troupes lituaniennes peuvent donner l'impression que l'armée du grand-duc est plus «sarrasine» que chrétienne, mais le résumé que donne Pintoin ne permet pas de préciser si le chroniqueur connaissait ces détails. Étant donné le climat d'animosité qui a suivi la bataille, il y a lieu de penser que le messager peut avoir lui-même qualifié le grand-duc et ses sujets de «Turcs» ou de "Sarrasins», pour mieux faire ressortir la trahison du roi de Pologne $e^{222}$. La lettre que Sigismond lui a ordonné de transmettre parle toutefois de Teutoniques "vaincus par des cohortes et une foule nombreuse de païens féroces

Annales..., p. 41 ; PR 1, p. 38, n. 102. Monstrelet, que Vinchant suit certainement pour ce passage, précise également que les deux seigneurs fuyards étaient accompagnés de «bien vingt quatre gentilz hommes de leur pays» (Douët d'Arcq, vol. 2, p. 76).

220 S. EKDAhl, Die Schlacht bei Tannenberg..., p. 185-186.

221 Bellaguet, vol. 4, p. 335.

222 A. Demurger, «Le Religieux de Saint Denis et la croisade», dans F. Autrand, C. Gauvard, J.-M. Moeglin (dirs.), Saint-Denis et la royauté, Paris 1999, p. 186. Dans sa lettre de 1410, Henri de Plauen parle de "Sarrasins" pour désigner l'armée des alliés polonais et lituaniens; si l'on admet que l'envoyé de l'Ordre teutonique ait bien utilisé le terme de Sarrasins pour qualifier les Lituaniens, et que ce ne soit pas une interprétation de Pintoin, ce passage serait une attestation supplémentaire du fait que ce mot, appliqué aux Lituaniens, revient de Prusse vers l'Europe occidentale, où il semble avoir pris source. 
lituaniens, sarmates [Samartanorum], ruthènes et tatars, et d'autres ennemis et persécuteurs célèbres de la croix du Christ et de toute la religion chrétienne»" ${ }^{23}$. Le vocabulaire utilisé par Pintoin n'est donc pas une simple reprise d'un texte qu'il aurait eu sous les yeux.

Par la suite, le chroniqueur raconte qu'une fois entrés en Prusse, les hommes de Jagellon "coururent» le pays, comme cela se fait dans une guerre médiévale typique. Après deux semaines d'inaction ${ }^{224}$, les Teutoniques réagissent, et alignent une force certes inférieure en nombre à celle des envahisseurs, mais assez redoutable pour que ceux-ci doivent mettre au point une ruse de guerre:

"Mais, ayant appris que les chevaliers chrétiens sétaient réunis au nombre de sept cents, et s'étaient adjoint quatre-vingt mille Prussiens, ils se mirent en embuscade dans une épaisse forêt, laissant deux cent mille de leurs gens parcourir le plat pays. Dès que les chrétiens se trouvèrent en présence de ces derniers, ils fondirent sur eux, en invoquant l'assistance du Seigneur. Après un combat acharné, ils en tuèrent cent trente mille, et mirent le reste en déroute. Cette victoire éclatante leur eût acquis une gloire immortelle, et eût jeté l'épouvante parmi leurs adversaires, sills se fussent arrêtés quelque temps pour reprendre haleine. Mais, emportés par une folle ardeur et par le désir de signaler leur vaillance, ils poursuivirent les fuyards jusqu'à la forêt. Alors les trois cent mille hommes qui étaient en embuscade sortirent tout à coup de leur retraite et assaillirent vigoureusement ces gens harassés de fatigue. Les chrétiens, dans l'état de désordre et d'épuisement où ils se trouvaient, ne purent soutenir avec leur petit nombre un choc si rude; ils furent vaincus, et des sept cents chevaliers de l'Ordre teutonique quinze seulement parvinrent à s'échapper. Parmi les autres chrétiens, il y en eut, dit-on, soixante mille de tués; le reste fut fait prisonnier. ${ }^{225}$

La fuite des Lituaniens, qui ont attiré à leur poursuite les cavaliers de l'armée ennemie et ont permis au reste des troupes coalisées de vaincre, est relatée par plusieurs chroniques contemporaines, polonaises comme teutoniques ${ }^{226}$. On a supposé qu'il s'agissait d'une ruse employée notamment par les Tatars, qui composaient une partie importante du contingent lituanien; Vytautas, commandant en chef de l'armée coalisée, aurait pu s'en inspirer pour tromper

\footnotetext{
223 SRP 3, p. 403.

224 Bellaguet, vol. 4, p. 335.

225 Ibid., p. 335-337.

226 Par exemple, la Chronica Conflictus et la Chronique de Posilge. La fuite des Lituaniens est reprise par Długosz, pour décrédibiliser ces derniers et mettre en avant la bravoure polonaise (Annales XI, dans Opera Omnia..., vol. 13, p. 54-55). Jacques Lenfant, dans son Histoire du Concile de Constance (2 vols., Amsterdam, 1724, p. 19), remarquait déjà que la version rapportée par le Religieux de Saint Denis diffère passablement de celle du chroniqueur polonais: S. EKdahl, Die Schlacht bei Tannenberg..., p. 183-186; Idem, "The Turning Point in the Battle of Tannenberg (Grunwald/ Žalgiris) in 1410", Lituanus 56/2, 2010.
} 
l'adversaire ${ }^{227}$. Une lettre découverte par Sven Ekdahl confirme cette hypothèse, et précise que ce sont essentiellement les hôtes (volontaires comme mercenaires) qui se sont précipités à la poursuite des Lituaniens, disloquant ainsi l'ordre de l'armée prussienne ${ }^{228}$. La narration de l'émissaire telle que rapportée par le chroniqueur laisse entendre que si les «chrétiens» ont été vaincus, c'est par trop de bravoure de leur part; à l'inverse, les ennemis n'ont pas triomphé grâce à leur valeur, mais en tendant une embuscade ${ }^{229}$. C'est dire au fond que Tannenberg n'a pas seulement opposé deux camps religieux (des «vrais» chrétiens du côté de l'Ordre contre des parjures, de faux convertis, des infidèles et des schismatiques de l'autre), mais aussi deux manières de combattre: l'une chevaleresque, quitte à devenir téméraire, l'autre lâche et rusée ${ }^{230}$. Par l'imprudence des Teutoniques et de leurs hôtes, Tannenberg ressemble à un autre Nicopolis ${ }^{231}$.

Le chevalier hongrois conclut son récit au chroniqueur français par l'intervention du roi Sigismond, qui préparait une contre-offensive au moment où le messager a quitté la cour ${ }^{232}$ : "Le roi de Hongrie, informé de la déplorable issue de cette bataille et de l'appui que le roi de Cracovie avait prêté aux Sarrasins, en fut vivement courroucé. Il manda aussitôt à son frère monseigneur Wenceslas, roi de Bohême, de lui envoyer des secours, et avant que je partisse pour venir ici, il était déjà en marche pour aller ravager les terres de Cracovie et de Pologne et le pays adjacent»" ${ }^{233}$. Motivé par une alliance avec l'Ordre et une méfiance commune envers la Pologne, le comportement de Sigismond est réduit, chez Pintoin, à une simple question de morale: le seul fait que le roi de Pologne se soit allié à des "Sarrasins" expliquerait que l'on monte une coalition internationale contre lui ${ }^{234}$.

Enguerrand de Monstrelet donne une version un peu plus détaillée des événements, mais où le beau rôle est également joué par les Chevaliers

\footnotetext{
227 Id.

${ }^{228}$ Il s'agit du document Nr. 2024 dans les Ordensbriefarchiv (OBA), XX. Hauptabteilung Staatsarchiv Königsberg, Geheines Staatsarchiv de Berlin. S. Ekdahl attribue cette lettre à un chef militaire ami de l'Ordre, sans doute un mercenaire; S. EKDahl, "Die Flucht der Litauer in der Schlacht bei Tannenberg», Zeitschrift für Ostforschung, 12, 1963, p. 11-19; PR 2, p. 162.

229 S. Gouguenheim, Tannenberg..., p. 44-45.

${ }^{230}$ L. Sтомма (Krolów Polskich Przypadki, Varsovie 1993, p. 76-81) remarque que Jagellon agit plus comme un commandant "moderne" sur un champ de bataille que comme un roi idéal du Moyen Âge, à la Jean l'Aveugle.

${ }^{231}$ Sur les critiques de Pintoin envers la chevalerie française, jugée responsable du désastre de Nicopolis: N. Housley, "Le Maréchal Boucicaut à Nicopolis», dans J. Paviot, M. ChauneyBouillot (dirs.), Nicopolis 1396-1996..., p. 85-99; E. GAUCHER, «Deux regards... », p. 93-104.

232 S. EкDAнL, Die Schlacht bei Tannenberg..., p. 184.

233 Bellaguet, vol. 4, p. 337.

${ }^{234}$ L'argument est proche de celui que donne Guillebert de Lannoy, qui dit avoir appris, une fois en Prusse, que «les seigneurs de Prusse feroient rèse, sur l'esté, sur le roy de Poulane et sur le duc de Pomère qui favorisoient les Sarrasins" (Potvin, p. 26), mais rappelle aussi d'autres anecdotes, comme l'attaque du duc de Bourbon sur «le chastel de Caillé» (Chazaud, p. 251), dont les défenseurs sont accusés par les Génois de commercer avec les Turcs.
} 
teutoniques et leurs hôtes occidentaux. Le chroniqueur picard raconte, quelques pages avant la bataille proprement dite, les événements survenus en 1409. D'après ses informateurs, le conflit ne serait pas dû à une malencontreuse livraison d'armes aux païens, mais aux intrigues du roi de Pologne, animé de haine à l'encontre du grand-maître à la suite d'une "grande discorde» ${ }^{235}$. Celle-ci semble due à l'ambition de Jagellon, dont la personnalité est présentée selon le point de vue teutonique:

"Ce roy de Poulaine avoit jadis esté Sarrazin, et fut filz du roy de Lictuaire [Lituanie], qui par grant convoitise de régner et ambicion, occist son père, et pour ceste cause, fut-il chassé hors du pays, et s'en ala à refuge devers le roy de Poulaine qui pour lors régnoit, lequel le reçeut honnorablement, et fut grandement privé et familler de lui, et aussi acquist l'amour des princes et du royaume, pour quoy, après la mort dudit roi de Poulaine, les Poulenois esleurent icellui homicide à Roy, et le firent baptizer et estre chrestien, et puis espousa et print à femme la vesve dudit Roy." ${ }^{236}$

On sait cependant que Jagellon n'a pas été un intime de Louis d'Anjou, qu'Hedwige n'est pas la veuve de ce dernier mais sa fille, et que ce n'est pas le père, mais l'oncle du Lituanien qui a vraisemblablement été victime d'assassinat. L'extrait de Monstrelet comporte bien quelques erreurs, mais le ton général ressemble beaucoup à l'image diffusée par les Chevaliers teutoniques. Le dernier point, en particulier, semble avoir joué un certain rôle dans la "propagande" anti-Jagellon, puisque les délégués polonais au concile de Constance se sont sentis obligés de laver leur roi de telles accusations $^{237}$. Plus tard, lorsqu'il raconte la bataille de juillet 1410, Monstrelet insère une autre digression: "le roy de Poulane, qui estoit grant ennemy au Grant maistre de Pruce, lequel roy s'estoit naguères fait faintement chrestien pour parvenir à ce royaume ${ }^{238}$. On reconnaît un autre poncif de la propagande teutonique; le prince meurtrier et fuyard parvenu au pouvoir dans son pays d'accueil ne peut qu'être un mauvais chrétien, un converti hypocrite.

Pour le chroniqueur bourguignon, l'homme qui occupe le trône de Pologne est non seulement un fourbe et un "homicide», mais encore un insatiable ambitieux. On apprend en effet que Jagellon convoitait non seulement la Lituanie et la Pologne, mais encore la Hongrie:

"Et depuis le temps que ledit roy de Poulaine fut baptizé, il obtint ledit royaume assez euresement, et tant que par son orgueil il convoita le royaume de Hongrie,

235 Douëtd'Arcq, vol. 2, p. 61.

236 Ibid., p. 62.

237 S. C. Rowell, «Pious Princesses...», p. 25.

238 Douët d'Arcq, vol. 2, p. 75. 
disant qu'il y avoit droit en partie à cause de sa femme ${ }^{239}$. Et pour ce, print occasion de travailler ceulx de Hongrie et de Pruce, en mandant secrètement par ses lectres au roy de Lictuaire, son cousin germain, à lui alié, qu'il entrast en Pruce. Du maistre duquel pays, le roy de Hongrie estoit grant ami. $»^{240}$

On en déduit que le roi entendait réduire la puissance des Teutoniques avant de se tourner vers son principal objectif. Voilà pourquoi il entre en Prusse avec "très grant ost de diverses nacions"; mais voyant l'armée que lui opposent les Teutoniques, "le roy de Poulaine avecques tout son ost se parti, ouquel estoient vingt mille Poulenois, sans les Tartarins et autres chrestiens à lui aliez dont il avoit grand nombre ${ }^{241}$, et retourna en son pays ${ }^{242}$. Entre-temps, le plan machiavélique du Lituanien est déjoué par les espions hongrois, qui interceptent ses lettres ${ }^{243}$. L'année suivante, le temps de la contre-attaque est venu. À l'été 1410, "le Grant maistre de Pruce, acompaigné de plusieurs ses chevaliers frères et autres de diverses nacions [...] descendirent ou royaume de Lictuaire pour le destruire et dépopuler ${ }^{244}$, et écrasent une première armée "sarrasine». Parmi les morts, "l'admiral de Lictuaire et le connestable de Sarmach ${ }^{245}$; les survivants préférèrent s'enfuir. Jagellon a-t-il profité de cette défaite pour exciter les Lituaniens à reprendre le combat? On pourrait le croire:

"Et assez tost après, le roy de Poulane, qui estoit grant ennemy au Grant maistre de Pruce, [...] vint avec ses Poulenois en l'aide desdiz Sarrasins, ausquelz il exhorta moult de recommencer la guerre à l'encontre des Pruciens. ${ }^{246}$

Huit jours après la première bataille "se rassemblèrent l'un contre l'autre, c'estasavoir ledit roy de Poulane [...] contre ledit maistre de Pruce et plusieurs autres grans seigneurs chrestiens. Lesquelz par lesdiz Sarrasins furent déconfis». L'affrontement fait de nombreuses victimes ${ }^{247}$. Forts de leur victoire, les «Sarrasins» ravagent la Prusse, prennent douze villes et les mettent à mal; le pays doit son salut à l'énergie d'"ung vaillant chevalier, nommé Charles de Maroufle, de l'Ordre de Pruce», qui, rassemblant "grant nombre de chrestiens", arrive à

\footnotetext{
${ }^{239}$ Monstrelet semble confondre la généalogie de la reine Hedwige ( $\mathrm{m}$. 1399) avec celle d'Anne de Cilley, seconde épouse de Ladislas Jagellon (m. 1416) : Douët d'Arcq, vol. 2, p. 62.

${ }^{240}$ Ibid., p. 62-63.

${ }^{241}$ L'édition d'A. Buchon (Enguerrand de Monstrelet, Chroniques..., p. 124) a "auquel étoient vingt mille Tartarins et plus, sans les Poullenois et autres chrétiens à lui alliés, dont il avoit grand nombre», ce qui insiste sur les Tatars, et a plus de sens puisque "autres chrétiens» devrait faire référence aux Polonais, non aux Tatars.

${ }^{242}$ Douët d'Arcq, vol. 2, p. 62.

243 Ibid., p. 63.

244 Ibid., p. 75.

$245 \mathrm{Id}$.

246 Id.

${ }^{247}$ Ibid., p. 76-77.
} 
chasser l'envahisseur. Même si le nom ne correspond pas, on aura reconnu le rôle joué par Henri de Plauen ${ }^{248}$.

Comme chez Michel Pintoin, le rôle principal dans la victoire polonolituanienne revient aux Lituaniens, qualifiés de Sarrasins, ce qui peut être une reprise du terme dont se servaient les informateurs de nos chroniqueurs. Toutefois, contrairement au Religieux de Saint-Denis, Monstrelet fait figurer les Tatars dans l'ost du roi de Pologne, ce qui n'est peut-être pas sans lien avec le fait que la "propagande» teutonique ait insisté sur la cruauté et le comportement blasphématoire de ces farouches guerriers musulmans ${ }^{249}$. Monstrelet mentionne, aux côtés des Lituaniens, un roi puis un connétable de Sarmac(h), autrement dit Sarmatie, un terme général utilisé pour désigner l'Europe orientale ${ }^{250}$ : il est possible d'y voir une allusion au chef du contingent tatar, Dzelal-ed-Dinn' 251 à moins que ce terme ne se soit confondu avec le nom de la Samogitie. À cet égard, la lettre envoyée par le roi Sigismond parle bien de "paganorum rabidorum Littuanorum, Samartanorum, Rutenorum et Tartarorum ${ }^{252}$ - le deuxième de ces termes pouvant être un amalgame de Samagitorum et de Sarmatorum, c'est-à-dire les noms latins des habitants de la province rebelle et des "barbares" de l'Est européen. Même si rien n'indique que Monstrelet ait eu accès à la lettre du roi de Hongrie, celle-ci semble attester qu'une confusion s'est opérée au moment où la nouvelle de Tannenberg s'est répandue en Europe occidentale.

Dans le récit de Monstrelet, les Polonais semblent n'avoir participé que de manière marginale à l'affrontement: "lesdiz Sarrasins n'emportèrent point la gloire, ne la victoire, sans perte. Car, sans les Poulenois, dont il en mourut bien dix mille, moururent bien aussi le nombre de six vingt mil Sarrasins» ${ }^{253}$. L'affaire opposait, essentiellement, les Teutoniques aux Lituaniens; les Polonais, que l'on sait être chrétiens de longue date, ne s'y trouvent engagés que parce qu'ils ont un roi d'origine lituanienne. Celui-ci apparaît, chez le chroniqueur bourguignon, comme le principal moteur de la coalition anti-teutonique; c'est

\footnotetext{
${ }^{248}$ Ce nom reste énigmatique. S. Gouguenheim, «Das Echo...", p. 198, note que le terme maroufle a, dans le français du $\mathrm{Xv}^{\mathrm{e}}$ siècle, le sens de voleur, homme malhonnête - ce qui ne correspond pas au rôle attribué à ce personnage.

${ }^{249}$ La diabolisation des Tatars infidèles, alliés devant porter opprobre au roi de Pologne, est restée un poncif de l'argumentaire teutonique jusqu'à l'époque du Concile de Constance: S. EKDahl, Die Schlacht bei Tannenberg..., p. 219-221, publie côte à côte des extraits de la chronique de Posilge (v. 1413), d'une lettre d'Henri de Plauen datée du 21 février 1412, et du discours prononcé par le procureur de l'Ordre en février 1416 à Constance. La façon dont sont décrites les atrocités commises à Gilgenbourg est très similaire; on peut donc penser que, dans ce cas du moins, la lettre de 1412, et éventuellement la chronique de Posilge, ont servi de canevas au discours de Constance. Voir aussi S. Gouguenheim, Tannenberg..., p. 193-197.

250 Douët d'Arcq, vol. 2, p. 75; G. Mickūnaité, Making..., p. 42.

251 Id.

252 SRP 3, p. 403.

${ }^{253}$ Douët d'Arcq, vol. 2, p. 76-77.
} 
lui qui, incapable de vaincre par ses propres forces, appelle les Lituaniens. S'il n'est pas explicitement condamné pour avoir collaboré avec des infidèles, il porte la responsabilité d'avoir mené des troupes «sarrasines» ravager la Prusse. Un point de vue somme toute assez proche de l'hypothèse récemment avancée par S. Jóźwiak et al., pour qui la guerre aurait été voulue et minutieusement préparée par Jagellon et Vytautas ${ }^{254}$.

Toutefois, Jagellon n'est pas le seul responsable de la tragédie. En énumérant les pertes du côté teutonique, Monstrelet se fait l'écho d'une rumeur étonnante: "comme il fut commune renommée, la bataille fut perdue par la coulpe du grant connestable de Hongrye, lequel estoit en la seconde bataille des chrestiens, et se parti, lui et ses Hongrois, sans cop férir ${ }^{255}$. On sait qu'en 1411, le nouveau grand-maittre Henri de Plauen fit exécuter le chef de file de la Ligue du Lézard, organisation de nobles prussiens hostiles au pouvoir de l'Ordre, et qui étaient accusés d'avoir provoqué la défaite en cessant de se battre. À lire Monstrelet, cette explication était parvenue jusqu'en France, mais pourquoi attribue-t-il ce rôle peu glorieux aux Hongrois? À ce sujet, Sven Ekdahl remarque que la politique du roi Sigismond, qui avant la reprise des hostilités en été 1410 prétendait imposer la paix, a perturbé le recrutement des mercenaires par Ulrich de Jungingen, tout en permettant à ses adversaires de s'armer. Les rescapés de la débâcle en tenaient certainement rigueur à Sigismond de Luxembourg, et ont pu faire entendre un autre son de cloche que l'ambassadeur hongrois questionné par Michel Pintoin ${ }^{256}$.

Une autre explication est amenée par Sylvain Gouguenheim, pour qui la défaite de Nicopolis a servi de modèle à ce passage ${ }^{257}$. Le souvenir du désastre, encore fort au sein du parti bourguignon jusqu'au milieu du $\mathrm{Xv}^{\mathrm{e}}$ siècle, n'a sans doute pas échappé à Monstrelet au moment où il s'agissait de raconter la perte d'une armée croisée. Or, les Hongrois, connus pour leur combat face aux Turcs et jusqu'alors représentés en tant qu'alliés fidèles de la cause chrétienne (notamment dans le Mélusine de Jean d'Arras ${ }^{258}$ ), perdent en prestige après la célèbre desconfiture. Si Froissart ou le Religieux de Saint-Denis font part des conseils judicieux que le roi Sigismond tenta de donner aux seigneurs français avant que l'on engage le combat ${ }^{259}$, les laudateurs de ces derniers attribuent la défaite à la prétendue lâcheté du monarque et de ses troupes ${ }^{260}$. Les Hongrois,

\footnotetext{
254 S. Jóźwiak et al., Wojna....

255 Douët d'Arcq, vol. 2, p. 76. Le "grant connestable de Hongrye» est vraisemblablement le palatin Nicolas Gara, commandant de l'unité hongroise.

256 S. EKDahl, «Politics, Diplomacy...», p. 329-336.

257 S. Gouguenheim, «Das Echo...», p. 205.

258 Jean d'Arras, Mélusine..., p. 516.

259 Jean Froissart, Chroniques..., éd. J. Kervyn de Lettenhove, vol. 15, p. 313-315; Bellaguet, vol. 2, p. 483-485, 495, 499.

${ }^{260}$ Notamment le Livre des Fais..., p. 106-107, ou Eustache Deschamps, balade 1316, dans Euvres complètes, éd. G. Raynaud, Paris 1891, vol. 7, p. 77-78. Froissart attribue la fuite de Sigismond au
} 
boucs émissaires commodes pour les partisans de l'aristocratie française, sont naturellement désignés comme les responsables de l'autre défaite majeure subie aux mains de l'infidèle au tournant du siècle. L'ombre de Nicopolis plane sur les récits français de Tannenberg; pour Pintoin, les Teutoniques ont perdu à cause de leur témérité, tout comme les chevaliers français sur le Danube. Pour Monstrelet, ils ont été trahis par les Hongrois, qui avaient déjà abandonné leur poste quatorze ans plus tôt. Ces deux clefs d'interprétation, somme toute assez simples, permettent d'expliquer une défaite qui, prise en tant que telle, n'est pas pour faire briller l'étoile de la chevalerie chrétienne ${ }^{261}$.

La nouvelle de la défaite ayant été transmise auprès de la cour et de la noblesse française par des croisés de Prusse et des messagers de l'Ordre teutonique, il n'est pas surprenant que l'entourage du roi ait pris fait et cause pour les chevaliers à la croix noire. Ceux-ci étaient, sans doute, plus familiers aux princes français que leurs adversaires, contre qui allaient encore se battre de nombreux chevaliers dans les années $1390^{262}$. En tout cas, Charles VI, tout comme le roi anglais Henri IV, se fend de quelques lettres en faveur des Teutoniques - mais rien de plus ${ }^{263}$. Dès 1411, le roi de France écrit au pape Jean XXIII pour lui demander de prendre l'Ordre sous sa protection ${ }^{264}$, et le 12 janvier 1412, il s'adresse directement à Jagellon pour l'inciter à respecter la paix avec les Teutoniques ${ }^{265}$. La lettre est chargée de menaces: pour l'amour de

fait que, les Français n'ayant pas écouté son avis, ses barons lui conseillèrent de fuir pour sauver le royaume de Hongrie (Chroniques..., éd. J. Kervyn de Lettenhove, vol. 15, p. 316-317). Sur les deux points de vue quant à la défaite, E. GAUCHER, "Deux regards...», p. 93-104; N. Housley, "Le Maréchal Boucicaut...», p. 93-95; E. Antoche, «Expéditions de Nicopolis et de Varna: une comparaison (part. 2)", Analele Universitatii Dunarea de Jos din Galati. Istorie 4, 2005, p. 97-98.

${ }^{261}$ Commentant la supposée fuite des Hongrois à Nicopolis, N. Housley, "Le Maréchal Boucicaut...", p. 93, parle d' une explication, donc, recourant principalement à l'accusation familière de trahison par des gens lointains et étrangers».

262 Pour S. Gouguenheim ( $D$ Das Echo...», p. 198), le parti-pris pro-teutonique de la cour peut s'expliquer par l'influence allemande venant de l'entourage de la reine Isabeau de Bavière. À partir de 1392, le roi Charles VI souffrait d'une grave maladie mentale, ce qui laissait libre cours aux différentes factions.

${ }^{263}$ Le continuateur de Posilge mentionne que les rois de France et d'Angleterre ont écrit au pape pour lui demander de prendre l'Ordre sous sa protection, et au roi de Pologne pour lui demander de respecter la paix; SRP 3, p. 328. Des lettres du roi d'Angleterre et du duc de Bourgogne sont également mentionnées dans la correspondance du procureur de l'Ordre à la Curie sous la date du 18 février 1412; Die Berichte..., vol. 2, doc. 68, p. 136-140. Pour les lettres des rois de France et d'Angleterre au pape, à Jagellon et à Sigismond de Luxembourg, PR 1, p. 40, n. 119; sur l'attitude d'Henri IV après Tannenberg, J. H. Wylie, History of England..., vol. 4, p. 18-21.

${ }^{264}$ Ordensbriefarchiv/Regesta I, n 1544, Geheimes Staatsarchiv Preussischer Kulturbesitz, cité par PR 1, p. 40, n. 119.

265 S. Gouguenheim, «Das Echo...», p. 198; K. Polejowski, "The Teutonic Order's Propaganda...», p. 238. La lette est éditée dans Quellen..., doc. 31, p. 186-189. Comme le souligne H. Boockmann (Johannes Falkenberg..., p. 91, n. 162), le fait que le roi Charles demande à Jagellon de respecter la paix avec l'Ordre peut être un écho des lettres envoyées par Plauen en Europe occidentale. 
Dieu et du Christ autant que pour l'intérêt du bien public, le roi de Pologne devrait s'efforcer de parvenir à une paix avec l'Ordre, et si cela ne devait pas avoir lieu, «il nous appartient d'apporter, avec les autres bons et fidèles chevaliers catholiques, notre aide et notre faveur à la défense du dit ordre", afin de le protéger de la destruction ${ }^{266}$. L'attitude relativement hostile de la cour française peut expliquer que Jagellon ait confié à Guillebert de Lannoy des lettres par lesquelles il se plaint de la froideur du monarque français à son égard ${ }^{267}$; gageons que si le message de congratulation adressé au Lituanien peu après sa conversion en 1387 n'est pas parvenu à destination, et que la seule missive délivrée est celle de 1412, le roi de Pologne a pu se sentir quelque peu froissé.

Pourtant, l'engouement pour une campagne contre l'alliance polonolituanienne n'est pas à la hauteur de ce qu'aurait pu espérer Marienbourg. Relativement peu de chevaliers se mettent en marche, même dans les régions où la noblesse était traditionnellement engagée dans la croisade nordique ${ }^{268}$. Si aucun Anglais ne fait le déplacement, on trouve encore quelques Français, parmi lesquels Guillebert de Lannoy, qui nous renseigne admirablement bien sur cette période ${ }^{269}$. La question se pose toutefois de savoir ce qui a poussé ce jeune noble à aller prêter main forte aux Teutoniques en 1413. Dans ses Voyages et ambassades, il dit être parti "pour aller en Prusse contre les mescréans en une armée que faisoient les seigneurs de Prusse " ${ }^{270}$, ce qui peut être un écho de la "propagande" teutonique répandue en France ${ }^{271}$. À titre d'exemple, le grand-maître écrivait en avril 1413 au roi de France et au duc de Bourgogne pour leur demander des renforts, évoquant le bon souvenir de la table d'honneur et rappelant le rôle de la dynastie française dans la défense de la Chrétientée ${ }^{72}$. Une lettre qui, en l'occurrence, ne saurait avoir provoqué le départ de Guillebert, puisque celui-ci dit être parti au mois de mars déjàa ${ }^{273}$.

Du reste, ce jeune noble amateur de voyages n'avait peut-être pas besoin d'entendre ces appels à l'aide pour partir faire "son" voyage de Prusse, activité très prisée de la génération antérieure à la sienne. De son temps encore, plusieurs nobles des provinces de la France du Nord vont combattre sur les rives de la Baltique. C'est le cas notamment de son frère aîné Hugues, qui autour de 1406 y accompagne le sénéchal de Hainaut Jean de Werchin, mentor des

266 Quellen..., doc, 31, p. 188.

267 S. Gouguenheim, «Das Echo...», p. 198-199.

${ }^{268}$ PR 1, p. 39-41.

${ }^{269}$ PR 1, p. 40.

270 Potvin, p. 20.

271 J. Svátek, Discours..., p. 232; K. Toomaspoeg, «La guerre baltique...», p. 408.

${ }^{272} \mathrm{CEV}$, doc. 542, p. 261-262. L'appel mentionne l'attaque menée par Jagellon et Vytautas «cum Lithwanis, Ruthenis, Tartaris, paganis». Sur cette lettre, O. Halecki, "Gilbert de Lannoy...", p. 318; H. Boockmann, Johannes Falkenberg..., p. 112, n. 262.

${ }^{273}$ Potvin, p. 20; O. Halecki, «Gilbert de Lannoy...", p. 318. 
deux frères ${ }^{274}$. En 1411, soit après Tannenberg, quelques chevaliers français font également le déplacement ${ }^{275}$. Les derniers d'entre eux, originaires du Hainaut, iront encore en Prusse aussi tard que $1419^{276}$. Peut-être plus que la "propagande» de l'Ordre ou le parti-pris de la cour en faveur de ce dernier, le maintien d'une tradition de croisade balte dans le milieu nobiliaire de la France du Nord explique que Guillebert ait décidé de se rendre en Prusse, même à une date relativement tardive ${ }^{277}$. En guise de comparaison, le dernier hôte anglais des Teutoniques dont nous connaissons l'identité n'est autre que le petit-fils de Thomas Beauchamp, Richard, vraisemblablement pour payer tribut à la tradition familiale 278 . Il s'y arrête en été 1409 , en rentrant d'un long voyage qui lui a fait voir la Terre sainte, Venise, et à en croire le Beauchamp Pageant, "la Russie, la Lituanie, la Pologne, la Prusse, la Westphalie et d'autres côtes d'Allemagne ${ }^{279}$; la Prusse n'était qu'une étape parmi d'autres, et d'après un relevé de compte trouvé à Cologne, on sait que Richard avait déjà quitté le grand-maître avant que celui-ci ne déclare la guerre à la Pologne le 6 août ${ }^{280}$.

Il n'en reste pas moins que le seigneur de Lannoy n'était pas un croisé tout à fait ordinaire. L'examen des sources teutoniques a mené Werner Paravicini à en déduire qu'il était seul lors de son voyage de 1413; contrairement à ses pairs, il ne faisait pas partie d'un groupe de voyageurs ${ }^{281}$. On sait également qu'il rencontra personnellement plusieurs têtes couronnées d'Europe du Nord-Est, et que Jagellon ainsi que le grand-maître de l'Ordre lui ont confié chacun une mission diplomatique ${ }^{282}$. Même s'il est hasardeux de postuler qu'il ait pu

\footnotetext{
${ }^{274}$ PR 1, p. 32-33, 101; W. Paravicini, "Jean de Werchin, sénéchal de Hainaut, chevalier errant", dans U. C. Ewert, A. Ranft, S. Selzer (dirs.), Noblesse..., p. 254; B. de Lannoy, Hugues de Lannoy..., p. 21-25. Jean de Werchin et les siens, dont Hugues de Lannoy, avaient prévu de se rendre une deuxième fois en Prusse en 1408; en mai, ils donnèrent une fête de départ dans une auberge de Tournai, mais le comte de Hainaut les rappelle à son service, coupant court aux préparatifs de départ. Sur le rôle de Werchin dans la formation du jeune Guillebert et de son aîné: W. Paravicini, «Nobles Hennuyers... », p. 291-292.

${ }^{275}$ Il s'agit de l'écuyer Laurent du Jars, peut-être originaire du Berry, de Charles d'Estouville, et d'Aubert de Villequierville, tous deux de Normandie, et de l'écuyer la Roque, bourguignon; un certain «K. de P.» est repéré en 1414; PR 1, p. 40-41.

${ }^{276} \mathrm{Il}$ s'agit d'un petit groupe de nobles réunis autour d'un certain seigneur d'Audrignies, puis de Jean et Michel de Ligne: W. Paravicini, «Kreuzzug... », p. 124.

277 J. SvÁtek, Discours..., p. 231.

278 PR 1, p. 34, 169-170. Le père de Richard, également appelé Thomas, a fait «son» voyage en Prusse avec deux de ses frères en 1367-1368; voir PR 1, tab. 20, p. 171. En 1410, des Anglais anonymes ont participé à Tannenberg; PR 1, p. 127. La présence de Richard en Prusse est mentionnée dans le Beauchamp Pageant, composé entre 1485-1490: Pageant..., tab. XXII; PR 1, p. 34.

${ }_{279}$ Pageant, tab. XXII; PR 1, p. 206.

280 PR 1, p. 34-35.

281 Ibid., p. 41 ; la lettre de recommandation du grand-maître Michael Küchmeister ne mentionne que son seul nom; doc. 20, annexe 2, dans PR 4 (à paraître).

282 J. Svátek, Discours..., p. 140.
} 
remplir le rôle d'un ambassadeur officieux, tout porte à croire que la présence d'un chevalier français, échanson du duc de Bourgogne qui plus est ${ }^{283}$, était la bienvenue pour des rivaux en mal de reconnaissance internationale. Aussi, on peut suivre Jaroslav Svátek, qui postule que les égards du grand-maitre envers Guillebert peuvent se lire comme une tentative visant à séduire l'un des rares croisés d'importance venus auprès de l'Ordre ${ }^{284}$, et qui pouvait influencer la manière dont la situation balte serait comprise par ses compatriotes. Il n'y a ainsi rien d'étonnant au fait que, lors de son séjour en Prusse, Guillebert se soit vu confier une lettre du grand-maitre, par laquelle celui-ci appelle le duc de Bourgogne et d'autres nobles de France et des Pays-Bas à lui envoyer des renforts ${ }^{285}$. Les Teutoniques avaient fort à coeur de recruter des croisés français, et Guillebert était l'homme de la situation.

On le voit, notre Bourguignon se trouvait en Prusse à une époque bien particulière. Les années qui suivent Tannenberg sont relativement difficiles pour l'Ordre teutonique, en proie à des difficultés économiques et financières, mais aussi politiques ${ }^{286}$. Incités par la montée en puissance de la Pologne, plusieurs partenaires se désolidarisent. Les ducs poméraniens de Szczecin et de Wolgast-Słupsk, qui depuis la fin du XIv e siècle essayaient de protéger leur indépendance en s'alliant tantôt avec l'un, tantôt avec l'autre des adversaires, se rangent du côté de Jagellon ${ }^{287}$. La noblesse de Prusse tente quant à elle de secouer le joug des Teutoniques, dont la mainmise sur les affaires du pays est de moins en moins tolérée ${ }^{288}$. Plus grave peut-être, les riches villes de Gdańsk et Toruń sont tentées par une alliance polonaise, velléités violemment réprimées par Henri de Plauen ${ }^{289}$. Ce dernier, qui rêve de revanche et refuse

\footnotetext{
${ }^{283}$ Ibid., p. 230-231.

${ }^{284}$ Ibid., p. 262. Notamment, Potvin, p. 25. Guillebert a été reçu de manière tout aussi honorable par le roi Éric de Danemark et Ladislas Jagellon, tous deux ennemis du grand-maître.

${ }_{285}$ PR 1, p. 40 ; doc. 108, édité dans PR vol. 4 (à paraître).

286 S. Gouguenherm, Les Chevaliers teutoniques..., p. 479-480, explique que l'indemnité demandée par Jagellon n'était pas particulièrement élevée, et qu'elle n'est pas seule à avoir ruiné l'Ordre. Cette somme ne venait "que» s'ajouter aux dévastations de la guerre, au coût des mercenaires et aux emprunts à rembourser à la Hongrie et à la Bohême.

${ }^{287}$ Ainsi, le 29 août 1410, le duc de Słupsk Bogusław VIII rend hommage au souverain polonais pour une partie de ses terres, et jusqu'à sa mort (1418), il se tiendra de son côté: J. ZDRENKA, Polityka Zagraniczna..., p. 264; G. BŁAszczYK, Dzieje..., p. 479.

${ }^{288}$ W. Paravicini note que jusqu'à la moitié du XIv ${ }^{e}$ siècle, Prussiens et Polonais pouvaient être intégrés à l'Ordre, avant que les chevaliers originaires d'Allemagne ne bloquent les accès aux offices et ne s'entre-déchirent en factions différentes; "L'Ordre teutonique et les courants migratoires... ", p. 312, 315-316. Naît alors l'idée que les détenteurs légitimes de la Prusse ne sont pas les Teutoniques, tous nés en Allemagne, mais la vieille noblesse prussienne, d'origine autochtone ou immigrée; S. Gouguenheim, Les Chevaliers teutoniques..., p. 541-544; M. Burleigh, Prussian Society..., p. 37-41.

${ }^{289}$ En 1411, le grand-maître réunit les délégués des villes et de la noblesse pour faire voter de nouvelles taxes afin de pouvoir payer les mercenaires et les indemnités dues à la Pologne, mais il fait face au refus de Gdańsk et Toruń. Son courroux s'abat sur la première des deux villes, qui
} 
de licencier ses mercenaires, ne fait pas que des heureux, même parmi les Chevaliers. Au retour de la rèse menée en automne 1413 en compagnie de l'Ordre teutonique, Guillebert de Lannoy eut vent de la chute de l'ombrageux grand-maître ${ }^{290}$ :

"Et tantost après le retour d'icelle [rèse], fut le hault maistre, qui par maladie estoit demouré à Mariembourg, prins prisonnier par le mareschal et autres commandeurs, ses hayneurs. Sy fut degradé et déposé de son estat pour aucunes deffautes qu'ilz luy imposoient, et fut mis en une forte tour où il fut grant temps plain d'impacience, mais depuis, ung peu après ce, se rafferma et luy fut rendue une petite commanderie, puis fut mis hors de prison, mais finablement il morut de doel et d'anoy. $»^{291}$

Détesté par la noblesse et la bourgeoisie urbaine, le grand-maitre n'était pas en faveur auprès de ses propres officiers, lassés autant par la mainmise du "clan Plauen" sur les fonctions prestigieuses que par sa politique jusqu'auboutiste ${ }^{292}$. À la tête des mécontents se trouve le maréchal Michael Küchmeister de Sternberg, qui relègue les partisans d'Henri de Plauen, puis se fait élire au poste suprême au début de l'année suivante. L'ancien grand-maître est envoyé dans la commanderie d'Engelsbourg, au sud-ouest de la Prusse ${ }^{293}$. Lannoy, qui entretenait de bonnes relations avec lui ${ }^{294}$, semble déplorer ce "putsch"; en tout cas, il rend visite à l'infortuné au printemps 1414, lorsqu'il repasse en Prusse après avoir visité Novgorod et la Lituanie, et avant d'aller en Pologne: «Et passay par ung chastel nommé Ingleseberch [Engelsbourg ${ }^{295}$ ] ouquel on tenoit le hault maistre qui la saison devant avoit esté dégradé et demis de sa seignourie, et alay devers luy pour le visiter en sa misère, dont j'en euz grant pitiée ${ }^{296}$. Si Guillebert

tente de résister, alors que les riches citoyens de la deuxième fuient en Pologne. Les magistrats de Gdańsk se rendent le 5 avril 1411, mais le jour suivant, deux bourgmestres et un conseiller sont exécutés sans aucune procédure, sur ordre du commandeur de l'Ordre, qui n'est autre que le frère du grand-maître. Peu après, c'est au tour de Nicolas de Renys, le chef de la Ligue du Lézard d'être accusé de complot en même temps qu'un officier de l'Ordre. Renys est décapité, incriminé de la trahison qui aurait entraîné la défaite de Tannenberg (voir p. 262). S. Gouguenheim, Les Chevaliers teutoniques..., p. 549-551.

${ }^{290}$ Potvin, p. 28, n. 4. Guillebert n'a vraisemblablement pas assisté à l'événement (octobre 1413), puisqu'il dit s'être rendu à Gdańsk après la rèse. Sur la guerre préventive menée par Henri de Plauen contre la Pologne, PR 1, p. 39.

${ }^{291}$ Potvin, p. 27-28.

${ }^{292}$ Sur le "putsch" de Küchmeister, les différentes stratégies et les tensions internes à l'Ordre teutonique, M. Burleigh, Prussian Society..., p. 81-83; W. Nöвel, Michael Küchmeister. Hochmeister des Deutschen Ordens. 1414-1422, Bad Godesberg 1969, p. 59-68.

${ }^{293}$ Ibid., p. 83.

${ }^{294}$ Le grand-maître lui fit visiter ses domaines (Potvin, p. 25) et il fut adoubé par un membre de sa famille, sans doute un homonyme (Ibid., p. 27); J. SvÁteK, Discours..., p. 212, 262.

295 Ibid., p. 262, n. 303.

${ }^{296}$ Potvin, p. 45. 
s'abstient de commentaires trop explicites quant à l'action de Küchmeister ${ }^{297}$, Cracovie n'hésite pas à faire savoir qu'il lui dénie toute légitimité, du moins pendant un certain temps ${ }^{298}$.

Comme l'atteste la rèse à laquelle Guillebert de Lannoy a participé, la situation politique reste tendue, malgré la paix de Toruń ${ }^{299}$. Le fait que l'attaque porte précisément contre la Pologne et le "duc de Pomère» est révélateur: ce dernier personnage est vraisemblablement Bogusław VIII de Słupsk, le duc de Poméranie qui s'est rangé fermement du côté polonais ${ }^{300}$. Guillebert ajoute que ces deux princes "favorisoient les Sarrasins", ce qui rappelle la "propagande" teutonique auprès des cours d'Europe occidentale. Par ailleurs, Jagellon continue sa campagne épistolaire auprès des princes chrétiens pour faire valoir son bon droit ${ }^{301}$. À l'été 1412, Sigismond de Hongrie, récemment élu roi des Romains, propose un arbitrage et l'envoi d'un commissaire qui devra définir les frontières des territoires disputés entre l'Ordre, la Lituanie et la Pologne - entre autres, celles de la Samogitie ${ }^{302}$. Les conclusions de celui-ci, le juriste hongrois Benedict Macra, sont taxées de partialité par les Teutoniques et l'arbitrage rendu en 1414 par Sigismond à Buda reste pour ainsi dire lettre morte ${ }^{303}$. Les armes sont destinées à parler à nouveau: alors que le nouveau grand-maître Küchmeister entendait jouer la carte de l'apaisement, Jagellon envahit à nouveau la Prusse à l'été 1414 , sans résultat déterminant ${ }^{304}$. C'est alors que l'on choisit de porter la cause devant un arbitre peut-être encore plus prestigieux que Sigismond de Hongrie.

\footnotetext{
${ }^{297}$ Pour L. Quarré-Reybourbon (La vie, les voyages et aventures de Gilbert de Lannoy, chevalier lillois au XV siècle, Lille 1890, p. 9), Guillebert «accepte le fait accompli».

298 W. Urban, Tannenberg..., p. 199.

299 Selon l'interprétation de J. Lelewel, le témoignage du chevalier français prouverait que l'Ordre a rompu la paix avec la Pologne; (Guillebert de Lannoy, Guillebert de Lannoy et ses voyages..., p. 23, n. 19, suppl., p. 17, n. 19), cité par Potvin, p. 27, n. 6.

300 J. Zdrenka, Polityka Zagraniczna..., p. 264.

301 Voir par exemple les lettres de Jagellon aux princes chrétiens éditées par E. Raczyński, Codex Diplomaticus Lithuaniae..., doc. 6.11, p. 150-151, doc. 7.2, p. 161-164.

${ }^{302}$ Le juriste hongrois Benedict Macra (ou Makrai), accompagné de l'évêque de Poznań André Laskary, représentant du roi de Pologne, et du secrétaire de Vytautas, le Polonais Mikołaj Cebulka, se rend en 1412 et 1413 en Lituanie, en Samogitie puis dans les régions disputées entre l'Ordre teutonique et le royaume de Pologne: W. Sieradzan, «Benedek (Benedict) Makrai as a Subarbiter in the Conflict between the Teutonic Order and its Neighbour Countries in 1412-1413", dans Idem (dir.), Arguments and Counter-Arguments..., p. 157-168; les actes relatifs à la mission de Macra sont édités dans Lites..., éd. I. Zakrzewski, J. Karwasinska.

303 Sur l'arbitrage de Buda, D. Buschinger, M. Olivier, Les Chevaliers teutoniques..., p. 271-273. Un certain "domino archanorum consiliano ac capellano regis Francie» est mentionné au côté de Sigismond: Lites..., éd. I. Zakrzewski, J. Karwasinska., vol. 2, p. 69, 90.

${ }^{304}$ Afin d'éviter une bataille rangée, Küchmeister retire ses troupes et les fait se barricader dans les châteaux: T. BrenNAN, Just War..., p. 115-116.
} 


\section{La Lituanie au concile de Constance}

Dans les années qui suivent la bataille de Tannenberg, l'idée s'impose de mener l'affaire devant le concile tenu à Constance pour mettre fin au schisme et réformer l'Église ${ }^{305}$. Dès le 15 août 1414 , Jean, comte Palatin du Rhin et duc de Bavière, incitait Jagellon à ne pas tenter l'invasion de la Prusse, mais à demander un arbitrage au concile qui allait s'ouvrir ${ }^{306}$. À l'automne 1414, l'évêque de Lausanne Guillaume de Challant est envoyé par le pape «conciliaire» Jean XXIII pour demander aux princes et prélats polonais de se rendre à Constance ${ }^{307}$. Le légat est également chargé de négocier une trêve de deux ans, par laquelle les deux parties acceptent que leurs différends soient arbitrés par le plus grand tribunal de la Chrétienté latine d'alor ${ }^{308}$. À la fin de l'année, l'Ordre, la Pologne et la Lituanie envoient leurs représentants dans la ville impériale $e^{309}$.

Au début de l'année 1415, le procureur du grand-maître, Pierre Wormditt, appelle contre le roi de Pologne ${ }^{310}$. Rappelant les services que l'Ordre teutonique a rendus à la Chrétienté en la protégeant des infidèles, il évoque la symbiose entre l'Ordre et ses protecteurs occidentaux, en ce qui peut être une allusion aux rèses des décennies précédentes ${ }^{311}$. Mais convaincre le concile n'est pas une tâche aisée: dès le 17 janvier, Jean XXIII retire à l'Ordre les privilèges reçus deux siècles auparavant, avant de revenir sur cette décision quelques mois plus $\operatorname{tard}^{312}$. À la fin du mois de février, le souverain pontife nomme Jagellon vicaire général à Novgorod, Pskov et dans les autres provinces où vivent «des schismatiques et des hérétiques, des rebelles infidèles et des ennemis de la foi et de l'Église» ${ }^{313}$, avec pour mission de les soumettre à l'autorité de Rome ${ }^{314}$. En somme, la mission traditionnelle des Teutoniques passe à leurs adversaires ${ }^{315}$.

305 G. BłaszczyK, Dzieje..., p. 428-429; S. F. Belch, Paulus Vladimiri..., p. 112. Sur ce qui suit, W. Brandmüller, Das Konzil von Konstanz, Padeborn 1997, vol. 2, p. 150-175; et les belles études de H. Boockmann, Johannes Falkenberg...; S. F. Belch, Paulus Vladimiri..., vol. 1.

306 Codex Diplomaticus Lithuaniae..., doc. 8.6, p. 187-188.

307 Vetera monumenta..., vol. 2, doc. 16, p. 14; BP 3, doc. 1450, p. 233; Index actorum..., doc. 775, p. 93. Jean XXIII est le successeur d'Alexandre V, élu par le concile de Pise en 1409 et reconnu par la Pologne, la Lituanie et l'Ordre teutonique.

308 Die Staatsverträge... 1, doc. 105, p. 107-109.

309 Ibid., doc. 107, p. 109; Die Berichte..., vol. 2, n 110, p. 222-223; CES 2, doc. 56, p. 64-67; Skarbiec..., II, doc. 1087, 1088, p. 29.

${ }^{310}$ Le traité est édité dans Die Staatsschriften... 1, doc. 2, p. 70-111, et résumé par T. Brennan, Just War..., p. 122-126.

311 Die Staatsschriften... 1, p. 74; M. Olivier, "Veteres relegentes historias": la place des chroniques dans la polémique entre l'Ordre teutonique et la Pologne au Concile de Constance (1414-1418)", dans P. H. Andersen et D. Buschinger (éds.), Chroniques en tous genres. Actes du colloque d'Amiens (Mars 2006), Amiens 2006, p. 91.

312 CES 2, doc. 57, p. 67-69.

313 Ibid., doc. 58, p. 70.

${ }^{314} \mathrm{Id}$.

315 Sur la "polonophilie» de Jean XXIII, T. Brennan, Just War..., p. 127; E. Christiansen, The Northern Crusades..., p. 224. Pour W. Urban ("The Teutonic Knights at the Council of 
Mais Jean XXIII n'est pas un allié solide; installé comme un jouet entre les mains du puissant Sigismond de Luxembourg, il est contesté par le concile, qui le dépose après qu'il ait tenté de fuir (29 mai 1415) ${ }^{316}$. À défaut de convaincre un pape délégitimé, les deux parties essayent de s'attirer la sympathie des princes et des ecclésiastiques présents au concile, qui sont autant d'appuis potentiels. Norman Housley a notamment remarqué que chaque prélat peut influencer la décision du prince auquel il est attaché, ce qui compte dans une lutte où Teutoniques comme Polono-Lituaniens cherchent à consolider leurs réseaux d'alliance, ne serait-ce que pour s'assurer le recrutement des mercenaires ${ }^{317}$.

Dans la longue passe d'arme entre délégués teutoniques et polonolituaniens, la délégation d'une soixantaine de nobles samogitiens, arrivée à Constance le 28 novembre 1415, a été particulièrement remarquée ${ }^{318}$. Quelques jours plus tard, l'évêque de Poznań André Laskary introduit les nouveaux venus devant le concile, en les présentant comme un témoignage de l'action évangélisatrice menée par le roi de Pologne et le grand-duc de Lituanie ${ }^{319}$. Après avoir attendu en vain le retour de Sigismond, qui parcourait l'Europe pour convaincre les papes rivaux de se retirer ${ }^{320}$, les délégués polonais lancent une première liste d'accusations contre l'Ordre teutonique, qui répond aussitôt ${ }^{321}$. Nous sommes le 13 février 1416. Peu

Constance...», p. 4046-4049), l'Ordre teutonique comptait sur la sympathie traditionnelle des papes pour les ordres militaires et l'idéologie de croisade, mais Jean XXIII avait pris conscience que la Pologne et la Lituanie étaient devenues les plus puissantes.

316 Ibid., p. 4052. Jean XXIII est abandonné par les prélats français Pierre d'Ailly et Guillaume Fillastre, qu'il avait pourtant créés cardinaux; B. Guenée, Entre l'Église et l'État, Paris 1987 , p. 270, 280-281.

317 N. Housley, The Later Crusades..., p. 358-359; Idem, "A crusade against the Poles? Johannes Falkenberg's "Satira" (1412)", à paraitre. L'importance de la communication peut être illustrée par la remarque de Robert Hallam, évêque de Salisbury et l'un des principaux conseillers de Sigismond, qui reproche au procureur de l'Ordre Pierre Wormditt que les Teutoniques ne s'occupent plus de défendre l'Église, mais plutôt de la corrompre. Un avis que Wormditt attribue aux manœuvres des délégués polonais, Die Berichte..., vol. 2, doc. 125, p. 264-265; H. Boockmann, Johannes Falkenberg..., p. 205-206.

318 P. Rabikauskas, «La Cristianizzazione... », p. 229.

319 Le discours de Laskary est rapporté par le journal de Jacopo Cerretano, Acta Concilii Constanciensis, éd. H. Finke, J. Hollnsteiner, H. Heimpel, Münster 1823 (ci-après: ACC), vol. 2, p. 266-267, trad. dans The Council of Constance: the Unification of the Church, trad. L. R. Loomis, J. H. Mundy, K. M. Moody, New York 1961, p. 502-504; D. Baronas, S. C. Rowell, The Conversion..., p. 349-350.

320 Ibid., p. 350 ; H. Boockmann, Johannes Falkenberg..., p. 206-207 passim.

321 D. Baronas, S. C. Rowell, The Conversion... p. 351. La Propositio Polonorum contra Ordinem, lue à cette occasion, est éditée dans CEV, Appendix, doc. 6 A, p. 1001-1018, et Codex Mednicensis Seu Samogitae Diocensis, éd. P. Janutis, Rome 1984 (ci-après: CM), doc. 2, p. 13-18. Le texte peut être attribué au recteur et diplomate Paul Vladimiri (Paweł Włodkowic) ou à Nicolas Trąba, archevêque de Gniezno et chef de la délégation polonaise; S. GouguenheIm, Tannenberg..., p. 225 , n. 60 . 
après, vraisemblablement le 17 février, le porte-parole des Samogitiens délivre un discours connu comme la Propositio samagitarum ${ }^{322}$.

L'auteur de ce texte reste inconnu: les recherches récentes tendent à l'identifier comme un membre de la chancellerie du grand-duc de Lituanie, peut-être Nicolas Sepienski, secrétaire de Vytautas ${ }^{323}$. Ce qui est certain, c'est que celui ou ceux ${ }^{324}$ qui ont préparé le texte devaient avoir une bonne connaissance de la réalité samogitienne, et un certain talent pour dénicher des exemples concrets parlant en défaveur de l'Ordre teutonique ${ }^{325}$. L'envoi de cette délégation appartient à une stratégie élaborée sous l'égide de Jagellon et de $V_{\text {ytautas }}{ }^{326}$. L'enjeu était de présenter la Lituanie, convertie depuis une trentaine d'année, comme un partenaire essentiel de la Chrétienté latine, capable de faire progresser la foi là où les Chevaliers teutoniques n'avaient été d'aucune utilité327. La politique prudente de ces derniers vis-à-vis de la Samogitie, par ailleurs partagée par Vytautas lors de ses rapprochements avec l'Ordre ${ }^{328}$, peut servir de preuve visant à démontrer l'hypocrisie des Teutoniques, qui accusent leurs ennemis de laxisme mais négligent de baptiser la population des provinces dont ils ont la charge ${ }^{329}$.

322 Édité dans CEV, Appendix, doc. 6 B, p. 1018-1024 et CM, doc. 1, p. 1-13. La date de lecture du texte, habituellement considérée comme le 13 février, est mise en cause par D. Baronas et S. C. Rowell (The Conversion..., p. 347-353), qui lui préfèrent le 17, conformément aux indications données par le cardinal français Guillaume Fillastre; Fillastres Gesta concilii, ACC 2, p. 58; trad. M. Loomis, The Council of Constance..., p. 280. L'intervention des Samogitiens est également rapportée par Ulrich de Richental, Chronik des Constanzer Concils, éd. M. R. Buck, Hilesheim etc. 2004 p. 88-89, 92-93 (ci-après: Richental), trad. dans The Council of Constance..., p. 139.

323 K. OżóG, Uczeni..., p. 211 ; V. GidžIŪnas, «Konstanz», dans S. Suziedelis (dir.), Encyclopedia Lituanica, Boston 1973, vol. 3, p. 164.

324 D. Baronas, S. C. Rowell, The Conversion..., p. 352, y voient le résultat d'un travail d'équipe, effectué à la chancellerie du grand-duc. Sur la présence de Polonais proches des milieux académiques à la chancellerie lituanienne, S. Szyвкоwsкi, «Polish Staff as a Social Group in the Chancellery of Grand Duke Witold», Quaestiones Medii Aevi Novae 3, 1998, p. 75-94.

325 G. MickŪNAité, Making..., p. 93, n. 169.

326 Ibid., p. 43-44; l'envoi de cette ambassade de néophytes peut avoir été suggéré par la délégation polonaise à Constance.

327 D. Baronas, S. C. Rowell, The Conversion..., p. 347-353.

328 R. Petrauskas, «Litauen... », p. 245.

329 Par exemple, la lettre de septembre 1409, vraisemblablement emmenée en France par le banneret Jarosław d'Iwno, CEV, doc. 427, p. 201. Voir L. CHollet, "D'une cohabitation à l'autre: controverses autour des Chevaliers teutoniques et de la Samogitie, dernière province païenne d'Europe (1398-1417)", dans C. Maurer, C. VinCENT (dir.), La coexistence confessionnelle en France et en Europe Germanique et Orientale du Moyen Âge à nos jours, Lyon 2015, p. 191-205. La conversion très "politique» de la Samogitie est perçue de manière différenciée par l'historiographie francophone. L'historien du concile de Constance, Jacques Lenfant, qui construit son récit à partir de Długosz (Annales XI, dans Opera Omnia..., vol. 13, p. 159-163) et le suit en plaçant une première conversion des Samogitiens en 1413, fait du passage de la Samogitie au christianisme un changement en douceur, presque naturel: Histoire du Concile de Constance..., vol. 1, p. 342-343. Une idée reprise par E. Lavisse quant à l'ensemble de la Lituanie: «Ladislas Jagellon [...] ne rencontra pas grande résistance; pour la Lithuanie, ce temps était venu où les dieux s'en vont tout seuls" (Études 
Le discours reflète donc les idées que Vilnius et Cracovie souhaitaient faire circuler auprès des princes et des prélats d'Europe catholique. Dès le préambule, on annonce que les Samogitiens sont, par leur langue et leurs origines, des Lituaniens ${ }^{330}$, et que c'est du grand-duché qu'ils doivent recevoir le christianisme ${ }^{331}$. En tout cas pas des Chevaliers teutoniques, qui n'ont rien fait pour les évangéliser ${ }^{332}$ : «avec une raison simple et tout à fait inexpérimentés dans la foi du Christ, nous avons compris que [les Teutoniques] ne connaissaient que les choses du monde, mais ne pensaient pas aux choses célestes" "333. Le texte reprend les critiques déjà anciennes contre les ordres militaires baltes, supposés être motivés par la rapacité et la soif de territoire plus que par l'évangélisation des infidèles. L'on fait ainsi dire aux Samogitiens qu'eux-mêmes ont constaté le manque de zèle des Teutoniques, ce qui les aurait poussés à demander l'aide de Vilnius: « $i l$ se trouve qu'ils [les Teutoniques] n'ont baptisé personne des nôtres pendant qu'ils ont gouverné notre terre, excepté ceux que les illustres princes et seigneurs Ladislas, roi de Pologne, et Alexandre alias Vytautas, grand-duc de Lituanie, ont baptisés " ${ }^{334}$. L'idée est de démontrer que le seul pouvoir légitimement à même d'évangéliser les Samogitiens est celui du grand-duc de Lituanie, parent «naturel» qui a, lui, pris la tâche missionnaire à cœur. Les ambassadeurs concluent en demandant que l'on respecte leur volonté, et que l'on confie leur évangélisation à des prélats lituaniens, l'évêque de Vilnius et l'archevêque latin de Lvivi35.

Le 24 février, les délégués de l'Ordre teutonique tentent de répondre par une longue Responsio Ordinis contra propositionem Polonorum in causa Samaytarum, que le concile refuse d'écouter jusqu'au bout ${ }^{336}$. C'est une réfutation du discours des Samogitiens, que l'on dit avoir été écrit à l'injonction de Vytautas ${ }^{337}$. Concernant le baptême des Samogitiens, les délégués de l'Ordre se contentent de faire savoir que ceux-ci sont si «durs du cerveau et féroces" que l'on craignait une rébellion ${ }^{338}$; aussi, seuls quelques dizaines de nobles ont été baptisés à

sur l'histoire de la Prusse..., p. 185). À l'inverse, pour H. Bogdan, Les Chevaliers teutoniques..., p. 166, le baptême de la Samogitie a été imposé par Jagellon "par le fer et le feu» (toujours, suivant Długosz, en 1413).

${ }^{330}$ L'appartenance des Samogitiens au peuple lituanien est mise en avant par Vytautas: CEV, doc. 391, p. 166-167; A. Dubonis, «Das Grenzgebiet zwischen Litauen und dem Deutschen Orden", dans W. Paravicini, R. Petrauskas, G. Vercamer (dirs.), Tannenberg - Grunwald Žalgiris..., p. 6.

${ }_{331}$ CM, p. 2-3.

332 Ibid., p. 10.

333 Ibid., p. 5-6.

334 Ibid., p. 10-11.

335 Ibid., p. 12. Comme le montre S. F. Belch (Paulus Vladimiri..., vol. 1, p. 449-451), nous sommes ici très proche des idées développées au même moment à l'Université de Cracovie, notamment par le recteur Paul Vladimiri.

${ }^{336}$ Fillastre, ACC 2, p. 58. La réponse des délégués de l'Ordre est éditée dans CEV, Appendix doc. $6 \mathrm{D}$, p. 1033-1038.

337 Ibid., p. 1038.

${ }^{338}$ CEV, Ap. doc. 6, p. 1034. 
Marienbourg, et leurs enfants gardés comme otages ${ }^{339}$. Toutefois, l'auteur de la réponse se dit ravi d'apprendre que les Samogitiens désirent recevoir le baptême, mais réclame qu'une délégation du concile accompagne les prélats demandés par leur porte-parole ${ }^{340}$.

La présence de ces païens venus du Nord, qui disent ardemment désirer le baptême que leur refuseraient les officiers teutoniques, a dû provoquer une certaine émotion parmi les auditeurs ${ }^{341}$ - ce qui n'est peut-être pas sans rapport avec la distribution de riches cadeaux que le procureur de l'Ordre mentionne dans une lettre au grand-maitre ${ }^{342}$. Le chroniqueur de Constance Ulrich de Richental raconte même qu'un important prélat, l'Italien Jean Dominici, manifesta l'envie de se charger en personne du travail de mission ${ }^{343}$ :

"Après que les envoyés furent entendus, le cardinal Jean de l'église de St-Sixte, cardinal de Raguse, [...] demanda la permission d'aller à eux, parce qu'il irait, selon la volonté de Dieu, sincèrement et avec joie essayer de récupérer les brebis égarées de Notre Seigneur Dieu. La permission lui fut donnée, et deux évêques élus ainsi que trois docteurs de l'Ordre des Mendiants allèrent avec lui pour enseigner la foi chrétienne. " 344

Le cardinal ne se rendit peut-être pas lui-même en Samogitie, mais quelques observateurs ont dû y être envoyés ${ }^{345}$, puisque le chroniqueur raconte que le 17 juin suivant, "toutes les nations s'assemblèrent et les envoyés qui étaient allés auprès des païens apparurent devant eux. Ils se plaignirent des seigneurs Teutoniques, les frères de Prusse, qui s'opposèrent à eux et empêchèrent les païens de devenir chrétiens» ${ }^{346}$. D'après Richental, les arguments des Teutoniques étaient d'ordre juridique, puisqu'ils répondirent qu' "ils avaient une fois conquis ce peuple par l'épée, et que [les Samogitiens] appartenaient à l'archevêque de Riga, en Livonie,

\footnotetext{
$339 \mathrm{Id}$.

340 Sur la réponse des Teutoniques, H. Boockmann, Johannes Falkenberg..., p. 206-207.

341 D. Baronas, S. C. Rowell, The Conversion..., p. 353.

${ }_{342}$ Lettre datée du 4 janvier 1416, édité dans Die Berichte..., vol. 2, doc. 139, p. 290; W. NöBeL, Michael Küchmeister..., p. 88.

343 Pour D. Baronas, S. C. Rowell, The Conversion..., p. 353-354, le cardinal Dominici entendait se consacrer à l'union avec l'église grecque plutôt qu'au baptême des Samogitiens; H. Boockmann, Johannes Falkenberg..., p. 208, n. 66, et W. Brandmüller, Konzil..., vol. 2, p. 161, préferrent l'option samogitienne, ce qui correspond au texte de Richental, puisque dans la narration, la volonté de départ du prélat suit immédiatement l'appel des Samogitiens. On sait par ailleurs que ce proche de Sigismond de Luxembourg reçut, en 1418, le mandat de Martin V pour négocier le retour dans le giron de Rome des hussites de Bohême et des Byzantins; B. WeBer, "Toward a Global Crusade? The Papacy and the Non-Latin World in the Fifteenth Century", dans N. Housley (dir.), Reconfiguring the Fifteenth-Century Crusade, Londres 2017, p. 20.

344 Richental, p. 89.

345 H. Boockmann, Johannes Falkenberg..., p. 208, n. 66, précise que Richental est le seul à mentionner le fait que le cardinal de Raguse, avec les deux évêques et les trois docteurs, soient envoyés en Samogitie.

346 Richental, p. 92-93.
} 
qui est une province de l'Ordre ${ }^{347}$. Les revendications territoriales qui avaient empêché l'évêché de Vilnius d'être étendu à la Samogitie refont surface. Le concile n'entend toutefois pas se laisser distraire ${ }^{348}$ :

"si ce peuple désirait devenir chrétien, les seigneurs [teutoniques] et l'archevêque [de Riga] les feraient chrétiens [selon les Teutoniques]. Mais le concile assemblé interdit aux seigneurs Teutoniques de le faire et leur ordonna, par leur obéissance au concile, de ne plus mettre d'obstacles sur le chemin de ce peuple et de ne plus interagir avec lui. Dorénavant, la Samogitie devrait appartenir au Saint Empire romain, et être sujet de l'Empereur pour les questions temporelles et de ses prêtres et évêques pour les questions spirituelles. Et les messagers furent renvoyés avec les pleins pouvoirs. ${ }^{349}$

Au mois d'août suivant, le concile confie officiellement la tâche d'organiser la nouvelle province ecclésiastique à l'archevêque de Lviv et à l'évêque de Vilnius ${ }^{350}$. Ceux-ci s'y rendent en été 1417 , et commencent leur travail missionnaire dans une région où les pratiques païennes sont en grande partie déjà abandonnées ${ }^{351}$. Un évêché est fondé pour la Samogitie avec à sa tête Mathias de Trakai, qui comprend le dialecte local ${ }^{352}$. Malgré des révoltes qui secouent la région en mai $1418^{353}$, le christianisme se répand peu à peu. En 1422, la province revient définitivement à la Lituanie à la suite de la paix du lac de Melno signée entre le grand-duché et l'Ordre teutonique ${ }^{354}$.

Convaincre le concile que le baptême de la Samogitie doit s'opérer sous l'égide de Vilnius est une première victoire pour les dirigeants de Pologne et de Lituanie. L'évangélisation de la dernière province païenne balte remet directement en question le rôle de l'Ordre teutonique. Trente ans après le

\footnotetext{
347 Ibid., p. 93.

348 D. Baronas, S. C. Rowell, The Conversion..., p. 354.

349 Richental, p. 93. Même si la Samogitie relève politiquement de la Lituanie et non de l'Empire, la mention de la suzeraineté impériale doit sans doute se lire comme une allusion au rôle traditionnellement attribué à l'Empereur comme protecteur des chrétiens.

${ }^{350}$ ACC 2, p. 576.

351 C'est l'interprétation de D. Baronas, S. C. Rowell, The Conversion..., p. 354-361, qui remarquent d'une part que les documents datant de quelques années avant 1417 montrent qu'un certain nombre de Samogitiens nobles portaient déjà des noms chrétiens, et font même état d'une forêt "que Sancta tempore paganorum vocabatur» (Lites..., éd. I. Zakrzewski, J. Karwasinska, vol. 2, doc. 32, p. 137) dans les négociations menées en 1413 sous l'égide de l'envoyé de Sigismond de Hongrie, Benedict Macra. Les auteurs remarquent d'autre part que les lettres échangées entre le grand-duc et l'Ordre teutonique ne mentionnent aucune opposition de la population locale à la venue des missionnaires sur ses terres. Ainsi, la description épique de Długosz (Annales XI, dans Opera Omnia..., vol. 13, p. 159-163), qui montre des missionnaires fracassant les objets de culte devant des païens tétanisés, est à prendre avec réserve.

352 D. Baronas, S. C. Rowell, The Conversion..., p. 358-360.

353 D. Baronas, "Christians in Late Pagan...", p. 68-71, préferre ne pas voir dans ces révoltes des «réactions païennes», mais des troubles sociaux.

354 Die Staatsverträge... 1, p. 160.
} 
baptême de la Lituanie proprement dite, plus aucune exception ne pourrait justifier que l'on continue à soutenir une corporation qui n'a plus de «Sarrasins" à combattre ${ }^{355}$. Pour parfaire le travail, la délégation polonaise entend tailler en pièce les arguments des Chevaliers teutoniques, dont les liens étroits avec de nombreuses cours européennes pouvaient encore leur assurer une certaine sympathie ${ }^{356}$. C'est notamment l'affaire du recteur de l'Université de Cracovie, Paul Vladimiri (Paweł Włodkowic) ${ }^{357}$. Celui-ci n’est pas le chef de la délégation polonaise, mais il est rôdé à la diplomatie et connait très bien les rouages de la chancellerie pontificale. Né autour de 1370 dans la région de Dobrzyń, contestée par l'Ordre teutonique et la Pologne, Vladimiri étudie le droit canon à Prague et à Padoue, où il fait la connaissance de Francesco Zabarella, champion du conciliarisme et l'un des chefs de file du concile de Constance. Une partie de l'historiographie polonaise attribue à l'influence de Paul Vladimiri et d'André Laskary, son compagnon d'étude en Italie, la décision de Boniface IX d'interdire les rèses sur la Lituanie en $1403^{358}$. Ce qui est sûr, c'est que les Polonais bien en place auprès des papes pouvaient présenter les intérêts de leur pays de manière favorable; ainsi, lorsqu'il se trouvait auprès d'Alexandre $\mathrm{V}$ en 1409, Vladimiri a déjà pu attirer l'attention du pontife "pisan" sur le sort de la Samogitie ${ }^{359}$. Nommé recteur de l'Université de Cracovie en 1414 et 1415,

355 Notamment H. Boockmann, Johannes Falkenberg..., p. 207.

356 P. Kras, "The Conversion...", p. 31-38; D. Baronas, S. C. Rowell, The Conversion..., p. 347-353; P. KNOLL, "A Pearl of Powerful Learning”..., p. 234-244.

357 Sur la vie et l'œuvre de Paul Vladimiri, le travail de référence reste S. F. Belch, Paulus Vladimiri...; voir aussi les études plus récentes de P. Kras, "The Conversion...", p. 23-53; P. Knoll, "A Pearl of Powerful Learning"..., p. 237-244; A. Lenartowicz, "Paweł Włodkowic and Andreas Laskary as the Authors of the Polish Revindication Programme against the State of the Teutonic Order in 1412-1418», dans W. Sieradzan (dir.), Arguments and Counter-Arguments..., p. 111-122; L. Chollet, "Croisade ou évangélisation? La polémique contre les Chevaliers teutoniques à l'aune des témoignages des voyageurs français de la fin du Moyen Âge", Ordines Militares 20, 2015, p. 175-203; Idem, "Paul Vladimir et le Ius Gentium polonais: un droit de résistance au début du XV siècle?", dans P. Arabeyre, K. Fiorentino (dirs.), Résistances au droit et droit de résistance, Dijon 2012, p. 43-67; T. WüNsch, «Paulus Wladimiri und die Genese des „realistischen Denkens” in der Lehre von den internationalen Beziehungen: Der Krieg zwischen Polen und dem Deutschen Orden als Stimulus für ein neues politiktheoretisches Paradigma", dans W. Paravicini et al., Tannenberg - Grunwald - Žalgiris..., p. 27-42; K. OżóG, Uczeni..., p. 206-217; Idem, The Role of Poland in the Intellectual Development of Europe in the Middle Ages, Cracovie 2009, p. 111-119; F. Russell, «Paulus Vladimiri's attack on the Just War: a Case Study in Legal Polemics", dans B. Tierney, P. Linehan (dirs.), Authority and Power. Studies on Medieval Law and Government presented to Walter Ullmann on his Seventieth Birthday, Cambridge etc. 1980, p. 237-254; T. Brennan, Just war...; C ReID, "Paulus Vladimiri...», p. 418-423; S. Kwiatkowski, Der Deutsche Orden im Streit mit Polen-Litauen. Eine theologische Kontroverse über Krieg und Frieden auf dem Konzil von Konstanz (1414-1418), Stuttgart-Berlin-Cologne 2000 ; H. Boockmann, Johannes Falkenberg....

358 Voir notamment S. F. Belch, Paulus Vladimiri..., p. 122-124.

359 A. Lenartowicz, «Paweł Włodkowicz...», p. 116. 
cet intellectuel et diplomate sera choisi pour présenter les pamphlets polonais devant le concile de Constance.

$\mathrm{Au}$ début de l'été 1416, il prononce un discours devant la "nation germanique» du concile, c'est-à-dire devant les représentants des principautés d'Empire, d'Europe centrale, de Scandinavie et d'Écosse ${ }^{360}$. Le Tractatus de potestate papae et imperatoris respectu infidelium pose l'essentiel de son argumentation juridique et philosophique ${ }^{361}$. Ce long discours se trouve résumé dans un second traité, Opinio Ostiensis, lu peu après devant l'ensemble du concile $^{362}$. Le propos est de démontrer que les infidèles vivant dans la région balte jouissent de droits leur permettant de posséder licitement leurs terres et d'avoir des États, et que même le Pape ou l'Empereur n'ont pas à distribuer leurs biens sans leur consentement. Son argumentaire repose essentiellement sur les idées développées par Stanislas de Skarbimierz, mais aussi sur le débat entre Innocent IV et Hostiensis, qui avaient théorisé les relations entre les chrétiens et les infidèles, et la pensée de son maître de Padoue, Francesco Zabarella, lequel est plus proche de la ligne du célèbre pape juriste ${ }^{363}$.

S'il s'agit de mettre en cause les donations faites à l'Ordre teutonique au XIII $^{\mathrm{e}}$ siècle, Vladimiri se garde bien d'attaquer les principes mêmes de la croisade balte; le prologue du De potestate expose que du temps où Conrad de Mazovie avait fait appel à l'Ordre, la Pologne était effectivement menacée par ses voisins païens, mais qu'une fois ceux-ci pacifiés, il n'y avait plus de raison de continuer à les harceler. La défense de la Chrétienté reste en principe un motif légitime pour user de violence, mais il ne peut être valide qu'en cas de menace réelle. C'est dire, implicitement, que la présence de l'Ordre teutonique sur le rivage balte n'a plus raison d'être puisque les Samogitiens sont en passe d'être convertis, mais que l'on pourrait avoir besoin d'une force armée en cas d'attaque menée par d'autres infidèles. Ainsi, on ménage la possibilité du roi polonais ou de son allié lituanien à recourir à la croisade contre leurs rivaux orientaux, Russes ou Tatars $^{364}$.

Du reste, Paul Vladimiri ne cherche pas à cacher le fait que le roi de Pologne et le grand-duc de Lituanie avaient recours à des soldats infidèles; au contraire, la présence de ces derniers dans l'armée polono-lituanienne, qui avait été largement dénoncée par l'Ordre teutonique, doit être justifiée ${ }^{365}$. Aussi, une partie du De potestate vise à démontrer que la Pologne et la Lituanie menaient

\footnotetext{
${ }^{360}$ Le concile est organisé en «nations»; B. Guenée, Entre l'Église et l'État..., p. 281.

361 S. F. Belch, Paulus Vladimiri..., vol. 2, p. 792-844; Paul Vladimiri, Pisma Wybrane Pawta Wtodkowica $=$ Works of Paul Wladimiri (a selection), éd. L. Ehrlich, Varovie 1968, vol. 1, p. 2-112. 362 S. F. Belch, Paulus Vladimiri..., vol. 2, p. 864-884; éd. et trad. L. Ehrlich, Paul Vladimiri, Pisma Wybrane..., vol. 1, p. 113-137.

363 C. ReId, «Paulus Vladimiri...», p. 418-420.

364 N. Housley, The Later Crusades..., p. 360-361.

365 S. Gouguenheim, Tannenberg..., p. 193-197. Par exemple, la remarque de Guillebert de Lannoy, pour qui le roi de Pologne et le duc de Poméranie «favorisoient les Sarrasins».
} 
une guerre juste, et que par conséquent, on avait le droit de recourir à l'aide de non-chrétiens. Puisqu'en vertu de la doctrine d'Innocent IV, ceux-ci ont des droits politiques, ils peuvent légitimement posséder une armée, et un pouvoir chrétien forcé de résister contre un agresseur illégitime peut leur demander assistance $^{366}$.

Dans un autre discours lu au cours de la seconde moitié de 1416, Causa inter Reges Poloniae et Cruciferos ${ }^{367}$, Paul Vladimiri lance une charge directe contre l'Ordre teutonique. Les membres de celui-ci auraient abandonné leur statut originel d'hospitaliers pour jouer le rôle de seigneurs en Prusse; leurs activités militaires ne seraient ainsi plus dédiées à la défense de la Terre sainte, mais à la conquête de pays qui appartenaient aux païens, et s'ils prétendent vouloir convertir ceux-ci, user de la force pour imposer le baptême est interdit par le droit canon ${ }^{368}$. En cachant de sombres desseins sous l'apparence de la vertu, l'Ordre teutonique ferait preuve de simulation, et répandrait une doctrine dangereuse ${ }^{369}$. Les discours suivants poursuivent cette polémique ${ }^{370}$, amplifiée par la découverte, à Paris, d'un traité composé quelques années plus tôt (autour de 1412) par un défenseur de l'Ordre teutonique présent au concile, le dominicain Johannes Falkenberg ${ }^{371}$. La Satira contra haereses et

${ }^{366}$ L. Chollet, «Paul Vladimir...», p. 43-67.

367 La date exacte de rédaction et de distribution du traité devant le concile est discutée: S. F. BeLch, Paulus Vladimiri..., vol. 1, p. 169 sq. penche pour juillet 1416, alors qu'en se référant à la mention de la bataille de Tannenberg, Paul Vladimiri, Pisma Wybrane..., vol. 1, p. XXXI et p. 265, situe la rédaction du texte à la fin de 1416 ou au début de 1417. Le texte est édité, publié et traduit par L. Ehrlich, Paul Vladimiri, Pisma Wybrane..., vol. 1, p. 144-271 et vol. 2, p. 2-168, qui l'appelle selon son incipit "Ad Aperiendam».

368 Ibid., p. 166-167. Vladimiri fait notamment référence au canon De Iudeis du concile de Tolède, intégré dans le Décret de Gratiens; voir D. 45, c. 5, trad. et cité par I. Poutrin, «La conversion... », p. 841.

369 Causa, cité par Paul Vladimiri, Pisma Wybrane..., p. 161-162, 168, 199-200, 203 passim.

370 Notamment Tractatus de Ordine, présenté en novembre 1417 : S. F. Belch, Paulus Vladimiri..., vol. 2, p. 984.

371 Johannes Falkenberg a écrit l'un des discours en faveur de l'Ordre, appelé, selon son incipit, Veteres relegentes historias, sans doute terminé au tournant de 1416-1417; ce texte est édité par E. Weise dans Die Staatsschriften..., doc. 8, p. 175-228. Falkenberg avait vécu un certain temps en Pologne, qu'il a dû quitter après quelques démêlées avec les partisans de Jagellon. Ce pamphlétaire zélé avait sans doute composé le texte incriminé par la délégation polonaise, la Satira contra haereses, en pensant le soumettre à Henri de Plauen pour lui servir dans sa "guerre de plume» contre Jagellon et Vytautas, mais le grand-maitre devait le refuser, ne voyant probablement rien de bien neuf à ce long traité verbeux et bourré de stéréotypes habituellement dirigés contre les infidèles et les hérétiques; H. Boockmann (Johannes Falkenberg...., p. 96-102) remarque en effet que la ligne de la Satira est en grande partie celle des lettres envoyées par Henri de Plauen pour demander du secours après Tannenberg. Il semble qu'en 1412, le dominicain ait essayé de faire approuver sa thèse par l'Université de Paris, ce qui explique que c'est de là que le texte a pu rebondir sur le devant de la scène quelques années plus tard. Voir aussi F. Cheneval, "Jean Falkenberg et Paul Vladimiri critiques de Dante", dans S. WŁodek (éd.), Société et Église. Textes et discussions dans les universités d'Europe centrale pendant le Moyen Âge tardif: Actes du Colloque International de 
cetera nefanda Polonorum et eorum regis Iyageyel fideliter conscripta décrit le roi de Pologne comme un faux converti hypocrite et manipulateur, responsable de nombreuses atrocités habituellement attribuées aux païens, et réclame sa mise à mort ainsi que celle de ses sujets. À la fin de l'année 1416, ce pamphlet est à Constance, en mains polonaises ${ }^{372}$. Remarquant que les conclusions de celui-ci rappellent la thèse du tyrannicide, condamnée par le concile l'année précédente, les délégués polonais attaquent son auteur pour hérésie. L'idée est de flétrir l'Ordre teutonique en faisant condamner l'un de ses principaux défenseurs ${ }^{373}$.

Tous les écrits en faveur des Teutoniques n'avaient pas une tonalité aussi extrême, mais la ligne générale reste celle inaugurée par le discours du procureur Pierre Wormditt : les chevaliers à la croix noire protègent efficacement la Chrétienté face aux hordes impies et cruelles que les machinations du roi de Pologne ont lancé contre des pays chrétiens. Pour répondre à Vladimiri, les délégués de l'Ordre ont fait appel à d'autres plumes ${ }^{374}$, dont celle d'un évêque bénédictin portugais, André Dias d'Escobar, qui en novembre 1417 produit une défense de l'Ordre reposant essentiellement sur l'argument d'Hostiensis, pour qui la terre entière est soumise aux chrétiens, en tant qu'héritiers de Jésus Christ. Par conséquent, toute guerre contre des infidèles serait juste, et peut même leur apporter le baptême, une fois ceux-ci vaincus ${ }^{375}$. La réponse la plus aboutie est sans doute celle d'un docteur de Bamberg, Johannes Urbach, qui

Cracovie organisé par la Société Internationale pour l'Etude de la Philosophie Médiévale, Turnhout 1995, p. 101-115; S. Sobiecki, "Cracow», dans D. Wallace (dir.), Europe, a literary history, Oxford 2016, p. 561-562.

372 On sait qu'à la fin de l'année 1416 la Satira se trouve à Constance, en provenance de Paris. D’après Jan Długosz (Annales XI, dans Opera Omnia..., vol. 13, p. 199-201), les docteurs de l'Université de Paris ont donné le texte de Falkenberg à l'archevêque de Gniezno, qui accompagnait le roi Sigismond dans une mission diplomatique. Pour H. Boockmann (Johannes Falkenberg..., p. 263, n. 352), quelques universitaires parisiens proches du parti orléanais auraient pu amener eux-mêmes la Satira à Constance, peut-être parce que Falkenberg leur était connu comme un défenseur de Jean Petit, l'auteur de la thèse du tyrannicide. Ce pamphlet, d'abord une pièce au dossier franco-bourguignon, serait passé en mains polonaises pour servir à la campagne contre l'Ordre teutonique. Voir ibid., p. 263-264. Sur Jean Gerson et son combat contre les idées de Jean Petit, M. Turchetti, Tyrannie et tyrannicide de l'Antiquité à nos jours, Paris 2001, p. 319-328. 373 H. Boockmann, Johannes Falkenberg..., p. 263-265.

${ }^{374}$ D'autres auteurs ont été engagés par l'Ordre teutonique; la recherche tend à les identifier comme Giacomo Balardi Arrigoni, évêque de Lodi, Ardicinus de Novare, Dominique de Ponte, de la région de Venise et Rudolf Arzt, un clerc d'Augsbourg. H. Boockmann, Johannes Falkenberg..., p. 246-256.

375 Le discours d'André d'Escobar, évêque de Cividad Rodrigo, est édité dans Die Staatsschriften... 1, doc. 16, p. 391-413. Voir H. Boockmann, Johannes Falkenberg..., p. 252-256; P. Buc, Guerre sainte..., p. 349-351. Pour M. Olivier (“"Veteres relegentes historias”...», p. 90), la trame historique du discours d'André Diaz d'Escobar s'inspire directement du prologue du mémoire de Pierre Wormditt, lu au début de l'année 1415. 
lit son De statu Fratrum Ordinis B. Mariae Virginis Teutonicorum et pugna eorum adversus infideles entre juillet 1416 et $1417^{376}$. Il s'agit d'une défense des actions de l'Ordre teutonique, légitimées notamment par l'agressivité dont feraient preuve les infidèles ${ }^{377}$. Autant les attaques de Vladimiri que la défense de l'Ordre par Urbach montrent que la croisade comme moyen de défendre une Chrétienté attaquée n'est pas remise en cause: tout l'enjeu est de savoir si les infidèles concernés sont pacifiques ou non, d'où l'importance de la perception que l'on se fait de ces derniers lorsqu'il s'agit de décider de la validité de la guerre qu'on leur fait.

Aussi, une partie importante de l'argumentaire des partis rivaux repose sur l'histoire, ancienne ou récente ${ }^{378}$. L'angle d'attaque polono-lituanien consiste à peindre les actions des Chevaliers teutoniques sous un jour très sombre, ceci afin de délégitimer leur combat contre l'infidèle. Alors que l'Ordre entend se poser en défenseur d'une Chrétienté harcelée par d'intraitables païens, l'auteur de la plainte lue par les représentants des Samogitiens illustre son propos par plusieurs exemples nominatifs, devant éclairer la vraie nature de la guerre teutonique ${ }^{379}$. Parmi ceux-ci, l'histoire tragique de cette famille:

"Un homme, parmi les plus puissants barons de notre terre, nommé Kircutis, ayant une fille très belle, fut privé avec violence de sa fille par ces frères [les Teutoniques]. Son fils, le frère de cette vierge, ne pouvant plus supporter de tels abus, tua, ce qui est bien connu, l'un de ces frères qui violait sa soeur, en le transperçant de son épée. " ${ }^{380}$

La description précise de l'acte et la mention du nom du boyard concerné vise sans doute à donner un parfum de réel aux accusations ${ }^{381}$. D'autres

\footnotetext{
376 T. Brennan, Just War..., p. 229-296. S. F. Belch, Paulus Vladimiri..., vol. 2, p. 1112, pense que le traité a été lu peu après juillet 1416, alors que E. Weise dans Die Staatsschriften... 1, p. 309, le situe en juillet 1417.

377 J. Sarnowsky, "Military Orders and Crusading in the Fifteenth Century: Perception and Influence», dans N Housley (dir.), Reconfiguring the Fifteenth-Century Crusade..., p. 126-127. Le traité est édité par S. F. Belch, Paulus Vladimiri..., vol. 2, p. 1116-1180, et dans Die Staatsschrifften... 1, doc. 14, p. 318-380; trad. T. BrennAN, Just War..., p. 422-532.

378 Sur l'utilisation de l'histoire par les délégués polonais et lituaniens et les défenseurs de l'Ordre teutonique: M. Olivier, "Veteres relegentes historias"...», p. 87-97; L. Chollet, "Écrire l'histoire...", p. 17-47.

379 CM, p. 9-10; L. Chollet, «D'une cohabitation à l'autre... », p. 202.

380 CM, p. 10.

${ }^{381}$ Comme le montre R. KотескI, «The Desecration of Holy Places according to Witnesses' Testimonies in the Polish-Teutonic Order Trials of the $14^{\text {th }}$ Century», dans W. Sieradzan (dir.), Arguments and Counter-Arguments..., p. 84 sq., les faits reprochés aux Teutoniques correspondent aux accusations habituellement formulées lorsqu'il s'agit d'accabler l'adversaire. Le même auteur (ibid., p. 87) affirme toutefois que les témoignages détaillés compilés dans les actes des procès du XIV $^{e}$ siècle entre Pologne et Ordre teutonique permettent d'appréhender la réalité de la guerre, au-delà des stéréotypes.
} 
exemples, plus généraux, participent à forger l'image de Chevaliers teutoniques à mille lieux des guerriers de Dieu célébrés en France:

"Trois nobles hommes, qui se cachaient pour ne livrer d'aucune manière leurs fils comme otages, furent brûlés par le feu avec deux fermmes captives et des hommes, en assez grand nombre, furent enchaînés avec leurs épouses et emmenés en Prusse; hélas! Ces croisés, ayant rejeté le respect de la croix - ce que nous rapportons avec douleur - violèrent nos saurs et nos petites filles prises de force; cela est connu du public et pourra être prouvé. ${ }^{382}$

Nous reconnaissons dans cet extrait la pratique de la déportation et de la prise d'otages, que reflète par exemple la Chronique de Metz. Le viol n'est bien sûr pas mentionné comme un fait glorieux par les sources occidentales ni teutoniques, et les quelques notes concernant des femmes lituaniennes ramenées par les croisés d'Europe occidentale ne nous permettent pas de savoir comment celles-ci étaient traitées. Tout ce que nous pouvons en dire, c'est que l'une d'entre elles fut mariée à un noble du comté de Namur, et qu'une deuxième donna un fils au comte Guillaume de Gueldre $^{383}$. D’une manière générale, et ce en dépit de la morale courtoise affichée dans les romans de chevalerie, le viol était couramment pratiqué par les gens de guerre, notamment dans la France de la guerre de Cent Ans ${ }^{384}$. De même, nous avons vu à travers le récit des misères de Guillebert de Lannoy à Azincourt que la mise à mort par le feu était un moyen d'exécution parfois utilisé sur le champ de bataille, même entre armées chrétiennes. Rien n'interdit donc de supposer que des crimes du genre de ceux mentionnés par la Propositio samagitarum aient été pratiqués lors des rèses ou par les forces armées qui devaient tenir le pays pour le compte des Teutoniques. Il s'agirait alors de ces crimes "faisant partie d'une "normalité" du temps de guerre», qui ne deviennent visibles que lorsqu'ils sont dénoncés ${ }^{385}$.

Si la Propositio ne fait pas explicitement référence aux rèses impliquant des croisés étrangers à l'Ordre et à ses troupes, ce n'est pas le cas des discours de Paul Vladimiri. Le recteur de Cracovie se base certes essentiellement sur le droit, mais ne néglige pas de faire référence à l'histoire, comme dans le prologue du De potestate ${ }^{386}$. On y lit que l'Ordre teutonique avait été

\footnotetext{
${ }^{382}$ CM, p. 9-10.

383 Voir chap. V.

${ }^{384}$ Par exemple, Bellaguet, vol. 5, p. 324-327. Notamment N. Gonthier, «Les victimes de viol devant les tribunaux à la fin du Moyen Âge d'après les sources dijonnaises et lyonnaises", Criminologie 27/2, 1994, p. 10, 26-27; D. Buschinger, «Le viol dans la littérature allemande au Moyen Âge", dans D. Buschinger, A. CRÉpIn (dirs.), Amour, mariage et transgressions au Moyen Age, Göppingen 1984, p. 369-385.

385 O. BERGER, "José Cubero, La femme et le soldat, viols et violences de guerre du Moyen Âge à nos jours", Revue historique des armées [En ligne], 270 | 2013.

386 Sur les sources de Paul Vladimiri, J. Wyrozumski, "L'idée de tolérance à l'université de Cracovie dans la première moitié du Xv $v^{e}$ siècle», dans S. WŁODEK (dir.), Société et Église..., p. 139; S. Wielgus, The Medieval Polish Doctrine..., p. 68-72.
} 
installé par les princes polonais pour protéger leurs possessions contre des Prussiens alors violents, puis que les "Porte-Croix" (Cruciferi - les Chevaliers teutoniques), mirent toute la région sous leur coupe, y construisirent des villes fortes et des châteaux, "et ils sont appelés en conséquence seigneurs de Prusse» ${ }^{387}$. La pacification des Prussiens ne signifiait pas pour autant l'arrêt des activités belliqueuses des nouveaux maîtres des lieux, qui s'en prirent aux Lituaniens, quand bien même ceux-ci désiraient vivre en paix avec les chrétiens. C'est ainsi qu'est née l'institution des rèses:

"Et bien que, une fois les Prussiens soumis à sa force, la cruauté des païens ait cessé de s'en prendre aux chrétiens - sauf quand provoqués par les insultes des chrétiens, ils les leur rendaient - ces Porte-Croix ne cessèrent d'attaquer les infidèles, même doux et tranquilles, d'envahir leurs terres et leurs domaines, et de les dresser les uns contre les autres en les excitant. Au premier prétexte, comme si la rage des païens se déchainnait toujours contre les fidèles du Christ, ils appellent les chrétiens à l'aide, et ils se font presque une règle d'envahir avec une grande armée deux fois l'an les régions païennes à deux moments, l'Assomption et la Purification de la glorieuse Vierge Marie; ces occasions, ils les appellent vulgairement des rèses [reysas].

C'est ainsi qu'une erreur se transforme en coutume: les fidèles du Christ, pour combattre en troupe, croyant faire preuve de zèle envers Dieu, se réunissant en foule pour étendre la foi catholique, attaquent durement le peuple tranquille des païens. S'ensuivent des homicides, et les fidèles s'avancent avec les infidèles dans le même danger de damnation; des pillages ont lieu, ainsi que d'innombrables autres crimes. " 388

En citant l'extension de la foi comme but supposé des rèses, le maitre de Cracovie fait directement référence à l'un des arguments utilisés depuis le XIII siècle en faveur de la croisade balte; si défendre la Chrétienté contre des infidèles agressifs était légitime (justifiant ainsi l'appel aux Teutoniques par Conrad de Mazovie), on ne saurait par contre propager le christianisme à tout prix. Sous la plume de Vladimiri, les rèses se résument à des déchaînements de violence inutiles à la progression de la foi. Celle-ci ne s'obtient pas à la pointe de l'épée, mais par l'intercession de l'Esprit saint, lequel agit dans le cas qui nous intéresse par l'intermédiaire des Polonais ${ }^{389}$. Les Teutoniques, qui avaient considérablement augmenté leurs richesses aux temps des rèses, "regardent ces événements miraculeux et comme s'ils supportaient mal que la raison d'occuper les terres et domaines s'amenuise à ce point pour eux, ils envahissent avec une plus grande cruauté [...] ces néophytes " ${ }^{390}$.

Les agresseurs commettent alors de nombreux crimes, dont certains apparaissent dès le $\mathrm{XIII}^{\mathrm{e}}$ siècle dans les accusations portées contre les ordres

\footnotetext{
387 Paul Vladimiri, Tractatus de potestate, éd. dans S. F. BeLCH, Paulus Vladimiri..., vol. 2, p. 792.

388 Ibid., p. 792-793.

389 Ibid., p. 793.

390 Ibid., p. 794.
} 
religieux: "tant parmi les baptisés que parmi ceux qui ne le sont pas encore, ils en font périr beaucoup cruellement, ne respectant même pas la condition ecclésiastique. Ils brûlent leurs églises toutes neuves, et commettent d'innombrables actes que l'honnêteté commande de taire» ${ }^{391}$. Fait-il allusion aux viols dénoncés dans la Propositio samagitarum? Ce que l'on doit comprendre du discours, c'est que la violence dont font preuve les Teutoniques a décuplé depuis que la Lituanie a été baptisée ${ }^{392}$. Or, les extraits de chroniques ou autres récits de rèse des chevaliers occidentaux ne permettent pas d'affirmer que l'on se soit particulièrement déchaîné après la date de 1387, et que l'on traitait plus mal les néophytes que les Samogitiens restés païens quasiment jusqu'à l'époque du concile.

L'avis du recteur Vladimiri sur les rèses est sans appel: qu'elles soient dirigées contre des néophytes ou contre des païens pacifiques, elles sont illégales, car il ne s'agit plus de défense, mais de conquête. Faire "grant destruccion de Sarrasins", pour reprendre l'expression du biographe de Boucicaut ${ }^{393}$, ne saurait se légitimer par le seul désir d'accroître la foi chrétienne. La sixième question de la seconde partie du De potestate concerne directement la pratique des rèses: "[on se demande] s'il est tolérable ou licite que les chrétiens affluent au secours des Porte-Croix pour attaquer les infidèles parce qu'ils sont infidèles, soit sous le prétexte d'augmenter la foi chrétienne, soit qu'il s'agisse d'exercer la chevalerie?»394. À quoi la réponse est explicite:

"C'est une erreur qu'aucune raison ne peut faire admettre [...] car tous ceux qui prêtent volontairement leur être aux Porte-Croix pour attaquer les infidèles dociles ne peuvent être excusés d'un péché mortel, qu'ils soient leurs sujets ou pas [...]. La guerre des Espagnols contre les Sarrasins est juste, car elle vise à récupérer des terres chrétiennes dans lesquels les Chrétiens habitaient d'abord. Ainsi, le chevalier catholique qui n'est pas le sujet de celui qui combat doit être parfaitement certain de la justice de la guerre qu'il mène, sinon, s'il est dubitatif ou incertain, il s'expose à un grave danger. " 395

Ceux qui s'embarquent dans une expédition contre l'infidèle devraient donc se renseigner, car si la croisade ibérique est juste, ce n'est pas le cas de son pendant nordique, qui n'est pas une reconquête, mais une simple invasion. On peut certes imaginer que la Pologne ait entendu se ménager des appuis auprès des puissances engagées dans la Reconquista, mais il est remarquable que, selon Vladimiri, tous les fronts de croisades ne se valent pas. Une position qui tranche avec l'habitude de la chevalerie française ou anglaise et les idées de la plupart de ses thuriféraires. Les «hôtes» venus appuyer l'Ordre teutonique participent

\footnotetext{
391 Id.

392 C'est une impression qui ressort d'une partie de l'historiographie; par exemple, W. Urban, The Samogitian Crusade...

${ }^{393}$ Le Livre des fais..., p. 77.

394 S. F. Belch, Paulus Vladimiri..., vol. 2, p. 796.

395 Ibid., p. 823.
} 
donc à une guerre injuste, ce qui est encore prouvé par un examen des critères devant définir la justice d'un conflit. Aux cinq points de Raymond de Peñafort, devenus classiques, Vladimiri ajoute une particularité d'une grande importance en ce qui concerne les rèses ${ }^{396}$ :

"On peut ajouter un sixième point: à savoir la période favorable, car il y a des périodes durant lesquelles les guerres, même justes, sont interdites. Et cette interdiction est en vigueur surtout durant les jours de grande fête, durant lesquelles on doit interrompre tout travail et vaquer à la prière et aux ouvres spirituelles. Seule la nécessité qui ne connaît plus la loi excuse du péché de combattre durant ces jours; se défendre soi ou ses biens, mais non attaquer les autres. » 397

On se souvient que les expéditions internationales lancées contre la Lituanie avaient traditionnellement lieu à l'occasion des fêtes mariales, ce qui, d'après le recteur polonais, constitue une atteinte au respect dû aux jours saints ${ }^{398}$. Les chevaliers qui se rendent en Prusse, attirés par les lettres du grand-maître leur promettant la table d'honneur et autres vanités ${ }^{399}$, risquent leur âme, car la politique de l'Ordre a causé la mort de nombreux soldats chrétiens, mercenaires ou simples volontaires abusés par ses mensonges. C'est le propos d'un autre discours, Causa inter Reges Poloniae et Cruciferos, où l'auteur fait allusion au sort des hôtes tombés à Tannenberg:

"Il doit être dit, quoiqu'avec tristesse, que récemment, même pas sept ans plus tôt, comme l'atteste la renommée générale, ils [les Teutoniques] ont perdu en un jour jusqu'à cent mille, ou à peu près, chrétiens en armes, qu'ils ont séduits par cette erreur et par le salaire, lesquels ils menaient témérairement à la guerre pour la domination de la Samogitie qu'ils essayaient, et essaient encore, d'usurper.» ${ }^{400}$

À lire Paul Vladimiri, on a l'impression que les hôtes de l'Ordre teutonique sont plus des dupes que des criminels. Trompés par les flatteries du grandmaître, ils croient accomplir leur devoir chevaleresque en combattant dans une guerre injuste alors que, bien souvent, les Teutoniques se contentent de les faire attendre pour mieux sucer leurs biens: "ces dits frères, par leur ruse et tromperie, tiraient d'eux or et argent sous le prétexte de causes honnêtes, c'est-à-dire pour les personnes qui leur fournissent la nourriture contre de l'argent» ${ }^{401}$. Autrement dit,

\footnotetext{
396 F. Russell, «Just War...», p. 237-254.

397 S. F. Belch, Paulus Vladimiri..., vol. 2, p. 824-825.

398 N. Housley, The Later Crusades..., p. 359; PR 2, p. 55.

${ }^{399}$ Le discours Articuli contra Cruciferos contient une description du système de communication épistolaire de l'Ordre ainsi que de la table d'honneur, par laquelle les Teutoniques prétendent honorer leurs hôtes; S. F. BeLch, Paulus Vladimiri..., vol. 2, p. 929; PR 1, p. 320-321.

400 Causa, Paul Vladimiri, Pisma Wybrane..., vol. 1, p. 207.

401 Articuli contra Cruciferos, dans S. F. Belch, Paulus Vladimiri..., vol. 2, p. 929 ; trad. A. S. Cook, «Beginning the Board...", p. 377.
} 
ceux que nomme Enguerrand de Monstrelet dans sa relation de la fameuse bataille sont loin d'avoir connu une mort glorieuse.

Quel effet cette condamnation du voyage en Prusse a-t-elle pu produire sur ceux qui assistaient au concile? Le sujet a sans doute moins occupé les délégués occidentaux que la polémique autour de la Satira de Johannes Falkenberg, qui est examinée par une Commission de la Foi à partir de septembre 1417. Voyant que ce pamphlet ne sera pas condamné, les délégués polonais, Vladimiri en tête, en appellent bruyamment à un futur concile lors de la dernière session, le 22 avril $1418^{402}$, un événement raconté en détail par l'un des participants français les plus en vue, Jean Gerson ${ }^{403}$. L'affaire n'a pas manqué d'intéresser la délégation française, étant donné la proximité entre ce traité et les thèses soutenues par Jean Petit, l'auteur de la Justification du duc de Bourgogne (1408), qui faisait l'apologie du meurtre de Louis d'Orléans, qualifié de tyrannicide ${ }^{404}$. Un court texte de l'un des chefs de file du parti "anti-bourguignon ", le cardinal Pierre d'Ailly, touche plus particulièrement à la question de la guerre contre les infidèles ${ }^{405}$. Il s'agit sans doute d'un travail préparatoire composé dans la première moitié de l'année 1417, visant à élaborer la sentence de la Commission de la Foi devant statuer sur la Satira, et dans laquelle siégeait Pierre d'Ailly ${ }^{406}$. Le cardinal y discute non seulement les thèses de Falkenberg, mais aussi celles de Vladimiri ${ }^{407}$. Sur le principe, la position du Français est assez proche de celle $\mathrm{du}$ recteur polonais ${ }^{408}$, mais il précise qu'une enquête devrait être menée pour que l'on puisse juger les torts de chacun en toute connaissance de cause ${ }^{409}$. Sa directive est un document essentiellement juridique, qui reste très général, et n'a pas pour ambition de s'étendre sur le cas balte; l'ethnonyme des Lituaniens, des Samogitiens ou des Tatars n'est même pas mentionné ${ }^{410}$. Quoiqu'il en soit,

\footnotetext{
${ }^{402}$ H. Boockmann, Johannes Falkenberg..., p. 282 sq.; P. Knoll, "A Pearl of Powerful Learning»..., p. 243-244.

403 Jean Gerson, Acta in Consilio Constantiensi, dans Opera Omnia, vol. 5, éd. L. Ellies du Pin, La Haye 1728, col. 713-716.

${ }^{404}$ H. Boockmann, Johannes Falkenberg..., p. 265-279; B. Diaz Kayel, "At the Threshold of Modernity: the Relationship with Non-Christian Peoples in Paweł Włodkowic and Francesco de Vitoria", conférence donnée à l'Université de Varsovie, 26 février 2016.

${ }^{405}$ Sur la participation de Pierre d'Ailly au concile de Constance, B. Guenée, Entre l'Église et l'État..., p. 275-291.

${ }^{406}$ H. Boockmann, Johannes Falkenberg..., p. 265-266, n. 362. Il nous est resté plusieurs projets de sentences, édités dans AAC, vol. 4, doc. 450 et 454; un résumé de la sentence est donné par Jan Długosz, Opera Omnia..., vol. 13, p. 212-214. L'un des autres membres de la commission était le cardinal Francesco Zabarella, le maître de Paul Vladimiri durant ses études à Padoue.

407 Die Staatsschrifften... 1, doc. 11, p. 265-270, qui en donne une interprétation erronée, puisqu'il assure qu'Ailly soutenait les thèses de Falkenberg, alors que le texte dit exactement le contraire; P. Buc, Guerre sainte..., p. 352; H. Boockmann, Johannes Falkenberg..., p. 252, n. 305.

${ }^{408}$ Ibid., p. 266, n. 362,

409 Die Staatsschrifften... 1, doc. 11, p. 270.

${ }^{410}$ S'il parle de "Materia dominorum Prutenorum cum dominis Polonis» (ibid., p. 268), d'Ailly se contente de mentionner la catégorie très générale des «infideles».
} 
l'homme qui avait, semble-t-il, donné des indulgences aux soldats du Hainaut partis prêter main-forte aux Teutoniques avant Tannenberg se montre bien plus mesuré.

L'arrière-plan politique permet également d'expliquer l'intérêt des délégués danois pour les pamphlets de Vladimiri, dont le De potestate a été copié dans un manuscrit du Xve siècle ${ }^{411}$. Pour Janus Jensen, les arguments du recteur cracovien avaient été soigneusement relevés par les hommes du roi Éric de Danemark, alors en pleins démêlés avec l'Ordre teutonique ${ }^{412}$. Ce dernier n'est certes pas condamné, comme le demandait Paul Vladimiri, mais la victoire du camp polono-lituanien est ailleurs. L'essentiel était de profiter du forum international qu'était le concile pour s'imposer comme un acteur incontournable de l'accroissement de la foi catholique, auprès des païens de Samogitie, mais aussi en ce qui concerne l'union des églises grecque et romaine ${ }^{413}$. Les charges contre la croisade balte n'étaient qu'une pièce d'un jeu plus large.

Jagellon et Vytautas entendant assurer à la Lituanie une place parmi les nations chrétiennes, le mouvement pacificateur qui émane du concile constitue une bonne occasion pour démontrer l'importance politique de leurs pays respectifs. Des diplomates polonais participent à une trêve négociée à Paris entre la France et l'Angleterre, et le roi Charles VI appuie le renouvellement de la trêve entre Pologne et Ordre teutonique ${ }^{414}$. Au mois d'août 1416, Jagellon écrit au concile pour lui faire part de sa volonté de respecter cette paix, d'écraser l'hérésie, de baptiser la Samogitie et de ramener les Ruthènes dans le giron de Rome ${ }^{415}$. Quelques jours plus tard, l'Université de Cracovie écrit sur les mêmes matières ${ }^{416}$. En septembre, le concile répond en félicitant le roi pour ses bonnes intentions ${ }^{417}$, et peu après son élection, le pape Martin V écrit à son tour à Jagellon pour approuver l'attitude de ce dernier qui se tient loin des hérétiques hussites ${ }^{418}$. En novembre 1417, l'archevêque Jean de Lviv et l'évêque Pierre de Vilnius, chargés l'année précédente de mettre en œuvre la mission en

\footnotetext{
411 Il s'agit d'un manuscrit exécuté en Suède (alors unie au Danemark) et conservé à la bibliothèque d'Uppsala: Mittelalterliche Handschriften der Universitätsbibliothek Uppsala: Katalog über die C-Sammlung, éd. M. Andersson-Schmitt, H. Hallberg, M. Hedlund, vol. 1, Stockholm 1988, doc. C. 43, p. 288 ; J. M. Jensen, Denmark and the Crusades, 1400-1650, Leiden 2007, p. 56.

412 Ibid., p. 55-56; le roi de Danemark a envoyé deux ambassadeurs au concile.

413 D. Baronas, S. C. Rowell, The Conversion..., p. 361, 366-378; G. Mickūnaité, Making..., p. 43-47.

${ }^{414}$ K. Polejowski, "The Teutonic Order's Propaganda... », p. 239.

415 Skarbiec..., II, doc. 1158, p. 40-41; Index actorum..., doc. 912, p. 108; W. BRANDMÜLLER, Konzil..., vol. 2, p. 164-165.

416 Ibid., doc. 913, p. 108; Codex diplomaticus Universitatis studii generalis Cracoviensis, éd. F. C. Skobel, vol 1, Cracovie 1870, doc. 58, p. 110-113. Peu avant, en juillet 1416, le grand-maitre de l'Ordre teutonique avait écrit au concile quant aux affaires concernant la paix avec la Pologne: Magnum Oecumenicum Constantiense, éd. H. von der Hardt, vol. 4, Francfort 1699, col. 871-874.

417 CES 2, doc. 67, p. 80-81.

418 Skarbiec..., II, doc. 1180, p. 46.
} 
Samogitie, écrivent au concile et au "futur unique et suprême pontife romain" pour les tenir au courant du bon déroulement de leur mission, rendue possible par la pleine collaboration de Jagellon et de Vytautas ${ }^{419}$; une courte lettre écrite par la chancellerie du roi de Pologne accompagne le rapport ${ }^{420}$. En janvier 1418, Sigismond de Luxembourg félicite ce dernier et son «frère» Vytautas pour leur zèle à étendre la foi ${ }^{421}$.

Le même mois, Vytautas et Jagellon envoient auprès du concile le moine orthodoxe Grégoire Tsamblak, créé "archipresu[l] seu metropolitu[s] tocius Russie ac plage orientalis»" ${ }^{422}$, afin qu'il puisse négocier la réunion des églises grecque et romaine. Ulrich de Richental, visiblement impressionné, a eu l'occasion d'assister à une messe orthodoxe donnée par l'archevêque pour les hommes de sa suite: "je les ai vu à beaucoup d'autres occasions, mais jamais ils n'ont été aussi splendides ni aussi solennels» ${ }^{423}$. Tsamblak n'étant pas reconnu par une grande partie des institutions de rite grec, l'entreprise est vouée à l'échec, mais elle attire un certain prestige à ses commanditaires ${ }^{424}$. Richental note que le prélat lituanien était accompagné de princes de foi grecque et de serviteurs au nombre de trois cents, mais aussi de "païens de Tatarie et de Turquie, qui tiennent la foi de Mahomet»" 425 ; "beaucoup pensèrent que, si la réforme de l'Église avait déjà eu lieu, ils seraient devenus chrétiens ${ }^{426}$.

D’autres exemples montrent que certaines personnalités ayant assisté au concile ont été sensibles aux velléités missionnaires des dirigeants de Pologne et de Lituanie. Ulrich de Richental a cité le cas de l'archevêque de Raguse, qui entendait se consacrer à l'évangélisation de la Samogitie, et lui-même a décrit les échanges entre Teutoniques, Polonais et Samogitiens d'une manière qui ne laisse pas de doute sur ses sympathies. Le cardinal français Guillaume Fillastre, qui tient lui aussi une chronique du concile, fait preuve d'un certain intérêt pour cette région ${ }^{427}$. Son commentaire est plus neutre que celui de Richental,

\footnotetext{
${ }^{419}$ CES 2, doc. 78, p. 93-96.

420 Ibid., doc. 77 , p. $92-3$.

421 Ibid., doc. 88, p. 108-109.

${ }^{422}$ Ibid., doc. 81, p. 98-100.

${ }_{423}$ Richental, p. 141. Le manuscrit Konstanz, Rosgartenmuseum, Hs. 1, Bl. 1r-150r, fol. 120r-122r (v. 1465) présente cinq illustrations de la messe célébrée par Grigory Tsamblak. Voir Ulrich de Richental, Chronik des Konzils zu Konstanz, Faksimile der Konstanzer Handschrift, éd. J. Klöcker, Darmstadt 2015.

${ }^{424}$ G. Podskalsky, "L'intervention de Grigorij Camblak, métropolite de Kiev, au concile de Constance (février 1418)", Revue des Études Slaves 70, 1998, p. 289-297. L'intervention de Tsamblak est aussi rapportée par Fillastre, qui mentionne que des lettres du roi de Pologne et du grand-duc de Lituanie ont été lues après le discours du prélat orthodoxe: ibid., p. 295-296; Fillastre, AAC 2, p. 164-167.

${ }_{425}$ Richental, p. 136.

426 Id.

427 Sur ce qui suit, C. Deluz, «L'Europe selon Pierre d'Ailly ou selon Guillaume Fillastre? De l'Ymago Mundi aux légendes de la carte de Nancy", dans D. Marcotte (dir.), Humanisme et
} 
mais il prend soin de noter que le pays des Samogitiens "est une vaste région, grande, disent-ils, comme la moitié de l'Italie» ${ }^{428}$. Quelques années après la fin du concile, en 1420, il participe à un arbitrage entre Teutoniques et Polonais, en exhibant une carte aujourd'hui perdue ${ }^{429}$. Sa prise de position semble avoir été en faveur de la cause polono-lituanienne; quatre ans plus tard, il est invité par Ladislas Jagellon à assister au baptême de son fils, le futur Ladislas III, mais il doit décliner, en raison de son âge ${ }^{430}$. Enfin, au début des années 1420, Vytautas commande une carte de Constantinople au Florentin Cristoforo dei Buondelmonti, qui avait vécu plusieurs années en Grèce ${ }^{431}$. Des contacts se sont donc noués entre les souverains de Pologne et de Lituanie et quelques humanistes occidentaux ${ }^{432}$. Au lendemain du concile de Constance, les petits-fils de Gediminas, secondés par une administration composée essentiellement de clercs polonais et par l'élite intellectuelle, politique et ecclésiastique du royaume, semblent avoir réussi à imposer la présence d'un grand-duché de Lituanie encore en grande partie non-catholique dans l'Europe chrétienne ${ }^{433}$. L'exception balte touche à sa fin.

culture géographique à l'époque du Concile de Constance, Turnhout, 2002, p. 155-158; J. BaBicz, "Le cardinal Fillastre (1347-1428), rédacteur présumé de la carte utilisée pendant le procès polonoteutonique", Communication au 12e Congrès d'Histoire de la Cartographie, Paris, 1987, p. 1-10.

${ }^{428}$ Fillastre, AAC 2, p. 58.

${ }^{429}$ Il s'agit peut-être d'une ouvre du Danois Claudius Clavus (Claus Clausson Swart), à qui Fillastre avait commandé une carte pour illustrer sa traduction de la Géographie de Ptolémée (1427); U. Ehrensvërd, The History of the Nordic Map, Helsinki 2006, p. 35-37.

${ }^{430}$ CES 2, doc. 145, p. 182-183. Une inscription sur la copie conservée à Cracovie parle de "Gregorius cardinalis sancti Marci» (ibid., p. 183), mais il doit bien s'agir de Guillaume Fillastre.

${ }^{431}$ D'après G. Ragone, Guillebert de Lannoy aurait pu jouer le rôle d'intermédiaire entre Vytautas, qu'il avait rencontré en 1421, et Buondelmonti, qui a pu se trouver à Constantinople en même temps que Guillebert, en 1422; G. RaGone, «Il Liber insularum archipelagi di Cristoforo dei Buondelmonti : Filologia del testo, filogogia dell'immagine", dans D. Marcotte (dir.), Humanisme et culture géographique..., p. 177-217; Idem, " "Membrana maxima”: Christoforo dei Buondelmonti, Vytautas of Lithuania and the First Modern Map of Constantinople», dans I. Valikonyté (dir.), Lietuva ir jos kaimynai: nuo normanu iki Napoleono, Vilnius 2001, p. 150-188.

432 À cet égard, on rappellera le rôle du concile de Constance comme "foyer majeur de la diffusion du premier humanisme»: F. Delivré, "1414. Le concile de Constance», dans P. Boucheron (dir.), Histoire du Monde au XV siècle, Paris 2009, p. 309-310. Voir aussi C. Revest, Romam veni. L'humanisme à la curie de la fin du Grand Schisme, d'Innocent VII au concile de Constance (14041417), Paris 2012 (thèse de doctorat non publiée).

433 Sur l'appui des lettrés polonais à la politique de Ladislas Jagellon et Vytautas, S. SobieckI, «Cracow...», p. 551-565; K. OżóG, «University masters...», p. 156-160. 


\section{Chapitre VI VERS D'AUTRES HORIZONS}

\section{Les derniers Croisés de Prusse}

Le concile de Constance marque un tournant non seulement dans la manière dont la Lituanie est perçue par les responsables politiques de l'Europe chrétienne, mais aussi dans le destin des voyages en Prusse, deux phénomènes étroitement liés ${ }^{1}$. La première moitié de la décennie $1390 \mathrm{a}$ vu un pic de participation à la croisade balte, qui bénéficie sans doute de l'effet d'entraînement provoqué par l'expédition de Louis de Bourbon contre Mahdia (1390) et les différents projets visant à arrêter la progression des Turcs dans les Balkans, jusqu’à la défaite de Nicopolis. En étudiant la croisade dans l'Angleterre de la fin du Moyen Âge, Timothy Guard a montré que la mainmise croissante de la couronne sur la noblesse diminuait la possibilité des chevaliers d'aller chercher l'aventure loin du royaume, et ceci même si la croisade gardait une grande importance dans l'idéologie royale ${ }^{2}$. Dans le cas qui nous concerne, les coûts du voyage en Prusse étaient devenus tels que seuls les plus riches seigneurs pouvaient encore se le permettre. À la fin du XIV siècle, les participants prenaient rarement l'initiative eux-mêmes, mais se réunissaient en général autour d'un prince, tel qu'Henri de Derby, le futur Henri IV. Une fois devenu roi (4 février 1399), celui-ci entretenait scrupuleusement son image d'ancien croisé, mais ne fit rien pour relancer le mouvement, ni en Prusse ni ailleurs ${ }^{3}$.

Malgré une baisse de participation depuis la fin des années 1390, un certain nombre de chevaliers continuent à se rendre en Prusse au moins jusqu'à la bataille de Tannenberg. La conversion du grand-duché de Lituanie était certes connue des principales têtes couronnées, mais il restait assez de "Sarrasins" à combattre en Samogitie. À l'occasion, les croisés pouvaient même s'allier au grand-duc converti Vytautas pour harceler ces irréductibles païens ou mener campagne contre les princes tatars rivaux du maitre de Vilnius. L'interdiction

\footnotetext{
1 W. Paravicini, «Kreuzzug...», p. 119-126; D. Baronas, S. C. Rowell, The Conversion..., p. 327-378.

2 T. Guard, Chivalry..., p. 114-115, 211-216.

${ }^{3}$ Idem, p. 86-87.
} 
d'attaquer la Lituanie chrétienne, proclamée par le roi des Romains Wenceslas en 1395 et confirmée par le pape Boniface IX en 1403, ne signifie donc pas la fin immédiate du voyage de Prusse.

À partir de la seconde décennie du $\mathrm{xv}^{\mathrm{e}}$ siècle, la situation évolue. Lorsque Guillebert de Lannoy se trouve en Prusse, en 1413, il évoque les rèses au passé. La mention suit immédiatement une description de Königsberg, où l'on se souvient que les armoiries des participants aux rèses étaient peintes sur les murs de la cathédrale: "et voit on en celle ville les armes, le lieu et la table d'honneur du temps des reises de Prusse»". La variante du manuscrit de la famille de Lannoy, vraisemblablement copié au XVI ${ }^{\mathrm{e}}$ siècle, est encore plus explicite: "où on solloit jadis couvrir la table d'honneur, au temps des rèses de Prussen. 5 . Le jeune homme, parti auprès des Teutoniques comme son frère aîné avant lui, constate que les grandes heures des "rèses de Prusse» appartiennent au passét. Il est vrai qu'après lui, bien peu de chevaliers accompliront le voyage; un certain K. de P., Français, en 1414, puis un groupe de Hennuyers en 1419 sont les derniers hôtes francophones repérés par Werner Paravicini ${ }^{7}$. Plusieurs princes allemands, réunis autour de l'archevêque de Cologne et de son frère, se rendent encore en Prusse en 1422, mais arrivent trop tard pour changer quoi que ce soit à la guerre qui s'est soldée par la paix de Melno et le retour définitif de la Samogitie au grand-duché $e^{8}$. Pour la noblesse allemande, l'Ordre teutonique reste une importante institution aristocratique, qui recevait bon nombre de cadets dans ses rangs ${ }^{9}$. Pourtant, si le combat qu'il mène est toujours perçu comme dirigé contre les ennemis de la foi, il ne concerne plus les païens de Lituanie: les croisés princiers de 1422 pensaient marcher contre les hussites, et non contre d'éventuels néophytes baltes ${ }^{10}$.

Au moins deux sources concernant les événements qui ont suivi la bataille de Tannenberg laissent voir l'évolution du profil des hôtes. En énumérant les participants à la bataille de Koronowo, gagnée par Jagellon en octobre 1410, Jan Długosz fait tenir la bannière de l'Ordre à un certain "Henri, originaire de France»" ${ }^{11}$. À lire le chroniqueur polonais, on peut voir en lui un hôte comme nous les connaissons, qui ne diffère guère de ces Hennuyers, Normands ou Picards qui ont participé à Tannenberg et dans quelques cas, y ont laissé la

\footnotetext{
${ }^{4}$ Potvin, p. 25; W. Paravicini, "Verlorene Denkmäler...», p. 85; D. KraAcK, Monumentale Zeugnisse..., p. 398-399.

5 Potvin, p. 25, n. 8.

${ }^{6}$ PR 1, p. 41.

7 Id.

${ }^{8}$ Ibid., p. 41-42, qui note que les croisés se montrèrent particulièrement exigeants en ce qui concerne les remboursements de leurs frais - ce qui signifie que prêter main-forte à l'Ordre teutonique n'avait désormais plus rien d'un devoir généreux!

9 W. Paravicini, «Kreuzzug...", p. 126; PR 1, p. 42-43.

${ }^{10}$ Ibid., p. 42.

11 Jan Długosz, Annales XI, dans Opera Omnia..., vol. 13, p. 99.
} 
vie. D'autres types de personnages ne tardent toutefois pas à apparaître dans le récit; peu après cette nouvelle victoire polonaise, l'Ordre contre-attaque avec "un grand nombre de nouveaux chevaliers mercenaires, de langues et de nationalités diverses» ${ }^{12}$. Pour échapper aux duels que leur offrent les Polonais, ceux-ci proposent de se battre devant le roi de France, d'Angleterre ou de Naples ${ }^{13}$. Ces chevaliers, peut-être Français ou Anglais, sont moins sourcilleux quant à leur honneur que leurs prédécesseurs qui, vingt ans auparavant, avaient accepté de se battre contre les Polonais à Prague, défi un peu plus facile à relever.

Długosz, thuriféraire de la noblesse polonaise écrivant plusieurs décennies après les faits, avait sans doute intérêt à présenter les hôtes de l'Ordre comme des individus douteux, motivés par l'appât du gain plutôt que comme les parangons de la chevalerie que mettent en scène les sources françaises ou anglaises. Toutefois, nous sommes ici dans un contexte bien précis: le chroniqueur ne relate pas une rèse contre des païens, mais la guerre qui mettait aux prises l'Ordre et la Pologne, longtemps après la conversion de la majeure partie de la Lituanie. Cela suffit-il à expliquer que les hommes se battant aux côtés des Teutoniques après Tannenberg soient dépeints comme de simples mercenaires? Nous avons déjà cité la lettre d'Henri de Plauen, envoyée en juillet 1410, et par laquelle il priait ses destinataires de laisser leurs sujets aller servir l'ordre «amore Christi et tocius Christianitatis aut prorsus potenti solacio et stipendio" ${ }^{14}$.

Les Teutoniques, longtemps habitués à bénéficier du service de volontaires, doivent se résoudre à engager des mercenaires, tout comme le roi de Pologne ${ }^{15}$. À lire l'appel du grand-maître, on a l'impression qu'après Tannenberg, le recours aux soudoyés s'impose comme une nécessité, à tel point qu'ils sont mis sur le même pied que les croisés. Autrement dit, aller en Prusse dans le seul but de combattre l'infidèle semble ne plus suffire ${ }^{16}$. Comment expliquer la perte de popularité de l'institution qu'était devenu le voyage en Prusse depuis la moitié du XIv $v^{e}$ siècle? Plusieurs réponses sont possibles, sans que l'une, bien entendu, n'exclue les autres.

Un premier élément d'explication peut se retrouver chez un contemporain de Guillebert de Lannoy, Gilles le Bouvier, dit «Berry». Ce héraut d'armes,

\footnotetext{
12 Ibid., p. 102.

13 Ibid., p. 107.

${ }^{14}$ M. Biskup, «Das Echo der Tannenbergschlacht...», p. 120.

15 PR 1, p. 35-36; S. EKDAHL, «The Teutonic Order's Mercenaries during the "Great War" with Poland-Lithuania (1409-1411), dans J. France (dir.), Mercenaries and paid men..., p. 345-361.

${ }^{16}$ Il est toutefois impossible de réduire la motivation des hommes qui rejoignent l'Ordre après Tannenberg à la seule volonté de gagner une solde, tout comme il serait osé de prétendre que les hôtes de la "grande époque" ne se montraient pas sensibles aux questions matérielles. Même si, au XIV siècle, l'Ordre teutonique semble ne pas avoir fourni de gages aux hôtes de passage, le remboursement des frais de ces derniers par leurs princes respectifs pouvait également constituer une incitation. Par ailleurs, ces derniers mettaient volontiers au service de l'Ordre une compagnie de soldats professionnels, payés: PR 1, p. 36; W. Paravicini, «La Prusse... », p. 184-187.
} 
qui a voyagé à travers l'Europe avant d'écrire son Livre de la description des pays, parle des rèses qui avaient lieu en Prusse "devant les guerres de France ${ }^{17}$. Contrairement à Lannoy, le Bouvier ne s'est vraisemblablement pas rendu en Prusse comme croisé, mais comme diplomate; d'après l'éditeur ErnestThéodore Hamy, il a dû parcourir l'Europe centrale entre 1440 et 1448, lors d'un ou de plusieurs voyages ${ }^{18}$. Même si environ trente ans séparent son périple de celui de Guillebert, le souvenir des rèses contre les infidèles était encore relativement présent à l'esprit de ses lecteurs. Les "guerres de France» semblent faire ici référence aux luttes qui opposèrent les partisans du duc de Bourgogne à ceux de feu Louis d'Orléans après l'assassinat de ce dernier en $1407^{19}$, ce qui, du point de vue chronologique, correspond assez bien à la période de déclin du voyage en Prusse. On pourrait même y voir l'une des causes du phénomène, en tout cas en ce qui concerne la chevalerie française: selon une hypothèse, la querelle des Armagnacs et des Bourguignons aurait trop occupé les nobles français pour qu'ils trouvent le temps d'aller en rèse ${ }^{20}$. La même réflexion peut être tenue en ce qui concerne la reprise de la guerre de Cent Ans à partir de 1410, surtout si l'on pense à la bataille d'Azincourt (1415), qui voit la mort de nombreux chevaliers français. Nous avons vu que les grandes croisades des années 1390 réunissant Français et Anglais étaient liées aux trêves ou aux efforts de rapprochement entre les deux royaumes, notamment à l'époque de Richard II; lorsque l'on ne se battait pas au pays, les nobles étaient libres d'aller exercer leurs armes sur les infidèles. Peut-on en déduire, a contrario, qu'un pays déchiré par la guerre avait beaucoup moins de croisés à envoyer en Prusse ${ }^{21}$ ?

De même, on a longtemps insisté sur le rôle de la bataille de Tannenberg dans le prétendu déclin de l'Ordre teutonique ${ }^{22}$. Dans cette optique, il serait tentant d'imaginer que l'écrasante défaite des Chevaliers ait entamé leur prestige auprès de la noblesse européenne. Même si ceux-ci essayaient de tourner l'événement à leur avantage en le faisait passer pour un martyre souffert des mains des ennemis du Christ, bien peu de chevaliers occidentaux ont volé à leur secours dans les années qui ont suivi la bataille. En outre, comme nous l'avons vu dans le cas de Guillebert de Lannoy, il est difficile de savoir si ceux qui allaient en Prusse après Tannenberg le faisaient pour protéger un Ordre teutonique menacé ou tout simplement par tradition

\footnotetext{
${ }^{17}$ Hamy, p. 116.

18 Ibid., p. 8-9. La mention du fait que le roi de Pologne est aussi roi de "l'Estau [Lituanie]" pourrait permettre de dater la visite du héraut Berry dans la région à une date postérieure au 25 juin 1447, quand Casimir IV Jagellon, grand-duc de Lituanie, a été couronné roi de Pologne. Ibid., p. 99-100.

${ }_{19}$ PR 1, p. 43.

20 E. Christiansen, The Northern Crusades..., p. 230; T. Guard, Chivalry..., p. 215.

${ }^{21}$ C'est l'hypothèse qu'avance W. van Anrooij, "Heralds... », p. 49.

22 Par exemple, A. Prioult, "La politique de Vytautas le Grand jusqu'en 1409 et la bataille de Tannenberg-Grünwald", Bulletin de la Société d'Émulation du Bourbonnais, 1948 (troisième trimestre), p. 105.
} 
familiale. En tout cas, malgré le soutien affiché à l'Ordre par les rois de France et d'Angleterre, la défaite ne permet pas de relancer les rèses de la "grande» époque de 1390-1395. La compensation financière exigée par les vainqueurs à la paix de Toruń (février 1411) et le recours aux mercenaires a sans doute pesé dans la balance, en mettant à mal les finances de l'Ordre. Néanmoins, Sylvain Gouguenheim remarque que Lannoy parle des terres de l'Ordre comme de régions encore riches en 1413. Malgré l'agitation de la noblesse et des villes après la défaite, la situation semble s'être rapidement stabilisée; en tout cas, la Prusse telle que le noble wallon a pu la voir ne ressemblait pas à un pays ruiné23. La situation économique ou politique de l'Ordre teutonique n'explique donc pas à elle seule le déclin des voyages en Prusse.

L'explication la plus convaincante, et qui a l'avantage d'inclure les autres, est sans doute celle avancée par Werner Paravicini, qui remarque que ni la défaite de Tannenberg ni les difficultés économiques rencontrées par l'Ordre après la paix de Toruń n'ont empêché les hôtes d'aller en Prusse, même si ce n'est qu'en plus petit nombre ${ }^{24}$. La véritable responsable de l'arrêt de la croisade balte est, à l'évidence, la christianisation de la Lituanie. Parcourant le grandduché dans les premiers mois de 1414, Guillebert de Lannoy note que «sont les gens dudit royaume cristiens nez nouvellement par la constrainte des seigneurs de l'ordre de Prusse et de Livland ${ }^{25}$. Fait-il le lien avec l'arrêt des rèses, qu'il avait constaté quelques mois plus tôt? Estimait-il que les Teutoniques ayant rempli leur mission en forçant les Lituaniens à accepter le baptême, et implicitement à les pacifier, il n'y avait plus lieu de se déplacer jusqu'en Prusse pour combattre l'infidèle? On ne peut que le supposer.

En 1410, un chevalier originaire de Misnie, Luppold de Köckritz, faisait savoir à Ulrich de Jungingen qu'il combattrait sans salaire contre Vytautas, perçu comme un païen, mais pas contre le roi chrétien de Pologne. Deux décennies plus tard, en 1429, une lettre envoyée par les représentants des commanderies d'Allemagne au grand-maître Paul de Rusdorf relate que les princes et les chevaliers de l'Empire voulaient bien combattre aux côtés de l'Ordre "pour la chevalerie» (c'est-à-dire gratuitement), mais seulement tant que l'ennemi était infidèle ${ }^{26}$. Pour Sven Ekdahl, il ne fait pas de doute que la nouvelle de l'évangélisation de la Lituanie ait forcé Marienbourg à recruter de plus en plus de mercenaires, ses hôtes habituels n'étant pas prêts à se battre gratuitement

\footnotetext{
23 S. Gouguenheim, «Das Echo...», p. 199.

${ }^{24}$ W. Paravicini, «Kreuzzug...», p. 125-126. Voir aussi N. Housley, The Later Crusades..., p. 362; W. Urban, "Tannenberg/Grunwald Today», dans K. OżóG, J. Trupinda (dirs.), Conflictus Magnus..., p. 91-97; W. van Anroolj, «Heralds...», p. 56-57.

${ }_{25}$ Potvin, p. 39-40.

${ }^{26}$ Ces exemples sont tirés de S. Ekdahl, "The Teutonic Order's Mercenaries...", p. 358;

N. Housley, The Later Crusades..., p. 362.
} 
contre des chrétiens ${ }^{27}$. Affaiblir le grand-duché fraîchement converti et son allié polonais manquait d'honneur ${ }^{28}$.

Déjà après le baptême de 1387, le caractère chrétien des maîtres du grandduché a poussé quelques nobles à changer d'attitude quant à la perspective de ravager leurs terres. Ainsi, Henri de Derby, qui participe à l'assaut contre Vilnius en automne 1390: si des chroniqueurs comme Thomas Walsingham et le moine de Westminster étaient au courant de la participation de Vytautas à la campagne, il y a fort à parier que la présence du Lituanien converti dans l'armée des Teutoniques était également connue du prince anglais. Lorsqu'à l'été 1392 ce dernier est de retour sur le rivage balte, Vytautas est devenu maitre dans son pays et s'est réconcilié avec Jagellon. Pour Giedre Mickūnaité, ce pourrait être l'une des raisons qui a motivé l'Anglais à abandonner la Prusse et à se rendre en pèlerinage à Jérusalem ${ }^{29}$. Rien ne prouve que le comte ait refusé d'attaquer le grand-duché puisqu'il savait que son prince était chrétien, mais l'historienne lituanienne n'a sans doute pas tort de rapprocher ce changement de programme des conclusions de Thomas Walsingham quant à la bataille de Tannenberg, présentée comme une juste punition contre un Ordre teutonique coupable d'avoir attaqué un prince converti ${ }^{30}$. Même s'il n'y a pas forcément corrélation entre les deux événements, le fait est que l'on se rendait compte que les Lituaniens n'étaient plus de simples «Sarrasins ${ }^{31}$.

L'attitude des Anglais peut aussi être le reflet d'une certaine mésentente avec les maîtres de la Prusse; dans les années 1380, des tensions sont apparues entre l'Ordre teutonique et l'Angleterre, sans doute nourries par une rivalité économique $^{32}$, et il semble que les troubles occasionnés par les suivants d'Henri de Derby en 1390-1391 - responsables, rappelons-le, de la mort d'un noble écossais - aient conduit les Chevaliers à préférer se passer des services de ces hôtes encombrants ${ }^{33}$. C'est ainsi que l'on peut expliquer une missive

\footnotetext{
27 Ibid., p. 345-361.

28 E. Christiansen, The Northern Crusades..., p. 230.

29 G. Mickūnaité, Making..., p. 37; à l'inverse, F. R. H. Du Boulay, "Henry of Derby's Crusade...", p. 167, suppose que c'est la défection de Vytautas qui incita le comte à quitter la Prusse, alors que pour C. Tyerman, England..., p. 273, le grand-maitre aurait incité son hôte à ne pas s'attarder sur ses terres. En tout cas, PR 1, p. 134 note qu'à l'été 1392, il n'y eut pas de rèse. Dans la suite d'Henri de Derby se trouvait le célèbre poète Othon III de Grandson, qui avait fui la Savoie pour l'Angleterre, et, accompagné de son fils bâtard, a fait le long voyage de 1392-1393 en compagnie du futur roi (Ibid., p. 86-87).

30 Walsingham, vol. 2, p. 594-596; G. Mickūnaité, Making..., p. 37.

31 Id.

32 Voir notamment, pour les années 1370-1385, les plaintes des marchands anglais contre l'Ordre teutonique lues devant le roi d'Angleterre: CDP 5, doc. 13, p. 11-16. Jusqu'en 1391, des tensions entre marchands prussiens et anglais persistent; ainsi, la demande du grand-maittre concernant les biens de ses sujets, Ibid., vol. 4, doc. 98, p. 140-141. Sur les négociations, Westminster, p. 330-331, 386-369; PR 1, p. 128.

33 W. URBAN, "When was Chaucer's Knight...", p. 351.
} 
au roi Richard II du grand-maitre Conrad de Jungingen, qui en 1394 cherche visiblement à décourager les vassaux de son destinataire à se rendre en Prusse ${ }^{34}$. Quoi qu'il en soit, après cette date, plus aucun Anglais ne fait le déplacement. Il faut attendre 1409 pour voir Richard de Warwick s'arrêter brièvement dans l'État de l'Ordre en rentrant de Terre sainte; seuls quelques anonymes, sans doute de moins haut rang, combattront à Tannenberg ${ }^{35}$.

Des documents concernant d'autres régions d'Europe peuvent nous renseigner sur l'état d'esprit des nobles à la suite de la conversion de la Lituanie. Une lettre envoyée au grand-maître par le procureur de l'Ordre à la Curie en mai 1403 rapporte que les seigneurs d'Italie du Sud font preuve d'intérêt pour les affaires de Prusse. Ainsi le commandeur teutonique des Pouilles est-il souvent questionné par "beaucoup de grands seigneurs $d u$ pays, qui sont allé en Prusse et aussi en Lituanie»; «ils lui demandent sans cesse, quand ils vont à lui, si l'Ordre mène toujours la guerre contre les païens, et à ce sujet il ne sait parfois pas quoi leur répondre ${ }^{36}$. Le commandeur de Sicile est dans la même situation: si l'on peut croire le contenu de la missive, on trouverait encore de nombreux chevaliers intéressés par un nouveau voyage de Prusse ${ }^{37}$. Or, la même année, le pape romain confirmait l'interdiction prononcée par Wenceslas de Luxembourg d'attaquer la Lituanie chrétienne (1395). Peut-être plus qu'une irrésistible envie d'en découdre, le rapport adressé par le procureur de l'Ordre semble refléter les questions qui agitaient la noblesse d'une région aussi éloignée que l'Italie du Sud, visiblement habituée aux rèses de Prusse, mais ignorant si de telles expéditions ont encore lieu d'être ${ }^{38}$.

La Prusse des Chevaliers teutoniques reste une destination prisée des aristocrates de toute l'Europe occidentale, mais dès la première décennie $\mathrm{du} \mathrm{Xv}^{\mathrm{e}}$ siècle, on ne s'y rend plus forcément pour combattre l'infidèle. Werner Paravicini postule que l'Ordre teutonique reste respecté par la noblesse européenne, plutôt comme institution aristocratique que comme athlète du $\mathrm{Christ}^{39}$. Les recherches du médiéviste allemand ont mis en lumière quelques voyages effectués autour de 1410, où la Prusse apparaît comme une étape, sans doute prestigieuse, mais non comme un but en soi. Richard Beauchamp, qui au retour d'Orient visite la région sans y combattre en 1409, est plus proche du voyageur ou du pèlerin «non armé» que du croisé, tout comme le Castillan Alfonso Mudarra, qui comptait visiter l'Ordensstaat en se rendant en Terre sainte, et est finalement passé par la Pologne et la Lituanie, où il rencontre

\footnotetext{
${ }^{34}$ PR 1, p. 128; document publié dans PR 4, doc. 103 (à paraître).

${ }^{35}$ PR 1, p. 127-128.

36 Die Berichte..., vol. 1, doc. 269, p. 378.

37 Ibid., p. 379. Sur les rapports entre les Teutoniques et la noblesse sicilienne, K. Toomaspoeg,

Les Teutoniques en Sicile, Rome 2003, p. 381-388.

${ }_{38}$ PR 1, p. 107-108.

${ }^{39}$ Ibid., p. 208.
} 
Vytautas en mai $1412^{40}$. Tout ceci sans que la bataille de Tannenberg, connue des princes et des chroniqueurs de France, d'Angleterre et d'ailleurs, ne remette en question le changement en cours dans la perception de l'Ordre teutonique.

À la suite de l'enthousiasme prussien des années 1390, la région balte perd en quelque sorte son statut de marge de la Chrétienté, et partant, de front de croisade. Nul doute que la conversion de la Samogitie, cible principale des rèses des dernières années du XIv ${ }^{e}$ siècle, y soit pour quelque chose. L'action des délégués polonais et lituaniens au concile de Constance a permis d'assurer à la monarchie jagellonienne le rôle clef dans la conversion de cette dernière province païenne balte (1417), mais surtout de diffuser la nouvelle loin à la ronde. L'information était alors rendue accessible non seulement aux chevaliers qui s'étaient rendus sur place et avaient constaté, comme c'est peut-être le cas de Guillebert de Lannoy, que les guerres de l'Ordre n'étaient plus dirigées contre des païens, mais encore aux prélats, diplomates, clercs et princes qui assistaient au concile et pouvaient à leur tour confirmer que les adversaires des Teutoniques étaient désormais bel et bien convertis. Les doutes qui pouvaient prévaloir quant au bien-fondé de continuer le combat en Prusse, tels qu'ils se dégagent des lettres des commandeurs italiens au procureur de l'Ordre, ont trouvé réponse, pour partie au moins, lors des débats du concile ${ }^{41}$.

Avec la diffusion de la nouvelle concernant le baptême de la Samogitie, l'Ordre perd une partie de sa crédibilitéf ${ }^{\prime 2}$. Bien qu'il ait encore trouvé des défenseurs lors du concile, son échec à faire approuver une nouvelle expédition contre la Pologne et la Lituanie peut avoir découragé la chevalerie européenne de renouer avec la pratique des rèses ${ }^{43}$. Comparé à la menace turque et à l'agitation hussite, le combat lituanien de l'Ordre teutonique paraissait relativement marginal, voir surannéf ${ }^{44}$. Non que la corporation en tant que telle soit négligée, mais l'on espère utiliser ses ressources dans un but considéré comme plus pressant. L'idée des ducs lituaniens Algirdas et Kęstutis, qui lors des négociations avec l'empereur Charles IV en 1358 avaient suggéré, en cas

\footnotetext{
${ }^{40}$ W. ParavicinI, "Fürschrifften und Testimonia." Der Dokumentationskreislauf der spätmittelalterlichen Adelsreise am Beispiel des kastilischen Ritters Alfonso Mudarra 1411-1412", dans J. Helmrath et al. (dirs.), Studien zum 15. Jahrhundert. Festschrift für Erich Meuthen, Munich 1994, vol. 2, p. 903-926. Mudarra avait avec lui une lettre de recommandation pour le grandmaître, mais l'a ramenée en Castille. S'est-il tout de même rendu en Prusse? Ou les tensions entre la Pologne, la Lituanie et l'Ordre teutonique l'ont-elles incité à rejoindre directement la Terre sainte par la Moldavie?

41 Sur ce point, D. Baronas, S. C. Rowell, The Conversion..., p. 347-361; N. Housley, The Later Crusades..., p. 362.

42 W. Paravicini, «Kreuzzug...», p. 126; A. Bujak, K. Ożóg, L. Sosnowski, The Glory of Grunwald..., p. 82.

${ }^{43}$ Pour le cas des chevaliers anglais, T. Guard, Chivalry..., p. 86.

${ }^{44}$ W. Paravicini, «Kreuzzug....", p. 125.
} 
d'acceptation du baptême, de déplacer l'Ordre "ad solitudines inter Tartaros et Rutenos $»^{45}$ refait surface. Ce sont d'abord les Polonais, puis les Danois, qui tentent d'employer les Teutoniques sur d'autres fronts de croisade, avant que l'idée ne soit reprise par le roi Sigismond de Hongrie. À partir de 1429, quelques contingents teutoniques servent sur le Danube, sans que l'entreprise ne prenne réellement forme ${ }^{46}$.

Quelques années auparavant, lors de son grand voyage diplomatique effectué en 1421-1422, Guillebert de Lannoy rend visite au grand-maître avant de rencontrer Jagellon et Vytautas. Le seigneur bourguignon, alors ambassadeur officiel des rois de France, d'Angleterre et du duc de Bourgogne, avait entre autres tâches de préparer une croisade contre les Turcs $^{47}$. C'est aussi l'objectif d'un envoyé du roi d'Aragon auprès du grandmaître, en $1455^{48}$. La lutte contre les infidèles - sans que l'on précise de qui il s'agit - continue de servir d'argument aux Teutoniques, notamment lors des quêtes effectuées en France ${ }^{49}$. En 1438, le roi Charles VII appuie les envoyés de l'Ordre venus récolter de l'argent "pour defendre et garder certains pors et passaiges contre les infideles et ennemis de la foi catholique" ". ${ }^{50}$ Quelques années après le début de la Guerre de Treize ans, alors que les Teutoniques manquaient cruellement de fonds, l'évêque d'Orléans autorise une quête en leur faveur (1455), justifiée par le fait que le grand-maitre "ne cesse de faire continuellement et assidument la guerre aux perfides Sarrasins, ennemis de la foi catholique et de Notre Seigneur Jésus-Christ " ${ }^{51}$. Fait caractéristique, les missions de paix - notamment bourguignonnes - envoyées auprès de Marienbourg et de Cracovie incitaient les belligérants à se réconcilier pour organiser une croisade commune contre les Turcs ${ }^{52}$.

\footnotetext{
45 Selon la chronique d' Hermann de Wartberge, Chronicon Livoniae..., SRP 2, p. 80.

46 J. Sarnowsky, "The Teutonic Order...», p. 259-262; H. Zimmermann, "Der deutsche Ritterorden...», p. 297. Sigismond de Luxembourg souhaitait utiliser les ressources de l'Ordre teutonique contre les Turcs ottomans, mais aussi contre les hussites.

47 Guillebert, courtisan de Philippe le Bon, était en premier lieu chargé d'annoncer la conclusion du traité de Troyes (1420) aux souverains de Pologne et de Lituanie et au grand-maître de l'Ordre teutonique; PR 1, p. 41.

48 Ibid., p. 113. En sens inverse, Hans von Baysen, un membre de l'entourage du grand-maître Michael Küchmeister, a participé à la lutte contre les Maures aux côtés du roi du Portugal entre 1416 et 1419: W. Paravicini, "Zeitenwende. Edelleute aus dem Ordensland Preussen und Livland im Westeuropa des 15. Jahrhunderts", dans P.-J. Heinig et al. (dir.), Reich, Regionen und Europa in Mittelalter und Neuzeit, Berlin 2000, p. 414-421; Idem, "Prusse...", p. $188-189$.

49 K. Polejowski, «The Teutonic Order's Propaganda... », p. 239-242.

50 C. Laloire (éd.), Collection des principaux cartulaires du diocèses de Troyes, vol. 3, Paris 1878, doc. 165, cité par ibid., p. 239, n. 20.

51 C. Laloire (éd.), op. cit., doc. 177, cité par K. Polejowski, "The Teutonic Order's Propaganda...", p. 241.

${ }_{52}$ Id.
} 
Le ton des chroniqueurs commentant la lutte de Casimir IV Jagellon, fils de Ladislas $\mathrm{II}^{53}$, contre les Chevaliers teutoniques se fait plutôt neutre, même si l'on rappelle volontiers que ces derniers «sont gens de relligion, et ordonnez pour faire resistence contre les infidelles ${ }^{54}$. Au début du siècle suivant, la danse macabre peinte par Niklaus Manuel Deutsch entre 1516 et 1519 dans l'ancien cimetière du cloître des Dominicains de Berne met en scène un chevalier teutonique à l'allure martiale (fig. 5), qui raconte ainsi sa destinée:

«La Mort s'adresse au chevalier:

Frère chevalier par la volonté de Dieu,

Vous avez beaucoup fait pour la foi

Et protégé la Chrétienté

Risquant votre vie avec bravoure.

\section{Le chevalier lui répond:}

J'ai combattu les Turcs et les païens

Et j'ai eu beaucoup à souffrir des incroyants. " 15

L'image, occupant un espace deux fois plus grand que les autres figures, peut se lire comme une démonstration de puissance, et le texte se fait moins moqueur que pour d'autres personnages appartenant à la noblesse et à l'Église. Sans doute le rôle de défenseur de la Chrétienté attribué aux Teutoniques trouvait-il grâce aux yeux du peintre, lui-même homme de guerre. À noter que le donateur de la scène, Rodolphe de Fridingen, n'était autre que le commandeur teutonique de Köniz, près de Berne ${ }^{56}$.

Ces exemples montrent que la Prusse teutonique reste liée à l'idée de croisade, même si la stratégie autant que l'adversaire sont totalement différents par rapport à la période faste des "voyages" contre les Lituaniens ${ }^{57}$. La défaite de Nicopolis (1396) a certes été un traumatisme pour la chevalerie chrétienne, mais si elle a contribué au déclin des voyages en Prusse, c'est surtout en tournant les regards vers l'adversaire redoutable qu'était devenu l'Empire ottoman, à prendre bien plus au sérieux que les princes néophytes de Lituanie ${ }^{58}$. Au combat contre les

\footnotetext{
53 Casimir IV est l'un des fils de Ladislas II Jagellon. Il a succédé à son frère ainé, lui aussi prénommé Ladislas (III), qui est mort en 1444 à la bataille de Varna.

54 Mathieu d'Escouchy, Chronique, éd. G. du Fresne de Beaucourt, Paris 1863, vol. 2, p. 272. Voir aussi Énée Sylvio Piccolomini, Historia de Europa, XXIX, SRP 4, p. 233-235.

55 J. Tripps, "Tu seras le festin des vers". La Danse macabre de Niklaus Manuel Deutsch à Berne, éd. et trad., Berne, 2006, p. 47; J. SARnowsky, «The Teutonic Order...», p. 262.

56 J. Tripps, "Tu seras le festin des vers»..., p. 46.

57 PR 1, p. 41; J. SARNOWsKY, "Military Orders...", p. 123-160.

58 W. Paravicini, «Kreuzzug... », p. 119; B. WeBER, Lutter contre les Turcs: les nouvelles formes de la croisade pontificale au $X V^{\bullet}$ siècle, Rome 2013, p. 36-37.
} 
Turcs s'ajoutent les guerres que mène, sans succès, Sigismond de Luxembourg pour faire revenir les partisans tchèques de Jean Hus dans l'obédience de l'Église romaine ${ }^{59}$. La répression anti-hussite, échelonnée entre 1420 et 1431, occupe essentiellement la noblesse de l'Empire ${ }^{60}$, mais la question n'était pas ignorée en terres francophones. Du fond de son cachot, le poète bourguignon Jean Régnier appelle "Ceulx qui vouldroint faire la guerre, / Soient de France ou d'Angleterre» à marcher:

«sur les Boesmïens.

\section{La pourront ilz conquester terre,}

Et leur salvation acquerre,

Et y faire beaucoup de biens;

Car Boesmes sont heresiens

Et vallent pis que Suriens. ${ }^{61}$

Cet extrait d'une œuvre composée en 1432 rappelle à maints égards les conseils que prodiguaient les poèmes didactiques un demi-siècle plus tôt. Notons toutefois que les hussites de Bohême n'étant pas de simples "mécréants» mais des hérétiques, ils sont considérés comme une cible encore plus légitime pour les gens de guerre ${ }^{62}$. Guillebert de Lannoy lui-même a été mandaté par son patron, Philippe de Bourgogne, pour rédiger un Avis pour entreprendre la guerre contre les herectiques de Behaigne (1428) ${ }^{63}$. Le duc, qui se pose volontiers en champion de la Chrétienté, et s'inquiétait par ailleurs de voir se développer des hérésies assimilables au hussitisme dans ses États (notamment dans les villes flamandes, terreau de contestation sociale et religieuse), entendait afficher son soutien envers le roi Sigismond ${ }^{64}$. C'est en ce sens qu'en 1429, il dépêche Guillebert "en ambaxade, pour le fait des Housses, en Hongrie, devers le roy des Rommains" ${ }^{65}$. Le seigneur de Lannoy est également l'un des représentants du duc au

\footnotetext{
59 W. Paravicinı, «Von der Preussenfahrt zum Hussitenkreuzzug», dans B. JäHnig (dir.), Beiträge zur Militärgeschichte des Preussenlandes von der Ordenszeit bis zum Zeitalter der Weltkriege, Marbourg 2010, p. 121-159.

${ }^{60}$ F. G. Heymann, "The Crusades against the Hussites», dans R. L. Wolff, H. W. Hazard (ÉDs.), A History of Crusades, vol. 3, The Later Crusades, Madison 1969, p. 586-647; P. Soukup, "Crusading against Christians...», p. 91-98.

${ }^{61}$ Jean Régnier, Les Fortunes et Adversitez, v. 2067-2078, éd. E. Droz, Paris 1923, cité par G. Gros, "Croisade contre les Boesmes, ou guerre et paix chez Jean Régnier", Cahiers de recherches médiévales 1, 1996, p. 123.

${ }^{62}$ Ibid., p. 123-126.

${ }^{63}$ Potvin, p. 227-249.

${ }^{64}$ O. MARIN, «Histoires pragoises. Les chroniqueurs français devant la révolution hussite», dans Francia - Forschungen zur Westeuropäischen Geschichte, 34/1, 2007, p. 44-45.

${ }^{65}$ Potvin, p. 164-165. J. Svátex (Discours..., p. 59) note que Guillebert participa probablement, avec d'autres ambassadeurs bourguignons, aux négociations que mène Sigismond à Presbourg (Bratislava) en avril 1429.
} 
concile de Bâle, où il prononce un discours plein de menaces envers les hussites ${ }^{66}$. Ceci sans que les pères du concile, finalement parvenus à un compromis avec ceux-ci (1431), ne tiennent compte des rodomontades bourguignonnes ${ }^{67}$.

Malgré ces quelques tentatives, qui tiennent autant du vœu pieux que du jeu politique, la Bohême ne devient pas la Prusse du Xve siècle. Quelques chevaliers originaires des régions francophones participent toutefois à la croisade, comme ces Liégeois mentionnés par Jean de Stavelot ${ }^{68}$, ou cet autre Wallon, Jean de Wavrin, proche des frères de Lannoy et auteur des Anchiennes cronicques d'Engleterre. Son récit nous apprend qu'un groupe de Savoyards y était aussi, sans doute avec l'approbation du duc Amédée VIII. Tous participaient à la campagne de 1421, qui s'est terminée par la débandade de l'armée croisée avant même que bataille ne soit livrée ${ }^{69}$. En 1427, Guillaume d'Aarberg, seigneur de Valangin, rejoint une nouvelle expédition. Son testament montre qu'au second quart $\mathrm{du} \mathrm{Xv}^{\mathrm{e}}$ siècle, la volonté "de partir en armes pour aller au saint voiage, compaingnie, guerre et armee qui de novel est ordonnée et emprinse faire sur les annemis et adversaires mescreans de la foy catholique et crestienne» ${ }^{70}$ pouvait encore habiter un noble ayant l'ambition de tenir son rang, notamment face à son suzerain et rival le comte de $\mathrm{Neuchâtel}^{71}$. Comme à l'époque des rèses contre la Lituanie, prendre part à ce genre de croisades reste un élément de distinction sociale.

D'autres destinations étaient en outre possibles, en lien avec la lutte contre les Ottomans. Les Anchiennes cronicques d'Engleterre, qui relatent des événements survenus bien loin de ce pays, intègrent les souvenirs du neveu de l'auteur, Waléran de Wavrin, capitaine général de la flotte du duc de Bourgogne, chargé en 1444 d'appuyer l'armée croisée qui devait attaquer le sultan. Alors que l'aide bourguignonne ne parvint pas à empêcher les troupes turques de traverser le Bosphore, l'on se livra pendant quelques années à la piraterie au détriment des

\footnotetext{
${ }^{66}$ Voir Monumenta Concilium Basiliense, t. V. Tagebücher und Acten, éd. G. Beckmann, R. Wackernagel et G. Coggiola, Bâle 1904, p. $46-47$ (à la date du 3 avril 1433), cité par J. SváteK, Discours..., p. 59-69, n. 155.

${ }^{67}$ Ibid., p. 59.

${ }^{68}$ Jean de Stavelot, Chronique..., p. 187-194; A. VANtuch, "La participation liégeoise à la croisade contre les Hussites en 1421, d'après Jean de Stavelot ", Liège et Bourgogne. Actes du colloque tenu à Liège les 28, 29 et 30 octobre 1968, Liège 1972, p. 45-54.

${ }^{69}$ O. MARIN, «Histoires pragoises...», p. 48-49. La chronique de Laurent de Březova, secrétaire de la cité de Prague, mentionne que l'armée réunie par le roi des Romains Sigismond en 1420 comporte des croisés venus non seulement des terres d'Empire (Suisse y compris) et d'Europe orientale, mais également de France et d'Angleterre; F. G. Heymann, «The Crusades against the Hussites...", p. 595-597.

${ }^{70}$ Extrait du préambule du testament de Guilllaume d'Aarberg, seigneur de Valangin, le 3 juillet 1427 (AEN, Anciennes Archives, U5, no 4).

71 J.-D. Morerod, C. de Reynier, "Nidau und Aarberg-Valangin», dans W. Paravicini et al. (dirs.), Höfe und Residenzen im spätmittelalterlichen Reich. Grafen und Herren, vol. 2, Sigmaringen 2012, p. 1069-1074.
} 
"Sarrasins", mais aussi des chrétiens orthodoxes comme catholiques. L'un des compagnons de Wavrin, Geoffroy de Thoisy, s'attira notamment les foudres de Gênes pour avoir écumé la mer Noire, jusqu'aux côtes géorgienne de Mingrélie $^{72}$. Aventuriers, nobles en mal de distinction ou défenseurs zélés de la cause chrétienne avaient encore de quoi faire, même cinquante ans après le baptême de Vilnius. Au détriment de la Baltique, la Méditerranée, l'Europe centrale et les Balkans deviennent le nouveau théâtre de ce genre de lutte. Toutefois, si l'on ne se rend plus aux côtés des Chevaliers teutoniques pour y combattre les Lituaniens, le souvenir du voyage en Prusse reste présent dans le domaine de la littérature jusqu'au milieu du $\mathrm{xv}^{\mathrm{e}}$ siècle. L'ennemi, alors, n'est plus celui que l'on s'attend à trouver dans des textes relatant les aventures des hôtes de l'Ordre teutonique.

\section{LES LITUANIENS, HÉROS DE LA CROISADE?}

Dès la conversion de Ladislas Jagellon, le pape de Rome écrit au nouveau maître de la Pologne et de la Lituanie pour lui enjoindre de s'allier à l'Ordre teutonique afin d'écraser les Tatars infidèles et de ramener les schismatiques dans le giron de l'église romaine ${ }^{73}$. Cela correspond tout à fait aux plans de Jagellon et de Vytautas, ou en tout cas à l'image qu'ils entendent donner d'euxmêmes ${ }^{74}$. Dès l'automne 1396, les cousins écrivent directement au patriarche de Constantinople pour lui proposer d'organiser un concile ocuménique en Lituanie devant rendre possible l'union entre les églises grecque et romaine, tout en promettant à Sigismond de l'aide dans le combat contre les Turcs: croisade et union de l'Église sont intimement liées ${ }^{75}$. Vytautas surtout a su mettre à profit la conversion de la Lituanie pour attirer sur ses ambitions orientales les faveurs de la Papauté. Après quelques succès militaires contre les Tatars en 1397-1398, le grand-duc tente une opération de grande envergure: il s'agit de défendre Kiev, alors possession lituanienne, menacée par le prince tatar Timur Kotluk, le protégé du puissant Tamerlan ${ }^{76}$. À cette occasion, Jagellon envoie l'évêque de Poznań Albert Jastrzębiec à Rome pour obtenir une bulle de croisade: le 5 mai,

\footnotetext{
${ }^{72} \mathrm{~J}$. РАviот, "La piraterie bourguignonne en mer Noire à la moitié du $\mathrm{Xv}^{\mathrm{e}}$ siècle», dans H. Dubois, J.-C. Hocquet, A. Vauchez (dirs.), Horizons Marins, Itinéraires spirituels, Paris 1995, p. 204-214; N. IorgA, «Les Aventures "sarrazines" des Français de Bourgogne au Xve siècle», dans C. Marinescu (dir.), Mélanges d'Histoire Générale, Cluj 1927, p. 7-56.

73 Voir ci-dessus, chap. V.

74 D. Baronas, S. C. Rowell, The Conversion..., p. 361, 379 sq.

75 Ainsi, la réponse du patriarche fait savoir que la menace représentée par les infidèles empêche de discuter de la réunion des Églises, et conseille donc aux princes Jagellon et Vytautas d'aider le roi Sigismond à combattre les Turcs; Acta Patriarchatus Constantinopolitani, 1315-1402, éd. F. Miklosich, I. Muller, Vienne 1862, doc. 515, p. 280-281, cité par D. Baronas, S. C. Rowell, The Conversion..., p. 380.

${ }^{76}$ Sur ce qui suit, notamment ibid., p. 380-382; G. Mickūnaité, Making..., p. 33-35; PR 1, p. 31 ; J. SARnowsy, "Military Orders...», p. 138-139.
} 
Boniface IX écrit à l'évêque de Cracovie et lui demande de prêcher la croisade pour défendre la foi catholique "contre la fureur haineuse des Tatars, païens, Turcs et autres nations barbares»" ${ }^{77}$. La riposte est attribuée à "l'illustre Ladislas, roi de Pologne, qui sans se lasser, est conduit à la défense et à l'exaltation de la Foi Catholique, son athlète promptissime, son vigile infatigable ${ }^{78}$. La bulle demande que la croisade soit prêchée "dans le royaume de Pologne, dans les principautés, duchés et autres seigneuries de Lituanie, Russie [Ruthénie], Podolie, Valachie»" ${ }^{79}$, ce qui indique qu'à cette date la Lituanie est considérée par Rome comme un pays où la croisade peut être prêchée; c'est-à-dire une terre chrétienne, et non une cible potentielle.

Si le grand-duc se pose volontiers en défenseur de la Chrétienté, il n'hésite pas à s'adjoindre les forces du prince tatar Tokhtamysh, l'un des prétendants au pouvoir suprême sur la Horde d'Or. L'aventure, à laquelle ont participé un contingent de l'Ordre teutonique mais aussi des chevaliers polonais et «de diverses parties du monde ${ }^{80}$, se termine par une cuisante défaite à la bataille de la Vorskla (12 août 1399). La politique subtile du Lituanien a cette fois-ci échoué, mais il n'en obtient pas moins un certain prestige et s'impose peu à peu comme un partenaire des chevaliers chrétiens désireux de croiser le fer avec les ennemis de la foi ${ }^{81}$. Lorsqu'en 1406, il marche sur Moscou, toujours en compagnie des Teutoniques, les hérauts du duc de Bourgogne et du comte de Hollande-Hainaut l'accompagnent, ce qui représente une sorte de consécration pour ce prince aspirant à faire sienne l'institution de la chevalerie ${ }^{82}$. À cet égard, l'épitaphe d'Hugues de Lannoy, le frère aîné de Guillebert, indique une évolution révélatrice:

"En l'âge de xx ans, receut l'ordre de chevalerie au très saint lieu de Jhérusalem, dont, au retour, avec le maistre de Liflant s'en alla en Prusse, frontière contre les Turcqz, ralla avec le duc Witolt encontre les Tartares, fist congnoître et eslever son nom en plusieurs haulx et valeureux faits, partout plus que home de sa nation piéçà.»83

\footnotetext{
77 Vetera monumenta..., vol. 1, doc. 1054, p. 771; la bulle est éditée dans Ibid., p. 769-771.

78 Ibid., p. 770. À noter que la bulle cite directement l'évêque de Poznań et envoyé de Jagellon comme source d'information.

79 id.

${ }^{80}$ Annales de Toruń, SRP vol. 3, p. 230;

${ }^{81}$ G. MickūNaité, Making..., p. 39-40. Par exemple, les Chroniques et Annales de Pologne adaptée par Blaise de Vigénère en 1573 pour Henri de Valois, mentionnent les deux «voyages» de Vytautas contre les Tatars (p. 270-271).

82 D'après les extraits du livre des dépenses de l'Ordre teutonique, édité dans CEV, p. 970.

R. Petrauskas, "Knighthood...", p. 48; W. Paravicini, "Litauer...", p. 266; J. Sarnowsky, «Military Orders...», p. 139.

83 B. De Lannoy, Hugues de Lannoy..., p. 167; le mausolée d'Hugues de Lannoy, édifié dans l'église St-Pierre de Lille, a été détruit, mais il nous reste le texte de l'épitaphe, recopié dans plusieurs manuscrits et édité plusieurs fois; Ibid., p. 168, n. 32.
} 
Le «duc Witolt» (autrement dit Vytautas) est donc mis sur pied d'égalité avec l'Ordre teutonique, comme s'il s'agissait d'un personnage connu des destinataires de l'épitaphe. Quand et à quelle occasion Hugues de Lannoy a-t-il rejoint Vytautas dans ses opérations militaires? A-t-il, comme Richard Beauchamp dans les mêmes années, fait halte en Prusse et en Lituanie à son retour de Terre sainte? Werner Paravicini place l'épisode à l'été 1406; l'aîné de notre Guillebert serait parti pour servir l'Ordre en compagnie de Jean de Werchin, le sénéchal de Hainaut, puis une fois en Prusse, serait parti combattre aux côtés de Vytautas ${ }^{84}$. Autre "écho" notable: le chroniqueur Jan Długosz raconte que lors d'une campagne lituanienne contre Novgorod, un chevalier polonais porte la bannière de Saint-Georges, une tradition éminemment liée au monde de la croisade, et que nous savons prisée des hôtes de l'Ordre teutonique ${ }^{85}$. Grâce à son énergique grand-duc, la Lituanie récemment christianisée paraît capable de capitaliser sur l'élan des voyages en Prusse pour damer le pion à son rival, et s'attirer les bonnes grâces des visiteurs de marque venus de toute l'Europe ${ }^{86}$. Une position qui, sur le long terme, n'est peut-être pas sans conséquence dans la perte de prestige de l'Ordre ${ }^{87}$.

Sous le règne de Vytautas, le pays voit ainsi naître une culture de cour à l'européenne, dont le développement a été favorisé par les contacts avec le monde catholique qui prévalaient, nous le savons, sous les prédécesseurs du grand-duc. Avec la christianisation du pays, le modèle de la chevalerie s'impose en Lituanie, influencé par les usages de Prusse, mais aussi de Pologne et de Silésie ${ }^{88}$. Limités dans un premier temps à la cour grand-ducale, les codes propres à la culture chevaleresque permettent de distinguer les nobles fidèles à Vytautas ${ }^{89}$. À partir de 1404, les boyards les plus importants sont adoubés, et un héraut d'armes, Nicklus Luczke, est appointé; son successeur, un certain Jonas, reçoit le nom de Litherland, selon l'habitude qui consiste à nommer les hérauts d'après les

\footnotetext{
${ }^{84}$ PR 1, p. 32, 206-207. Pour le comte B. de Lannoy (Hugues de Lannoy..., p. 22-23), Hugues aurait effectué deux voyages dans la région balte, autour de 1408-1409.

85 R. Petrauskas, «Knighthood...», p. 48.

${ }^{86}$ G. Mickūnaité, Making..., p. 39-40, note qu'un prince, apparemment de la région du Tyrol, a demandé aide et conseil à Vytautas pour se rendre en Terre sainte (Liber Cancellariae..., vol. 1-2, doc. 85 , p. 157).

${ }^{87}$ PR 1, p. 33-34.

88 Sur ce qui suit, R. Petrauskas, "Knighthood...», p. 39-66; W. Paravicini, "Litauer...», p. 253-282; L. PósÁN, "Ritterkultur im Spätmittelalterlichen Litauen", dans A. BÁRÁNY et al. (dirs.), Learning, Intellect and Social Roles, p. 51-58; R. ČApaitE, "The everyday life of Grand Duke Vytautas of Lithuania according to Contemporary Correspondance», Lithuanian Historical Studies, 8 2003, p. 1-26. Sur la chevalerie comme modèle commun à la noblesse européenne, W. Paravicini, "Adelskultur...», p. 273-302; Idem, Die ritterlich-höfische Kultur....

${ }^{89}$ R. Petrauskas, «Knighthood...»" p. 58. S. KuczyŃski, «Hérauts d'armes...», p. 654, constate que dans la Pologne jagellonienne comme en Lituanie, la culture chevaleresque et courtoise a été mise au service du prestige de la fonction royale.
} 
pays qu'ils représentent ${ }^{90}$. Des nobles étrangers ont même été adoubés de la main de Vytautas lui-même, à l'instar de Benedict Macra, l'envoyé hongrois chargé par le roi Sigismond, en 1413, de résoudre la dispute territoriale entre l'Ordre teutonique, la Lituanie et la Pologne ${ }^{11}$. Parfois adversaire, plus souvent partenaire, l'Ordre teutonique a largement influencé la naissance de la culture chevaleresque en Lituanie ${ }^{92}$, mais Rimvydas Petrauskas note que les hérauts étrangers et les autres visiteurs ont pour leur part joué un rôle non négligeable dans la diffusion des habitudes et des valeurs qui y sont propres ${ }^{93}$. Volontiers généreux ${ }^{94}$, Vytautas en profite pour resserrer les liens de son pays avec les cours d'où ses hôtes proviennent ${ }^{95}$. Ainsi, peut-être plus que d'actions strictement politiques et militaires, les expéditions réunissant Lituaniens, Teutoniques et hôtes occidentaux relèvent du processus d'intégration du grand-duché dans l'Europe catholique ${ }^{96}$.

Cette nouvelle manière de percevoir la Lituanie est favorisée par une certaine évolution de la culture chevaleresque quant à la pratique du voyage. À partir des dernières années du XIv $v^{e}$ siècle, les aristocrates ne se déplacent plus uniquement comme croisés ou comme pèlerins, mais aussi dans le but de parcourir d'autres pays, "à la manière noble»" . L'attitude préconisée par Geoffroi de Charny dès le milieu du XIV $v^{e}$ siècle, c'est-à-dire voyager pour "moult d'estranges choses et diverses $[\ldots]$ veoir ${ }^{98}$ est peu à peu entrée dans les mœurs de la noblesse. On ne cherche plus nécessairement à guerroyer contre les "Sarrasins" ou à obtenir des indulgences, mais on se contente de visiter les lointaines cours princières, qui deviennent des buts de voyage et non plus de simples étapes ${ }^{99}$. La curiosité pour les pays parcourus, l'envie de "vëoir le monde», pour reprendre une expression chère à Guillebert de Lannoy, devient un motif tout à fait louable ${ }^{100}$.

\footnotetext{
90 Ibid., p. 655; voir la liste des nobles lituaniens adoubés dans R. Petrauskas, «Knighthood...», p. 61-65.

${ }^{91}$ Ibid., p. 47. L'événement est connu par une lettre de protestation de l'Ordre teutonique, qui considérait l'adoubement de Macra comme un indice de sa partialité: CEV, doc. 709, p. 256-258.

92 R. Petrauskas, «Knightood...», p. 47.

93 Ibid., p. 48-51.

${ }^{94}$ La générosité de Vytautas est notée avec emphase par Guillebert de Lannoy; Potvin, p. 41.

95 R. Petrauskas, «Knighthood...», p. 50-51.

${ }_{96}$ Ibid., p. 48.

${ }^{97}$ Un sauf-conduit délivré en 1387 par le roi d'Aragon au seigneur Henri de Gera mentionne «more nobilium aliena climata lustraturus» (J. VINCKE, «Zu den Anfängen der deutsch-spanischen Kultur- und Wirtschaftsbeziehungen", Gesammelte Aufsätze zur Kulturgeschichte Spaniens, 14, 1959, p. 163, cité par W. Paravicini, "Von der Heidenfahrt... », p. 105).

${ }_{98}$ Geoffroi de Charny, The Book of Chivalry..., p. 90.

99 W. Paravicini, "Von der Heidenfahrt... ", p. 103-108, qui remarque également que la menace turque n'a pas joué un rôle mobilisateur pour relancer la pratique de la croisade au Xve siècle (Ibid., p. 98).

${ }^{100}$ Ibid., p. 100-103, 105; Idem, "Seigneur par l'itinérance? Le cas du patricien bernois Conrad de Scharnachtal", dans A. Paravicini Balgiani et al. (dirs.), L’itinérance des seigneurs...,
} 
Cette nouvelle manière de voyager s'étend rapidement à toute la Chrétienté: dès la seconde décennie $d u x^{e}$ siècle, des seigneurs prussiens, livoniens, mais aussi lituaniens, quittent leur pays pour fréquenter quelque temps les cours étrangères. Le chroniqueur Jan Długosz relate qu'en 1412, un Lituanien participa à un tournoi organisé à Buda par Sigismond de Luxembourg, tandis qu'en 1467-1469, un seigneur orthodoxe du grand-duché, Alexander Soltan, parcourt une grande partie de l'Europe, fréquentant notamment les cours de France, de Bourgogne, de Portugal et d'Angleterre après avoir été fait chevalier au Saint Sépulcre ${ }^{101}$. Dès les années qui suivent Tannenberg, la noblesse lituanienne fait donc sienne la pratique du "voyage nobiliaire", alors que la cour grand-ducale devient une étape prisée d'un certain nombre de voyageurs désireux de fréquenter de lointains centres de culture chevaleresque. On peut alors supposer que les voyages de Richard de Warwick en 1409 et d'Alfonso Mudarra en 1411-1412 soient plus motivés par ce but pacifique que par l'envie d'en découdre contre de supposés infidèles ${ }^{102}$. Quant à Guillebert de Lannoy, le vocabulaire qu'il emploie lors de sa traversée de la Lituanie en hiver 1414, où il semble avoir cherché à rencontrer le grand-duc, souligne que son but n'était pas, alors, de faire rèse "contre les mescréans» ${ }^{103}$. Si à la fin de l'automne 1413, Guillebert quitte la Prusse pour la Livonie dans l'espoir de pouvoir participer à une nouvelle rèse, ce n'est plus en croisé ni en combattant qu'il visite la Lituanie au début de l'année suivante: "de Zeghewalde [en Livonie, auj. Sigulda, Lettonie], me party, pour m'en aler vëoir le royaume de Létau, devers le duc Witholt, roy de Létau et de Samette et de Russie» ${ }^{104}$. Quelques mois plus tard, le chevalier bourguigon quitte l'État de l'Ordre teutonique "pour aler ou royaume de Poulane, devers le roy de Poulane, pour vëoir sa court, son estat et son païs» ${ }^{105}$.

p. 28-71; A. Bertrand, «Un seigneur bourguignon en Europe de l'Est: Guillebert de Lannoy (1386 - 1462)", Le Moyen Âge 95/2, 1989, p. 293-309.

${ }^{101}$ Les seigneurs de Prusse et de Livonie commencent à parcourir l'Europe au moment où leurs pairs arrêtent de participer aux rèses. Le premier cas connu est le Prussien Hans von Baysen, qui se rendit au Portugal pour rencontrer le roi et guerroyer contre les Maures: W. Paravicini, "Zeitenwende...», p. 413-442. Sur le voyage d'Alexandre Soltan, A. et W. Paravicini, " "Alexander Soltan ex Lithuania, ritum graecorum sectans". Eine ruthenisch-polnische Reise zu den Höfen Europas und zum Heiligen Land 1467-1469", dans E. HüBNER et al. (dirs.), Zwischen Christianisierung und Europäisierung, Stuttgart 1998, p. 367-401.

${ }_{102}$ D'après le poème illustré The Beauchamp Pageant, Richard "from Venuse toke his wey to Russy Lettowe Poleyn and Spruse Westvale and other coostes of Almayn toward Englond", Pageant..., tab. XXII; PR 1, p. 34. On a conservé plusieurs lettres de recommandation indiquant que le chevalier castillan Alfonso Mudarra a visité la cour de Vytautas en 1412, et peut-être la Prusse teutonique: W. Paravicini, «"Fürschrifften und Testimonia"...», p. 903-926.

${ }^{103}$ Pour reprendre l'expression qu'il utilise au tout début de son récit (Potvin, p. 20). Une fois en Lituanie, Guillebert dit avoir visité plusieurs "cours dudit Witholt» (p. 38), et a rencontré "deux des seurs de la femme dudit duc Witholt, sy alay devers elles» (p. 40) à Vilnius, avant de trouver le grand-duc, à la chasse, dans un lieu qu'il nomme Posur (p. 42).

${ }^{104}$ Ibid., p. 38.

${ }^{105}$ Ibid., p. 44-45. 
Le second voyage de Guillebert en particulier nous laisse comprendre quelle place avait pris la Lituanie dans les plans de croisade échafaudés en Europe occidentale. Guillebert, alors ambassadeur officiel des rois d'Angleterre et de France (nous sommes après le traité de Troyes), et surtout du duc de Bourgogne, "principal esmouveur» ${ }^{106}$, doit se rendre en Terre sainte via la Prusse, la Pologne, la Lituanie et les principautés de Valachie et de Moldavie, alors dépendantes du grand-duché. Le but de ce voyage est non seulement d'annoncer la conclusion du traité de Troyes aux souverains de ces pays, mais aussi de sonder les possibilités d'organiser une grande croisade contre les Turcs, ce qui assurerait à Philippe le Bon la première place parmi les princes chrétiens ${ }^{107}$. Notre chevalier bourguignon ne parcourt donc plus la région balte comme croisé, mais en tant que diplomate, et officieusement, espion ${ }^{108}$.

Les notes qu'il nous a laissées permettent de suivre de manière relativement détaillée son parcours: après avoir traversé l'Empire et les duchés poméraniens, Guillebert et ses compagnons se rendent en Prusse, où ils rencontrent le grandmaître, "nommé messire Micquiel Cocquemeistre» ${ }^{109}$. Celui-ci «fist grant honneur» à l'ambassadeur, "en [lui] donnant pluisieurs disners, puis [lui] donna ung ronssing et une belle haghenée", c'est-à-dire deux chevaux utilisés essentiellement pour le voyage ou le travail ${ }^{110}$. Les Bourguignons continuent leur route par la Pologne, où le roi les retient pendant six jours et leur offre lui aussi de très riches dîners, avant qu'ils ne pénètrent en Lituanie pour rencontrer le grand-duc $V_{\text {ytautas }}{ }^{111}$. Des dons sont échangés, "joyaulx du roy d'Angleterre» ${ }^{112}$ contre de luxueux habits, des chevaux et des armes offerts à Guillebert et aux hommes de sa suite ${ }^{113}$. Ceux-ci passent neuf jours aux côtés du prince lituanien, avant de traverser la Valachie et la Moldavie, accompagnés par les hommes du grand-duc, pour rejoindre Caffa, en Crimée, puis Constantinople.

\footnotetext{
106 Ibid., p. 51.

107 Sur les projets de croisade bourguignons et leur rôle dans la politique de Philippe le Bon, O. MARIN, "Filip Dobrý, Burgundsko a křížové výpravy», dans Guillebert de Lannoy, Cesty a poselstva..., p. 42-71; J. Paviot, Les Ducs de Bourgogne..., p. 117-176; J. Jefrerson, The Holy Wars of King Wladislas and Sultan Murad, Leiden 2012, p. 299-301.

108 J. Svátek, Discours..., p. 55-56; les activités d'espionnage de Guillebert se concentrent plus sur les régions proches de la Terre sainte, dominées par les Turcs et les Mamelouks.

109 Potvin, p. 52.

110 Id.

111 Potvin, p. 53. La visite de Guillebert (nommé Guillaume, Vilhelmus) est mentionnée par Jan Długosz, Annales XI, dans Opera Omnia...vol. 13, p. 273-274. Voir J. Svátek, Discours..., p. 264-265, n. 310 .

112 Potvin, p. 55; l'ambassade était faite au nom du roi d'Angleterre, institué héritier du royaume de France à la mort de Charles VI par le traité de Troyes (Ibid, p. 53, n. 5). On peut avoir une idée de ce qu'étaient ces «joyaulx» en se rapportant au texte de Jan Długosz, Opera Omnia..., vol. 13, p. 273.

${ }^{113}$ Potvin, p. 56-57.
} 
On ne sait pas combien de temps notre voyageur passa auprès des Chevaliers teutoniques, et le fait qu'il raconte avec bien plus de détails ses séjours polonais et surtout lituanien tient aux énumérations des dons qu'il y reçut, et aux aventures qu'il dit y avoir vécu en approchant la mer Noire. Toutefois, on peut déduire de son compte-rendu que la Lituanie, tout comme la Pologne, devait jouer un rôle tout aussi important que l'État des Teutoniques dans les plans de croisades élaborés par les Bourguignons. Alors qu'au début de son premier voyage (1413-1414), la préférence de Guillebert allait aux "seigneurs de Prusse» ${ }^{14}$, il semble accomplir son ambassade de 1421 de manière plus neutre. Du reste, Vytautas apparaît comme tout aussi bienveillant que son royal cousin, respectant les règles d'hospitalité et mettant ses ressources à disposition pour aider l'ambassadeur venu de l'Ouest.

Le temps où la Lituanie était un pays «sarrasin", contre lequel marchaient les croisés, semble doncbien loin ${ }^{115}$. En 1429, une année avant sa mort, Vytautas est admis dans l'Ordre du Dragon, que Sigismond de Luxembourg avait fondé en 1408, dans le but de réunir les tenants de la lutte contre les Ottomans. Le grand-duc reçoit le privilège d'y enrôler d'autres seigneurs, et sa femme, Juliana, devient également membre de l'Ordre, ce qui en fait la seule représentante de sexe féminin avec l'épouse de l'empereur ${ }^{116}$. Avec leurs grands-ducs successifs, les nobles lituaniens se sont progressivement intégrés au mouvement paneuropéen de croisade $^{117}$. En 1482, les palatins de Vilnius et de Trakai sont nommés parmi les destinataires d'une lettre de Sixte IV concernant la croisade contre les Turcs ${ }^{118}$, et deux ans plus tard, le staroste de Samogitie affirme au grandmaître se tenir prêt à défendre la Chrétienté aux côtés des Teutoniques ${ }^{119}$. La Lituanie devenue un athlète zélé du christianisme, ses rivaux se trouvent naturellement dépeints comme des ennemis de la foi ${ }^{120}$ : en 1500 , le grand-duc Alexandre entend fonder un ordre de chevalerie censé se consacrer à la lutte contre Moscou "et d'autres infidèles» ${ }^{121}$. Ambitions politiques et adaptation du style venu d'Occident au contexte local ne pourraient mieux se confondre.

\footnotetext{
114 J. SvÁTEK, Discours..., p. 262-265.

115 W. Paravicini, «Litauer...", p. 253, situe le processus d'intégration de la Lituanie à l'Europe chrétienne dans une période s'étendant de la fin du XIv siècle aux années 1430-1450.

116 R. Petrauskas, "Knighthood...», p. 54-55. Les privilèges accordés au Lituanien tiennent peut-être des tentatives de rapprochement entre celui-ci et Sigismond: Z. Kiaupa, J. Kiaupienė, A. Kuncevičius, The History of Lithuania before 1795..., p. 157-159.

117 R. Petrauskas, «Knighthood...», p. 53; W. Paravicini, «Litauer...», p. 270.

118 Brevia Romanorum Pontificum ad Poloniam, éd. H. Wojtyska, Rome 1986, p. 52, cité par R. Petrauskas, «Knightood...», p. 53.

119 Geheimes Staatsarchiv Preussischer Kulturbesitz, Berlin, PK, OBA 17114, cité par R. Petrauskas, "Knighthood...", p. 53, n. 66.

${ }^{120}$ D. Baronas, "Christians in Late Pagan...», p. 70; O. Halecki, «La Pologne et la question d'Orient de Casimir le grand à Jean Sobieski», dans La Pologne au VII congrès..., p. 434-437.

121 J. Caro, Geschichte Polens, vol. 5/2, Gotha 1888, p. 1022-1024, cité par R. Petrauskas, «Knighthood...», p. 54-55.
} 
La Lituanie comme partenaire et alliée des puissances chrétiennes apparait dans quelques romans français, et ceci quasiment dès les années qui suivent la conversion de 1387. Le premier auteur à mettre en scène une Lituanie intégrée aux projets de croisade paneuropéenne est sans doute Philippe de Mézières, qui avait à cœur de réunir les princes chrétiens dans une grande entreprise de libération de la Terre sainte. Rappelons que ce cadet d'une famille de la petite noblesse picarde se distingue par ses activités littéraires, mais aussi politiques. Ayant été le chancelier du roi de Chypre Pierre de Lusignan (mort en 1369), il devient conseiller à la cour de Charles V, qui lui confie entre autres l'éducation du dauphin, le futur Charles VI ${ }^{122}$. En 1380, il se retire au couvent des Célestins, à Paris, mais ne reste pas inactif ${ }^{123}$. Il travaille notamment à la création de son Ordre de la Passion de Jésus-Christ, qu'il rêve en fer de lance de la reconquête de la Terre sainte. Ayant lui-même participé lorsqu’il avait une vingtaine d'année à l'expédition du prince savoyard Humbert II du Viennois en 1347 contre Smyrne, où il fut fait chevalier ${ }^{124}$, puis à la croisade menée par Pierre de Lusignan contre Alexandrie en 1365, Philippe déplore que ces victoires n'aient pas été suivies d'effets durables. La faute, dénonce-t-il, à la désunion entre les princes chrétiens, et à la légèreté des croisés, qui se retirent aussitôt la victoire obtenue ${ }^{125}$. À ses yeux, seule une entreprise de grande envergure permettrait de libérer la Terre sainte et de mettre fin à l'expansion turque en Europe. Pour ce faire, la paix doit régner sur la Chrétienté; aussi Mézières placet-il beaucoup d'espoir dans les jeunes rois de France et d'Angleterre, Charles VI et Richard II ${ }^{126}$.

\footnotetext{
122 Philippe de Mézières, Le Songe du vieil pèlerin, trad. J. Blanchard, Paris 2008, p. 18-19; Idem, Une Epistre lamentable et consolatoire, éd. P. Contamine et J. Paviot, Paris 2008, p. 29-30.

${ }^{123}$ Tout en continuant de conseiller le roi Charles VI, il entretient de bons rapports avec le frère de ce dernier, Louis d'Orléans, et avec le roi d'Arménie, Léon de Lusignan, réfugié à la cour de France, et qui essaye de convaincre les princes chrétiens de le rejoindre dans une grande croisade; Blanchard, p. 19-20; J. РAviot, Les Ducs de Bourgogne..., p. 18-24.

124 Sur la vie de Philippe de Mézières, N. Iorga, Philippe de Mézières... (ici, p. 13; p. 29-32 passim.) ; A. Dupront, Le mythe de croisade, Paris 1997, vol. 1, p. 256-298; J. JaKštas, Das Baltikum..., p. 160 sq.; et les articles réunis dans R. Blumenfeld-Kosinki et K. Petkov (dirs.), Philippe de Mézières and his Age..., et dans J. Blanchard, R. Blumenfeld-Kosinski (dirs.), Philippe de Mézières et l'Europe...

125 J. Williamson, "Philippe de Mézières and the Idea of Crusade», dans Military Orders, vol. 1, p. 358-364; Blanchard, p. 15.

126 Une paix est signée en juin 1389 entre les deux souverains, l'année où Mézières rédige son Songe du vieil pelerin; A. Curry, "War or Peace? Philippe de Mezieres, Richard II and AngloFrench Diplomacy", dans Philippe de Mézières and his Age..., p. 305-306. Sur l'idéologie de Philippe de Mézières, P. Buc, "L'Epistre lamentable au regard de l'exégèse et de la tradition des croisades", dans J. Blanchard, R. Blumenfeld-Kosinski (dirs.), Philippe de Mézières et l'Europe, p. 205-220; M. GŁodek, Utopia Europy zjednoczonej. Życia i idee Filipa de Mézières (1327-1405), Słupsk 1997. L'idée d'établir la paix entre les États chrétiens pour pouvoir mener une résistance efficace contre les Turcs reste l'un des grands axes de la pensée politique jusqu'au début du $\mathrm{XVI}^{\mathrm{e}}$ siècle; par exemple Erasme de Rotterdam, La Formation du prince chrétien.
} 
Son œuvre majeure, Le Songe du vieil pelerin (1389), représente le programme politique de Mézières ${ }^{127}$. Dans les livres II et III, les personnages allégoriques se retrouvent en France après avoir parcouru le monde. La Reine Vérité y tient de longs discours au "jeune Moyse», autrement dit Charles VI, à qui est dédié le roman ${ }^{128}$. C'est l'occasion pour l'auteur de délivrer ses idées quant au «saint passage d'outremer", qui devra réunir toute la Chrétienté dans un même effort, afin de ne pas se solder de manière aussi pitoyable que les croisades auxquelles il a participé dans sa jeunesse. La première exigence est de conclure la paix entre les royaumes chrétiens, tâche qui revient au roi de France ${ }^{129}$. C'est dans ce but que l'on devra envoyer des ambassadeurs auprès de "tous les seigneurs du monde», y compris au "souldam de Babilone [Égypte]", au "Grant Caan de Tartarie» et "aus seigneurs de Thurquie» ${ }^{130}$. Il s'agira ensuite de conclure "bonne pais, ou si longues trives qui la vaille» avec l'Angleterre ${ }^{131}$, de préparer les troupes françaises et d'aviser "tous les roys, princes et seignouries de la Crestienté» par le truchement des ambassadeurs, "en requerant [...] qu'il se veullent disposer au service de Dieu» ${ }^{132}$ - en clair, qu'ils se préparent à la croisade. Celle-ci doit commencer, précise Philippe, par un message adressé au sultan d'Égypte, pour qu'il soit "honestement amonestés qu'il doie rendre et de fait la saincte cité de Jherusalem et toute la Terre Saincte, le royaume d'Armenie et tout ce qui appartient a la Crestienté»" ${ }^{133}$. Et si le sultan ne donne pas satisfaction, "vous procederés au service de Dieu, selonc ce que par sa sainte grace il vouldra doulcement inspirer»" ${ }^{134}$.

Le temps est venu pour Philippe de décrire l'assaut gigantesque des chrétiens en armes, qui fondront sur les puissances musulmanes, dans un effort parfaitement coordonné. Ici, comme lors de la description des ambassades, la Lituanie chrétienne fait son apparition dans une note de Philippe lui-même, ajoutée en marge du manuscrit "matrice ${ }^{135}$. On y lit que les Lituaniens, désormais chrétiens suite au mariage de Jagellon avec Hedwige de Pologne, accompagneront leurs anciens adversaires dans le grand mouvement vers la Terre sainte: "Et les signeurs de Prusse aveuc le roy de Laito [Lituanie] a toute leur poissance en conquestant a la foy catholique passeront parmy le roiame de Russie et

\footnotetext{
Institutio principis christiani, éd., trad. et introduction de M. Turchetti, Paris 2015, p. 43-70; P. Buc, Guerre sainte..., p. 53-54 passim.

127 M. Radkovska, "Le Songe du vieil pelerin: l'idée de croisade rêvée et vécue chez Philippe de Mézières ", dans M. NejedLÝ, J. Svátex (dirs.), La noblesse et la croisade..., p. 32-33.

128 D. Delogu, "How to become the "Roy des Frans" ", dans R. Blumenfeld-Kosinki et

K. Petкov (dirs.), Philippe de Mézières and his Age..., p. 148.

129 Blanchard, vol. 2, p. 1258-1259.

${ }_{130}$ Ibid., p. 1260-1261.

131 Ibid., p. 1268.

132 Ibid., p. 1272.

133 Ibid., p. 1280.

${ }_{134}$ Id.

135 Arsenal 2683. Voir chapitre V.
} 
des païs d'utour en venant vers Constantinople et se adjousteront aveuc les Allemans pour reprimer la poissance des Turs» ${ }^{136}$.

Ainsi, tout comme la France et l'Angleterre, la Lituanie et l'Ordre teutonique se trouvent réunis dans la paix et peuvent travailler ensemble à la lutte contre les infidèles. Il est vrai que des princes lituaniens ont souvent combattu un ennemi commun de concert avec les Teutoniques. Mézières a-t-il entendu des chevaliers de passage à la cour relater les entreprises menées par le grand-duc au tournant du siècle $e^{137}$ ? Quoi qu'il en soit, force est de remarquer qu'il considérait la Lituanie comme un partenaire chrétien, avec lequel on doit compter ${ }^{138}$. Un honneur qui n'est pas réservé aux chrétiens orthodoxes d'Orient et des Balkans, qui comptent plutôt parmi les adversaires que parmi les alliés des croisés, puisque parmi ceux-ci, "le roy de Honguerie et de Behaigne [Bohême] et l'Empereur, s'il y sera, et la puissance des Alemans alassent par terre tout droit en Constantinoble, en recouvrant a la foy catholique et obeissance de l'Église de Romme le royaume de Rasse ${ }^{139}$, l'empire de Boulgarie et l'empire de Constantinoble» ${ }^{140}$. Au moment où Mézières a ajouté la note marginale concernant la Lituanie, la place du pays dans le camp catholique était, pour lui, clairement établie; la "gent sans lettre et sans clergie, mais assés bien combatans ${ }^{141}$ de la première partie du Songe s'est par l'effet du baptême transformée en athlète du Christ, animé du zèle des néophytes ${ }^{142}$.

De quoi rappeler les souhaits du pape de Rome qui essayait d'organiser une croisade à la tête de laquelle devait se trouver Jagellon, roi de Pologne et grand-duc de Lituanie, réconcilié avec les Chevaliers teutoniques. Aussi Giedre Mickūnaitė relie-t-elle ce passage de Mézières, dont les idées étaient bien en vue à la cour du roi anglais Richard II, à un extrait de la Chronica Maiora de Thomas Walsingham, qui sous l'année 1401 rapporte cette nouvelle parvenue en Angleterre par le truchement de marchands grecs: un certain "rex de Letto» se serait converti au christianisme après avoir ravagé les environs de Jérusalem et défait le prince "Bassak, fils de Baltazardan". Ce dernier, placé parmi les ennemis de l'empereur byzantin, peut être le

\footnotetext{
136 Blanchard, vol. 2, p. 1273.

137 L'auteur étant mort en 1405, il n'a pas pu être tenu informé de l'expédition contre Moscou de 1406, à laquelle ont participé les hérauts Bourgogne et Hollande. Néanmoins, on sait que la cour de France avait été informée de la christianisation de la Lituanie par Jean de Strate, émissaire du roi de Pologne et membre de l'Ordre teutonique. Mézières a donc pu retenir l'information, et ajouter ainsi la Lituanie aux puissances croisées en même temps qu'il a noté le baptême du pays, quelques folios plus haut.

138 J. Jakštas, Das Baltikum..., p. 175-176; W. Paravicini, «Litauer...», p. 258.

${ }_{139}$ Il s'agit probablement de la Rascie, nom donné à une partie de la Serbie médiévale.

140 Blanchard, vol. 2, p. 1273; sur le traitement des chrétiens orthodoxes dans le projet de Mézières, J. Svátek, "Guillebert de Lannoy, un seigneur bourguignon espion", dans M. Nejedlý, J. Svátek (dirs.), La noblesse et la croisade..., p. 91-92.

141 Blanchard, vol. 1, p. 207.

142 J. JakšTas, Das Baltikum..., p. 176.
} 
sultan ottoman Bajazet, le vainqueur de Nicopolis ${ }^{143}$. L'écho des premières campagnes de Tamerlan en Turquie et les rumeurs sur sa conversion au christianisme se mêlent sans doute aux nouvelles concernant la lointaine Lituanie et son prince ${ }^{144}$. Peut-être que le programme élaboré par Mézières a renforcé cette tendance, mais on remarque qu'un certain nombre d'auteurs considèrent de plus en plus le Lituanien comme un partenaire potentiel du combat contre les Turcs ${ }^{145}$.

\section{LA MENACE TATARE: UN NOUVEAU FRONT DE CROISADE}

Une croisade internationale rassemblant tous les pays de la Chrétienté est mise en scène par Antoine de la Sale dans son roman Jean de Saintré, achevé en 1456. Contrairement à ce qu'imaginait Mézières, elle n'a pas pour terrain d'action le Proche-Orient mais l'Europe orientale, puisque son point de départ est la Prusse. La corporation chevaleresque par excellence qu'est l'Ordre teutonique joue le rôle d'organisateur de la croisade, qui ressemble fort à une rèse gigantesque ${ }^{146}$, dirigée contre une coalition de princes infidèles digne de rivaliser avec celle que mène le roi Marsile, adversaire de Charlemagne dans la Chanson de Roland ${ }^{147}$ :

"De la partie des Sarrasins estoient la plus grant armee que jamais, depuis la loy de Mahommet, ilz eussent faite, car tous les souldans, les roys, les seigneurs des troiz regions [Asie majeure, Perse ou Turquie, Syrie] [y furent] ... . Et de ces troiz regions a celle battaille furent tant de roys, de seigneurs et de peupple que toute la terre en estoit couverte, penssans concquerir le surplus. $»^{148}$

Un tel rassemblement de Sarrasins n'est pas sans rappeler le passage en revue des troupes de Bajazet par Froissart, au moment où il décrit la bataille

\footnotetext{
143 Walsingham, vol. 2, p. 310.

144 Ibid., p. 38. D'après Walsingham, cette nouvelle est parvenue à l'empereur Manuel de Byzance lors de sa visite en Angleterre, en hiver 1400-1401. Comme le rappellent les éditeurs de la Chronica Maiora, il ne saurait s'agir d'un compte-rendu de la capture de Bajazet à la bataille d'Ankara (1402), mais plutôt des premiers succès de Tamerlan face aux forces ottomanes (Ibid.., p. 310-311, n. 437). Ces événements étaient connus des chroniqueurs français, comme Michel Pintoin ou le biographe de Boucicaut: M. Rodinson, La fascination..., p. 188.

145 G. Mickūnaité, Making..., p. 38-40, 88-89, n. 123.

146 Sur ce point, on peut sans doute donner raison à F. PALL, "Bazgazul”, domn al Valahiei, într-un roman francez din secolul al XV-lea», Studii. Revista de Istorie 11/1, 1958, p. 95, pour qui la bataille est inspirée par les rèses du XIv ${ }^{e}$ siècle, auxquels ont participé le vrai Jean de Saintré et d'autres personnages du roman, dont Boucicaut; voir aussi V. Agrigoroaei, "Bazgazul, seigneur de Ballaquie. À la recherche du valaque musulman de steppe", Studia Patzinaka, 4, 2007, p. 197-198.

147 Pour K. KțAvin̦š, «Le tracé de l'identité européenne...", p. 102, l'expédition prussienne de Jean de Saintré se situe "dans la tradition de la Chanson de Roland».

${ }_{148}$ Blanchard, Quereuil, p. 372-374.
} 
de Nicopolis ${ }^{149}$. Tout comme le chroniqueur hennuyer faisait figurer les "Lectuaires" [Lituaniens] entre les "Sarrazins, payens, Persains, Tartres, [...], Turs et Suriens»" ${ }^{150}$, Antoine de la Sale n'hésite pas à mêler des populations d'Europe orientale non-musulmane à sa coalition "sarrasine»: "En la .iij.me battaille furent les roys de la grant Ermenie, de Fex et de Allappie; et Bagazul, seigneur de Ballaquie, qui avoient . $x l^{m}$. chevaulx et de troiz a quatre cens milles hommes a piet, de Hermenie, de Barbarie, de Russie, et de Samate, et de Tartarie, que toute la terre converte en estoit» ${ }^{151}$. Le personnage de $\mathrm{Ba}(\mathrm{z})$ gazul, seigneur de Balaquie, ressemble à une cristallisation de plusieurs princes balkaniques, chrétiens orthodoxes devenus "sarrasins" pour le besoin du roman ${ }^{152}$. La région appelée "Samate», d'où Bagazul et les siens ont tiré une partie de leurs troupes, pose un problème intéressant: pour Vladimir Agrigoroaei, il pourrait s'agir de la Samogitie ${ }^{153}$, nommée "Sammette» par Guillebert de Lannoy ${ }^{154}$, "Salmete» dans la Chronique de Metz ${ }^{155}$ et "Sameth» dans la Chronique de Saint Thiébaut de Metz ${ }^{156}$. Cette région située entre la Russie et la Tartarie pourrait aussi rappeler la Sarmatie, nom que la tradition classique donnait à l'Europe orientale ${ }^{157}$. Comme à d'autres occasions, nous sommes probablement devant un cas de confusion ou d'amalgame de plusieurs désignations, qui est peut-être ici un rappel du caractère "sarrasin" de la Samogitie, restée païenne plus longtemps que le reste du grand-duché. Si l'hypothèse est correcte, on serait face à une attestation du souvenir des rèses se déroulant précisément dans cette région, et ceci près de quarante ans après son évangélisation à l'époque du Concile de Constance.

\footnotetext{
149 "Sus le commandement et pryère du souldan, du caliphe de Baudas et de l'Amorath-Bacquin s'enclinèrent plusieurs roys sarrazins, et descendirent ces pryères et mandemens jusques en Perse, en Mède et en Tarse, et d'autre part sur le septentrion ou royaulme de Lecto [Lituanie] et tout oultre jusques sur les bornes de Prusse", Jean Froissart, Chroniques..., éd. J. Kervyn de Lettenhove, vol. 15, p. 263.

150 Ibid., p. 324.

151 Blanchard, Quereuil, p. 378.

152 V. Agrigoroaei, «Bazgazul...", p. 195-218, identifie plusieurs souverains valaques connus des auteurs latins ayant pu se confondre dans le même $\mathrm{Ba}(\mathrm{z})$ gazul, ennemi de la Chrétienté catholique: Jean Kalojan, prince des Bulgares et des "Blachi» (m. 1207), Basarab I ${ }^{\text {er }}$, prince de Valachie (m. 1352) et Alexandre le Bon (m. 1432), voïvode de Moldavie ayant fourni un contingent à l'armée polono-lituanienne à Tannenberg.

153 V. Agrigoroaei, «Bazgazul...», p. 201-203. Pour l'identification des autres régions vassales de Bagazul, ibid., p. 203-205.

154 Potvin, p. 28, 29.

155 Wolfram, p. 337.

156 Chronique ou Annales du Doyen de S. Thiébaut de Metz, SRP 3, p. 455.

157 Voir la description de la guerre entre l'Ordre teutonique de la Pologne (1409-1410) dans Douët d'Arcq, vol. 2, p. 75: "Au devant desquelz vint tantost à l'encontre le Roy d'icellui royaume [Lituanie], et avecques lui le roy de Sarmac ... [parmi les morts:] l'admiral de Lictuaire et le connestable de Sarmach». Un autre exemple de confusion peut être la lettre envoyée par le roi Sigismond de Hongrie aux princes d'Europe occidentale et centrale en août 1410, et qui parle de "paganorum rabidorum Littuanorum, Samartanorum, Rutenorum et Tartarorum» (SRP 3, p. 403).
} 
La Lituanie proprement dite est quant à elle bien présente dans la bataille, mais du côté des chrétiens ${ }^{158}$. Une longue liste des participants français, avec mention des armoiries et des cris de guerre ${ }^{159}$, ouvre la description de «ce tressaint passaige de Prusse» ${ }^{160}$, puis l'auteur énumère les princes, seigneurs et prélats impériaux "qui y furent» ${ }^{161}$, parmi lesquels, bien sûr, "le maistre de Prusse et tout l'Ospital, .iiij ${ }^{\text {m. }}$ chevaulx,.$i j^{m}$. hommes de trait et . $v^{\text {m. combatans a }}$ piet ${ }^{162}$. Suivent les représentants des empereurs d'Allemagne, Constantinople, Trébizonde et Bulgarie ${ }^{163}$, puis "le roy de Behaigne [Bohême] en personne»" avec de nombreux princes de sa compagnie, et "le duc de Lettonen, pour le roy de Pollayne, qui portoit de geulles au cheval d'argent, chevauchié d'um homme d'or armé, tenant une espee d'argent ou poing, croisee et pommee d'or", avec les ducs, comtes et seigneurs de sa suite ${ }^{165}$.

Les armoiries attribuées au "duc de Lettonen [Lituanie]» dans cet extrait correspondent au symbole utilisé sur les sceaux des grands-ducs, attesté depuis Algirdas en $1366^{166}$. À partir du moment où Jagellon devient roi de Pologne, le cavalier monté sur un cheval blanc fait son apparition aux côtés de l'aigle polonais sur le blason royal écartelé de Pologne et de Lituanie, dans le cérémonial de cour ou sur les pièces de monnaie. L'ancien emblème des princes païens est adapté au style héraldique en vigueur dans le monde catholique ${ }^{167}$.

158 A. Grabski, Polska w Opiniach Europy..., p. 186. C'est l'un des arguments qui permettent à V. Agrigoroaei, «Bazgazul...», p. 197-198, de réfuter l'interprétation selon laquelle la bataille est une réminiscence de Tannenberg; en effet, si les principaux protagonistes sont présents, les Polonais et les Lituaniens figurent pour La Sale dans le camp chrétien, ce qui est en contradiction avec les récits de Tannenberg connus en France.

159 Blanchard, Quereuil, p. 336-372; l'hypothèse que l'auteur se soit inspiré d'un recueil héraldique est discutée par P. KNudson, «Saintré’s Prussian Expedition... », p. 271-277.

160 Blanchard, Quereuil, p. 332.

${ }_{161}$ Ibid., p. 368-372.

162 Ibid., p. 368.

163 Ces trois derniers étant curieusement placés du côté des Latins; pour V. Agrigoroaei, "Bazgazul...", p. 198, l'empereur de Bulgarie est une allusion au titre de Basileus, que portaient les souverains bulgares à partir de Jean Kalojan (m. 1207).

164 Blanchard, Quereuil, p. 370.

165 Ibid., p. 370.

166 D. Baronas, S. C. Rowell, The Conversion..., p. 283; J. Galkus, Lietuvos Vytis / The Vytis of Lithuania, Vilnius 2009, p. 13-15, qui note que de nombreux princes et seigneurs se faisaient représenter à cheval, l'épée dégainée; l'adoption d'un tel symbole par Algirdas peut avoir été influencée par les standards occidentaux ou russes.

167 Ibid., p. 15-16. Un traité géographique et héraldique castillan datant des années 1340-1350, le Libro de Conoscimento de todos los reynos, attribuait une étoile à six branches comme armoirie au "roi de Litefamia" [Lituanie]; Book of knowledge of all the kingdoms, lands, and lordships that are in the world, éd. et trad. C. R. Markham, Londres 1912, p. 8, fig. 11. L'étoile à six branches, également attribuée à quelques souverains musulmans ou orthodoxes, peut être un rappel du caractère "étranger" de la Lituanie; toutefois, on ne saurait y voir un lien avec le judaïsme, puisque ce n'est qu'en 1356 et uniquement à Prague que ce symbole a été adopté comme drapeau de la communauté juive. Voir G. Scholem, "The Curious History of the 
Dans le grand-duché, Vytautas utilise volontiers le cavalier sur ses sceaux et bannières: d'après Długosz, les étendards lituaniens déployés à Tannenberg présentent ce symbole, avec quelques variantes ${ }^{168}$. Les armoiries lituaniennes ont également été exposées au concile de Constance et recopiées à deux reprises par le chroniqueur Ulrich de Richental, et se trouvent dans des armoriaux du $\mathrm{Xv}^{\mathrm{e}}$ siècle, ceux de Bergshammar (Suède, 1436) et de Gymnich (Flandre, $1445)^{169}$. Le court passage d'Antoine de la Sale atteste qu'un écrivain français de la moitié du siècle, très versé dans l'héraldique, connaissait lui aussi les armoiries du grand-duché.

Dans Jean de Saintré, ce prince lituanien croisé, peut-être une réminiscence de Vytautas, joue un rôle non négligeable dans la victoire chrétienne. L'avantgarde est composée de "la baniere de France, celle de l'ordre de Prusse, celles des cincq prelas, avec celles de certains ducz, contes, princes et barons allemans, avec celles des Engloiz». L'aile droite est confiée au roi de Bohême, l'aile gauche au duc de Lituanie: "le duc de Lettonen, avec la banyere du roy de Pollayne, dont il avoit la charge, et sa compaignie, qui estoient . $x^{\text {m. }}$. chevaulz, feroient l'autre elle au senestre $\operatorname{costé»}^{170}$. Une fois la bataille engagée, le roi de Bohême et le duc de Lituanie viennent en aide à l'avant-garde, dont les combattants français, Jean de Saintré en tête, ont déjà défait "le Turcq", maître de l'armée sarrasine ${ }^{171}$ :

"Pour assembler ilz [les Sarrasins] venoyent; mais ad ce cop fust heure que, pour secourir l'avant-garde qui treslasse estoit, le roy de Behaigne et sa battaille, qui faisoit une des elles, de l'un des leez, et le duc de Lettonem, qui ... faisoit l'autre elle, de l'autre leez, et qui la baniere de Pollayne gouvernoit, les vindrent tellement hurter que tous passerent jusques aux banyeres, dont l'une fut portee a terre. ${ }^{172}$

Plus qu'un allié secondaire, le duc lituanien devient ici l'un des artisans de la défaite infligée aux Sarrasins, sorte d'anti-Nicopolis dont on pouvait encore rêver au milieu du $\mathrm{Xv}^{\mathrm{e}}$ siècle ${ }^{173}$. Discutant l'hypothèse faisant de la bataille un écho du célèbre Tannenberg ${ }^{174}$, V. Agrigoroaei remarque que

Six-Pointed Star. How the "Magen David" Became the Jewish Symbol», Commentary 8, 1949, p. 243-251; S. C. Rowell, Lithuania Ascending..., p. 32-33.

168 Jan Długosz, Annales XI, dans Opera Omnia..., vol. 13, p. 41-42; J. Galkus, Lietuvos Vytis..., p. 18-19.

169 Ibid., p. 21-23; l'original de la chronique illustrée de Richental est perdu, mais plusieurs copies ont été exécutées au xv siècle. On peut y voir deux blasons attribués à Vytautas, dont l'un présente le cavalier blanc, et les armoiries de Jagellon, écartelé de Pologne et de Lituanie: Ulrich de Richental, Chronik des Konzils zu Konstanz..., fol. 135v, 137v.

${ }_{170}$ Blanchard, Quereuil, p. 374-376.

${ }_{171}$ Ibid., p. 378 sq.

172 Ibid., p. 382.

${ }^{173}$ Antoine de la Sale, Jean de Saintré: A Late Medieval Education in Love and Chivalry, trad.

R. L. Krueger, J. H. M. Taylor, Philadelphia 2014, p. XXI .

${ }^{174}$ Id.; F. Pall, "Bazgazul”...", p. 95. 
dans le roman, Pologne et Lituanie se trouvent dans le camp chrétien: "pour un français $d u X V^{*}$ siècle elles étaient des terres catholiques, bien comprises entre les frontières de la vraie foi soutenue par les efforts de la Papauté»" ${ }^{175}$. Il n'est pas à exclure que l'affrontement épique décrit par Antoine de la Sale soit une réminiscence tournée en positif des grandes défaites "chrétiennes» de la fin du Moyen Âge, Nicopolis et Tannenberg en tête, mais l'on doit remarquer que les Lituaniens, encore considérés comme infidèles et assimilés aux Turcs par Michel Pintoin ou Enguerrand de Monstrelet, sont devenus de solides alliés de la chevalerie chrétienne. Comme dans le projet de Philippe de Mézières, Teutoniques et Lituaniens se battent côte à côte pour la cause de la Chrétienté, unis derrière la bannière du royaume de France, représenté en l'occurrence par Saintré et les siens.

Plus que jamais, le caractère chrétien de la Lituanie est établi, et confirmé par l'identification de l'adversaire contre qui cette rèse géante se met en marche. En effet, un glissement apparaît à partir du milieu du $\mathrm{Xv}^{\mathrm{e}}$ siècle, où l'ennemi principal des croisés de Prusse, quand il est nommé, n'est plus lituanien mais turc ou tatar. De la même manière qu'Antoine de la Sale fait combattre les Lituaniens, les Teutoniques et leurs hôtes contre une coalition de musulmans et de schismatiques, le héraut Berry donne des adversaires clairement définis aux chevaliers qui allaient en Prusse «devant les guerres de France» ${ }^{176}$ :

"Ou moys de février partoient de Pruce, et [...] entroient au païs de Tartarie [...] Et quant ilz sont en Tartarie ilz boutent feux par les pays, et font de domaige beaucoup. Puis s'en retournent avant que les glaces fondent qu'ilz ne porroient résister contre la puissance du grant Can de Tartarie. " ${ }^{177}$

Cette scène de guerre en pays tatar peut faire écho à un célèbre texte composé une centaine d'années plus tôt, le Livre des merveilles de Jean de Mandeville (v. 1356-7). Le visage que l'auteur prête aux adversaires des croisés de Prusse interdit de les identifier sans équivoque aux seuls Lituaniens. Lors de la courte description des rèses que Mandeville donne en évoquant les différents chemins de pèlerinage pour Jérusalem, il précise qu'une fois "les christiens qe y vont touz les aunz pur combattre» entrés dans "la terre de Sarazins habitable», ils sont aisément repérés par des espions: "Et quant ly espeyes voient ly christiens venir sur eux, ils corrent as villes et crient a haute voiz: "Kera, Kera, Kera", et tantost ils s'arment et s'assemblent» ${ }^{178}$. Dans la partie de son Livre consacrée à l'Empire mongol, Mandeville précise que ces redoutables guerriers des steppes "alerent gaigner mointe païs et mointe regioun jusqes a la terre de Prusse et de Rossie et se

75 V. Agrigoroaei, «Bazgazul...», p. 214.

176 Hamy, p. 116.

177 Ibid., p. 117.

${ }^{178}$ Jean de Mandeville, Le livre des merveilles..., p. 268. 
firent appeler Chan ${ }^{179}$. Il n'y aurait donc rien d'étonnant à ce que l'auteur, qui dit avoir voyagé "en la terre de Russie, et en la terre de Niflan, et el roialme de Crake et de Leto " ${ }^{180}$ mais ne précise pas avoir participé à une rèse, ait donné les Tatars comme adversaires aux chrétiens de Prusse. Une hypothèse à laquelle se rallie Walter Xavier, pour qui le «Kera, Kera, Kera» poussé par les "Sarrasins» dont il est question ne serait autre qu'un cri de guerre mongol ${ }^{181}$.

Le très populaire récit de Mandeville a-t-il influencé Berry et La Sale pour leurs mises en scène de rèses parties de Prusse mais dirigées contre les Tatars, les descendants des Mongols convertis à l'islam au XIv e siècle? On ne saurait l'exclure $^{182}$. Il existe toutefois une autre possibilité, en aucun cas contradictoire. $\mathrm{Au}$ lendemain de la bataille de Tannenberg, et surtout lors du concile de Constance, l'Ordre teutonique insistait sur la participation des auxiliaires tatars à l'invasion lituano-polonaise de la Prusse. Les chroniqueurs Michel Pintoin et Enguerrand de Monstrelet ont, eux aussi, bien noté ce fait, au point que le premier qualifiait les adversaires des Teutoniques de "Turcs»" ${ }^{183}$. Alors que les Lituaniens - Samogitiens mis à part - étaient déjà connus comme chrétiens, les Tatars constituaient sans doute des ennemis bien plus crédibles. Et leur puissance n'a pas été démentie au cours des premières décennies $\mathrm{du} \mathrm{Xv}^{\mathrm{e}}$ siècle: leurs raids sur les marges orientales de la Lituanie, et jusqu'en Pologne, n'avaient rien à envier aux expéditions menées par leurs coreligionnaires turcs dans les Balkans. Alors que face à ces derniers, la Hongrie était perçue comme le bouclier de la Chrétientée ${ }^{184}$, ce rôle était attribué, pour l'Europe orientale, aux Chevaliers teutoniques et à la Lituanie chrétienne, mais peut-être plus souvent encore à la Pologne.

Le Livre de la description des pays du héraut Berry, composé autour de 1451 mais qui ne mentionne pas la défaite subie par la coalition polono-hongroise à Varna $(1444)^{185}$, fait de la Pologne un pays aux prises avec toutes sortes de pillards sarrasins ou pirates catalan ${ }^{186}$ :

\footnotetext{
179 Ibid., p. 385.

180 Ibid., p. 266-267.

181 X. Walter, Avant les grandes découvertes..., p. 337. Juste avant de parler de la Prusse et de la Lituanie, Mandeville avait décrit le pays des Tatars (Jean de Mandeville, Le livre des merveilles..., p. 265-266), ce qui peut renforcer la confusion entre les différents "Sarrasins» de la région.

182 A. V. Murray, "Saracens...", p. 413-429, considère que c'est Mandeville qui a popularisé l'identification des Lituaniens comme Sarrasins.

${ }^{183}$ Monstrelet fait non seulement figurer les «Tartarins» dans l'armée polono-lituanienne (Douët d'Arcq, vol. 2, p. 62), mais parle encore du «roy» et du «connestable de Sarmac(h)» (Ibid., p. 75), ce qui peut être un amalgame entre la Samogitie et la Sarmatie antique; G. MicKūnaité, Making..., p. 42.

184 N. Housley, Crusading and the Ottoman Threat..., Oxford 2013, p. 40-50.

${ }^{185}$ Le héraut Berry a sans doute visité la Hongrie en 1443, soit juste avant la célèbre bataille (Hamy, p. 8-9); il note toutefois que les Hongrois font «souvent grant guerre aux Sarazins» (Ibid., p. 98).

${ }_{186}$ Commentant la question des preneurs d'esclaves, A. Grabski (Polska w Opiniach Europy..., p. 39-40, n. 65) suppose que Le Bouvier fait référence aux victimes ruthènes, parmi lesquels pouvaient se trouver des sujets de Casimir IV, roi de Pologne et grand-duc de Lituanie.
} 
"Les Sarazins et les Castelans qui sont subgetz du roy d'Aragon viennent souvent descendre en son pä̈s [au roi de Pologne], et là prennent hommes et femmes, et enffans masles et fumelles et les mainent vendre en leur païs, ou là où bon leur samble, et sont esclaves toute leur vie. Ce roy tient moult de païs dont il en a moult de désert pour la guerre qu'il a à iceulx qui lui font guerre du costé de la mer, car il est roy de Poulaine, de Craco, et de l'Estau, et duc de Wirot. Et tient toute la terre qui est de la mer maiour jusques en Nortvèghe qui est sur la mer occident et puet finer ce roy de troys cent mille hommes à cheval, armes à la guise de son païs, c'est cellui qui garde de venir le Can deçà la Russie, pour ce que il est seigneur d'une partie d'icelle Russie, et pour les grans guerres, qui sont et ont esté d'une part à d'aultre entre crestiens et sarrazins en celle marche. ${ }^{187}$

Le roi polonais doit non seulement défendre son pays contre les raids des marchands d'esclaves, musulmans autant que chrétiens, mais c'est encore lui qui interdit au puissant chef tatar de passer en Europe catholique. Alors que les rèses de l'Ordre teutonique sont reléguées à un passé datant de quelques décennies, la Pologne représente désormais le principal adversaire des infidèles dans les marges orientales de la Chrétienté. Les Polonais, qui «entendent latin, espécialement prestres et clers», méritent de ce fait les louanges du héraut d'armes: "croient bien en Dieu et sont bons catholiques et deffendeurs de la foy ${ }^{188}$. Du reste, le pays, que l'auteur a probablement visité après le couronnement de Casimir IV (25 juin 1447), qui est aussi grand-duc de Lituanie, apparaît "dans tout l'éclat de sa plus grande puissance» ${ }^{189}$. Le roi possède non seulement la Pologne et la Lituanie, mais encore une partie de la Russie, et curieusement, jusqu'à la Norvège ${ }^{190}$. Le grand-duché, qui n'est listé que comme possession du roi de Pologne, est même confondu avec la Livonie: "Du costé de devers le couchant [de la Pologne] est le royaulme de l'Estau que pluseurs gens appellent le païs de l'Inflent [Livonie] "191. À

\footnotetext{
${ }^{187}$ Hamy, p. 99-100.

188 Ibid., p. 101; A. Grabski, Polska w Opiniach Europy..., p. 82-83.

189 Pour reprendre une expression d'E. Hamy, p. 19.

190 Hamy, p. 99-100: "Ce roy tient moult de païs [...] car il est roy de Poulaine, de Craco, et de l'Estau, et duc de Wirot. Et tient toute la terre qui est de la mer maiour jusques en Nortvèghe qui est sur la mer occident». On reconnaît la juxtaposition des titres de roi de Pologne et de Cracovie, propre aux auteurs français des XIV $\mathrm{XV}^{\mathrm{e}}$ siècles. Le terme Wirot, que E. Hamy rapproche de Vironia (nord de l'Estonie, alors possession teutonique) n'est pas clair; peut-il révéler un souvenir de la figure de Vytautas? En ce qui concerne la mention de la Norvège parmi les possessions polonaises, il peut s'agir d'une confusion entre la Pologne-Lituanie et l'autre grande union dynastique d'Europe du Nord, celle des trois royaumes scandinaves suite à l'Union de Kalmar (1397).

191 Ibid., p. 101. La Lituanie et la Livonie sont en réalité situées au nord-est de la Pologne. L'identification de la Lituanie (Lestau, L'Estau) avec la Livonie (Linflent, L'Inflent) revient dans une deuxième partie du Livre, quand Le Bouvier décrit les pays voisins des Tatars: "Et le roy de Lestau, que aucunes gens appellent son païs, Linflent qui est oultre Norveghe et Pruce, joignent à Tartarie» (Ibid., p. 80). Cette province, située entre le "païs de Tartarie», la Suède et ses possessions finlandaises, la Norvège et la Prusse, est vraisemblablement la Livonie (Liflant, etc.).
} 
une époque où les rèses de Prusse n'étaient plus qu'un souvenir, la géographie balte était devenue quelque peu confuse.

De son côté, Antoine de la Sale précise dans son Jean de Saintré que le «duc de Lectonem" a la charge de la bannière du roi de Pologne, tout comme un certain duc de Misgrave "o la baniere du roy de Honguerie» ${ }^{192}$; il s'agit donc d'un vassal. Lorsque Vytautas (m. 1430) était encore vivant, la dépendance formelle de celui-ci par rapport à Jagellon semble avoir échappé à Pintoin et à Monstrelet, qui lui donnent un titre royal et précisent qu'il est le "frère» du roi de Pologne; autrement dit, son allié, et non son subordonné. À l'inverse, la prépondérance de la Pologne par rapport à la Lituanie apparaît clairement chez le héraut Berry et Antoine de la Sale, qui écrivent un peu plus tard. Une évolution révélatrice de la perception que l'on se faisait de la situation politique et religieuse de l'Europe orientale.

Au XIV ${ }^{\mathrm{e}}$ siècle, le royaume de Pologne, qui depuis le règne de Ladislas le Bref (m. 1333) aimait se voir en "bastion de la Chrétienté» ${ }^{193}$, était certes moins connu que l'Ordre teutonique, mais apparaissait tout même dans quelques textes relatifs à la croisade. Le roi Casimir le Grand joue notamment un rôle dans la Prise d'Alexandrie de Guillaume de Machaut (v. 1369), où le poète mentionne la présence de Pierre de Lusignan au congrès organisé en automne 1364 par Casimir, l'empereur Charles de Bohême et le roi de Hongrie Louis d'Anjou ${ }^{194}$. Malgré le bon accueil qu'on lui fit, le Lusignan n'obtint rien de plus que des promesses ${ }^{195}$, et trois ans plus tard, le pape Urbain $\mathrm{V}$ écrit au roi polonais pour l'encourager à soutenir l'effort de croisade, ceci alors que l'expédition du roi de Chypre s'est soldée par un échec, en dépit de la prise retentissante d'Alexandrie $^{196}$. Le royaume de Pologne, qui retrouvait une certaine importance dans la politique régionale, joue donc un rôle dans les projets de croisade qu'on essaye d'organiser à l'échelle européenne en cette seconde moitié du XIV siècle. Curieusement, la Pologne n'est pourtant pas mentionnée parmi les pays dont partiront les croisés du Songe du vieil pelerin. Philippe de Mézières estimait-il que les chevaliers polonais accompagneraient Jagellon, "roy de Layco", pour combattre aux côtés des Lituaniens et des Prussiens? Alors que l'auteur a

\footnotetext{
192 Blanchard, Quereuil, p. 370. Faut-il voir dans le nom «Misgrave» une influence du margraviat de Misnie (Meissen en allemand), une province relevant non pas de la Hongrie, mais de l'Empire? 193 P. KNOLL, "Poland as "antemurale christianitatis"...», p. 381-401.

${ }_{194}$ Contrairement à son habitude, Machaut ne mentionne pas avoir été présent, ce qui peut indiquer qu'il n'a pas assisté personnellement à la rencontre entre les monarques: S. KuCZYŃsKI, "Hérauts d'armes ...», p. 653. Mézières, qui secondait alors Pierre de Lusignan dans ses efforts diplomatiques, n’a pas non plus assisté au congrès: N. Iorga, Philippe de Mézières..., p. 188-201. Froissart, ainsi que d'autres chroniqueurs, font assister le Lusignan aux noces de Charles IV de Bohême avec Elisabeth, la fille de Casimir et d'Aldona de Lituanie en 1363; or, le voyage de Pierre à Prague puis à Cracovie est à situer une année plus tard, en 1364: M. Nejedlú, Stredověký mýtus..., p. 333.

195 Philippe de Mézières, Une Epistre..., p. 20-21.

196 Ibid., p. 25.
} 
consacré de longues pages au pays des Teutoniques et à celui de leurs adversaires, il ne s'étend pas sur le royaume à l'aigle blanc. La seule information qu'il donne concerne le mariage de la reine avec Jagellon, "roy" de Lituanie, un pays qui semble l'avoir bien plus intéressé.

C'est ce mariage qui a, pour ainsi dire, donné toute sa place à la Pologne sur la scène européenne ${ }^{197}$. Si, dans les années qui ont suivi la conversion de Jagellon, quelques chroniqueurs ou romanciers français ont pu placer le "roy de Craco» parmi les adversaires de la Chrétienté ${ }^{198}$, la Pologne devient par la suite un allié recherché. Et ceci non seulement du pape et des poètes rêvant à la croisade, mais également de certaines têtes couronnées. En 1419, le roi de Danemark Éric de Poméranie s'allie avec Jagellon contre l'Ordre teutonique, qu'il accuse... de collaborer avec des infidèles ${ }^{199}$. Peu avant la bataille d'Azincourt (1415), le roi d'Angleterre Henri V écrivait à Jagellon pour lui demander de soutenir sa cause contre Charles VI de France ${ }^{200}$, ce à quoi le monarque polonais répond qu'il vaudrait mieux s'employer à défendre la foi contre les infidèles, et incite donc le roi anglais à conclure la paix avec son rival ${ }^{201}$. D'après Jaroslav Svátek, le principal motif de l'ambassade de Guillebert de Lannoy en Pologne et en Lituanie, en 1421, était d'annoncer la conclusion du traité de Troyes, qui proclamait Henri V d'Angleterre héritier du royaume de France: tout porte à croire que le Lancastre était loin de considérer ses pairs d'Europe centrale comme marginaux ${ }^{202}$. Si l'on peut se fier au style hyperbolique du chroniqueur polonais Jan Długosz, qui relate le passage de l'ambassadeur à la cour de Jagellon, Guillebert garda un bon souvenir du roi de Pologne: "Rentré dans sa patrie, il fut plein des louanges du roi de Pologne Ladislas, et de sa courtoisie auprès des Bourguignons et des Anglais; et jusqu'au jour de sa mort, il célébrait des actions de grâces en faveur du roi Ladislas» ${ }^{203}$.

Plus directement lié au contexte de croisade, il semble attesté que plusieurs chevaliers polonais ont participé aux opérations contre les Maures en Afrique du

\footnotetext{
197 D. Barons, S. C. Rowell, The Conversion..., p. 327 sq.

198 Notamment le Mélusine de Jean d'Arras (1393) et la Chronique des Quatre Premiers Valois (après 1393). Dans ces deux cas, il peut s'agir d'échos de la "propagande» teutonique, qui considérait le baptême de Jagellon comme une ruse et le rapprochement de la Pologne avec le grand-duché comme une trahison à la cause chrétienne.

199 J. M. Jensen, Denmark..., p. 56.

${ }^{200} \mathrm{CEV}$, doc. 738, p. 391-392; l'éditeur, A. Prochaska, situe cette lettre en 1417, mais O. Halecki ("Gilbert de Lannoy...», p. 324, n. 25) a montré qu’à partir de la réponse de Jagellon (CEV, doc. 714, p. 377-378), on doit la dater d'avant la bataille d'Azincourt.

${ }^{201}$ CEV, doc. 714, p. 377-378. Sur cet épisode, O. HALECKI, «Gilbert de Lannoy... », p. 323-324.

202 J. Svátek, Discours..., p. 271. Les lettres d'Henri V à Jagellon et à Vytautas sont éditées dans Liber cancellariae..., vol. 1-2, doc. 46-47, p. 85-86, et une lettre de Jagellon à Charles VI dans Ibid., doc. 54, p. 94-96; Index actorum..., doc. 1116, p. 131 et doc. 1185 p. 138.

${ }^{203}$ Jan Długosz, Annales XI, dans Opera Omnia..., vol. 13, p. 274; J. Svátek, Discours..., p. $264-265$, n. 310 .
} 
Nord, lors des premières décennies du Xve siècle ${ }^{204}$. Antoine de la Sale énumère ainsi les participants à l'attaque portugaise sur Ceuta en 1415 dans son $D u$ réconfort de Madame de Fresne (1458): "et si estoient le seigneur de Plomellau baron, et messire Henry de Donru, chevaliers de Poullayne»205. Le même auteur raconte encore qu'à Paris, Jean de Saintré affronta lors d'une emprise un certain seigneur de Loisellench, chevalier polonais qui, par la suite, participa à la croisade de Prusse sous la bannière de son roi, portée par le duc de Lituanie ${ }^{206}$. Si l'on en croit Philippe de Mézières, l'un des premiers adhérents à son Ordre de la Passion serait le voïévode polonais "Albert Pachost» (Wojciech z Pakości), héros de la défense de la Cujavie contre l'Ordre teutonique et grand dévot, que le Vieux Pèlerin aurait rencontré à Jérusalem en $1347^{207}$. Lorsqu'il relate la bataille de Varna (1444) à partir des souvenirs de son neveu Wallerand, le chroniqueur Jean de Wavrin fait combattre les "Poullans» aux côtés des "Hongres», accomplissant de beaux actes de bravoures face aux Turcs ${ }^{208}$. Dans le domaine littéraire également, le pays figure comme allié épisodique de quelques héros courtois. Ainsi, dans le roman Cleriadus et Méliadice, composé à la cour du duc de Bourgogne Philippe le Bon, vers 1440-1450, le «roy de Poulaine» appelle le héros pour le soutenir dans sa lutte contre un certain «duc de Gravelaine», qui n'est toutefois pas caractérisé comme «sarrasin ${ }^{209}$. En dépit des querelles

${ }^{204}$ O. HaleCKI, «Gilbert de Lannoy... », p. 321-322; A. SzWedA, «Polish and Teutonic diplomatic activity...» note que Jarosław d'Iwno, qui joua le rôle d'ambassadeur de Jagellon auprès des cours occidentales en 1409, combattit peut-être contre les Maures en Espagne.

${ }^{205}$ Antoine de la Sale, Antoine de la Salle: sa vie et ses ouvrages d'après des documents inédits, suivi du "Réconfort de madame du Fresne», éd. J. Nève, Paris-Bruxelles 1903, p. 143; A. Grabski, Polska w Opiniach Europy..., p. 63.

${ }^{206}$ Blanchard, Quereuil, p. 370. Ce personnage est peut-être inspiré par un certain Bartosz de Wezenborg, un baron polonais qui autour de 1375 s'est vraisemblablement rendu jusqu'à Paris pour participer à un tournoi, et en 1379-1380 rançonna un groupe de chevaliers français rentrant de Prusse; PR 1, p. 239-242; T. Poklewski-Koziell, "Barthossius Wezenborg, un grand chevalier polonais qui ne savait pas parlementer ( $2^{\mathrm{e}}$ moitié du XIV ${ }^{\mathrm{e}}$ siècle) » dans Châteaux, nobles et aventuriers. Actes des Rencontres d'archéologie et d'histoire en Périgord. 27, 28, 29 septembre 1996, Bordeaux 1999, p. 54-56. Pour sa part, M. Szkilnik, "Jean de Saintré...», p. 383-384, remarque que le personnage de Loisellench tient autant du géant exotique que du chevalier courtois: "Polonais, le chevalier vient des marges de l'Europe, d'une région où peut-être, aux yeux d'Antoine, les moeurs et les codes chevaleresques ne sont pas solidement établis" (p. 383).

207 M. GŁodek, Utopia Europy..., p. 133-134; L. Burkiewicz, «A Cypriot royal mission to the Kingdom of Poland in 1432», Crusades 10, 2011, p. 103.

${ }^{208}$ Jean de Wavrin, Anchiennes cronicques d'Engleterre..., vol. 2, p. 83 passim. À ce sujet, A. Grabski, Polska w Opiniach Europy..., p. 418-423, qui cite le discours de l'évêque de Chalon, Jean Germain, au roi Charles VII : «si [...] le roy de Polene ne fut mort, la Grece estoit recouvrée pour les chrestiens» («Le Discours du voyage d'outremer», éd. C. Schefer, Revue de l'Orient latin III, 1895, p. 330). N. Housley, The Later Crusades..., p. 370, note toutefois qu'avant la fin du $\mathrm{Xv}^{\mathrm{e}}$ siècle, la croisade contre les Turcs n'est pas une priorité pour la cour polonaise.

${ }^{209}$ Cleriadus et Meliadice, éd. G. Zink, Genève 1984, p. 613; V. Agrigoronei, "Bazgazul...», p. 198, considère le duc de Gravelaine comme «un ennemi non identifiable». 
momentanées ayant suivi le baptême de Jagellon, les Polonais semblent, pour les écrivains français, faire partie de "l'internationale de la chevalerie» ${ }^{210}$.

La montée en puissance de la Pologne apparaît dans les textes de manière presque simultanée à un effacement de la Lituanie, ce qui correspond à la destinée de la dynastie régnant dans ces pays ${ }^{211}$. Après la mort de Vytautas le 27 octobre 1430, la Lituanie est divisée entre deux factions soutenant chacune un prétendant au trône grand-ducal, Švitrigaila et Sigismond. Le premier est vaincu en 1435 et doit s'exiler, alors que son vainqueur est assassiné le 20 mars 1440. Après quoi, les boyards lituaniens choisissent le jeune fils de Jagellon, Casimir, âgé de 13 ans, comme grand-duc. En juin 1447, celui-ci devient également roi de Pologne, après trois ans d'interrègne ayant fait suite à la mort de son frère Ladislas III à la bataille de Varna, événement qui a peut-être contribué à renforcer l'identification du royaume comme fer de lance de la Chrétienté ${ }^{212}$. À partir de Casimir, le roi de Pologne sera aussi grand-duc de Lituanie. Même si le grand-duché, dirigé par une oligarchie composée des principaux magnats, gardera une certaine autonomie, le fait de ne plus avoir à sa tête un prince aussi charismatique que Vytautas a sans doute contribué à assimiler la Lituanie à la Pologne pour les auteurs occidentaux de la seconde moitié du $\mathrm{Xv}^{\mathrm{e}}$ siècle. Ainsi, le couple antagoniste "Ordre teutonique / Lituanie» familier aux auteurs du siècle précédent cède la place à celui formé par la Pologne chrétienne et les principautés tatars, nouveaux avatars de l'ennemi infidèle en Europe orientale.

\section{Vaine gloire et Cadre grivois : la Croisade de Prusse brocardée}

Les rèses auxquelles accourait la noblesse pendant la seconde moitié du $\mathrm{XIV}^{\mathrm{e}}$ siècle perdent de leur importance après la christianisation du grand-duché: aux Lituaniens chrétiens on préfère d'autres adversaires, comme les rebelles hussites, les Tatars, les Turcs Ottomans, ou les Mamelouks d'Égypte, véritables maîtres de la Terre sainte. Longtemps populaire parmi les écrivains et les chroniqueurs de tout le continent, la croisade de Prusse tombe en désuétude. Or, déjà au XIV ${ }^{\text {e }}$ siècle, quelques voix dissonantes se faisaient entendre ${ }^{213}$. À Vienne, en pleine terre d'Empire, le poète Henri le Teichner (m. 1378) n'hésitait pas à qualifier les rèses d'inutile gaspillage des ressources ${ }^{214}$ : «ils

\footnotetext{
210 A. Grabski, Polska w Opiniach Europy..., p. 61-84. Les armoiries des principaux clans polonais figurent dans l'armorial de la Toison d'Or, à la suite d'une représentation du roi de Pologne monté et armé: Le Grand Armorial équestre de la Toison d'or, fac-similé effectué par M. Pastoureau et M. Popoff, Saint-Jorioz 2001, vol. 1, fol. 119-121; identifications dans ibid., vol. 2, p. 244-258.

211 Sur les événements politiques et dynastiques, Z. Kiaupa, J. Kiaupienė, A. Kuncevičıus, The History of Lithuania before 1795..., p. 204-222.

212 J. Jefrerson, The Holy Wars..., p. 493-496.

213 W. van Anrooij, "Heralds...», p. 49-50, cite quelques critiques contre l'habitude du voyage aristocratique datant de la chute d'Acre et des premières décennies du XIV siècle.

${ }^{214}$ Henri le Teichner, "Daz di herren nicht frid schaffen ", Die Gedichte Heinrichs des Teichners, éd. H. Niewöhner, Berlin 1954, vol. 2, poème 353, p. 95-97.
} 
ne font qu'emporter l'argent de leur pays dans celui des païens» ${ }^{215}$. Loin d'un Jean Petit ou d'un Guillaume de Machaut, le poète autrichien entend rappeler à la noblesse que sa tâche principale est de maintenir l'ordre sur ses terres, et non de courir l'aventure à l'étranger ${ }^{216}$. Le voyage en Prusse, dont "un sage ne peut se réjouir ${ }^{217}$, ne serait que l'occasion d'aller s'encanailler dans de lointains pays: alors que "celui qui part en croisade contre les Prussiens devrait avoir un courage plein de chasteté", le poète nous avoue que "j'en ai entendu plus d'un dire que s'il devait rester à la maison, il n'aurait pas la possibilité d'aller voir d'autres femmes» ${ }^{218}$.

Lui aussi en relation avec la cour des Habsbourg, le Teichner est un ami de Pierre Suchenwirt, l'auteur de Von Herzog Albrechts Ritterschaft; fait intéressant, ce dernier se montre à certaines occasions tout aussi critique envers ces nombreux hommes d'armes "de haute et de basse condition", qui "vont accomplir des raids dans de nombreux pays étrangers et laissent leur propre population dévastée et désolée par le pillage et l'incendie ${ }^{219}$. Le fait d'avoir rapporté dans un style plein d'emphase les hauts faits de son patron lors d'une croisade en Lituanie n'empêche pas notre héraut d'armes de se montrer réservé quant à la mode qui consiste à partir chercher l'aventure au loin - même si la Prusse n'est pas explicitement mentionnée dans cet extrait. Ici, le devoir de protection auquel le seigneur est lié prime sur la recherche d'honneur personnel220.

À la même époque, autour de 1376-1379, le poète anglais John Gower dénonçait dans son Mirour de l'Omme les chevaliers qui partaient "devers Espruce et Tartarie » ${ }^{221}$ pour trois raisons, dont seule la dernière (servir Dieu) est méritoire:
"La primere est, si j'ensi die
De ma prouesce enorguillie,
"Pour loos avoir je passeray"
Ou autrement, "C'est pour m'amye,

\footnotetext{
${ }^{215}$ V. 100, Ibid., p. 97 ; trad. H. Birkhan, «Les croisades... », p. 49. Voir aussi SRP 2, p. 170-173. ${ }_{216}$ PR 2, p. 182; O. Brunner, Land and Lordship: Structures of Governance in Medieval Austria, Philadelphie 1992, p. 219, n. 78.

217 Henri le Teichner, poème 353, v. 51-52, dans Die Gedichte..., p. 96; S. Gouguenheim, Les Chevaliers teutoniques..., p. 579.

${ }^{218}$ Henri le Teichner, poème 353, v. 122-124, 129-130, dans Die Gedichte..., p. 97.

219 Pierre Suchenwirt, Peter Suchenwirt's Werke aus dem 14. Jahrhundert, éd. A. Primisser, Vienne 1827, doc. 12, v. 44-47, p. 38; trad. O. BRunNer, Land and Lordship..., p. 219.

${ }^{220}$ Ibid., p. 218-222. À noter qu'autour de 1356-1357, Suchenwirt a écrit un poème satirique et ludique où un personnage aspirant à la noblesse se rend en Prusse, mais rentre immédiatement après son départ. Pour W. van Anrooij, ce poème se situe probablement dans une tradition carnavalesque et de moquerie envers les roturiers prétendant à noblesse; W. van AnrooIJ, «Heralds... », p. 54-55, 60, n. 52 .

${ }^{221}$ John Gower, Le Mirour..., v. 23895, dans Complete Works..., vol. 1, p. 264.
} 
Dont puiss avoir sa druerie,

Et pour ce je travailleray"

[...]

Si tu d'orguil voes travailler

Pour vaine gloire seculer,

Dont soietz le superiour

Des autres, lors t'estuet donner

Ton garnement et ton denier

As les heraldz, qu'il ta valour

Et ta largesce a grant clamour

Facent crier;

[...]

Et d'autre part si ta covine

Soit pour la cause femeline

Dont tu as le cuer enamouré,

Et sur ce passes la marine,

A revenir si la meschine

Ou dame slonc son degré,

Pour quelle tu t'es travaillé,

Ne deigne avoir de toy pité,

Tout as failly du medicine. $»^{222}$

Rares sont les chevaliers à partir pour de bonnes raisons: à en croire Gower, la plupart d'entre eux sont motivés par l'orgueil et la vaine gloire, quand ce n'est pas dans le but de plaire à une femme. Le voyage contre les infidèles effectué dans cet état d'esprit ne peut être qu'incertain; non seulement il exige de fortes dépenses, puisque le chevalier qui veut que son nom soit célébré doit payer les hérauts d'armes, mais encore il ne permet pas d'assurer le succès auprès des dames qu'un Jean Petit promettait à ses lecteurs ${ }^{223}$. La raison est, bien sûr, qu'une entreprise de la sorte ne saurait être faite pour des raisons mondaines: "Car nul puet estre bien vaillant, / s'il dieu ne mette a son devant»"224.

Dans une œuvre plus tardive, la Confessio Amantis (entre 1390-1393), le poète va plus loin, en suggérant que faire usage de violence, même contre des infidèles, va à l'encontre des principes de la foi ${ }^{225}$. Une position qui le

\footnotetext{
222 Ibid., v. 23899-23937, p. 264.

223 S. VANDer Elst, "Chivalry... », p. 289-291; voir ci-dessus, chap. III.

224 John Gower, Le Mirour..., v. 23911-2392, dans Complete Works..., vol. 1, p. 264.

225 Idem, Confessio..., v. 3.2488-2515, dans Complete Works, vol. 2, p. 293-294.
} 
rapprocherait de son compatriote Roger Bacon ou du Polonais Paul Vladimiri, même si dans d'autres poèmes, il prend parti en faveur de la lutte contre l'infidèle. Gower n'était certainement pas opposé à toute forme de croisade, mais à celles entreprises pour de "mauvais" motifs, tels qu'énumérés dans le Mirour de l'Omme ${ }^{226}$. Parmi ce genre d'expéditions, celles qui avaient la Lituanie pour cible figurent en première place. Ainsi dénonce-t-il ceux "qui cherchent la grâce de l'amour», et se précipitent "somtime in Prus, somtime in Rodes, / And somtime into Tartarie», pour que les hérauts crient devant eux "Vailant, vailant, lo, wher he goth!» ${ }^{227}$. Une prise de position qui ne l'a pas empêché de dédier deux versions de sa Confessio Amantis à Henri de Derby, qui représente l'archétype du prince préoccupé par la "vaine gloire seculer»" ${ }^{228}$, étalant sa fortune et sa puissance par sa participation aux voyages de Prusse ${ }^{229}$.

En France, le plus virulent des critiques est sans doute Philippe de Mézières, qui pourtant ne tarit pas d'éloge envers les Chevaliers teutoniques eux-mêmes, mais n'hésite pas à flétrir leurs hôtes. À première vue, il paraît évident que ce chantre de la moralisation de la chevalerie n'ait pu être que favorablement disposé envers l'Ordre ${ }^{230}$. Parmi les pays évoqués par les figures allégoriques du Songe $d u$ vieil pelerin, seule Venise mérite autant de louanges ${ }^{231}$. Le poète a-t-il été ébloui par la force déployée par un Ordre teutonique qu'il a connu à son apogée lors de son passage en Prusse en 1364? A-t-il été séduit par la politique dite «illusionniste» menée, selon la théorie d'Erich Maschke, par les Teutoniques au XIV ${ }^{\mathrm{e}}$ siècle pour faire revivre un monde chevaleresque en déclin ${ }^{232}$ ? Prenons garde à ne pas prendre toutes les louanges de Mézières comme des témoignages d'admiration sans recul. L'État des Chevaliers teutoniques joue en effet un rôle bien précis dans son programme politique: celui de tendre un miroir aux souverains de l'Europe chrétienne, et en premier lieu au roi de France et à ses conseillers ${ }^{233}$. C'est ce qu'exprime la reine Vérité, le personnage allégorique qui sert en quelque sorte de guide moral au lecteur: "Ceste saincte religion [...] fait grant vergongne, non tant seulement aus autres religions de chevalerie de l'esglise de mon Pere, mais a tous les princes des Crestiens "234.

Il est toutefois permis de penser que Philippe a été réellement enthousiasmé par cette organisation de moines-guerriers à la tête d'un État

\footnotetext{
226 S. VAnder Elst, "Chivalry...», p. 288-289; T. Guard, Chivalry..., p. 177-178.

227 John Gower, Confessio..., v. 4.1620-33, dans Complete Works, vol. 2, p. 345.

228 Idem, Le Mirour..., v. 23918, dans Complete Works, vol. 1, p. 264.

229 S. VAnder Elst, «Chivalry...", p. 288.

${ }^{230}$ Philippe de Mézières, Le Songe du vieil pelerin, éd. G. W. Coopland, Cambridge 1969, vol. 1, p. 127.

${ }^{231}$ M. Balard, «Les Républiques Maritimes italiennes», dans R. Blumenfeld-Kosinski, K. Petкov (dirs.), Philippe de Mézières and his Age..., p. 273-276.

${ }^{232}$ M. GŁodek, Utopia Europy..., p. 83. Sur la politique «illusionniste» de l'Ordre teutonique,

E. Maschke, «Burgund...», p. 15-34.

233 S. Gouguenheim, Les Chevaliers teutoniques, p. 586.

${ }^{234}$ Blanchard, vol. 1, p. 215.
} 
puissamment tenu, considéré jusqu'à la fin du $\mathrm{XIV}^{\mathrm{e}}$ siècle au moins comme un modèle de chevalerie par la noblesse européenne ${ }^{235}$. Marzena Głodek a remarqué que derrière la description de la Prusse mise dans la bouche de la Vérité se cache un plaidoyer pour l'organisation de l'Ordre de la Chevalerie de la Passion de Jésus-Christ ${ }^{236}$. La corporation rêvée par l'auteur ressemble en beaucoup de points à l'Ordre teutonique, notamment par le fait qu'elle devra assumer la conquête puis la défense de la Terre sainte, mais encore sa colonisation. D’après le programme développé dans les règles de l'Ordre de la Passion, les membres mariés y seront envoyés avec leurs épouses, en tant que colons; ceux-ci devront faire souche et permettre un peuplement d'origine européenne, ce qui garantirait une présence catholique sur le long terme $^{237}$. Si la règle de l'Ordre teutonique n'envisageait pas le mariage pour ses membres, il est connu que les Chevaliers ont eu recours à de nombreux colons pour peupler la Prusse et la Livonie. Tout comme le grand-maître teutonique, les dirigeants de l'Ordre de la Passion seront à la fois guerriers et administrateurs territoriaux.

Rien ne prouve que Philippe de Mézières se soit inspiré de l'action de l'Ordre teutonique pour établir le fonctionnement de son ordre de chevalerie, mais le parallèle est frappant. De la même façon, l'auteur, qui montre une certaine admiration pour le fonctionnement des États guerriers que sont l'Égypte des Mamelouks, l'Empire ottoman ou la "Tartarie», sait rester pragmatique quant à l'organisation militaire de son ordre. Les chevaliers en seront certes le fer de lance, mais à leurs côtés combattront des archers, des arbalétriers, et de nombreux gens de pieds. En observant les armées turques, tatares et surtout mameloukes, Philippe a compris que la discipline est la clef de la réussite dans le domaine militaire ${ }^{238}$. En somme, si l'Ordre de la Passion entend atteindre son but, il ne devra pas perdre de vue les impératifs stratégiques, et faire bon usage des auxiliaires moins nobles mais dont l'action peut être décisive sur le champ de bataille. Ce mélange d'idéal chevaleresque et de pragmatisme n'est pas sans rappeler le fonctionnement militaire et administratif de l'Ordre teutonique, dont l'efficacité a fait ses preuves lors du siècle précédent la visite de Philippe en Prusse.

\footnotetext{
235 J. JaKštas, Das Baltikum..., p. 182-183.

236 M. GŁodeK, Utopia Europy..., p. 82.

${ }^{237}$ J. Williamson, "The "Chevallerie de la Passion Jhesu Crist": Philippe de Mezieres' Utopia", dans D. Buschinger, W. Simwor (éds.), Gesellschaftsutopien im Mittelalter / Discours et figures de l'utopie au Moyen Âge, Greisfwald 1994, p. 165-173; P. Contamine, «La place des femmes dans les deux premières règles (1367-1368 et 1384) de l'ordre de la chevalerie de la Passion de Jésus-Christ de Philippe de Mézières", dans P. Henriet et A.-M. Legras (dir.), Au cloître et dans le monde. Femmes, hommes et sociétés, Paris, 2000, p. 79-88.

${ }^{238}$ J. France, «Philippe de Mézières and the Military History of the Fourteenth Century», dans

R. Blumenfeld-Kosinski et K. Petkov (dirs.), Philippe de Mézières and his Age..., p. 283-294;

N. Iorga, Philippe de Mézières..., p. 70-71.
} 
À l'inverse des Teutoniques, dont le fonctionnement a pu servir de modèle pour les projets de Mézières, leurs hôtes représentent tout ce que l'auteur du Songe abhorre. Alors que les «seigneurs de Prusse» ont choisi de consacrer leur vie au combat contre les "ennemis de la foi», les chevaliers qui participent aux rèses ressemblent à ceux que Philippe a connus lors des croisades de Smyrne et d'Alexandrie. Une fois la victoire obtenue, ou la saison terminée, on se retire et on ne se préoccupe plus de la situation du pays où l'on faisait mine de combattre. Sans doute n'est-ce pas un hasard si, dans le long passage consacré à la Prusse, Mézières ne fait aucune mention de la présence des chevaliers qui, à son époque, viennent accomplir une rèse aux côtés des Teutoniques ${ }^{239}$.

Le portrait laudatif de ces derniers doit être mis en parallèle avec les critiques adressées à l'aristocratie chrétienne dans les textes relatifs à l'Ordre de la Passion de Jésus-Christ. Mézières avait rédigé environ trois versions successives de la règle de «son" ordre: la première, semble-t-il, à la fin de l'année 1367, puis une deuxième en 1384 et une troisième en 1396, peu avant que la chevalerie française ne parte pour l'expédition qui devait aboutir à la catastrophe de Nicopolis ${ }^{240}$. Il nous est resté plusieurs manuscrits de la troisième et dernière rédaction de l'Ordre de la Passion de Jésus-Christ. Celui de la bibliothèque de l'Arsenal à Paris (ms. 2251) nous laisse voir ce que Philippe de Mézières pouvait penser des voyageurs de Prusse ${ }^{241}$. Fidèle au style allégorique qui lui est cher, il place dans la bouche de la reine Providence cette condamnation sans appel:

"Il sont aucuns chevaliers dit la royne Providence es vii. langaiges de la crestiente et par especial es royaumes de France et d'Engleterre, d'Almaigne et d'Escosse, trop plus qu'es autres langes, qui pour acquerre voullance et prouesse mondaine vestus par dehors d'un manteau de devocion [...] emprendant les voyages, c'est assavoir en Prusse ou en Grenate en Barbarie en Turquie en Honguerie en Servie ou en la double Ablaquie. Et toutes les foiz que aucuns chevaliers au monde renommez des dessus diz royaumes de leur propre voulente et sans meur conseil precedent emprenderent les voyages, les autres les sivent ligierement encores moins avisez, comme une brebis fait l'autre et ce avient aucunesfoiz pour aucunes nouvelles ligieres et volans qui ne sont point toutes vrayes ny entieres ilz se mettent au chemin et ont ja determine combien ilz dovient demourer aiant petit regart a la neccessite et pourfit de la guerre qu'ilz trouveront. ${ }^{242}$

\footnotetext{
239 Mézières mentionne pourtant «l'aide des Crestiens d'Alemaigne et de Polane» apportée à l'Ordre teutonique lors de ses premières années (Blanchard, vol. 1, p. 214).

${ }^{240}$ Philippe de Mézières, Une Epistre..., p. 25, 36-37, 41.

${ }^{241}$ Philippe de Mézières, The Order of the Passion: an annotated edition, éd. M. Brown, Lincoln, Nebraska 1971 (thèse de doctorat non publiée), p. 67-74; Arsenal, ms. 2251, fol. 4 et 31, cité par P. Contamine, "Les princes, barons et chevaliers qui a la chevalerie au service de Dieu se sont ja vouez". Recherches prosopographiques sur l'ordre de la Passion de Jésus-Christ (13851395)", dans M. Nejedlý, J. Svátek (dirs.), La noblesse et la croisade...p. 62-63; W. Paravicini, "Fahrende Ritter...", p. 217-218.

${ }^{242}$ Philippe de Mézières, The Order of the Passion..., p. 67 (ponctuation simplifée).
} 
La méconnaissance de la situation politique dans laquelle on va se battre, la volonté d'obtenir "vaillance et prouesse» sous couvert de dévotion, le fait de s'imiter les uns les autres, par effet de mode: voilà ce qui correspond assez bien au profil majoritaire des croisés de Prusse. Autre élément qui dérange Mézières, le luxe dont s'entourent certains croisés de haut rang ${ }^{243}$ :

"Et toutesfoiz au chemin ilz ne vont pas comme pellerin humblement au service de Dieu mais comme princes, les menistreulz et les hyraux precedens a grans $p o[\mathrm{~m}]$ pes et a grans paremens en robes et en vaiselle d'argent saisans les grans disuers garnis des viandes oultrageuses. [Ces chevaliers] despendent plus en un moys qu'ilz ne deverolent faire en iii. si n'est pas grant merveille s'ilz s'en retournent tost a pou de prouffit de la guerre. $»^{244}$

Une telle façon de faire est non seulement inutile, mais encore dangereuse pour la cause chrétienne, car "quant les dessus diz chevaliers se sont partiz voire a moitie ou a quart de leur ouvraige et du service qu'ilz deussent faire a Dieu lors les ennemis queurent sus aux crestiens et ont les grans victoires ${ }^{245}$, comme cela arriva en Terre sainte après l'époque de Richard Couur de Lion et de Saint Louis. Ces chevaliers, qui "a l'indignacion de la crestiente des frontieres» ${ }^{246}$, "ainsi légierement emprendent leur voyage et tost s'en retournent aiment par amours une royne qui est appellee Vayne Gloire» ${ }^{247}$. C'est ainsi que, s'adressant directement à un personnage représentant ce genre de guerriers frivoles, la reine Providence lui demande s'il a bien accompli son voyage pour l'amour de Dieu, et en essayant de cacher ses hauts faits aux yeux du monde; or, force est de constater que "entre les chevaliers errans telle monnoye se treuve pou aujourduy» ${ }^{248}$. Ainsi, ledit personnage se voit accusé par la figure moralisatrice: "tu es vrays amoureux de la dicte royne emplumee [la Vaine Gloire] et pour estre guerredonne de sa monnoye volage, et a ton retour estre assiz par grant honneur a la table de marbre tu as fait ton voyage principalment et est plus tost retourne pour acquester nouvel honneur et estre escrips en nombre des preux» ${ }^{249}$.

Il serait tentant de voir dans ce passage une allusion à la table d'honneur dressée pour les participants les plus méritants aux rèses, ou plus largement, à ceux qui font figurer leurs blasons dans la cathédrale de Königsberg. Néanmoins, le texte indique que le chevalier concerné se dépêche de rentrer pour siéger à la «table de marbre»; celle-ci doit donc être située en France. Plusieurs ordres de chevalerie, comme celui de l'Étoile, fondé par le roi de France Jean le Bon,

\footnotetext{
${ }^{243}$ Par exemple, le riche appareil du comte Henri de Derby nous est connu grâce aux notes laissées par son trésorier: Expeditions...

${ }_{244}$ Philippe de Mézières, The Order of the Passion..., p. 67-68.

245 Ibid., p. 69.

$246 \mathrm{Id}$.

247 Id.

248 Ibid., p. 73.

${ }^{249}$ Ibid., p. 73-74.
} 
avaient pour coutume de se réunir autour d'une table d'honneur, sur le modèle des chevaliers du roi Arthur ${ }^{250}$. La matière dont cette dernière est faite nous donne un élément supplémentaire: Mézières connaissait certainement la table de marbre du palais royal, à Paris, consacrée à la connétablerie, l'amirauté et la juridiction des eaux et forêts. On peut donc supposer qu'il ait visé à la fois l'habitude de siéger aux différentes tables d'honneur et l'ambition d'obtenir un office à la cour; ainsi, le "mauvais» chevalier voyagerait non seulement pour enrichir sa gloire personnelle, mais aussi pour favoriser son avancement ${ }^{251}$. Ce comportement bien éloigné de l'idéal chrétien laisse deviner le mépris dans lequel Philippe tenait les rèses de Prusse et autres expéditions du même genre.

Tout comme John Gower, qui dédicace sa Confessio Amantis à Henri de Derby, meilleur exemple anglais du croisé «mondain» qu'il dénonce ${ }^{252}$, Mézières se place en porte-à-faux avec ses puissants soutiens. En effet, le comportement qu'il brocarde correspond au profil même de célèbres chevaliers qui ont accepté de participer à la création de l'Ordre de la Passion de Jésus-Christ ${ }^{253}$. Parmi eux, Boucicaut, archétype du "voyageur" belliqueux et prêt à tout pour mettre à mal les Sarrasins, et Othon de Grandson, qui a accompagné Henri de Lancastre en Prusse en 1392 et dont la poésie est admirée par beaucoup de "mondains» ${ }^{254}$. Le moraliste Mézières, qui échafaudait de grands projets depuis sa cellule du couvent des Célestins, parlait-il encore le même langage que ceux qui avaient promis de le rejoindre ${ }^{255}$ ? Peut-on imaginer que les nobles français, anglais ou écossais qui pensaient intégrer l'Ordre ne voyaient en celui-ci qu'une corporation chevaleresque de plus, avant tout honorifique? Pour Christopher Tyerman, l'Ordre de la Passion aurait surtout séduit le roi anglais Richard II et ses proches, favorables à un rapprochement avec Paris, et pour qui la perspective d'une croisade en Terre sainte aurait servi à orienter l'énergie belliqueuse de la noblesse anglaise vers un autre objectif que la France. Une fois que le roi apporta son soutien au projet de Mézières, même ceux qui étaient loin de partager ses idéaux se sont plus ou moins vu contraints d'y adhérer ${ }^{256}$.

\footnotetext{
${ }^{250}$ PR 1, p. 328. Contrairement à son habitude, Mézières ne dit pas explicitement que la «table de marbre» est une allégorie.

${ }^{251}$ Plusieurs des compagnons soldés par Henri de Derby lors de son voyage en Prusse ont reçu un office important après la prise de pouvoir du Lancastre et son couronnement comme Henri IV; C. Tyerman, England..., p. 271.

252 S. VANDER Elst, "Chivalry... », p. 287-288.

253 Philippe de Mézières nomme ces personnages «évangélistes». Voir P. Contamine, "Les princes, barons et chevaliers..."”, p. 43-67.

${ }^{254}$ Pour M. Nejedlý, «Spisy...», p. 105-106, les poèmes de jeunesse de Guillebert de Lannoy reflètent l'influence d'Othon de Grandson.

255 Sur le caractère utopique du projet de Mézières, P. Contamine, " "Les princes, barons et chevaliers..."”, qui demande: "en 1395-1396, y croyait-il encore?» (p. 63).

256 C. Tyerman, England..., p. 294-295. T. Guard, Chivalry..., p. 171-173, attribue à l'Ordre de la Passion une fonction diplomatique, liée au rapprochement franco-anglais des années 1390.
} 
L'année où Mézières rédige cette troisième règle, plusieurs membres voués à son ordre sont pris ou tués à Nicopolis. Parmi eux, d'anciens croisés de Prusse, dont Boucicaut, Philippe de la Trémoille et Philippe d'Artois, le connétable de France qui a dévasté la Bosnie deux ans auparavant alors qu'il pensait aller combattre les Turcs ${ }^{257}$. Notre infatigable moraliste saute sur l'occasion pour adresser au duc de Bourgogne son Epistre lamentable et consolatoire, où, sous prétexte d'expliquer les causes de la défaite, il répète les idées qui lui sont chères ${ }^{258}$. Pour Mézières, les croisés ont cédé à "Orgueil, Envie et Division, Inobedience, Legierté, Oultrecuidance et Propre Voulenté et pluseurs autres vices de la mesnie d'Orgueil ${ }^{259}$. Comme pour Michel Pintoin, le désastre s'explique par le comportement des nobles français, débauchés et plus préoccupés par leur confort et leur gloire personnelle que par les considérations stratégiques propres à ce type de guerre ${ }^{260}$.

Ce qui ressort des écrits de Philippe de Mézières, c’est que les expéditions aristocratiques telles que les rèses de Prusse ou les «voyages» dans les Balkans, effectués sans planification, sont inutiles et même dommageables à la cause chrétienne. À première vue, on pourrait penser que l'auteur du Songe du vieil pelerin distingue drastiquement les Chevaliers teutoniques de leurs hôtes, qui se rendent en Prusse pour dorer leur blason, puis rentrent se vanter de leurs exploits avant de repartir ailleurs. Or, on peut imaginer que Mézières, plutôt bon observateur de la réalité de son temps, savait parfaitement que les Teutoniques étaient les premiers à favoriser le climat d'ostentation qu'il déplore chez les croisés "mondains»: derrière la description très favorable de la Prusse teutonique, on trouve moins un panégyrique des frères de l'Ordre tels que Mézières les a connus qu'un discours sur ce que devrait être la chevalerie. $\mathrm{Du}$ portrait idéalisé des Teutoniques et défavorable de leurs hôtes découle une critique cinglante visant l'institution du voyage en Prusse, entrepris avec légèreté, en méconnaissance des réalités locales et surtout sans lien avec l'objectif ultime que s'est fixé le Vieil Solitaire - ainsi qu'il se présente dans l'Epistre -: la libération de la Terre sainte. Sans doute, le fait que Philippe de Mézières soit l'un des premiers auteurs européens à avoir reconnu la christianisation de la Lituanie, et implicitement, la désuétude de la croisade balte, n'est-il donc pas un hasard ${ }^{261}$.

\footnotetext{
257 Pour une liste des membres de l'expédition de Hongrie, J.-M. Delaville Le RoulX, La France en Orient au XIV siècle. Les expéditions du maréchal Boucicaut, Paris 1886, vol. 2, p. 78-86 et B. Schnerb, "Le contingent franco-bourguignon à la croisade de Nicopolis», dans J. РAviot, M. Chauney-Bouillot (dirs.), Nicopolis 1396-1996..., p. 72-74.

${ }^{258}$ N. Iorga, Philippe de Mézières..., p. 500-503.

259 Philippe de Mézières, Une Epistre..., p. 121.

260 Bellaguet, vol. 2, p. 483-485, 495, 499; D. Lalande, Jean II le Meingre..., p. 60-61.

261 Comme dans le Songe du vieil pelerin écrit plusieurs années auparavant, Mézières entend utiliser la "chevalerie d'Allemaigne" contre les Turcs, et cite "les seigneurs de Prusse» en exemple: Une Epistre..., p. 189; P. Buc, «L'epistre lamentable...», p. 215.
} 
Un contemporain de Mézières, membre du même cercle et lui aussi partisan de la croisade en Terre sainte, fait preuve d'une réserve similaire au sujet des expéditions prussiennes. Les critiques d'Eustache Deschamps sont toutefois d'un genre bien différent. Poète de cour ayant à cœur de célébrer le pouvoir royal, il soutient, comme d'autres auteurs gravitant autour du trône de France à la fin du Moyen Âge, la récupération des valeurs chevaleresques au profit de la cause royale. Tout comme Mézières, il se fait le chantre d'une chevalerie disciplinée, domptée. S'il célèbre un Bertrand du Guesclin ou un Enguerrand de Coucy, c'est qu'ils ont su mettre leur valeur au service du roi: liée aux vertus chevaleresques traditionnelles, la fidélité au monarque représente pour le poète une forme d'idéal ${ }^{262}$.

Pour Eustache Deschamps comme pour Philippe de Mézières, la libération de la Terre sainte serait possible si les princes de toute la Chrétienté pouvaient oublier leurs querelles et mettre leurs forces en commun ${ }^{263}$. À l'inverse de ce qu'on lit chez le Vieil Solitaire, la croisade de Nicopolis aurait pu pour Deschamps représenter la concrétisation d'un tel programme; les Français y sont tombés en héros, et la cause de la défaite est à chercher dans la fuite honteuse du roi de Hongrie ${ }^{264}$. Le voyage en Prusse est traité de manière plus ambiguë265. Dans son Miroir $d u$ mariage, le poète affirme, en conformité avec les idées dominantes de son temps, qu'un chevalier doit sans cesse courir guerres et tournois ${ }^{266}$ :

\author{
«[...] Et puis après \\ Fault d'aller en Pruce soit près \\ Ou en Yfflelent [Livonie], a la rese \\ De l'esté: cilz est bien sur brese, \\ Qui a telz faiz a poursuir. ${ }^{267}$
}

\footnotetext{
${ }^{262}$ T. Lassabatère, La Cité des Hommes. Eustache Deschamps, expression poétique et vision politique, Paris 2011, p. 324-331.

${ }^{263}$ Voir notamment son poème Pour conquerir de cuer la Terre sainte, 49, dans Eustache Deschamps, Euvres complètes..., vol. 1, p. 138-139; commenté et cité par H. Millet, dans J.-P. Boudet, H. Millet (dirs.), Eustache Deschamps en son temps, Paris 1997, p. 72-73. Sur Deschamps et la croisade, Ibid., p. 83-86; A. Dupront, Le mythe de croisade..., p. 212-217.

264 Notamment la balade dite "Pour les Français morts à Nicopolis», 1316, Euvres complètes, éd. G. Raynaud, 1891, vol. 7, p. 77-78, qui est proche du point de vue défendu par le Livre des Fais de Boucicaut (p. 106-107). Plus ambiguë est une autre balade, «Faicte pour ceuls de France quant ilz furent en Hongrie» (1427, Ibid., 1893, vol. 8, p. 85-86), qui, sous la forme d'un ubi sunt, insiste sur l'orgueil puni par Dieu.

265 Enguerrand de Coucy, notamment, était en Prusse en en hiver 1364-1365, et y retourna peut-être en hiver 1369-1370 (PR 1, p. 96-97).

266 T. Lassabatère, " “Comment Dieux a confermée noblesce". Identité fonctionnelle et culturelle de la noblesse dans l'œuvre d'Eustache Deschamps", Cahiers de recherches médiévales et humanistes 13, 2006, p. 61.

${ }^{267}$ Eustache Deschamps, Le Miroir de Mariage, XXIII, v. 2191-2195, dans Euvres complètes..., vol. 9, p. 74 .
} 
Toutefois, bien qu'il en reprenne les ficelles, le Miroir du mariage n'est pas un simple poème didactique comme nous en avons déjà vu: déployant toute la verve de son pessimisme, Deschamps y énumère plutôt les maux qui attendent les parents, depuis la naissance de leurs enfants jusqu'à l'arrivée de ceux-ci à l'âge adulte ${ }^{268}$. Parmi les problèmes qui se posent, le choix de carrière de sa progéniture n'est pas le moindre; faire de son fils un clerc, un magistrat ou un marchand coûte cher et n'est pas sans risque, d'autant plus que les parents sont rarement payés de reconnaissance pour les sacrifices consentis. La chevalerie représente certes le métier le plus prestigieux, mais c'est aussi le plus exigeant, car il suppose une vie pleine de dangers, et demande une haute moralité à celui qui veut être digne de cet état. Le chevalier le plus prisé du royaume perd «le bien, / l'oneur, la grace et le renom "269 s'il a le malheur de fuir ne serait-ce qu'une seule fois lors d'une bataille. Le meilleur moyen d'assurer à son fils une honnête carrière chevaleresque est de l'envoyer à l'étranger, pour qu'il soit toujours occupé à montrer sa bravoure:

"Or fault avoir pour voyagier

Grant argent, pour boire et mangier

Et pour acquerir renommée.

Sera ta vie bonneurée,

Qui bon fil chevalier aras,

Qui tant de coust y metteras,

Et si mourra en my les champs? „270

Le bon chevalier, celui qui mérite les louanges du poète, assure en mourant le salut de son âme et le renom de sa lignée, mais une telle destinée "advient po souvent»" ${ }^{271}$. Même la participation à la rèse de "Pruce» et $\mathrm{d}$ ' "Yfflelent», à grand prix, ne permet pas d'assurer une fin honnête. Comme chez Philippe de Mézières, la croisade de Prusse est identifiée à un phénomène mondain, étape obligée des jeunes aristocrates désireux de tenir leur rang, et souvent source de gaspillage. On remarque un certain décalage par rapport au ton employé par le biographe de Boucicaut ou Cabaret d'Orville, lesquels cherchaient tous deux à défendre les valeurs de l'ancienne chevalerie.

Comme en pied de nez aux chantres de la noblesse "voyageuse", Deschamps n'hésite pas, à d'autres occasions, à traîner l'institution aristocratique des voyages en Prusse dans la boue. Dans une ballade laissée sans titre, des roturiers

\footnotetext{
${ }^{268}$ J. Quillet, «Le Miroir de mariage d'Eustache Deschamps», dans D. Buschinger, A. Crépin (éds.), Amour, mariage..., p. 457-464.

269 Eustache Deschamps, Le Miroir de Mariage, XXIII, v. 2227-2229, dans Euvres complètes..., vol. 9, p. 75-76.

${ }^{270}$ Ibid., v. 2369-2375, p. 80.

271 Ibid., v. 2392, p. 81.
} 
devenus brigands se font passer pour des chevaliers: "Reprandre leur fault leur mestier / mais pour faire nouvelle prusse, / donnez leur l'ordre du cordier »"2. La moquerie envers les trop nombreux ordres de chevalerie se double d'une allusion sarcastique aux rèses contre les lointains «Sarrasins» du Nord, lorsque dans le même poème, l'auteur dit à ces faux chevaliers, mais vrais pillards: "Il vous vaulsist mieulx estre en Russe» ${ }^{273}$ ! Dans le même ordre d'idée, Deschamps dédie un rondeau entier au phénomène des rèses, sur le mode d'une plainte envers un proche voulant aller en Prusse:

"En Pruce vont pluseurs ceste saison,

Et je doubt bien de vostre voulenté,

Que ne soyez du voyage tempté.

De vostre honneur ay joye, c'est raison;

Maiz quant partout ara vo cuer pensé,

En Pruce vont pluseurs ceste saison,

Et je doubt bien de vostre voulenté.

Un tour vendrez avant en vo maison,

Si vous vaudra ce que j'ay amassé

Et direz lors comme réconforté:

En Pruce vont pluseurs ceste saison,

Et je doubt bien de vostre voulenté,

Que ne soyez du voyage tempté. $»^{274}$

Le ton est ambigu; s'agit-il de regrets, de reproches ou de moquerie? Si l'on choisit de lire ce poème comme le préconise l'éditeur Auguste Queux de SaintHilaire, c'est-à-dire "une dame parle à son mari allant guerroyer en Prusse»" ${ }^{275}$, on ne peut exclure que la phrase "Si vous vaudra ce que j'ay amassé» en particulier ne soit chargée de sous-entendu grivois ${ }^{276}$ : Eustache Deschamps délaissait à

${ }^{272}$ Eustache Deschamps, Ballade 909, v. 19-20, dans Euvres complètes..., vol. 5, p. 103. Contrairement à ce que suppose l'éditeur (ibid., n. f), "prusse" ne doit sans doute pas se lire "prouesse».

${ }^{273}$ Ibid., v. 47. Qu'il s'agisse d'une allusion à une région de Samogitie, comme le pense W. URBan, "The correct translation...", p. 12-18, dans le cas de Geoffrey Chaucer, ou d'une confusion entre la Russie et les pays ciblés par les croisés de la Baltique, ce terme nous renvoie sans équivoque à l'univers des rèses de Lituanie. Sur la portée critique et ironique de cette balade, L. Hablot, "L'emblématique princière dans l'œuvre d'Eustache Deschamps", dans M. Lacassagne, T. Lassabatère (dir.) «Les “dictez vertueulx” d'Eustache Deschamps, Paris 2005, p. 105.

${ }^{274}$ Eustache Deschamps, Rondeau 686, dans Euvres complètes..., vol. 4, p. 145.

275 Ibid.

${ }^{276}$ L'éditeur traduit par "Et ce que j'aurai économisé vous servira» (Ibid., n. a). 
l'occasion son style moralisateur pour se laisser aller à de belles gauloiseries ${ }^{277}$. Mais l'hypothèse est fragile, d'autant plus que rien ne permet d'affirmer que le rondeau doive être mis dans la bouche d'une épouse et non d'un père, par exemple. Dans ce cas, l'allusion porterait plutôt sur le gaspillage des biens, déjà abordé par le poète.

Le thème de l'infidélité de la femme laissée seule pendant le voyage de son mari, bien connu des fabliaux ${ }^{278}$, est explicitement transféré au voyage de Prusse dans au moins deux œuvres littéraires. En accusant les participants aux rèses d'infidélité, le poète viennois Henri le Teichner fait remarquer que les femmes de ces chevaliers aux mœurs légères ne sont pas non plus faites de fer ${ }^{279}$. Le croisé de Prusse cocufié apparaît également dans le recueil au ton très libre des Cent Nouvelles Nouvelles, composé à la cour de Philippe le Bon autour de 1462. Sur le modèle du Décaméron de Boccace, il met en scène le duc et ses courtisans se racontant des histoires drôles ou étranges, souvent truculentes, qui mettent en scène des personnages de conditions diverses. La seizième nouvelle concerne directement notre sujet $^{280}$. En voici le prologue:

"En la conté d'Artoys nagueres vivoit ung gentil chevalier, riche et puissant, lyé par mariage avecques une tresbelle dame et de hault lieu. [...] Et car alors, la Dieu mercy, le trespuissant duc de Bourgoigne, conte d'Artois, et leur seigneur, estoit en paix avec tous les bons princes chrestians, le chevalier, qui tresdevot et craignant Dieu estoit, delibera a Dieu faire sacrifice du corps qu'il luy avoit presté, bel et puissant [...]. Et pour faire son oblacion en lieu eleu et de luy desiré [...] se mect a voye devers les bons seigneurs de Perusse, vraiz champions et defenseurs de la tressaincte foy chrestiane. Tant fist et diligenta qu'en Perusse après pluseurs adventures que je passe, sain et sauf se trouva, ou il fist assez largement de grans proesses en armes. ${ }^{281}$

Jusque-là, nous avons une description complète, quoique stéréotypée, du voyage de Prusse: le chevalier qui profite de la situation paisible de sa contrée pour partir au loin, accomplir de belles prouesses au service de Dieu, et y gagner quelque renom. La suite du texte entraine toutefois le lecteur dans une direction

\footnotetext{
277 J.-P. Boudet, H. Millet (dirs.), Eustache Deschamps..., p. 219-239.

${ }^{278}$ Par exemple, "L'enfant de neige», qui relate l'histoire d'un marchand découvrant que son épouse a eu un fils pendant qu'il effectuait un long voyage. Elle lui raconte que cet enfant lui est venu d'un flocon de neige avalé par mégarde.

${ }^{279}$ Henri le Teichner, poème 353, v. 138-139, dans Die Gedichte..., p. 97; H. Birkhan, «Les croisades...", p. 49.

${ }^{280}$ Les Cent Nouvelles Nouvelles, éd. F. P. Sweetser, Genève 1966 (ci-après: Sweetser), p. 109-114; PR 1, p. 44.

${ }^{281}$ Sweetser, p. 109. Sur ce recueil, J. Devaux et A. Velissariou (dirs.), Autour des Cent Nouvelles nouvelles, Sources et rayonnements, contextes et interprétations. Actes du colloque de Dunkerque (2011), Paris 2016.
} 
tout à fait différente, qui tranche drastiquement avec ce à quoi nous ont habitués les auteurs des décennies précédentes:

"Or ne vous fault pas celer que madame, qui demourée est, ne fut pas si rigoreuse que a la pryere d'ung gentil escuier, qui d'amours la requist, elle ne fust tantost contente qu'il fust lieutenant de monseigneur, qui aux Sarrazins se combat. Tantdiz que monseigneur jeune et fait penitence, madame fait gogettes avecques l'escuier. Le plus des foiz monseigneur se disne et souppe de bescuit et de la belle fontaine, et madame a de tous les biens de Dieu si largement que trop; monseigneur au mieulx se couche en la paillace, et madame en ung tresbeau lit avec l'escuyer se repose. Pour abreger, tantdiz que monseigneur aux Sarrazins fait guerre, l'escuier a madame combat. ${ }^{282}$

Ce qui s'écrivait déjà à Vienne dans le second quart du $\mathrm{XIV}^{\mathrm{e}}$ siècle, à une époque où la pratique du voyage en Prusse battait son plein, est gaillardement assumé par l'auteur anonyme des Cent Nouvelles Nouvelles: l'héroïque croisé de Prusse, qui se pense volontiers comme un parangon de la chevalerie, a bien des chances de se trouver cocu à son retour.

Chez Antoine de la Sale, ce n'est qu'après l'épisode prussien que le roman devient graveleux. La grande croisade balte, où le héros est adoubé par le roi de Bohême en personne, représente la dernière étape nécessaire à accomplir quand un jeune noble prétend à la chevalerie. La faute de Saintré est d'avoir voulu en faire trop, et d'être reparti courir l'aventure alors que tous s'attendaient à ce qu'il demeure à la cour. La punition que lui inflige Madame des Belles Cousines est à mettre en parallèle avec le courroux du roi : les mésaventures de Saintré, humilié par Madame et son nouvel amant, Monsieur l'Abbé, sont les conséquences directes de son zèle à rechercher l'honneur sans en avoir été requis. Du reste, après une période d'humiliations, le malheureux chevalier parvient à tuer l'abbé puis à se venger de Madame. La position du héros est rétablie, mais son prestige en prend un coup: que vaut l'honneur gagné contre les Sarrasins si, peu après son retour, le gentilhomme est traîné dans la boue par une amante infidèle?

Cette parodie de biographie chevaleresque place la croisade de Prusse dans une position très ambiguë. Dans les Cent Nouvelles Nouvelles, la moquerie est bien plus claire: "Comme vous avez oy fut le chevalier trompé. Et n'ay point sceu, combien que pluseurs gens depuis le sceurent, qu'il en fut jamas adverty" ${ }^{283}$. L'intrigue est assez commune à ce genre de littérature, mais le fait que le cocu rentre précisément de Prusse ne manque pas d'intérêt. Même l'insistance sur les conditions de vie spartiate du malheureux croisé est peut-être ironique; en tout cas, si ce n'était peut-être plus le cas au milieu du $\mathrm{Xv}^{\mathrm{e}}$ siècle, les contemporains d'un Henri de Derby devaient savoir qu'un voyageur de Prusse était loin de dormir sur de la paille.

\footnotetext{
282 Sweetser, p. 110.

283 Ibid., p. 114.
} 
La nouvelle dont il est question, du reste, est bien dans le ton général du recueil; les maris trompés sont légion, y compris les nobles, et ce sont bien souvent des clercs qui en sont responsables. Une des histoires tranche toutefois avec cette ambiance de vaudeville. Sans doute n'est-ce pas insignifiant pour notre propos qu'elle ait comme thème la défaite de Nicopolis. La $69^{\mathrm{e}}$ nouvelle raconte l'histoire du chevalier Clais de Utenhove, un Flamand ayant réellement pris part à l'expédition ${ }^{284}$. D'après le narrateur, il se fait capturer par les Turcs, mais à l'inverse de Jean sans Peur ou de Boucicaut, il n'est pas rançonné: les vainqueurs le gardent comme esclave, et il reste neuf ans en Turquie. Pendant ce temps, «sa bonne et loyale femme» ${ }^{285}$, restée à Gand, est poussée à se remarier par sa famille, ce qui ne l'enchante guère, car contrairement à la protagoniste de la seizième nouvelle, tout ce qu'elle désire est de rester fidèle à son mari :

"[elle] prioit Dieu journellement que bref le peust ravoir et reveoir par deçà, si encores il estoit vif; s'il estoit mort, que, par sa grace luy voulsist ses pechez pardonner et le mettre ou nombre des glorieux martirs qui pour le reboutement des infideles et l'exaltacion de [1] a saincte foy catholicque se sont voluntairement offers et habandonnez a la mort temporelle. ${ }^{286}$

Mais sa maisonnée parvient à la persuader que son héros de mari est mort, du fait que s'il était vivant, les Turcs auraient demandé une rançon. En conséquence, elle accepte de prendre pour nouveau mari un autre chevalier. Mais après quelques mois, Clais parvient à s'échapper de sa prison orientale, et peut rentrer en Flandre. Le thème est ici proche d'une nouvelle du Décaméron, qui met en scène un croisé fait prisonnier en Orient, et qui rentre dans les mêmes conditions pour retrouver sa femme juste avant que celle-ci ne doive céder à la pression de nouvelles noces ${ }^{287}$. Or, dans la version des Cent Nouvelles Nouvelles, les époux sont bien moins chanceux: quand le héros de Nicopolis rentre, sa femme, déjà remariée, se meurt de regret en apprenant qu'elle lui a été infidèle.

Alors que la croisade de Prusse peut servir de cadre à une bonne histoire d'adultère, on constate que la mésaventure de Nicopolis reste entourée d'un respect certain: le fait que l'on n'ironise pas sur les malheurs conjugaux de Clais de Utenhove, mais qu'au contraire on raconte son histoire sur un ton tragique, est significatif. Sans doute le fait que l'entreprise était étroitement liée à la maison de Bourgogne a-t-il poussé l'auteur à faire preuve de retenue devant les malheurs d'un compagnon de Jean sans Peur, père du commanditaire

\footnotetext{
${ }^{284}$ Sweetser, p. 422-425. Clais de Utenhove survécut, et fut, plus tard, récompensé pour son courage par Jean sans Peur qui le fit bailli de Biervliet en 1411: B. Schnerb, "Le contingent franco-bourguignon...", p. 70 .

${ }^{285}$ Ainsi dit le résumé placé dans la table des matières: Sweetser, p. 14.

286 Ibid., p. 423.

287 Boccace, Le Décaméron, dixième journée, neuvième nouvelle, éd. V. Branca, Turin 1980, vol. 2, 1429-1463 ; trad. C. Bec, M. Dozon, C. Guimbard, M. Scialom, Paris 1994, p. 821-840.
} 
du recueil ${ }^{288}$. Toutefois, on ne peut que faire ressortir la différence entre les protagonistes des deux nouvelles, toutes deux racontées par Monseigneur le duc en personne: au chevalier d'Artois, parti en Prusse pour y faire retentir sa prouesse, s'oppose son malheureux pair de Flandre, capturé alors qu'il tentait d'arrêter les Turcs. Face à l'héroïsme un peu suranné des "voyages» nordiques auxquels on participait deux ou trois générations auparavant, les affaires orientales restent d'une actualité brûlante ${ }^{289}$.

En effet, Philippe le Bon avait fait de l'idée d'une grande croisade contre les Turcs un pilier de sa politique européenne ${ }^{290}$. Le projet n'a finalement jamais eu lieu, mais le duc semble y avoir tenu, envoyant même quelques espions en Europe orientale et en Terre sainte: parmi eux, Guillebert de Lannoy, que nous connaissons bien, puis Bertrandon de la Broquière en 1432-1433. Fait significatif, Lannoy semble avoir passé plus de temps dans les dépendances balkaniques de la Lituanie que dans l'État de l'Ordre; sans doute le pays de Vytautas, allié à la Pologne, était-il pensé comme une pièce importante d'un hypothétique front oriental de la Chrétienté. Comme chez le héraut Gilles le Bouvier ou le romancier Antoine de la Sale, les Lituaniens convertis depuis quelques générations sont intégrés au réseau des puissances chrétiennes. La croisade de Prusse tombe en désuétude, et devient objet de moquerie, l'énergie étant désormais dirigée contre l'Empire ottoman. Les textes littéraires semblent suivre ici l'évolution géopolitique. La quatrième et dernière partie de cet ouvrage porte précisément sur l'imaginaire spécifique qui se développe dans les textes consacrés à la Baltique, bien au-delà des aspects liés à la croisade.

\footnotetext{
${ }^{288}$ Le culte autour des héros de Nicopolis persiste jusqu'au milieu du $\mathrm{Xv}^{\mathrm{e}}$ siècle dans les milieux bourguignons; M.-G. Martenet, «Le Récit de la bataille de Nicopolis (1396) dans les Chroniques de Jean Froissart: de l'échec à la gloire", Questes 30, 2015, p. 125-139.

${ }^{289}$ Contrairement à ce qu'affirme l'un des éditeurs du texte, P. L. Jacob, il y a lieu de penser que l'auteur était loin de confondre la Prusse et la Hongrie. Les Cent Nouvelles Nouvelles, éd. P. L. Jacob, Paris 1858, p. 88, n. 4.

${ }^{290}$ J. Paviot, Les Ducs de Bourgogne..., p. 117-176.
} 


\section{QUATRIÈME PARTIE \\ UN MONDE D'HONNEUR ET DE GLACE LES IMAGINAIRES BALTES}





\section{INTRODUCTION DE LA QUATRIÈME PARTIE}

$\mathrm{E}$ n parallèle à la croisade contre les païens de la Baltique, un imaginaire particulier s'est élaboré autour de ces régions des marges de la Chrétienté. Les lettrés d'Europe occidentale ont découvert le monde balte au moment où les premières entreprises de christianisation étaient échafaudées, avant que la conquête de la Livonie et de la Prusse ne mette les savants occidentaux au contact d'informations neuves. Dans la seconde moitié du XIII ${ }^{\mathrm{e}}$ siècle, un savoir partagé par les lettrés de toute l'Europe latine se met peu à peu en place au sujet de ces lointaines plantations nordiques de la Chrétienté et des hommes qui y vivent. Enfin, entre le $\mathrm{XIV}^{\mathrm{e}}$ et le $\mathrm{XV}^{\mathrm{e}}$ siècle, époque où de nombreux chevaliers français et anglais participent au combat contre les «Sarrasins" de Lituanie, une certaine image littéraire du monde balte se cristallise.

Nous connaissons la manière dont ces textes présentent les activités des chevaliers allés combattre en Prusse: aux appels de l'Ordre teutonique, qui reposent sur l'idéologie de la defensio et propagatio fidei mise en place au $\mathrm{XII}^{\mathrm{e}}$ siècle par Rome, répondait la soif d'aventure et d'héroïsme d'une chevalerie chrétienne en mal de croisade. Nous avons parcouru les descriptions des batailles épiques que livraient les Jean de Luxembourg, Boucicaut ou Henri de Lancastre contre des «Sarrasins» et des "mécréants» identifiés comme lituaniens jusqu'à la fin du XIv ${ }^{\mathrm{e}}$ siècle, puis comme tatars à partir du moment où la conversion effective de la Lituanie est devenue un fait connu de tous les lettrés d'Europe. Inséparable du succès de la croisade balte, le décorum chevaleresque mis en scène sous l'égide des Teutoniques est bien représenté dans ces textes: l'adoubement avant le combat, la table d'honneur, les bannières fièrement dressées et même la mort au combat. Toutefois, les choses de la guerre n'étaient pas seules à intéresser nos auteurs. La géographie et la nature balte, les bêtes qui y vivent et que l'on y chasse, trouvent un intérêt non négligeable aux yeux de certains d'entre eux, souvent eux-mêmes d'anciens voyageurs. Les hommes ne sont pas en reste: avant leur conversion, les Lituaniens étaient certes représentés comme des ennemis, mais cela n'empêchait pas que leur religion intrigue les hôtes venus de l'Ouest, qui savaient à l'occasion apprécier les qualités de quelques individus. Par 
le truchement des croisés, les princes païens de la Baltique deviennent des personnages littéraires, courtois ou cruels, parfois individualisés, souvent très colorés.

Un certain nombre de textes nous ont laissé, outre les récits des croisades, une peinture assez détaillée du monde balte et de ses habitants. La plupart d'entre eux ont été composés en français et datent de l'époque où les «voyages de Prusse» battent leur plein, entre 1360 et 1400: le Songe du vieil pelerin de Philippe de Mézières (1389), le Myreur des Histors de Jean d'Outremeuse (v. 1400), le Livre de Jean de Mandeville (1356) et le Mélusine de Jean d'Arras (1393). Un peu plus tardif sont les notes de voyage du chevalier bourguignon Guillebert de Lannoy, l'un des derniers Occidentaux à avoir participé à une «rèse» en 1413-1414. Pour lui, qui est retourné en Prusse puis en Lituanie et en Pologne comme ambassadeur quelques années plus tard (1421), il s'agissait moins d'une croisade que d'un voyage de découverte. Tel est aussi le cas de son contemporain Gilles le Bouvier, le héraut d'armes Berry, dont le Livre de la description des pays (v. 1451) renferme quelques informations sur la région balte, sans doute obtenues lors d'un voyage autour de 1447. À quoi s'ajoutent des chroniques, comme celle consacrée au duc Louis de Bourbon, dictée par l'ancien croisé de Prusse Jean de Chastelmorand à l'auteur, Jean Cabaret d'Orville (1429), ou la Chronique de Metz, composée par un autre croisé de Prusse, le patricien Jacques d'Esch (m. 1455).

Une fois les Lituaniens convertis, les rèses perdent du prestige, et le grandduché s'efface peu à peu des lettres. La Lituanie intéresse encore l'humaniste italien et futur pape Énée Sylvio Piccolomini, qui y consacre notamment plusieurs pages de son De Europa (1458). Son récit est composé à partir d'informations glanées auprès d'un missionnaire qu'il dit avoir rencontré lors du concile de Bâle, et de sources antérieures. À partir de la fin $\mathrm{du} \mathrm{xv}^{\mathrm{e}}$ siècle, les textes produits en France relèvent moins de témoignages directs de voyageurs que de compilations d'œuvres écrites en Pologne ou en Allemagne. C'est le cas des chroniques commandées par Henri de Valois à l'occasion de son couronnement comme roi de Pologne (1573) et reposant sur la tradition historiographique polonaise ${ }^{1}$, ainsi que de la Cosmographie Universelle de François de Belleforest (1575), adaptation française de Sebastian Münster (1544), lequel s'appuie notamment sur Énée Sylvio Piccolomini et le Tractatus de duabus Sarmatiis, Asiana et Europiana de Mathias de Miechow (1517), mais aussi sur le témoignage du voyageur et diplomate Sigismond de Herberstein, lui-même auteur d'un Rerum Moscovitarium Commentari (1549)². À cette

\footnotetext{
${ }^{1}$ Histoire des Roys et Princes de Pologne de François Bauduin (1573), Chroniques et Annales de Pologne (1573) de Blaise de Vigénère et Description du Royaume de Pologne et pays Adjacens (1573) par le même auteur; J. KŁoczowski, M. Wozniweski, "Les premières histoires de la Pologne...", p. 103-109.

2 T. Jaroszewska, "À la découverte de l'Europe de l'Est: Tractatus de duabus Sarmatiis, Asiana et Europiana de Mathias de Miechow (1517)", dans E. Berriot-Salvadore, R. Aulotte (dirs.), Les
} 
tradition appartient également la Cosmographie Universelle d'André Thevet (1575), qui consacre un passage à la Lituanie ${ }^{3}$. Dans les cosmographies françaises du XVI ${ }^{\mathrm{e}}$ siècle, cette dernière est traitée comme un pays relativement marginal, entre Moscovie et Pologne; les notes concernant les coutumes des habitants ou la tyrannie des grands-ducs sont en bonne partie inspirées de Piccolomini et, dans une moindre mesure, de Münster ${ }^{4}$. Il faut attendre l'œuvre du baron von Wal, lui-même allemand et membre de l'Ordre teutonique, qui diffuse son Histoire de l'Ordre teutonique en langue française (1784-1790), pour voir un certain regain d'intérêt pour la question.

Voyons donc quelle image du monde balte savants, chevaliers, chroniqueurs et poètes du Moyen Âge ont laissée à leurs successeurs. Après un commentaire concernant la transmission de l'information et le rôle de l'oralité dans la construction de l'imaginaire balte, le chapitre VII est consacré au cadre dans lequel on situait les aventures des croisés. Les descriptions de l'hiver balte, probablement inspirée par les témoignages des chevaliers revenus de la rèse hivernale, deviennent dès le $\mathrm{XIV}^{e}$ siècle une étape obligée de tout texte contant les affaires de Prusse et de Lituanie. La nature sauvage, les immenses forêts et les marais couverts de glaces ajoutent une touche d'exotisme nordique aux récits des combats entre les chevaliers chrétiens et les "Sarrasins» de la Baltique. Un décor qui prend, sous la plume de certains auteurs, une couleur arthurienne ou antiquisante lorsque certains noms aux consonances épiques s'intercalent au milieu du récit. Des détails du paysage ou des anecdotes concernant l'installation des Teutoniques en Prusse sont utilisées pour renforcer l'ambiance héroïque du récit ou pour éveiller la curiosité du lecteur; la faune, et en particulier le grand gibier que l'on trouve dans les forêts baltes, ne manque pas d'intéresser également le public occidental.

Enfin, le dernier chapitre de cet ouvrage est dédié à la manière dont les lettrés d'Europe de l'Ouest représentaient les hommes et les femmes contre qui les croisades baltes étaient dirigées. Depuis les premiers extraits de chroniques racontant les débuts de la mission en Prusse autour de l'an mil jusqu'aux œuvres $\mathrm{du} \mathrm{Xv}^{e}$ siècle, l'image des païens de la Baltique a passablement évolué. Les chroniqueurs relatant le martyre des premiers apôtres de la Prusse avaient besoin de persécuteurs païens relativement stéréotypés, tout comme les auteurs écrivant pour justifier la croisade balte à ses débuts: ainsi, la première image des Baltes dans les lettres européennes est celle de païens sanguinaires, dont la cruauté ne manque pas de rappeler les tyrans de l'Antiquité chrétienne. En parallèle de cette construction littéraire se met en place tout un savoir concernant la culture

représentations de l'Autre du Moyen Âge au XVII' siècle, Saint-Étienne 1995, p. 17-29; M. McLEAN, The Cosmographia of Sebastian Münster: Describing the World in the Reformation, Farnham 2007, p. 233-238; S. Mund, Orbis Russarum. Genèse et développement de la représentation du monde "russe» en Occident à la Renaissance, Genève 2003, p. 242.

3 Ibid., p. 421-422; G. Mickūnaité, Making..., p. 249, n. 488.

${ }^{4}$ Ibid., p. 203-206. 
religieuse attribuée aux Baltes: dans la foulée des missionnaires franciscains et dominicains, les encyclopédistes et autres savants à ambition universaliste intègrent des descriptions se voulant objectives des rituels païens. Les funérailles des Prussiens et des Livoniens trouvent un écho particulier dans ce genre de littérature. Lorsque les chevaliers revenus de Lituanie et des provinces tenues par l'Ordre teutonique intègrent à leurs œuvres des descriptions de la religiosité balte, ils sont en partie tributaires de cette tradition; mais ils l'enrichissent en y apportant leurs propres interprétations. Pour les auteurs issus de l'aristocratie, les Lituaniens sont des adversaires qui se définissent par leur paganisme, mais aussi par leur noblesse: loin de les décrire comme des brutes, ceux qui font preuve d'intérêt pour les guerriers de Lituanie en font des alter-égos qui seront amenés à se muer en des modèles de chevalerie ou en des personnages de romans courtois. 


\section{Chapitre VII \\ LE CADRE}

\section{De L'ORAL À L'ÉCRIT, OU LES LONGS CHEMINS DE LA TRANSMISSION}

La première question qui se pose concernant l'émergence d'un imaginaire «balte» dans la tradition littéraire d'Europe occidentale est celle des sources. Le jeu entre tradition écrite (autorités) et orale (témoignages, récits de voyage) est sans doute à la base de la majeure partie de nos textes ${ }^{1}$. S'il est relativement aisé d'établir une tradition littéraire ${ }^{2}$ la question de l'oralité pose plus de problèmes. Pour comprendre comment une certaine perception du monde balte et de ses habitants s'est imposée dans la littérature occidentale, on peut partir des conclusions de Marek Tamm concernant l'image de la Livonie et les réseaux d'informations des Cisterciens et des Mendiants au XIII ${ }^{\mathrm{e}}$ siècle. Le médiéviste estonien a montré que les clercs écrivant en terres francophones ou germanophones (Barthélemy l'Anglais, Roger Bacon, Albéric de Trois-Fontaines, Césaire de Heisterbach) ont eu recours à des informations transmises oralement, de manière directe ou non, par des confrères de leurs ordres respectifs ayant été actifs sur le terrain de la mission balte ${ }^{3}$. Roger Bacon a de surcroît bénéficié d'un informateur de qualité, en la personne de Guillaume de Rubrouck, qu'il a rencontré à Paris après son retour du pays des lointains Tatars ${ }^{4}$.

Quant à eux, les nobles qui effectuaient le très aristocratique voyage de Prusse avaient l'occasion de rencontrer de nombreux pairs, et de discuter avec eux. Les échanges verbaux entre chevaliers voyageurs faisaient partie intégrante de la culture commune de la noblesse; partager la route avec d'autres nobles permettait de raconter ses aventures, de parler des pays que l'on avait déjà visités, et d'apprendre aussi en écoutant ses compagnons. Autrement dit, se forger une opinion et influencer

\footnotetext{
${ }^{1}$ Ainsi en est-il d'Adam de Brême, le premier auteur qui nous renseigne en détail sur la région: N. BLomkvist, Discovery..., p. 572.

${ }^{2}$ Un bon exemple est celui des Amazones et de la Scythie, repris des auteurs classiques par Adam de Brême; J.-C. DucÈne, "L'île des Amazones...", p. 171-182.

${ }^{3}$ M. Tамм, "Communicating Crusade...", p. 341-372.

${ }^{4}$ N. Bouloux, «Les formes d'intégration...», p. 119-146.
} 
celle d'autrui'. Il n'y avait certes pas que la route comme lieu d'échange; les cours, qui accueillaient autant de poètes que de chevaliers ou de hérauts revenus de voyage, constituaient d'importants centres de diffusion des nouvelles ${ }^{6}$.

Dans le contexte méditerranéen, Maxime Rodinson postule que Charles de Savoisy, l'un de ces grands seigneurs ayant combattu sur les fronts balte, méditerranéen et pendant la guerre de Cent Ans, a eu l'occasion d'évoquer la civilisation maghrébine avec Pero Niño, le corsaire espagnol qui le guida lors d'un raid maritime contre l'Angleterre. De retour à la cour de France, le même Savoisy aurait pu discuter avec un poète tel qu'Eustache Deschamps, qui se plaît à parsemer son œuvre de quelques «souvenirs" d'Orient ${ }^{7}$. Autre exemple, le chevalier poitevin Perceval de Coulonge, ancien croisé de Prusse, a peut-être été l'un des informateurs de Guillaume de Machaut pour sa Prise d'Alexandrie. Cet infatigable baroudeur ayant servi le roi de Chypre Pierre de Lusignan a certainement rencontré Philippe de Mézières; on sait encore qu'il connaissait Jean d'Arras, qui le mentionne dans son Mélusine ${ }^{8}$. Même si Coulonge n'a vécu que quelque temps en Prusse, et ceci au début de sa carrière (en hiver 1368/1369), on peut imaginer qu'il a transmis quelques anecdotes sur la région aux poètes et romanciers qu'il fréquentait.

Les récits concernant les contrées lointaines devaient être, à en croire Geoffroi de Charny, fort populaires. En amorçant sa courte description du voyageur idéal, notre expert en chevalerie annonce que:

"Ceulx qui entendent leurs corps a faire par grant emprise d'entreprendre a aler en lointains voiages et pelerinages et en pluseurs payjs estranges et lointains, et moult d'estranges choses et diverses peuent veoir, dont autres gens qui point n'avroient hors esté s'esmerveilleroient pour les merveilles estranges et diverses choses que racontent et dient ceulx qui les ont veues, et envis le peuent croire, et s'en moquent li aucun et dient que c'est tout bourde.»"

En effet, d'aucuns moralistes se devaient de mettre en garde contre la vantardise des voyageurs rentrés au pays, toujours prompts, disait-on, à forcer

\footnotetext{
M. NejedlÝ, «Spisy... », p. 101 ; PR 1, p. 230-231.

${ }^{6}$ P. Dobrowolski, "Miles...», p. 44-45; W. van Anrooij, "Heralds...», p. 54. Sur la cour des Anjous comme lieu d'échange, notamment en ce qui concerne les affaires de Hongrie: V. Agrigoroaei, "Bazgazul...", p. 213-214. Sur la transmission orale des nouvelles à la fin du Moyen Âge: V. NovÁk, «La source du savoir...», p. 151-163.

${ }^{7}$ M. Rodinson, La fascination..., p. 187-188, qui précise que Deschamps dit avoir été rudoyé par le même Charles de Savoisy - qu'il devait donc connaître personnellement.

${ }^{8}$ P. Contamine, "De Chypre à la Prusse et à la Flandre...", p. 149-157; PR 1, p. 97; M. Nejedlý, Stréedověký mýtus..., p. 86; W. Paravicini, "Mercenaires...", p. 286-288. D'après Guillaume de Machaut, son informateur principal est l'écuyer Jean de Reins; Guillaume de Machaut, La Prise d'Alexandre..., éd. S. Hardy, p. 170-171, v. 5899-5940. Sur le possible rôle de Perceval de Coulonge comme informateur supplémentaire, ibid., p. cxx, n. 149.

${ }_{9}$ Geoffroi de Charny, The Book of Chivalry..., p. 90.
} 
le trait pour s'assurer un maximum de succès. Ainsi, dans sa dernière rédaction de l'Ordre de la Passion (1396), Philippe de Mézières met dans la bouche de la reine Providence cette remarque:

"quant tu emprens ton voyage ensivant les autres ou estre des primiers, se tu estoies certains comme de la mort que quant tu seraz retournez a ton hostel, c'est assavoir que mal [nul?] homme vivant ou femme ne sceust riens de ton voyage, ou que de tout en tout les gens l'eussent oublie, sans jamaiz estre nouvelle que tu eus esté hors par creature mortele, excepte le doulz Jhesu Crist mon tres amé pere qui tout scet et tout voit, pour le quel sans moyen et non pour acquerir la favour de la royne emplumee [Vaine Gloire] tu devoyes emprendre ton voyage; je te demande en bonne verite sil estoit ainsi [...]. Mais toutesfoiz entre les chevaliers errans telle monnoye se treuve pou aujourduy. ${ }^{10}$

Un voyage accompli pour le seul amour du Christ se ferait donc en toute discrétion, et supposerait que l'on ne raconte pas ses aventures au retour. On comprend en creux que l'un des traits caractéristiques des «mauvais» chevaliers serait la vantardise. Jean Petit est plus explicite. Dans son poème didactique Le Livre du champ d'or, le théologien raconte comment un jeune noble doit partir "En ces voyages d'oultremer / Et de Pruce et de Barbarie», pour le service d'une dame ou par désir de venger "la mort nostre Seigneur»" ${ }^{11}$ Les conseils d'un "expert et bon chevalier», l'expérience de voyages lointains et les souffrances vécues lors du périple en feront un chevalier digne de ce nom, prisé des dames et des pucelles. Mais gare à celui qui, voulant se donner plus de prix, exagérerait la teneur des nouvelles que l'on ne manquera pas de lui demander:

"Pluseurs prieront qui leur die

L'estat du pais de Surye,

Et la manière de la guerre

Du pais de la Sainte Terre.

Lors fault qu'en plusieurs lieux le compte,

Mais garde bien qu'il ne raconte

Fors que la pure verité;

Car ce qui sera recité

Par lui sera de ville en ville

Porté, si tost com tourne bille.

Pourquoy seroit grant villennie

S'il estoit prins en menterie. " ${ }^{12}$

\footnotetext{
10 The Order of the Passion..., éd. M. Brown, p. 72-73.

${ }_{11}$ Jean Petit, Les condicions qui sont requises..., p. 132; M. NeJEDLÝ, «Spisy...», p. 107-108.

${ }_{12}$ Jean Petit, Les condicions qui sont requises..., v. 2889-2904, dans Le Livre du champ d'or, éd. P. Le Verdier, p. 133.
} 
Dans le même ordre d'idée, John Gower rappelle que les chevaliers rentrés de croisade qui voudraient entendre leurs hauts faits chantés par les hérauts d'armes doivent payer ces derniers; les nouvelles ne circulaient pas toujours gratuitement ${ }^{13}$. En ce qui concerne plus particulièrement notre sujet, rappelons le rapport du procureur de l'Ordre teutonique à la Curie, qui écrit que les seigneurs de Sicile et des Pouilles aiment entendre parler des affaires de Prusse, où plusieurs parmi eux se sont rendus lors de leur jeunesse ${ }^{14}$. Henri de Derby, une fois roi d'Angleterre, se plaît également à évoquer ses souvenirs de rèse avec les envoyés du grand-maittre, qui viennent lui demander de l'aide contre la Pologne et la Lituanie à la fin de l'année $1409^{15}$. La transmission orale des nouvelles concernant la Baltique, apparemment populaires parmi l'aristocratie, explique que plusieurs auteurs aient pu saisir des informations parfois non négligeables, tel que l'atteste le récit de la bataille de Tannenberg chez Michel Pintoin et Enguerrand de Monstrelet, qui disent tous deux avoir été mis au courant de l'événement par des messagers, croisés et hérauts d'armes.

À l'occasion, un document écrit peut être une source digne d'être mentionnée, comme ce "rouleau du maréchal» (rotulus mareschalli) que cite à plusieurs reprises le moine de Westminster. Cette pièce comptable se référant à la rèse de 1390 et probablement parvenue en Angleterre par le truchement d'un homme du comte de Derby a également servi de sources à un autre chroniqueur, Thomas Walsingham ${ }^{16}$. La communication épistolaire est pour sa part attestée dans certains cas, par exemple lorsque le comte de Foix Gaston Fébus écrit depuis Königsberg à deux de ses agents pour leur demander de payer une dette contractée en Prusse (février 1358) ${ }^{17}$. La matière de la lettre est ici toute pratique; toutefois, on ne peut exclure que ce medium ait parfois été utilisé dans un autre but, puisque l'on apprend de l'hôte des Teutoniques dont parle l'auteur des Cent Nouvelles Nouvelles que «le grand bruyt de sa vaillance fut tantost espandu en pluseurs marches, tant a la relacion de ceulx qui veu l'avoyent, en leur païs retournez, que par lectres que les demourez rescripvoient a pluseurs qui grand gré leur en sceurent» ${ }^{18}$. Tant l'oral que l'écrit constituaient donc des moyens répandus de se tenir informé des affaires de la Baltique.

Les auteurs qui ont eu l'occasion de se rendre eux-mêmes en Prusse et en Lituanie peuvent, quant à eux, se prévaloir de leur propre expérience;

\footnotetext{
${ }_{13}$ John Gower, Le Mirour..., dans Complete Works..., vol. 1, p. 264.

${ }_{14}$ PR 1, p. 107-108.

${ }_{15}$ Hanserecesse... 1/5, doc. 639, p. 493; J. H. Wylie, History of England..., vol. 4, p. 8-9. Pour F. R. H. Du Boulay, «Henry of Derby's Crusade... », p. 153, cette supposée nostalgie appartient au registre de la politesse diplomatique.

${ }_{16}$ PR 1, p. 328, n. 510; PR 2, p. 104.

17 F. Pasquier, Gaston Phoebus en Prusse..., avec la lettre éditée (à partir d'une copie fautive), p. 8-11; voir les points de correction amenés par W. Paravicini, Gaston Fébus en Prusse: une aventure chevaleresque au XIV siècle, Ostfildern 2008, p. 44, 63, n. 96.

${ }^{18}$ Sweetser, p. 110.
} 
une bonne partie de nos descriptions de combats ou de traversées de la Wildnis reposent sans doute sur des souvenirs personnels, peut-être exagérés, il est vrai. Guillaume de Machaut tient ainsi à faire savoir qu'il a assisté en personne aux événements qu'il décrit: "Je le vi, pour ce le tesmong / Car partout en seray tesmong ${ }^{{ }^{19}}$, dit-il en préambule de sa narration des campagnes de Jean de Luxembourg en Pologne et en Lituanie. Puis au moment de décrire le baptême des défenseurs du fort de Medvegalis attaqué par les croisés: "Car presens fui a ceste feste, / Je le vi des yeus de ma teste»" ${ }^{20}$. En outre, les auteursvoyageurs ont pu avoir accès à des données supplémentaires en s'informant directement auprès des Teutoniques. Philippe de Mézières annonce tenir certaines histoires "pour vraye[s] des anciens et vaillans chevaliers de la religion susdite [i. e., de l'Ordre teutonique] $\aleph^{21}$. Cet autre amateur d'anecdotes qu'est Guillebert de Lannoy a sans doute appris beaucoup auprès de ses guides. La question reste à savoir dans quelle langue ce noble possessionné sur la frontière linguistique entre dialectes romans et germaniques pouvait s'entretenir avec le grand-maître et ses hommes. Tout ce que l'on sait, c'est que lors de son deuxième passage en Prusse en 1421, il laissa "Aggregy de Hem", un seigneur de sa parenté "avecq le hault maistre, nommé messire Micquiel Cocquemeistre [Küchmeister], où il demoura deux ans pour apprendre alemant»" ${ }^{22}$. Les études menées au sujet du passage du même Guillebert dans les principautés russes de Novgorod et de Pskov ont montré qu'il utilise des termes d'origine germanique pour désigner les réalités locales; on peut supposer qu'une partie au moins de ses informateurs appartenaient au milieu des marchands hanséatiques ${ }^{23}$. Dans le domaine de la communication, les hérauts d'armes ont sans doute joué un rôle, puisque la maitrise des langues faisait partie de leurs qualités, au moins pour certains d'entre eux ${ }^{24}$.

Un élément supplémentaire attestant de la communication orale entre visiteurs francophones et membres de l'Ordre teutonique est l'utilisation d'un terme d'origine germanique pour désigner la Livonie, la province "nordique» de l'Ordre, moins parcourue que la Prusse, mais connue des hôtes. Il est aisé de voir que nos auteurs français avaient faite leur la forme allemande ${ }^{25}$ : Jean de Mandeville parle de «la terre de Niflan» ${ }^{26}$, Philippe de Mézières de

\footnotetext{
${ }^{19}$ Guillaume de Machaut, «Le Confort d'ami», v. 3027-3028, p. 107.

${ }^{20}$ Ibid., v. 3049-3050, p. 108. Pour F. Hartog (Le Miroir..., p. 272-279), le «j'ai vu» est la marque d'énonciation par excellence visant à légitimer un récit de voyage.

${ }^{21}$ Blanchard, vol. 1, p. 209. Sur l'usage de témoignages oraux (directs ou indirects) comme outil de légitimation, F. Hartog, Le Miroir..., p. 279-282.

22 Potvin, p. 52; W. Paravicini, «Zeitenwende...», p. 413.

${ }^{23}$ S. Mund, "Guillebert de Lannoy...", p. 188-191; A. V. Soloviev, "Le voyage de messire de Lannoy...», p. 793.

24 W. van AnrooiJ, «Heralds... ", p. 52.

${ }^{25}$ K. Kựavin̦š, "The Ideology... », p. 267-268.

${ }^{26}$ Jean de Mandeville, Le livre des merveilles..., p. 266.
} 
"Iffelant ${ }^{27}$, Jacques d'Esch de "Yflandre» ${ }^{28}$, Guillebert de Lannoy du "païs de Liuf(f)lant ${ }^{29}$, alors que l'épitaphe funéraire de son frère Hugues a "Liflant»" ${ }^{30}$. Jean Cabaret d'Orville, quant à lui, reprend vraisemblablement la forme utilisée par son informateur, le vieux Jean de Chastelmorand: "Niffelant» ${ }^{31}$. À l'inverse des auteurs proches du milieu des voyageurs de Prusse, ceux du XIII ${ }^{\mathrm{e}}$ siècle, qui écrivaient en latin, désignaient la même province comme Livonia ou Liuonia, tout comme les chroniques latines de l'Ordre teutonique et les documents pontificaux $^{32}$. Marek Tamm a remarqué que l'utilisation de la forme latine est typique du monde clérical, et révèle que le réseau d'informateurs était lié au milieu des Cisterciens ou des Mendiants ${ }^{33}$. On peut en déduire que nos auteurs français ont bénéficié d'une source parallèle: qu'ils soient eux-mêmes passés par l'Ordensstaat ou non, ils ont entendu désigner la province par le terme germanique, sans doute utilisé par les Teutoniques eux-mêmes, leurs hôtes de langue allemande et les guides mis à disposition des voyageurs francophones. À cet égard, le "Layco" ${ }^{34}$ que Philippe de Mézières utilise pour désigner la Lituanie, ainsi que les termes phonétiquement proches que l'on trouve dans les textes français, révèlent sans doute une même origine ${ }^{35}$.

Certes, la volonté d'assurer le lecteur de la véracité du récit n'empêche pas nos auteurs de grossir le trait à l'occasion; ainsi, même Guillebert de Lannoy, qui rapporte avec exactitude la distance séparant deux lieux identifiables par les historiens modernes, ne résiste pas toujours à la tentation de l'hyperbole ou de la

\footnotetext{
27 Blanchard, vol. 1, p. 225.

${ }^{28}$ Wolfram, p. 339.

29 Potvin, p. 28: «Liufflant»; puis «Liuflant» (p. 29 sq.).

30 B. De Lannoy, Hugues de Lannoy..., p. 167.

${ }^{31}$ Chazaud, p. 64-65.

32 Pour les auteurs écrivant en Europe occidentale: Albéric de Trois-Fontaines, Chronica..., p. 872, 887, 912; Roger Bacon, Opus Maius..., éd. J. H. Bridges, vol. 1, p. 358-360; Gervais de Tilbury, Otia..., II, 7, p. 246; Barthélemy l'Anglais, De proprietatibus rerum ..., dans M. TAMM, «Signes...», p. 169.

33 M. TАмм, «Inventing Livonia...», p. 193-195.

34 Blanchard, vol. 1, p. 207 sq.

35 V. Kiparsky, «Philippe de Mézières...», p. 62, n. 1. Ibid., p. 66, note que dans le Songe du vieil pelerin, les Prussiens sont désignés par un terme dérivé de l'allemand, "prûzenaere». De la même manière, Guillebert de Lannoy utilise la forme allemande "Correlant» (Potvin, p. 29-30) et non le Curonia latin pour désigner la Courlande; mentionnant l'isthme de cette région, longue presqu'île permettant de passer de "Keininczeberghe» (Königsberg/Kaliningrad) à "Memmelle» (Memel/ Klaipeda), Guillebert indique que "nomme l'on ce chemin le Strang» (Potvin, p. 28), là aussi d'après le terme allemand. À cet égard, C. Potvin note que "l'orthographe de Ghillebert de Lannoy semble avoir pour but de rendre aussi exactement que possible, pour un lecteur français, la prononciation allemande» (p. 25, n. 5). L'isthme de Courlande était, au Moyen Âge, tenu par les Chevaliers teutoniques. Cette région est aujourd'hui séparée entre la Russie (enclave de Kaliningrad) et la Lituanie: A. Gierszewski, "Organization of Teutonic Military Infrastructure on Curonian Spit from 1283 A. D. up to 1525 A. D. ", Baltijos Regiono Istorija ir Kultura: Lietuva et Lenkija = History and Culture of Baltic Region: Lithuania and Poland, Klaipeda 2007, p. 9-24.
} 
vantardise $e^{36}$. En aucun cas les récits de nos voyageurs ne doivent être lus comme des sources fiables quant aux réalités qu'ils prétendent rapporter. Néanmoins, ils reflètent autant qu'ils participent à créer un imaginaire, une perception partagée du monde balte qui n'est sans doute pas sans lien avec le succès du voyage de Prusse. L'action performative de la littérature sur le phénomène du tourisme moderne a été bien mise en lumière: un écrivain célèbre incite fréquemment ses lecteurs à marcher sur les traces de ses personnages, et une région dans laquelle se déroule l'action d'un roman à succès peut se voir, soudain, fort prisée ${ }^{37}$. La littérature didactique et les chroniques louant les mérites des chevaliers les plus fameux de leur époque ont sans doute contribué à rendre le voyage de Prusse populaire auprès des jeunes nobles. Dans un second temps, certains poèmes ou romans ont pu, à leur tour, participer à l'émergence d'un imaginaire lié à ces voyages $^{38}$. De terrain de croisade, la Baltique devient ainsi terre de légende; moins populaire que l'Orient et moins énigmatique que le Nord lointain, elle fournit tout de même quelques figures romanesques aux auteurs francophones et s'impose comme un monde à part, aux marges de la Chrétienté. Jusqu’à l'adoption du christianisme par la Lituanie et la fin des rèses menées par l'Ordre teutonique, la région balte présente un certain nombre de curiosités «exotiques» qui n'étaient pas dédaignées par les auteurs francophones.

\section{DES FORÊTS ENNEIGÉES ET DES MARAIS GELÉS}

Le succès des croisades de Prusse est sans doute dû, en grande partie, au cadre. Werner Paravicini a montré que l'Ordre teutonique savait mettre à profit un décor raffiné pour créer une ambiance éminemment chevaleresque permettant à ses hôtes de se sentir à leur place. Les tournois, la chasse, mais plus encore l'adoubement devant l'ennemi infidèle, la coutume de porter les bannières et la table d'honneur devaient évoquer aux chevaliers de passage le monde littéraire qui leur était familier ${ }^{39}$. Ce cadre créé par l'homme a sans doute joué un rôle dans le succès de cette entreprise, mais la nature n'est pas en reste. L'un des éléments clefs de cette plongée dans l'univers arthurien devait être le passage de la Wildnis, cet immense espace forestier et marécageux qui séparait les terres tenues par l'Ordre de celles de leurs ennemis. Plusieurs jours étaient nécessaires pour traverser cette région quasiment inhabitée: Jean de Mandeville, l'un des

\footnotetext{
${ }^{36}$ M. Holban, «Du caractère...", p. 423 sq.

37 B. LÉvy, "Géographie et littérature...», p. 25-52. En ce qui concerne la littérature médiévale, C. Deluz, «Partir, c'est mourir un peu...», p. 296, postule que les romans de chevalerie, mais aussi toutes les histoires relevant du folklore ou de la mythologie christianisée, peuvent avoir sensibilisé les nobles à la recherche aventureuse d'un autre monde - et plus prosä̈quement, à la fièvre du voyage. En tout cas, P. Dobrowolski, «Miles...», p. 44, remarque que la famille d'Henri de Derby possédait un manuscrit du Livre de Mandeville.

${ }^{38}$ B. LÉVY, "Géographie et littérature...", p. 12.

39 W. Paravicini, «La Prusse... », p. 176-191.
} 
premiers auteurs à l'évoquer, raconte qu' "il y ad bien III jornees de tiel chemin a passer par Prusse jusques a la terre de Sarazins habitable» ${ }^{40}$; mieux encore, Jean de Chastelmorand parle des "grans fourest de Prusse, qui durent plus de huit journées $"$, alors que pour le héraut Berry, les marais entre la Prusse et le pays infidèle "durent XIIII journées»" ${ }^{42}$. Guillebert de Lannoy, qui dit avoir traversé les forêts qui séparent la Prusse de la Pologne, relate: "m'en alay avecq eulz en armes parmy les forestz de Prusse, l'espace de huit jours, costiant les frontières de Poulane» ${ }^{43}$.

Pénétrer pour la première fois dans un univers où la nature règne en maître, et y vivre plusieurs jours d'affilée, devait produire une impression certaine sur ces jeunes nobles originaires d'une France où la déforestation avait réduit les espaces sauvages à une peau de chagrin ${ }^{44}$. Aussi Werner Paravicini postulet-il que si la cour du grand-maitre évoquait un autre Camelot aux visiteurs, la Wildnis devait être Brocéliande, la "forêt aventureuse " ${ }^{45}$. Familière au lectorat de Chrétien de Troyes et de ses héritiers, elle était l'endroit où l'aventure guette le héros, mais aussi, sur le plan symbolique, un monde en marge de la civilisation chrétienne, peuplé de figures inquiétantes, longtemps associées au paganisme ${ }^{46}$. Pour les aristocrates nourris aux romans de chevalerie, traverser la Wildnis devait être une manière digne de commencer l'expédition contre les «Sarrasins» de Lituanie.

Dans les textes plus anciens, la nature apparait sous une forme plutôt contrastée. Alors qu'aux $\mathrm{IX}^{\mathrm{e}}$ et $\mathrm{X}^{\mathrm{e}}$ siècles, le navigateur anglo-saxon Wulfstan et le voyageur andalou Ibrahim Ibn Yaqub décrivaient la relative richesse des côtes poméraniennes et prussiennes ${ }^{47}$, le chroniqueur Thietmar de Mersebourg (m. 1018) situe la mise à mort d'Adalbert de Prague par les Prussiens dans un pays inculte, sec et plein d'épines ${ }^{48}$. À l'inverse, dans la lettre envoyée depuis Magdebourg aux princes et prélats de la Chrétienté pour les appeler à combattre les Slaves païens (début XII ${ }^{\mathrm{e}}$ siècle), leur terre est décrite comme très prometteuse ${ }^{49}$. Ici s'affrontent deux topoï largement répandus: celui de la

\footnotetext{
40 Jean de Mandeville, Le livre des merveilles..., p. 267.

${ }^{41}$ Chazaud, p. 64.

${ }^{42}$ Hamy, p. 117.

43 Potvin, p. 26.

${ }^{44}$ J. Le GofF, «Lévi-Strauss en Brocéliande», dans L'Imaginaire médiéval..., p. 184-186.

45 W. Paravicini, "L'Ordre teutonique et les courants migratoires...», p. 320. L'impression produite sur l'un des premiers témoins de la croisade balte, le chroniqueur Henri de Livonie, a été étudiée par T. K. Nielsen, "Henry of Livonia on Woods and Wilderness», dans M. TAMm et al. (éd.), Crusading and Chronicle Writing..., p. 157-178.

46 M. Tамм, "Signes...", p. 161-162; M. Pastoureau, "La forêt médiévale: un univers symbolique", dans A. Chastel (dir.), Le Château, la chasse et la forêt, Bordeaux 1990, p. 83-98.

47 D. Mishin, «Ibrahim Ibn-Ya'qub...», p. 184-199.

${ }^{48}$ D. Fraesdorff, Der barbarische Norden..., p. 248-249.

49 Vincent de Prague, Annales..., p. 626; M. Tамм, «A New World...», p. 21-22.
} 
terre promise, de la richesse des pays étrangers, et celui du paysage oppressant et inhabitable, caractéristique supposée des terres païennes ${ }^{50}$.

Le contraste entre une mise en scène de la fertilité et de la nature sauvage peut s'expliquer par le programme idéologique qui sous-tend les productions textuelles à partir du XII ${ }^{\mathrm{e}}$ siècle. D'une part, la description de terres riches et fertiles devait attirer les colons, comme c'est le cas pour l'appel de Magdebourg; d'autre part, la présence de forêts et de marécages marque le caractère sauvage de l'espace à conquérir ${ }^{51}$. Autrement dit, ces "terres promises" n'attendent que d'être prises pour que l'on puisse en tirer le maximum ${ }^{52}$. Ainsi, il n'est peut-être pas innocent que Barthélemy l'Anglais, pas plus que l'auteur du Descriptiones terrarum, ne mentionnent aucunement les villes et les forteresses de Livonie, qui pourtant existaient déjà à leur époque ${ }^{53}$. Cela dit, le fait de voir l'abondance de lacs, de rivières, de marais et de forêts apparaître dans les descriptions de la région balte à côté de mentions d'une relative richesse en blé ou en poisson peut également être le reflet d'une certaine réalité contemporaine ${ }^{54}$. Gardonsnous donc d'y voir uniquement des clichés littéraires; Barthélemy mentionne la fertilité et l'abondance d'eau pour des régions que rien ne permet de considérer comme païennes ${ }^{55}$.

Entre le stéréotype de la fertilité et celui de la nature inhospitalière, c'est clairement ce dernier qui l'emporte. Déjà pour le géographe Muhammad Al-Idrīsī, qui écrivait à la cour de Sicile au $\mathrm{XI}^{\mathrm{e}}$ siècle, les villes baltes et leurs habitants sont plongés dans un monde glacial, hivernal ${ }^{56}$; le caractère païen des Baltes semble aller de pair avec la rudesse de la nature qui les entoure. Les marais en particulier sont liés à l'habitat des païens baltes depuis Adam de Brême, qui raconte que les Prussiens vivent "au-delà de marécages inaccessibles et n'admettent le joug d'aucun maître " ${ }^{57}$; à noter que déjà chez

\footnotetext{
50 Ibid., p. 22-25; R. Siminski, «Ex Livonia... », p. 200. Pour comparaison, le premier chroniqueur de la Pologne médiévale Gallus Anonymus fait de la "Sclavinia» une terre promise: Gallus Anonymus, Gesta..., p. 14-15.

51 M. TAmm, «Signes...», p. 162-163; P. Gautier Dalché, «Représentations...», p. 74.

52 M. ТАмм, "A New World...", p. 21-22.

53 M. Tамм, "A New World...», p. 25. S. Rossignol, «Early Towns...», p. 241-252, fait la

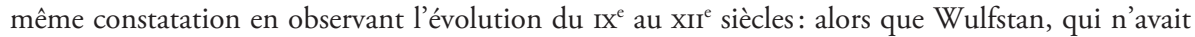
aucun intérêt à présenter les Prussiens comme barbares, mentionne leurs villes, le chroniqueur polonais Gallus Anonymus décrit leur pays comme désert - autrement dit, une terre païenne prête à être conquise.

${ }^{4}$ D. Maкоwiecki, «Exploitation of Early Medieval Aquatic Environments in Poland and other Baltic Sea Countries: and Archaeozoological Consideration", dans L'Acqua nei secoli altomedievali, Spoleto 2008, vol. 2, p. 757. Les chroniques russes du XII et $\mathrm{XIII}^{\mathrm{e}}$ siècles mentionnent la richesse des terres des Jatvingiens; A. Kuncevičıus, «Les Origines... », p. 40-41.

55 M. ТАмм, «Signes...», p. 163.

${ }^{56}$ Muhammad Al-Idrīsī, Livre de la récréation..., $4^{\mathrm{e}}$ section, $7^{\mathrm{e}}$ climat, vol. 2, p. 431.

${ }^{57}$ Adam de Brême, Gesta... IV, 18, p. 246. On rapprochera cet extrait de Gallus Anonymus au sujet de l'habitat des Prussiens: Gesta..., p. 194-195.
} 
Tacite, les marais et les forêts recouvraient l'essentiel de la Germanie ${ }^{58}$. Pour Barthélemy l'Anglais, la Lituanie "est protégée par des forêts et des marais, il y a peu de protections autres que les rivières, les forêts et les marais. C'est pourquoi il difficile de conquérir cette région en été; on ne le peut qu'en l'hiver, lorsque les plans d'eau et les fleuves sont gelés" ${ }^{59}$. On sait par d'autres sources que les lacs, les marécages et les grands espaces forestiers appartiennent à la réalité du terrain à l'époque des croisades baltes ${ }^{60}$ : une donnée topographique ou naturelle a donc pu être mise en avant dans la littérature, peut-être au détriment d'autres éléments qui avaient moins de sens pour les auteurs ${ }^{61}$. Si parmi les réalités très diverses de la nature balte on ne parle que de la forêt et des marécages, c'est parce qu'ils marquent un paysage symbolique, que leur évocation pose une ambiance connue des lettrés occidentaux, et qui appartient à l'horizon d'attente de leurs lecteurs.

Du reste, il n'y a pas que les provinces baltes où les éléments naturels servent à évoquer un autre monde littéraire. Lorsque Guillebert de Lannoy relate son voyage au "trau Saint-Patrice», lieu de pèlerinage en Irlande où la légende situe une porte vers le purgatoire, notre Bourguignon prend soin de raconter les forêts si épaisses que l'on doit y pénétrer à pied, "pour ce que nulz chevaulx n'y peuvent passer, pour les arbres abatus» ${ }^{62}$, et les lacs que l'on doit traverser pour atteindre le but du pèlerinage, situé, comme il se doit, sur une île ${ }^{63}$. Guillebert semble avoir tenu à ce voyage, qu'il dit avoir tenté de faire déjà après son premier périple balte, avant qu'il ne soit capturé par les Anglais. À en croire ses notes, il put l'accomplir en 1430, après une ambassade auprès du roi d'Écosse ${ }^{64}$. Autant que la Prusse, le nord-ouest des îles Britanniques semble avoir plongé notre voyageur dans un univers romanesque: au moins trois châteaux construits près de la frontière anglo-écossaise seraient, d'après la rumeur, liés aux histoires de Lancelot et d'Arthur ${ }^{65}$. À l'inverse des villes relevant du roi d'Angleterre, la terre des "Hirlandois sauvaiges» ${ }^{66}$ est caractérisée par sa pauvreté. Même le "roy Auraly", un vassal du roi d'Angleterre, "demeure en une meschante place et povre tour sur la ville» de Cavan, "povre ville non fermée" ${ }^{67}$. Avec ses îles, ses lacs, ses

\footnotetext{
58 Tacite, La Germanie, 5, éd. et trad. J. Perret, p. 73.

59 M. ТАмм, «Signes...", p. 168; voir aussi Ibid., p. 169.

${ }^{60}$ Notamment les Lithauische Wegeberichte, des rapports préparés pour faciliter les rèses, et en particulier la traversée de la Wildnis; T. Čelkis, "Keliais po viduramžių Lietuvą. II: XIII-XV amžiaus pradžios karo žygių sąlygos", Lituanistica 59/3 (93), 2013, p. 125-137 (résumé en anglais); S. C. Rowell, Lithuania Ascending..., p. 49.

${ }^{61}$ T. Barnwell, Missionaries..., p. 213.

${ }^{62}$ Potvin, p. 170.

${ }^{63}$ Potvin, p. 169-171. Sur cet épisode, M. Nejedlý, "Spisy...», p. 111-112 et l'étude de

W. Paravicini, «Fakten und Fiktionen...", p. 111-163.

${ }_{64}^{6}$ Potvin, p. 166-167.

${ }^{65}$ Ibid., p. 168-169.

${ }^{66}$ Ibid., p. 171.

${ }^{67}$ Ibid., p. 169.
} 
forêts, sa désolation et ses légendes, l'Irlande, fréquemment traitée comme une terre des marges de la Chrétienté ${ }^{68}$, n'a rien à envier à la Lituanie - si ce n'est, bien sûr, les Sarrasins à combattre ${ }^{69}$.

En ce qui concerne les pays de la Baltique, ce qui ressort des textes occidentaux est moins la forêt en tant que telle que le climat glacial qui accompagnait les rèses d'hiver, les plus fréquentées mais aussi les plus racontées ${ }^{70}$. Le jugement du célèbre encyclopédiste du XIII siècle Barthélemy l'Anglais, pour qui l'on ne pouvait envahir la Lituanie qu'en hiver à cause des cours d'eau et des marais, est répété par de nombreux auteurs. Déjà en 1356, Jean de Mandeville développe cette idée ${ }^{71}$ :

"Qar homme ne poet faire ceo chemin bonement, sy noun par temps d'yvern, pur les chaitives eawes et pur les marois qe sont en celles parties, qe homme ne poet passer s'il ne giele durement, et s'il n'ad durement neigee par dessure. Qar si la noif n'estoit, homme ne porroit passer la glace, ne homme ne chival. ${ }^{72}$

Par la suite, cette donnée est intégrée à plus d'une description des campagnes lituaniennes. Pour Philippe de Mézières, c'est le golfe de Courlande qui marque l'entrée sur le territoire des païens: "toutes les fois qu'i [le grand maitre] fait besoing aler en ost contre le roy de Laito et passer la glace de l'estanc de Quemsberch [Königsberg], qui a en travers .vii. lieues d'Alemaigne » ${ }^{73}$. Lorsqu'il raconte la rèse de l'hiver 1400 contre les Samogitiens, l'ancien croisé Jacques d'Esch précise que:

"On queil payx ait pou de forteressez for que plaitez villez; car on ne puet entrer on dit pays, se dont n'est par tres grant sachoibre ou per tres grant temp de gellee et de nois. [...] Car le dit payx est baix et plain de crallierez et de mairesierez et n'est d'autre chose fort. Et se tiennent pour ainsi fort payx qu'ilz ne veullent a nullui obeyr for qu'a yaulx meysmez, se dont n'est par maistrie. $»^{74}$

Un dernier point qui n'est pas sans rappeler Adam de Brême et sa description des Prussiens de Sambie, vivant au-delà des marécages et ne reconnaissant l'autorité d'aucun maitre: l'insubordination politique et le fait d'habiter dans un environnement inhospitalier devait évoquer le caractère barbare des païens

\footnotetext{
${ }^{68}$ Voir par exemple J.-M. Borvin, L'Irlande au Moyen Âge, Paris-Genève 1993.

${ }^{69}$ Le parallèle entre les «confins» baltes et celtiques est proposé par P. Dembowski, "Reflets chevaleresques...», p. 137-143, notamment à partir du Méliador de Jean Froissart. Voir aussi W. Paravicini, «Fakten und Fiktionen...», p. 140.

${ }^{70}$ W. Paravicini (PR 2, p. 54-55) remarque qu'en Europe occidentale, on menait rarement une expédition militaire en hiver; aussi, les rèses d'hiver devaient être vues comme "typiquement" prussiennes, quand bien même d'importantes rèses avaient lieu en été.

${ }_{71}$ Sur l'identification de cet extrait aux guerres de Prusse, PR 2, p. 53 ; A. V. MurraY, «Saracens... », p. 416-417.

72 Jean de Mandeville, Le livre des merveilles..., p. 267.

73 Blanchard, vol. 1, p. 215. V. Kiparsky, «Philippe de Mézières...", p. 66, précise que le golfe de Courlande, "en effet, est large d'environ 45 kilomètres, c'est-à-dire presque 61/2 lieues allemandes».

${ }^{74}$ Wolfram, p. 337-338.
} 
de la Baltique. Ces deux éléments forment un topos qui reste attaché aux pays «infidèles" de la région, même après la fin de la croisade contre les Lituaniens. Au milieu du Xve siècle encore, le héraut Berry (Gilles le Bouvier) présente ainsi le territoire où les croisés pénétraient à l'époque où l'on venait en Prusse pour harceler ce qu'il appelle la "Tartarie»"

"Et joignant de ce païs [la Prusse] sont les maraiz de Multitude, où devant les guerres de France aloient voiager les nobles chevaliers et escuiers des Marches de France, et des aultres royaulmes joignans. Et montoient en mer, en Flandres, et s'en aloient en Pruce. Ou moys de février partoient de Pruce, et passoient iceulx maraiz, et menoient leur vivres en charrectes et charios. Et entroient au païs de Tartarie et passoient les glaces qui estoient en ce maraiz. Et de nuit se repousoient sur yllectes de boys et de terre qui sont esdits marais, qui durent XIIII journées, car aultrement ne porroient passer, sinon l'iver. Et quant ilz sont en Tartarie ilz boutent feux par les pays, et font de domaige beaucoup. Puis s'en retournent avant que les glaces fondent qu'ilz ne porroient résister contre la puissance du grant Can de Tartarie. Et y passent cent mille personnes de tous les royaulmes crestiens. Et appellons ce voiage le Reses de Pruce. ${ }^{76}$

En ce qui concerne les représentations symboliques, le fait d'insister sur les marais impénétrables devant protéger les infidèles n'est pas innocent; l'élément aquatique est, tout comme la forêt, un marqueur d'altérité mettant en évidence le caractère "barbare», non-chrétien de ceux que l'on va combattre ${ }^{77}$. Il est relativement aisé de suivre, sur ce point, une tradition littéraire prenant forme à l'époque où les rèses de Prusse sont devenues populaires. Associée à la Baltique depuis Adam de Brême, la thématique du marais est popularisée par l'encyclopédie de Barthélemy l'Anglais, adaptée en français sur commande du roi Charles VI en $1372^{78}$. Les auteurs écrivant au tournant $\mathrm{du} \mathrm{xv}^{\mathrm{e}}$ siècle ont pu tout simplement trouver cette information chez le célèbre encyclopédiste, ou chez Jean de Mandeville. Ce dernier, que l'on sait être au moins partiellement un voyageur de cabinet, a vraisemblablement puisé une partie de sa peinture du périple hivernal en partance de Prusse dans les récits de voyage en Orient, fort populaires à partir du XIII ${ }^{\mathrm{e}}$ siècle:

"Il y ad bien III jornees de tiel chemin a passer par Prusse jusques a la terre de Sarazins habitable. Et convient qe les christiens qe y vont touz les aunz pur combattre a eux portent toutes les vitailles ovesqez eux, qar la ne troeveront ils

\footnotetext{
75 Les marais séparant la Prusse du "pays des Tatars" sont mentionnés à une autre occasion: Hamy, p. 80.

${ }^{76}$ Ibid., p. 117.

77 M. Tамм, «Signes», p. 162-163.

78 Barthélemy l'Anglais, Le Grand Propriétaire de touttes choses, trad. J. Corbechon, éd. P. Farget, Paris 1556, col. 130. Voir l'introduction de B. Ribémont dans Barthélemy l'Anglais, Le Livre des propriétés des choses...
} 
nuls biens. Et font charoier lour vitaille par dessure la glace as charioz sans roes q'ils appellent soleies. Et tant come lour vitaille dure ils poent la demorer, et nient plus, qar la ne troveroient ils qe lour vende rien. ${ }^{79}$

La nécessité de prendre ses vivres avec soi, du fait que l'on ne saurait acheter quoi que ce soit auprès des habitants, rappelle le récit de Guillaume de Rubrouck, l'émissaire franciscain de Louis IX parti en 1253 auprès du grand khan mongol. À noter que cet auteur, dont l'œuvre a connu une immense popularité, ne parle pas en ces termes de la Prusse ni des régions baltes, mais de la Russie soumise au joug $\operatorname{tatar}^{80}$. Tout comme Marco Polo, dont la description des bains de vapeurs russes a vraisemblablement donné une autre idée à Mandeville pour sa dépiction des terres sarrasines situées non loin de la Prusse ${ }^{81}$ :

"Et sachez q'y gele plus fort assez en celles parties qe de cela. Et pur ceo ad chescun estuves en sa maisoun, et en celles estuves ils mangent et font lour besoignes ceo qu'ils poent. Qar ceo est as parties septentrionels, ceo est a dire vers bise ou il fait vivement froid, qar le solail n'approche point ou poy vers celles parties. Et pur ceo en droit septentrion, ce est au droit north, est la terre si froide qe l'em ne poet habiter. " ${ }^{82}$

Jean de Mandeville a sans doute compilé ici plusieurs encyclopédies et récits de voyages composés au siècle précédent, tout en influençant peut-être à son tour Jacques d'Esch et Gilles le Bouvier. Les marais gelés de Lituanie ne seraient-ils donc qu'une création littéraire, popularisée par des auteurs ayant, consciemment ou non, su capter la charge symbolique d'une telle description?

Certains détails techniques laissent imaginer que plusieurs d'entre eux parlaient d'expérience, ou avaient au moins entendu quelques récits de croisés revenus de rèse. Ainsi en est-il du passage où Mandeville parle des «charioz sans roes q'ils appellent soleies " ${ }^{83}$; Guillebert de Lannoy, qui s'est sans aucun doute rendu sur la Baltique, dit avoir parcouru la Livonie, la Russie et la Lituanie

\footnotetext{
79 Jean de Mandeville, Le livre des merveilles..., p. 267-268.

${ }^{80}$ Racontant leur progression dans la région du Don soumis aux Tatars, Guillaume de Rubrouck précise qu'il lui était impossible ainsi qu'à ses compagnons d'acheter de la nourriture avec de l'argent européen; aussi étaient-ils totalement dépendants de leurs guides (Guillaume de Rubrouck, dans The Texts and Versions..., p. 162). Ce qui peut également attester une reprise de Rubrouck par Mandeville est la mention de Batu Khan, juste avant la description des rèses de Prusse (Jean de Mandeville, Le livre des merveilles..., p. 266), le puissant chef mongol étant nommément mentionné par le voyageur flamand (Guillaume de Rubrouck, dans The Texts and Versions..., p. 162 passim).

${ }^{81}$ Le voyageur vénitien lie explicitement l'usage des étuves à la rigueur du climat: "et s'il n'y avait pas les nombreuses étuves, les gens ne pourraient éviter de mourir de froid» (Marco Polo, Il Milione, éd. L. F. Benedetto, Florence 1928, trad. S. Mund, "Constitution...», part. 2, p. 565); sur les étuves comme symbolisant le froid russe, ibid., p. 549, 565-566.

82 Jean de Mandeville, Le livre des merveilles..., p. 268.

${ }^{83}$ Ce point a été soulevé par A. V. MurraY, «Saracens... », p. 417-418. Voir aussi PR 2, p. 52-66.
} 
sur des «sledes»" ${ }^{84}$. Il s'agit ici de traîneaux, appelés sledy en russe, slede en bas-allemand et en flamand, slito en haut-allemand ${ }^{85}$; comme le remarque Stéphane Mund, c'est probablement aux langues germaniques de ses guides que Guillebert a emprunté le mot $^{86}$. Du reste, l'utilisation de traîneaux pour permettre à l'armée croisée de traverser les marais gelés lors d'une rèse d'hiver est bien documentée ${ }^{87}$. Il n'y a donc rien d'improbable à ce que nos auteurs se soient contentés de rapporter ce qu'eux-mêmes avaient vu ou entendu raconter. Il en va de même des "yllectes de boys et de terre qui sont esdits marais" ${ }^{88}$ sur lesquels les croisés se reposent. Le héraut Berry, qui a visité la région plusieurs décennies après la fin des rèses, a simplement gardé en mémoire le souvenir des camps que l'armée teutonique dressait pour passer la nuit dans la Wildnis ${ }^{89}$. De même, les Wegeberichte, de courtes descriptions des routes à utiliser par l'armée teutonique, font état des difficultés climatiques et naturelles, et laissent entendre qu'il était effectivement préférable d'attendre que les zones marécageuses soient gelées ou très sèches pour s'y aventurer ${ }^{90}$. Enfin, les comptes laissés par certains croisés font état de haches utilisées pour se tailler un chemin dans la Wildnis, qui était donc bien connue des futurs hôtes de l'Ordre teutonique. Même les chariots devant porter les bagages du riche Henri de Derby n'ont pas été assez solides pour affronter les conditions du terrain ${ }^{91}$.

Vécue par ceux qui participaient à la rèse d'hiver et avaient l'occasion de quitter les châteaux de l'Ordre pour pénétrer en territoire ennemi, la traversée de la Wildnis couverte de neige et de glace devient un motif obligé de toute narration d'un voyage en Prusse ${ }^{92}$. L'une des descriptions les plus saisissantes de l'hiver lituanien est peut-être due à Guillaume de Machaut, qui dans le Confort d'ami, rappelle que son patron, Jean de Bohême, mena la guerre "par les glaces en Letoe ${ }^{93}$. D'après Albert Prioult, un extrait d'un autre poème, Le dit dou lyon (1342), pourrait être un rappel de ce que vécut l'auteur lors de

\footnotetext{
${ }^{84}$ Potvin, p. 32 sq.

85 A. Soloviev, "Le voyage de messire de Lannoy...", p. 792, n. 10; J. Svátek, Discours..., p. 356-357. Voir aussi les termes actuels «schlitten» (allemand), «sleigh» (anglais).

${ }^{86}$ S. Mund, "Guillebert de Lannoy...", p. 191.

${ }^{87}$ PR 2, p. 55, 77. L'éditrice du Livre de Mandeville, C. Deluz (Jean de Mandeville, Le livre des merveilles..., p. 271, n. 35), fait également le rapprochement entre le «soleies» de Mandeville et le terme flamand sledde, qu'elle suppose que l'auteur a pu apprendre à Liège, où il semble avoir longtemps séjourné.

${ }^{88}$ Hamy, p. 117.

${ }^{89}$ PR 2, p. 88-89, 112. T. Čelkis note que des ponts étaient parfois construits pour permettre aux armées teutoniques de traverser certaines rivières: «Keliais po viduramžių Lietuvą... », p. 125-137.

${ }_{90}$ Id; S. C. Rowell, Lithuania Ascending..., p. 49.

91 T. Guard, Chivalry..., p. 87-88, qui mentionne les comptes relatifs à l'expédition de Thomas Stafford, lequel devait accompagner le duc de Gloucester en 1391 (Staffordshire Record Office, D644/1/2/4 mm. 3, 4), ainsi que Expeditions..., p. 50.

${ }_{92}$ PR 2, p. 94.

${ }^{93}$ Guillaume de Machaut, «Le Confort d'ami...», v. 3034, vol. 3, p. 107.
} 
sa participation à l'aventure ${ }^{94}$. Pestant contre les jeunes seigneurs douillets qui n'osent s'aventurer au-delà de la cour, Guillaume leur oppose une vie de véritable guerrier:

"Je soushaide que tels gens fussent

En païs ou il ne sceüssent

Chemin, ne voie, ne sentier;

[...]

Et si feïst si grant froidure,

Comme il doit faire par nature

A Noël, pour vëoir la guise;

Et si ventast li vens de bise

Taillans, bruians, fort, roide et sec,

[...]

Et qu'il fust noire nuit serrée,

Pleinne de froit et de jalée,

Si ne peüssent chevauchier;

N'il n'eüst ville ne clochier

Près a trois lieues ou a quatre,

Par quoy il s'alassent esbattre;

Et que d'aucune mortel guerre

Fussent espandu par la terre

Tout environ li annemi. ${ }^{95}$

Le poète champenois ne précise pas s'il s'agit d'une allusion à son équipée lituanienne, mais la nature hivernale et le climat extrême forment le décor d'une aventure guerrière jugée digne d'un vrai chevalier ${ }^{96}$. Dans les textes plus tardifs, même l'arrivée en Prusse, pourtant terre des très chrétiens Chevaliers teutoniques, ressemble à un périple à travers un désert de neige et de glace. Pour se rendre à Marienbourg, les figures allégoriques du Songe du vieil pelerin de Philippe de Mézières «se mistrent au chemin et trespasserent par mainte grant forest, par mainte riviere engellee, passant dessus la glace»" ${ }^{97}$. De manière encore

\footnotetext{
94 A. Prioult, «Un poète voyageur... », p. 18-20.

95 Guillaume de Machaut, «Le dit dou Lyon», v. 1271-1299, dans Euvres..., vol. 2, p. 203-204.

${ }_{96}$ Un climat extrême n'est toutefois pas le propre des campagnes en territoire balte. Sans y trouver d'équivalent avec la Wildnis en termes d'espace entièrement sauvage, la Flandre et les principautés situées au nord du royaume de France avaient de quoi rivaliser avec la Prusse: voir par exemple la campagne de Charles VI contre Gand, en novembre 1382 (F. Autrand, Charles VI, Paris 1986, p. 126).

${ }^{97}$ Blanchard, vol. 1, p. 210.
} 
plus formidable, Jean de Chastelmorand et ses compagnons «entrèrent es glaces gelées des palus de Prusse, et tant se trainèrent par les glaçons, comme il est delà la coustume, qu'ils vindrent à Mariembourg, le grant hostel de la religion des chevaliers de Prusse»" 98 .

À la fin du XIv ${ }^{e}$ siècle, le pays des Teutoniques est devenu, dans le milieu aristocratique, synonyme de nature farouche et désolée. Ainsi Froissart fait-il dire aux barons et écuyers de France qui suivirent l'amiral Jean de Vienne dans une expédition en Écosse: "En quelle Prusce nous a chi amenés li amiraux?"》99. Toutefois, contrairement aux rèses contre les païens baltes, la campagne menée pour appuyer les alliés écossais "ne nous est point proufitable, ne honnerable» ${ }^{100}$ : le pays est pauvre, la noblesse en est absente, et les seigneurs français n'ont pas droit au confort auquel ils sont habitués. Et surtout, il n'y a pas d'infidèles à combattre. L'habitude de parler de manière imagée de la Prusse comme des confins du monde est illustrée par Eustache Deschamps, qui, dans sa ballade "Helas! bien doy mon temps plaindre et gemir», dit avoir cherché la Vérité jusqu'en Prusse et en Russie ${ }^{101}$. Le même poète lie également les expéditions baltes à l'inconfort et au froid, lorsque dans son "Autre balade sur les mandemens faiz pour la guerre de France", il déconseille de participer à une guerre ayant lieu en hiver: "Et si estes du chief trop dolereux: / Autre querez qui ceste rese face» ${ }^{102}$. Le mot étranger rèse est cité sans explication, ce qui laisse penser qu'à l'époque où Deschamps écrivait, il était entré dans le vocabulaire de son public, qui devait comprendre de quoi il s'agissait ${ }^{103}$.

Au Xv $v^{e}$ siècle, non seulement la Prusse et la Lituanie, mais aussi la Pologne et la Russie, sont couramment décrites comme des régions froides ${ }^{104}$. Guillebert de Lannoy, qui a visité les principautés de Novgorod et de Pskov pendant l'hiver 1413-1414, garde ses expressions les plus épiques pour dépeindre l'hiver russe et ses "merveille $[s]$ de froit»" ${ }^{105}$, mais note tout de même que "fit cette saison sy grant froidure es païs de Russie, de Létau et de Liuflant, que moult de poeuple morut et engella de froit» ${ }^{106}$. Quant à lui, Gilles le Bouvier reconnaît que la Prusse "est un très bon païs de blez et de bestial et de poissons»" ${ }^{107}$, "moult fertil paï et abondant en blez» ${ }^{108}$, mais fait de la Lituanie «le plus froit païs du monde,

\footnotetext{
98 Chazaud, p. 64.

99 Jean Froissart, Chroniques..., éd. J. Kervyn de Lettenove, vol. 10, p. 336; PR 2, p. 94.

100 Jean Froissart, Chroniques..., éd. J. Kervyn de Lettenove, vol. 10, p. 337.

101 Eustache Deschamps, "Helas! bien doy mon temps plaindre et gemir» (Chançon royal 40), 355, dans Euvres complètes..., vol. 3, Paris 1882, p. 85.

102 Ibid., vol. 5, p. 63, n 879 .

103 PR 2, p. 112.

104 A. Grabski, Polska w Opiniach Europy..., p. 113-114.

105 Potvin, p. 34-35; S. Mund, «Constitution... », Part. 2, p. 548-550.

106 Potvin, p. 44.

107 Hamy, p. 81.

108 Ibid., p. 116.
} 
car il est entre le couchant et le levant ${ }^{109}$. Humanistes voyageurs ou écrivant à partir de sources de deuxième main leur emboîtent le pas, à l'exemple du futur Pie II, Énée Sylvio Piccolomini, qui raconte que la Lituanie est un désert de glace que l'on doit parcourir de nuit, en s'orientant d'après les étoiles, comme sur la mer ${ }^{110}$. Un avis amené à passer chez les cosmographes du Xvi ${ }^{\mathrm{e}}$ siècle, à l'exemple de l'adaptateur de Sebastian Münster, François de Belleforest ${ }^{111}$.

\section{DE L'HÉRoÏSATION À L'INTÉRÊT «TOURISTIQUE»}

Activité éminemment aristocratique encadrée par des officiers de l'Ordre teutonique soucieux de faire vivre leurs hôtes dans le cadre le plus chevaleresque possible, mais aussi plongée dans un monde d'aventures où l'on traverse d'immenses forêts pour aller combattre les ennemis de la foi, le voyage en Prusse est célébré par ceux qui entendaient honorer le mode de vie des nobles de leur époque. Le réalisme avec lequel on peignait ce phénomène s'évapore quelque peu à partir $\mathrm{du} \mathrm{Xv}^{\mathrm{e}}$ siècle, quand se rendre auprès des Teutoniques pour combattre les païens devient de plus en plus rare. Le voyage de Prusse entre progressivement dans le domaine de la fiction pure, se confondant avec les grandes croisades épiques chez Antoine de la Sale, et même avec le cycle arthurien, lorsqu'un armorial imaginaire des Chevaliers de la Table Ronde (v. 1440-1450) intègre et attribue des armories, comme à tous les autres chevaliers, à un certain Hoscalem le Prussien, qui crie «Pruce, Pruce! ${ }^{112}$.

De même, si l'immense Wildnis enneigée, avec ses forêts impénétrables et ses marais gelés, avait de quoi rappeler une autre Brocéliande aux croisés - et plus encore au public des écrivains relatant leurs aventures - il n'y a rien d'étonnant à voir certaines figures littéraires apparaitre dans nos récits. Après avoir raconté l'arrivée épique de ses héros à Marienbourg, Jean Cabaret d'Orville nous apprend que ceux-ci «estoient venus si bien à point que merveilles. Car le roi de Letho, sarrasin, avoit fort emprins de grever et conquester l'ordre de Prusse, et pour estre plus fort, s'estoit adjoint au roi de Norgalles» ${ }^{13}$. Ce dernier personnage est difficilement identifiable ${ }^{114}$ : peut-être s'agit-il de Korybut, le prince lituanien de Novhorod-Siverskyi (actuellement dans le nord de l'Ukraine), contre qui les Teutoniques et leurs hôtes combattaient dans les années $1390^{115}$. Même si

\footnotetext{
${ }^{109}$ Ibid., p. 80.

110 Énée Sylvio. Piccolomini, Historia de Europa, XXVI, SRP 4, p. 237.

111 François de Belleforest, La Cosmographie Universelle..., col. 1815.

112 PR 1, p. 43, n. 154a; Armorial des chevaliers de la table ronde, éd. M. Pastoureau, Paris 1983, doc. 100 , p. 76 .

113 Chazaud, p. 64.

114 A. V. Murray, «Heathens...», p. 219, traduit par «Novgorod»; S. Gouguenheim, Les Chevaliers teutoniques..., p. 585, par «Norvège».

${ }^{115}$ La participation de Korybut et de ses «Russes» à la guerre menée contre l'Ordre en 1390-1391 est mentionnée par les chroniques et les traités de paix; Wigand de Marbourg, Chronica..., SRP 2, p. 641 passim; SRP 3, p. 172-176; Codex Diplomaticus Lithuaniae..., p. 76-78. Sur le problème de
} 
le récit de Cabaret d'Orville et de son informateur, Chastelmorand, se réfère probablement à la rèse de 1374-1375, le fait que le chroniqueur mentionne la présence de Boucicaut à Marienbourg peut laisser entendre qu'il y a eu confusion avec une autre expédition, peut-être celle à laquelle le maréchal prit part en été 1391.

Quoiqu'il en soit, le roi de Norgalles n'apparaît sans doute pas ici par hasard: ce terme révèle une connotation romanesque, arthurienne, qui n'est pas sans intérêt. Le même mot désignait à l'origine le nord du Pays de Galles, mais le sens est peu à peu devenu flou pour les auteurs français ${ }^{116}$. Dans le cycle de Tristan en prose, Norgalles est un royaume dont le souverain, Lamorat, combat le roi d'Irlande, lequel est aidé par Tristan ${ }^{117}$. C'est dans ce sens que le terme apparaît dans Le Chevalier errant, roman rédigé par Thomas III d'Aléran, marquis de Saluces, autour de $1394^{118}$. Quelques décennies plus tard, un certain Galegantin, roi de Norgalles, fait son apparition aux côtés d'Hoscalem le Prussien dans le même armorial factice de la Table ronde ${ }^{119}$. À la fin du Moyen Âge, le mot avait pris, au moins dans certains contextes, une forte connotation arthurienne. La présence d'un "roi de Norgalles» comme allié du "roi de Letho" n'est donc pas surprenante. Bien sûr, Cabaret d'Orville ou Chastelmorand (qui écrivaient en 1429, soit presque un demi-siècle après les événements) n'avaient certainement pas imaginé qu'un éventuel souverain gallois serait accouru au secours de Jagellon; il s'agit plutôt de contamination d'un terme propre à l'espace baltique (peut-être Novhorod, ici) avec ce vague "Norgalles» chargé d'un coloris arthurien qui n'est pas étranger à l'ambiance des voyages en Prusse.

Le même processus est sans doute à l'œuvre chez les auteurs qui utilisent des termes issus non pas de la matière de Bretagne, mais de la géographie classique pour désigner certaines régions proches de la Prusse - à l'instar de la "Sarmatie», qui fait son apparition aux lendemains de la bataille de Tannenberg pour désigner, dans la chronique d'Enguerrand de Monstrelet, l'origine d'une partie des vainqueurs ${ }^{120}$. Chez le héraut Berry, c'est dans «les maraiz de Multitude»

datation quant à l'extrait prussien de Cabaret d'Orville, voir chapitre III. Novhorod-Siverskyi, en actuelle Ukraine, ne doit pas être confondue avec la principauté médiévale russe de Novgorod (act. Veliki Novgorod), ni avec Nijni Novgorod, deux villes actuellement en Russie.

116 J. Marx, La Légende arthurienne et le Graal, Genève 1952 p. 365, n. 4.

117 Le Roman en prose de Tristan, éd. E. Löseth, Genève 1974, p. 341-347.

118 Thomas III de Saluces, Il libro del Cavaliere errante (BnF ms. fr. 12559), éd. Marco Piccat, Boves 2008, p. 720-721; Thomas III de Saluces, Le Chevalier errant, trad. D. Chaubet, Turin 2001, p. 111-112.

119 M. Pastoureau, Armorial..., doc. 79, p. 68.

${ }_{120}$ Monstrelet parle du «roy» et du «connestable de Sarmac(h)» (Douët d'Arcq, vol. 2, p. 75). Il s'agit peut-être d'un amalgame entre le nom de la Samogitie et celui de la Sarmatie antique; voir aussi la lettre du roi Sigismond de Hongrie transmise par le chevalier Wenceslas de Miska (20 août 1410): SRP 3, p. 403. De la même manière, Énée Sylvio Piccolomini appelle les Samogitiens «Massagètes »: De Livonia, SRP 4, p. 231. 
qu' "aloient voiager les nobles chevaliers et escuiers des Marches de France» ${ }^{121}$. Un peu plus tôt, l'auteur précise que dans ces "marés de Motilde», situés "entre Pruce et Tartarie", naissent les rivières qui coulent en Russie ${ }^{122}$. Pour l'éditeur, il s'agit des marais de Pinsk (ou marais du Pripiat), au sud de l'actuelle Biélorussie, qui sont ici désignés par le terme antique "marais méotides». Or, il semble peu probable que les Teutoniques, dont les rèses visaient avant tout la Samogitie, aient pu traverser tout le grand-duché pour pénétrer dans cette région située beaucoup plus au sud. Au $\mathrm{XI}^{\mathrm{e}}$ siècle, Adam de Brême utilisait la même dénomination (en parallèle de "marais de Scythie») pour qualifier soit l'ensemble de la mer Baltique, soit un espace correspondant au lagon de Szczecin, aujourd'hui partagé entre l'Allemagne et la Pologne ${ }^{123}$. Chez ce chroniqueur, les marais méotides, qui dans la géographie antique désignent la mer d'Azov" ${ }^{124}$, ont visiblement migré avec toute la cosmographie "scythe" pour être collés aux régions mal connues d'Europe du Nord ${ }^{125}$. Gilles le Bouvier, notre héraut d'armes écrivant au milieu $\mathrm{du} \mathrm{Xv}^{\mathrm{e}}$ siècle, a sans doute lui aussi fait appel au vocabulaire classique pour désigner une réalité propre au monde balte: la Wildnis. Le terrain marécageux que devaient traverser les croisés pour aller attaquer les "Sarrasins» au-delà de la Prusse est alors rangé avec le bassin de la Pripiat sous le même terme aux couleurs antiques de «marais méotides». Parlant d'un phénomène encore très médiéval, le héraut Berry a su s'adapter à l'horizon d'attente et aux connaissances de son public, aux goûts déjà marqués par la culture de la Renaissance ${ }^{126}$.

L'attrait de la culture classique et de l'histoire ancienne explique sans doute que Le Bouvier place dans les environs de la terre des Teutoniques une cité mythique liée au passé légendaire de la France: "Près de ce païs de Pruce est la cité de Cinquambre où ceulx de Troyes la grant, après le siège qui y fut, vindrent habiter, et de là vindrent en France, et fondèrent la cité de Paris» ${ }^{127}$. D'après une légende née au Haut Moyen Âge, les ancêtres des Francs quittèrent Troie pour fonder la ville de Sicambre, près des marais méotides, avant de migrer en Gaule ${ }^{128}$. Dès le $\mathrm{XI}^{\mathrm{e}}$ siècle, cette cité est identifiée à Buda, qui était déjà une importante ville du jeune royaume de Hongrie ${ }^{129}$. Gilles le Bouvier intègre donc

\footnotetext{
${ }^{121}$ Hamy, p. 116.

122 Ibid., p. 99.

${ }^{123}$ Adam de Brême, Gesta..., II, 22, p. 79-80; ibid., IV, 10, schol. 116, p. 237; ibid., IV, 20, p. 248-249 .

124 S. Mund, Orbis Russiarum..., p. 305.

125 M. TAмm, "A New World...", p. 12; D. Fraesdorff, Der barbarische Norden..., p. 291-294.

${ }^{126}$ L'influence des humanistes sur les auteurs français du Xv siècle est soulignée par M. VALE, War and Chivalry..., p. 163.

127 Hamy, p. 117.

128 Sur la question, J. PoucET, «Le mythe de l'origine troyenne au Moyen Âge et à la Renaissance: un exemple d'idéologie politique", Folia Electronica Classica 5, 2003 (en ligne).

129 A. Joly, Benoit-de-Sainte-More et le Roman de Troyes ou les métamorphoses d'Homère et de l'épopée gréco-latine au Moyen Âge, Paris 1871, p. 122-124. Plus proche du héraut Berry, l'humaniste italien
} 
dans sa description de l'Europe orientale la tradition de l'origine troyenne des Français. Remarquons que curieusement, il place Sicambre "près de ce païs de la Pruce» et non à côté de la Hongrie, qu'il mentionne pourtant ailleurs dans le Livre de la description des pays. Tout se passe comme si les lieux mythiques, qui ont ici une forte résonnance avec la tradition politique française, font partie du même monde "prussien" que les personnages aux noms arthuriens mentionnés dans les chroniques du $\mathrm{Xv}^{\mathrm{e}}$ siècle.

Outre la nature sauvage, le climat extrême et le décorum mis en scène par les Teutoniques, plusieurs légendes ont visiblement frappé l'imagination de quelques visiteurs. Parmi celles-ci, une au moins est directement liée à la forêt, qui sert de cadre à la valorisation des maîtres de la Prusse. Utilisant explicitement les Chevaliers teutoniques comme modèles pour la chevalerie occidentale ${ }^{130}$, Philippe de Mézières se plaît à dépeindre ceux-ci sous un jour héroïque, mais leur prête encore un caractère spirituel plus marqué que la majorité de nos auteurs. Ainsi en est-il de la longue louange qu'ilplace dans la bouche de la Reine Vérité, dans le Songe du vieil pelerin. Après que le test des besants ${ }^{131}$ eut révélé la quasi-perfection des Teutoniques, celle-ci commente en donnant un aperçu de l'histoire de l'Ordre:

"Il me souvient et de veue que la lumiere du besant de ceste sainte religion fu si grande a son comencement que .xii. chevaliers tant seulement de la religion, qui s'estoient partis de Surie et de la terre de promission quant la malediction de Dieu fu mandee sus la Crestienté d'orient pour leurs pechiés, et la grant cite d'Acre derrainement perdue aux Crestiens. Lors .xii. chevaliers de ceste saincte religion, qui la vraye croix plongie en la fontaine de lumiere portoient en leurs cuers, tous desarmés et a pié, chascun s'espee, sa lance et son escu, vindrent en ceste contree de Prusse qui estoit lors ydolastre. Et en la parfonde forest espierent ung grant chaisne; firent un fossé entour, et en petites logetes, qu'il firent sur ledit arbre lesdis chevaliers se herbergoient de jour, et a la nuit couroient sus aux mescreans. Les dessusdiz .xii. chevaliers de ceste religion gaingnoient grandement de la despouille des anemis de la foy et petit a petit tant multiplierent a l'aide des Crestiens d'Alemaigne et de Polane qu'il firent entour le chaisne une ville cloose de palis; et monterent a cheval et chevaucherent de jours par telle maniere que en procés de tamps, par grans labours et merveilleuses batailles, multipliant leur besant, conquistrent ceste region de Prusse a la foy de mon Pere. Et la ou l'arbre dessusdit estoit, aujourd'uy est la meilleur cité de Prusse appellee Thoron. ${ }^{132}$

\footnotetext{
Antonio Bonfini (m. 1502) rappelle l'identification de Buda avec la mythique Sicambre en nous parlant de "Budam vetere, quam Sicambria prius appelabant» (Rerum Ungaricarum, Francfort 1581, p. 141).

${ }^{130}$ Voir chapitre VI.

131 Sur la symbolique des besants, voir ci-dessus, p. 198-199.

132 Blanchard, vol. 1, p. 213-214.
} 
L'histoire du château sur le chêne est mentionnée dans plusieurs sources prussiennes, notamment chez Pierre de Dusbourg, et dans différents documents iconographiques, diplomatiques ou dans les chroniques $\mathrm{du} \mathrm{Xv}^{\mathrm{e}}$ siècle ${ }^{133}$. D'après la tradition historique interne à l'Ordre, une forteresse aurait été construite autour d'un grand chêne, non loin de la Vistule. Une ville aurait par la suite été fondée à proximité de ce château, mais dû être transférée là où se situe l'actuelle Torun à cause des inondations ${ }^{134}$. Philippe de Mézières a pu recueillir cette histoire directement auprès des Chevaliers teutoniques ${ }^{135}$ : l'adaptation vernaculaire de Dusbourg par Nicolas de Jeroschin ayant vraisemblablement été lue aux membres de l'Ordre ${ }^{136}$, tout porte à croire qu'aux moins une partie de ceux-ci avaient en tête le "mythe fondateur" de leur corporation, et auraient été à même d'en communiquer oralement la substance à Mézières.

Illustration de la "persistance obstinée de la propagande de l'Ordre»" ${ }^{137}$, ce passage du Songe du vieil pelerin fait en outre ressortir la manière dont l'auteur se réapproprie la tradition teutonique à ses propres fins. Les débuts de l'Ordre racontés par Mézières correspondent, dans les grandes lignes, à ce que l'on connaît: la fondation en Terre sainte, le combat contre les Prussiens, et même l'aide apportée par les croisés allemands et polonais. Cependant, la chronologie qu'avance Mézières est erronée; les Teutoniques ont en effet entrepris la conquête de la Prusse bien avant la chute d'Acre et la disparition des États latins en Terre sainte ${ }^{138}$. De plus, la chronique de Dusbourg ne présente pas Toruń comme le premier avant-poste de l'Ordre en Prusse ${ }^{139}$. L'orientation donnée au récit montre pourtant la permanence d'un thème cher à l'historiographie teutonique, à savoir la centralité de la mission prussienne parmi les tâches de l'Ordre. En présentant la chute d'Acre comme point de départ de l'aventure balte des Teutoniques, le récit rapporté par Mézières expose la conquête de la Prusse comme la continuation des croisades en Terre sainte. N. Housley peut ainsi faire le parallèle avec l'Oesterreicher Reimchronik (1301-1319) d'Ottokar de Styrie, qui dit que le grand-maitre Conrad de Feuchtwangen jura de venger la perte

\footnotetext{
133 Pierre de Dusbourg, Chronicon..., SRP 1, p. 49-50. Le poste renforcé dans le chêne est également mentionné par un rapport attribué à Hermann de Salza, la Translatio et miracula sanctae Barbarae, les chroniques d'Oliwa et de Blumenau, et par une pièce des procès polono-teutoniques de 1339; voir SRP 1, p. 50, n. 3; S. SzcZEPANSKI, "Arbor custodie que vulgariter dicitur Wartboum. The function and existence of the so-called "watchtower trees" in Pomesania and Zuuławy Wiślane in the $13^{\text {th }}$-14th centuries", Zapiski Historyczne, 76/1, 2011, p. 7-8; PR 1, p. 270-271.

134 SRP 1, p. 50.

135 M. GŁodeK, Utopia Europy..., p. 81-82. Sans se référer à Philippe de Mézières en particulier, S. SzCZEpanski ("Arbor ...», p. 8-9) indique que la légende du château de Toruń a pu se transmettre par la tradition orale.

${ }_{136}$ Nicolas de Jeroschin, The Chronicle of Prussia..., p. 13-14.

137 PR 1, p. 270.

138 Ibid., p. 270, n. 59.

${ }^{139}$ Un château appelé Vogelsang aurait été fondé peu de temps auparavant sur l'autre rive de la Vistule: Pierre de Dusbourg, Chronicon..., SRP 1, p. 46-7.
} 
d'Acre en détruisant le paganisme en Prusse et en Livonie ${ }^{140}$. Une fois évincé d'Orient par l'ultime victoire musulmane, les Teutoniques auraient entrepris de continuer le combat contre d'autres infidèles; la croisade balte, et partant, l'institution des rèses de Prusse, seraient ainsi la suite logique des aventures en Terre sainte. Cette vue s'est également imposée à Énée Sylvio Piccolomini, et à travers lui à Sebastian Münster et François de Belleforest, au détail près que l'humaniste italien et ses continuateurs rapprochent la chute d'Acre du règne de Frédéric II, de manière à ce que celui-ci apparaisse comme le protecteur de l'Ordre ${ }^{141}$.

D'autres détails, aux connotations plus mystiques, renforcent l'identification de l'Ordre teutonique avec un corps missionnaire, presque apostolique. Le nombre de douze chevaliers venus de Terre sainte vers la Prusse (qui peuvent correspondre aux sept frères laissés dans le château de Toruń, chez Dusbourg ${ }^{142}$ ) ne manque pas de rappeler les douze apôtres ${ }^{143}$. De même, le motif du refuge dans le chêne témoigne d'une forte charge symbolique. Des postes d'observations installés sur des arbres existaient dans l'Allemagne médiévale (ils sont notamment bien attestés en Saxe et en Hesse), et des défenses militaires ont parfois été incorporées aux forêts sous la forme de haies renforcées ou d'arbres entrelacés ${ }^{144}$. En ce qui concerne la Prusse, l'étude de Seweryn Szczepanski montre que des Wartbaumen étaient utilisés dans l'État de l'Ordre teutonique, et rien n'interdit de penser que le premier château de Toruń ait effectivement été bâti autour d'un édifice de cette sorte ${ }^{145}$. Néanmoins, au-delà de l'image spectaculaire ayant pu séduire Mézières, ce thème appelle quelques réflexions.

Il est établi que le chêne a été un arbre sacré pour la religiosité balte comme germanique - et pour beaucoup d'autres ${ }^{146}$. L'Histoire de l'Ordre teutonique $\mathrm{du}$ baron von Wal explique que l'arbre autour duquel les Chevaliers ont bâti Toruń faisait partie d'un groupe de quatre grands chênes sacrés pour les Prussiens ${ }^{147}$. Il pourrait être tentant de voir ici un indice attestant qu'au-

\footnotetext{
140 N. Housley, The Later Crusades..., p. 327; S. Lotan, "The Teutonic Knights... », p. 324.

141 Énée Sylvio. Piccolomini, Historia de Europa, XXVI, SRP 4, p. 232; Sebastian Münster, Cosmographie Universelle: contenant la situation de toutes les parties du monde, Bâle 1552, p. 874-875; François de Belleforest, La Cosmographie Universelle..., col. 1602-1603, qui parlent tous deux de la chute de "Ptolémaïde, qui est une ville de Syrie», et non d'Acre.

${ }_{142}$ Pierre de Dusbourg, Chronicon..., SRP 1, p. 50.

${ }_{143}$ PR 1, p. 270, n. 58.

144 R. Bourdu, M. Joussaume, "Mystique ou profane. L'arbre, les dieux et les hommes", L'Univers $d u$ Vivant 9, 1986, p. 74. Commentant l'histoire du chêne de Toruń, qu'il relate avec plus de détails que Mézières, W. von WAL (Histoire de l'Ordre teutonique..., vol. 1, p. 241, n. 1) mentionne une citadelle bâtie dans un arbre en Westphalie.

145 S. SzCZepanski, "Arbor...", p. 5-18.

146 J. Brosse, Mythologie des Arbres, Paris 1989, p. 112-115.

147 W. von WAL, Histoire de l'Ordre teutonique..., vol. 1, p. 201-202, 240. L'historien allemand reprend ici un thème apparu au Xve siècle chez Simon de Grunau, Lucas David, Preussische Chronik, vol. 1, p. 180, cité par S. SzCZepanski, «Arbor...», p. 7; loc. cit.
} 
delà des différences religieuses, un même système de pensée, encore teinté de paganisme, prévalait chez les Teutoniques comme chez leurs adversaires baltes et païens ${ }^{148}$. L'arbre-refuge, immortalisé par Dusbourg et repris par Mézières, rappellerait un ancien culte des arbres commun aux populations baltes et germaniques, et adapté à la légende de l'Ordre teutonique ${ }^{149}$. Ce serait aller bien vite en besogne. En effet, le fait même que l'arbre, et peut-être plus encore la forêt, ait été lié au culte préchrétien semble en faire un enjeu essentiel du processus de christianisation. La Légende dorée de Jacques de Voragine recueille plusieurs histoires de saints qui ont coupé des arbres afin de détourner les païens de leur culte traditionnel ${ }^{150}$. La prise de possession symbolique du paysage passe également par l'édification de monastères en forêt, qui ont pour fonction de "neutraliser les forces démoniaques qui s'y étaient réfugiées»" 151 . Une telle "christianisation" de la nature a également existé dans les pays baltes à l'époque médiévale ${ }^{152}$. D'après l'informateur d'Énée Sylvio Piccolomini, le missionnaire Jérôme, les Samogitiens auraient adoré de nombreux bosquets sacrés, que l'on avait bien du mal à faire couper ${ }^{153}$. De même, l'un des quatre chênes sacrés mentionnés par von Wal, qu'il situe sur les lieux de l'ancienne Romowe, la capitale païenne balte inventée par Dusbourg ${ }^{154}$, aurait été abattu sur ordre du grand-maitre Winrich de Kniprode pour être remplacé par un monastère augustin, "en réparation à cet outrage fait au vrai Dieu" qu'était l'utilisation de ce chêne pour un culte polythéiste ${ }^{155}$. Qu'elles aient un fondement historique ou non, ces anecdotes s'insèrent parfaitement dans la tradition hagiographique du missionnaire devant couper l'arbre sacré des païens pour les amener au christianisme, bien connue d'un auteur comme Philippe de Mézières.

De plus, la symbolique du chêne comme refuge est attestée dans un contexte chrétien, comme dans la légende du prophète Isaïe, scié avec le

\footnotetext{
${ }_{148}$ C'est l'hypothèse avancée, non sans réserves, par K. Kı̦Avin̦š ( The Ideology... », p. 260-276) à partir des procès de l'enquête du légat pontifical Francis de Moliano (1312).

149 Une telle hypothèse aurait comme conséquence de renforcer la nature "païenne» des Teutoniques, mise en avant de manière polémique par certains auteurs (par exemple, R. AllEaU, Hitler et les sociétés secrètes, Paris 1969), qui entendent montrer que les fondements du nazisme se trouvent enfouis dans l'histoire ancienne de l'Allemagne, et notamment dans l'Ordre teutonique. S’il est impossible de séparer drastiquement le monde "chrétien " du monde "païen ", gardons-nous de voir les Teutoniques comme les héritiers inchangés d'un vieux paganisme «germanique».

${ }^{150}$ Par exemple, la légende de saint Nicolas de Patras ou celle de saint Germain d'Auxerre: Jacques de Voragine, Legenda aurea, éd. G. P. Maggioni, trad. G. Agosti, Florence 2007, vol. 1, p. 46-47, 772-773; J. M. Howe, "The Conversion of the Physical World. The Creation of a Christian Landscape», dans J. Muldoon, Varieties of Religious Conversions..., p. 63-78.

${ }^{151}$ J. Brosse, Mythologie..., p. 226, 263-267.

152 Ibid., p. 224-226.

153 Énée Sylvio Piccolomini, Historia de Europa, XXVI, SRP 4, p. 239.

154 S. C. Rowell, Lithuania Ascending..., p. 126.

155 W. von WaL, Histoire de l'Ordre teutonique..., vol. 1, p. 201-202; ibid., vol. 3, p. 446-448. L'auteur suit ici des textes du Xvi ${ }^{\mathrm{e}}$ siècle, l'Historia Prussiae de Jan Leo (m. 1635), et les Acta Borussica de Gaspar Stein (m. 1652).
} 
chêne dans lequel il s'était caché156. En France, «le symbolisme du chêne allie habituellement robustesse, abri, résistance et force spirituelle» ${ }^{157}$, pour reprendre Jean-Loïc Le Quellec, qui montre que de nombreuses légendes de chouans réfugiés dans un chêne ont essaimé pendant les guerres de Vendée, soit dans un autre contexte de lutte armée de chrétiens contre des «ennemis de la foi»" Dans le domaine français toujours, on trouvait jusqu'au $\mathrm{XIX}^{\mathrm{e}}$ siècle plusieurs dizaines de chapelles construites dans des arbres (dont beaucoup de chênes) ${ }^{159}$,

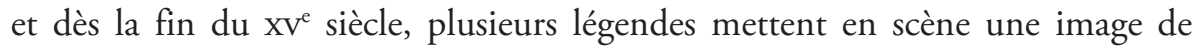
la Vierge découverte dans un arbre ${ }^{160}$. Restons prudent: plusieurs siècles séparent le récit de Mézières de la révolte chouanne. Mettre en parallèle des éléments puisés à des époques éloignées et dans des contextes différents ne permet bien sûr pas d'échafauder une théorie complète, mais on peut imaginer que Philippe de Mézières, dans sa volonté d'assimiler les Teutoniques à une chevalerie aux reflets christiques, ait été sensible à ce genre de topoï.

$\mathrm{Du}$ reste, la "parfonde forest» dans laquelle les Teutoniques auraient établi leur forteresse est à elle seule un refuge bien connu, pour les bandits et toutes sortes d'êtres inquiétants, mais aussi pour les malheureux persécutés ${ }^{161}$. Lieu de refuge mais aussi zone frontière entre le monde civilisé, chrétien, et le monde étranger, à proprement parler "sauvage ${ }^{162}$, la forêt appelle à la métamorphose, notamment spirituelle ${ }^{163}$. Les Teutoniques, cachés sur leur chêne au cœur des bois, et qui ne sortent que la nuit pour courir «sus aux mescreants», rappellent les chrétiens de Prusse, mentionnés au XIII ${ }^{\mathrm{e}}$ siècle dans une lettre du pape Grégoire IX:

"Nous avons appris que les Prussiens païens, qui répugnent à reconnaître le vrai Dieu et le Seigneur Jésus-Christ, ont brûlé plus de dix mille villages situés aux frontières de la Prusse ainsi que plusieurs églises et monastères. C'est pourquoi aujourd'hui il n'y a pas d'autre lieu pour le culte divin que les bois dans lesquelles se cachent de nombreux fidèles. ${ }^{164}$

Comme le montre bien Sylvain Gouguenheim, cette missive réactive le motif des fidèles réfugiés au fond des bois, un lieu commun de la littérature

156 M. Pastoureau, "La forêt médiévale... », p. 91; R. Bernheim, "The Martyrdom of Isaiah", The Art Bulletin, 34/1, 1952, p. 19-34.

157 J.-L. Le Quellec, "Le chouan dans le chêne», dans Idem, Voyage en mythologie: Dragons et Merveilles, Arles 2013, p. 79.

158 Ibid., p. 63-95.

159 R. Bourdu et M. Joussaume, «Mystique ou profane... », p. 71-72.

160 Ibid., p. 70-71.

161 M. Pastoureau, «La forêt médiévale...", p. 84. Il suffit de penser aux figures de la littérature médiévale qui trouvent momentanément leur refuge dans la forêt, comme Tristan et Iseult.

${ }^{162}$ Le terme «sauvage» (silvaticus) vient du latin silva, signifiant «forêt»: ibid., p. 97, n. 22.

163 Ibid., p. 84, 90.

164 PUB 1-1, nº 87, trad. S. Gouguenheim, Les Chevaliers teutoniques..., p. 152. 
hagiographique des premiers siècles ${ }^{165}$. Sous la plume de Mézières, les Teutoniques ressemblent autant aux héritiers vengeurs de ces malheureux qu'aux moines venus implanter le christianisme dans cette terre "païenne» par excellence qu'était la forêt balte. À la différence près que le Vieil Solitaire ne fait aucune mention de la cruauté des païens. Les Teutoniques ne sont pas des persécutés mais des défenseurs du christianisme, des athlètes du Christ: en Prusse, ils n'ont pas gagné la couronne du martyr, mais la gloire du conquérant. La conclusion du discours de la Reine Vérité se veut une valorisation de cet ordre religieux-militaire modèle: "Chascune nuit se lievent a matines et en leur chastiaus et convens, mainent vie de moisnes, et as chevauchies contre les anemis de la foy, quant il sont armés, soubz la baniere de la crois, chascun ressamble un prince» ${ }^{166}$.

Guillebert de Lannoy, qui parcourt les terres de l'Ordre teutonique quelques décennies après Mézières, a lui aussi eu vent de l'histoire du chêne. Attendant de recevoir le sauf-conduit qui doit lui permettre de pénétrer en Pologne, le seigneur bourguignon en profite pour visiter la Prusse. Parmi les quelques lieux qu'il a retenus dans ses notes, on trouve Altenhaus, ou Vieux-Toruń. Guillebert évoque rapidement le pèlerinage que l'on y fait, et les reliques de sainte Barbe que l'on y garde, avant de raconter l'histoire marquante du lieu:

"Et de là, fus mené sur le rivière de le Wisle, à une lieue de Thore, en une islette où jadis, du temps que tout le païs de Prusse estoit mescréant, les seigneurs des Blans Manteaux, de l'ordre de Prusse, firent leur première habitacion sur ung gros foeullu arbre de quesne, assis sur le bort de la rivière, où ilz firent ung chastel de bois et le fortefièrent de fossez autour arrousez de laditte rivière, dont depuis par leur vaillance, à l'ayde et retraitte dudit chastel, concquirent tout le païs de Prusse et le mirent à nostre créance, et est ce lieu là nommé Aldenhoux. ${ }^{167}$

La mention "fus mené» indique que des guides lui faisaient visiter la région; on peut donc supposer que ceux-ci lui ont raconté l'histoire du chêne, sans doute bien connue des Teutoniques et des hommes à leur service. Le fait que l'on trouve la même anecdote chez Mézières et Lannoy laisse entendre que celle-ci devait être un thème apprécié des guides narrant l'histoire de la région aux voyageurs. L'image des Teutoniques réfugiés sur un chêne pour y installer leur première base dans une région alors païenne avait sans doute de quoi frapper les visiteurs venus de l'Ouest; le ton, chez Lannoy, est toutefois moins connoté religieusement que dans le Songe du vieil pelerin. L'image des Teutoniques que l'on peut dégager des notes de notre voyageur est globalement positive, mais elle ne jouait sans doute pas le même rôle que chez Mézières.

\footnotetext{
${ }_{165} \mathrm{Id}$.

166 Blanchard, vol. 1, p. 216.

167 Potvin, p. 46.
} 
Aristocrate et diplomate voyageant autant par plaisir que par devoir, Guillebert de Lannoy sait apprécier les curiosités qu'il voit sur sa route. Par exemple, lors de son passage en Égypte en 1422, il rapporte la légende voulant que le Prêtre Jean, dont, à partir du XIV ${ }^{e}$ siècle, on situe le royaume en Afrique et non plus en Inde, puisse dévier le cours du Nil à sa guise ${ }^{168}$. Les mentions plutôt sèches que Guillebert nous a laissées de ses différents périples interdisent de dire ce qu'il pensait des merveilles qu'il y décrit; si M. notre voyageur pensait utiliser ses notes pour en faire un récit de voyage plus développé, peut-être avait-il prévu de donner un peu plus de relief à ces épisodes, qui n’auraient pas manqué de plaire à ses éventuels lecteurs ${ }^{169}$. Gageons que l'histoire du chêne de Toruń appartienne à la même catégorie d'anecdotes plaisantes au goût de Guillebert et de ses contemporains.

Au-delà de l'identification à un monde littéraire ou d'une héroïsation aux couleurs christiques, le monde balte renferme son lot de curiosités, vues ou entendues par nos voyageurs, qui les intègrent soigneusement à leurs écrits ou les racontent autour d'eux, une fois rentrés au pays. Ainsi, Guillebert relate l'histoire du château construit sur un chêne par les premiers Teutoniques de Prusse d'un ton plus neutre que Mézières, presque badin; sans doute qu'en composant ses notes de voyage, il retenait plus les curiosités devant plaire à ses lecteurs potentiels que les images à même de les édifier. De même, la Samogitie (Guillebert l'a sans doute traversée en automne) n'est pas particulièrement froide, mais inhabitée: "quant on a passé oultre ledit Strang ${ }^{170}$, on entre ou païs de Sammette, mais on treuve bien douse lieues de désertes solitudes, sans trouver quelque trace de humaine habitacion tousjours costoyant la mer à main senestre ${ }^{171}$.

Parmi les curiosités, on connaît les terribles hivers, les marais recouverts de neige et de glace, le "désert», la forêt, et ses arbres-refuges; les animaux qui peuplaient ce paysage ne manquaient pas d'intérêt pour les chasseurs passionnés qu'étaient nos nobles voyageurs. Certains passages du Livre de la Chasse de Gaston Fébus pourraient être des souvenirs du voyage que celui-ci accomplit auprès de l'Ordre teutonique en 1357-1358; la mention du renne, «veӥ en Nouroegue et Xuedene» indique vraisemblablement que le célèbre vicomte de Foix profita de ce voyage en Europe du Nord-Est pour visiter non seulement la Prusse, mais encore la Livonie et les possessions du roi de Suède et

\footnotetext{
${ }^{168}$ L'historien d'origine arménienne Héthoun de Korikos, mort en 1308, est l'un des premiers à situer le royaume du Prêtre Jean en Afrique et à rapporter qu'il peut dévier le cours du Nil; communication de Ahmed Abdelkawy Sheir, "The Legend of Prester John and its Implications on the Crusading-Muslim Conflict in the Twelth and Thirteenth Centuries», lors de la conférence Diversity of Crusading, Odense, juin 2016. Sur le traitement du Prêtre Jean par Guillebert de Lannoy, M. NeJEDLÝ, «Spisy...», p. 114-116.

${ }_{169}$ Id.

${ }^{170}$ Il s'agit de l'isthme de Courlande, tenu par l'Ordre teutonique.

171 Potvin, p. 28-29.
} 
de Norvège, Magnus Eriksson ${ }^{172}$. Sur les terres de l'Ordre teutonique, les hôtes les plus prestigieux étaient emmenés à la chasse aux bêtes sauvages, dont les plus prisées étaient les bisons et les aurochs, inconnus en Europe occidentale ${ }^{173}$. Guillebert de Lannoy ne dit pas avoir eu le privilège de chasser auprès du grandmaître, mais peut se vanter d'avoir été invité à partager cette très noble activité avec le roi de Pologne Ladislas Jagellon, qu'il rencontre à deux reprises alors que celui-ci est à la chasse ${ }^{174}$. La plus impressionnante de ces expéditions devait être celle à laquelle le seigneur bourguignon prit part en 1421, non loin de Lviv:

"Item, de Prusse, m'en alay devers le roy de Poulane, [...] lequel je trouvay parfont es désers de Poulane, en ung povre lieu, nommé Oysemmy ${ }^{175}$, vers lequel je fis mon ambaxade de la paix [...], lequel me fist très grant honneur, et envoya au devant de moy bien trente lieues, pour moy faire venir à ses despens. Et me fist faire oudit désert ung très beau logis tous de vertes foeulles et ramsseaux, pour tenir mon estat emprès luy, et me mena à ses chasses pour prendre ours sauvaiges en vie. ${ }^{176}$

Ambassadeur introduit auprès des principales têtes couronnées d'Europe du Nord et de l'Est, Guillebert de Lannoy est aussi l'un des rares privilégiés à avoir pu parcourir la Lituanie quelques décennies après sa conversion. En 1414 déjà, il a eu l'occasion de visiter le zoo privé du grand-duc Vytautas, aux abords de sa résidence de Trakai. Guillebert raconte qu'il avait quitté Vilnius pour "une très grosse ville en Létau, nommée Trancquenne» ${ }^{177}$, qui "est [...] au duc Witholt» ${ }^{178}$. Notre voyageur ne rencontre pas le prince lituanien, mais bénéficie de ses largesses; ce sont vraisemblablement ses hommes qui lui font visiter la réserve d'animaux sauvages que Vytautas, conformément à la mode de son temps, entretient pour émerveiller les visiteurs ${ }^{179}$. Le zoo de Trakai laisse voir les plus impressionnantes des bêtes autochtones:

"Item, en laditte ville de Trancquenne, y a ung parcq enclos, ouquel sont de toutes manières de bestes sauvaiges et de venoisons dont on peut finer es forests et marches de par de là. Et sont les aucunes comme boeufz sauvaiges, nommez

\footnotetext{
172 Gaston Fébus, Livre de Chasse, éd. G. Tilander, Karlshamn 1971, p. 67. Les rennes, comme d'autres animaux nordiques, deviendront à la mode dans les ménageries des princes de la fin du $\mathrm{XV}^{\mathrm{e}}$ siècle; W. Paravicini, «Des animaux....", p. 464-466.

${ }^{173}$ PR 1, p. 300-303; A. Pluskowski, "What is exotic? Sources of animals and animal products from the Edges of the Medieval World», dans G. Jaritz, J. Kreem (dirs.), The Edges of Medieval World, Budapest 2009, p. 123; P. Dовrowolski, «Miles...», p. 40.

${ }^{174}$ Potvin, p. 46.

${ }^{175}$ Ozimina, un village situé entre Sambir et Drohobytch, actuellement en Ukraine. Potvin, p. 53, n. 3 .

176 Potvin, p. 53.

177 Ibid., p. 40.

178 Ibid., p. 41.

179 R. ČApaité, "Everyday life... », p. 19-20.
} 
ouroflz, et autres en y a comme grans chevaulz nommez weselz et autres nommez hellent, et y a chevaulz sauvaiges, ours, porcz, cerfz et toutes manières de sauvagines. $»^{180}$

Les "bøufz sauvaiges nommez ouroflzs" peuvent être des bisons d'Europe, qui vivaient dans les forêts de l'ancienne Lituanie, ou plus probablement des aurochs $s^{181}$. Werner Paravicini traduit le nom du deuxième animal par "bison", alors qu'en son temps, Joachim Lelewel remarquait que le terme "weselz» rappelle l'allemand ezel (âne), ce qui pourrait indiquer que Guillebert parle de chevaux oreillards, qui lui auraient simplement évoqué des ânes ${ }^{182}$. Quant à eux, les "chevaulz sauvaiges", sont probablement les tarpans ou konik, qui vivaient à l'état sauvage en Europe orientale jusqu'au XIx ${ }^{e}$ siècle ${ }^{183}$. L'animal nommé "hellent» pose moins de problème; il s'agit vraisemblablement de l'élan, animal rare et imposant qui vivait près des marécages lituaniens ${ }^{184}$. D'après les linguistes, ce mot prend racine dans le lituanien elnis, avant de transiter par l'allemand elend; Guillebert de Lannoy serait le premier auteur à importer le nom de cet animal en français ${ }^{185}$ - ce qui attesterait que ceux qui lui faisaient visiter la Lituanie communiquaient avec lui en allemand.

Les maîtres de la Prusse, de la Pologne et de la Lituanie eux-mêmes utilisent volontiers cette faune particulièrement imposante pour mettre en avant leur puissance $^{186}$. L'Ordre teutonique envoie, à l'occasion, des faucons, aurochs ou bisons aux cours princières, jusqu'en France et en Bourgogne ${ }^{187}$. Pétrarque (m. 1374) note en marge de son manuscrit de Virgile que d'aucuns procureurs de l'Ordre teutoniques lui ont parlé des aurochs (uri), qui vivent "aux confins du pays des Lituaniens, contre qui l'Ordre mène une guerre incessante", avant de préciser: "j'ai vu les cornes de la bête de mes propres yeux; elles sont étonnantes de par leur taille et leur beauté» ${ }^{188}$. Plus tard, au début de l'année 1417, Jagellon envoie trois "grandes bêtes" au concile de Constance en guise de cadeau diplomatique. Les animaux ne survivent pas au voyage, aussi doit-on les saler

\footnotetext{
180 Potvin, p. 41-42.

181 J. Lelewel (Guillebert de Lannoy, Guillebert de Lannoy et ses voyages..., p. 43) et J. Svátek (Discours..., p. 365) proposent d'y voir des bisons, alors que pour l'article du Dictionnaire Historique de la Langue Française (ci-après DHLF), il s'agirait d'une première attestation de l'auroch en langue française: DHLF, 1, p. 144.

182 W. Paravicini, "Tiere aus Norden...», p. 259; Guillebert de Lannoy, Guillebert de Lannoy et ses voyages..., p. 43-44, n. 40 ; J. SvÁtek, Discours..., p. 365.

183 A. Grabski, Polska w Opiniach Europy..., p. 114-115.

184 D. Makowiecki, "Exploitation of Early Medieval Aquatic Environment... », p. 770-771.

185 J. SvÁtek, Discours..., p. 365-366; DHLF, 1, p. 668. Les élans sont appelés «hellez» par Philippe de Commynes: W. Paravicini, «Des animaux...», p. 450.

186 A. Grabski, Polska w Opiniach Europy..., p. 114-115.

187 W. Paravicini, «Tiere aus Norden...», p. 249-272.

${ }_{188}$ Petrarcae Vergilianus Codex, Géorgiques II, 373-375, folio 31, cité et trad. S. C. Rowell, «A Pagan's Word: Lithuanian diplomatic procedure 1200-1385", Journal of Medieval History 18, 1992, p. 160.
} 
pour les conserver. Le chroniqueur Ulrich de Richental dit avoir pu goûter la chair de ces animaux, et admiré l'un d'entre eux, "qui est le plus grand [...] [qui] ressemblait au bouf que l'on appelle büffel ${ }^{189}$.

Les commentateurs ne voient pas uniquement la faune lituanienne avec des yeux de chasseurs impressionnés par un tel gibier, mais savent aussi apprécier la valeur commerciale que représentent les bêtes à fourrure de l'Europe du Nord-Est. Depuis le Moyen Âge, la richesse générée par le commerce des fourrures en Russie est si célèbre qu'elle en devient un stéréotype ${ }^{190}$; si ce trait apparaît moins souvent dans les descriptions de la Lituanie, il ressort néanmoins de quelques textes. Dans le récit que le chroniqueur Cabaret d'Orville rapporte d'après le témoignage de Jean de Chastelmorand, l'armée croisée prit le château d'Endrach (Trakai?) aux Lituaniens, "et les chassièrent es grans fourests de Prusse, qui durent plus de huit journées, esquelles sont les bestes hermines, létisses, gris et martres sebellines, dont les riches fourreures sont apportées par les provinces du monde» ${ }^{191}$. Quant à lui, le héraut Gilles le Bouvier se plaît à énumérer les animaux que l'on mange et que l'on vend dans le royaume de Pologne (qui recouvre, dans ses écrits, le grand-duché de Lituanie), mais aussi en Livonie, confondue alors avec "le royaulme de l'Estau [Lituanie] " ${ }^{192}$. Son intérêt semble avoir été surtout économique ${ }^{193}$, voir "ethnographique», lorsqu'il raconte que les habitants de Livonie "peschent moult de poissons en la mer, qui sèchent à la froideur, et les marchans de Danemarche et d'Angleterre les vont acheter", alors que "ces gens menguent les poissons tous crus» ${ }^{194}$. Chez Gilles le Bouvier, le climat et le milieu naturel expliquent les mœurs alimentaires des Livoniens: «ces gens ne boivent point de vin, car il n'y en croist point. Ilz sont blons et blans, et sont noris de letaiges et de cervoises, de chers et de poissons et sont gens de sang, et sont grans mengeurs pour la froideur du païs» ${ }^{195}$.

La nature sauvage et hivernale faisait assurément partie de l'horizon d'attente de ceux qui étaient amenés à lire ou à se faire lire les aventures de nos croisés de la Baltique; il s'agissait d'un décor convenu, s'insérant aisément dans une narration héroïsante où, à l'occasion, l'ennemi se voyait attribuer un nom issu du monde arthurien. Mais ni la Prusse, ni la Livonie, ni même la Lituanie longtemps païenne ne faisaient office de «réserves de merveilles». Le

\footnotetext{
189 Richental, p. 100.

190 S. Mund, "Constitution...", part. 2, p. 545-546. Adam de Brême parlait déjà du commerce des fourrures pratiqué par les Prussiens (Gesta..., IV, 18, p. 245-246).

${ }^{191}$ Chazaud, p. 64-65.

192 Hamy, p. 101.

193 Pour la Pologne: "En ce royaulme a assez chevaulx, martres, gris, bièvres, et menuvier, blez, gros bestial, et n'y croist point de vin» (ibid., p. 99); et sur les régions séparant la Lituanie des pays tenus par les Tatars: "Il y a XIIII journées de désers et là prent-on les bestes dont on fait les pannes [fourrures], plus qu'en nul autre païs» (ibid., 100).

${ }_{194}$ Ibid., p. 101.

195 Ibid., p. 80.
} 
Nord mythique ne commençait, pour nos auteurs, qu'à partir de la rive nord de la mer Baltique, au-delà de la Finlande (alors possession suédoise) et de la lointaine Laponie. Chez Philippe de Mézières, Suède et Norvège se trouvent "dessoulz l'estoille tremontane»" ${ }^{196}$; la "mer Occeane devers septentrion" est peuplée de "mervailles, fantosmes et deableries, que c'est une mervaille a ouir, si comme il me fu conté pour vray ou royaume de Norwegue»" 197 . Philippe, "pour que nature humaine se leite fort d'oÿr choses merveilleuses, especiallement quant elles procedent de Dieu", se plaît à décrire l'une d'entre elles, à laquelle il prétend avoir lui-même assisté: la pêche au hareng dans le détroit du Sund, avec ses pêcheurs zélés et ses poissons pris en grand nombre ${ }^{198}$. Néanmoins, il se contente de mentionner les fantômes de la mer et quelques particularités du climat norvégien ${ }^{199}$, et n'évoque pas les monstres que les médiévaux aiment à imaginer aux limites du monde ${ }^{200}$.

D'autres auteurs n'ont pas cette réserve. Immédiatement après avoir mentionné pour la deuxième fois la Livonie, avec ses pêcheurs, ses marais gelés et ses guerres contre les Tatars, le héraut Berry enchaîne sur une évocation de ce qui peut être la Finlande ou la Laponie:

"Entre ce païs de l'Inflent et le royaulme de Sueghe, en une contrée dudit païs, a petites gens qui n'ont que deux piés de grant au plus et habitent en terre. Et quant on va en leur païs ilz s'enfuient et se boutent en terre quant ilz voient les grans gens. Aultre païs y a il ès ysles de ce mesme païs ou a géans merveilleusement grans qui vivent des bestes sauvaiges qui mengussent et ne bougent de là où ils sont pour la profondeur des eaues qui sont entre eulx et les aultres païs. En ce païs a une aultre contrée où n'est point de nuit, ains y est continuellement jour. Et aultres païs y a où est peu de jour, ains y est continuellement nuit. En ces contrées sur la mer sont les merveilleux et grans poissons plus que en nulles des autres mers. $»^{201}$

Aux échos des réalités «ethnographiques» ou naturelles locales ${ }^{202}$ se mêlent des légendes issues de l'Antiquité et du Haut Moyen Âge, faisant des «îles» du Nord un refuge de géants, et d'autres «races monstrueuses». Tout comme Adam de Brême plaçait ses Amazones et autres cynocéphales aux confins du royaume de Suède alors qu'il décrivait de manière relativement précise la Prusse

${ }^{196}$ Cette formule est employée au sujet de la région qu'il appelle «Godlant», à savoir une partie de la Suède; Blanchard, vol. 1, p. 226; J. JaKšTas, Das Baltikum..., p. 165-166.

197 Blanchard, vol. 1, p. 227.

198 Ibid., p. 227-230.

199 Ibid., p. 227.

200 D. FraesdorfF, Der barbarische Norden....

201 Hamy, p. 101-102.

202 Pour l'éditeur E. T. Hamy (p. 101, n. 5), les "petites gens» dont parle Berry seraient les Sami; les "grans poissons" rappellent les orques, baleines ou narvals alors que les contrées de jour et de nuit continuelle peuvent être un écho du phénomène bien connu en Laponie, où le soleil ne brille que quelques heures en hiver, et ne se couche presque jamais en été. 
et la Courlande, Le Bouvier renvoie les merveilles nordiques dans la même région, moins connue et plus fantastique que les pays du sud de la mer Baltique. Le déterminant n'est pas ici religieux (les possessions suédoises de Finlande sont chrétiennes depuis le $\mathrm{XII}^{\mathrm{e}}$ siècle), mais géographique: bien peu d'Occidentaux ont participé aux croisades occasionnellement lancées par les rois suédois, et qui visaient plus à soumettre les territoires orthodoxes de Novgorod qu'à évangéliser les lointains $\mathrm{Sami}^{203}$. Le Nord reculé sert donc de refuge aux mirabilia que les lecteurs pouvaient espérer trouver sous la plume du héraut Berry ou de Mézières.

Ainsi, la Lituanie païenne, longtemps terre de croisade et connue des nobles d'Europe occidentale, n'est pas à proprement parler une contrée merveilleuse, mais elle est tout à fait digne de servir de cadre à de belles aventures chevaleresques. L'immense forêt enneigée que l'on doit traverser pour pénétrer sur le territoire ennemi n'abrite ni géants ni animaux fantastiques, mais elle pouvait plonger les croisés (et leurs lecteurs) dans une ambiance héroïque. Malgré le caractère exceptionnellement sauvage de la Wildnis et le climat qui doit avoir marqué les nombreux participants aux rèses d'hiver, la nature balte était relativement familière à nos auteurs ${ }^{204}$. Les marais gelés et les bois enneigés sont décrits de manière presque conventionnelle dans de nombreux textes, et servent peut-être à renforcer le caractère païen de cette terre de croisade. En effet, au-delà de son cadre géographique, ce sont surtout ses habitants qui caractérisaient cette région, ceux que l'on venait combattre: ce sera l'objet du chapitre suivant.

\footnotetext{
203 W. Paravicini, Gaston Fébus en Prusse..., p. 51, postule que Gaston Fébus a pu être l'hôte du roi de Suède et Norvège Magnus Eriksson, lequel était marié avec une princesse wallonne, Blanche de Namur, et avait guerroyé contre Novgorod.

${ }^{204}$ Idem, "Tiere aus Norden...", p. 271-272.
} 



\section{Chapitre VIII LES HoMmes}

\section{« HUMANUM SANGUINEM SITIENTES» : DE CRUELS PERSÉCUTEURS}

Une tradition remontant au Haut Moyen Âge, et qui emprunte autant à la Bible qu'aux Autorités classiques, situe toute sorte d'êtres monstrueux dans les terres païennes d'Europe du Nord. L'aura fantastique qui entoure les derniers représentants d'une religion polythéiste vivant relativement près des chrétiens occidentaux ${ }^{1}$ permet de réactiver les codes anciens définissant, sur le plan symbolique, les peuples des confins: Scandinaves, Finnois, Slaves et Baltes². Après l'évangélisation de ces pays autour de l'an mil et la conquête de la région balte par les ordres militaires au XIII ${ }^{\mathrm{e}}$ siècle, des informations détaillées - et moins fantastiques - parviennent aux auteurs européens ${ }^{3}$. Amazones, cynocéphales ou anthropophages sont progressivement rejetés dans les espaces les plus lointains possibles: à l'extrême Nord et à l'extrême Est, bien loin d'une Baltique désormais familièré

Cependant, les souvenirs de cette tradition ne disparaissent pas tout à fait. Une carte de l'Italien Giovanni da Carignano (v. 1310) fait figurer les Amazones près de la mer Baltique, en indiquant qu'elles y auraient autrefois demeurés. Les cynocéphales apparaissent, eux, dans quelques textes épiques allemands, mais dont l'action porte plus sur l'Orient que sur la Baltique ${ }^{6}$.

\footnotetext{
${ }^{1}$ Les Sami et les Caréliens vivent dans des régions bien plus éloignées que les Baltes. Voir D. Baronas, "Christians in Late Pagan...», p. 52.

2 D. Fraesdorff, Der barbarische Norden..., p. 290-308.

3 R. Siminski, «Ex Livonia... », p. 190, 203; M. Tамм, «A New World...», p. 11-35.

${ }^{4}$ D. White, Myths..., p. 63-64.

5 W. IwanczaK, «La Mer Baltique...», p. 34-35. Durant le Moyen Âge central et tardif, ces êtres ne sont liés à la Baltique quasiment plus que sur les cartes, ce qui est sans doute le reliquat d'une vieille tradition.

${ }^{6}$ La plupart des cynocéphales de la littérature allemande apparaissent en lien avec l'épopée d'Alexandre. Dans un cas au moins, le poème Guillaume d'Autriche de Jean de Würzburg (1314), des Lituaniens portent des têtes de chien: Jean de Würzburg, Wilhelm von Osterreich aus der Gothaer Handschrift, v. 7771-7775, éd. E. Regel, Berlin 1906, p. 107. Plus d'un siècle plus tôt, des
} 
On chercherait en vain des descriptions aussi fantastiques dans les textes produits en France et en Angleterre. Jusqu'au XIII siècle, c'est plutôt la violence qui caractérise les païens de la Baltique. C'est même, avant tout, leur comportement prétendument agressif envers les missionnaires qui sert de justification aux croisades lancées en Europe du Nord, comme nous l'avons vu:déjà dans les appels de la première moitié du XII ${ }^{\mathrm{e}}$ siècle, ils sont dépeints sous des traits menaçants ${ }^{7}$. De concurrents commerciaux ou militaires, ils se transforment dans les textes en tenants d'une religion militante, qui fait preuve d'une farouche intolérance envers les chrétiens. La violence provoquée par l'incompréhension mutuelle entre les représentants de deux sociétés obéissant chacune à ses propres conventions se traduit, pour les auteurs chrétiens, par une attitude unilatéralement hostile de la part des Baltes ${ }^{8}$.

C'est avec le récit du voyageur anglo-saxon Wulfstan que ceux-ci font leur apparition dans la littérature de l'Occident médiéval, à la fin du $\mathrm{IX}^{\mathrm{e}}$ siècle. L'auteur, très vraisemblablement un navigateur proche de la cour du roi Alfred le Grand, ne s'intéresse pas à l'évangélisation des habitants de la Baltique, et donne une description relativement neutre de leurs mœurs ${ }^{9}$. Tel n'est pas le cas des Vies de saint Adalbert et saint Bruno de Querfurt, couvrant les premières tentatives missionnaires auprès des Baltes $^{10}$. Les personnages auxquelles sont consacrées ces deux œuvres ayant gravité dans l'entourage des empereurs Othon III et Henri II, ils sont devenus à leur mort des célébrités, dont on relatait le martyre jusqu'en France et en Italie ${ }^{11}$. Les textes consacrés aux martyrs de Prusse produits en Europe occidentale autour de l'an mil nous montrent des tueurs de saints tels que l'on s'attend à en trouver dans ce genre de littérature ${ }^{12}$, même si l'on peut y déceler quelques nuances. La première Vie de saint Adalbert (Vita Prior), très vraisemblablement due au bénédictin italien Jean Canaparius (m. 1004) $)^{13}$, précise que le missionnaire aurait d'abord été capturé, puis emmené devant des personnages importants parmi les Prussiens,

hommes à têtes de chien pouvant être identifiés aux païens slaves apparaissent dans le Rolandslied du clerc Conrad (v. 1170): Das Rolandslied des Pfaafen Konrad, v. 2655-2658, éd. D. Kartschocke, Stuttgart 1993, p. 190, cité par M. A. WAGner, Le cheval dans les croyances germaniques. Paganisme, christianisme et tradition, Paris 2005, p. 474, n. 4; S. C. Rowell, «Of Men...», p. 75.

7 N. Blomkvist, Discovery..., p. 132-140; 170-177.

${ }^{8}$ Ibid., p. 536-537. Le regard biaisé des chroniqueurs catholiques peut être illustré par Henri de Livonie, Heinrichs Livländische Chronik..., I, 9, p. 4, qui raconte que les Lives sont allés laver le baptême qu'ils ont reçu dans l'eau du fleuve, ce qui aurait été une mauvaise interprétation de la coutume du sauna, inconnue du chroniqueur. Voir C. S. Jensen, "The Early Stage...», p. 213 , n. 20.

9 Baltu Religijos..., p. 53-54.

${ }^{10}$ Voir p. 16 et 60-61.

11 D. Baronas, «The Year 1009... », p. 1-22.

${ }_{12}$ M. Sosnowski, "Prussians as bees...", p. 25-47.

${ }^{13}$ C. Gaspar, "The Life of Saint Adalbert...", p. 88-92. 
qui lui auraient fait savoir qu'il devait quitter la région au plus vite, faute de quoi il serait tué:

" "Tu as bien de la chance", lui dirent-ils, "d'avoir pu venir jusqu'ici impunément! Seul un retour rapide peut te faire espérer de garder la vie sauve; rester ici ne serait-ce qu'un court instant causerait ta perte. Nous-mêmes et tout ce royaume, dont nous tenons l'entrée, obéissons à une seule loi et vivons selon un seul ordre. Mais vous, qui êtes d'une loi étrangère et inconnue, si cette nuit vous ne disparaissez pas, vous serez décapités demain matin". " ${ }^{14}$

La religion des païens se résume ainsi à une coutume ethnique, pratiquée par tous les habitants du pays ${ }^{15}$. L'introduction d'étrangers, porteurs d'une "loi ${ }^{16}$ inconnue, risque de mettre en danger la cohésion sociale: bien que décrite dans un style épique et avec force références bibliques, comme on peut l'attendre d'un clerc, la mise à mort de l'évêque tchèque répond ici à une logique sociale, celle de "barbares", certes, mais pas de simples caricatures d'idolâtres. La longue digression sur le successeur d'Adalbert, Bruno, que le bénédictin italien Pierre Damien insère dans sa Vie de Romuald (v. 1042), donne une image assez similaire du paganisme balte. Il est dit, en effet, que c'est la conversion d'un "roi» local ${ }^{17}$ qui a poussé le frère de ce dernier à tuer le missionnaire ${ }^{18}$. L'histoire est assez détaillée: on apprend d'abord que Bruno était allé chercher le martyre parmi les Prussiens, qui, dérangés par les miracles ayant suivi la mort d'Adalbert, ne voulaient pas répéter l'expérience en tuant un deuxième personnage de la sorte ${ }^{19}$. Expulsé, le missionnaire se serait rendu dans une région indéterminée, vraisemblablement sous domination russe ${ }^{20}$, aux confins de la Prusse et de la Lituanie, comme nous le disent les Annales de Quedlimbourg ${ }^{21}$. Toujours selon Pierre Damien, le «roi» de la région se convertit après avoir soumis Bruno à une épreuve du feu, visant à tester la force de la divinité dont il se faisait le messager ${ }^{22}$. À la suite de quoi, l'auteur raconte le martyre proprement dit, où l'on peut lire le déchirement provoqué

${ }_{14}$ C. Gaspar, "The Life of Saint Adalbert...», p. 172-173.

15 S. C. Rowell, "Customs...", p. 46-47 sq.

${ }^{16}$ Le terme de «loi» est, au Moyen Âge, fréquemment utilisé pour désigner les différentes obédiences religieuses, sans être en soi connoté péjorativement; ibid., p. 51.

${ }^{17}$ Le texte dit "rex russorum»; étant donné que Bruno est dit avoir été expulsé de Prusse, où il était venu chercher le martyre, il peut s'être rendu aux confins de la Rus' kievienne, ce qui expliquerait qu'un tel titre ait été attribué au chef local: D. Baronas, "The Year 1009...", p. 6-7, 18-19.

${ }_{18}$ Pierre Damien, Petri Damiani vita beati Romualdi..., XXVII, p. 59-60.

19 Ibid., p. 58.

${ }^{20}$ D. Baronas, "The Year $1009 \ldots »$ p. 6-7.

${ }^{21}$ Voir chap. I.

22 Pierre Damien, Petri Damiani vita beati Romualdi..., XXVII, p. 58-59; J. Tolan, Le Saint chez le Sultan. La rencontre de François d'Assise et de l'islam. Huit siècles d'interprétation, Paris 2007, p. 209-210. 
dans cette société païenne par la conversion du roi et les luttes de pouvoir qui l'ont suivie:

"Le roi décida qu'il laisserait le royaume à son fils, et qu'il ne se séparerait en aucune manière de Boniface [Bruno] tant qu'il vivrait. Alors en l'absence de Boniface, le frère du roi, qui habitait avec lui, a été tué par le roi en personne, parce qu'il ne voulait pas croire. Et un autre frère, qui vivait alors séparé $d u$ roi, vint bientôt vers l'homme vénérable; il ne voulut pas écouter ses paroles, mais, était rempli d'une grande colère contre lui à cause de la conversion de son frère, il le fit prisonnier. Ensuite, craignant que s'il ne le laisse en vie, le roi ne le sauve d'entre ses mains, il le fit décapiter en sa présence, et en la compagnie de nombreux hommes. ${ }^{23}$

Le fait que le meurtre du frère qui "ne voulait pas croire» ait eu lieu en l'absence du missionnaire ne permet pas de dire que Pierre Damien l'attribue à l'influence de Bruno. Toutefois, nous voyons ici l'éclatement de la structure sociale, présenté par l'hagiographe comme un préalable à l'évangélisation de toute la société, puisque les miracles apparus immédiatement après la mort du saint permettent la conversion de tous les païens et la réconciliation des deux frères ${ }^{24}$. Sous la plume des hagiographes italiens, les Prussiens ne sont pas de simples brutes tuant le missionnaire avant même d'essayer de comprendre son message. À la lecture de tels récits, certes bourrés de lieux communs et de références bibliques ${ }^{25}$, on serait tenté de voir la suppression du missionnaire comme une tentative de la part des païens de remédier au désordre provoqué par l'introduction d'une nouvelle religion. La mise à mort des futurs saints, nécessaire à la structure narrative $\mathrm{du}$ récit, s'explique en quelque sorte par l'assimilation du paganisme à une coutume qui ne tolérerait pas d'autres cultes ${ }^{26}$.

Les destins des deux martyrs sont également parvenus aux Français Adémar de Chabannes (m. 1034) et Raoul Glaber (m. env. 1047). Les contacts n'étant alors pas rares entre les royaumes de France, de Pologne et de Russie ${ }^{27}$, les chroniqueurs se tenaient informés du vaste mouvement d'évangélisation de ces régions $^{28}$, qui tend à être réduit aux figures des célèbres Adalbert de Prague

\footnotetext{
${ }^{23}$ Pierre Damien, Petri Damiani vita beati Romualdi..., XXVII, p. 59-60.

${ }^{24}$ Ibid., p. 60.

25 C. Phipps, Saint Peter Damian's..., p. 222-3, 228.

26 S. C. Rowell, "Customs... ", p. 47-48. Sur la religion comme coutume sociale dans la Lituanie médiévale et ailleurs en Europe, ibid., p. 46-64.

${ }^{27}$ V. Sidorova, "The Slavic World in French Historical Writings of the Eleventh Century", dans M. Homza et al. (éds.), Slovakia and Croatia. Historical Parallels and Connections (until 1780), Bratislava-Zagreb 2013, p. 98, 101; I. Wood, Missionary Life..., p. 251-252 note que la Prusse était plus "étrangère" aux contemporains que les pays slaves, déjà en grande partie christianisés.

${ }^{28}$ Adémar de Chabannes, Chronique..., p. 39-40.
} 
et Bruno de Querfurt ${ }^{29}$. Adémar de Chabannes consacre quelques pages de sa chronique à ces deux évêques missionnaires, qu'il présente comme des courtisans d'Othon III ayant décidé de se rendre auprès des "Slaves» pour leur amener l'évangile ${ }^{30}$. À l'inverse de l'auteur de la Vita Prior, Adémar ne précise pas que le missionnaire tchèque ait reçu un premier avertissement des Prussiens, mais ne raconte que sa mort, survenue neuf jours après son entrée sur leur territoire ${ }^{31}$ :

"Le trouvant plongé dans son oraison, ces gens, rendus très féroces par l'idolatrie, le percèrent de leurs traits et de leurs épées et le firent martyr du Christ. Ensuite, ils lui coupèrent la tête, engloutirent son corps dans un grand lac, et jetèrent sa tête aux bêtes dans un champ. $\|^{32}$

La mise à mort de l'évêque par les javelots et sa décapitation figurent également dans la Vita prior de saint Adalbert (v. 999) ${ }^{33}$, ce qui laisse de prime abord supposer que le chroniqueur ait eu accès à ce texte ou qu'il ait simplement entendu relater la même histoire. Une autre piste est cependant possible. En étudiant les sources narratives concernant l'autre grand missionnaire du temps, Bruno de Querfurt, Darius Baronas postule qu’Adémar aurait été tenu au courant de l'histoire de ce saint par des moines grecs, que l'on sait avoir visité l'Aquitaine depuis le mont Sinaï ${ }^{34}$. En effet, le chroniqueur français raconte que "la nation des Russes" racheta le corps du martyr, "et construisit un grand monastère en son honneur ${ }^{35}$, ce qui est absent des textes saxons ${ }^{36}$. Bruno de Querfurt, qui a collaboré autant avec l'empereur Othon et le roi Boleslas de Pologne qu'avec le grand-prince de la Rus' kiévienne Vladimir, a été pendant quelques années après sa mort «revendiqué» autant par les églises grecque que romaine ${ }^{37}$. Rien n'empêche donc de penser que notre chroniqueur ait eu vent de cette page d'histoire non par des Latins, mais par des Grecs; on peut ainsi envisager que les mêmes informateurs lui aient également conté les aventures du premier martyr de Prusse, Adalbert ${ }^{38}$.

Quant à lui, Raoul Glaber donne davantage de détails. Plus proche des textes hagiographiques italiens que d'Adémar de Chabannes, il s'efforce d'expliquer la

\footnotetext{
${ }^{29}$ V. Sidorova, «Slavic World...», p. 100.

30 Adémar de Chabannes, Chronicon..., III, 31, p. 152-154.

31 Le texte a Pincenati. Pour D. Baronas ("The year 1009... », p. 12), Adémar confond l'ethnonyme des Prussiens avec celui des Petchenègues, un peuple turc d'Europe orientale auprès de qui Bruno de Querfurt est allé prêcher.

32 Adémar de Chabannes, Chronicon..., p. 153.

33 C. Gaspar, "The Life of Saint Adalbert...», p. 176-181.

${ }^{34}$ D. Baronas, "The Year $1009 \ldots$... p. 13.

35 Adémar de Chabannes, Chronicon..., p. 153.

${ }^{36}$ D. Baronas, "The Year $1009 \ldots$... p. 13.

37 Ibid., p. 9-13.

38 R. MAŽEıKa, "Probleme der ersten urkundlichen Erwähnung Litauens...», p. 98-99, rappelle qu'Adémar entretenait une confusion certaine entre les différents peuples et principautés d'Europe orientale, ce qui nous interdit de trop spéculer à partir de ses écrits.
} 
fureur des païens, provoquée par le fait qu'Adalbert, qui avait déjà converti un certain nombre de Prussiens, se soit attaqué à leurs lieux sacrés:

"Un jour, il fit abattre un arbre impie, situé au bord d'un fleuve, et auquel le peuple, par superstition, offrait des sacrifices. Ayant érigé et consacré un autel en cet endroit, l'évêque s'apprêta à dire la messe. Mais, alors même qu'il célébrait le sacrement, il fut frappé des traits lancés par les impies, et la fin de la célébration fut aussi celle de sa vie. "39

L'arbre sacré, auquel les païens sont censés vouer un culte, constitue un motif ancien, qui apparaît déjà dans la littérature chrétienne de l'Antiquité. De la même manière, le fait qu'Adalbert détruise l'arbre pour construire un autel au même endroit rappelle la politique traditionnellement attribuée à Grégoire le Grand, qui consistait à détruire les idoles mais à garder les temples pour les convertir en églises ${ }^{40}$. Rien n'interdit de penser que Raoul ait puisé ces éléments dans un fond littéraire qu'il connaissait bien pour les appliquer à l'histoire d'Adalbert. En outre, on retrouve dans cet extrait l'idée que le missionnaire, en s'attaquant à l'arbre sacré, commet un sacrilège aux yeux des Prussiens; comme pour les auteurs italiens, ceux-ci réagiraient ainsi à une provocation, alors que pour Adémar ils sont simplement "rendus très féroces par l'idolâtrie». Le chroniqueur aquitain est, dans sa concision, le plus sévère envers les Baltes: ceux-ci passent, pour lui, pour de simples persécuteurs et leur comportement est réduit à une mise à mort particulièrement cruelle des missionnaires.

Le supplice que font subir les Prussiens à leur malheureux pasteur, tout classiquement "hagiographique» qu'il soit, n'en souligne pas moins leur brutalité. Mais le sort de Bruno tel que rapporté par Adémar de Chabannes se révèle pire encore et, à maints égards, plus éloquent: "Les Pincenati [Prussiens] en effet, enragés par une fureur diabolique, lui tirèrent toutes les entrailles du ventre par un petit trou qu'ils lui firent sur le flanc et achevèrent d'en faire un très valeureux martyr de Dieu $»^{41}$. L'éviscération figure dans d'autres textes parmi les supplices que les Baltes sont censés infliger aux chrétiens qu'ils capturent; d'après Henri de Livonie, des païens lives ont procédé de la sorte avec quelques malheureux captifs ${ }^{42}$. Si ce genre de torture ne peut que rappeler les martyrs antiques, le chroniqueur du $\mathrm{XIV}^{\mathrm{e}}$ siècle Pierre de Dusbourg prend la peine de préciser que les supplices infligés par

\footnotetext{
39 Raoul Glaber, Histoires..., Livre I, 10, p. 60-61.

${ }^{40}$ B. Judic, «Le corbeau et la sauterelle. L'application des instructions de Grégoire le Grand pour la transformation des temples païens en églises", dans L. MARY et M. Sот (dirs.), Impies et païens entre Antiquité et Moyen Âge, Paris 2002, p. 97-125.

41 Adémar de Chabannes, Chronicon..., p. 153.

${ }^{42}$ Henri de Livonie, Heinrichs Livländische Chronik..., X, 5, p. 36. Un supplice du même acabit est dit avoir été infligé à l'advocatus danois Hebbe, XXVI, 6; ibid., p. 190; T. K. NielseN, "Mission and submission...", p. 223.
} 
les Prussiens révoltés (c'est-à-dire des apostats, et non de «simples» païens ${ }^{43}$ ) surpassent ceux auxquels se livraient les Romains:

"Parmi eux il y avait un frère [de l'Ordre teutonique] qui a été tué de cette façon: les Prussiens le ligotèrent vivant à un arbre par les mains, et ils coupèrent son nombril, qui retenait attachées ses viscères, et les attachèrent à l'arbre; avec force coups, ils le forcèrent à tourner autour de l'arbre jusqu'à ce que ses viscères restent collés à l'arbre, et ainsi dans la confession de la vraie foi il rendit l'âme à Dieu et mourut. On peut tourner et retourner les pages des écrits martyrologiques, on ne trouvera pas un tel martyre. Même Tarquin le Superbe, l'inventeur de tous les tourments, n'en a pas inventé un de la sorte. D'où il ressort que ceci est inhabituel, et n'a jamais été entendu dans le monde. ${ }^{44}$

Le chroniqueur se trompe quand il dit que personne n'a jamais entendu parler d'un tel supplice. Robert le Moine nous rapporte que dans son sermon lançant la première croisade (1095), Urbain II a décrit les tortures pratiquées par les "Persans" qui s'étaient emparés de la Terre sainte dans des termes très proches: "ceux qu'ils veulent faire périr d'une mort honteuse, ils leur percent le nombril, en font sortir l'extrémité des intestins, la lient à un pieu; puis, à coups de fouet, les obligent de courir autour jusqu'à ce que, leurs entrailles sortant de leur corps, ils tombent à terre, privés de vie»" ${ }^{45}$. L'éviscération apparaît, aux côtés d'autres atrocités, parmi les supplices que l'on attribue aux Vendes dans l'appel dit de Magdebourg, datant du début du $\mathrm{XII}^{\mathrm{e}}$ siècle; ce qui n'a rien d'étonnant, puisque ce texte, rempli par ailleurs de références bibliques, reflète la diffusion des idées de croisade en Europe du Nord, en particulier celles contenues dans les œuvres de Robert le Moine ${ }^{46}$. Quelques décennies plus tard, Helmold de Bosau reprend l'histoire des intestins enroulés autour d'un poteau dans une description pathétique des tortures que les mêmes païens slaves infligeraient aux chrétiens ${ }^{47}$. Il semble que ce motif soit resté un topos attaché aux infidèles, ou plus généralement, aux persécuteurs de chrétiens ${ }^{48}$ : on le trouve jusqu'à l'époque moderne au détour de divers récits cherchant à souligner

${ }^{43}$ R. MAŽEıKA, «Violent Victims... », p. 134-135.

${ }^{44}$ Pierre de Dusbourg, Chronicon..., SRP 1, p. 88.

${ }^{45}$ Robert le Moine, Histoire de la première croisade, livre 1, éd. et trad. M. Guizot, Collection des mémoires relatifs à l'histoire de France, vol. 24, Paris 1825, p. 302; L. TRACY, Torture and Brutality in Medieval Literature, Woodbridge 2012, p. 15, 125-126, n. 76.

${ }^{46}$ K. Jensen, "Crusading at the End...", p. 168-169.

${ }^{47}$ Helmold de Bosau, Chronica Slavorum..., I:52, cité par N. Blomkvist, Discovery..., p. 134.

48 À l'inverse, le chroniqueur polonais du xv e siècle Jan Długosz raconte que c'est un chef prussien, ennemi des chrétiens, qui a été torturé de la sorte après sa capture: Annales VII, dans Opera Omnia..., vol. 11, p. 236. M. Tamm a montré que les chroniqueurs (à l'instar d'Henri de Livonie) n'hésitaient pas à mettre en scène des guerriers chrétiens affligeant d'épouvantables tortures à leurs ennemis païens ou hérétiques; M. TамM, "Martyrs and Miracles: Depicting Death in the Chronicle of Henry of Livonia", dans M. Tамм et al. (dirs.), Crusading and Chronicle Writing..., p. 153-154. 
la cruauté des protagonistes, par exemple celle des soudards protestants dans les pamphlets écrits lors des guerres de religion dans la France du Xvi ${ }^{e}$ siècle $^{49}$. Rien de vraiment étonnant, donc, à ce qu'il apparaisse sous la plume d'auteurs cherchant à noircir les Baltes, païens endurcis ou apostats.

Dans le cas des Vendes, Nils Blomkvist a remarqué que leurs activités maritimes qualifiées par les auteurs chrétiens de "piraterie» ressemblent beaucoup à celles de leurs voisins, aussi fallait-il exagérer leur altérité, les rendre inhumains, pour justifier "l'élimination de ce concurrent efficace des réseaux commerciaux ${ }^{50}$. Réduire l'Autre à une simple figure de brute sanguinaire peut donc cacher une attaque envers un adversaire commercial, surtout si celui-ci est resté païen ${ }^{51}$. Le but "politique» de telles descriptions horrifiantes n'est pas à perdre de vue, mais une autre clef d'interprétation est proposée par Marek Tamm, au moins pour le XIII ${ }^{\mathrm{e}}$ siècle. L'utilisation d'un registre rappelant la martyrologie antique n'est pas chose rare dans les chroniques du temps, et les récits d'Henri de Livonie ou de Pierre de Dusbourg s'inscrivent sans doute dans ce renouveau du macabre hagiographique. Ce qui est attesté par ces descriptions effroyables est moins la cruauté propre à une région ou à une époque que la réappropriation de motifs anciens par les auteurs, et dans le cas balte, l'assimilation des païens avec les persécuteurs de l'Antiquitéé2.

Bien que les premiers textes hagiographiques écrits dans le milieu monacal d'Italie nous présentent des païens relativement policés, du moins assez pour avertir les missionnaires avant de les exécuter, les Prussiens d'Adémar ont tous les qualificatifs requis pour servir d'épouvantails à même de justifier une croisade. C'est cette image sombre que l'on trouve sous la plume des papes au début du $\mathrm{XIII}^{\mathrm{e}}$ siècle. La liste des atrocités qu'Honorius III attribue aux Prussiens dans ses lettres aux évêques allemands est longue: meurtre des petites filles ${ }^{53}$, prostitution des femmes, immolation des prisonniers "à leurs dieux», pratiques magiques sanglantes ${ }^{54}$. Étant donné que le souverain pontife mentionne explicitement l'évêque Christian de Prusse comme source d'information, on peut imaginer que ces descriptions viennent du missionnaire lui-même, et qu'elles ont pour but de stimuler le zèle des prélats à financer son entreprise ou à soutenir la croisade, qui en servant de bras armé à la christianisation de ces régions pourrait

\footnotetext{
${ }^{49}$ D. Crouzet, Les Guerriers de Dieu, Seyssel 1990, p. 624. Une torture similaire était également attribuée à certains pirates de l'époque moderne: B. R. BURG, Sodomy and the Pirate Tradition, New York 1983, p. 162.

${ }^{50}$ N. Blomkvist, Discovery..., p. 140. E. Christiansen, The Northern Crusades..., p. 114, rapporte que plusieurs princes chrétiens, notamment scandinaves, recouraient fréquemment à la piraterie. Saxo Grammaticus (Gesta..., 14, 6.2, vol. 2, p. 1024-1027) mentionne le zèle des pirates chrétiens de Roskilde, qui font pénitence avant de partir en mer.

${ }^{51}$ N. Blomkvist, Discovery..., p. 132-140.

52 M. ТАмм, «Martyrs and Miracles...», p. 152-154.

53 PUB 1-1, doc. 24, p. 18. Il convient de rappeler que du point de vue chrétien, un rapport différent au genre est en lui-même un marqueur d'altérité; N. BLомкvist, Discovery..., p. 169-198.

${ }^{54}$ PUB 1-1, doc. 29, p. 20.
} 
mettre fin à de telles pratiques ${ }^{55}$. Le successeur d'Honorius, Grégoire IX, ajoute de nouveaux détails dans la lettre qu'il destine en 1232 aux Dominicains de Bohême, afin qu'ils prêchent une croisade contre les Prussiens, suivant une demande des évêques de Mazovie, Włocławek et Wrocław, qui s'étaient plaints des ravages causés par lesdits païens:

"Ces païens en effet ont frappé à mort du glaive plus de vingt mille chrétiens et les ont condamnés à une mort ignominieuse, en outre ils en détiennent plus de quinze mille dans les chaînes de la servitude et pressant ce qui reste des populations de Mazovie, Cujavie et Poméranie, ils s'acharnent à les mener à leur perte. Ils épuisent par des travaux continuels et épouvantables les jeunes gens qu'ils ont capturés; ils immolent par le feu en l'honneur de leurs démons les jeunes filles couronnées de fleurs par dérision; ils tuent les vieillards, ils assassinent les enfants, empalant les uns sur des pieux, fracassant les autres contre des arbres. Que dire d'autre? Ils s'abreuvent de sang humain, à la manière des bêtes sauvages, et outrageant le Seigneur, que bon nombre d'entre eux ont abandonné après avoir reçu la grâce du baptême, préférant les ténèbres à la lumière, ils infligent aux fidèles de telles tortures que l'on est frappé de stupeur et qu'elles offrent plus matière à pleurer qu'à discourir. ."

Sylvain Gouguenheim n'a pas tort de lire cet extrait comme une réactualisation de thèmes issus de la martyrologie ayant pour but de réchauffer le zèle des lecteur ${ }^{57}$. Derrière les éléments factuels destinés à susciter l'horreur, nous retrouvons en filigrane les principaux axes du discours justifiant la croisade balte: à la nécessité de protéger les fidèles de la cruauté des Prussiens s'ajoute le fait que "bon nombre» d'entre ceux-ci ne sont pas d'authentiques païens ignorant tout du christianisme, mais des apostats, contre qui la violence est légitime. Leur attribuer toutes ces cruautés ne semble être au fond qu'un exercice de style, un ornement censé rehausser le caractère détestable de ceux contre qui l'on va se battre. Le fait que cette lettre reprenne certainement le texte des suppliques des évêques polonais ${ }^{58}$, et ne soit donc pas forcément attribuable à la seule imagination de l'entourage pontifical, n'empêche pas de voir ici un sommet du style dans lequel Rome dépeint les Baltes restés attachés à leurs coutumes traditionnelles, au moment où la croisade se met en place ${ }^{59}$.

\footnotetext{
55 S. Gouguenheim, Les Chevaliers teutoniques..., p. 151.

56 PUB 1-1, doc. 87, p. 66-67; S. Gouguenheim, Les Chevaliers teutoniques..., p. 152.

57 Sur ce qui suit, ibid., p. 152-153. On pense aussi au discours d'Urbain II pour prêcher la première croisade, tel que rapporté par Robert le Moine, qui clôt la liste des viols et tortures attribuées aux "Persans" par la formule "il serait plus fâcheux d'en parler que de s'en taire», Robert le Moine, Histoire de la première croisade..., p. 302.

58 S. Gouguenheim, Les Chevaliers teutoniques..., p. 152.

59 Pour une comparaison avec l'exemple finnois, M. LAmberg, "Finns as aliens and compatriots in the late Medieval kingdom of Sweden", dans O. Merisalo (dir.), Frontiers
} 
En comparaison avec ce que nous venons de lire, le cistercien Albéric de Trois-Fontaines fait preuve d'une étonnante sobriété quand il note, sans aucun commentaire, les martyres d'un certain Philippe, qui a accompagné le missionnaire Godefroy prêcher auprès des Prussiens, de l'évêque Berthold de Livonie, tombé au combat contre les Lives, puis de Théodoric, fer de lance de la Livonie chrétienne et l'un de ses probables informateurs ${ }^{60}$. La guerre contre les païens peut également servir de cadre à des récits de miracle, comme pour le clerc de l'abbaye de Saint-Gilles en Provence, Pierre Guillaume, qui dans ses Miracula beati Egidii situe un épisode miraculeux juste après l'entrée de Boleslas Bouche-Torse dans Szczecin, prise sur les "païens, qui étaient ses voisins, et qui étaient dits Poméraniens». Le duc polonais mérite d'être appelé «de noble mémoire» pour les avoir longtemps combattus, mais aucune mise en scène de la cruauté de ces infidèles slaves n'apparait dans le texte ${ }^{61}$. La Livonie inspire d'autres récits de miracles. Le cistercien Césaire de Heisterbach, de Cologne, qui a été informé par l'abbé de Dunamunde puis évêque de Sémigallie Bernard de Lippe, fait jouer dans plusieurs exempla le rôle de paisibles néophytes aux Livoniens, qui lui servent à introduire quelques points de doctrine ${ }^{62}$. Tous les Baltes des écrits cléricaux ne sont donc pas des Nérons.

\section{Des PAÏENS DRAPÉS À L'ANTIQUE}

Fondamentalement, l'élément qui marque la différence des Baltes par rapport aux auteurs médiévaux écrivant à leur sujet est leur vie religieuse. J'emprunte à Rasa Mažeika une analyse de la manière dont la religiosité balte était interprétée par les élites chrétiennes, et par les auteurs proches de l'Ordre teutonique en particulier $^{63}$. Lorsque Pierre de Dusbourg raconte l'arrivée des Teutoniques en Prusse, le trait qui caractérise les autochtones est l'ignorance: «les Prussiens n'avaient pas connaissance de Dieu; ceci parce qu'ils étaient ignorants, ils ne pouvaient pas le comprendre grâce à leur raison, et parce qu'ils ne connaissaient pas les lettres ${ }^{64}$. On ne peut pas demander à des gens n'ayant jamais eu connaissance des Écritures d'être chrétiens. Mais les païens vivant à l'époque du chroniqueur n'ont pas droit au même traitement. Cent ans après l'implantation de l'État de

\footnotetext{
in the Middle Ages. Proceedings of the Third European Congress of the FIDEM (Jyväskylä, June 2003), Turnhout-Louvain-la-Neuve 2006, p. 125-127.

${ }^{60}$ Albéric de Trois-Fontaines, Chronica..., p. 887, 902, 912. Contrairement aux chroniqueurs baltes, Albéric fait du premier évêque de Livonie, Meinhard, un martyr : ibid., p. 872. Le martyre d'Adalbert de Prague est également mentionné avec sobriété: ibid., p. 781. Voir M. TAMM, "Communicating Crusade...", p. 365-367.

${ }^{61}$ Pierre Guillaume, Petri Guillelmi Miracula beati Egidii, éd. G. Pertz, MGH SS t. 12, Hanovre 1856, p. 320; A. Grabski, Polska w opiniach obcych..., p. 263.

${ }^{62}$ Caesarii Heisterbacensi, Dialogus miraculorum, IX, 37; Libri VIII miraculorum II, 18; I, 31, cités par M. TAмM, «Les miracles en Livonie...», p. 37-39; ibid., p. 29-78.

${ }^{63}$ Sur ce qui suit, R. MažEIKA, "Granting... », p. 158-159.

${ }^{64}$ Pierre de Dusbourg, Chronicon..., SRP 1, p. 53.
} 
l'Ordre teutonique sur leur terre, l'excuse de l'ignorance n'est plus recevable: refuser le baptême et se conduire en païen alors que l'on aurait pu apprendre à connaître la vraie foi au contact des chrétiens établis en Prusse passe pour de l'entêtement aux yeux du chroniqueur. Ce qui correspond à l'attitude générale du monde chrétien, qui sait dans certaines régions, notamment les principautés hispaniques, se montrer tolérant envers les musulmans soumis, mais qui refuse, officiellement du moins, de reconnaitre le droit aux polythéistes vivant au contact des chrétiens de pratiquer leurs rites ${ }^{65}$. Cependant, cette intolérance envers le paganisme est loin d'avoir été absolue, même au sein des provinces teutoniques ${ }^{66}$.

Expliquer le paganisme des Prussiens par leur ignorance n'empêche pas Dusbourg de reconnaître une certaine puissance aux entités que vénèrent ceux-ci, toutefois moins en tant que divinités proprement dites qu'en tant que démons $^{67}$. Le christianisme médiéval considère en effet, à la suite d'Augustin, que les dieux des païens sont des démons ${ }^{68}$, aux pouvoirs desquels est attribué le succès de nombreuses pratiques magiques ${ }^{69}$. De la même manière, l'auteur de la Chronique rimée de Livonie, destinée aux membres de l'Ordre et à la noblesse allemande, en fait des êtres surnaturels dotés de pouvoirs tout à fait redoutables ${ }^{70}$.

L'avis des chroniqueurs de la région est loin d'être isolé, puisqu'il se trouve même partagé par la tête de l'Église. Dans sa bulle de croisade de 1199, Innocent III se fend d'une courte notice sur les païens de Livonie: ceux-ci sont qualifiés de "peuples barbares, qui rendent l'honneur dî̀ à Dieu à des bêtes brutes, à des arbres feuillus, à des eaux limpides, à des herbes verdoyantes et à des esprits immondes " ${ }^{71}$. La religion des Baltes se définit, pour le puissant pontife, par deux grandes tendances: d'une part, le culte des éléments de la nature, et de l'autre celui des "esprits immondes", les démons. Dans une lettre de l'un de ses successeurs, Innocent IV (1244), on apprend que les habitants de la Baltique "détournant la gloire du Dieu incorruptible pour la semblance de l'image corruptible des hommes, des oiseaux,

\footnotetext{
${ }^{65}$ R. MažEika, "Granting...", p. 159, n. 20; voir aussi R. Bartlett, The Making of Europe..., p. 296.

${ }^{66}$ Ce qui est source de critiques envers les Teutoniques: K. Kụ,Avin̦š, "The Ideology...", p. 260-276.

${ }^{67}$ R. Mažeika, "Granting... », p. 160 sq. Pour le Haut Moyen Âge occidental, B. Filotas, Pagan survival. superstitions and popular cultures in Early Medieval pastoral literature, Toronto 2005, p. $95-97$.

68 R. Mažeika, "Granting... », p. 160 ; A.-I. Bouton-Touboulic, «Le De divinatione daemonum d'Augustin", dans F. Lavocat, P. Kapitaniak, Closson (dirs.), Fictions du diable, Genève 2007, p. 15.

${ }_{69}$ M. TAMm, «Signes...», p. 165-166.

${ }^{70}$ R. MažEIKA, "Granting...", passim; A. V. MurraY, «Heathens...", p. 211-216.

${ }^{71}$ Bulle Sicut Ecclesiasticae, dans Register Papst Innocenz' III über den deutschen Thronstreit, éd. W. Holtzmann, vol. 2, Bonn 1948, n 182, p. 348.
} 
des quadrupèdes et des serpents, ils préferent servir la créature plutôt que le créateur $»^{72}$. Un même propos se retrouve presque cent ans plus tard chez Pierre de Dusbourg, qui juste après avoir introduit l'ignorance des Baltes, nous dit que "parce qu'ils ne connaissaient pas Dieu, il se trouve qu'ils adoraient par erreur toute créature comme un dieu: ainsi le soleil, la lune et les étoiles, le tonnerre, les oiseaux et les quadrupèdes, jusqu'aux crapauds. Ils avaient des bois, des plaines et des sources sacrées, où ils n'osaient pas faucher ou cultiver les champs, ni pêcher " ${ }^{73}$. Pour le chroniqueur de l'Ordre, les païens sont des ignorants, mais qui n'ont rien en commun avec les tortionnaires décrits plus haut. Dusbourg, tout comme Henri de Livonie au XIII ${ }^{\mathrm{e}}$ siècle, garde ses imprécations les plus violentes pour les apostats qui, reniant le baptême, se salissent d'un crime ne concernant pas les "vrais» païens ${ }^{74}$. Si l'on considère qu'en écrivant sa Chronicon Terrae Prussiae, Dusbourg devait fournir au grand-maitre un récit à même de justifier la raison d'être de l'Ordre teutonique auprès du Pape, il n'est guère surprenant que l'on y trouve des Prussiens dépeints sous un jour qui pouvait correspondre à l'horizon d'attente de l'entourage de Jean XXII"75.

De manière générale, l'image des Baltes comme adorateurs des éléments de la nature est largement répandue, y compris en France, comme nous l'avons vu avec Raoul Glaber ${ }^{76}$. Depuis les Germains de Tacite $^{77}$ et les pénitentiels du Haut Moyen Âge, la religion des peuples du Nord est fréquemment liée à l'adoration de la nature ${ }^{78}$. Dans le cas qui nous intéresse, les archéologues, mythologues et anthropologues confirment que certains bois, sources ou pierres jouaient un rôle dans la religiosité balte traditionnelle; le fait que les bois et autres sources sacrées des "barbares» soient devenus d'inévitables topoï littéraires n'empêche pas ces éléments d'avoir réellement formé une topographie sacrée pour les anciens Baltes ${ }^{79}$.

\footnotetext{
${ }^{72}$ LUB 1-1, doc. 179, col. 234; M. TAмm, "A New World...", p. 28-29; T. Kala, "The Incorporation...", p. 17, pour qui il est difficile de savoir si cette information était parvenue spécifiquement à Innocent IV ou s'il s'agissait d'une reprise d'une correspondance plus ancienne.

73 Pierre de Dusbourg, Chronicon..., SRP 1, p. 53.

${ }^{74}$ R. MažEIKA, "Violent Victims... », p. 134-135

${ }^{75}$ Ibid., p. 123-137. Les lettres pontificales ne figurent pas parmi les sources identifiées du chroniqueur, mais comme l'indique J. Wenta, on sait que Dusbourg s'est servi de nombreux documents qui nous restent inconnus. J. WentA, «Od tradycji utsnej...», p. 73-74.

${ }_{76}$ M. ТАмм, «A New World... », p. 29-30, cite Henri de Livonie, Heinrichs Livländische Chronik..., XXIII, 9, p. 164-167 ou l'auteur anonyme de la Descriptiones terrarum, dans M. Colker, «America rediscovered...", p. 722.

77 Tacite, La Germanie..., 9-10, p. 75-77.

78 B. Filotas, Pagan survival..., p. 120-152, 195-200.

79 A. Pluskowski, The Archeology..., p. 68-75. Pour B. Filotas, Pagan survival..., p. 145-146, la même réflexion peut être menée quant aux bois sacrés des Celtes et des Germains des VI-VIII ${ }^{\mathrm{e}}$ siècles; voir aussi J.-L. BrunauX, "Les bois sacrés des Celtes et des Germains", dans Les Bois sacrés. Actes du Colloque International (Naples 1989), Naples 1993, p. 57-65.
} 
La vénération des bois, déjà présente chez Adam de Brême pour les Prussiens, apparaît notamment chez les encyclopédistes du XIII ${ }^{\mathrm{e}}$ siècle ${ }^{80}$. Parmi les ordres mendiants, des informations commencent à circuler sur la région balte, où la particularité religieuse permet de puiser plusieurs exemples venant illustrer des thématiques plus générales. Voyons notamment le dominicain Thomas de Cantimpré, qui termine vers 1263 son Bonum universale de apibus, un long traité doctrinal dans lequel il incorpore de nombreux exempla ou souvenirs personnels ${ }^{81}$. Dans un passage consacré aux démons, l'auteur fait référence aux Prussiens, qui servent à illustrer une rubrique consacrée «à la troisième espèce de démons", ceux "desquels les païens conservent les bois sacrés depuis un temps ancien ${ }^{82}$. Ainsi, nous explique-t-il, "jusqu'à maintenant, les infidèles de Prusse révèrent les bois consacrés et n'osent pas les entailler, ni jamais y pénétrer, sauf s'ils veulent y faire des sacrifices à leurs dieux ${ }^{83}$. Étant donné l'implication des Dominicains dans la prédication en Prusse, notre encyclopédiste a pu être en contact personnel avec les membres de son ordre qui s'y sont rendus et ont eu l'occasion d'entendre parler des pratiques des Baltes ${ }^{84}$. Une certaine connaissance des pratiques religieuses de ces derniers pouvait donc, par le truchement des contacts entre frères prêcheurs, parvenir à un savant originaire du Brabant. Une fois cette description posée, l'auteur identifie les divinités auxquels ces bois sont consacrés avec les démons mentionnés par Augustin dans la Cité de Dieu ${ }^{85}$. Comme dans la bulle d'Innocent III citée plus haut, l'usage des bois sacrés est directement lié à l'adoration des démons.

$\mathrm{Du}$ reste, la couleur classique ne se limite pas aux références aux Pères de l'Église pour définir le paganisme balte. Marek Tamm a bien montré que la description des pratiques divinatoires qu'un autre encyclopédiste, Barthélemy l'Anglais, attribue aux habitants de Livonie est saturée de termes qui renvoient directement à l'Antiquité romaine: "ils adoraient de nombreux dieux par des offrandes impures et non consacrées, demandaient aux démons des prédictions [responsa], faisaient appel aux arts prémonitoires [auguriis] et divinatoires [diuinationibus] ${ }^{86}$. L'art de la divination, rendue possible par l'intercession de démons, est l'une des pratiques traditionnellement attribuée aux païens ${ }^{87}$; les Baltes des auteurs du XIII $^{\mathrm{e}}$ siècle sont autres, mais pas inconnus. Depuis Adam de Brême, on utilise un vocabulaire et des références

\footnotetext{
${ }^{80}$ R. MAŽEIKA, «Granting... », p. 61.

${ }^{81}$ Ibid., p. 60-61.

${ }^{82}$ Thomas de Cantimpré, Bonum universale de apibus, éd. G. Colvenerius, Douai 1627, L. 2, chap. 57, p. 548.

${ }^{83}$ Thomas de Cantimpré, Bonum universale..., p. 548.

84 W. Mannhardt, Letto-Preussische Götterlehre..., p. 48.

85 Thomas de Cantimpré, Bonum universale..., p. 548.

${ }^{86}$ M. Tамм, «Signes...», p. 166; pour le texte de Barthélemy, p. 169. L'auteur de Descriptiones terrarum note au sujet des Prussiens de Sambie "Auguria multum sequebantur», éd. dans M. Colker, "America rediscovered...", p. 722.

${ }^{87}$ M. Tамm, «Signes...», p. 166; B. Filotas, Pagan survival..., p. 95-97.
} 
familières aux lecteurs pour rendre intelligibles leurs pratiques religieuses ${ }^{88}$. Le prélat historiographe Olivier de Paderborn va plus loin dans les quelques phrases de son Historia regum Terre Sancte (v. 1220) qu'il dédie aux progrès de la christianisation dans l'Europe du Nord-Est ${ }^{89}$ :

"Le peuple de Livonie, d'Estonie, de Prusse, abusé par de nombreuses erreurs et ignorant le fils de Dieu et le mystère du verbe incarné, adorait les bois des gentils, les dryades, hamadryades, oréades, napées, hydriades, les satyres et les faunes. Il séparait pour eux des bois sacrés, qu'aucune cognée n'était supposée violer, et où les sources et les arbres, les monts et les collines, les grottes et les vallées étaient vénérées, comme si une quelconque vertu ou auspice pouvait être trouvée en ceux-ci. $»^{90}$

La religion des Baltes, dont on peut penser que certaines pratiques avaient effectivement lieu dans les bois ou près de sources ou de pierres spécifiques ${ }^{91}$, n'est plus simplement réduite à une adoration de la nature pour elle-même. Elle est lue ici avec le vocabulaire de la poésie classique, ce qui trahit peut-être moins une assimilation stricto sensu du paganisme balte à celui des anciens Romains qu'un goût tout littéraire pour la matière antique ${ }^{92}$. Plus d'un siècle plus tard, Pétrarque note, en marge de son manuscrit de Virgile, que la pratique romaine consistant à sacrifier un animal pour confirmer un traité est encore attestée de son temps en Lituanie ${ }^{93}$. Il faisait sans doute référence au geste spectaculaire du duc Kęstutis, qui en 1351 saigna un bœuf lors de la confirmation d'un traité passé avec le roi Louis de Hongrie, ce que le célèbre poète a pu apprendre cinq ans plus tard lors d'une mission diplomatique à Prague, à la cour de l'empereur Charles IV ${ }^{94}$. Non seulement on utilise habituellement des termes tirés du registre classique pour interpréter la religion balte, mais encore, sous la plume de l'un des premiers humanistes, les derniers païens d'Europe servent-ils de modèles pour aider à comprendre les coutumes des anciens Romains.

Peut-être faut-il lier à la «romanisation» du paganisme balte une tradition qui fait d'un peuple en particulier, les Sémigalliens, les descendants de Gaulois égarés en Europe du Nord. Certes, en un temps où Français comme Anglais prétendaient descendre des Troyens et des Romains, se voir attribuer de

\footnotetext{
${ }^{88}$ M. TАмм, «A New World...», p. 27, 34-35.

89 Ibid., p. 29.

${ }^{90}$ Olivier de Paderborn, Historia regum Terre Sancte, dans Die Schriften..., p. 156-157, cité par M. TAмM, "A New World...», p. 29, n. 72.

91 S. C. Rowell, Lithuania Ascending..., p. 120-122; A. Pluskowski, The Archaeology..., p. $72-75$.

92 Baltu Religijos..., p. 68; sur l'habitude des auteurs du Moyen Âge et de la Renaissance à donner des noms inspirés de l'Antiquité aux divinités des Baltes, ibid., p. 61.

${ }^{3}$ Petrarcae Vergilianus Codex, Enéide VII, 641, folio 174, cité et trad. S. C. Rowell, "A Pagan's Word...", p. 160.

94 Ibid., p. 159-160.
} 
prestigieuses origines antiques n'a rien de spécifiquement balte. L'assimilation des Sémigalliens à un peuple ancien semble être due à un jeu de mot, ce qui est au fond assez typique de la culture historiographique du Moyen Âge ${ }^{95}$. Pour Barthélemy l'Anglais, "les Sémigalliens [Semigalli] sont appelés ainsi parce qu'ils descendent des Gaulois [Gallis], ou des Galates et de ces peuples»" Albéric de Trois-Fontaines, le chroniqueur cistercien de la région de Liège, nous raconte une histoire plus détaillée sur les origines fabuleuses de ce peuple (v. 1232) $)^{97}$ :

"Pourquoi cette terre est-elle dite Sémigallie? Réfere-toi à l'histoire de Brennus et de Belus, et des Gaulois sénonais qui une fois Rome prise, édifièrent Sena la Vieille, Senigallia, et d'autres cités d'Italie. Certains d'entre eux entrèrent dans la mer Noire [mare Ponticum] par la mer Adriatique et le bras de saint Georges, et de là par le fleuve Dniepr [Nepre] ils obtinrent une terre près de la Russie, qu'ils nommèrent Semigallie; et ainsi l'ancien s'accorde au nouveau. ${ }^{98}$

Le chroniqueur danois Saxo Grammaticus, qui appelle les Sémigalliens "Hellespontin[s]", semble faire référence à la même légende ${ }^{99}$. Le premier chroniqueur de la Pologne, Gallus Anonymus, attribue quant à lui une origine saxonne aux Prussiens; l'ancienneté n'impose pas autant de respect que dans le cas des Sémigalliens, mais faire de ces païens les descendants du puissant peuple vaincu par Charlemagne, qui auraient refusé le christianisme et migré dans une autre région de l'Europe nordique ne manque pas de sel ${ }^{100}$.

Comme le veut la mode de l'époque, le passé, carolingien ou antique, est mis à contribution pour définir les peuples nouveaux qui apparaissent dans les textes du XIII siècle. Dans l'effort des clercs pour définir l'identité des Baltes, et surtout leur religion, l'interpretatio romana rejoint l'interpretatio christiana ${ }^{101}$. Néanmoins, ces deux filtres se rejoignent pour nous laisser voir une image assez cohérente de la vie spirituelle des Baltes telle qu'on la comprenait en Europe occidentale: c'est l'ignorance du vrai Dieu qui explique que les païens vénèrent les forces de la nature, qu'Olivier de Paderborn assimile aux nymphes et aux faunes de l'Antiquité. Livrés aux illusions des démons, que, selon l'avis d'Augustin, ils prennent pour des dieux, ils se distinguent par des pratiques magiques telles que la divination. En cela, les Baltes païens ressemblent aux anciens Grecs ou Romains, ou aux adversaires des Hébreux dans l'Ancien

\footnotetext{
95 B. Guenée, Histoire et culture historique..., p. 175-176; A. Grabski, «La Pologne... », p. 32.

${ }_{96}$ M. ТАмм, «Signes...», p. 170.

${ }^{97}$ Idem, «Communicating Crusade....", p. 369.

${ }_{98}$ Albéric de Trois-Fontaines, Chronica..., p. 930.

99 T. Baranauskas, «Saxo Grammaticus...", p. 68.

100 Gallus Anonymus, Gesta..., 2, 42, p. 194-195.

101 A. Pluskowski, The Archaeology..., p. 67. Le phénomène apparaît également dans les sources russes concernant la religiosité des Lituaniens; A. Greimas, "Le dit de Sovys, conducteur des âmes", Lalies 6, 1984, p. 55-57.
} 
Testament ${ }^{102}$. Avec la pénétration des missionnaires dans le monde balte, ce tableau d'ensemble intègre quelques éléments "ethnographiques", qui reflètent sans doute les coutumes des autochtones et nous éclairent sur la compréhension de leur religiosité dans les milieux lettrés à partir du XIII ${ }^{\mathrm{e}}$ siècle.

\section{COMPRENDRE LA RELIGION PAÏENNE: LE BÛCHER FUNÉRAIRE}

S'il est une coutume spectaculaire des Baltes païens qui marque l'imaginaire occidental, c'est la crémation des morts et l'offrande que l'on place sur leurs bûchers ${ }^{103}$. Ces éléments sont déjà en partie visibles dans le court récit du navigateur Wulfstan qui, à la fin $\mathrm{du} \mathrm{IX}^{\mathrm{e}}$ siècle, nous a laissé une première description détaillée des rites funéraires des Estum (vraisemblablement une tribu prussienne). La crémation, avec armes et vêtements, clôture une série de rituels, parmi lesquels l'exposition du mort dans son domicile, des banquets en son honneur, une course à cheval et la division de son patrimoine entre les vainqueurs ${ }^{104}$. Dans les grandes lignes, ces quelques notes correspondent avec ce que l'on sait des pratiques funéraires baltes ${ }^{105}$. La crémation des morts, bien attestée par l'archéologie, a été établie parmi les peuples baltes entre le $\mathrm{IX}^{\mathrm{e}}$ et le $\mathrm{XI}^{\mathrm{e}}$ siècle, coexistant selon les régions avec d'autres pratiques funéraires (notamment l'ensevelissement avec armes, bijoux et chevaux pour les nobles) avant de se répandre parmi les guerriers au XIII ${ }^{\mathrm{e}}$ siècle $^{106}$. Il est donc probable que le peuple dont nous entretient Wulfstan ait eu recours à ce type de funérailles. Notre navigateur doit, en toute logique, avoir une source pour ces informations: sans doute a-t-il entendu raconter ces faits lors de ses voyages dans la région ${ }^{107}$. Le fait qu'il insiste sur les rites funéraires, inconnus et vraisemblablement étonnants du point de vue de son public, n'est pas un hasard ${ }^{108}$ : pour les voyageurs chrétiens, le bûcher funéraire revient quasiment toujours comme l'un des points marquants de la description des Baltes et de leurs coutumes. Si pour Tacite et les auteurs de l'Antiquité, les Baltes sont liés à l'ambre, pour les auteurs du Moyen Âge, ils tendent à se définir par leurs habitudes funéraires, et en particulier par le fait de brûler leurs morts ${ }^{109}$.

\footnotetext{
102 R. Maž́eika, L. Chollet, «Familiar Marvels?... », p. 56.

103 M. TАмм, «A New World...», p. 30-31.

104 "Wulfstan's voyage and his description of Estland", éd. et trad. J. Bately, "Wulfstan's Voyage...", p. 16-17. Sur le terme Estum/Aesti et son emploi chez Wulfstan, S. LebecQ, Hommes, mers et terres..., p. 229.

105 Même si P. UrbańcZyK, «On the reliability...», p. 47, rappelle que cette description ne saurait être prise pour argent comptant; une remarque qui s'applique à l'ensemble de notre corpus.

106 E. Bazaraitė, T. Heitor, "Comparative study...", p. 318.

107 P. URBAŃCZYK, "On the reliability...», p. 45-46.

${ }^{108}$ M. Jagodzinski, «The Settlement of Truso", dans A. Englert, A. Trakadas (dirs.), Wulfstan's Voyage..., p. 194.

109 T. Jonuks, «Archeology of Religion...», p. 43.
} 
La crémation et l'offrande funéraire réapparaissent dans plusieurs textes $\mathrm{du} \mathrm{XIII}^{\mathrm{e}}$ siècle et restent intimement liés à l'imaginaire de la Baltique. Ces témoignages, concordants entre eux, peuvent nous aider à comprendre les mécanismes d'interprétation de la religion des natifs. Ils illustrent notamment l'intérêt que l'on porte aux éléments les plus «exotiques» de la culture balte, qui se distingue alors sensiblement d'une simple réduction à la religion des anciens Romains. Si l'on excepte le navigateur anglo-saxon $\mathrm{du} \mathrm{IX}^{\mathrm{e}}$ siècle, le premier auteur d'Europe occidentale à décrire en détail les funérailles baltes est Barthélemy l'Anglais, dans le paragraphe consacré à la Livonie du Livre XV de son De proprietatibus rerum (v. 1245). Après avoir dit que les habitants ont récemment abandonné le culte des démons, il se fend de quelques précisions sur leur religion, et notamment sur leurs coutumes funéraires:

"Les dépouilles des morts n'étaient pas enterrées: ils faisaient un très grand bûcher et les brûlaient jusqu'à ce qu'elles soient réduites en cendres. Après la mort, ils revêtaient leurs amis de vêtements nouveaux et leur donnaient pour viatique des moutons, des boeufs et d'autres animaux. Ils leur attribuaient de même des esclaves hommes et femmes ainsi que bien des objets, qu'ils brûlaient avec les morts, croyant que ceux-ci, après la crémation, arriveraient sans encombre dans une région d'êtres vivants, où ils trouveraient, avec tous les esclaves et les bêtes qui avaient été brûlés pour eux, une terre où ils vivraient longtemps dans l'abondance. ${ }^{110}$

Le rituel funéraire est ce qui distingue le mieux le christianisme du paganisme; autrement dit, le bûcher et l'offrande funéraire apparaissent comme étant les marqueurs d'altérité par excellence ${ }^{111}$. Marek Tamm remarque que les rites tels que relatés par Barthélemy sont "opposés dans tous les détails à ceux pratiqués par les chrétiens» ${ }^{112}$. Cette description, qui succède précisément à la mention des pratiques divinatoires des Lives, ferait de la religion balte une inversion du christianisme, construite à l'aide de topoï hérités de l'Antiquité ${ }^{113}$. La crémation d'un païen mort pourrait, par exemple, trahir une influence du récit des funérailles de César chez Suétone ${ }^{114}$.

\footnotetext{
${ }_{110}$ Barthélemy l'Anglais, De proprietatibus rerum..., éd. par M. TAмM, « «ignes...», p. 169.

111 M. TAmм, "A New World...", p. 30, qui cite cette belle formule de F. Hartog, Le Miroir..., p. 149: "dis-moi comment tu meurs et je te dirai qui tu es».

112 M. TАмм, «Inventing Livonia...», p. 207.

113 Ibid., p. 206-207. Pour une réflexion sur les problèmes de méthodologie concernant l'approche des pratiques païennes à travers les sources écrites chrétiennes, et l'écueil de la réduction à de simples «reprises littéraires», M.-A. WAGNER, Le cheval..., p. 435-444.

114 Suétone, Vies des douze Césars, LXXXIV, éd. et trad. H. Ailloud, Paris 1989, p. 59-60. Sur la réappropriation de Suétone par les auteurs du Moyen Âge, J. Monfrin, "Humanisme et traductions au Moyen Âge», Journal des savants, 1963, p. 161-190. Tacite mentionne la pratique de la crémation chez les Germains: La Germanie..., 27, p. 86.
} 
Bien au-delà du cas balte, cette pratique fait, pour les auteurs du Moyen Âge, partie prenante des mœurs païennes. La littérature médiévale d'inspiration antique utilise volontiers ce thème pour illustrer les derniers honneurs rendus aux guerriers tombés sur le champ de bataille. Si dans son adaptation du Roman de Troie, Benoît de Sainte-Maure fait ensevelir et non brûler Patrocle ${ }^{115}$, l'auteur du Roman d'Enéas raconte que lors de l'invasion du Latium par Enée et ses compagons, on profite d'une trêve pour dresser les bûchers et brûler les morts, "selonc la coustume de Troie»" ". L'épisode est narré sans aucune nuance de condamnation, comme si l'on considérait logique que des païens aient accompli ces rites "A la lor loy et a lor guise»" ${ }^{17}$.

Du reste, des témoignages arabes du $\mathrm{x}^{\mathrm{e}}$ siècle rapportent également que les Slaves ou les Varègues scandinaves brûlaient leurs morts et sacrifiaient des êtres humains, des animaux et des biens, ce qui indique que des auteurs indépendants les uns des autres attribuaient des usages analogues aux païens nordiques ${ }^{118}$. L'offrande funéraire, par inhumation ou incinération, et notamment celle du cheval, parait avoir été largement pratiquée dans l'Europe préchrétienne et une grande partie de l'Asie, ce que l'archéologie atteste en Europe centrale ${ }^{119}$. Dans le contexte balte, un certain nombre de sites a été mis au jour, lesquels indiquent que la crémation d'humains, de chevaux et d'objets précieux telle que le racontent les sources écrites semble avoir été pratiquée jusqu'aux XIII-XIV ${ }^{e}$ siècles ${ }^{120}$. On sait également que l'inhumation côtoyait la crémation (peut-être réservée aux nobles) ${ }^{121}$; quant à elle, la pratique de l'offrande funéraire est attestée de l'ancienne Prusse à l'Estonie, en passant par la Lituanie ${ }^{122}$. Même s'il reste bien sûr très difficile d'interpréter ces trouvailles, il semble envisageable que les deux pratiques fondamentales rapportées par nos auteurs aient pu exister, à tout le moins dans certains contextes et dans certaines régions du monde balte.

\footnotetext{
115 Benoît de Sainte-Maure, Le Roman de Troie, v. 10371-10398, éd. et trad. E. Baumgartner et F. Vieillard, Paris 1998, p. 252-255.

116 Le Roman d'Eneas, v. 6157, éd. et trad. A. Petit, Paris 1997, p. 388.

117 V. 6149, ibid. Voir aussi v. 6133-6157, p. 387-388 pour le passage entier, et v. 2110-2213, p. 166-173. Le bûcher funéraire fait son apparition dans le poème anglo-saxon de Beowulf (v. VII ${ }^{\mathrm{e}}-\mathrm{IX}^{\mathrm{e}}$ siècle); Beowulf, strophe LII, éd. J. Queval, Paris 1981, p. 178-179. Le court passage de l'adaptation russe de la Chronique de Malalas (XIII siècle) concernant l'histoire légendaire de Sovij, censé avoir introduit la crémation parmi les Lituaniens, lie explicitement cette pratique avec celle des anciens Hellènes: A. Greimas, «Le dit de Sovys...», p. 55.

${ }^{118}$ Le témoignage le plus célèbre est celui du voyageur Ibn Fadlân, secrétaire d'une mission du calife de Bagdad auprès des Bulgares de la Volga; "Récit de voyage», dans Voyageurs arabes, textes traduits, présentés et annotés par P. Charles-Dominique, Paris 1995, p. 58.

119 M.-A. WAGNER, Le cheval..., p. 101-111.

${ }^{120}$ M. Bertasius, «Horse Graves, Sacrifice, and the Performers of Public Rituals», Archeologia Baltica 11, 2009, p. 305-313; A. Pluskowski, The Archaeology..., p. 77-81.

121 E. Bazaraité, T. Heitor, "Comparative study...", p. 316-321.

${ }^{122}$ H. VALK, «Christianisation in Estonia...», p. 575; S. UrbanavičIEnĖ, «Survivals of Paganism in $14^{\text {th }}-17^{\text {th }}$ Century Graves in Lithuania", dans M. MüLler-WILle (dir.), Rom und Byzanz..., vol. 2, p. 131-142.
} 
Il est bien clair que les descriptions qui nous occupent ne doivent pas être lues comme des documents ethnographiques, mais comme des tentatives d'intégrer dans un système de représentation ancien des données nouvelles, produites par la rencontre avec des peuples méconnus ${ }^{123}$. Ce qui nous importe est moins de savoir si Barthélemy l'Anglais a fidèlement rapporté ce qui se passait lorsqu'un Prussien ou un Live décédait, que la manière dont lui et ses pairs ont traité et retranscrit les informations qui leur étaient parvenues. Car l'analyse de Barthélemy l'Anglais est rapidement rejointe par d'autres textes. Une courte notice du Descriptiones terrarum rapporte que les Sambiens, un peuple prussien, "consumaient les morts avec des chevaux, des armes et de nobles vêtements. De fait, ils croient qu'ils peuvent les utiliser, avec d'autres choses brûlées, dans un monde à venir» ${ }^{124}$. Quant à lui, Roger Bacon n'échappe pas à l'habituelle réduction de la religion balte à l'adoration de la nature ${ }^{125}$, mais ce qu'il nous dit des coutumes funéraires des Prussiens permet de rapprocher son texte de celui de Barthélemy l'Anglais, ce qui laisse entendre qu'il a puisé ses informations auprès du même réseau franciscain ${ }^{126}$. Pour Bacon, les païens se caractérisent par un fort attachement à leurs coutumes, ce qui ne saurait nous étonner étant donné que leur religion était fréquemment considérée en Occident comme un ensemble de rites cimentant la société ${ }^{127}$. Le franciscain anglais met de plus l'accent sur un certain matérialisme, qui se traduirait selon lui par la crémation des corps et la pratique de l'offrande funéraire, devenues un élément habituel des descriptions des mœurs des païens baltes:

"Les vrais païens, comme les Prussiens et ceux des nations voisines, ont l'habitude de vivre selon la coutume et pas selon la loi de la raison. Leurs intérêts sont centrés sur les plaisirs, les richesses et l'honneur de cette vie, et ils croient que la vie à venir est similaire à celle-ci dans tous les aspects. Ainsi à leur mort ils se font brûler en public, avec leurs pierres précieuses, de l'or, de l'argent, leurs destriers, leur famille, leurs amis, toutes leurs richesses et leurs biens, espérant profiter de toutes ces choses après la mort. ${ }^{128}$

L'interprétation des trois auteurs est la même: l'au-delà en lequel croient les Baltes est une répétition de la vie terrestre, où le défunt retrouvera les biens qui lui ont appartenu ${ }^{129}$. Une telle "croyance» semble être généralement attribuée aux païens par les auteurs ecclésiastiques, du moins si l'on se réfere à un extrait

${ }^{123}$ M. TAMM, «Inventing Livonia... », p. 208.

124 Descriptiones terrarum, éd. M. Colker, «America rediscovered...», p. 722. Le fait que la première phrase soit au passé, mais la seconde au présent, indique-t-il que, pour l'auteur, la croyance a survécu à la pratique?

${ }^{125}$ Roger Bacon, Opus Maius..., éd. J. H. Bridges, vol. 2, p. 372.

${ }^{126}$ M. Tамм, "A New World...», p. 19, n. 32.

127 S. C. Rowell, "Customs...», p. 46 sq.

${ }^{128}$ Roger Bacon, Opus Maius..., éd. J. H. Bridges, vol. 2, p. 369.

${ }^{129}$ Baltu Religijos..., p. 76. 
du De cognitione sui d'Hélinand de Froidmont (m. v. 1229), qui, citant la description des Enfers dans l'Enéide, commente en disant qu'il est erroné de croire «que les âmes des défunts apparaissent à beaucoup de gens pleurant les châtiments de leurs péchés avec l'apparence qu'ils avaient lorsqu'ils vivaient: c'est-àdire les paysans en habits campagnards, les chevaliers en armes, comme le vulgaire l'affirme au sujet de la mesnie Hellequin ${ }^{130}{ }^{13}$. L'allusion à ce cortège des âmes des morts permet à l'auteur d'opposer la conception supposément païenne de l'autre monde à celle que défend le christianisme ${ }^{131}$. Ainsi, l'au-delà des païens ne peut qu'être «inférieur» à celui des chrétiens, puisqu'il ne constituerait qu'une répétition de la vie terrestre. C'est ce qui ressort de la chronique de Pierre de Dusbourg:

"Les Prussiens croyaient aussi à la résurrection des corps, mais pas comme ils le devaient. Ils croyaient en effet que l'on soit noble ou homme du commun, riche ou pauvre, faible ou puissant, on le resterait dans la vie future, après la résurrection. Pour cette raison, il était d'usage, quand un homme noble mourait, que ses armes et son cheval, tous ses serviteurs, ses parures précieuses, ses chiens de chasse et ses faucons et beaucoup d'autres choses rappelant son statut soient brûlés avec lui. Quand un homme du commun mourait, tout ce qui avait rapport avec son activité était brûlé. Ils croyaient que tout cela allait ressusciter avec lui pour lui servir comme dans sa vie précédente. ${ }^{132}$

Dusbourg n'est pas le seul chroniqueur de la région balte à mentionner ce genre de rites. Henri de Livonie note qu'après une tentative d'assaut menée contre Riga, les Coures se replient puis récupèrent leurs morts sur le champ de bataille, et qu'une fois de l'autre côté de la Daugava, ils les brûlent et les pleurent pendant trois jours ${ }^{133}$. Pour Nils Blomkvist, l'utilisation de la première forme du pluriel dans sa description du siège de Riga pourrait indiquer que le chroniqueur a été présent lors des événements, et donc qu'il a pu être témoin de la scène de crémation ${ }^{134}$. À la différence de Dusbourg, Henri ne lie pas la crémation des corps à la croyance en un au-delà; cependant, lorsqu'il relate que des femmes lituaniennes se sont pendues en apprenant que leurs maris ont été tués dans une bataille, il ajoute qu'elles l'ont fait en pensant les retrouver dans une autre $v^{13}{ }^{135}$. On a alors l'impression que ces auteurs essayent de donner du sens à des événements à première vue incompréhensibles: si ces femmes se suicident, c'est parce qu'elles croient qu'elles retrouveront leurs maris. De la

\footnotetext{
${ }^{130}$ Hélinand de Froidmont, Flores Helinandi, part. 2, cap. 10, dans Patrologia latina, vol. 212, col. 731.

${ }^{131}$ M.-A. WAGNER, Le cheval..., p. 563-565.

132 Pierre de Dusbourg, Chronicon..., SRP 1, p. 54.

${ }_{133}$ Henri de Livonie, Heinrichs Livländische Chronik..., XIV, 5, p. 77.

134 N. Blomkvist, Discovery..., p. 173-174.

${ }^{135}$ Henri de Livonie, Heinrichs Livländische Chronik..., IX, 5, p. 28 ; M. Gimbutas, The Balts..., p. 188.
} 
même manière, si les amis et les parents d'un personnage décédé brûlent ses biens avec lui, c'est parce qu'ils croient qu'il les utilisera après la mort ${ }^{136}$. Un tel processus de rationalisation ne date pas des historiens du Moyen Âge, et a notamment été repéré à l'œuvre par François Hartog chez Hérodote et ses pairs de l'Antiquitéér7.

Le parallèle entre les écrits des savants anglais et les documents produits sur le rivage balte peut nous aider à comprendre la manière dont la religiosité des païens était interprétée dans l'Occident médiéval. Outre les chroniqueurs Henri de Livonie et Pierre de Dusbourg, qui, d'une certaine manière, n'étaient pas plus à l'abri d'une interpretatio romana que les auteurs écrivant à Magdebourg ou à Paris, un document juridique nous donne quelques éclaircissements. Il s'agit du traité de Christbourg, conclu en 1249 sous la houlette du légat Jacques Pantaléon entre les représentants des Teutoniques et des Prussiens, lesquels doivent jurer de renoncer aux pratiques païennes. Parmi celles-ci, les rédacteurs du traité mentionnent des coutumes funéraires qui nous sont maintenant familières:

"En outre, les dits néophytes, [...] promirent fermement et fidèlement, d'une volonté spontanée, qu'eux ou leurs descendants ne conserveront pas leurs morts brûlés ni enterrés avec des chevaux ou des hommes, ni avec des armes ou des habits ou n'importe quoi d'autre de précieux, ni selon n'importe quels autres rites des païens, mais qu'ils enseveliront leurs morts selon la coutume des chrétiens, dans le cimetière et pas en dehors. ${ }^{138}$

L’ensevelissement est mentionné au côté de la crémation, ce qui pourrait indiquer que les rédacteurs du traité ont bénéficié de renseignements assez précis quant aux différentes pratiques funéraires des Baltes ${ }^{139}$, et que contrairement aux chroniqueurs et aux savants, ils ne se sont pas contentés de retenir uniquement la très spectaculaire crémation. Le document donne encore d'autres détails que taisent Barthélemy ou Roger. Un peu plus loin, le texte du traité nous dit par exemple que les Prussiens:

"promirent de ne plus recevoir parmi eux les Tulissones ou Ligaschones, ces fieffés menteurs et histrions, qui pour ainsi dire en tant que prêtres des païens, président aux funérailles des défunts et sont, hélas!, promis aux tourments infernaux. Tenant pour bien ce qui est mal, ils louent les défunts pour les vols, pillages et autres crimes et péchés que ces derniers commirent de leur vivant. Criant les yeux levés au ciel, ils affirment mensongèrement voir le défunt voler au milieu du ciel

\footnotetext{
${ }^{136}$ Notons que dans l'Occident chrétien, certains princes ou prélats sont enterrés avec leurs attributs; voir notamment T. MeIER, Die Archäologie des mittelalterlichen Königsgrabes im christlichen Europa, Stuttgart 2002 (compte-rendu par E. DabrowsKa, Le Moyen Âge 111, 2005, p. 709-714).

137 F. Hartog, Le Miroir..., p. 194-199.

138 PUB 1-1, doc. 218, p. 161 ; D. Buschinger, M. Olivier, Les Chevaliers teutoniques..., p. 98.

139 A. Pluskowski, The Archaeology..., p. 78-80.
} 
sur son cheval, orné de ses armes étincelantes, tenant au poing un épervier, et s'avançant dans l'autre monde à la tête d'une grande troupe. Avec de pareils et semblables mensonges, ils séduisent le peuple et le ramènent aux rites païens. $»^{140}$

La présence de ces personnages semble à première vue confirmer ce que disent les chroniqueurs et encyclopédistes de la même époque: quoi de plus "normal», en effet, que de voir un mort chevaucher en armes, avec son faucon sur le bras, s'il doit jouir de tous ses biens dans l'autre monde? Du point de vue des rédacteurs du traité, les Tulissones et les Ligaschones auraient tout intérêt à profiter d'un événement aussi important pour la communauté que les funérailles d'un puissant pour maintenir leur pouvoir en prétendant voir le défunt s'élever au-dessus du bûcher. Cependant, les recherches sur la mythologie balte peuvent éclairer ce passage d'une lumière différente. Endre Bojtár compare ces personnages aux chamanes eurasiatiques ${ }^{141}$, dont on retrouve les caractéristiques fondamentales chez de nombreux «sorciers" de l'Europe médiévale et moderne ${ }^{142}$. Le chroniqueur Pierre de Dusbourg attribue un trait similaire à un prêtre païen nommé Criwe, dont il fait une sorte de figure inversée du pape, obéi de tous les Baltes ${ }^{143}$ :

"Au sujet de leurs morts, il y avait aussi cette illusion diabolique: quand un membre de la famille d'un homme mort va voir Criwe, et lui demande s'il a vu quelqu'un passer autour de sa maison tel ou tel jour, ou lors d'une nuit particulière, Criwe décrit avec une grande précision l'apparence du mort avec ses armes et ses habits, ses familiers et ses chevaux, et pour plus de certitude, il affirme souvent qu'il a laissé une certaine figure avec sa lance ou un autre instrument sur le linteau de la porte. ${ }^{144}$

Que l'on considère les Tulissones, Ligaschones et autres Criwe comme des chamanes ou comme de simples "fieffés menteurs", on doit en déduire que l'image du mort s'élevant au-dessus du bûcher, en armes et sur son cheval, avait une signification particulièrement importante dans la religiosité traditionnelle des Prussiens. Les spécialistes estiment que la pensée préchrétienne balte concevait l'au-delà comme un lieu lointain, que l'on rejoignait à cheval ou

\footnotetext{
140 PUB 1-1, doc. 218, p. 161.

141 E. Bojtár, Foreword..., p. 327-329. Voir aussi A. Pluskowski, The Archaeology..., p. 68.

142 Sur ce point, voir non sans réserve C. GinzBurg, Le Sabbat des Sorcières... et Idem, Les Batailles nocturnes: sorcellerie et rituels agraires en Frioul, XVI-XVIT siècle, Paris 1966; Idem, "Les origines du sabbat", dans N. Jacques-Chaquin et M. Préaud (dir.), Le sabbat des sorciers. XV'-XVIII siècles, Grenoble 1993, p. 17-21; E. Pócs, «Le sabbat et les mythologies indo-européennes», dans ibid., p. 23-31. Pour le cas balte, E. Bojtár, Foreword..., p. 277.

143 S. C. Rowell, Lithuania Ascending..., p. 125-128; A. V. Murray, "Heathens... », p. 208-209. D’après Dusbourg, Criwe est censé siéger dans un lieu nommé Romowe, qu'il fait dériver du mot «Rome».

144 Pierre de Dusbourg, Chronicon..., SRP 1, p. 54.
} 
en bateau, en suivant le chemin du soleil ${ }^{145}$. Si l'on compare avec ce que nous savons des autres systèmes mythologiques d'Europe et d'Asie centrale, il est envisageable de considérer le cheval comme un agent psychopompe, rendant possible l'accès à l'au-delà ${ }^{146}$. Un même raisonnement peut être, avec une certaine prudence, tenté pour ce qui concerne la crémation. Les anthropologues et mythologues qui se sont penchés sur la question supposent que le feu était un élément sacré chez les Baltes, permettant d'entrer en communication avec l'autre monde $^{147}$. Comme le cheval, le feu possédait sans doute un rôle symbolique important dans les funérailles. On peut alors supposer que le scribe chargé de rédiger le traité de Christbourg a noté assez fidèlement les coutumes funéraires des Baltes, sans doute connues par le truchement des missionnaires et de divers témoins, mais leur a donné un sens correspondant à la vision chrétienne du paganisme: les chamanes conduisant la cérémonie funéraire deviennent des manipulateurs qui «avec de pareils et de semblables mensonges, ... séduisent le peuple et le ramènent aux rites païens». On retrouve l'idée d'infidèles naïfs, qui du fait de leur ignorance sont aisément trompés par des "histrions» avides de pouvoir. Selon cette logique, les vrais ennemis du christianisme ne seraient pas les païens eux-mêmes, mais leurs prêtres ${ }^{148}$.

En partant de l'hypothèse que la crémation et l'offrande funéraire, ont, au moins dans certains cas, été pratiquées, il y a lieu de penser que les différents acteurs aux contacts de la réalité balte avaient entendu parler de ces impressionnantes funérailles ou en ont été eux-mêmes témoins, comme cela semble être le cas d'Henri de Livonie au moment où il décrit la scène lors de laquelle les guerriers coures brûlent leurs morts après l'attaque sur $\mathrm{Riga}^{149}$. Un phénomène aussi marquant devait être connu de beaucoup parmi la communauté des chrétiens de la Baltique ${ }^{150}$. Ces éléments, "exotiques" à souhait, n'ont pas manqué d'être notés par les missionnaires franciscains, qui ont diffusé leurs connaissances auprès de collègues en France ou ailleurs. La courte notice du Descriptiones terrarum concernant la crémation des morts en Sambie atteste du fait que des missionnaires actifs sur le terrain ont pris soin de collecter ces informations ${ }^{151}$. Barthélemy l'Anglais ou Roger Bacon ayant

\footnotetext{
145 M. Bertasius, «Horse Graves... », p. 307-312.

146 C. Westerdahl, "The Horse as a liminal agent», Archeologia Baltica 11, 2009, p. 323-324;

M.-A. WAGNER, Le cheval..., p. 11 sq.

147 P. Walter, "The Ditty of Sovijus (1261)», Archaelogia Baltica 15, 2011, p. 75-76; A. Greimas, "Le dit de Sovys...», p. 41-58.

148 L'idée du prêtre ou du sorcier «infidèle» et manipulateur comme principal adversaire des missionnaires apparaît encore en plein $\mathrm{xx}^{\mathrm{e}}$ siècle, dans le contexte de la mission belge au Congo: P. Delisle, "Un Tintin au Congo flamand au service des missions chrétiennes. Le Bâton du Féticheur, de Renaat Demoen (1949-1950)", Revue d'histoire de l'Église de France, 101/246, 2015, p. 121-140.

149 N. Blomkvist, Discovery..., p. 173.

150 A. Pluskowski, The Archaeology..., p. 80.

151 M. Colker, "America rediscovered...», p. 722; M. TAMм, «A New World...», p. 31.
} 
vraisemblablement eu l'occasion d'entendre de telles histoires de leurs confrères qui ont séjourné dans la région balte, il n'y a rien d'étonnant à ce que ces auteurs intéressés par cette "nouvelle" terre de mission les aient incorporées à leurs œuvres respectives ${ }^{152}$. Ce qu'Anne Kehnel appelle le "frisson de l'érudit», qui parsème son texte de quelques curiosités exotiques pour maintenir éveillée l'attention de ses lecteurs, n'est sans doute pas étranger à l'intérêt des hommes de lettres occidentaux pour ces coutumes spectaculaires et «barbares" ${ }^{153}$.

Face à la diversité des types de funérailles pratiquées parmi les différents peuples et groupes sociaux baltes, seuls ceux qui faisaient le plus de sens pour les auteurs chrétiens ont donc été retenus: la crémation et l'offrande de biens et de chevaux. Ce genre d'obsèques, peut-être réservées aux princes ${ }^{154}$, pouvait évoquer des souvenirs de l'histoire antique. La pratique, aux antipodes de la façon de faire chrétienne, est comprise comme un trait typique du paganisme; aussi, elle impressionne et pose des questions. On essaye de l'expliquer par ce que l'on croit savoir de la religion des païens, autrement dit que leur au-delà n'est qu'une répétition de la vie terrestre. Implicitement, c'est la tradition antique qui est, encore une fois, appelée pour donner les clefs d'interprétations. Le fait que les Baltes placent les richesses du mort sur le bûcher pour être brûlées avec lui est considéré comme une preuve que leur conception de la vie après la mort correspond bien à ce que l'on imaginait. Choisies parmi d'autres pratiques, vidées du sens qu'elles avaient pour les natifs, la crémation et l'offrande funéraire deviennent, dans la littérature du XIII ${ }^{\mathrm{e}}$ siècle, des éléments distinctifs de la religion balte.

Cette tradition reste bien établie pour les auteurs des siècles suivants relatant les périples des chevaliers français venus prêter main-forte aux Teutoniques dans leur croisade contre la Lituanie païenne. Ainsi, Jean Cabaret d'Orville, qui a consigné les souvenirs que lui dicta le vieux croisé Jean de Chastelmorand (Chronique du bon duc Loys de Bourbon, 1429), évoque le traité passé à l'issue d'une rèse entre les chevaliers chrétiens et leurs adversaires:

"Et tant firent chrestiens que les sarrasins furent tous lies d'eulx en realler en leur pays, parmi l'ordonnance faite que, de certain temps, les Sarrasins de Letho ne de Norgalles ne pilleroient nulles esglises des chrestiens ne les brusleroient, ne aussi les chrétiens, chevaliers de la religion, tant de Prusse, comme de Niffelant,

\footnotetext{
152 Sur l'attitude de Roger Bacon et de Barthélemy l'Anglais quant aux «nouvelles» régions de l'Europe orientale, N. Bouloux, "Les formes d'intégration...", p. 119-146.

153 A. KeHNeL, "Le sacrifice du cheval...», p. 22-24, qui rappelle que cette perspective impliquait souvent un sentiment de supériorité de l'auteur "civilisé» écrivant au sujet des "barbares»; décrire des coutumes étranges, en opposition avec la conception chrétienne du monde, pouvait aussi faire ressortir la sauvagerie du peuple concerné et ainsi justifier la mainmise chrétienne sur celui-ci.

154 Pour E. Bazaraité et T. Heitor, "Comparative study...», p. 320, c'est le cas aux XiII et XIV ${ }^{e}$ siècles.
} 
en leur pays de Letho ou es marches, n'arderoient les saints bois (que ainsi ils appellent) des pins, ou ils consumoient les corps de leurs morts par feu, et en faisoient sacrifice. Si fut octroyé d'une part et d'autre, et par ainsi fut la paix criée par les provinces. ${ }^{155}$

Le respect des bois sacrés et leur usage dans la crémation des morts sont ici mentionnés en passant, comme une curiosité livrée au lecteur dans le feu de l'action; le récit enchaîne directement sur la conclusion du traité et l'honneur qui en découle pour les participants à la rèse. Jacques d'Esch, racontant dans sa Chronique de Metz l'expédition à laquelle lui-même a participé en hiver 1400, opère exactement selon le même processus:

"quant ilz sentont la force desdis Crestiens, ilz [les Samogitiens] recullont arrier et s'en allont fuiant en ung mervilleux boix, qu'ilz appelloient le Saint Boix, ou onque Crestien n'avoit esteit, et onqueil boix, quant ilz se sentient constrains, ilz s'i alloient adez salver. Et y avoit de tres fort fermeteit de gros mairiens on dit boix et de belz edeficez et fuit gaingniez par les Crestiens. Et quant ilz se sentont ainsi promonez, ilz vinxent a obeysance permey ce qu'ilz debvoient avoir leur femez et enffens qui estoient prins et donnont seuretei d'estre en obeyxance. ${ }^{156}$

Là encore, la mention du bois sacré des Samogitiens est immédiatement suivie des termes de l'accord que leur imposent les vainqueurs. Ces deux descriptions portent sur les adversaires des croisés, Lituaniens dans un cas, Samogitiens dans l'autre. Un troisième auteur qui évoque les rites des natifs baltes, Guillebert de Lannoy, ne le fait pas dans le cadre de ses souvenirs de rèse proprement dits ${ }^{157}$, mais lorsqu'il rend compte de son voyage de Königsberg à Riga, le long de la côte, en automne 1413. Fait intéressant, ce n'est pas dans une Samogitie déserte qu'il situe ces pratiques, mais dans un territoire appartenant à la province teutonique de Livonie: la Courlande. L'extrait dont il est question atteste que pour notre voyageur bourguignon, des rites manifestement païens étaient pratiqués au sein d'une population pourtant soumise à l'Ordre teutonique au XIII ${ }^{\mathrm{e}}$ siècle:

"Idem, ont lesdis Corres, jasoit ce qu'ilz soient cristiens natifz par force une secte que après leur mort ilz se font ardoir en lieu de sépulture, vestus et aournez chascun de leurs meilleurs aournemens, en ung leur plus prochain bois ou forest qu'ilz ont, en feu fait de purain bois de quesne. Et croyent, se la fumière va droit ou ciel, que l'âme est sauvée, mais, s'elle va soufflant de costé, que l'âme est périe. ${ }^{158}$

\footnotetext{
155 Chazaud, p. 65.

156 Wolfram, p. 337.

157 Il a combattu les Poméraniens chrétiens alliés aux Polonais.

${ }_{158}$ Potvin, p. 30.
} 
Ces trois textes réactivent les traits caractéristiques attribués aux païens baltes, autant dans les encyclopédies occidentales que dans les chroniques écrites par des membres de l'Ordre teutonique (on pense inévitablement à Pierre de Dusbourg) ou dans différentes lettres pontificales et documents administratifs. Chez Chastelmorand et Lannoy, la crémation des morts est directement liée aux bois sacrés, un autre poncif des descriptions du paganisme balte depuis Adam de Brême au moins ${ }^{159}$. Pour Jacques d'Esch, ceux-ci font figure d'ultimes refuges pour les païens de Samogitie; on ne saurait trouver de meilleur exemple illustrant l'assimilation de la forêt au paganisme!

Il y a fort à parier que ces voyageurs, que l'on devine curieux et s'enquérant volontiers de détails sur les régions qu'ils traversent, aient entendu ces récits directement de leurs guides, ou de quelque officier teutonique avec qui ils auraient pu s'entretenir. Ceux-ci leur auraient alors raconté des anecdotes tirées de la tradition interne à l'Ordre, reposant en bonne partie sur les chroniques et les souvenirs personnels des chevaliers. À ce sujet, Philippe de Mézières précise à deux reprises avoir entendu une anecdote directement liée au bûcher funéraire de la bouche de vieux Chevaliers teutoniques, qui l'ont par ailleurs assuré de son authenticité: "je recorderay ce qui me fu recordé et pour verité, et n'a pas trop long tamps qu'il avint»" ${ }^{160}$. Puis, après avoir raconté l'aventure: "ceste histoire contee pour vraye des anciens et vaillans chevaliers de la religion susdite» ${ }^{161}$. La transmission orale étant attestée dans ce cas, rien n'interdit de penser que nos autres voyageurs aient eux aussi obtenu leurs informations de membres de l'Ordre teutonique, ou de guides connaissant l'histoire locale. Il est également possible que, par ailleurs, nos chevaliers français aient eu connaissance du passage sur les rites funéraires des habitants de Livonie, dans l'adaptation vernaculaire de Barthélemy l'Anglais par Jean Corbechon (1372) ou dans le passage lituanien du Songe du vieil pelerin de Mézières, resté relativement populaire jusqu’à la fin du $\mathrm{Xv}^{\mathrm{e}}$ siècle ${ }^{162}$. Toutefois, Guillebert de Lannoy semble considérer la Courlande comme une province distincte de la Lituanie et de la Livonie; si influence il y a pu avoir, il ne s'agit pas d'une simple reprise. En outre, aucun de nos textes n'est directement tiré de l'adaptation de Barthélemy en français ${ }^{163}$.

\footnotetext{
159 Le fait d'imaginer que la crémation des morts ait lieu dans un bois sacré est à priori étonnant; d'après l'archéologie, des sites particuliers dédiés aux funérailles et/ou aux banquets rituels ont pu exister. Ceux-ci se trouvaient-ils dans une clairière ou une zone déboisée, elle-même à proximité d'une forêt?

160 Blanchard, vol. 1, p. 207.

161 Ibid., p. 209.

162 Philippe de Mézières, Une Epistre..., p. 37-38.

${ }^{163}$ Voici comment Corbechon a rendu le passage consacré aux rites funéraires des natifs de Livonie: "Ilz ne mettoient point en terre les corps mors; mais les ardoient iusques à la cendre. Et quand vn de leurs amys estoit mort ilz le vestoient de robes neusves \& luy bailloient bestes, or \& argent, varletzs \& chamberieres ainsi comme pour aller en vn grand voyage, \& tout ce ilz boutoient au feu auec le mort \& cuydoivent que tout ce qui estoit auec luy deuil denenir en vne region de vie \& anoir le seruice des choses qui estoient arses auec luy", Barthélemy l'Anglais, Le Grand Propriétaire..., col. 130.
} 
De même, Guillebert est le seul à lier directement la crémation à la divination quant au sort de l'âme du défunt. Comme nous le savons, l'au-delà des Baltes est parfois évoqué, mais sans que la fumée du bûcher ne soit mise à contribution. Ce passage de Lannoy a été rapproché, à juste titre, de l'extrait du traité de Christbourg (1249) faisant mention des pratiques divinatoires des Tulissones et Ligaschones, ces prêtres païens dont on dit qu'ils prétendent voir les morts chevaucher en armes au-dessus de leur bûcher ${ }^{164}$. Étant donné la dernière phrase de l'extrait ${ }^{165}$, qui mentionne la salvation de l'âme, Jean Meuvret a cru y voir une preuve attestant l'influence du christianisme sur l'ancienne coutume païenne de la crémation ${ }^{166}$. Toutefois, la mention de la fumée comme indicateur du sort de l'âme rappelle trop une légende médiévale bien précise pour ne pas penser à un emprunt de la part de Guillebert: celle voulant que ce soit par la direction de la fumée que Caïn et son frère Abel aient su si Dieu avait refusé ou accepté leurs sacrifices ${ }^{167}$. Rien n'exclut bien sûr que le jeune Bourguignon n'ait entendu parler des pratiques divinatoires auxquelles les Baltes étaient censés se livrer lors de funérailles; cherchant à rendre compréhensible ce qui lui avait échappé, il a vraisemblablement eu recours à une légende connue de lui-même pour donner un sens à la pratique à première vue étrange de brûler les corps des défunts.

Selon l'habitude bien connue des anthropologues, la peinture d'un peuple «étranger" met souvent en valeur les pratiques funéraires de ceux dont on parle ${ }^{168}$. Représentant l'opposé de ce à quoi les auteurs chrétiens étaient habitués, ce type de funérailles constituait un puissant marqueur d'altérité, signifiant sans équivoque le caractère païen, étranger, des Baltes ${ }^{169}$. La crémation des corps comme inversion des normes chrétiennes est clairement soulignée dans le Roman de Mélusine de Jean d'Arras (1393), et dans sa mise en vers par Coudrette (1401). Deux des fils de la fée, Antoine et Renaud de Lusignan, accompagnés du roi d'Alsace, volent au secours du frère de celui-ci, Frédéric, roi de Bohême, assiégé dans sa capitale par un certain Selodus, roi de Cracovie, à la tête d'une armée de "Sarrasins». Nous avons vu que cet épisode, qui met en scène l'intronisation du premier Lusignan/Luxembourg comme roi de Bohême, peut être un écho des guerres de Jean l'Aveugle contre les Lituaniens autant que des accusations teutoniques contre Jagellon, le prince converti couronné roi de Pologne contre qui les hôtes de l'Ordre teutonique se battaient dans les années $1390^{170}$. Non content d'avoir tué le roi de Bohême avant que les

\footnotetext{
164 S. C. Rowell, Lithuania Ascending..., p. 124, n. 32.

165 Voir ci-dessus, p. 409.

166 J. Meuvret, Histoire des pays baltiques: Lituanie - Lettonie - Estonie - Finlande, Paris 1934, p. $40-41$.

167 Baltu Religijos..., p. 513 (trad. Rūta Valaitytè); A. Scheiber, «La fumée des offrandes de Caïn et d'Abel. Historique d'une légende», Revue des Études Juives, nouv. série 15 (115), 1956, p. 9-24.

${ }_{168}$ M. TAмм, "A New World...", p. 30.

169 Id., passim; F. Hartog, Le Miroir..., p. 225-237.

${ }^{170}$ Voir chapitres III et V.
} 
Lusignans ne viennent délivrer Prague, le dénommé Selodus inflige à sa dépouille un sort absolument contraire à ce que les lois de la courtoisie auraient exigé: "Et le roy de Craquo fait prendre le corps du roy Fedric tout mort et le fist ardoir devant la porte pour plus esbahir ceulx de la cite de Prange»" ${ }^{171}$. Le poème de Coudrette ajoute un détail technique, qui évoque le bûcher funéraire de manière plus terrible encore: "Lors alumer ung grant feu font / Et de busche mette en ung mont, / Pres de la porte le feu firent» ${ }^{172}$. Brûler les chrétiens semble faire partie du plan de Selodus, qui cherche à faire céder les assiégés par la terreur: apprenant que ceux-ci refusent de se rendre, le roi des païens «fu moult courrouciéz et jura ses dieux que tous seroient ars en pouldre» ${ }^{173}$.

La ville est sauvée, on s'en doute, par l'arrivée d'Antoine et de Renaud, avec à leurs côtés le roi d'Alsace et le duc Othon de Bavière. À l'issue d'un combat épique, Renaud de Lusignan tue Selodus et met en fuite l'armée sarrasine. Alors que les deux frères s'installent dans le camp ennemi - qu'ils mettent au pillage le roi d'Alsace et le duc Othon sont accueillis par Églantine, la malheureuse fille du roi de Bohême : "Mon chier oncle, vous soiéz le tresbienvenus! Mais, s'il eust pleu a Dieu que vous feussiéz venu deux jours plus tost, vous eussiéz tronvé monseigneur mon pere en vie, que le roy Selodus a mis mort et puis a fait ardoir le corps pour plus despiter la foy catholique» ${ }^{174}$. Pour venger l'affront, le roi d'Alsace décide à son tour de faire brûler tous les ennemis qui seraient trouvés, "mors ne en vie» ${ }^{175}$. Sur une colline près de la ville, on construit un immense bûcher, où l'on place les corps des ennemis, avec celui du roi Selodus au sommet: «feussent tous les payens ars et bruiz, et tous les crestiens enseveliz et mis en terre saincte» ${ }^{176}$. Des funérailles dignes de lui sont organisées pour le roi Frédéric, dont les restes reçoivent une sépulture ${ }^{177}$. La situation est donc rétablie. L'importance des rites funéraires peut se refléter dans le fait que les vignettes peintes sur l'un des manuscrits (Arsenal 3353, première moitié $\mathrm{du} \mathrm{Xv}^{\mathrm{e}}$ siècle) ne représentent pas de scènes de batailles, mais la crémation du roi Frédéric par les païens, puis la mise au tombeau de sa dépouille (fig. 6 a et b).

Si l'on admet que les «Sarrasins» du roi de Cracovie sont des Lituaniens et non des musulmans, force est de constater qu'à la fin de cette aventure, chacun quitte le monde d'ici-bas en accord avec ses propres rites - et ceci même si la crémation des païens est présentée comme une punition infligée en guise de vengeance. Du reste, Selodus n'est pas stigmatisé parce qu'il aurait fait brûler le corps de ses hommes tombés au combat, mais pour avoir réservé le même sort à celui du roi de Bohême. Si la crémation représente l'inversion

\footnotetext{
${ }^{171}$ Jean d'Arras, Mélusine..., p. 518.

172 Coudrette, Mélusine..., v. 2357-2359, p. 208.

${ }_{173}$ Jean d'Arras, Mélusine..., p. 520.

174 Ibid., p. 528-530.

175 Ibid., p. 530.

176 Id.

177 Ibid., p. 530-542.
} 
de la norme, Selodus la transgresse en réduisant en cendres la dépouille d'un roi chrétien, lequel devrait recevoir une sépulture en accord avec sa religion. La transgression est soulignée par la réponse d'Antoine de Lusignan au roi d'Alsace, lequel lui apprend comment il se vengea de leur ennemi, qui «avoit fait ardoir le corps [de Frédéric] ou despit de toute crestienté» ${ }^{178}$ : "Par mon chief, [...] vous avéz tres bien fait! Et vrayement, le roi Selodus fist grant mesprison et grant cruaulté, car puisque uns homs est mort, c'est honte a son ennemy de le plus touchier $"{ }^{179}$.

Même si l'on peut imaginer que les aventures pragoises des fils de Mélusine aient été, dans une certaine mesure, inspirées par des figures contemporaines, cet épisode n'en appartient pas moins au monde de la fiction: Jean d'Arras n'a pas la prétention de décrire quelque chose de réel, mais de plonger ses lecteurs dans un monde épique, où ses héros affrontent des Sarrasins particulièrement haïssables. Si la crémation des corps est dépeinte en termes aussi noirs, c'est plus pour le besoin de la narration (faire ressortir la cruauté de Selodus) que pour condamner le paganisme ipso facto, d'autant plus que c'est la dépouille d'un chrétien qui est brûlée. Force est de constater que les voyageurs Jean de Chastelmorand ou Guillebert de Lannoy ne parlent pas dans les mêmes termes des rites que les païens appliquent à leurs propres morts ${ }^{180}$.

Alors qu'un Barthélemy l'Anglais annonçait triomphalement que les Livoniens ne pratiquaient leurs rites qu'avant "d'avoir été forcés de passer $d u$ service des démons à la foi et au culte du Dieu unique ${ }^{181}$ ou qu'un Roger Bacon entendait utiliser la prétendue simplicité des païens de Prusse pour illustrer sa théorie de la conversion par la parole, ni Lannoy ni Chastelmorand ne portent de jugement explicite sur les rites funéraires des Baltes. Comme l'a remarqué François Hartog, décrire des pratiques barbares d'un ton neutre, en utilisant un vocabulaire technique, peut être un moyen de produire de l'altérité182 - et sans marques d'énonciation, de "livrer de l'altérité à l"état brut" ou "sauvage" ${ }^{183}$. On ne saurait donc voir dans l'absence de condamnation une preuve de respect ou de tolérance. Nos croisés de Prusse ne considéraient certainement pas que le paganisme ait pu valoir la foi chrétienne. Or, à l'inverse peut-être des clercs écrivant dans le sillage de leurs collègues missionnaires, ces nobles participant occasionnellement aux rèses de l'Ordre teutonique avant de rentrer chez eux ne percevaient plus forcément le paganisme des Baltes comme une menace. Bien loin d'être un culte aux démons tel qu'on l'écrivait au XIII ${ }^{\mathrm{e}}$ siècle dans le milieu ecclésiastique, cette religion étrangère - réduite à ses seuls rites

\footnotetext{
${ }^{178}$ Ibid., p. 530-532.

179 Ibid., p. 532.

180 Sur cet épisode, R. Mažeika, L. Chollet, «Familiar Marvels?...», p. 46-47.

${ }^{181}$ M. TAMm, "Signes...", p. 169; trad. ibid, p. 165.

${ }^{182}$ F. Hartog, Le Miroir..., p. 266-268.

183 Ibid., p. 268.
} 
funéraires - devient une curiosité, au même titre que les forêts recouvertes de neige ou les marais protégeant la Lituanie en été184.

Il est même un auteur comme Philippe de Mézières, ardent propagandiste de la moralisation de la chevalerie, qui n'hésite pas à faire des Lituaniens un miroir permettant une critique de la société française de son temps; un rôle dans lequel ces farouches guerriers païens rejoignent leurs adversaires teutoniques ${ }^{185}$. Le grand-duché apparaît dans le premier livre du Songe, où l'auteur met en scène le voyage des figures allégoriques devant juger l'état spirituel des différentes parties du monde. Avant de se rendre en Prusse, l'auteur, la reine Vérité et ses compagnes visitent le "royaume de Layco [Lituanie]", "es darraines confines de Tartarie» ${ }^{186}$. Contrairement aux auteurs qui assimilent les Lituaniens aux Tatars, Philippe semble distinguer les deux peuples, puisque les deux États sont traités séparément, dans des chapitres différents. Les habitants de ce "royaume de Layco" sont "gent sans lettre et sans clergie, mais assés bien combatans, tesmoings les vaillans croisiés de Prusse. Les chambrieres des dames firent leur enqueste et trouverent que cest gent sont ydolatres ${ }^{187}$. Les Lituaniens sont donc des guerriers respectables, mais païens. Comme pour ce qui suit, les sources de Philippe sont essentiellement de seconde main: en l'occurrence, le portrait des Lituaniens tient beaucoup aux récits et aux témoignages glanés auprès des membres de l'Ordre teutonique ${ }^{188}$ ou de leurs hôtes occidentaux («croisiez» pourrait être compris dans ce sens-là, même s'il semble plus probable d'y voir les Teutoniques eux-mêmes $\left.{ }^{189}\right)$. S'il y a lieu de penser que l'écrivain s'est bien rendu en Prusse, comme ambassadeur du roi de Chypre en 1364, il n'a probablement pas visité la Lituanie lui-même, mais a pu en entendre parler à Marienbourg ${ }^{190}$.

Ce qui a le plus impressionné Mézières chez les Lituaniens, ce sont les coutumes funéraires accompagnant la mort du grand-duc, ici appelé roi, selon l'habitude occidentale ${ }^{191}$. Au $\mathrm{XIV}^{\mathrm{e}}$ siècle, les descriptions de funérailles ne concernent plus d'anonymes guerriers, mais les princes lituaniens, comme Gediminas (1342) ou son frère Vytenis (1316), décédés avant que Philippe ne

\footnotetext{
184 S. C. Rowell, "Of Men...», p. 93.

185 Si l'utilisation des Lituaniens comme miroirs n'est pas explicitée, tel est le cas en ce qui concerne les Tatars, qui «se gouvernent [...] si sagement, si justement et a telle magnificence qu'il se puet dire que leur biau gouvernement condampne la policie et orgueil des princes crestiens», Blanchard, vol. 1, p. 546. 186 Blanchard, vol. 1, p. 207.

187 Id.

188 PR 1, p. 270.

189 Philippe de Mézières, Le Songe..., trad. J. Blanchard, p. 176, n. 1.

190 W. Paravicini, "Litauer...", p. 258; Mézières décrit Marienbourg d'une manière qui correspond à ce à quoi le siège de l'Ordre pouvait ressembler dans la seconde moitié du XIV siècle, ce qui signifie qu'il l'a probablement visité personnellement: S. Jóźwiak, J. Trupinda, Organizacja życia na zamku krzyżackim $w$ Malborku w czasach wielkich mistrzow (1309-1457), Malbork 2011 ( $2^{\mathrm{e}}$ édition), p. 214-215.

191 S. C. Rowell, "The Letters...", p. 343-345.
} 
visite la Prusse ${ }^{192}$. De tels événements devaient produire une forte impression sur les chroniqueurs de la région. Ainsi, Hermann de Wartberge raconte-t-il qu'Algirdas, "grand roi des Lituaniens», mourut en 1377 et qu'il fut brûlé «en grande pompe, avec dix-huit destriers, selon leurs rites» ${ }^{193}$. Comme l'a remarqué Rasa Mažeika, Wartberge, qui écrit à la fin du XIv ${ }^{e}$ siècle et dans une optique plus «militaire» que missionnaire, s'abstient de condamner explicitement ce type de funérailles - ce en quoi il rejoint nos voyageurs français ${ }^{194}$. Lisons donc ce que rapporte Philippe de Mézières:

"Et quant leur roy est mort ses barons l'arment de toutes ses armes, et le metent sus un biau cheval bien armé de ses armes et entour le roy mort il font une grant assamblee de sapins composee en maniere que on fait les mesengiers, et par election les barons prendent le plus grant ami que le roy avoit, et li presentent cest honnour, c'est assavoir qu'il doye tenir compaignie a son seigneur qui tant l'ama et estre ars avec lui et aler en Paradis. Ledit ami se tient pour honnouré a toujours maiz de tenir compaignie a son seigneur et de sa propre volenté se met dedans le mesengier de bois emprés du roy son seigneur mort, qui est assis sus son cheval tout vif. Et lors les barons a grant devocion et a grans oroisons et regrés boutent le feu oudict mesengier de bois et ardent leur roy et son bon ami. Et les ames s'en vont tantost en Paradis ordené a telz gens. ${ }^{195}$

Le tableau rappelle, encore une fois, l'entrée «Livonie» de l'encyclopédie de Barthélemy l'Anglais ${ }^{196}$. L'adaptation de Jean Corbechon ayant été commandée en 1372 pour la bibliothèque du roi Charles V, Mézières n'aurait eu aucune difficulté à puiser quelques renseignements dans ce "best-seller» de la fin du Moyen Âge. Toutefois, il est probable que le Vieil Solitaire ait plutôt obtenu l'essentiel de ses connaissances directement en Prusse, auprès des Teutoniques: immédiatement après avoir évoqué le bûcher funéraire, il enchaine avec une anecdote qu'il dit tenir "des anciens et vaillans chevaliers de la religion susdite»" ${ }^{197}$.

Que Mézières ait puisé dans la tradition écrite ou dans ses souvenirs personnels, sa peinture des funérailles lituaniennes est révélatrice de la façon dont il pouvait percevoir et utiliser l'altérité balte. Tout d'abord, l'usage du terme "paradis" suggère une intéressante adaptation des catégories chrétiennes à un contexte païen. Aux premiers siècles du christianisme, les théologiens Tertullien, Jean Chrysostome ou Clément d'Alexandrie admettaient que des païens vertueux qui n'ont pas eu connaissance du Christ pouvaient être sauvés et aller au paradis; plus tard, vers le $\mathrm{XII}^{\mathrm{e}}$ siècle, l'opinion selon laquelle un païen vertueux pouvait être in extremis sauvé par un miracle s'est développé,

\footnotetext{
S. C. Rowell, Lithuania Ascending..., p. 130-131.

${ }^{193}$ Hermann de Wartberge, Chronicon Livoniae..., SRP 2, p. 113.

194 R. MažEıKa, L. Chollet, «Familiar Marvels?...», p. 55.

195 Blanchard, vol. 1, p. 207.

${ }^{196}$ M. Tамм, "A New World...", p. 31.

197 Blanchard, vol. 1, p. 209.
} 
plus dans le domaine littéraire que purement théologique ${ }^{198}$. Mais ces cas sont exceptionnels, et ce n'est sans doute pas l'idée de Mézières en ce qui concerne les Lituaniens païens, qui ne sont pas destinés au salut, mais dont les âmes vont simplement "en Paradis ordené a telz gens». Or, l'utilisation du terme "paradis" est attestée au XIII ${ }^{\mathrm{e}}$ siècle, notamment dans le Roman de la Rose, pour désigner, par analogie avec le sens chrétien, "le lieu de séjour des divinités païennes»"${ }^{199}$. Comme dans le Paradis de la reine Sibylle d'Antoine de la Sale (v. 1442-1444), le terme prend un sens différent, plus proche d'un au-delà, d'un autre monde, qui n'est pas forcément celui auquel les âmes des justes sont destinées. C'est dans ce sens-là qu'il faut comprendre l'utilisation de ce terme par Mézières: celui-ci ne suggère probablement pas que les Lituaniens non-baptisés puissent aller au paradis promis, selon la tradition chrétienne, aux justes après leur mort, mais il semble imaginer que les païens, qui ont une religiosité "erronée», croient en un au-delà analogue à celui des chrétiens. Au fond, il s'agit du même mécanisme que l'appel à la fumée du sacrifice de Caïn et d'Abel par Guillebert de Lannoy.

Le sacrifice du meilleur ami du «roi » pose un problème différent. Si l'on en croit M. Gimbutas, la mise à mort des familiers d'un prince peut être envisagée pour expliquer les tombes "collectives" que l'on trouve dans les régions baltes depuis l'époque chalcolithique; la famille, les amis et les esclaves préférés du prince défunt auraient eu l'obligation de l'accompagner dans sa dernière demeure ${ }^{200}$. Ce fait semble plus rare pour l'époque médiévale. Toutefois, une source tardive, la Chronique polonaise, lituanienne, samogitienne et de toute la Russie de Matthieu Stryjkowski (m. vers 1582) mentionne la mise à mort d'une compagne du grand-duc Gediminas lors de ses funérailles - événement auquel Mézières peut avoir fait allusion ${ }^{201}$. Stephen C. Rowell note que le chroniqueur polonais du $\mathrm{XVI}^{\mathrm{e}}$ siècle ne connaissait pas le récit de l'auteur français ${ }^{202}$; nous aurions donc deux sources indépendantes qui décriraient, de manière assez proche, la même histoire. Néanmoins, nous savons que la mise à mort d'humains apparaît souvent dans les descriptions des funérailles des païens d'Europe du Nord, et des Baltes en particulier; l'influence d'une tradition littéraire commune ne saurait être exclue.

De la même manière, le fait de brûler le prince mort «sur son cheval tout vif» fait écho aux récits qui, jusqu'à Długosz et Stryjkowski (respectivement pour la crémation des Samogitiens au début du Xve et pour celle de Gediminas en 1342), décrivent les funérailles des Baltes païens, lors desquelles le mort est assis

\footnotetext{
198 J. Russell, A History of Heaven, Princeton 1997, p. 128-129.

199 DHLF, vol. 2, p. 1422; A. Tobler - E. Lommatsch (dir.), Altfranzösisches Wörterbuch, Berlin 1969, vol. 7, p. 192.

${ }^{200}$ M. Gimbutas, "Religion and Mythology of the Balts», dans J. Trinkunas (éd.), Of Gods and Holidays, p. 26-27.

${ }^{201}$ Maciej Stryjkowski, Kronika polska, litewska, zmodzka i wszystkiej Rusi, éd. M. Malinowski, vol. 1, Varsovie 1846, p. 385-386.

202 S. C. Rowell, Lithuania Ascending..., p. 130-131.
} 
sur un cheval sellé, prêt à être montée ${ }^{203}$. Quelques traces laissées sur des sites de crémation, en Prusse, laissent entendre que des chevaux étaient brûlés lors de rituels, jusqu'au XIII ${ }^{e}$ siècle - ce genre de matériaux étant bien sûr difficile à interpréter. D'après les archéologues, il peut s'agir de restes de repas rituels pris sur les lieux de crémations, mais une offrande funéraire ne saurait être exclue ${ }^{204}$. Pour les périodes antérieures ( $v^{e}$ siècle environ), les preuves archéologiques attestent que dans plusieurs cultures de la région, des chevaux étaient enterrés aux côtés des défunts ${ }^{205}$. Rien n'empêche donc de penser que le sacrifice d'un cheval ait pu avoir lieu en guise d'adieu des boyards à leurs princes.

Du reste, la présence de chevaux et d'armes aux funérailles d'un grand ne devait pas être entièrement étrangère à un homme tel que Philippe de Mézières. Il est en effet attesté que lors d'obsèques princières ou nobiliaires, il était de coutume en France, en Angleterre, en Savoie ou en Flandre d'offrir les chevaux et les armes du défunt à l'abbaye où devait reposer le corps ${ }^{206}$. Les animaux, revêtus de housses armoriées ou bardés de fer, étaient conduits par des écuyers lors du cortège funéraire, et prenaient ainsi une part importante à la cérémonie ${ }^{207}$. Dans son étude consacrée au symbolisme du cheval dans les cultures germaniques, Marc-André Wagner a bien montré que, dès l'Antiquité, le cheval psychopompe mis en scène lors des funérailles des personnages de haut rang (que ce soit par un sacrifice ou par une course de chevaux) se confondait avec une marque de prestige, réservée à l'aristocratie guerrière. De ce double symbolisme, seul le deuxième a survécu un certain temps parmi les usages de la noblesse européenne ${ }^{208}$.

Fait rare dans la littérature ecclésiastique, Jacques de Vitry (m. 1240) fait du cheval un symbole du guerrier de Dieu. Sur le plan de l'allégorie, il assimile les quatre chevaux de Zacharie 6:1-3 ("roux ou rouge, blanc, noir et bai») aux

\footnotetext{
${ }^{203}$ Jan Długosz, Annales XI, dans Opera Omnia..., vol. 13, p. 160 ; Maciej Stryjkowski, Kronika..., p. 385-386. Voir aussi N. VėLIus, "Mythology and religion of the early Lithuanias", dans J. Trinkunas (éd.), Of Gods and Holidays..., p. 49.

${ }^{204}$ Correspondance privée avec M. Aleksander Pluskowski. Sur les sources narratives en rapport avec les sources archéologiques, S. C. Rowell, Lithuania Ascending..., p. 128-130.

205 M. Bertasius, «Horse Graves...», p. 305-313.

206 A. Paravicini Bagliani, "L'offrande des chevaux. Une question ouverte», dans E. Maier, A. Rochat, D. Tappy (dir.), À Cheval entre histoire et droit. Hommage à Jean-François Poudret, Lausanne 1999, p. 109-117; N. Pollini, La Mort du Prince: rituels funéraires de la Maison de Savoie (1343-1451), Lausanne 1994, p. 88-90; C. BEAunE, "Mourir noblement à la fin du Moyen Âge», dans La Mort au Moyen Âge. Actes des congrès de la Société des historiens médiévistes de l'enseignement supérieur public, Ge congrès, Strasbourg 1975, p. 125-143; M. Gaude-Ferragu, D’or et de cendres. La mort et les funérailles des princes dans le royaume de France au bas Moyen Âge, Villeneuve d'Ascq 2005, p. 178-182.

207 Par exemple, les cérémonies funèbres du duc de Bourgogne Philippe de Rouvres (1361),

E. Petit, Histoire des ducs de Bourgogne, vol. 9, Paris 1905, p. 252-253; de Bertrand du Guesclin (1380), M.-A. Wagner, Le cheval..., p. 111 sq; de Louis de Male, comte de Flandre (1384),

B. SCHNERB, L'État bourguignon..., p. 75-78.

${ }^{208}$ M.-A. WAGNER, Le cheval..., p. 121-131, 511-513.
} 
quatre ordres religieux-militaires engagés dans la défense de la foi: alors que le cheval bai représente autant l'Ordre de Calatrava que "les frères dits de la Chevalerie du Christ de Livonie et de Prusse», le cheval noir "figure les frères de l'Hôpital de Sainte-Marie des Allemands qui portent une croix noire ${ }^{209}$. Le même auteur ajoute que le cheval mène le croisé mort pour la foi directement auprès de Dieu; plutôt qu'une allusion au rôle psychopompe de l'animal (ce qui n'aurait aucun sens en contexte chrétien), Marc-André Wagner préfère y voir une héroïsation du cavalier combattant pour la cause de Dieu et de son Église $^{210}$. Une certaine valorisation du cheval accompagnant son cavalier dans la mort existait donc en contexte chrétien, essentiellement comme marque du prestige aristocratique. En insistant sur le rôle du cheval dans la cérémonie funéraire des grands-ducs lituaniens, Philippe de Mézières donne ainsi une touche éminemment aristocratique à l'événement: ne concernant que le «roi» et ses boyards, celui-ci met en scène des Lituaniens nobles, miroirs des courtisans français qui devaient constituer le lectorat du Songe du vieil pelerin.

Par ailleurs, les archéologues tendent à penser que dans la Lituanie du $\mathrm{XIV}^{\mathrm{e}}$ siècle (et peut-être était-ce aussi le cas dans la Courlande du début $\mathrm{du} \mathrm{XV}^{\mathrm{e}}$ ), la crémation était réservée à la caste guerrière, voire aux seuls membres de la famille régnante ${ }^{211}$. Alors qu'au XIII ${ }^{\mathrm{e}}$ siècle, une lettre d'Innocent IV ou un traité de Roger Bacon mentionnaient les «superstitions» telles que l'idolâtrie au côté de la crémation et de l'offrande funéraire, ni Mézières, ni Lannoy, ni Chastelmorand ne semblent s'être préoccupés de ce que pouvaient adorer ces «ydolatres» et ces "Sarrazins». Les cultes des arbres et des serpents qui avaient attiré l'attention des clercs avant d'être consignés par Énée Sylvio Piccolomini (par le truchement du missionnaire Jérôme de Prague, que l'humaniste dit avoir rencontré au concile de Bâle ${ }^{212}$ ) ne trouvent pas grâce aux yeux de nos très aristocratiques voyageurs. Leur Lituanie est un pays d'héroïsme, où l'on se bat avec des gens qui nous ressemblent; les païens devaient être des adversaires dignes des nobles chevaliers venus les affronter. Quand bien même auraient-ils entendu parler d'autres pratiques religieuses locales, les auteurs ont décidé de ne retenir, pour leurs écrits, que celle qui faisait sens et permettait d'entretenir cette atmosphère d'héroïsme: les flammes du bûcher funéraire, le corps du

\footnotetext{
209 J.-B. Pitra, Analecta novissima spicilegii Solesmensis, t. II, Frascati 1888, p. 405, trad. par P.-V. Claverie, Honorius III et l'Orient, p. 236.

210 M.-A. WAGNER, Le cheval..., p. 552 sq.

211 M. Gimbutas, "Religion and mythology...", p. 24-26; A. Bliujiene, Northern Gold..., p. 206-209.

${ }_{212}$ Énée Sylvio Piccolomini, Historia de Europa, XXVI, SRP 4, p. 237; le fait que Piccolomini ne mentionne pas le bûcher des Lituaniens s'explique par le fait qu'à l'époque où Jérôme de Prague (un homonyme du réformateur et compagnon de Jean Hus) a pu accomplir sa mission en Lituanie, la noblesse était entièrement chrétienne; de plus, les rites qu'il mentionne relèvent probablement plus d'un syncrétisme que de "pur» paganisme. Voir D. Baronas, "Christians in Late Pagan...", p. $71-75$.
} 
païen en armes juché sur son cheval ${ }^{213}$. Une mise en scène très proche des sacrifices humains qui, si l'on en croit les chroniqueurs de l'Ordre, avaient parfois lieu en l'honneur des dieux ancestraux. L'immolation de prisonniers de guerre, en armes et montés sur leurs chevaux, a, semble-t-il, eu lieu jusqu’à une époque très tardive (le dernier cas est situé par Wigand de Marbourg en 1389, en Samogitie $\left.{ }^{214}\right)$. De telles pratiques ont dû frapper les imaginations. Or, jusqu'à preuve du contraire, aucune de nos sources françaises ou anglaises n'y fait allusion. Seule la crémation du corps du roi Frédéric de Bohême dans le Mélusine de Jean d'Arras en est, peut-être, un lointain écho.

\section{L'HONNEUR DES PAÏENS}

Les Lituaniens auxquels ont affaire les voyageurs français de la Baltique sont dépeints comme des membres de la caste guerrière qui entourait le grand-duc et participait à ses guerres contre l'Ordre teutonique; ce sont des pairs, qui partagent certaines valeurs avec leurs adversaires venus d'Europe occidentale. À lire Jean de Chastelmorand, on a l'impression que les Lituaniens sont traités en égaux des «chrestiens» avec lesquels ils passent l'accord concernant le respect mutuel des lieux de cultes. Les chroniqueurs de Prusse ou de Livonie racontent plusieurs épisodes mettant en scène des rapports égalitaires entre hauts responsables teutoniques et lituaniens: on s'invective sur un ton bravache, on dîne ensemble, on pactise parfois. Dans ces textes, les princes lituaniens n'ont rien du triste Selodus de Jean d'Arras! Fait remarquable, ce n'est qu'à partir de la conversion de Jagellon et de Vytautas que le ton des chroniqueurs se fait plus dur, ce qui reflète l'attitude des officiers teutoniques, visiblement bien moins à l'aise face à ces princes convertis - et jouissant donc d'une légitimité aux yeux du reste de l'Europe - qu'à leurs prédécesseurs ouvertement païens. Trop individualisés pour être réduits à de simples figures de "nobles sauvages", les ducs de l'époque païenne sont, pour les chroniqueurs teutoniques, des aristocrates qui méritent une considération certaine - et c'est aussi le cas pour certains de leurs hôtes ${ }^{215}$.

Quelques sources occidentales mettent en scène des rapports d'amitiés, ou en tout cas de respect mutuel, entre nobles chrétiens et païens, rendus possibles par le partage de valeurs communes. La description des funérailles réservées aux princes lituaniens permet à Philippe de Mézières d'introduire, "pour faire un paou rire les lisans de cestui Songe» ${ }^{216}$, une histoire dont le

\footnotetext{
${ }^{213}$ F. HaRtog, Le Miroir..., p. 302, précise que le voyageur racontant ses souvenirs tend à adapter son récit à ses auditeurs ou à ses lecteurs, et essaye de capter leur intérêt en sélectionnant ce qui est à même de plaire au public.

214 Wigand de Marbourg, Chronica..., SRP 2, p. 638; S. C. Rowell, Lithuania Ascending..., p. 124.

215 Sur ce point, R. Mažeika, L. Chollet, «Familiar Marvels? ... », p. 41-62.

216 Blanchard, vol. 1, p. 207.
} 
thème littéraire peut être rapproché d'une nouvelle du Décaméron mettant en scène un noble de Pavie fait prisonnier lors de la croisade par Saladin, et qui, par ses talents de fauconnier, devient l'intime de celui-ci ${ }^{217}$. Au vu des contacts qu'il entretenait avec les poètes de son temps (notamment Pétrarque et Chaucer), il est probable que Mézières ait eu connaissance de l'œuvre de Boccace ${ }^{218}$. Le motif peut donc avoir été emprunté à un auteur influent du temps, mais le cadre de l'histoire appartient bien au contexte balte: un chevalier, membre de l'Ordre teutonique, a été capturé par les Lituaniens à l'issue d'une bataille, lors de laquelle il a perdu un œil. Le chevalier borgne est amené auprès du "roi", qui le garde à ses côtés. Les deux hommes se lient d'amitié, et au décès du roi, on doit choisir qui aura l'honneur de l'accompagner dans la mort:

"Les barons orent leur conseil pour veoir qui averoit l'onnour d'acompaigner le roy. Et fu entre eulz une grant altercation, pour ce que chascun voloit avancier son ami $i^{219}$. À la fin de leur question fut trouvé et de tous accordé que le chevalier susdit de Prusse estoit celui qui devoit avoir l'onnour, et que c'estoit celui que le roy avoit mieulx amé. Penserent les barons qu'il en averoit grant joye, et lui vindrent presenter cest honnour avec belles parolles, en lui loant et approuvant ses vertus et l'amour que le roy li avoit moustré. "220

Le malheureux accepte en apparence, mais cherche à échapper au bûcher funéraire: "Quant le chevalier crestien ouj̈ ces nouvelles et qu'il convenoit qu'il fust ars tous vifs avec le roy, s'il ot dolour au cuer nulz le ne doit demander»" ${ }^{221}$. Après s'être recommandé à Dieu, il dit à ses hôtes:

"Seigneurs, [...] vous savéz bien et je le say les grans vertus, vaillances et perfections que nostre seigneur et roy avoit, si me suy apensé que mon imperfection ne li faisse domage a l'ame. Vous veés que je n'ay que un eul, dont j'ay tresgrant desplaisir. Et pour ce que je n'ay pas tous mes membres, j'ay grant paour que je ne soye pas dignes d'acompaigner a un si parfait seigneur. Toutefois se vous jugiés que je li doye tenir compaignie, je suy tout pres, ne je ne porroye avoir plus grant joye. ${ }^{222}$

217 Boccace, Le Décaméron..., dixième journée, neuvième nouvelle, éd. V. Branca, vol. 2, 1429-1463.

${ }_{218}$ M. Hanly, «Philippe de Mézières and the Peace Movement», dans R. Blumenfeld-Kosinski, K. Petkov (dirs.), Philippe de Mézières and his Age..., p. 61-82.

219 V. Kiparsky, «Philippe de Mézières...», p. 63, n. 1, remarque que le terme "avancier» prête à confusion; plutôt que le sens de «mettre en avant» (selon Philippe de Mézières, Le Songe..., trad. J. Blanchard, p. 177), ce qui sous-entendrait que les barons lituaniens essayeraient de se dérober, il vaudrait mieux y lire celui de "devancer».

${ }^{220}$ Blanchard, vol. 1, p. 208.

${ }^{221} \mathrm{Id}$.

${ }^{222}$ Ibid., p. 208-209. 
Les «barons» lituaniens constatent qu'en effet, le Teutonique borgne ne peut pas avoir l'honneur d'être brûlé avec leur roi défunt: "Ilz pristrent un aultre des amis du roy, remercierent au chevalier crestien, et le tindrent pour bon et loyal» ${ }^{223}$. Le chevalier est laissé libre de partir, et rentre auprès des siens alors que le roi lituanien est brûlé avec un autre de ses amis: "Bonne fu la perte de l'euil du chevalier, car sill en eust eu .ii., il eust esté ars aveuc le roy» ${ }^{224}$. Une conclusion qui n'est pas sans rappeler un commentaire d'Adam de Brême sur les pratiques sacrificielles des Estoniens, qui se doivent d'offrir une victime sans infirmité physique à leurs dragons, sans quoi ceux-ci refuseraient l'offrande ${ }^{225}$.

Cette anecdote, insérée pour amuser les lecteurs du Songe et leur donner à lire quelques détails piquants sur les coutumes des Lituaniens ${ }^{226}$, possède-t-elle un fondement historique? Mézières précise à deux reprises, avant de raconter son histoire et juste après la conclusion de celle-ci, qu'elle lui a été relatée par des vétérans de l'Ordre teutonique qui lui ont assuré qu'elle est vraie et qu'elle s'est déroulée "n'a pas trop long tamps» ${ }^{227}$. Pour Werner Paravicini, cette histoire, tout comme la légende du chêne de Toruń relatée peu après, appartient au système d'autoreprésentation de l'Ordre teutonique ${ }^{228}$. S'il est vrai que le chêne de Toruń est mentionné en termes proches par les chroniques de l'Ordre, celles-ci ne donnent qu'un écho sensiblement amoindri de l'histoire qui nous intéresse ici. La Chronique de Wigand de Marbourg mentionne effectivement l'existence d'un chevalier allemand qui aurait été capturé par les Lituaniens, amené auprès de Gediminas et serait devenu l'un de ses favoris. Mais ce personnage, dont l'histoire paraît vraisemblable ${ }^{229}$, est censé avoir quitté le service du grand-duc avant la mort de celui-ci ${ }^{230}$.

L'anecdote telle que Philippe la rapporte montre qu'il avait saisi un point essentiel de la guerre menée en terre balte: en dépit des différences religieuses, hyperbolisées par la pratique de la crémation et la mise à mort volontaire d'un proche du souverain lituanien, un certain respect mutuel, allant même jusqu'à l'amitié, pouvait unir des membres de l'Ordre teutonique et de la cour

\footnotetext{
${ }^{223}$ Ibid., p. 209.

$224 \mathrm{Id}$.

${ }^{225}$ Adam de Brême, Gesta..., IV, 17, p. 244; V. Kiparsky, «Philippe de Mézières... », p. 65. Ce thème se rapproche d'un conte présent notamment en Inde, qui met en scène des adorateurs de la déesse Kali refusant de sacrifier un homme parce que celui-ci vient de se couper un doigt, lequel conclut que "tout fut pour le mieux»; M. Quentric-SÉGuY, Au Bord du Gange. Contes des sages de l'Inde, Paris 1998, p. 166-171.

226 J. JaKšTAS, Das Baltikum..., p. 178.

227 Blanchard, vol. 1, p. 207; 209.

${ }_{228}$ PR 2, p. 116. Voir ci-dessus, chap. VII.

${ }^{229}$ Des chrétiens étaient employés à la chancellerie grand-ducale et des prisonniers teutoniques étaient affectés à l'éducation des jeunes princes; A. NikžENTAITIs, «Die litauische Gesellschaft...», p. 126-127.

${ }^{230}$ Wigand de Marbourg, Chronica..., SRP 2, p. 494-495; S. C. Rowell, Lithuania Ascending..., p. 131.
} 
lituanienne. Au moment fatidique, le chevalier teutonique «se recommanda a Dieu et a la saincte vraye crois, et quant il ot faicte son oroison a Dieu, il appella tous les barons ${ }^{231}$. On ne mentionne pas que ce fut une démarche secrète, ce qui n'a rien de surprenant, étant donné la relative tolérance dont les chrétiens bénéficiaient dans le grand-duché. L'auteur picard avait donc conscience du fait qu'un chrétien intégré à la cour du souverain païen de Lituanie pouvait continuer à pratiquer sa religion: "de tout en tout si fioit de lui, nonobstant qu'il fust crestien ${ }^{232}$. Nous sommes ici bien loin des croyants forcés à se cacher dans les forêts que mettait en scène la lettre de Grégoire IX au début de la conquête de la Prusse. Le souverain lituanien est présenté chez Philippe comme un personnage digne de respect, ce qui n'est pas sans rappeler les documents produits à l'occasion des démarches de Gediminas auprès du pape Jean XXII.

De même, les codes de la courtoisie semblent, sous la plume de notre auteur, s'appliquer aux nobles lituaniens: le chevalier teutonique, du fait d'avoir attiré l'attention des boyards sur son infirmité, est tenu pour «bon et loyal». À ce sujet, Joël Blanchard a fait remarquer que le terme «honneur», dont Mézières, prenant le contre-pied de la littérature chevaleresque de son temps, est pourtant avare ${ }^{233}$, apparaît avec force en ce passage: dans le court extrait qui concerne les pratiques funéraires baltes et l'aventure du Teutonique borgne, le mot est utilisé pas moins de neuf fois, dont sept en lien avec la pratique du sacrifice volontaire ${ }^{234}$. S'agit-il d'ironie? Mézières marque-t-il son dédain pour l'utilisation abusive du concept d'honneur en le liant à une pratique incontestablement païenne? Gardons-nous d'une interprétation anachronique trop affirmative ${ }^{235}$.

Plusieurs chroniqueurs de la région balte font état de la propension au suicide des Lituaniens, comme lorsque des femmes se pendent en apprenant que leurs maris ont été tués au combat, chez Henri de Livonie $(1205)^{236}$, ou qu'une "vieille païenne» extermine la garnison du fort de Pilenai avant que celui-ci ne tombe aux mains des croisés, puis se tue de ses propres mains, chez Wigand de Marbourg (1336) ${ }^{237}$. Crime absolu selon la doctrine chrétienne, le suicide peut, au moins dans le dernier cas, se transformer en une mort honorable, digne des ennemis que les croisés de la Baltique étaient invités à combattre: mieux vaut mourir libre que survivre enchaîné ${ }^{238}$. On retrouve la même ambiguïté chez Philippe de Mézières. Le sacrifice consenti par les

\footnotetext{
231 Blanchard, vol. 1, p. 208.

232 Id.

233 J. Blanchard, "Les hiérarchies de l'honneur. Avatars d'une grille conceptuelle à la fin du Moyen Âge: Mézières et le Pseudo-Denys", Revue historique 648/4, 2008, p. 799-801.

234 Blanchard, vol. 1, p. 207-209.

235 J. BlanCHARD, «Les hiérarchies de l'honneur...", p. 799, n. 27: "On pense naturellement à une forme de dérision, mais peut-être est-ce un réflexe de notre temps".

236 Henri de Livonie, Heinrichs Livländische Chronik..., IX, 5, p. 28.

237 Wigand de Marbourg, Chronica..., SRP 2, p. 489-490.

238 R. MAŽEIKA, «Nowhere...», p. 242-243.
} 
guerriers lituaniens pour suivre leur souverain dans la mort pourrait être assimilé au rôle idéalisé du chevalier chrétien qui dans son souci d'honorer le serment vassalique, n'hésiterait pas à donner sa vie pour protéger celle de son suzerain ${ }^{239}$. Les boyards lituaniens seraient alors à rapprocher des guerriers sarrasins qui, dans un autre passage du premier livre du Songe, couvrent de leur corps leur seigneur lâchement assassiné par le roi de Castille Pierre le Cruel ${ }^{240}$. Le récit de ce crime commis par un roi chrétien sur un prince musulman appelle un commentaire quant à l'état de la moralité de la chevalerie chrétienne: "Je ne say pas bien, a grant dolour recitant, se un tel cas avenoit a un roy crestien s'il trouveroit aujourdui ses chevaliers qui autel li feissent ${ }^{241}$. Philippe laisse ses lecteurs comprendre que les princes occidentaux et leurs vassaux auraient certaines choses à apprendre des Teutoniques, mais également des "mécréants", musulmans espagnols ou païens baltes. L'insistance sur le sens de l'honneur des nobles lituaniens pourrait indiquer une reconnaissance de la part de Mézières envers ces guerriers infidèles qui semblent respecter un certain code chevaleresque mieux que bon nombre de chrétiens.

Le terme «honneur» apparaît encore à deux reprises lorsque l'auteur parle de l'Ordre teutonique; la Reine Vérité et ses compagnes ont été "bien recueillies et grandement hounourees $»^{242}$ en Prusse, et le traitement égalitaire des Chevaliers en ce qui concerne les provisions, les armes et les biens matériels est qualifiée d' "ononour gardee de la religion" ${ }^{243}$. La Prusse et la Lituanie apparaissent comme un ensemble géographique à la fois très réaliste et fantasmé, un «étranger proche» où les valeurs chères à Philippe - les "vraies" valeurs chevaleresques qu'il entend défendre dans l'Ordre de la Passion - sont encore respectées par les deux adversaires, bien que ceux-ci soient divisés par leur appartenance religieuse. En cela, cet épisode participe à une forme d'idéalisation du monde balte, où

\footnotetext{
${ }^{239}$ Le parallèle avec les martyrs chrétiens, très present dans les chroniques teutoniques, fait moins de sens car Mézières ne dit pas que les boyards acceptent de mourir pour leurs dieux, mais pour accompagner leur «roy». Une conception aussi «jusqu'au-boutiste» de la fidélité vassalique n'est toutefois attestée, en littérature du moins, que dans des cas marqués par une certaine ambiguïté, comme Roland ou Vivien; Y. Robreau, L'Honneur et la honte: leur expression dans les romans en prose du Lancelot-Graal (XII'-XII" siècles), Genève 1981, p. 130-132; L. HaLKIN, "Pour une histoire de l'honneur", Annales. Économies, Sociétés, Civilisations 4/4, 1949, p. 434-435; S. Rigby, "Wise but worthy?: Virtuous and Non-Virtuous Forms of Courage in the Later Middle Ages ", Studies in the Age of Chaucer 35, 2013, p. 329-371.

${ }^{240}$ Blanchard, vol. 1, p. 446-447. Il s'agit de Mohammed al-Ahmar, sultan de Grenade tué en 1362 par Pierre de Castille. Les Nasrides de Grenade possédaient, jusqu'au Xv siècle, une garde composée de chrétiens; J. Svátek, «Les voyages de Guillebert de Lannoy en péninsule Ibérique au début du Xv siècle", Publication du Centre Européen d'Etudes Bourguignonnes 51, 2011, p. 29.

${ }^{241}$ Tout comme pour l'histoire du Teutonique borgne, Mézières mentionne sa source d'information: "Cest cruaulté du roy Piere fu recitee au Viel Pelerin par une personne notable qui estoit lors privés et singuler serviteur dudit roy Piere et se trouva present avec son seigneur a la mort du roy ronge dessusdicte», Blanchard, vol. 1, p. 447.

${ }^{242}$ Ibid., p. 209.

243 Ibid., p. 216.
} 
semblent s'affronter deux corporations éminemment chevaleresques; un monde que les croisés laïcs, aristocrates imbus de leur gloire personnelle et mondaine, semblent souiller par leur présence, si l'on se réfère aux pamphlets que le même Philippe de Mézières écrira quelques années après avoir terminé le Songe ${ }^{244}$.

Ce ne serait pas la première fois que Philippe interpréterait des sociétés étrangères de façon à en faire des mondes idéaux, à même de servir de modèles à ses propres desseins: dans le Songe du vieil pelerin, la "Tartarie» régie par les lois des khans, où règne la justice ${ }^{245}$, et le monde pacifique mais très ordonné des Bragamains indiens, qui "tiennent a la lettre la loy de nature»" ${ }^{246}$, sont des exemples de sociétés utopiques, à qui il ne manquerait que le christianisme pour qu'elles soient parfaites ${ }^{247}$. Notons toutefois que dans ces deux cas, il ne se base que sur des sources de seconde main; n'étant jamais allé ni en Inde ni en Chine, il cite les témoignages prétendument fiables de marchands qu'il dit avoir rencontrés personnellement, et qui auraient vécu longtemps dans ces pays $^{248}$. Les descriptions de ces lointaines contrées sont toutefois bien moins précises que celles des régions où Philippe s'est lui-même rendu; le légendaire, l'utopique, prend le pas sur le réalisme habituel du récit ${ }^{249}$.

L'Inde de Mézières est celle du Prêtre Jean et de l'apôtre Thomas, dont la foi aurait été abandonnée suite à l'invasion mongole. Il est à noter que tout comme les Lituaniens, les Bragamains, l'une des figures positives alimentant l'imaginaire merveilleux de l'Inde au Moyen Âge, honorent un roi, qui semble, dans cette société idéale, ne jouer qu'un rôle représentatif: "Il ont un roy, non pas pour faire justice de eulz, car le cas ne si offre point, mais il ont roy tant seulement pour honnour et reverence et monstrer une honeste obedience»" 250 . La reine Vérité et ses compagnes visitent la Chine des Tatars après avoir transité par «la terre et ysle de Femenie ${ }^{251}$, où vivent les Amazones - autre merveille exotique chère à

\footnotetext{
${ }^{244}$ Voir ci-dessus, chap. VI.

${ }^{245}$ Ibid., p. 195

246 Ibid., p. 188.

247 J. Blanchard, "Les hiérarchies de l'honneur...", p. 802. À la suite des voyageurs du milieu du XIII $^{\mathrm{e}}$ siècle, le caractère raffiné, civilisé et ordonné des pays d'Orient, et en particulier de la Chine des Yuan (héritiers de Kubilai Khan), s'est imposé comme stéréotype dans les lettres occidentales; K. P. Phillips, Before Orientalism: Asian Peoples and Cultures in European Travel Writing, Philadelphie 2013, p. 148-171. Sur l'idéalisation des "autres» à des fins politiques, T. Todorov, Nous et les Autres..., p. 304-310 (qui, à partir d'exemples des Lumières, constate que l'on savait que les sociétés lointaines n'étaient pas "parfaites", mais que l'on se contentait d'en tirer quelques traits communément admis dans le but de tendre un miroir à la société occidentale).

${ }^{248}$ Philippe dit tenir ses renseignements sur l'Inde d'un certain marchand génois, rencontré lorsqu'il servait le roi de Chypre, et qui affirmait y avoir vécu 50 ans: Blanchard, vol. 1, p. 187. Pour ce qui concerne la Chine, Philippe dit écrire "selonc ce que me raconta un mien ami especial appellé Bargadin, nés a Mes en Loraine, qui avoit demouré.viii. ans en la cité de Cambalech [Pékin]" (Blanchard, vol. 1, p. 195).

249 Philippe de Mézières, Le Songe..., éd. G. W. Coopland, vol. 1, p. 118-120.

250 Blanchard, vol. 1, p. 189.

${ }^{251}$ Ibid., p. 194.
} 
l'imaginaire médiéval. Elles visitent Cambalech (Pékin), la capitale du pays, puis se rendent vers le grand khan, qui nomadise avec son armée "enmy les champs, en une cité portative, faicte de tentes et de paveillons» ${ }^{252}$. À cette étape du voyage, le pays est l'un des plus dignes de louange: "justice, pais et misericorde y regnoient plus qu'en nul autre royaume qu'elles [les dames] eussent trespassé excepté la terre des Bragamans ${ }^{253}$.

Mézières livre moins une analyse nuancée de la politique tatare - les khans, souvent divisés entre eux, ne reculent pas devant la violence pour s'imposer face à leurs rivaux - qu'une critique indirecte de la politique française, en préparant le terrain pour les parties suivantes du Songe $e^{254}$. Dans le livre II, la justice rapide du khan est explicitement citée comme un exemple d'efficacité à même d'instaurer la discipline dans son immense armée ${ }^{255}$ : "toutefois il [les Tatars] sont ydolatres, sans science divine ou civile, et par la loy naturele et morale il se gouvernent [...] si sagement, si justement et a telle magnificence qu'il se puet dire que leur biau gouvernement condampne la policie et orgueil des princes crestiens ${ }^{256}$. L'Égypte, bien que soumise aux Mamelouks sans scrupules et volontiers pillards ${ }^{257}$, ressemble, du moins en apparence, car «il n'est pas or, quanqu'il appert»" ${ }^{258}$, à un pays bien ordonné: "[les dames] n'avoient trouvé en tout le Quayre ung mal vestu [n]e meshaigné en la rue, ne aucun malade, et que les hospitaus estoient tous ouvers et plains de malades bien servis, les uns garis et les autres en convalessence ${ }^{259}$. Mézières, dont le but ultime était de plaider pour une réforme en profondeur de la Chrétienté, n'hésitait donc pas à invoquer des exemples étrangers, orientaux ou musulmans, pour souligner les aspects que l'on devrait améliorer dans l'Europe chrétienne. Il est donc tout à fait envisageable que «sa» Lituanie païenne, dont les guerriers sont "assez bien combatant» et où les nobles n'hésitent pas à suivre leur roi dans la mort tout en traitant avec respect leur hôte chrétien, réponde à un même usage.

La description de la Lituanie dans cette première partie du Songe du vieil pelerin montre que Philippe a saisi toute la complexité du monde balte, où malgré le climat de guerre entretenu par la croisade, une véritable cohabitation était de mise, entre nobles du moins. Il faut dire que la coexistence culturelle n'était pas étrangère à l'ancien chancelier de Chypre. Le monde méditerranéen étant, à l'époque médiévale, une "zone d'intelligibilité»"200 par excellence, les contacts entre chrétiens et infidèles n'étaient sans doute pas pour surprendre

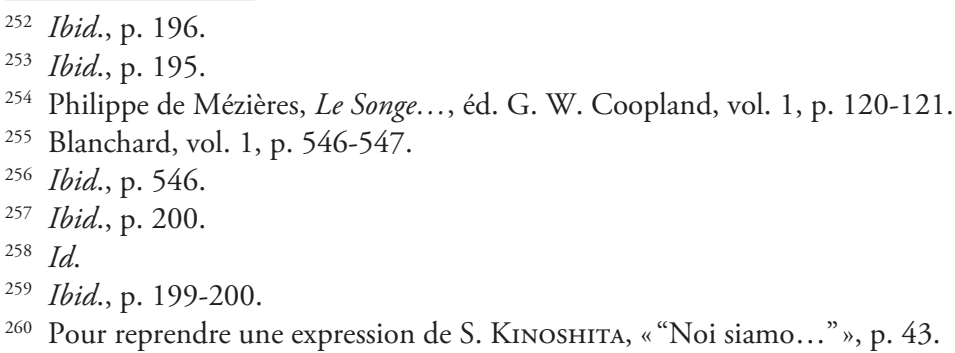


Philippe de Mézières. Mais il n'est pas sans intérêt de constater que, du moins dans le cas de l'anecdote du prisonnier du grand-duc, c'est par la bouche des Teutoniques que Philippe a entendu ce portrait «chevaleresque» des Lituaniens. Le respect qui prévalait entre les hommes du grand-maître Kniprode et ceux du duc Kęstutis renforce l'image de l'adversaire païen que donnent les chroniques écrites au sein de l'Ordre depuis le XIII ${ }^{\mathrm{e}}$ siècle: des guerriers certes infidèles mais honnêtes et pieux à leur manière, vision que l'auteur picard, tout comme les historiographes de l'Ordre, peut avoir utilisé afin de tendre un miroir à ses lecteurs chrétiens ${ }^{261}$.

L’amitié entre nobles chrétiens et païens telle que racontée par Mézières et les chroniqueurs de l'Ordre teutonique présuppose le partage de normes communes. Pour les auteurs écrivant au cœur de l'Europe chrétienne, celles-ci ne peuvent être que chevaleresques. Le Liégeois Jean d'Outremeuse, auteur du Myreur des Histors (v. 1400), une chronique universelle qui tire volontiers sur le roman d'inspiration arthurienne, met en scène l'histoire de Jean de Luxembourg, roi de Bohême, qui livra un duel avec un «roi» lituanien avant de devenir l'ami de celui-ci ${ }^{262}$. Plusieurs chroniques d'Europe centrale racontent que Jean de Bohême aurait terrassé un gigantesque Lituanien ${ }^{263}$, événement qui n'avait rien d'un duel chevaleresque ${ }^{264}$, mais dont un écho a pu parvenir à l'auteur liégeois, lequel aura transformé l'histoire à sa guise. Du reste, nous savons que depuis Guillaume de Machaut, les aventures baltes de Jean de Luxembourg sont un sujet prisé des poètes et écrivains francophones. Aussi, Jean d'Outremeuse a pu tout simplement développer la scène du baptême de la forteresse lituanienne «Medouagle» (Medvegalis) selon sa propre imagination $^{265}$. Quoiqu'il en soit, cet extrait dénote une appropriation de la "matière de Prusse» par les auteurs de la fin du Moyen Âge, et indique que jusqu'en Wallonie, on supposait qu'un code commun régissait la conduite des nobles païens et chrétiens.

Le nom prêté au roi lituanien, Margalis, ne manque également pas d'intérêt. Ce nom peut être rapproché de Marger (lit. Margiris), un prince mentionné par Wigand de Marbourg, qui en fait le chef de la garnison de Pilenai, attaquée en 1337 par un groupe de croisés ${ }^{266}$. Il est toutefois difficile d'affirmer que le Marger de Wigand et le Margalis d'Outremeuse soient le même personnage ${ }^{267}$. La forme du nom donnée par l'auteur liégeois rappelle également le personnage

\footnotetext{
261 S. C. Rowell, Lithuania Ascending..., p. 39.

${ }^{262}$ Les princes lituaniens, même ceux qui n'appartiennent pas à la famille de Gediminas, sont fréquemment appelés «rex» par les sources latines; ibid., p. 240, n. 54.

263 Jean de Victring, Iohannis abbatis Victoriensis..., vol. 2, p. 135 135; Chronicon Aulae Regiae, dans Fontes Rerum..., p. 294; W. Paravicini, «Litauer...», p. 256.

264 W. Paravicini, «Litauer... », p. 256.

265 S. C. Rowell, Lithuania Ascending..., p. 240.

266 Wigand de Marbourg, Chronica..., SRP 2, p. 489-490.

267 PR 2, p. 135.
} 
de Margariz, un chef sarrasin mis en scène dans la Chanson de Roland et dépeint de manière plutôt positive ${ }^{268}$. Jean d'Outremeuse aurait-il entendu un voyageur rentré de Prusse prononcer le nom d'un certain chef balte, qu'il aurait retranscrit dans son œuvre en Margalis, par contamination avec le personnage du célèbre roman? La question reste ouverte. Nommé «roy» au début de l'histoire, Margalis porte également le titre oriental de «soldans», autrement dit sultan. Pourtant, et même si le chroniqueur ne précise à aucun moment qu'il s'agisse d'un Lituanien, le contexte ne nous laisse pas de doute.

Le texte du Myreur des Histors raconte que le roi de Bohême alla en Prusse avec plusieurs compagnons ${ }^{269}$. Une fois arrivés "al Hospital», autrement dit auprès des Chevaliers teutoniques, ils apprennent que les "Sarazins» viennent de faire une razzia sur les terres chrétiennes. Entendant cela, le roi Jean jure de récupérer le bétail volé, et envoie ses espions se renseigner. On apprend que les Lituaniens tiennent leurs prises près d'une "forte maison qui avoit non Galidane, où ilh avoit grant planteit de Sarazins» ${ }^{270}$. Thierry d'Orge, l'un des hommes de la suite de Jean de Bohême, se charge d'aller reprendre "buefs, vaches et mutons" et tue le chef des gardes: "Thiri le ferit teilement del espee qu'ilh le fendit jusqu'en dens»" ${ }^{271}$. Appeurés, les païens "s'enfuirent parmi I montagne»" ${ }^{272}$, alors que ceux de la ville sortent à la rencontre des chrétiens: "si les conduisoit li roy Margalis qui estoit I vielh homme» ${ }^{273}$. Prévenu, le roi de Bohême arrive à la tête de ses troupes. C'est alors qu'une grande bataille commence, opposant 20000 païens à 4000 chrétiens. Les Wallons y font tant de prouesses que «là furent les Sarazins affolleis et ochis et reculeis laidement, et s'enfuirent y pluseurs ${ }^{274}$.

Jusque-là, le récit de Jean d'Outremeuse ressemble à une chanson de geste dont l'action se passerait en Lituanie; le style épique, la description de combats héroïques ne peuvent que rappeler la Chanson de Roland et les textes du même genre. Autrement dit, nous sommes ici dans la même tradition que le Roman de Mélusine ou le Petit Jean de Saintré. C'est alors que le chroniqueur introduit l'histoire du duel qu'offre Margalis à son ennemi :

"Quant Margalis veit chu, si escriat ses gens et jurat que ilh ferat as Cristiens doleur; et regardat à diestre de li, si voit le roy de Bohemme, et le cognut à lyon d'argent à la cowe forchue: si alat vers luy et li escrie haltement que ilh presist batalhe contre li corps à corps, par teile convent: s'ilh le poioit conquere,

\footnotetext{
268 "Margariz est mult vaillant chevalers, / Et bels et forz e isnels e legers", La Chanson de Roland..., Strophe CIII, v. 1311-1312, éd. et trad. P. Jonin, p. 160.

269 Ceux-ci sont identifiés à des nobles de l'entourage de Jean de Luxembourg par T. DE Puymaigre, "Une campagne...", p. 416-417.

270 Bormans, vol. 6, p. 412.

271 Ibid., p. 413.

272 Id.

${ }^{273} \mathrm{Id}$.

${ }^{274}$ Ibid., p. 414.
} 
qu'ilh s'en r'yroit en Ycoine ${ }^{275}$ ne jamais ne feroit guere al Hospitale, et yroient tous marchans en sa terre; et se li roy de Bohemme estoit conquis, ilh li auroit enconvent d'aidier conquere le royalme de Franche; et enssi l'ont-ilhs creanteit; et fisent leur batables departir. $»^{276}$

S'il est plus que contestable qu'un duc lituanien ait eu l'ambition de conquérir la France, l'ouverture au commerce proposée par Margalis rappelle la politique des grands-ducs, qui concluaient volontiers des arrangements commerciaux avec leurs voisins chrétiens ${ }^{277}$. Stephen C. Rowell note en outre que Medvegalis, la ville où le baptême décrit par Machaut a eu lieu (événement qui a peut-être servi de base à l'intrigue du Myreur des Histors) se situe sur un important axe commercial ${ }^{278}$. Dans l'ensemble, cet accord montre néanmoins que pour le chroniqueur, le souverain païen ressemblait à un roi comme un autre, qui maitrise l'héraldique et est capable de reconnaître le prestigieux roi de Bohême à ses armes ${ }^{279}$; tout comme il respecte les règles du duel aristocratique, ce qui n'est pas forcément le cas de son peuple. En effet, on apprend que lors du combat singulier, livré le lendemain devant la ville lituanienne, les habitants de celle-ci volèrent au secours de leur prince:

"Les Sarazins qui de la vilhe regardoient la batalhe, dessent entre eaux: "Se nos perdons Margalis, nos n'aurons jamais honneur. Ors li alons aidier, car chi Cristiens est durement fors et valhans." Adonc s'en armat XIIII et s'en vinrent vers la batalhe; quant li roy Johans les choisit [aperçut ${ }^{280}$ ], si dest à Margalis: "Faux trahitre, nuls ne se puet gardeir de trahison: je voy chis mult de Sarazins venir por moy destruire." Quant Margalis veit chu, si fut trop corochiet et dest al roy de Bohemme: "Par ma foid, riens n'en savoie; et partant je me reng à toy, salve ma vie et que je puisse escaper peir par ranchon; et en-alons al Hospitale”. " ${ }^{281}$

Les deux rois rentrent au château de l'Ordre - "l'Hospitale» -, Jean de Luxembourg demandant aux «Cristiens [...] qu'ilh portassent honneur le sarazin, car ilh estoit proidhomme» ${ }^{282}$. Il propose au vaincu de s'en tenir quitte

\footnotetext{
275 S. C. Rowell, Lithuania Ascending..., p. 33, propose d'y voir une déformation de Jukainiai, en Samogitie, et non pas de l'Iconium (Konya) turque, comme le suggère l'éditeur $S$. Bormans (p. 414, n. 1). Encore qu'une influence du nom de la ville anatolienne, plus connue, ait pu prévaloir sur celui de la localité balte.

276 Bormans 6, p. 414.

277 S. C. Rowell, Lithuania Ascending..., p. 33; voir notamment R. MAžEIKA, «Of cabbages and knights: Trade and trade treaties with the infidel on the northern frontier, 1200-1390", Journal of Medieval History 20 (1994), p. 63-76.

278 S. C. Rowell, Lithuania Ascending..., p. 240, n. 54.

279 T. de Puymaigre, «Une campagne...», p. 177-178.

${ }^{280}$ Bormans 6, p. 414, n. 5.

${ }^{281}$ Ibid., p. 414.

${ }_{282} \mathrm{Id}$.
} 
quant à la rançon, mais Margalis insiste pour payer 20000 florins d'Allemagne, tout en lui restant attaché: "Là soy departirent les oust et cascon r'allat en son lieu; mains Margalis s'en alat aveque le roy de Bohemme, où ons li faisoit mult grant honeur: et li prioit-ons tous les jours de croire en Dieu, mains ilh le refusoit todis» ${ }^{283}$. C'est ainsi que Jean d'Outremeuse introduit l'histoire d'une pucelle chargée de convertir le roi lituanien par amour ${ }^{284}$. Anecdote galante, qui renforce la touche courtoise de l'épisode tout en rappelant que l'on pouvait attribuer la conversion d'un souverain non-chrétien à l'action d'une femme, ou du moins, à la promesse d'un mariage avantageux, ce qui n'est peut-être pas sans rapport avec l'union du prince Jagellon et de la reine Hedwige de Pologne. L'histoire de Margalis se conclut par son décès, puis la mention que son fils devint "sultan" après lui, et "oit [comme épouse] la filhe le conte de Clermont en Franche»" 285 . Comme le note Werner Paravicini, un tel mariage n'est pas attesté dans l'aristocratie française, mais le simple fait qu'un chroniqueur imaginatif le tienne pour crédible est révélateur du respect dont on pouvait faire preuve envers un prince lituanien, évidemment converti ${ }^{286}$.

\section{COUTUME SOCIALE ET DIVERSITÉ RELIGIEUSE}

Si l'on se réfère à l'histoire de Margalis et de la pucelle chrétienne, on doit convenir que le Myreur des histors, chronique romancée écrite par un homme qui, d'après nos connaissances, ne s'est jamais rendu sur le rivage balte, fait partie des textes médiévaux présentant le paganisme lituanien d'une manière assez conforme à ce qu'avancent les recherches récentes ${ }^{287}$. Jean d'Outremeuse nous raconte que "li roy de Bohemme se volt aviseir que amour de femme faisoit toute faire " ${ }^{28}$, et envoie la fille de Thierry d'Orge, "la plus belle pucelle, jovene et tenre» auprès de Margalis, avec pour mission explicite de le séduire: "li roy l'infourmat d'aleir al soldant Margalis et entrast à parleir à li d'amours». Ce qu'elle fit très bien. Dans une scène archétypale, la jeune fille va se promener de beau matin dans un verger, où se trouve le Lituanien; elle chante une douce chanson d'amour et cueille des fleurs, quand sa cible "vint à lee [...] et le saluat en Dieu qu'elle creoit". Dès lors, elle lui déclare son amour:

"Vos m'aveis enchantee, car onques n'amay homme por amours; or suy-je de vos enamoree, et se vos creiiés en Dieu et en sa meire, je ay mis en vos toute mon amour de cuer, de corps et de penseez; et seroit nostre amour asseis toist achivee,

\footnotetext{
${ }^{283}$ Ibid., p. 415.

${ }^{284}$ Voir chapitre III. Dans ce récit, ce sera en vain, comme nous le verrons plus loin.

${ }^{285}$ Bormans 6, p. 416.

286 W. Paravicini, «Litauer...", p. 256.

287 Notamment D. Baronas, S. C. Rowell, The Conversion....

${ }^{288}$ Bormans 6, p. 415.
} 
se en mon loy créiez; mains à homme de vostre loy ne seray jà donnee. Dols sire, car soit vostre cuer à no loy atournee et baptiziés, et je seray toute vostre. ${ }^{289}$

Margalis est immédiatement séduit, mais il doit repousser ses avances: "cherte, belle, nullement ne guerpiroie ma loy, ne qui me donroit Franche, le royaulme; mains se vos tenoie en Prusse, vos en sieriés damme et royne soveraine ${ }^{290}$. Courroucée, la pucelle lui répond qu'elle "ameroie mies eistre arse en I feu que guerpir la loy cristiane ${ }^{291}$, puis s'en va, laissant le païen à ses réflexions: «ly renoier ma loy m'est trop dure, car je n'auroie parens ne ami, se je chaioie en povreteit, qui me dewist aidier ${ }^{292}$. Ce n'est ainsi pas par respect ou par crainte d'éventuelles divinités païennes que Margalis refuse le baptême, mais pour une raison que nous appellerions sociologique. La religion, ici appelée "loy", selon l'une des acceptions de ce terme, est l'expression d'un ensemble de liens sociaux rendant possible le mariage entre deux personnes et permettant de s'assurer de la solidarité de la communauté. Bien que le Lituanien soit traité en ami par le roi de Bohême, et que sa conversion lui permettrait d'être intégré à l'aristocratie chrétienne, il préfere rester païen pour ne pas s'aliéner l'aide des siens. Un peu plus tard, lors du banquet d'adieu pris en commun, le roi Jean dit à la jeune séductrice que si le Lituanien l'épousait, elle recevrait le duché de Luxembourg, ce qui ne parvient pas à faire céder Margalis ${ }^{293}$.

Quelle explication Jean d'Outremeuse donne-t-il à l'attitude de ce dernier? Revenons à la scène du verger: laissé seul, Margalis comprend que le baptême le condamnerait à l'isolement social, mais qu'importe! L'amour de sa belle compenserait tous ses maux: "tous solas, tous desduis en lee troveroie»" ${ }^{294}$. C'est alors que tombe cette phrase, qui tranche curieusement par rapport au ton presque sociologique de l'ensemble: "et s'en faloit pou qu'ilh ne renoiast sa loy; mains li dyable le tenoit trop fort en ses laches, car ilh dest qu'ilh amoit mies à morir d'amours que eistre recreans ${ }^{295}$. Le diable comme garant du paganisme semble n'être ici qu'un ornement littéraire. Il n'en révèle pas moins une condamnation certaine de l'attitude du roi lituanien, qui se traduit par sa fin tragique - on comprend que c'est bien d'amour qu'il mourut. La situation est restaurée par le destin de son fils et successeur, qui a sans doute reçu le baptême pour pouvoir épouser la fille d'un puissant comte français.

L'histoire tragique du roi Margalis, qui s'insère dans la tradition des amourettes entre chrétiens et sarrasins ${ }^{296}$, donne au lecteur moderne un aperçu

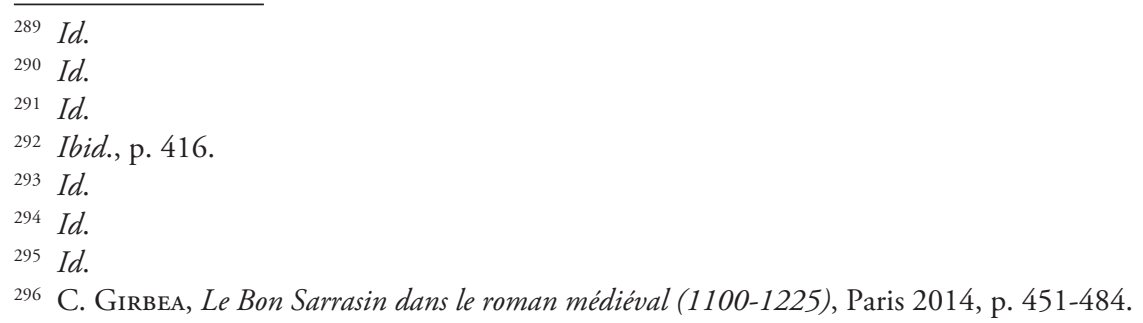


de la manière dont les milieux lettrés pouvaient considérer la religion des païens baltes. Si l'on considère l'allusion au diable comme une simple figure de style, le paganisme du roi se réduit à une coutume sociale lui assurant la solidarité de sa communauté. À en croire le chroniqueur anglais Thomas Walsingham (Chronica Maiora, 1422), c'est à cause de sa conversion au christianisme que les "connaissances et amis» de Ladislas Jagellon "se distancèrent de lui, et décidèrent qu'ils le renverseraient ou assurément le tueraient en bataille ${ }^{297}$. Un prince voulant accepter le baptême et qui se trouve en conséquence menacé par ses sujets, voilà qui n'est pas sans rappeler la manière dont le grand-duc Gediminas, grand-père de Jagellon et de Vytautas, est présenté dans les rapports des envoyés des légats, dépêchés en 1324 pour négocier sa conversion à la foi catholique ${ }^{298}$.

Le paganisme balte comme ciment de la société est présenté dans plusieurs textes antérieurs à la pratique du voyage de Prusse parmi la noblesse occidentale, et ceci dès que l'écho des premiers martyres baltes parvint en Occident, soit peu après l'an mil. Dans la digression consacrée par Pierre Damien à Bruno de Querfurt, c'est lorsque la conversion du roi par le missionnaire perturbe la structure traditionnelle de la société que des meurtres surviennent ${ }^{299}$. De manière plus explicite, Jean Canaparius fait dire aux les Prussiens, lesquels menaçaient le prédécesseur de Bruno, Adalbert, que "nous-mêmes et tout ce royaume, [...] obéissons à une seule loi et vivons selon un seul ordre. Mais vous, qui êtes d'une loi étrangère et inconnue, si cette nuit vous ne disparaissez pas, vous serez décapités demain matin ${ }^{300}$. Deux siècles plus tard, Roger Bacon fait de la coutume le fondement de la société des païens: «les vrais païens, comme les Prussiens et ceux des nations voisines, ont l'habitude de vivre selon la coutume et pas selon la loi de la raison ${ }^{301}$. Dans leur rapport, les émissaires des légats français dépêchés par Jean XXII pour négocier la conversion du prince lituanien Gediminas (1324) font dire à celui-ci «que les chrétiens rendent un culte à leur dieu selon leur usage, les ruthènes selon leur rite, les polonais selon leur usage et nous honorons dieu selon notre rite, et nous avons tous un seul dieu "302. Une phrase qui n’a probablement pas été inventée par des émissaires chrétiens, sans doute peu habitués à ce genre d'arguments ${ }^{303}$.

L'exemple de Gediminas permet à Stephen C. Rowell de définir le paganisme lituanien comme une coutume sociale ${ }^{304}$. Jusqu'à la conversion de Jagellon, les

\footnotetext{
297 Walsingham, vol. 2, p. 594.

8 GL, p. 116-145.

299 Pierre Damien, Petri Damiani vita beati Romualdi..., XXVII, p. 59-60.

300 C. Gaspar, "The Life of Saint Adalbert...», p. 172.

301 Roger Bacon, Opus Maius..., éd. J. H. Bridges, vol. 2, p. 369.

${ }^{302}$ GL, p. 128.

303 R. MAŽEIKA, «Granting...», p. 170.

304 S. C. Rowell, "Customs...", passim. L'assimilation du paganisme à la coutume intervient dans d'autres contextes, par exemple le drame liturgique Le jeu de l'Antéchrist (XII siècle); P. Buc, Guerre sainte..., p. 132.
} 
grands-ducs successifs pouvaient se montrer ouverts à la culture chrétienne, marier leurs enfants à des princes catholiques ou orthodoxes et employer des clercs franciscains à leur cour. Néanmoins, il était essentiel qu'ils continuent à officier lors des cérémonies religieuses traditionnelles, sans quoi leur rôle de dirigeant aurait été remis en question. Si l'on en croit les chroniques russes, Mindaugas continua de présider aux crémations et de sacrifier aux dieux anciens même après sa conversion ${ }^{305}$. De même, la Chronique rimée de Livonie attribue le retour au paganisme du même personnage à son sens de l'honneur, ce qui en d'autres termes peut se comprendre comme une solidarité "clanique» envers ses pairs restés païens ${ }^{306}$. Une notion similaire pourrait éclairer la scène rapportée par Thomas Gray concernant l'évasion de Kęstutis, aidé par un serviteur lituanien des Teutoniques ${ }^{307}$.

D’après cette interprétation, les religieux chrétiens auraient été tolérés en Lituanie tant qu'ils servaient auprès de leurs coreligionnaires; mais gare à ceux qui se livraient à un prosélytisme trop agressif. À ce sujet, Darius Baronas et Stephen C. Rowell considèrent que les martyrs aussi bien catholiques qu'orthodoxes mis à mort sous le règne de Gediminas et de ses fils auraient été supprimés pour avoir attaqué trop violemment le culte païen et le mode de vie de la population locale. Il se serait donc agi de mesures exceptionnelles prises pour éviter des troubles sociaux, et non d'une politique de terreur visant à tenir les Lituaniens éloignés du christianisme ${ }^{308}$.

Les textes produits dans le milieu des croisés français et anglais ne disent pas explicitement que l'importance sociale du paganisme lituanien ait été perçue par les témoins occidentaux, mais les extraits de Jean d'Outremeuse et Thomas Walsingham que nous venons de lire peuvent parler en ce sens. Certes, l'histoire du roi Margalis aurait tout aussi bien pu se situer dans l'Orient des croisades; néanmoins, le fait que le chroniqueur liégeois ait donné à son protagoniste un nom à consonance «balte» indique qu'il disposait d'informations assez précises, sans doute obtenues par le truchement des nombreux chevaliers des pays wallons qui, au tournant du $\mathrm{Xv}^{\mathrm{e}}$ siècle, accomplissaient le voyage en Prusse et pouvaient s'informer des coutumes lituaniennes auprès de leurs hôtes. Qui plus est, la solide tradition cléricale et savante quant au caractère «coutumier» du paganisme devait être connue d'une partie au moins du public aristocratique. Malgré l'universalisme du christianisme, amené à se répandre aux confins du monde, on pouvait comprendre que l'attachement au paganisme n'était pas qu'entêtement diabolique, mais respect de liens sociaux auxquels la noblesse occidentale était sensible. L'attachement de l'adversaire païen à sa religion peut ainsi devenir compréhensible.

Ceci explique qu'un homme comme Guillebert de Lannoy, l'un des derniers hôtes des Chevaliers teutoniques, n'ait pas été outre mesure rebuté par la diversité

\footnotetext{
305 The Galician-Volynian Chronicle... , p. 63; cité par E. Christiansen, The Northern Crusades..., p. 137.

306 R. MAŽEIKA, "When Crusader...», p. 197-214.

307 Thomas Gray, Scalacronica..., p. 196-198. Voir chap. IV.

308 D. Baronas, S. C. Rowell, The Conversion..., p. 217-218.
} 
religieuse de la cour du grand-duc Vytautas. Lors de son premier voyage en 1413-1414, le seigneur de Lannoy cherche à rencontrer le grand-duc de Lituanie. Après être passé par «l'une des cours dudit Witholt [Vytautas] nommée la Courtle-roy ${ }^{309}$, il arrive à Vilnius, "la souveraine ville de Létau» ${ }^{310}$. Le prince n'est pas là, mais le jeune Bourguignon peut rendre visite à deux princesses lituaniennes, "deux des seurs de la femme dudit duc Witholt»" ${ }^{311}$. En ce qui concerne la ville, il y voit un château de pierre, de terre et de bois, édifié sur une colline sablonneuse, où «se tient coustumièrement ledit duc Witholt, prince de Létau, et y tient sa court et sa demeure». Le reste de la ville est "très mal amaisonnée de maisons de bois», mais " $y$ a aucunes [quelques] esglises de bricque»" ${ }^{312}$. En effet, nous sommes plus de 25 ans après le baptême de Jagellon et de son cousin Vytautas; la Lituanie est désormais chrétienne. Aussi, Guillebert peut-il constater que "sont les gens dudit royaume cristiens nez nouvellement», ce qu'il attribue à la contrainte exercée par les "seigneurs de l'ordre de Prusse et de Liuflant" ${ }^{313}$; "et ont es bonnes villes esglises fondées, et aussy par les villaiges en font fonder de jour en jour, et y a oudit pays de Létau douse évesquiez»" ${ }^{314}$. Le chiffre de douze évêchés est sans doute exagéré, mais l'intérêt est de noter que le pays est considéré comme définitivement chrétien ${ }^{315}$, et c'est dans cette Lituanie fraîchement évangélisée que Guillebert de Lannoy va faire sa première rencontre avec une certaine diversité religieuse ${ }^{316}$.

Notre voyageur, soucieux de détails, nous renseigne sur la langue et l'apparence des Lituaniens: "et ont ung langaige à part eux. Et ont les hommes leurs cheveulz longs et espars sur leurs espaules, mais les femmes sont aornées simplement aucques à la coustume de Picardie». On compare à ce que l'on connaît ${ }^{317}$. Le même mécanisme se répète lorsque Guillebert décrit une autre grande ville de Lituanie, Trakai:

"Et y a deux chasteaulz dont l'un est moult viel, fait tout de bois et de cloyes de terre placquies, et est ce viel chastel assis sur ung costé d'un lacq, mais d'autre part siet en plaine terre. Et l'autre chastel est en la moyenne d'un autre lacq, au trait d'un canon près du viel chastel, lequel est tout neuf, fait de bricque à la manière de France.»118

\footnotetext{
309 Potvin, p. 38. Il s'agit probablement de Švenčionys, à l'est de l'actuelle Lituanie; J. SvÁteK, Discours..., p. 265, n. 311.

310 Potvin, p. 39.

311 Ibid., p. 40.

312 Ibid., p. 39.

313 Id.

314 Ibid., p. 39-40.

315 Le manuscrit de la famille de Lannoy a le nombre plus modeste de "troys» évêchés; Potvin, p. 40 , n. 1.

$316 \mathrm{Ou}$ en tout cas, c'est la première fois qu'il en rend compte: d'après ses Voyages et ambassades, Guillebert s'est rendu quelques années plus tôt auprès de l'émir de Grenade. Or, il ne nous dit rien de son parcours à travers la principauté musulmane, ce qui laisse S. Mund, "Guillebert de Lannoy... ", p. 185, supposer que l'Europe du Nord-Est était moins connue, plus «exotique» que l'émirat de Grenade.

317 F. Hartog, Le Miroir..., p. 237-242.

318 Potvin, p. 40.
} 
La ville de Trakai paraît donc familière au voyageur, quand bien même elle est "malement maisonnée de maisons toutes de bois, et non point fermée»" ${ }^{319}$. Le lieu porte la marque de Vytautas: son château de briques, construit sur une île, a été érigé sous ses ordres selon les meilleurs standards du temps. C'est, comme le zoo que ses hommes ont fait visiter à Guillebert, un moyen de démontrer sa puissance aux hôtes ${ }^{320}$. Ce qui ne manque pas d'effet:

"Item, tient ledit Witholt, prince de Létau, ceste ordre d'honneur parmi son pays que nulz estrangiers, venans et passans par icelui, riens n'y despendent, ains leur fait le prince délivrer vivres et les conduire sauvement partout où ilz veulent aller parmy ledit païs, sans coustz et sans frais. Et est ledit Witholt moult puissant prince, sy a conquesté douse ou trèse que royaumes, que païs, à l'espée. Et a toudis dix mille chevaulz de sa selle, appartenans pour son corps. ${ }^{321}$

Parmi ces royaumes figure la Samogitie, longtemps disputée aux Chevaliers teutoniques. En introduisant son arrivée en Lituanie, notre voyageur reprend la titulature des souverains lituaniens en vigueur depuis Gediminas: "me party, pour m'en aller [...] devers le duc Witholt, roy de Létau et de Samette et de Russie»"322. Voici l'homme que Guillebert a pu connaître, quelques années après son aîné, dont l'épitaphe nous apprend qu'il combattit "avec le duc Witolt encontre les Tartares", autour de $1406^{323}$. Les deux frères semblent avoir été séduits par ce prince catholique aux airs de protecteur de la chevalerie, comme Vytautas lui-même aimait se mettre en scène. Le crypto-païen qui servait d'épouvantail aux pamphlétaires de l'Ordre teutonique jusqu'au concile de Constance se révèle être un prince tout à fait digne de son statut, qui sait accueillir généreusement les visiteurs. La Lituanie n'est plus, comme chez Jean de Mandeville un demi-siècle plus tôt, un pays où les chrétiens doivent emporter leurs vivres avec eux «qar la ne troveroient ils qe lour vende rien ${ }^{324}$. Bien sûr, il ne s'agit plus de visiter le pays en croisé, mais en hôte d'honneur. Toutefois, la générosité de Vytautas n'est pas nécessairement le reflet de son seul statut de chrétien, puisque Guillebert raconte également avoir bénéficié, lors d'un voyage antérieur, de la bienveillance de l'émir de Grenade, qu'il visitait pourtant après l'avoir combattu $^{325}$. Les règles de la diplomatie internationale ne connaissent pas la frontière religieuse.

\footnotetext{
319 Ibid., p. 40.

320 J. Svátek, Discours..., p. 365.

321 Potvin, p. 41.

322 Ibid., p. 38.

323 B. De Lannoy, Hugues de Lannoy..., p. 167.

324 Jean de Mandeville, Le livre des merveilles..., p. 267-268.

325 J. Svátek, Discours..., p. 261.
} 
Venons-en maintenant aux sujets du grand-duc. Dès son premier voyage, en 1414, Lannoy remarque que la ville de Trakai a une population passablement cosmopolite:

"Item, demeurent en laditte ville de Trancquenne et au dehors en pluisieurs villaiges, moult grant quantité de Tartres, qui là habitent par tribut, lesquels sont drois Sarrasins, sans avoir riens de la loy de Jhésucrist, et ont ung langaige à part nommé le Tartre. Et habitent samblablement en laditte ville Allemans, Létaus, Russes et grant quantité de juifz, qui ont chascuns langaige espécial. „326

La cohabitation de ces différents peuples est mentionnée sans le moindre commentaire négatif. La présence de Russes ou de Ruthènes orthodoxes ne choque guère notre Bourguignon, pas plus que celle des juifs - lesquels sont probablement des Karaïtes, une population de langue turque convertie au judaïsme et installée par Vytautas en Lituanie, où ils servent comme mercenaires ${ }^{327}$. Autre auteur et autre lieu, le héraut Berry note sans sourciller dans son Livre de la description des pays (v. 1451) que "en ces Espaignes, et en Arragon a grant multitude de Sarrazins et de Juifs, qui tiennent terres, maisons et possessions, et communiquent avecques les crestiens»" ${ }^{32}$; si leur présence pouvait paraitre relativement exotique aux yeux des Français, elle reste acceptable ${ }^{329}$. Celle des Tatars, qui «sont drois Sarrasins», ne semble pas déranger Guillebert en tant que telle; comme nous allons le voir, c'est leur proximité avec le grand-duc qui le perturbe quelque peu.

Notre Bourguignon, qui en 1414 rencontre finalement Vytautas lors d'une partie de chasse ${ }^{330}$, parle plus en détail du prince et de sa cour à l'occasion de son ambassade effectuée en 1421 pour le compte du duc de Bourgogne et des rois de France et d'Angleterre. Lors de son passage par la Pologne, l'ambassadeur profite de la bonne entente entre le roi Ladislas Jagellon et le sultan pour lui demander une lettre de recommandation devant lui faciliter la traversée de l'Empire ottoman. Entreprise qui, d'après son hôte royal, risque d'être difficile étant donné les troubles survenus après la mort du sultan Mehmet I ${ }^{\mathrm{er} 331}$ :

"Et me bailla lettres, que je demandoie de luy, adreschans à l'empereur de Turquie, avec lequel il estoit alyez contre le roy de Hongrie, pour moi faire

\footnotetext{
326 Potvin, p. 41.

327 R. WIткошsкI, «Some remarks on the history of the Karaites in the Grand Duchy of Lithuania in the $15^{\text {th }}$ century", Karaite Archives 1, 2013, p. 217-218; A. B. ZakrZEwsKI, "Les tatares dans le Grand Duché de Lituanie, Xve-XVIII ${ }^{\mathrm{e}}$ siècles", dans I. VALIKonYtĖ (dir.), Lietuva ir jos kaimynai..., p. 208-227.

328 Hamy, p. 132.

329 Pour le héraut Berry, la présence en terres chrétiennes de «Sarrazins et de Juifs» s'explique par des raisons économiques: "Et les tiennent les roys, pour le prouffit qu'ilz ont d'eulx", id.

${ }^{330}$ Potvin, p. 43.

331 J. Svátek, Discours..., p. 56.
} 
avoir mes saufconduits parmy la Turquie, mais il me dist que ledit empereur estoit mort, par quoy toute la Turquie estoit en guerre, et n'y pourroye passer par terre. " 332

Après six jours passés au côté du roi de Pologne, Guillebert de Lannoy se rend auprès de Vytautas, qu'il rencontre dans une ville nommée "Kamenich»"333, "enssamble sa fermme, acompaigné d'un duc de Tartarie et de pluisieurs autres ducs, ducesses et chevalliers en grant nombre» ${ }^{334}$. Lorsque Vytautas lui offre "cent ducas d'or et vingt cincq keuchelles ${ }^{335}$ d'argent, vaillant cent ducas", il se doit de refuser, "pour ce que à celui temps et heure s'estoit aliez avecq les Housses contre nostre foy ${ }^{336}$. Le voyageur bourguignon fait ici référence à la politique du grand-duc, qui soutenait son neveu Korybutas, auto-proclamé régent de la Bohême hussite, contre Sigismond de Luxembourg, lequel avait hérité de la couronne du pays à la mort de son frère Wenceslas ${ }^{337}$. L'alliance avec les hérétiques pose problème, d'autant plus que Philippe le Bon prenait fait et cause contre les partisans de Jean Hus - et Guillebert lui-même a été chargé de rédiger divers traités sur la question. Toutefois, les autres cadeaux sont acceptés, et Lannoy se fait fort d'en énumérer la longue liste ${ }^{338}$. Les réceptions officielles lui permettent d'observer la cour cosmopolite du grand-duc:

"Et me donna trois fois à disner, me assit à sa table où estoit assise la ducesse, sa femme, et le duc sarrasin de Tartarie, parquoy je vëy mengier char et poisson à sa table, par ung jour de vendredy. Et y avoit ung Tartre qui avoit sa barbe longue jusques dessoubz le genoul, enveloppée d'un coeuvrechief.» ${ }^{339}$

L'apparence physique de ce dernier personnage ajoute au caractère exotique de la scène. En outre, fait étonnant pour un chrétien - Guillebert se doit de le relever -, Vytautas accepte que l'on mange de la viande à sa table un vendredi. La présence des Tatars nous renvoie à un point particulier de la "propagande» teutonique ayant suivi la bataille de Tannenberg. En effet, les lettres envoyées par le grand-maitre Henri de Plauen et les discours des pamphlétaires chargés de

\footnotetext{
332 Potvin, p. 53-54.

333 Ibid., p. 53. Il peut s'agir soit de Kamenets au sud de l'actuelle Biélorussie, soit de Kremenets en Ukraine occidentale; nous sommes donc dans la partie orthodoxe et slavophone du grandduché. Plus loin, Guillebert parle d' "un autre Kemenich», en "Lopodolie» (Podolie). Les toponymes "Kamenets» et ses dérivés sont fréquents dans les pays de langue slave; le "Kemenich en Lopodolie» peut être Kamianets-Podilsky en Ukraine occidentale. Voir Potvin, p. 55, n. 4; J. Svátek, Discours..., p. 258, n. 286.

${ }^{334}$ Potvin, p. 55.

335 Lorsqu'il décrit son séjour à Novgorod, Guillebert explique que la «keuchelle», ou «keucelle», est une monnaie utilisée en Russie; ibid., p. 33.

336 Ibid., p. 57.

337 G. Mickūnaité, Making..., p. 48.

338 J. SVÁTEK, Discours..., p. 268-273.

339 Ibid., p. 55-56.
} 
défendre l'Ordre teutonique au concile de Constance insistaient sur la cruauté de ces guerriers musulmans, auxiliaires de l'armée polono-lituanienne accusés de tous les maux: meurtre, viol, infanticide, blasphème et anthropophagie. Les Lituaniens, et même les Samogitiens, païens jusqu'en 1417, n'étaient sans doute plus assez effrayants, plus assez "étrangers», pour jouer le rôle du persécuteur impitoyable. Depuis 1390 environ, les principales cours d'Europe savaient que la Lituanie avait reçu le baptême, et les princes polono-lituaniens faisaient connaître partout où ils le pouvaient leurs intentions de convertir les Samogitiens au plus vite. Si les Teutoniques voulaient évoquer des infidèles à même de soulever le cœur de leurs lecteurs, il fallait appeler les Tatars à la rescousse. Du reste, déshumaniser un auxiliaire de l'adversaire, à défaut de viser directement celui-ci, était une technique assez fréquente dans l'Europe médiévale. Ainsi trouve-t-on dans la chronique d'Enguerrand de Monstrelet un passage où les Irlandais employés par le commandement anglais lors du siège de Rouen (1418) sont dépeints comme des croque-mitaines n'ayant rien à envier aux guerriers des steppes:

"Et avoit ledit roy d'Angleterre en sa compaignie bien huit mille Yrlandois, dont la plus grant partie aloient de pié, ung pié chaussé et l'aultre nu, sans braies et povrement habillez, aians chascun une targète et petites javelines avec gros couteaulx d'estrange façon [...] Lesquelz Yllandois, durant ledit siège, couroient souvent le pays de Normandie avecques les autres Anglois et faisoient maulx infinis et inestimables, ramenans à leur ost grans proyes. Et mesmement lesdiz Yrlandois de pié prenoient petis enfans en leurs berceaulx et autres bagues, à tous lesquelz montoient sur vaches, portant lesdiz petis enfants et bagues devant eulx sur lesdictes vaches, et furent par plusieurs foiz trouvez des François en cel estat. . ${ }^{340}$

Là encore, l'Irlande rejoint la Lituanie comme marges du monde chrétien. Guillebert de Lannoy, qui a visité ces deux pays, ne semble pas avoir été témoin d'une telle agitation. Déjà en 1414 , soit avant que les porte-paroles de l'Ordre teutonique ne lisent leurs pamphlets à Constance, il remarque la présence des Tatars à Trakai, sans en être autrement ému. Il aura l'occasion de faire plus ample connaissance avec ceux-ci lors de son second voyage. Prince d'un immense territoire à la limite de l'Europe catholique, Vytautas n'a pas de scrupule à composer avec les coutumes de ses nombreux sujets, et à s'allier avec des voisins de foi étrangère. Ainsi, Guillebert note qu'il «estoit aliez avecq le roy de Poulane et avecq les Tartres contre le roy de Hongrie " ${ }^{341}$ - une politique qui, au lendemain de Tannenberg, a valu de vifs reproches aux Polonais et aux Lituaniens, mais dont notre ambassadeur ne tarde pas à bénéficier:

"Et me bailla ledit duc, au partir, telles lettres qu'il me failloit pour passer par son moyen parmy la Turquie, escriptes en tartarie, en russie et en latin. Et

\footnotetext{
${ }_{340}$ Douët d'Arcq, vol. 3, p. 284-285. Sur la mauvaise réputation des Irlandais, J.-M. Borvin, L'Irlande au Moyen Âge....

${ }^{341}$ Potvin, p. 56.
} 
me bailla pour moi conduire deux Tartres, et sèze que Russes, que Wallosques [Valaques], mais me dist bien que ne pourroye passer par la Dunowe [Danube], pour la guerre qui estoit partout en Turquie pour la mort de l'empereur. $)^{342}$

L'avertissement déjà donné par Jagellon est répété; on en déduit que les souverains de Lituanie et de Pologne étaient bien informés de la situation des Balkans sous domination ottomane ${ }^{343}$. Optant, selon les conseils de son hôte, pour une route plus à l'est, Lannoy et son escorte pénètrent aux confins méridionaux du grand-duché, puis en Valachie et en Moldavie. Le gouverneur de la province lituanienne de Podolie lui ayant lui aussi vivement déconseillé de se rendre en Turquie, Guillebert décide de rejoindre Caffa, possession génoise en Crimée.

Guillebert vivra alors successivement plusieurs aventures, lors desquelles sa vie aurait selon ses dires été mise en danger. Le voyageur bourguignon reconnaît à deux reprises avoir été sauvé par des Tatars: la première fois, lorsque "ung Tartre, très loyal homme", ramena tous les chevaux de l'escorte qui s'étaient enfuis, sans quoi "nous estièmes tous mors dedens lesdittes forests et grands désers, car nous estièmes loing de ville qui fut habitée, plus de sept journées»" ${ }^{34}$. Plus loin durant son périple, lorsqu'il traverse une région déchirée par des troubles politiques, lui et son escorte sont attaqués par les hommes d'un des khans rivaux: "par quoi je fus en grant péril, mais sy bien m'en vint que, à ce jour, moy et mes gens, portièmes les chapeaux et livrées de Witholt, et iceulx Tartres de celle embusche estoient des gens du viel empereur de Salhat, qui estoit mort et qui avoit esté grant amy audit Witholt» ${ }^{345}$. Lannoy et les siens en sont quittes pour une rançon.

Il est difficile d'établir si ces anecdotes remplissent le rôle de simples aventures exotiques placées là pour amuser le public auquel Guillebert de Lannoy destinait ses notes ${ }^{346}$, ou si elles reflètent les dangers réels encourus par notre voyageur dans des régions politiquement troublées. Quoi qu'il en soit, nous remarquons que les Tatars respectent les codes militaires que les hommes d'Henri $\mathrm{V}$ semblent avoir négligés, eux qui, sur ordre de leur roi, n’ont pas hésité à brûler vifs leurs prisonniers après la bataille $d^{\prime}$ Azincourt ${ }^{347}$. Que ces épisodes aient été inventés ou non, il est apparent que pour Guillebert, les Tatars sont moins «barbares», moins "étrangers» que ne l'étaient les Anglais. Quant au grand-duc

\footnotetext{
${ }^{342}$ Id.

343 Sur les contacts diplomatiques entre les grands-ducs lituaniens, les sultans et les khans tatars,

D. KoŁodziejczyк, «Entre l'antemurale Christianitatis et la raison d'État. L'idée de Croisade en Pologne aux Xv ${ }^{\mathrm{e}}$ et $\mathrm{XVI}^{\mathrm{e}}$ siècles» dans M.-M. DE Cevins, L'Europe centrale au seuil de la modernité, Rennes 2010, p. 24-25.

344 Potvin, p. 62.

345 Potvin, p. 63.

346 C'est le point de vue de M. Holban, «Du caractère...", p. 419-434.

347 Potvin, p. 49-50.
} 
lui-même, on chercherait en vain le manipulateur des pamphlets de l'Ordre, ou le tyran que dépeindra, quelques décennies plus tard, Énée Sylvio Piccolomini dans son De Europa (1458). Sous la plume du voyageur bourguignon, Vytautas n'a rien du despote amateur d'ours et de supplices sanglants présenté par le futur pape $\mathrm{e}^{348}$. De même, Jagellon ne ressemble pas à l'ambitieux qui, d'après les informateurs de Michel Pintoin et Enguerrand de Monstrelet, aurait entraîné la Pologne dans une longue guerre pour écraser l'Ordre teutonique à la bataille de Tannenberg (1410). Les princes d'origine lituanienne Jagellon et Vytautas sont certes des convertis - Guillebert le note explicitement dans le cas du premier - qui pratiquent une politique religieuse pour le moins souple, mais ils ne méritent pas pour autant la condamnation du Bourguignon.

Au contraire, Vytautas semble l'avoir séduit par sa puissance, et la présence de Tatars à sa cour peut avoir été vue comme un signe de sa suprématie, tout comme les ambassadeurs de Novgorod et de Pskov que Guillebert de Lannoy a eu l'occasion de rencontrer en $1421^{349}$. Tout comme ses auxiliaires tatars ne sont ni de «nobles sauvages" ni l'«image inversée du christianisme», Vytautas est une figure quelque peu ambiguë certes, mais plutôt positive. Ce prince puissant, décrit comme un protecteur de la chevalerie si ce n'est de l'orthodoxie chrétienne, annonce le portrait laudateur du défenseur de la Chrétienté que l'on trouvera dans le Petit Jehan de Saintré et dans le Livre de la description des pays du héraut Berry, lequel, conformément à l'évolution géopolitique, fait jouer ce rôle au roi de Pologne.

\footnotetext{
${ }^{348}$ Voir notamment Énée Sylvio Piccolomini, Historia de Europa, XXVI, SRP 4, p. 237. Pour G. Mickūnaité, Making..., p. 206, 255-259, le sombre portrait de Vytautas s'explique par la tradition classique chère à Piccolomini et à ses continuateurs, et qui tend à considérer qu'un dirigeant aux pouvoirs étendus est nécessairement un tyran, caractérisé par une forte propension à la cruauté et préférant la compagnie des bêtes sauvages à celle des hommes; une tradition visiblement étrangère à Guillebert de Lannoy et à ses contemporains. Voir aussi C. Carpini, "Contra Gentem...", p. 199-201. Sur l'image du tyran dans les écrits humanistes, M. Turchetti, Tyrannie..., p. 335-365; et sur le motif de la tyrannie des Orientaux face à la liberté des Occidentaux, N. Bisaha, Creating East and West. Renaissance Humanists and the Ottoman Turks, Philadelphia 2004, p. 79-81.

${ }^{349}$ Potvin, p. 56.
} 



\section{Conclusion}

Nous voilà au terme de ce voyage. Il est l'heure de nous pencher sur ce qui nous reste de cette longue aventure. Quels legs nous ont laissé les acteurs, les commentateurs, les penseurs de la croisade balte, et en particulier les Français et les Anglais qui, six ou huit siècles avant nous, ont été en contact, direct ou indirect, avec le monde païen de la Baltique?

\section{La Baltique et les marges de la Chrétienté}

Résultat de l'adaptation d'une idéologie élaborée au cœur de la Chrétienté à un contexte local, la croisade du Nord était intimement liée à la vie intellectuelle et artistique de l'Europe occidentale. Saint Bernard de Clairvaux joue ici le rôle d'un passeur: sa proclamation de Francfort en mars 1147 a eu pour effet d'inscrire une "guerre sainte», née de la confrontation entre les derniers païens de la région balte et les puissances chrétiennes locales (Saint Empire, royaumes de Pologne et du Danemark), dans un système idéologique international, celui de la Chrétienté latine en expansion, unie sous la tutelle de la Papauté. L'européanisation de la lutte contre les païens baltes est à l'origine de l'apparition des ordres militaires dans le Nord-Est de l'Europe et l'incorporation de nouvelles provinces dans la culture commune à l'Occident chrétien. Les régions passées sous le contrôle des croisés ont reçu la foi chrétienne et la culture latine, mais le processus est également allé en sens inverse; les membres de l'entourage pontifical, tout comme les clercs écrivant en France, en Italie, en Allemagne, en Angleterre, ont dû intégrer ces nouvelles provinces à leurs connaissances.

Cette intégration est visible notamment dans les écrits historiographiques et

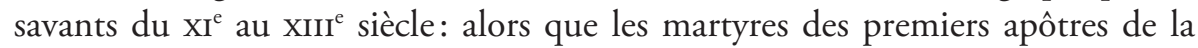
Prusse $(997,1009)$ trouvent un écho chez les hagiographes et les chroniqueurs, l'intérêt pour la région diminue en Europe occidentale jusqu'à la conquête chrétienne en Livonie puis en Prusse au $\mathrm{XIII}^{\mathrm{e}}$ siècle. Les réseaux monastiques permettent la diffusion des informations concernant ces nouvelles plantations de la foi; ainsi, savants et encyclopédistes peuvent-ils utiliser de nouvelles connaissances au sujet de ces lointains pays et de leurs habitants. Les textes donnent désormais une image relativement cohérente du monde balte, de la 
nature, du climat, et des mœurs des habitants, construite à partir d'observations récoltées sur le terrain par divers informateurs (marins, commerçants, militaires, missionnaires), mais également de poncifs littéraires, souvent hérités des auteurs de l'Antiquité.

Dans ce jeu entre perception du réel et adaptation de topoï anciens, les pays «infidèles» proches de la mer Baltique sont définis par une nature à la fois fertile et hostile. Fertile, parce que terre promise dont les chrétiens sont invités à se saisir; hostile, parce que dernier refuge du paganisme dans un continent presque entièrement évangélisé. Les habitants de ces lointaines régions païennes sont essentiellement réduits à leur religiosité, caractérisée par un certain matérialisme, un attachement aux coutumes, et la conviction que l'au-delà équivaut à une répétition de la vie terrestre. Autrement dit, une croyance considérée comme naïve, inférieure au christianisme, qui évoque aux lettrés une réminiscence de l'ancienne religion romaine.

Pour les commentateurs du XIII ${ }^{\mathrm{e}}$ siècle, le monde des païens baltes est un monde ancien, amené à disparaître sous l'impulsion du christianisme. Tous, toutefois, ne sont pas d'accord sur la façon dont l'évangélisation doit se réaliser. Si un Barthélemy l'Anglais ou un Guillaume de Rubrouck louent l'Ordre des Chevaliers teutoniques pour avoir conquis la Prusse et la Livonie et y avoir implanté la foi du Christ, Roger Bacon accuse cette puissante corporation religieuse et militaire de n'être intéressée que par la domination temporelle, et de retarder l'évangélisation des natifs par sa brutalité et sa rapacité. Des critiques couramment adressées aux puissances séculières chargées de la mission, et auxquelles la Papauté romaine puis avignonnaise prête l'oreille, surtout lorsque la conversion d'un prince balte est mise dans la balance.

Au tournant du XIV ${ }^{e}$ siècle, la dernière puissance païenne du continent est le grand-duché de Lituanie. Devant l'échec de plusieurs tentatives d'évangélisation pacifique, l'idée s'impose que seule la force parviendra à faire plier les princes réfractaires. L'Ordre teutonique bat le rappel pour faire venir de nombreux hôtes, des chevaliers laïcs qui s'engagent à ses côtés le temps d'une saison, pour la «rèse" d'été ou celle d'hiver; si le terrain le permet, l'on s'engage en territoire ennemi pour dévaster la campagne, prendre ou édifier une forteresse. Une sorte de rituel militaire s'installe; raids et contre-raids se succèdent pendant un demi-siècle, jusqu'à ce que le prince lituanien Jagellon épouse la reine Hedwige de Pologne et introduise, par sa conversion, le christianisme en Lituanie (1387). Avec l'interdiction formelle d'envahir le grand-duché désormais chrétien, les rèses se concentrent dès lors sur la Samogitie, dernière région païenne, jusqu’à son évangélisation en 1417.

En privant la chevalerie européenne de tout espoir un tant soit peu réaliste de reconquérir la Terre sainte, la chute d'Acre (1291) a eu un effet inattendu sur l'émergence du monde balte dans les lettres occidentales. Jusqu'à la première moitié du XIv ${ }^{e}$ siècle, les rares auteurs écrivant sur le sujet étaient des clercs assez curieux pour s'intéresser aux aléas de la Chrétienté dans ces lointaines régions 
du Nord-Est. Peu de Français ou d'Anglais faisaient eux-mêmes le déplacement, et les rares à s'être rendus en Pologne pour y combattre les païens ne nous ont laissé aucun témoignage connu. L'Ordre teutonique reçoit volontiers l'aide de croisés laïcs, mais jusqu'à la fin du XIII ${ }^{\mathrm{e}}$ siècle ceux-ci viennent essentiellement d'Europe centrale et de l'Empire. Dans la première moitié du xiv siècle, le voyage en Prusse devient un phénomène prisé des nobles de toute l'Europe, de France et d'Angleterre en particulier. Les romanciers et poètes de cour, comme les chroniqueurs louant les hauts faits de la noblesse, ne vont pas tarder à s'emparer de cette aventure nordique.

Alors que plusieurs poèmes didactiques incitent le jeune noble à tester la valeur de ses armes contre les "Sarrasins" en Prusse et en Orient, des moralistes réfléchissent au bien-fondé de l'entreprise: ne vaudrait-il pas mieux se concentrer sur la reconquête de la Terre sainte? Qu'à cela ne tienne: la guerre des «seigneurs de Prusse» contre les "mécréants» offre un cadre à de belles intrigues romanesques et sert de miroir à une chevalerie que l'on voudrait toujours meilleure. Dans les œuvres produites en milieu nobiliaire, le monde balte prend une teinte aristocratique, arthurienne: les marais gelés, les forêts couvertes de neiges, servent de décor à une aventure où l'on combat des "Sarrasins" qui nous ressemblent. Le paganisme, réduit à une coutume sociale et illustré par la crémation des guerriers morts, est le trait distinctif d'adversaires "étrangers" mais nobles, capables de respecter les traités de paix et de faire preuve de loyauté à l'égard de leurs hôtes.

Suivie de loin par quelques auteurs du XIII ${ }^{\mathrm{e}}$ siècle, la croisade balte était donc connue, presque familière, des aristocrates des $\mathrm{XIV}^{\mathrm{e}}$ et $\mathrm{Xv}^{\mathrm{e}}$ siècles. Il reste à se poser la question de l'impact que le phénomène a pu avoir sur la représentation du monde de ceux qui y ont participé, et sur celle de leurs contemporains, de leurs successeurs, de leurs descendants. Les conséquences, intimement liées entre elles, sont de plusieurs sortes. La première, assez évidente, est l'apparition d'une délimitation orientale de la Chrétienté, de l'Europe chrétienne, puis de l'Europe tout court, dans la pensée ouest-européenne. Jusqu’à la conversion de la Lituanie en 1387-1417, la région balte était perçue comme une vaste zone frontière, divisée entre la Prusse et la Livonie qui faisaient offices de bastions chrétiens, et la Lituanie païenne ${ }^{1}$. Au-delà, c'était la Russie schismatique, la Tartarie, puis le lointain

\footnotetext{
${ }^{1}$ Sur le concept de zone frontière et son application à la Baltique médiévale, I. Sooman, S. Donecker (dirs.), The "Baltic Frontier" Revisited, Vienne, 2009; W. Urban, «Frontier thesis and the Baltic Crusade», dans A. V. Murray (dir.), Crusade and Conversion..., p. 45-71; K. KḶAVIN̦Š, «Le tracé de l'identité européenne... », p. 95-110; A. SELART, «Political Rhetoric and the Edges of Christianity: Livonia and its Evil Enemies in the Fifteenth Century ", dans G. JARITZ, J. Kreem (dirs.), The Edges of Medieval World, Budapest 2009, p. 55-69; A. Bues, "Die letst gegent und provintz der cristen", or where is the Baltic?», dans A. Bues (dir), Zones of Fracture in Modern Europe, Wiesbaden 2005, p. 27-43; N. Berend, "Frontiers", dans H. Nicholson (dir.), Palgrave Advances in the Crusades, Basingstoke 2005, p. 148-171; R. BARTLETt, "Heartland and Border: The Mental and Physical Geography of Medieval Europe», dans H. PrYce (dir.),
} 
Nord et ses merveilles. Une fois le grand-duché converti et dynastiquement lié au royaume de Pologne, il devient antemurale christianitatis, fer de lance de la croisade $^{2}$. Ses maitres successifs s'efforcent d'intégrer leurs plans d'expansion politique au schéma idéologique défendu par Rome. Dans le domaine des lettres, le changement de camp de la Lituanie s'observe facilement: au milieu du Xv siècle, ce sont eux qui font face à l'envahisseur infidèle - un rôle joué dorénavant par les Tatars «sarrasins» ou les Russes «schismatiques». La christianisation des Lituaniens a éliminé, en quelques décennies, leur caractère païen des textes occidentaux; les bûchers funéraires et les pouvoirs démoniaques des divinités disparaissent progressivement. Certes, un esprit curieux tel qu'Énée Sylvio Piccolomini peut, au milieu du $\mathrm{Xv}^{\mathrm{e}}$ siècle encore, intégrer ce qu'un missionnaire lui a raconté des rites lituaniens dans son De Europa $a^{3}$; des rites qui, encore teintés de réminiscences antiques, rappellent plus les descriptions "proto-ethnographiques» du temps de la Renaissance et de la contre-réforme que les mises en scènes stéréotypées chères aux médiévaux. L'approche du paganisme balte, et lituanien en particulier, évolue. À l'image de païens "antiquisants» et nobles des auteurs médiévaux succède celle de campagnards engoncés dans d'archaïques superstitions. Ainsi, on ne brûle plus les guerriers morts sur leurs destriers, mais on élève des serpents dans un coin de sa ferme. Pour les lettrés qui s'y intéressent, la Lituanie est, à partir du Xve siècle, une terre chrétienne, dirigée par des princes chrétiens, mais où la population est un peu plus superstitieuse quailleurs ${ }^{4}$.

De plus, les changements dynastiques survenus après la mort du grand-duc Vytautas ont fait du grand-duché de Lituanie un État plus ou moins dépendant de la Pologne. Si, formellement, les boyards lituaniens gardent une autonomie certaine par rapport à Cracovie, à partir de 1447, le titre de grand-duc est porté par l'héritier du trône de Pologne. En conséquence, les auteurs occidentaux tendent à considérer la Lituanie comme une simple province polonaise. À la christianisation du pays correspond, dans les textes occidentaux, son effacement; à l'inverse, la Pologne gagne en reconnaissance. Avec l'incorporation de la Lituanie, le royaume à l'aigle blanc a hérité du contact direct avec la Moscovie et les pays tatars. Les historiens ont montré que l'identité nationale polonaise a été marquée par la fonction d'antemurale christianitatis prétendument dévolue à tout le royaume, mais il n'est pas douteux que ce rôle ait également été perçu

Power and Identity in the Middle Ages, Oxford 2007, p. 23-36; L. JeAnpierre, "Frontière», dans O. Christin (dir.), Dictionnaire des Concepts Nomades, Paris 2010, vol. 1, p. 157-169.

2 W. Paravicini, "Litauer...", p. 253-282; E. Gudavičrus, "Lithuania’s Road to Europe...", p. 15-27.

${ }_{3}^{3}$ Énée Sylvio Piccolomini, Historia de Europa, XXVI, SRP 4, p. 238-239.

${ }^{4}$ S. C. Rowell, "Customs...", p. 46-64, remarque qu’à l'époque moderne, la situation religieuse de la Lituanie, pourtant évangélisée bien plus tard que le reste de l'Europe, n'est pas fondamentalement différente des autres pays européens, où jésuites comme pasteurs réformés traquent les "superstitions" perçues comme des reliquats du paganisme, mais qui relèvent plutôt d'un syncrétisme. 
en Europe de l'Ouest ${ }^{5}$. Pour les auteurs occidentaux, la Pologne jagellonienne puis la République des Deux Nations (1569-1795) ressemble à celle que décrit le héraut Berry dans son Livre de la description des pays (v. 1451): un pays des marges, attaché fermement à la foi catholique et perpétuellement en guerre contre des ennemis infidèles, schismatiques ou mauvais chrétiens ${ }^{6}$. La Pologne-Lituanie remplace l'Ordre teutonique comme marteau des infidèles, et la limite de l'Europe chrétienne se déplace un peu plus à l'Est. Fait emblématique, l'adaptation française des Chroniques et Annales de Pologne par Blaise de Vigénère (1573) raconte que le grand-duc Vytautas "entra dans la Scythie»" pour combattre les hommes de Tamerlan, en 1399; la Lituanie chrétienne ne plus relève donc plus de la catégorie «scythe» propre aux ennemis de la foi.

À n'en pas douter, la croisade nordique a joué un rôle dans l'élaboration d'une carte mentale de l'Europe. Les provinces de la Baltique une fois converties au christianisme romain deviennent "nôtres", et émerge l'idée d'une région de contact avec le monde non-catholique, puis non-occidental; un contact souvent décrit comme belliqueux, volontiers émaillé d'atrocités de part et d'autre. L'image de "bouclier de la Chrétienté" que les rivaux polonais et teutoniques tentaient, à partir du XIv ${ }^{e}$ siècle, de donner d'eux-mêmes s'est définitivement ancrée dans l'imaginaire occidental. La croisade a eu un impact à long terme sur les pays qui en étaient le théâtre, mais aussi dans la perception que les lettrés du cour de l'Europe avaient de ceux-ci. Dans la littérature française ou anglaise, l'identité des «zones frontières» est durablement marquée par la longue confrontation entre chrétiens et infidèles. À l'héroïsation du temps des premiers croisés a succédé une méfiance, un mépris pour ces régions où les chrétiens se confondent volontiers avec leurs adversaires, leur empruntant des traits posés comme caractéristiques des "autres»: cruauté, duplicité, irrationalité, mais aussi magnificence, sens de la démesure. Autrement dit, les chrétiens du Levant, d'Espagne, des Balkans et d'Europe orientale deviennent rapidement aussi «exotiques» que ceux qu'ils sont supposés combattre ${ }^{8}$.

\footnotetext{
5 A. Lawaty, "The Figure of "Antemurale" in the Historiography at Home and in Exile», dans M. Zadencka, A. Plakans, A. Lawaty (dirs), East and Central European History Writing in Exile, p. 360-375; J. TazBir, "The Bullwark Myth...», p. 73-97.

${ }^{6}$ Ainsi, les Chroniques et Annales de Pologne de Blaise de Vigénère (Paris 1573, p. 472-477) et la Cosmographie Universelle de François de Belleforest (col. 1813) mettent en valeur l'héroïsme des commandants polonais et lituaniens contre les Tatars et les Moscovites. Au processus d'héroïsation de la résistance polonaise contre l'infidèle ou le schismatique appartient un document supposément publié en 1590 à Lyon puis à Paris, et dont une édition moderne est rendue par Karol Sienkiewicz: La deffaicte des Tartares et Turcs faicte par le seigneur Jean Zamoïsky, chancelier et capitaine général de la couronne de Pologne, éd. K. Sienkiewicz, Paris 1859. Dans le domaine littéraire, cette tradition est illustrée à merveille par la trilogie d'Henryk Sienkiewicz consacrée à la Pologne-Lituanie du XviI ${ }^{e}$ siècle: Par le Fer et le Feu (1884), Le Déluge (1886) et Messire Wolodyowski (1888).

7 Blaise de Vigénère, Chroniques..., p. 270.

${ }^{8}$ Le mépris et l'incompréhension des Français d'Europe pour leurs coreligionnaires établis en Terre sainte sont bien attestés dans les textes médiévaux; voir M. Aurell, Des chrétiens.... En ce
} 
Le fait que les mêmes chevaliers allaient combattre en Prusse, en Livonie, en Hongrie a sans doute participé à forger, dans l'imaginaire des lettrés occidentaux, l'idée d'un vaste front oriental de la Chrétienté, d'une immense zone frontière s'étendant des pays de la Baltique à ceux des Balkans9. À la "légende noire» espagnole répond sans doute une «légende noire» de l'Est européen ${ }^{10}$ : aussi n'est-ce pas un hasard de voir, dans les écrits d'Énée Sylvio Piccolomini, un Vytautas despotique et sanguinaire - à l'opposé du prince généreux que Guillebert de Lannoy dit avoir connu! - côtoyer l'emblématique Vlad Dracula comme figure du tyran oriental, du cruel satrape des marges européennes ${ }^{11}$. Les hommes à tête de chiens et les Amazones disparaissent, mais les monstres des confins restent.

\section{Héritage et RÉMINISCENCES}

Un saut dans le temps s'impose; l'histoire des idées s'écrit sur la durée ${ }^{12}$. Un exemple suffira: sans souscrire aux idées qui la sous-tendent, on ne peut être que frappé par le parallèle entre les textes $\mathrm{du} \mathrm{Xv}^{\mathrm{e}}$ siècle faisant de la Pologne et de la Lituanie des avant-postes de la Chrétienté latine contre un monde

qui concerne l'Espagne et la "légende noire espagnole», A. SANChez Jimenez, «La Leyenda Negra: para un estado de la cuestión", dans Y. Rodríguez Pérez, A. SÁnchez Jiménez (dirs.), España ante sus críticos: las claves de la Leyenda Negra, Madrid 2015, p. 23-44.

9 A. Selart, «Political Rhetoric...», p. 65.

${ }^{10} \mathrm{~K}$. KựaVin̦š, «Le tracé de l'identité européenne...», p. 105-110, a remarqué que les historiens baltes du XVIII ${ }^{e}$ et du XIX ${ }^{\mathrm{e}}$ siècle ont pris l'habitude de lire la conquête de la Prusse et de la Livonie selon le "paradigme de Las Casas", les traits des Teutoniques étant calqués sur ceux prêtés aux conquistadores. Dans l'historiographie et la littérature française, les Teutoniques autant que leurs adversaires slaves et baltes sont en général dépeints de manière relativement sombres: brutaux et fanatiques pour les premiers, barbares et arriérés pour les seconds: D. Buschinger, M. Olivier, Les Chevaliers teutoniques..., p. 459-488. Sur les stéréotypes généralement défavorables au sujet de l'Europe du Centre-Est au XIX et $\mathrm{Xx}^{\mathrm{e}}$ siècles, P. WAndyCZ, "Western Images and Stereotypes of Central and Eastern Europe", dans A. Gerrits, N. Adler (dirs.), Vampires Unstaked. National Images, Stereotypes and Myths in East and Central Europe, Amsterdam, etc. 1995, p. 5-23.

${ }^{11}$ Énée Sylvio Piccolomini, Historia de Europa, XXVI, SRP 4, p. 237; Idem, Mémoires d'un pape de la Renaissance, trad. I. Cloulas et al., Paris 2001, p. 379-382. Voir l'analyse de G. Mickūnaité, Making..., p. 255-259, sur la construction du tyran oriental dans les œuvres des penseurs politiques occidentaux de l'époque moderne - laquelle remarque que les auteurs étrangers sont bien plus durs envers Vytautas que les chroniqueurs lituaniens du XVI ${ }^{\mathrm{e}}$ siècle. À titre d'exemple, André Thevet reprend l'histoire selon laquelle un Lituanien préférait se pendre lui-même plutôt que d'être mis à mort sur l'ordre de Vytautas, "le plus cruel des hommes» (Cosmographie moscovite, éd. A. Galitzin, Paris 1863, p. 82). Un thème également abordé par Montaigne, mais dans un sens positif cette fois-ci : "On dict que Vuitolde, prince des Lituaniens, fit autrefois cette loy que les criminels condamnez eussent à executer eux mesmes de leurs mains la sentence capitale ... trouvant estrange qu'un tiers, innocent de la faute, fust employé et chargé d'un homicide» (Les Éssais, éd. Pierre Villey, 1965, p. 799, cité par G. Mickūnaité, Making,... p. 250, n. 496).

${ }_{12}$ Par exemple, F. Rosset, "Infinitude et labilité: d'une frontière fantôme à l'est de l'Europe», dans S. Ghervas, F. Rosset (dirs.), Lieux d'Europe. Mythes et limites, Paris 2008, p. 139-147. 
oriental, infidèle et orthodoxe, et la théorie dite du «choc des civilisations» de Samuel Huntington ${ }^{13}$. Pour le géopoliticien américain, la Lituanie, la Lettonie et l'Estonie, catholiques et protestantes, appartiennent à la civilisation occidentale, tout comme les pays d'Europe centrale, alors que la Biélorussie et l'Ukraine font partie d'une civilisation qu'il définit comme «slavo-orthodoxe» et dont le centre serait la Russie. La théorie de Huntington a été, a juste titre, critiquée et en bonne partie rejetée par le milieu académique, mais les développements politiques récents semblent indiquer que l'idée des États baltes comme une frontière armée entre l'Ouest et l'Est n'est visiblement pas près de disparaître ${ }^{14}$.

Heureusement, les contacts dans les zones frontières ne sont pas que guerriers, et l'image que se sont forgés les lettrés au sujet de ces régions n'est pas faite que de fer et de feu ${ }^{15}$. En ce qui concerne plus particulièrement les pays de la Baltique, l'imaginaire né au Moyen Âge est amené à une longue survie littéraire. La figure du païen noble ou redoutable s'efface, mais le décor reste le même - tout au plus se déplace-t-il à partir du XVI ${ }^{\mathrm{e}}$ siècle vers une Moscovie jugée

13 S. Huntington, Le choc des civilisations, Paris 1997, p. 175-183. Pour une analyse de l'approche "huntingtonienne» des croisades, K. V. Jensen, «Cultural Encounters and Clash of Civilisations. Huntington and Modern Crusading Studies", dans K. V. Jensen et al. (dirs.), Cultural Encounters during the Crusades, p. 15-26.

${ }^{14}$ M. Klare, "À Washington, scénarios pour un conflit majeur», Le Monde diplomatique, septembre 2016, p. 1-9. À cet égard, la théorie de P. Buc, Guerre sainte..., selon laquelle un même fond culturel expliquerait la violence dont peut, dans certains contextes, faire preuve l'Occident chrétien et postchrétien, prend tout son sens. Même si une telle réactualisation a toujours ses limites (et l'auteur en est conscient), le lien qui est fait entre les arguments des défenseurs de l'Ordre teutonique à Constance et ceux du président américain George W. Bush justifiant l'invasion de l'Irak en 2003 ne manque pas d'intérêt: dans les deux cas, la guerre était présentée comme une mesure de défense préventive et devant apporter, à terme, le salut ou la liberté au peuple visé (Ibid., p. 351-352 passim).

${ }^{15}$ Un point de vue plus nuancé apparaît par exemple chez le voyageur et écrivain François Le Gouz de La Boulaye (1623-1668), qui, fidèle à la tradition, considère la Pologne comme un bastion de la Chrétienté, mais note sans commentaire négatif que plusieurs religions cohabitent dans le royaume, et que les dirigeants de celui-ci préferent l'entente à la confrontation face aux Turcs et aux Tatars; G. Cesbronon, "En passant par la Pologne...” avec François Le Gouz de La Boulaye voyageur angevin du Xvir iècle" ", dans E. Berriot-Salvadore, R. Aulotte (dirs.), Les représentations de l'Autre..., p. 31-38. Prenant le contre-pied du stéréotype guerrier illustré par les textes de la fin du Moyen Âge et de l'époque moderne, certains historiens proposent une vision positive de la zone frontière est-européenne et insistent sur le rôle de "passeur» de la Lituanie multiculturelle. Ainsi, J. Wyrozumski, «L'idée de tolérance... », p. 143; D. KoŁodziejczyK, «Entre l'antemurale Christianitatis et la raison d'État...», p. 19-26; A. B. ZAKrzewski, «Les Tatares dans le Grand Duché de Lituanie...», p. 220-222; B. Diaz Kayel, "Just War against Infidels? Similar Answers from Central and Western Europe», Studia Philosophiae Christianae 3, 2017, p. 55-76. Sur les contacts relativement pacifiques entre catholiques, orthodoxes, juifs et musulmans dans la Lituanie de l'époque médiévale et moderne, S. C. Rowell, "Christian Understanding of the Faith through contacts with Non-Christians in the late-mediaeval Grand Duchy of Lithuania ", Bažnyčios Istorijos Studijos - Studies in Church History 6, 2013, p. 9-22. 
plus «exotique ${ }^{16}$. Martin Nejedlý a raison de considérer Guillebert de Lannoy comme un précurseur de la longue lignée d'écrivains ayant consacré des morceaux de bravoure à l'hiver russe ${ }^{17}$, mais son récit repose sur une tradition bien établie: les impressions des «merveilles de froid" vécues lors de son périple entre Novgorod et Pskov sont certes personnelles et ne relèvent pas uniquement du topos littéraire, mais l'ambiance glaciale et les forêts gelées appartiennent bien à l'imaginaire de la croisade balte. Le cas du voyageur bourguignon permet de voir comment s'effectue le glissement de l'exotisme "prussien " à l'exotisme russe ou moscovite: ce n'est plus en traversant la Wildnis que l'hiver se fait le plus féroce, mais en parcourant en traîneau les vastes étendues séparant les deux puissantes cités russes. De même, ce ne sont pas les Lituaniens, "cristiens nez nouvellement ${ }^{18}$, qui impressionnent, mais les habitants de Novgorod, qui achètent leurs épouses au marché, et "changent leurs femmes, l'une pour l'autre, pour une keucelle d'argent ou deux» ${ }^{19}$. À la cour du grand-duc Vytautas, les boyards lituaniens semblent être passés inaperçus; ce sont les Tatars que Guillebert remarque, avec leurs longues barbes et leur habitude de manger de la viande le vendredi, et les ambassadeurs russes avec leurs somptueux présents ${ }^{20}$.

Comme une conséquence de la conversion des Lituaniens, l'exotisme propre à la représentation de l'Europe du Nord-Est se déplace en même temps que la frontière religieuse. La disparition progressive du monde balte des lettres françaises s'explique sans doute par la fin de la croisade et l'assimilation de la Lituanie au modèle commun de la Chrétienté latine ${ }^{21}$. Pour reprendre les catégories de Tzvetan Todorov ${ }^{22}$, la conversion des Lituaniens les a fait passer du statut d' "autres» parce qu'infidèles au vaste "nous» que constituait la Chrétienté médiévale. Une fois devenus chrétiens, ces célèbres "Sarrasins» du Nord perdent leur altérité et cessent d'intéresser les écrivains; les "autres» fascinent sans doute plus que ceux qui sont devenus «comme nous»" Pour les auteurs de l'époque moderne, ce ne sont plus les Baltes qui font figure de «nobles sauvages» ou de terribles croque-mitaines, mais les lointains Amérindiens.

\footnotetext{
${ }^{16}$ Voir S. Mund, Orbis Russarum.... À partir du xv siècle, l'ennemi face à qui la Livonie et la Prusse sont censées jouer le rôle de bouclier n'est plus la Lituanie païenne, mais la Russie orthodoxe: A. Selart, «Political Rhetoric... », p. 55-69.

17 M. NejedlÝ, «Spisy...», p. 111.

${ }^{18}$ Potvin, p. 39.

19 Ibid., p. 33-34. L'information concernant l'échange des épouses a été remise en question par certains historiens, lesquels s'entendent toutefois sur fiabilité d'ensemble du témoignage de Lannoy sur la Russie; S. Mund, "Guillebert de Lannoy....”, p. 190.

${ }^{20}$ Potvin, p. 55-56.

${ }^{21}$ D. Buschinger, M. Olivier, Les Chevaliers teutoniques..., p. 461.

${ }_{22}$ Notamment T. Todorov, Nous et les Autres....

${ }^{23}$ Il existe toutefois une petite dizaine de mémoires de voyageurs français du XVII ${ }^{e}$ siècle relatant leurs expériences de voyage en Lituanie; voir R. Kamuntavicius, «Memoirs of French travellers: a source of Lithuanian History in the Second Half of the Seventeenth Century», Lithuanian Historical Studies 3, 1998, p. 27-48.
} 
À partir du $\mathrm{XVI}^{\mathrm{e}}$ siècle, les Lituaniens, les Prussiens, les Livoniens, n'intéressaient plus guère que les missionnaires soucieux d'extirper les superstitions de leurs diocèses, ou les savants désireux de les recueillir. À cette double tradition, inaugurée par Énée Sylvio Piccolomini et son informateur Jérôme, appartiennent pour l'essentiel des Allemands de la Baltique et des Polonais (ou des Lituaniens polonisés) ${ }^{24}$. Tout au plus les cosmographes de la cour française comme André Thevet ou François de Belleforest reprennent-ils les histoires racontées par Piccolomini ${ }^{25}$. Il faudra attendre le mouvement romantique et l'intérêt pour l'univers d'inspiration médiévale pour que le paganisme balte réapparaisse dans toute sa splendeur, d'abord chez les PolonoLituaniens, à commencer par Adam Mickiewicz, qui publie deux nouvelles mettant en scène des princes lituaniens en lutte contre l'Ordre teutonique: Grażyna en 1823 et Conrad Wallenrode en 1828, et à la fin du siècle, par Henryk Sienkiewicz et son célèbre Les Chevaliers teutoniques (1900) ${ }^{26}$. Après avoir servi d'étendard aux patriotes romantiques du $\mathrm{XIX}^{\mathrm{e}}$ siècle et de la première moitié du $\mathrm{Xx}^{\mathrm{e}}$, le paganisme reste lié à l'identité des trois Républiques baltes, comme manière de s'auto-définir par rapport aux voisins catholiques et orthodoxes ou de revendiquer un particularisme culturel et historique ${ }^{27}$.

En France, le caractère païen, sauvage, de la Lituanie est merveilleusement illustré par la nouvelle Lokis de Prosper Mérimée (1869), lequel a choisi la Samogitie pour raconter l'histoire d'un homme né d'une comtesse enlevée par un ours ${ }^{28}$. Un thème commun au folklore européen, mais que l'érudit slavophile Mérimée ne situe sans doute pas par hasard dans la dernière province païenne d'Europe ${ }^{29}$. Giedre Mickūnaitè y voit une persistance du thème de l'«oursophilie» lituanienne, qui prendrait ses sources dans le portrait par Piccolomini du grand-duc Vytautas et de son frère et successeur malchanceux, Sigismond (Zigimantas), censés garder des ours comme animaux de compagnie ou instruments de supplice ${ }^{30}$. Du reste, la Samogitie de Lokis ressemble, l'hiver

\footnotetext{
${ }^{24}$ Notamment Simon Grunau (v. 1470-1537), Lucas David (1503-1583), Jan Lasicki (15341602), Mattias Prätorius (v. 1635-1704) : A. Greimas, Des dieux et des hommes...; Baltu Religijos..., p. 50-78.

${ }_{25}$ André Thevet, Cosmographie moscovite..., p. 84-90; François de Belleforest, La Cosmographie Universelle..., col. 1816. La crémation des morts apparait toutefois chez Belleforest, dans la description consacrée à la Samogitie: ibid., col. 1818.

${ }^{26}$ D. Buschinger, M. Olivier, Les Chevaliers teutoniques..., p. 431-442.

27 I. Sooman, S. Donecker (dirs.), The "Baltic Frontier» Revisited..., p. 22. Voir aussi la postface de J.-P. Minaudier au roman d'Andrus Kivirähk, L'Homme qui savait la langue des serpents (2007, trad. fr. 2013).

${ }_{28}$ M. Pastoureau, L'Ours..., p. 288-290.

29 Ibid., p. 285-290; R. Schmittlein, Lokis. La dernière nouvelle de Prosper Mérimée, Bade 1949, p. 35-39. En ce qui concerne ses sources, Mérimée utilise les œuvres littéraires d'Adam Mickiewicz et Charles Edmont Chojecki; ses contacts avec les émigrés polonais et lituaniens lui ont permis d'obtenir quelques détails supplémentaires: Ibid., p. 39-76.

30 Énée Sylvio Piccolomini, Historia de Europa, XXVI, SRP 4, p. 237; G. Мicкūnaité, Making..., p. 256. L'ours comme animal de compagnie du grand-duc Sigismond semble avoir été inventé par
} 
mis à part, à celle que dépeignent les chroniques et les récits de voyage de nos auteurs médiévaux: un pays sauvage, couvert de forêts et de marécages, où abondent les "superstitions» archaïques, préchrétiennes. Au combat héroïque entre christianisme et paganisme succède, chez Mérimée, celui de l'homme et de l'animal, de la civilisation et de la nature - l'un de ses thèmes favoris, qu'il aime placer dans les contrées qu'il concevait sans doute comme les marges de son monde: Espagne, Corse, Maghreb et Lituanie ${ }^{31}$.

Après leur conversion, les Lituaniens ont donc cessé de fasciner, mais leur pays, confondu avec la plus familière Pologne, reste l'une des parties de l'immense zone frontière orientale qui se dessine dans l'esprit des penseurs européens; une région au caractère éminemment ambigu, ni vraiment "nôtre", ni tout à fait "étrangère». Voilà le premier legs de cette page d'histoire européenne. Néanmoins, la croisade menée contre les Baltes, et la participation de nombreux chevaliers occidentaux à celle-ci, ont eu d'autres résultats que l'émergence d'une frontière mentale à l'Est de la Chrétienté. Dans la longue histoire du voyage, ce mouvement en effet représente une étape à part. Pendant exclusivement aristocratique des grands pèlerinages à Jérusalem, Rome ou SaintJacques de Compostelle, la pratique des rèses, ouverte à une large partie de la noblesse, a pu servir à diffuser le goût du voyage et de l'exploration parmi les Européens de cette classe sociale. Là encore, l'intérêt porté à la croisade balte ne fait sens que si on la met en parallèle avec les expéditions du même genre lancées ailleurs, mais auxquelles participaient les mêmes personnes (ou au moins des individus issus du même milieu).

Pour les hommes qui nous ont occupés au cours de cette étude, la Baltique comme zone frontière faisait partie d'un ensemble cohérent, défini comme les marges de la Chrétienté. Pour les clercs comme pour les chevaliers, le christianisme doit progresser partout où il y a des hommes à convertir, des schismatiques ou des hérétiques à ramener dans le giron de l'Église. Ceux qui refusent d'accueillir les missionnaires, ou qui menacent leurs vies, doivent être combattus sans pitié; religion à vocation universaliste, le christianisme ne saurait souffrir d'entrave à son expansion ${ }^{32}$. Fondamentalement, il importe peu aux idéologues de la croisade et à ceux qui mettent cette idéologie en pratique que "l'ennemi» soit païen ou musulman: ce qui compte est son statut d'infidèle, et son caractère prétendument agressif, réfractaire ${ }^{33}$.

Alors que les thuriféraires de l'Ordre des Chevaliers teutoniques présentent leur action dans la Baltique comme une prolongation de la guerre en Terre sainte, les panégyriques et autres poèmes didactiques à destination des jeunes

Piccolomini; S. C. Rowell, «Of Bears and Traitors, or: Political Tensions in the Grand Duchy, ca. 1440-1481", Lithuanian Historical Studies 2, 1997, p. 45-53.

31 K.-B. Tolo, L'intertextualité chez Merimée: l'étude des sauvages, Birmingham, Alabama, 1998.

32 K. V. Jensen, "Cultural Encounter... », p. 22-24; P. Buc, Guerre sainte..., p. 337-357.

33 J. FLORI, Guerre sainte..., p. 228-230. 
nobles postulent une équivalence entre les différents théâtres de la lutte pour la foi. À première vue, le comportement des acteurs semble correspondre au modèle imprimé par les textes. À cet égard, le chevalier poitevin Gadifer de la Salle est presque archétypal, mais annonce en même temps quelque chose de foncièrement nouveau. L'homme avait, comme beaucoup de nobles de son temps, pris part à la croisade de Prusse en 1378-1379 et en 1390-1391, puis à celle de Mahdia la même année. En 1402, alors qu'il avait atteint une position tout à fait honorable à la cour, il décide de suivre un aventurier normand, Jean de Béthencourt, qui entendait voguer jusqu'aux îles Canaries pour les conquérir et les soumettre à la foi chrétienne ${ }^{34}$.

L'aventure canarienne est un fiasco, mais elle reste une étape importante dans l'expansion occidentale par-delà les océans ${ }^{35}$. Le prologue de la chronique consacrée aux péripéties des deux hommes place l'expédition dans la suite des entreprises d'évangélisation auxquelles les chevaliers des temps passés se consacraient ${ }^{36}$. L'une des premières aventures coloniales européennes plongerait donc ses racines dans l'idéologie de croisade, soutenue notamment par l'institution des rèses de Prusse $^{37}$. L'américaniste Irving Leonard a montré que les conquistadores, tout comme Gadifer de la Salle, avaient emporté des romans de chevalerie avec eux ${ }^{38}$. La conquête de l'Amérique apparaît ainsi, par certains aspects, comme l'héritière des croisades européennes: entreprise visant, en théorie, à imposer la foi aux non-chrétiens, elle est nourrie d'idéaux chevaleresques tirés des lectures favorites des nobles et de ceux qui aspiraient à la noblesse ${ }^{39}$. Plus qu'avec la conquête de la Terre sainte - motivée par un autre but que la christianisation des infidèles - celle du Nouveau Monde présente des ressemblances frappantes avec la Reconquista ibérique et la croisade balte. Un rapprochement au moins temporel est assez évident: 1492 est l'année du premier voyage de Colomb et celle de la prise de Grenade.

Le parallèle entre la conquête de la Baltique et celle de l'Amérique a été tenté dès le $\mathrm{XVI}^{\mathrm{e}}$ siècle $^{40}$. Les présupposés idéologiques des conquérants (les «infidèles» valent moins que «nous»), leurs justifications (étendre le christianisme et supprimer les comportements «barbares» ou "contre nature»), et jusqu’à leurs techniques militaires (s'appuyer sur les peuples «faibles" pour vaincre les «forts»)

\footnotetext{
${ }^{34}$ M. Keen, "Gadifer de la Salle...», p. 74-81.

35 A. Sadourny, «Les expéditions...», p. 201-208; M. Keen, "Gadifer de la Salle... », p. 85.

${ }^{36}$ Le Canarien..., vol. 3, p. 15.

37 W. Paravicini, «La Prusse... », p. 187.

38 I. LeOnARD, Books of the Brave. Being an Account of Books and of Men in the Spanish Conquest and Settlement of the Sixteenth-Century New World, Cambridge, Mass. 1949.

39 P. Rousset, Croisade. Histoire d'une idéologie, Lausanne 1983, p. 195; W. Paravicini, "Von der Heidenfahrt...», p. 98, 101.

${ }^{40}$ K. Kựavin̦š, "Le tracé de l'identité européenne...", p. 105-110; R. Williams, The American Indian in Western Legal Thought. The Discourses of Conquest, New York/Oxford 1990, p. 62-67.
} 
se ressemblent ${ }^{41}$. Même les arguments des opposants à ces entreprises semblent sortis du même moule. Aussi a-t-on souvent proposé de voir une filiation entre les défenseurs des droits des infidèles au concile de Constance et ceux des Indiens au $\mathrm{XVI}^{\mathrm{e}}$ siècle $^{42}$. Formulé autrement: la croisade balte a-t-elle été, aux côtés de la Reconquista et des autres formes d'expéditions chevaleresques contre l'infidèle, l'un des marchepieds à la conquête de l'Amérique? En effectuant les fameuses rèses aux côtés de l'Ordre teutonique, les nobles européens ont-ils pris goût à l'aventure exotique, à la conquête au détriment des infidèles?

L'aristocratie chrétienne n'a cependant pas eu besoin des rèses pour apprendre à partir au loin s'emparer de nouveaux territoires et les exploiter à son avantage. Pour ne prendre qu'un exemple, on pense à l'incroyable énergie des barons normands, qui, aux $\mathrm{XI}^{-\mathrm{XII}^{\mathrm{e}}}$ siècles, conquirent non seulement l'Angleterre, mais aussi la Sicile et le sud de l'Italie ${ }^{43}$. Ces expéditions, relativement rares et ponctuelles, avaient d'autres buts que les rèses de Prusse. Tout comme celles qui aboutiront à l'établissement des États latins de Terre sainte, elles supposaient en général un voyage sans retour: le seigneur qui s'y engageait entendait se saisir d'un nouveau fief et s'y établir. Cet aspect se retrouve chez les conquistadores et les Chevaliers teutoniques, mais pas chez les hôtes de ces derniers. À l'exception de ceux qui adhéraient à l'Ordre, les nobles européens qui allaient combattre l'infidèle sur le front balte n'y restaient pas très longtemps: quelques semaines, un mois ou une saison. Tout au plus y revenaient-ils à une autre occasion. À part quelques cas exceptionnels, ils ne pouvaient pas non plus espérer un avantage matériel de leur participation aux rèses: les plus chanceux voyaient leurs dépenses remboursées par un prince, mais beaucoup devaient voyager à leurs frais. Les grands seigneurs qui ramenaient des captifs ne voyaient certainement pas ces derniers comme un gain matériel; un comte de Derby ou un seigneur de Châteauroux avaient assez de serfs attachés à leurs domaines pour se soucier d'en gagner un de plus au retour de la Baltique!

Le gain que l'on escomptait en participant aux rèses était, sinon spirituel ou psychologique, social. C'était le prestige, l'honneur que l'on allait chercher en Prusse, en Livonie, comme en Espagne, à Chypre, en Méditerranée. Même si un moraliste comme Philippe de Mézières n'y voyait que "Vaine Gloire», cet honneur recherché par les hôtes de l'Ordre teutonique est chargé d'une religiosité toute aristocratique: la prouesse accomplie au service de la foi est acte

\footnotetext{
${ }^{41}$ Comme point de départ, T. Todorov, La Conquête de l'Amérique. La question de l'autre, Paris 1982. P. Buc, Guerre sainte..., p. 368, fait le parallèle entre la justification scholastique de l'invasion des territoires païens et les mots du défenseur des conquistadores Juan Ginés de Sepúvleda.

${ }^{42}$ Notamment A. Dufour, «Droit international et chrétienté: des origines espagnoles aux origines polonaises du droit international. Autour du sermon De bellis justis du canoniste polonais Stanisłas de Skarbimierz (1360-1431)» dans P. Dupuy, V. Chetail (éds.), The Roots of International Law, Leiden 2013, p. 95-119; B. Diaz KaYeL, "Just War against Infidels...", p. 55-76.

${ }_{43}$ R. BARTLETt, The Making of Europe...
} 
de dévotion. Autrement dit, ce qui plaît à Dieu peut aussi plaire aux hommes. La religiosité "mondaine» des croisés de Prusse, leur intégration à un modèle de vie chevaleresque, leur volonté de s'afficher en continuateurs d'un idéal ancien, les distingue des conquistadores du début du XvI siècle. Dans son essai consacré à la conquête de l'Amérique, Tzvetan Todorov a mis en lumière la modernité caractéristique des aventuriers espagnols, au sens où ceux-ci se seraient comme affranchis des règles chrétiennes qui, en Europe, commençaient à s'effacer sous l'influence de l'esprit de la Renaissance ${ }^{44}$. La recherche du profit immédiat remplace celle de l'honneur; après tout, comme le dit le célèbre défenseur des Indiens Bartholomé de Las Casas, "avec l'argent les hommes acquièrent toutes les choses temporelles dont ils ont le besoin et l'envie, telles que honneur, noblesse, biens, famille, luxe» ${ }^{45}$. La rapacité des conquistadores serait donc l'effet d'un changement de valeurs interne à la culture européenne, l'un des éléments constitutifs du passage du Moyen Âge à la modernité.

Si l'on peut suivre l'éminent sémiologue sur ce point, la croisade balte appartient clairement au monde médiéval. Les croisés de la Baltique sont non seulement des chrétiens tenant à l'orthodoxie de leur foi, mais aussi des nobles jaloux de leur statut. Dans son Instruction au jeune prince, Hugues de Lannoy ne cache pas son mépris pour les conseillers de basse extraction, nouveaux riches issus de la roture, et dont les princes ont trop tendance à s'entourer ${ }^{46}$. Pour ces chevaliers issus de vieilles familles aristocratiques, l'argent n'achète pas tout, et surtout pas la noblesse. Au contraire, participer à la croisade de Prusse leur permet de vivre leur condition de manière intense, entre pairs; la vie héroïque et digne qui leur est, par la force des choses, interdite en France ou en Angleterre, devient possible sur les terres de l'Ordre teutonique et dans la Wildnis $^{47}$. Même les païens que l'on va harceler sont présentés comme nobles. À en croire les récits de croisade balte, les hôtes des Teutoniques n'avaient vu, comme autochtones, que les guerriers promis au bûcher funéraire, et non les humbles dont les "superstitions" horrifiaient les clercs avant d'intriguer les humanistes ultérieurs.

\section{De LA CROISADE À LA CONNAISSANCE DE L'AUTRE}

Ces aristocrates conservateurs n'allaient pas chercher de l'or en Prusse, mais du prestige, de l'honneur; ils espéraient sans doute y trouver aussi une part de rêve, d'idéal, artificiellement entretenu par les officiers teutoniques, et favorisé, si le climat le permettait, par la nature particulière à la région balte.

\footnotetext{
T. Todorov, La Conquête de l'Amérique....

45 Cité par ibid., p. 182.

46 Potvin, p. 371; C. van Hoorebeeck, «Item, ung petit livre en franchois... La littérature francaise dans les librairies des fonctionnaires des ducs de Bourgogne», Le Moyen francais, 57-58, 2005-2006, p. 384.

47 W. Paravicini, «La Prusse...., p. 176-191.
} 
Accomplir le voyage en Prusse était une manière de se rassurer sur son statut, mais aussi de vivre l'aventure à laquelle tout lecteur de roman chevaleresque pouvait aspirer. Aventure qui passait, bien sûr, par la participation «standard" aux rèses, le cérémonial de la table d'honneur, la traversée de la Wildnis et le combat contre les Lituaniens, mais qui dans certains cas, prend une autre ampleur. Ainsi Guillebert de Lannoy, qui dit entreprendre son long voyage de 1413 pour aller "vëoir le monde» ${ }^{48}$. Si l'on met de côté le rôle d'ambassadeur officieux que ce personnage a pu jouer lors de ce premier voyage, il apparaît que son motif principal était la curiosité, l'envie de visiter ces lointains royaumes, de découvrir la vie de cour que l'on y mène. Habitués à la cour des grandsmaîtres, aux splendeurs de Marienbourg et de Königsberg, quelques chevaliers avaient manifestement entendu parler de la cour qu'entretenait Vytautas, prince converti tour à tour allié et ennemi de l'Ordre; l'envie devait leur être venue de voir l'état de sa chevalerie - en amis, et non en agresseurs ${ }^{49}$.

Les nobles de la fin du Moyen Âge ne se rendaient pas en Prusse ou ailleurs uniquement pour remplir leurs quotas de hauts faits chevaleresques. Considérant les motivations des participants à l'expédition de Nicopolis, Elisabeth Gaucher parle de l'envie de "voir du pays, rechercher l'exotisme», de chevaliers "enthousiasmés par la perspective d'aventures lointaines» ${ }^{50}$. Hugues de Lannoy n'hésitait pas à recommander aux jeunes nobles de partir au loin pour affronter les "Sarrasins", mais aussi pour découvrir un monde différent de ce à quoi ils étaient habitués: "car jone homme ne peut nulle part mieulx apprendre les affaires $d u$ monde que par voyagier et hanter le fait des armes en estranges contrees et pays $»^{51}$. Comme l'exprimait déjà Geoffroi de Charny presque un siècle plus tôt, le voyage n'impliquait pas uniquement le combat pour la foi et la recherche d'honneur, mais également l'envie de découvrir, de connaitre de nouveaux horizons, de "vëoir le monde». Les expéditions des jeunes nobles dans les pays lointains font donc partie d'un apprentissage; les relations de leurs aventures se veulent à la fois instructives et distrayantes, et force est de constater que le récit de voyage reste un genre populaire, jusque loin dans le $\mathrm{xx}^{\mathrm{e}}$ siècle. Plus qu'aux conquistadores, nos chevaliers s'apparentent donc, à certains égards, aux premiers touristes: l'institution des rèses peut, dans une certaine mesure, avoir posé les bases du "grand tour " ${ }^{52}$.

Pour que les brutales parties de destructions qu'étaient les rèses "classiques" se transforment en visites pacifiques, un changement a dû se produire dans l'esprit des chevaliers se rendant sur le rivage balte. Les princes polonais, tchèques, saxons qui assistaient l'Ordre teutonique au $\mathrm{XIII}^{\mathrm{e}}$ siècle étaient

\footnotetext{
48 A. Bertrand, «Un seigneur bourguignon...», p. 293-309.

${ }^{49}$ R. Petrauskas, «Knighthood...», p. 50-51; PR 1, p. 41.

${ }^{50}$ E. GAUChER, «Deux regards sur une défaite...», p. 97.

51 Bruxelles, K. B. R. ms. 11 047, fo 84 vo s., cité par B. STerchi, «Hugues de Lannoy... », p. 113.

52 W. Paravicini, «Von der Heidenfahrt...», p. 91-130.
} 
idéologiquement soutenus par la Papauté. Quels qu'aient pu être leurs intérêts à participer à la croisade balte, leur geste trouvait justification non seulement dans la tradition postcarolingienne commune à toute la Chrétienté, mais aussi dans la doctrine de Bernard de Clairvaux. Tant qu'il restait des païens dans l'immense espace allant des rives de la mer Baltique aux puissantes principautés russes, la guerre se justifiait en elle-même. La défense et l'expansion de la foi figuraient parmi les principaux motifs des "hôtes» de l'Ordre teutonique. Ces hommes, dont les motivations profondes au plan spirituel ou psychologique nous sont souvent inconnues, faisaient coïncider leur honneur de caste avec le but avoué du voyage. Combattre l'infidèle équivalait à défendre la foi, ce qui était recommandable pour un noble désireux de dorer son blason.

Sur le plan de l'idéologie, les païens de la Baltique sont des infidèles comme tant d'autres. Pourtant, les textes réunis au cours de cette étude montrent qu'une partie au moins des voyageurs ont essayé de connaître ceux qu'ils venaient affronter. Le portrait des Lituaniens que nous ont laissés chroniqueurs, voyageurs ou romanciers répond certes aux impératifs de la construction du récit, puisqu'il s'agissait avant tout de donner aux croisés des adversaires dignes d'eux-mêmes. Néanmoins, force est de constater qu'un Philippe de Mézières, un Jacques d'Esch, un Jean de Chastelmorand ou un Guillebert de Lannoy avaient d'assez bonnes connaissances sur la situation balte pour rapporter quelques impressions des coutumes religieuses des autochtones et de leurs rapports avec les chrétiens. Dans la noblesse française, on savait non seulement que les Lituaniens, les Coures ou les Samogitiens brûlent leurs morts et vénèrent des bois sacrés, mais encore que leurs dirigeants sont capables de conclure des trêves avec les Teutoniques et d'entretenir une amitié toute chevaleresque avec certains officiers de l'Ordre. Ces impressions sont confirmées par les chroniques écrites en Prusse et en Livonie, ce qui laisse entendre que nos témoins se sont renseignés oralement auprès de leurs hôtes.

Quand bien même leur perception des «infidèles" baltes était biaisée - mais quand la perception d'autrui ne l'est-elle pas? -, ces aristocrates partis en croisade faisaient preuve d'une certaine curiosité. Cet effort de compréhension de l'autre n'a rien à envier à celui d'un Barthélemy l'Anglais et d'un Roger Bacon: ces clercs, qui ne se sont vraisemblablement jamais rendu eux-mêmes sur le territoire balte, se sont efforcés de recueillir les témoignages de ceux qui étaient familiers de cette région, pour essayer de comprendre le mode de vie des Prussiens ou des Livoniens. Les connaissances ainsi acquises étaient certes intégrées à des schémas mentaux préexistants, mais le simple fait que l'on trouve mention des Baltes dans un manuscrit composé à Paris ou ailleurs démontre de l'intérêt dont on faisait preuve pour ces lointains «étrangers». Une attention partagée par tous les témoins que nous avons pu convoquer, ecclésiastiques ou aristocrates. La volonté de connaissance des premiers n'a, au fond, rien d'étonnant puisqu'ils devaient, par leur fonction, s'enquérir des progrès de la foi et réfléchir à la manière la plus efficace de la propager. 
Le second cas est plus intéressant. Pour l'essentiel, les hôtes de l'Ordre teutonique allaient en Prusse afin d'être reconnus comme des pairs par les autres nobles et par les hérauts d'armes, lesquels pouvaient accroître leur honneur en diffusant leur renommée loin à la ronde. À priori, les autochtones de la Baltique ne faisaient pas partie de leurs centres d'intérêt. Pourtant, la manière dont certains voyageurs nobles parlent de ceux-ci remet en question l'idée, largement répandue dans l'historiographie, que les croisés ne se souciaient pas de savoir contre qui ils se battaient ${ }^{53}$. Les quelques textes produits par nos chevaliers peuvent, si l'on y prend garde, ouvrir une brèche sur leur manière de voir le monde. Celle-ci apparaît comme bien complexe: le fait que Guillebert de Lannoy dise, dans ses notes de voyage, avoir suivi les Teutoniques dans leur attaque sur le roi de Pologne et le duc de Poméranie simplement parce qu'ils "favorisoient les Sarrasins»" ${ }^{54}$ 'empêche pas le même homme de prêter une attention toute particulière aux coutumes, aux langues, au style vestimentaire des peuples rencontrés sur son parcours. Philippe Buc a sans doute raison de voir dans les croisades l'expression d'une certaine propension à la violence induite par l'idéologie chrétienne, depuis Augustin au moins. Néanmoins, la nécessité d'entraîner l'humanité entière vers le seul vrai Dieu, et l'idée selon laquelle il vaut mieux forcer les réfractaires que les laisser à leurs mauvaises coutumes ${ }^{55}$, n'induit pas nécessairement un combat à mort ni une indifférence ou un dégoût absolu pour ceux qui sont définis comme ennemis.

Il vaut ici la peine de différencier l'idéologie telle qu'exprimée par les nombreux documents normatifs de ce que l'on sait du comportement des acteurs eux-mêmes. L'exemple du seigneur de Lannoy permet de démonter l'impression du croisé brutal, borné et agressif que font ressortir les poèmes didactiques ou les biographies chevaleresques du type du Livre des fais consacré au maréchal Boucicaut. Même ce que l'on sait de ce dernier devrait être considéré avec prudence; au fond, il nous est impossible de savoir ce qu'il se passait dans la tête de ce guerrier professionnel, érigé en archétype littéraire. Le simple fait qu'il ait, à un certain moment de sa carrière, combattu dans les rangs du sultan Murad, en 1388, nous laisse comprendre que sa vision du monde devait être bien plus complexe que ce que nous laisse croire son biographe ${ }^{56}$.

L'histoire de la christianisation des Baltes est, pour reprendre le titre du beau livre de Nils Blomkvist, celle d'une découverte ${ }^{57}$. Terres mal connues autour de l'an mil, presque mythiques, les régions riveraines de la Baltique émergent comme un terrain de mission puis de croisade; clercs et chevaliers participent aux événements, s'informent, prennent position sur la manière dont l'évangélisation

\footnotetext{
53 Par exemple, N. Housley, The Later Crusades..., p. 402.

${ }_{54}$ Potvin, p. 26.

55 À ce sujet, P. Buc, Guerre sainte..., p. 349-352.

${ }^{56}$ Le Livre des Fais..., p. 61-62; N. Housley, "One man and his wars...", p. 33.

57 N. Blomkvist, Discovery...
} 
doit être menée dans cette partie de l'Europe. Au centre des discussions se trouvent les habitants de ces lointaines provinces, ceux à qui l'on doit amener le christianisme. Ce sont eux que l'on entend convertir, et que peu à peu, on est amené à découvrir. Ecclésiastiques comme voyageurs nobles ont tôt fait de leur donner une image cohérente: ce sont des pagani, qui ont leur identité propre. En dépit du qualificatif de "Sarrasins" qu'on leur attribue, on sait qu'ils ne sont pas musulmans, qu'ils n'ont que peu en commun avec les Turcs ou les Maures. Même s'ils jouent un rôle similaire dans l'idéologie de la propagatio et defensio fidei, on sait que tous les infidèles ne se valent pas, qu'ils sont différents les uns des autres. Et qu'aucun d'entre eux n'est irrémédiablement mauvais. Combattus en tant que représentants d'une foi différente, les Lituaniens, les Prussiens, les Lives, les Estoniens, sont néanmoins traités comme des hommes à part entière; doctrine universaliste amenée à s'imposer aux quatre coins du monde, le christianisme ne présuppose pas moins l'égalité de tous devant Dieu ${ }^{58}$.

La connaissance que possédait visiblement un certain nombre de chevaliers occidentaux au sujet des Baltes explique qu'après le baptême des derniers d'entre eux, l'on ait été moins motivé à appuyer l'Ordre teutonique dans un combat désormais dépourvu de charge religieuse et honorifique. Derniers païens de la Baltique, les Lituaniens changent d'image après leur baptême: d'adversaires, ils deviennent fers de lance de la croisade. Une fois devenus chrétiens, ils sont assimilés au modèle dominant de l'Europe médiévale latine; d' «autres" ils deviennent "nôtres», un changement de statut rendu possible par la connaissance qui prévalait à leur sujet. Le christianisme fonctionne certes comme clef d'intégration dans le modèle commun à l'Europe médiévale, mais à elle seule, la religion ne suffit pas: encore faut-il que la conversion soit reconnue et acceptée loin à la ronde. Les efforts de Jagellon et de Vytautas pour faire connaître leurs baptêmes et celui de leur pays sont révélateurs, et le changement est accepté avec rapidité, en dépit de l'obstruction faite par l'Ordre teutonique. En effet, même avant les dates de 1387 puis 1417, les Lituaniens et les Samogitiens étaient loin d'être tout à fait étrangers aux Occidentaux: la reconnaissance de leur statut d'hommes à part entière, de pairs valeureux, avait déjà préparé le terrain à l'acceptation de leur conversion, et par conséquent, l'inutilité d'aller les combattre. Une vingtaine d'années après le baptême officiel de la Lituanie, les rèses disparaissent, devenues superflues: quel intérêt, quel honneur y aurait-il pour un comte anglais ou un seigneur français à aller saccager un pays désormais chrétien? Plus fondamentalement, une fois la question religieuse évacuée, quelle motivation y avait-il à traverser tout un continent pour croiser le fer avec quelqu'un qui partage un même mode de vie, de mêmes valeurs?

Expérience commune à une partie relativement importante de la noblesse occidentale, la croisade balte nous laisse un héritage ambigu et paradoxal. Malgré un schéma idéologique opposant, de manière binaire, un «nous» à un «eux», et

58 N. Housley, Contesting the Crusades, Oxford 2006, p. 160-161. 
ne pouvant se résorber que par la conversion des païens au christianisme - soit la transformation de tous les «eux» en "nous», l'institution du voyage en Prusse a fait découvrir une autre réalité à ceux qui y participaient. Il était certes inimaginable pour un chrétien du $\mathrm{XIV}^{\mathrm{e}}$ siècle d'accepter l'autre dans toute sa différence, de postuler que sa religion puisse être égale au christianisme ${ }^{59}$. Toutefois, ceux qui ont été en contact, même momentané, même superficiel, avec ces "Autres par excellence» qu'étaient les Baltes ont rapidement appris à leur donner un visage, à les sortir de la masse informe des infidèles que mettaient en scène les chansons de gestes et autres romans chevaleresques. Au milieu du choc des épées, du crépitement des flammes, de la fumée des champs que l'on brûle, une pointe d'intérêt pour l'adversaire émergeait. La curiosité, volontiers entretenue par ces représentants de la "zone frontière» qu'étaient les Chevaliers teutoniques, a permis d'atténuer les tensions, d'aller "au-delà des manichéismes» ${ }^{60}$. En s'informant sur ceux qu'ils étaient allés massacrer, certains parmi les hôtes de l'Ordre teutonique faisaient l'effort de les comprendre, de saisir une partie de leur humanité61.

Ici se situe le pivot de notre histoire. La connaissance de l'autre tempère les envies belliqueuses; on a moins envie de combattre quelqu'un que l'on sait nous ressembler ${ }^{62}$. Née dans l'idéologie de l'Église triomphante, de l'absolutisme pontifical, la croisade balte a eu pour effet de donner, sur le long terme, une frontière mentale à l'Europe culturelle, mais aussi, en même temps, de préparer les Européens du Moyen Âge au contact avec des populations différentes au point de ne pas pratiquer une religion du Livre ${ }^{63}$. Dans cette perspective, le legs le plus précieux de notre longue histoire, ou le moment à retenir, se situe au tournant $\mathrm{du} \mathrm{xv}^{\mathrm{e}}$ siècle, lorsque l'on accomplissait le voyage vers la Baltique non plus pour combattre, mais pour découvrir un pays nouveau, des gens jusque-là méconnus: lorsque le mépris et la volonté d'en découdre ont cédé la place à la curiosité, au respect, quand l'ennemi est devenu un partenaire

\footnotetext{
59 Quelques exceptions peuvent toutefois apparaître, notamment en marges de mouvements dissidents; voir par exemple le cas du meunier frioulan du XvI ${ }^{\mathrm{e}}$ siècle étudié par C. Ginzburg, $L e$ Fromage et les Vers, Paris 1980. Fait intéressant, le meunier Menocchio s'appuie notamment sur Jean de Mandeville pour postuler une certaine égalité entre religions chrétiennes et non-chrétiennes (ibid., p. 79-88).

${ }^{60}$ Pour reprendre le titre de la conclusion de T. Todonov, La Peur des barbares. Au-delà du choc des civilisations, Paris 2008, p. 323.

${ }^{61}$ L'auteur de ces lignes a eu le privilège d'aborder ces points avec R. MAŽEIKA dans «Familiar Marvels?...", p. 41-62.

${ }^{62}$ C'est notamment le propos de T. Todorov, La Peur des barbares...

${ }_{63}$ À cet égard, une comparaison avec la situation américaine citée plus haut (voir p. 451) prend tout son sens. Je ne résiste pas au plaisir d'emprunter une dernière citation à l'un de nos grands esprits contemporains, et lui-même un voyageur digne héritier de nos croisés de la Baltique: "Je revivrais donc l'expérience des anciens voyageurs, et à travers elle, ce moment crucial de la pensée moderne où, grâce aux grandes déconvertes, une humanité qui se croyait complète et parachevée reçut tout à coup, comme une contre-révélation, l'annonce qu'elle n'était pas seule, qu'elle formait une pièce d'un plus vaste ensemble, et que, pour se connaître, elle devait d'abord contempler sa méconnaissable image en ce miroir», C. LÉvi-Strauss, Tristes tropiques, Paris 1955, p. 387.
} 




\section{Bibliographie}

\section{SOURCES MANUSCRITES}

Archives de l'État de Neuchâtel:

AEN, Anciennes Archives, U5, n 4 (Testament de Guillaume d'Aarberg, seigneur de Valangin)

Bibliothèque de l'Arsenal, Paris:

Mss. 2682-2683 (Philippe de Mézières, Le Songe du vieil pelerin)

Ms. 3353 (Jean d'Arras, Roman de Mélusine)

Bibliothèque Nationale de France, Paris:

BN fr. 1437 (Armorial des chevaliers de la table ronde)

BN fr. 5230 (Armorial Bellenville)

BN fr. 10132 (continuation de Jean de Saint-Victor, Memoriale historiarum) British Library, Londres:

BL Add. MS 48976 (The Rous Roll)

Burgerbibliothek, Berne:

Mss.h.h.I.1 (Diebold Schilling, Berner Chronik)

Mss.h.h.I.16 (Diebold Schilling, Spiezer Chronik)

Médiathèque d'agglomération de Cambrai:

Ms. 940, nº 100 (Lettre de Charles VI à Ladislas Jagellon)

Sächsische Landesbibliothek-Staats- und Universitätsbibliothek, Dresde:

Mscr. Dresd. Q.133, Nr. 4 (Annales de Quedlimbourg, copie manuscrite par P. Albinus et G. Fabricius, 1550)

\section{SOURCES ÉDITÉES}

$1413 \mathrm{~m}$. Horodles aktai: dokumentai ir tyrinejjimai = Akty horodelskie z 1413 roku (dokumenty i studia), éd. J. Kiaupienè, L. Korczak, P. Rabiej, E. Rimša, J. Wroniszewski, Vilnius \& Cracovie 2013. 
Acta Concilii Constanciensis, éd. H. Finke, J. Hollnsteiner, H. Heimpel, 4 vol., Münster 1896-1928.

Adam de Brême, Histoire des archevêques de Hambourg, trad. J.-B. Brunet-Jailly, Paris 1989.

Adam de Brême, Gesta Hammaburgensis ecclesie pontificum, éd. B. Schmeidler, Hanovre 1917.

Adémar de Chabannes, Chronicon, éd. J. Chavanon, Paris 1897.

Adémar de Chabannes, Chronique, trad. Y. Chauvin, G. Pon, Turnhout 2003. Akta unji Polski z Litwa 1385 - 1791, éd. St. Kutrzeba, W. Semkowicz, Cracovie 1932.

Albéric de Trois-Fontaines, Chronica Albrici monachi Trium Fontium, a monacho Novi Monasterii Hoiensis interpolata, éd. P. Scheffer-Boichorst, MGH Scriptores 23, Hanovre 1874.

André Thevet, Cosmographie moscovite, éd. A. Galitzin, Paris 1863.

Annales Pragensis, suivi de Annales Otakariani, éd. R. Koepke, MGH SS 9, Hanovre 1851.

Annales Quedlinburgenses, éd. M. Giese, MGH SRG 72, Hanovre 2004.

Anonymi Descriptio Europae Orientalis, éd. O. Górka, Cracovie 1916.

Anonymi Descriptio Europae orientalis, éd. et trad. T. Živković, V. Petrović, A. Uzelac, D. Kunčer, Belgrade 2013.

Antoine de La Sale, Jehan de Saintré, éd. J. Blanchard, trad. M. Quereuil, Paris 1995.

Antoine de La Sale, Jean de Saintré: A Late Medieval Education in Love and Chivalry, trad. R. L. Krueger, J. H. M. Taylor, Philadelphia 2014.

Antoine de La Sale, Antoine de la Salle: sa vie et ses ouvrages d'après des documents inédits, suivi du "Réconfort de madame du Fresne», éd. J. Nève, ParisBruxelles 1903.

Antoine de la Sale, Euvres complètes, vol. 1, éd. F. Desonay, Paris-Liège 1935.

Antonio Bonfini, Rerum Ungaricarum, Francfort 1581.

Armorial Bellenville, éd. M. Pastoureau, M. Popoff, Lathuile 2004.

Armorial de Gelre, éd., M. Pastoureau, M. Popoff, Paris 2012.

Armorial des chevaliers de la table ronde, éd. M. Pastoureau, Paris 1983.

"Aus Handschriften", éd. W. Wattenbach, Neues Archiv der Gesellschaft für dältere deutsche Geschichtskunde 7, 1882.

Baltu Religijos ir Mitologijos Šaltiniai, éd. N. Vèlius, Vilnius 1996.

Barthélemy l'Anglais, Le Grand Propriétaire de touttes choses, trad. J. Corbechon, éd. P. Farget, Paris 1556.

Barthélemy l'Anglais, Le Livre des propriétés des choses: une encyclopédie au XIV siècle, trad. J. Corbechon, éd. B. Ribémont, Paris 1999. 
Baudouin de Condé, Dits et contes de Baudouin de Condé et de son fils Jean, éd. A. Scheler, 3 vols., Bruxelles 1866-1867.

Benoît de Sainte-Maure, Le Roman de Troie, éd. et trad. E. Baumgartner, F. Vieillard, Paris 1998.

Die Berichte der Generalprokuratoren des Deutschen Ordens an der Kurie, 4 vols., éd. K. Forstreuter, H. Koeppen, Göttingen 1960-1976.

Beowulf: L'épopée fondamentale de la littérature anglaise, éd. J. Queval, Paris, Gallimard, 1981.

Blaise de Vigénère, Description du Royaume de Pologne et pays Adjacens, Paris 1573.

Blaise de Vigénère, Chroniques et Annales de Pologne, Paris 1573.

Boccace, Le Décaméron, trad. C. Bec, M. Dozon, C. Guimbard, M. Scialom, Paris 1994.

Boccace, Le Décaméron, 2 vols., éd. V. Branca, Turin 1980.

Book of knowledge of all the kingdoms, lands, and lordships that are in the world, éd. et trad. C. R. Markham, Londres 1912.

Bruno d'Olomouc, Relationes Episcopi Olomucensis Pontifici Porrectae, éd. J. Schwalm, MGH Const. 3, Hanovre 1906.

Bullarium Danicum Pavelige Aktstykker vedrørende Danmark 1198-1316, éd. A. Krarup, Copenhague 1932.

Bullarium Poloniae: litteras apostolicas aliaque monumenta Poloniae Vaticana continens, 7 vol., éds. I. Sułkowska-Kuraś, S. Kuraś, M. Kowalczyk, A. et H. Wajs, Rome-Lublin, 1982-2006.

"Campagne de Boucicault en Prusse», Bibliothèque de l'École des chartes, 38, 1877, p. 491-492.

Le Canarien - Crónicas francesas de la conquista de Canarias, 3 vols., éd. E. Serra, A. Cioranescu, La Laguna de Tenerife 1959-1965.

La Chanson de Roland, éd. C. Segre, M. Tyssens, B. Guidot, vol. 1, Genève 2003.

La Chanson de Roland, éd. et trad. P. Jonin, Paris 1979.

Charles IV de Luxembourg, Vita Karoli, éd. et trad. P. Monnet, J.-C. Schmitt, Paris 2010.

Chartularium Lithuaniae res gestas magni duci Gedeminne illustrans, éd. S. C. Rowell, Vilnius 2003.

Les Cent Nouvelles Nouvelles, éd. F. P. Sweetser, Genève 1966.

Les Cent Nouvelles Nouvelles, éd. P.-L. Jacob, Paris 1858.

Chronicque de la traïson et de la mort de Richart deux roy Dengleterre, éd.

B. Williams, Londres 1846.

Chronique des Quatre Premiers Valois, éd. S. Luce, Paris 1862. 
Chronique du Religieux de Saint-Denis, 6 vols. éd. L. Bellaguet, Paris 1839-1852. The Chronicle of Novgorod. 1016-1471, éd. R. Michel, N. Forbes, Londres 1914. Cleriadus et Meliadice, éd. G. Zink, Genève 1984.

Codex Diplomaticus Ecclesiae Cathedralis necnon Dioeceseos Vilnensis, vol. 1, éd. J. Fijalek, W. Semkowicz, Cracovie 1932.

Codex Diplomaticus Lithuaniae, éd. E. Raczyński, Wrocław 1845.

Codex Diplomaticus Maioris Poloniae = Kodeks dyplomatyczny wielkopolski, 10 vols., éd. I. Zakrzewski, F. Piekosiński, J. Kraszewski, W. Lebinski, A. Gąsiorowski, R. Walczak, T. Jasinski, Poznań \& Varsovie, 1877-1990.

Codex Diplomaticus Poloniae quo continentur Privilegia, vol. 1, éd. L. Rzyszczewski et. al., Varsovie 1847.

Codex Diplomaticus Prussicus. Urkunden-Sammlung zur älteren Geschichte Preussens aus dem Königl. Geheim-Archiv zu Königsberg nebst Regesten, 6 vols., éd. J. Voigt, Königsberg 1836-1861.

Codex Diplomaticus Regni Poloniae et Magni Ducati Lithuaniae, éd. M. Dogiel, Vilnius 1754-1759.

Codex Diplomaticus Universitatis studii generalis Cracoviensis, éd. F. C. Skobel, vol 1, Cracovie 1870.

Codex Epistolaris Saeculi Decimi Quinti, 3 vol., éd. A. Sokolowski, S. Szujski, A. Lewicki, Cracovie 1876-1894.

Codex Epistolaris Vitoldi, éd. A. Prochaska, Cracovie 1882.

Codex Mednicensis Seu Samogitae Diocensis, éd. P. Jatulis, Rome 1984.

Conrad Justinger, Berner Chronik, éd. E. Stierlin, J. R. Wyss, Berne 1819.

Coudrette, Mélusine (Roman de Parthenay ou Roman de Lusignan), éd. et trad. M. W. Morris, Jean-Jacques Vincensini, Lewiston 2009.

The Council of Constance: the Unification of the Church, trad. L. R. Loomis, J. H. Mundy, K. M. Moody, New York 1961.

La deffaicte des Tartares et Turcs faicte par le seigneur Jean Zamoïky, chancelier et capitaine général de la couronne de Pologne, éd. K. Sienkiewicz, Paris 1859.

Deutsche Liederdichter des 13. Jahrhunderts. T. 1, éd. C. von Kraus, Tübingen 1952 (réimpr. 1978).

Diplomatarium Danicum. Raekke 1, éd. C. A. Christiansen et al., Copenhague 1958-1990.

Eginhard, Vie de Charlemagne, éd. et trad. M. Sot et al., Paris 2014.

Énée Sylvio Piccolomini, Europe (c. 1400-1458), trad. R. Brown, N. Bisaha, Washington 2013.

Énée Sylvio Piccolomini, Mémoires d’un pape de la Renaissance. Les Commentarii de Pie II, trad. I. Cloulas, V. Catsiglione Minischetti et al., Paris 2001.

Enguerrand de Monstrelet, Chroniques, 8 vols., éd. J. A. Buchon, Paris 1826. 
Enguerrand de Monstrelet, Chronique: en deux livres, avec pièces justificatives: 1400-1444, 6 vols., éd. L. Douët d'Arcq, Paris 1857-1862.

Erasme de Rotterdam, La Formation du prince chrétien. Institutio principis christiani, éd., trad. et introduction de M. Turchetti, Paris 2015.

Eulogium historiarum sive temporis..., vol. 3, éd. F. S. Haydon, Londres 1863.

Eustache Deschamps, Euvres complètes, 11 vols., éd. A. Queux de Saint Hilaire, G. Raynaud, Paris 1878-1903.

Expeditions to Prussia and the Holy Land made by Henry, earl of Derby (afterwards King Henry IV), in the years 1390-1391 and 1392-1393, being the accounts kept by his treasurer during two years, éd. L. Toulmin Smith, Londres 1894.

Fontes Rerum Bohemicarum, vol. 4, éd. J. Emler, Prague 1874.

Fontes Historiae Latviae Medii Aevi, 2 vols., éd. A. Švābe, Riga 1937-1940.

François Bauduin, Histoire des Roys et Princes de Pologne, Paris 1573.

François de Belleforest, La Cosmographie Universelle de tout le Monde, Paris 1575.

François Vinchant, Annales de la Province et Comté du Hainaut, vol. 4, Mons 1860.

The Galician-Volynian Chronicle, éd. G. A. Perfecky, Munich 1973.

Gallus Anonymus, Gesta Principum Polonorum: The Deeds of the Princes of the Poles, éd. et trad. P. W. Knoll, F. Schaer, Budapest 2003.

Gaston Fébus, Livre de Chasse, éd. G. Tilander, Karlshamn 1971.

Gedimino Laiskai (Poslanija Gedimina), éd. V. Pašuto, I. Stal', Vilnius 1966.

Geoffrey Chaucer, Les Contes de Canterbury et autres ouvres, éd. et trad. A. Crépin et al., Paris 2010.

Geoffroi de Charny, The Book of Chivalry, éd. et trad. R. W. Kaeuper, E. Kennedy, Philadelphia 1996.

La Geste du Prince Igor, trad. C. Pighetti, Paris 2005.

Gervais de Tilbury, Otia imperialia: recreation for an emperor, éd. et trad. S. E. Banks, J. W. Binns, Oxford 2002.

Gilles Le Bouvier, Le Livre de la description des pays de Gilles le Bouvier, dit Berry, éd. E.-T. Hamy, Paris 1908.

Le Grand Armorial équestre de la Toison d'or, 2 vols., éd. M. Pastoureau, Michel Popoff, Saint-Jorioz 2001.

Les Grandes chroniques de France, éd. J. Viard, vols. 7 à 9, Paris 1932-1937.

La Guerre de Metz en 1324, éd. E. de Bouteiller, Paris 1875.

Guillaume d'Egmond, Willelmi Capellani in Brederode postea Monachi et Procuratoris Egmondensis Chronicon, éd. C. Pijnacker Hordikj, Amsterdam 1904.

Guillaume de Machaut, La Prise d'Alexandre, éd. S. Hardy, Orléans 2011 (thèse de doctorat non publiée). 
Guillaume de Machaut, La Prise d'Alexandre, éd. M.-L. de Mas Latrie, Genève 1877.

Guillaume de Machaut, Euvres, 3 vols., éd. E. Hoepffner, Paris 1908-1921.

Guillaume de Machaut, Poèsies lyriques, éd. V. Chichmarev, 2 vols., Genève 1973.

Guillaume de Rubrouck, Jean de Plan Carpin, The Texts and Versions of John de Plano Carpini and William de Rubruquis, éd. C. Raymond Beazley, Londres 1903.

Guillaume de Rubrouck, Marco Polo, Deux voyageurs en Asie au XIIf siècle: Guillaume de Rubruquis et Marco Polo, éd. E. Muller, P. Bergeron, Paris 1888.

Guillebert de Lannoy, Cesty a poselstva, éd. et trad. J. Svátek, M. Nejedlý, O. Marin, P. Soukup, Prague 2009.

Guillebert de Lannoy, Guillebert de Lannoy et ses voyages en 1413, 1414 et 1421, éd. J. Lelewel, Poznań-Bruxelles 1844.

Guillebert de Lannoy, Euvres de Ghillebert de Lannoy, voyageur, diplomate et moraliste, éd. C. Potvin, Louvain 1878.

Hanserecesse Abt. 1, Bd. 1-8, éd. Karl Koppmann, Leipzig 1870-1897.

Hélinand de Froidmont, Flores Helinandi, dans Patrologia latina, vol. 212 [en ligne sur www.mlat.uzh.ch].

Helmold de Bosau, Chronica Slavorum, éd. G. Pertz, Hanovre 1866.

Henri de Herford, Liber de rebus memorabilioribus sive Chronicon Henrici de Hervordia, éd. A. Potthast, Göttingen 1859.

Henri Knighton, Knighton's Chronicle. 1337-1396, éd. et trad. G. H. Martin, Oxford 1995.

Henri de Livonie, Chronicle, trad. J. Brundage, New York 2004.

Henri de Livonie, Heinrichs Livländische Chronik (Heinrici Chronicon Livoniae), éd. L. Arbusow, A. Bauer, MGH SRG 31, Hanovre 1955.

Henri le Teichner, Die Gedichte Heinrichs des Teichners, 3 vols., éd. H. Niewöhner, Berlin 1953-1956.

Hérodote, Thucydide, Euvres complètes, éd. et trad. A. Barguet, D. Roussel, Paris 1964.

Humbert de Romans, Opusculum Tripartitum, dans Fasciculum Rerum Expentendarum et Fugiendarum (Appendix), éd. E. Brown, Londres 1690.

Humbert de Romans, De Predicatione Crucis, éd. V. Portnykh, Turnhout 2018. Index actorum saeculi decimi quinti $X V$ ad res publicas Poloniae spectantiumin “Codice epistolari saeculi XV”, éd. A. Lewicki, Cracovie 1888.

Itinéraires de Philippe le Hardi et de Jean sans Peur, ducs de Bourgogne (13631419), d'après les comptes de leur hôtel, éd. E. Petit, Paris 1888. 
Jacques d'Esch, Die Metzer Chronik des Jaique Dex über die Kaiser und Könige aus dem Luxemburger Hause, éd. G. Wolfram, Metz 1906.

Jacques Lenfant, Histoire du Concile de Constance, 2 vols., Amsterdam 1714 .

Jacques de Voragine, Legenda aurea con la miniatura del codice Ambrosiano C 240 inf., 2 vols., éd. G. P. Maggioni, trad. G. Agosti et al., Florence 2007.

Jan Długosz, Annals, trad. et abr. M. Michael, Chichester 1997.

Jan Długosz, Opera Omnia, 15 vols., éd. Ż. Pauli, A. Przezdziecki, Cracovie 1863-1887.

Jean d'Arras, Mélusine ou la noble histoire de Lusignan, éd. et trad. J.-J. Vincensini, Paris 2003.

Jean le Bel, Chronique, 2 vols., éd. J. Viard, E. Déprez, Paris 1904-1905.

Jean Bodel, La Chanson des Saxons, éd. F. Menzel, E. Stengel, vol. 1, Marbourg 1906.

Jean Brandon, Chronodromon, éd. J. Kervyn de Lettenhove, Chroniques relatives à l'histoire de Belgique sous la domination des ducs de Bourgogne, vol. 1, Bruxelles 1870 .

Jean Cabaret d'Orville, Chronique de Savoye, éd. D. Chaubet, Chambéry 2006.

Jean Cabaret d'Orville, Chronique du bon duc Loys de Bourbon, éd. A.-M. Chazaud, Paris 1876.

Jean le fèvre, Chronique, éd. F. Morand, vol. 1, Paris 1876.

Jean Froissart, Chroniques, 15 vols., éd. S. Luce, G. Raynaud, L. et A. Mirot, Paris 1869-1975.

Jean Froissart, Chroniques, dans Euvres complètes, vols. 2 à 25, éd. J. Kervyn de Lettenhove, Bruxelles 1867-1877.

Jean Gerson, Acta in Consilio Constantiensi, dans Opera Omnia, vol. 5, éd. L. Ellies du Pin, La Haye 1728.

Jean de la Gogue, Histoire des princes de Deols, seigneurs de Chasteau-Raoulx, éd. A. Grillon des Chapelles, dans Esquisses biographiques du département de l'Indre, vol. 3, Paris 1865.

Jean Juvénal des Ursins, Histoire de Charles VI, éd. A. Pacard, Paris 1614.

Jean de Mandeville, Voyage autour de la Terre, trad. C. Deluz, Paris 1993.

Jean de Mandeville, Le livre des merveilles du monde, éd. C. Deluz, Paris 2000.

Jean d'Outremeuse, Ly Myreur des Histors. Chronique et geste de Jean des Preis dit d'Outremeuse, éd. S. Bormans, vol. 6, Bruxelles 1880.

Jean Petit, Les condicions qui sont requises à l'enfant d'un seigneur à estre droit gentilz, v. 2858-2859, dans Le Livre du champ d'or et autres poèmes inédits, éd. P. Le Verdier, Rouen 1895.

Jean de Plan Carpin, Dans l'Empire mongol, trad. T. Tanase, Toulouse 2014. Jean de Plan Carpin, Storia dei Mongoli, éd. et trad. E. Menestò, M. C. Lungarotti et al., Spoleto 1989. 
Jean de Stavelot, Chronique, éd. A. Borgnet, Bruxelles 1861.

Jean de Victring, Iohannis abbatis Victoriensis liber certarum historiarum, éd. F. Schneider, vol. 2, MGH SS 36, Hanovre 1910.

Jean de Wavrin, Anchiennes cronicques d'Engleterre, éd. É. Dupont, 3 vols., Paris 1858-1863.

Jean de Winterthour, Die Chronik Johanns von Winterthur, éd. F. Baethgen, Berlin 1924.

Jean de Winterthour, Die Chronik Johann's von Winterthur, trad. B. Kreuler, Winterthour 1866.

Jean de Würzburg, Wilhelm von Osterreich aus der Gothaer Handschrift, éd. E. Regel, Berlin 1906.

John Capgrave, The Chronicle of England, éd. F. C. Hingeston, Londres 1858. John Gower, Complete Works, 4 vols., éd. G. C. Macaulay, Oxford 1899-1902. John Rous, The Rous Roll. With an historical introduction éd. C. Ross, Gloucester 1980.

Jordanès, Histoire des Goths, trad. O. Devillers, Paris 1995 (rééd. 2004).

Jordanès, Romana et Getica, éd. T. Mommsen, Munich 1882.

Khronika Bykhovtsa, éd. N. N. Ulaszczik, Moscou 1966.

Liber Cancellariae Stanislae Ciotek: ein Formelbuch der polnischen Königskanzlei aus der Zeit der Husitischen Bewegung, vol. 1-2., éd. J. Caro, Vienne 1871.

Lites ac res gestae inter Polonos Ordinemque Cruciferorum: akta postępowania przed Antonim z Mediolanu w latach 1422-1423, éd. S. Jóźwiak, A. Szweda, S. Szybkowski, Toruń 2015.

Lites ac res gestae inter Polonos ordinemque Cruciferorum, éd. H. Chłopocka, Varsovie 1970.

Lites ac res gestae inter Polonos Ordinemque Cruciferorum, éd. I. Zakrzewski, J. Karwasinska, 3 vol., Poznań \& Varsovie 1890-1935.

Liv-Esth- und Kurländisches Urkundenbuch, 14 vols., éd. F. G. von Bunge, H. Hildebrand, Tallinn 1853-1914.

Livländische Reimchronik, éd. L. Meyer, Padeborn 1876.

Livländische Reimchronik, éd. F. Pfeiffer, Stuttgart 1844.

The Livonian Rhymed Chronicle, trad. W. Urban, J. Smith, Chicago 2001.

Le Livre des Fais du bon messire Jehan le Meingre dit Boucicquaut, mareschal de France et gouverneur de Jennes, éd. D. Lalande, Genève 1985.

Lucas David, Preussische Chronik, éd. E. Hennig, vol. 7, Königsberg 1815.

Maciej Stryjkowski, Kronika polska, litewska, zmodzka i wszystkiej Rusi, éd. M. Malinowski, vol. 1, Varsovie 1846. 
Magnum Oecumenicum Constantiense, vol. 4: Rerum Concilii Constantiensis, éd. H. von der Hardt, Francfort 1699.

Marino Sanudo, Secretum Fidelium Crucis, Lib. 1, part. V, chap. 1, éd. J. Bongars, Gesta Dei per Francos, vol. 2, Hanovre 1611.

Mathieu d'Escouchy, Chronique, éd. G. du Fresne de Beaucourt, vol. 2, Paris 1863.

Matthieu Paris, Grande Chronique, vol. 5 et 6, trad. A. Huillard-Bréholles, Paris 1840.

Mittelalterliche Handschriften der Universitätsbibliothek Uppsala: Katalog über die C-Sammlung, éd. M. Andersson-Schmitt, H. Hallberg, M. Hedlund, vol. 1, Stockholm 1988.

Monumenta Poloniae Historica, nova series 7/2, éd. J. Wikarjak, K. Liman, Varsovie 1969.

Monumenta vaticana res gestas Bohemicas illustrantia, éd. L. Klicman, vol. 1, Prague 1903.

Muhammad Al-Idrīsī, Livre de la récréation de l'homme désireux de connaître les pays, 2 vols., trad. P. A. Jaubert, Paris 1836-1840.

Nicolas de Jeroschin, The Chronicle of Prussia. A History of the Teutonic Knights in Prussia, 1190-1331, trad. M. Fischer, Aldershot 2011.

Olivier de Paderborn, Die Schriften des Kölner Domscholasters, späteren Bischofs von Paderborn und Kardinal-Bischofs von S. Sabina Oliverus, éd. H. Hoogeweg, Tübingen 1894.

Pageant of the birth, life and death of Richard Beauchamp, Earl of Warwick, K.G., 1389-1439, éd. J. Hope, H. Dillon, Londres 1914.

Paul Vladimiri, Pisma Wybrane Pawta Wtodkowica = Works of Paul Wladimiri (a selection), éd. L. Ehrlich, Varsovie 1968.

Philippe de Mézières, Le Songe du viel pelerin, 2 vol., éd. J. Blanchard, Genève 2015.

Philippe de Mézières, Le Songe du vieil pèlerin, trad. J. Blanchard, Paris 2008.

Philippe de Mézières, Une Epistre lamentable et consolatoire, éd. P. Contamine, J. Paviot, Paris 2008.

Philippe de Mézières, The Order of the Passion: an annotated edition, éd. M. J. A. Brown, Lincoln, Nebraska 1971 (thèse de doctorat non publiée).

Philippe de Mézières, Le Songe du vieil pelerin, 2 vols. éd. G. W. Coopland, Cambridge 1969.

Pierre Damien, Petri Damiani vita beati Romualdi, éd. G. Tabacco, Rome 1957.

Pierre de Dusbourg, Chronik des Preussenlandes, éd. et trad. K. Scholz et D. Wojtecki, Darmstadt 1984.

Pierre de Dusbourg, Kronika ziemi pruskiej, trad. S. Wyszomirski, J. Wenta, Toruń 2005. 
Pierre de Dusbourg, Kronika ziemi pruskiej, éd. J. Wenta, S. Wyszomirski, Cracovie 2007.

Pierre de Dusbourg, Cronaca della terre di Prussia, éd. et trad. P. Bugiani, Spoleto 2012.

Pierre Guillaume, Petri Guillelmi Miracula beati Egidii, éd. G. Pertz, MGH SS 12, Hanovre 1856.

Pierre Suchenwirt, Peter Suchenwirt's Werke aus dem 14. Jahrhundert, éd. A. Primisser, Vienne 1827.

Pierre le Vénérable, Letters of Peter the Venerable, 2 vol., éd. G. Constable, Cambridge, Mass. 1967.

Pline l'Ancien, Histoire naturelle: Livre IV, éd. et trad. H. Zehnacker et A. Silberman, Paris 2005.

Pline l'Ancien, The Natural History, 6 vols., trad. J. Bostock, Londres 1855-1857.

Polski wyktad prawa wojny xv wieku: kazanie Stanistawa ze Skarbimierza De bellis iustis, éd. L. Ehrlich, Varsovie 1955.

Pommersches Urkundenbuch, vol. 4/2, éd. G. Winter, Szczecin 1903.

Pomponius Mela, Cosmographie, éd. et trad. L. Baudet, Paris 1843.

Preussisches Urkundenbuch, vol. I, 1, éd. R. Philippi, Königsberg 1882.

Quellen zur Geschichte des Deutschen Ordens, éd. W. Hubatsch, Göttingen 1954.

Raoul Glaber, Histoires, éd. et trad. M. Arnoux, Turnhout 1999.

Rationes Curiae Vladislai Jagielli $=$ Rachunki dworu Króla Wladyslawa Jagielly, éd. F. Piekosinski, Cracovie 1896.

Register Papst Innocenz' III über den deutschen Thronstreit, 2 vol., éd. W. Holtzmann, Bonn 1947-1948.

Regesta Norvegica, vol. 1, éd. E. Gunnes, Oslo 1989.

Regesten zur Geschichte der Slaven an Elbe und Oder (vom Jahr 900 an), éd. C. Lübke, 5 vol., Berlin 1984-1988.

Rimbert, Vita Anskarii auctore Rimberto, éd. G. Waitz, Hanovre 1884.

Robert le Moine, Histoire de la première croisade, dans M. Guizot, Collection des mémoirs relatifs à l'histoire de France, vol. 24, Paris 1825.

Roger Bacon, Opus Maius, éd. J. H. Bridges, 3 vol., Oxford 1897-1900, rééd. Frankfurt am Main 1964.

Roger Bacon, Opus Maius, trad. R. B. Burke, Philadelphie \& Londres 1928.

Le Roman d'Eneas, éd. et trad. A. Petit, Paris 1997.

Le Roman en prose de Tristan, éd. E. Löseth, Genève 1974.

Die sogenannte Rufuschronik, dans Die Chroniken der Niedersächsischen Städte: Lübeck, éd. C. Hegel, K. Koppman, vol. 3, Leipzig 1902. 
Saints of the Christianisation of Central Europe (Tenth-Eleventh Centuries), éd. G. Klaniczay, Budapest 2012.

Samuel Guichenon, Histoire généalogique de la royale maison de Savoie, vol. 1, Lyon 1660.

Saxo Grammaticus, Gesta Danorum, éd. K. Friis-Jensen, trad. P. Fischer, Oxford 2005.

Scriptores Rerum Prussicarum. Die Geschichtsquellen der preußischen der preußischen Vorzeit bis zum Untergang der Ordensherrschaft (SRP), 6 vols., éd. T. Hirsch, M. Töppen, E. Strehlke, W. Hubatsch, Leipzig 1861-1968.

Sebastian Münster, La cosmographie universelle: contenant la situation de toutes les parties du monde, Bâle 1552.

Solin, Polyhistor, 16, éd. et trad. M. Agnant, Paris 1847.

Skarbiec diplomatów papiezkich, cesarskich, krolewskich, ksiażęcych..., 2 vols., éd. I. Daniłowicz, Vilnius 1860-1862.

Die Staatsschriften des Deutschen Ordens, vol. 1, éd. E. Weise, Göttingen 1970.

Die Staatsverträge des Deutschen Ordens in Preußen im 15. Jahrhundert, 3 vol., éd. E. Weise, Königsberg 1939-1969.

Die Statuten des Deutschen Ordens nach den aeltesten Handschriften, éd. M. Perlbach, Halle 1890.

Suétone, Vies des douze Césars, éd. et trad. H. Ailloud, Paris 1989.

Tabulae Ordinis Theutonici, éd. E. Strehlke, Berlin 1869.

Tacite, La Germanie, éd. et trad. J. Perret, Paris 1949.

Thietmar de Mersebourg, Chronicon, éd. R. Holtzmann, W. Trillmich, Darmstadt 1974.

Thomas de Cantimpré, Bonum universale de apibus, éd. G. Colvenerius, Douai 1627.

Thomas Gray, Scalacronica, éd. A. King, Woodbridge 2005.

Thomas Walsingham, The Chronica Maiora, 2 vols., éd. et trad. J. Taylor, W. R. Childs, L. Watkiss, Oxford 2003-2011.

Thomas Walsingham, The Chronica Maiora, trad. D. Preest, J. C. Clark, Woodbridge 2005.

Thomas III de Saluces, Il libro del Cavaliere errante (BnF ms. fr. 12559), éd. M. Piccat, Boves 2008.

Thomas III de Saluces, Le Chevalier errant, trad. D. Chaubet, Turin 2001.

Ulrich de Richental, Chronik des Konzils zu Konstanz. Faksimile der Konstanzer Handschrift, éd. J. Klöcker, Darmstadt 2015.

Ulrich de Richental, Chronik des Constanzer Concils, éd. M. R. Buck, Hilesheim etc. 2004. 
Vetera monumenta Poloniae et Lithuaniae ..., 4 vol., éd. A. Theiner, Rome 1860-1864.

Vincent de Prague, Annales, éd. W. Wattenbach, MGH SS 17, Hanovre 1861.

Vita Adalberti Prior, éd. J. Karwasinska, Varsovie 1962.

Voyageurs arabes, textes traduits, présentés et annotés par P. Charles-Dominique, Paris 1995.

Watriquet de Couvin, Dits, éd. A. Scheler, Bruxelles 1868.

The Westminster Chronicle, éd. et trad. L. C. Hector, B. F. Harvey, Oxford 1982.

Das Zeugenverhör des Franciscus de Moliano (1312), éd. A. Seraphim, Königsberg 1912.

\section{LITTÉRATURE}

Aeschbacher, Paul, Die Grafen von Nidau und ihre Erben, Bienne 1924.

Agrigoroaei, Vladimir, "Bazgazul, seigneur de Ballaquie. À la recherche du valaque musulman de steppe», Studia Patzinaka 4, 2007, p. 195-218.

Aleksandravičiūté, Aleksandra "Research into the Sacral Art of Lithuania: General Trends and Specific Aspects", Acta historiae atrium Balticae 1, 2005, p. 26-38.

Aleksiun, Natalia, et. al., Histoire de l'Europe du Centre-Est, Paris 2004.

Ališauskas, Vytautas (dir.) Dzieje Chrześcijaństwa na Litwie, trad. Panstwowy Instytut Wydawniczy, Varsovie 2014.

AnrooIJ, Wim van, "Heralds, knights and travelling», E. Kooper (dir.), Medieval Dutch Literature in its European Context, Cambridge 1994, p. 46-61.

Antoche, Emanuel Constantin, «Expéditions de Nicopolis et de Varna: une comparaison (part. 1)", Analele Universitatii Dunarea de Jos din Galati. Istorie 3, 2004, p. 47-78.

Antoche, Emanuel Constantin, «Expéditions de Nicopolis et de Varna: une comparaison (part. 2)", Analele Universitatii Dunarea de Jos din Galati. Istorie 4, 2005, p. 91-113.

Arbois de Jubainville, Henri d', «L'Ordre teutonique en France», Bibliothèque de l'école des chartes 32, 1871, p. 63-83.

Arbusow, Leonid, "Die mittelalteriche Schriftüberlieferung als Quelle für die Frühgeschichte der ostbaltischen Völker», Baltische Lande 1, 1939, p. 167-203.

Ashcroft, Jeffrey, «Konrad's Rolandlied, Henry the Lion, and the Northern Crusade», Forum for Modern Language Studies 22, 1986, p. 184-208.

Aurell, Martin, Girbea, Catalina (dirs.), Christianisme et chevalerie, Rennes 2011. 
Aurell, Martin, Des chrétiens contre les croisades, Paris 2013.

Autrand, Françoise, Charles VI, Paris 1986.

BABICZ, Jozef, «Le cardinal Fillastre (1347-1428), rédacteur présumé de la carte utilisée pendant le procès polono-teutonique", Communication au $12 e$ Congrès d'Histoire de la Cartographie, Paris 1987, p. 1-10.

Balard, Michel, «Les Républiques Maritimes italiennes», dans R. BlumenfeldKosinski, K. Petкov (dirs.), Philippe de Mézières and his Age. Piety and Politics in the Fourteenth Century, Leiden \& Boston 2012, p. 271-282.

Baltrusaitis, Jurgis, Lithuanian Folk Art, Munich 1948.

Baranauskas, Tomas, "On the Origin of the Name of Lithuania", Lituanus 55/3, 2009, p. 28-36.

Baranauskas, Tomas, "Saxo Grammaticus on the Balts», dans T. Nyberg (dir.), Saxo Grammaticus and the Baltic Region, Odense 2004, p. 63-79.

BaranausKienĖ, Inga, "Survila ir Survilaičiai - dar kartą apie nepripažintus Kęstučio palikuonis", Istorija 99/3, 2015, p. 18-33.

BARnwell, Timothy M., "Fragmented identities: otherness and authority in Adam of Bremen's History of the Archbishops of Bremen", dans C. Gantner, R. McKitterick, S. Meeder (dir.), The Ressources of the Past in Early Medieval Europe, Cambridge 2015, p. 206-224.

Barnwell, Timothy M., Missionaries and Changing Views of the Other from the Ninth to the Eleventh Centuries, Leeds 2011 (thèse de doctorat non publiée).

Baronas, Darius, Rowell, Stephen C., The Conversion of Lithuania: from Pagan Barbarians to Late Medieval Christians, Vilnius 2015.

Baronas, Darius, "Christians in Late Pagan, and Pagans in Early Christian Lithuania", Lithuanian Historical Studies 19, 2014, p. 51-81.

Baronas, Darius, "The year 1009: St Bruno of Querfurt between Poland and Rus'", Journal of Medieval History 34, 2008, p. 1-22.

Baronas, Darius, "Kestucio pabegimas is Marienburgo", Lietuvos istorijos studijos 11, 2003, p. 23-33.

Bartlett, Robert, "Heartland and Border: The Mental and Physical Geography of Medieval Europe», dans H. PryCE (dir.), Power and Identity in the Middle Ages, Oxford 2007, p. 23-36.

Bartlett, Robert, "The Conversion of a Pagan Society in the Middle Ages", History 70, 1985, p. 185-201.

Bartlett, Robert, The Making of Europe. Conquest, Colonization, and Cultural Change, 950-1350, Londres 1994.

Bataille, Jules, Cysoing, les seigneurs, l'abbaye, la ville, la paroisse, Lille 1934.

BAtely, Janet, "Wulfstan's Voyage and his description of Estland: the text and the language of the text", dans A. Englert, A. Trakadas (dirs.), Wulfstan's Voyage, Roskilde 2009, p. 14-28. 
Bazaraite, Egle, Heitor, Teresa, "Comparative Study of Christian and Pagan Burial Constructions", Mosklas - Lietuvos Ateitis / Science - Future of Lithuania 5/3, 2013, p. 316-321.

Beaune, Colette, "Mourir noblement à la fin du Moyen Âge», dans La mort au Moyen Âge. Actes des congrès de la Société des historiens médiévistes de l'enseignement supérieur public, Ge congrès, Strasbourg 1975, p. 125-144.

Beauvois, Daniel, "Les controverses historiographiques autour de l'UkraineRuthénie (France, Russie, Pologne)", dans N. Aleksiun et. al., Histoire de l'Europe du Centre-Est, Paris 2004, p. 643-666.

Bechmann, Roland, Des arbres et des hommes: La forêt au Moyen Âge, Paris 1984.

Belch, Stanislaus F., Paulus Vladimiri and his doctrine concerning international law and politics, 2 vol., Londres \& La Haye 1965.

Benninghoven, Friedrich, "Zur Technik spätmittelalterlicher Feldzüge im Ostbaltikum " Zeitschrift für Ostforschung 19, 1970, p. 631-651.

Benninghoven, Friedrich, Der Orden der Schwertbrüder: Fratres milicie Christi de Livonia, Cologne 1965.

Berend, Nora, Urbańczyk, Przemysław, Wiszewski, Przemysław (dirs.), Central Europe in the High Middle Ages. Bohemia, Hungary and Poland, c.900-c.1300, Cambridge 2013.

Berend, Nora, Christianization and the Rise of Christian Monarchy. Scandinavia, Central Europe and Rus'c. 900-1200, Cambridge 2009.

Berend, Nora, At the Gate of Christendom. Jews, Muslims and 'Pagans' in Medieval Hungary, c.1000-c.1300, Cambridge 2006.

Berend, Nora, "Défense de la Chrétienté et naissance d'une identité. Hongrie, Pologne et péninsule Ibérique au Moyen Âge», Annales. Histoire, Sciences Sociales 58/5, 2003, p. 1009-1027.

Berend, Nora, "Frontiers", dans H. Nicholson (dir.), Palgrave Advances in the Crusades, Basingstoke 2005, p. 148-171.

Beresnevicius, Gintaras, "Religious Reforms of the Balts", dans J. Trinkunas (dir.), Of Gods and Holidays. The Baltic Heritage, Vilnius 1999, p. 56-61.

Berger, Olivier, "José Cubero, La femme et le soldat, viols et violences de guerre du Moyen Âge à nos jours", Revue historique des armées [En ligne], 270 | 2013.

Bernheimer, Richard, "The Martyrdom of Isaiah», The Art Bulletin 34/1, 1952, p. 19-34.

Bertasius, Mindaugas, "Horse Graves, Sacrifice, and the Performers of Public Rituals», Archeologia Baltica 11, 2009, p. 305-313.

Bertrand, Anne, «Un seigneur bourguignon en Europe de l'Est: Guillebert de Lannoy (1386-1462)», Le Moyen Âge 95, 1989, p. 293-309.

Besançon, Alain, "Les baptêmes de l'Europe de l'Est», dans M. Long, F. Monnier (dirs.), La France, l'Église. Quinze siècles déjà, Genève 1997, p. 13-24. 
Besnardeau, Wilfrid, Représentation littéraires de l'étranger au XII siècle. Des chansons de geste aux premières mises en roman, Paris 2007.

Birkhan, Helmut, "Les croisades contre les païens de Lituanie et de Prusse: idéologie et réalité», dans D. Buschinger (dir.), La Croisade: réalités et fictions, Göppingen 1989, p. 31-50.

Bisaha, Nancy, Creating East and West. Renaissance Humanists and the Ottoman Turks, Philadelphia 2004.

Biskup, Marian, «Das Echo der Tannenbergschlacht und der Belagerung Marienburgs im deutschen Zweig des Deutschen Ordens im Sommer 1410 ", dans U. Arnold (dir.), Beiträge zu der Geschichte des Deutschen Ordens, vol. 2, Marbourg 1993, p. 116-123.

Blanchard, Joël, «Les hiérarchies de l'honneur. Avatars d'une grille conceptuelle à la fin du Moyen Âge: Mézières et le Pseudo-Denys ", Revue historique 648/4, 2008, p. 789 à 817.

Blanchard, Joël, Blumenfeld-Kosinski, Renate (dirs.), Philippe de Mézières et l'Europe. Nouvelle histoire, nouveaux espaces, nouveaux langages, Genève 2017.

BŁaszczyK, Grzegorz, Dzieje Stosunków Polskich-Litewskich. Tom II, Od Krewa do Lublina, Poznań 2007. Bliujiené, Audronė, Northern gold: amber in Lithuania (c. 100 to c. 1200), Leiden 2011.

Blomkvist, Nils, Discovery of the Baltic: the reception of a Catholic worldsystem in the European north, Leiden 2005.

Blumenfeld-Kosinski, Renate, Petkov, Kiril, (dirs.), Philippe de Mézières and his Age. Piety and Politics in the Fourteenth Century, Leiden \& Boston 2012.

Bogdan, Henry, Les Chevaliers teutoniques, Paris 1995.

Bogucka, Maria, "The court of Anne Jagiellon. Its size, Structure and Functions", dans U. Borkowska, M. Hörsch (dirs.), The Culture of the Jagellonian and related Courts, Ostfildern 2010, p. 91-105.

Bohdanowicz Arslane, "La Horde d'Or, la Pologne et la Lithuanie (12421430)", Revue Internationale d'Histoire Politique et Constitutionelle. Nouvelle Série 19-20, 1955, p. 186-200.

Borsa, Paolo, Høgel, Christian, Mortensen, Lars Boje, Tyler, Elizabeth, "What is European Medieval Literature?», Interfaces 1, 2015, p. 7-24.

Boudet, Jean-Patrice, Millet, Hélène (dirs.), Eustache Deschamps en son temps, Paris, Sorbonne, 1997.

Bouton-Touboulic, Anne-Isabelle «Le De divinatione daemonum d'Augustin ", dans F. Lavocat, P. Kapitaniak, Closson (dirs.), Fictions $d u$ diable, Genève 2007, p. 15-34.

Borvin, Jeanne-Marie, L'Irlande au Moyen Âge. Giraud de Barri et la Topographia Hibernica (1188), Paris \& Genève 1993. 
Bojtár, Endre, Foreword to the past: a cultural history of the Baltic People, trad. Szilvia Rédey, Michael Webb, Budapest \& New York 1999.

Bombi, Barbara, "Innocent III and the praedictio to the Heathens in Livonia (1198-1204)», dans T. Lehtonen et K. V. Jensen (dirs.), Medieval History Writing and Crusading Ideology, Helsinki 2005, p. 232-238.

Boockmann, Hartmut, Der Deutsche Orden, Munich 1982.

Boockmann, Hartmut, Johannes Falkenberg, der Deutsche Orden und die polnische Politik. Untersuchungen zur politischen Theorie des späteren Mittelalters. Mit einem Anhang: Die Satira des Johannes Falkenberg, Göttingen 1975.

Boucheron, Patrick, "L'invitation au voyage», dans Héros et merveilles du Moyen Âge. Arthur, Renard, la licorne et les fées, Paris 2013, p. 74-79.

Boucheron, Patrick (dir.), Histoire du Monde au XV siècle, Paris 2009.

Boudreau, Claire, «Messagers, rapporteurs, juges et «voir-disant». Les hérauts d'armes vus par eux-mêmes et par d'autres dans les sources didactiques (XIV -XVI $^{\mathrm{e}}$ siècles)», dans C. Boudreau, K. Fianu, C. Gauvard et M. Hébert (dirs.), Information et société à la fin du Moyen Âge. Actes du colloque international tenu à l'Université du Québec à Montréal et à l'Université d'Ottawa (9-11 mai 2002), Paris 2004, p. 233-245.

Bouloux, Nathalie, «Les formes d'intégration des récits de voyage dans la géographie savante. Quelques remarques et un cas d'étude: Roger Bacon, lecteur de Guillaume de Rubrouck", dans H. Bresc, E. Tixier du Mesnil (dirs.), Géographes et voyageurs au Moyen Âge, Nanterre 2010, p. 119-146 [en ligne].

Bourdu, Robert, Joussaume, Monique, «Mystique ou profane. L'arbre, les dieux et les hommes", L'Univers du Vivant 9, 1986, p. 68-74.

Bourgeors, Nicolas, «Les Cisterciens et la croisade de Livonie», Revue Historique 307/3, 2005, p. 526-538.

Brandmüller, Walter, Das Konzil von Konstanz 1414-1418, 2 vols., Padeborn 1997.

Brennan, Timothy M., Just war, sovereignty, and canon law: Legal arguments over the Lithuanian Crusade and the rights of unbelievers at the Council of Constance (1414-1418), Lawrence, Kansas 2006 (thèse de doctorat non publiée).

Brewer, Keagan, Prester John: the Legend and its Sources, Ashgate 2015.

Brincken, Anna-Dorothee von den, «Die kartographische Darstellung Nordeuropas durch italienische und mallorquinische Portolanzeichner im 14. und in der ersten Hälfte des 15. Jahrunderts», Hansiche Geschichtsblätter 92, 1974, p. 45-58.

Brunaux, Jean-Louis, «Les bois sacrés des Celtes et des Germains", dans Les Bois sacrés. Actes du Colloque International (Naples 1989), Naples 1993, p. 57-65. 
Brunner, Otto, Land and Lordship: Structures of Governance in Medieval Austria, Philadelphie 1992.

Brundage, James, Medieval Canon Law, Londres \& New York 1995.

Brundage, James, The Crusades. A documentary survey, Milwaukee 1962.

Brundage, James, "The Thirteenth-Century Livonian Crusade: Henricus de Lettis and the First Legatine Mission of Bishop William of Modena", Jahrbücher für Geschichte Osteuropas. Neue Folge 20/1, 1972, p. 1-9.

Brosse, Jacques, Mythologie des Arbres, Paris 1989.

Buc, Philippe, "L'Epistre lamentable au regard de l'exégèse et de la tradition des croisades", dans J. Blanchard, R. Blumenfeld-Kosinski (dirs.), Philippe de Mézières et l'Europe. Nouvelle histoire, nouveaux espaces, nouveaux langages, Genève 2017, p. 205-220.

Buc, Philippe, Guerre sainte, martyre et terreur, Paris 2017.

BuEs, Almut, "Die letst gegent und provintz der cristen", or where is the Baltic?», dans A. Bues (éd.), Zones of Fracture in Modern Europe, Wiesbaden 2005, p. 27-43.

BüHrer-Thierry, Geneviève, Aux Marges du monde germanique: l'évêque, le prince, les païens (VIIT-XI siècles), Turnhout 2014.

Bujak, Adam, OżóG, Krzysztof, Sosnowski, Leszek, The Glory of Grunwald, Cracovie 2010.

Buкo, Andrzej, "Between Wolin and Truso: the Southern part of the Baltic Rim at the time of Rise of the Polish State (an archaeological perspective)», dans The Image of the Baltic. A Festschrift for Nils Blomkvist, Visby 2012, p. 53-70.

Bumblauskas, Alfredas, "The Heritage of the Grand Duchy of Lithuania: perspectives of historical consciousness", dans G. РотAšEnko (éd.), The Peoples of the Grand Duchy of Lithuania, Vilnius 2002, p. 7-44.

Burg, Barry Richard, Sodomy and the Pirate Tradition: English Sea Rovers in the Seventeenth-Century Carribean, New York 1983.

Burkiewicz, Lukasz, "A Cypriot royal mission to the Kingdom of Poland in 1432 ", Crusades. The journal of the Society for the Study of the Crusades and the Latin East 10, 2011, p. 103-118.

Burleigh, Michael, Prussian society and the German Order: An Aristocratic Corporation in Crisis c.1410-1466, Cambridge 1984.

Buschinger, Danielle, "Le viol dans la littérature allemande au Moyen Âge», dans D. Buschinger, A. Crépin (dirs.), Amour, mariage et transgressions au Moyen Âge, Göppingen 1984, p. 369-388.

Buschinger, Danielle, Olivier, Mathieu, Les Chevaliers teutoniques, Paris 2007.

Buschinger, Danielle, Crépin, André (dirs.), Amour, mariage et transgressions au Moyen Âge, Actes du Colloque des 24, 25, 26 et 27 mars 1983, Göppingen 1984. 
Bysted, Ane, Jensen, Carsten Selch, Jensen, Kurt Villads, Lind, John H., Jerusalem in the North: Denmark and the Baltic Crusades, 1100-1522, Turnhout 2012.

Campbell, Thomas P., "Machaut and Chaucer: "Ars Nova" and the Art of Narrative", The Chaucer Review 24/4, 1990, p. 275-289.

Calin, William, "Machaut's Legacy: the Chaucerian Inheritance Reconsidered», Studies in the Literary Imagination 20/1, 1987, p. 9-22.

Carpini, Claudio, Storia della Lituania. Identità europea e cristiana di un popolo, Rome 2007.

Carpini, Claudio, «Dilitatio Christianitatis: Nota sull'insediamento della Chiesa Cattolica in Lituania", Res Balticae 10, 2004, p. 223-229.

Carpini, Claudio, "La Crociata senza Terrasanta. Nota preliminare per una ricerca sulla Crociata nel Baltico", Res Balticae 9, 2004, p. 179-193.

Carpini, Claudio, "Contra Gentem Potentem et Durissime Cervicis: l'immagine della Lituania e del suo popolo tra mito, propaganda e modelli culturali», Res Balticae 8, 2002, p. 193-207.

Carpini, Claudio, "The Conversion of a People: the Catholic Church in Lithuania between Crusade, Mission and Settlement", Studia Russica 18, 2000, p. 35-38.

Carver, Martin (dir.), The Cross goes North: Processes of Conversion in Northern Europe, AD 300-1300, Woodbridge 2003.

ČAPAItĖ, Ruta, "The everyday life of Grand Duke Vytautas of Lithuania according to Contemporary Correspondance", Lithuanian Historical Studies 8, 2003, p. 1-26.

ČElKIs, Tomas, «Keliais po viduramžių Lietuvą. II : XIII-XV amžiaus pradžios karo žygių sąlygos ", Lituanistica, 59/3 (93), 2013, p. 125-137.

ČErnÝ, Václav, "Guillaume de Machaut au service du roi de Bohême», dans Guillaume de Machaut, poète et compositeur. Colloque-Table Ronde organisé par l'Université de Reims, Reims, 19-22 avril 1978, Paris 1982, p. 67-68.

Cesbron, Georges, "En passant par la Pologne...” avec François Le Gouz de La Boulaye voyageur angevin du XVII ${ }^{\mathrm{e}}$ siècle" ", dans E. BErriotSalvadore, R. Aulotte (dirs.), Les représentations de l'Autre..., p. 31-38.

Champonnois, Suzanne, Labriolle, François de, La Lituanie, un millénaire d'Histoire, Paris 2007.

Champonnois, Suzanne, Labriolle, François de, La Lettonie, Paris 1999.

Chase, Thomas G., The Story of Lithuania, New York 1946.

Chekin, Leonid S., Northern Eurasia in medieval cartography. Inventory, text, translation and commentary, Turnhout 2006.

Cheneval, Francis, "Jean Falkenberg et Paul Vladimiri critiques de Dante», dans S. Włodek (éd.), Société et Église. Textes et discussions dans les universités 
d'Europe centrale pendant le Moyen Âge tardif: Actes du Colloque International de Cracovie organisé par la Société Internationale pour l'Étude de la Philosophie Médiévale, Turnhout 1995, p. 101-115.

Chєopocka, Helena, Procesy Polski z zakonem krzyzackim w XIV wieku, Poznań 1967.

Chmielowska, Bożena, "Stanislas de Skarbimierz, le premier recteur de l'Université de Cracovie», Mediaevalia Philosophica Polonorum 24, 1979, p. 73-112.

Chollet, Loïc, "Croisade ou évangélisation? La polémique contre les Chevaliers teutoniques à l'aune des témoignages des voyageurs français de la fin du Moyen Âge", Ordines Militares. Yearbook for the Study of the Military Orders 20, 2015, p. 175-203.

Chollet, Loïc, "Les "Voyages en Prusse" vus de France: la perception de la croisade contre la Lituanie dans quelques sources francophones (13841414)", Studia z Dziejów Średniowiecza 19, 2015, p. 51-80.

Chollet, Loïc, «D'une cohabitation à l'autre: controverses autour des Chevaliers teutoniques et de la Samogitie, dernière province païenne d'Europe (1398-1417)", dans C. Maurer, C. VinCent (dir.), La coexistence confessionnelle en France et en Europe Germanique et Orientale du Moyen Âge à nos jours, Lyon 2015, p. 191-205.

Chollet, Loïc, «Ecrire l'histoire de la conquête: l'utilisation de l'histoire dans la polémique contre l'Ordre teutonique au sujet des droits des infidèles (1386-1418)», Hereditas Monasteriorum 4, 2014, p. 17-47.

Chollet, Loïc, "Vom Friedenverträgen bis zum Konzil von Konstanz: Schemaiten und die Rechtliche Stellung von Heidnischen Völkern", dans A. Bues, J. Grabowski, J. Krochmal, G. Vercamer, H. Wajs (dirs.), Od traktatu kaliskiego do pokoju oliwskiego. Polsko-krzyżacko-pruskie stosunki dyplomatyczne w latach 1343-1660 / Vom Frieden von Kalisch bis zum Frieden von Oliva. Diplomatische Beziehungen zwischen dem Königreich Polen und dem Deutschen Orden/Herzogtum Preußen in den Jahren 1343-1660, Varsovie 2014, p. 227-240.

Chollet, Loïc, "Paul Vladimir et le Ius Gentium polonais: un droit de résistance au début du $\mathrm{XV}^{\mathrm{e}}$ siècle?», dans P. Arabeyre et K. Fiorentino (dir.), Résistances au droit et droit de résistance: Actes du colloque international de Lausanne organisé par la Société pour l'Histoire du Droit et des Institutions des anciens pays bourguignons, comtois et romands (Mémoires de la Société pour l'histoire du droit et des institutions des anciens pays bourguignons, comtois et romands 69), Dijon 2012, p. 43-67.

Christiansen, Eric, The Northern Crusades: the Baltic and the catholic frontier 1100-1525, Londres-New-York 1980 (réimpr. 1997).

Claverie, Pierre-Vincent, Honorius III et l'Orient (1216-1227): étude et publication de sources indites des archives vaticanes (ASV), Leiden 2013. 
Colker, Marvin, "America Rediscovered in the Thirteenth Century?», Speculum 54/4, 1979, p. 712-726.

Cook, Albert S., "Beginning the Board in Prussia», Journal of English and German Philology 14, 1915, p. 375-388.

Constable, Giles, "The Place of the Magdebourg Charter of 1107/1108 in the History of Eastern Germany and of the Crusades", dans F. Felten, N. Jaspert (dirs.), Vita Religiosa. Festschrift für Kaspar Elm zum 70. Geburtstag, Berlin 1999, p. 283-299.

Contamine, Philippe, "Les princes, barons et chevaliers qui a la chevalerie au service de Dieu se sont ja vouez". Recherches prosopographiques sur l'ordre de la Passion de Jésus-Christ (1385-1395)», dans M. Nejedlý, J. Svátek (dirs.), La noblesse et la croisade à la fin du Moyen Âge (France, Bourgogne, Bohême), Toulouse 2009, p. 43-68.

Contamine, Philippe, «De Chypre à la Prusse et à la Flandre. Les aventures d'un chevalier poitevin: Perceval de Couloigne, seigneur de Pugny, du BreuilBernard et de Pierrefite (133.-141.)», dans D. Coulon, C. Otten-Froux, P. Pagès, D. ValÉRIAN, (dirs.), Chemins d'Outre-Mer: Ét'des d'histoire sur la Méditerranée médiévale offertes à Michel Balard, vol. 1, Paris 2004, p. 149-157.

Contamine, Philippe, "La place des femmes dans les deux premières règles (1367-1368 et 1384) de l'ordre de la chevalerie de la Passion de JésusChrist de Philippe de Mézières ", dans P. Henriet, A.-M. Legras (dirs.), $A u$ cloître et dans le monde. Femmes, hommes et sociétés ( $I X^{e}-X V^{e}$ siècle). Mélanges en l'honneur de Paulette L'Hermite-Leclercq, Paris 2000, p. 79-88.

Contamine, Philippe, La Guerre au Moyen Âge, Paris 1980.

Contamine, Philippe, "L'idée de guerre à la fin du Moyen Âge; aspects juridiques et éthiques", Comptes rendus des séances de l'Académie des Inscriptions et Belles-Lettres 123/1, 1979, p. 70-86.

Contamine, Philippe, "Points de vue sur la chevalerie en France à la fin du Moyen Âge", Francia - Forschungen zur westeuropäischen Geschichte 4, 1976, p. 255-286.

Contamine, Philippe, Azincourt, Paris 1964 (réimpr. 2013).

Conte, Francis, Les Slaves, Paris 1986 (réimpr. 1996).

CRÉpIN, André, "Quand les Anglais parlaient français", Comptes rendus des séances de l'Académie des Inscriptions et Belles-Lettres, 148/4, 2004, p. 1569-1588.

Crouzet, Denis, Les guerriers de Dieu. La violence au temps des troubles de religion, vers 1525-vers 1610, Seyssel 1990 (rééd. 2009).

Curry, Anne Elisabeth, "War or Peace? Philippe de Mezieres, Richard II and Anglo-French Diplomacy", dans R. Blumenfeld-Kosinski et K. Petkov (dirs.), Philippe de Mézières and his Age. Piety and Politics in the Fourteenth Century, Leiden \& Boston 2012, p. 295-320. 
David, Pierre, «La Pologne et les pays slaves dans l'Obituaire de Saint-Gilles au $\mathrm{XII}^{\mathrm{e}}$ siècle», Comptes rendus des séances de l'Académie des Inscriptions et BellesLettres 83/6, 1939, p. 614-616.

David, Pierre, "Un disciple d'Yves de Chartres en Pologne - Galon de Paris et le droit canonique", dans La Pologne au VII congrès des sciences historiques, vol. 1, Varsovie 1933, p. 99-113.

Delaville Le Roulx, Joseph, La France en Orient au XIV siècle. Les expéditions du maréchal Boucicaut, Paris 1886.

Delisle, Philippe, "Un Tintin au Congo flamand au service des missions chrétiennes. Le Bâton du Féticheur, de Renaat Demoen (1949-1950)», Revue d'histoire de l'Église de France 101/246, 2015, p. 121-140.

Delivré, Fabrice «1414. Le concile de Constance», dans P. Boucheron (dir.), Histoire du Monde au XV siècle, Paris 2009, p. 308-311.

Delogu, Daisy, "How to become the "Roy des Frans": The Performance of Kingship in Philippe de Mezieres's Le songe du vieil pelerin», dans R. Blumenfeld-Kosinski et K. Petkov (dirs.), Philippe de Mézières and his Age. Piety and Politics in the Fourteenth Century, Leiden \& Boston 2012, p. 147-164.

Deluz, Christiane, «L'Europe selon Pierre d'Ailly ou selon Guillaume Fillastre?

De l'Ymago Mundi aux légendes de la carte de Nancy", dans D. Marcotte (dir.), Humanisme et culture géographique à l'époque du Concile de Constance, Turnhout 2002, p. 155-158.

Deluz, Christiane, «Partir c'est mourir un peu. Voyages et déracinement dans la société médiévale", dans Voyages et voyageurs au Moyen Âge-Actes des congrés de la Société des historiens médiévistes de l'enseignement supérieur public, $26^{e}$ congrès, Aubazine 1996, p. 291-303.

Deluz, Christiane, «Des lointains merveilleux (d'après quelques textes géographiques et récits de voyage du Moyen Âge)», dans C. Deluz (dir.), De l'étranger à l'étrange ou la conjointure de la merveille: En hommage à Marguerite Rossi et Paul Bancourt, Aix-en-Provence 1988, p. 157-169 [en ligne].

Deluz, Christiane, Le livre de Jehan de Mandeville: une "géographie" au $X I V^{e}$ siècle, Louvain-la-Neuve 1988.

Dembowsкi, Peter, "Reflets chevaleresques du Nord-Est dans l'œuvre de Jean Froissart», Roczniki Humanistyczne 34/2 (1986), p. 137-143.

Demurger, Alain, Les Hospitaliers: de Jérusalem à Rhodes, 1050-1317, Paris 2013.

Demurger, Alain, Chevaliers du Christ, Paris 2002.

Demurger, Alain, "Le Religieux de Saint Denis et la croisade», dans F. Autrand, C. Gauvard et J.-M. Moeglin (dirs.), Saint-Denis et la royauté. Etudes offertes à Bernard Guenée, Paris 1999, p. 181-196. 
Derwich, Marek, «Les deux fondations de l'abbaye de Lubin dans le cadre de l'implantation du monachisme bénédictin en Pologne (moitié du XI ${ }^{\mathrm{e}}$-fin du XII ${ }^{e}$ siècle)", Le Moyen Âge, 108, 2002, p. 9-24.

Devaux, Jean, Velissariou, Alexandra (dirs.), Autour des Cent Nouvelles nouvelles, Sources et rayonnements, contextes et interprétations. Actes du colloque de Dunkerque (2011), Paris 2016.

Devillers, Léopold, «Sur les expéditions des comtes de Hainaut et de Hollande en Prusse", Compte rendu des séances de la Commission royale d'histoire 5/4, 1878, p. 127-144.

Diaz Kayel, Barbara, "Just War against Infidels? Similar Answers from Central and Western Europe", Studia Philosophiae Christianae 3, 2017, p. 55-76.

Dobrowolski, Pawel, "Miles christianus" czy turysta? Uwagi o wyprawie Henryka Hragiego Derby do Prus w r. 1390-1391", Poznańskie Towarzystwo Przyjaciót Nauk. Sprawozdania 100, 1984, p. 36-46.

Donner, Gustav A., Kardinal Wilhelm von Sabina, Helsingfors 1929.

Doutrepont, Georges, La littérature Française à la cour des ducs de Bourgogne, Paris 1909.

Du Boulay, Francis R. H., "Henry of Derby's crusade in Prussia», dans F.R.H. Du Boulay and C. Barron (éds.), The Reign of Richard II: Essays in Honour of May McKisack, Londres 1971, p. 153-172.

Dubonis, Arturas, "Das Grenzgebiet zwischen Litauen und dem Deutschen Orden", dans W. Paravicini, R. Petrauskas, G. Vercamer (dir.), Tannenberg - Grunwald - Žalgiris 1410: Krieg und Frieden im späten Mittelalter, Wiesbaden 2012, p. 53-69.

DucÈne, Jean-Charles, «L'Europe dans la cartographie arabe médiévale», Belgeo 3-4, 2008, p. 251-268 [en ligne].

DucÈne, Jean-Charles, "L'île des Amazones dans la mer Baltique», Rocznik Orientalistyczny 54, 2002, p. 171-182.

Dufour, Alfred, «Droit international et chrétienté: des origines espagnoles aux origines polonaises du droit international. Autour du sermon De bellis justis du canoniste polonais Stanisłas de Skarbimierz (1360-1431)» dans P. Dupuy, V. Chetail (dirs.) The Roots of International Law / Les fondements du droit international. Liber Amicorum Peter Haggenmacher, Leiden 2013, p. 95-119.

DumÉzIL, Georges, Le Problème des Centaures. Études de mythologie comparée indo-européenne, Paris 1929.

Dunin-Wasowicz, Teresa, "Autour du baptême de Mieszko Ir de Pologne», dans M. Rouche (dir.), Clovis. Histoire et Mémoire. Actes du Colloque International d'Histoire de Reims, du 19 au 25 septembre 1996, Paris 1997, vol. 2, p. 369-385.

Dupront, Alphone, Le mythe de croisade, 4 vols., Paris 1997. 
Duggan, Lawrence G., "For Force Is Not of God"? Compulsion and Conversion from Yahweh to Charlemagne», dans J. Muldoon (dir.), Varieties of Religious Conversions in the Middle-Ages, Gainesville 1997, p. 49-62.

Dvornik, Francis, Les Slaves: histoire et civilisation de l'Antiquité aux débuts de l'époque contemporaine, Paris 1970.

EArp, Lawrence, Guillaume de Machaut. A Guide to Research, New York \& Londres 1995.

Ehlers, Axel, "The Use of Indulgences by the Teutonic Order in the Middle Ages", dans V. Mallia-Milanes (dir.), The Military Orders 3. History and Heritage, Aldershot 2008, p. 139-146.

Ehlers, Axel, Die Ablasspraxis des Deutschen Ordens im Mittelalter, Marbourg 2007.

Ehlers, Axel, "The crusade against Lithuania reconsidered", dans A. V. Murray (dir.), Crusade and Conversion on the Baltic Frontier, 1150-1500, Aldershot 2001, p. 21-44.

Ehrensvärd, Ulla, The History of the Nordic Map, Helsinki 2006.

Ekdahl, Sven, "Crusades and Colonisation in the Baltic: A Historiographic Analysis", dans A. V. Murray (dir.), The North-Eastern Frontiers of Medieval Europe: the expansion of Latin Christendom in the Baltic Lands, Farnham 2014, p. 1-43.

Ekdahl, Sven, "Politics, Diplomacy and the Recruitment of the Mercenaries before the Battle of Tannenberg-Grunwald-Zalgiris in 1410", dans P. W. Edbury (dir.), The Military Orders 5. Politics and Power, Aldershot 2012, p. 329-336.

Ekdahl, Sven, "The Turning Point in the Battle of Tannenberg (Grunwald/ Žalgiris) in 1410», Lituanus 56/2, 2010 [en ligne].

Ekdahl, Sven, "The Teutonic Order's Mercenaries during the "Great War" with Poland-Lithuania (1409-1411), dans J. France (dir.), Mercenaries and Paid Men. The Mercenary Identity in the Middle Ages, Leiden 2008, p. 345-351.

Ekdahl, Sven, «Christianisierung - Siedlung - Litauerreise. Die Christianisierung Litauens als Dilemma des Deutschen Ordens", dans V. Dolinskas (dir.), Lietuvos krikščionejjimas Vidurio Europas kontekste, Vilnius 2005, p. 189-205.

Ekdahl, Sven, "Treatment of Prisoners of War», dans M. Barber (dir.), The Military Orders 1. Fighting for the Faith and Caring for Sick, Aldershot 1994, p. 263-269.

Ekdahl, Sven, Die Schlacht bei Tannenberg 1410: Quellenkritische Untersuchungen, Berlin 1982. 
EkDahl, Sven, "Die Flucht der Litauer in der Schlacht bei Tannenberg", Zeitschrift für Ostforschung 12, 1963, p. 11-19.

Englert, Anton, Trakadas, Athena (dirs.), Wulfstan's Voyage: The Baltic Sea Region in the early Viking Age as seen from shipboard, Roskilde 2009.

Erdmann, Carl, The Origin of the Idea of Crusade, trad. M. W. Baldwin, W. Goddart, Princeton 1977.

Favier, Jean, La Guerre de Cent Ans, Paris 1980.

Favreau-Lilie, Marie-Luise, «Mission to the Heathen in Prussia and Livonia: The Attitudes of the Religious Military Orders Toward Christianization", dans G. Armstrong, I. Wood (dirs.), Christianizing People and Converting Individuals, Turnhout 2000, p. 147-154.

FeIstNer, Elisabeth, "Vom Kampf gegen das "Andere": Pruzzen, Litauer und Mongolen in lateinischen und deutschen Texten des Mittelalters", Zeitschrift für deutsches Altertum 132, 2003, p. 281-294.

Fleckenstein Josef, "Die Rechtfertigung der geistlichen Ritterorden nach der Schrift "De laude novae militiae" Bernhards von Clairvaux", dans J. Fleckenstein, M. Hellmann (dir.), Die geistlichen Ritterorden Europas, Sigmaringen 1980, p. 9-22.

Fleckenstein, Josef, Hellmann, Manfred (dirs.), Die geistlichen Ritterorden Europas, Sigmaringen 1980.

Filipowiak, Władysław, Konopka, Marek «The Identity of a Town: Wolin, Town-State $-9^{\text {th }}-12^{\text {th }}$ Centuries", Quaestiones Medii Aevi Novae 13, 2008, p. 243-288.

Filotas, Bernadette, Pagan survivals, superstitions and popular cultures in Early Medieval pastoral literature, Toronto 2005.

Fletcher, Richard, The Conversion of Europe: from paganism to Christianity, 371-1386 AD, Londres 1988.

Flori, Jean, La Guerre sainte. La formation de l'idée de croisade dans l'Occident, Paris 2001.

FlorI, Jean, Croisade et Chevalerie: XI -XII siècles, Paris \& Bruxelles 1998.

Fonnesberg-Schmidt, Iben, The Popes and the Baltic Crusades, 1147-1254, Leiden \& Boston 2007.

Fonnesberg-Schmidt, Iben, «Pope Alexander III (1159-1181) and the Baltic Crusades", dans T. Lehtonen et K. V. Jensen (dirs.), Medieval History Writing and Crusading Ideology, Helsinki 2005, p. 242-256.

Forstreuter, Kurt, «Die Bekehrung des Litauerkönigs Gedimin», Jahrbuch der Albertus-Universität 6, 1955, p. 142-158.

Fowler, Kenneth, The King's Lieutenant. Henry of Grosmont, First Duke of Lancaster 1310-1361, Londres 1969. 
FraesdorfF, David, Der barbarische Norden: Vorstellungen und Fremdheitskategorien bei Rimbert, Thietmar von Merseburg, Adam von Bremen und Helmold von Bosau, Munich 2005.

Fraesdorff, David, "The Power of Imagination: The Christianitas and the Pagan North during Conversion to Christianity (800-1200)», Medieval History Journal 5/2, 2002, p. 309-332.

France, John, «Philippe de Mézières and the Military History of the Fourteenth Century», dans R. Blumenfeld-Kosinski et K. Petkov (dirs.), Philippe de Mezières and his Age. Piety and Politics in the Fourteenth Century, Leiden \& Boston 2012, p. 283-294.

Fray, Jean-Luc, "Le mécénat artistique des ducs de Bourbon ( $\mathrm{xv}^{\mathrm{e}}$ et début $\mathrm{XVI}^{\mathrm{e}}$ siècles): entre culture du Nord, Italie et France centrale", dans A. Bárány, I. Orosz, K. Papp, B. Vinkler (dirs.), Learning, Intellect and Social Roles: Aristocrats in Hungary and Europe, Debrecen 2014, p. 13-28.

Friedman, John B., Monstrous Races in Medieval Art and Thought, Cambridge, Mass. 1981.

Friedman, John B., Figg, Kristen (dirs.), Trade, Travel, Exploration in the Middle Ages: an encyclopedia, New York 2000.

Frost, Robert, The Oxford History of Poland-Lithuania: Volume I: The Making of the Polish-Lithuanian Union 1385-1569, Oxford 2015.

GACHET, Emile, Examen critique des Voyages et ambassades de Ghillebert de Lannoy, 1399-1450, Bruxelles 1843.

GaIER, Claude, "Achats d'armes et expéditions militaires en Prusse et autres lieux du comte Guillaume II de Hainaut (1336-1344)», dans C. Gaier (dir.), Armes et combats dans l'univers médiéval, Bruxelles 1995, p. 229-242.

GAIER, Claude, "La cavalerie lourde en Europe occidentale du XII ${ }^{e}$ au XVI ${ }^{e}$ siècle: un problème de mentalité", dans C. GAIER (dir.), Armes et combats dans l'univers médiéval, Bruxelles 1995, p. 299-310.

Galkus, Juozas, Lietuvos Vytis / The Vytis of Lithuania, Vilnius 2009.

Garipzanov, Ildar H., "Christianity and Paganism in Adam of Bremen's narrative", dans I. Garipzanov (dir.), Historical Narratives and Christian Identity on a European Periphery. Early History Writing in Northern, East-Central, and Eastern Europe (c.1070-1200), Turnhout 2011, p. 13-29.

Gaucher, Elisabeth, "Deux regards sur une défaite: Nicopolis», Cahiers de recherches médiévales 1,1996 , p. 93-104.

Gaude-Ferragu, Murielle, D’or et de cendres. La mort et les funérailles des princes dans le royaume de France au bas Moyen Âge, Villeneuve d'Ascq 2005.

Gautier, Alban, Rossignol, Sébastien, De la Mer du Nord à la mer Baltique: Identités, contacts et communications au Moyen Âge. Actes de l'atelier de jeunes chercheurs, Boulogne-sur-Mer, les 15-17 octobre 2009, Lille 2012. 
Gautier Dalché, Patrick, "Géographie arabe et Géographie latine au XII ${ }^{e}$ siècle", Medieval Encounters 19/4, 2013, p. 408-433.

Gautier Dalché, Patrick, "Représentations géographiques de l'Europe - septentrionale, centrale et orientale - au Moyen Âge», dans I. Baumgärtner, H. Kugler (éds.) Europa im Weltbild des Mittelalters: kartographische Konzepte, Berlin 2008, p. 63-79.

Gautier Dalché, Patrick, «À propos de la mappemonde d'Ebstorf», Médiévales 55, 2008 [En ligne].

Gautier Dalché, "Remarques sur les défauts supposés, et sur l'efficace certaine de l'image du monde au XIV e siècle", dans La Géographie au Moyen Âge. Espaces pensés, espaces vécus, espaces rêvés. Supp. au no 24 de Perspectives Médiévales, 1998, p. 43-56.

Gawlas, Sławomir, "Polen - eine Ständegesellschaft an der Peripherie des lateinischen Europa», dans R. C. Schwinges, C. Hesse, P. Moraw (dirs.) Europa im späten Mittelalter. Politik - Gesellschaft - Kultur, Munich 2006, p. 237-261.

GÉnicot, Léopold, "Wallons en Pologne au moyen âge», Annales de la Société archéologique de Namur 64, 1985/86, p. 9-16.

Gersdorf, Harro, Der Deutsche Orden im Zeitalter der polnisch-litauischen Union, Marbourg 1957.

Giedroyć , Michal, "The Arrival of Christianity in Lithuania: Baptism and Survival (1341-1387)», Oxford Slavonic Papers 22, 1989, p. 34-57.

Gierszewski, Andrzej, "Organization of Teutonic Military Infrastructure on Curonian Spit from 1283 A. D. up to 1525 A. D.", Baltijos Regiono Istorija ir Kultura: Lietuva et Lenkija $=$ History and Culture of Baltic Region: Lithuania and Poland, Klaipeda 2007, p. 9-24.

Gieysztor, Aleksander, "Sylvestre II et les Églises de Pologne et Hongrie», dans Gerberto. Scienza, storia e mito. Atti del Gerberti Symposium (Bobbio 25-27 Iuglio 1983), Bobbio 1985, p. 733-746.

Ginzburg, Carlo, "Les Origines du sabbat», dans N. Jacques-Chaquin, M. PrÉAud (dirs.), Le sabbat des sorciers. XV'-XVIII siècles, Grenoble 1993, p. 17-21.

Ginzburg, Carlo, Le Sabbat des sorcières, Paris 1992.

Ginzburg, Carlo, Les Batailles nocturnes: sorcellerie et rituels agraires en Frioul, XVI-XVII siècle, Paris 1966.

Ginzburg, Carlo, "Ekphrasis and Quotation», Tijdschrift Voor Filosofie 50/1, 1988, p. 3-19.

Ginzburg, Carlo, Le Fromage et les Vers, Paris 1980.

Gimbutas, Marija, "Religion and Mythology of the Balts", dans J. Trinkunas (dir.), Of Gods and Holidays. The Baltic Heritage, Vilnius 1999, p. 18-45. 
Gimbutas, Marija, The Balts, Londres 1963.

Girbea, Catalina, Le Bon Sarrasin dans le roman médiéval (1100-1225), Paris 2014.

GŁadysz, Mikołaj, The Forgotten Crusaders. Poland and the Crusader Movement in the Twelfth and Thirteenth Centuries, trad. Paul Barford, Leiden-Boston 2012.

GŁodek, Marzena, Utopia Europy zjednoczonej. Życia i idee Filipa de Mézières (1327-1405), Słupsk 1997.

Goetz, H.-W., "Constructing the Past. Religious Dimensions and Historical Consciousness in Adam of Bremen's Gesta Hammaburgensis ecclesiae Ponificum", dans L. B. Mortensen (éd.), The Making of Christian Myths in the Periphery of Latin Christendom, Copenhague 2006, p. 46-47.

Gonthier, Nicole, "Les victimes de viol devant les tribunaux à la fin du Moyen Âge d'après les sources dijonnaises et lyonnaises", Criminologie 27/2, 1994, p. 9-32.

Górski, Karol, "The Author of the Descriptiones Terrarum: A New Source for the History of Eastern Europe", The Slavonic and East European Review 61/2, 1983, p. 254-258.

Górski, Karol, "L'Ordre teutonique. Un nouveau point de vue», Revue Historique 230/2, 1963, p. 285-294.

Górski, Karol, Tomczak, Andrzej, Polska-Francja: dziesiec wieków zwiazków politycznych, kulturalnych i gospodarczych, Varsovie 1983.

Górski, Karol, "The Teutonic Order in Prussia», dans A. V. Murray (dir.), The North-Eastern Frontiers of Medieval Europe: the expansion of Latin Christendom in the Baltic Lands, Farnham 2014, p. 227-246.

Gouguenheim, Sylvain, Tannenberg 1410, Paris 2012.

Gouguenheim, Sylvain, "Les Guerres des ordres militaires furent-elles des guerres chevaleresques?", dans M. Aurell, C. Girbea (dirs.), Chevalerie et christianisme aux XII et XIII siècles, Rennes 2011, p. 291-313.

Gouguenheim, Sylvain, «Das Echo der Schlacht bei Grunwald im Frankreich des XV. und XVI. Jahrhunderts", dans K. Ożóg, J. Trupinda (dirs.), Conflictus Magnus apud Grunwald 1410. Między Histori a Tradycją, Malbork 2013, p. 192-206.

Gouguenheim, Sylvain, «Le procès pontifical de 1339 contre l'Ordre teutonique", Revue historique 647/3, 2008, p. 567-603.

Gouguenheim, Sylvain, Les Chevaliers teutoniques, Paris 2007.

Gouguenheim, Sylvain, "Un Italien dans la Baltique. Guillaume de Modène en Norvège et en Suède", dans T. M. S. Lehtonen, E. Mornet (éds.), Les élites nordiques et l'Europe occidentale (XII-XVe siècle), Paris 2007, p. 139-152. 
Gouguenheim, Sylvain, "L'Ordre teutonique en Prusse», dans L'expansion occidentale (XI $-X V^{e}$ siècles). Formes et conséquences (Actes des congrès de la Société des historiens médiévistes de l'enseignement supérieur public. $33^{e}$ congrès, Madrid, 2002), Paris 2003, p. 97-113.

Graboïs, Aryeh, "Militia and Malitia: the Bernardine Vision of Chivalry", dans M. Grevers (dir.), The Second Crusade and the Cistercians, New York 1992, p. 49-56.

Grabski, Andrzej F., Polska w Opiniach Europy Zachodniej, XIV-XV w., Varsovie 1968.

Grabski, Andrzej F., "Jadwiga-Wilhelm-Jagiello w opiniach europejskich», Nasza Przeszlosc 23, 1966, p. 117-166.

Grabski, Andrzej F., «La Pologne et les Polonais vus par les étrangers du $\mathrm{X}^{\mathrm{e}}$ au XIII" siècle", Acta Poloniae historica 13, 1965, p. 22-43.

Grabski, Andrzej F., Polska w Opiniach Obcych, X-XIII w., Varsovie 1964.

Greimas, Algirdas Julien, Des Dieux et des hommes: études de mythologie lituanienne, Paris 1985.

Greimas, Algirdas Julien, «Les voix du mythe en Lituanie. Entretien avec Algirdas Julien Greimas", Lalies 10, 1992, p. 9-39.

Greimas, Algirdas Julien, "Le dit de Sovys, conducteur des âmes», Lalies 6, 1984, p. $42-58$.

Gros, Gérard, "Croisade contre les Boesmes, ou guerre et paix chez Jean Régnier", Cahiers de recherches médiévales 1, 1996, p. 105-127.

Guard, Timothy, Chivalry, Kingship and Crusade. The English Experience in the Fourteenth Century, Woodbridge 2013.

GudavičIus, Edvardas, "Lithuania's Road to Europe», Lithuanian Historical Studies 2, 1997, p. 15-27.

GuÉNOlÉ, Agnès, Les peuples païens et l'expansion des États chrétiens au nord-est de l'Europe: discours et politique (fin $X^{e}$ - début XIV siècle) (thèse de doctorat non-publiée), Poitiers, 2011.

GuÉNÉE, Bernard, Histoire et culture historique dans l'Occident médiéval, Paris 1980.

GuenÉE, Bernard, Entre l'Église et l'État. Quatre vies de prélats français à la fin du Moyen Âge (XII'-XV' siècle), Paris 1987.

GuenéE, Bernard, L'Occident aux XIV et XV siècles. Les États. Paris 1971.

Guéret-Laferté, Michèle, «Le voyageur et le géographe: l'insertion de la relation de voyage de Guillaume de Rubrouck dans l'Opus majus de Roger Bacon", dans La Géographie au Moyen Âge. Espaces pensés, espaces vécus, espaces rêvés. Supp. au no 24 de Perspectives Médiévales, 1998, p. 81-96.

Guerrie Dall'oro, Guido, «Les mercenaires dans les campagnes napolitaines de Louis le Grand, roi de Hongrie, 1347-1350», dans J. France (éd.), Mercenaries and Paid Men, Leiden 2008, p. 61-88. 
GütTner-Sporzynski, Darius von, «Holy War and Proto-Crusading. TwelfthCentury Justifications for the Campaigns against the Pomeranians and Prussians", dans T. Nielsen, I. Fonnesberg-Schmidt (dirs.), Crusading on the Edge. Ideas and Practice of Crusading in Iberia and the Baltic Region, 1100-1500, Turnhout 2016, p. 225-244.

Güttner-Sporzynski, Darius von, Poland, Holy War, and the Piast Monarchy, 1100-1230, Turnhout 2014.

GüTTNER-SPORZYNSKI, Darius von, "Constructing memory: holy war in the Chronicle of the Poles by Bishop Vincentius of Cracow", Journal of Medieval History 40/3, 2014, p. 276-291 [numeration de l'auteur: p. 1-16].

GütTner-Sporzynski, Darius von, "Poland and the papacy before the second crusade", dans M. Balard (dir.), La Papauté et les croisades / The Papacy and the Crusades, Farnham 2011.

Guth, Klaus, "Pomeranian Missionary Journeys of Otto I of Bamberg", dans M. Grevers (éd.), The Second Crusade and the Cistercians, New York 1992, p. 13-23.

Guyot-Bachy, Isabelle, Moeglin, Jean-Marie, "Comment ont été continuées les Grandes Chroniques de France dans la première moitié du XIV siècle», Bibliothèque de l'école des chartes, 163/2, 2005, p. 385-433.

Guzman, Gregory G., "European clerical envoys to the Mongols: Reports of Western merchants in Eastern Europe and Central Asia, 1231-1255", Journal of Medieval History 22/1, 1996, p. 53-67.

Guzman, Gregory G., "The encyclopedist Vincent de Beauvais and his Mongol extracts", Speculum 49, 1974, p. 287-307.

Навцот, Laurent, «L'emblématique princière dans l'œuvre d'Eustache Deschamps", dans M. Lacassagne, T. Lassabatère (dir.), Les "dictez vertueulx" d'Eustache Deschamps: forme poétique et discours engagé à la fin du Moyen Âge, Paris 2005, p. 87-107.

Hacketт, Jeremiah M. G., "Roger Bacon: his life, career and works», dans J. Hacketт (dir.), Roger Bacon and the sciences. Commemorative essays, Leiden 1997, p. 9-23.

Halecki, Oskar, Jadwiga of Anjou and the rise of East Central Europe, Boulder etc. 1991.

Halecki, Oskar, "Problems of the New Monarchy: Jagello and Vitold» dans W. F. Reddaway et al. (éd.), The Cambridge History of Poland, vol. 1, New York 1950, (réimpr. 1971), p. 210-231.

Halecki, Oskar, "Gilbert de Lannoy and his Discovery of East Central Europe", Bulletin of the Polish Institute of Arts and Sciences in America 2, 1944, p. 314-331.

Halecki, Oskar, «La Pologne et la question d'Orient de Casimir le Grand à Jean Sobieski», dans La Pologne au VII congrès des sciences historiques, vol. 1, Varsovie 1933, p. 431-443. 
Halkin, Léon-E., "Pour une histoire de l'honneur», Annales. Économies, Sociétés, Civilisations 4/4, 1949, p. 433-444.

Hanly, Michael, "Philippe de Mézières and the Peace Movement», dans R. Blumenfeld-Kosinski et K. Petrov (dirs.), Philippe de Mézières and his Age. Piety and Politics in the Fourteenth Century, Leiden \& Boston 2012, p. 61-82.

Harf-Lancner, Laurence, "Le roman vrai de Mélusine", dans Héros et merveilles du Moyen Age, Paris 2013, p. 40-43.

Hartog, François, Le Miroir d'Hérodote, Paris 1980.

Hautala, Roman, "The Teutonic Knights' Military Confrontation with the Cumans during Their Stay in Transylvania (1211-1225)", Golden Horde Civilisation 8, 2015, p. 80-89.

Heckmann, Dieter, "L'Ordre teutonique à Metz et à Liège au Moyen Âge», dans J. Sarnowsky, Mendicants, Military Orders, and Regionalism, Aldershot 1999, p. 59-68.

HÉlAVY, Xavier, "Le "dégoût" de la noblesse française à l'égard de la croisade à la fin du XIII e siècle», dans M. Nejedlý, J. Svátek (dirs.), La noblesse et la croisade à la fin du Moyen Âge (France, Bourgogne, Bohême), Toulouse 2009, p. 17-30.

Heller Michel, Histoire de la Russie et de son empire, trad. Anne ColdefyFaucard, Paris, Flammarion, 1997.

Hellmann, Manfred, «Die Päpste und Litauen», dans La Cristianizzazione della Lituania. Atti del Colloquio internazionale di storia ecclesiastica in occasione del 6 centenario della Lituania cristiana (1387-1987). Roma, 24-26 giugno 1987, Vatican 1989, p. 27-62.

Helmont, Jan van, Gelre. B.R. Ms. 15652-56, Louvain 1992.

Henrix, Hermann, «Adalbert von Prag (um 956-23. April 997) - ein europäischer Heiliger", dans H. Henrix (dir.), Adalbert von Prag. Brückenbauer zwischen dem Osten und Westen Europas, Baden-Baden 1997, p. 9-15.

Herrmann, Joachim, "Les Slaves du Nord", dans D. Wilson (dir.), Les mondes nordiques. Histoire et héritage de l'Europe barbare, Ve-XII s, Paris 1980, p. 193-206.

Hess, Cordelia, The Absent Jews. Kurt Forstreuter and the Historiography of Medieval Prussia, New York 2017.

Heullant-Donat, Isabelle, "En amont de l'observance», dans F. Meyer, L. Viallet (dirs.), Identités franciscaines à l'âge des réformes, ClermontFerrand 2005, p. 73-100.

Heymann, Frederick G., "The Crusades against the Hussites», dans R. L. Wolff, H. W. Hazard (ÉDs.), A History of Crusades, vol. 3, The Later Crusades, Madison 1969, p. 586-647. 
Hicks, Michael, Warwick the Kingmaker, Oxford 1998.

Higounet, Charles, Les Allemands en Europe centrale et orientale, Paris 1989.

Higounet, Charles, «De La Rochelle à Toruń : aventure de barons en Prusse et relations commerciales" dans Idem, Paysages et villages neufs du Moyen Âge, Bordeaux 1975, p. 443-447.

Hlaváčex, Petr, "A Reflection on the Political and Religious Role of Bohemia», dans J. KŁoczowski, H. Łaszkiewicz (éd.), East-Central Europe in European history, Lublin 2009, p. 131-145.

Hockay, Jean, "Alexandre et Gauthier. Deux Malonnois en Pologne au XII ${ }^{\mathrm{e}}$ siècle», Le Guetteur Wallon, 1978, n 2, p. 41-61; n 3, p. 81-95.

Holban, Maria, "Du caractère de l'ambassade de Guillebert de Lannoy dans le nord et le sud-est de l'Europe en 1421 ", Revue des études sud-est européennes: Civilisations - Mentalités 5, 1967, p. 419-434.

Hoorebeeck, Céline van, «Item, ung petit livre en franchois... La littérature francaise dans les librairies des fonctionnaires des ducs de Bourgogne», Le Moyen francais 57-58, 2005-2006, p. 381-413.

Housley, Norman, Crusading and the Ottoman Threat, 1453-1505, Oxford 2013.

Housley, Norman, Contesting the Crusades, Oxford 2006.

Housley, Norman, "One man and his wars: the depiction of warfare by Marshal Boucicaut's biographer", Journal of Medieval History 29/1, 2003, p. $27-40$.

Housley, Norman, "Le Maréchal Boucicaut à Nicopolis», dans J. PAviot, M. Chauney-Bouillot (dirs.), Nicopolis 1396-1996. Actes du colloque international "Nicopolis, 1396-1996", Dijon 1996 (Annales de Bourgogne 68), Dijon 1997, p. 85-99.

Housley, Norman, The Later Crusades, 1274-1580: from Lyon to Alcazar, Oxford 1992.

Housley, Norman, The Avignon papacy and the Crusades, 1305-1378, Oxford 1986.

Housley, Norman, "A crusade against the Poles? Johannes Falkenberg's "Satira" (1412)», à paraître.

Howe, John M., "The Conversion of the Physical World. The Creation of a Christian Landscape», dans J. Muldoon (dir.), Varieties of Religious Conversions in the Middle-Ages, Gainesville 1997, p. 63-78.

Huizinga, Johan, L'Automne du Moyen Âge, Paris 1975.

Huntington, Samuel, Le choc des civilisations, Paris 1997.

IorgA, Nicolae, "Les Aventures "sarrazines" des Français de Bourgogne au $\mathrm{XV}^{\mathrm{e}}$ siècle», dans C. Marinescu (dir.), Mélanges d'Histoire Générale, Cluj 1927 , p. 7-56. 
Iorga, Nicolae, Philippe de Mézières (1327-1405) et la croisade au XIVe siècle, Paris 1896.

InNo, Karl, "Aestii, the Estonians, and the Origin of Eesti», Ural-Altaische Jahrbücher 54, 1982, p. 57-85.

Iwanowska, Grazyna «Excavations at the Jegliniec hillfort - recent developments in Balt archaeology", Antiquity 65/248, 1991, p. 684-695.

IwANCZAK, Wojciech, "La Mer Baltique dans la cartographie médiévale» dans A. Gautier, S. Rossignol (dirs.), De la Mer du Nord à la mer Baltique: Identités, contacts et communications au Moyen Âge. Actes de l'atelier de jeunes chercheurs, Boulogne-sur-Mer, les 15-17 octobre 2009, Lille 2012, p. 27-44.

Jagodzinski, Marek, "The Settlement of Truso", dans A. ENGLert, A. Trakadas (dirs.), Wulfstan's Voyage: The Baltic Sea Region in the early Viking Age as seen from shipboard, Roskilde 2009, p. 182-197.

JÄHNIG, Bernhardt, Johann von Wallenrode O.T. : Erzbischofvon Riga, Königlicher Rat, Deutschordensdiplomat und Bischof von Lüttich im Zeitalter des Schismas und des Konstanzer Konzils (um 1370-1419), Bonn-Godesberg 1970.

JAKštas, Juozas, Das Baltikum in der Kreuzzugsbewegung des 14.Jhs. Die Nachrichten Philipps de Mézières über die baltischen Gebiete, Bonn 1959.

Jaroszewska, Teresa, "A la découverte de l'Europe de l'Est: Tractatus de duabus Sarmatiis, Asiana et Europiana de Mathias de Miechow (1517)», dans E. Berriot-Salvadore, R. Aulotte (dirs.), Les représentations de l'Autre du Moyen Âge au XVII siècle, Saint-Etienne 1995, p. 17-29.

Jasinski, Tomasz, "The Golden Bull Allegedly Issued in 1226 by Friedrich II for the Teutonic Order", Quaestionnes Medii Aevi Novae 3, 1998, p. 221-244.

Jasinski, Tomasz, "Uwagi a autentycznosci Przywileju Kruszwickiego z Czerwca 1230 R.», Personae Colligationes Facta, Toruń 1991, p. 226-239.

Jeanpierre, Laurent, "Frontière", dans O. Christin (dir.), Dictionnaire des Concepts Nomades, Paris 2010, vol. 1, p. 157-169.

Jefferson, John, The Holy Wars of King Wladislas and Sultan Murad, Leiden 2012.

Jensen, Carsten Selch, "The Early Stage of Christianisation in Livonia», dans T. Lehtonen et K. V. Jensen (dirs.), Medieval History Writing and Crusading Ideology, Helsinki 2005, p. 207-215.

Jensen, Kurt Villads, "Crusading at the End of the World. The Spread of the Idea of Jerusalem after 1099 to the Baltic Sea Area and to the Iberian Peninsula», dans T. Nielsen, I. Fonnesberg-Schmidt (dirs.), Crusading on the Edge. Ideas and Practice of Crusading in Iberia and the Baltic Region, 1100-1500, Turnhout 2016, p. 153-176.

Jensen, Kurt Villads, Salonen, Kirsi, Vogt, Helle (dirs.), Cultural Encounters during the Crusades, Odense 2013. 
Jensen, Janus Møller, Denmark and the Crusades, 1400-1650, Leiden 2007.

JÉQuier, Léon, L'Armorial Bellenville. Cahiers d'Héraldique V, Paris 1993.

Johansen, Paul, Nordische Mission: Revals Gründung und die Schwedensiedlung in Estland, Stockholm 1951.

Joly, Aristide, Benoit-de-Sainte-More et le Roman de Troyes ou les métamorphoses d'Homère et de l'épopée gréco-latine au Moyen Âge, Paris 1871.

Jones, Terry, Chaucer's Knight: The Portrait of a Medieval Mercenary, Londres 1980.

Jonuks, Tonno, "Archeology of religion: possibilities and prospects", Journal of Estonian Archelogy, 9/1, 2005, p. 32-59.

JóźwIAK, Sławomir, Trupinda, Janusz, Organizacja życia na zamku krzyżackim w Malborku $w$ czasach wielkich mistrzów 1309-1457. Wydanie II uzupetnione i poprawione, Malbork 2011.

Jóźwiak, Sławomir, Kwiatkowski, Krzysztof, Szweda, Adam, Szybkowski, Sobiesław, Wojna Polski i Litwy z zakonem krzyżackim w latach 1409-1411, Malbork, 2010.

Judic, Bruno, «Le corbeau et la sauterelle. L'application des instructions de Grégoire le Grand pour la transformation des temples païens en églises», dans L. Mary et M. Sot (dirs.), Impies et païens entre Antiquité et Moyen Âge, Paris 2002, p. 97-125.

KajACKAS, Algimantas, "Archeological Investigations of Vilnius Cathedral», dans La Cristianizzazione della Lituania. Atti del Colloquio internazionale di storia ecclesiastica in occasione del 6 centenario della Lituania cristiana (13871987). Roma, 24-26 giugno 1987, Vatican 1989, p. 263-284.

KaHL, Hans-Dietrich, "Compellere intrare. Die Wendenpolitik Bruns von Querfurt im Lichte hochmittelalterischen Missions-und Völkerrechts», Zeitschrift für Ostforschung 4, 2/3, 1955, p. 161-193, 360-401.

KalA, Tiina, «Rural society and religious innovation: Acceptance and Rejection of Catholicism among the Native Inhabitants of Medieval Livonia", dans A. V. Murray (dir.), The Clash of Cultures on the Baltic Frontier, Farnham 2009, p. 169-190.

KaLA, Tiina, "The Incorporation of the Northern Baltic Lands", dans A. V. Murray (dir.), Crusade and Conversion on the Baltic Frontier, 1150-1500, Aldershot 2001, p. 3-20.

Kaljundi, Linda, Waiting for Barbarians. The Imagery, Dynamics and Functions of the Other in Northern German Missionary Chronicles, $11^{\text {th }}$-Early $13^{\text {th }}$ Centuries. The Gestae Hammaburgensis Ecclesiae Pontificum of Adam of Bremen, Chronica Slavorum of Helmold of Bosau, Chronica Slavorum of Arnold of Lübeck, and Chronicon Livoniae of Henry of Livonia, Tartu 2005 (mémoire de licence non publié). 
Kaluza, Z., "L'œuvre théologique de Richard Brinkley, O.F.M.», Archive d'histoire doctrinale et littéraire du Moyen Âge 64, 1989, p. 169-273.

Kamuntavicius, Rustis, "Memoirs of French travellers: a source of Lithuanian History in the Second Half of the Seventeenth Century", Lithuanian Historical Studies 3, 1998, p. 27-48.

Kappeler, Andreas, La Russie empire multiethnique, Paris 1994.

Karwasinska, Jadwiga, Les trois rédactions de "Vita I» de Saint Adalbert, Rome 1958.

Katzir, Yael, "The Second Crusade and the Redefinition of Ecclesia, Christianitas and Papal Coercive Power», dans M. Grevers, The Second Crusade and the Cistercians, New York 1992, p. 3-11.

Kedar, Benjamin Z., Crusade and mission: European approaches toward the Muslims, Princeton 1984.

KeEn, Maurice, "Gadifer de la Salle: a late medieval knight errant», dans C. Harper-Bill et R. Harvey (dirs.), The Ideals and Practice of Medieval Knighthood. Papers from the First and Second Strawberry Hill Conferences, Woodbridge 1986, p. 74-85.

Keen, Maurice, Chivalry, New Haven 1984 (rééd. 2005).

Keen, Maurice, "Chaucer's Knight, the English Aristocracy and the Crusade», dans V. J. Scattergood, J. W. Sherborne (éd.), English Court Culture in the Later Middle Ages, Londres 1983, p. 45-61.

Kehnel, Anne, "Le sacrifice du cheval. Une brève histoire de sa découverte d'Hérodote à Dumézil", dans B. Andennatten, A. Paravicini Bagliani et E. Pibiri (dirs.), Le cheval dans la culture médiévale, Florence 2015, p. 5-32.

Kiaupa, Zigmantas, The History of Lithuania, trad. S. C. Rowell, J. Smith, V. Urbonavicius, Vilnius 2005.

Kiaupa, Zigmantas, Kiaupienė, Jūrate, Kuncevičius, Albinas, The History of Lithuania before 1795, Vilnius 2000.

Kienzle, Beverly, Walton, James, "Bernard of Clairvaux (1090-1153)...» dans A. V. Murray (dir.), The Crusades: an Encyclopedia, vol. 1, p. 162-163.

Kinoshita, Sharon, "Noi siamo mercatanti Cipriani": How to Do Things in the Medieval Mediterranean", dans R. Blumenfeld-Kosinski, K. Petrov (dirs.), Philippe de Mézières and his Age. Piety and Politics in the Fourteenth Century, Leiden \& Boston 2012, p. 41-60.

Kiparsky, Valentin, "Philippe de Mézières sur les rives de la Baltique», Neuphilologische Mitteilungen 41/3-4, 1940, p. 61-67.

Klaczko, Julian, "Une Annexion d'autrefois. — Le royaume de Jagello et son dernier historien. Première partie», La Revue des Deux Mondes 82, 1869, p. 5-38.

KLaczкo, Julian, «Une Annexion d'autrefois. - II. - L'Ordre teutonique et le royaume de Jagello. Dernière partie", La Revue des Deux Mondes 82, 1869, p. 652-681. 
KLARE, Michael, "À Washington, scénarios pour un conflit majeur ", Le Monde diplomatique, septembre 2016, p. 1-9.

KL̦avinsš, Kaspars, "Le tracé de l'identité européenne de l'Espagne aux Pays Baltes", dans F. Sabaté (éd.), Identities on the Move, Berne 2014, p. 95-110.

KL,AVinsš, Kaspars, "The Significance of the Local Baltic Peoples in the Defence of Livonia (Late Thirteenth-Sixteenth Centuries) », dans A. V. Murray (dir.), The Clash of Cultures on the Baltic Frontier, Farnham 2009, p. 321-340.

KL,Avinš̌, Kaspars, "The Ideology of Christianity and Pagan Practices among the Teutonic Knights ", Journal of Baltic Studies 37/3, 2006, p. 260-276.

Klimas, Petras, Ghillebert de Lannoy in medieval Lithuania; voyages and embassies of an ancestor of one of America's great presidents, New York 1945.

KŁoczowski, Jerzy, Wozniweski, Muriel, «Les premières histoires de la Pologne publiées en France, à l'occasion de l'élection d'Henri de Valois", dans R. SAuzet (dir.), Henri III et son temps. Actes du colloque international du Centre de la Renaissance de Tours, octobre 1989, Paris 1992, p. 103-109.

KŁoczowski, Jerzy, La Pologne dans l'Église médiévale, Aldershot 1993.

KŁoczowski, Jerzy, "La Pologne et la christianisation de la Lituanie», dans La Cristianizzazione della Lituania. Atti del Colloquio internazionale di storia ecclesiastica in occasione del 6 centenario della Lituania cristiana (1387-1987). Roma, 24-26 giugno 1987, Vatican 1989, p. 137-157.

KŁoczowski, Jerzy (dir.), Histoire religieuse de la Pologne, Paris 1987.

KŁoczowski, Jerzy, «Les pays d'Europe du Centre-Est du XIV au XvII ${ }^{\mathrm{e}}$ siècle», dans N. Aleksiun et al., Histoire de l'Europe du Centre-Est, Paris 2004, p. 107-254.

Knoll, Paul W., "A Pearl of Powerful Learning": The University of Cracow in the Fifteenth Century, Leiden 2016.

Knoll, Paul W., "Wenta, Jarosław, Kronika tzw. Galla Anonima: Historyczne (monastyczne i genealogiczne) oraz geograficzne konteksty powstania», Speculum 88/1, 2013, p. 357-358.

Knoll, Paul W., "Poland as "Antemurale Christianitatis" in the Late Middle Ages ", The Catholic Historical Review, 60/3, 1974, p. 381-401.

Knoll, Paul W., The Rise of the Polish Monarchy: Piast Poland in East Central Europe, 1320-1370, Chicago 1972.

Knudson, Charles, "Saintré's Prussian Expedition", dans Études de langue et de littérature du Moyen Âge, offertes à Félix Lecoy, Paris 1973 p. 271-277.

KoŁodziejczyк, Dariusz, "Entre l'antemurale Christianitatis et la raison d'État. L'idée de Croisade en Pologne aux Xv ${ }^{\mathrm{e}}$ et Xvi ${ }^{\mathrm{e}}$ siècles", dans M.-M. DE CEvins (dir.), L'Europe centrale au seuil de la modernité: Mutations sociales, religieuses et culturelles. Autriche, Bohême, Hongrie et Pologne, fin du XIV siècle-milieu du XVI siècle. Actes colloque international de Fontrevaud (15-16 mai 2009), Rennes 2010, p. 19-26. 
Koncius, Joseph, Vytautas the Great, Great Duke of Lithuania, Miami 1964.

KöRntGen, Ludger, "The Emperor and his Friends: the Ottonian realm in the year 1000", dans P. UrbańCZyK (dir.), Europe around the Year 1000, Varsovie 2001, p. 465-488.

KотескI, Radosław, «The Desecration of Holy Places according to Witnesses' Testimonies in the Polish-Teutonic Order Trials of the $14^{\text {th }}$ Century", dans W. Sieradzan (dir.), Arguments and Counter-Arguments. The Political Thought of the 14th-and 15th Centuries during the Polish-Teutonic Order Trials and Disputes, Torun 2012, p. 69-110.

Kotov, Anton, «Novoe "pole boya” Tevtonskogo ordena», dans I. Dementiev (dir.), Studia Teutonica. Issledovaniya po istorii Nemetskogo Ordena, Kaliningrad 2012, p. 87-102.

KraAcK, Detlev, Monumentale Zeugnisse des spätmittelelalterlichen Adelsreise. Inschriften und Graffiti des 14.-16. Jahrhunderts, Göttingen 1997.

Kras, Paweł, "The Conversion of Pagans and Concept of Ius Gentium in the Writings of Cracow Professors in the First Half of the Fifteenth Century: An Overview", Bažnyčios Istorijos Studijos - Studies in Church History 6, 2013, p. 23-53.

Kristo, Gyula, Engel, Pal, Kubinyi, Andras, Histoire de la Hongrie médiévale, 2 vols., Rennes 2008.

Kruse, Holger, Paravicini, Werner, Ranft, Andreas (dirs.), Ritterorden und Adelsgesellschaften im spätmittelalterlichen Deutschland. Ein systematisches Verzeichnis, Francfort etc. 1991.

Kubon, Sebastian, "Der Friede von Racianz/Raciazek», Ordines Militares. Yearbook for the Study of the Military Orders 18, 2013, p. 39-53.

KuczyŃski, Stefan K., "Les hérauts d'armes dans la Pologne médiévale», dans B. Schnerb (dir.), Le héraut, figure européenne (XIV-XVI siècle). Actes du colloque de Lille, 2005 (Revue du Nord 88), Villeneuve d'Ascq 2006, p. 651-658.

Kuncevičius, Albinas, "Les Origines», dans Y. Plasseraud (dir.), Histoire de la Lituanie. Un Millénaire, Crozon 2009, p. 21-45.

Kwiatкowski, Krzysztof, "New Research into the Battle of Grunwald/ Tannenberg/Žalgiris. Attempt at an Overview», Historical Annals 79, 2013, p. 1-31.

Kwiatкowsкi, Krzysztof, «Prolog und Epilog temporis sanctis. Die Belagerung Kauens 1362 in der Beschreibung Wigands von Marbourg», Zeitschrift für Ostmitteleuropa-Forschung 57/2, 2008, p. 238-254.

Kwiatкowski, Stefan, Der Deutsche Orden im Streit mit Polen-Litauen, eine theologische Kontroverse über Krieg und Frieden auf dem Konzil von Konstanz (1414-1418), Stuttgart-Berlin-Cologne 2000. 
Lalande, Denis, Jean II le Meingre, dit Boucicaut (1366-1421): étude d'une biographie héroïque, Genève 1988.

Lalkoù, Ihar, Aperçu de l'histoire politique du Grand-Duché de Lithuanie, Paris 2000.

LAmberg, Marko, "Finns as aliens and compatriots in the late Medieval kingdom of Sweden", dans O. Merisalo (dir.), Frontiers in the Middle Ages. Proceedings of the Third European Congress of the FIDEM (Jyväskylä, June 2003), Turnhout - Louvain-la-Neuve 2006, p. 121-132.

Lannoy, Baudouin de, Hugues de Lannoy, le bon seigneur de Santes, Bruxelles 1957.

Lassabatère, Thierry, La Cité des Hommes. Eustache Deschamps, expression poétique et vision politique, Paris 2011.

Lassabatère, Thierry, "Théorie et éthique de la guerre chez Eustache Deschamps", dans P. Contamine, O. Guyotjeannin (dirs.), La guerre, la violence et les gens au Moyen Âge, vol. 1, Paris 1996, p. 35-48.

Lassabatère, Thierry, "Comment Dieux a confermée noblesce”. Identité fonctionnelle et culturelle de la noblesse dans l'œuvre d'Eustache Deschamps ", Cahiers de recherches médiévales et humanistes 13, 2006, p. 53-68.

Lavisse, Ernest, Études sur l'histoire de la Prusse, Paris 1879.

Lawaty, Andreas, "The Figure of "Antemurale" in the Historiography at Home and in Exile», dans M. Zadencka A. Plakans, A. Lawaty (dirs), East and Central European History Writing in Exile, Leiden 2015, p. 360-375.

LebecQ, Stéphane, Hommes, mers et terres du nord au début du Moyen Âge, vol. 1, Villeneuve d'Ascq 2011.

LebecQ, Stéphane, "Ohthere et Wulfstan: deux marchands-navigateurs dans le Nord-Est européen à la fin du $\mathrm{Ix}^{\mathrm{e}}$ siècle», dans H. Dubois, J.-C. HocQueT, A. VAuChez (dirs.), Horizons marins, itinéraires spirituels ( $V^{e}-X V I I T^{e}$ siècles). Mélanges Michel Mollat, Paris 1987, p. 167-182.

Lecouteux, Claude, "Paganisme, christianisme et merveilleux», Annales. Économies, Sociétés, Civilisations 37/4, 1982, p. 700-716.

Lecouteux, Claude, "Les cynocéphales. Étude d'une tradition tératologique de l'Antiquité au XII ${ }^{\mathrm{e}}$ s.", Cahiers de civilisation médiévale 24/94, 1981 p. 117-128.

Le Goff, Jacques, L'Imaginaire médiéval. Essais, Paris 1985.

LeguaI, André, «Bourbonnais et Auvergnats à la croisade de Prusse», Etudes Bourbonnaises 1991, p. 93-97.

Lehtonen, Tuomas, Jensen, Kurt V. (dirs.), Medieval History Writing and Crusading Ideology, Helsinki 2005.

Lelewel, Joachim, Géographie du Moyen Âge, 5 vols., Bruxelles, 1850 et 1852-1857. 
Lemeshrin, I., "Baltijskaja "basnja” v sostave khronografa 1261 goda. Folklornyj narrativ o Sovii», Tautosakos darbai (Folklore Studies) 30, 2005, p. $140-165$.

Lenartowicz, Aleksandra, "Paweł Włodkowic and Andreas Laskary as the Authors of the Polish Revindication Programme against the State of the Teutonic Order in 1412-1418", dans W. Sieradzan (dir.), Arguments and Counter-Arguments. The Political Thought of the 14th-and 15th Centuries during the Polish-Teutonic Order Trials and Disputes, Torun 2012, p. 111-122.

Leonard, Irving A., Books of the Brave. Being an Account of Books and of Men in the Spanish Conquest and Settlement of the Sixteenth-Century New World, Cambridge, Mass., 1949 (première édition).

LE Quellec, Jean-Loïc, "Le chouan dans le chêne", dans Idem, Voyage en mythologie: Dragons et Merveilles, Arles 2013, p. 63-95.

Leuridan, Théodore Histoire des seigneurs et de la seigneurie de Roubaix, vol. 2, Roubaix 1862.

LÉvi-Strauss, Claude, Anthropologie structurale, Paris 1958.

LÉvi-Strauss, Claude, Tristes tropiques, Paris 1955.

LÉvy, Bertrand, "Les racines culturelles de l'exotisme géographique, du Moyen Âge à la Renaissance européenne», Le Globe 148, 2008, p. 31-45.

LÉvy, Bertrand, "Géographie et littérature. Une synthèse historique ", Le Globe 146, 2006, p. 25-52.

Lewicki, Tadeusz «La voie Kiev-Vladimir (Wodzimiercz Wolynski) d'après le géographe arabe de XII ${ }^{\mathrm{e}}$ siècle», Rocznik Orientalistyczny 13, 1937, p. 91-105.

LEwis, Bernard, Comment l'Islam a découvert l'Europe, Paris 1992.

LIND, John H., "Mobilisation of the European Periphery against the Mongols», dans J. Staecker (dir.), The Reception of Medieval Europe in the Baltic Sea Region. Papers of the XIIth Visby Symposium held at Gotland University, Visby 2009, p. 75-90.

Lind, John H., "Consequences of the Baltic crusades in Target Areas: The Case of Karelia", dans A. V. Murray (dir.), Crusade and Conversion on the Baltic Frontier, 1150-1500, Aldershot 2001, p. 133-150.

Lotan, Shlomo, "The Teutonic Knights and their Attitude about Muslims: Saracens in the Latin Kingdom of Jerusalem and in the Baltic Region ", dans C. Hess, J. Adams (dirs.), Fear and Loathing in the North, Berlin 2015, p. 315-330.

Lotan, Shlomo, "The Battle of La Forbie (1244) and its Aftermath Re-eximination of the Military Order's Involvement in the Latin Kingdom of Jerusalem in the mid-Thirteenth Century", Ordines Militares. Yearbook for the Study of the Military Orders 17, 2012, p. 53-67. 
Lotter, Friedrich, "The Crusading Idea and the Conquest of the Region East of the Elbe», dans R. Bartlett, A. MacKay (dirs.), Medieval Frontier Societies, Oxford 1989 p. 265-306.

LüBKE, Christian, "The Polabian Alternative: Paganism between Christian Kingdoms", dans P. UrbańczyK (dir.), Europe Around the Year 1000, Varsovie 2001, p. 379-389.

MaAlouf, Amin, Les croisades vues par les Arabes, Paris 1983.

Magee, Jim, "Le temps de la croisade bourguignonne: l'expédition de Nicopolis", dans J. Paviot, M. Chauney-Bouillot (dirs.), Nicopolis 1396-1996. Actes du colloque international "Nicopolis, 1396-1996", Dijon 1996 (Annales de Bourgogne 68), Dijon 1997, p. 49-58.

MaIer, Christoph T., Preaching the Crusades: mendicant friars and the cross in the thirteenth century, Cambridge etc. 1994.

Maкоwiecki, Daniel, «Exploitation of Early Medieval Aquatic Environments in Poland and other Baltic Sea Countries: and Archaeozoological Consideration", L'Acqua nei secoli altomedievali: Spoleto, 12-17 aprile 2007, Spoleto 2008, vol. 2, p. 753-778.

Manteuffel, Tadeusz, "La mission balte de l'ordre de Cîteaux", dans La Pologne au $X^{*}$ Congrès international des sciences historiques à Rome, Varsovie 1953, p. 108-123.

Mannhardt, Wilhelm, Letto-Preussische Götterlehre, Riga 1936.

Marchal, Guy, «Schweizerfahne und Schweizer in der Schlacht bei Tannenberg 1410?: zum schweizergeschichtlichen Ertrag einer Faksimileedition der "Banderia Prutenorum" ", Revue d'Histoire Suisse 28/1, 1978, p. 66-72.

Marin, Olivier, "Filip Dobrý, Burgundsko a kř́rzové výpravy», dans Guillebert de Lannoy, Cesty a poselstva, éd. et trad. J. Svátek, M. Nejedlý, O. Marin, P. Soukup, Prague 2009, p. 42-71.

Marin, Olivier, "Histoires pragoises. Les chroniqueurs français devant la révolution hussite", Francia - Forschungen zur Westeuropäischen Geschichte 34/1, 2007, p. 59-58.

Marin, Olivier, L'archevêque, le maître et le dévot. Genèses du mouvement réformateur pragois. Années 1360-1419, Paris 2005.

Markman, Kristina, Between Two Worlds: A Comparative Study of the Representations of Pagan Lithuania in the Chronicles of the Teutonic Order and Rus', Los Angeles, 2015 (thèse de doctorat non publiée).

Markman, Kristina, "Tactics of Manipulation: A Revisionist Study of Gediminas and the Threat of Teutonic Invasion, 1315-1342», Comitatus 42, 2011, p. 115-133.

Margue, Michel, "Jean l'Aveugle, prince idéal et chevalier parfait: images et réalité", Hémecht. Zeitschrift für Luxemburger Geschichte 48, 1996, p. 367-378. 
Martenet, Marie-Gaëtane, "Le Récit de la bataille de Nicopolis (1396) dans les Chroniques de Jean Froissart: de l'échec à la gloire», Questes 30, 2015, p. 125-139.

MarX, Jean, La Légende arthurienne et le Graal, Genève 1952.

Maschke, Erich, «Der Ordensstaat Preußen in seinen deutschen und europäischen Beziehungen " publication originale dans Syntagma Friburgense. Historische Studien Hermann Aubin dargebracht zum 70. Geburtstag am 23. 12. 1955, Lindau \& Konstanz, 1955. Réimprimé dans E. MaschKe (dir.), Domus Hospitalis Theutonicorum. Europäische Verbindungslinien der Deutschordensgeschichte. Gesammelte Aufsätze aus den Jahren 1931-1963, Bonn-Bad Godesberg, 1970, p. 1-14.

Maschke, Erich, "Burgund und der preußische Ordensstaat. Ein Beitrag zur Einheit der ritterlichen Kultur Europas im Spätmittelalter», dans E. Maschke (dir.), Domus Hospitalis Theutonicorum. Europäische Verbindungslinien der Deutschordensgeschichte. Gesammelte Aufsätze aus den Jahren 1931-1963, Bonn-Bad Godesberg, 1970, p. 15-34.

MattÉoni, Olivier, "Portrait du prince idéal et idéologie nobiliaire dans "La Chronique du bon duc Loys de Bourbon" (1429)", Studi Francesi 115, 1995, p. 1-23.

Mattéoni, Olivier, Servir le prince: les officiers des ducs de Bourbon à la fin du Moyen Âge (1356-1523), Paris 1998.

Matthews, William K., "Baltic Origins», Revue des études slaves 24/1, 1948, p. $48-59$.

Matthews Sanford, Eva, "Ubi lassus deficit orbis», Philological Quarterly 13/4, 1934, p. 357-369.

Matuzova, Vera, "Mental Frontiers: Prussians as Seen by Peter von Dusburg», dans A. V. Murray (dir.), Crusade and Conversion on the Baltic Frontier, 1150-1500, Aldershot 2001, p. 253-259.

Mažeika, Rasa, Chollet, Loïc, "Familiar Marvels? French and German Crusaders and Chroniclers Confront Baltic Pagan Religions", Francia - Forschungen zur westeuropäischen Geschichte 43, 2016, p. 41-62.

MažEıka, Rasa, «Pagans, Saints, and War Criminals: Direct Speech as a Sign of Liminal Interchanges in Latin Chronicles of the Baltic Crusades", Viator 45/2, 2014, p. 271-288.

Mažeika, Rasa, "An Amicable Enmity. Some Peculiarities in Teutonic-Balt Relations in the Chronicles of the Baltic Crusades", dans C. Ingrao, F. Szabo (dirs.), The Germans and the East, West Lafayette 2008, p. 49-58.

MažEıKA, Rasa, «Probleme der ersten urkundlichen Erwähnung Litauens und der Interpretation der biographischen Quellen des heiligen Bruno», dans V. Dolinskas (dir.), Lietuvos krikščionëjimasVidurio Europas kontekst, Vilnius 2005, p. 86-108. 
Mažeika, Rasa, "Granting Power to the Enemy Gods in the Chronicles of the Baltic Crusades", dans D. Abulafia, N. Berend (dirs.), Medieval Frontiers: Concepts and Practices, Aldershot 2002, p. 153-171.

MažEIKA, Rasa, «Violent Victims: Surprising Aspects of the Just War Theory in the Chronicle of Peter von Dusburg", dans A. V. Murray (dir.), The Clash of Cultures on the Baltic Frontier, Farnham 2009, p. 123-137.

MažEıKA, Rasa, "When Crusader and pagan agree: conversion as a point of honour in the baptism of King Mindaugas of Lithuania (c.1240-1263)» dans A. V. Murray (dir.), Crusade and Conversion on the Baltic Frontier, 1150-1500, Aldershot 2001, p. 197-214.

MažEIKA, Rasa, "Nowhere was the Fragility of their Sex Apparent": Women Warriors in the Baltic Crusade Chronicles", dans A. V. Murray (dir.), From Clermont to Jerusalem: The Crusades and Crusader Societies, 1095-1400, Turnhout 1998, p. 229-248.

MAŽEIKA, Rasa, "Bargaining for baptism: Lithuanian negotiations for conversion, 1250-1358", dans J. Muldoon (dir.), Varieties of Religious Conversion in the Middle Ages, Gainesville 1997, p. 131-145.

MažEIKA, Rasa, "The Grand Duchy rejoins Europe», Journal of Medieval History 21, 1995, p. 289-303.

MažEIKa, Rasa, "Of cabbages and knights: Trade and trade treaties with the infidel on the northern frontier, 1200-1390", Journal of Medieval History 20, 1994, p. 63-76.

Mažeika, Rasa J., Rowell, Stephen C., "Zelatores Maximi: Pope John XXII, Archbishop Frederick of Riga and the Baltic Mission 1305-1340 ", Archivum Historiae Pontificiae 31, 1993, p. 33-68.

McLean, Matthew, The Cosmographia of Sebastian Münster: Describing the World in the Reformation, Farnham 2007.

Medeiros, Marie-Thérèse de, "L'Idée de croisade dans la "Mélusine" de Jean d'Arras", Cahiers de recherches médiévales et humanistes 1, 1996, p. $147-155$.

MeIER, Thomas, Die Archäologie des mittelalterlichen Königsgrabes im christlichen Europa, Stuttgart 2002.

Melville, Gert, "Pourquoi des hérauts d'armes? Les raisons d'une institution", dans B. Schnerb (dir.), Le héraut, figure européenne (XIVe-XVI siècle). Actes du colloque de Lille, 2005 (Revue du Nord 88), Villeneuve d'Ascq 2006, p. 491-502.

Melvinger, A., Les premières incursions des Vikings dans les sources arabes, Upsalla 1995.

Menache, Sophia, The Vox Dei: Communication in the Middle Ages, Oxford 1990. 
Mentzel-Reuters, Arno, Arma Spiritualia. Bibliotheken, Bücher und Bildung im Deutschen Orden, Wiesbaden 2003.

Meuvret Jean, Histoire des pays baltiques: Lituanie - Lettonie - Estonie Finlande, Paris 1934.

Meysztowicz, Valérien, La Pologne dans la Chrétienté, 966-1966, Paris 1966.

Michalowski, Roman, The Gniezno Summit. The Religious Premises of the Founding of the Archbishopric of Gniezno, Leiden 2016.

Michalowski, Roman, "La christianisation de la Pologne aux $\mathrm{x}^{\mathrm{e}}$-XII ${ }^{\mathrm{e}}$ siècles", dans M. Rouche (dir.), Clovis. Histoire et Mémoire. Actes du Colloque International d'Histoire de Reims, du 19 au 25 septembre 1996, Paris 1997, vol. 2, p. 419-434.

Mickūnaité, Giedre, Making a Great Ruler: Grand Duke Vytautas of Lithuania, Budapest 2006.

Mickūnaité, Giedre, "Art historical research in Lithuania: making local global and the other way around", Acta historiae artium Balticae 1, 2005, p. 14-25.

Militzer, Klaus, Von Akkon zur Marienburg: Verfassung, Verwaltung und Sozialstruktur des Deutschen Ordens 1190-1309, Marbourg 1999.

Militzer, Klaus, "The Teutonic Knights between Emperors and Popes", dans J. Sarnowsky, Mendicants, Military Orders, and Regionalism, Aldershot 1999, p. 71-82.

Milliman, Paul, The Slippery Memory of Men. The Place of Pomerania in the Medieval Kingdom of Poland, Leiden 2013.

Millet, Hélène, "Qui a écrit Le livre des faits du bon messire Jehan Le Maingre dit Bouciquaut?», dans M. Ornato, N. Pons (dirs.), Pratiques de la culture écrite en France au XV siècle, Turnhout 1995, p. 135-149.

Minaudier, Jean-Pierre, Histoire de l'Estonie et de la nation estonienne, Paris 2007.

Mishin, Dimitrij, «Ibrahim Ibn-Ya'qub At-Turtuhi's Account of the Slavs from the Middle of the Tenth Century», Annual of Medieval Studies at Central European University Budapest, 1994/95, p. 184-199.

Monfrin, Jacques, «Humanisme et traductions au Moyen Âge», Journal des savants, 1963, p. 161-190.

Moranvillé, Henri, «Relations de Charles VI avec l'Allemagne en 1400 », Bibliothèque de l'Ecole des Chartes 47, 1886.

Moranvillé, Henri, «Note sur l'origine de quelques passages de Monstrelet», Bibliothèque de l'École des chartes 62, 1901, p. 52-56.

Moritz, Eduard, Die Entwicklung des Kartenbildes der Nord-und Ostseeländer bis auf Mercator. Mit besonderer Berücksichtigung Deutschlands, Amsterdam 1967.

Morerod, Jean-Daniel, de Reynier, Christian, "Nidau und AarbergValangin", dans W. Paravicini, J. Hirschbiegel, A. P. Orlowska, 
J. Wettlaufer (dirs.), Höfe und Residenzen im spätmittelalterlichen Reich. Grafen und Herren, Sigmaringen 2012, vol. 2, p. 1069-1074.

Morerod, Jean-Daniel, «La Force du vœu. Le pèlerinage à Jérusalem de Guillaume de Chalon et ses témoins (1453-1454)", dans A. Paravicini Bagliani, E. Pibiri, D. Reynard (dirs.), L'itinérace des seigneurs (XIV-XVt siècles), Lausanne 2003, p. 89-102.

Mugurevics, Evalds, "The Military Activity of the Order of the Sword Brethen (1202-1236)", dans A. V. Murray (dir.), North Eastern Frontiers of Medieval Europe: the expansion of Latin Christendom in the Baltic Lands, Farnham 2014, p. 117-122.

MüHlethaler, Jean-Claude, «D’Énée à Jehan de Saintré: l'idéal littéraire à l'épreuve de la cour", dans L. Harf-Lancner, L. MatheyMaille, M. Szkilnik (dirs.), Conter de Troie et d'Alexandre. Pour Emmanuèle Baumgartner, Paris 2006, p. 115-133.

Muldoon, James, Popes, Lawyers, and Infidels. The Church and the Non-Christian World, 1250-1550, Philadelphie 1979.

Mund, Stéphane, "Constitution et diffusion d'un savoir occidental sur le monde "russe" au Moyen Âge (fin $\mathrm{x}^{\mathrm{e}}$-milieu $\mathrm{xv}^{\mathrm{e}}$ siècle) ( $1^{\text {re }}$ partie)", Le Moyen Âge, 110/2, 2004, p. 275-314.

Mund, Stéphane, "Constitution et diffusion d'un savoir occidental sur le monde "russe" au Moyen Âge (fin $\mathrm{x}^{\mathrm{e}}$-milieu Xv $\mathrm{xv}^{\mathrm{e}}$ siècle) ( $2^{\mathrm{e}}$ partie) », Le Moyen Age, 110/3, 2004, p. 539-593.

Mund, Stéphane, Orbis Russarum. Genèse et développement de la représentation du monde "russe» en Occident à la Renaissance, Genève 2003.

Mund, Stéphane, "Opisanie Novgoroda i Pskova v memuarakh Voyages et ambassades rytsarya Gil'bera de Lannoa (1413)", Drevniaia Rus': Voprosy medievistiki 1 (7), 2002, p. 47-50.

Mund, Stéphane, "Guillebert de Lannoy, un observateur fiable de la réalité russe au début du XVème siècle», dans C. Billen et al. (dir.), Hainaut et Tournaisis. Regards sur dix siècles d'histoire, Bruxelles 2000, p. 179-193.

Münzinger, Mark R., "The Profit of the Cross», dans A. V. Murray (dir.), The North-Eastern Frontiers of Medieval Europe: the expansion of Latin Christendom in the Baltic Lands, Farnham 2014, p. 329-352.

Murray, Alan V., "Heathens, Devils and Saracens. Crusader Concepts of the Pagan Enemy during the Baltic Crusades (Twelfth to Fifteenth Centuries)", dans T. Nielsen, I. Fonnesberg-Schmidt (dirs), Crusading on the Edge. Ideas and Practice of Crusading in Iberia and the Baltic Region, 1100-1500, Turnhout 2016, p. 199-223.

Murray, Alan V. (dir.), The North-Eastern frontiers of medieval Europe: the expansion of Latin Christendom in the Baltic Lands, Farnham 2014. 
Murray, Alan V., "Henry of Livonia and the Wends of the Eastern Baltic", Studi Medievali 54, 2013, p. 807-833.

Murray, Alan V., "Saracens of the Baltic: Pagan and Christian Lithuanians in the Perception of English and French Crusaders to Late Medieval Prussia», Journal of Baltic Studies 41/4, 2010, p. 413-429.

Murray, Alan V. (dir.), The Clash of Cultures on the Baltic Frontier, Farnham 2009.

Murray, Alan V. (dir.), The Crusades: an Encyclopedia, 4 vols., Santa Barbara etc. 2006.

Murray, Alan V. (dir.), Crusade and Conversion on the Baltic Frontier, 1150-1500, Aldershot 2001.

Murray, Alan V., "The structure, genre and intended audience of the Livonian Rhymed Chronicle", dans A. V. Murray (dir.), Crusade and Conversion on the Baltic Frontier, 1150-1500, Aldershot 2001, p. 235-250.

Nazarova, Evgenia, "The Crusades against Votians and Izhorians in the Thirteenth Century", dans A. V. Murray (dir.), Crusade and Conversion on the Baltic Frontier, 1150-1500, Aldershot 2001, p. 177-195.

Nederman, Cary J., "Toleration in Medieval Europe: Theoretical Principles and Historical Lessons», dans J. Muldoon (dir.), Bridging the MedievalModern Divide: Medieval Themes in the World of the Reformation, Farnham 2013, p. 45-64.

Nicholson, Helen (dir.), Palgrave Advances in the Crusades, Basingstoke 2005.

Niess, Ulrich, Hochmeister Karl von Trier (1311-1324). Stationen einer Karriere im Deutschen Orden, Marburg 1992.

Nef, Annliese, "Al-Idrīsī, un complément d'enquête biographique", dans H. Bresc, E. Tixier du Mesnil (dir.), Géographes et voyageurs au Moyen Age, p. 53-66.

Nejedlý, Martin, Středověký mýtus o Meluzinè a rodová pověst Lucemburkì, Prague 2014.

Nejedlý, Martin, " "Comment le roy Selodus fist ardoir le corps du roy Fedric de Bahaigne devan la porte de Prange". Les Tchèques et la croisade contre les Sarrasins dans Mélusine de Jean d'Arras (vers 1393)", dans M. NejedLÝ, J. Svátek (dirs.), Histoires et mémoires des croisades à la fin du Moyen Âge, Toulouse 2012, p. 255-272.

NejedlÝ, Martin, «Spisy středověkých cestovatelů jako podnět $\mathrm{k}$ "poutím mimo vyšlapané stezky" ", dans Guillebert de Lannoy, Cesty a poselstva, éd. et trad. J. Svátek, M. Nejedlý, O. Marin, P. Soukup, Prague 2009, p. 101-130.

Nielsen, Torben Kjersgaard, Fonnesberg-Schmidt, Iben (dirs.), Crusading on the Edge. Ideas and Practice of Crusading in Iberia and the Baltic Region, 1100-1500, Turnhout 2016. 
Nielsen, Torben Kjersgaard, "Henry of Livonia on Woods and Wilderness", dans M. Tамм et al. (dirs.), Crusading and Chronicle Writing: A Companion to the Chronicle of Henry of Livonia, Farnham 2011, p. 157-178.

Nielsen, Torben Kjersgaard, "Mission and Submission: Societal Change in the Baltic in the Thirteenth Century", dans T. Lehtonen et K. V. Jensen (dirs.), Medieval History Writing and Crusading Ideology, Helsinki 2005, p. 216-231.

Nikžentaitis, Alvydas, Mikailiené, Živilè, «Lithuanian Žalgiris, Polish Grunwald: two National Topoï in the Context of Comparative Analysis», Zapisky Historyczne 75/2, 2010, p. 5-16.

Nikžentaitis, Alvydas, "The "Imperial” Diplomacy of Lithuania», Lithuanian Foreign Policy Review, 2004, no 1-2 (13-14), p. 41-47.

Nikžentaitis, Alvydas, "Litauen unter den Großfürsten Gedimin (1316-1341) und Olgerd (1345-1377", dans M. Löwener (dir.), Die "Blüte” der Staaten des östlichen Europa im 14. Jahrhundert, Wiesbaden 2004, p. 65-76.

Nikžentaitis, Alvydas, "Prisoners of War in Lithuania and the Teutonic Order State (1283-1409)», dans Z. H. Nowak, R. Czaja (dirs.), Der Deutsche Orden in der Zeit der Kalmarer Union, 1397-1521 (Ordines militares. Colloquia Torunensia Historica 10), Toruń 1999, p. 193-208.

Nikžentaitis, Alvydas, "Die litauische Gesellschaft der vorchristlichen Zeit (13.-14. Jahrhundert) zwischen Rom und Byzanz", dans M. Müller-Wille (dir.), Rom und Byzanz im Norden, Stuttgart, 1997, vol. 2, p. 115-130.

NöвеL, Wilhelm, Michael Küchmeister. Hochmeister des Deutschen Ordens. 1414-1422, Bad Godesberg 1969.

Nordenskiöld, Adolf E., Facsimile-Atlas to the early history of cartography with reproductions of the most important maps printed in the XV and XVI centuries, New York 1973.

Norkus, Z., "Grand Duchy of Lithuania: A Comparative Historical Sociology Retrospective", World Political Science Review, 3/4, 2007, p. 1-41.

Norris, Harry, Islam in the Baltic: Europe's Early Muslim Community, Londres \& New York 2009.

Novák, Veronika, «La source du savoir. Publication officielle et communication informelle à Paris au début du $\mathrm{Xv}^{\mathrm{e}}$ siècle», dans C. Boudreau, K. Fianu, C. Gauvard, M. Hébert (dirs.), Information et société à la fin du Moyen Âge. Actes du colloque international tenu à l'Université du Québec à Montréal et à l'Université d'Ottawa (9-11 mai 2002), Paris 2004, p. 151-163.

NowaKowsKI, Wojciech, «Baltes et proto-Slaves dans l'Antiquité. Textes et archéologie», Dialogues d'histoire ancienne 16/1, 1990, p. 359-402.

Olivier, Mathieu, "La figure du roi de Lituanie Mindaugas dans l'Ancienne Chronique des Grands Maîtres", Bulletin d'Information de la Mission Historique Française en Allemagne 42, 2006, p. 234-248. 
Olivier, Mathieu, "Veteres relegentes historias": la place des chroniques dans la polémique entre l'Ordre teutonique et la Pologne au Concile de Constance (1414-1418)», dans P. H. Andersen et D. Buschinger (dirs.), Chroniques en tous genres. Actes du colloque d'Amiens (Mars 2006), Amiens 2006, p. 87-97.

Ossowska, Jadwiga, "Polish Contribution to the expeditions to the Holy Land", Folia Orientalia 26, 1989, p. 167-182.

OżóG, Krzysztof, Trupinda, Janusz (dirs.), Conflictus Magnus apud Grunwald 1410. Między Histori a Tradycją, Malbork 2013.

OżóG, Krzysztof, «University masters at the royal court of Hedwige of Anjou and Wladyslaw Jagiello", dans P. GoreckI et al. (dirs.), Central and Eastern Europe in the Middle Ages: a cultural history, Londres-New-York 2009, p. 147-160.

OżóG, Krzysztof, Uczeni w monarchii Jadwigi Andegaweńskiej $i$ Wtadystawa Jagietty (1384-1434), Cracovie 2004.

OżóG, Krzysztof, The Role of Poland in the Intellectual Development of Europe in the Middle Ages, Cracovie 2009.

Paladilhe, Dominique, La Bataille d'Azincourt, 1415, Paris 2002.

PALl, Francisc, "Bazgazul", domn al Valahiei, într-un roman francez din secolul al XV-lea», Studii. Revista de Istorie 11/1, 1958, p. 93-95.

Paravicini, Anke, Paravicini, Werner, "Alexander Soltan ex Lithuania, ritum graecorum sectans". Eine ruthenisch-polnische Reise zu den Höfen Europas und zum Heiligen Land 1467-1469", dans E. HüBNER et al. (dirs.), Zwischen Christianisierung und Europäisierung. Beiträge zur Geschichte Osteuropas in Mittelalter und Früher Neuzeit. Festschrift für Peter Nitsche zum 65. Geburtstag, Stuttgart 1998, p. 367-401.

Paravicini, Werner, Petrauskas, Rimvydas, Vercamer, Grischa (dirs.), Tannenberg - Grunwald - Žalgiris 1410: Krieg und Frieden im späten Mittelalter, Wiesbaden 2012.

Paravicini, Werner, "Mercenaires au Voyage de Prusse», dans G. Pépin, F. Lainé, F. Boutoulle (dirs.), Routiers et mercenaires pendant la guerre de Cent Ans, Bordeaux 2016, p. 277-301.

Paravicini, Werner, "Vom Kreuzzug zum Soldzug: Die Schlacht bei Tannenberg und das Ende der Preussenfahrten des europäischen Adels", dans K. Ożóg, J. Trupinda (dirs.) Conflictus Magnus apud Grunwald 1410. Między Histori a Tradycją, Malbork 2013, p. 119-126.

Paravicini, Werner, «Litauer: vom heidnischen Gegner zum adligen Standesgenossen", dans W. Paravicini, R. Petrauskas, G. Vercamer (dirs.), Tannenberg - Grunwald - Žalgiris 1410: Krieg und Frieden im späten Mittelalter, Wiesbaden 2012, p. 253-282.

Paravicini, Werner, "Jean de Werchin, sénéchal de Hainaut, chevalier errant", dans U. C. Ewert, A. Ranft, S. Selzer (dirs.), Noblesse: Studien 
zum adeligen Leben im spätmittelalterlichen Europa; gesammelte Aufsätze, Ostfildern 2012, p. 251-272.

Paravicini, Werner, "Nobles Hennuyers sur les chemins du monde: Jean de Werchin et ses amis autour de 1400 ", dans U. C. Ewert, A. Ranft, S. Selzer (dirs.), Noblesse: Studien zum adeligen Leben im spätmittelalterlichen Europa; gesammelte Aufsätze, Ostfildern 2012, p. 273-320.

Paravicini, Werner, Die ritterlich-höfische Kultur des Mittelalters, Munich 2011.

Paravicini, Werner, "Von der Preussenfahrt zum Hussitenkreuzzug", dans B. JäHnig (dir.), Beiträge zur Militärgeschichte des Preussenlandes von der Ordenszeit bis zum Zeitalter der Weltkriege, Marbourg 2010, p. 121-159.

Paravicini, Werner, «Prasmingas švaistymas: žygiai į Prūsiją ir Lietuvą Pierre’o Bourdieu kapitalų teorijos požūiriu", Lietuvos istorijos studijos 26, 2010, p. 9-21.

Paravicini, Werner, Gaston Fébus en Prusse: une aventure chevaleresque au $X I V^{\mathscr{V}}$ siècle, Ostfildern 2008.

Paravicini, Werner, «Von der ritterlichen zur höfischen Kultur: Der Deutsche Orden in Preußen", dans J. Wenta, S. Hartmann et G. Vollmann-Profe (dirs.), Mittelalterliche Kultur und Literatur im Deutschordensstaat in Preussen: Leben und Nachleben, Torun 2008, p. 15-54.

Paravicini, Werner, "Fakten und Fiktionen: Das Fegefeuer des hl. Patrick und die europäische Ritterschaft im späten Mittelalter», dans E. BREMER et S. RöHL (dirs.), Jean de Mandeville in Europa. Neue Perspektiven in der Reiseliteraturforschung, Münich 2007, p. 111-163.

Paravicini, Werner, "Das Haus Namur im Ostseeraum», dans J. Hirschbiegel, A. Ranft, J. Wettlaufer (dirs.), Edelleute und Kaufleute im Norden Europas. Gesammelte Aufsätze, Ostfildern 2007, p. 49-86.

Paravicini, Werner, «Fürstliche Ritterschaft: Otto von BraunschweigGrubenhagen", dans J. Hirschbiegel, A. Ranft, J. Wettlaufer (dirs.), Edelleute und Kaufleute im Norden Europas. Gesammelte Aufä̈tze, Ostfildern 2007, p. 87-126.

Paravicini, Werner, "Tiere aus Norden", dans J. Hirschbiegel, A. Ranft, J. Wettlaufer (dirs.), Edelleute und Kaufleute im Norden Europas. Gesammelte Aufsätze, Ostfildern 2007, p. 249-272.

Paravicini, Werner, "Gab es eine einheitliche Adelskultur Europas im späten Mittelalter?», dans J. Hirschbiegel, A. Ranft, J. Wettlaufer (dirs.), Edelleute und Kaufleute im Norden Europas. Gesammelte Aufä̈tze, Ostfildern 2007, p. 273-302.

Paravicini, Werner, «Edelleute, Hansen, Brügger Bürger: Die Finanzierung der westeuropäischen Preussenreisen im 14. Jahrhundert", dans J. Hirschbiegel, A. Ranft, J. Wettlaufer (dirs.), Edelleute und Kaufleute im Norden Europas. Gesammelte Aufsätze, Ostfildern 2007, p. 315-327. 
Paravicini, Werner, "Nobles artésiens et marchands lubecquois: une opération de change en 1349", dans J. Hirschbiegel, A. Ranft, J. Wettlaufer (dirs.), Edelleute und Kaufleute im Norden Europas. Gesammelte Aufä̈tze, Ostfildern 2007, p. 329-335

Paravicini, Werner, "Des animaux pour un roi mourant: Louis XI et les Hanséates de 1479 à 1483", dans J. Hirschbiegel, A. Ranft, J. Wettlaufer (dirs.), Edelleute und Kaufleute im Norden Europas. Gesammelte Aufsätze, Ostfildern 2007, p. 450-471.

Paravicini, Werner, "Le héraut d'armes: ce que nous savons et ce que nous ne savons pas", dans B. Schnerb (dir.), Le héraut, figure européenne (XIV-XVI siècle). Actes du colloque de Lille, 2005 (Revue du Nord 88), Villeneuve d'Ascq 2006, p. 465-490.

Paravicini, Werner, "Vom Erkenntniswert der Adelsreise: Einleitung», dans R. Babel, W. Paravicini (dirs.), Grand Tour. Adeliges Reisen und Europäische Kultur vom 14. bis zum 18. Jahrhundert. Akten der internationalen Kolloquien in der Villa Vigoni 1999 und im Deutschen Historischen Institut Paris 2000, Ostfildern 2005, p. 11-20.

Paravicini, Werner, "Bellenville". Wappenbücher, Herolde und Preußenfahrten in europäischer Forschung", Francia - Forschungen zur westeuropäischen Geschichte 32/1, 2005, p. 185-190.

Paravicini, Werner, "Seigneur par l'itinérance? Le cas du patricien bernois Conrad de Scharnachtal", dans A. Paravicini Balgiani, E. Pibiri, D. Reynard (dirs.), L'itinérance des seigneurs (XIV'-XVI siècles), Lausanne 2003, p. 28-71.

Paravicini, Werner, "Zeitenwende. Edelleute aus dem Ordensland Preussen und Livland im Westeuropa des 15. Jahrhunderts", dans P.-J. HeInig et al. (dirs.), Reich, Regionen und Europa in Mittelalter und Neuzeit. Festschrift für Peter Moraw, Berlin 2000, p. 413-442.

Paravicini, Werner, «Fahrende Ritter: Literarisches Bild und gelebte Wirklichkeit im Spätmittelalter», dans M. Neumeyer (dir.), Mittelalterliche Menschenbilder, Ratisbonne 2000, p. 204-254.

Paravicini, Werner, "La Prusse et l'Europe occidentale», Cahiers de recherches médiévales et humanistes 1, 1996, p. 176-191.

Paravicini, Werner, " "Fürschrifften und Testimonia." Der Dokumentationskreislauf der spätmittelalterlichen Adelsreise am Beispiel des kastilischen Ritters Alfonso Mudarra 1411-1412», dans J. Helmrath, H. Müller, H. WolfF (dirs.), Studien zum 15. Jahrhundert. Festschrift für Erich Meuthen, Munich 1994, vol. 2, p. 903-926.

Paravicini, Werner, «L'Ordre teutonique et les courants migratoires en Europe centrale XIII-XIv ${ }^{\mathrm{e}}$ siècles", dans S. Cavaciocchi (dir.), Le Migrazioni in Europa Secc. XIII-XVIII. Atti della "Venticinquesima Settimana di Studi" 3-8 maggio 1993, Florence 1994, p. 313-323. 
Paravicini, Werner, "Von der Heidenfahrt zur Kavalierstour. Über Motive und Formen adeligen Reisens im späten Mittelalter», dans H. Brunner, N. R. Wolf, (dirs.), Wissensliteratur im Mittelalter und in der Frühen Neuzeit, Wiesbaden 1993, p. 91-130.

Paravicini, Werner, «Verlorene Denkmäler europäischer Ritterschaft: Die heraldischen Malereien des 14. Jahrhunderts im Dom zu Königsberg», dans E. Böckler (dir.), Kunst und Geschichte im Ostseeraum. Tagungen 1988 und 1989. Homburger Gespräche. Heft 12, Kiel 1990, p. 67-168.

Paravicini, Werner, Die Preussenreisen des Europäischen Adels, 2 vols., Sigmaringen 1989-1995 (vols. 3-5 à paraître).

Paravicini, Werner, "Heraldische Quellen zur Geschichte der Preußenreisen im 14. Jahrhundert", Ordines Militares. Yearbook for the Study of the Military Orders 4, 1987, p. 111-134.

Paravicini, Werner, "Die Preußenreisen des europäischen Adels ", Historische Zeitschrift 232, 1981, p. 25-38.

Paravicini Bagliani, Agostino, "Autour de la Rose d'or du "comte de Neuchâtel” au Musée de Paris», dans P. Henry, M. de Tribolet (dirs.), In Dubiis Libertas. Mélanges d'histoire offerts au Professeur Rémy Scheurer, Hauterive 1999, p. 59-65.

Paravicini Bagliani, Agostino, «L'offrande des chevaux. Une question ouverte", dans E. Maier, A. Rochat, D. Tappy (dirs.), A Cheval entre histoire et droit. Hommage à Jean-François Poudret, Lausanne 1999, p. 109-117.

Päsler, Ralf G., Deutschsprachige Sachliteratur im Preussenland bis 1500. Intersuchungen zu ihrer Uberlieferung, Cologne etc. 2003.

Pasquier, François, Gaston Phoebus en Prusse (1357-1358), Foix 1893.

Pastoureau, Michel, L'Ours: histoire d'un roi déchu, Paris 2007.

Pastoureau, Michel, "Jouer au roi Arthur: anthroponymie littéraire et idéologie chevaleresque", dans M. Pastoureau (dir.), Une histoire symbolique du Moyen Âge occidental, Paris 2004.

Pastoureau, Michel, "La forêt médiévale: un univers symbolique», dans A. Chastel (dir.), Le Château, la chasse et la forêt, Bordeaux 1990, p. 83-98.

PAszKIEWICZ, Henryk, The Origin of Russia, Londres 1954.

PAtze, Hans, «Der Frieden von Christburg vom Jahre 1249», Jahrbuch für die Geschichte Mittel- und Ostdeutschlands 7, 1958, p. 39-91.

Paviot, Jacques, «Boucicaut et la croisade» dans M. Nejedlý, J. Svátek (dirs.), La noblesse et la croisade à la fin du Moyen Âge (France, Bourgogne, Bohême), Toulouse 2009, p. 69-83.

Paviot, Jacques, "Noblesse et croisade à la fin du Moyen Âge», Cahiers de recherches médiévales et humanistiques 13, 2006, p. 69-84.

Paviot, Jacques, Les ducs de Bourgogne, la croisade et l'Orient (fin XIVe-XVe siècle), Paris 2003. 
Paviot, Jacques, La Politique navale des ducs de Bourgogne, Lille 1995.

Paviot, Jacques, «La piraterie bourguignonne en mer Noire à la moitié du $\mathrm{XV}^{\mathrm{e}}$ siècle», dans H. Dubois, J.-C. Hocquet, A. Vauchez (dirs.), Horizons Marins, Itinéraires spirituels ( $V^{e}$-XVIII siècles). Mélanges Michel Mollat, Paris 1995, p. 204-214.

PÉPOrté, Pit, «When "Jan Lucembursky” meets "Jean l'Aveugle”: a comparison of King John of Bohemia's representation in the Czech Lands and Luxembourg", Husitsky Tabor 17, 2012, p. 29-49.

PÉPORTÉ, Pit, Constructing the Middle Ages: historiography, collective memory and nationbuilding in Luxembourg, Leiden 2011.

Petit, Ernest, Histoire des ducs de Bourgogne de la race capétienne, avec des documents inédits et des pièces justificatives, vol. 9, Paris 1905.

Petrauskas, Rimvydas, "Litauen und der Deutsche Orden: Vom Feind zum Verbündeten", dans W. Paravicini, R. Petrauskas, G. Vercamer (dirs.), Tannenberg - Grunwald - Žalgiris 1410: Krieg und Frieden im späten Mittelalter, Wiesbaden 2012, p. 237-252.

Petrauskas, Rimvydas, "Knighthood in the Grand Duchy of Lithuania from the Late Fourteenth to the Early Sixteenth Centuries ", Lithuanian Historical Studies 11, 2006, p. 39-66.

Petrauskas, Rimvydas, "La formation du Grand Duché aux XIII et $\mathrm{XIV}^{\mathrm{e}}$ siècles", dans Y. Plasseraud (dir.), Histoire de la Lituanie. Un Millénaire, Crozon 2009, p. 49-64.

Phillips, Kim H., Before Orientalism: Asian Peoples and Cultures in European Travel Writing, Philadelphie 2013.

Phipps, Colin, Saint Peter Damian's Vita Beati Romualdi, Londres 1988 (thèse de doctorat non publiée).

Piaget, Arthur, "Ballades de Guillebert de Lannoy et de Jean de Werchin», Romania 39/154-155, 1910, p. 324-368.

Pitz, Ernst, Papstreskript und Kaiserreskript im Mittelalter, Tübingen 1971.

Plasseraud, Yves (dir.), Histoire de la Lituanie. Un Millénaire, Crozon 2009.

Pleszczynski, Andrzej, "Poland as an ally of the Holy Roman Empire», dans P. UrbańczyK (dir.), Europe around the Year 1000, Varsovie 2001, p. 409-425.

Pluskowski, Aleksander, The Archaeology of the Prussian Crusade: Holy War and Colonisation, Londres 2013.

Pluskowski, Aleksander, "What is exotic? Sources of animals and animal products from the Edges of the Medieval World», dans G. JARITZ, J. KreEM (dirs.), The Edges of Medieval World, Budapest 2009, p. 113-129.

Pócs, Eva, "Le sabbat et les mythologies indo-européennes", dans N. JacQUEsChaquin, M. Préaud (dirs.), Le sabbat des sorciers. XVe-XVIII siècles, Grenoble 1993, p. 23-31. 
Podskalsky, Georges, "L'intervention de Grigorij Camblak, métropolite de Kiev, au concile de Constance (février 1418)", Revue des Études Slaves 70, 1998, p. 289-297.

Poklewski-Koziell, Tadeusz, "Barthossius Wezenborg, un grand chevalier polonais qui ne savait pas parlementer ( $2^{\mathrm{e}}$ moitié du XIV ${ }^{\mathrm{e}}$ siècle)" dans Châteaux, nobles et aventuriers. Actes des Rencontres d'archéologie et d'histoire en Périgord. 27, 28, 29 septembre 1996, Bordeaux 1999, p. 51-62.

Polejowski, Karol, "The Teutonic Order's Propaganda in France during the Wars against Poland and Lithuania (Fifteenth Century)", dans K. Borchardt, L. Jan (dirs.), Die geistlichen Ritterorden in Mitteleuropa. Mittelalter, Brno 2011, p. 233-242.

Polejowski, Karol, "Les comtes de Brienne et l'Ordre teutonique (XIII ${ }^{\mathrm{e}}$ $\mathrm{XIV}^{\mathrm{e}}$ siècle)", La Vie en Champagne 32, 2002, p. 4-8.

Pollini, Nadia, La Mort du Prince: rituels funéraires de la Maison de Savoie (1343-1451), Lausanne 1994.

Portal, Roger, Les Slaves: peuples et nations, Paris 1965.

Portnykh, Valentin, "La croisade anti-russe a-t-elle jamais existé au treizième siècle? Réflexions sur le livre récent d'Anti Selart", Revue d'histoire ecclésiastique 113/3-4, 2018, p. 885-894.

PósáN, László, "Ritterkultur im Spätmittelalterlichen Litauen», dans A. Bárány, I. Orosz, K. Papp, B. Vinkler (dirs.), Learning, Intellect and Social Roles: Aristocrats in Hungary and Europe, Debrecen 2014, p. 51-58.

Pósán, László, "Prussian mission and the invitation of the Teutonic Order into Kulmerland", dans A. V. Murray (dir.), The North-Eastern Frontiers of Medieval Europe: the expansion of Latin Christendom in the Baltic Lands, Farnham 2014, p. 135-154.

PoтаšEnko, Grigorijus, Multinational Lithuania. History of Ethnic Minorities, trad. Goda Sodeikaitè, Vilnius 2008.

Poucet, Jacques, «Le mythe de l'origine troyenne au Moyen âge et à la Renaissance: un exemple d'idéologie politique», Folia Electronica Classica 5, 2003 [en ligne].

Poutrin, Isabelle, "La conversion des musulmans de Valence (1521-1525) et la doctrine de l'Église sur les baptêmes forcés", Revue historique 648/4, 2008, p. 819-855.

Power, Amanda, Bacon and the defense of Christendom, Cambridge 2013.

Powierski, Jan, «Die Stellung der pommerellischen Herzöge zur PreussenFrage im 13. Jahrhundert", dans U. Arnold, M. Biskup (dirs.), Der Deutschenordensstaat Preussen in der polnischen Geschichtsschreibung der Gegenwart, Marbourg 1982, p. 103-132.

Prioult, Albert, "La politique de Vytautas le Grand jusqu'en 1409 et la bataille de Tannenberg-Grünwald", Bulletin de la Société d'Émulation $d u$ Bourbonnais, 1948 (troisième trimestre), p. 92-105. 
Prioult, Albert, "Un poète voyageur: Guillaume de Machaut et la "Reise" de Jean l'Aveugle, roi de Bohême en 1328-1329", Les Lettres Romanes 4/1, 1950, p. 3-29.

Puymaigre, Théodore de, "Jean l'Aveugle et la France», Revue des questions historiques 52, 1892, p. 391-432.

Puymaigre, Théodore de, "Une campagne de Jean de Luxembourg, roi de Bohême", Revue des questions historiques 42, 1887, p. 168-180.

QuARré-Reybourbon, Louis, La vie, les voyages et aventures de Gilbert de Lannoy, chevalier lillois au $X V^{e}$ siècle, Lille 1890.

Quentric-SÉguy, Martine, Au Bord du Gange. Contes des sages de l'Inde, Paris 1998.

Quillet, Jeannine "Le Miroir de mariage d'Eustache Deschamps", dans D. Buschinger, A. Crépin (éds.), Amour, mariage et transgressions au Moyen Âge, p. 457-464.

Rabikauskas, Paulius, "Les Jagellons», dans M. Rouche (dir.), Clovis. Histoire et Mémoire. Actes du Colloque International d'Histoire de Reims, du 19 au 25 septembre 1996, Paris 1997, vol. 2, p. 387-398.

Rabikauskas, Paulius, "La Cristianizzazione della Samogizia», dans La cristianizzazione della Lituania. Atti del Colloquio internazionale di storia ecclesiastica in occasione del 6 centenario della Lituania cristiana (1387-1987). Roma, 24-26 giugno 1987, Vatican 1989, p. 219-233.

Radkovska, Marie, "Le Songe du vieil pelerin: l'idée de croisade rêvée et vécue chez Philippe de Mézières", dans M. Nejeduŕ, J. Svátek (dirs.), La noblesse et la croisade à la fin du Moyen Âge (France, Bourgogne, Bohême), Toulouse 2009, p. 31-42.

Ragone, Giuseppe, «Il Liber insularum archipelagi di Cristoforo dei Buondelmonti: Filologia del testo, filogogia dell'immagine», dans D. Marcotte (dir.), Humanisme et culture géographique à l'époque du Concile de Constance, Turnhout 2002, p. 177-217.

Ragone, Giuseppe, "Membrana maxima”: Christoforo dei Buondelmonti, Vytautas of Lithuania and the First Modern Map of Constantinople", dans I. VAlikonyté (dir.), Lietuva ir jos kaimynai: nuo normany iki Napoleono. prof. Broniaus Dundulio atminimui, Vilnius 2001, p. 150-188.

Rebane, Peep Peter, "From Fulco to Theodoric: The Changing Face of the Livonian Mission", dans A. V. Murray (dir.), The North-Eastern Frontiers of Medieval Europe: the expansion of Latin Christendom in the Baltic Lands, Farnham 2014, p. 85-116.

ReID, Charles J. "Paulus Vladimiri, the Tractatus, Opinio Hostiensis, and the Rights of Infidels", dans P. Krafl (dir.), Sacri Canones Servandi Sunt, Prague, 2008, p. 418-423. 
Requemora, Sylvie, "L'espace dans la littérature de voyage», Études littéraires 34/1-2, 2002, p. 249-276.

Revest, Clémence, Romam veni. L'humanisme à la curie de la fin du Grand Schisme, d'Innocent VII au concile de Constance (1404-1417), Paris 2012 (thèse de doctorat non publiée).

Riasanovsky, Nicholas, Histoire de la Russie, trad. A. Berelowitch, Paris 1994.

Ribémont, Bernard, "M. Szkilnik, Jean de Saintré. Une carrière chevaleresque au XV siècle», Cahiers de recherches médiévales et humanistes [En ligne], 2003, mis en ligne le 15 juillet 2008, consulté le 17 août 2014. URL: http://crm. revues.org/255

Richard, Jean, «Les Papes d'Avignon et l'évangélisation du monde non-latin à la veille du grand schisme", dans Genèse et début du grand schisme d'Occident, Paris 1980, p. 305-315.

Richard, Jean, "L'Extrême orient légendaire au Moyen Âge: Roi David et Prêtre Jean", Annales d'Ethiopie 2/1, 1957, p. 225-244.

Rigby, Stephen H., "The Knight», dans A. J. Minnis, S. H. Rigby (dirs.), Historians on Chaucer. The "General Prologue" to the Canterbury Tales, Oxford 2014, p. 42-62.

Rigby, Stephen H., "Wise but worthy?: Virtuous and Non-Virtuous Forms of Courage in the Later Middle Ages", Studies in the Age of Chaucer 35, 2013, p. 329-371.

Riley-Smith, Jonathan, "Some Modern Approaches to the History of the Crusades", dans T. Nielsen, I. FonnesberG-Schmidt (dirs.), Crusading on the Edge. Ideas and Practice of Crusading in Iberia and the Baltic Region, 1100-1500, Turnhout 2016, p. 9-27.

Riley-Smith, Jonathan, The Crusades: a short history, Londres 1987 (trad. fr. Les Croisades, Paris 1990).

Riley-Smith, Louise, Riley-Smith, Jonathan, The Crusades. Idea and Reality, Londres 1981.

Robinson, Charles, Ansgar: The Apostle of the North, Londres 1921.

Robreau, Yvonne, L'Honneur et la honte, leur expression dans les romans en prose du Lancelot-Graal (XII'-XIII siècles), Genève 1981.

Rodinson, Maxime, La fascination de l'islam suivi de Le seigneur bourguignon et l'esclave sarrasin, Paris 1989.

RöHL, Susanne, "Le Livre de Mandeville à Paris autour de 1400", dans G. Croenen, P. Ainsworth, Patrons, Authors and Workshops: Books and Book Production in Paris Around 1400, Louvain etc. 2006, p. 279-295.

Rosset, François, "Infinitude et labilité: d'une frontière fantôme à l'est de l'Europe», dans S. Ghervas, F. Rosset (dirs.), Lieux d'Europe. Mythes et limites, Paris 2008, p. 139-147. 
Rossignol, Sébastien, «Early Towns and Regional Identities on the Eastern Coast of the Baltic Sea and in the Land of the Rus' as Perceived in Western and Central European Sources (9th - Early 12th Centuries)", dans J. Nómm (dir.), Ethnic Images and Stereotypes - Where Is the Border-line? (RussianBaltic Cross-cultural Relations), Narva 2007, p. 241-252.

Rousseau, Félix, "L'Expansion wallonne et lorraine vers l'Est, aux $\mathrm{XI}^{\mathrm{e}}$ et $\mathrm{XII}^{\mathrm{e}}$ siècles", Les dialectes belgo-romans 1, 1937, p. 171-198.

Rousset, Paul, Croisade. Histoire d'une idéologie, Lausanne 1983.

Rowell, Stephen C., "Christian Understanding of the Faith through contacts with Non-Christians in the late-mediaeval Grand Duchy of Lithuania", Bažnyčios Istorijos Studijos - Studies in Church History 6, 2013, p. 9-22.

Rowell, Stephen C., "The Grand Duchy of Lithuania and the Beginning of the Union with Poland: the Background to Grunwald", dans W. Paravicini, R. Petrauskas, G. Vercamer (dirs.), Tannenberg - Grunwald - Žalgiris 1410: Krieg und Frieden im späten Mittelalter, Wiesbaden 2012, p. 43-51.

Rowell, Stephen C., "Customs, rites and power in mediaeval and early modern Lithuanian society", dans D. Kaukenas, Kulturu Sankirtos, Vilnius 2000, p. 46-64.

Rowell, Stephen C., "Of Bears and Traitors, or: Political Tensions in the Grand Duchy, ca. 1440-1481», Lithuanian Historical Studies 2, 1997, p. 28-55.

Rowell, Stephen C., "Unexpected Contacts: Lithuanians at Western Courts, c. 1316-1400", The English Historical Review 111/442, 1996, p. 557-577.

Rowell, Stephen C., Lithuania Ascending: A Pagan Empire within East-Central Europe, Cambridge 1994.

Rowell, Stephen C., "Pious Princesses or the Daughters of Belial: Pagan Lithuanian Dynastic Diplomacy, 1279-1423", Medieval Prosopography 15/1, 1994, p. 3-79.

Rowell, Stephen C., "Of Men and Monsters: Sources for the History of Lithuania in the Time of Gediminas", Journal of Baltic Studies 24, 1993, p. 73-112.

Rowell, Stephen C., "The Letters of Gediminas: "Gemachte Lüge" ? Notes on a Controversy", Jahrbücher für Geschichte Osteuropas. Neue Folge 41/3, 1993, p. 321-360.

Rowell, Stephen C. "Lithuania and the West, 1337-41 - A Question of sources", Journal of Baltic Studies 20/4, 1989, p. 303-326.

Rowell, Stephen C., "A Pagan's Word: Lithuanian diplomatic procedure 1200-1385", Journal of Medieval History 18, 1992, p. 145-160.

Ruotsala, Antti, "The Crusaders and the Mongols», dans T. Lehtonen et K. V. Jensen (dirs.), Medieval History Writing and Crusading Ideology, Helsinki 2005, p. 302-309. 
Ruotsala, Antti, Europeans and Mongols in the Middle of the Thirteenth Century: Encountering the Other, Helsinki 2001.

Russell, Frederick H., "Augustine: Conversion by the Book", dans J. Muldoon (dir.), Varieties of Religious Conversions in the Middle-Ages, Gainesville 1997, p. 13-30.

Russell, Frederick H., «Paulus Vladimiri's attack on the Just War: a Case Study in Legal Polemics", dans B. Tierney, P. Linehan, Authority and Power. Studies on Medieval Law and Government presented to Walter Ullmann on his Seventieth Birthday, Cambridge etc. 1980, p. 237-254.

Russell, Jeffrey B., A History of Heaven. The Singing Silence, Princeton 1997.

Sadourny, Alain, "Les expéditions de Jean de Béthencourt aux Canaries: une préfiguration des expéditions du début des temps modernes?», dans M. Arnoux, A.-M. Flambard Héricher (dirs.), La Normandie dans l'économie européenne (XII'-XVII siècle), Caen 2010, p. 201-208.

Samsonowicz, Henryk, "Histoire de l'Europe du Centre/Est des origines au débuts du Xiv e siècle» dans N. Aleksiun et. al., Histoire de l'Europe du Centre-Est, Paris 2004, p. 3-106.

Samsonowicz, Henryk, "L'ordre des Chevaliers teutoniques", dans N. Aleksiun et. al., Histoire de l'Europe du Centre-Est, Paris 2004, p. 667-698.

Sanchez Jimenez, Antonio, «La Leyenda Negra: para un estado de la cuestión», dans Y. Rodríguez Pérez, A. SÁnchez Jiménez (dirs.), España ante sus críticos: las claves de la Leyenda Negra, éd. Madrid 2015, p. 23-44.

SARnowsky, Jürgen, "Military Orders and Crusading in the Fifteenth Century: Perception and Influence", dans N. Housley (dir.), Reconfiguring the Fifteenth-Century Crusade, Londres 2017, p. 123-160.

SARNOwsky, Jürgen, "Preussen und Rhodos als multiethnische Gesellschaften des 15. Jahrhunderts", Beiträge zur Geschichte Westpreussens 20/21, 2006/2008, p. 175-188.

Sarnowsky, Jürgen, "The Teutonic Order Confronts Mongols and Turks", dans M. Barber (dir.), The Military Orders 1. Fighting for the Faith and Caring for Sick, Aldershot 1994, p. 253-262.

SAW ICKI, Zbigniew et al., "Survival at the Frontier of Holy War: Political Expansion, Crusading, Environmental Exploitation and the Medieval Colonizing Settlement at Biała Góra, North Poland», European Journal of Archeology 18/2, 2015, p. 282-311.

Scheiber, Alexander, "La fumée des offrandes de Caïn et d'Abel. Historique d'une légende", Revue des Études Juives. Nouvelle Série 15 (115), 1956, p. 9-24.

Schmieder, Felicitas, "Tartarus valde sapiens et eruditus in philosophia. La langue des missionnaires en Asie», dans L'étranger au Moyen Âge. Actes des 
congrès de la Société des historiens médiévistes de l'enseignement supérieur public, $30^{\circ}$ congrès, Göttingen 1999, p. 271-281.

Schmidt-Chazan, Mireille, "Aubri de Trois-Fontaines, un historien entre la France et l'Empire", Annales de l'Est 36/3, 1984, p. 163-192.

Schmittlein, Raymond, Lokis. La dernière nouvelle de Prosper Mérimée, Bade 1949.

SchneIder, Barbara, Erich Maschke. Im Beziehungsgeflecht von Politik und Geschichtswissenschaft, Göttingen 2016.

Schnerb, Bertrand, Jean sans Peur: le prince meurtrier, Paris 2005.

Schnerb, Bertrand, L'État bourguignon 1363-1477, Paris 1999.

Schnerb, Bertrand, "Le contingent franco-bourguignon à la croisade de Nicopolis", dans J. Paviot, M. Chauney-Bouillot (dirs.), Nicopolis 1396-1996. Actes du colloque international "Nicopolis, 1396-1996", Dijon 1996 (Annales de Bourgogne 68), Dijon 1997, p. 59-74.

Schnippel, Emil, «Vom Streitplatz zum Tannenberge», Prussia: Zeitschrift für Heimatkunde und Heimatschutz 31, 1935, p. 7-67.

Scholem, Gershom, "The Curious History of the Six-Pointed Star. How the "Magen David" Became the Jewish Symbol», Commentary 8, 1949, p. 243-251.

Schubert, Ernst, «L'étranger et les expériences de l'étranger dans l'Allemagne médiévale et moderne", dans L'étranger au Moyen Âge. Actes des congrès de la Société des historiens médiévistes de l'enseignement supérieur public, $30^{\circ}$ congrès, Göttingen 1999, p. 191-215.

Scior, Volker, Das Eigene und das Fremde. Identitat und Fremdheit in den Chroniken Adams von Bremen, Helmolds von Bosau und Arnolds von Lubeck, Berlin 2002.

Selart, Anti, Livonia, Rus' and the Baltic Crusades in the Thirteenth Century, Leiden 2014.

Selart, Anti, «Political Rhetoric and the Edges of Christianity: Livonia and its Evil Enemies in the Fifteenth Century", dans G. Jaritz, J. Kreem (dirs.), The Edges of Medieval World, Budapest 2009, p. 55-69.

Seymour, Maurice C. et al., Bartholomaeus Anglicus and his Encyclopedia, Aldershot 1992.

Setton, Kenneth et al. (dir.), A History of the Crusades, 6 vols., Madison 1969 (rééd. 2006).

Sidorova, Vasilina, "The Slavic World in French Historical Writings of the Eleventh Century", dans M. Homza et al. (éds.), Slovakia and Croatia. Historical Parallels and Connections (until 1780), Bratislava-Zagreb 2013, p. 97-101.

Sieradzan, Wiesław (dir.), Arguments and Counter-Arguments. The Political Thought of the 14th-and 15th Centuries during the Polish-Teutonic Order Trials and Disputes, Toruń 2012. 
SieradzAN, Wiesław, "Benedek (Benedict) Makrai as a Subarbiter in the Conflict between the Teutonic Order and its Neighbour Countries in 1412-1413", dans W. Sieradzan (dir.), Arguments and Counter-Arguments. The Political Thought of the 14th-and 15th Centuries during the PolishTeutonic Order Trials and Disputes, Torun 2012, p. 157-168.

Sikorski, Dariusz, Przywilej kruszwicki: studium z wczesnych dziejów zakonu niemieckiego w Prusach, Varsovie 2001.

Silnicki, Tadeusz, "Queen Jadwiga (1374-1399)», dans J. Braun (dir.), Poland in Christian Civilisation, Londres 1985, p. 211-244.

Siminski, Rafal, "Ex Livonia ultima regione Europae. L'image de la Livonie dans la Littérature de l'Europe occidentale du $\mathrm{IX}^{\mathrm{e}}$ au début du Xvi ${ }^{\mathrm{e}}$ siècle", dans A. Gautier, S. Rossignol (dirs.), De la Mer du Nord à la mer Baltique: Identités, contacts et communications au Moyen Âge. Actes de l'atelier de jeunes chercheurs, Boulogne-sur-Mer, les 15-17 octobre 2009, Lille 2012, p. 189-204.

Smedt, Raphaël de (dir.), Les Chevaliers d'Ordre de la Toison d'or au XVe siècle. Notices bio-bibliographiques, Francfort 2000.

Sobiecki, Sebastian, "Cracow", dans D. Wallace (dir.), Europe, a literary history, Oxford 2016, vol. 2, p. 551-565.

Soloviev, Alexandre V., "Le voyage de messire de Lannoy dans les pays russes», dans D. Gerhard (éd.), Orbis scriptus. Festschrift für Dmitrij Tschižewskij zum 70. Geburtstag, Munich 1966, p. 791-796.

Sooman, Imbi, Donecker, Stefan (dirs.), The "Baltic Frontier" Revisited. Power Structures and Cross-Cultural Interactions in the Baltic Sea Region, Vienne 2009.

Sosnowski, Milosz, "Prussians as Bees, Prussians as Dogs: Metaphors and the Depiction of Pagan Society in the Early Hagiography of St. Adalbert of Prague", Reading Medieval Studies 39 (2013), p. 25-48.

Soukup, Pavel, "Crusading against Christians in the Fifteenth Century: Doubts and Debates", dans N. Housley (dir.), Reconfiguring the Fifteenth-Century Crusade, Londres 2017, p. 85-122.

Soukup, Pavel, "Religion and violence in the hussite wars", dans W. PALAver, H. Rudolph, D. Regensburger (dirs.), The European Wars of Religion. An Interdisciplinary Reassessment of Sources, Interpretations, and Myths, Farnham 2016, p. 19-44.

Spence, Richard T., "Pope Gregory IX and the Crusade in the Baltic», The Catholic Historical Review 69/1, 1983, p. 1-19.

Starnawska, Maria, "Military Orders and the Beginning of Crusades in Prussia», dans A. V. Murray (dir.), The North-Eastern Frontiers of Medieval Europe: the expansion of Latin Christendom in the Baltic Lands, Farnham 2014, p. 123-134. 
Sterchi, Bernhard, «Hugues de Lannoy, auteur de l'Enseignement de vraie noblesse, de l'Instruction d'un jeune prince et des Enseignements paternels", Le Moyen Âge 110/1, 2004, p. 79-117.

Steuer, Heiko, "Principles of trade and exchange: trade good and merchants", dans A. Englert, A. Trakadas (dirs.), Wulfstan's Voyage: The Baltic Sea Region in the early Viking Age as seen from shipboard, Roskilde 2009, p. 294-308.

Stomma, Ludwik, Krolów Polskich Przypadki, Varsovie 1993.

Sulowski, Zygmunt, "Le baptême de la Pologne», dans Millénaire du catholicisme en Pologne, Lublin 1969, p. 33-85.

Suziedelis, Saulius (dir.), Encyclopedia Lituanica, 6 vols., Boston 1970-1978.

SvÁtek, Jaroslav, Discours et récit de noble voyageur à la fin du Moyen Âge (Ogier d'Anglure, Nompar de Caumont, Guillebert de Lannoy, Bertrandon de la Broquière), Lille-Prague 2012 (thèse de doctorat non publiée).

SvÁter, Jaroslav, «Les voyages de Guillebert de Lannoy en péninsule Ibérique au début du Xv $v^{e}$ siècle", Publication du Centre Européen d'Etudes Bourguignonnes 51, 2011, p. 17-30.

SVÁtek, Jaroslav, "Guillebert de Lannoy, un seigneur bourguignon espion", dans M. Nejedlý, J. Svátex (dirs.), La noblesse et la croisade à la fin du Moyen Âge (France, Bourgogne, Bohême), Toulouse 2009, p. 69-84.

ŚWIEBODA, Wojciech, Innowiercy w opiniach prawnych uczonych polskich w XV wieku. Poganie, żydzi, muzutmanie, Cracovie 2013.

Szacherska, Stella Maria, "Valdemar II's expedition to Pruthenia and the mission of Bishop Christian", Mediaeval Scandinavia 12, 1988, p. 44-75.

Szczepanski, Seweryn, "Arbor custodie que vulgariter dicitur Wartboum. The function and existence of the so-called "watchtower trees" in Pomesania and Żuławy Wiślane in the 13th-14th centuries", Zapiski Historyczne 76/1, 2011, p. 5-18.

Szkilnik, Michelle, Jean de Saintré. Une carrière chevaleresque au XVe siècle, Genève 2003.

Szkilnik, Michelle, "Jean de Saintré ou le rêve d'une internationale chevaleresque", dans R. Bellveser (dir.), La Novel-la de Joanot Martorell i l'Europa del segle XV, Valence 2011, p. 371-387.

SzWEDA, Adam, «Polish and Teutonic diplomatic activity in Europe during the conflict of 1409-1411», History.pth.net.pl 1 (2011) [en ligne].

SzYвкошsкi, Sobiesław, "Polish Staff as a Social Group in the Chancellery of Grand Duke Witold», Quaestiones Medii Aevi Novae 3, 1998, p. 75-94.

Tamm, Marek, Kaljundi, Linda, Jensen, Carsten Selch (dirs.), Crusading and Chronicle Writing on the Medieval Baltic Frontier: A Companion to the Chronicle of Henry of Livonia, Farnham 2011. 
Tamm, Marek, "The Livonian Crusade in Cistercian Stories of the Early Thirteenth Century", dans T. Nielsen, I. FonnesberG-Schmidt (dirs), Crusading on the Edge. Ideas and Practice of Crusading in Iberia and the Baltic Region, 1100-1500, Turnhout 2016, p. 365-398.

TAмm, Marek, "How to justify a crusade? The conquest of Livonia and new crusade rhetoric in the early thirteenth century", Journal of Medieval History 39/4, 2013, p. 431-455.

TAMm, Marek, "Inventing Livonia: The Name and Fame of a New Christian Colony on the Medieval Baltic Frontier", Zeitschrift für OstmitteleuropaForschung 60/2, 2011, p. 186-209.

Tamm, Marek, "When Did the Dominicans Arrive in Tallinn?», Past: Ajalookultuuri ajakiri. Special issue on the history of Estonia, 2009, p. 35-45

Tamm, Marek, "A New World into Old Words: The Eastern Baltic Region and the Cultural Geography of Medieval Europe», dans A. V. Murray (dir.), The Clash of Cultures on the Baltic Frontier, Farnham 2009, p. 11-35.

Tамм, Marek, "Communicating Crusade. Livonian mission and the Cistercian network in the thirteenth century", Ajalooline Ajakiri 3/4 (129/130), 2009, p. 341-372.

TAмm, Marek, "Signes d'altérité. La représentation de la Baltique orientale dans le De proprietatibus rerum de Barthélemy l'Anglais (vers 1245)», dans O. Merisalo (dir.), Frontiers in the Middle Ages. Proceedings of the Third European Congress of the FIDEM (Jyväskylä, June 2003), Turnhout-Louvainla-Neuve 2006, p. 147-170.

Tамм, Marek, "Culture ecclésiastique et culture folklorique dans la Livonie médiévale. Echos des 'exempla' dans les contes populaires estoniens", Etudes finno-ougriennes 28, 1996, p. 29-68.

TAMM, Marek, «Les miracles en Livonie et en Estonie à l'époque de la christianisation (fin XII ${ }^{e}$-début XIII ${ }^{e}$ siècles)", dans J. KivimäE, J. KreEM (dirs.), Quotidianum Estonicum: Aspects of Daily Life in Medieval Estonia, Krems 1996, p. 29-78.

Tамм, Marek, «Martyrs and Miracles: Depicting Death in the Chronicle of Henry of Livonia", dans M. Tамм et al. (dirs.), Crusading and Chronicle Writing on the Medieval Baltic Frontier: A Companion to the Chronicle of Henry of Livonia, Farnham 2011, p. 135-156.

TAYLOR, Craig, Chivalry and the Ideals of Knighthood in France during the Hundred Years, Cambridge 2013.

Taylor, Jane H. M., "La Fonction de la Croisade dans Jehan de Saintré», Cahiers de recherches médiévales et humanistes 1, 1996, p. 193-204.

Tazbir, Janusz, «The Bullwark Myth», Acta Poloniae Historica 91, 2005, p. 73-97.

TANase, Thomas, "L'universalisme romain à travers les registres de lettres de la Papauté avignonnaise", Mélanges de l'École française de Rome - Moyen Âge 123-2, 2011, p. 577-595. 
Tanase, Thomas, "Exotisme, merveilles et mission dans les récits des Frères mendiants (XIII ${ }^{\mathrm{e}}-\mathrm{XIV}^{\mathrm{e}}$ siècles)», Hypothèses 11/1, 2008, p. 37-46.

Teiberis, Leonas, La Lituanie, trad. F. de Labriolle, Paris 1995.

Thomas, Paul-Louis, "L’Église médiévale de Bosnie était-elle dualiste? ", Slavica occitania 16, 2003, p. 113-131.

Tilman, Jean Paul, Geographical works of Albertus Magnus and his contributions to geographical thought, Ann Arbor 1971.

Todorov, Tzvetan, La Peur des barbares. Au-delà du choc des civilisations, Paris 2008.

Todorov, Tzvetan, Nous et les Autres. La réflexion française sur la diversité humaine, Paris 1989.

Todorov, Tzvetan, "La notion de littérature», dans La notion de littérature et autres essais, Paris 1987, p. 9-26.

Todorov, Tzvetan, La Conquête de l'Amérique. La question de l'autre, Paris 1982.

Todorov, Tzvetan, Littérature et signification, Paris 1967.

Tolan, John V., Le Saint chez le Sultan. La rencontre de François d'Assise et de l'islam. Huit siècles d'interprétation, Paris 2007.

Tolan, John V., Les Sarrasins: l'islam dans l'imagination européenne au Moyen Âge, trad. P.-E. Dauzat, Paris 2003.

Tolo, Khama-Bassili, L'intertextualité chez Merimée: l'étude des sauvages, Birmingham, Alabama 1998.

Toomaspoeg, Kristjan, «La guerre baltique au regard des sociétés de l'Europe méditerranéenne à la fin du Moyen Âge», dans D. Baloup, Ph. Josserand (dirs.), Regards croisés sur la guerre sainte. Guerre, religion et idéologie dans l'espace méditerranéen latin (XI'-XIII siècle), Toulouse 2006, p. 398-412.

Toomaspoeg, Kristjan, Les Teutoniques en Sicile (1197-1492), Rome 2003.

Toomaspoeg, Kristjan, Histoire des Chevaliers teutoniques, Paris 2001.

Tracy, Larissa, Torture and Brutality in Medieval Literature: Negotiations of National Identity, Woodbridge 2012.

Tripps, Johannes, "Tu seras le festin des vers". La Danse macabre de Niklaus Manuel Deutsch à Berne, d'après les copies à la gouache d'Albrecht Kauw (1649), Berne 2006.

Troubat, Olivier, La Guerre de Cent Ans et le Prince Chevalier. Le "Bon Duc" Louis II de Bourbon, 1337-1410, 2 vols., Montluçon 2001.

Tumler, Marian, Der Deutsche Orden im Werden, Wachsen und Wirken bis 1400 mit einem Abriss der Geschichte des Ordens von 1400 bis zur neuesten Zeit, Vienne 1955.

Tummuscheit, Astrid, "Pre-Christian Cult at Arkona. A short summary of the archeological evidence», dans A. Andren, K. Jennbert, C. Raudvere 
(dirs.), Old Norse Religion in long-term perspectives. Origins, Changes and Interactions, Lund 2006, p. 234-237.

Turchetti, Mario, Tyrannie et tyrannicide de l'Antiquité à nos jours, Paris 2001.

Tyerman, Christopher J., "Henry of Livonia and the Ideology of Crusading", dans M. Tамм et al. (dirs.), Crusading and Chronicle Writing on the Medieval Baltic Frontier: A Companion to the Chronicle of Henry of Livonia, Farnham 2011, p. 23-24.

Tyerman, Christopher J., England and the Crusades. 1095-1558, ChicagoLondres 1988.

Tyerman, Christopher J., "Marino Sanudo Torsello and the Lost Crusade: Lobbying in the Fourteenth Century", Transactions of the Royal Historical Society 32, 1982, p. 57-73.

Urban, William, "Frontier thesis and the Baltic Crusade», dans A. V. Murray (dir.), Crusade and Conversion on the Baltic Frontier, 1150-1500, Aldershot 2001, p. 45-71.

Urban, William, The Teutonic Knights: a Military History, Londres 2003.

Urban, William, Tannenberg and After, Chicago 2002 (revised edition).

Urban, William, "Victims of the Baltic Crusades», Journal of Baltic Studies 29/3, 1998, p. 195-212.

Urban, William, "The Teutonic Knights at the Council of Constance», dans M. Pelaez (dir.), Estudios de Historia de la Iglesia y de las instituciones ecclesiasticas en Europa: Trabajos en homenaje a Ferran Valls $i$ Taberner, Barcelone 1990, p. 4043-4063.

Urban, William, "The Teutonic Knights and Baltic Chivalry", The Historian 56/3, 1994, p. 519-530.

Urban, William, The Samogitian Crusade, Chicago 1989 (rééd. 2006).

Urban, William, "The Teutonic order and the Christianization of Lithuania», dans La Cristianizzazione della Lituania. Atti del Colloquio internazionale di storia ecclesiastica in occasione del 6 centenario della Lituania cristiana (13871987). Roma, 24-26 giugno 1987, Vatican 1989, p. 105-135.

Urban, William, «Tannenberg/Grunwald Today», dans K. OżóG, J. Trupinda (dirs.), Conflictus Magnus apud Grunwald 1410. Między Histori a Tradycja, Malbork 2013, p. 91-98.

Urban William, "Roger Bacon and the Teutonic Knights», Journal of Baltic Studies 19/4, 1988, p. 363-370.

Urban, William, "Peter von Suchenwirt», Lituanus 31/2, 1985.

Urban, William, "When was Chaucer's Knight in "Ruce"?", The Chaucer Review 18/4, 1984, p. 347-353.

Urban, William, "The Correct Translation of "Ruce" ", Journal of Baltic Studies 13/1, 1982, p. 12-18. 
Urban, William, "The Diplomacy of Teutonic Knights at the Curia», Journal of Baltic Studies 9/2, 1978, p. 116-128.

Urban, William, The Baltic Crusade, DeKalb 1975.

UrbanavičIenĖ, Saule, "Survivals of Paganism in $14^{\text {th }}-17^{\text {th }}$ Century Graves in Lithuania», dans M. Müller-Wille (dir.), Rom und Byzanz im Norden, Stuttgart 1997, vol. 2, p. 131-142.

Urbańczyk, Przemysław, Rosik, Stanisław, "The Kingdom of Poland with an Appendix on Polabia and Pomerania between paganism and Christianity", dans N. BEREnd (dir.), Christianization and the rise of Christian Monarchy. Scandinavia, Central Europe and Rus' c. 900-1200, Cambridge 2007, p. 263-318.

UrbańczyK, Przemysław, "On the reliability of Wulfstan's report», dans A. Englert, A. Trakadas (dirs.), Wulfstan's Voyage: The Baltic Sea Region in the early Viking Age as seen from shipboard, Roskilde 2009, p. 43-49.

UrbańczyK, Przemysław (dir.), Europe around the Year 1000, Varsovie 2001.

Valaityté, Rūta, "The Myth of Sovijus and its Relation to Lithuanian Cultural Memory", Tarpdalykiniai kultūros Tyrimai 1/1, 2013, p. 14-30.

VALE, Malcolm, War and Chivalry. Warfare abd Aristcratic Culture in England, France and Burgundy at the End of the Middle Ages, Londres 1981.

VALK, Heiki, "Christianisation in Estonia: A Process of Dual-Faith and Syncretism", dans M. CARver (dir.), The Cross goes North: Processes of Conversion in Northern Europe, AD 300-1300, Woodbridge 2003, p. 571-580.

VAlois, Noël, La France et le grand schisme d'Occident, vol. 2, Paris 1896.

VANA, Zdenek, Le Monde slave ancien, Paris 1983.

VAnder Elst, Stefan, "Chivalry, Crusade, and Romance on the Baltic Frontier", Mediaeval Studies 73, 2011, p. 287-328.

VANTUCH, Anton, «La participation liégeoise à la croisade contre les hussites en 1421, d'après Jean de Stavelot", Liège et Bourgogne. Actes du colloque tenu à Liège les 28, 29 et 30 octobre 1968, Liège 1972, p. 45-54.

VAuchez, André, "La christianisation comme élément d'intégration», dans J. KŁoczowski, H. Łaszkiewicz (dirs.), East Central Europe in European history, Lublin 2009, p. 97-107.

Vauchez, André, "La notion de Miles Christi dans la spiritualité occidentale $\operatorname{aux~XII}^{\mathrm{e}}$ et XIII ${ }^{\mathrm{e}}$ siècles», dans M. Aurell, C. Girbea (dirs.), Christianisme et chevalerie, Rennes 2011, p. 67-76.

VĖLIUS, Gintautas, «Istoriniai šaltiniai apie mirusųju deginimo paprotị Lietuvoje, išimtys ar taisyklè?" Lituanistica, 2001, p. 65-72.

VĖLIUs, Norbertas, "Marija Gimbutas: The Investigator of Baltic Mythology», dans K. Jones-Bley, M. E. Huld (éds.), The Indo-Europeanization of Northern Europe, Washington CD 1996, p. 181-190. 
VÉLIUS, Norbertas, "Mythology and religion of the early Lithuanias», dans J. Trinkunas (dir.), Of Gods and Holidays. The Baltic Heritage, Vilnius 1999, p. 46-55.

VicaIre, Marie-Hubert, Dominique et ses prêcheurs, Fribourg \& Paris 1979.

VoIsé, Waldemar, "Guillaume de Machaut en Pologne», dans Guillaume de Machaut, poète et compositeur. Colloque-Table Ronde organisé par l'Université de Reims, Reims, 19-22 avril 1978, Paris 1982, p. 49-54.

Voisé, Waldemar, "Guillaume de Machaut w Polsce i o Polsce», Muzyka: kwartalnik Instytutu Sztuki Polskiej Akademii Nauk 10/3, 1965, p. 52-62.

Wagner, Marc-André, Le cheval dans les croyances germaniques. Paganisme, christianisme et tradition, Paris 2005.

WaL, Wilhelm E. J. von, Histoire de l'Ordre teutonique par un chevalier de l'Ordre, 8 vols., Paris 1784-1790.

WalczaK, Dorota, Vandenborre, Katia, «Entretien avec Jean-Charles Ducène», Slavica bruxellensia 7, 2011 [en ligne].

Walter, Xavier, Avant les grandes découvertes: une image de la terre au XIV siècle, "Le voyage de Mandeville", Roissy-en-France 1997.

Walter, Philippe, "The Ditty of Sovijus (1261)», Archaelogia Baltica 15, 2011, p. $72-76$.

Wandycz, Piotr, "Western Images and Stereotypes of Central and Eastern Europe", dans A. Gerrits, N. Adler (dirs.), Vampires Unstaked. National Images, Stereotypes and Myths in East and Central Europe, Amsterdam, etc. 1995 , p. 5-23

Weber, Benjamin, "Toward a Global Crusade? The Papacy and the Non-Latin World in the Fifteenth Century», dans N. Housley (dir.), Reconfiguring the Fifteenth-Century Crusade, Londres 2017, p. 11-44.

Weber, Benjamin, Lutter contre les Turcs: les nouvelles formes de la croisade pontificale au $X V^{e}$ siècle, Rome 2013.

Weibel, Ernest, Mille Ans d'Allemagne: histoire et géopolitique du monde germanique, Paris 2004.

Wenskus, Reinhard, "The Teutonic Order and the Non-German Population of Prussia", dans A. V. Murray (dir.), The North-Eastern Frontiers of Medieval Europe: the expansion of Latin Christendom in the Baltic Lands, Farnham 2014, p. 207-238.

Wenskus, Reinhard, "Das Ordensland Preußen als Territorialstaat des 14. Jahrhundert», dans H. PATzE (dir.), Der deutsche Territorialstaat im 14. Jahrhundert, Sigmaringen 1970, vol. 1, p. 347-382.

Wenskus, Reinhard, "Über die Bedeutung des Christburger Vertrages für die Rechts- und Verfassungsgeschichte des Preußenlandes", dans E. BAHr (dir.), Studien zur Geschichte des Preußenlandes. Festschrift Erich Keyser, Marbourg 1963, p. 97-118. 
Wenskus, Reinhard, Studien zur Historisch-Politischen Gedankenwelt Bruns von Querfurt, Münster-Cologne 1956.

Wenta, Jarosław, Hartmann, Sieglinde (dirs.), Mittelalterliche Kultur und Literatur im Deutschordensstaat in Preussen: Leben und Nachleben, Toruń 2008.

Wenta, Jarosław, "Zu Gog und Magog. Einige Bemerkungen über die Verfasserschaft der "Descriptiones Terrarum" ", Etudes médiévales 7, 2006, p. 331-339.

Wenta, Jarosław, "Od tradycji ustnej do tradycji pisanej na przykladzie Kroniki Piotra z Dusburga", Res Historica 3, 1998, p. 73-85.

Westerdahl, Christer, "The Horse as a liminal agent», Archeologia Baltica 11, 2009, p. 314-327.

White, David G., Myths of the Dog-Man, Chicago 1991.

Wielgus, Stanisław, The Medieval Polish Doctrine of the Law of Nations: Ius Gentium, trad. J. M. Grondelski, Lublin 1998.

Williams, Robert A., The American Indian in Western Legal Thought. The Discourses of Conquest, New York/Oxford 1990 (réimpr. 2005).

Williamson, Joan B., "The "Chevallerie de la Passion Jhesu Crist": Philippe de Mezieres' Utopia», dans D. Buschinger, W. Spiewok (éds.), Gesellschaftsutopien im Mittelalter / Discours et figures de l'utopie au Moyen Age. V. Jahrestagung der Reineke-Gesellschaft / Sème Congrès annuel de la Société Reineke (Cala Millor - Mallorca, 20.-23. Mai 1994), Greifswald 1994, p. 165-173.

Williamson, Joan B., "Philippe de Mézières and the Idea of Crusade», dans M. Barber (dir.), The Military Orders 1. Fighting for the Faith and Caring for Sick, Aldershot 1994, p. 358-364.

Witкowski, Rafal, "Some remarks on the history of the Karaites in the Grand Duchy of Lithuania in the $15^{\text {th }}$ century ", Karaite Archives 1, 2013, p. 211-241.

Wood, Ian, "Categorising the cynocephali», dans R. Corradini, M. Gillis, R. McKitterick, I. van Renswoude (dirs.), Ego Trouble: authors and their identities in the Early Middle Ages, Vienne 2010, p. 125-36.

Wood, Ian, Missionary Life, New York 2001.

Woodward, David, Howe, Herbert M., "Roger Bacon on geography and cartography", dans J. НACKetT (dir.), Roger Bacon and the sciences. Commemorative essays, Leiden 1997, p. 199-222.

WüNsCh, Thomas, "Paulus Wladimiri und die Genese des "realistischen Denkens" in der Lehre von den internationalen Beziehungen: Der Krieg zwischen Polen und dem Deutschen Orden als Stimulus für ein neues politiktheoretisches Paradigma», dans W. Paravicini, R. Petrauskas, 
G. Vercamer (dirs.), Tannenberg - Grunwald - Žalgiris 1410: Krieg und Frieden im späten Mittelalter, Wiesbaden 2012, p. 27-42.

Wylie, James H., History of England under Henry the Fourth, 4 vols., Londres, 1884-1898.

Wyrozumski, Jerzy, "The East and the West in the Politics of Casimir the Great ", dans J. KŁoczowski, H. Łaszkiewicz (dirs.), East-Central Europe in European History, Lublin 2009, p. 193-203.

Wyrozumski, Jerzy, "L'idée de tolérance à l'université de Cracovie dans la première moitié du $\mathrm{Xv}^{\mathrm{e}}$ siècle», dans $\mathrm{S}$. WŁOdeK (dir.), Société et Église. Textes et discussions dans les universités d'Europe centrale pendant le Moyen Âge tardif: Actes du Colloque International de Cracovie organisé par la Société Internationale pour l'Etude de la Philosophie Médiévale, Turnhout 1995, p. 133-143.

Wyrozumski, Jerzy (dir.), L'université et la ville au Moyen Âge et autres questions du passé universitaire, Cracovie 1993.

Wyrwa, Tadeusz, La pensée politique polonaise à l'époque de l'humanisme et de la Renaissance: un apport à la connaissance de l'Europe moderne, Paris-Londres 1978.

Zadencka, Maria, Plakans, Andrejs, Lawaty, Andreas (dirs.), East and Central European History Writing in Exile, Leiden 2015.

Zahajkiewicz, Marek, "Théorie et pratique de l'évangélisation dans le processus de christianisation de la Lituanie», dans La Cristianizzazione della Lituania. Atti del Colloquio internazionale di storia ecclesiastica in occasione del 6 centenario della Lituania cristiana (1387-1987). Roma, 24-26 giugno 1987, Vatican 1989, p. 205-218.

ZajączKowski, Stanisław, "Wilhelm de Machaut i jego wiadomosci do dziejéw Polski i Litwy w XIV w.», Kwartalnik Historyczny 43/1-2, 1929, p. 217-228.

Zajączkowski, Zdzisław, "The Christianisation of Lithuania by Poland», dans J. Braun (dir.), Poland in Christian Civilisation, Londres 1985, p. 181-209.

Zakrzewski, Andrzej B., "Les Tatares dans le Grand Duché de Lituanie, $\mathrm{XV}^{\mathrm{e}}$-XVIII ${ }^{\mathrm{e}}$ siècles", dans I. VALIKonYté (dir.), Lietuva ir jos kaimynai: nuo normanu iki Napoleono. prof. Broniaus Dundulio atminimui, Vilnius 2001, p. 208-227.

Zdrenka, Joachim, Polityka Zagraniczna Ksiażat Szczecinsskich w Latach 1295-1411, Słupsk 1985.

Zimmermann, Harald, Der deutsche Orden in Siebenbürgen. Eine diplomatische Untersuchung, Cologne etc. 2001.

Zimmermann, Harald, "Der Deutsche Ritterorden in Siebenbürgen", dans J. Fleckenstein, M. Hellmann, Die geistlichen Ritterorden Europas, Sigmaringen 1980., p. 267-298. 
ŽŮREK, Václav, «Sur les traces des grands croisés. Le goût pour la croisade de Jean et Charles de Luxembourg et l'inspiration française", dans M. NejeduÝ, J. Sváter (dirs.), Histoires et mémoires des croisades à la fin du Moyen Âge, Toulouse 2012, p. 273-291.

\section{USUELS ET RESSOURCES ÉLECTRONIQUES}

Alffranzösisches Wörterbuch, éd. Adolf Tobler, Erhard Lommatzsch, Berlin puis Wiesbaden 1925-.

Dictionnaire Historique de la Langue Française, 2 vols., dir. Alain Rey, Paris 1992.

Dict. de l'ancienne langue française, 10 vols., dir. Frédéric Godefroy, Paris 1881-1902.

British Library - Catalogue of Illuminated Manuscripts:

http://www.bl.uk/catalogues/illuminatedmanuscripts/welcome.htm

Dictionnaire du Moyen Français:

http://www.atilf.fr/dmf/"

E-Codices - Bibliothèque virtuelle des manuscrits en Suisse:

http://www.e-codices.unifr.ch/fr

Gallica - Bibliothèque numérique de la Bibliothèque nationale de France:

http://gallica.bnf.fr

Sächsische Landesbibliothek :

http://www.slub-dresden.de/startseite/ 


\section{INDEX}

A

Absalon, archevêque de Lund 68

Adalbert de Prague 16, 60, 61, 100, 360, 386, 387, 388, 389, 390, 394, 431

Adam de Brême 17, 50, 53, 58, 61, 101, 102, 108, 353, 361, 363, 364, 371, 381, 382, 397, 410, 421

Adémar de Chabannes 16, 121, 388, 389, 390, 392

Agrigoroaei, Vladimir 322, 324

Albéric de Trois-Fontaines 98, 100, 107, 108, 353, 394, 399

Albert de Buxhövden 18, 72, 73

Albert le Grand 100

Albert Jastrzębiec 263, 311

Albert Suerbeer 99, 106, 109, 110

Albert III de Habsbourg 146, 162, 202

Albrecht Kauw 138

Alexander Soltan 315

Alexandre, grand-duc de Lituanie 317

Alexandre de Malonne 65, 66, 120

Alexandre III, pape $64,67,70$

Alexandre IV, pape 33, 97, 106, 117

Alexandre V, pape 263, 280, 286

Alexandrie 176, 318, 328, 336

Alfonso Mudarra 305, 306, 315

Alfred le Grand 53, 386

Algirdas, grand-duc de Lituanie 94, 194, 196, 221, 235, 236, 306, 323, 415

Allemagne 15, 17, 24, 29, 36, 62, 80, 89, 99, 100, 108, 110, 125, 180, 189, 190, 212, 259, 262, 264, 276, 277, 303, 323, 350, 371, 374, 375, 429, 441

Alphonse XI, roi de Castille 166

Amédée de Viry 212
Amédée VI, comte de Savoie 177

Amédée VIII, duc de Savoie 310

André Dias d'Escobar 289

André Laskary 263, 279, 281, 286

André Thevet 351, 446, 449

Andrzej Jastrzębiec 238

Angleterre 15, 16, 21, 24, 35, 36, 37, 39, 46, 59, 75, 76, 88, 104, 109, 120, 126, $127,142,143,146,147,149,150,157$, 158, 190, 208, 213, 219, 220, 223, 224, 233, 234, 247, 251, 258, 259, 264, 296, 299, 304, 306, 309, 310, 315, 319, 320, $321,354,356,381,386,417,441,443$, 452, 453

Annales de Prague 106

Annales de Quedlimbourg 49, 387

Annales de Toruń 18, 202, 203, 204, 252

Anne (Aldona), reine de Pologne 89

Anne de Cilley, reine de Pologne 263,

271

Antoine de Lusignan 411, 412, 413

Antoine de la Sale 17, 162, 165, 167, 184, 185, 187, 234, 244, 321, 322, 323, $324,325,326,328,330,344,346,369$, 416

Aragon, roi d' 174, 307, 314, 327

Arbois de Jubainville, Henri d' 75

Arnold de Lübeck 17, 97

Arthur de Richemont 243

Artois 169

Auguste, empereur romain 52

Augustin d'Hippone 395, 397, 399, 456

Autriche 106, 144, 181, 202, 236, 237 , 239, 249, 385 
Avignon 87

Avignon, papauté d' 16, 24, 37, 197,

240, 248, 263, 442

Azincourt, bataille d' 214, 291, 302, 329, 438

\section{B}

Bajazet $I^{\text {er }}$, sultan ottoman 248, 321

Bâle, concile de 310, 350

Baronas, Darius 235, 254, 261, 389, 432

Barthélemy, évêque d'Alet 91

Barthélémy l'Anglais 16, 40, 59, 97, 98, 99, 102, 104, 105, 111, 149, 353, 361, 362, 363, 364, 397, 399, 401, 403, 405, 407, 408, 410, 413, 415, 442, 455

Bartholomé de Las Casas 453

Bartlett, Robert 29, 65

Baudoin d'Aulne 98, 103, 107

Baudoin de Lannoy 145

Baudouin, évêque de Cracovie 65

Bavière 412

Bellenville, armorial 135, 144, 146, 227

Benedict Macra 279, 285, 314

Benoît de Sainte-Maure 402

Bernard, abbé de Saint-Chaffré 91, 92

Bernard de Clairvaux 15, 17, 32, 33, 39, $45,63,64,65,68,69,70,71,72,79,94$, 141, 205, 441, 455

Bernard de Lippe 77, 394

Berne 308

Berthold, évêque de Livonie 69, 71, 394

Bertrand du Guesclin 340, 417

Blaise de Vigénère 445

Blanchard, Joël 243, 422

Blomkvist, Nils 25, 56, 392, 404, 456

Boccace 343, 420

Bodzanta de Kosowice 237

Bogusław VIII de Słupsk, duc de

Poméranie 207, 277, 279

Bohême 47, 81, 102, 106, 116, 119, $125,143,167,168,169,170,171,172$, $173,176,180,185,186,187,189,191$, 193, 194, 195, 196, 197, 200, 201, 209, $212,215,226,228,253,269,277,284$, $309,310,320,323,324,328,344,393$, 411, 412, 419, 427, 428, 430, 436

Bojtár, Endre 406
Boleslas I ${ }^{\mathrm{er}}$, roi de Pologne 60, 389

Boleslas III, prince de Pologne 62, 65, 66, 70, 394

Boleslas le Frisé 66

Bonaventura, cardinal 241

Boniface, évêque de Lausanne 104

Boniface IX, pape 242, 286, 300, 312

Bosnie 209, 210, 339

Boucicaut, Jean II le Meingre dit 145 , $148,152,154,158,159,160,161,162$, $176,177,178,179,180,181,182,185$, $187,202,203,205,208,219,230,251$, 293, 321, 338, 339, 340, 341, 345, 349, 370, 456

Bourbon 20, 144, 159, 160, 161, 171, $177,178,180,182,187,205,210,212$, 228, 269, 350, 408

Bourgeois, Nicolas 68

Bourgogne 21, 126, 142, 143, 157, 158, 159, 163, 178, 247, 248, 256, 258, 274, $275,277,295,302,307,310,312,315$, 316, 330, 339, 345, 380, 417, 435

Bower, Walter 179

Brandebourg 87, 106, 115, 224

Brême 53, 58, 69, 88, 95

Bretagne 126, 165, 210, 370

Brétigny, paix de 144

Brundage, James 80

Bruno d'Olomouc 116, 119

Bruno de Querfurt 16, 49, 61, 100, 386, 387, 388, 389, 390, 431

Buc, Philippe 456

Buda (act. Budapest) 279, 315, 371, 372

Bulgarie 55, 248, 322, 323, 402

Butautas 195, 196, 222, 223, 226

C

Caen 210

Caffa 316, 438

Calatrava, voir Chevaliers de Calatrava

Canaries, îles 40, 158, 165, 197, 451

Casimir le Juste 64

Casimir III, roi de Pologne 87, 89, 113, 114, 180, 193, 206, 236, 238, 328

Casimir IV, roi de Pologne 302, 308, 326, 327, 331

Cassiodore 52 
Castille 74, 174, 306, 423

Caupo 77, 94

Cent Nouvelles Nouvelles 17, 40, 343, 344, 345, 356

Césaire de Heisterbach 77, 353, 394

Ceuta 143, 330

Champagne 126, 168

Chanson de Roland 121, 176, 230, 321,

427

Charlemagne 49, 52, 71, 321, 399

Charles d'Anjou-Durazzo 162

Charles de Bohême, voir Charles IV, empereur

Charles de Moravie, voir Charles IV, empereur

Charles de Savoisy 157, 225, 354

Charles le Téméraire, duc de Bourgogne 152

Charles de Trèves 114

Charles II le Mauvais, roi de Navarre

$168,169,174$

Charles IV, empereur 117, 167, 171,

$175,180,185,193,194,195,199,215$, 222, 226, 306, 328, 398

Charles IV, roi de France 91, 167, 170

Charles V, roi de France 160, 318, 415

Charles VI, roi de France 144, 165, 208, 209, 213, 225, 242, 243, 244, 245, 246, $247,248,250,256,257,258,274,275$, 296, 316, 318, 319, 329, 364, 367

Charles VII, roi de France 145, 307, 330

Chazaud, A.-M. 160

Chełmno (Pologne) 81, 85, 257, 262

Chevaliers de Calatrava 74, 418

Chevaliers hospitaliers 74, 143, 165

Chevaliers Porte-Glaives 15, 72, 76, 81, $85,95,103,104,105,107,108,418$

Chevaliers de la Table Ronde, armorial des 369, 370

Chevaliers du Temple 72, 73, 74, 87, 103, 107

Chevaliers teutoniques $15,17,18,19,20$, $23,24,25,26,27,28,29,30,31,32,33$, 34, 37, 39, 46, 57, 58, 59, 73, 74, 75, 76, $77,78,79,80,81,83,84,85,86,87,88$, $89,90,91,92,93,94,95,96,98,99,101$, 103, 104, 105, 106, 107, 108, 109, 110,
$111,112,113,114,115,116,117,118$, $119,120,125,126,141,144,145,148$, $149,152,153,154,156,157,159,160$, $161,163,166,167,169,170,172,173$, $177,178,181,187,188,189,190,192$, 193, 195, 196, 197, 198, 199, 200, 201, 202, 204, 206, 207, 208, 213, 214, 215 , 216, 217, 218, 219, 220, 221, 222, 227 , 228, 229, 230, 233, 234, 236, 237, 238, 239, 240, 241, 242, 243, 244, 245, 246, 247, 248, 249, 250, 251, 252, 253, 254, $255,256,257,258,259,260,261,262$, 263, 264, 265, 266, 267, 268, 269, 270, 271, 272, 274, 275, 276, 277, 278, 279, 280, 281, 282, 283, 284, 285, 286, 287 , 288, 289, 290, 291, 292, 293, 294, 296, 297, 298, 300, 301, 302, 303, 304, 305, 306, 307, 308, 311, 312, 313, 314, 315, $317,320,321,322,325,326,327,328$, 329, 330, 331, 334, 335, 336, 339, 349, 351, 352, 356, 357, 358, 359, 366, 367, 368, 369, 371, 372, 373, 374, 375, 376, 377, 378, 379, 380, 391, 394, 395, 396, 405, 408, 409, 410, 411, 413, 414, 415, 419, 420, 421, 423, 426, 427, 432, 434, 437, 439, 442, 443, 445, 446, 447, 449, 450, 452, 453, 454, 455, 456, 457, 458

Chichmaref, Vladimir 190

Chine 83, 424

Christbourg, traité de 57, 81, 104, 405, 407, 411

Christian, évêque de Prusse 73, 74, 80, 102, 105, 106, 392

Christiansen, Eric 32, 250

Christophe Colomb 451

Chronique de Bychow 19

Chronique de Galicie-Volhynie 19

Chronique des Grands Maîtres 18

Chronique de Novgorod 19

Chronique des Quatre Premiers Valois 154, 252, 329

Chronique de Westminster 156, 179, 180, 203, 221, 224, 251, 252, 255, 304, 356

Chronique rimée de Livonie 18, 23, 26, 56, 59, 77, 78, 97, 216, 395, 432

Chypre 186, 194, 195, 198, 223, 244, $318,328,354,414,424,425,452$ 
Clais de Utenhove 345

Clément d'Alexandrie 415

Clément IV, pape 81, 108, 216

Clément V 88

Clément VI 167, 171, 194

Clément VII, pape 240

Cleriadus et Méliadice 330

Cluny 64

Colker, Marvin 99

Cologne 77, 240, 245, 276, 300, 394

Conrad, duc de Mazovie 74, 78, 80, 98,

120, 287, 292

Conrad de Feuchtwangen 373

Conrad de Jungingen 240, 242, 247, 305

Conrad Justinger 265

Conrad de Wallenrode 18, 119, 252

Conrad Zöllner de Rothenstein 247, 249

Constance, concile de 15, 37, 230, 234,

236, 252, 258, 263, 270, 272, 280, 281, 286, 287, 289, 295, 296, 298, 299, 306, 322, 324, 326, 380, 434, 437, 447, 452

Constantinople 100, 236, 298, 311, 316, 320, 323

Contamine, Philippe 162

Coudrette 17, 167, 186, 411, 412

Courlande 52, 57, 100, 358, 363, 378, 383, 409, 410, 418

Cracovie 113, 155, 170, 186, 190, 195, 226, 234, 236, 237, 238, 248, 249, 252, 253, 257, 258, 267, 269, 279, 283, 286, 291, 292, 296, 307, 312, 327, 328, 411, 412, 444

Crécy, bataille de 141, 167, 168, 171, 186

Crimée 316, 438

Cristoforo dei Buondelmonti 298

Cujavie 170, 330, 393

\section{D}

Danemark 17, 63, 67, 70, 99, 100, 102, 143, 243, 277, 296, 329, 441

David de Grodno 115

Deluz, Christiane 151

Dembowski, Peter 164

Descriptiones terrarum 59, 99, 101, 105, 106, 110, 111, 189, 361, 396, 397, 403, 407

Diebold Schilling l'Ancien 136, 137, 265

Dietrich de Logendorf 258
Dimitri, grand-prince de Moscou 237

Dobrogost, évêque de Poznan 241

Dobrzyń (Pologne) 74, 79, 80, 114, 170, 257, 286

Dominique de Guzman 77, 80

Dumézil, Georges 60

Dzelal-ed-Din 272

\section{E}

Écosse 126, 287, 362, 368

Édouard I ${ }^{\text {er }}$, roi d'Angleterre 252

Édouard III, roi d'Angleterre 166

Eginhard 49, 52

Égypte 21, 76, 143, 316, 319, 331, 335, 378, 425

Ekdahl, Sven 266, 269, 273, 303

Elbląg (Pologne) 81, 158

Empire mongol 59, 82, 83, 88, 93, 98, 99, 105, 325, 326, 365, 424

Empire ottoman 17, 88, 143, 152, 208, 209, 210, 233, 234, 242, 247, 251, 266, 267, 269, 273, 299, 307, 308, 309, 310, $311,312,316,317,318,321,325,326$, 330, 331, 335, 339, 345, 346, 435, 445, 447, 457

Énée Sylvio Piccolomini 264, 350, 351, 369, 370, 374, 375, 418, 439, 444, 446, 449

Engelsbourg (Prusse) 278

Enguerrand de Coucy 340

Enguerrand de Monstrelet 19, 259, 266, 267, 269, 270, 271, 272, 273, 274, 295,

325, 326, 328, 356, 370, 437, 439

Éric de Poméranie, roi de Danemark 279, 296, 329

Eskil, archevêque de Lund 67, 68

Espagne 33, 36, 40, 45, 72, 73, 74, 78, 89, 114, 121, 126, 143, 146, 152, 164, $175,214,224,293,330,423,445,446$, 450, 451, 452

Est-Anglie 126

Estonie 15, 29, 36, 50, 51, 56, 67, 68, 70, 77, 80, 95, 97, 98, 100, 101, 327, 398, 402, 447

Eugène III, pape 15, 33, 39, 45, 63, 64, 69

Eustache Deschamps 164, 169, 340, 341, $342,354,368$ 


\section{F}

Finlande 15, 32, 36, 51, 120, 382, 383

Fischer, Mary 26

Flandre 67, 126, 158, 168, 247, 248,

252, 264, 324, 345, 346, 364, 367, 417

Fonnesberg-Schmidt, Iben 67, 72, 77, 83

Forstreuter, Kurt 91

Fraesdorff, David 53

France 15, 16, 21, 24, 30, 33, 35, 36, 37, 39, 40, 46, 48, 59, 62, 67, 75, 88,

99, 104, 109, 114, 126, 127, 141, 142, $143,147,152,154,158,161,167$, $172,180,182,183,184,185,186$, 191, 197, 205, 208, 210, 211, 213, 230, 233, 243, 245, 246, 247, 248, 251, 252, 258, 259, 264, 265, 266, 273, 274, 275, 276, 277, 282, 291, 296, 300, 301, 302, 303, 306, 307, $309,310,315,316,318,319,320$, 323, 324, 325, 329, 334, 336, 337, $338,339,340,350,354,360,364$, $367,368,371,376,380,386,388$, 392, 396, 407, 417, 428, 433, 435, 441, 443, 449, 453

Francesco Zabarella 286, 287, 295

François d'Assise 77

François de Belleforest 350, 369, 374, 445, 449

François Vinchant 266

Frédéric de Pernstein 87, 90, 91, 94, 113, 117

Frédéric II Hohenstauffen, empereur 80, 88, 104, 374

Frise 226

Fulco, évêque des Estoniens 67, 68

G

Gadifer de la Salle 40, 158, 162, 164, $165,185,196,197,451$

Galicie 19, 59, 83, 171, 206

Galles, Pays de 370

Gallus Anonymus 48, 54, 61, 62, 66, 361, 399

Galon, évêque de Paris 65

Gand 345, 367

Gaston Fébus 126, 144, 356, 378

Gaucher, Elisabeth 454
Gdańsk 49, 88, 153, 156, 277, 278

Gediminas, grand-duc de Lituanie 46, $86,89,91,92,93,94,111,112,113$, 114, 115, 169, 171, 173, 190, 193, 194, 196, 217, 218, 221, 235, 298, 414, 416, 421, 422, 426, 431, 432, 434

Gelre, armorial de 146

Gênes 101, 311

Geoffrey Chaucer 17, 36, 146, 174, 175, $176,181,342,420$

Geoffrey Scrope 206

Geoffroi de Charny 142, 180, 314, 354, 454

Geoffroy de Thoisy 311

Geoffroy le Meingre 158, 177

Georg Eglinger 262

Géorgie 311

Gervais de Tilbury 100, 101, 103

Geste du Prince Igor 84

Giedroyć, Michal 29, 30

Gilles le Bouvier, dit Berry 17, 20, 21, 145, 146, 225, 234, 301, 302, 325, 326, $327,328,346,350,360,364,365,366$, $368,370,371,381,382,383,435,439$, 445

Ginzburg, Carlo 25

Giovanni da Carignano 101, 385

Gładysz, Mikółaj 65, 66

Głodek, Marzena 335

Gniezno (Pologne) 61, 237, 238, 257,

263, 281, 289

Górski, Karol 118, 246

Gotland 252

Gouguenheim, Sylvain 29, 78, 119, 264, 273, 303, 376, 393

Grabski, Andrzej 35, 253, 254

Grandes Chroniques de France 168

Grèce 103, 146, 174, 298

Grégoire le Grand 390

Grégoire Tsamblak 297

Grégoire IX, pape 74, 77, 80, 83, 98,

103, 104, 376, 393, 422

Grégoire X, pape 111, 116, 119

Grégoire XI, pape 202

Greimas, Algirdas 57

Grenade 41, 170, 174, 211, 423, 433, 434, 451 
Guard, Timothy 299

Guillaume d'Aarberg 310

Guillaume de Challant 280

Guillaume de Chalon 147

Guillaume d'Egmond 115, 172, 191

Guillaume Fillastre 281, 282, 297, 298

Guillaume de Gueldre 226, 291

Guillaume de Habsbourg 236, 239, 249

Guillaume de Hainaut 227

Guillaume de Machaut 17, 21, 37, 38, 126, $144,152,167,168,169,170,171,172$, $173,174,175,176,177,178,183,185$, 187, 188, 189, 190, 191, 192, 193, 194, 195, 196, 198, 199, 200, 201, 211, 213 , 230, 328, 332, 354, 357, 366, 367, 426, 428 Guillaume de Modène 77, 78, 79, 80, 95, 103, 107

Guillaume de Rubrouck 99, 105, 109, 110, 111, 150, 151, 353, 365, 442 Guillaume de Tignonville 248

Guillebert de Lannoy 17, 20, 21, 22, $142,143,144,145,163,182,197,198$, 199, 206, 207, 208, 210, 211, 214, 245, 246, 248, 269, 275, 276, 277, 278, 279, 287, 291, 298, 300, 301, 302, 303, 306, $307,309,312,313,314,315,316,317$, $322,329,338,346,350,357,358,360$, $362,365,366,368,377,378,379,380$, 409, 410, 411, 413, 416, 432, 433, 434, 435, 436, 437, 438, 439, 446, 448, 454, 455, 456

Günther de Hohenstein 218

Güttner-Sporzynski, Dariusz von 65

Guy II de Chauvigny 202, 203, 211, 224,452

\section{$\mathbf{H}$}

Habsbourg (famille) 236, 239, 240, 241, 332

Hainaut 126, 196, 218, 225, 227, 259, 275, 296, 312, 313

Halecki, Oskar 208

Hambourg 58, 69, 95

Hamy, Ernest-Théodore 302

Hartog, François 405, 413

Hartwig, archevêque de Hambourg-

Brême 69, 95
Hedwige d'Anjou, reine de Pologne 196, 236, 237, 238, 239, 240, 241, 244, 245, 249, 256, 263, 270, 271, 319, 429, 442

Hélinand de Froidmont 404

Helmold de Bosau 17, 108, 391

Henri le Barbu, duc de Silésie 74

Henri de Derby, duc de Lancastre 144 , 156, 157, 162, 182, 203, 206, 221, 224, 251, 252, 253, 258, 274, 299, 304, 334, 338, 344, 349, 356, 366, 452

Henri de Grosmont, duc de Lancastre 144, 155

Henri Knighton 156

Henri le Lion, duc de Saxe 24, 63

Henri de Livonie 18, 24, 31, 58, 77, 84, 97, 148, 390, 392, 396, 404, 405, 407, 422

Henri de Plauen 245, 260, 261, 262, 265, 272, 273, 277, 278, 301, 436

Henri de Schöningen 222

Henri de Valois, roi de France et de Pologne 27, 350

Henri II, empereur 386

Henri III, roi d'Angleterre 76

Henri IV, roi d'Angleterre, voir Henri de

Derby, duc de Lancastre

Henri V, roi d'Angleterre 329, 438

Henri VII, empereur 167

Henri le Teichner 331, 343

Herburt de Fulstin, Jan 27

Hermanaric 52

Hermann de Salza 79, 373

Hermann de Wartberge 18, 23, 119, 194, 224, 415

Hérodote 51, 98, 405

Hirsch, Theodor 28

Hongrie 47, 48, 74, 82, 88, 157, 171, 172, 178, 193, 195, 196, 206, 208, 209, 210, 236, 239, 247, 248, 252, 253, 260, 269, 270, 271, 272, 273, 274, 285, 307, $309,322,326,328,339,340,346,354$, $370,371,372,398,435,437,446$

Honorius III 74, 77, 79, 80, 81, 83, 392, 393

Horodło, union de 28, 227, 260

Hospitaliers, voir Chevaliers hospitaliers Hostiensis 82, 116, 287, 289 
Housley, Norman 32, 208, 241, 281

Hugues Butyr 66, 120

Hugues de Lannoy 17, 142, 145, 163 ,

$164,214,275,276,312,313,358,453$,

454

Huizinga, Johan 34

Humbert de Romans 111

Humbert de Savoie 120

Humbert II du Viennois 318

Huntington, Samuel 447

\section{I}

Ibrahim Ibn Yaqub 49, 55, 360

Inde 378, 421, 424

Inigo Lopez Mendoza 175

Innocent III, pape $70,71,72,73,77,82$, 95, 395, 397

Innocent IV, pape $81,82,83,85,86,98$, 99, 104, 109, 287, 288, 395, 396, 418

Irlande 109, 362, 363, 370, 437

Isidore de Séville 98, 150

Italie $15,36,40,59,61,85,114,126$, 202, 226, 286, 298, 305, 386, 392, 399, 441, 452

Iziaslav, prince de Polotsk 84

$\mathbf{J}$

Jacob Kurdwanowski 263

Jacques, bâtard de Briffoeil 218

Jacques d'Esch 17, 20, 178, 179, 182, 204, 205, 208, 215, 217, 221, 222, 228, $230,255,291,322,350,358,363,365$, 409, 410, 455

Jacques de Vitry 73, 417

Jacques de Voragine 375

Jacques Lenfant 28, 268, 282

Jacques Pantaléon 81, 104, 405

Jakštas, Juozas 200, 244, 246, 248

Jan Długosz 18, 19, 27, 28, 59, 201, 238, 245, 253, 254, 256, 260, 265, 268, $282,283,285,289,295,300,301,313$, $315,324,329,391,416$

Janusz de Mazovie 218, 220

Jan Žižka z Trocnova 259

Jarosław d'Iwno 257, 258, 282, 330

Jatvingie 100, 102

Jean, duc de Berry 186, 223, 253
Jean sans Peur, duc de Bourgogne 247, 345

Jean d'Arras 17, 19, 139, 167, 186, 187 , 229, 253, 273, 350, 354, 411, 413, 419

Jean le Bel 210

Jean de Béthencourt 165, 197, 451

Jean Brandon 264

Jean du Bueil 165

Jean Cabaret d'Orville 20, 120, 160, 161, 203, 208, 210, 212, 228, 247, 341, 350, 358, 369, 370, 381, 408

Jean Canaparius 386, 431

Jean de Chastelmorand 20, 145, 160, $161,177,180,183,203,205,228,229$, 230, 350, 358, 360, 368, 370, 381, 408, 410, 413, 418, 419, 455

Jean Chrysostome 415

Jean Corbechon 410, 415

Jean Courtecuisse 248

Jean Dominici 284

Jean Froissart 141, 145, 163, 167, 169, 175, 205, 210, 273, 321, 328, 368

Jean Gerson 289, 295

Jean de la Gogue 202

Jean Hus 309, 418, 436

Jean Juvénal des Ursins 213

Jean de Luxembourg, roi de Bohême 34, 125, 144, 149, 167, 168, 169, 170, 171, $172,173,174,175,177,180,185,186$, $187,188,189,190,191,193,194,195$, 199, 211, 227, 228, 253, 269, 349, 357, $366,411,426,427,428$

Jean Malalas 59

Jean de Mandeville 17, 37, 150, 151, $152,325,326,350,357,359,363,364$, $365,366,434,458$

Jean de Montfort 210

Jean d'Outremeuse 17, 19, 167, 186, $187,228,350,426,427,429,430,432$

Jean Petit 183, 289, 295, 332, 333, 355

Jean de Plan Carpin 97, 98, 102, 109

Jean de Posilge 18, 156, 157, 204, 227 , 252, 268, 272, 274

Jean Régnier 309

Jean de Reading 223

Jean de Roubaix 164

Jean de Saint-Victor 149, 168, 191 
Jean de Sempy 158,159

Jean de Strate 242, 243, 244, 245, 246, 320

Jean Surville 135, 227

Jean de Tancarville 210

Jean de Victring 228

Jean de Vienne 368

Jean de Wallenrode 252

Jean de Wavrin 310, 330

Jean de Werchin 225, 275, 313

Jean de Winterthour 112, 113, 115, 173, 224

Jean II, roi de France 166, 168, 337

Jean XXII, pape 39, 46, 88, 89, 90, 91, $93,94,111,113,114,115,146,170$, 396, 422, 431

Jean XXIII, pape 263, 274, 280, 281

Jensen, Janus 296

Jérusalem 15, 22, 32, 33, 37, 39, 45, 62, $63,67,72,73,74,75,78,81,83,87,96$, $103,107,111,119,120,121,143,144$, $147,149,150,151,152,158,164,165$, $170,171,217,223,225,244,250,276$, 288, 304, 305, 306, 313, 316, 318, 319, $320,321,325,330,331,335,337,338$, 339, 340, 346, 373, 374, 391, 442, 443, 445, 450, 451, 452

Johannes Falkenberg 288, 295

Johannes Urbach 289, 290

John Capgrave 156, 264

John Gower 21, 36, 146, 176, 181, 332, 333, 334, 338, 356

John Loudham 206

John Rous 134, 223

Jones, Terry 176

Jordanès 52

Josse, margrave de Moravie 186

Jóźwiak, Sławomir 28

\section{K}

Kalisz 87, 112, 113, 245

Kaunas (Lituanie) 49, 190, 203, 217, 219, 220, 224, 235

Keen, Maurice 167, 206

Kehnel, Anne 408

Kęstutis, duc de Trakai 23, 94, 193, 194, 196, 215, 217, 218, 219, 220, 221, 235. 236, 306, 398, 426, 432
Kiev 19, 58, 59, 90, 311

Klaipèda (Lituanie) 49, 358

Kl̦aviņš, Kaspars 96

Königsberg (act. Kaliningrad, Russie) 15, 36, 49, 106, 147, 153, 155, 156, 160, $167,169,206,221,222,227,252,300$, 337, 356, 358, 363, 409, 454

Koronowo, bataille de 300

Korybutas 161, 436

Krewo, union de 237

Kruschwitz, traité de 78, 79, 152

L

Ladislas le Banni 64

Ladislas le Bref, roi de Pologne 47, 87, $88,89,113,114,115,170,173,180$, 207, 237, 328

Ladislas II Jagellon, roi de Pologne et grand-duc de Lituanie 156, 196, 198, 204, 207, 217, 221, 233, 234, 236, 237 , 238, 239, 240, 241, 242, 244, 245, 246, $247,248,249,250,251,252,253,254$, 256, 257, 258, 260, 263, 268, 269, 270, $271,273,274,275,276,277,279,280$, 282, 283, 288, 296, 297, 298, 300, 304, $307,308,311,312,319,320,323,324$, 328, 329, 330, 331, 370, 379, 380, 411, 419, 429, 431, 433, 435, 438, 439, 442, 457

Ladislas III, roi de Pologne 298, 331

Le Caire 22

Le Chancelier, poète 112

Lelewel, Joachim 28, 246, 380

Leonard, Irving 451

Léopold III de Habsbourg 144

Le Quellec, Jean-Loïc 376

Lettonie 15, 29, 36, 50, 51, 57, 68, 315, 447

Liège 65, 75, 98, 107, 148, 150, 211, 248, 252, 366, 399

Lincolnshire 126

Lituanie 15, 16, 17, 24, 27, 28, 29, 30, 32, $33,36,37,39,40,46,47,49,50,51,57,77$, $82,84,85,86,88,90,91,92,93,94,96,97$, 98, 99, 100, 101, 102, 106, 112, 117, 118, $119,125,126,127,141,143,145,147$, $148,149,167,168,169,170,171,172$, 
174, 175, 176, 189, 190, 191, 193, 194, 195, 196, 197, 200, 201, 202, 203, 204, 205, 207, 212, 213, 214, 215, 217, 218, 219, 220, 221, 222, 223, 224, 226, 227 , 229, 233, 234, 235, 236, 237, 238, 239, 240, 241, 242, 243, 244, 245, 246, 248, $249,250,251,252,256,257,258,259$, 260, 270, 276, 278, 279, 280, 281, 282, 285, 286, 287, 293, 294, 296, 297, 298, 299, 300, 301, 303, 305, 306, 307, 308, $310,311,312,313,314,315,316,317$, $318,319,320,321,322,323,324,325$, 326, 327, 328, 329, 331, 332, 334, 339, 342, 346, 349, 350, 351, 352, 356, 357, $358,359,360,362,363,365,368,379$, $380,381,383,387,388,398,402,408$, $410,414,418,422,423,425,427,432$, 433, 434, 435, 437, 438, 442, 443, 444, 445, 446, 447, 448, 449, 450, 457

Livonie $15,16,17,18,26,32,36,37$, $46,51,58,60,68,71,72,73,76,77,79$, $80,84,85,87,94,95,96,97,98,99$, $100,101,102,103,104,111,119,125$, 143, 148, 153, 163, 179, 197, 198, 201, 218, 224, 228, 245, 249, 260, 264, 284, $315,327,335,340,349,353,357,361$, $365,374,378,381,382,394,395,397$. 398, 401, 409, 410, 415, 418, 419, 441, 442, 443, 446, 448, 452

Londres 223

Lorraine 65, 114, 126, 178, 179, 180, $182,204,211,212$

Lotharingie 48, 62, 66, 75

Louis d'Anjou, roi de Hongrie 171, 193, 196, 236, 240, 244, 270, 328, 398

Louis de Brandebourg 224

Louis, duc d'Orléans 160, 295, 302, 318

Louis II, duc de Bourbon 159, 160, 177, $178,180,182,187,208,212,228,269$, 299, 350

Louis IV de Bavière, empereur 91, 114, $115,172,173,224$

Louis VII, roi de France 68

Louis IX, roi de France 75, 83, 93, 99, $105,337,365$

Lucques 242

Luppold de Köckritz 303
Luther de Braunschweig 166

Lviv 283, 285, 296, 379

M

Maffiolo Lampugnano 237, 240, 245

Magdebourg 62, 64, 67, 97, 360, 361, 391, 405

Magnus Eriksson, roi de Suède et de

Norvège 379, 383

Mahdia (Tunisie) 148, 159, 165, 177, 179, 208, 233, 299, 451

Majorque 101

Mamelouks, voir Égypte

Marcin Cromer 27

Marco Polo 150, 151, 365

Marie de Bar 186

Marienbourg (act. Malbork, Pologne) 76, $87,115,148,153,160,161,167,198$, 204, 216, 218, 219, 220, 234, 247, 248, $249,255,260,261,265,275,284,303$, 307, 367, 369, 370, 414, 454

Marino Sanudo 101

Markman, Kristina 84

Martin V 284, 296

Maschke, Erich 334

Mathias de Miechow 350

Mathias de Trakai 285

Mattéoni, Olivier 160

Matthieu Paris 88

Matthieu Stryjkowski 416

Mažeika, Rasa 24, 25, 30, 31, 113, 216, 394, 415

Medvegalis (Lituanie) 190, 191, 192, 193, 198, 200, 357, 426, 428

Mehmet I ${ }^{\text {er }}$, sultan ottoman 435

Meinhard, évêque de Livonie 68, 69, 71, 72, 107, 394

Mélusine 17, 139, 165, 186, 187, 229, 253, 273, 329, 350, 354, 411, 413, 419, 427

Mérimée, Prosper 449, 450

Metz 148, 178, 179, 182, 204, 211, 212 Meuvret, Jean 411

Michael Küchmeister de Sternberg 276, 278, 279, 307, 357

Michel Pintoin 19, 38, 208, 209, 210, 212, 213, 266, 267, 268, 269, 272, 273, $274,321,325,326,328,339,356,439$ 
Mickiewicz, Adam 449

Mickūnaitè, Giedre 304, 320, 449

Mieszko, prince de Pologne 47, 48, 60

Mindaugas 85, 86, 90, 94, 106, 109,

216, 217, 221, 235, 254, 432

Moldavie 236, 306, 316, 322, 438

Moscou (Moscovie) 19, 235, 236, 237 ,

312, 317, 320, 351, 444, 447

Muhammad Al-Idrīsī 54, 361

Mund, Stéphane 366

Murad Ir, sultan ottoman 219, 456

Murray, Alan V. 26, 31, 149, 151, 213

\section{N}

Namur 225, 291, 383

Naples 162, 203, 301

Narbutt, Theodor 28

Nejedlý, Martin 253, 448

Neuchâtel 36, 146, 310

Neumark 252, 257, 260

Nicklus Luczke 313

Nicolas de Jeroschin 18, 26, 78, 119,

181,373

Nicolas Kurowski 263

Nicolas de Renys 262, 278

Nicolas Sepienski 282

Nicopolis, bataille de 160, 179, 233, 247 , 248, 269, 273, 274, 299, 308, 321, 322,

324, 325, 336, 339, 340, 345, 346, 454

Niklaus Manuel Deutsch 138, 308

Niklot 63

Nikžentaitis, Alvydas 29, 218

Norbert de Xanten 67

Normandie 126, 213, 260, 276, 437

Norvège 56, 67, 163, 243, 327, 369, 382

Novgorod 19, 22, 50, 58, 68, 105, 143, $197,215,278,280,313,357,368,369$, 370, 383, 436, 439, 448

Novhorod-Siverskyi (Ukraine) 161, 369, 370

\section{O}

Olivier de Paderborn 105, 398, 399

Orose 53, 98

Othon de Bamberg 49, 62, 70

Othon de Bavière 412

Othon de Brunswick 79
Othon III de Grandson 145, 175, 182, 304, 338

Othon III, empereur 386, 389

Ottokar II, roi de Bohême 81, 102, 106, 116, 119, 169, 189, 193

\section{$\mathbf{P}$}

Padoue 286, 287, 295

Papauté 16, 24, 33, 37, 40, 47, 65, 69, 73, 76, 80, 82, 83, 94, 104, 108, 114, $117,142,179,197,216,233,237,240$, 242, 248, 263, 280, 284, 296, 297, 309, 311, 312, 320, 349, 393, 442, 444

Paravicini, Werner 31, 35, 38, 120, 143, 153, 164, 166, 223, 227, 228, 229, 243 , 276, 300, 303, 305, 313, 359, 360, 380, 421, 429

Paris 24, 27, 28, 33, 48, 65, 97, 109, 110, 200, 227, 244, 248, 288, 289, 296, 318, 330, 338, 353, 371, 405, 455

Passau 111

Paul de Rusdorf 303

Paul Vladimiri 176, 258, 281, 283, 286, 287, 288, 289, 290, 291, 292, 293, 294, 295, 296, 334

Pékin 424, 425

Perceval de Coulonge 195, 196, 354

Pero Nińo 354

Pétrarque 196, 380, 398, 420

Petrauskas, Rimvydas 29, 31, 196, 215, 314

Philippe d'Artois 208, 209, 219, 339

Philippe le Bon, duc de Bourgogne 21, 22, 145, 307, 309, 316, 330, 343, 346, 436

Philippe le Hardi, duc de Bourgogne 157, 158, 159, 178, 247

Philippe de Mézières 17, 20, 21, 27, 145, 150, 153, 198, 199, 218, 228, 230, 243, 244, 245, 248, 318, 319, 320, 321, 325, 328, 330, 334, 335, 336, 337, 338, 339, $340,341,350,354,355,357,358,363$, $367,372,373,374,375,376,377,378$, 382, 383, 410, 414, 415, 416, 417, 418, 419, 420, 421, 422, 423, 424, 425, 426, 452, 455

Philippe de la Trémoille 339 
Philippe VI, roi de France 167, 168 Pierre, duc de Bourbon 144, 171 Pierre d'Ailly 37, 259, 281, 295 Pierre de Celle 67, 68 Pierre le Cruel, roi de Castille 423 Pierre Damien 61, 387, 388, 431 Pierre de Dusbourg 18, 23, 24, 25, 26, 27, 31, 57, 59, 71, 78, 106, 114, 116, 119, 125, 149, 190, 191, 192, 201, 213, $217,373,374,375,390,392,394,395$, 396, 404, 405, 406, 410

Pierre Guillaume 394

Pierre de Lusignan, roi de Chypre 176, 194, 195, 223, 318, 328, 354

Pierre Suchenwirt 146, 162, 181, 182, 202, 205, 332

Pierre de la Trémoille 159

Pierre le Vénérable 64

Pierre Wormditt 263, 280, 281, 289

Pierre de Zittau 167, 172, 189, 228

Pinsk (Biélorussie) 371

Pline l'Ancien 50, 52, 98

Płock (Pologne) 65, 263

Poitou 126, 153

Pologne 15, 17, 27, 28, 32, 33, 36, 39, $47,48,49,54,60,65,66,74,79,80,82$, $87,88,89,90,91,100,110,112,113$, $114,121,126,143,155,170,172,173$, 174, 180, 189, 191, 197, 207, 223, 227, 233, 235, 236, 237, 238, 239, 240, 245, 246, 248, 251, 252, 253, 254, 256, 257 , 259, 260, 261, 262, 263, 269, 276, 277, 278, 279, 280, 281, 285, 286, 287, 288, 290, 293, 296, 297, 301, 305, 306, 307, $311,312,313,314,316,317,322,323$, 324, 325, 326, 327, 328, 329, 331, 346, 350, 351, 356, 357, 360, 361, 368, 371, 377, 380, 381, 388, 399, 435, 438, 439, 441, 443, 444, 445, 446, 447, 450

Poméranie 36, 54, 61, 65, 70, 87, 101, 114, 170, 206, 207, 279, 393

Porte-Glaives, voir Chevaliers Porte-

Glaives

Pouilles 305, 356

Prague 171, 172, 180, 186, 195, 222, 226, 238, 253, 286, 301, 310, 323, 328, 398, 412, 418
Prioult, Albert 366

Propositio samagitarum 282, 291, 293

Prusse 15, 16, 17, 20, 21, 23, 24, 26, 27 , $28,35,36,37,38,40,46,51,52,54,57$, 58, 70, 72, 73, 76, 77, 78, 79, 80, 81, 84, $86,87,95,97,98,99,100,101,102$, $105,106,107,108,111,112,116,117$, $118,119,120,125,126,127,141,143$, $144,145,146,147,148,149,150,151$, $153,154,155,156,157,158,159,160$, $161,162,163,164,165,166,167,168$, $169,170,171,172,173,174,175,176$, $177,178,179,180,181,182,184,185$, $187,188,190,191,192,193,194,196$, 197, 198, 199, 201, 202, 203, 205, 206, $207,208,210,211,212,213,214,215$, $217,218,219,220,221,222,223,224$, $225,226,227,228,229,233,234,235$, 243, 244, 245, 247, 248, 249, 251, 252, 258, 259, 261, 264, 266, 267, 268, 269, $271,273,274,275,276,277,278,279$, 280, 284, 288, 291, 292, 294, 295, 299, 300, 301, 302, 303, 304, 305, 306, 308, $310,311,312,313,315,316,317,319$, $321,322,323,324,325,326,327,328$, 330, 331, 332, 334, 335, 336, 337, 338, 339, 340, 341, 342, 343, 344, 345, 346, 349, 350, 351, 353, 354, 356, 357, 358, 359, 360, 362, 363, 364, 365, 366, 367, 368, 369, 370, 371, 372, 373, 374, 376, $377,378,379,380,381,382,386,387$, 388, 389, 392, 394, 395, 397, 398, 402, 408, 413, 414, 415, 417, 418, 419, 420, $422,423,426,427,430,431,432,433$, $441,442,443,446,448,451,452,453$, 454, 455, 456, 458

Pskov 19, 22, 143, 197, 215, 280, 357, 368, 439, 448

Ptolémée 52, 298

Puymaigre, Théodore de 168, 169

Q

Queux de Saint-Hilaire, Auguste 342

$\mathbf{R}$

Racianz, traité de 204, 254

Raczyński, Edward 28 
Raoul de Brienne 210

Raoul Glaber 16, 61, 388, 389, 390, 396

Raoul de Gruyère 163, 164, 185, 205

Raymond de Peñafort 294

Rhodes 143, 165, 225, 334

Richard Beauchamp, comte de Warwick 223, 276, 305, 313, 315

Richard Cœur de Lion, roi d'Angleterre 337

Richard II, roi d'Angleterre 120, 144 , 147, 157, 206, 302, 305, 318, 320, 338

Riga 72, 85, 87, 89, 90, 91, 93, 94, 95, 98, 99, 101, 106, 109, 112, 113, 114,

117, 169, 252, 284, 285, 404, 407, 409

Riga, archevêque de 85, 252

Riley-Smith, Jonathan 32, 166

Robert de Flandre 62

Robert le Moine 62, 391, 393

Robert Morley 120

Rodinson, Maxime 354

Rodolphe de Fridingen 308

Rodolphe de Nidau 146

Roger Bacon 17, 59, 100, 108, 109, 110, $111,113,114,334,353,403,405,407$, 408, 413, 418, 431, 442, 455

Roman de la Rose 416

Rome 69, 77, 86, 89, 165, 311, 399, 406, 450

Rome, papauté de 16, 33, 40, 47, 65, 69, 73, 76, 80, 82, 83, 94, 104, 108, $114,117,142,179,216,233,237$, 240, 242, 263, 280, 284, 296, 297. 305, 309, 311, 312, 320, 349, 393, 442, 444

Rowell, Stephen C. 29, 30, 31, 91, 92, 93, 99, 104, 223, 224, 254, 261, 416, 428, 431, 432

Rus' kiévienne 19, 68, 84, 90, 91, 173, 236, 312, 387, 389

Russie 15, 19, 32, 36, 49, 50, 51, 85, 100, 103, 105, 106, 151, 152, 173, 174, 176, 195, 201, 223, 245, 276, 297, 312, 315, 319, 322, 326, 327, $342,358,365,368,370,371,381$, 388, 399, 434, 436, 443, 447, 448 Ruthénie, voir Rus' kiévienne

\section{S}

Saint Empire Romain Germanique 15, $17,26,36,39,45,51,61,66,74,75,96$, $115,119,120,126,144,146,194,196$, $248,259,285,287,303,309,310,316$, 328, 331, 441, 443

Saint-Gilles (Provence) 66, 394

Saint-Jacques de Compostelle 450

Saint-Jean-d'Acre 15, 37, 46, 73, 76, 87, 119, 143, 331, 372, 373, 374, 442

Saint Thomas 424

Saladin (Ṣalāḥ ad-Dīn), sultan d'Égypte 64, 420

Salinwerder, traité de 254

Sambie 98, 100, 102, 106, 119, 153, 189, 193, 363, 397, 407

Samogitie 28, 46, 49, 51, 92, 105, 149, 153, 162, 173, 190, 191, 193, 196, 204, 216, 217, 221, 230, 233, 234, 239, 254, $255,256,257,258,260,267,272,279$, 282, 284, 285, 286, 294, 296, 297, 299, $300,306,317,322,326,342,370,371$, 378, 409, 410, 419, 428, 434, 442, 449 Samsonowicz, Henryk 88

Saule, bataille de 81,85

Savoie 16, 36, 39, 120, 126, 164, 172, $177,180,187,304,417$

Saxe 24, 62, 63, 89, 107, 374

Saxo Grammaticus 18, 49, 63, 392, 399

Scandinavie 36, 56, 64, 120, 287

Scythie 53, 99, 100, 353, 371, 445

Sebastian Münster 350, 351, 369, 374

Sémigallie 77, 98, 100, 102, 103, 107, 394, 399

Sicile 54, 55, 305, 356, 361, 452

Sienkiewicz, Henryk 449

Sigismond de Herberstein 350

Sigismond de Luxembourg, roi de Hongrie 208, 209, 210, 239, 247, 252, 253, 258, 260, 266, 267, 269, 272, 273, 274, 279, 281, 284, 285, 289, 297, 307, $309,310,311,314,315,317,322,370$, 436

Sigismond, grand-duc de Lituanie 331, 449

Sigurd, roi de Norvège 64

Sikorski, Dariusz 79 
Silésie 74, 125, 170, 189, 190, 313

Simon de Cramaud 248

Sixte IV 317

Skirgaila 156, 206, 221, 236, 251, 255

Skomantas 86

Smyrne (Izmir, Turquie) 318, 336

Souzdal 83

Stanislas de Skarbimierz 263, 287, 452

Stjepan Dabiša, roi de Bosnie 209

Strehlke, Ernst 28

Suède 67, 100, 243, 296, 324, 327, 382

Suétone 401

Svátek, Jaroslav 208, 277, 329

Švitrigaila, duc de Lituanie 215, 331

Szczecin 277, 371, 394

Szczepanski, Seweryn 374

Szkilnik, Michelle 184

Szweda, Adam 28

Szybkowski, Sobiesław 28

\section{$\mathbf{T}$}

Tacite 50, 52, 60, 362, 396, 400, 401

Tallinn 98, 99

Tamerlan 311, 321, 445

Tamm, Marek 31, 70, 353, 358, 392,

397, 401

Tannenberg, bataille de 19, 29, 30, 37, $38,233,234,250,256,259,262,263$, 265, 266, 269, 272, 274, 276, 277, 278, 280, 288, 294, 296, 299, 300, 301, 302, 303, 304, 305, 306, 315, 322, 323, 324, $325,326,356,370,436,437,439$

Tartarie 83, 200, 222, 319, 322, 325, 327, 332, 334, 335, 364, 371, 414, 424, 436, 437, 443

Tatars 41, 82, 90, 99, 105, 109, 110, $152,155,194,222,226,234,237,242$, 255, 258, 259, 261, 262, 267, 268, 271, 272, 287, 295, 311, 312, 321, 325, 326, $327,331,335,349,353,364,365,381$, 382, 414, 424, 425, 435, 436, 437, 438, 439, 444, 445, 447, 448

Templiers, voir Chevaliers du Temple Tertullien 415

Teutoniques, voir Chevaliers teutoniques Theiner, Augustin 28

Théodoric, cistercien 69, 72, 77, 98, 107, 394
Théodoric le Grand 52

Thietmar de Mersebourg 17, 49, 360

Thomas d'Aquin 79

Thomas Beauchamp, comte de Warwick

117, 134, 222, 223, 230, 276

Thomas de Cantimpré 17, 397

Thomas Clifford 179

Thomas Gray 155, 219, 220, 432

Thomas de Hollande 210, 211

Thomas de Mowbray 157

Thomas Stafford 366

Thomas Surville 135, 222, 226, 227

Thomas d'Ufford 207, 222

Thomas Walsingham 156, 221, 251,

255, 264, 304, 320, 356, 431, 432

Thomas de Woodstock 158

Thomas I ${ }^{\text {er }}$, comte de Savoie 120

Thomas III d'Aléran 370

Timur Kotluk 311

Todorov, Tzvetan 448, 453

Tokhtamysh 312

Töppen, Max 28

Toruń (Pologne) 81, 153, 183, 184, 260, 261, 262, 264, 277, 279, 303, 373, 374,

377, 378, 421

Trakai (Lituanie) 49, 94, 160, 203, 217 , 219, 317, 379, 381, 433, 434, 435, 437

Transylvanie 75

Trébizonde 323

Treniota 217

Tyerman, Christopher 148, 338

U

Ulrich de Jungingen 256, 260, 273, 303

Ulrich de Richental 282, 284, 297, 324,

381

Urbain II, pape 62, 391, 393

Urbain IV, pape 81

Urbain V, pape 117,328

Urbain VI, pape 237, 240, 241, 242

Urban, William 29, 30, 32, 106, 109, $110,166,173,213,261$

V

Vaidutis 226

Valachie 236, 312, 316, 322, 438

Valdemar I ${ }^{\text {er }}$, roi de Danemark 63 
Valois, Noël 242

Vander Elst, Stefan 119, 181

Varna, bataille de 308, 326, 330, 331

Venise 76, 87, 101, 143, 158, 276, 289, 334

Vienne 88, 331, 344

Vilnius 39, 49, 86, 90, 92, 125, 156, 203, 206, 215, 217, 218, 221, 224, 233, 234, 236, 237, 239, 241, 245, 248, 249 , 251, 252, 253, 254, 283, 285, 296, 299, $304,311,315,317,379,433$

Vincent de Beauvais 88, 150

Vincent Kadłubek 18, 48, 63, 64, 65

Vincent de Prague 64

Vlad Dracula, prince de Valachie 446 Vorskla, bataille de la 226, 312

Vytautas, grand-duc de Lituanie 156 , 164, 204, 207, 215, 218, 219, 221, 222, 230, 233, 234, 235, 236, 239, 249, 250 , 253, 254, 255, 256, 257, 258, 260, 261, 268, 273, 275, 279, 282, 283, 288, 296, 297, 298, 299, 303, 304, 306, 307, 311, $312,313,314,315,316,317,324,327$, 328, 329, 331, 346, 379, 419, 431, 433, 434, 435, 436, 437, 439, 444, 445, 446, 448, 449, 454, 457

Vytenis, grand-duc de Lituanie 86, 89, 414

W

Wagner, Marc-André 417, 418

Waléran de Wavrin 310
Wal, Wilhelm E. J. von, 28, 351, 374, 375

Wenceslas de Luxembourg, roi de

Bohême 186, 212, 242, 253, 258, 269, 300, 305, 436

Wenceslas de Miska 266, 370

Werner de Homberg 125, 162, 166, 190

Werner d'Orseln 24, 115, 116, 169, 170, 189, 191, 192

Werner Tetinger 254

Wigand de Baldersheim 213, 221

Wigand de Marbourg 18, 23, 119, 156, $160,191,193,206,213,217,218,219$, 220, 252, 254, 419, 421, 422, 426

William Douglas 179

Winrich de Kniprode 118, 160, 166, 203, 215, 217, 236, 375, 426

Wojciech z Pakości 330

Wolgast-Słupsk 277

Wrocław 183, 190, 393

Wulfstan 17, 53, 360, 361, 386, 400

$\mathbf{X}$

Xavier, Walter 326

Y

Yorkshire 126

Yves de Chartres 65

Z

Zeno, Antonio 28 


\section{TABLE DES MATIÈRES}

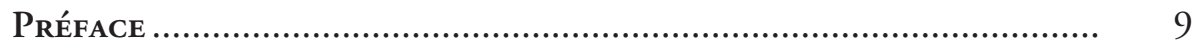

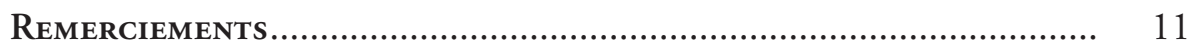

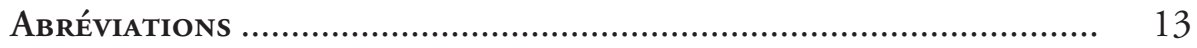

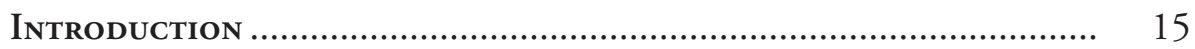

Sources et méthodologie ....................................................... 16

État de la question ................................................................... 27

Questions de recherche et plan de l'ouvrage ................................. 35

\section{Première partie \\ Aux Marges de la Chrétienté}

INTRODUCTION DE LA PREMIÈRE PARTIE.............................................. 45

Chapitre I: Sous L'EIL De Rome ……............................................. 47

Les derniers païens d'Europe ...................................................... 47

Une croisade dans le Nord: propagatio et defensio fidei .................. 60

Les ordres militaires en Prusse et en Livonie ............................... $\quad 72$

Le grand-duché de Lituanie, un partenaire païen......................... 82

Chapitre II : Croisade et mission vues d'Occident .......................... 95

De nouvelles terres chrétiennes................................................... 95

Pour la foi ou pour le pouvoir? ................................................. 103

L'alternative lituanienne............................................................ 114 


\section{DEUXIÈME PARTIE \\ LE Temps DES CROISÉS}

INTRODUCTION DE LA DEUXIÈME PARTIE

Chapitre III : À la ReCherche de L'HonNeUr................................... 141

Les rèses de Prusse et les Sarrasins de Lituanie.............................. 141

Un idéal aristocratique ......................................................... 153

Guillaume de Machaut et Jean l'Aveugle : un croisé modèle.......... 167

L'amour et le renom: les poètes et la croisade balte ....................... 175

Chapitre IV : Entre le verbe et L'ÉPÉE …....................................... 189

Convertir ou conquérir? ......................................................... 189

"Grant destruccion de Sarrasins» : la guerre en pays balte ................ 199

Les Lituaniens et la chevalerie occidentale.................................... 215

\section{TroisièMe PARTIE \\ LE GRAND TOURNANT}

INTRODUCTION DE LA TROISIÈME PARTIE

Chapitre V: La Lituanie Chrétienne ……................................... 235

Un roi lituanien pour la Pologne............................................ 235

L'Ordre teutonique face à la nouvelle donne .............................. 249

La bataille de Tannenberg.......................................................... 256

L'écho de la défaite en Europe occidentale................................... 263

La Lituanie au concile de Constance........................................... 280

Chapitre VI: Vers D'Autres horizons ........................................... 299

Les derniers croisés de Prusse .................................................... 299

Les Lituaniens, héros de la croisade?............................................ 311

La menace tatare: un nouveau front de croisade.......................... 321

Vaine gloire et cadre grivois: la croisade de Prusse brocardée ......... 331 


\section{QUATRIÈME PARTIE \\ UN MONDE D'HONNEUR ET DE GLACE \\ LES IMAGINAIRES BALTES}

INTRODUCTION DE LA QUATRIÈME PARTIE

Chapitre VII: Le CADre

De l'oral à l'écrit, ou les longs chemins de la transmission ............. 353

Des forêts enneigées et des marais gelés....................................... 359

De l'héroïsation à l'intérêt «touristique »....................................... 369

Chapitre VIII : Les Hommes ............................................................ 385

«humanum sanguinem sitientes»: de cruels persécuteurs ................ 385

Des païens drapés à l'antique..................................................... 394

Comprendre la religion païenne: le bûcher funéraire.................... 400

L'honneur des païens ................................................................. 419

Coutume sociale et diversité religieuse ....................................... 429

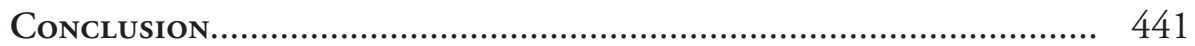

La Baltique et les marges de la Chrétienté................................... 441

Héritage et réminiscences.......................................................... 446

De la croisade à la connaissance de l'autre.................................... 453

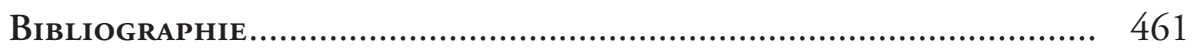

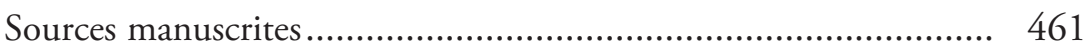

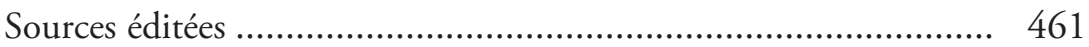

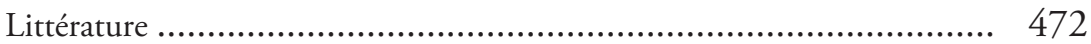

Usuels et ressources électroniques .............................................. 526

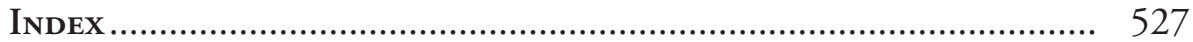


Achevé d'imprimer

en novembre 2019

pour le compte des Éditions Alphil-Presses universitaires suisses

Responsable de production: Anne-Caroline Le Coultre 
À l'instar du roi Jean l'Aveugle et du poète Guillaume de Machaut en 1329, des chevaliers de toute l'Europe traversent chaque hiver les forêts glacées de Prusse pour mettre à feu et à sang la Lituanie, où vivent les derniers païens d'Europe. Dans la foulée des croisades en Terre sainte, des seigneurs de France et d'Angleterre prennent les armes pour affronter les "Sarrasins » de la Baltique. La plupart y vont pour l'honneur; certains rapportent des impressions personnelles sur ces pays lointains et leurs habitants.

Tout au long du Moyen Âge, de nombreux auteurs suivent la progression de la foi dans les provinces baltes et commentent le rôle de l'Ordre teutonique, fer de lance de la lutte contre les païens d'Europe du Nord. Les Baltes sont considérés comme des adversaires nobles, et pas uniquement comme des ennemis à convertir ou à tuer. L'on s'intéresse à leurs mœurs et l'on tente de comprendre leur spiritualité. Plus qu'un combat à mort entre christianisme et paganisme, la croisade balte est une étape clef dans la formation d'une culture européenne du rapport à l'Autre, faite à la fois de volonté d'assimilation, de respect et de curiosité. À partir des sources narratives produites en France et en Angleterre entre le $\mathrm{xII}^{\mathrm{e}}$ et le $\mathrm{xv}$ siècle, cet ouvrage explore la représentation de cette épopée nordique en Europe occidentale.

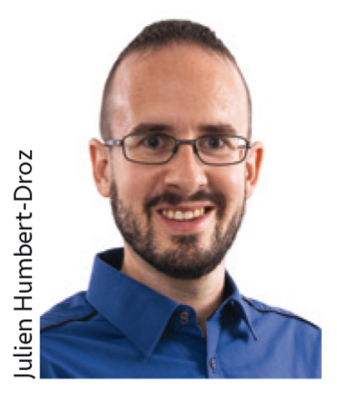

Loïc Chollet est chercheur post-doc en histoire médiévale à l'Université de Neuchâtel. Ses recherches portent sur les croisades tardives, la perception de la différence religieuse et des «marges » de la Chrétienté ainsi que les droits des peuples non-chrétiens. Actuellement, il participe au projet de recherche FNS Pouvoir, hérésie et religion dans l'Occident et le Japon médiéval: étude comparée. 